

Digitized by the Internet Archive in 2010 with funding from University of Ottawa 


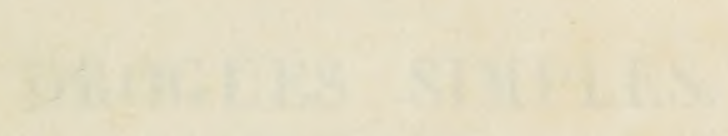

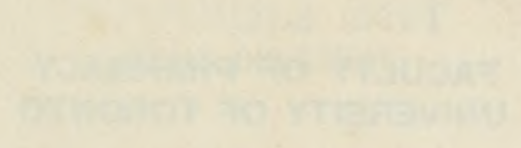


TWE LUE...

FACULTY OF PHARMACY UNIVERSITY OF TORONTO 


\section{IISTOIRE NATURELLE}

DES

\section{DROGUES SIMPLES.}

TOUE DEUXIÉME.

FACULTY OF PHARMAGCY UNIVERSITY OF TORONTO 


\section{Dn trovve ches le mêne Libraire.}

PHARMACOPÉE RAISONNÉE, ou Traité de pharmacie pratique et théorique, par N.-E. Henry el N. J.-B. G. Gulbourt; troisième édition, revue el considérablement augmentée, par N. J.-B. G. GuibourT, professeur à l'École de pharmacic, membre de l'Académic nationale de médecine. Paris, 184i, in- 8 de 800 pages a deux colonnes, avec 22 planches. 


\section{HISTOIRE NATURELLE}

\section{DES \\ DROGUES SIMPLES}

OU

\section{COURS D'HISTOIRE NATURELLE}

Professé à l'École à Pharmacie de Paris

PAR

\section{N. J.-F. G. CUIBOUE',}

Professcur titulaire de l'École de pharmacie de Paris, membre de l'Académie nationale de medecine, de l'Academie nationale des seiences et belles lettres de Rouen, et.

\section{QUATRIĖME ĖDITION ,}

CORRIGÉ ET CONSIDÉRABLEMENT AUGMENTÉE,

De plus de 600 figures interealées dans le texte.

TOME DEUXIENE.

-.*0

\section{PARIS,}

CHEZ J.-B. BAILLIERE,

LIBRAIRE DE L'ACADÉMIE NATIONALE DE MÉDEGINE, Rue de l'École-rle-Múlecine, 17.

A Loxdres, chez H. Ballliére, 219, Regent-Streget.

A MADRID, CHEZ CH. BAILLY-BAILLIERF, LIBRAIRL.

1849. 


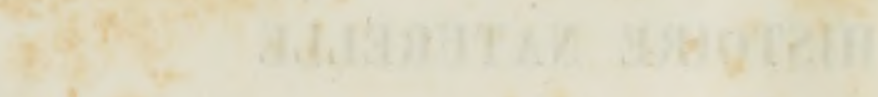

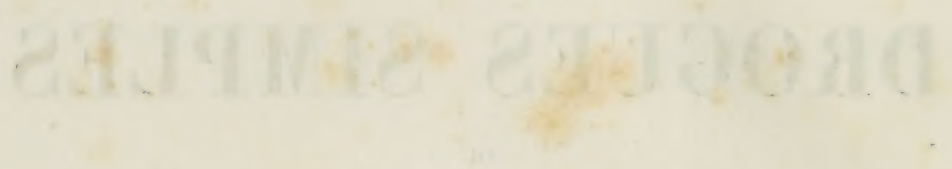

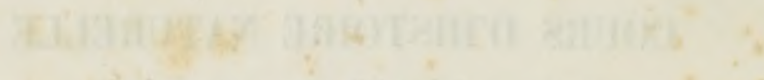

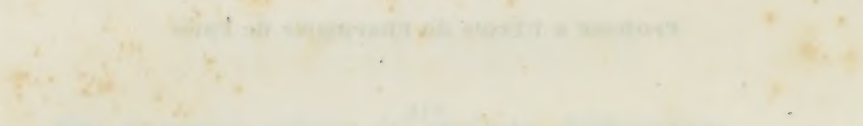

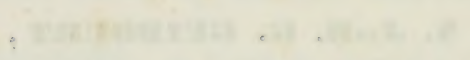

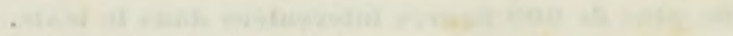

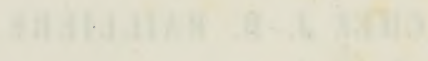




\section{()RDRE I)ES MITIERES}

\section{DU TOME DEUXIEME.}

DEUXIEIE PARTIE. - VELLTIUT . . . . . . . . I

Tableau des fruits. . . . . . . . . 17

Système de Linné . . . . . . . . . . . . . . . . . . . . 30

Méthode de Jussieu. . . . . . . . . . . . . . . . 3ii

— de De Candolle . . . . . . . . . . il

Distribution des végétaux en huil classes. . . . . . . . . . . 12

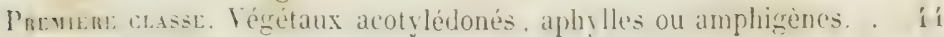

Ordre des algues. . . . . . . . . . í

- des champignons. . . . . . . . . . . . . ös

- des lichens ................. . . . . . . . . .

Famille des fougères. . . . . . . . . . . . . . . . . . . s'

— des lycopodiacées . . . . . . . . . . . . . . . . 9:i

— des équisétacées . . . . . . . . . . . . . . . . . . . . . . . .

Groupe des rhizanthés . . . . . . . . . . . . . 1010

Qutrateme Classe. Végélaus monocolvlédonés......... I01

Famille des aroïdées. . . . . . . . . (t)

- des cypéracées. . . . . . . . . . . . 10:

- des graminées................. I11

- des palmiers. ................ . . 136

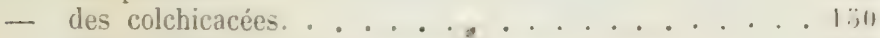

. des liliacées. . . . . . . . . . . 1:39

- des asparaginées. . . . . . . . . . . . 171

— des dioscorées. ............... 187

- des amaryllidées. .............. 18.

— des broméliacées. . . . . . . . . . . . 190

— des iridées. .. . . . . . . . . . . . ib.

— des musacées... . . . . . . . . . . 197

— des amomacées. . . . . . . . . . . . 198

— des orchidées ..............2.23

Cinquiene classe. Dicolylédones monochlamydées. . . . . . . . 230

Famille des conifères. . . . . . . . . . . . . . 231

- des pipéritées. . . . . . . . . . . 262

Groupe des amentacées. . . . . . . . . . . . 2667

Famille des myricées . . . . . . . . . . . . . . . 268

Famille des cupulifères . . . . . . . . . . . . . . . . 270

— des juglandées . . . . . . . . . . . . 237

— des platanées et balsamifluées . . . . . . . . . . . 291

- des salicinées. . . . . . . . . . . . . 29:3

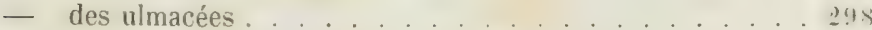

- des morées. . . . . . . . . . . . . . . 299

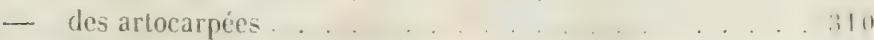

- des cannabinées. . . . . . . . . . . . . . . . . . . .

II. 
Famille des euphorbiacées.

- des aristolochiées.

- des santalacées.

- des daphnacées ou thymélieacées. . . . . . . . . . 33̆

- des lauracées. . . . . . . . . . . . . 361

- des myristacées. . . . . . . . . . . . . 387

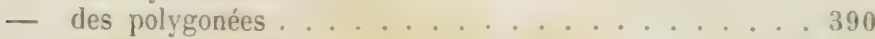

- des chénopodées. ............. 403

Amarantacées, nyctaginées, phytolaccacées........ 411

Sixtème CLasse. Dicotylédones corolliflores. . . . . . . . . 11

Famille des plantaginées. . . . . . . . . . 11

— des plumbaginées. . . . . . . . . . 11:;

- des primulacées. . . . . . . . . . . . 418

- des labiées . . . . . . . . . . . . . . 421

— des verbénacées............. 14i0

- des scrophulariacées. . . . . . . . . . 1 1 13

- des solanacées. . . . . . . . . . . . . . . . . . . . . . . . .

- des borraginées. ............ if . . . . . . . .

— des convolvulacées ............. i (7f

— des bignoniacées............ i ... 19s

— des gentianacées. ............. . . . . . . . . .

— des loganiacées. . . . . . . . . . . . . . . . . ;

— des asclépiadées . . . . . . . . . . . \$11

- des apocynacées .............. 521

— des jasminées et oléacées . . . . . . . . . 530

— des sapotacées. . . . . . . . . . . 342

- des ébénacées. . . . . . . . . . . . . 517

— des styracinées ............... 519 


\section{IIISTOIRE NATURELLE}

DES

\section{DROGUES SIMPLES.}

\section{DEUXIÈME PARTIE.}

\section{จE์CEAUX.}

Les végétaux sont des êtres virants, dépourvus de sensibilití et incapables d'aucun mourement rolontaire. Ce peu de mots les définit; car le défaut de sensibilité et de locomobilité les distingue des animaux, et l'épithète de rivants indique qu'ils jouissent des autres facultés de la vie, qui sont la nontriture par intus-susception, la croissance, le déveIoppement et la reproduction de l'espèce au moỵen d'organes appropriés à ces différentes fonctions.

Les régétaux, de même que les animaux, sont tantôt composés d'un nombre considérable de parties distinctes à la simple vue, qui naissent ou se déreloppent successirement, et d'autres fois ils ne paraissent formés que d'une masse sans appendices, dans laquelle on a peine à décourrir des traces d'organisation. Dans tous les cas, cependant, si l'on soumet au microscope une petite partie quelconque d'un végétal, on la trouve composée, en dernière analyse, d'un nombre considérable de petits sacs ou carités dont la forme varic, et qui sont la base desdifférents tissus végétaux. Ces petits organés élémentaires portent les noms de cellules ou utricules, de clostres et de vaisseaux.

La cellule, ou mieux l'utricule (fig. 1), est le point de départ de toute l'organisation végétale. C'est un petit sac à paroi propre, Fig. 1. de forme sphérique ou ellipsoüde lorsqu'il se développe librement, et cui furme, par sa réunion arec d'autres sacs sembables, le tissu végétal le plus simple nommé tissu utriculaire on 
parenctigne. Lorsque les utricules sont peu serrés les uns contre les autres (fig. 2), ils conservent leur forme arrondie, et laisornt nécessairement entre eux des intervalles nommés mirnts inter-ntriculnires; mais lorsqu'ils se trouvent comprimés les uns par les autres, en raison

liig. 2.

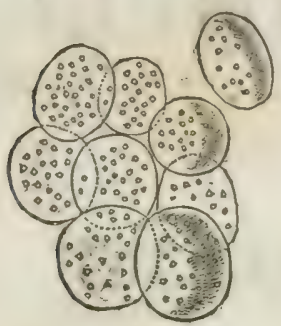

Fig. 3 .

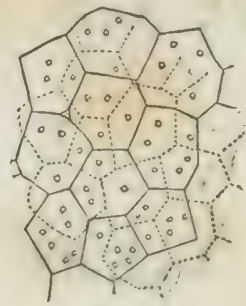

Fig. 4.

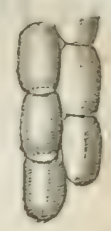

du peu d'espace gui leur est accordé, les méats disparaissent et les utricules prennent une forme polyédrique (fig. 3), qui est sourent celle d'un dodécaèdre pentagonal dont la coupe représente un hexagone; mais qui peut être aussi cubique, rectangulaire ou cylindrique arrondie (fig. 4).

Le rlostre (de xh.ustro, fuseauj est une cellule gui s'est allongée au point de devenir beauconp plus longue que large, el qui se termine en pointe à

Fig. ร, $6 . \quad$ Fig. 7.

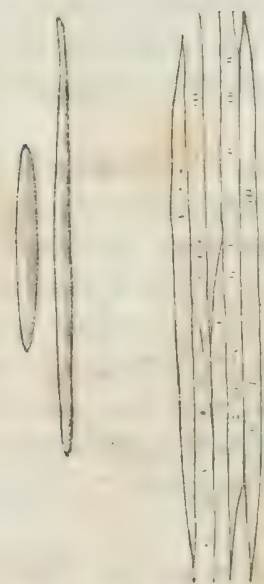
ses deux extrémités (fig. 5, 6). Ces cellules, en se serrant les unes contre les autres et en se joignant par leurs extrémités amincies, de manière à remplir les vides qu'elles laisseraient sans celte disposition (fig. 7), forment un tissu résistant qui paraît composé; à la simple vue, de parties solides, minces, longues et parallèles, auxquelles on dome le nom de fibres, et le tissu prend également le nom de tissu fibreux. Ce tissu forme la partic solide et résistante des végétaux, ou le bois.

La cellule, au moment où elle commence à paraître, comme organe distinct, est un pelit sac formé par une membrane simple, continue et homogène (fig. 1); elle peut persister à cet état.en changeant seulement de volume et de forme fig. $4,5,6)$; mais d'autres fois, à une certaine époque ulterieure, il se forme ì l'intericur une seconde mrmbarte, une treisiène, elc.

lorsque ces nouvelles metibranes s'étendent uniformément à l’intérieur de la première, la cellule ne change pas d'aspect au microscope, si 


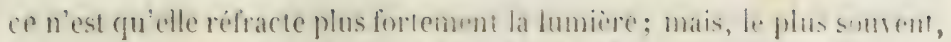

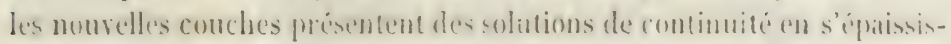

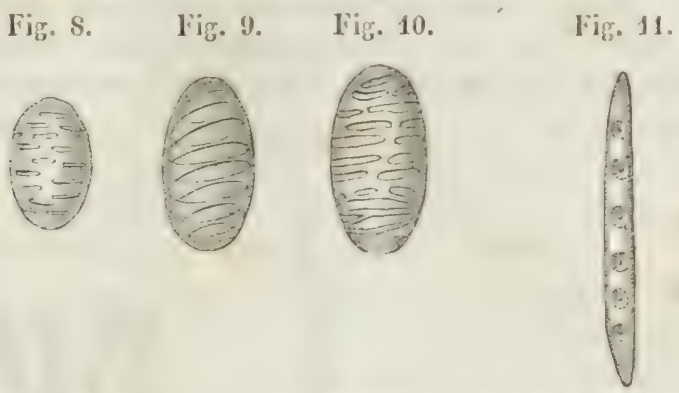

sant à cerlains cudroils plus qu'ì d'aumes, ce qui dounc aux cellules differentes apparences ir!less que celles reprexentés fig. 8, 9, 10, 11.

I.es cellules peurent aussi se remplir de matière élrangère à leur propre nature; tels sont des gramules d'amidon, de la chlorophọlle, des cristaux de sels calcaires, etc.

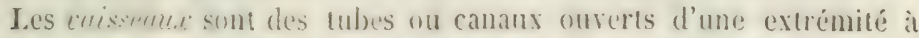
l'atutre, et propres par conérgucint ì la transmission des fluides végré lamx, lignides on acrifomes. On pene en conceroir la formation en

Fig. 12. Fig. 13. Fig. 14.

Fig. 13.
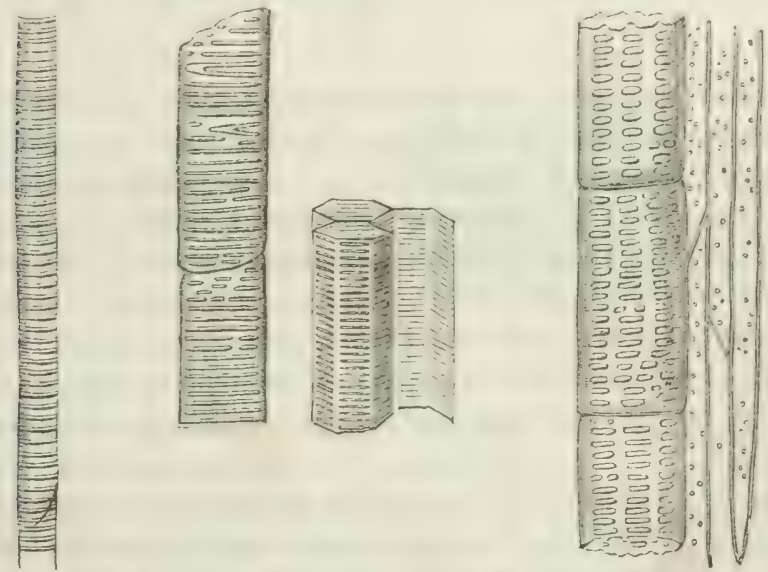

supposant que des cellules cylindriques (fig. 4) ou des clostres (fir. 7), s'étant joints bout ì bout, le plan de séparation a été résorbé ou dífruit par l'effort du fluide. Cetle hyponhèse est appuyce par ce:tr: cirronstance que les raisseaux, esaminés au microsenpe, présentent i leur surface les mèmes apparences de points, de raies, de handes ou dr :pirales que les cellules (fig. $12,13,14$ et 15 ). 


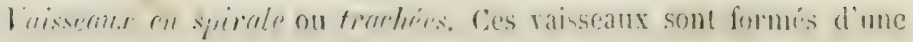
mombranc colindrique dans l'interiour de laquelle s'enronle un fil d'un banc nacré, disposi en spires serrés comme le fil de laiton d'une bretolle (fig. 16 et 17), et pourant se dérouler comme lui lorsqu'on le soumet à une traction longitudinale. On a donné à ces raisseaux le nom lig. 18.

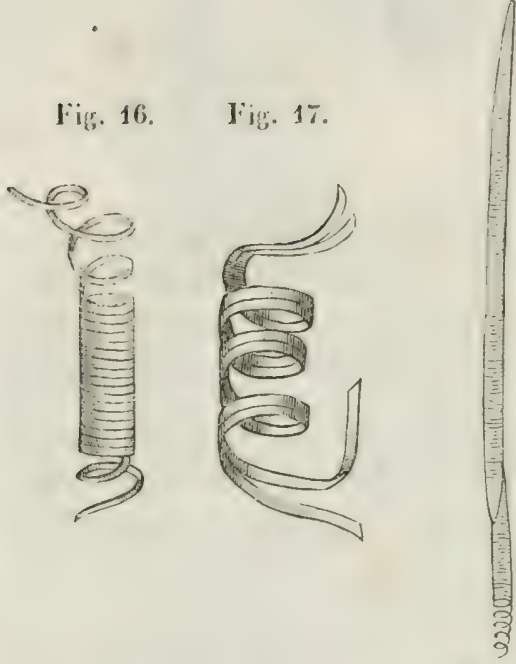

Fig. 19.

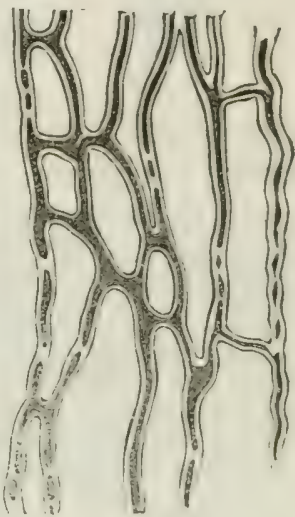

de trutres, en raison de ce qu'ils paraissent servir à la circulation de l'air dans les végélaux, et on a supposé pendant longtrmpls qu'ils ćtaient formés du fil spiral seul rapproché et serré, sans membrane exteriure ; parce que celle-ci se déchire ordinairement à l'effort de traclion que l'on fait éprouver à la trachée. Mais, en examinant ces organes dans une longueur suffisante, on a reconnu qu'ils se terminaient cu fuseau aux extremités et (qu'ils se continuaient arec d'autres semblables (fig. 1s', exactement comme le font les clostres du tissu ligneux (fig. 7 ), de sorte qu'il faut les regarder comme une simple modification de certe esplice de cellule.

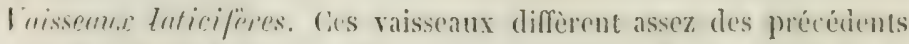
pour qu'on hésite à les regarder comme le résultat d'une modification. Ils some rylindrigues ou inigalement renflés, formés d'une membrane homogione et transparente, et anastomoses cntre cux par des branches transwersiles (fig. 19). 1ls servent au transport de la sève éliboré qui doit servir à la mutrition du régétal ot (fue .1. Sclubltz a plus parliculicirement désignée sous le nom de latex.

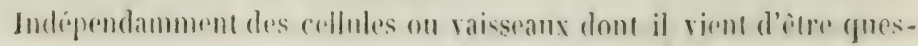


tion, les régétaus présentent encore deux sortes de carités qui sont les larunes et les reservoirs de sucs propnes. Les premières sont des carités pleines d’air, qui se forment dans l’intérieur des plantes par la rup ture du tissu cellulaire; elles occupent souvent une grande partic des tiges herbacées, de manière que tous les tissus en paraissent rejetés a la circonférence (par exemple, les tiges creuses des graminées el des ombelliferes). Les secondes sont des cavités formées cà et la dans le tissu cellulaire, par l'accumulation de sucs spéciaux, gommenx, résineux, gommo-résineux, huileux, etc., et probablement d'abord par l'expansion des méats inter-cellulaires.

Éfielerme. Dans les véxétaux, l'épiderme est un organe qui, sous la forme d'une membrane incolore et transparente, recoure lontes les parties exposées à l'action de l'air. Celle membrane est formée de deux partios: d'abord d'une pellicule exlérieure tris mince, nomméc cuticule, n'ofirant presque aucunc trace d'organjation, si ce n'est qu'elle présente sourent, ça et là, des petiles fentes en forme do bontomnières, qui correspondent aux stomates; ensuite de unc on, plus rareuent, de plasieurs couches do cellules desiéchées, géniralenient plus grandes que celles du tissu cellulaire sons jacent. L'épiderme des végétaux cellulaires on acolylédonés, et celui des racines de vergéaus rasculaires, non exposées à l'air, n’offrent pas d'autres parties; mais celui des parties de plantes vasculaires exp̧osées à l'air présente, de distance

lig. 20.

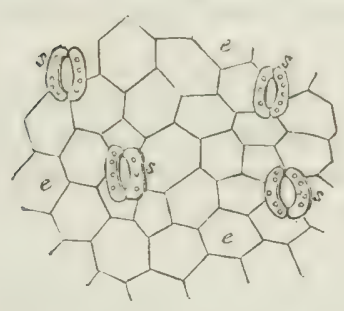

Fig. 21 .

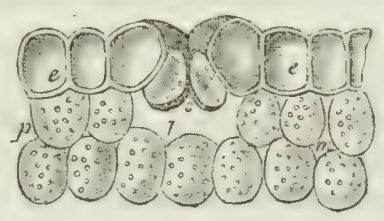

en distance, des organes particuliers nommés stomntes ou pores corticuux, qui sont formés d'un double bourrelet séparé par une fente, et qui paraissent destinés, soit à une sorte de respiration au moyen de l'introduction de l'air dans Ieur intérieur, soit à l'exhalation de vapeurs on à la transpiration. La figure 20 représente un lambeau d'épiderme pris sur la face supérieure d'une feuille de renoncule aquatique : $e, e$ sont les cellúes épidermiques et $s, s$ représentent les stomates. La figure $\vdots 1$ représente la coupe verticale de l'épiderme d'une feuille de garance; $e, e$ sont les cellules transparentes et incolores de l'épiderme, p'représente les cellules du parenchyme vert sous-jacent, $s$ représente un sto- 
mate, el lat ligure fiat soir gue les deux collules qui le forment sont de mène nature que celles dlu parenchyne; l est une lacune, o! m léphond aux méats inter-cellulaires.

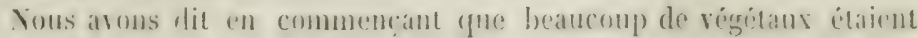
formes, a la simple une, d'un framd nomber de parties qui naissitent les unc's des antres. La's principales de ces parties, qui en compremnent

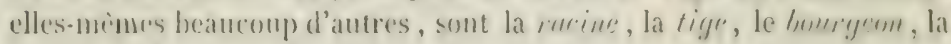
fenille, la fleme et le finit. Yous allons les examiner successirement.

\section{Racine.}

La racine est cente partie du végrital qui s'enfoner dans la terre el l'y tient antaché. (guelyuefois clle s'étend dans l'ean : d'antres fois anssi elle s'implante sur d'antres vergélaux; dans ce cas, on nomme funusite la plante qui la produit.

Parlies primeipulas. On distingue denx parties dans la plupart des racines : le conps, qui en est la partie la plus apparente, et qui peut ètre simple ou divisé; les smtirules, qui sont les divisions extrèmes du premier, et qui serent de sugeirs pour transmette les sucs de la terre an reste de la plante. Quelques auteurs admellent une troisieme partie daus la racine, c'est le crllet; mais la plupart du temples ce collet n'est qu'une tige, ou extremenent raccourcie, comme dans beancoup de plantes herbacies, ou modifie dans son aspect et quelques unes de ses fonctions par son séjour dans la terre, comme dans les fougères. Dans les regritanx lignenx qui ont me racine (t) une tigge biend distinctes, le coll'ct n'est rqu'un plan imaginaire chute l'un ct l'autre organe.

Imuree. Les racines, eu cigard à leur durée, sont dites: ammurlles, lorsqu'elles naissent et meurent dans la mème anné bismmulles. lorsqu'elles meurent a la fin de la seconde annee; rivares, quand clles vivent plus de deux ans (1).

1. I.es plantes, de mème que les racines, sont distingueses en ammelles, bistmmuelles et vivares. Les p'antes annuelles naissent, fructilient ot menrent dans le cours d'une annee; exemple. Ie coquelicot pupares rheras'. Les plantes bisannuelles accomplisent leur vegetation dans le cours de deux anness, èe-à-dire que la commeneant a l'époque de la di-persion des semences de leur espece, vers l'arrière-sitionn, elles pounent au printemps suivant des feuilles et une faible tire dont elles... dejounillent it l'aulomne; la raciue reste l'hiver dans une sorte dinourdiwement dont elle sort an printemps, pour repou-ser avee plus de forre. Aleurir en fruetifier: la plante entière meurt is la fin de la saison : telle en l'angilinge angelien archengelica). Les plantes vivaces sont celles qui sisent plus de deux ans, et qui penvent fructifier un certain nombre de fois ar ant gue de perir. On les distingne en vivaces herbacies et en vivaces ligneusps. Dann les premieres les racines 


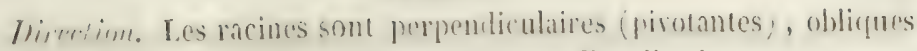
ou horizontales : ces mots ne demandent pas d'explication.

Division. Les racines sont simples, rameuses, fasciculées on chevelues. basis le premier as le cerpe de la racine es unique on mon divire; formugh, la carote. Dans le second, il se disise en rameanx distincts peu nombrenx, et d'un diametre encore considínable; retrunple, la rhubarb. Dans les suivants, la petitesse et le noinbre des divisions. aurmentent de manière ì représenter, ou des fibres encore distinctes et nombrenses comme dans l'angiticgue, ou une sorte de clievelure, comme dans le fraisier.

Finm. Les formes des racines sont tellement varites, qu'il est difficile de: donner une grande exactitude aux rermes (fu'on emploie pour les décrire. On distingue cependant les racines:

Fusifurmes, gui vout en s'anumeissant du collet à la partie inférieure; exemple, la betterare.

Tintu uses, rmuturiorios; diversement contournées sur clles-mêmes; exemples, le polygala, la bistorte.

L.trultes, agant de distance en distance des articulations ; eremp/le, la racine de la gratiole.

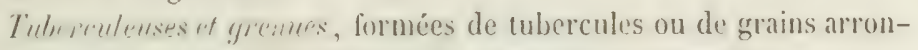
dis, séparés par les parties fibreuses; exrmple, ha filipendule.

Linbrifires, Rich.; présentant sur ditherents points de leur étendue des tuberrosités rolumineuses et d'une forme arrondie. Ces tubrrosités sont des espèces de bourgeons snuterrains et non de véribables racines (1). Elles sont presque entierement composées de fécule amşla-

seules sont riraces et les tires meurent charue année; ces plantes peurent virre une dizaine d’années; excmple, la rhuharbe rheum palmalum.

Les plantes viraces liggnenses, qui sont les sous-arbrisseaux, les arbrisseaux et les arbres, conservent leur lige et peuvent sive un yrand nombre d'année. Il en est mème beancoup dont il e-t impossible de fixer le terme, tant il surpasse de fois la plus longue durée de la vie humaine; exemples, le

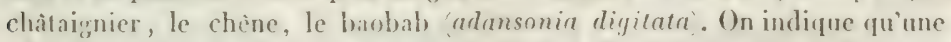
plante eat annuelle par le sione , symbole de l'année ou d'une révolution de la terre autour du soleat. Les plantes hi-annuelles sont marqués par ${ }^{A}$, signe caractéristique de nuns, qui achève sa révolution en près de deux annces terrestres; mais comme le même signe est également emploỵé pour desizrner les plantes mâles ou les fleurs màles, on indique à prèsent gu'une plante es bisannuelle par le signe ?. Les plantes vivaces herbacies premn nt le signe $\div$ du Zev gree, ou de Jipiter, qui fait sa rérolution en onze ans et quelques jours. Les plantes viraces lignieu-es se marquent ainsi $h$, figure de la faux de satorie et symbole du temps.

(1) Quelle que soit la justesse de celte observation et de plusicurs autres analogues, que l'on pourrait faire sur la partie soulerraine d'un grand nombre de régétaux, je continucrai sourentà désigner ces parties, sous le nom 


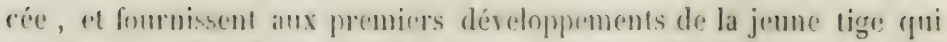
s'! tromse renfermie ; remules, la pomme de terre, les orchis, etc.

Bulliferes; terminées supériturement par un plateau (igge raccourcie) qui porte un bulbe. (ie bulbe ne constitue pas la racine; c'est un véritable bourgeon.

(rigunisution. L'organisation des racines ressemble beaucoup à celle des tiges, dont je parlerai bientôt : il y a cependant ces différences remarquables que les vraies racines n'offrent pas de canal médullaire, qui'elles sont privées de trachées déroulables à l'irtérieur, de stomates sous l'épiderme, et qu'elles ne croissent que par leurs extrémitis. Line autre différence non moins grande entre ces deux genres d'organes, et qui parât être une suite dés premières, c'est que les racines tendent tonjours vers le centre de la terre, tandis que les tiges cherchent à s'en éloigner. Les racines des plantes parasites qui s'étendent en lous sens sous l'écorce du régétal qui les supporte, ne forment qu'une exception apparente à cette règle; le contre vers lequel elles tendent est le centre de l'arbre, et c'est la résistance que leur oppose le bois qui les force à s'étendre sous l'écorce.

Tise.

La tige est la partie du régétal gqui naì de la racine, s’úlève dans l'air, et supporte le's rameaux, les fenilles et les organes de la fructification.

Esigures. On a distingué plusieurs espèces de tiges par les noms particuliers de :

rollet ou plutear; tige extrênement courte de beaucoup) de plantes herbacées et des plantes bulbifères.

Sorche ou rhizome; tige souterraine ou superficielle qui émet des radicules de différents points de sa surface; comme dans la fougère ct l'iris.

Stipe ; lige cylindrique des palmiers qui se trouve composée des débris de leurs pétioles.

Chmune; tige creuse, et entrecoupée de nouds, des plantes graminées.

Trone; lige ligneuse des arbres en général.

lin outre, beaucoup d'auteurs ont mis au nombre des liges la lemmere,

commun de racines, parce gu'une des premières conditions, dans l'applicacation médicale des substances, est la stabilite du langage : mais j’aurai soin d'indiģuer la nature particulière de celles que l'on doit regarder plutôt comme des tiģes souterraines, que comme de véritables racines. 


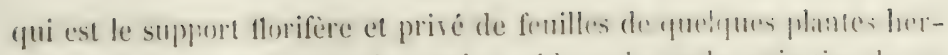

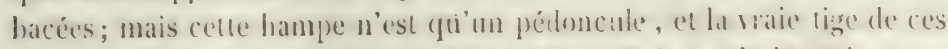
plantes est le collet qui se troure à la parlie superieure de la racine.

Toture ot dure. Les tiges sont herbacies, ligneuses, arborescentes, frutescentes, ou suffrutescentes (1).

Consistmure. Succulentes, charnues, spongieuses, creuses ou fistuleuses, roides, faibles, fragiles, flexibles.

Forme. Cylindriques, comprimées, trigones, tétragones, anguleuses, cannelées, noueuses, articulées, effilées.

Compusition. Simples, dichotomes, trichotomes, rameuses, branchues.

Jirection. Rampantes, conchies, obliques, redressées, verticales, penchées, arquées, flexueuses, volubiles, sarmenteuses.

Organisution. Les végétaux présentent pour leurs tiges deux modes d'organisation bien distincts, qui penvent servir à les diviser en deux grandes classes très naturelle's. Lo's uns offrent des tiges droite's, ćlancéés, rarement ranifíes, formérs de libres lighienses, droites et parallèles; ces fibres sont dissémincés an milien d’une substance médullaire, et on remarque qu'elles sont plus rapprochies et plus consistantes a la circonfésence yu'au centre, elfet dù à ce que les régétaux qui les offrent s'accroissant par le centre ou tout au moins par un butrgeon central, les fibres nourelles qui s'y forment refoulent les anciennes vers la circonférence. On nomme ces régétaux endengines, c'est-it-dire firmés pur le dedans. Dans ceux de la seconde classe, qui offrent sunvent des tiges ramifiées et des bourgeons latéraux, lés fibre's ligneuses sont disposées autour d'un canal médullaire unique et central, et forment des couches superposiés, dont les plus jeunes sont à la circonférence el les plus âgées vers le centre. On nomme ces régétaux exogènes, c'est-à-dire formés por lir delurrs. Leurs tiges, lorsqu'elles sont ligneuses, sont composées de trois parties principales, qui sont l'écuree, le bois et la moelle.

L'écorce est clle-mêne formée de l'épiderme, du tissu cellulnire et du liber. L'épiderme est la partic la plus extérieure; c'est, comme je l'ai déjà dit, une menbrane mince, comparable à du rélin, (qui recouvre toutes les parties de la plante. Le tissu cellulaire est la matière tendre, verte et succulente, qui se trouve immédiatement sous l'épiderme et

(1) Les ouvrages élémentaires qui traitent de la signification des termes orgyanographiques des plantes, se trouvant entre les mains de tous les éléves, je me dispenserai d'expliquer tous les mots que je vais citer. Je rensuie également d'arance aux mêmes ourrages, pour l'explication des termes presque infinis employés dans la description des feuilles, et pour tous les autres ditails que je ne puis comprendre dans celui-ci. 
remplit les mailles du liber. Te liber est la partic fibrense de l'ecorce;

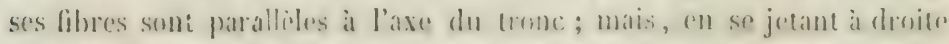
et it ganclue et en se remissint anx sinmosites, clies compo-ent des mailles dont la forme varie suivant les vígétanx:

Le bois est la parlin la plus solide du viegétal. On y distingne fucore l'ouldion et le ctrur : colui-ci, qui occupe le centre, est parremu is son dernier degre de dureté at de développement; le premier, plus extérieur, est encore imparfait et ne doit derenir vrai bois que par les progrès de la végétation.

La moelle est une substance spongiense, renfermée dans un canal intérieur nommé caurl médullnire, qui s'étend depuis la racine exclusivement, jusqu'anx pxtrímités du végrital. Elle paraît ètre de mème nature que le tissu cellulaire de l'écorce, arre leguel elle comnunique au mosen d'irradiations ou de conduits fui traversent le bois.

\section{Bourfeons.}

En gínéral on désigne sous ce nom toutes les parties des plantes qui serrent ì envelopper les jeunes pousses, pour les mettre à l'abri de l'hiver, "t qui sont ordinairement formées de feuilles ou de stipules arortées. On distingue parmi les bourgeons:

1" Le bulbe, qui est le bourgeon permanent des plantes liliaciers. On l'a mis pendant longtemps au rang des racines; mais la vraie racine de ces plantes se comprose dı faisceau de fibres qui se trouve à l'estrínité inféricure : au-dessus se troure la ligge raccourcie ou le collet, et enlin le bulbe ou bourgeon.

On distingue quatre genres de bulbe : dans l'un, que l'on nomme bulbe ir écuilles, les écailles, on feuilles arortées dont il se compore, sont peu serróes, peu étendues et ne forment yu'une petite partie de la circonférence : $e x$. , le lis.

J)ans le second, fque l'on nomme bulbe it thmiques, les envelopjers plus serrées et beancoup plus itendues se recourrent presque antierement, quelguefois meme font plus gue la circonférence du bulbe, mais ne sont pas soudées; $e x$. , la scille et la jacinthe.

Dans le troisiome, que l'on pourrait nommer hulbe mbé, les tuniques. forment toute la circonfírence de l'oignnon, sont entièrement soudées, et resscmblent alors à des sphéroüles yui se recourrent entièrement les uns les autres: e e. comme bullhe à tuniques, el la tulipe, que: l'on qualifie de bulbe s.licle; il n'y a aucune différence entre eux.

bans le quatrième, que lon nomme bulbe solide ou fuldritrue, les uniques qui la formaient primitivement se sont entièrement soudiers, et 
n'offrent qu'une substance homogène qui présente alors beaucoup d'antlogrie avec les racines tuberenses. Lit., le safran et le colehigue.

2" Le turion : c'est le houregenn des plantes siraces, sime a leur collet et se confondant quelquefois arec lui.

3" Le brutem, on lumengeon proprement dit; c'est celui qui nail sur la tige et sur ses ramifications.

\section{Fenilles,}

Il est impossible de donner une définition cxacte el en meme temps grencrale des feuilles. Je me restreindrai done à dire que ce sont ordinairement des parties larges, peu ćpaisses, vertes, mobiles, yni ornent la tign des plantes herbacées comme celle des arbres, et qui leur servent d'organes inspiratoires et expiratoires.

I.es fenilles sont portées sur une (quene, on frifiule, plas ou moins longue, quelquefois très courte on mème sensiblement nulle; alen's la feuille adhere immédiatement ì la tige et prend l'épithète de s'ssils: dans le premier cas on la nomme feuille pétiolée.

On distingue encore les feuilles en simples et en comprosires. Eilles sont simples lorspue le limbe, ou la partie large de la feville, est contimu dans toutes ses parties, comme dans le tilleul; compories, quand il :c divise en plusicurs parties distincles et séparés jusqu'an pétiole, yuelquefois mème porties chacune sur un pétiole partiel, comme dans le rosicr : chaçue petile feuille se nomme alors foliole.

I.e contour des fenilles est anguleux, ou en cône arrondi, ou orale; entier, on découpé. Ieur surface est lisse ou velue; leur ípaisseur ést souvent celle d'une feuille de papier, mais elle peut ère plus considérable. Elle est quelyucfois telle, comme dans certains rurfus, que la feuille ressemble à un large gâteau charnu.

La couleur des feuilles est ordinairement verte; lorsqu'clle est tnut autre, mime blanche, les feuilles sont dites rolurres. Quand les fenille's ne snnt colorées ru'accidentellement et partiellement, on dit qu'elless sont panachées.

Stmerture. Is limbe de la feuille est l'épanonissement du pétiole, et celui-ci est composé des mèmes parlies que la tige. On retroure done dans la feuille, de l'épiderme, du tissu cellubaire ou du parenchyme, et du tissu rasculaire on des fibres. Ces dernières se dirisent de plus ('n plus à partir du péliole: elles sont d'abord en faisceaux distincts et proéminents, que l'on nomme neveures; ensuite elles forment de simples reines; enfin elles disparaissent et se mêlent au parenchyme.

$I$ 'serye. Les feuilles sont les organes inspiratoires et expiratoires des vígétaux : elle leur servent à absorber dans l'air les fluides nécessaires 
à lenr accroissenent, et à rejeter ceux qui leur sont inutiles; elles font anssi fonction d'urganes excrétoires, car elles laissent passer le superflu de's humenrs qui nuirait à la vie clu virgélat. I.es feuilles transpirent principalement par leur surface supérieure, qui est lisse, serrée et comme vernissce : elles alosorbent surtout par leur surface inféricure, qui est ordinairement recourerte d'un tendre duvet.

\section{Fleur.}

La fleur est la partie du végétal qui renferme les organes de la fructification. Lille est ordinairement formée de quatre parties, qui sont: le colire, la comolle, l'etomine et le pistil. Elle est complete lorsgu'elle comprend ces quatre parties, et incomplete lorsqu'une ou plusieurs lui manquent.

Le culice est l'enveloppe la plus extérieure de la fleur. Il sert comme de rempart aux autres parties; aussi est-il d'une texture plus solide et phus durable. Il est ordinairement vert, et manque quelquefois. It peut être formé de plusieurs pièces distinctes nommées séfules. Lorsque ces pièces sont adhérentes ou soudées dans une partie plus ou

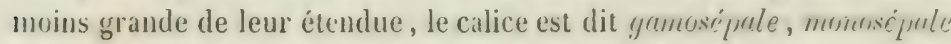
ou monophylle.

La corolle est une enreloppe moins extérieure que le calice, et qui entoure immédiatement les organes reproducteurs. C’est la partie de la fleur cqui est susceptible de prendre le plus d'écliat en raison des britlantes couleurs dont il plaît souvent à la nature de l'orner. C'est anssi celle qui a communénent le plus d'odeur. Elle manque plus sourent que le calice.

La corolle peut être d'une ou plusieurs pièces, dont chacune porte le nom de pétule. Lne corolle d'une seule pièce est dite monopéfule on ymmopretale, et celle de plusieurs, jolypétule. Lorsqu'une fleur manque de corolle, on la nomme apétale.

L'étumine est l'organe mile de la fleur. Lille est le plus soment formée d'un filet plus ou moins long, qui porte à son extrémite une petite boìte ou anthere, contenant la poussière fécondante on lo fmllen. Quelquefois le filet manque, et alor's l'anthere, qui n'en constitue pas moins une étamine, prend l'épithète de sessile. Le pollen fournit an stigmate, par contact on sans contact, la substance qui doit féconder l'ovaire.

Le pistil est l'organe femelle de la fleur. Il est tout à fait au centre et comme défendu par les autres parties. On y distingue l'uxnim, le style et le stigmute. Loucrire est la partie la plus inférieure; il e'st presque tonjours renfle, et contient le greme du fruit. II est tantot libre de 
tonie adherence arec les antres vrananes de la lleur, et tantôt plus ou moins soudé avee le calice, ce qu'on exprime en disant gue l'ovaire est libre, mblhisent ou demi-adherent. Le style est un prolongement rélréci de l'oraire, placé entre lui ct le stigmale. I.e stigmute cist l'extrémilé entière on divisée du sly le. Onelquefois le style manque : alors le stigmate est sessile.

On se fait aujourd'hui, sur l'origine et la réritable nature des diflérentes parties qui composent une fleur, une idée bien différente de celle gu'en avaient autrefois les botinistes, et Limé en particulier. Ce grand naturaliste supposait gue la ligneou le rameau, à l'endroit de la fleur, se dilatait et s'élarginsait en mu platean, et que les différentes parties de la hemé élaient une continnation de celles de la tige. Ainsi, d'après Limné,

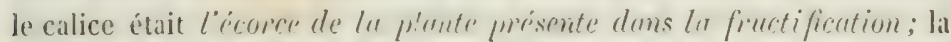
corolle en etait le liber; les chamines dérivaient des conches lignenses, (t le pistil repondait au canal médullaire. Mais des observations nommbreuses tendent plutòt à nous laire considérer la fleur comme un rameau atrophié, dans lefuel les espaces d'insertion ont prestue complétement disparu; de telle manière que les fenilles, de plus en plus amoindries et dénaturées, paraissent former des rerticilles concentriques dont le premier, rosté le p’us exterieur, constitue le calice; un second la corolle; un troisiome l's ctamines, et un quatrieme le pistil. Voici quelgues unes des obseriations sur lesfuelles cette manière de voir est fondée.

1" Dans un grand nombre de plantes, on peut voir les feuilles dimimuer et se modifier iusensiblement à mesure (ju'elles se rapjrochent des fleurs, tollement qu'entre les plus proches et les divisions du calice, on ne troure presque ancune diflerence; et, récipropuement, les divisons dn calice, en se déreloppant, açuièrent quelguelinis une si grande ressemblance arec les feniles, qu'il devient évident que ce sont de véritables fenilles (ex. la rose).

$2^{\circ}$ Il y a des fleurs, telles que celles des tulipiers, des magnoliers et des nénuphars, (qui offrent un passage manifeste des folioles du calice aux pélales, et les fleurs de nénuphar présentent un grand nombre de rerticilles de pétales gui prennent peu à peu la forme et font fonctions d'ütamines, en s'approchant du pistil. Réciproquement, la culture des végétaux, en produisant des fleurśs duhles, ne fait que convertir les élamines en pétales, par une surabondance de nourviture qui augmente l'ampleur et la beauté de la fleur, mais s'oppose à la reproduction de l'espèce. Toutes ces transformations montrent que les étamines et les pétales ne sont pas d'une nature autre que le calice, el que les feuilles par consćquent.

3० Beancoup d'ovaires et même de péricarpes des fruits, présentent si 
manifestement la structure et l'apparence d'une feuille pliée et sondée, win de plusieurs feuilles rapprochées et soudées, qu'il est encore certin que les uns et les autres ne sont que des fevilles modifiées; par exrmple, les oraires et les péricarpes de haricots, de baguenaudiers, de séné, etc.

\section{Fruit.}

Le fruit est l'oraire dércloppé et accru par suite de la fécondation. On y distingue toujours deux parties essenticlles, le privicurpe et la grmine. Mais on y comprend sourent des parties accessoires gue leur position rapprochée de l'ovaire et leur déreloppement simultané rattachent ì cet organc. Tel est le calice quand il est adhérent, ou lorsque, sans ètre adhérent, il persiste en devenant membraneux ou charnu. Enfin on considère souvent comme un scul fruit un assemblage de plusieurs fruits rémnis sur un rapport commun, comme on le roit dans le cine dés pins et des sapins, dans li figue, la mûre, ctc.

\section{pericarpe.}

Le péricarpe répond aux parois de l'ovaire fécondé et détermine la forme du firuit. On! distingue toujours trois parties : l'epuicurpe, l'endocarpe et le sarcocarpe ou mésocarpe.

L'éficurpe est la membrane extérienre qui recourre le fruit. Il répond à l'épiderme de la surface inférieure de la fenille ou des fenilles carpellaires lorsque le fruit est isolé du calice, ou à l'épiderme de la feuille ou des feuilles calicinales, lorsque le calice était soulé avec l'ovaire.

L'endocerpe est la membrane pariétale interne du péricarpe; il rípond ì l'épiderme de la surface supéricure de la fouille ou des fetuille's qui formaient les carpelles de l'oraire.

Le sarcocarye ou mésocarpe est une partic parenchỵmateuse comprise entre l'épicarpe et l'endocarpe, et qui répond au parenchụme des feuilles carpellaires. Il est très développé dans les fruits charmus; peu apparent, au contraire, dans les fruits secs; mais il existe toujour's.

La carité intérieure du péricarpe porte le nom de logre et peut ìtre simple ou muliphe. Fu péricarpe à une seule loge est dit unilormluire;

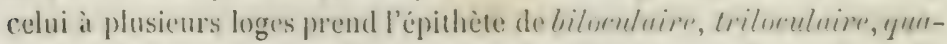
driloculnire,... muldilorulaire, suivant qu'il présente 2, 8, 4, ou un plus grand nombre de loges. L n péricarpe uniloculaire e'st généralement formé par une seule feuille carpedlaire dont les bords se replient et se soudent du cooté de l'axe du véerétal; mais il peut aussi prosenir de plusieurs fenilles non repliées, réunies par l’accolement de leurs bords. Ln 
péricarpe pluriloculaire est toujours formé d'autant de funilles carpe!laires repliées jusqua'au centre qu'il y a de loges.

D'après ce yui précede, les cluisms qui forment la séparation de's loges, résultent de la juxtaposition des replis de deux feuilles contiguës, et sont composíes de deux lames d'endocarpe réunies par une couche plus ou moins mince de mésocarpe. Il faut ajouter qu'elles alternent toujours arec les divisions du stigmate. Ces caractères distinguent les cloistres verres de certaines divisions incompletes observees dans quelques fruits, et qui sont formées par une extension des trophospermes.

Ou donne le nom de tiruphenterme ou de plarentrire à un corps placé le plus ordinairement à la jonction des feuilles carpellaires, mais quelquefois aussi sur leur nerrure mediane, et auquel sont autachées les graines. La place occupéc par le trophosperme fuurnit des caractères assez importants. Cet organe est dit:

Fentrel, lorsqu'il occupe le centre d'un péricarpe uniloculaire, sans aucune adherence arec les parois laterales. E.r. dans les primulacées et les santalacées;

Acilluire, lorsgu'il occupe l'angle central des loges d'un fruit multiloculaire, on, ce qui est la nềme chose, le bord replié jusqu’au centre des fenilles carpellaires formant les loges : p.t., les anomées

Sutmenl, quand il occupe la suture ou le point de jonction de la feuille ou des fevilles carpellaires qui forment un péricarpe uniloculaire: ex., le haricot;

Puriétul, quand il est placé sur la paroi même du jéricarpe, par exemple, dans les cucurbitacées, les loasées, les caricées.

Le nombre des graines contennes dans un péricarpe peut varier considérablement. Lorsqu'il n'y en a qu'une seule, soit que céla dérive dr la présence d'un seul orule dans l'uraire, ou de l'arortement des autres, lorscu'il y eu a plusieurs, le péricarpe ou le fruit est dit momespermer. Quand il y a plusicurs semences dans le fruit, on le dit disperme, titrespurme, olignsperme, prolysyerme, suivant le nombre qui correspond à cè appellations.

Pour que les graines puissent sortir dn péricarpe à leur maturité, il paraît nécessaire que celui-ci s'unre d'une manière quelconque; cependant il y a des péricarpes qui ne s'ourrent pas et auxquels on donne le surnom d'indréliscents; ceux qui s'ourrent naturellement sont nommés déliscents.

Les péricarpes déhiscents peuvent s'ourrir par des dents qui s'écartent à leur sommet, ou par des rpeercules d'une étendue limitée, qui se détachent du fruit; ou bien ils se partagent en un nombre déterminé de pièces ou de panneaux de dimensions à peu près égales, auxquuels on 
donne le nom de calies. Alors on dit que le fruit est bicalie, tricralie, qualrivaler, multicalee, suirant le nombre de parties. Généralement le nombre des valves est égal a celui des loges, parce que leur rupture s'opère à l'endroit de la suture marginale des carpelles, par le décollement des cloisons. Dans ce cas, la déhiscence est dite septicide. I)'autres fois le nombre des ralses restant le même, la déliscence, au lieu de s'opérer par le bord des carpelles, a lieu par la nerrure médiane de la feuille, ou par le milieu des carpelles, auguel cas charue valve emporte avec elle une cloison et la moitié de deux loges contiguës. On nomme cette déhiscence lormlicidr. Enfin la séparation des valves peut aroir lieu à la fois par les sutures marginales et par la ligne uédiane des carpelles: alors le nombre des valves est double de celui des loges.

D'après le peu que j'ai dit jusçu'ici, on peut comprendre combien la forme et la disposition des péricarpes, et celles des fruits par consérquent, sont susceptibles de varjer, et l'on ne sera pas élonné d'entendre dire que toutes les classifications de fruits qui ont été proposées n’embrassent que la plus petite partie des modificatinns que ces organes peurent présenter. Je vais essayer d'étendre un peu celle classification, tout en domnant plus de précision aux termes déjà employés par les botanistes.

Je remaripue d'abord qu'il y a des fruits qui provicnnent d'une seule fleur, et d'autres qui résultent de la connexion de pistils fécondés alpartenant à plusieurs fleurs. Ces derniers portent le nom de fimits agrégés.

Quant aux fruits qui proviennent de la fécondation d'une seule fleur, je fais l'observation que les uns dérivent d'un seul pistil (qu'il soit simple en réalité, ou (gu'il résulte de la soudure plus ou moins complète de plusieurs), et que les antres proviennent de pistils distincts et forment, la plnpart du temps, autant de fruits séparés; on les nomme firuits multiples, ou mieux fruits séparés.

Enfin, parmi les fruits qui succèdent à la fécondation d'un pistil simple en apparence, mais yni pent ètre en réalité composć, il y en a qui n'éprouvent pas de division bien manifeste en mùrissant, je leu' conserve le nom de fruits simples ou de fruts indiris; mais les antres se séparent en parties tellement distinctes, que beaucoup de personnes considirent chacune d'elles comme un fruit complet; je les nomme fruils divisés ou partayjes. Voici le tableau abrégé de cette classification: 


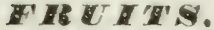

A. - Provenant d'une seule fleur. Exeuples.

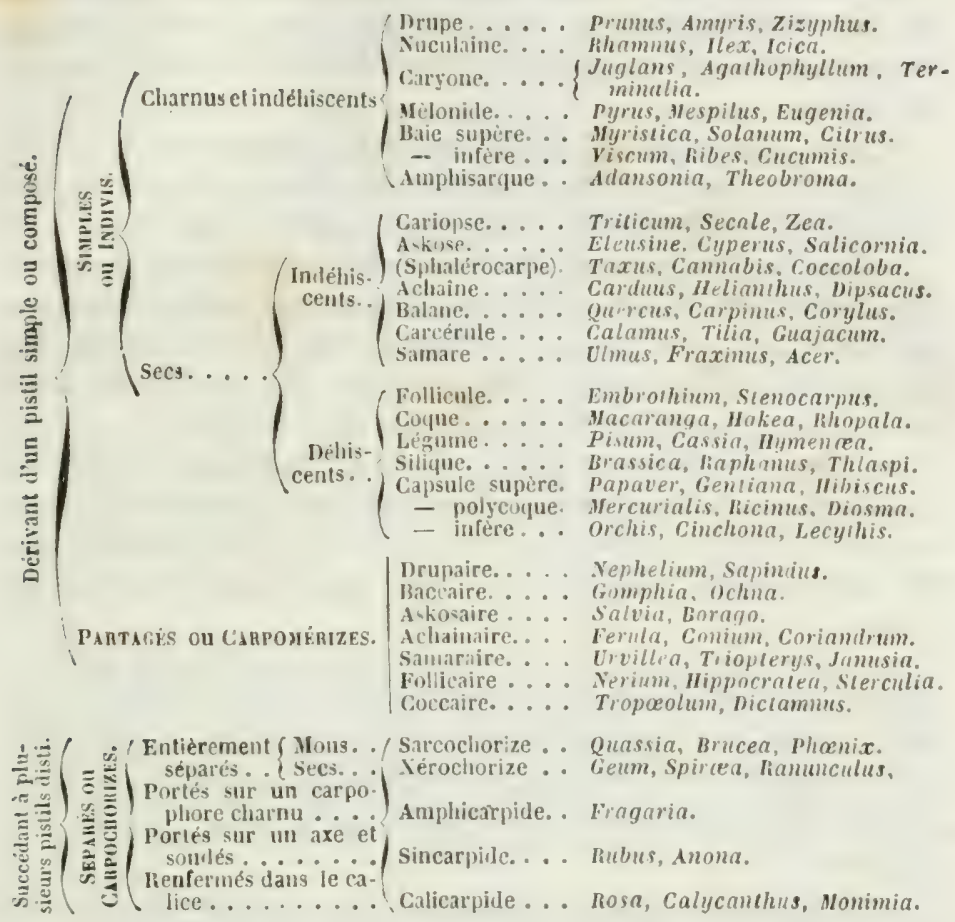

B. - Provenant de plusieurs fleurs.

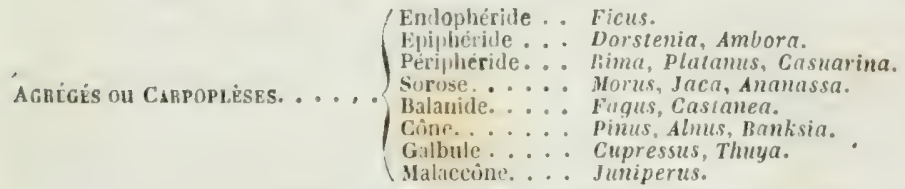

FRUITS SIMPLES OU INDIVIS.

\section{Fruits clarnus.}

DRLPE. Fruit provenant d'un ovaire libre ou non soudé arec le calice, et formé d'un péricarpe charnu et indéhiscent, dont l'endocarpe est endurci en forme de noỵa. Le noyau peut être à une ou plusieurs loges, et il peut être osseux, ligneux ou cartilagineux. Lorsque l'endo- 
carpe, par sa consislance molle, cesse d'être facilement distingue du sarcocarpe, le fruit devient une baie.

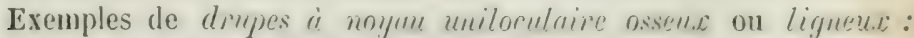
Toutes les rosacées drupacées des genres amy!ydalus, prunus, repasus; les térébinthacées des genres schimus, ihns, pistucin, mungifera; les genres andira, rlipterix, commilobium de la famille des papilionacées.

Drupes i noyau uniloculnire cortilngineus : genre amyris.

IJupes a noyau pluriloculaire, pourant devenir uniluculuire par avortement : genres spondias, eleocrmpus, zizyphus, olea, cocos.

Ncculaixe. Fruit provenant d'un oraire libre, à péricarpe charnu et dont l'endocarpe durci forme des loges distinctes auxciuelles on donne le nom d'osselets ou de mucules. La nuculaine ne differe du drupe que parce qu'elle contient plusieurs noyaux distincts. Ex., les genres rhammus, ilex, bulsamodendron, icica, bursern, hedmigia, etc.

Caryone (noix). Fruit provenant d'un ovaire soudé avec le calice et à péricarpe charıu, dont l'endocarpe endurci forme un noyau uniloculaire, comme dans les genres juglans, pterocarya, agathoyhlyglum; ou biloculaire devenant uniloculaire par arortement, comme dans le genre Cornus.

Mèlonide (pomme). Fruit provenant de plusieurs ovaires infères, soudés entre eux et arec le calice. Il est formé d'un péricarpe charnu dont l'endocarpe est partagé en plusieurs loges, disposées en rayons aulour du centre du fruit. Il présente à l'extrémité opposée au pédoncule une rosette ou une couronne formée par les dents du calice yui ont persisté.

On distingue deux rariétés de mèlonide : l'une dont les loges de l'endocarpe sont cartilagineuses, comme dans les gemes mulus, jyjus,

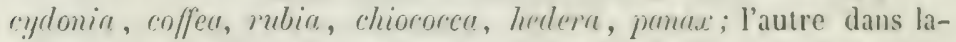
quelle les loges sont osseuses, comme dans les genres mespilus, mmelamelier, rotomeaster, croteryus, myrtus, rugenire, el genres analogues; cephachis, psychotria, etc.

BATE. On donne communément ce nom à tout fruit d'un petit volume, assez succulent pour s'écraser facilement dans les duights. A ce litre, les fruits de l'if, du sureau, du nerprum, du groseiller, de la bryone, de la helladone, de la morelle, de l'asperge, du berberis, du sorbier, du rosier, de la fraise, de la framboise, du genévrier, du mùrer, du fignier et beancoup d'autres, sont des bries. Yais, pour donner a ce mot unc vat leur plus scientifigue, il faut d'abord faire abstraction du volume, ce qui pourra faire domner le nom de lmir à de tries gros fruits, tels yue le melon et le potiron; ensuite il faut retrancher du gemre tous les fruits qui ne sont pas simples, c'est-d-dire tous cenx qui proviemnent de plu- 
sieurs nvaires distincts, suit qu'ils appartientent à une seule fleter ou à plusieurs. De celle maniere, partni les fruits nommés ci-dessus, nous éliminons déjà les sejot derniers, à commencer par le fruit du rosier; ensuite nous remarquerous que la baie, comme le drupe et la medonide, pent présenter des Ioges; mais comme il est de son essence d'ètre molle ct parenchrmmateuse, il firut que la matière des loges, ou l'endocarpe, soit peu distincte de la pulpe, autrement le fruit deviendrait une murulaine comme le fruit des nerprons, ou une milonide comme celui des sorbicrs. Souvent mème, en raison de sa faiblesse, l'endocarpe disparaitra dans la pulpe, et la haie ne paraitra formée que de parenchyme st de semences. Enfu, pour (fu'unc baie soit complète, il faut que, même en conservant des loges, celles-ci soient peu apparentes ou remplies de résicules succulentes; car si les logges étaient rides et d'une certaine capacité, la baie, réduite à un péricarpe de peu d'épaisseur, deviendrait plutòt une copscule rlummu. Tout en faisant les restrictions qui précèdent, il reste encore un unmbre considérable de fiuits mous auxguels on ne pent refuser le nom de buie, et dont roici un certain nombre d'exemples :

Baies nues.

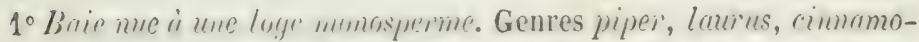
mum, prosen, myristirn. Les fruits qui appartiennent à cefte section seraient des drupe's, si la membrane endocarpienne arait plus d'épaisseur et de consistance. Les baies de laurier et de cannellier sont entourées, à leur partie inférieure, par le calice persistant. Celle du muscadier est déhiscente à maturité.

2o Buir me à plusians laygrs monospormes. Le fruit peut devenit monosperme par arortement. Eid., les genres arlucts, rhrysopllyllum,

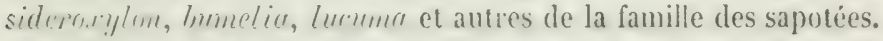

3n Burr me à zne loge prolyspreme. Genres berberis, prossiforn, ravica. Dans les deux derniers genres, la baic, pourvue de trophospermes pariétaux, ressemble heaucoup à celle des cucurbitacées (péponide); mais celle-ci est infère on soudée arec le calice.

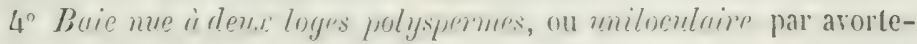
ment. Genres ritis, strychums, atropr, mandrayorn, solanum, lycium, phlygsulis. Dans ce dernier genre (ullielinngr: la baie est entourée par le calice persistant et accru, sous forme d'une ressie rouge, d'un volume beaucoup plus considérable que celui du fruit.

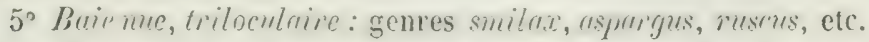

6 Brie me, pluriloculuire, prolysycrine: genres pleytoluccu, nymjucea, citrus. Le fruit des ritrus (orange, citron, higarade, etc.) a reçu le nom particulier d'lespripidie. C'est une baie dont le péricarpe, plus 
ou moins épais et pulpenx, comtient, au centre, de 5 à 12 liges séparées par des cloisons membraneuses qui peurent se dédoubler sans déchirement. L'intérieur des loges est occupé par des utricules remplies de suc, qui sont une extension cellulaire des parois de l'endocarpe. Les semences sont pourrues d'un épisperme cartilagineur, et sont fixées à l'angle interne de chaque loge.

\section{Baies inferes ou soudées avec le calice.}

7. Baie införe i une loge monosperme : genres antidaphue, vismun, loranthus et autres de la famille des loranthées.

$8^{\circ}$ Baie infere a 2 logges monospermes : genre symphoricurpos.

9० Brie infere à 3-5 loyes monospermes, dont les loges disparaissent par la destruction des cloisons. Exemples : les genres sumbucus tet riburmum.

$10^{\circ}$ Baie infere à 3 loges polyspermes et iplacentation arile : genres musa, lonicera.

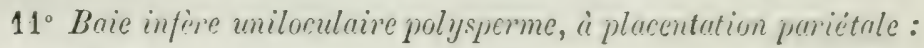
genres ribes, cactus, opuntia.

$12^{\circ}$ Buic infore triloculaire à placentation pariétale. Ce fruit peut devenir complétement charnu par l'oblitération des loges, et peut offrir, d'un autre côté, une vaste cavité irrégulière provenant de la déchirure du parenchyme et des trophospermes. Exemples : la jlupart des fruits cucurbitacés, et notamment ceux des genres brymin, cilrullus, cucumis, cucurbita, Ingenaria. Celte espèce de baie a reçu le nom particulier de péponide, dérivé du nom spécifique du potiron, curmibita pepo, ou du nom grec du melon ( $\pi \dot{\varepsilon} \pi \omega)$.

13. Braie infere multiloculaire, ip placentution purietule: exemple la grenade. On a donné à ce fruit, remarquable par son épicarpe coriacé, ses deux rangs superposés de loges, et ses graines renfermées dans une utricule pleine d'une pulpe succulente, le nom particulier de bulurste, qui est celui par lequel les anciens désignaient la fleur et non le fruit du grenadier.

AMpusınece. Fruit poly̧sperme, indéhiscent, dur et comme ligneux à l'extérieur, charmu on rempli d'une pulpe fibreuse à l'interieur. Exemple: le fruit du babab frmlnusmuitr), (gu'on peut aussi considérer comme une baie nue et pluriloculaire, ì épicarpe solide, et le fruit du calebassier (crescentiu) qui paraît être uniloculaire.

\section{Frults secp et indèlscents.}

Caniopst. Fruit monosperme et généralement nu, dont le péricarpe tris mince est intimement sondé arec la graine el no peut en ètre 
séparé. Exemples : la plupart des fruits de planies graminées, tels que le blé, le seigle et le maïs. Dans l'avoine et dans l'ivraie, le cariopse adhère à la glume supérieure, et dans l'orge il est adhérent aux deux glumes. Le fruit des polygonées est sourent aussi un cariopse; mais il est presque toujours entouré par le périgone persisiant, et quelquefois plus ou moins soudé avec lui.

ASKOSE (de árxòs, outre). Fruit supère et nu, see, monosperme et indéhiscent, dont le péricarpe est distinct du tégument propre de la graine et peut en ètre séparé. Ce fruit se rencontre surtout dans la fitmille des cypéracées et dans une partie des polygonées, des chénopodées et des amarantlacées. Dans ces deux dernières familles, où l'askose se montre pourru d'un péricarpe très mince et membraneux, il a reçu le nom d'utricule ; mais ce mot peut être difficilement employé en ce sens, étant déjà usité pour exprinoer la cellule la plus simple du règne végétal. C'est pour cette raison que je propose le nom d'asliuse, auquel je clonne un sens qui le distingue à la fois du cariopse el de l'achaine.

Achane (prononcez alime). Fruit infere, sec, monosperme et indéhiscent, dont le péricarpe, confondu arec le tube du calice, est distinct de la graine. Ce fruit appartient à la famille des synanthérées dont il forme un des caractères les plus essenticls. Il est souvent couronné par une aigrette on par un anneau membraneux qui représente la partie libre du calice.

Balane (de ßrixus, grland). Fruit indéhiscent, provenant d'un ovaire infère et pluriloculaire, mais presque toujours réduit à une loge et à une graine par l'arortement des autres. Il offre toujours à son sommet les dents excessivement petites du calice soudé arec le péricarpe, et tous deux réunis sont à peine distincts du tégument propre à la graine. J.e fruit est en outre renfermé, en tout ou en partie, dans un involucre écailleux ou foliacé. Exemple : les fruits des genres carpinus, corylus, quercus, lithocarpus, de la famille des cupulifères.

Carcértce. Fruit sec on presque sec, uni oupluriloculaire, polysperme, mais pourant devenir monosperme par arortement. Ce fruit est toujours indéhiscent, et les loges, par conséequent, lorsqu'it y en a plusieurs, ne se séparent pas et ne s'ourrent pas à maturité. On peut citer comme exemple de carcérules les fruits des genres culamus, sagus, tilia, apeiba, lawsonia, guajacum, etc.

Samare. Fruit non adhérent au calice, uni ou pluriloculaire et indéhiscent, dont le péricarpe est prolongé en ailes membraneuses. Exemples: les fruits de l'orme champêtre, de l'ailante, des ptelen, des frênes et des érables. A la rigueur, ces fruits ne forment pas une espèce particulière, et ne sont qu'un askose ou un carcérule dont le péricarpe retourne à la forme foliacée Ainsi le fruit de l'orme champêtre est un 
askose qui occupe le centre d'une membrane à peu pres circulaire. Ie fruit du pelén tivfolinte est tout i fait semblable pour la forme, mais c'est un carcerule à deux legges. Celui du frène est encore un carcerule dont une des deux loges arorte, et qui se prolonge, suivant l'ase du fruit, en une large feuille membraneuse. Le fruit des érables est un carcirule a deux loges presque distinctes, terminées chacune par une aile.

\section{Fruits secs délilscents.}

Folticule. l'ruit sec, supère, uniloculaire, poly̧sperme, déhiscent, formé par une seule feuille carpellaire repliée du còté de l'axe végétal. Il ne présente (qu'une suture reutrale suivant laquelle s'opère la déhiscence et un trophosperme simple on biparlible. qui derient quelyuefois libre par le décollement des bords du péricarpe. Le follicule est très répandu à l'état de fruit composé, dirisé on multiple ; mais il est très rare comme fruit simple, et on ne peut gucre en citer pour exemples

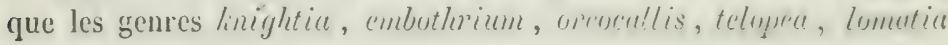
et stenocarpus de la famille des protéacées.

Cogte. Fruit sec, supère, formé par une seule fenille carnellaire repliée du côté de l'axe végétal. C'est égalenent de ce cùté que s'opère la principale déhiscence du fruit et que sont fixées les graines. Ce fruit offre donc de très grands rapports arec le follicule, dont il n'est peutêtre qu'une variété. Foici cependant ce qui l'en distingue le plus ordinairement : il ne conticnt qu'une graine, et quand il en renferme deux, elles sont fixées collatéralement ì la suture ventrale, au lieu d'ètre placées l'une au-dessus de l'autre. Le péricarpe est plus épais, surtuul du côté externe; de sorte que la loge est excentrique et rapjprochée du bord interne. L'endocarpe est solide, quelyuefois ligneux, the rompt avec élasticité par la dessiccation; ct la rupture se fait non seulement par la suture rentrale, mais sourent aussi par la suture dorsale; alors la corpue est bivalve, et non univalve comme le follicule. Enfin, la corpue est souvent indéhiscente et se rapproche alors de l'askose. Cipumlant il y a toujours entre eux cette différence que l'ashose est un fruit axien , concentrique èt régulier, tandis que la coque est excentrique et irrégulière.

La coque est très rare à l'état simple, et ne se rencontre guère que dans les genres maracunga et crutunupsis de la famille des euphorbiacées, daus le grenre blacliburnin des zanthoxilées, et dans qquelgues genres de la famille des protéacées. Elle est plus commune parmi les fruits composés, partagés ou multiples.

Légume ou Gotsse. Liruit non adhérent au calice, sec, généralement bitalie, ou, tout au moins, portant deux sutures apparentes, 
l'une ventrale, l'autre dorsale. Les graines sont portées sur un seul trophosperme qui suit la suture ventrale; mais ce trophosperme se parage en deux branches, et, lorscu'on ouve le péricarpe, les graines restent antachées alternativement al l'une et a l'autre valve. Exemple: les fruits de la grande famille des légumineuses.

La gousse est, en général, uniloculaire, polysperme et à péricarpe mince el foliacé, par exemple dans les genres pisum, rubinin, colutén, cýtisus, resulpiniu, etc.; mais elle présente, sous ces différents rapports, des variations tris considérables. Linsi, il peut arriver que les bords de la feuille carpellaire, qui forment la suture où sont atlachées les graines, se prolongent dans l'intérieur de la gousse, et alteignent même la suture dorsale, ainsi que cela a lieu dans le genre ustrengulus ; alors le frnit est véritablement biloculaire. D'antres fois l'endosperme donne naissance à un parenchỵme gui remplit l'intersalle des semences et les isole les unes des autres daus autant de cavilés patrticulières; alors la gousse parait transversalement pluriloculaire, comme dans les genres

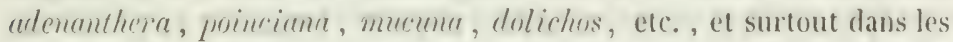
casses fistuleuses, dont l'intérieur est divisé en un grand nombre de loges par des diaphragmes transversaux presque ligneux, qui ne sont cependant encore que des exubérances de l'endocarpe, ou des fumsses rloisums. Sourent encore, lorsque la gousse est ainsi partagée en plusieurs carités monospermes, il arrive qu'elle se rétrécit fortement dans l'intervalle des graines, de manière à paraìtre formée de petites gousses monospermes ajoutées les unes au bout des autres, comme dans l'mer-

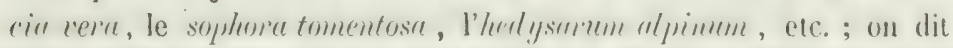
alors qu'elte est moniliforme ou lomentencere. On la dit artirulee, lorsque les pièces se séparent facilement par une sorte d'articulation, comme

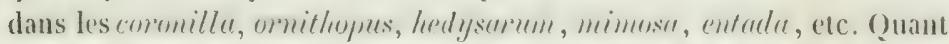
à la déhiscence, indépendamment de tous les légumes dont le péricarpe est solide, charnu ou pulpeux, tels gue les cussin, cerctunia, algurubia, hymenere, tamerindus, etc., qui ne s'onrrent pas, plusieurs gousses ordinaires, telles que celles du pismme satimme, sont indihiscentes. D'autres légumes sont monospermes, el, parmi ceus-ci, less uns sont cntourés ou prolongés par une aile membraneuse qui les fait ressembler à une samare (genre pterocorpus et myrospermum); les autres sont épais et charnus et ressemblent à un drupe : tels sont les fruits des cymometra, ropulhifera, geoffroya, andira, dipterid, commilobium, etc.; seulement, la déhiscence en deux valses des trois premiers rappelle encore l'origine ligumineuse du fruit. Les autres sont indéhiscents comme de véritables drupes.

SilıQve. Fruit sec, déhiscent, polysperme, formé de deux feuilles carpellaires à soudure pariétale, et qui, par suite, présente deux tro- 
phospermes suturaux opposés aux stigmates, et auxquels sont atlachées les graines. Les deux trophospermes sont réunis par un prolongement membraneux formant cloison, et qui sépare le fruit en deux loges. La déhiscence se fait par la rupture du péricarpe, et ordinairement de bas en haut, tout le long des sutures qui portent les trophospermes; de telle sorte que le fruit ouvert présente trois pièces, à savoir deux valves et une troisième pièce mitoyenne formér par les deux sutures, les trophospermes, la fausse cloison et les graines.

La silique appartient à toutes les plantes de la famille des crucifères. Cependant on est convenu de n'accorder ce nom rqu'aux fruits dont la longueur dépasse manifestement la largeur. On donne le nom de silienle à la silique qui est à peu près aussi large que longue; le nombre de celles-ci est aux premières environ comme 3 est à 2 .

Ajoutons que la silique peut devenir lomentacée, articulíe ou indrhiscente, dans les mêmes circonstances que la gousse, et qu'un assez grand nombre de silicules se trourent réduites par arortement à l'état d'un fruit indéhiscent, uniloculaire et monosperme.

Quelques plantes étrangères à la famille des crucifures, comme la chélidvine, le glaucium et l'hypecoum de la famille des paparéracées, ont pour fruit une siliq̣ue qui diffère de celle des crucifères par la situation des trophospermes qui sont alternes, et non opposés aux lobes du stigmate.

Capscle. On domne ce nom, en général, à tous les fruits secs et déhiscents qui ne sont ni des légumes ni des siliques. Il en résulte qu'on l'applique à des fruits très variables, non seulement en raison de l'ovaire libre ou adhérent qui les a formés, mais encore par le nombre des loges, leur soudure plus ou moins intime, ou leur séparation presque complète, leur mode de déhiscence, etc. Il y a des capsules (qui s'ourrent par des trous qui se forment à la partie supérieure (papuner nigmun, antirhhimm majus), ou à leur partie moyenne (campanula persicafolia); d'autres qui s'ourrent par une solution de continuité circulaire qui les sépare en deux parties : une supérieure formant couvercle ou opercule, et une inférieure très sourent sondée arec le calice. On donne à cette espèce de capsule le nom particulier de pixide et rulgairement celui de boite ì surometle. La pixide la plus simple appartient aux genres amaranthus et chamissoa (amaranthacées). Fille est uniloculaire et monosperme, à péricarpe nu, et s'ourre par une fissure circulaire. Dans le genre murgullis (primulacées) la pixide est uniloculaire, polỵsperue, et le calice adhère ì la partie inférieure; la mème adhérence se montre dans la pixide biloculaire des jusquiames, dans celle triluculaire des fevillec et dans quelques autres.

Les autres espèces de capsules ont une déhiscence valvaire, et cette 


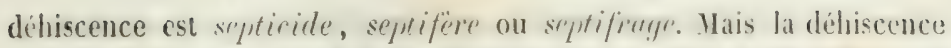
peut difficilement servir à la classification des capsules, ru'il raut mieux diviser par leur siluation supere ou infere et par le nombre de leurs loges.

\section{FRUITS PARTAGES OU CARIOMÉRIZES.}

On nomme ainsi les fruils qui, étant parfaitement distincts les uns des autres, proviennent cependant d'un seul oraire; mais cet ovaire était nécessairement composé ef formé de carpelles gui se sont séprarées peudant leur développement. Les carpomérizes ne peurent d'ailleurs ètre formés que des fruits les plus simples, parmi ceux précédemment étu-

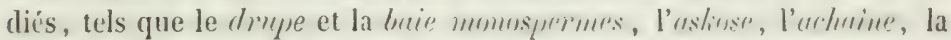
samere, le follicule et la rorpue, et ils en prennent le nom auguel on ajoute la déhiscence aire ou rimm. I.es fruits parlagés retournent d'ailleurs facilement à l'état de fruit simple par l'arortement d'une partie plus ou moins considérable des carpelle's de l'orate; mais ils n'en doirent pas moins ètre compris dans celle dirision, en ratison de ce qu'ils ne rejrésentent qu'une partie et non la totalité de l'oraire. Foici des exemples de fruits partagés :

Drtpane. Exemple, le fruit des sopindus qui provient d'un oraire central, sessile, triloculaire, et qui se tronve sourent réduit à 200 ì 1 lobe drupacé, indéliscent, monosperme : les autres lobes se montrent avortés, à la base du lobe développé.

Baccinre. Dans les gemres ordina et gomplia qui ont un oraire multiloculaire surmonté d'un seul style, le fruit consiste en un certain nombre de baies monospermes implantées sur un grnophore accru (sarcobase de quelques auteurs).

Asrosarre. Fruit des labiées et des raies boraginces, formé de 4 askoses nus au fond du calice persistant.

Achatyane. La famille des ombellifères, indépendamment de la disposition de ses fleurs en ombelles, est caractérisée par un fruil conposé de deux achaînes qui se séparent à maturité, en restant suspendus à la partie supérieure d'une columne centrale ou retrpophorf, ct ch emportant avec eux la moitié du calice 'fui était soudé arec l'oraire. M. Mirbel arait donné à ce fruit le nom très expressif de rémocarpe. (fruit suspendu); mais on le nomme plus ordinairement di-achaine. De Candolle, de son côté, a proposé de donner, à clarjue partie du fruit, le nom de móricrmpe (part de fruit). Il arrive quelquefois que l'une des deux parties avorte ou que le fruit ne se sépare pas à maturité.

Follicalre. Deux follicules parfaitement distincts, mais quelquefois solitaires par avortement, constituent le fruit de la plupart des apocynées et des asclépiadées. 
Coccame. Fruit composé de plusieurs coques séparées à maturité; tel est celui des tropremlum qui est formé de trois corgues, el celui de la fraxinelle qui en a ciny.

\section{FRLTS MLYTIPLS OU SEPARS (CARPOCHORIZES).}

Ces fruits proviennent d'ovaires distincts contenus dans unc mème fleur. Il n'est pas toujours facile de les distinguer des fruits partagés, un raison du passage insensible que l'on observe entre les ovair's distinc'ts qui produisent les premicrs, et les oraires soudés qui donnent naisance aux seconds. Dans les cas douteux, l'unité ou la pluralité des style's sert à décider la question. Ainsi, quelle que soit la séparation des loges de l'ovaire dans les labiées, les boraginées et les ochnacées, comme ces loges ne portent qu’un seul style qui part de leur centre déprimé, on les considere comme un seul oraire, et l'on regarde les askoses ou les baies qui en proviennent comme formant un fruit partagé. Par contre, dans les simaroubées, et dans le's genres brucee, brunellin, zanthorcylon, ailunthus, des zanthoxylées, où les ovaires sont libres ou presyue libres, et pourvus chacun d'un style, on les considère comme distincts, el les fruits (qui en proviennent, comme des fruits séparés.

Les fruits séparés, de même que les fruits partagés, sont formés de's espèces les plus simples parmi les fruits indivis; mais leur association variable arec différentes parties de la fleur persistantes et accrues, et leur cilat de séparation complète ou de soudure plus ou moins arancéc, sont autant de raisons pour en distinguer plusieurs genres qu'il a fallu designer par des noms particuliers.

SARCocinorize, c'est-à-dire fruits (sous-entendu) rlen'mus et sifumir. Fruit multiple composé de carpelles charnues et libres, portées sur un torus peu déreloppé. Ex., les genres quussia, simurulu, bruceu, anumirtu, dylopia, ueure, drymis, phemid. On remarquera que la datte et la cocpue du Levant sont comprises dans les sarcochorizes. C'est (jue, in effet, l'une et l'autre proviennent d'une fleur qui contenait trois ovaires distincts, et ru'on trouve quelquefois les trois carpelles developpées at formant un fruit multiple; mais elles sont le plus souvent réduites à 2 ou à 4 par avortement.

Xerochorize, c'est-à-dire firuits (sous-entendu) sers et sipumés Je nomme ainsi les fruits multiples, secs el non soudés, qui sont portés sur un torus ou sur un axe peu développé. On en distingue de plusieurs espèces, tels que :

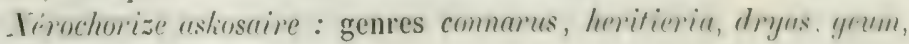
clematis, hepatica, ranunculus, anemone, etc.;

Yérochorize samaridaire : liriodendron, ailanthus. 


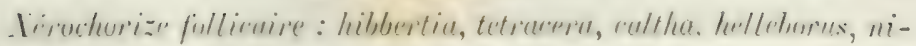
yella, delphinium, aconitum, peonia, etc.

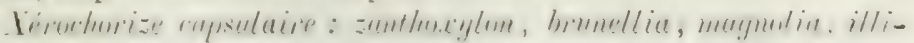
cium.

AMPHCarpade. Fruit multiple compose' d'un grand nombre d'ashoses ou de cogues indihiscentes fixes a la surface d'un carpophore charmu

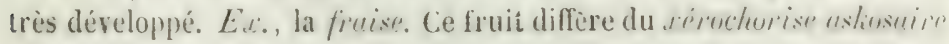
par l'amplear et la succulence de son carpophore qui en devient la partie principale et utile, et par la petitesse relative de ses astuses. II dilfère du sinnempide qui le suit, par les mèmes caracteres et par la secheresse de ses carpelles.

Sricarade. Fruit multiple composé d'un grand nombre de baies portées sur un axe, et soudées ensemble. Lit., les genres relus et anoita.

Calicarapes. Fruits multiples renfermés dans le calice de la fleur accru el derenu bacciforme; comme dans les genres resu, colyomulhus, mimimien.

\section{FRUITS AGRËGES OU CARPOPLĖSES.}

Te rappelle que ce sont des fruits qui proviennent d'oraires appartenant à des fleurs distinctes, mais qui sont soudés ou fixés sur un sup-port commun, de manièreà former un corps dense, it forme déterminé, que le rulgaire considire comme un seul fruit. Dans ce genre de fructification, le mode d'agrégation et la forme des parties accessuires ont plus d'importance, pour determiner les espices, que la nature mène des fruits. On pent y distinguer les formes suirantes:

L\DULHERDE, c'est à-dire fruits (sous-entendus) purtris en derluns. Telle est la figue, qui n'est d'abord qu'un réceptacle presque fermé, contenant un grand nombre de flears màles et fenelles entremètés, et qui devient, après la fécondation opérée dans son intérieur, un réceptacle de fruits indehiscents, soudés arec leur périgone devenu succulent.

EPIPHÉhide (fruits portés en dessus). Cet assemblage de fruits, yui appartient au genre drrstenia, ne diffère du précédent que parce que le réceptacle, au liéu d'ètre relevé en forme d'outre et de contenir les fruils dans son intérieur, est étalé en forme de plateau et porte les fruits à sa surface. 11. Mirbel a donné à cẹs deux assemblages de fruits réunis le nom de syncône.

Pérphéride. Fruits fixés tout autour d'un réceptacle charnu, sphérique ou oroïde. Tels sont ceux de l'ertucarpus incisn, du platane et des casuarina.

Sorose. Assemblage de fruits portés sur un axe peu déreloppé, et 
soudés ou au moins très rapprochés. Ce nom a été proposé par U. Mirbel pour les fruits charnus du mûrier et de l'ananas; mais il convient à plusieurs autres, tels gue les fruits agrégés de l'artucarpus. integrifintia, des morinda, du piper longum, etc.

BaLaxme. Fruit agrégé formé de un à trois balanes contenus dans un involucre épineux; ex. : le hêtre et le châtaignier.

Côxe ou STrobile. Fruit composé d'un grand nombre d'askoses, d'achaines, de samares ou même de semences nues, cachés à l'aisselle de bractées membraneuses ou ligneuses, rapprochées en forme de còne ou de cylindre arrondis. Tels sont les fruits de la plupart des arbres conifères (pins, sippins, cèdre, mélèzè); ceux de l'aune et du bouleau, celui du houblon, etc.

On a donné le nom particulier de galbule à des cônes à peu près sphériques, composés d'un petit nombre d'écailles un peu charnues, vertes et soudées avant leur maturité; ex. : le cyprès et le thuya. Enfin, d'autres ont employé le même nom de galbule, ou ont prop̧osé celui de pseudocirpe pour le fruit du genévrier qui porte vulgairement le nom de brie de geniere. Je pense que le nom de malaccune, qui signifie proprement cume mou, conviendra mieux pour exprimer un carpoplèze de conifère composé seulement de trois fruits avec leurs enreloppes, renfermés sous trois écailles devenues tout à fait succulentes et complétement soudées.

\section{Graine.}

La graine est véritablement ce qui constitue le fruit, de même que les élamines et le pistil constituent la fleur. Le péricarpe, le calice et la corolle sont des parties accessoires dont, à la rérité, nous tirons souvent un grand parti, mais qui ne servent que d'enveloppes aux parties essentielles.

La graine renferme les rudiments d'une nourelle plante; c'est un œuf fécondé qui doit, après avoir passé quelque teups dans le sein de la terre, reproduire un être semblable à celui d'où il est sorti.

La graine est reconverte d'une pellicule plus ou moins épaisse, que l'on nomme rolse ou spermorlerme. Sur un point quelconque de sa surface se trouve une cicatrice nommée hile ou ombilir, a laquelle abonit un prolongemient du trophosperme qui peut être comparé au cordon ombilical des animaux. On lui donne le nom de funicule ou de podosperme (1).

(1) Indépendamment de leur tégument propre ou robe, un certain nombre de graines présentent à lextérieur une expansion membraneuse du pudosperme, gui enveloppe plus ou moins la graine; on donne à cet or grane particulier le nom d'arille. Par exemple la muscade, dont l'arille est contu sous le non de macis. 
I. graine est composic interieurement de deux sortes de parties : le périsperme et l'embryon.

Le périsperme (endwsurne, Rich.; allumen, Gxitner) est une substance analogue à l'albumen de l'ouf, et qui sert à nourrir l'embryon, jusçu'i ce que les parties dont se compose celui-ci aient acquis assez de force pour tirer leur nourrume de la terre et de l'air. II est sec et farineux dans les graninées, huileux dans le ricin, corné dans le café ct le dattier, etc. Il semble manquer quelquefois. L'embrỵn est l'abrégé de la plante: il est composé de la rudirule ou jeune racine, de la plumule ou gemmule qui est le premier bourgeon d'où doit sortir la tige, et des catylédons.

Les cotylédons peuvent être défunis une ou plusieurs fenilles presentes duns ln graine. En effet, ce sont de véritables feuilles, et s'il arrive souvent qu'ils en diffèrent en apparence, cela tient à ce que leur déreloppenent a été arrêté par l'accroissement des autres parties de la graine, ou altéré par l'absorption du périsperme, comme cela a lieu dans le haricot, dans l'amandier, etc., dont les graines ne paraissent entierement composées que des deux cotylédons.

Il y a des graines qui ont deux cotylédons, et il y en a d'autres qui n'en ont qu'un; et cette différence, qui semble si perł de chose à la première vue, sert à diviser les plantes en deux grandes classes très naturelles, ou en dicrtylridumes et mumencotylédones. Ce qu'il y a de plus remarquable, c'est que cette division répond exactement à celle dent j’ai parlé précédemment (p. 9), fondée sur la manière différente. dont les végétaux s'accroissent. En effet, une observation qui ne s'est pas encore démentie montre que tous les régétaux dicoty̧lédonés sont exogènes, et les monocotylédonés endogènes.

L'usage des cotylédons, dans la graine, est d'élaburer la substance nutritive du périsperme, lorsqu'elle a été gonflée par l'humidité de la terre, et de la transmettre a l'emabryon. Lorsque les parties dont se compose celui-ci ont acrunis assez de force pour se passer de leur sccours, les cotglédons deviennent inutiles, et périssent.

\section{sléthodes.}

Les botanistes des différents siecles ont imaginé un grand nombre de méthodes pour faciliter l'élude des plantes. Les premières, comme on peut le penser, étaient très imparfaites. Elles reposaient, ou sur l'usage aurguel on destinait les régétaux, en raison de leurs propriétés médicinales ou alimentaires, ou sur l'habitule de ces mèmey régétaux, dont les uns virent sur les eaux, et les autres daus les bois, au milieu des plaines on sur les montagnes, b'autres botanisles encore 
classaient les plantes d'après la saison de l'épanouissement de leurs fleirs.

On comprend facilement combien des descriptions fondées sur des bases aussi sujettes à varier devaient etre, sinon pen fuleles, an moins peu intelligibles pour tont autre que celui qui les fai-ait. Iussi a-t-on peine à reconnaitre maintenant les plantes dont les ancions auteurs ont voulu parler.

Parmi les méthodes modernes, on en distingue trois surtout, dui sont, la méthode de Tournefort, le sysstène sexuel de Linné et la méthode de Jussieu.

Dans la méthode de Tournefort, qui parut en 1694, les régítanx sont d'abord divisés en herbes et sous-arbrisseaux, et en arbrisceaux et arbres; ensuite les vingt-denx classes dont elle se compose, sont fondées sur l'absence, la présence et la forme de la corolle : cette méthode, recommandable par sa simplicité, ne serait plus suffisante aujourd'hui.

Le système de Linné, plus ingénieux et bien plus étendu que la méthode de Tournefort, parut en 1736. Il est fondé sur le noinbre, la porisition, la proportion et la connexion des élamines. On peut lui reprocher de disperser, dans différentes classes, des végétaux qui ont entre eux un très grand nombre de rapports naturels; mais la facilité qu'il pu'ésente pour parrenir à la connaissance des végétaux, jointe à la nomenclature dionymique dont Limné est le créateur, a opéré une véritible rérolution dans la science, et a procuré à son sỵstème, tout artificiel, une prééminence que les méthodes naturelles ont eu peine à surmonter. Pour les esprits justes et non prérenus, une bonne méthode naturelle paraissait bien être préférable à la meilleure artificiełle, et, ce qu'il y a de remarguable, c'est que c'útait le propresentiment de Linné, qui avait proclamé la méthode naturelle le but le plus itmer des efforts des lottmistes. Il a fallu cependant, pour contrebalancer la puissance du șstème de Linné, que la méthude des familles naturelles, tentée par Magnol en 1689 , accrue par Idanson en 1763 , lentement perfectionnée par Bernard de Jussieu, ait reçu !a vie des mains d'Intoine Laurent de Jussieu, dans son célèbre ourrage le formeru puluntarum, publié en 1789.

\section{Système de Linné.}

Ca sỵsteme est fondé sur le nombre, la position, la proportion, et la connexion des étanines. Joignons-ỵ les différents cas où les étamines et les pistils se trourent sur des fleurs séparces, et celni où ces organes se dérobent à l'obserration, et nous compléterons les bases 
dont Linné s'est servi pour diviser tous les rígétaux comnus en 24 classes.

Les onze premières classes sont uniquement fondées sur le nombre des étamines, depuis 1 jusquà 12 , mais considérées seulement sur des fleurs qui réunissent les deux sexes, et que, par cette raison, on a nommées hermapherodites. Ainsi, tous les régétaux à fleurs hermaphrodites qui n'ont qu'une seule étamine, sont rangées dans la $1^{\text {re }}$ classe. Linné a nommé cette classe monandrie, du grec monos, un, et uner', andros, mari; l'étamine étant l'organe màle de la fleur. Exiemple, le gingembre.

La $2 \mathrm{~F}$ cl. se nomme Diandric, c'est-à-dire 2 maris ou 2 élamines ; cr. la véronique.

La $3^{\circ}-$ Triandric - 3 étamines, excmple le blé.

$\mathrm{La}_{4}$ - Tétrandrie, - 4 - le plantain.

La 5 e - Pentandrie, - 5 - la bourrache.

La 6e - Hexandric, - 6 - le lis.

La $7^{\circ}$ - Ileptandrie, - 7 - le marronn. d'Inde.

La 8 - Octandrie, - 8 - le garou.

La 9 - Ennéandrie, - 9 - la rhubarbe.

La 10. - Décandrie, - 10 - l'willet.

La110 - Dodécandrie, de12à20 - la joubarbe.

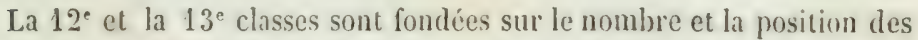
élamines. La 12• renferme les plantes hermaphrodites qui ont environ 20 étamines insérées sur le calice; exemple, le rosier. Cette classe se nomme icosandrie.

La $13^{e}$ classe comprend les plantes hermaphrodites qui ont 20 étamines, ou plus, adhérentes au réceptacle de la fleur; exemple, la renoncule. On nomme cette classe polyandrie.

La 14" et la $15^{\circ}$ classes sont fondées sur la grandeur respective des ćlamines. Ainsi dans la 14, nommée didynamie, se trourent encore des plantes à quatre étamines, mais dont deux plus courtes et deux plus grandes. Didynamic reut dire 22 puissances, c'est-à-dire, que deux étamines paraissent aroir une sorte de supériorité sur les autres; exemple, la menthe.

La 15 classe renferme des plantes à 6 élamines, qui en ont 2 petites et 4 grandes; ex., le chou. On nomme cette classe tritrudynamie, ce qui veut dire 4 puissances.

Les $16^{\circ}, 17^{\circ}, 18^{\circ}, 19^{\circ}$, et $20^{\circ}$ classes, sont fondées sur l'adhérence des étamines, soit entre elles, soit avec le pisti!.

La $16^{\text {e }}$ classe se nomme monadelylie, c'est-à-dire, un fière. Elle a lieu lorsfue toutes les étamines sont réunies en un seul faisceau par leurs filets, les anthères restant libres; ex., la maure.

Ia $17^{\circ}$ classe, ou la diredelphie, renferme les plantes dont les éta- 
mines, réunies par les filets, forment deux faisceaux; exemple, le haricot.

La 18" classe, qui est la pulyadelphie, a lieu lorsque les étamines, réunies par leurs filets, forment plus de deux faisceaux; ex. , l'oranger.

Dans la 19" classe, les étamines, au lieu d'être réunies par leurs filets, le sont par les anthères, et forment ainsi comme une petite voùte traversée par le style; ex. , la chicorée. On nomme cette classe synigrinésie, ce qui signifie engendrant ensemble.

Dans la $20^{\circ}$ classe les étamines sont adhérentes au pistil, ou sont immédiatement posées dessus; ex., l'aristoloche. On nomme cette classe gynoudrie, de gene, femme, et mer, mari; voulant ainsi ex. primer, par un seul mot, la réunion des sexes de la fleur.

Les $21^{\circ}, 22^{\circ}$ et $23^{\prime \prime}$ classes renferment des plantes dont les sexes sont séparés sur des fleurs différentes; ce que Linné a exprimé, en les nommant diclines, c'est-à-dire, deuc lits. Dans la $21^{\circ}$ classe, les fleurs mâles et les fleurs fenclles sont portées sur un même individı; $n x$, le ricin. Cette classe se nomme monocicie, de monos oilios, une seule maison.

Dans la $22^{e}$ classe, lesfleurs mâles et les fleurs femelles sont portées sur des pieds différents; ex., le genévrier. Cette classe se nomme diwcie, deux maisons.

La $23^{\text {e }}$ classe, nommée polyganie, comprend des régétaux dont la même espèce présente, sur le mème pied ou sur des pieds différents, des fleurs hermaphrodites et des fleurs mâles ou femelles; ex. , le figuier.

La $24^{\circ}$ et dernière classe renferme tous les régétaux dont la fructification n'est pas risible à l'œil nu. Linné l'a nommée cryptogyamie, ce qui veut dire mariage caché.

Limné a sous-divisé ses classes en ordres, ses ordres en genres, et ceux-ci en espèces. Voici sur quelles considérations il a fondé les ordres.

Dans les 13 premières classes dont le caraclère classique est tiré du nombre des étamines, le caractère ordinal est pris du nombre des pistils ou des styles. Ainsi nous avons pour noms d'ordres.

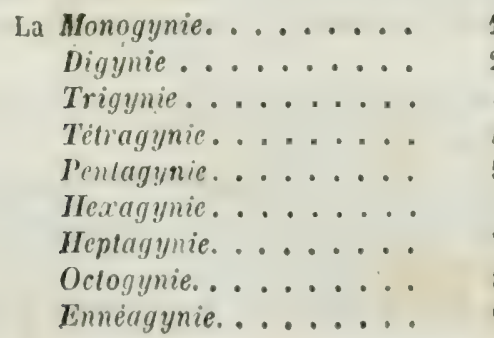

1 style ou une femme. 
Décagynie ........ 10

Dodécagynie....... de 11 ì 19

Polygynie........ 20 ou plus.

Ilais chargue classe ne renferme pas un si grand nombre d'ordres; par exemple, la monandrie n'en a que deux, qui sont la monogynie et la digynie. La diandrie et la triandrie n'en ont que trois, et ainsi des autres.

Dans la $14^{\circ}$ classe, qui est la didynamie, Linné a formé deux ordres fonclés sur la forme du fruit : tantôt ce fruit semble être composé de quatre graines nues au fond du calice; ex., la bétoine; tantôt il est enveloppé dans un seul péricarpe; ex., la digitale. Le premier cas se nomme gymnospermie, c'est-à-dire semences nues, et le second angiospermie, c'est-à-dire semences recouvertes.

La $13^{e}$ classe, qui est la tétradynamie, se divise pareillement en deux ordres. Dans le premier le fruit est court, ou n'est pas quatre fois aussi long que large; on le nomme silicule, et l'ordre, tétradynamie siliculpuse; ex., la moutarde. Dans le second ordre, le fruit, (qui est at moins quatre fois aussi long que large, se noume silique, et l'ordre est appelé tétradynamie siliqueuse; ex., le chou.

Dans la monadelphie, la diadelphie, la polyadelphie, la gynandrie, la monœcie et la diœecie, qui sont fondées sur l’adhérence des étamines par leurs filets, soit entre elles, soit avec l'ovaire, ou sur leur position dans des fleurs différentes, les ordres sont déduits du nombre des étamines, et portent les noms des premières classes. Ainsi l'on dit : momadelphie triandrie, monadelphie pentandrie, etc. Il est évident que la monadelphie monandrie est un cas absurde.

Dans la syngénésie les ordres sont très compliqués, et fondés sur les rapports qui existent dans la disposition des deux sexes, et sur celle des fleurs elles-mêmes. La classe est d'abord divisée en deux ordres, savoir, la syngénésie jolygamie, où les fleurs sont réunies plusieurs ensemble dans un calice commun (alors on les nomme fleurons, c'est-à-dire, petites fleurs), et la syngénésie monogamie, où les fleurs sont séparées. Ce dernier ordre ne se sous-dirise pas, mais le premier se partage en cinq autres, savoir :

$1^{\circ}$ La syngénésie polygamic égale, dont tous les fleurons sont hermaphrodites ;

$2^{\circ}$ La syngénésie polyganie sujerflue, dont les fleurs centrales sont hermaphrodites fertiles, et celles de la circonférence femelles également fertiles; de sorte qu'elles semblent superflues ;

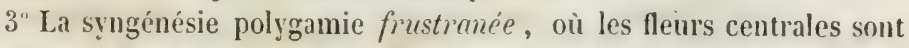
hermaphrodites fertiles, et les fleurs marginales femelles stériles; de 
sorte que, dans le style figuré de Limné, on ne-roit pas trop pourquoi on les a fait venir là ;

$4^{\circ}$ La syngénésie polygamie ureessnir liermaphrodites stériles, et celles de la circonférence femelles fécondes, de manière qu'elles sont nécessaires à la propagation de l'espèce ;

$5^{n}$ La syngénésie polyganie srifrure, ou les fleurs, qunique renfermées dans un calice commun, ont encore chacune un calice propre.

La $23^{e}$ classe, on la polyganie, se divise en trois ordres : dans le premier, nommé polyganie monucie, un même individu porte des fleurs hermaphrodites et des fleurs mâles ou femelles. Dans le second, nommé polygamie direcie, on troure dans la même espèce des iudiridus qui ont tontes leurs fleurs hermaphrodites, et d'autres qui ont des fleurs seulement màles ou femelles. Dans le troisième ordre, nommé polygamie tricecir, la même espèce offre des individus hermap̧hrodites, d'autres mâles et des troisièmes femelles,

Enfin la cryptogamie se divise en quatre ordres, déduits simplement du port des plantes. Ce sont les fourgìres, les mousses, les ulgues et les champignons.

Pour mieux faciliter l'intelligence de ce système, il n'est pas inutile d'en joindre ici le tableau.

SYSTEMIE SEXUEL DE LINNÉ.

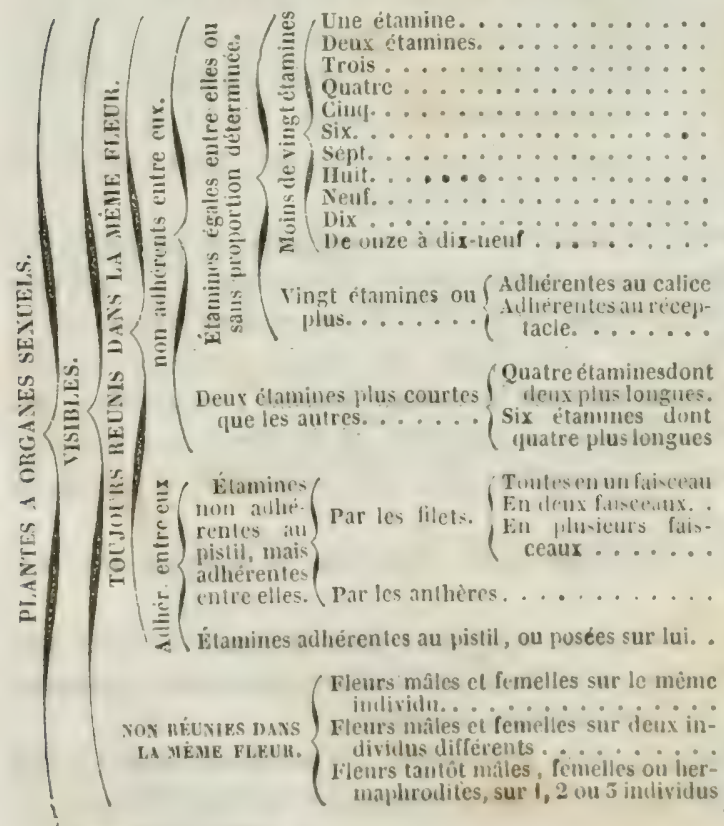

CLASSES.

I. Monandrie.

II. Diandrie.

11I. Triandrie

IV. Tẻrandrie

V. Pentandrie.

V. Hexandrie.

VII. Heptandrie.

VIII. Uclandive.

IX. Euneandrie.

X. Décandrie.

XI. Dutécantrio.

NII. Icosandrie.

XIII. Polyandrie.

XIV. Dilynamie.

XY. Tétradymamie.

Xit. Monatelphie.

XIII. Inanluylue.

xvin. Polyalelplie.

XIX. Syngénésie.

XX. Gynandrie.

XXI. Monureie.

XXII. Dinceic.

Xxil. Pulyganie.

Xxiv. Cryptogamie. 


\section{Yéthode naturelle de Jussien.}

Cette méllode est établie sur l'ásence ou la presence, el sur la forme de l'eubryon; sur la position cles ćtaminu's par rapport au pistil, et sur l'absence, la présence et la forme de la corolle.

La plante est dépoursue de rériable graine, d'umbryon, et par conséquent de cotglédon; ou bien clle posicele megrane et ma embryon pourvu de un ou de denx cotglédons. De la trois grandes disisions : les acotylédones, les monocotylèdones et les dicotylẹdonts.

Les étanines sfont portíes sur l'ovaire, ou sont placées dessous, ou enfun prennent naissance sur le calice qui l'environne; de la trois diri-

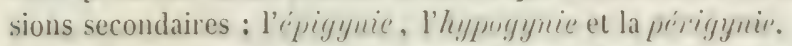

Cette insertion des étamines peut aroir lieu, soit immédiatement,

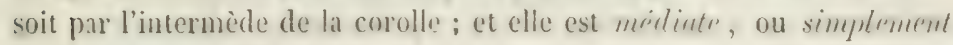
immédiate, ou immédiate nécessnire.

Elle est médiate toutes les fois que la fleur ayant une corolle, celle corolle est monopétale, c'est-à-dire que, dans ce cas, les étamines sont toujours prortées sur la corulle, gui est elle-nuême insérée sur l'uraire, ou sous l'ovaire ou sur le calice.

Elle est simplement immidiate, lorsque la fleur a! ant une corolle, mais celle corolle étant polypétale, les étamines n'y sont pas allachées el s'implantent immediatement, soit sur l'oraire, soit dessums, soit sur le calice. On peut remarguer cependant que, même dans ce cas, l'insertion des pétales suit cell des étamines, et réciprofuement.

Enfin, l'insertion des étamines est nécessairement immédiate, toutes les fuis que la fleur n'a pas de corolle, parce qu'alors il faut nécessairement que les étamines soient insérées sur l'oraire, ou à sa base, ou sur le calice.

Les plantes de la première grande division, qui comprend les acotylédones, n'ayant pas d'organes sexue's apparents, la loi des insertions est nulle pour elles. Iussi ne forment-elles qu'une seule classe, l'Arofylérlonie, que lauteur a parlagée en un certain nombre d'ordres ou de familles. Cette classe répond à la crỵptuganie de Limné.

Les monocotylédones, ou les plantes de la seconde disision, n'ont qu'une senle enveloppe florale, que Jussieu regarde comme un calice. Il s'ensuit qu'il ne leur reconnait qu'un seul mode d'insertion, qui est l'immódiate nécessaire; mais comme cette insertion peut être hỵpogyne, périgyne ou épigyne, il en résulte trois nouselles classes qui ont rẹ̣, par contraction des mots jui précèdent, les noms de monohyprogynie, monopérigynie, monoépigynie.

Les dicotylédones, beaucoup plus nombreuses que les acotylédones et les monocotylédones ensemble, ont rxigé un plus grand nombre de 
classes qui ont cté fournies par l'absence ou la présence et la forme de la corolle; caractère très secondaire en lui-même, mais qui derient essentiel par sa combinaison arec un caraclère principal.

Les dicotylédones sont "prétales, momopritules ou prolyprefales. Quand la fleur est apétale, c'est-à-dire lorsqu'elie n'a qu'une enveloppe florale que Jussieu a considérée comme un calice, l'insertion des étamines est nécessairement immédiate, de même que dans les monocoṭ̂lédones, et elle est épigyne, périgyne ou hypogyne; il en résulte encore trois nouvelles classes qui ont été nommées épistaminie, priristaminie, hyypostaminie : ce sont les $5^{\mathrm{e}}, 6^{\mathrm{e}}$ et $7^{\mathrm{e}}$ de la méthode.

Viennent ensuite les dicotylédones monopétales, chez lesguelles, suivant ce qui a été dit plus haut, les étamines sont toujours portées sur la corolle, qui est elle-même hỵpogyne, périggne ou épigyne; de là ont été formés les noms de hypocorollie, péricomollie, ifpicorollie, agui appartiennent aux classes suivantes.

Comme on peut s'en aperceroir, on place tonjours en tête de chaque division la classe dans laquelle l'insertion est la même que celle de la classe qui a fini la division précédente, afin de conserver le plus de rapports possible entre les classes voisines.

La huitième classe de la méthode, ou l'hỵpocorollie, comprend donc les dicotylédones monopétales à corolle hypogyne; la neuvième, ou la péricorollie, comprend les dicotylédones monopétales à corolle périgyne; (juant à l'épicorollie, elle a été divisée en deux classes qui se distinguent en ce que, dans la $1^{\text {rw }}$, les étamines sont réunies par leurs anthères, et que dans l'autre elles sont libres. De là les noms de ripirorollie-synantherie et de épricorollie-chorisantrie, affectés à la 10 e et à la $11^{*}$ classe de la méthode. La première répond à la sỵngénísie de Linné, et aux flosculeuses, demi-flosculeuses et radiées de Tournefort.

Tous arrirons aux dicotylédones polypétiles. Dans ces plantes, l'insertion des étamines suit celle des pétales, et elles forment trois classes, qui sont les $12^{-}, 13^{\mathrm{e}}$ et $14^{\mathrm{e}}$ de la méthode. On nomme ces classes ripipétalie, hypopétalie, péripétalie.

Voici dix classes de dicotylédones dont un des caractères essentiels a élé pris de la diverse situation des élamines ou de la corolle, par rapport au pistil; mais il y a des plantes de la même division qui ont les urganes sexuels séparés sur différentes fleurs, el qui n’ont pu être comprises dans ces classes, puisque les règles de l'insertion sont nulles pour elles. On hes a réunie's dans un seul groupe, nemmé dirlinie, qui forme la 1.5 et dernière classe de la méthode, et qui répond à la monacie, it la dimcie et ì la polygamie de Limné 
TABLEAU DE LA MÉTHODE DE JUSSIEU.

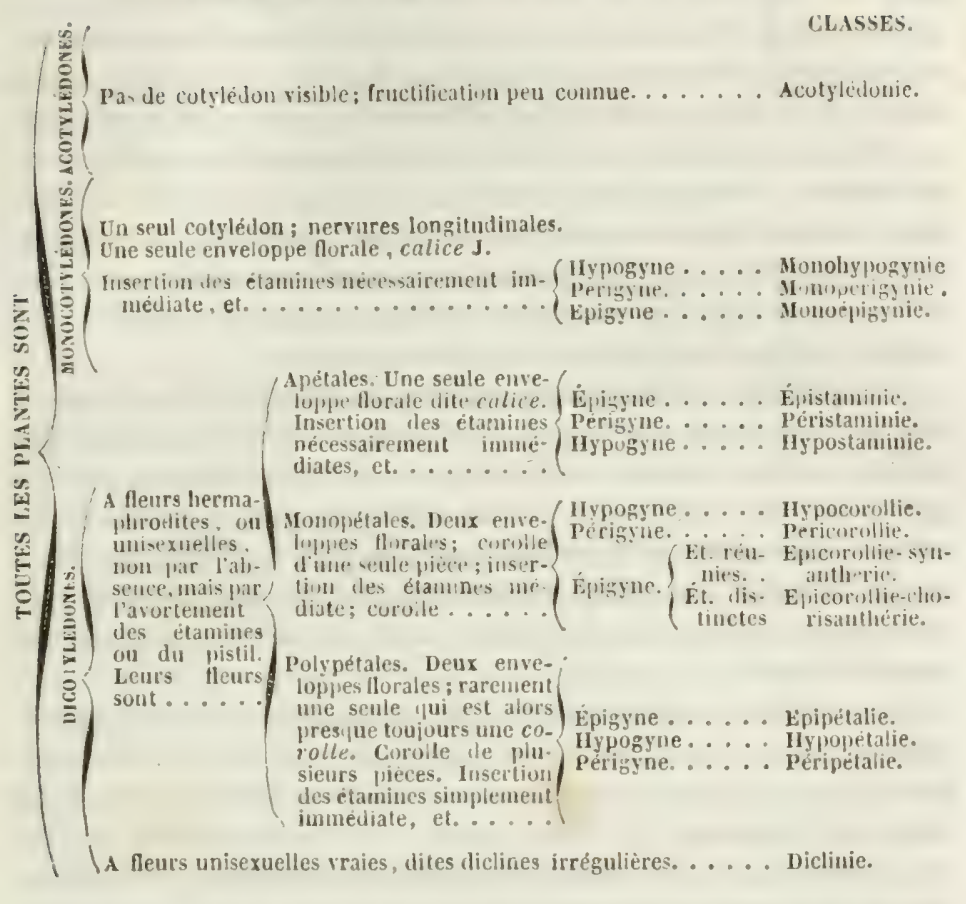

CLASSES.

Ant. -Laurent de Jussieu aurait peu fait pour la science s'il se fùt borné à former le tableau précédent, qui n'est encore, à plusieurs égards, qu'un cadre artificiel dont certaines divisions peuvent contenir des végétaux très dissemblables. Ce qui rendra son nom impérissable, c'est d'aroir partagé chacune de ses classes en groupes plus nombreux et incomparablement mieux définis qu'on ne l'arait fait jusqu'à lui; groupes fondés sur l'ensemble des caractères fournis par toutes les parties du végétal, de manière à rapprocher les uns des autres et à comprendre dans un même groupe tous ceux qui se touchent par un grand nombre de points de ressemblance, ainsi que les membres d'une même famille. Ces groupes. ainsi formés, ont donc conservé le nom de familles que leur avait donné Magnol; quel que soit l'ordre suivant lequel on les dispose à l'avenir, il est certain qu'ils resteront la base de l'étude de la botanique.

La division des végétaux par familles naturelles offre des arantages incontestables sous le rapport des applications, et réritablement ce qu'il faut s'efforcer de voir dans les sciences et d'en tirer, ce sont des appli- 
cations utiles au birn-itre de l'homme. Or, on a remarqué depuis lunertemps, et dug. P’ur. De Candolle a mis cette rérité dans tout son jour, qu'une grande ressemblance de forme gínérale réunic à la ressemblance des caractères tiris des organes sexuels "t du fruit, en un mot, que la réunion des régétaux dans une mime fanille indiquait presque toujours une grande conformité dans leurs qualités alimentaires, médicales ou vénéneuses. L'obserration de ce fait a sonvent permis it des navigateurs pris au dépourvo de nourriture dans des pars non cncore explorés, de recounaître dans des végétaux qu'ils voyaient pour la première fois, ceux qui pouraient leur être utiles comme aliments ou comme médicaments, et ceux qu'il fallait fuir comme dangereux.

C'est ainsi que la famille des gromiure's, si bien caractérisce par son fruit monosperme et indéhiscent, portant un embryon monocotslé ì la base de son còté convexe; par ses tiges fistuleuse's, entreconpées de nœuds pleins et proéminents; par ses feuilles longues, pointuss et rubanées; par ses fleurs disposées en épis ou en panicules, etc., mons présente des tiges sucrées, des feuilles non amères et des frutits amylacés, qui servent à la nourriture de l'homme et des animanx dans toutes les contrées de terre.

La famille des amminacies, très bien caractérisée aussi par l'organisation de ses racines, de ses feuilles, de ses fleurs et de ses fruits, nous fournit un grand nombre de rhizomes et de fruits aromatiques, et pas une plante vénéneuse.

Les labiées sont généralement aromatiques, stimulantes, et fournissent de l'huile volatile à la distillation.

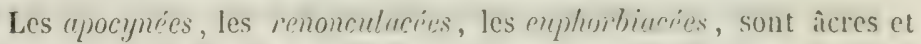
sourent très vénéneuses.

Les crucifüres doivent leur îcreté et lenr qualité stimulante à un principe rolatil sulfuré.

Le's maluares sont émollientes, les myptaréres aromaticjues.

Les térebintlacées et les conifres sont riches en principes résincux.

Enlin il est vai de dire que, thès sourent, les groupes qui ont rer.ll le nom de funilles nuturelles, offent des vígétaux de propriétis antlogues.

Il ne faut pas cependant exagérer la portée de ce principe et s'imaginer qu'il ne souffre pas d'exception. Ionin de là, il en offre d'assez nombreuses, non senlement entre les genres d'une meme !amille, mais encore entre les espèces d'un mème gente, ct qunlyutfois entre les variétés d'une mème espèce. Je citerai en exemple le geme stryltumes, dont plusienrs especes offent des semences tris ameres et riches en alcaloüdes vénéneux, telles que la noix romięue et lat fère de Saint- 
Ignace ; tandis que d'autres espèces sont dépourrues d'amertume et servent à différents usages économiques.

te citerai encore le genre comenteulus qui produit plusieurs racines fortement purgatives, telles que celles des $C$. offirinalis, scummumin, Turpethum; une racine purement alimentaire comme celle du $C$. Bututas, et une autre pourrue d'une huile volatile analogne a celle de la rose (C. serepurius). Enfin, je nommerai l'amandier à fruit doux et l'amandier à fruit aner, qui diffèrent à peine par la longueur respective du style et des étamines, et dont les semences offrent une très grande difference par certains produits que l'analyse chimicgue peut en retirer, et par la qualité très délétère de l'essence chargée d'acide cyanhỵdrifue, obtenue par la distillation de la seconde variété.

I'ai dit plus hant que le mérite de Laurent de Jussien consistait encore plus dans la délimitation de ses familles naturelles que dans la disposition de ses classes. On lui a reproché en effet d'aroir rejeté à la fin des dicot!lédones, dans sa diclinie, des régétaux qui, par leurs rapports arec les acotylédones et les monocotylédones, semblent plutît intermédiaires entre les uns et les autres. Les cieas, par exemple, prísentent des rapports évidents de forme et d'organisation arec les fougères, de mème que les coniferes avec les prèles et les lycopodes, et les conifères c'ntrainent arec, eux le groupe si puissant dés végétaux à chàtons ou des amentacées (1); secondement, l'insertion ćpigyıique, périgrnique et hypoggnique des éiamiines, qui a servi de base à la distinction de lit plupart des classes, présente beaucoup d'anomialies et d'exceptions, surtnut dans ce qui regarde les deux premiers modes qui passent de l'un à l'autre sans séparation bien tranchée. Iussi les botanistes st sont-ils accordés depuis pour n'admettre, comme base secondaire de classification, que deux modes d'insertion, l'hypogınique et le pririgyniçue. Hais ici recommencent, pour la disposition des familles, des divergences pen importantes sans doute, mais (pui n'en sont pas moins cmbarrassantes lorsqu'il faut se décider entre des méthodes nourelles que recommandent des uoms tels que ceux d'Aug. Pyr. De Candolle et de MII. Lindley, Endlicher, Adrien de Jussien, Adolphe Brongniart et Achille Richard. Obligé de choisir entre toutes, pour l'ordre à suivre dans l'étude des familles qui fournissent de leurs parties ou des produits utiles à l'art de guérir, je donnerai la préférence à la méthode la plus simple, qui est celle d'.lug. PJran. De Candolle, me réserrant cependant

(1) On peut dire que lectude des régélaux fosciles vient à l'appui de ces rapprochements et ne permet pas de ne pas y avoir égard. Les premiers végétaux fossiles qui paraissent après les fourères, les prèles el les lycopodes, sont les cieadées et les conifères. Einsuite sont venus les palmiers, les amentacées, les juglandées et successivement tous les autres. 
d'emprunter quelquefois à ceux qui l'ont suivi une plus exacte dételmination des familles.

De Candolle établit d'abord entre tous les régétaux une grande division fondée sur des caractères tirés, tout à la fois, de leurs organes de nutrition et de leurs organes de reproduction.

Ainsi, en examinant d'abord les organes de nutrition, on trouve que les végétaux sont pourrus, tantôt de vaisseaux séveux et de stomates ou de pores corticaux; ou bien qu'ils sont privés des uns et des autres, et qu'ils sont uniquement formés de tissu cellulaire. Ces derniers se nomment, en conséruence, végriturix callulaires et les premiers végétaux vasculaires.

En examinant ensuite les organes de la reproduction, on observe des végétaux qui produisent des fruits et des graines, dans lesquelles on trouve un embryon pourvu de un ou de plusieurs cotylédons; ou bien on roit des végétaux dépourvus de semences et par consérquent de cotylédons, et qui se multiplient par de petits corpuscules très simples (qui se détachent de la plante mère, comme le feraient des bulbilles, et qui ont reçu le nom de Gongyles ou de Spores. Les végétaux compris dans la premiere division sont dits cotylérlonés, et ceux de la seconde acrotylédonés, ainsi que les avait nommés de Jussieu.

En comparant alors ces deux modes de division, on roit qu'ils se correspondent parfaitement et qu'ils ne forment qu'une seule et même division entre tous les régétaux. Ainsi les végétaux vasculaires sont à la fois cotỵlédonés, et les cellulaires sont tous acotỵlédonés, ce qui montre combien cette double distinction est bonne et naturelle.

Les régétaux cellulaires, étant formés d'organes peu apparents, ne comprennent que deux classes, fondées sur l'absence on la présence d'expansions foliacées. Cette même distinction se retrouve dans toutes les classifications modernes; seulement on l'exprime autrement.

Les régétaux vasculaires ou cotỵlédonés ont été divisés, de même que les précédents, à l'aide de caractères tirés de leurs organes de régétation et de reproduction. Tantôt, en effet, ils offrent des tiges presque toujours cylindriqques, élancées, non ramifiées, formées de fibres droites et parallèles, disséminées au milieu d'une substance médullaire. Ces fibres sont plus rapprochées el plus consistantes rers la circonférence qu'au centre, ce qui tient à ce que les plus nourelles et les plus succulentes se forment au centre, en ćcartant et refoulant les autres vers la périphérie. Ainsi que je l'ai déjà dit (page 9) on nomme ces végétaux endogimes, c'est-à-dire croissant au dedans; on bien, les végétaux vasculaires présentent des tiges coniçues, très sourent ramifiées, formées de fibres ligneuses disposées antour d'un canal médullaire central, en couches concentriques superposées, dont les plus 
dures el hes plus abfies sont an centre, et les plus jemene a la circonfi-

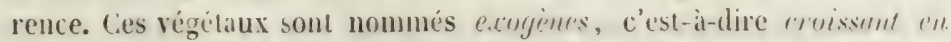
dehor's. Ainsi que j’ai déjà éu occasion de le dire (page 29), cette division des régétaux en endogènes et exugònes répond exactement à celle des végétaux monocotylédonés et dicotylédonés.

Les régétaux endogènes ou monocotylédonés se divisent en deux classes, fondées sur ce que les uns ont des fleurs et des sexes distincts, tandis que les autres en sont privés. Ces derniers, très rapprochés des végétaux cellulaires foliacís, se nomment. Vonocotyledomes cryptoygmes; ils faisaient partie de la crỵtogamie de Linné et des acotylédones de Jussieu. Les autres forment la classe des monocotylédones phanérogames, parmi lesquels nons trouvons les graminces, les palmiers, les iridées, les orchidées, etc.

Les régétaux exogènes un dicotylédonés ont toujours des fleurs distinctes; mais tantôt ces fleurs n'ont qu'une seule enveloppe, tantôt elles en ont deux. Lorsgu'clles n'en ont qu'une, on considère généralement celle-ci comme un calice et non comme une corolle; ce sont les dicotylédones apétales de Jussicu. II. De Candolle, se bornant à constater l'existence d'une seule enreloppe florale, noume ces régétaux monochlomydres, c'est-à-dire n'oynunt quiun munteuu. I)ans sa méthode ils ne forment gu'une classe, dans laquelle on trouve les conifères, la grande famille des amentacées, les euphorbiacées.

Les dicotylédones à périgone double, ou à calice et corolle distincts, forment trois classes qui se distinguent par le nombre des divisions de la corolle et par son insertion. Lorsçue la corolle est d'une seule pièce et qu'elle est lé,pogyne, c'est-à-dire insérée sous l'ovaire ou sur le réceplacle, elle constitue la classe des Corolliores (Labiées, Sulanacées, Boraginces, Apocynées, etc).

Quand la corolle est formée de plusieurs pétales libres ou (quelquefois soudés, mais toujours prérigynes, c'est-à-dire insérées antour de l'ovaire ou sur le calice, elle forme la classe des raliciflores, oir se troure la grande famille des plantes à fleurs composées ou synanthérées, les rubiacées, les ombellifères, etc.

Eufiu quand la corolle est polypétale, ou formée de plusieurs pétales distincts et que ces pétales sont insérés sur le réceptacte arec les étamines, on entre dans la classe des therlamiftures qui comprend les rutacées, les malvacées, les crucifòres, etc. 


\section{DISTRIBUTION DES VEGETALX FX IIUTT CLASSES,}

\section{Par De Candolis.}

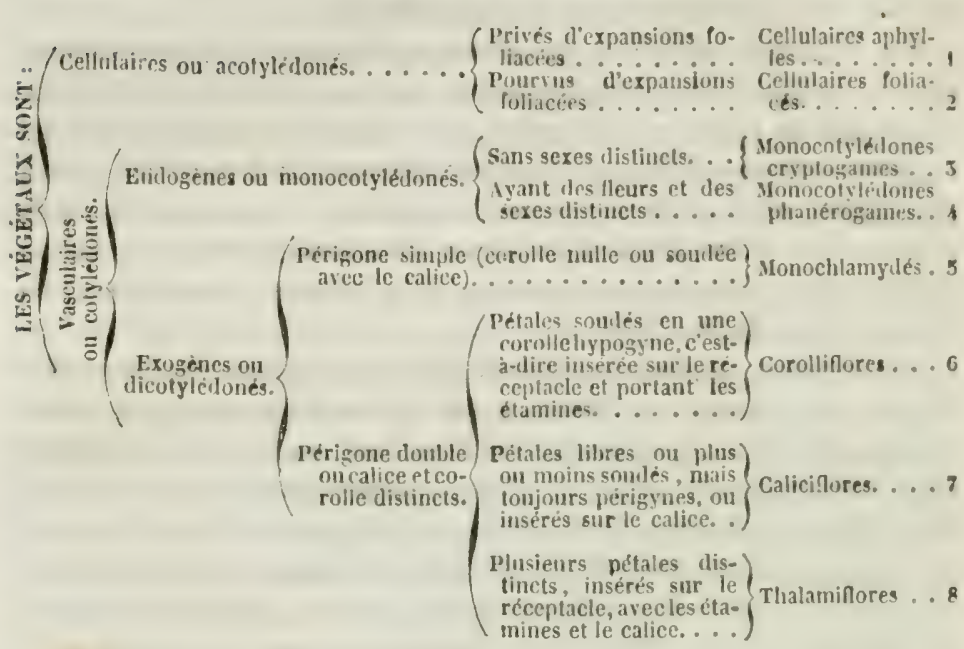

Telle est la méthode de De Candolle; seulement je l'ai prise ì rebours, parce que ce grand botaniste commençait sa classification par les rigétaux les plus complets, composés du plus grand nombre de parties ou d'organes distincts, tandis qu'i l'exemple de Jussieu, d'Endlicher et du plus grand nombre des bolanistes morlernes, il me parait plus naturel de commencer par les vérétaux les plus simples, ou gui n'ont ni feuilles ni organes distincts; puis par ceux qui nous offient des feuilles, sans fleurs ni fruits, etc. Ensuite je fais subir dès le commencement à la méthode de De Candolle une modification qui, sans changer la série des végétaux, fait mieux cadrer la míthode arec colle de Jussien, et d'antres plus modernes. Cette modification consiste à retirer des monocotylídones, les cryptogames de l'ordre leplus élivé, que be candolle y avait comprises, à cause de leur tissu en partie raseulaire et, sans donte aussi, parce que quelques observateurs ont annoncé aroir observe la prisence on la formation d'un cotylédon pendant la crermination de leurs corpuscules reproducteurs. Mais comme, en réalité, ces corpuscules noffrent aucun des caractires des véribables semences, et yu’ils sont en eux-mèmes dépourvus de tout organe coṭlédonaire, il paraît plus régulier de réunir tous les végétaus yui les présentem dans une seule division, sous la dénomination d'urntyludonr's. Eufin je joins encore aux acotylédonés un petit nombre de plantes d'une organisation 
plus élevéc, puisfu'elles sont pourrues de fleurs et d'organes sexuels bien déterminés; et gu'elles font partie des phlanérogames dans la plupart des méthodes: mais ces phantes ne contenant dans leur grane, au lieu d'endosperme et d'embrỵon coislédoné, qu'un amas de gramules reproducteurs analogucs aux spores des acotylédones, doirent encore faire partie de ceux-ci. Voici donc, en délinitive, l’ordre que je suirrai dans la classification des familles.

\section{Végetaux.}

aphylles, s'accrois. par toute leur périphérie. Ampucìss.

Acotylédonés. - \{ foliacés, s'accroissant par l'extrémilé des axes. Acrocỉnes. anthosés, ou ............ Ruzhanthés.

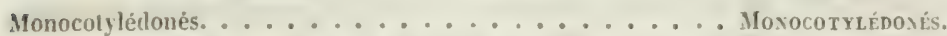

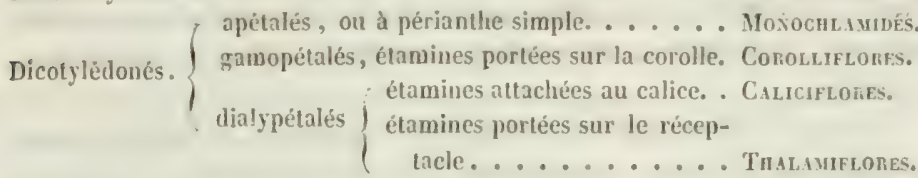

Indication des princlpax groupes i ou des principales familles uaturelles comprises dans les classes ci-dessus.

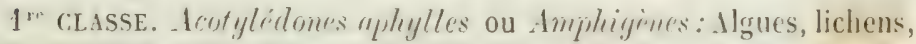
champignons.

(1) Depuic plusieurs années, les botanistes ont senti l'ulilité d'introduire entre la division par classes et celle par fumilles, une disision intermédiaire qui indiquat entre certaines familles une afinite plus grande que celles qu'elles montrent pour les autres. Cette alliance particuliere desient surtout évidente pour plusieurs des grandes familles de Jussieu, dans lesuguelles on a élabli des divisions ultericures qui les ont converties en groupes de familles; tels sont les alyues, les lichens, les champignons, les coniferes, les amentacies, les térébenthacées, les léyumineuses, les malvacees, etc. W. Endlicher a étendu celle di-position à tout le rèrgne végétal, et dans son Genera plantarum, publié de 1836 à 1840,277 familles, comprenant 6838 genres, sont réparlies en 62 groupes auxquels l'auteur donne le nom de Classes. Wais alor. il donne aux divisions qui répondent aux classes de Jussicu, de De Candolle el de Richard, le nom de Cohortes, el aux divisions supátieures les noms de sections, de régjions ou d'embranchements. Je pense qu'en conservant le nom de classes aux divisions moyennes des diverses méthodes (22 dans Tournefort, 21 dans Linné, 19 dans Jussieu, 8 dans De Candolle, 10 dans Endlicher. 20 chez M. Richard), on pourrait appliquer aux groupes immédiatement inférieurs le nom dordres; alors la classilication véfétale comprendrait les subdivisions suivantes: embranchements, classes, ordres, faurues, tribus, grvnes, sous-genres, espèces, variétés; dont les principales el les plus essentielles à bien défuir seraient toujours les faumbles, les grxings et les EsPĖces. 


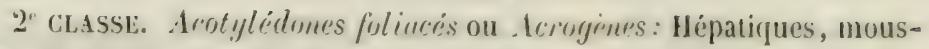
ses, fougères, marsiléacées, lycopodiacées, équisétacées, cliaracées.

3. CLASSE. Acotyledones anthesés ou Rhizanthe's: Balanophorées, cytinées, raflésiacées.

$4^{r}$ cLasse. Monocotylédones: Aroüdées, cypéracées, graminées, palmiers, mélanthacées, liliacées, asparagincées, iridées, amomées, orchidées.

5r CLASSE. Dicotylédones monochlamydres: Cicadées, conilères, amentacées, urticées, euphorbiacées, protéacées, santalacées, elieagnées, daphnacées, laurinées, polygonées, chénopodées, amaranthacées, nỵctaginées, phytolaccacées.

$6^{*}$ cLASSE. Dicotylódones corolliflores : Plantaginées, plumbaginées, Globulariées, myoporacées, labiées, rerbénacées, acanthacées, scrophulariacées, sulanacées, boraginées, cunvolvulacées, sésanées, bignoniacées, gentianées, loganiacées, asclépiadées, apocỹues, oléacées, ébénacées, sapotacées.

$7^{\text {C }}$ CLASSE. Dicotylédones caliciflores: Ericacées, vacciniées, can panulacées, lobéliacées, ș̣nanthérées, dipsacées, valérianées, rubiacées, caprifoliacées, araliacées, ombellifères, grossulariées, cactées, cucurbitacées, mỵtacées, rosacées, légumineuses, térébinthacées, rhamnées.

8 CLaSSE. Dicotylédones thalamiflores: Ochnacées, simaroubées, rutacées, zygophỵllées, oxalidées, géraniacées, ampélizlées, méliacées, sapindacées, acérinées, guttilères, hypéricinées, aurantiacées, tiliacées, byttnériacées, bombacées, malracées, caryophỵllées polygalées, violariées, cistinées , capparidées, crucifères, fumariacées, paparcracír's, ménispermées, anonacées, magnoliacées, renonculacées.

\section{PREMIERE CLASSE.}

Végétaux acotylédonés aphylles ou Ampigènes.

ORDRE DES ALGUES.

Végrétaux très simples, virant dans l'eau douce ou saléc, et quêlquefois dans l'air très humide; quelques uns (genre protucuccus) se composent de vésicules isolées qui, chacune, forment un individu. D'autres fois, les utricules sont réunies en chapelets et engagées dans une membrane gélatiniforme (mostuch). Plus sourent ce sont des filitments simples ou rameux, continus ou articulés, des lanières ou des expansions, de forme et de consistance variées. Les uns flottent tlans 
l'ean sans tenir au sol; mais les autres se fixent aur rochers au moven d'un empàtement ou d'unc griffé qui ressemble à une racine, mais gui est dépourve de tout pouroir d'absorption. I.es organes de reproduction sont assez variés: tantòt ils sont formés par la matière même de la plante qui, dans certains points, se condense en corpuscules reproducteurs; tantòt les spores sont contenues dans cies utricules (spridirs) réunies en grand nombre dans des conceptacles sur la paroi desfuels elles sont fixées, entremêlées de filaments que l'on regarde comme des organes mâles (anthéridies).

1I. Decaisne divise les algues en quatre sous-ordres:

$1^{\circ}$ Les zumanrés, caractérisées par des spores rertes, développées dans les cellules du tissu même de la plante. Ces spores exécutent des mourements spontanés, immédiatement après leur sortie, an moyen de cils vibratoires dont elles sont pourvues. Eilles sont donc, à ce moment de leur existence, tout à fait comparables à des animaux infusoires ; mais bientôtle mourement s'arrête et la spore se développe en un régétal immobile.

Familles : Oscillatoriées, nostorlinées, comfervarres, "ulurres, caulerpées.

20 Les synsprries ou ronjugures; elles ont les spores formées dans l'intérieur d'un article, par la concentration de la matière verte résultant de la conjugaison de deux articles distincts.

$3^{\circ}$ Les aplusporées: Spores rertes ou brunes rléveloppées isolimeml dans des utricules, dépourvies de mourements spontanés, el générate. ment accompagnées de filaments à la base desquels elles s'insèrent.

Familles: linuchrivies, spmmördres, Inminaripes, furrocés.

$4^{\circ}$ Les choristoporées (c'est-à-dire spores se formant ensemble). Spores rouges privées de mourements spontanés, développées 4 par 4 dans des cellules spéciales faisant partic du tissu général de la plante; souvent aussi renfermées dans des conceptacles.

Familles: C'érumiées, rytiphles, corallineses, chondripes, sylurrococcoïdées, yastérocarpées.

Les algues sont généralement composées d’une matière gélatineuse amylacée qui les rend propres à la nourriture de l'homme, tomes les fois qu'elle n'est pas accompagnée d'une huile odorante qui en rend l'usage désagréable. Presque toutes celles qui vivent dans la mer renferment un certain nombre de sels qui en ont été soutirés et qu'elles se sont appropriés. ¿n assez grand nombre contiennent de l'iode, gui s'y troure, soit à l'élat d'iodure alcalin, soit en combinaison directe avec leur propre substance. Nous ne mentionnerons que les algues qui sont utilisćes comme médicament, comme aliment, ou pum l'extraction de l'iode. 


\section{Varec vesiculeux.}

F'ucus resirulosus, L. Sons-ordre des aplosporées, famille des fucacées. Cetle plante abonde sur les côtes de france, dans l'Océan et dans la Iéditerranée. Elle adhère aux rochers par un court pédicule qui s'élargit en une fronde membraneuse, itroite et rubane, plusieurs fois ıanifiée, entière sur les bords, pourve d'une nerrure médiane proéminente et de vésicules aériemnes, sphériques ou orales, formées çà et

Fig. 22.

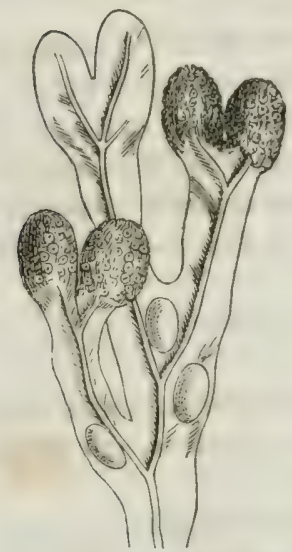

Fir. 23.

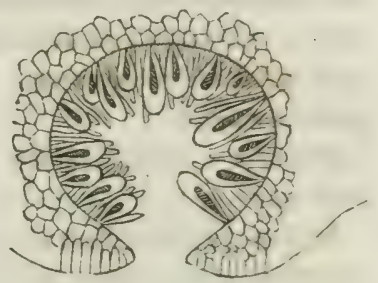

la par le dédonblement de la lame du fucus. Ia fruclification est renfermée dans des renflements tuberculeux portés a l'extrémité des divisions de la fronde (fig. 22); chaque point tuberculeux ćlant percé d'une ourerture gui répond à une cavité intérieure ou conceptucle (fig. 2i.) rempli de spores renfermées chacune isolément dans un tégument propre (périspore), et entremêlées de filaments stériles (anthéridies).

Le rarec résiculeux est long de 30 à 50 centimètres; il est d'un rert brunàtre foncé et eshale une odeur forte et désagréable. Fin le distillant arec de l'eau et en traitant le produit distillé par l'éther, on en cxtrait une huile blanche, demi-solide, qui en est le principe odorant. Le fucus bouilli avec de l'ean donne une liqueur tout à fait neutre, qui contient du chlorure de sodium, du sulfate de soude, du sulfate de chaux et une substance mucilagineuse qui jouit de toutes les propricités de la yrussulime ou pertime. Cotte liqueur n'offre que des indices d'iode par l'anidon (1) le chlore; mais l'essai est trompeur: pour y trourer l'iode, il faut précipiter la pectine et une partie des sulfates par l'alcool, éraporer l'alcool, y ajouter de la potasse et calciner. Le résidu cxhale une forte odeur d'acide sulfhỵdrigue; on dígage cet acide par l'acide chlorhỵ- 
àrique, on chauffe, on filtre et on! ajoute de l'amidon et du chlore: alors on obtient une coloration bleue assez foncée, preuse de la présence de l'iode.

Le varec vésiculeux, réluit en charbon dans un crenset fermé, forme ce qu'on nomme l'Ethings régritul. Cer charbon exhale une forte odeur hépatique, et ne doit pas être sans action dans les maladies du système Jymphatique, contre lesquelles il a été conseillé; mais il agit d'une manière différente du charbon d'éponge, qui doit sa propriété à liodure de calcium qu'il contient.

On trouve sur les côtes de France un grand nombre d'espèces de

Fig. 24.

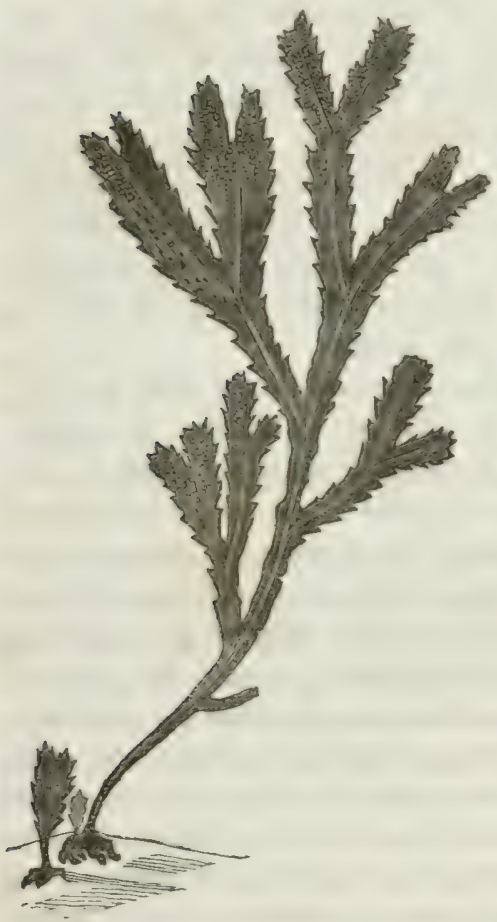

Fig. 23.

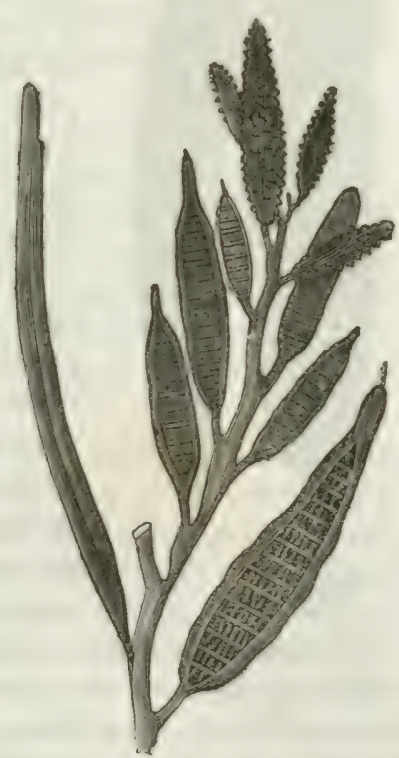

varecs qui jouissent des mêmes propriétés que le précédent et qui servent concurremment aux mêmes usages; tels sont entre autres le furus semutus (fig. 24) et le fucus siliquosus (fig. 25). 


\section{Laminaire saccharine (fig. 26).}

Laminurn surcharinn, Iamx. Sous-ordre des aplosporées, famille des laminarićes. Cette plante adthère fortement aux rochers par une griffe rameuse qui donne naissance à un ou plusieurs stipes arrondis,

Fig. 26.

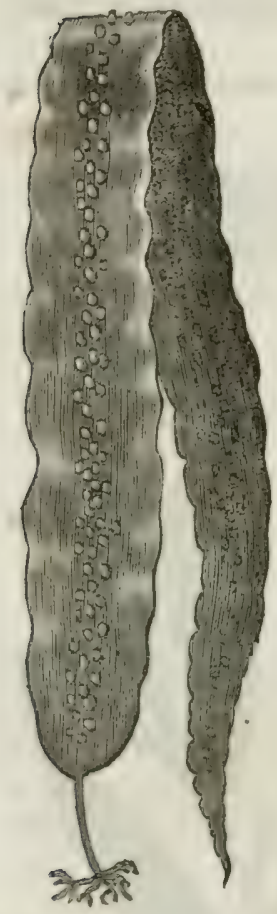

longs de 15 à 25 centimètres, terminés chacun par une fronde plane, entière, longue et étroite, qui peut acquérir 2 ou 3 mètres de longueur sur 20 à 30 centimètres de largeur. Cette fronde est mince, jaunâtre, transparente et ondulée sur les bords, tandis que la partie moyenne est sensiblement plus épaisse, plus consistante, presque opaque et d'une teinte verdâtre foncée. Cette différence tient à ce que la fructification se trouve étendue par plaques sur toute la surface mitoyenne de la fronde. Cette fructification se compose d'ailleurs de sporidies à une seule spore incluse, accompagnées de filaments stériles, élargis an sommet, plus ou moins soudés.

La laminaire, préalablement lavée pour enlever l'eau salée qui la mouille, et séchée, présente une couleur rousse ou verdâtre, une odeur peu marquée et une saveur donceâtre et nauséabonde. Elle se recourre, quelque temps après sa dessiccation, d'une eflorescence blanche qui offre un goût sucré et qui parait être du sucre cristallisable (Leman, Dict. sciences natur.) ; mais ce caractère n'est pas particulier à la laminaire saccharine, et beancoup d'autres varecs le prisentent igalement; tels sont entre autres les laminurin digitotor et bullussu, les furres siliquesus, resirulosus, etc. D'après II. Gaultier de Claubry, de tontes les plantes qui rinnent d'etre nommées, la laminaire est celle qui contient le plus d'iode et elle le contient à l'état d'iodure alcalin.

\section{Polysiphonie brune-noiratre.}

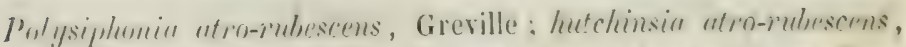
A cardli; sous-ordre des choristosporées, famille des rịtiphlées. Cette petite algue desséchée parait formée de filaments noirs, assez lins et III pen feutris, d'une structure articulie ou cloisommere. Jille a une tris 
forle odeur de varec, une conleur brune presigue noire et une saveur salée. Traitée par l'alcool, clle lui cède une matière grasse, verte et odorante, une substance rouge soluble dans l'cau, et des sels dians lesquels l'amidon et le chlore n'indignent pas la présence de l'iode. Le fucus traité ensuite par l'eau lui cède encore de la matière colorante ronge, de la gomme, un sel calcaire tres abondant et quelques autres sels qui prennent une teinte à peine viulacée par l'anidon et le chlore.

Il semblerait d'après cela que l'hutchinsie noiràtre ne derrait pas contenir d'iode ; mais si on la prend après l'avoir épuisée par l'eau et l'alcciol, si on l'humecte de potasse et si on la clauffe au rouge, alors on obtient une masse chan bonneuse yui devient pyrophorique et ammoniacale par son exposition a l'air humide, et gui ceprendant ne contient pas de cyanure de potassimn (la production de l'ammoniaque est due a la décomposition simulanie de l'air et de l'eau par le charbon) (1); mais ceite masse charbonneuse ạant été traitée par l'eau, la liqueur filtrée a pris une couleur blene très intense et a produit un abondant précipité bleu arec l'amidon et le clilore.

Ces essais mont prouvé que l'hutchinsie noiràtre contient, comme léponge, une assez forte proportion d'iode combiné à sa propre substance, et non à l'élat d'iodure alcalin; mais elle differe de l'éponge en ce qu'elle ne contient pas d'azote au nombre de ses éléments. Cette substance si riche en iode fait partie de la Pourle de Sency contre le goitre; et il est remaryuable que les âuteurs de cette poudre aient su la choisir au milieu des autres fucus préconisés contre cette maladie.

SLR L'IODE. L'iode a élé décourert en 1812, dans les eaux-mères des soudes de rarecs, par Courtuis, salpêtrier à Paris. Il a été étudié d'abord par MM. Clément, Gay-Lussac et Dary, mais c'est à 11. Gay-Lussac surtout qu'on doit la connaissance de ses propriétés (Amn. de Chim., xCI). Il résulte des expériences de ce chimiste célèbre, que l'iode est un corps simple, analogue au chlore et au soufre, et qui, dans l'ordre nature', doit se trouver placé entre cux, mais beaucoup plus près du premier que du second. Iussi fait-il partie du genre des bromoüdes, avec le brome, le chlore et le plthore ou fluore.

Extrutim. On obtient cin Yormandie, par la combustion et l'incinération des rarecs, une sorte de soude de fort mauraise qualité, et qui, arant la décourerte de Courtois, n'étiat guère employće que pour la fabrication du rerre. Injourd'hui on lessive cetle soude, on ¿puise la liqueur, par des cristallisations successives, de tout le carbo-

(1) Ce fait, anciennement observé par moi, a élé publié en 1836 dans la troisième édition de cet ourrage.

II. 
nate alcalin et di la plupart des autres sels (un'elle contient. L'eau-mère retient l'iodure de sorlium mèlé à du sulfure, du bromure et du chlorure; on y ajonte du bi-oxide de manganese en poudre fine et on érapore à siccité. Le sulfure aỵant été décomposé par ce moyen, on introduit le mélange dans des cornues à col très court; on y ajoute une quantité déterminée d'acide sulfurique concentré dont l'action se porte sur l'iodure de sodium, de préférence au bromure et au chlorure, ef l'on chauffe dans des fourneaux à réverbère. L'iode mis à nu et volatilisé vient se condenser dans le récipient.

On peut également retirer l'iode des eaux-mères de soude de varec, en les traitant d'abord par l'oxide de manganèse, pour se débarrasser des sulfures; faisant dissoudre le résidu, assez fortement chanflé, au moyen de l'eau, et faisant passer dans la liqueur filtrée un courant de chlore jusqu’à ce que tout l'iode ait été précipité. On le sépare de la liqueur surnageante, et on le distille pour l'obtenir plus pur.

Propriétés. L'iode se présente sous la forme de paillettes ou de tables quadrangulaires aplaties et obliques; il jouit de l'éclat métallique et de la couleur grise foncée du carbure de fer (plombagine). Il a une odeur forte et fatigante analogue à celle clu chlore, mais plus faible; il possède une saveur très âcre, et forme sur la peau une tache jaune brune foncée, qui finit par se dissiper à l'air; sa pesanteur spécifique est de 4,948 à la température de 17 degrés centigr.

J'iode entre en fusion à 107 degrés et bout à 175 ou 180 degrés; cependant il se volatilise dans l'eau bouillante en raison du mélange de sa vapeur arec celle de l'eau. De rquelque manière qu'on le rolatilise, arec l'eau ou dans l'air, sa rapeur offre une conleur violette magnifique qui lui a ralu son nom d'iode, tiré de i wòñs, violet.

L'iode est à peine soluble dans l'eau, qui en acquiert cependant une conleur jaune très niarquée et des propriétés énergiques; il est soluble en grande proportion dans l'alconl et dans l'éther, et leur communique une couleur rouge très foncée. Il est inattaquable par l'oxigène ct par les acides qui en sont saturés; mais avec l'interinède de l'eau, qu'il décompose, il exerce une action puissante sur les acides qui sont au minimmun d'oxigénation et il les fait passer à l'état d'acides très oxigénés, 'nl drenant lui-même aride iodluydrique (iodide hydrique). Cet rfict a particulièrement lieu arec l'acide sulfureux, et néanmoins, à l'aide de la chaleur, l'acide sulfurique concentrí décompose l'acide

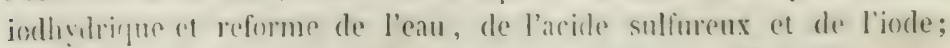
c'est même par ce procédé qu'on obtenait d’abord l'iode des eauxmères de rarec.

Lintyes. Lin 1819, 11. Coindet, de Genève, ayant constaté l'oflicacité

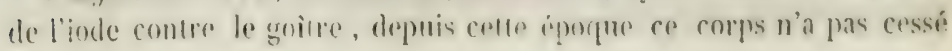


d'être empluyé comme médicament, sous toutes les formes, et principalement depuis l'heureuse application que le docteur Lugol en a faite au traitement des maladies scrofuleuses. L'iode est encore employé comme réactif pour décourrir l'amidon dans le's substances régétales. Il suffit en effet de verser aquelques gouttes de teinture d'iode dans une liqueur contenant de l'amiclon, ou mème de plonger dans cette teinture, étendue d'eatu, une racine ou une partie végétale quelcongue amylacée pour y développer une belle couleur bleue due à la combinaison de l'iode avec l'amidon.

Fulsification. L'iode est quelquefois falsifié dans le commerce avec de l'eau, différents sels, ou de la houille. L'iode pur ne doit pas mouiller le papier dans lequel on le presse; après aroir été traité par l'eau, l'eau éraporée à siccité ne doit laisser aucun résidu; enfin il doit être complétement solubie dans l'alcool, et entièrement rolatil au feu.

\section{Coralline blanche ou officinale.}

Corrallinu ufficinalis L., production marine très commune sur toutes les côtes d'Europe, sur la nature de litquelle les naturalistes ont été en grand désaccord; les uns, tels que Ellis, Limné, Lamarck, Lamomroux, l'asant regardée comme un polypier, tandis que Pallas et Spallanzani, l'ont considérée comme une plante. Anjourd'hui cette dernière opinion parait decoir l'emporter sur la premiere, et dans la classification de

Fig. $2 \pi$.

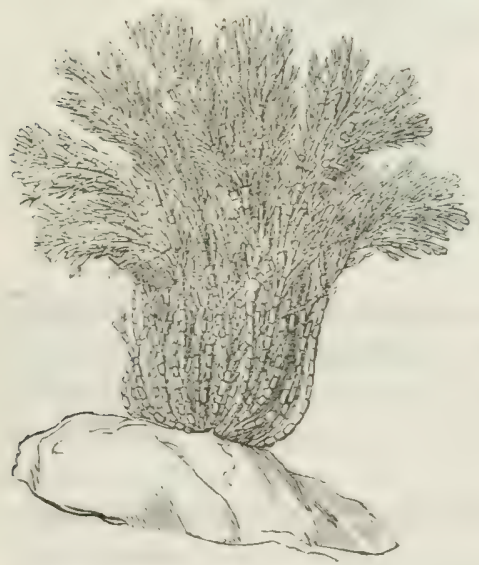

Fig. 28.

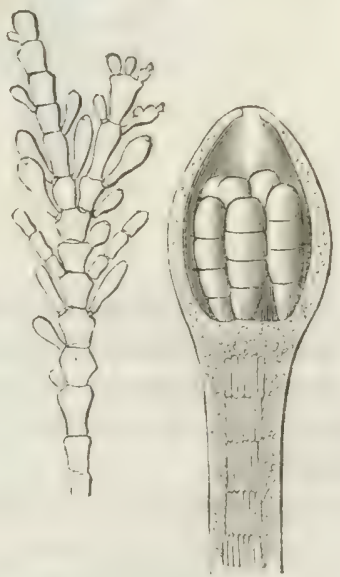

II. Decaisne, les corallinées forment une famille dans le sous-ordre des algues choristosporées.

Ja coralline officinale se présente sous la forme de pelites touffes d'un blane verditre, comprosies d'un trìs grand nombere de tiges fincs, articulés et ramifués (figg. 27). Conservée sèche, dans mo lien exposé à la 
lumière, elle devient tout à fait blanche; clle est de plus complétement opaque et très cassante, propriétés qu'clle doit à la grande quantité de carbonate de chaux qu'elle contient. On ne peut cependant la comparer au corail qui est un axe calcaire continu, entonré d'une écorce charnue, dans laquelle sont logés des animaux à huit tentacules ravonnés : d'abord parce qu'on n'a jamais pu décourrir d'animaux dans la coralline, ensuite parce que la matiere calcaire est uniformément répandue dans toute sa masse et entre les mailles d'un réseau cartilagineux, qu'il est facile de mettre en éridence en dissolvant le carbonate de chaux par un acide faible. Enfin la coralline blanche est poursue d'organes de fructification tout à fait comparables à ceux des algues choristosporées. Cee sont des conceptacles pédicellés, ovoïdes, ouverts à d'extrémité, qui naissent à l'aisselle des articles de la tige ou des ramifications, et qui contiennent un certain nombre de sacs nommés fricispores on sporidice, dont chacun contient $/ 4$ spores superposés (fig. 28).

L'analyse de la coralline faite anciennement par Bouvier a donné :

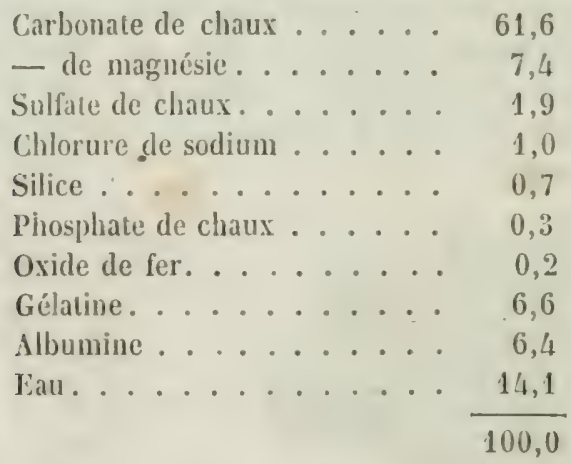

Cette analı̣se a ćté regardée eomme une preure de la nature animale - de la coralline; mais, dans l'analyse de Bouvier, rien ne prouse que les: deux corps nommés par lui grélntince et albumine, soient réellenrent de la gélatine el de l'albumine animales. (Voir Anmeles de rhimie, 1. vin, p. 308.)

On attribue à la coralline blanche des propriétés anthehnintirjues.

Mousse de Corse.

Nommée aussi coralline de Corse ou helminthocorton.

La mousse de Corse est un milange de plusieurs petites algues qui croissent sur les rivages de l'ile de corse, qu'on ramasse sur les rochers et qu'on nous envoie telle's qu'on les ramasse, c'est-it-dire mé- 
langées cn outre d'impurelés et de beaucoup de gravier. Les botanistes ont compté dans la mousse de Corse jusqu’à vingt-deux respèces d'algues, qui n'ont pu être comprises dans les senls genres de Linné, ce qui a forcé à en faire de nouveaux. Les principales sont : le Giigurtinu heelmintherrijton, Lamx., qui a reçu son nom de la mousse de Corse, et qui en fait la partie essentielle et principale; les Fucus purpureus et plumusus; le corallinu offirinalis; le rmferru fusciculatu, etc. Sans entrer dans le détail des caractères de cess différentes substances, voici ceux qui appartiennent au gigartina helminthocorton.

Cette plante appartient au sous-ordre des choristosporíes et à la famille de's spharocen̈lées. Elle est composie d'un nombre infini de petiles fibes réunies par leur base à de's parcelles du gravier sur lequel elles regétaient (fig. 29). Chargue fibre doit être comsidérée comme une pelite lige (qui se bifurque en denx rameanx bifurqués deux fois cuxmèmes, c'est-à-dire, qu'clle est dirflutmer. Cés fibres sont d'un gris-

Fig. 29.

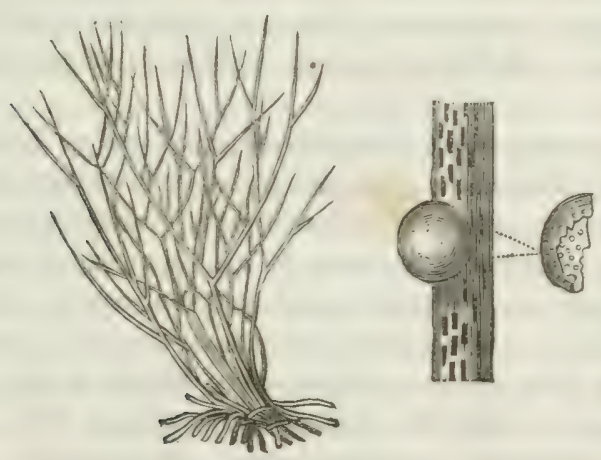

rongeitre sale à l'extérieur, ce qui furme érgalement lit couleur de la masse; mais elles sont blanches en dedans. lilles sont sèches et assu dures à casser lorscru'on conserve la monsse de Corse dans un lieu sec; elles deviennent souples et humides Iorsqu'on la garde dans un lieu humide; enfin la mousse de Corse a une odeur marine forte et désagréable et une saveur fortement salée. On doit la choisir légère et conte- nant le moins de gravier possible. Elle est estimće comme vermifuge. On l'emploie en poudre, en infusion, en gelée ou en sirnp.

On trouve dans le neuvième volume des Annales de chimie une analỵse de la mousse de Corse faite par Bourier, et dont roici les résultats: 100 parties de cette substance ont fourni : gélatine végétale 60,2 ; squelette végélal 11,0 ; sulfate de chaux 11,2 : sel marin 9,2 ; carbonate de 
chaux $7, . ;$; fer, magnesie, silice, phosphate de chaux 1,7 : total 100,8 . I) après cette analỵse, la mousse de corse contiendrait plus de la moitié de son poids d'une matière propre à former gelée arec l'ean; a cependant cette substance, prise dans le commerce, ne produit pas de gelée. Je pense que l'analyse de Bourier est exacte, mais que la mauraise habitude qu'ont les commerçants de placer la mousse de Corse dans des lieux très humides est la cause de la destruction du principe gélatincux. La mousse de Corse ne contient qu'une très petite quantité d'iode.

\section{Carrageen ou viousse perlée.}

Nommée aussi mouseg d'Trloude; fuscus crispus de Linné, chourlmes polymorplus de Lamouroux, sous-ordre des choristosporées, famille des spharococcoüdées. Cette substance sert de nourriture au peuple dans les pays paurres qui aroisinent les mers du Yord, et même en Irlande, où elle est commune. Il ! a (quelques ammées, efle a été proposée en Angleterre comme un aliment médicamenteux analogue an salep ou a l'arrow-root; et en effet aucun autre fucus ne peut lui être comparé pour cet usage, à cause de sa blanchcur parfaite, et de l'absence complète de l'iode et de l'huile fétide qui rendent si désagréables les autres espèces.

Le carrageen est formé d'un pédicule aplati qui se dércloppe en une fronde plane, dichotome, à segments linéaires-cunéiformes, sur lesquels on olsserve quelquefois des capsules hémisphériques, sessiles et concaves en dessous. Il est long de 2 it 3 pouces, et rarie beaucoup dans sa forme, qui est tantôt plane on toute crispuée, élarugie ou filiforme, obtuse on pointue. Tel que le commerce nous l'offre, il est sec, crispé, d'un blanc jaunàtre, d'une odem faible et d'une sarcur mucilagineuse non désagréable. Lorsqu'on le plonge dans l'eau, il s'y gonfle presque aussitôt considérablement, derient blanc, gélatineux et paraìt même se dissoudre en partie. A la chaleur de l'ébullition, il se dissout presque complétement et forme 5 ou 6 fois son poids d'une gelée tres consistante el insipide. Jomirl. de Chim. méd., t. vill, p. 662.)

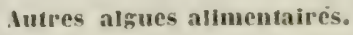

Dans nos pays civilisés, où la culture est ordinairement abondante et variée, les algues ne formeront jamais $u$ aliment important et seront restreintes à l'usage de la médecine; mais dans beaucoup de contrées du globe oì l'agriculture est peu arancéc et ou les animaux manquent ou sont proscrits pour la nourriture par des motifs religieux, les algues forment une partie importante de la nourriture du peuple, comme ì Ceỵlan, aux îles de la Sonde et aux îles Moluques. An nombre 
de ces algues qui nous parriennent quelguefois par la voie du commerce, je dois citer la mousse de Jufnu ou mousse de C'eylen sur laquelle j’ai publié une notice en 1842 , dans le $8^{\text {e }}$ volume du Journal de chimie médicale.

Cette substance est le gracilaria lichenoides de Greville, appartenant à la famille des chondriées de M. Decaisne et au sous-ordre des choristosporées. Elle est en filaments presque blancs, ramifiés, longs de 8 i 11 centimètres lorsque la plante est entière, el de l'épaisseur d'un gros fil à coudre. Elle paraît cylindriq̨ue à la rue simple, mais à la Joupe elle offre une surface inégale et comme nerreuse ou réticulée. La disposition des rameaux est quelquefois dichotome, quelquefois pédalée, le plus souvent simplement alterne. La terminaison des rameaux est semblable à leur subdivision; c'est-à-dire que l'extrémité en est rarement bifurquée ou formée de deux parties également écartées de l'axe commun. Le plus souvent les rameaux se terminent par un prolongement unique et effilé, beaucoup plus fort et plus déreloppé que leur dernière ramification.

La mousse de Ceylin présente une saveur légèrement salée ar ec un goût peu prononcé d'algue marine. Elle croque sous la dent. Eille se gonfle fort peu dans l'eau froide, et n'y devient ni gluante ni transparente, comme le fait le carrageen, qui s'y dissout d'ailleurs en partie. Lille reste parfaitement sèche et cassante à l'air, ce qui montre qu'elle a été privée par des lavages à l'eau douce des sels hygroscopiques de l'eau marine. L'iode la colore en bleu nuirâtre, mèlé d'une teinte rouge. Elle renferme donc une certaine quantité de matière anylacée. Sille contient de plus à l'intérieur une sorte de squelette calcaire.qui produit une grande quantité de bulles d'acide carbonique, lorsqu'on la plonge dans de l'eau aiguisée d'acide chlorhydrique.

30 grammes de mousse de Ceylan ont été bouillis avec 1000 gram. d'eau, jusqu'à réduction d'un quart. Il en est résulté 750 gram. d'un mélange qui ressemble à un épais potage au vermicelle. La décoction ayant été continuée encore quelque temps et le liquide exprimé, j'en ai obtenu une liqueur épaisse, opaque et blanchattre qui, additionnée de 30 gram. de sucre et d'une petite quantité d'hydrolat de cannelle, a formé 150 gram. d'une gelée très consistante, demi-opaque et comme cassante, qualités qu'clle doil sans doute au sul calcaire qui s'y trouve interposé.

Cette gelée est d'un goût fort agréable, en raison de l'aromate que j'y ai joint, et je pense qu'elle doit former un aliment médicamınteux fort nourrissant; mais le marc de la décoction pourrait lui-même être utilisé comme aliment. En effet, ce résidu, quoique fortement exprimé, est sous forme de filaments demi-transparents, qui occupent assez de 
volume pour remplir deux assicttes ordinaires, et susceptible d'ètre accommodé comme des choux ou des graines de lígumincuses : tel est, en eflet, l'usage principal de cette alsue dans les contrées où elle crôt.

100 parties de mousse de Cenlan produisent par la calcination 11 parties d'un résidu grisâtre qui conserve la forme du végétal, comme le phosphate de chaux garde celle des os de mammifères. Ce résidu, traité par l'eau, se dissout en partie. Ia ligueur est complétement neutre, ce qui exclut la présence dans le véryétal d'un sel à acide organiogue. Cecte liqueur se trouble à peine par le nitrate d'argent, mais précipite très fortement par le nitrate de baryte et l'oxalate d'ammoniaque. Le comrogeen se conduit de même, et il est remarquable de roir deux plantes, qui virent au sein de l'eau salée, ne pas contenir sensiblement de chlorure de sodium, mais se charger en abondance des sulfates qui l'accompagnent. Pour le carrageen, ces sulfates sont principalement ceux de soude on de chaur. et ponr la mousse de Cerlan les sulfates de chaux et de magnésie, que l'on sépare en tritant le produsit de l'éraporation des deux sels par de l'eau alconlisée, qui dissout stulement le sulfate de magnésie. On le reconnait alors facilement à son amertume propre, et à la propriété de former du phosphate ammoniaco-magnésien par l'addition du phosphate d'ammoniaque.

La portion de cendre que l'eau ne dissout pas est formée de carbonate de chaux, que l'on peut décomposer et dissontre par un acide, et d'un résidu insoluble qui offre un mélange de petits grains de quarz roulé et d'une sorte d'argile rougeâtre.

Inn opérant de cette manière, les onze parties de cendre produites par cent parties de mousse de Ceylan, ont été trouvées composées de

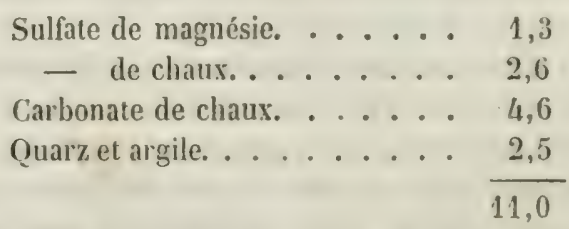

Enfin, je me suis assuré que la mousse de Cẹlan ne contient pas d'iode, en l'humectant de potasse et la calcinant. Le produit cie la calcination, traité par l'eau, fournit me liqueur alcaline qui, neutralisée d'abord par un acide, n'íproure pas ensuite la moindre coloration bleue par une addition d'amidon et d'acide sulfurique.

A l'occasion de la mousse de Jafna, gue plusiemrs auteurs ont regardée comme la matière première des célèbres nids d'hirondelles salanganes, je dirai quelques mots de ces nids eux-mèmes. Beaucoup d'opinions ont été émises sur la substance qui les compose. Suivant l'une, la salangane 
tire de son jabut ou de son estomac, par des efforts analogues a ceux du romissement, tous les matiriaux dont elle compose son nid; ct Ererard Home a cru recomnaitre dans le jahot de cette hirondelle l'orsane sérriteur de cette sorte de mucus. Mais cette opinion ne sarcorde pas aree le fait bien avéré que le's salanganes qui habitent an milien desterres, volent incessamment par troupe's, vers le rivage de la mer, dans la saison où elles construisent leurs nids, et y recherchent une matière muqueuse sous forme de filaments, qu'elles rapportent à leur habitation. Cette matière doit donc entrer dans la fabrication du nid; mais furtlo peut en être la natıre? Suivant les uns, elle est d'origine rérétiale et se compose de fucus abandonnés sur la plage par la marée descendante, et

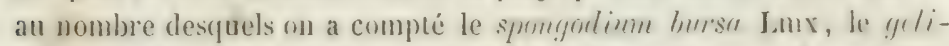

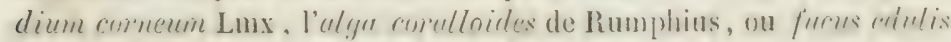
de Gmelin, et le gruriluria lichenuide's ou monsse de cirglan. Suisant les autres, elle est de nature animale et se compose de paritirs molles de mollusques ou polspes, auxquelles les salangane's font subir un conmencement de deglutition. Cette dernière opinion est conforme à l'examen chimigue qui a eté fait par Doebereiner de la matiere gábatineuse de ces nids; celte substance lui ayant paru ère de nature complitement animale, ct très analogue an mucus. Hais la premiere opinion peut être également vraie, parce que les nids de salangane variont beaucoup dans leur contexture et par la nature des materiaux dont ils somt formés. On en trouve, en effet, qui sont presque uniquement formés d'une matiere gélatineuse demi-transparente, dure, compacte ct continue, commo une membrane desséchée; ce sont les plus estimés, et c'est à celle sorte de nid que se rapporte l'analyse de Doeberiner. I)'autres offrent une sorte de réseau formé de cette mème matière gélatinense, d'algues marines et mème de lichens terrestres, auxquels la première substance sert de ciment; d'autres enfin paraissent prirés de matière gélatincuse et sont complétement rejetés comme aliment. II. Delessert possède un nid de la première espèce, et l'Ĺcole de pharmacie un de la seconde, qui Jui a été donné par M. O. IIenry. Ce dernier nid, en forme de conpuille on de bénitier, se compose de quatre couches assez distinctes : la plus inférieure ou li première, qui a été appliquée sur le plan incliné en avant qui supportait le nid, est brune, terne, dure, rugueuse, non compacte ni continue, mais formée plutôt de filaments gélatineux agglutinés. Audessus de cette matière brune, et en suirant la direction inclinée du support, se présente peu à peu une couche d'une substance plus pure, blanche, transp̣arente, d'apparence gommeuse ou gélatineuse, en partic compacte et membraneuse comme celle qui forme le nid dela collection de II. Delessert; mais en partie aussi sous forme d'un réseau incolore et transparent, qui ressemble à une matière muqueuse élaborée et non 
oryemisrie. Au-dessus de cette couche gélatineuse on trouve, surtout du côté externe du nid, une couche assez épaisse d'un fucus rouge-rosé, à raneaux dichotomes, neveenx, comprimés, représentant asscz bien le gracilaria compressa de Greville, représenté par lui sous le nom de

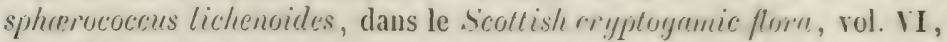
tab. 341.

Enfin la partie supérieure et interne du nid est formée par un lichen terrestre, blanc, cylindrique, très fin, qui est, d'après la détermination de II. Montagne, l'ulectorin crinal is d'Acharius. I.e tout est entremelé ça et là d'une bare muqueuse, qui en maintient les différentes parties. Telle est la description exacte du nid de salangane de l'École de pharmacie, qui m’a suggréré une explication de la différence peu commune de texture el de composition que l'on observe dans les nids d'une même espèce d'viscau. Je pense que les salanganes sont d'autant plus portées à composer leur nid d'une matière gélatineuse continur qui, une fois desséchée à l'air, devient complétement imperméable, qu'elles habitent plus près des bords de la mer; parce qu'elles sentent la nécessité de mettre leurs œufs et leurs petits à l'abri de l'air froid et chargé de vésicules salées, qui s'ilève des rochers battus par les ragues; tandis que celles qui construisent leurs nids dans des lieux éloignés du rivage, ou dans des carernes abritées du vent de mer, éprourent un moins grand besoin d'employer cette même substance, et se contentent d'en former un réseau ou un ciment non continu. Au surplus ces nids si vantés, formés principalement d'une natière azotée, en partie digérée et dégngée par des oiseaux, ne peuvent avoir de prix, ainsi que je l'ai dit en commençant, que pour des peuples auxquels des idées religieuses prescrivent de ne pas se nourrir de chair, ou qui virent dans une grande pénurie de substances alimentaires.

\section{ORdRe des Chaupigrons.}

Les champignons sont des régétanx terrestres nés dans des lieux humides et ombragés, sur des corps organisés languissants ou morts, et en état de décomposition. Ils se composent en général de deux parties distinctes, l'une régétative, l'autre de reproduction. La première, nommée mycrlium, qui parait être l'élat primitif de tout champignon, est formée de filaments grêles, simples ou ramifiés, nus ou engagés dans la substance même du corps sur lequel le champignon rit en parasite. La seconde partie, qui naît de la première, se compose de spores quelquefois nues, mais plus souvent contenues dans un réceptacle de forme et de grandeur très variées, qui porte le nom de péridium dans les champignons de forme arrondie, et qui est communément regardé comme le champignon proprement dit. 
On divise les chanplignons en cind sous-ordres, qui sont :

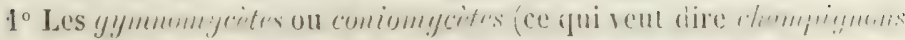

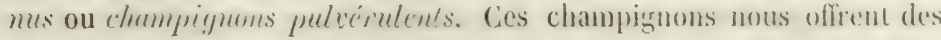
sporidies simples ou à plusieurs loges qui, i une certaine époque de leur existence, paraissent composer tonte la plante. Tels sont les uredn, champignons parasites qui semblent uniquement composés de sporidies uniloculaires, développées en quantités innombrables sous l'épiderme des tiges, des fleurs ou des fruits, qu'elles font périr et détruisent quelquefois complétement. Les plus muisibles à l'argriculture sont, sans contredit, ceux rqui attaquent le ble, et qui sont connus sous le nom de churbon, de carie el de rouille des blés juredo segrtum, uredo curies, uredo rubigo.

2 Les hyphomeycites, champignons composés d'un mycélimm filamenteux, libre et distinct, dont une partie des filaments dressés portent des sporidies, tantòt nues, tantôt renfermées dans le son:met des tubes qui se déchire pour les laisser à nu. Telles sont les murpilinies, les byssées et les mucorées.

3" Les gastéromycètes, champignons consistant en nn péridium charnu, membrancux ou floconneux, d'abord clos, puis se déchirant irrégulièrement, dont la substance intérieure se conrertit rn sporidies répandues sur les fibres ou contennes dans des réceptacles (sporanges ou thèques).

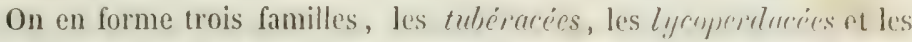

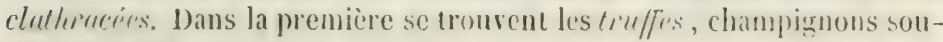
terrains, très recherchés pour la table, à cause de leur parfum et de leurs propriétés excitantes. Ces champignons, prirés de racines, sont formés de tubérosités arrondies on lobées, lisses ou hérissées de rugosi-

Fig. 30 .

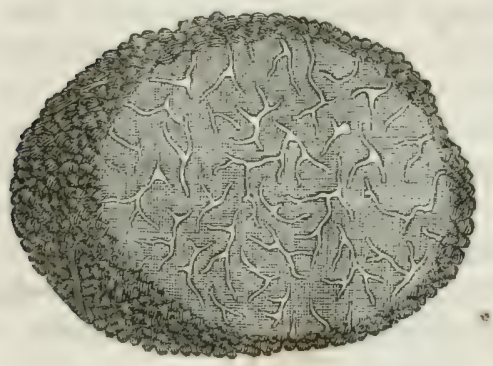

Fig. 31 .

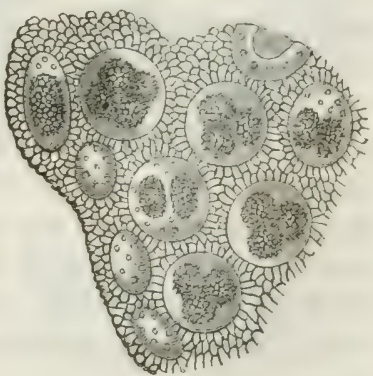

tés. Leur substance intérienre est charnue, entièrement formée d'utricules pressées, rondes, oblongues ou allongées, dont un certain nombre se développent et donnent naissance intérieurement à de petites truffes qui se dispersent dans la terre après la destruction de la truffe mère (voir les figures 30 et 31 , qui représentent la truffe noire comestible 
(tuber riburium) de grandeur naturelle et fortement grossice). Dans la seconde famille se tromsent les lycroperden ou resess-de-lomp (ligg. 32), champignons formés d'un mẹcélium radiciforme, duguel s'des. un ou phisieurs péridimms arrondis et sonvent tries voluminenx, dont la chair,

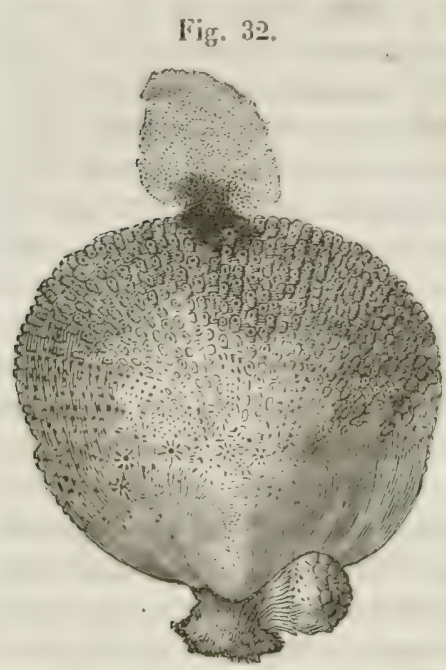

ferme et blanchâtre dans la jeunesse, se convertit en une poussière (sporidies) de couleur fauve ou verdâtre, portée sur des filaments d'une apparence feutrée. Arrivé à maturité, le péridium s'ouvre irrégulièrement au sommet pour laisser échapper la poussière reproductrice. Cette poussic̀re peut être employée comme dessiccative, à l'instar de celle de lycopode, et comme hémostatique, propriété qu'elle possède à un haut degré. Les clathracées sont di's champignons produits par un mycélium radiciforme duquel s'élève un corps sphérique ou ovoîde dont l'enveloppe se déchire pour laisser passer un péridium treillagé et percé à jour, remarquable par la beauté et la régularité de ses dessins, et coutenant un réceptacle muqueux rempli de sporidies, qui s'écoulent arec la matière difluente du réceptacle. Tels sont entre autres les phrollus, les clathres et les lanternes.

4" Les scléronnycotes ou pyprénomycetes : mycélium produisant des cxcroissances fonguenses, la plupart noiràtres, cmlurcies, d'une texture obscurément celluleuse, solitaires, agrégées ou soulcées, d’abord fermées, puis s'ourrant par le sommel; à noỵau distinct, mou, sousdéliquescent. Sporidie's entourées par la mucosité ou renfermées dans des thicques. Exemples, les sphurria et les hyprixyloms.

$5^{n}$ Les hymmónomiyrites : mycélium produisant de's excroissances fonguenses, dont une partie de la surfane (hymenium) est formée par les utricules productrices des spores. On peut y former quatre familles, qui sont les trimmllinées, les clacuriées, les helcelluries et les piltintres. Ce sont ces familles qui fomrnissent le plus grand nombre des champignons tant comestibles quie vénéneux. Parmi les premiers, je citerai :

La trẻmelle mésentère,

La clavaire corail,

La morille comestible, tremella mesenteriformis. clavaria coralloides. Morchella esculente. 
Les hydnes,

Le mérule chanterelle,

Le bolet comestible,

L'agaric comestible, presque toutes comestibles.

merulius cantharellus.

boletus edulis (fig. 37).

agaricus campestris (fig. 33 ).

Ce dernier est le seul usité à Paris. Cultivé sur des couches, il est formé d'un stipe court, épais, cylindrique, formant une sorte de collet i) la partie supérieure, et d'un chapeau arrondi, presque hémisphérique, blanc en dessus, à lames rougeâtres en dessuus, d'une consistance ferme, d'un goût et d'une odeur agréables.

l'armi les champignons vénéneux, je citerai, comme ceux qui le sont le plus,
Les agarics meurtrier,
agaricus necator.

- à verrues,
- fausse-oronge,
- bulbeux,
- verrucosus.
- muscarius.
- bulbosus.

Les moillenrs remèdes à emplover dans les cas d'emp̨oisonnement par les champignons sont l'éther et l'úmétrue : l'úther pour calmer les acridents déja déclarén; l'émétigue pour éracuer cr pui reste de proison dans le canal alimentaire.

Il n'y a pas de régétaux qui se jouent plus que les champignons, ou que les agarics de Linné, de la loi que l'on a voulu troi généraliser, que des organes semblables dans les végétaux répondent à une composition chimique et à des proprićtés médicinales analogues. La composition chimique est cependant as.ez rígulière dans ces vérgétaux, ('t se fait remarcuer dans tous par une grande prédominance de principes azotés, qui les met presque sur le même rang que les substances animales, et qui est cause que, parmi les animaux, ce sont principalement les carnivores qui les mangent; mais à côté de ces principes nourrissants, il Fig. 33 . s'en trouve d'autres qui sont éminemment rénéneux dans queldues espèces, et qui manquent dans les espèces les plus voisines, de sorte que la plus grande habitude ne met pas toujours à l'abri des accidents les plus funestes. 
Ln des exemples les plus frappants de cette discordance de la forme arec les proprićtés médicinales on alimentaires, est fourni par les deux champignous qui portent les noms d'ormye uraie et de fausse orunge. 'Tous deux appartiennent aux mmenites ou aux agaries à volcu, c'est-àdire ru'ils sont enfermés, prndant leur jeune âge, dans une poche que le champignon perce en grandissant. Leur principale différence consiste en ce que, dans l'oronge vaie (ngaricus aurantiacus, Bull., fig. 31), aucune parlie du volva n'est retenue par le chapeau qui s'élève, tandis que dans la fausse oronge (agarions muscorius, L., fig. 35 ) le volva laisse sur le chapeau des débris sous forme de tubercules anguleux,

Fig. 3 .

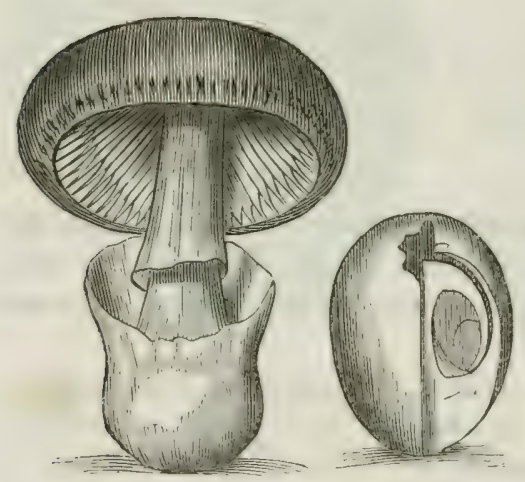

Fig. 3ว.

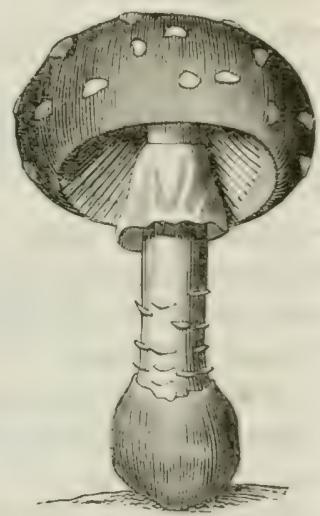

dont la couleur blanche tranche avec la belle teinte orangée du chapeau. Or, celte différence assez légère en dénote une bien grande dans la qualité; car l'oronge vraic est un des champignons les plus recherchés comme aliment, ctl'agaric moucheté est un des plus rénéncux.

On demandera sans doute pourquoi, quand il est si difficile de distinguer les bons champignons des mauvais, on ne se met pas pour toujours à l'abri de leurs effets muisibles en les bamnissant tous du nombre de nos aliments. Cette question est aisée à faire dans les villes ou dans les pays ahondants en blé et en piturages, où les champignons sont une nourriture de luxe; mais il y a beaucoup de contrées moins farorisées nii le peuple troure diuns les champignons des bois un supplément d'antant plü utile it sa nourriture, que leur nature animalisée les rend très nutritifs sous un petit rolume.

- Vampuelin et .1. Jiaconnot ont fait sur les champignons des recherches chimignes qui confirment pleinement ce que je viens de dire.

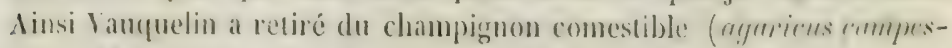
frisj: 1" de l'adipocire ou graisse cristallisable; "2o de l'huile granse; 
3" une matière sucré $4^{\circ}$ de l'albumine; $5^{\circ}$ de l'osmazome ou matière animale soluble; 6" une autre substance animale insolnble dans l'alcool; $7^{\circ}$ de la fongine ou partie fibreuse des champignons; $8^{\circ}$ de l'acétate de potasse. Il est vaiment remarquable qu'un champignon, dont la structure paraît si simple et si homogène, contienne tant de principes différents; il l'est encore plus de voir que sur ces huit principes cinc appartiennent au règne animal. (Aun. de chim., t. LXXXV, p. 5.)

Polypore du mélèe ou Agarle blanc.

Limné a défini les aymir's des champignons à chapean horizontal, lamelleux en dessous, et les bolets des champignons horizontaux, poreux en dessous. Suivant cette division, le champignon comestible s'est trouré compris dans les agarics, et d'autres champignons, qui araient porté de tout temps le nom d'ugarics, ont été rangés dans les bolets. A ujourd'hui ce dernier genre est partagé en trois.

$1^{\circ}$ Boletus, champignons à stipe central, à clapean hémisphérique et charnu, dont la partie inférieure est formée de tubes tapissés intérieurement par la membrane fructifère (hymenimu). Ces tubes sont indépendants les uns des autres ou séparables, et non continus avec la substance du chapeau.

Exemples : le bolet du bouleau, boletus betulinus (fig. 36 ).

- comestible, - edulis (fig. 37).

- indigotier, - cyanescens.

2 Polypurus, champignous à chapeau charnu ou subéreux, dont Fig. 37.

Fig. 36.
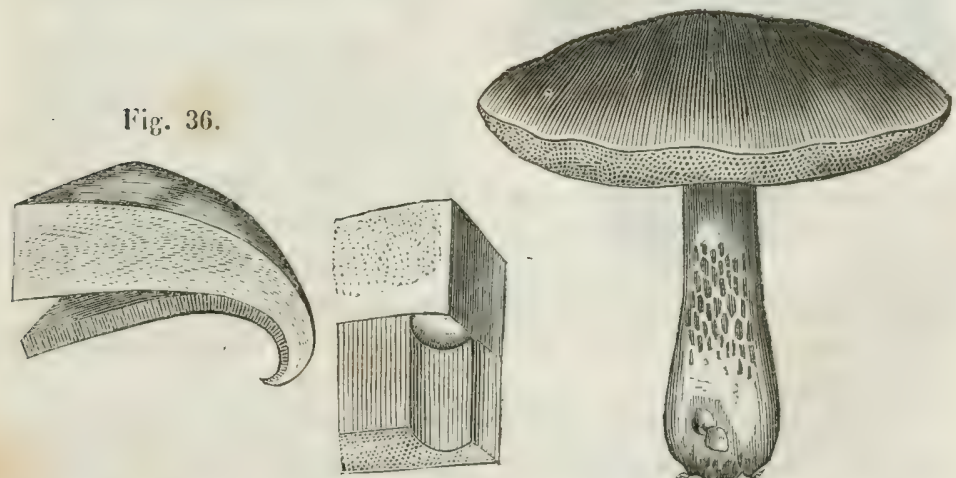

les tubes sont séparés par une cloison simple, et font corps aree la substance même du chapeau. 
Exemples: le polypore du mélèze, pulyjurus officiunlis.

$$
\begin{aligned}
& \text { - amadouvier, -- igmiarius. } \\
& \text { - ongulé, - fomentarius. }
\end{aligned}
$$

$3^{\circ}$ Diedalea, champignons à chapeau sessile présentant inférieurement des lames anastomosées qui forment des cellules irrégulières d'une substance homogène à celle du chapeau.

Exemple: l'agaric labyrinthiforme, declalea betulina.

Ce dernier gemre nous intéresse peu; mais le polypore du nélize et les polypores ongulé et amadourier doirent être examinés spécialement.

\section{Polypore du meleze.}

Le polspore du mélèze ou agaric: Ulener croît sur le trone des vieux mélezes, dans la Circassie en Asie, dans la Carinthie en Europe, et sur le's. Mpes du Trentin et du Dauphiné. Il se présente sous la fortine d'un

Fig. 38.

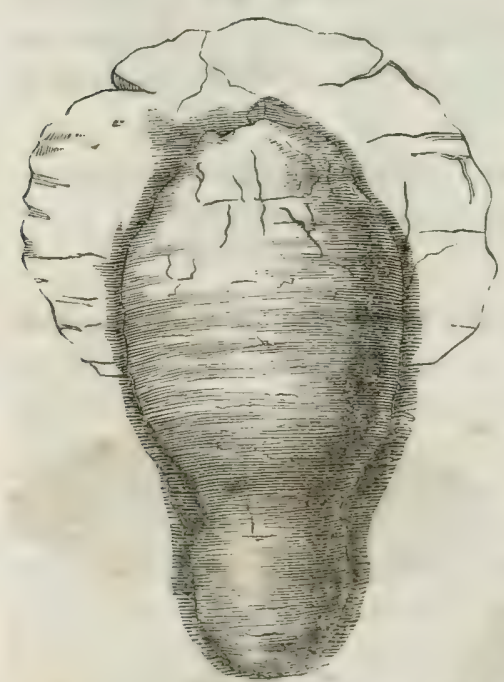
cône arrondi, recouvert d'une écorce rude, dur's, ligneuse, et marquée en dessus de sillons circulaires qui indiquent son âge (fig. 38) : sa substance intérieure est blanche, légère, spongieuse. Il varie en bonté, suivant le pays d'où il vient : celui d'Asie el de la Carinthie est le plus estimé; celui du Dauphiné, qui est petit, pesant et jaunâtre, est le moins bonl.

L'agaric blanc se troure dans le commerce privé de son écorce et mondé au vif. On doit le choisir bien blanc, léger, sec, non ligneux, spongieux et pulvérulent; il est pourvu d'une sareur douceâtre, devenant hientôt, et tout à la fois, amère, sucrée, et d'une acreté considérable; il irrite fortement la gorge lursegu'on le pulvérise? il est inodore.

L'agaric blane est un purgatif drastique et hỵdragngue. M. Bracommot en a fait l'analyse, et en a retiré, sur 100 parties : 72 d'une matière résincuse particulière, 2 d'un extrait amer, et 26 de matière fongreuse insoluble. La matière résineuse jonit de propriétés bien singulières: elle est blanche, oparuue, granuleuse dans sa cassure et peu sapide; 
(lle se fond et brûle comme les résines. Elle est plus soluble à chaud qu'a froid dans l'alcool, et s'en précipite en tubercules allongés par le refroidissement; elle est insoluble dans l'eau froide, qui cependant la dirise arec beaucoup de facilité; une petite quantité d'eau bouillante la dissout et en forme un liquide épais, visqueux, filant comme du blanc d'œuf, moussant très fortement par l'ébullition, coagulable par l'eau froide. L'éther, les huiles fixes et rolatiles, les alcalis, la dissolvent; clle rongit la teinture de tournesol; l'acide nitrique parait aroir peu d'action sur elle. (Bull. de phomm., 1812, p. 304.)

\section{Agaric de chenc.}

Deux polypores servent à préparer la substance connue sous le nom d'aygric de chène : l'un est le Poryorr oxgule, polyporus fomentarius, Fries et Pers. (boletus fomenturius, I. ; brietus ungulatus, Bull.); l'autre est le Pompore alradovirer (polyporus igniarius, Fries et Pers. ; boletus ignimius, L., Bull.)

Le polypore ongulé (fig. 39) est un champignon sans tige, fixé par le côté et par la partie supérieure au tronc des vieux arbres, et surtout des chênes, des hêtres et des tilleuls. Il présente à pen près la forme d'un sabot de cheval et peut acquérir jusqu'à '2 pieds de diamètre. Il est formé d'une écorce brune, très lure, marquée d'impressions circulaires qui indiquent son âge; l'intéricur est plus ou moins rouge, fibreux el un p: u ligneux. Pour le préparer, on le prive de son écorce, on le fait tremper dans l'eau et on le bat avec des maillets, afin

Fig. 39.

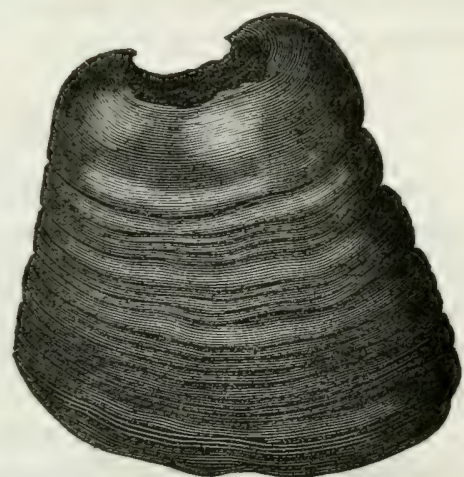
de rompre les fibres ligneuses. On le fait sécher et on le bat de nouveau jusqu'à ce qu'il soit devenu peu épais, très souple et moclleux au toncher. On doit choisir celui qui réunit ces qualités au plus haut degrí. Il est employé principalement pour arrêter le sang des sangsues ou des vaisseaux rompus.

I. bolet amadouvier est moins ligneux que le précédent, presque mou ct ćlastique dans sa jeunesse, ce qui est cause qu'il se gerce cn vieilissant. On le prépare comme le précédent et il sert aux mêmes nsagrs; mais c'est lui surtout qui sert à faire l'amadou. A cet effet, on leé:ent, en le battant toujours, cn lames très minces dout on augmente 
encore souvent la combustibilité en le trempant dans une solution de nitrate de potasse ou de poudre à canon.

Ni l'un ni l'autre des polypores précédents ne parait aroir été examiné chimiquement : celui dont M. Braconuot a publié l'analỵse paraît être le polyporns dryadeus de Fries et Persoon (boletnes jsendo-igniarius, Bull.), (qui diffère des premiers par sa consistance plus molle, sa couleur plus pâle, sa largeur (qui ne dépasse pas 3 ou 4 pouces, et surtout par sa composition chimique; car M. Braconnot n'y signale pas de principe astringent, et il est connu que les polyporus fomentarius et igniarius serrent à la teinture en noir. Quoi qu'il en soit, 1!. Braconnot a retiré du polypore faux-amadouvier récent : de l'eau, de la fongine, un sucre incristallisable, une matière adipeuse jaune, de l'albumine, de l'acide acétique, un autre acide régétal particulier nommé aridle bolétique (ayant beaucoup de rapports arec l'acide succiniçue), de l'acide phosphorique, de la potasse et de la chaux saturant en partie les acides précédents." (Ann. de chim., t. LXXX, p. 272.)

La fongine forme la partie solide des champignous et joue chez eux le même rôle que le ligmeruci dans les végétaux phanérogames. Yais elle diffère beaucoup du ligneux par sa constitution chimique; car elle contient de l'azote, domue de l'ammonianne it la distilation, ot se putrifie a la manière du gluten.

\section{Ergot du seigle ou Seigle ergote.}

Dans les années pluvienses, piusieurs graines céréales, mais principalement le seigle, présentent une altération singulière: on troure à la place d'un certain nombre de grains, dans les épis, un corps solide. brunâtre, allongé, recourbé, aỵant (quelçue resemublance de forme avec l'ergot d'un cog, d'où lui est renu le nom de scigle argoté ou d'ergot ( fig. 40).

L'ERGot est un corps brun-violet, souvent recouvert d'une efllorescence grisìtre, long de 1 à 3 centimètres, mais pourant en accuérir le (louble en conservant une épaisseur de 2 à 3 millimètres, rarement 4 (fig. 41). Il est d'une forme irrégulièrenent carrice on triangulaire, aminci aux extrémités, sourent margué de une ou de plusieurs crevasses longitudinales, et quelquerfois aussi de crevasses transtersales. On observe a l'extrémité supérieure un petit pacpuet hlanchatre d'une matière molle et cérébriforme, dont la substance coule en partie le long de l'argot (royez fig. 12, qui reprisente deux crgots fortement grossis; Io premier très jeune et à l'état récent; le second plus igé et descéché). Cette substance diminue beaucoup de rolume par la dessiccation et mançue presque inujours dans l'eronot du rommeree. en ạant été 
détaché par le choc ou par le frottement. L'ergot médicinal se compose donc presque exclusivement du corps allongé brun-riolel décrit d'abord.

Fig. 40.

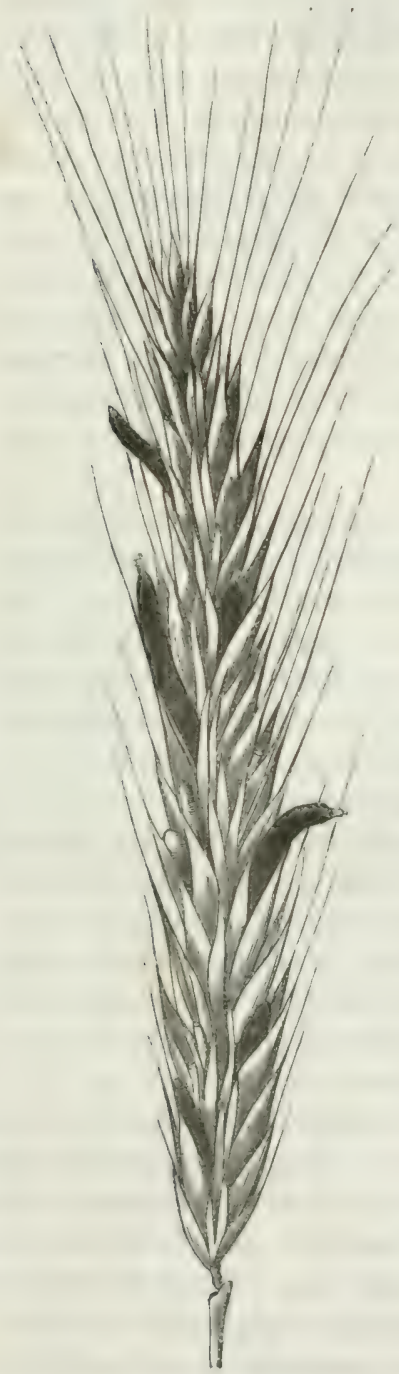

Fig. 41.
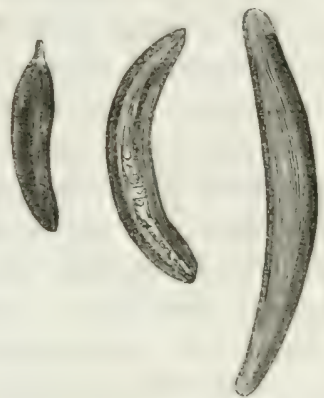

Fig. 42

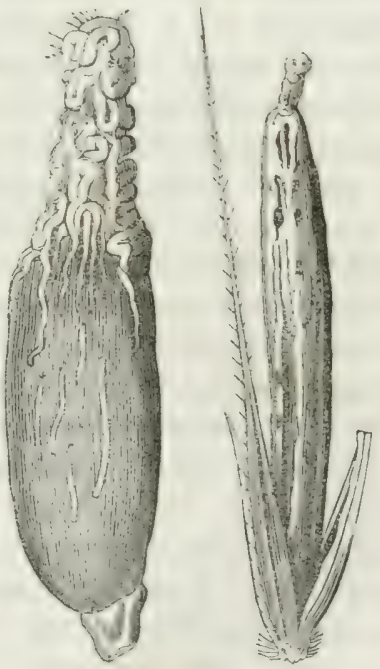

L'ergot est ferme, solide et casse net lorsqu'on veut le plover. La cassure en est compacte, homogène, blanche au centre, se colorant 
d'une teinte vineuse près de la surface; d'une sarour peu marquire: d'abord, suivie d'une astriction persistante vers l'arrière-bouche.

L'odeur de l'ergot récent rappelle celle des champignons; desséclé et respiré en masse, il présente une odeur plus forte et désagréable; conservé dans un air humide, il éprouve une altération putride, dégage une odeur de poisson pourri et devient la proie d'un sarcopte semblable à celui du fromage. Il est donc important pour les pharmaciens d'avoir l'ergot récemment séché el de le conserver dans un lieu bien sec.

I'analyse de l'ergot a élé faite par plusieurs chimistes. Vaurquelin en a retiré : $1^{\circ}$ une matière colorante jaune fauve, soluble dans l'alcool, d'une saveur d'huile de poisson ; $2^{\mathrm{n}}$ une huile grasse, abondante, d'une saveur douce; $3^{\circ}$ une matière colorante violette, soluble dans l'eau et dans l'alcool, applicable sur la laine et la soie alunées, ayant beaucoup l'analogie avec celle de l'orseille; $4^{\circ}$ un acide libre (phosphorique ?); $5^{\circ}$ une matière azotée abondante, très putrescible, fournissant une huile ípaisse et de l'ammoniaque à la distillation ; $6^{\circ}$ de l'ammoniaque libre ou du moins qu'on peut obtenir à la température de l'eau bouillante. Il n'y a trouvé ni amidon ni gluten.

Tels sont les résultats obtenus par Vauquelin. Ce grand chimiste ayant examiné comparativement un sclerotium, y troura des différences notables, et crut pouroir regarder comme probable que l'ergot n’élait pas un sclerotium, ainsi que l'admettait De Candolle (.1 $\mathrm{mm}$. de chim. ef de pliys., t. III, p. 202 et 337). Mais si l'on fait attention, au contraire, que celte analyse offre une grande analogie arec celle des champignons comestibles, il paraitra bien plus probable que l'ergot est en effet un champirnon. Je reviendrai plus loin sur cette opinion.

On doit à $\mathbf{M}$. Wiggers une analyse plus récente et plus complète de l'ergot (Joum. pharm., to XVIII, p. 525). Ce chimiste ayant traité d'abord 100 parties d'ergot pulvérisé par l'éther, en a retiré 36 parties d'une huile brune-rerdâtre, d'où l'alcool a extrait une petite quantité d'une huile grasse, rouge-brune, d'une odeur fort désagréable, et un peu de cérine cristallisable; le reste se composait d'une huile doure, blanche, très soluble dans l'éther ( 35 pour 100 ).

Le seigle ergoté, traité ensuite par l'alcool, lui cède 10,56 d'un extrait rouge, d’une odeur de viande rôtie, grenu, déliquescent, que l'eau sépare en deux parties : l'une est insoluble, pulvérulente, tl'un rouge brun, d'une saveur amère un peu âcre, ni acide ni alcaline, insoluble dans l'eau et dans l'éther, soluble dans l'alcool. 11. Wiggers Ini donne le nom d'ergotine. L'autre substance est soluble dans l'eau, et contient un extrait azoté semblable à l'osmazome, du sucre cristallisable, et des sels inorganiques.

t.e scigle ergoté épuisé par l'alcool, avant élé traité par l'eau, lui a 
cide un estrait contenant du phosphate acide de potisse, de la gromme et un principe azoté d'une couleur rouge de sang. Le résidu était composé de fongine, d'albumine, de silice et de phosplhate de chaux. Voici les r'ésultats de cette analyse :

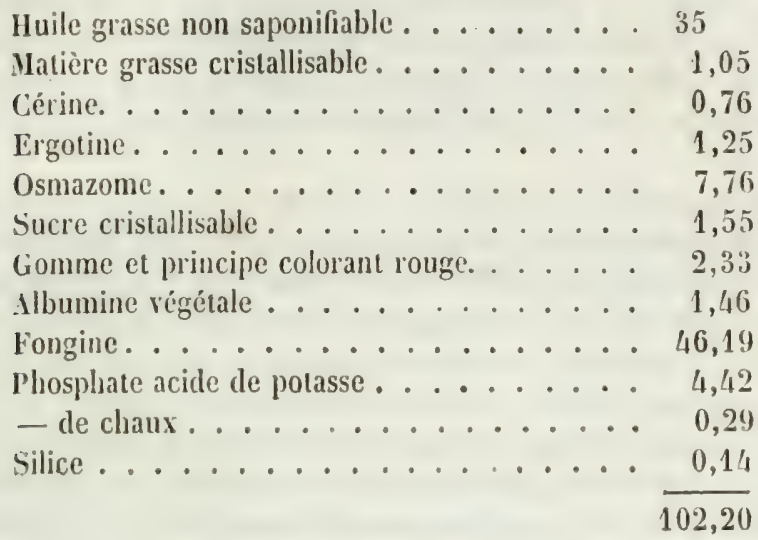

L'ergotine de I. Wiggers est probablement une matière colorante résinoüde. Elle est différente de la préparation qui porte aujourd'hui le nom d'ergotine, et bien à tort, parce qu'il ne faudrait pas donner un nom qui doit être réservé pour un principe sui generis, à un produit aussi complexe que l'est la préparation inventée par .1. Bonjean.

Pour préparer son ergotine, II. Bonjean épuise de la poudre de seigle ergoté par de l'eau. Il érapore les liqueurs jusqu'en consistance de sirop et y ajoute un grand excès d'alcool qui en précipite toutes les parties gommeuses et les sels insolubles dans l'alcool.

Inis ce liquide retient évidemment en dissolution les sels déliquesconts, l'ergotine de II. Wiggers, l'osmazome, le sucre et d'autres substances encore. C'est ce mélange, obtenu par l'évaporation de l'alcool et nommé ergotine par II. Bonjean, que ce pharmacien propose conme un spécifique contre les hémorrhagies de toutes natures, et aucquel il attribue aussi la propriété obstétricale, bien qu'il ne l'applique pas à cet usage.

Maintenant que nous connaissons l'ergot par ses caractères physiques et par sa composition chimique, examinons les opinions qui ont été émises sur sa nature.

Pendant longtemps, l'ergot a été regardé comme un grain altéré et déreloppé d'une manière anormale; mais en 1802 , De Candolle le considéra comme un champignon du genre des sclerotium, lequel, en s'implantant sur l'oraire, le faisait périt et se développait it sa place : il 
lui donna le nom de selermizm clans. Les caraclères physiques des sclerotium s'accordaient en effet arec ceux de l'ergot; cependant ces champignons n'étaient pas très bien définis, et récemment 11 . le docteur Léveillé, s'appuyant sur ce que la plupart des botanistes n'ont pu ubserver dans ces régétaux ni lı̣méninm ni spores, a regardé les sclérotium comme des champignons arrêtés dans leur développement, ou comme un my célium condensé qui, placé dans des circonstances farorables, se transforme en agarics, en claraires ou en divers autres champignons. (Ammles des sciences unturelles, 181.3, Botaxigue, t. XXIX.)

En 1823, I. Fries composa de l'ergot du seigle et d'une autre espèce observée sur un pasyulum, un genre particulier de champignons auquel il donna le nom de sputuretlic, mais en mettant lui-menne en question si ce n'était pas une mulndie du grain. Cette dernière opinion, qui est aussi la plus ancienur, est aujourd'hui là plus gémíralement adoptée; je ne crois pas cependant qu'elle soit conforme à la vériti.

- Tous les observatcurs ont constaté que l'apparition cie l'ergot est précédée dans la fleur de celle d'une substance mielleuse gui colle ensemble Ies étamines et le stṛle el s'oppose à la fécondation, cel la plupart ont admis que l'oraire non fécondé se développe alors d'une manière anormale, con formant une sorte de môle sourent recouverte par les débris de la substance mielleuse desséchée.

D’après II. Léreilli, ce suc mielleux qui précède l'ergot constitue un noureau champignon de l'ordre des gymnomscites, aurjuel il a donné le nom de splureliu segetum. Il prend naissance au sommet de l'oraire, dont il délache l'épiderme garni de poils, et il forme un corps mou, visqueux, difforme, d'un blanc jaunàtre, au-dle:suus duçuel applaraît un point noir qui est l'oraire non fécondé ct altéré. Celui-ci crôt bientôt d'une manière anormale et sort de l'épi en poussant devant lui la sphacélie. II. Léreillé pense que cette sphacélie constitue la partie active de l'ergot et que celui-ci est incrte lorsqu'il en est privé. (Mémoires de la Surietre limiéenne de Paris, t. V, p. 565.)

Il ue faut pas confondre la sphacélie de II. Léreillé avec le spermuetion de .I. Lries. La sphacélie est la partie blanchàtre qui surmonte l'ergot et qui manque presque complétement dans celui des pharmacies, ce qui n'est pas farorable à l'opinion de II. Léreillé sur l'innocuité de celui-ci. Le spermodia de II. Fries est l'ergot lui-mêne.

Plusieurs autres observateurs, tels que M.M. Phillipar, Phocbus, et Quekett, dont je n'ai pu consulter les mémoires en original, paraissent aroir adopté l'opinion que l'ergot est une maladie du seigle causée par la présence d'un champignon de la nature de celui décrit 
par M. Léreillé; seulement II. Quekett lui a donné le nom d'ergutertiu abortifaciens, et en a présenté une figure qui ne me paraît pas exacte, ou qui se rapporte à quelque autre coniomỵcète étranger à la production de l'ergot.

I. I'ée est le dernier botaniste qui se soit occupé de l'ergot (1). On peut lui reprocher d'avoir admis plusieurs opinions inconciliables sur la nature de ce singulier corps; mais la description exacte qu'il a donnée des différentes parties de l'ergot, me permettront, je crois, de formuler une opinion plus précise que celles qui ont précédé, sur la nature de l'ergot.

D'après mon honorable et sarant collègue, la sphacélie se développe dans la fleur des graminées entre l'orule, fécondé ou non, et la feuille carpe'llaire qui doit former le péricarpe; il détache complétement celleci et la soulève sous la forme d'une coiffe à larguelle l'auteur donne le nom de succulus. L'orule mis à nu, recevant tonjours les sucs nourriciers de la plante, se développe d'une manière anormale, s'hypertrophie et forme l'ergot, aucpuel II. Fúe donne le nom de usiscarya (grain malade). Ainsi l'auteur, après avoir commencé par dire gu'il regardait, avec Je Candolle, l'ergot comme un champignon, finit par conclure que c'est une production pathologique ou une hỵpertrophie du périsperme. Il fant cependant opter entre ces deux opinions qui ne peurent pas être vraies toutes les deux; pour moi, je préfère la première, et pour l'établir d'une manière pliss nette, je sépare d'abord la sphacélie de l'ergot et je dis que la sphacélie est un champignon gymnomycite, que j’ai trouvé uniquement formé de denx espèce's de parties (2) : 1" d'une masse de sporidies oroüles-allongées, appliquées les unes contre les autres, très

1.ig. 43.

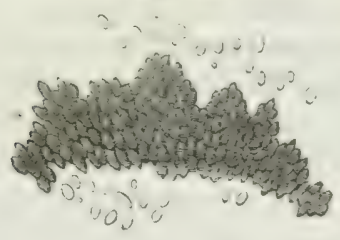

Fig. 44.

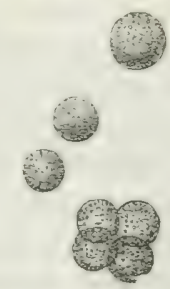

faciles à séparer par l'eau, et dont quelques unes ofirent des spores trìs petites dans leur intérieur; "2" de krstes sphériques ou peut-être seulement d'anas circulaires composés d'une quantité considérable de spores très petits. J'emprunte à $\mathbf{H}$. Fée les deux figures qui les représentent (fig. 43, 44).

(1) Mémoire sur l'ergot du seigle, elc., Strasbourg, 1813.

(2) J'avais préalablement traite la sphacélic par l'éther et l'alcoul afin de $\mathrm{l}$ priver de matière grasse. 
J'ai pris ensuite l'ergot lui-même ou le nusocarıa de I. Fée; je l'ai coupé en tranches minces et l'ai traité plusieurs fois par l'éther et par l'alcool pour le priver de l'huile qu'il contient; mais il est d'une sub)stance tellement compacte que ces menstrues y pénètrent à peine, et que la plus grande partie du corps gras y reste enfermée. J'ai traité ensuite cet ergot par l'eau et je l'ai écrasé par petites parties sous le microscope: je n'y ai trouvé que deux sortes de substances :

$1^{\circ}$ Des gouttelettes d'huile (fig. 45) reconnaissables à leur forme exactement sphérique, à leur transparence et à leur pesanteur spécifique inférieure à celle de l'eau.

$2^{\circ}$ Des cellules polymorphes isolées, soit telles que II. Fée les a représentées (fig. 46), soit telles que je les ai vues (fig. 47). Je ne puis décider si les petits corps sphériques qui paraissent contenus dans ces cellules, sont de l'huile ou des spores. Si ce sont des spores, il n'y a pas

Fig. 46.

Fig. 47.

Fig. 43̈.

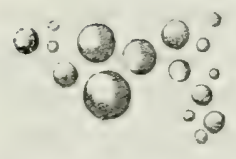

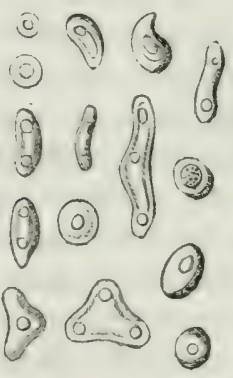

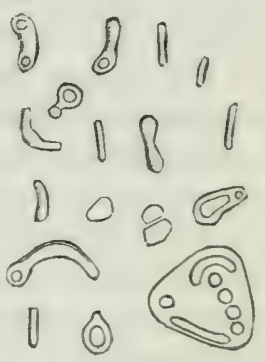

le moindre doute que l'ergot lui-même ne soit un champignon ; si c'est de l'huile, la (question est plus difficile à résoudre : cependant je remarquerai que les cellules polymorphes de l'ergot ont la plus grande analogie avec les cellules stériles des truffes, et que l'absence (même supposée constatée) des spores dans l'ergot, serait une ressemblance de plus entre l'ergot et les sclérotium, que ॥. Léveillé regarde comme des champignons arrêtés dans leur déreloppement, et privés de spores. DeCandolle avait done eu raison de faire de l'ergot une espèce de sclérotimm. Comment d'ailleurs soutenir l'opinion que l'ergot est un oraire ou un grain devenu malade par l'application extéfieure d'un champignon (la sphacélie), n'offrant jamais rien cependant de l'organisation primitive, ni de la nature chimifue du grain; présentant au contraire toute la composition d'un champignon et que ce ne soit pas un champigıon!

En résumé l'ergot n'est pas un ovaire ou un grain altéré. L'ergot e'st III champignon qui, "yprès lu destruction de l'mercire, s'est greffé à sa 
place sur le pedoncule. Quant à la production de l'ergot par la sphacidie, je l'admets sans l'expliquer (1). Je crois d'ailleurs qu'on est hin de connaître tout ce qui se rapporte à la filiation, aux développements successifs ou aux métamorphoses des champignons. Eufin, si l'on reut admettre une ressemblance de plus entre l'ergot du seigle et les sclérotiums, je dirai que je conserve plusieurs ergots recueillis par H. Gendrot, pharmacien à Rennes, et que ces ergots ont donné naissance, sur un grand nombre de points de leur surface, à des champignons composés d'un stipe grêle et cylindrique, terminé par un corps charmu sphérique ou quelquefois didyme, finement tuberculeux sur toute sa surface. Cic champignon (fig. 48) paraît bien se former dans l'intérieur de l'ergot, car il en soulève la surface, lorsqu'il commence à paraîtıce à Fig. 48. l'extérieur, sous la forme d'un bouton jaunâtre. In peu plus arancé, ce bouton, devenu sphérique, est porté sur un second tubercule qui en s'allongeant forme le stipe. Ce champignon ressemble beaucoup), quant à la forme, au sphoropus fungomm de Paulet. (Pl. 183 bis, fig. 6.) Conclusion dernière: l'ergot est un champignon analogue aux srlémtizm, et derra suiwre ceux-ci partont où il plaira aux mycologistes de les placer.

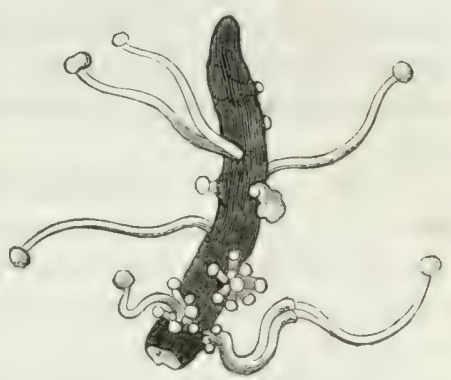

ORDRE DES LICIENS.

Les lichens sont de pelites plantes agames qui croissent sur les murs, sur la terre, les écorces d'arbres, les bois en décomposition, et qui, de même que les autres régétaux cellulaires, ne peuvent se développer que

(1) La masse intérieure de la spluacélie m'a paru se continuer d'une manière non interrompue avec celle de l'ergot, et on ne peut dire où l'une finit et oi l'autre commence. L'ergot, au contraire, est arlisulé sur le pédoncule (fig. 42) et présente une terminaison nette de ce cóté. Cependant, de même que cela a lieu dans une greffe ordinaire, on peut suivre des lignes fibreuses qui, tout cu changeant de nature, se continuent du pédoncule dans la base de l'ergot. Cette observation parait favorable à ceux qui regardent l'ergot comme un grain altéré el toujours nourri par le végétal qui l'a produit. Mai, je la crois peu importante en ce sens, parce que la même continuité de fibres se remarque cutre l'éeorce des arbres qui portent les polypores et la substance de ceux-ci; ct je ne pense pas que l'on venille prélendre que les polypores ne soient qu’une écorce modifiéc. 
dans un milieu humide. Lorsque la sécheresse arrive, ils meurent on se sèchent seulement, en conservant leur force vitale qui leur permet de crôtre de noureau, lorsque la condition d'humidité qui leur est nécessaire est revenue. Les lichens sont formés d'une expansion cellulaire très variable dans sa forme et sa consistance, nommée thullus, et d'organes reproducteurs dispersés sur le thallus ou fixés à ses extrémités. Ces organes reproducteurs consistent dans des conceptacles ou $\left(1\right.$ m $^{\prime \prime}-$ thrócions tantòt ouverts, lantôt fermés, contenant des noyaux ou thiequers, dans l'intérieur desquels sont contenues les spores.

Autrefois on classait les lichens d'après la consistance et la forme de leur thallus en lichens pulcripulents, crustacés, folincés et filumenteur. Waintenant on les divise en quatre familles d'après les caractères de leurs organes reproducteurs.

$1^{\circ}$ Comiothalamées. Apohlécions ouverts, à noyau se dissolvant en spores nues; thallus fugace ou pulsérulent.

$2^{\circ}$ Id inthalamées. Apothécions d'abord clos, puis déhiscents, laissant échapper un noyau gélatineux composé de spores nues. Genres opegirepha, graphis, urceotaria, etc.

$3^{\circ}$ Gasterothalamées. I pothécions toujours clos, ou s'ourrant irrégulièrement par la rupture de leur base; nọau intérieur déliquescent ou sans consistance. Genres verrucaria, endocarpon, etc.

4. Hyménothalamés. Apothécions ourerts, scutelliformes, à noyau discoide persistant. Genres leciden, prolellurin, clndonin, stereacaulom, parmelia, sticta, cetruriu, roccella, ctc. Tous les lichens alimentaires, médicamenteux ou tinctorianx, appartiennent à cette dernière famille.

Lichen d'Islande (fig. 49).

Cetraria islandicu, Ach.; physcia islundicu, DC.; lirhen islandicus, L. Cie lichen croit très abondamment dans le nord de l'Europe,

Fig. 49.

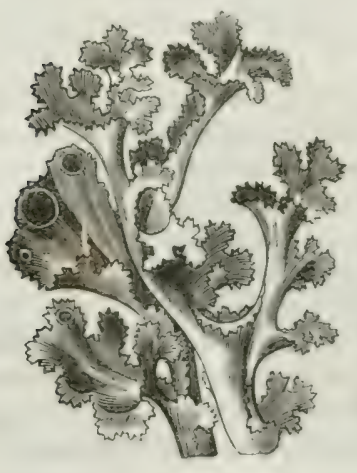

et surtout en Islande. Mais on le troure aussi dans presque toute l'Europe; notamment en France, dans les Vosges et sur les montagnes de l'Auvergne. II croît sur l'écorce des arbres et sur la terre. Il est formé d'un thallus blancgrisâtre, lacinié et souvent cilié sur le bord, offrant sur une de ses faces des taches blanches que l'on pourrait prendre pour un organe fructifère; mais elles sont dues à des interruptions de la membrane extérieure du thallus, qui est de nature amylacée, toujours plus 
ou moins colorée, et qui laisse voir la partie interne, formée principalément de sels calcaires et d'un blanc de craie.

La fructification consiste dans d's conceplacles orbiculaires et planes, fixés oblicfuement à la marge du thallus, mais elle manque sourent. Le lichen d'Islande sec est coriace, sans odeur marquée, d'une saveur anère désagréable; mis à tremper dinns l'eau froide, il se gonfle, devient membraneux, et cède au liquide une partie de son principe amer et un peu de mucilage. Si on y ajoute une dissolution d'iode, toute la membrane externe du thallus se colorera en bleu noiràtre, et la partie centrale calcaire paraîtra alors, dans les parties interrompues, arec toute sa couleur blanche. Le lichen, soumis à l'ébullition dans l'eau, se dissout en grande partie, et le liquide se prend en gelée par le refroidissement.

II. Berzélius a retiré de 100 parties de lichen d'Islande:

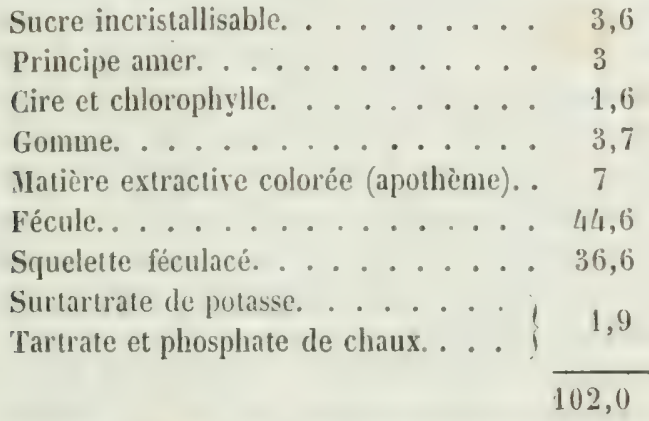

Le principal but de .I. Berzélius, en s'occupant de cette analyse, était de trouver un moyen de priver le lichen d'Islande de son amertume, qui, seule, empêche que le peuple en fasse sa nourriture habituelle dans les pays paurres en substances alimentaires; car on ne parvient que frès inparfaitement à lui ôter cette amertume par la décoction dans l'eau, et d'ailleurs la décoction dissout également la partie nutritive du lichen. Le procédé qui a le mieux réussi à $\mathbf{1 1}$. Berzélius consiste à faire macérer le lichen, une ou deux fois, dans une faible dissolution alcaline; à l'exprimer, à le laver exactement et à le faire sécher, si l'on n'aime nieux l'employer humide, pour en préparer toutes sortes de mets. (Am. de chim., t. XC, p. 277.)

On a proposé d'appliquer le même procédé aux préparations pharmacentiques du lichen; mais indépendamment de ce que la présence d'une petite quantité de principe amer peut être utile à l'action médicatrice du lichen, il serait à craindre que le lavage n'enlevât pas tout le: sel alcalin. Je pense qu'il vaut mieux, dans les pharmacies, faire chauffer 
le lichen une ou deus lois arec de l'eau, pres(jue juscju'au point d'ébullition (à 80 degrés environ). Ce procédé sulfit pour priver le lichen de la plus grande partie de son amertume; ce qui en reste alors n'est nullement désagréable.

Pour retirer le principe amer du lichen, auquel on a donné le nom de cétren'in, le docteur Iterberger a indiqué le procédé suivant : on traite le lichen pulvérisé par de l'alcool à 0,883 de pesanteur spécifique; on fait bouillir, on filtre et on ajonte à la liqueur 12 grammes d'acide chlorhydrique liquide par 500 grammes de lichen employé. On additionne le mélange de quatre fois et demie autant d'eau en rolume, et on abandomne le tout pendant vingt-(juatre heures.

Il se forme un précipité que l'on sépare au moyen d'un filtre et qu'on exprime. On traite ce précipité à froid par de l'alcool ou de l'éther pour le priver des matières grasses qu'il contient. On le traite enfin par deux cents fois son poids d'alcool bouillant, on filtre et on laisse refroidir. Le cétrarin se précipite. On distille l'alcool pour avoir le reste.

Le cétrarin se présente sous la forme d'une poudre trìs blanche, légère, inodore, inaltérable à l'air, décomposable au feu. Il a une saveur très amère, surtout lorsqu'il est dissous dans l'alcool. 100 parties d'alcool absolu n'en dissolvent cependant que 0,28 à froid et 1,70 lorsqu'il est bouillant. Il est moins soluble dans l'éther et encore moins soluble dans l'eau. Il est tout à fait neutre par rapport aux couleurs régétales; les alcalis le dissolvent facilement et le laissent précipiter par les acides. L'acide sulfurique concentré le dissout et le colore en brun; l'acide nitrique le transforme en acide oxalique et en corps résinoïde; l'acide chlorhydrique concentré le colore en bleu foncé et le dissout en partic, etc.

\section{Lichen pumonaire.}

Pulmonaire de chêne. Lichen pulmonarius, L.; Loburiujulmonarin, UC.; Sticta pulmonarie, Ach. Ce lichen crồt au pied des vieux troncs, dans les forêts ombragées; son thallus est cartilagineux, très grand, étalé, divisé en lobes profonds et sinueux. Il est marqué en dessus de concarilés séparées par des arêtes saillantes, réticulées, d'un rert faure ou roussàtre. La surface inférieure est bosselée, blanche et glabre sur les convexités, brune et relue dans les concavités. Enfin ce thallus, ¿̀ l'élat récent, présente une certaine analogie d'aspect arec un poumon conpé; de la le nom de la plante, et probablement aussi l'idée que l'on a eue de l'employer contre les maladies du poumon. Elle est inusitéc aujourl'hui pour cet usage; mais on l'emploic pour la teinture. 


\section{Liehen pixlité.}

Lichen pividutus et lichen corrifurus, I.; Scyphophorus pididatus ct Sryphophorus cocciferus, DC.; Cenomyce, Ach. Ces deux espicrs different en ce que le lichen cocriferus est moins denté à son bord supérienr, et porte des tubercules d'un rouge vif, tandis que le lirhen picidatus est plus profondément denté et porte des tubercules bruns. Du reste, tous deux sont formés d'un thallus membraneux ducpuel s'ílèrent des pédicules (podritimss) droits, fistuleux, cṣlindriques, s'élargissant par le haut, et terminés par une coupe hémisphérique qui leur domne à peu près la forme d'un bilboquet. Ces podétions produisent sur leurs bords des conceptacles ou apothécions convexes, privés de rebord, bruns ou rouges, recouverts d'une lanie prolifère gélatineuse. Ce lichen est moins gélatineux que celui d'Islande, moins amer et cependant plus désagréable. II est peu usité.

Ia petite plante que l'on nommait autrefois usure du crine humain, qui a ćté si vantée contre l'épilepsie, ct que l’on avait, dit-on, la folie de payer jusqu'à mille francs l'once, est le lichme sneratilis de linné (parmetia saxentilis, Ach.). Ce qui la rendait si rare élait la condition imposée de n'employer seulement que celle qui croissait sur les crànes humains exposés à l’air. On lui substituait sourent un aulre petit lichen filamenteux, lichen plicutus de Linné (usuer plicutr, D)(... Tous deux sont entièrement oubliés.

\section{Lichens tinctoriaux.}

I.es lichens fournissent à la ieinture quatre couleurs principales : la brune, la jaune, la pourpre et la bleue. Les teintes brunes sont fournies par le lichen pustuleux (gyrophoma pustulate) et par le lichen pulmonaire (sticta pulmonariu). Ce dernier prodnit sur la soie, en employant comme mordant le bitartrate de potasse et le chlorure d'élain, une couleur carmélite fort belle et très solide. On le rícolte principalement pour cet usage en Irance, dans les Vosges; mais il est peu abondant.

Les couleurs jaunes sont produites par les deux espèces suirantes :

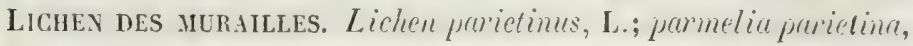
Ach. Ce lichen, le plus commun de ceux qui se montrent chez nous sur les vieux murs et sur le tronc des arbres, est formé d'un thallus orbiculaire et lobé, vert, jaune doré ou gris, suirant son âge. Schrader cn a retiré une matière colorante janne, soluble dans l'alcool et l'élher, cristallisable, très fusible, deremant rouge par les alcalis. Il a une odeur 
semblable à celle du quinquina, et donne à la distillation une huile volatile butyreuse et verdâtre. Il a été émployé comme fébrifuge et est usité dans la teinture.

LACHex velpis. Lichen culpinus, L.; Evemin vulpinu, Ach. Ce lichen est d'un beau jaune; il est composé d'expansions filamenteuses quui se dépriment diversement par la dessiccation. Lorssu'on l'agite arec la main, il s'en sépare une poussière jaune très irritante. Le principe colorant réside uniquement dans la croûte ou membrane extérieure, car l'intérieur' est parfaitement blanc. II. Bébert, pharmacien à Chambéry, a extrait de ce lichen un principe colorant jaune, très facilement cristallisable, peu soluble dans l'cau, très soluble dans l'alcool, l'éther et les alcalis, qui n'en altèrent pas la couleur. Il jouit de caractères acides et a été nommé acide rulpinique (Journ. de plorim., t. XVII, p. 696). Ce lichen pourrait être très utile à la teinture; il croît entrabondance dans les forêts de l'Iusbourg, au pied du mont Cenis et au petit Saint-Bernard.

Les lichens qui produisent la couleur rouge-violette ou bleue portent le nom d'Onseidre, qui cst aussi le nom de la pâte d'un rouge-violacé qui 'n est préparée. Il ! en a de deux gunres bien différents, cenx de mer et ceux de terere. Les grieilles de mer croissent sur les rnchers, au bord de la mer, dans un grand nombre de lieux; d!les appartiennent an gronre referella, et portent dans le commerce le nom d'herhe de fel ou tel

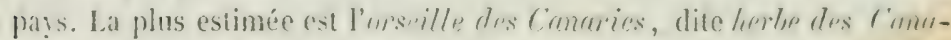

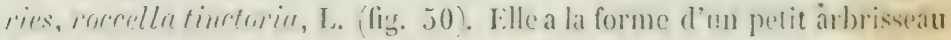

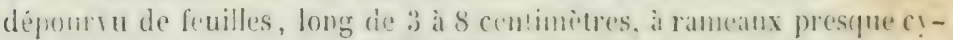
limbigues, d'un blane grisitre, derenant quelepuefois brunatre.

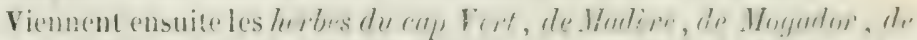
Surdnigum, etc. L'herbe du cap Vert differe peu de celle des Canaries et appartient, comme elle, au murrlln tinetwin. L'herbe de Watère est mélangée de roreella furiformis, tres paure en principe colorant, toujours blanche, at thallus plane, rubane, dichotome, long do 5 a 10 centimetres. L'herbe de Mogador appartient an rucepllu timetomin

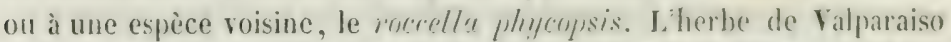
est le rocrellu fluscidn (Bory Saint-Vincent); celle de l'ìte de la Réunion (Boubon), roccelln Wrmtrigni te Bellanger, est wès blanche, plate, rubanée, analogue au rocrell" furifurmis et d'aussi mauraise qualité.

I.es orscilles de terre régètent sur les rochers dénudés des Pyrémées, des Ilpes et de la Scandinarie. Elles affectent la forme de petites croùtes irrégulières, d'une couleur blanchitre ou grisìtre, qui adhèrent fortement aux rochers; elles portent dans le commerce le nom de lirfen de tel ou tel pavs. Ie lichen blane des Pỵénées est te rarinlariu 
dealbatu, de cind. Le lichen d'Auvergne, ou purelle d'Auerergue, est

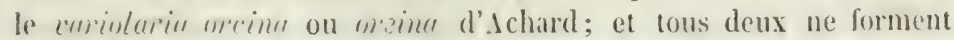
(qu'une espèce, cariolurin sorcallimu d'Ichard, qu'il ne faut confondre ni arec le lichen parellus $\mathbf{L}$. LLecumore perrella, Ach.), ni avec le lishen corallinus, L. (isidium corallinum, $\Lambda$ ch.).

Le lichen tartareux de Suède est le lirhen tartareus, I., ou lecumora tartarea, Ach., etc.

Aucun de ces lichens ne contient de matière colorante toute formée. Pour leur faire produire une couleur rouge-violette, il fant les mettre

Fig. 50.

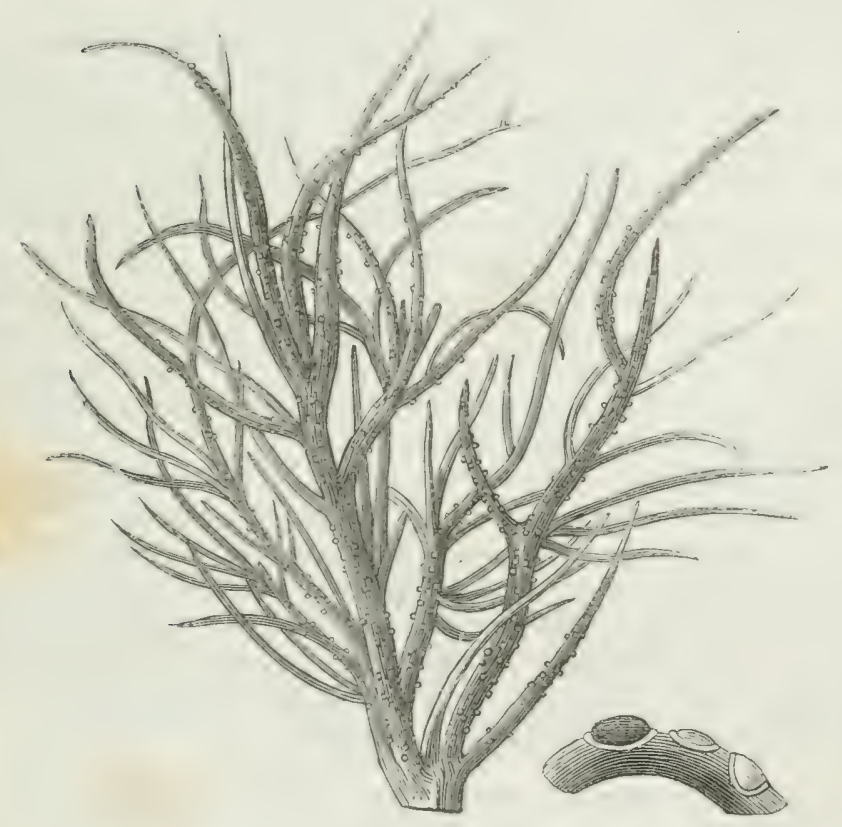

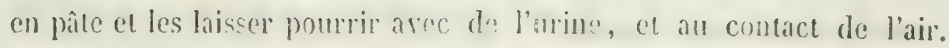
Après ryuelugue tempss on y ajoute de la chanx, quui met à nu l'ammoniaque produite, et on y ajunte de temps en temps, s’il est nécessaire, de nourelle urine : c'est cette pate qui porte dans le commerce le nom d'orswill'. En roici les caractères phrsiques : elle est d'une consistance solide, d'une couleur ronge-riolette très foncée, d'une odeur forte et disagréable; elle offre à la vuc beaucoup de débris presque entiers de la plante, et elle est parsemce d'un grand nombre de points blancs, paraissant ètre un sel ammoniacal. Elle communique it l'eau une cou- 
leur rouge foncée, et fournit aux tissus des teintes très rives, mai peu durables.

Les travanx de Robiquet ont jeté un grand jour sur la production de cette matière colorante. Cet habile chimiste a opéré sur le variolaria dealbata des Pyrénées et l'a traité par l'alcool bouillant. Pour ne plus revenir sur la partie du lich'n insoluble dans l'alcool, je dirai qu'elle ne cède à l'eau qu'un peu de gomme accompaguce d'un sel calcaire soluble, et que le nouveau résidu insoluble est formé de tissu cellulaire contenant une grande quantité d'oxalate de clıax.

La teinture alcoolique, faite à chaud, dépose, en se refroidissant, une maliere blanche (variolarine), cristalline, insoluble dans l'eau, non fusible au feu qui la déconıpose, peu soluble dans l'éther. Par aucun moyen on ne peut faire prendre à cette matière une couleur violette.

La teinture alcoolique a été évaporíe à siccité, et l'extrait a été traité par l'eau froide. Le résidu insoluble ćlait formé de chlorophylle, d'une matiere grasse, blanche, cristallisable, fusible, volatile, foutes deux solubles dans l'é. ther, et d'une matière résinoïle, d'un brun-rougeâtre, soluble dans l'alcool. Aucune de ces trois substances ne pourait produire la couleur de l'orseille.

Il ne restait plus à examiner que la partie de l'extrait alcoolique rui avait été dissoute par l'eau. La liqueur évaporée élait sirupeuse, très sucrée, et a laissé cristalliser une malière suclée, ayant la forme de longs prismes opaques et jaunâtres. L'analyse arrivée à ce point, tout espoir d'obtenir la matière colorigène de l'orscille semblait perda; mais bientôt la dernière substance, qui semblait n'ètre qu'mne sorte de sucre, a présenté des différences essentielles arec ce principe immédiat.

Le sucre ordinaire, exposé au feu, se fond, se boursoufle, dégage une odeur de caramel, ct laisse enfin un charbon très rolumineux.

Le sucre de variolaire se fond en un liquide transparent qui entre facilement en ébulliıion et qui se volatilise entièrement. Enfin ce sucre de varlolaire, qui a recu le nom d'orcine, étant mis en contact arec du gaz ammoniac et de l'oxigìne absorbe les éléments du premier, un certain nombre de molécules du second, et se convertit en une belle couleur violette nommée orcéine, qui est celle même de l'orseille.

$$
\begin{aligned}
\text { L'orcine cristallisée } & =\mathrm{C}^{18} \underline{\mathrm{H}}^{12} \mathrm{O}^{8}=\mathrm{C}^{18} \underline{\mathrm{H}}^{7} \mathrm{O}^{3}+5 \underline{\mathrm{H}} \mathrm{O}(1) . \\
\text { L'orcéine } & =\mathrm{C}^{18} \underline{11}^{10} \mathrm{O}^{8} \mathrm{Az},
\end{aligned}
$$

La réaction s'exprime ainsi :

$$
\mathrm{C}^{18} \mathrm{H}^{7} \mathrm{O}^{3}+\mathrm{O}^{5}+\underline{\mathrm{Az}} \underline{H}^{3}=\mathrm{C}^{18} \underline{H}^{10} \mathrm{O}^{8} \underline{\mathrm{Az}} \text {. }
$$

Analyse du variolaria lactea, par Schuncli. Celle varioliaire aỵant été traitée par l'éther daus un appareil à eléplacement, l'éther évaporé a fourni une masse cristalline qui, lavée avec un peu d'élher froid el dissonte dans l'alcool bouillant, cristallise de noureau, el constilue un corps nommé licanorinc. Ce corps est tres soluble dans les alcalis; les solutis, additionnés

(1) D'après les formules de M. K. Kíanc. 
immélatenent dïun acide, lasssnt précipiter de la lécanorine unn al:éré; mais si on allend guelques heures, on si l'on fait bonillir le soluté aicalin, les arides en diggagent de liacide carbonique, et la liqueur contient alors de loreine. Pareiliement, lorsquon fait bonillir un soluté saturé de lécanorine dans de l"ean de baryle, laalcali se précipite a l'état de carlonate, el l'or- o cine resie pure dans la liqueur.

La licanorine $=\mathrm{C}^{20} \mathrm{H}^{9} \mathrm{O}^{9}$ : lorcine cristallisée $=\mathrm{C}^{15} \mathrm{H}^{12} \mathrm{O}^{8}$; la réaction prut être ainsi representée :

$$
\mathrm{C}^{20} \underline{\mathrm{H}}_{9} \mathrm{O}^{9}+3 \underline{\mathrm{H}} \mathrm{O}-\mathrm{C}^{2} \mathrm{O}^{4}=\mathrm{C}^{18} \underline{\mathrm{I}}^{12} \mathrm{O}^{8} \text { (Kane). }
$$

Analyse duroccella tincloria. Ce lichen a été analysé par deux chimistes, 11. Ireren et II. R. Kane. Ge dernier en a reliré cing malières organigurs diflerentes, mais qui peurent ètre des modifications les unes des autres.

1. Erylhiline. Vatiere amorphe. jamne pâtre, soluble dans lalconl, l'ellue co les solutes alcalins d'vit clle est précipitée par les acides. Elle se combine aux oxicles métalligues par roie de double décomponition. Elle est jusoluble dans leau froide ou chancie; mais, soumise a lébullition dans

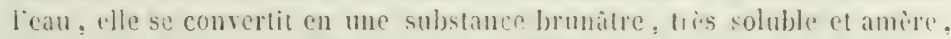
nomméc amaryllerine. L'érthriline $=\mathrm{C}^{22} \mathrm{H}^{15} \mathrm{O}^{6}$.

2. Rosel'iue ou acide ruscelliyue. Matiere blanche, crislalline, inso. luble dins l'eau, tris soluble dins l'alrool, soluble dans l'élher, fusible ì 130 degrés, analoguc anx acides gras, $=\mathrm{C}^{17} \mathrm{H}^{16} \mathrm{O}^{4}$.

3. Eryllurine. Natière blanche, crislablisable, it peine soluble dans l'eau froide, lris soluble dans l'eau bonillante, et formant un solute incolore gui brunit rapidement à l'air. Elle est tries soluble dan; l'alcool, l'élher él les solulés alcalins, doù les acides la précipitent. Le soluté alcalin brunit à lair. Celui formé par l’ammoniague posse au rouge vineux. l'érythrine est

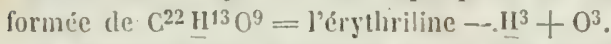

1 Amaryllerine. Subiance brume, tres soluble dans l'eau, peu siluble

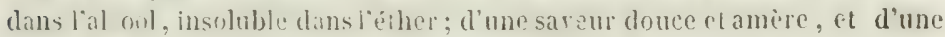
odeur diramel. Elte est liquide et ne pent être desséchée sans décomposilion. Elie est frrmée de $\mathrm{C}^{22} \mathrm{H}^{13} \mathrm{O}^{14}=$ érythrine $+\mathrm{O}^{5}$.

5. Telerylurine. Lne forte solution d'amarghrine, expose pendant longle:nps à l'air, se conveltit gradurllement en cristaux blancs, granulaires, auxquals 11 . Kane a donne le nom de féleryllrine. Ce nour an composé est tress suble dans l'eat, moins soluble dans l'alcool, insoluble dans l'étirr. Il a une saveur douce $\mathrm{et}$ amiere; il cont:ent $\mathrm{C}^{22}, \mathrm{H}^{\mathrm{y}} \mathrm{O}^{1 \mathrm{~s}}=\mathrm{ama-}$ rythrine - $\mathrm{H}^{4}+\mathrm{O}^{4}$.

Analyse de lorseille en prife, par M. R. Ii (In. I)'après cetle analyse, pour laquelie je renvoie au mímoire de l’auteur (Am. chim. phys., $18\{1$. t. II, p. 21), lorseille en pate contient an moins trois principes colorants rouges, qui sy trourent combines d lammoniague. Le premier, nommé orceine, est une belle matiere rouge, peu soluble dans l'eau, trìs pen suluble dans l'aicrool, à peine soluble dans l'éther; elle est très soluble dans les alcalis, arec lesquels elle forme des combinaisons d'un pourpre magnifigur. Elle est formóe por lo mélange de denx malieres oxideses a denx 
degrés différents, jouissunt des mêmes propriélés, th ne poutant potre distinguées que par l'analyse.

La première, nommée alpha-orcéine, $=\mathrm{C}^{18} \mathrm{H}^{10} \mathrm{Az}^{5}$.
La seconde, dite béla-orcéine,

Elle paraît être identique avec l'orcéine de Robiquet.

Si l'on représente l'orcine anhydre par $\mathrm{C}^{8} \mathrm{H}^{7} \mathrm{O}^{3}$ et quon ajoute $\mathrm{H}^{3} \mathrm{Az}+$ $\mathrm{O}^{2}$, on formera l'aipha-orcéine. $\mathrm{si}$ on admet que celle-ci absorbe en plus $0^{3}$, on aura la bêta-orcéine, ou orcéine de Robiquet.

Le second principe culorant de lorseille préparée en nommé uzoerythrine. Il est solide. d'un rouge vinum, insoluble dans l'ean, labool ut

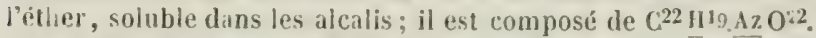

Le: Iroisieme, dil aride érylhroléque, est densi-liquide. oléiginenx. soluble dans l'éther el lalcoul, prearue insolubli' dams l'eau, insoluble dums l'essence de lérébenthine, soluble dans les alcalis. Composilim: $0^{26} \mathrm{H}^{22} \mathrm{O}^{5}$.

\section{Tournesol en pains.}

On nomme ainsi de perits pains carris formes principalement de carbonate de chanx et d'une matière colorante blene, trìs soluble dans l'eau et dans l'alcool, et très sensible à l'actions des acides (fui la rougissont, ce gui est cause qu'on l'emploie tr's fréquemment comme réacif. Le's alcalis la ramènent au blen, sans la rerlir, co rui la distingur des couleurs de la maure et de la violette.

Pendant longtemps, sur la foi de plusieurs auteurs et notamment de Vahmont de Bomare, on a cru que le tommesol en pain était obtenu, ('n

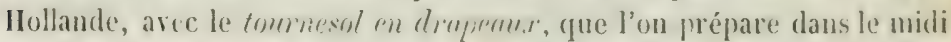
de la France, et surtout au villagge de Grand-Gallargues (Gard) arre ume planie euphorbiacée nommée maurelle (crozophorn tinctoriu, ..). Ce qui pourait autoriser à soutenir celte opinion, c'est que, en effet, presque tout le tournesol en drapeaux était transporté en Hollande ou à Ilambourg, et que c'était de Hollande que nous renait le tomrnesol e'n pains. J'ai partagé pendant quelque temps cette opinion; mais j'ai dù l'abaudonner lorsque, ayant fait renir du Midi du tomrnesul en drapeaux, je n'ai pu en retirer qu'une teinture vineuse que les alcalis ne faisaicnt pas virer au bleu.

Dejà, anciennement, Bonvier, chaptal et llorelot, araient annonce (fue le tournesol en pains pouvai itre prepari arec la parelle d'Aurergne

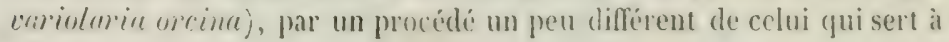
prëparer l'orseille.

On ramasse celte plante (dit Morelot), on la fait sécher, on la pulrérise, et on la mềe dans une angre aree la moitié de son poids de cendres gravelees, également pulverisés. On arrose le melange d'urine humaine, 
de manière à en former une pâte, et on y ajoutr de l'mime do tempss en temps pour remplacer celle qui s'érapore.

On laisse ce mélange se putréfier pundant quarante jours, durant lesquels il passe peu à peu au pourpre. Alors on le met dans une seconde auge parallèle à la première, et on y mêle encore de l'urine; quelques jours après, la pâte devient bleue. A cette époque, on la divise daus des baquets, on y ajoute encore de l'urine et on y incorpore de la chaux. Jinfin on ajonte à la pâte, qui est devenue d'une belle couleur bleue, assez de carbonate de cham pour lui donner une consistance ferme; on la divise en perits parallélipipèdes droits, gue l'on fait sécher.

Plus récemmeni, différents auteurs ont annoncé que le tournesol était

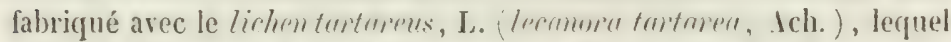
sert, en Allemagne ef en Angleterre, à la falurication de pà'es linctoriales, comnues sous les noms de persin et de cutbear. Fnfin 31. Galis a montré que le roncerle timetorin lui-mème pourait servir à la fabrication ?u tournesol, en faisant voir, par des expériences directes, que cette plante, exposée à l'action réunie de l'air, de l'urine putréfiée et de la chaux, ne produit que de l'orseille; tandis que par l'addition du carbonate de potasse ou de soude, il se produit une belle couleur bleue, qui est celle du tournesol.

Analyse du tourucsol en pain, $y$ ar M. R. Fianc. Il résulle de relle analyse que les matieres colorantes du tournesol sont rouges et non blenes on le savait déjii), et que la coulenr bleue est due à la combinaison de trois principes colorants nommés azolirmine. érylhrolimine, el irythrolime, avec les alcalis du tournesol, qui sunt la polasse ou la soude, la chaux et l'ammoniaque. () nand on rougit le tournesol par un acide, on ne fait que metre en liberté, ses trois matièes colorantes.

L'érylroléine est demi-fluide, soluble dans l'éther et dans l'alcool arec une belle couleur rouge; elle est faiblement soluble dans l'au; soluble dans l'ammoniaque avec une magnifigue cnaletur pourpre sans mance de blen; elle forme arec les oxides mélalliques blanes des latues violetles. Elle niest pas volatile. Elle est formée de $\mathrm{C}^{20} \mathrm{H}^{22} \mathrm{O}^{4}$. Ciest de hacicle cirylibroleique (page 82 ) avec moitié moins d'oxigène.

L'éryfhrolimine est d’un rouge pur. Elle est un peu soluble dius l'cau, rres soluble dans l’alcool. Le soluté saluré à chaud cristallise par rufroidissement. Elle forme arec la potase un soluté bleu, et arec l'ammoniaque un composé bleu insoluble dans l"cau. Vlle forme arec plusieurs oxides métalliques des laques d'une belle coulcur pourpre. Elle est composée de $\mathrm{C}^{2} 6 \mathrm{H}^{23} \mathrm{O}^{13}$ ou $\mathrm{C}^{26} \mathrm{H}^{22} \mathrm{O}^{12}+\mathrm{HO}$. C'est le troisième degré doxidation d'un radical $\mathrm{C}^{26} \underline{\mathrm{H}}^{22}$, dont les deux premiers sont :

$$
\begin{aligned}
& \text { L'érythroléine. . . . . . } \quad \mathrm{C}^{26} \mathrm{H}^{22} \mathrm{O}^{4} \\
& \text { L'acide érythroléique.. . } \quad \mathrm{C}^{26} \Pi^{22} \mathrm{O}^{8} \\
& \text { L'érythrolitmine. . . . = }=\mathrm{C}^{26} \underline{H}^{22} \mathrm{O}^{12}
\end{aligned}
$$




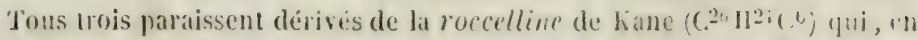

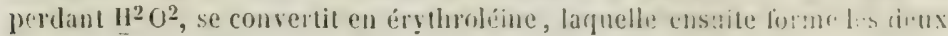
intres en se combinant avec l'oxigène.

L'azolitmine est d'un rouge brun foncé ct inso'uble dans l'ean. l)i soulc dius la potasse ou l'ammoniague, cest elle surtont gui forme be blem parliculier du tomrnesol. Elle ne differe des deux orcéines de l'orsejll: ylie par une origination plus avancée, ainsi quon le vojt dans le lableitu surrant.

$$
\begin{aligned}
& \text { Alpha-orcéine. . } \mathrm{C}^{18} \mathrm{H}^{10} \mathrm{Az} \mathrm{O}^{\mathrm{B}} \\
& \text { lièta-orcéine... } \mathrm{C}^{18} \mathrm{H}^{10} \overline{\mathrm{Az}} \mathrm{O}^{8} \\
& \text { Azolitminc. . . } \mathrm{C}^{18} \mathrm{H}^{10} \overline{\mathrm{Az}} \mathrm{O}^{10}
\end{aligned}
$$

\section{FAMIJLE DES FOUGלRES.}

Plantes herbacées et viraces, pourant devonir ligneuses at arborescentes sous les tropiques; elles présentent alors le port d'un palmier. Leurs feuilles sont quelquefois entières; le plus somvent, ciles sout profondément découpées, pimnatifides ou décomposées; toujours elles sont roulées en crosse ou en volute au moment oì elles naissent de la ligge. Les organes de la fruclification sont généralement silués à la face inférieure des fenilles, le long des nerrures on ì l'extrémité du limbe; dans un certain nombre, la fruclification est disposée en epis on en grapuns isulées des feuilles. Daus le premier cas, c'est-à-dire lorsrugue la frurlification est dispersée sur les feuilles, généralement elle est groupée en petits amas de for!nes rariées, nommés sores, fantôt nus, tantôt recrallrerls d'une membrane ou indusium, dont l'origine de luode de dihiscence rarient beancoup également, et serrent a caracterrere les nomblems genres de cette famille. Ces amas sont formés par des capusules celluletres, sourent pédicellées, nommées therpues ou symoneges, el qui pardissent entièrement composées de spores libres, retenues par un anmean rircu-

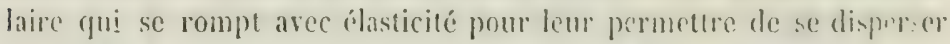
(lig. 51). Lorsque la fructifeation est isolé dhe foulles, olle se pristontr sous la forme de capsules bien différentes de celles ri-elessus decrites, et qui paraissent provenir du limbe des folioles suppricures qui anrait arorlé, et qui se serait replié de manièce à former chacun une cuque à parois épaisses, pleine de spores libres. Par excmple l'usmmol, commune.

Les fougeres fomrnissent i la pharmacic leurs stipes somberains ou rampants, qui portent improprement le nom de racimes, of lems fenithes.

- Ces deux parties sont donées de propriélés génélalement assez dilli:rentes, les feuiles étant soment pourvmes d'un arome agriable qui permed de les emploger en infusion bichienu el adoncissante, fandis

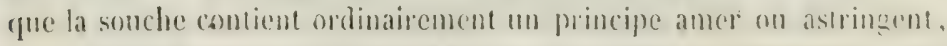

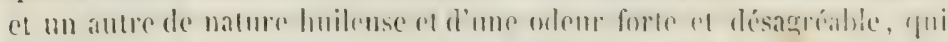




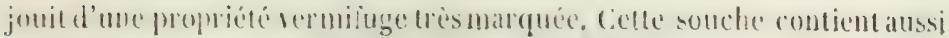
de l'amiden; mais il n'y a gue les peuples les plus mallecureux de l'Ausfralie ct de la Tourelle-Zélande qui aient pu en faire leur nourriture habituclle. En Europe, cen'est que dans les temps de grande disctte que les habitants des campagnes y ont eu recours.

\section{Fougère malc.}

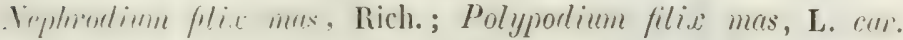
y'" Sproranges ou thèrues fédicellées, à anneau vertical, fixées sur une veine sonflè au milien du réceptacle; sores arrondis, disposés par séries sur la face inférieure des feuilles. Indusium rénifome fixé à la feuille à l'endroit du sinus. Car. spéc., feuillage bipinné; pinnules oblongues, obtuses, dentées; sores rapprochées de la côte du milieu; stipe garni de pailletles (fig. 51).

Ia parlic de la plante qui est cmployéc en médecine porte cornmunément le nom de racine; mais c'est plutôt me tige souterraine, une souche, enfin ce que Linné nommait stipes. Celle souche est composée d'm grand nombre de tubarcules oblongs, rangés tout autour et le loigg d'un axe commun; recourerts d'uncenveloppe brune, roriace ct foliacée, et séparés l's uns des autres par desécailles fris fines, soyeuses et d'une couleur dorée. La vraie racinc de la plante consiste dans les petites fibres dures et ligneuses qui sortent d'entre les tubercules que je viens de décrire. l'interieur de la souche est Fig. อั1.

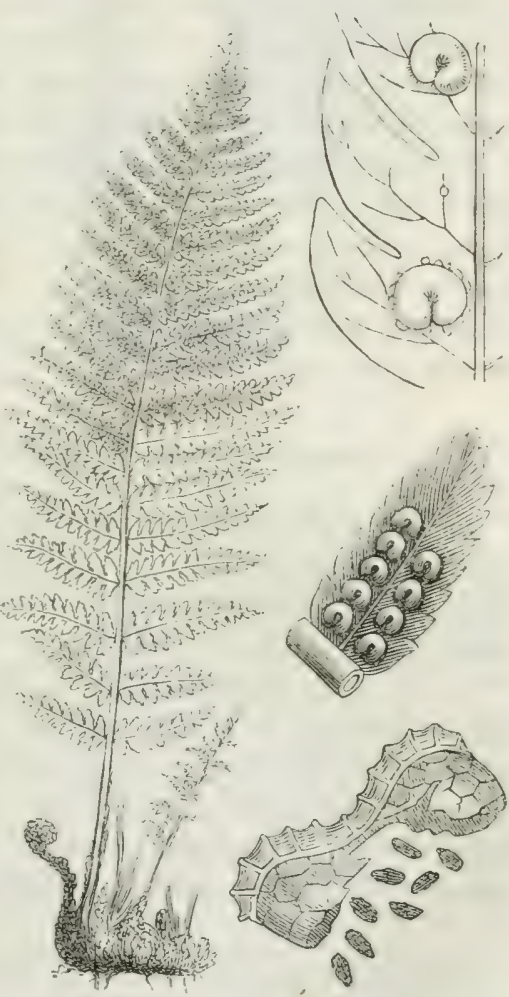
d'ıne consistance solitle; d'une couleur verdàtre à l'état récent et jaumâtre à l'état sec; d'une saveur astringente un peu amère et désagréab!e; d'une odeur nauséeuse.

La sutuche de fongère mâle a été analı̧ sée par IJ. Morin, de Rouen, 
qui en a retiré, par le moven de l'éther, une substance grasse d'un jaune brunàtre, d'une odeur nauséabonde d't d'une saveur très déagréable. Cielte substance, indépendammnt de sa matière colorante (chloriphylle altérée?), était formée d'huile volutile volurante, d'relcuine et de sécerine. L'alcool appliqué au résidu épuisé par l'éther, en a extrait de l'meide yullique, du tmenin et du sure incristallisable; l'eau a dissous ensuite de la yomme et de l'amidun; le résidu était formé de lignests. Les cendres obtenucs de la souche non traite par les menstrues, étaient formées de carbonate el sulfate de potasse, chlorure de potassium, carbonate et phosphate de chanx, alumine, silice et oxide de fer. (Journ. de pharm., t. X, p. 223.)

L'huile de fongère màte parait jouir d'une propriété anthelmintiqque 't henifuge très marquée; aussi a-t-on proposé plusicurs procédés pour l'obtenir; le plus simple consiste dans l'emploi de l'écher appliqué à la racine pulsérisée, par la méthode de déplacement ( 1 \%

On employait autrefois, concurremment arec la racine de fougère màle, celle de deux autres plantes de la même famille, qui portaient l'une et l'antre le nom de frumgerse femelle; l'une est la petite fougère femelle (polypordium filix fomina, L.; athyrinm filix fuminu, R.); l'autre est la grande fougère femelle (ptoris aquilina, L.). Ces espèces ne sont plus usitées.

Polypote commun, vulgărement polgpode de chène.

I'olypurlium culyarm, I. C'ar. géu. Fructification réunie en groupes distincts, épars sur le dos des fenille's, tion courerts d'un tégument.'ar. spéc. Feuillage pinnatifide; ailes oblungues, sous-dentées, obtuses; racine squameuse (fig. 52).

Ce que nous désignons sous le nom de racine polypode n'est, de mème que dans la fougère, qu'une tige radiciforme, ou une sotiche. Ciette souche récente est courerte d'écailles jaunatres, dont quelques unes subsistent après la dessiccation; sechee, elle est grosse comme un tuyau de plune, cassante, aplatie, oflrant deux surfaces bien distinctes : l'une iuherculeuse, qui donnait naissance aux feuilles; l'autre

1. Celle huile varie en conleur et en consintance suivant la partic de la souche d'ou elle provient. La partie inférieure de la souche, celle qui est la plus ancienne et la plus éloignée de la pousse de l'année, fournit une huile brune, Irès épaisse el d'une odeur fort désagriable. La parlie supérieure de la souche donne une huile lig̨uide, d'une belle conleur verte et d'une odeur bien moins désagréable. Je ne sais quel'e peut ètre la plus aclive. J'ai reçu de Genéve. où l'buile de fougère màle est très usitée contre le ver solitaire, quelquefois de l'huile brune, le plus souvent de l'huile verte. 
unie, est garnic de quelques épines prorenant des radicules; du reste elle est brune ou jaunâtre à l'extérieur, verte à l'intérieur, d'une lig. 52. saveur donceâtre et sucrée, mêlée d'âcreté, et d'un goùt nauséeux; son odeur est désagréable el analogue à celle de la fougère. La souche de polypode passe pour ètre laxative et apéritive. Elle contient, d'après l'analyse faite par II. Desfosses, de Besançon, de la glı ou plutôt un corps complexe moitié résineux et moitié huileux, du sucre fermentescible, un corps analogue à la sarcocolle, une matière astringente, de la gomme, de l'amidon, de l'albumine, des sels calçaires et magnésiens, etc.

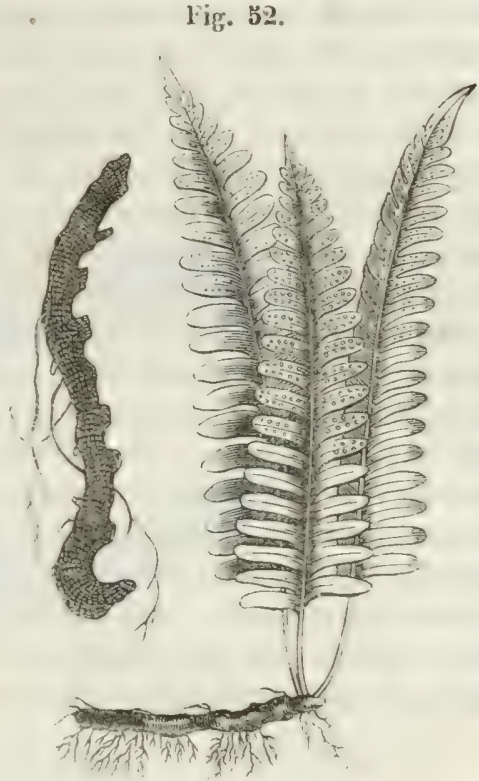

Souche de Galagruala.

D’après huiz, l'un des anteurs de la Flore primecienue, le réritable calaguala est le stipe d'une fougère du Pérou, cu’il a décrite sous le

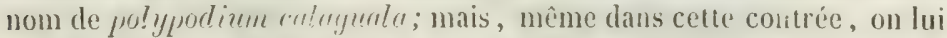
substitue la souche de deux autres fougères, qui sont le polypodium rassifolium, L. , et l'urrosticum imacsan'u, Ruiz. Suivant Ruiz, également, le vrai calaguala, dans son élat naturel, est une souche crlindrique un peu comprimée, mince, horizontale, rampante et flexucuse, couverte sur sa surface inférieure par de longues fibres branchues, d'un gris foncé, ef portant sur la face supérienre des feuilles disposées par rangs alternatifs. Elle est d'une couleur cendrée à l'extéricur, et converte sur toute sa longueur par de larges écailles; à l'intérieur elle est d'un rert clair, et remplie de beancoup de petites fibres. A près sa dessiccation, el lorsque les écailles ont éré enlevées, clle est, à l'extérieur, d'un gris foncé; tandis que l'intérieur est jaunatle, compacte et offre une certaine ressemblance arec la canne ì sucre. Le goùt, yui est d'ahord doux, est suivi d'une amertume forte et désagréable, jointe à une légère iscosité. Enfin, ha racine, entièrement mâche,e, offre une sorte d'odeur d'huile rance. 
D'après cette description de liuiz, je puis dire qui je n'ai janais I le véritable calaguala, et je suppose que celte substance a ciû être ậportie bien rarement en france. D'aillems, on s'accorde ginerilenicm à penser que le calaguala venu en Europe est produit par l'msirdlume coriacem de Swartz, arec lequel on confond le polyporlium udimutiforme de Forster, et que l'on suppose, d'après cela, renir iggalement dans les Antilles, à l'île Bourbon, à la Yourelle-Ilullinde et à la Youvelle-Zélande. Quoi qu’il en soit de cette opinion, voici la description des racines de calaguala cque j'ai en ma possession, et auxrquelles je? m'abstiendrii d'assigner aucune origine.

Première espèce. Souche brune rougeâtre à l'extéricur, et d'une grosseur variable depuis celle d'une petite plume jusgu'à celle du doigt: clle est flexueuse, ou contourriéc par la dessiccation; aplatic et marquée de rides profondes, longitudinales; la surface en est unie et luisante sur toutes les parties proéminentes exposées an frottement, tandis que les sillons sont remplis par des écailles fines et rougeâtres. La face inférieure se reconnaît à des pointes piquantes peu apparentes, qui proviennent des radicules, et la face supérieure à des chicots ass'" $\%$ forls, durs et ligneux, qui sont formés par la partie inférieure du pétiole des fenilles. Ces chicots ne partent pas du milieu de la face supérieure, mais

Fig. 53.

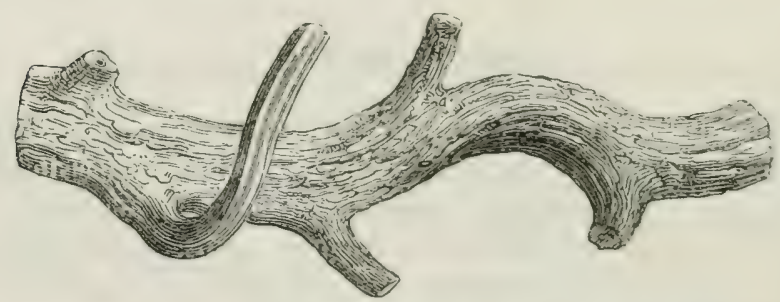

sont dispessés alternatirement d'un côté et de l'antre, sans suitre crpendant une régularité constante. L'intérieur de la souche est d'un rougre pàle et rosé comme la racine de bistorte. Sa sareur est douce, rans ancune astringence ni amertume; sa consistance est assez molle, et clle s'ecrase facilement sous la dent. Les insecte's la piguent assez promptement, et l'iode g démontre la préscnce de l'amidon. In intal, celte espece de caliguala, représentíc figure 53 , a la forme d'une grose racine de polypode commun.

Deuxieme esyere (lig. 54). Souche brune is l'extériem, grosec cumme une forte plume, longue, droite on un peu arguse ; s lindrigue et offrant sur un côté une nervure longitudinale qui dome naisance à de nombreus's radicules, dont il ne reste que des pointes ligmenses et 
piquantes. Tout le reste de la surface est comert de longues fibres ligneues, cylindrigues, roildes, dures el prignantes, conchées ou dressées le leng de la souche commune : ces libes sont cillemment la partie inférjeure du péliole des feuilles. I, 'intéticin de la sonche estrougratre,

Fig. 3\%.

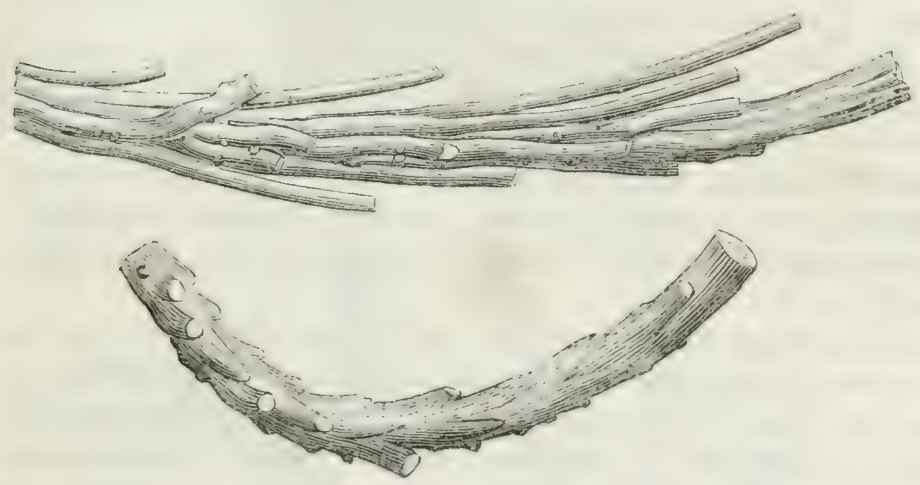

tres dur et tres difficile a brover sous la dent; la coupe en est compacte, luisante el comme gorgrie d'un suc desséché. I a sareur est astringente, sans aucune amerlume.

Je regar:lo: comnic appartenant a la meme espece une souche qui ofre la même forme cylindrique, la mème nervure saillante inferieure chargée de gadicules, el la même disposition des pétioles sur iont le reste de la surfare du rhizone. Ceprendant cette sorte ent creore plus dure et plus compacte, et les pélioles sont réduils à l'úlat de tuberculcs allongés non isolés du rhizome; mème saveur astringente, dépourvue d'amertume.

Troisieme esprese (lig. 5j). Souche petile, de la grosseur d'une

Fig. bu.

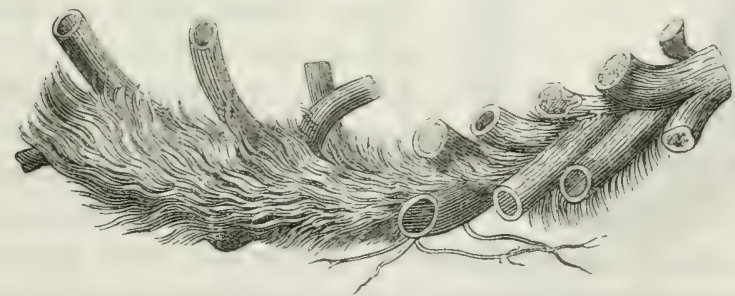

plume, d’un ğris rumgeatre à l'extéreur, offrant une surface inférieure 
plane, inégale ou creusée en goultière, et couverte de pointes radiculaires. La surface supérieure est bombée, demi-çlindrique, toute hérissée de tubercules courts, recourbés, couchés contre le rhizome, ou formant le plus souvent arec lui un angle très marqué; l'intéricur est compacte, brunâtre, dur sous la dent, et d'une sarcur très astringente. L'amertume manque dans toutes ces racines.

Vauquelin a soumis à l'analyse chimique la souche de calagnala (probablement la première espèce), et en a retiré les principes suivants, que j'énonce d'après l'ordre de leur plus grande quantité: matière ligncuse, matière gommeuse, résine rouge, àcre ct anère; matière sucrée, matière amylacée, matière colorante particulière, acide malique, chlorure de potassium, chaux et silice. (.1 mm. rlime, t. $L V$, p. 22.)

Facx-Calaguala, Champigaon be Malte. J'ai tromé me fois dans du calaguala venu de Harseille une substance fort différente et qui était formée par une plante très singulière nommée rhmmpignon de. Walte, laquelle croìt en plusieurs lieux du littoral de la Véditerranée. Cette plante naît sur les racines de plusicurs arbres ou arbrisseaux, il la manière des hypocistes et des orobranches. Elle est formée d'une simple

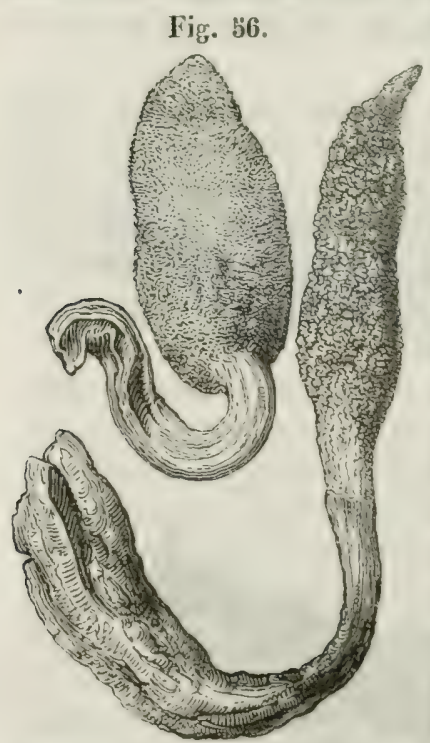
tige charnue, courerte d'écailles et terminée supérieurement par un chaton en massue, de couleur écarlate, tout couvert de fleurs mâles à une étamine, entremêlées de fleurs femelles composées d'un ovaire uniloculaire, d'un style et d'un stigmate. Le fruit est formé d'un péricarpe sec, uniloculaire, renfermant un noyau sans embryon et dont l'amande est remplacée par une agglomération de spores. Cette plante appartient donc à la division des acotylédones phanérogames ou anthosées, qui portent aussi le nom de rhisanthées. Le champignon de Malte desséchẻ et privé de ses écailles, est formé par un stipe sourent contomine, ridé, d'une coulcur brume, lerminć par son chaton non développé (figr. 56 ). Il possède une saveur astringente a légèrement acide. Il se ramollit dans l'air humide, s'altere et derient la proie des insécles. Limné le renardait conme utile contre les hémor. rhagies, le flux de sang, la dyssenteric, ele. On le prenait en pondre dins du vin 001 da bouillon. 


\section{Capllialres.}

On a donné ce nom à des plantes appartenant primitivement aux genres adiantum et asplenium, telles sont le capillaire du Canada, le

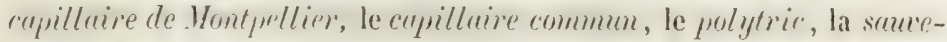
vie, le cétérach et la scolopendre.

Capillatre du Cinada. Adiuntum pedutum, L. I"il' ypin. Sporanges disposées en sores marginaux, oblongs ou arrondis, pourrus d'un indusium continu arec le bord de la feuille et libre du côté inté-

Vig. 57 .

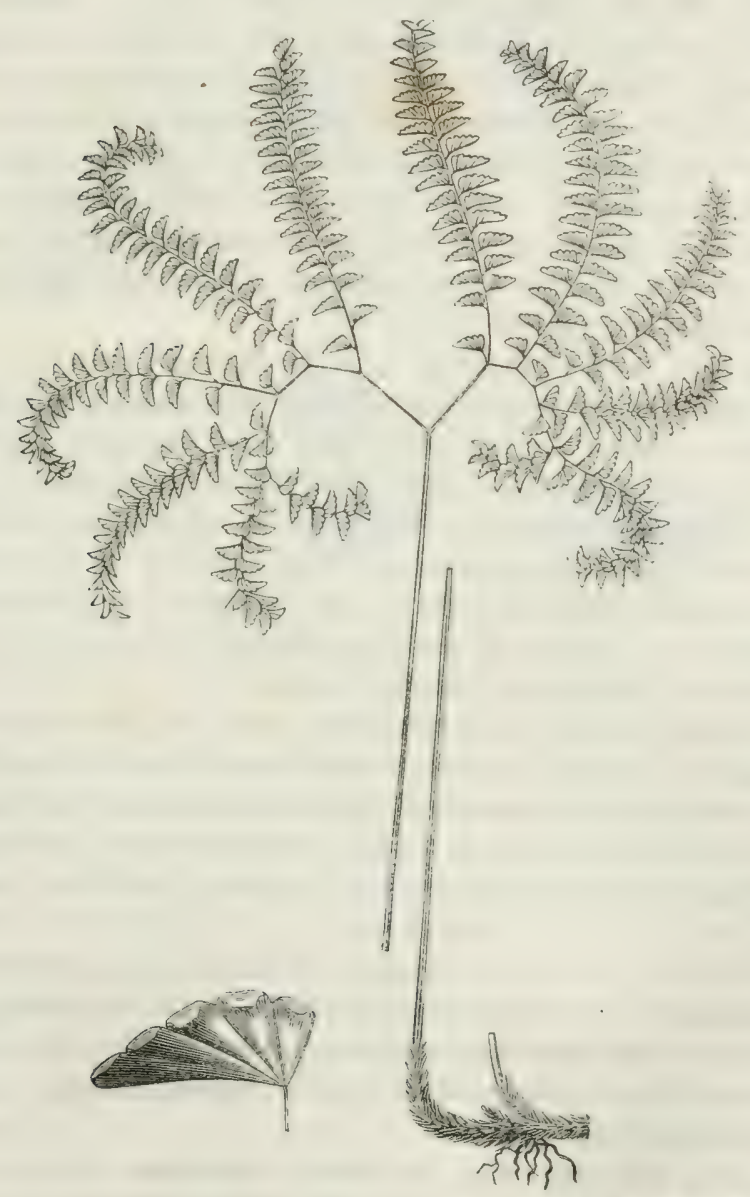

rieur. - Car. spréc. Fenillage pédalé; rameaux à folioles pinnées, oblongues, incisćes seulement sur la marge interne et représentant comme une moitić de feuille. Pétioles très glabres (fig. 57). 


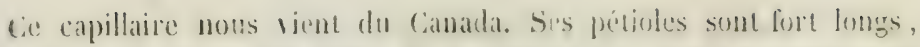
ronges ou bruns et très lisses. Ils se divisent ì la partie supericure e'n deux branches égales fui portent des ramifications du côté interne scuIement : c'est ce qui constitue le feuillago pédalé. Les folioles sont touffues, donces au toucher, d'un beau vert, d'une odeur agréable, d'unc saren douce un peu styptique : on en fait par infusion un sirop très igréable el très usité. Il entre également dans la composition de l'élixir de Garus.

Capll.tame ou Mexinge. Il y a quelques années que, pendant un lomps assez long , le capillaire du Canada avait complétement displaru du commerce. Alors on a tenté de hui substituer une autre espèce appportie du Mexigne, l'adientum trapeziforme, L. Ce capillaire est pourru de pétioles ligneux longs de 60 à 100 centimètres, branchus, tries ramifiés, lisses et d'une couleur noire; les folioles sont alternes, Homboülales ou trapéziformes, incisées et pourves de sores sur les deux còtés opprosés au pétiole; efles sont d'un rert foncé et comme noirâtre, d'une consistance ferme el très faciles à se détacher de la tige, ce qui présente un grand inconrénient pour le commerce. Mais à l'usage, ce capillaire m’a paru être aussi aromatique et fournir des médicaments aussi agréables que celui du Canada.

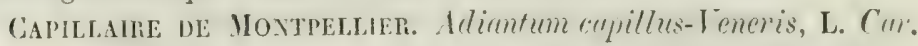
spréc. Feuillage décomposé; folioles alternes, cunéiformes, pédicellées. Ce capillaire diffère des précédents par ses pétioles grêles, longs au plus de 20 à 30 centimètres, portant de petits rameaux alternes, ćcartés, subdivisés cux-mèmes et munis de folioles cunéiformes, à deux ou trois lobes terminaux ou opposés au pétiole (fig. 58). Il croît surtout aux curirons de Iontpellier, dans les lieux humides et pierrenx. Il a une odeur peu marquée et moins agrciable que celle des deux précédents, et peut difficilement leur être substitué.

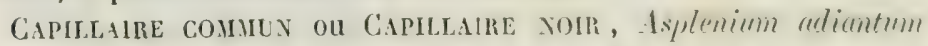
nigrem, I. Car. gén. Sporangres fivées sur des reines transversales et rassemblées en sores linéares. Indusium membraneux né lateralement d'une reine et libre du côté de la côte médiane. - Car. sprér. Fronde cous-tripinnée, folioles alternes; foliolules lancéolées, incisées, dentécs.

Ce capillaire croît sur les muraillès, el dans le's lieux humides, au picul des arbres; il pousse des pétioles longs de 10 à 20 centimètres, garnis à leur partie supérieure de folioles profondément incisées, diminuant graduedlement de grandeur juscquan sommet, et d'un vert très foncé. Il est peu usité.

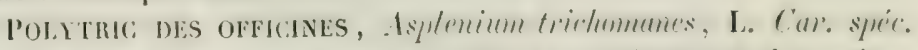
Fenillage pinne; folioles oborées crénclées, les inférieures plus petites. 
Ce capillaire se distingue des autres par la petitesse de ses folioles, qui, sans être opposées, sont rangées comme par paire le long du pétiole, al qui sont presfue rondes, lígèrement crénelées, et tris

Fig. 58.

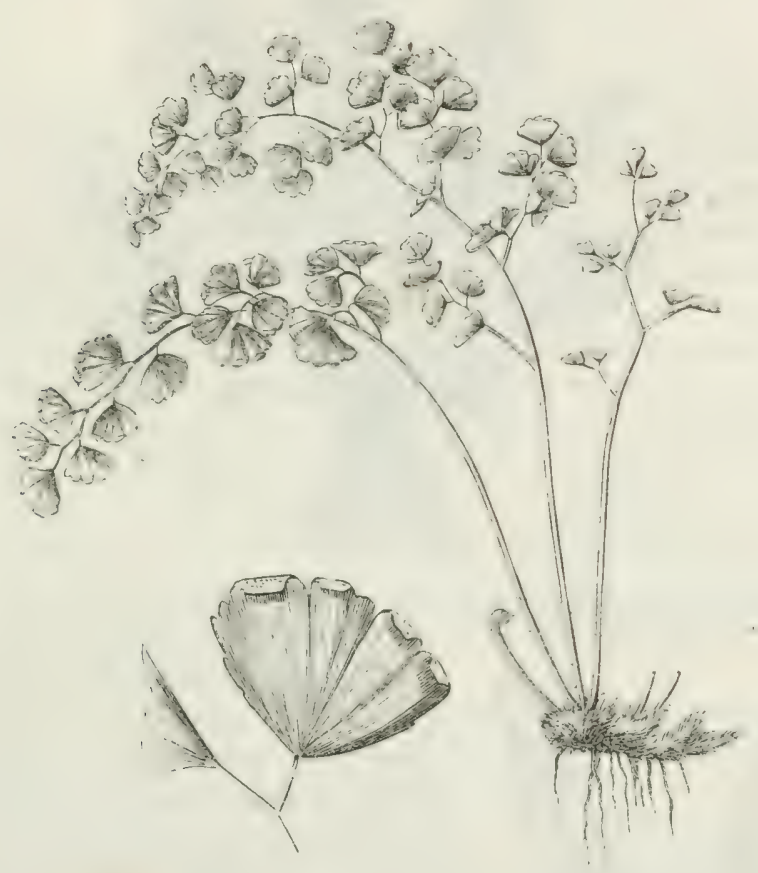

chargées sur l'une de leurs fares d'écailles faures qui conrent la fructification. Il est pen employé dans lá ville; mais les hôpitaux en consomment une assez grande qunantití, comme succédani des espèces précédentes. Il a peu d'orleur.

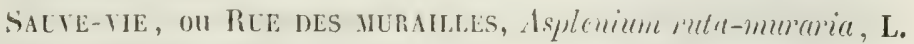
l'ar. spréc. Feuillage alternativement décomposí; folioles cunéiformes crénclées.

Coteracit, Dacrade on Dacradile. Ceterach officinamum, D C.; Asplenium ceterach, L. Car. gru. Sporanges rasscmblées en sores diniaires ou oblongs, dépourvus de véritahle légument, mais recouverts d'écailles qui on liennent lien. - Car. syrer. Fenillage pinnatifide lobes alternes, confluents, obtus.

Culle plante pousse des pétioles conrts. gai furment, à leur partie superienre, comme nne sento fenile décotpóe alternativement d'un 
côté et de l'autre, juscju'à la côte dı milieu ( fig. 59 ) cette feuille est chargée sur le dos d'un nombre infini d'écailles (qui en conrrent entip-

Fig. 59.

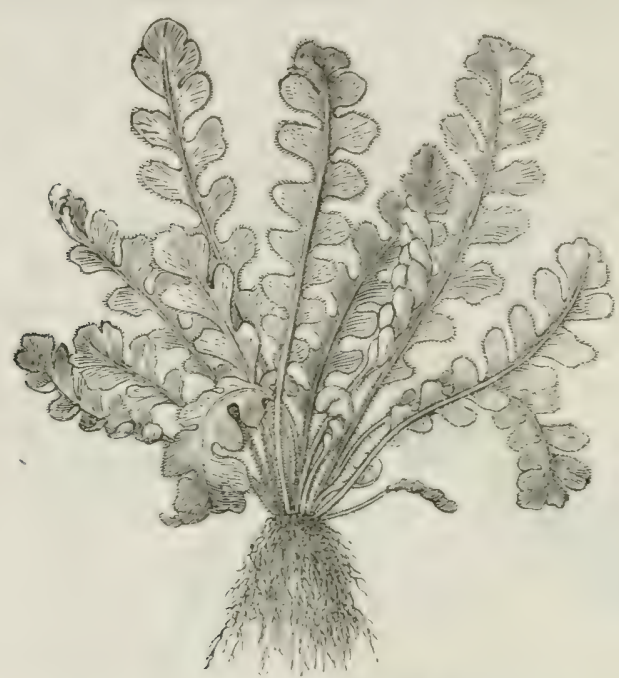

rement la fructification, et qui, lorsque la plante est sur la terre et

Fig. 60 .

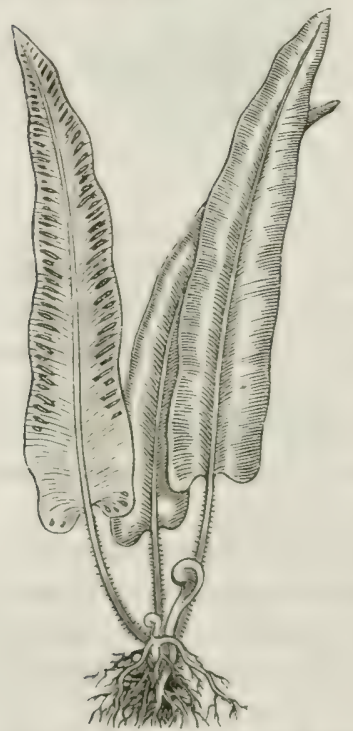
riue le soleil frappe dessus, la font paraître dorée, d'où lui sont venus ses deux derniers noms. Séchée, elle a une odeur agréable et une sareur astringente semblable à celle de la racine de fougère, paí conséquent assez désagréable. Le cétérach est fort vanté contre les maladies du poumon et les affections calculeuses de ha ressie.

SCOLOPENDTE, scolopendrium officinals" Smith; asplenium scolopendrium, I. Car. gén. Sporanges réunies en sores géminés, placés sur deux reines contiguës, et courerts de deux indusium comirents, s'ouvrant enfin par une ligne longitudinale. - Car. spréc. Fronde simple, cordée, ligulíe, très entic̀re; stipe relu (fig. 60).

Cente plante pousse, de sa souche, des feuilles pétiolées, très entières, longues,

verte's, luisantes. Ces feuilles présentent sur le dos deux rangs de lignes 


\section{IYCOPODIACEES.}

paralliles, formées par la fructification. Filles ont une sareur douce et une odeur de capillaire assez agréable.

La scolopendre se nomme aussi langue de cerf, à cause de la forme de ses feuilles, qui a été comparée à celle de la langue d'un cerf. On l'emploie en infusion; clle entre dans la composition du sirop de rhubarbe composé, et des électuaires lénitif et catholicum composés.

\section{FAMLLE DES TYCOPODIACEES.}

Les lycopodiacées sont des plantes très rameuse's, sourent étalées ou rampantes, toutes courertes de petites feuilles verticillées ou disposées en spirales, et portant en outre deux sortes d'organes, dont la nature et les fonctions sont encore inccrtaines. Tantòt ce sont des capsules globuieuses ou réniformes, mniloculaires, s'ouvrant par une fente transversale, et renfermant un grand nombre de granules tris petits, d'abord réunis quatre par quatre, puis devenus libres par la destruction des cellules qui les araient engendrés. Tantôt ce sont des capsules plus grosses, a $30 u$ 4 valses, à 3 ou 4 loges, contenant seulement 3 ou / spores volumineuses. Ces deux espèces de capsules sont quelgnefois rütmies sur le mème individu, et semblent jouer dans ces plantes le mème rojle que les flenrs mâles et femelles, dans les végútanx monoïques et dioïques, et beancoup de botanistes pensent que les petitrs capsules remplies d'une poussière jaune très fine, sont des anthères arec leur pollen, et les autres des fleurs femelles.

Cette opinion très probable est corroborie par la nature chimique de la poussière jaune que nous nommons lyrrumodre, glui est semblable à celle du pollen des plantes phanérogammes.

I.es lycopodiacées paraissent dotées de proprictés très actires; l'herbe même de lycoperdinm clueatum est romitise, et l'on rapporte que des paysans dı Tyrol, ayant mangé des légumes cuits dans l'eau où arait macéré du lycuportimm selago, iprourèrent des stmptomes d'irresse et des romissements.

Le lycopode officinal (lycopodium clmatume, fig. (j1) croît surtont ('n . Ilemagne et en Suisse. Il se plaì dans les bois et à l'ombre; il pousse des tiges très longues, rampantes, qui se ranifient prodigieusement en s'étendant toujours davantage sur la terre. Il s'élère d'entre ces ramifications des pédoncules longs comme la main, ronds et déliés, portant a leur extrémité deux petits épis ç̣lindriques géminés, qui sont composés de capsules réniformes, sessiles, à deux valves. C'est dans cescapsules que se troure contenue la poussière que nous nommons lycopode.

Le lycopode est une poussière d'un jaune tendre, très fine, très légère, sans ncieur ni savenr, el prenant feu arec la rapidité de la poudre, 


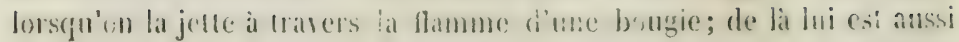

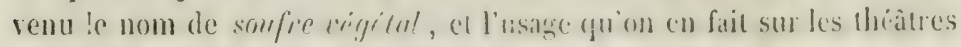
pour produire des feux effrayants mais pen dangereux.

1.e lycopode est employé en pharmacie pour rouler les pilules, et, par suite, empecher gu'elles n'athèrent entre elles; on l'emploie aussi avec succés pour dessécher les écorchures qui surviennent entre les cuisses des enfants.

Le lycopode, jeté sur l'eau, reste ì sa surface; par l'agitation, une partic tombe an fond; par l'action du calorique, tout se précipite, et l'eau acquiert une sareur cireuse, et contient une assez grande quantité

lig. 61 .

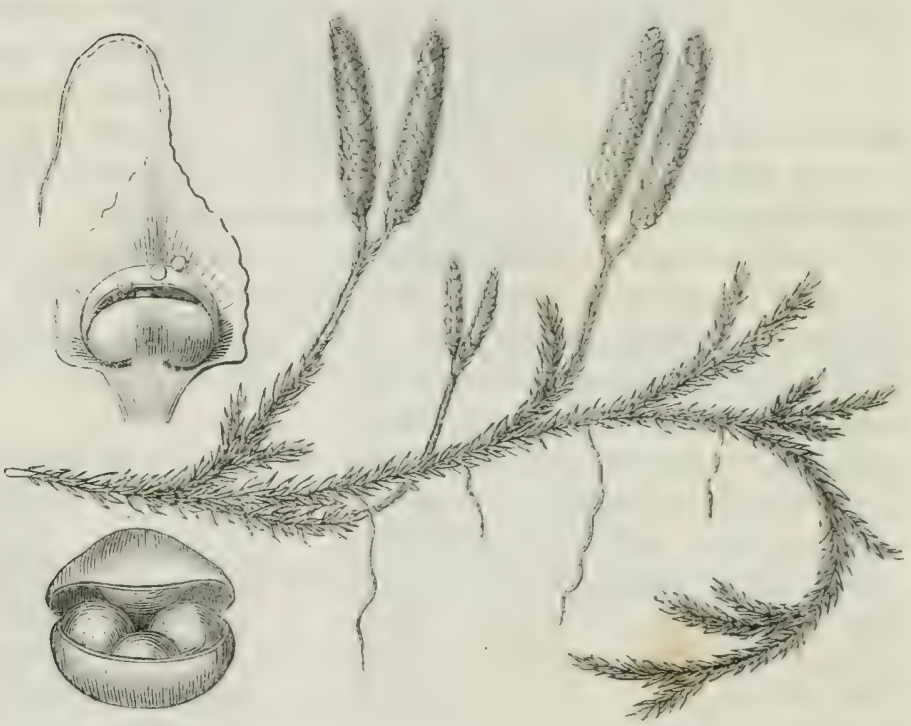

de muscilage suscrptible de se prendre en gelée par la concentration, comme celui du lichen.

L'alcool pénètra sur-le champ lre lycopode, (1 la poutre lombe au fond. $A$ l'aide te la chateur, on oblient une teinture legrere que l'eanblanchit. Ia teinture alcosligue, rapproche et précipitic par l'au, domne ensuite un extrait dans lefued la savener et la fermentaltion, à l'aide de la levure, indiquent la présence du suere. L'âher, versé sur du lycopode, se colore en janne-verditre; celle trinture, meilie d'alconl ef d'ent, laisse prépipier de la cire. Enfin la partie du lycopode insoluble dans ces diflérents menstrues, of qui équisam anx 0,89 de la pondre primi-

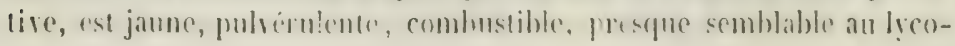




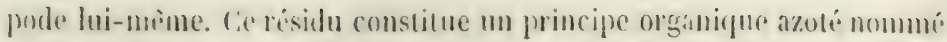
frollinime, degageant de l'ammoniargue par la potasse canstique, susceptible de se putréfier lorsgn'il est humide, el de se convertir en un. sorte de fromage.

Le licopode est sourent falsifié, dans le commerce, par du tale (crair de Briançon) ou par de l'amidon. Pour reconnaître le premier, on peut battre dans une fiole, arec de l'ean, la substance falsifiéc; par le repos, le lycopode vient surnager en trìs grande pratie, tandis que le tale : précipite. L'amidon se connaît, soit en traitant directement le mélange par de l'ean iodée, soit en faisant botillir le lycopode falsifie arec de l'eau, et versant dans la liqueur filtrée un soluté d’iode, qui la colone cn beu foncé dans le cas dẹ la présence de l'amidon.

I.e l! copode parait aussi aroir été falsific aree le pollen de plusienirs régétaux; et notamment arec celui des pins et des sapins, du cèdre on de; typhra. Je ne pense pas que cette falsification, qui serait an reste pen iuportante, soit aussi commune qu'on l'a supposé. () uant à moi, je ne l'ai jamais rencontrie. Dans tous les cas, il est facile de la reconnaître a l'aide du microscope, de même que les dens falsilications précédentes, a cause des caractires phrsiques très tranchés et rès uniformes du lycopode.

Le lycopode mouillé arec de l'alcuol, el ru au microscope, est essentiellement formé de granules isolés qui sont à peu près dés sections de spheres formées par trois plans clirigés rers le centre (fig. (52). Il est trìs rare qu'on tronve ces grains réunis, mais ils affectent différentes

Fig. 62.
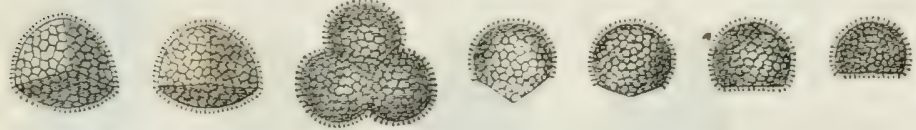

formes, suirant la maniere dont ils se présentent. Tous ces grains sont thès imparfaitement transparents, formés d'un tissu cellulaire dense, granuleux à leur surface, et de plus munis dans l'inierralle de's cellule's de très petits poils ou appendices terminés en massue.

I.e pollen des conifères est plus jaune que le lỵcopode et en parlicules moins fines. Celui dn pin, ru au microscope, affecte un grand nombre de formes bizarres fig. 63;, qui me paraissent résulter de la snudure de trois granules, dont un mitoşen, généralement plus volumineux, et deux autres plus petits, placés comme en aile anx extrémitís du premier; de plus, le grain du milieu offre presque toujours une tache opactue, it hords imriguliers, que je considion comme le restige d'm 
quatrieme granule avorté. Tous ces granules sont formes de lissu rollulaire, et sont dépourvus d'appendices superficiels.

Fig. 63.
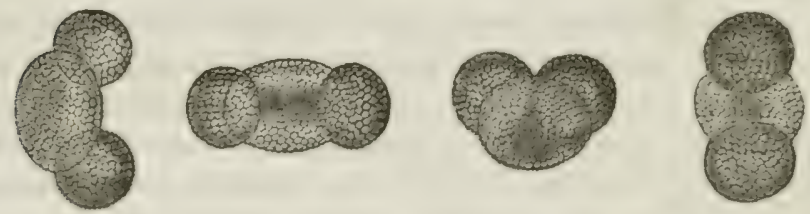

Le pollen de cèdre m'a paru être formé quelquarfois de trnis gramuleu distincts accoles (fig. (i4); mais le plus sourent les granules sont folle-

lig. 64.
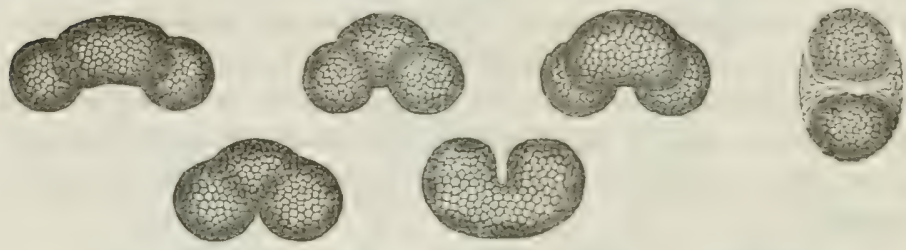

ment sondés un continus, que les grains paraissent formés d'une seule masse de tissu cellulaire, de form elliptique, ct renflée anx denx estrimités.

Le pollen de typha est d'un jaune foncé, en poudre assez urosciarer, Fig. 6ว.
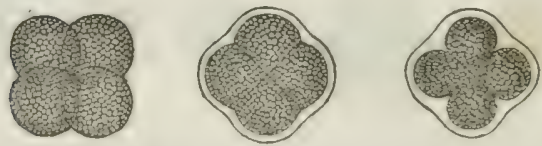

non mobile, comme colle du lyceprode, et à peine inflammalste. Il pitrait toujours formé, au microscope, de quatre granules soudtés, tantos! nus, tantot recourerts d'une ('nveloppe membrancuse, transparentu (fig. 65).

\section{FAMILLE DES ÉQUISETACELS.}

Les seules plantes qui nous restent à mentionncr, parmi les creplogames foliacres facotylédones acrogènes', ef qui, a mesure que nons appro hons davantage des phanerogames, montrent des organes de:

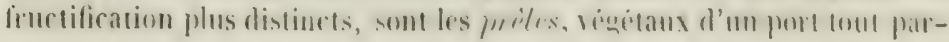


liculier, que Limné avait compris dans la famille des fongères; mais qui forment anjourdhui un groupe séparé, et dont le nom latin cyuisefun (crin de cheval feur a été donné à cause d'une certaine réssemblance de forme arec la gueue d'un cheral.

Ce sont des plantes d'une organisation semblable (les conlumites) yui ont paru des premières à la surface du globe, lorsque le refroidissement ("t la solidification des couches superficielles permirent aux ètres organisés de s'y développer. Cie sont c'lles qui, par leur profusion at leur taille gigantesjue, ont formé, après lcur enfouissement, ces amas c'n!silerables que la chaleur centrale, jointe a une forte pression, a dans la suite convertis an homille. Les precles d'anjurd'hui, faibles restes de colle végétation primitive, n'olfrent gutrere plus de 2,5 à 3,5 mìtres de

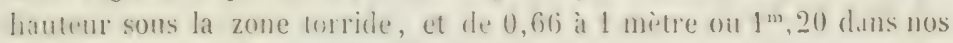

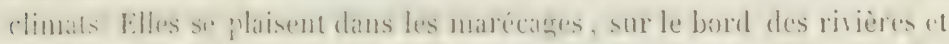

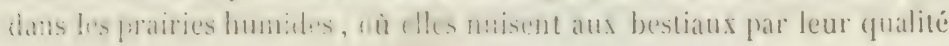
fortement dimétique.

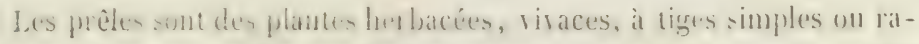

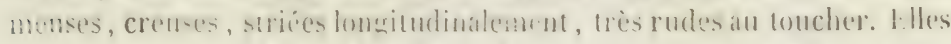

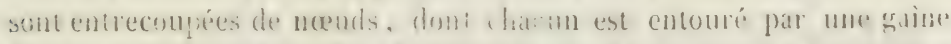

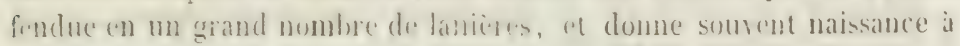

Jiv. Gili. Fig. 67 .

Jig. 68.
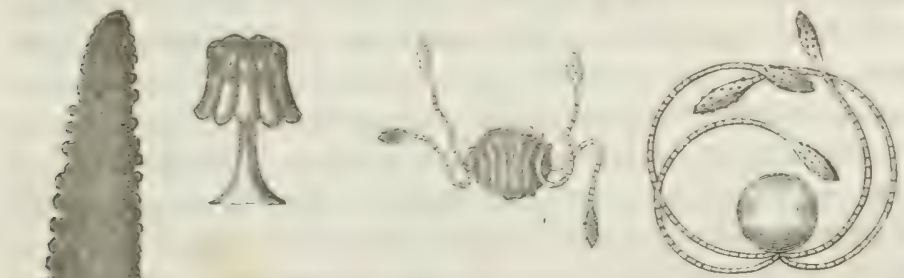

des rameaux verticillés, filiformes et articulés comme la tige principale. La fructification est portée sur des rameaux particuliers et constitue un épi ou un chaton cylindrique terminal (fig. 66), tout couvert de réceptacles particuliers, verticillés, stipités, terminés par un écusson pelté. Celni-ci (fig. 67) porte inférieurement de six à huit capsules uniloculaires, déhiscentes du côté interne par une fente longitudinale, el pleine de petits corpuscules rerts et sphériques (fig. 68), autour desquels sont enroulés quatre filaments partant de leur base, $\in t$ terminés par un renflement en forme de massue. On suppose que ces quatre renflements som

des anthères. 
La principale espece de prêle d'Europe est la prêle d'hirer (riphisetum hirmale), qui s'élère à la hauteur de 1 mètre it 1 mètre $1 / 2$, et qui a la tige dure et les articulations très écartées, ce qui permet que l'on s'en serve pour polir les ourrages d'ébénisterie et mème les métaus. Cette dureté de la prêle est due à ce que son épiderme est incrusté de silice. Dary, en poussant au chalumeau un fragment de prêle d'hiver, en a obtenu un globule de verre transparent. Plus récemment, M. Braconnot a extrait de la prêle fluviatile un acide particulier, auçuel il a donné le nom d'acide équisétique. Iais, d’après I. Victor Regnault, cet acide est identique arec l'acide pyromalique de M. Bracomnot (acide maléiçue de Pelouze), obtenu en distillant de l'acide nalique pur ì une température de 180 it 200 degrés (Ann. de chim. et plhys., 2 série, 1. LXII, p. 208).

Ia prêle a élé conseillée comme diurétique et emménagogue: elle doit être employée avec une certaine réserve.

\section{GROUPE DES RHIZANTHES.}

Ce groupe ne renferme que des plantes très extraordinaires, rirant sur la souche d'autres régétaux, composées de lissu cellulaire, avec quelques vaisseaux en spirale imparfaite. Elles sont généralement pourvues de feuilles squamiformes, imbriquées, prirées de raisseaux et de stomates; les fleurs sont hermaphrodites ou unisexuelles; le fruit est à une ou plusieurs loges, et renferme un grand nombre de semences dépourrues d'embryon et uniquement formées d'un tissu cellulaire rempli de spores. Ce groupe comprend trois familles, dont la première, celle des balanophorées a élé précédemment citẻe à l'occasion d'une de ses espèces, le cynomorium rreccineum, qui est quelquefois sulsstituće par fraude au calaguala.

I a seconde famille, celle des raflésiacées, renferme des plantes qui sont presque uniquement formées d'une fleur colossale, entourée de larges écailles. La troisième, celle des cỵtinées, contient l'hỵpociste (rytimus hyporist is), petite plante parasite, épaisse et charnue, qui croit dans fe midi de la lirance, en Espagne, en Italie, en Turguie et dans l'Asie-Mineure, sur la racine des cistes, ainsi que l'indirgue son nom. On en obtient un extrait astringent, dit sur d'hypureiste, qui n'est plus guère employé que pour la thériaque.

Sure hyporiste. - Pour obtenir ce suc, selon les uns, on pile les baies de la plante; selon d'autres, la plante entière, et on en cxprime le suc, que l'on fait ́ipaissir au soleil jusqu’ì ce qu'il soit tout ì fait solide. Suivant d'antresencore, on préparerait certerait par macération 
et decoction dans l'eau, el par éraporation de la ligueur an mosen du fert.

Le rai sue d'hrpociste a mo forme toute particulière; il est e'n masses de 2 à 3 hilogrammes, formées par lit réunion de petits pains orbiculaires du poids de 30 grammes environ, qui sont devenus diversement anguleux en se soudant les uns avec les autres, et qui se distinguent encore dans la masse par leur surface propre, qui est grisàtre; du reste, cet extrait a une cassure noire et luisante, et une saveur aigrelette et astringente. Il est sourent altéré daus le commerce avec du suc de réglisse, gui lui communique sa saveur douceitte particulière.

\section{QUATR IEME CLASSE.}

Végétaux monocotylédonés.

\section{FAMLLE DES ALUÏUEES.}

Plantes vivaces, herbacies, dont les fleurs, le plus souvent unisexuees, sont réunies sur un spadice unique et ordinairement enveloppées par une spathe. On les divise en deux tribus principales (1):

10 Les aracées on colocasiées, dont les fleurs sont dépourrues d'icailles et séparées sur le spadice, de manière que les fleurs femelles ou les pistils en occupent la partie inférieure, le's fleurs màles ou les élamines la partie moyemne, la partie supéricure restant nue. Genres arisurum, biarum, arum, dracunculus, colocasia, caludium, etc.

2" Les cullacées on orontincées, dont les étamines sont disposées autour des pistils, de manière à former des fleurs hermaphodites qui peurent ètre nues, comme dans le genre call", ou munies d'un périgone régulier, comme dans les genres pothos, dracontium, orontium, acorus.

\section{liaclue d'Arum.}

Xum valguite: Gonet, on Pied-de-Fean.

1.um culyure, Lamarch; 1. marulutum, L. (fig. 69). Cette plante croit en France dans les lieux ombragés; la racine est formée d'un tubercule oroüde de la grosseur d'un marron, garnie de radicules à la naissance

1. T.es pistiacées, que beancoup de botanistes réunissent aux aroüdècs, doivent plutot en être séparées. pour former une famille distincle plus approchec des lemnacées; je ne parterai d'ailleurs ni des mes ni des autre- 
des tiges, qui partent de différents points de la surface, ct qui produisent d'autres tubercules succédant an prenier. l'annéc d'après. Cés tubercules sont jaumâtres au dehors, d'un blanc d'anidon en dedans, d'une caveur âcre et caustique; les feuille's sont toutes rarlicales, longuement

Fig. 69.

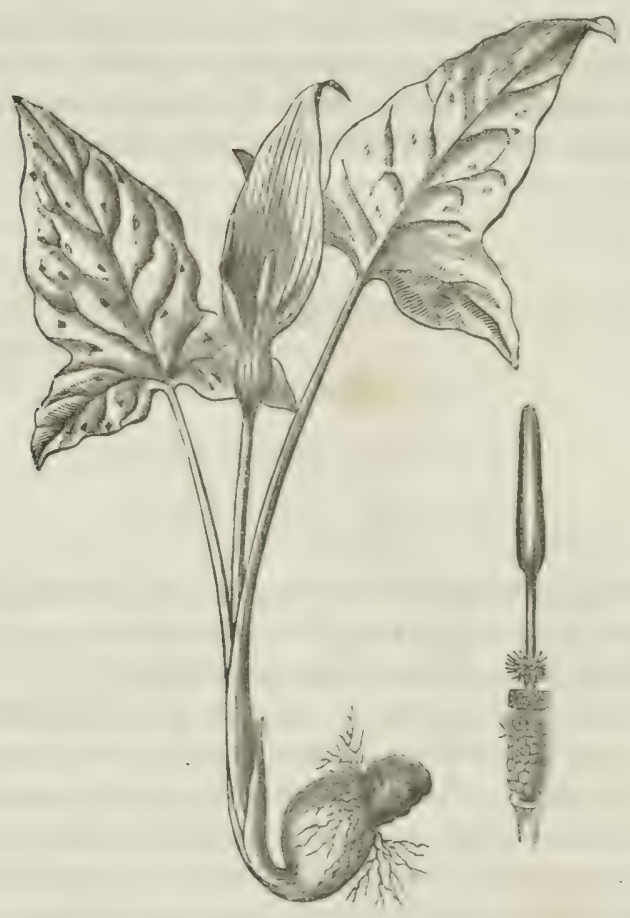

pétiolées, hastées, ettières, offrant, contrairement à celles de's autres monocotylédones, des nerrures latirales disersumb anastomonérs com

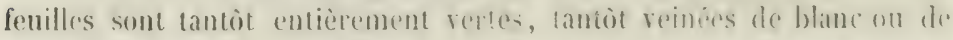

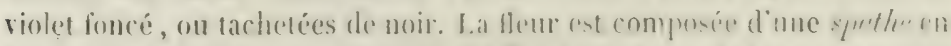

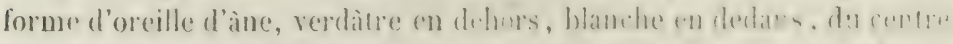

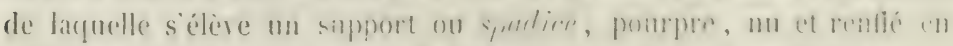

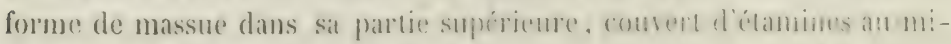

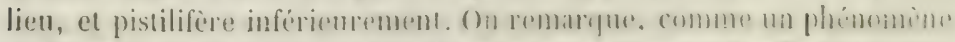

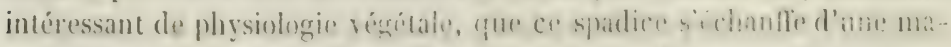

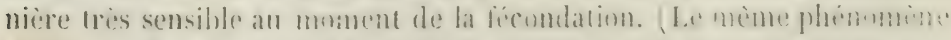

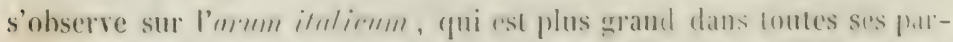

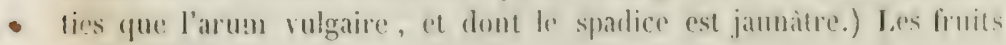


sont des baies globuleuses, rapproches en une grappe serrie, uniloculaires et polyspermes.

La racine d’arum, telle (pue le commerce la fournit, est assug géniralement ovoüle comme dans l'élat récent, ayant depuis la grossem d'une aveline jusyu'à colle d'une petite moix. Elle pat mondée de son épiderme, blanclie à l’intérieur, jaunâtre par places an dehors, d'unr odem presque nulle.

Ciette racine, lorsqu'elle n'est pas irop ancienne, jouit encore d'une ìcrete brulante, et cependant le principe caustique de la racine d'armu, dr mòme que ceux du manihot et d'autres vérgétaux à la fois amylacés cl vencineux, peut se délruire par la torréfaction et la fermentation : il ne faut donc pas s'étonner si I.emery annonce qu'on a essạé d'en faire dı pain dans les temps de disette.

b'après llurray la racine d'arum contient deux sucs différents; un laiteus, et l'autre aqueux beaucoup plus àcre que le memier. Mura! ajoute également, d'après Gessner, que le suc exprimé de la racine récente verdit le sirop de violettes et est coagulé par les acides. М. D॥Iongg, pharmacien à Istafort, ayant romlủ vérilier ces faits, n'a obtenu de la racine d'arum pilée dans un mortier, (qu'un suc blanchitre, très cipais, tenant beancoup d'anidon ('n suspension, prespue entièrement

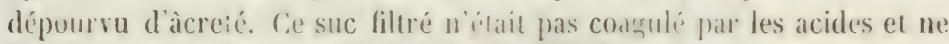
verdissait pas le sirop de violettes; il rougissait au cuntraire le papier de tournesol (Jumrn. de pharm., XII, 157).

\section{Racine d'Arum-Serpentaire on de Serpentaire commume.}

L.mm dracunculus, L. Inrocunculus rulgaris, Schout. Celle plante croìt surtont dans le midi de la France; elle est plus grande dans fontes ses parties que la précédente et s'en distingue par ses fruilles pédalées et à folioles lancéolées, par sa hampe lachelée de: noir comme la peau d'un serpent. Lat spathe rsi furt grande, blanchàtre

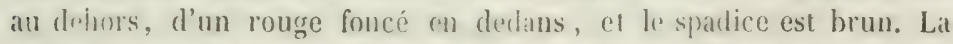
racin' cel sous la forme d'un pain orbiculaire, de 5 à 8 centimères de. diamitur, portant ia la surface supérieure un collet écailloux el des madiculas. On nous ensoic rette racine reche du Midi, et clle est prespue la seule yue l'on debile aujourd'hui comme la racine d'arum. Elle en diflìe , cependint, en ce qu'elle est bien moins âcre et moins aclive; rgue son rolume est beaucoup plus considérable; qu'elle a la forme de rondell:s plates, ou de pains orloiculaires, sur la face supérieme desquels on observe encore des restiges concentriques d'écailles foliacées; l'intéricur est d'un blanc d'amidon.

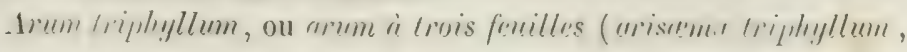


Schott). Certe espece croit dans la Virginie et au Brésil. L'Lcole de pharmacie en possède la racine envoyée par II. E. Durand, de Philadelphic. Elle a la forme de rondelles droites ou obliques, larges de 25 à 10 millimètres, épaisses de 15 à 20 ; clle possède du reste tous les caractères de la racine d'arum vulgaire.

Plusieurs antres aroüdées sont à citer pour leurs propriétés nutritics ou rénéneuses. Parmi les premières, il faut compter la culurnsis d' liIypte (arum colocasia, L. ; colocasin antiquesum, Schott), et le chou curcaibe (armen exculentun, L.; ruludium esculentum, Vent.), dont les feuilles et les racines sont également emplosées comme aliment. Parmi les secondes, je nommerai l'mrum se'guimum des dntilles (dieffenburtic seguince, Schott), qui a l'aspect d'un bananier, mais dont l'odeur est repoussante, et dont le suc brûle et corrode la peau. La fleur de l'armm muscivorum, L., répand également une odeur cadarércu:e qui attire les mouches; mais elle est garnie à l'intérieur de longs poils plongeant vers le fond du cornet, qui retiennent l'insecte imprudent qui s'y est précipité. Dans le nord de l'Europe, on mange les feuilles du cullu pulustris; le dracontium pertusum (munstere pertust, Schott, au contraire, est emploré comme résicatoire par les Indiens de Démérari.

\section{liacine d'Mcore vrat.}

Armus culumus, L. L'acore (fig. 70 ) est une plante virace qui crôt dans les lieux humides et marécageux, en Europe, dans la Tartaric et dans les Indes; on la cultive aussi dans les jardins. Ses fuilles lessemblent à celle de l'iris, mais sont plus étroites, plus droites et ì deux tranchants; clles sortent immédiatement de la partie supérieure de la racine, et parmi elles s'élère une hainje, de laquelle sort un long épi serré de fleurs hermaphrodites, au-delì durguel s'élève la fenille étroite de la hampe prolongée. Chaque petite fleur est munie d'un pérignne unique composé de six écailles, de six étamines attachées au périgone, et d'un ovaire surmonté d'un stignate sessile. I.c fruit devient une capsule en pyramide trigone renverséc.

La racine d'acore est grosse conme le doigt, articuléc et conchée obliquement à la superficie de la terre. Telle que le commerce nous la donne, elle est spongicuse, et d'une sécheresse rariable, suivant l'élat hygrométrique de l'air ; clle est d'un faure clair à l'extérieur, d'un blanc rosé à lintéricur, d'une odeur trè's suare. Fitle offre deux surfaces bien distinctes : l'une, inférieure, garnie de points noirs d'où partaient le's rarlicules; l'autre, mar(puée de restiges transversaux d’où s’élèaicnt les fenilles. Il fau la choisir noun elle el non piquaie des vers.

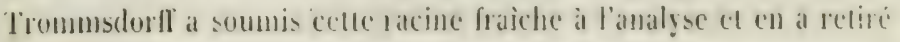




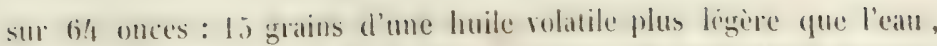
I once d'inuline, 9 gros de matière extractive, 3 onces $1 / 2$ de gomme, 1 once 1/2 de résine visquense, rig. 70. 13 onces 6 grros de matière ligneuse, 42 onces d'eau ( $4 \mathrm{~mm}$. de chim, I. LXXXI, p. 332 ).

II est douteux que la racinc d'acore contienne de l'imuline, principe qui paraît n'appartenir jusqu'ici qu'aux plantes synanthérées. D'ailleurs la racine d'acore noircit par le contact d'une dissolution d'iode, et ce fait seul proure qu'elle contient de l'amidon.

La racine d'acore rrai est ordinairement demandée et livréc dans les officines sous le nom de calamus aromaticus; mais elle est bien différente du calamms aromaticus des anciens: celui-ci était la tige odorante et amère d'une plante des Indes, de la famille des gentianées. Enfin il convient de toujours désigner la racine qui fait le sujet de cet article sons le nom d'acore vrai, pour la distinguer de la racine d'une espèce d'iris, que la ressemblance de ses feuilles avec l'acore a fait nommer irispseudoacorus, c'est-ì-dire iris faucacore.

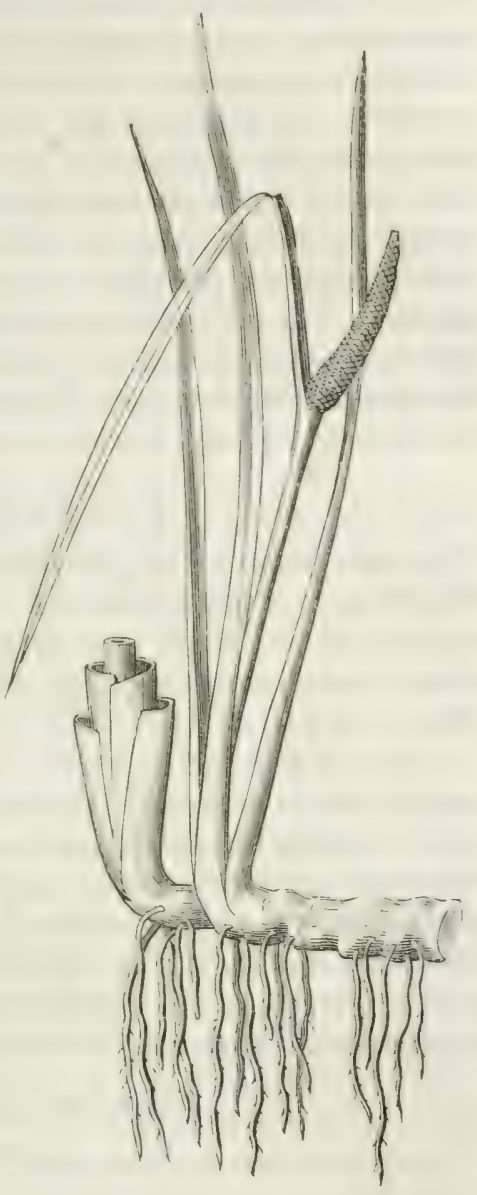

FAIILLI: DES GIPÉRACÉS.

Végélaux herbacés croissant en gênéral dans les lieux humides et sur. le bord des rivieres. Leur tige est sourent triangulaire, munie de feuilles engainantes, longues, rubanées, et dont liı gaine est entière et non fenduc, caractère qui les distingue des graninées. Les lleurs sont hermaphrodites ou unisesuées, disposíes en épis courts, composées cha- 
cune d'une écaille a l'aisselle de laquelle on troure généralement trois ćtamines et un pistil composé d'un oraire uniloculaire e't d'un style à trois stigmates filiformes et velus. On troure somvent anture de l'ovaire des soies hypogynes gui tiemnent lieu d'un périanthe, ou une grlumelie en

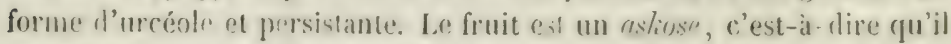
est supère, monosprome. ind hihisent, poursu d'un péricarpe distinct du tégument propre de la graine. Il est nu on entonré par l'urcéole. L'endosperme est farineux.

les cypéracíes forment une famille trìs naturelle et très roisine des graminces; elle ne comprend aucune plante dangerense. Ses fruits farineux pouraient servir a la nourriture de Thomme s'ils étaient plus abondants. L'herbe rerte contient peu de matière nutritise ct les animaux en font peu de cas. Plusieurs esjèces ont été employéés comme diurétiques et diaphorétiques. Trois espèces, surtout, ont été considèrées comme médicinales, et une comme alimentaire.

\section{Racine de Souchet long.}

C'yperus longus, I. Cirr. grin. Épillets multiflores, à glumes distigueg imbriquées, les inférienres rides et rquelquefois plus petites. Périgone. nul, 3 ctamines, ovaire surmonté d'un style à 3 stigmates. - C'ur. spirce Chaume feuillu; ombelle feuillue, surdécomposée; épillets fasciculés. alternes, linéaires.

Le souchet long croît en France et en Italie, dans les lieux marécageux. Sa racine est composée de jets traçants, de la grosseur d'une plume de crgne, marqués d'anneaux circulaires et pourrus, de distance en distance, de renflements oblongs qui idoment natssance aux liges. L'épiderme est d'un brun noirâtre; l'intérieur est rougreàtre, d’applarence ligneuse; la saveur est amère, astringente et aromatique. La racine respirée en masse présente une faible odeur de violette. On en préparait autrefois une eau distillée aromatiçne; elle n'est plus usitée.

\section{Racine de Souchet rond.}

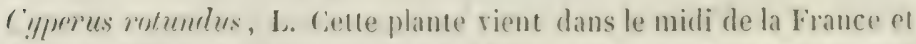
en Oricnt. Elle se distingue do la préciolme, sur:ont par sa racine, qui est formée de tubercules ovoüles gros comme de petites noix. quelyuefois tries rapprochés, mais le plus sourent séparies par une radicule longue, lignneuse, traçante el délice. Les tuburcules, qui domnent naissance aux liges, sont märqués d'anneaux circula res el parallèles, et

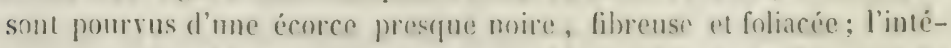
rieur est blanchâtre, spongieux. aussi désagríable à mirher que du liegre; la saseur est légèrement aromatique; l'odeur assez donce, mais faible. 


\section{Sorref conestible.}

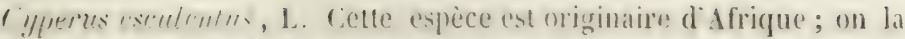
cultive c'ans le midi de l'Europe. Sa racine se rompone de radicules déliees qui purtent à l'extrimilé un tubercule oroüle, de la grossem d'une olive. Ce tubercule est marcué d'anneaux circulaires et présente à la partie inférieure un petit plateau couvert de fibrilles. Il est jaunc en dehors, blanr en dedans, d'un goutt doux, sucré et hoileux, co:mmo? celni de la noisette. Il contient de l'huile et forme une émulsion lorsynin le prile arec de l'ean. C'est une véritable amande souterraine, ansi que l'exprim son nom allemand erdmandel). Le sonchet co-

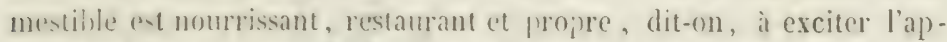

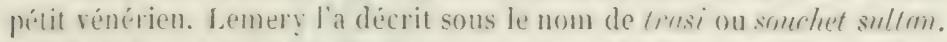
Lubul la figure dans ses fllswrentions, page '11, figure 2. Il porte dans le nord de l'Afrique le nom de habel-assis.

11. Isusisuil a rapporté en $1 \$ 22$, du fort de la Mine, sur la côte de Guince, unc variété de snuchne comestible gui est an tubercules plus grous gue le précélent, arrondis, à épiderme noiràtre, d’un goùt assez.

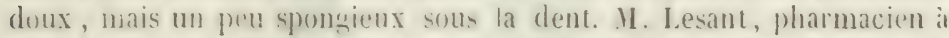
Santes, yui en a fail l'analyse, ens a reliré un sisiome d'huile fise, de la fécule, du sucre, de la gomme, do l’albumine, ete. (Jomon. plerrme, t. VIII, p. 497.)

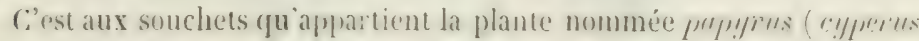

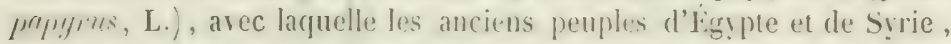
et par suite les Grecs et les Romains, fabriquaient leur papier. Cette plante ent remarguable pall sa tigre, yui est au moins de la grosseur du has, friangulaire an smmet, et hame de 2 motres 1,2 i 3 mètres. On divisait cette lige en renillets très uninces que l'on appliquait à angle droit, les mos sur les autres, contme on le pratique encore en Chine. Aujourd'hui mème en Lurope, cent principalement arec la tige des cypéracies rue l'un púprare, mais par un procédé différent, le papiex dit de Chine, qui sert à l'impression des grarures de prix.

\section{hacine de Carex des Sables (fis. il).}

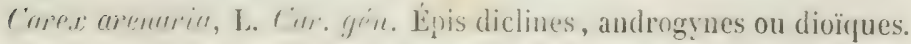
Épillets mniflores. Fl. mrilm: 1 glume, 2013 étamines. Fl. fenclles: 2 glumes dont l'estipieure est semblable ì celle de la fleur mâl' ; l'inté-

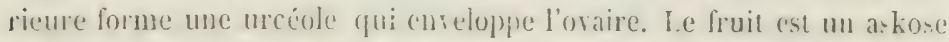
trigone renfermé daus l'urcénle. -- C'or. spre. Épis androg!nes conposis; épillets alternes, entassés; les supérieurs nuâles, les inférienrs 
femelles: 2- stignates; capsules ovales, marginées, bilides, denties, ciliées; chatume courbe en arc.

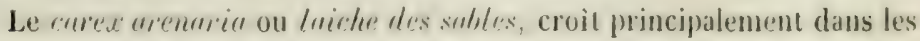
sables, sur le bord de la mar, en France, en Hollande et en Allemagne. Il pousse des rhizomes trarants et fort longs qui sont utiles,

Fig. 71 .

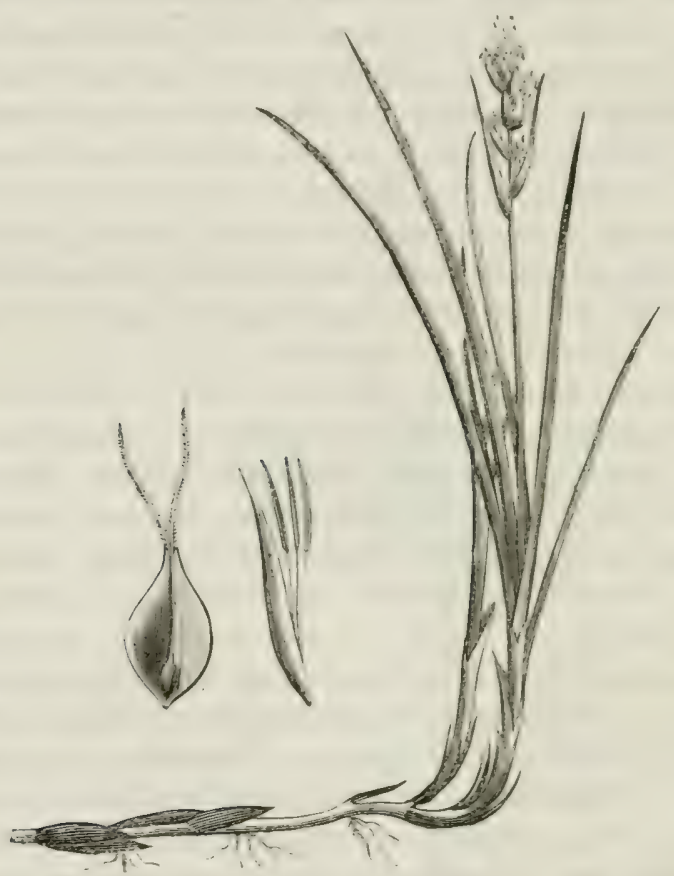

surtout en Hollande, pour domner de la solidité aux dunes. Ces rhizomes ayant été usités en Allemagne, comme succédanés de la salsepa-

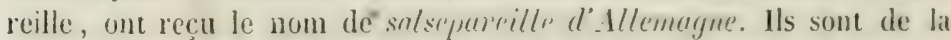
grosseur du gros chiendent, articulés, mais a nouds non proéminents, et courerts de fibres déliées qui sont un débris des écailles foliacées qui entourent chargue noud. Ils sont rougeitres an dehors, blanchitres et libreux en dedans, d'une sareur donceàtre, un peu désagréable et analogue a celle de la fomgère. On leur substitue sourent les rhizomes d'autres carex, et spécialement celui du $C$. hirta, L.

\section{FAMILLE DES GRAMIXEES.}

Plantes herbacés, plus rarement ligneuses, dont lat lige, momme

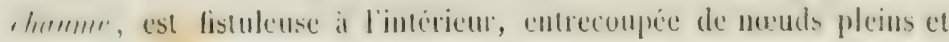


proéminents, d'où maissent des fenilles allernes of distiques à pétioles engainants. La gaìne, yui se prolonge d'ua nueud à l'aulre, est fondue dans toute sa longueur; le limbe est étroit, rubanć, à fibres longitudinales et parallèles; à la réunion de la gaine et du limbe se tromre un bord saillant sous la forme d'une lame membraneuse ou d'une rangíe de poils, auquel on donne le nom de ligule.

Les fleurs sont disposées en épis et en panicules plus ou moins rameuses. lilles sont solitaires ou réunies plusieurs elisemble an pelits groupes qui portent le nom d'rpillets. I la base des ipillets ou des

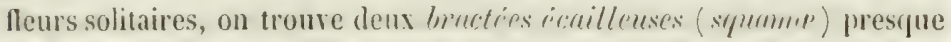
de niveau, l'une externe, l'autre interne, formant ensemble ce qu'on appelle la ylume. La braclée interne manque quelquefois, comme datss l'irraie. Chaque flem est pourve en outre d'une enveloppe particulière nommée brile ou glumelle, formée de deux jurllettes' julpr) dont une inférieure et externe, plus grande, carénée, est souvent munie d’une arète dorsale et terminale, et dont l'autre, interne, porte deux nervures dorsales et représente deux sipules soudés par leurs bards contigus; car ces deux pailletes, dont une double, formant 'nsemble la ylumelle, répondent au périanthe externe de la fleur des aubres monocotylédones. Plus à l'intérieur encore, et tout auprès des organes sexucls, se trouve une dernière enveloppe on périanthe interne, nommée ylumellule, formée par un rerticille de trois écailles comrtes nommées fulrivles, mais dont l'interne manque le plus ordinairement. Lces ctamines sont hypogynes, le plus souvent au nombre de trois, rarement de deux (flouve), quelquefois de six (riz), thès rarement plus. Les antheres sont linéaires, à deux loges séparées par les extrúmités. L'oraire est uniloculaire, uniovulé, margué sur le côté interne d'un sillon longitudinal et surmonté par deux sţ̣les distincts ou plus ou moins soulés, terminés chacum par un stignate plumeux. Le fruit est un cariopse nu ou enveloppé par la glumelle. L'embryon est placé à la face inférieure et externe d'un gros endosperme amylacé.

La famille des graminées compose le groupe le plus naturel, le plus nombreux et le plus répandu du règne végétal. Fille ne renferme qu'un petit nombre de plantes dangereuses ou douées de propriétés actives, telles que l'irraie (lolium temulentume), dont les fruits mềés aux céréales causent des vomissements, l'ivresse et des vertiges. Ja mélique bleue (motimia ceralea, Mœnch.), qui croît aussi en Europe, dans les prés humides et dans les forêts, devient dangereuse pour les bestiaux rers l'époque de sa floraison. Le festuere quarlvidentrutu, Kumbh, fréquent à Quito, est très vénéneux. Le rhizome du bromus jmorgms, I., qui croît daus l’Amérique septentrionale, el celui du bromus conflun'lives, trìs commu au chili snus le nom de grilme, sont fortement pur- 
gatifs. Plusieurs espèces d'ondtropurgm sont très aromatiques ef riches en huile volatile. Mais le nombre de ces plantes ent très borné, et presque toutes les graminées sont éminemment nutritives et salubres. Ces propriétés sont sirtont amarquables dans les fruits, (qui sont principalement formés d'amidon, d'albumine, de grlutine, de sucre, etc. et qui servent à la nourriture de l'homme et des animaux dans toute l'étendue du monde.

$\mathrm{Si}$ des fruits nous descenduns aux liges, nous! trourerons une semblable uniformité de principes, et principalement du sucre, qui abonde non seulement dans la canne à sucre, mais cucore dans les liges du bambou, du sorgho, du maīs, dans les rhizomes du chiendent et dans la plupart des autres.

\section{liacine de chientent.}

On emploie sous ce nom les rhizomes traçants de dens plantes diffi-

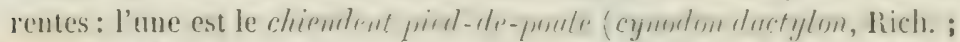

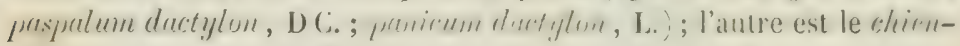
dent commun ou petit chiendent (triticum repens, L.).

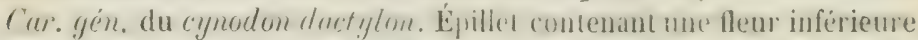
liermaphrodite sessile, et une fleur supérieure réduite à l'élat d'un pédoncule tubulé qui manque mène quelquefois. Glume à 2 écaiiles carénées dépunutes d'arête, la smérieure embrastant l'inférienre. Glumelle formée de 2 écailles, l'inférieure carénée, pointue, déponirue d'arête ou mucronce; la supéricure a 2 nersures dorsale's. Glumilule à

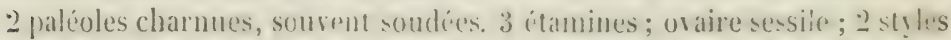
terminaux; stigmates plumenx; cariopse libre. - Cor. spér. Épis digités surerts, gatrin de poils à lat base interieure; jets traçanis.

Cette plante croîl à la lanteur de 30 à 40 centimètres; ses jets traçants sont très longs, de la grosseur d'une plume de corbean, çlindriques et entrecoupés d'un srand nombre de noeuds. De chacun de

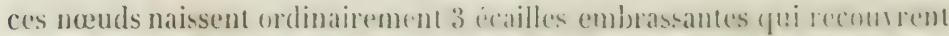

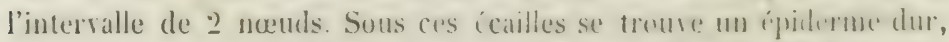
jaune, vernissi, et a l'interieur une substance blanche, furinense ef sucrée.

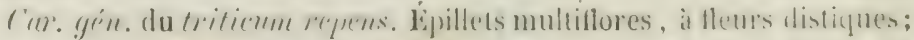
glume à 2 écailles sous-igales, unes on pourvurs diacle; ghtmontle a

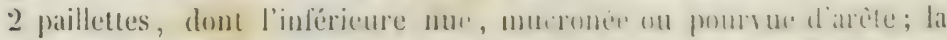

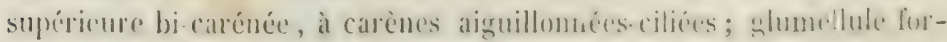

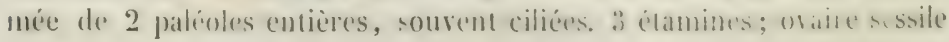
poilu au somnel; 2 stigmates terminaux, plumenx. Caringse libre ou

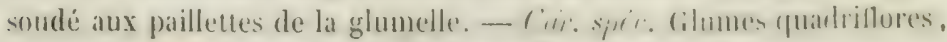
subulés, armés d'une arête; fenilles planes. 
Cé chiendent s'élère à la hauteur de 60 à 100 centimètres; ses jets Irançants sont très longrs, moins gros que ceux du précédent, plus droils, moins noueux et plus rarement entourés d'écailles foliacées. P'ar la dessiccation, ils deviennent anguleux et presque carrés. Ils sont moins farineux à l'intérieur et ont une sareur sucrée un peu plus prononcée.

Les rhizomes de chiendent sont adoucissants et apéritifs étant employés en tisane on en extrait. La tisane se prépare par décoction arec le rhizome mondé de ses radicules el de ses écailles et contusé; l'extrait est obtenu par infusion.

\section{Racine de canne de provence ou de grand rosean.}

Arumle domu, $\mathrm{L}$. Epillets contenant de 2 a 5 fleurs disticgues, hermaphrodites, celle du sommet langnissante. Glume à écailles carénées, aiguës; ghumelle à 2 pailletles, l'inférieure bifide an sommet, ponrsme d'une arete courte, soyeuse a la base; la superieure plus courte, bicarénée. Glumeltule lormée de 2 paléoles charnues; :3 itanines; oraire sessile, glabre; 2 styles terminaux allongés; stigmates plumeux. Cariopse libre.

Ce ruseau s'élève à hat haterur de $2^{m}, 5$ à $3^{m}, 5$. Ses tigres, noueuses el creuses, servent à faire des instruments à rent; ses feuilies sont largers de 5 centimètres, longues de 60 centimètre's, lisses, un pen rudes sur les bords; es fleurs forment une belle panicule, purpurine et un peu dense; sa racine est longne, forte, charnue, d'une sareur légèrement sucrée. On mous lapporte sèche diu midi de la France, et surtout de la Protence; ce qui est cause: (qu'on la prescrit ordinairement sous le

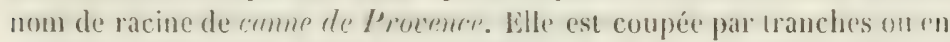
tronçons de diverses grosseurs; inodure, d'un blanc jaunàtre à l'intérienr, spongiense et cependant assez dure. Elle est reconserte d'un ipiderme jaune, luisant, coriace, ridé longitudinalenent, et marqué transversalement d'un grand nombre d'anneaux. Eille n'a presque pas de saveur.

11. Chevallier, ayant analysé la racine de canne, en a retiré, entre antres produits, unc matière résineuse qui a une sareur aromatique analogue à celle de la vanille, é arec laquelle il a aromatisé des pastilles qui se sont trouvées très agréables an goût (Jourm. de pharm., I. III, 1). 244).

Le même chimiste a analysé les cendres de la racine de canne et en a retiré de la silice, mais sans aucune mention particulière. Avant lıi, le cétèbre Day! avait remar(pué qu’un grand nombre de végétaux de la famille des joncs et des graminées contenaient de la silice, ef que cente 
terre existail surtout dans l'ipiderme, lisse cl si dur, qui recombre ces plantes. Ille ! est jointe, dans les cendres, it uise certaine quantité de potasse, de sorte que ces cendres, poussées à la fusion sans ancunn autre addition, donnent un rerre transparent (Anmeles do chimie, t. X XXII, p. 169 ). On sait, d'un autre còte, quue les tiges du bambou, graminée gigantesque de l'Inde (bandusu armulinucen, lielz) offrent assez fréquemment, dans l'interieur de leurs arliculations, des concrétions blanches nommées tulyosheer on tabracir, composées, d'après Vauquelin, de silice 70 , potasse et chaux $30(.1 \mathrm{~mm}$. du . Yustum, I. IV, p. 478. Voir également Arin. chim., t. XI, p. 64).

La racine de canne est employée comme antilaiteuse.

Les médecins ont quelquefois prescrit, comme dépurative el anti-

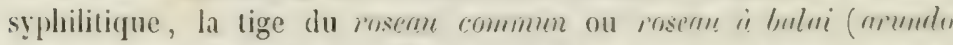
phrogmites, L.s), plante plus petite que la précédente, a panicule plus làche et tournée d'un seul còté. Les épillets portent de 3 à 6 fleurs, dont l'inférieure est màle et les autres hermaphrodites. (ie roseau croit en France el dans presque toute l'liurope, dans les élangs, les ruisseaux et les rivières. Sa tige est herbacée, creuse, entrecotupée de nouls pleins; sa racine est longue et rampante. Les panicules, coupées arant la floraison, servent à faire des balais d'appartement. Arec les liges, coupées et aplaties, on fabrique des naties et des tapis à mettre sous les pieds. La partie inférieure de la tige est séchée pour l'usage de l'herboristerie. Lille a la forme de tronçons creux, flexibles, celluleux, fermés sourent par une cloison transtersale répondant ì un noud, at ce neud présente à l'extériem des restes d'écailles o dr.: radicules. Cette tige est inodore et presque insipide.

\section{Schonanthe ofticinal.}

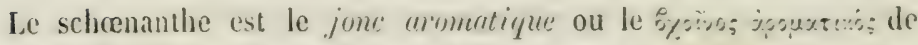
Dioscorides, qu'il dit croìtre en Afrique, en Arabie, et surtout au pays de Yabathe (Arabie déserte). Suirant Lemery, le scheranthe est tellement abondant dans celte derniere contréc et at pied du mont Liban, gu'on le fait servir de fourrage el de litière aux chameaux, ce qui est contirmé par les noms de firmum ou de strmurn cermelmmen, qu'il porte également. I la première vue, il est formé d'une touffe de feuilles paléacées, longue de 14 a 16 centimitres, termince en pointe par le bas, (gui ofire un pelit nombre de ralicules blanches, renflec au milien, et se terminant a la partie supréreure par des débris de tiges graminées. Examinée plus en délail, cette substance offre it la partie inferieure un rhizome unique, oblique, très comr, ligneus, ç lindrique,

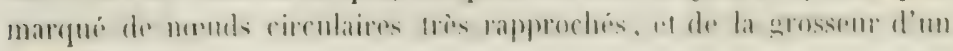


brin de chiendent. Chaque noud dome naissance à une ramificalion fui se ranifie souvent de la même manière, et le tout se terminc par un assez grand nombre de chaumes très déliés, entourés chacun à la base de fruilles serrées, assez larges et engainnantes, et pourvus chacun d'une radicule blanche, longue de 5 à 8 centimètres. Les chaumes, dont il ne reste que les débris à la partie supérieure, sont un peu plus gros qu'un fil, hauts de 30 à 45 centimètres, et terminés par une panicule munic d'involucres rougeâtres, d'où sort un amas de fleurs très petites, longuement pédicellées, et dont le calice propre est entièrement couvert par de longs poils soyeux qui partent de la base. L'ancienneté des échantillons ne permet guère de s'assurer de la nature des organes sexucls; mais il n'est pas douteux que les fleurs ne soient en partie mâles et en partie hermaphrodites comme dans les andropingon, dont cette plante est une espèce.

Les feuilles de schœenanthe sont pourvues d'une odeur persistante, analogue à celle du bois de Rhodes; cette odeur derient plus forle, mais moins agréable, lorsqu'on les froisse entre les doigts; leur saveur est âcre, aromatique, résincuse, très amère et très désagréable. La racine offre les mèmes propriétés, mais dans un degré inférieur ; enfin les fleur's, qui sont la partic de la plante que l'on devait faire entrer dans la thériaque, doivent avoir, au dire de Lemery, une odeur et une sareur 'ncore plus prononcées que les feuilles; mais celles que j'ai ont peu d'odem, et n'ont qu'une sareur faible, peut-être en raison de leur vétusté; aussi leur substitue-t-on la touffe radicale des fenilles, qui, comme je viens de le dire, jouit encore de propriétés assez énergiques.

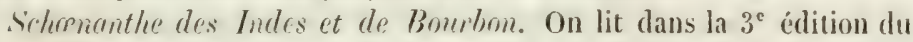
lirtiomarive de I.emery , qu'on apporte de l'île Bourbon et de Hadagascar un gromen qui a l'odeur et le goût du schœnanthe, mais qui est plus vert et à panicules plus petites et moins chargées de fleurs. I'ai reçu anciennement cette plante de l'île de la liéunion, où elle est connue sous te nom d'esquine. Ln botaniste anglais, II. Royle, m'a dit gu'elle res. semblait beaucoup à une plante commune dans l'intérieur do l'Inde, regardée par les médecins comme le öjõzs; de Dioscorides, et servant à l'extraction d'une huile volatile nommée grass oil of. Tamm. Elle diffère du schœenanthe officinal en ce que, au lieu d'offrir une touffe de fenilles radicales courte et épaisse, partant d'un rhizome unique, elle rst formée d'un petit nombre de bourgeons ou de tubercules se déviloppant les uns à côté des autres, pourvus d'assez fortes rarlicules, et portant chacun une lige haute de 60 à 100 centimètres, grosse comm? une plume et munic de nœuds très espacés qui donnent naissance à des fenilles très longues et très ámites. Cette tige est terminéc par une ponicule dont les insolures, an lien de renformer un anas de llewroms 
pédicellés et soveux, donnent naissance à des épillets verdàtres rgui portent des fleurons sessiles et presque dépoursus de poils. Enfin, toute la plante est moins aromatique que le schœnanthe officinal.

Origine du schananthe. La description des deux plantes précédentes était indispensable pour établir nettement quelle espèce botanique peut produire le schœnanthe officinal. Limné l'a attribué à un ond prypoyon de l'Inde et de Ceylan qu'il a nommé, à cause de cela, madromurgme schur-

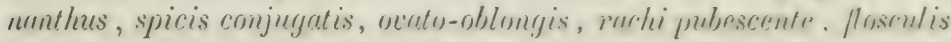
sessilibus, aristr tortusasa ; et il a été suivi par tous les botanintes sans exception; mais cette plante, qui est bien anssi l'ondrupurgun sciumunthus de Roxburgh et de Wallich, ne produit que le schœenanthe de l' Inde. qui est bien inférieur à celui d'Arabie. Tous les échantillons d'and,rupogron schenenthus qui se trourent dans l'herbier de II. Delessert se rapportent à la plante de l'Inde et sont identiques arec l'rsquiner de Bourbon. Un seul échantillon, trouvé par M. Bové dans les déscrts qui aroisinent le Caire, en Egypte, se rapporte au schœnanthe d'Irabie, ce qui s'accorde arec les lieux d'origine indiqués par Dioscorides. 13. De'caisue y a reconnu l'omdroporgon lunigerum de Desfontaine (Flome utlanticu, t. II , p. 379), qui est également l'andiropogron erioplermus de Willdenow. C'est donc bien cette espèce seule qui produit le schormantho officinal.

\section{Andropogon a odeur de citron de la Martinique.}

D'après le docteur Fleming, cité par Wallich (Plunt. usiut. ru.,

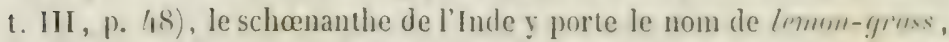
ou de chiendent-citron. Y. Petroz, ancien pharmacien en chef de la Charité, a reçu de la Martinique, sous le nom de ritromilln, un tutdroprogrm que les médecins du pays confondent aussi arec le schonanthe et qui y passe pour vénéneux, ou au moins comme propre à firire arorter les frmmes et les bestianx; cette plante se rapproche heaucoup en effet du schoenanthe, mais elle est bien plus grande dans toutrs ses parties. Elle commence, à la partie inférieure, par un rhiznne unique,

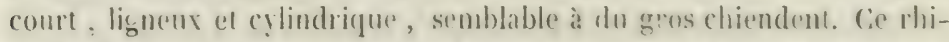
zome s'est accro successirement charue ammée, par la partie supérienre, de maniere a former une souche grosse comme le doigt, courbere, ramifiée, longue do 13 à lfi contimères, garnie dans tonte sa lonğnentr de radicules blanches semblables à celles du schonanthe; à l'extrémite surieure se trourent ij a 6 bourgeons foliacís, formés par les pétioles cmbrassants a comme imbriqués des fenilles; ces pétioles somt longs de 13 à 16 centimetres, et offrent une articulation arece le limbe de la leuille, qui cost étroit el long de 65 a 80 centimetres. Il n'y a pas d'ap- 
parence de tige. La plante entière a une odeur de rose for't agréable, quoiqu'elle ait beaucoup souffert de l'humidité et qu'elle ait perdu presque toute saveur.

\section{Racine de vétiver.}

Depuis une trentaine d'années déjà, on trouve dans le commerce, sous le nom de étiver, ou mieux de vittic-zayjr, une racine qui sert dlans l'Inde à parfumer les appartements, étant humectée d'eau, ou à préserrer les hardes et les lissus de l'attaque des insectes. Cette racine ressemble à celle du chiendent à balai (andropogon ischamum, L.) : aussi la nomme-t-on vulgairement chiendent des Indes; clle est chevelue, d'un blanc jaunâtre, tortueuse, longue tantôt de quelques fouces, tamlòt de près l'un pied; donée d'une odeur forte et tenace analogue à celle de la myrrhe, et offrant une sareur amère et aromaliyue. Cette racine, ou plutot ces radicules sortent en grand nombre d'une souche qu'on y trouve quelquefois réunie, el qui est tantôt oblique et traçante, munic de bourgeons foliacés à la partie supérieure, tantôt furmée de tubercules qui naissent les uns à côté des autres ; la tige, lorsffu'elle existe, ext moins grosse que le petit doigt, aplatie, presque à deux tranchants, courerte de pétioles embrassants, lisse et d'une couleur jaune; les autres parties manquent completement.

I.e ríliver est produit par une plante très commune dans l'Incle, qui est l'andrupurgm muricatus, de Retz. Ses tiges sont nombreuses, unies, très droiles, hautes de 1,3 à 2 mètres; ses feuilles sunt étroites, longues de 0,6 i 1 mètre, inodores; les fleurs sont nombreuses, petites, ́pineuses sur une des deux feuilles de la glume, ciliées sur l'autre. Suivant quelques botanistes, qui font de cette plante un genre particulier sous le nom de entiveriu, elle serait diö̈que; mais cette observation est loin d'ètre prourée.

La racine de vétiver a élé analysée par Vauquelin, qui en a retiré : $1^{\circ}$ une matière résineuse d'un rouge brun foncé, ayant une saveur âcre et une odeụr semblable à celle de la myrrhe; $2^{\circ}$ une matière colorante soluble dans l'eau ; $3^{\prime \prime}$ un acide libre; $4^{\circ}$ un sel calcaire; $5^{\prime \prime}$ de l'oxide de f'r en assez grande quantité; $6^{\prime \prime}$ me grande quantité de matière ligneuse (Ann. chim., t. LXXII, p. 302).

On emploie dans l'Inde, aux mêmes usages rgue le schonanthe ef le rétiver, les racines ou les feuilles de plusiurs autres mondroproyon peu connus, et qui se confondent prut-être en partic les uns arec les autres: tels sont les A. nardus, L. (ginger-grass, Engl.); - imurancusa, Roxb.; - parancura, Blanc; - citratus, DC. C'est à l'une de cas espèces, probablement à l'iwarancusa, (qu'il faut attribuer une racine 
d'origine indienne que l'on substitue souvent dans le commerce au véritable rétiver, et qui s'en distingue par des radicules longues de 25

30 centimètres, blanchâtres, peu cortucuses, faciles à réminir en faisceaux réguliers, d'une odeur assez faible et fugace; tandis que le vétiver est formé de radicules jaunes, courtes, fortement tortueuses, formant des amas très emmêlés et pourvus d'une odeur plus forte e bien plus tenace.

\section{Canne à sucre.}

Saccharum officinarum, I. (fig. 72). Epillets biflores, poilus à la base, à fleur inférieure neutre, à une seule pailletle; la supérieure

Fig. 72.

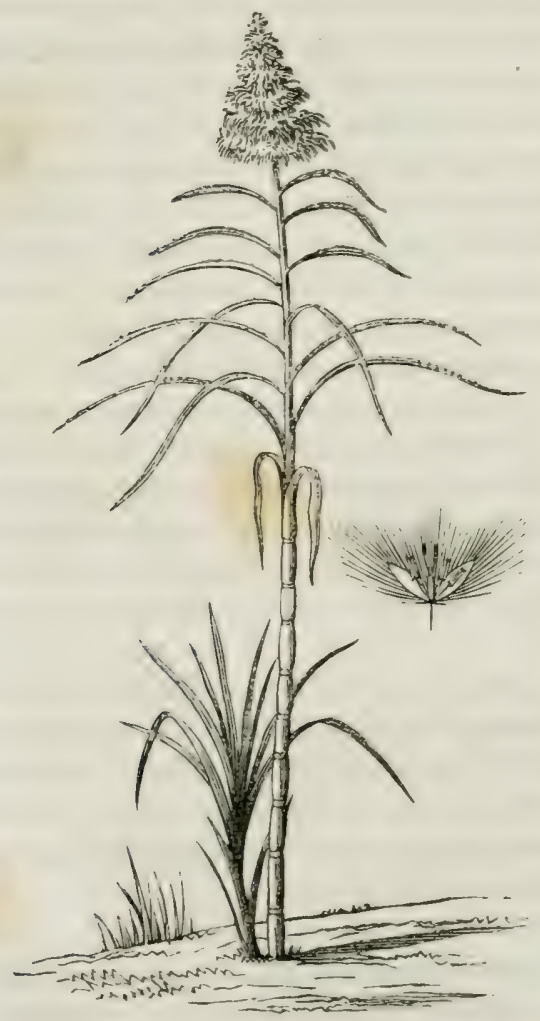

hermaphrodite; 3 étamines; ovaire sessile glabre; 2 styles terminaux, allongés; stigmates plumeux.

Très belle plante graminée qui, jusque dans ces derniers temps, a fourni la presque totalité du sucre consommé dans le monde entier; et, bien qu'aujourd'hui elle partage cette production arec la betterase, la grande importance qu'elle conserve encore pour les pays qui la cultirent, m'engage à en parler arec quelque détail.

Le sucre parait avoir ¿́cé comu, à une époque Irès reculée, des liabitanis de l'Inde et de la chine ; mais il ne l'a été en liurope que par les conquêtes d'Alexandre. Le mot Saccharon se troure dans

Dioscorides at dans Pline; cependant, d'après leurs descriptions, nn pent croire rgue le produit qu'ils nommaient ainsi différait un pen du nôtre. 
l'endant plusieurs siècles. son usage dans l'occident a eté restreint a la uédecine; mais la consommation s'en augmentait peu à peu; et, après le temps des Croisades, les Yénitiens, qui l'apportèrent de l'Orient ct le distribuèrent aux parties septentrionales de l'Europe, en firent un commerce très lucratif.

Pendant ce temps également, la culture de la canne ì sucre, originaire de l'Inde, se rapprochait de l'Europe, comme en . Irabie, en Syrie et en Égypte; enfin, on la planta en Sicile, en Italie, et mêne dans la Provence; mais la rigueur de certains hivers, dans cette dernière contrée, força d'en abandonner la culture. En 1420 , Ilenri, régent du l'ortugal, fit planter la canne à sucre dans l'île de Iadère, qui venait d'être déconverte; elle y réussit parfaitement, et passa de là aux Canaries et à l'île de Saint-Thomas.

Enfin, Christophe Colomb ayant décourert le noureau monde, en 1506 un nommé Pierre d'Arrança porta la canne à Hispaniola, aujourd'hui Saint-Domingue, et clle s'y multiplia arec une si prodigieuse vitesse, qu'en 151 is il y arait déjà dans cette île vingt-huit sucrerie's, et fqu'on a dit que les magnifiques palais de Madrid et de Tolède, bâtis par Charles-(Quint, avaient été payés arec le seul produit des droits inposés sur les sucres de l'île espagnole.

I. canne est done étrangère non seulement à l'A mérique, mais encore à l'Europe, à l'. Ifrique et à toute la partie de l'Isie située en deçì du Gange. Quelques historiens ont prétendu qu'elle élait naturelle à l'I Imérique; mais, outre qu'on ne l'y troure pas à l'état saurage, clle y est stérile la plupart du temps, et ne s'y reproduit que par boutures.

La culture de la canne à sucre varie suisant les climats et les contrées. Dans l'Indostan on la plante par boutures vers la fin de mai, lorsfue le terrain est réduit à l'état de limon très doux par les pluies ou par des arrosements artificiels; on la coupe en janvier et férrier, c'est-à-dire neuf mois après sa plantation, et arant sa floraison qui diminuerait beaucoup sa richesse en sucre.

En Imérique, où le terrain lui est moins convenable, la canne ne mùrit que douze à vingt mois après sa plantation. On reconnaît qu'elle est bonne à récolter à la couleur jaune qu'elle prend : alors on la coupe, et on laisse pousser les rejetons, qui sont bons ì couper au bout d'un an environ. Lorsque le même plant a poussé ainsi quatre ou cinq fois, on le détruit pour le replanter tout à fait.

La tige de la canne est un chanme comme celle rles autres graminées, et elle présente dans sa hauteur, qui est de 3 à 4 mètres ou davantagce, quarante, soixante ou même quatre-ringts nouds. Cette tige n'est pas igalement sucrée dans toute sa longueur; le sommet l'est bien moins que le reste, et c'est pour cette raison qu'on le retranche arant la récolte 
pour servir de bouture. Cetle première oprération faite, on coupe Ir reste des cannes très près de la terre, el on en forme des bottes fque l'on porte au moulin.

Ce moulin est composé de trois gros cyllindres de fer, élevés rerticilement sur un plan horizontal, le(quel est entouré d'une rainure destinée à l'écoulement du suc. Cés ç̣lindres sont traversés par "un axe de bois terminé en pirot aux deux extrémités : celıi dn milieu est mu par une force ruelconque, et, au moyen d'engrenages, communique son mourement en sens contraire aux deux autres. On présente un parpet de cannes entre deux de ces cylindres dont le mourement tend à les? faire entrer ; elles y passent, s'écrasent, et le suc en découle. Pour mieux les épuiser, une autre personne, placée derrière le moulin, les reçoit, et les présente de l'autre côté du cylindre du milieu : elles ? entrent de noureau, sont encore écrasées, et repassent dı premier côté.

La canne ainsi exprimée se nomme bayasse : on la fait sécher, et on l'emploie comme combustible.

Le suc exprimé se nomme cesou : on le fait couler, au moven d'unc rigole, jusque dans deux grands réservoirs placés proche du fourneau: il s'y dépure un peu; mais on ne l'y laisse que le temps strictement nécessaire pour cela, car il fermente de suite, et le sucre se détruit.

Le fournoau sur lequel sopèrent la clarification et l'éraporation dı resou a la forme allongée d'une galère, et porte quatre ou cing chandieres, dont la plus grande est placée à côté des réservoirs, et la plus petite à l'extrémité où est lé foyer. Par cette disposition, c'est celte dernière chaudière qui chauffe le plus, et la première le moins. Toutes ces chaudières sont d'abord remplies d'eau que l'on vide à mesure (qu' le sirop y arrive : leur capacité est calculée de manière que la derniere peut recevoir le produit concentré des deux réservoirs remplis chacun deux fois.

On remplit la première chaudière de vesou, et on l'y mèle avec un' petite quantité de lait de chaux, qui donne de la consistance à l'écume qui se forme, et en facilite la séparation ; dans cette chaudière le liquide ne sélève pas à plus de 60 degrés, et ne bout pas par conségutent. Lorsque l'écume est bien rassemblée à la surface, on l'enlève avec une large écumoire, et on fait passer la ligueur dans la seconde chandicre. Le liquide commence à bouillir dans cette chaudière et se clarifie mieus. A un point determiné de cuisson et de clarification, on te fait passer dans la troisième : dans toutes les deux, on ajoute une nouvelle quantité d'eau de chaux, si cela parait nécessaire pour hàter la clarilication,

Lorsque le sirop est parfaitement transparent et cuit comme un sirop) ordinaire, on le fait passer dans la dernière chatudière, où l'ébullition e't 
l'ésaporation sonu cextrèmement rapides, et daus laupuelle on le rappunche jusqu’a ce qu'il puisse cristalliser par le refroidissement.

Les opérations que je viens d'indiquer sont assez ginéralement sui vies dans toute l'Amérigue; il n'en ést pas dr mème de celles qui suivent.

Dans les possessions anglaises, par exemple, on se contente de fair couler lo sirop cuit dans une grande chandière isolée du fournean, "t nommée mfrarlhissoir; il s'y refroidit et cristallise en partie; on l'agite pour rendre le grain plus fin et plus uniforme, et on le distribue dans des tonneaux percés au fond de quelques trous que l'on tient bouchés avec la queue d'une feuille de palmier.

Iorsque la cristallisition est acherée dans ces tonneaux, on débouche rin partie les trous, afin de faire écouler la portion restée liquide, que l'on nomme milasw; on laisse égoutter entierement le sucre solide, et on l'envoie en Europe sous le nom de surre brut, corssunate ou mosconade.

Dans les possessions françaises, on fait de même en partie refroidir et cristalliser le sirop dans un rafraîthissoir ; mais ensuite en le distrihue dans des formes coniques on terre cuite, renversées sur des pots de même matière. Ces formes sont percées au sommet d'un trou que l'on timt houché jusculà ce que la cristallisation soit acherée; alors on lés débouche pour laisser écouler le sirop, et on laisse égnutter les pains pendant un mois : après ce temps on procède au terrage.

Cette opération consiste à recouvrir uniformément la surface des pains de sucre ares une couche d'argile détrempée; sette argile rède peu à peu sun eau, qui traverse également toute la masse du sucre et en dissout le sirop. On rafraìchit cette terre trois fois en quatre jours; le cinquième on la remplace tout à fait par de nourelle, et on continue ainsi jusfju'à ce qu'on ait fait trois terrages ou neuf rafraîchis : alor's, le sucre étant autant que possible privé de sirop, on le retire des formes. on le renrerse sur sa base pour y répandre uniformément l'humidité arcumulée au sommet, et on le laisse sécher à l'air pendant six semaines; en dernier lieu, on le met en poudre grossière, et on l'envoie en Europe sous le nom de sucre terré ou de cassonade.

P'endant longtemps la cassonade, arrivée en France, a été en partie emplovée à l'état brut par les confiseurs et les pharmaciens, et n'était guère raffinée que pour l'usage de la table ou pour les sucreries délicates ; mais aujourd'hui elle est presque entièrement amenée à l'état de sucre en pains.

Dans les raffineries on se sert d'une grande chaudière placée isolément sur sm fourneau en maçonnerie, et de deux autres chaudières plus petiles, placées sur un mème fourneau, el dont une seule, de 
tueme que dans les sucreries, se troure inmédiatement au-dessus du feu.

On met dans la grande chaudière des quantités déterminées de sucre et d'eau de chaux claire, el. on chauffe le tout lentement. Lorsque l'écume est formée, on l'enlève très exactement, et on ajoute à la liqueur du sang de boeuf délayé dans de l'eau; alor's on la chauffe jusqu'à la faire bouillit, on l'écume et on continue d'y ajouter du sang de bœuf et d'écumer jusqu'à ce que la clarification soit parfaite. On fait passer le sirop clarifié dans la première bassine du second fourneau; on l'écume et en le cuit encore; enfin on le passe dans la chaudière où l'on doit e'l acherer la cuite. On agit pour la cristallisation et pour le terrage de la même manière que dans les sucreries.

Lorsçu'on reut avoir du sucre encore plus beau, on lui fait subir de noureau les mêmes opérations, et alors on l'obtient en pains sonores, très durs, translucides et d'un blanc parfait.

Depuis plusieurs années, les procédés qui viennent d'ètre exposés ont recu de grandes améliorations, mais en attendent encore de plus considérables. II. Arequin, pharmacien français, qui a dirigé l'exploitation de grandes sucreries en dmérique, a d'abord montré que les anciens monlins ne retirent guère que jo pour cent de sue de la canne, tandis que celle-ci en renferme en réalité 90 centièmes. Jusqu’à présent , les perfectionnements apportés aux appareils de pressage n'ont pu en faire obtenir que de 60 à 68 .

I.e resou contient de 15 a 20 centièmes de sucre, et, par l'ancien procédé d'extraction, on n'en obtient que 7 à ? tout au plus. Le surplus se trouve détruit par la fermentation, ou par la conversion du stecte cristallisable en sucre incristallisable pendant l'action continuée du callorique, ou enfin reste dans la mélasse mélangé à des sels qui s'opposton à sa cristallisation.

Pour parer à ces divers inconvénients, on procide le plus tòt possille à la défécation du vesou par le mosen de la chaux, et on le porte immediatement à l'ébullition, au lieu de le chauffer lentement dans une chaudière très éloignée du feu, comme on le faisait aupararant.

On filtre deux fois le sirop au noir animal en grains : une prenience fois, lorsqu'il vient d'ètre déféqué ; une seconde, lorsgu'il est concentrí i 25 degrés du pèse-sirop.

On évapore le sirop clarifié, par très petites parlies, dans des chan-

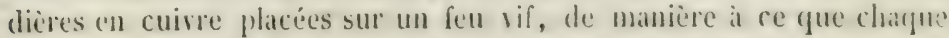

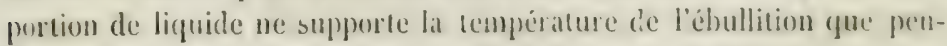
dant quelques minntes; ou bien on le concentre daus le vide, el, par conséquent, à une température bien inférieute a 100 degrés.

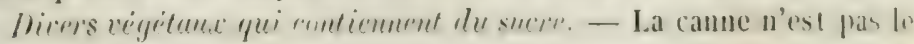


seul regélal qui comberme du sucre cristallisible, yusique aucun autre ne puisse somtenir la concurrence avee elle pour la quantite. Indépendamment des tiges des autres graminées précédemment citées, le tronc de plusieurs érables en contient, et surtont celni de l'urer' surhorium, arlore indig̀̀̀e aux forêts de l'Amérigune septentrionale. La racine do betterare en renferme également et en fournit une certaine quantité au commerce. On pourrait ígalement en extraire des navets, des carottes, des balates douces (butritas edtulis), des fruits sucrés non acides, tels que les melons. Ies chataignes, les baies de geniève. Quant aux fruits acides, ils ne peurnt contenir que do glucose, en raison de la transformation que les acides font éprourer au sucre cristallisable. Tels sont les raisins, les groseilles et autres fruits rouges de nos climats, les oranges, etc.

Propricitr. Le sucre est soluble dans la moitié de son poids d'eau froide, et dans toute proportion d'eau bouillante. Il cristallise facilement, surtout par éraporation lente dans une étuve. On le nomme alor's sucre candi.

Il est insoluble a froid dans l'alcool pur ; mais il s'y dissout a claud, et cristallise par te refroidissement. Il se dissout facilement à froid dans l'eau-de-rie, ce qui offre un moyen de reconnaitre lorsqu'il est melé de sucre de lait, lequel y est insoluble ; mais cette fraude serait sans objet, au prix où est le sucre aujourd'hui. Lne autre falsification guton Iui fait subir, consiste à le mólanger de grlucose, on sucre d'amidon. On recommaît celle falsification par le moven de la potasse qui se combinc avec le sucre de canne sans le colorer sensiblement, tandis qu'elle décompose le glucose en lui communiquant une couleur brune foncéc. Pour faire cet essai, on introduit dans un petit matras de verre 10 grammes de sucre, 30 grammes d'eau, 5 décigrammes de prasse pure, ct on fait bonillir pendant puelques minutes. La coloration brune indigue le mélange de glucose.

Le sucre, exposti au feu, se fond, se hoursoufle, brunit et exhale unc odeur particulière assez agréable. A cet état, il porte le nom de craramel; exposéà une plus forte chaleur, il brûle avec une belle flamme blanche, et laisse un charbon rolumineux. Celui-ci, incinéré, laisse un peu de cendre blanche, principalement composée de carbonate et de phosplate de chaux. L'acide nitrique dissout le sucre et le transforme, à l'aide du calorique, en une série d'acides dont les termes principaux sont l'acide saccharique $\left(\mathrm{C}^{12} 111^{10} \mathrm{O}^{16}\right)$, l'acide oxalique $\left(\mathrm{C}^{2} \mathrm{IIO}^{4}\right)$ et l'acide carbonique $\left(\mathrm{C}^{2} \mathrm{O}^{4}\right)$. Le sucrepur, cristallisé, a pour formule $\mathrm{C}^{12} \mathrm{H}^{11} \mathrm{O}^{11}$. On suppose qu'il contient deux molécules d'eau, et que sa composition à l'élat anlydre $=\mathrm{C}^{12} \mathrm{H}^{9} \mathrm{O}^{9}$. Ce qu'il y a de certain, c'est que le sucro cristallisé, en se combinant avec les bases, perd 1 ou 2 molécules d'eau, 
qui se trourent remplacies par 1 om 2 molécules de base. Le saccharate de chaux a pour formule $\left(121 \mathrm{I}^{9} \mathrm{O}^{9}+\mathrm{CaO}, \mathrm{IIO}\right)$; le saccharate de plomb $=\mathrm{C}^{12} \mathrm{H}_{9}^{9} \mathrm{O}^{9}+2 \mathrm{PbO}$.

Le sucre, dissous dans l'eau et additimné de levure ou d'un ferment azoté, se convertit en ulcoml et en acide corlonique, avec des phénomènes de chaleur et d'efforvescence qui ont été désignés sons le nom

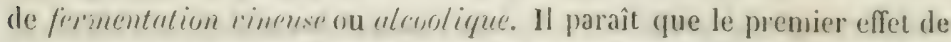
la les ure ou du ferment est de convertir le sucre cristallisable de la canne ('n un sucre incristallisable de la formule $C_{:}^{12} \|^{12}()^{12}$, et que c'est celuici qui, prar un dédoublement de principes, se convertit en alcool et en acide carbonique :

$$
\begin{aligned}
\text { Sucre liquide } & =\text { alcool }+ \text { acide carbonique } \\
\mathrm{C}^{12} \mathrm{H}^{12} \mathrm{O}^{12} & =\mathrm{C}^{8} \mathrm{H}^{12} \mathrm{O}^{4}+\quad \mathrm{C}^{4} \mathrm{O}^{8}
\end{aligned}
$$

fire de la canne à sucre, ou cérnsie. Lin grand nombre de végétaux laissent exsuder sur leurs tiges, leurs fenilles ou leurs fruits, une sul). stance qui a été désignée généralement sous le nom de cire vígrétule, mais qui est loin d'itre la mème pour tous. La canne à sucre, particulièrement, présente sur toute sa tige et à la base amplexicaule des feuilles, un poussière blanchàtre gu'on peut en séparer en la grattant arec un couteau, et qui abonde sur la crme violette plus que sur les autres rariétćs. 153 cannes grattées ont fourni 170 gram. de cire; la cume à rubans en fournit un peu moins; la comme dit)tuhiti en contient à peine le tiers de la canne à rubans; la comne erróle, origituaire de l'Inde, n'en donne presque pas.

On pourrait obtenir la cérosie par le grattage des tigges; on la traitcrait ensuite par l'alcool froid pour la priver de chlorophỵlle ; on la dissoudrait dans l'alcool bouillant, et on l'obtiendrait par la distillation de l'alcool. Ihais, comme cette substance est entraince, en grande partie, par le suc qui sort des cannes pendant leur expression, et qu'elle y reste suspendue on vient nager à sa surface, il est préférable de porter le verou à l'ébullition sans addition de chaux, afin d'ubtenir la cérosie mélangée à l'albumine et à la chlorophỵille sons forme d'écume. On lave cette écume à l'ean d'abord, puis a l'alcool froid, et on la traite entin par l'alcool houillant. Bien que, par ces procédés, on percle une grande partie de la cérosie qui existe sur les cannes, cependant 11. Arequin a calculé qu'un arpent de cannes, qui produit emviron 18,000 cannes, fournirait 36 kilogrammes de cérosie, el qu'une hulvitutiun cultirant par an 300 arpents de cannes, en produirait 10000 kilogrammes. Ce produit peut donc devenir très important pour le commerce.

La cérosic est insoluble dans l'eau et à froid dans l'alcool rectifié. 
Elle se dissout dans l'alcool bouillant et fe fait prendre en masse par le refroidissement. Elle est peu soluble dans l'éther; elle est très dure et peut se pulvériser dans un mortier; elle fond entre 8() et 82 degrés, brùle arec une belle flamme blanche et serait d'un emploi très avantageux dans la falnication des bongies. Eile est très difficilement saponifiable. II. Dumas l'a trourée formée de $\mathrm{C}^{48} I^{50} \mathrm{O}^{2}$, coupusition très remarquable qui lait entrer la cérosie daus la série des alconls, ainsi que le montre le tableau suivant :

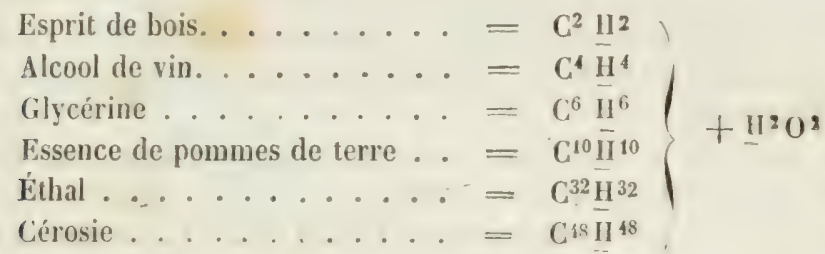

Fruits alimentaires de graminees.

Tous les fruits des plantes graminées peuvent être considérés comme alimentaires, il l'exception de celui de J'irraie, qui possède une qualité malfaisante; mais on ne cultive que ceux qui produisent le plus ou que lenr volume rend plus faciles à récolter; tels sont, dans prescue toutes les contrées du monde, le hé ou froment, l'épeautre, le seigle, l'orge', le riz, le maïs, l'aroine; et particulièrement à quelques paỵs, les millets, les sorghos, les éleusines, les poas, etc.

Fronext. Tritimen sutimu, Lamk., comprenant comme sousespèces les tritirum rpstivum, luybernum et turgirlum, de Linné. Tiges hautes de 100 a 130 centimètres, garnies de $/ 1$ ou 5 feuilles, et terminées par un épi long de 8 à 12 centimètres; ceux-ci sont composés de 15 à 24 épillets sessiles, ventrus, imbriqués, glabres ou velus selon les variétés; mutiques ou garnis de barbe. Chaque glume renferme ordinairenent 4 fleurs fertiles et une cinçuième imparfaite. Le fruit est un cariopse ovale, mousse par les deux bouts, conrexe d'un côté, creusé d'un sillon longitudinal de l'autre; le battage le privant de sa glume, il ne conserve que son tégument propre, mince, dur, transparent, qui, séparẻ de la farine par le blutoir, constitue le son.

La farine de froment contient sur 100 parties:

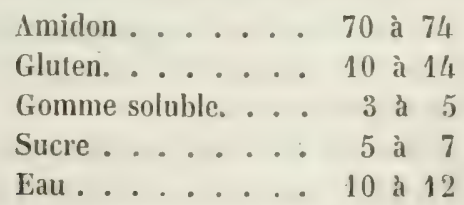


100 parties de froment ne fourninsent que $0,1.5$ de cendre composic principalcment de phosphates de soude, de chaux et de magnésie. Celte cendre ne renferme pas de sulfate ou n'en présente que des traces, ce qui permet de recomnaitre la farine pure de celle qui a été falsifice arec du sulfite de chanx.

Pour faire l'analyse de la farine de froment, on la met en pàte arec de l'eau, on la renferme dans uis nouet de linge et on la malaxe sous un filet d'eau. L'eau dissout la gomme et le sucre et entraîne l'amidon yqui se dépose au fond. La liqueur filtrée et concentrée fournit une petite quantité d'albumine coagulée que l’on sépare par le filtre. On érapore à siccitć et on traite par de l'alcool bouillant qui dissout le sucre; la gomme reste.

La partic de la farine qui reste dans le linge est sous forme d'une masse molle, trìs colląnte et élastique qui porte le nom de gluten; mais comme elle retient toujours une grande quantité d'amidon, il faut la retirer du linge et la malaxer ì nu sous un filet d'eau et au-dessus d'un tamis de soie, jusqu'i ce que l'cau cesse d'être laiteuse. La masse qui reste alors, et qui constitue le gluten dr Beccrizia, pèse sèche de 0, 10 ì 0,1/4 du poids de la farine. Cette substance a d'abord été considérée comme un principe immédiat particulier; mais Einhoff a montré qu'elle était formée au moins de deux principes azolés, dont l'un est de l'alfmemine végrétule naturellement soluble, mais qui reste unie au second principe par une adhérence moléculaire. Ce second principe, nommé glutine, est insoluble dans l'eau, soluble dans l'alcool bouillant et peut ètre obtenu par ce moyen. C"est à la présence de ces deux principes réunis que la farine de froment doit de former un pain très nourrissant et de facile digestion : nourrissant en raison de l'azote qu'ils contiennent; facile à digérer parce que le gluten communigue à la pâte une ténacité qui retient l'acide carbonique produit pendant la fermentation et la rend poreuse et légère. La farine de blé est donc d'autant plus estimée qu'elle fournit plus de gluten par le procédé qui vient d'être indiqué.

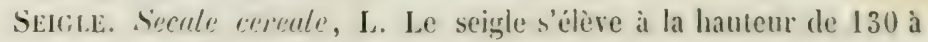
160) centimètres. Les fleurs sont disposées, an hant de la tige, en un épi simple, compriní, long de 11 it 15 centmètres; les ípillets sont composés de 2 lleurs hermaphrodites, arec un rudiment linéaire d'une troisieme fleur terminale. Le fruit est un cariopse long de 5 millimètres, poilu an sommet, d'une forme un peu conique, conrexe d'un côté, crensé de l'autre d'un sillon longitudinal, d'un jaune grisitre, à surface légèrement plissíe lorsqu'il est sec.

I.e seigle vient facilement dans des terrains nu be ble ne pourait rroitle arec arantingr, el il résiste mieux à la geclée, ce qui permet de 
le cultiver dans les pays du Nord; il mûrit ausai plus tôt. Il fournit une farine un peu bise, pourve d'une odeur et d'une savenr qui lui sont propres. Il forme un pain lourd, mais nutritif, d'mne saveur douceitre particulière, et qui se conserve frais pendant longtemps. On l'emploie ordinairement mêlé au froment, sous Ie nom de méteil. D'après Einhof, la farine de seigle contient :

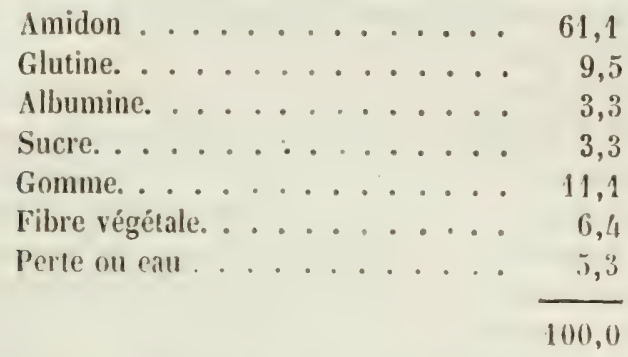

Ia farine de seigle ne peut être analyssée comme colle de froment; car si on veut la malaxer sous l'eat, dans un nouet de linge serré, rien II'en est séparé, et si l'on veut s'affranchir du linge, toute la farine se délaie dans l'eau et passe même, sauf quelques impuretés, ì travers un tamis de soie. Par le repos l'amidon se précipite, mais coloré et mélangé de glutine. Ia liqueur décantée et filtrée contient le restant de la glutine unie à la gomme, au sucre et à l'albumine. On la soumet à l'ébullition pour faire coaguler l'albumine; on la fait éraporer en consistance de sirop et on l'étend d'alcool qui dissout le sucre et la glutine. On ajoute de l'eau ct on distille pour retirer l'alcool : le sucre reste dissous et la glutine se sépare.

Orge. Hordeum vulgare, L. Tige droite, haute de 50 à 70 centimètres; fleurs en épi; épillets biflores, mais dont la tleur supérieure est réduite à l'état d'un rudiment subulé. Fleurs toutes hermaphirodites, imbriquées sur six rangs, dont deux plus proéminents. Glume à 3 écailles linéaires-lancéolées; glumelle à 2 paillettes persistantes, embrassant le fruit et dont l'extérienre est termince par une arc̀te très longue; dans une variété, nommée orge céleste, les paillettes s'écartent du grain qui s'en sépare avec facilité.

Autres espèces : orge à 6 rangs ( $H$. hexustichon) dont l'épi est conrt, renflé, à 6 rangs de fleurs égaux; orge distique (H. distichom), à épi comprimé, formé seulemont de 2 rangs de fleurs hermaphro lites pourvues d'arêtes.

L'orge, à cause de la nature particulière de son amidon, ne produit ron'un pain dur et indigeste : anssi est-il principalement ríservé pour la 
nourriture des animaux herbivores et pour la fabrication de l'orge mondé et perlé qui sont d'un usage assez fréquent en médecine.

Ces deux préparations de l'orge s'obtiennent de la même manière, en faisant passer le grain entre deux meules placées horizontalement à distance. Pour l'orge mondé, la distance est telle que le grain roulé entre les meules perd seulement sa glume et sa glumelle et conserve sont tégument propre. Pour l'orge perlé, un travail plus long et une distance diminuée graduellement font que l'orge se trouve réduit à sa partie blanche et farineuse.

La farine d'orge se conduit avec l'eau comme celle de seigle, c'est-àdire que si on la malaxe à l'état de pâte, dans un linge serré, rien ne passe au travers du linge, à cause de l'adhérence du gluten à l'amidon, et que si le linge est d'un tissu clair, presque tout passe au travers. Cependant, en opérant dans un linge médiocrement serré, Einhof a pu conserver dans le linge un résidu composé de fibre régétale, de glutine et d'amidon, 7,3 pour 100 , et la liqueur trouble a déposé 67 parties d'amidon recouvert de glutine. L'eau qui surnage retient en dissolution de l'albumine, du sucre, de la gomme, encore une certaine quantité de glutine. On les sépare ainsi qu’il a été dit pour le scigle. Cette anaIyse a fourni :

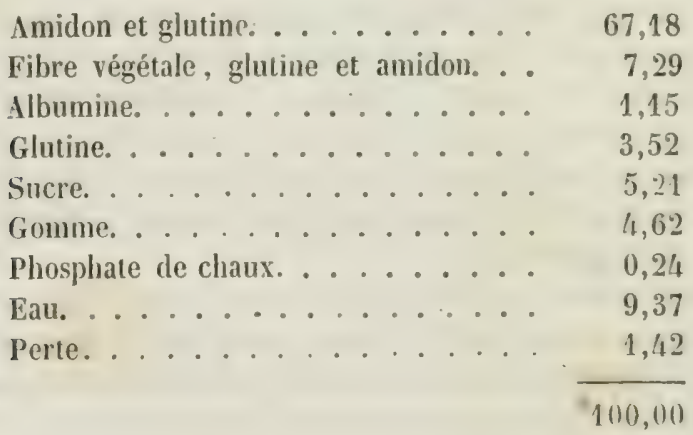

Avorne. Avenic sativa. Cette plante pousse plusieurs tiges hantes de 6 ì 10 décimètres, munies de 4 à 5 nouds d'où sortent des fenilles assez larges et aiguës. Les fleurs sont disposcies cn panicules lìches et réunies dans des épillets pédicellés et pendants. Charque épillet contient 3 fleurs pédonculées, dont la première cst seule fertile; la druxième, mal conformée, est stérile; la troisième est rudimentaire. I.es écailles de la glume sont courtes, mutiques, carénces; la paillette extérieure de la glumelle est pourvue d'une arête tortue. Le cariopse est presque 
cylindrique, aminci en pointe aux denx'bouts, adhérent à la paillente supérieure de la glumelle, et enveluppé dans la glume, dont on le sépare par le battage. L'avoine, ainsi obtenue, sert à la nourriture des cheraux et des animaux de basse cour; on l'emploie aussi pour la nourriture de l'homme et pour en faire des tisanes adoucissantes et nourrissantes, mais après l'avoir préparée sous des meules, à la manière de l'orge perlé. Sous cet état, on lui donne le nom de gruan; mais ce n'est pas elle qui sert à la fabrication du pain de luxe auquel on donne le nom de perin de grumu. Celui-ci se prépare arec la plus belle et la plus fine farine de froment.

La farine d'aroine dépouillée de ses enveloppes, ou la farine de gruau, présente quelques particularités dans sa composition. Elle contient 2 centièmes d'une huile grasse, jaune verditre et odorante a laquelle le gruau doit sá sareur particulière et sa demi-tránsparence. On y trouve ensuite 8,25 d'un extrait amer, sucré et déliquescent qui est cause que l'avoine renferme de 20 à 24 pour 100 d'eau, tandis que les antres céréales n'en contiennent guère que la moitié. lille contient enfin 2,5 de gomme, 4,3 d'albumine et 59 d'amidon.

Ruz. Oriza sutic\%. Le riz est originaire de l'Inde et de la chine, oì il occupe de vastes terrains inondés, et où il sert, de toute antiquité, à la nourriture des habitants. Il était peu connu en Europe du temps de Dioscoride et de Pline. Ce n'est que plus tard que la culture s'en est répandue en Égyte, en Italie, c'n Espagne et en Amérique. On a vonlı à plusieurs fois en introduire la culture dans le midi de la France; mais comme on ne peut le placer cue dans des terrains marécageux qui exercent une influence très délétere sur la santé des habitants, il a failu y renoncer. Le riz pousse plusieurs tiges hautes de 100 à $130 \mathrm{con-}$ timètres, munies de feuilles larges, fermes, très longues, semblable's à colles de nos roseaux. Les fleurs forment une longue et belle panicule terminale, composée d'épillets courtement pédicellés et uniflores. Les fleurs sont hermaphrodites, à 6 étamines, et appartiennent à l'hexandrie de I.inné. Le fruit est un cariopse comprimé, étroitement serré dans les pailles de la glumelle. On le trouve dans le commerce privé de toutes ses enreloppes et même de son tégument propre. Celui que l'on consomme en France vient principalement de la Caroline et du Piémont. I.c premier est le plus estimé ; il est tout à fait blanc, transparent, anguleux, allongé, sans odeur, et a une sareur farineuse franche. Te sccond est jaunâtre, moins allongé, arrondi, opaque, a une légère odeur qui lui est propre, et une saveur un peu âcre. Tous deux sont fort nourrissants, et donnent du ton aux intestins.

On doit à I. Braconnot une excellente analyse du riz, dont voici les résultats : 
Eau.

Amidon .

Parenchyme.

4,80

Matière azotée.

3,60

Sucre incristallisable. . . . . . .

0,29 .

0,05

Matière gommeuse. . . . . . .

1,71

0,10

Huile.

0,13

0,25

Phosphate de chaux. . . . ....

0,40

0,40

Chlorure de potassium. . . . . . .

Phosphate de potasse. . . . . . .

Acide acélique. . . . . . . . .

Siel régétal calcaire.

0,00
0,00
0,00
0,00
0,00
11,00

10,00

, 00

0,00

indires,

$\mid \begin{aligned} & 0,00 \\ & 0,00\end{aligned}$

$\int_{0,00}^{0,110}$

Sollfie.

à base de potasse . . . . .

(Ann. de chim. et de pluys., t. IV, p. 370).

Hais. Zen mais, I.; monocie triandrie. Cetle belle gramince parait originaire de l'Amérique; mais elle s'est bien acclimatéc dans les contrées chaudes et tempérées de l'ancien continent. On en cultire beaucoup en France, où elle porte vulgairement le nom de blé dr. Turquie. Elle s'élève à la hauteur de 2 mètres et plus. Sa tige cst roide, noueuse, remplie d'une moelle sucrée; ses feuilles sont très longues, larges, semblables à celles du roseau. Les fleurs mâles sont disposées ('n une panicule terminale composée d'épillets biflores, à flurs sessiles, uriandres. Les fleurs femelles naissent au-dessous et sont enreloppées de plusieurs feuilles roulées, d'où pendent les styles sous formt d'un faiscrau de soie verte; l’épi, rui succèle il ces fleurs, croit par degré jusfu’'i une gro sseur considérable; les grains sessiles dont il est entièrement recourert, sont gros comme des pois, lisses, arroudis it l'everiem, lerminés en pointe à la parlic qui tient à l'axe. Ils sont le plus sourent jatunes, mais quelquefois rouges, violels ou blancs, suivan les rariélés.

Le mais est après le froment ed le riz la plus mile des gramines; aussi est-elle une des plus généralement cultivées. C ne partie des periples d'Asie, d'Afrique el d'Amérique en font lenr nomriture. Son usage? est égalenent tres répandu en Jalie, en lispagne et dans le midi de la France, non senlement pour l'homme, mais principalement pour fos bestiaus et volatiles de tomles sortes, qu'il engaisse promplentent. II est composi de: 


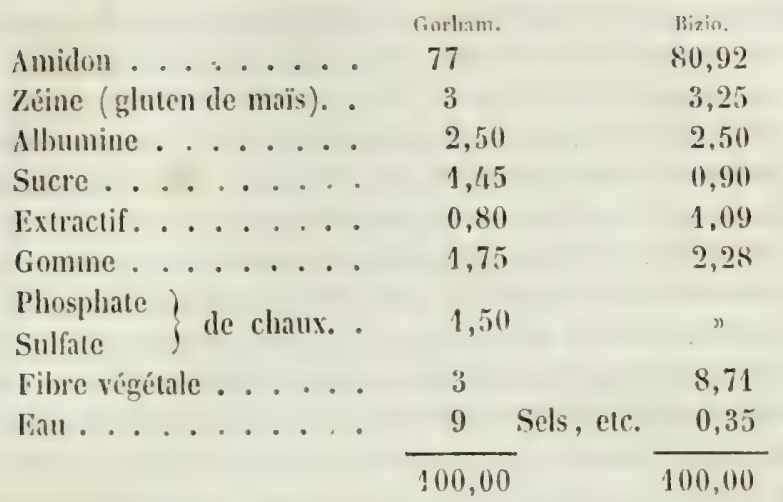

Le gluten de maïs parait diflérer de celui des antres graminés par une moindre proportion d'azote; sa faible quantité empeceche d'aillents que la farine de maïs soit propre à la fabrication du pain, à moins qu'ou n'y ajoute un tiers an moins de farine de froment. Mais on en fait des bouillies et des espèces de gàieaux qu'on prépare de beaucoup de manières différentes, suivant les paṣs, et qui forment un aliment sain ot nourrissant.

\section{Sur l'amidon (1).}

Pendant longtemps l'amidon a été considéré comme un produit inorganisé, ou comme un principe immédiat analogue au sucre ou à la gomme, mais complétement insoluble dans l'eau froide, et soluble, au contraire, dans l'eau bouillante, arec laguelle il était susceptible de former, par le refroidissement, une masse gélatineuse. Cependant, dès l'année 1716 , Lcenwenhoeck avait déterminé, à l'aide du microscope. gue l'amidon était un corps organisé, de forme globuleuse, et formé d'une enveloppe extérienre, résistant ì l'eau et quelquefois anx forces digestives des animaux, ct d'une manière intérieure facilement soluble dans l'eau et très facile à digérer; mais ces observations étaient complétement oubliées lorsíue, en 182.5, .1. Raspail (2) annonça de nourean

(1) Dans le langyage chimique, les mots amidon, fécule, fécule amylarée, peuvent étre considérés comme synonymes; dans les usages économiques, on donne plus spécialement le nom d'amidon à la fécule des graines céréales, et relui de fécule à celle retirée d'autres parties des plantes, et principalement des racines. II m’arrivera souvent de me servir indifféremment de ces deux. expressions.

(2) Vogez l'ourrage de M. Raspail, Nouveau système de chimie organique, 2: édition, Paris, 1838, I. I, 1. 129. 
que chaque grannle d'anidon est un conpes oreanisé forme d'une enve. ioppe ou tégument inallaquable par l'ean froide, succeptible d'une: coloration durable par l'iode, et d'une matière intérieure soluble daus l'eau froide, pourant également s. colorer en blen par l'iode, mais perdant facilement cette propriété par l'action de la chaleur on de l'air ; d’où .1. Raspail concluait que la propriété prosséclée par la fécule de se colorer en bleu par l'iode, était due à une substance volatile.

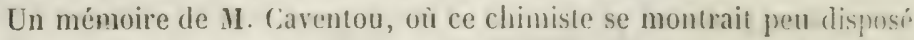
à admettre les résultats obtenus par .I. Raspail, m’ayant engage ì m’occuper de ce sujet, je fis un certain nombre d'expériences (qui, tnut (nì conlirmant l'organisation des grains de fécule, démentait prescyue tonles les autres assertions de .11. Raspail. Ainsi, tandis que la fécule de pomme de terre entière, examinée sons l'eau, au microscope, se prósente sous forme de grains transparents, tous finis et d'une épai-seur évidente, la fécule broyée, mise dans l'ean, y forme de's contants d'une vitesse extrême, dus à l'émission et à la dissolution de la matiơre soluble intérienre des grains déchirés. Une partie de cefte matione disparaît entièrement; une antre reste allachée aux grains sons f. rue de gelée, et disparaît aussi par l'application d'une légère chaleur. Alorson

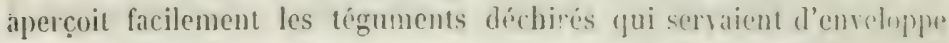
aux grains de fécule.

Hais, excepté cette expérience qui contirmait l'itat orquisisi des grains de fécule, toutes les antres tendaient a pronver (pur les truis parties observées, à savoir, le térgument, la mutirere yrilutinifurme ct la matiere soluble, ne sont qu'une senle? ('i meme substance gni st comporte de même avec l'iode, les acides, les alcalis, ha innix de gall!:" les dissolutions métalliques, et que ces trois parties ne liflerent ynu par la forme que l'organisation leur a donncéc. Telle est la conchnsion positive de mon mémoire, à lapuelle je suis arrivé par plusicurs ordres dr considérations qui ont été confirmées depuis. (Yoir Jommul de chimin médicale de 1829 , t. V, p. 97 et 158.)

H. Guérin-Varry, cependint, après aroir distingué comme moi trois parties dans l'anidon, a regardé ces trois parties comme trois malieres distunctes et de composition élémentaire differente; mais ces resultats

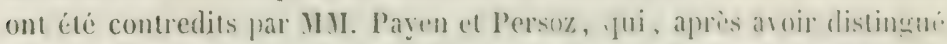
trois principes différents dans la senle matière soluble, ont ensuite aulunis que, à part un tégument excessivement minee, nom colorable prar l'iode,

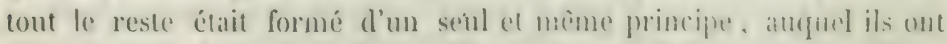

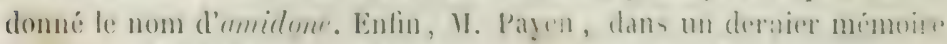

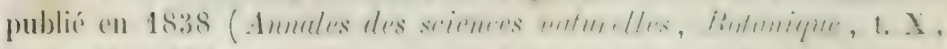

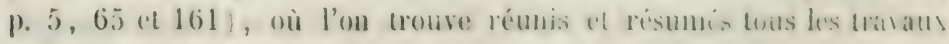
entrepris sur l'amidon, "y dont une grande partie lui appartiont, a deli- 
nitivement fixé l'opinion des chimistes sur la constitution de l'amidon, en le regardant comme une substance organisée, mais d'une seule nature et d'une composition constante, qui peut être représentée par $\mathrm{C}^{12} 1 \mathrm{II}^{10} \mathrm{O}^{10}$; composition proportionnell ment semblable à celle de la cellulose, de la gomme arabique et du sucre anhydre. Cette conclusion, moins la composition élémentaire dont je ne m'élais pas occupé, est bien celle que j'arais émise en 1829 ; mais il existe cependant une différence essentielle entre nos résultats. J'avais admis que la fécule de pommes de terre était formée d'une substance tégumentaire insoluble ct d'une matière intérieure soluble, toutes deux colorables par l'iode; II. Payen pense aujourd'hui que cette fécule est organisée et solide jus(ju'au centre, et ne contient aucune partie soluble à froid. Je me fondais, pour établir mon opinion, sur ce que la fécule broyée, non pas sculement à sec, mais sous l'eau, afin d'éviter l'échauffement causé par le frottement, se dissolvait en partie dans l'eau, et ce résultat ne peut itre réroqué en doute; mais .I. l'ayen, pensant tonjours que la fécule peut éprouver quelque modification moléculaire par le frottement, s'est borné à l'écraser en la pressant entre deux lames de verre, et c'est alors qu'il a ru, ainsi que je viens de le dire, que la fécule était solide et organisée jusqu'au centre, et qu'elle ne cédait à l'eau froide ancune partie soluble qui fùt colorable par l'iode. Je riens de vérifier l'exactitude de ce fait, d'où il parât résulter que, dans mon ancienne expérience, le broiement sous l'eau arait suffi pour altérer la constilution moliculaire de la fécule, au point d'en rendre une partie soluble. Je pense également, arec M. Pạ̣en, que la fécule est organisée jusqu'au centre, mais je dis toujours, en tant qu'il s'agit de la fécule de pomne de terre, qu'il existe une grande différence entre l'organisation forte et compacte de la partie extéricure, que j'ai rue se présenter sonrent sous la forme d'une outre en partie lacérée et vide à l'intérieur, et l'organisation de la partie centrale, qui se sépare de la première et se dirise dans l'eau, sous la forme de flocons colorables par l'inde. Il existe, d'ailleurs, ainsi que je me stiss efforcé de le démontrer dans le mémoire précité, de grandes diflérences dans l'organisation intérieure des diverses fécules, leşuelles, jointes à celles qui résultent de leur forme et de leur volume, déterminées au moyen du microscope, penvent très bien servir à les distinguer.

AMIDOY DE BLÉ (fig. 73). Globules circulaires et d'un volume très variable: les plus petits, vus sous l'eau, au microscope, paraissent comme des points transparents, et on peut en suive l'accroissement jusçu'aux plus gros; cependant les globules intermédiaires sont peu nombreux et on observe une discontinuité bien marquée entre les petits grains qui sont presque innombrables, et les plus gros qui arrivent sen- 
siblement au même volume, estimé à 50 millièmes de millimètres. A voir res granules en repos et presque tous bien circulaires, on les dirait sphériques; mais en faisant glisser le verre supérieur du porte-objet sur l'inférieur, on fait rouler les granules au milieu de l'eau, et on s'apercoit alors qu'ils sont aplatis et lenticulaires (royez fig. 73, Ictre a, (qui représente un granule d'amidon vu de champ).

L'amidon de blé, vu en masse, est d'un blanc mat et parfait. Il com-

Fig. 73.

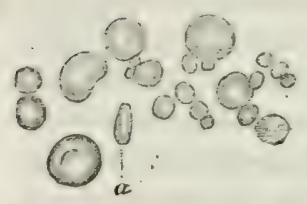
munique à l'eau, à l'aide de la chaleur, une consistance d'autant plus forte que ses granules ont un plus petit rolume et contiennent plus de matière tégumentaire et moins de matière véritablement soluble, et parce que la consistance de l'empois est due surtout à l'adhérence réciprofque des téguments gonflés et hydratés.

L'amidon de blé, soumis à l'ébullition dans une grande qunantité d'eau, ne forme plus d'empois, parce que le tégument finit par se dissoudre presque entièrement et constitue alors de la fécule soluble. Cep̧endant, si longtemps qu'on continue l'ébullition, il reste toujours un résidu insoluble, sous forme de flocons lígers et irréguliers, qui se colorent en violet par l'iode.

Pour l'usage des arts, on extrait en grand l'anidon des recoupettes ct gruaux de blé, des blés arariés, et quelquefois de l'orge. Voici ì peu près le procédé que l'on suit : on moud le blé grossièrement, on le met dans un tonneau avec de l'eau, et on entretient l'air enviromnant à une température de 15 à 1 s degrés, afin de déterminer la fermentation du mélange. Au bout de quinze ou ringt jours, on jette le tout sur un tamis de fer' l'eau passe avec l'amidon et une certaine quantití de son et de gluten altéré; on la laisse reposer : l'amidon, qui c'st le plus dense, se précipite le premier; le son et le gluten forment au-dessus une bonillie qu'on enlève avec une pelle, apprès avoir décanté l'ean qui la surnage. Cette eau, qui porte le nom d'eau sîre, est employie en place d'eau pure dans les opérations subséquentes, et alors la fermentation s'y développe beaucoup plus promptement. On délaie l'anidon daus de l'ean pure, et on le fait passer à travers un tamis de soic très fun; on le laisse précipiter de noureau, on décante l'eau, et on le fait sécher le plus promptement possible.

On remarque que la pâte d'amidon se divise toujours, en séchant, en especes de prismes ifuadrangulaires, irréguliers, mais semblables entre eux, et gut ost fait domner il l'anidon contier le nom d'unidun en aiguilles.

Le but de la fermentation que l'on fait subir au blé est d'en clésor-

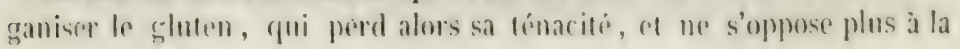


freciputation isolie de l'anidon. L'amidon sett en phatrmacie pour rouler ugueligues pilules, et pour saupoudrer la table sur lacpuelle on coule la pâte de guimauve.

On l'emploie aussi en larement, fréfuemment et arec succès, contre la diarrhée et la dyssenterie. .

AMIDON DE SEIGLE (fig. 74). Granules circulaires et lenticulaires ofliant les mèmes variations de volume que ceux du blé. Cependant les phus gros grains paraissent avoir un volume un peu plus considerable que ceux qui leur correspondent dans le blé, et de plus ils sont tiès souvent marqqués an centre d'une étoile noire à 3 ou 4 rayons. Cet

Fig. 74.

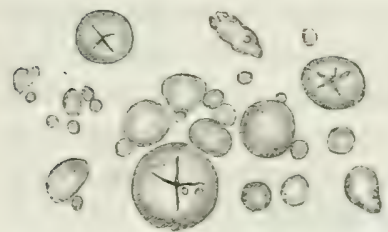

Fig. 7ว้.

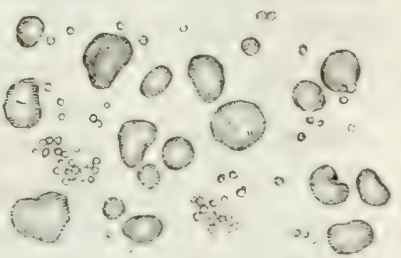

amidon, bouilli plusieurs fois dans l'eau distillée, laisse un résidu bicn plus considérable que celui de blé, plus dense, colorable en bleu par l'iode, offrant assez souvent la forme d'un fer à cheval, mais plus souvent encore celui de granules disposés assez régulièrement autour d'un centre commun, de sorte qu'on peut supposer que l'amidon de seigle lui-même est formé de granules semblables réunis et soudés par une matière plus attaquable par l'eau et qui disparait en partie par l'ébullition.

AMIdDon D'ORGE (fig. 75). De même que les deux précédents, cet amidon se compose d'un nombre très considérable de petits granules transparents, de granules intermédiaires et d'un grand nombre de granules circulaires qui atteignent sensiblement le même volume. Voici maintenant les différences : le diamètre des plus gros granules est manifestement plus grand que dans l'amidon de blé; l'épaisseur en est plus considérable et inégale; la coupe des granules passant par leurs plus grands diamètres, ne formerait pas une surface plane, mais ondulée; en un mot, ces granules, au lieu d'aroir la forme régulière d'une lentille, ont la forme bosselée et ondulée d'une semence de nandirobe. Il résulte de cette forme irrégulière jointe à une plus grande épaisseur, que l'amidon d'orge roule plus facilement dans l'eau que ccux du blé et du seigle; qu'il peut se reposer plus somrent sur la tranche et qu'il office assez souvent la forme irrégulière et comme triangulaire de la fécule de pommes de terre; mais son volume est bicn moindre. L'amidon 
d'orge diffère encore de celui du blé en ce qu'il est bien plus fortement organisé et qu'il résiste bien plus à l'action de l'eau bouillante : tandis que l'amidon de blé, après une ébullition prolongée, ne laisse pour résidu qu'un léger flocon colorable en violet par l’inde; dans les mêmes circonstances, l'amidon d'orge laisse un résidu dense et pesant, nettement dessiné 'n demi-lune, en reein ou en cercle coupé jusqun'an centre et entr'vurert. Ce résidu se colore en bleu foncé par l'iode. En renouvelant l'ébullition, une partie des téguments se déforme et se léchire; mais si longtemps qu'on la continue, le plus grand nombre conserve la forme d'un cercle ouvert ou d'un rein. Cette grande résistance des granules de l'amidon de l'orge à l'action de l'eau bouillante expligue la difficulté qu'ont les estomacs faibles à le diģérer. Pronst attribuait celte qualité indigeste de l'orge à un principe analogue au ligneux, qu'il

Fig. 76.
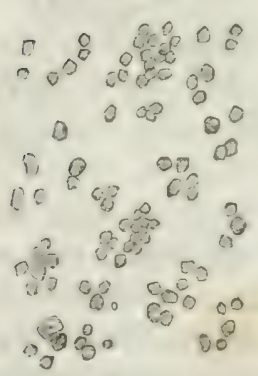
nommait homdéine, et dont il supposait que l'orge contenait 0,55 de son poids; mais j'ai montré que cette hordéine était principalement composée des téguments insolubles de l'amidon de l'orge (Jom'n. de chim. méd., t. V, p. 158).

durdox DE Riz (fig. 76). Cet amidon est remarquable par sa petitesse, par l'égalité de son rolume et par sa forme triangulaire ou carrée très marquée. Soumis à une longue ébullition dans l'eau, il laisse pour résidu de légers flocons formés de granules très minimes colorés en bleu par l'iode et liés entre eux par une matière muquense. L'amidon de riz paraìt donc être lui-même un assemblage de ces granules.

\section{Falsification de la farine de ble.}

Dans les temps de disette et mêne dans les circonstances ordinaires, la farine de blé est sujette à être falsifiée arec celle du seiggle, de l'orge, des pois, des haricots, etc., et, ce rui est beaucoup plus blimable, arec du plâtre, de la craie, de l'argile blanche. Je vais indiquer brièvement les moyens de reconnaître ces différentes filsifications.

Mel ange de la farine du blé aree celle du seigle ou de l'or'y". Ce mélange peut être connu au microscope par l'examen attentif de lit forrine délayée et étendue dans l'eau, en raison des caractères pluysiques différents des amidons contenus dans les farines. On le reconnaitra encore mieux après une longue ćbullition dans l'eau au moỵen des résidus laissés par les amidons de seigle ou d'orge.

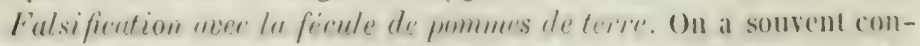
seille de recomaitre cette falsilieation en déterminant la quantite de 


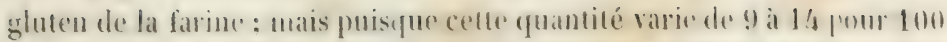
dans la farine normale, suivant sa qualité, il est évident que ent essai ne presente aucune certitude. L'examen microscopique est préférable. Lin effet, la fúcule de prommes de terre ( fig. 77 j présente toutes sortes de formes, depuis la sphéripue qui appartient aux plus petits, jusqu'a l'elliptique, l'ovoïde ou la triangulaire arrondie qui se montrent dans tous les antres. Les petits granules sont d'ailleurs peu nombreux et presque aussi volumineux que les gros grains d'amidon de blé. Les autres présentent souvent une surface bosselée et des stries irrégulièrement concentriques autour d'un point noir (hile) situé vers l'une des extrémités du grain. Enfin ces granules ovoïles ou triangulaires arron-

Nig. 77 .

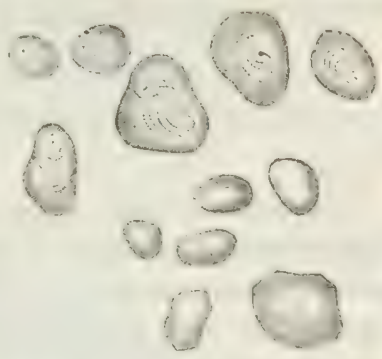
dis, (qui forment la presque totalité de la fécule, ont un diamère de 1,50 à 180 millièmes de millinithe et présentent, sur le champ du microscope, une surface au moins neuf fois plus grande que celle des gros granules d'anidon de blé. Il est done facile de distinguer au microscope de la farine de be pure de celle qui est mélangée de fécule.

Cerpendant 1. Donny, en meltant à profit l'action différente de la polasse sur l'amidon de blé et la fécule de pommes de terre, a rendu le mélange encore plus facile à saisir. En effet, les deux fécules se dissolvent également et disparaissent dans une solution de potasse caustique faite au dixième; mais si on prépare me solution au cinquantième ou au soixantième (1,75 de potasse pure pour 100 d'eau), cette liqueur n'aggira pas sensiblement sur l'amidon de froment, tandis que la fécule de pommes de terre acquerra un colume qui triplera au moins son diametre; alors il n'y aura plus moyen de la confondre avec les grains anylacés de la farine.

Furines de légumineuses. Ces farines sont généralement pourvues d'une couleur et d'une saveır qui rend leur mélange facile à reconnaitre. De plus eiles contiemnent toujours des fragments de tissu cellulaire hexagonal, qu'il est facile de distinguer au microscope après avoir dissout l'anidon an moven d'une solution de potasse au dixième. Eufin H. Donny a décourert dans les farines de resce et de fèrerole un caractère qui les fait reconnaìtre facilement, et qui consiste dans une belle coloration rouge que prend la farine de ces deux légumineuses lor's¿qu'on l'expose à la rapeur de l'ammoniaque, après l'avoir tenue suffisamment exposée à celle de l'acide nitrique. (Voir les Bulletins de le Suciété d'encouragement de 1847 , rapport de 11. Bussy.) 


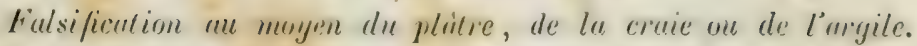
Celte folsification peut être reconnue en traitant la farine par une solıtion de potasse au dixième qui la dissout presque complétement en laissant la substance minérale dont il est facile ensuite de déterminer la nature.

On peut également brûler et incinérer la farine qui, dans son état normal, fournit à peine un centiène de cendre. La quantité de matière lixe et sa nature constatent la falsification.

\section{FAMILLE DES PALMIIESS.}

Les palmiers sont, en général, des arbres à tige élancée, simple et cylindrique, couronnée au sommet par une touffe de fenilles dont les plus inférieures se détruisent chaque année en lajssant sur le tronce les restiges de leur pétiole embrassant, et sont remplacées par celles qui sortcut du bourgeon terminal. Les fleurs sortent de l'aisselle des feuilles, enveloppées d'une spathe ligneuse et portées sur un spadice ramifié. lilles peurent être hermaphrodites, polygames, monö̈ques ou dioïques. Leur périanthe se compose de 2 verticilles de folioles coriaces dont les .3 intéricures n'ont pas toujours lat mème forme que les 3 extórieures et se soudent (quelquefois entre elles. Les étamines sont au nombre de 6 , rarement réduites à 3 et plus larement encore plus nombreuses que 6 . Le pistil est formé de 3 oraires distincts ou soudés, renfermant chacun 1 orule dressé. Le fruit se compose de 3 baies ou de 3 drupes séparés pourant se réduire à 2 ou à 1 par arortement, ou bien d'une seule baie ou d’un seul drupe à 3 loges, pouvant également se réduire à 2 ou à une seule loge par l'arortement des autres. La graine est pourrue d'un périsperme épais, souvent très lur, creusé sur un point de sa surface d'une cavité qui renferme l'embryon.

A l'exception du chamerops humilis, palmier presque privé de tige, qui vient spontanément dans le midi de l'Europe, mais où ses fruits unùrissent à peine, tous les autres palmiers croissent entre les tropiques. Ils remplacent, pour les peuples de ces contrées brùlées par le soleil, le blé, la vigne ct l'olivier des zones tempérées. En cffet, dans la plupart des espèces (sagouiers, dattiers), la tige renferme une fécule abondante propre à faire du pain; d'autres (arenga succhurifera, phumix, areere) fournissent un liqquide sucré que l'on convertit en vin par la fermentation. Les cocos eux-mèmes, asant leur maturité, sont remplis d'un suc laiteux et rafraichissant, et lorsqu'ils sont mùrs, ils servent, ainsi que les dattes, à la nourriture de la plupart des peuples des pays chatuls. Entin, le péricarpe de l'aroira de Guinée, comme pour le disputer en 
tout à l'olisier, fournit aux usages domestiques et and arts une huile très abondante.

Yous examinerons successirement la plupart de ces produits.

\section{Dattes et Dattier.}

Phenix dactylifera (fig. 7\$). On troure cet arlore dans l'Inde, dans la Perse et surtout en Afrique, dans le Biledulgérid (Belidel l) jeryd ou pays des dattes), vaste contrée au sud de l'Allas et de l'Algétie, qui s'étend du royaume de Maroc à la régence de Tunis. Il s'élève à la hauterr de 16 à 20 mètres. Sa lige est nue, cylindrique et formée d'un bois assez

Fig. 78.

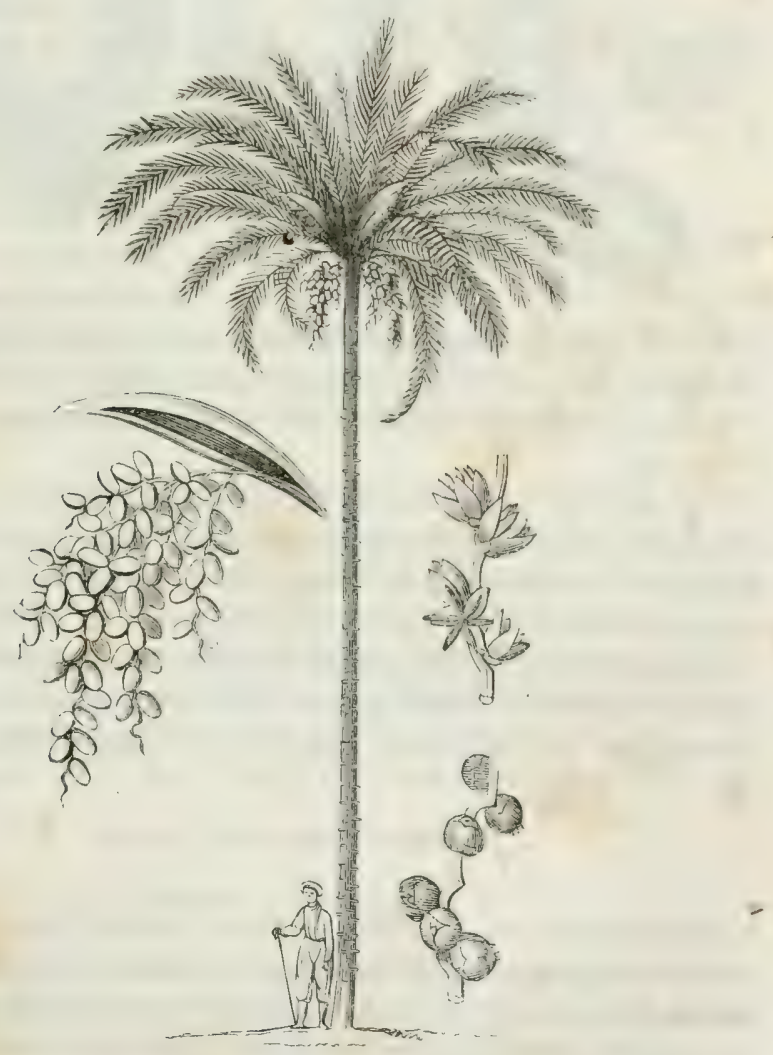

dur à l'extérieur, à fibres rougeàtres el longitudinales, qui est emploỵé comme bois de construction. Sille est marquée à l'extéricur d'anneaux très rapprochés et d'écailles provenant des feuilles tombées. Celles-ci 
sont très urandes, composées de leur pétiole garni sur toute sa longunim de folioles aiguës, disposcées sur deux rangs, comme les barbes d'une plume. De l'aisselle des feuilles sortent des spathes fort longues, d'une seule pièce, un peu comprimées, s'ourrant sur leur longueur pour domer passage ì une ample panicule ou rógime, composée de rameanx très nombreux, flechis en zigr-hag, pourvus de fleurs males ou femelles, selon les individus; car l'arbre est dioïque. Les fleur's nâles ont un périanthe à 6 divisions dont 3 externes et 3 internes, et 6 étamines. Les fleurs femelles contiement trois stigmates distincts et doment naisance a trois fruits (fig. 79), urais dont 1 ou 2 arortent le plus souvent. Chacun

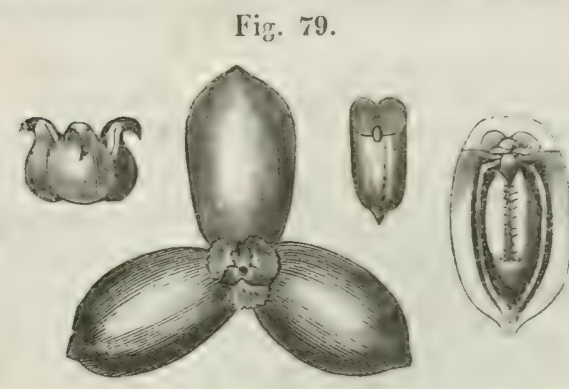
de ces fruits est une baie supère, de forme elliptique, longue et grosse comme le pouce environ; leur épiderme est mince, rouge-jaunâtre et recouvre une chair solide, d'un goût vineux, sucré et un peu visqueux. Cette chair renferme une semence composée d'un épisperme membraneux, lìche, blanc et soỵeux, et d'un périsperme très dur, osseux, oblong, profondément sillonné d'un còté et portant sur le milieu du côté conrexe une petite cavité qui renferme l'embryon.

C'est de l'Afrique et par la voie de Tunis que nous viennent les meilleures dattes. Il faut les choisir récentes, fermes, demi-mansparentes el exemptes de mites. On les conserve bien daus un entroit sec et dans un bocal de verre fermé par un simple papier.

On apporte aussi de Salé, port du royaume de Fez, des dattes qui sont blanchâtres, petites, sèches, peu sucrées et peu estimées. Il en rient en Provence qui sont fort belles, mais qui ne se conserrent pas.

\section{- Semence ou Koix d'Irec (fig. 80).}

Celle semence est produite par l'mern interlue, grand palmier de l'Inde, de Ceylan et des îles. Holuques. Le trone de cet arbre est parfaitement droit, haut de 13 a $1 / 4$ mètres et comronme par 100 12 12 feuilles longues de 5 mètres, composées clacune d'un gros pétiole engaînant à la base, et de deux rangs de larges folinles plissées en éremail. I.es régimes ou les panicules sont au dessous des fenilles, et ordinairement au nombre de trois ; l'un, supérieur, est compuse de fleurs mâles et femclles 
entourées d'une double spathe; le second porte des fruits verts, et le dernier des fruits mûr's.

Ces fruits sont d'un jaune doré, gros comme un œuf de poule, et renferment sons un bron fibreux une amande arrondie, oroïde ou conique, suivant les variétés, marbrée à l'intériem de blanc et de brun, à

Fig. 80 .
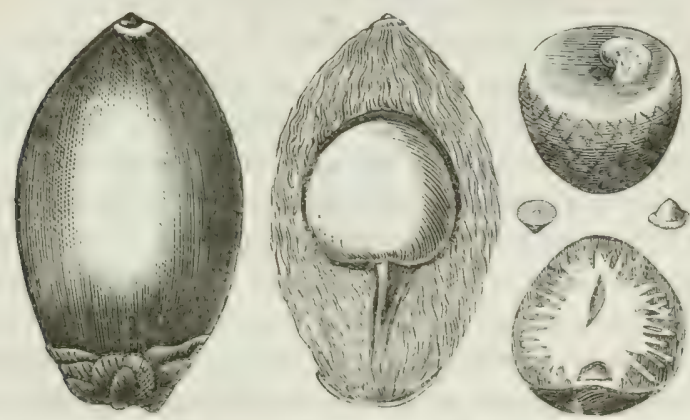

peüprès comme la noix muscade, mais très dure, cornée et inodore Cette auande, coupée par tranches, saupondrée de chaux et enfermée dans une feuille de poivre bitel, forme un masticatoire dont l'usage est répandu chez tous les peuples de l'Inde, des îles de la Sonde et des îles Moluques.

I. Morin (de Rouen) a fait l'analyse de l'amande de l'aree et en a retiré du tannin principalement, de l'acide gallique, de la glutine, une matière rouge insoluble, de l'huile grasse, de la gomme, de l'oxalate de chaux, du ligneux, etc. (Journal de pharm., t. vilr. p. 449.)

La noix d'arec sert à préparer, dans les provinces méridionales de l'Inde et à Ceylan, un cachou très estimé, qui porte le nom de Coury, et un autre d'une qualité inférieure, nommé Cassu; je me réserve de les décrire en traitant du cachou pröluit par l'acaria catechu, famille des Légumineuses.

\section{Cocotier et IItile de coco.}

Cocos mucifer $u$. Ce palmier habite le voisinage des mers sous les tropiques et à peu près par toute la terre. Sans lui, les îles du grand océan Pacifique seraient inhabitables, et les peuples répandus sur l'immensité des plages équatoriales périraient de faim et de soif, et manqueraient de cabanes et de vêtements; car cet arbre leur fournit du vin, du vinaigre, de l'huile, du sucre, du lait, de la crême, des cordages, de la toile, des 
vases, du bois de construction, des couvertures de cabanes, etc. C'est donc à bon droil qu'on l'a nommé le lioi des végétnux.

Les racines du cocotier sont peu profondes et touffues; la tige, qui u'a pas plus de 4 à 5 décim. de diamètre, s'élève comme une colonne jusqu’à une hauteur de 20 à 30 mètres, et se termine par une touffe de 12 à 15 feuilles ailées, longues de 5 à 6 mètres. Les spathes, qui snrtent de l'aissclle des feuilles inférieures, domnent naissance à des spadices rameux couverts de fleurs mâles et femelles : les premières à six élanines avec un rudiment d'oraire; les secondes, pourrnes d'un oraire à trois loges dont deux rudimentaires et une seule fertile. Le fruit est un drupe orale ou clliptique et trigone, pouvant arvir le rolume de la tète, formé d'un mésocarpe fibreux, recouvrant un endocarpe osseux, percé de trois trois à la base, et renfermant une amande vide à l'intérieur, creusée vers la base d'une cavité qui renferme l'embryon. Lorsque ce fruit a atteint sa grosseur, mais avant que l'amande ne soit formée, on le trouve rempli d'un liquide blanc, doux, sucré, un peu aigrelet et très rafraîchissant. L'amande, une fois mûre, se mange et sert de nourriture la plus ordinaire aux naturels de la Polynésie. On en retire par expression près de la moitié de son poids d'une huile incolore, presque aussi fluide et aussi limpide que de l'eau, à la température habituelle des tropiques; mais se solidifiant entre 18 el 16 degrés centigrades, ce qui est cause que nous la voyons souvent blanche, opaque et solide. Cette huile récente sert à la préparation des aliments; mais clle rancit très facilement et n'est plus alors appliqueée qu'à l'éclairage. Fille forme, arec la soude, un savon sec, cassant, moussint extraordinairement arec l'eau, et ne pouvant guère être employé que mélangé arec d’autres sarons plus mous et plus onctueux. Le saron de coco, décomposé par un acide, fournit un acide gras particulier, nommé acide coecinigue, fusible à 35 degrés, pouvant être distillé saus altération. D’ạprès M. Broméis, il a pour composition :

$$
\mathrm{C}^{27}{ }^{1127} \mathrm{O}^{4}=\mathrm{C}^{27} 1126 \mathrm{O}^{3}+110 .
$$

\section{Palmier avoira el Huile te palme.}

İlu'is yuimeensis. Grand palmier, cultivé également dans la Guinée, en Afrique, el dans la Guyane, en Amérique, où il porte le nom d'uoun're ou arvira. Les fenilles sont pimnées, à pétioles épineux qui persistent sur la tige. Les fleurs males et femelles sont síparies sur des régimes différents, munis d'une double spathe : le calice et la corolle sont à 3 divisions; les étamines sont an nombre de 6 , et l'ovaire est à 3 stygmates et a 3 loges dont denx sont oblitérées. le fruit est un drupe de la grosseur d'une noix el d'un jaune doré, forme d'un sarcocarpe fibreus et 
luilenx, ef d'un noyau très dur gni renferme ume amande grasse of solide. Ce fruit contient donc deux huiles différentes et yui sont extraites séparément. L'huile du sarcocarpe est jame, odorante, toujours liquide. en Afrique ou à la Guyane, ce qui fait qu'on lui donne le nom d'huile de pulme, et qu'on l'emploie à tous les usages de l'huile; landis que celle qu'on tire de l'amande est blanche, solide et sert aux mème's usages que le beurre. Cette dernière, beaucoup moins abondante que l'autre, ne vient pas en Europe; mais la première est aujourd'hui importée en quantité très considérable en . Ingleterre et en France, où elle sert surtout it la fabrication des savons.

L'hnile de palme, telle que le commerce nous la fournit, est solide, de la consistance du beture et d'un jaune orangé. Elle présente une sareur douce et parfumée, et une odeur d'iris; elle fond à 29 degrés et e'st alors très fluide et d'une couleur orangée funcée ; clle ne cède rion à l'eau froide ou bouillante; elle se dissout à froid dans l'alcool a lo) degrés; elle s'y dissout beaucoup plus ì chand et se précipite en partie par le refroidis:ement; elle se dissont en toutes proportions dans l'úther; elle sc saponifie très facilement par les alcalis, et forme un savon jaune et non rouge, comme cela pourait aroir lieu lorsque, l'huile de palme élant rare et d'un prix éleví, on en fabriquait d'artificielle arec de l'axonge aromatisée à l'iris et culorée avec du curcuma. Anjourd'hui cette falsification serait d'antant plus mal inspirée qu'on décolore la plus srande partie de l'huile de palme arant de la saponifier.

D'après My. Pelouze et Félix Boudet, l'huile de palme serait formée d'oléine el de margarine, ou si on l'aime mieux, d'oléate et de margarate de glycérine; mais, d'après Mu. l'rémy et Stenhonse, l'huile de palme contient, au licu de margarine, un autre corps gras qui a reçu te: le nom de julmitine, fusible, à la vérité, à 48 degrés comme la mar-garine, et fournissant comme clle, par la saponification, un acide fusible ¿ 60 degrés; mais cet acide palmitique est composé de

$$
\mathrm{C}^{32} \mathrm{H}^{32} \mathrm{O}^{4}=\mathrm{C}^{32} \underline{11}^{31} \mathrm{O}^{3}+\underline{H O},
$$

tandis que l'acide margarique $=$

$$
\mathrm{C}^{34} \mathrm{H}^{34} \mathrm{O}^{4}=\mathrm{C}^{34} \mathrm{H}^{33} \mathrm{O}^{3}+\mathrm{HO} \text {. }
$$

Cc qu'il y a de remarquable, c'est que l'acide palmitique est identique arec l'acide cétique ou éthaliqgue du blanc de baleine, et que la palmitine et la cétine diffèrent seulement par la nature de leur base, la première étant un palmitate de glycérine, ct la seconde un palmitate d'éthal.

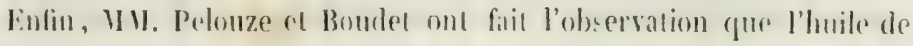


palme pouvait se convertir en acides gras, spontanément et sans le secours d'un alcali. L'huile, en rancissant, prend un point de fusion plus éleré, en même tempss que la quantité des acides gras augmente. Lne huile fusible à 31 degrés a fourni moitié de son poids d'acides gras; une autre, plus ancienne, en contenait les 4/5. Je puis ajouter à cette observation que l'acidification spontanée de l'huile de palme est le résultat d'une sorte de fermentation qui a besom, pour se produire, d'un commencement d'altération due au contact de l'air. En effet, l'huile de palme récente, fondue et introduite dans des vases pleins et hermétiquement fermés, se conserve indéfiniment arec sa belle couleur orangée, son odeur et ses autres propriétés; mais pour peu que l'air ait d'accès et commence l'altération de l'huile, on voit la décoloration et la rancidité s'étendre peu à peu de la surface au restant de la masse et ne s'arrêter que lorsque la transformation est complète. Cette transformation donne lieu à la production d'une certaine quantité de glỵcérine soluble dans l'eau; mais, d'après l'observation de MII. Pelouze et Boudet, cette quantité diminue au lieu d'augmenter avec la rancidité de l'huile, parce que la glycérine elle-même se décompose et se change en acide sébacique.

Indépendamment des matières grasses analogues à l'huile ou à la graisse, la famille des Palmiers en produit d'autres que l'on peut comparer à la cire; telles sont la cire du cervxylon undicola H. B, et celle du corygha cerifera de Martius, connu au Brésil sous le nom de C'arnauba.

Le ceroxylon andicula est un palmier magnifique, croissant sur les plateaux les plus élevés des andes du Pérou, et s'élevant luj-même à la hauteur de 60 mètres environ. La substance qu'il produit et qui porte au pérou le nom de ceŕu de pulmu, exsude des feuilles et surtout du tronc de l'arbre, à l'endroit des anneaux. Les Indiens l'enlèrent en grattant le tronc arec un couteau et la purifient par la fusion. Celte substance est d'un blanc sale et jaunâtre, assez dure, poreuse et friable, sans Sareur ni odeur. Suivant Vauquelin, elle serait formée de 2/3 de résine et de $1 / 3$ seuiement de cire; mais, d'après .I. Bonssingault. elle est composée d'une résine soluble dans l'alcool froid, jaunâtre, un pen amère, et d'une autre résine soluble seulement dans l’alcool bouillant ef ficilement cristallisable, à laquelle il a donné le nom de crivotyline.

Quant à la cire du coriphu ceriferen ou du curnumbn, il résulterait des expériences de Brandes que c'est uie véritable cire tout à fait analugue à celle des abeilles, quoiqu'clle en diffère beaucoup par sus caractères physigues. Ainsi elle est blanche, un peu jannàtre, llure, sèche, cassante, à cassure lisse, luisante et non grenue. 


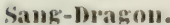

Résine rouge, insoluble dans l'eau, soluble dans l'alcool, dont on comnaît plusieurs espèces produites par des arbres fort différents; cependant le sang-dragon le plus usité provient d'un palmier du genre des rotangs, nommé par Willdenow culamus draco. Ces arbres ont un port tout particulier qui leur a fail domner par Rumphius le nom de palmiersjunc', et qui consiste en ce que leur lige, grosse comme le pouce ou moins, s'allonge presque sans fin dans quelques espèces, en s'élevant au sommet des plus grands arbres et en passant de l'un à l'autre, de manière à acquérir une longueur de plus de 160 mètres. Les jets flexibles qui les composent, surtout ceux du calamus viminalis, WI., coupés d'une longueur de 12 a 15 pieds, et mis par faisceaux de 50 environ, sont envoyés en Europe, ou ils servent à dégorger les conduits d'eau, à faire des badines et à labriquer différents ourrages et meubles en jumc, qui unissent la lígèreté à la solidité. I.es tiges d'une autre espèce, le colamus scipiorum, Lonr., forment ce's belles cannes nommées jomes, d'un seul jet, luisantes, roussàtres, pourvues d'un angle pen marqué. Je calumus draco en fournit d'autres d'un jaune pâle, de la grosseur du doigt, longues de 3 piens environ, ce qui est la distance de deux articulations. Celles qui proviennent du culumes verus sont lourdes, jaunâtres, parfaitentent rondes, munies de plusieurs noeuds espacés d'un pied.

Tous les frnits des rotrungs sont recouverts d'un péricarpe écailleux, comme celui des sagoniers, et ressemblent un peu en petit à un cône de pin; mais celui du culumus draco est le seul qui soit imprégné, lant à l'extérieur qu’à l'intériemr, d’une résine rouge qui est notre sangdragon.

Suivant Rumphius, on obtient cette substance en secorant pendant fonglemps les fruils dans un sac de toile rude; la résine pulrérisée passe à lravers le sac. On la fond à une douce chalcur et on lui donne, a l'aide des mains, la forme de globules que l'on enveloppe dans des fenilles sèches de licunlu sprimsa, autre espèce de palmier voisine des coripha. C'est là la première sorte de sang-dragon.

Ensuite, on concasse les fruits et on les fait bouillir avec de l'eau, jusqu'à ce qu'il surnage une matière résineuse que l'on forme en tablettes larges de trois ou quatre doigts; cufin, te marc lui-mêne, formé des débris de fruits contenant encore une grande quantité de résine, est inis ('n masses rondes ou aplaties, de 25 à 35 centim. de diamètre, et constitue le sang-dragon commun.

l'elle est, suivant Rumphius, la manière dont on prépare le sang- 
dragon a Jamby et ì Palinbang sur la côte orientale de Sumatra; mais il en rient aussi beaucoup de bager-Massing, ville située sur la plage méridionale de Burnéo. Cela explique pourquoi, au lien de trois sortes. décrites par Rumphius, on en tronve ruatre dans le commerce, en tête desfuelles il faut même place:" celle dont cet auteur ne parle pas.

Sang-dragon en braguettes. Batons longs de 30 à 50 centim., épais comme le doigh, entourés de fenilles de licualn, et fixés tout autnur au moyen d'une lanière très mince de lige de rotang. Ce sang-dragon est d'un rouge brun foncé, opargue, friable, fragile, insipide et inodore; sa poudre est d'un rouge vermilion.

J'ai vu autrefois un sang-dragon en masses cylindriques, un peu aplaties, longues de 20 a 30 centim. , larges comme deux doigts, qui ćtaient d'une qualité supérieure encore au précédent. Depuis bien longtemps, je n'ai pu en retrouver de semblable.

1)'après Rumphius, le sing-dragon chauffé exhale une odeur analogue à celle du sigrax. Il est possible qu'il jouisse de celte propriété lorsqu'il est récent; mais je n'en ai jamais trouvé qui la possédlit; seulement la fumie qu'il dégage irrite fortement la gorge. Plusicurs auteurs, tels que L.ewis et Thompson, ont attribué cet effet à la présence de l'acide benzoïque. J'avais toujours douté de ce fait, qui paraît cependant confirmé par l'analyse de II. Herberger. (Journ. de phurm., t. XriI, p. 225.)

Sirng-drugon en olives ou en glabules, de 18 à 20 millim. d'épaisseur, enveloppé d'une feuille de palmier, comıne le premier, et disposé en chapelet; toujours inodore, d'un rouge brun foncé, prenant une belle couleur vermillon par le froltement ou la pulvérisation. Ce sangdragon, de mème que les précédents, répond i la première sorte de: Rumphius.

Sany-drugon en masse. Celle sorte est en pains d'un poids assez considérable, d'un ronge vif, contenant une grande quantité de débris des fruits de calamus broyés. Il répond ì la dernière sorte de Rumphius. II est employé arec beaucoup d'arantage comme matiure colorante; mais il doit être rejeté des compositions pharmacentiques.

Sany-dragon en gulettes, ou en pains orbiculaires et plats, de 8 ia 11 centimètres de diamètre; d'un rouge assez vif, mais paile, arec un rommencement de demi-transparence. Ce sang-dragon est évidemment celui qui vient nager' à la surface de l'ean, lorsqu'on soumet à l'ébultition les fruits de calamus broyés. Il doit sa demi-transparence it la matiere grasse des amandes qui s'y troure contenue; il est infirieur au précédent pour la qualité, malgré sa pureté apparente el l'absence des débris de fruits.

Sung-drangm foru. Mélange fratudulenx et ignoble de résine com-

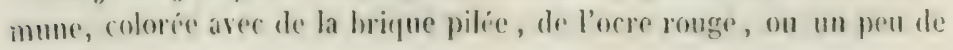


sang dragon. On le laisse en masse, on on le dirise en gros ghobules que l'on conveloppe d'une fenille de roseau, el que l'on five avec sme ficedle de chanse. Ce pretenlu sang-dragon, écrasé, prend une couleur faiblement rouge et blanchàtre, et développe une odeur de poix résine, caractère certain de sa falsification.

Srang-drengon du dracermu drucrio. On lit dans tous les autenrs qu'une partie du sang-dragon du commerce est fournie par le drar(pna drarn, I., arbre de la famille des Asparaginées, qui croìt aux fles Canaries, où il pent virre pendant des siècles, en acquérant des dimensions grigantesques. Lne description de cet arbre, insérée dans les Aun. des scim. untur., t. xis, p. 137, fait en effet mention d'un suc rouge obtenu par incision, de la nature du sang-dragon, et qui paraît aroir été exploilí par les Espagnols, dans les premiers temps de leur domination; mais depuis très longtemps on a cessé de le récolter, et mème aux îles Canaries il est impossible anjourd'hui de s'en procurer la moindre quantiti.

I.e dracene drare ne contribue done e'n rien à la production du sang-dragon du commerce.

Sang-dragom du pterocarpus derente, L. Je dois à l'obligrance de I. Fongeron, ancien pharmacien à Orléans, une espèce de sang-dragon pnlarmes, qui venait en ligne directe des Intilles, où je suppose qu'il a été produit par le pterocarpus draco, L. (Joum. de chim. métir. t. vi, p. 744). Ce song-dragom dont L'Lcluse a déjà fait mention, comme venant de Carthagène, en Imérique, est en petites masses irrégnlières, comme formées par une matiòre demi-liquide qui serait tombéc sur un corps froid; il est courert d'une poussière rouge, offre une cassure brune vitreuse, et est opaque dans ses fragments. Ies plus minces. De même que le sang-dragon des Ioluques, il est insipide, inolore, insoluble dans l'eau et soluble dans l'alcool. Il s'en distingue seulement parce que sa teinture alcoolique n'est pas précipitée par l'ammoniaque, de mème que la teinture de santal rouge; tandis que le soluté alcoolique du sang-dragon des Moluçues est précipité par ce réactif.

On lit dains les anciens auteurs que le nom de sang-dragon a dié donné à cette résine, à cause de sa couleur, et parce que le fruit de l'arbre offre dans son intérieur la figure d'un dragon. Ce sont les juternrorpus seuls, et en particulier le pteracarpus indirus (Rumph., Amh., i. II, tabl. 70), qui présentent quelque chose de cette image dans leurs fruits circulaires et membraneux.

\section{Sagou.}

I.e Sagou est une fécule qui est sous la forme de petits grains arrondis, blanchâtres, grisâtres, ou rongeâtress, très dur's, élastiques, demi-transparents, difficiles à brover et ì pulvériser, sans odeur et d'une saveur fade 
"t denceâtre. Il est apporte principalement des iles vilurgues, des iles Philippines, de la Courelle-Gnince, "t ejuelquefois anssi de l'Inde et do îles Maldives, et l'on cie comme pourant le produire les ricas circinol is et revolutu, et plusieurs palmiers, tels que l'arecu olevacru, le phroni, farinifera, l'arenga saccharifora et surtout les sagus genuina et fariniferct, qui sont des palmiers pourvus de fruits recouverts d'un péricarpe à écailles soudées, comme cenx des culamus. A une aussi grande distance des lieux, il est difficile de décider, entre ces arbres, quels sont ceux qui produisent véritablement les sagous du commerce; car il y en a plusieurs espèces. Planche, dans un mémoire inséré parmi ceux de l'Áadémie de médecine, en a décrit six variétés qu'il a désignées surtout par leur lieu d'origine. Préférant les classer d'après leur nature, j'en distingue seurlement trois espèces.

Première espèci. Säjou ancien on sagou premier. Je ne puis désigner autrement celte espèce qui provient de bien des lieux différents et affecte des couleurs très variées; ce sagou comprend :

$1^{\circ}$ Le sargou des Maldives de Planche, en globules sphérigues, de 2 à 3 millimètres de diamètre, translucides, d'un blanc rosé inégal, très durs et insipides.

$2^{\circ}$ Le sagou de la . Touvelle-Guinée du mème, en globules un peu plus petits, d'un rouge vif d'un côté ef blanc de l'autre. Tous les sagous colorés présentent, comme on le sait, celte disposition.

$3^{\circ}$ Je sagou gris des Molunues ou Broun suyn des Anglais; en globules variables, de 1 à 3 millimètres de diamètre, opacques, d'une conleur grisitre, terne d'un côti, blanchâtre de l'antre. Je pense que celte couleur grisâtre n'est pas naturelle, et qu'elle provient de l'altération de la couleur rose primitive; altération causée par le temps et l'humidité.

$4^{\circ}$ Le gros saguu gris des. Moluques. Lntièrement semblable au prícédent, si ce n'est qu'il est en globules de 4 à 8 millimètres de diamètre.

$5^{\circ}$ Le ereni sagou blanc des Moluques. Tout à fait semblable an $n^{n}$ "3, si ce n'est qu'il est d'une blancheur parfaite due an larage complet de la fécule qui a servi à le fabriquer (1).

Quels que soient le lieu d'origime et la couleur de cos sagous, boici quels sont leurs caractères:

(1) Il ne faut pas confondre ce sagou blanc qui vicnt quelquefois de l'Inde uu des Moluques, non plus que le sagon rouge de la Nouvelle-(ininéc et le sagou gris des Molugues, aver les faux sagous de fécule de pommes de terre. que l'on fait à volonte blancs, rougers on gris, el qui imitent parfaitement les irais sagous. Le sagou de fécule de pommes de terre se reconnail toujours facilement à son goû́ de fécule. 
Globules arrondis, généralement sphériques, lonss isules, tròs durs, élastiques, difficiles à broyer et à pulvériser.

t.es globules mis à tremper dans l'eau doublent génçalement de volume, mais ne contractent aucune adhérence entre eux.

Les granules (qui les composent, isolés les uns des autres par l'agitalion du liquide, et colorés Fig. 81.

par l'iode, se présentent au microscope sous une forme ovoïde, ou ellipique, ou elliptique allongée (fig. 81). Les grains elliptiques sont souvent rétrécis en forme de col à une extrẻmité, et ${ }^{-}$ce

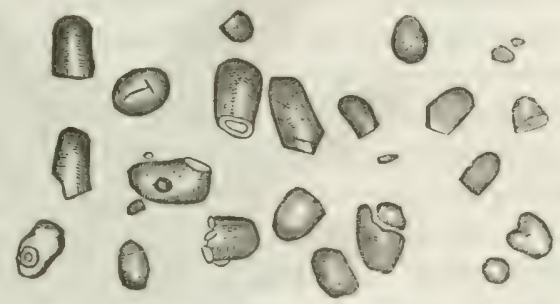
col est quel(uefois incliné sur l'axe. Les granules paraissent souvent coupés par un plan perpendiculaire à l'axe ou par deux ou trois plans inclinés entre eux.

Cette disposition est semblable à celle de la fécule du turea pimnatifirln; mais celle-ci est généralement sphérique, tandis que la fécnle du sagon est presque toujours allongée. Le hile est dilaté.

L'eau dans laquelle on a fait macérer le rrai sagou, étant filtrée, ne se colore pas par l'iode. Après une fhullition de plas d'une lieure dans une grande yuantité d'eau, la fécule du sagnu laisse un résidu considérable, dense et facile à séparer du liquide; ce résidu, coloré par l'inde et ru au microscope, parait formé de léguments très denses, presque entiers ou lacérés, colorés en blanc ou en violet, et de débris parenchynateux, très denses également, colorés en violet.

Ce sagon me paraît être celui qui est préparé aux îles Moluques avec: la moelle du sayus farinaria dr Rumphius (fig. 82), qui est différent du sarjus farinarin de Gartner, et que Willdenow a nommé saryus Rumplii, et Labillardière sıgus yenuina. Cet arbre s'élère à la hauteur de 30 pieds et acruiert un tronc assez gros pour (qu'un homme ne puisse pasl'embrasser. Il est bon is abattre lorsque ses feuilles se recourrent d'une farine blanchâtre, ou lorsqu'en retirant un peu de moelle arec une tarière, cette moelle laisse précipiter de l'amidon / ar sa division dans l'eau. L'arbre ilant abattu, on en coupe la tige par tronçons; on fend ces tronçons par quartiers, et on en arrache la moelle, qui est ensuite ćcrasée et délarée dans l'eau. Après aroir passé l'eau trouble à trarers un lamis clair, on la laisse reposer; on la décante lorsqu'elle est éclaircie, et l'on fait sécher la fécule à l'ombre: alors elle est très blanche et très fine. I.es Ioluquois emploient cette fécule à faire du pain et quelques mets agráables et nourrissants. Ce n'est guère que pour l'envoyer à l'extérieur 
qu'ils lui domment la forme que nous lui commaissons, et même ils paraissent s'être arisés assez lard de lui faire subir cotte préparation; car Rumplius, malgré qu'on ait souvent imprimé le contraire, n'en fait

Fip. 82.

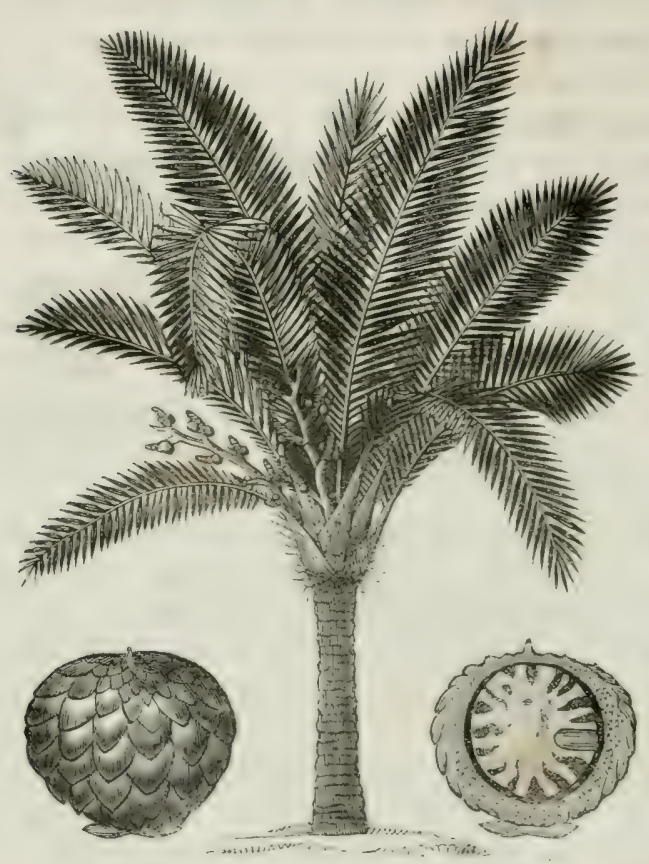

Pas mention, ot le sagou n'a été connu en Angleterre qu'en 1729 ; en lrance, en 1740; en Nllemagne en 1744: Lemery n'en parle pas.

Pour donner au sagou la forme qu'on roit, les Moluquois font sans donte passer à travers une platine perforée la pâte féculente, en partie desséchée, dont j’ai parlé tout a l'heure; par ce moven ils la réduisent en petits grains, dont ils obtiennent la dessiccation en les agitant sur des bassines plates, légèrement chauflées. Suivant d'autres persmnes, ce serait la moclle même de l'arbre qui, en se desséchant à l'air, se diviserait en petits grains arrondis; mais cette opinion est contredite par l'examen microscopique qui montre le sagou entièrement composé de granules d'amidon tous contier's et seulement soudés ensemble et diversement comprimés.

Pareillement', beaucoup de personnes admettent encore que le sagou doit sa couleur rousse inégale à un commencement de torrefaction ; mais l'intégrité des granules montre que la chaleur a élé très modérée, el j'attribue plutôt cette coloration à un principe étranger is la fécule ef

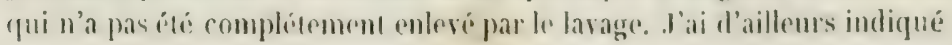




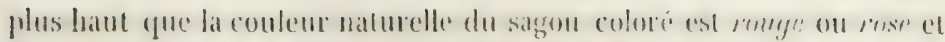
non rousse, et que la couleur grise des vicux sagons du commerce provient d'une altération de la couleur ronge primitive.

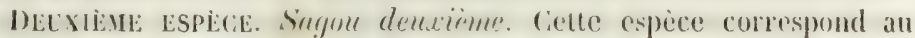
sungun rosi des Moluques de Planche; il est en globules très petits, moins réguliers que ceux du premier sigron, et quelquefois soudés cnsemble au nombre de 2 ou 3 ; trempé dans l'eau, il augmente de plus du double de son volume et l'eau paraît un peu mucilagineuse; cependant elle ne se colore pas sensiblement par l'iode. Les grains de fécule isolés ont exactement la mêne forme que ceux du sagou $n^{\circ}$ J, mais ils résistent moins à la coction dans l'eau. Après une heure d'ébullition, le liquide offre en suspension des parties de parenchyme amylacé, qui se colorent en violet rougeâtre par l'iode et qui offrent souvent un point oparque et plus fortement coloré au centre. Par le repos, il se forme au fond du liquide un dépôt plus dense, qui offre en outre des fragments de téguments membraneux, plissés, denses et colorés en violet, et d'autres léguments moins altérés, qui se présentent sous forme d'outres creuses, déchirées sur plusieurs points de leur surface et d'un bleu violet.

TroIstisie espèce. Saygu-tapiolirt. Je domne ce nom à cette espèce de sagou, aujourd'hui très répandue dans le commerce, parce qu'elle est exactement, à la fécule primitive dı sagou et même aux sagous précédents, ce que le tapioka est à la moussache, qui est la fécule du manioc. C'est-ì-dire que tandis que les deux sagous précédents, quoi qu'on en ait dit, n'ont été ni torréliés, ni cuits, ce qui est prouvé par l'intégrité de la presque tutalité des grains de fécule; le sagou-tapioka a subi l'action du feu, à l'ćlat de pàte humide; de là l'explication facile de toutes ses propriélés.

Ce sagou n'est pas en globule"s sphériques comme les deux précédents, ou du moins les globules splhíriques y' sont très peu nombreux : il est plutôt sous forme de très petites masses tuberculeuses irrégulières, formées par la sondure d'un nowbre rariable des premiers globules. Mis à tremper dans l'eau, il s'y gonfle beaucoup, et se prend en une masse pâteuse, blanche et opaçue; en ajoutant une plus grande quantité d'eau, il se divise davantage et se dissout en partic. La liqueur filtrée bleuit fortement par l'iode. La liqneur non filtrée, cxaminée au microscope, offre des grains entiers de fécule, semblables à ceux du vrai sagou, plus un grand Fig. 83. nombre de téguments rompus et déchirés (6ig. 83 ). In peu de cente 
fécule sounise a une coction d'une hrure, dans une grande quantite d'eau, se conduit comme celle du sagou $n^{\circ} 2$.

La facilité arec laquelle le sagou-tapioka se gonfle et se divise par l'eau, le fait aujourd'hui préférer, comme aliment, à l'ancien saugou.

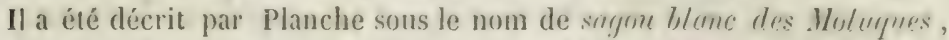
et par II. Pereira sous celui de sugon perlé (pearl sago). M. Joubent, négociant français établi à Sydney, m'en a remis un échantillon en me disant qu'il était originaire de Taïti. De là j’ai cru pendant quelẹue temps que ce sagou était le tapioka de la fécule du tucen piunutifidn; mais il est certain qu'il n'en est pas ainsi, et que la fécule du troisième sagou, bien différente de celle du trer'n pimatifula, se rapproche beaucoup plus de celle des deux premières espèces de sagon.

\section{Nolx de Palmier.}

Tayua ou cubeza de negro (tête de nègre); morphil on irvire crigritul. On donne ces différents noms à des semences grosses comme de petites pommes, arrondies d'un côté, anguleuses et un peu allongies én pointe de l'autre, composées d'un épisperme assez épais, dur et cassant, et d'un endosplerme blanc, opayue, très dur, susceptible d'ètre tounci. taillé et poli comme l'iroire. Anssi les emplosie-t-on pour en faire de's pommes de cannes et toutes sortes de petits objets de tabletterie. Ces semences viennent du Pérou, où elles sont produites pär un arloris-

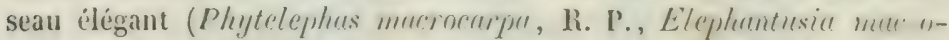
corpu, W.) qui a le port d'un petit palmier, mais qui a plus de rapports avec la famille des Pandances. Le fruit entier est très gros, hérissé, en forme de tête, composé de drupes agrégés, à quatre loges monospermurs. Avant leur maturité, les logres sont remplies d'une liqueur d'abord transparente, ensuite laiteuse el d'une saveur agréable, qui est d'un grand secours pour les royageurs. Peu à peu cette liqueur se condense et s'organise en un périsperme fort dur, ainsi qu'il a été dit.

\section{FAMILLE DES COLCHICACÉES.}

Mélanthacées de R. Brown. Plantes à souche bulbeuse, ubéreuse ou yuelyuefois formée en rhizome horizontal. Tige simple ou scapiforme; feuilles tantôt toutes radicales et ramassées, tanlòt conlinaires of alternes, tantôt graminées on sétacies, d'autrefnis elargies, nervenses. très entières; fleurs completes on incomplètes, réghtilieres, à prírigone corolliforme, à six divisions distinctes on soudées en lube ; six étanines opposées aux divisions du périgone, à filets libres, à anthères biloculaires extrorses; ovaire libre, formé de trois carpelles plus ou moin: 
sondés el surmontés chacun d'un style terminé par un stigmate glinduleur. Le fruit est une capsule a trois loges folliculeuses, plus ou moins distinctes et s'ourrant par une suture rentrale. Les semences sont nombreuses, couvertes d'un épisperme membraneux, surmonté quelquefois vers le hile d'un tubercule plus ou moins volumineux. L'endosperme est charnu ou cartilagineux, contenant un embryon cylindrique, placé rers le point opposé au hile.

Les Colchicacées sont divisées en deux tribus:

1' Les térutres: tiges scapiformes, sourent pourvues de feuilles. Fleurs en grappes ou en épis: styles courts; stigmates peu distincts; divisions du périgone libres, sessiles ou courtement onguiculées, on bien soudées par le bas en un tube très court. Genres helonias, schernocaulon, veratrum, melanthium, etc.

2" Colchicées: acaules, fleurs nées d'un collet souterrain; styles grêles, libres ou plus ou moins soudés; folioles du périgone longuement onguiculées, onglets le plus sourent soudés en un tube. Genres bulbocodium, colchicum, etc.

Les plantes de la famille des Colchicacées sont généralement très àcres, purgatives, vomitises, et doivent être emplovées avec une grande prudence. Les plus usitées sont le rolchique d'untomne, l'hermndarte, l'ellébore blane et la cévadille.

Colchique d'automne (fig. 84 ).

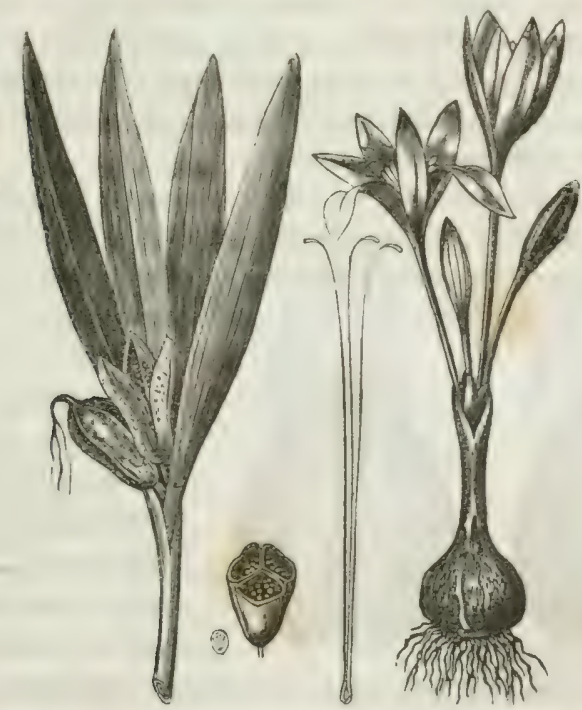

Colchicum cutumnale. Cette plante est composée d'abord d'un tuber- 
cule charnu et anylace faux bulbe, enveloppé dans un petit nonilore de tuniques brune's, foliacées; ce tubercule est assez profondément cufoncé dans la ferre. A la partie inférieure on observe, comme dans les vais buibes, un collet et des radicules. En enlerant les tuniques brunc's, on troure comme trois tiges courtes, dont deux à fleurs et une à fenilles. Les tiges à fleurs sont enveloppées chacune d'une spathe et sont enfermées, presque jusqun'au limbe de la fleur et jusqu'à la surface du sol, dans le prolongement supérieur de la tunique brune. L'une des spathes, c'est la plus déreloppée, part inmédiatement du collet inférieur, et monte extérieurement le loug du corps amỵlacé qui est creusé pour la receroir. L'autre spathe, plus petite, est due à un petit bulbe qui se forme au milieu du côté opposé; quant à la tige à feuilles, elle part directement du sommet du corps charnu et se confond d'un côté arec la tunique extérieure.

Le colchique est commun dans les prés et les pâturages d'une grande partie de l'Europe. Ses fleurs paraissent à l'automne. Elles partent, comme on l'a ru, du collet de la plante, et sont formées d'un périgone à tube très allongé terminé par un limbe à six divisions qui viennent s'épanouir à la surface du sol. Les étamines sont insérées au haut du tube du périgone. Les 3 ovaires soudés sont situés au contraire au fo:d du tube ct sont surmontés de 3 styles très longs, terminés chacun par 1 stigmate en massue. Ce n'est qu'au printemps suivant que les feuilles se dévelopırınt et que les fruits paraissent an milieu d'elles. Ceux-ci sont formćs d'une capsule à 3 loges, s'ourrant par le côté interne et contenant un grand nombre de semences globuleuses, d'un brun noiràtre, rugueuses à la surface, plus grosses que celles du colza, el d'une saveur amère suivie d'une âcreté très marquée. L'endosperme est corné, élastique et très difficile à pulrériser.

Le tubercule de colchique, tel que le commerce le présente, cst un corps oroïle ( fig. 85), rie la grosseur d'un marron, conrexe d'un côté et présentant une cicatrice occasionnće par la petile tige; creuse longi.

\section{Fìg. 8 s.}

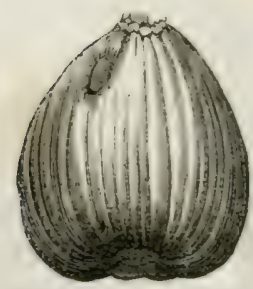

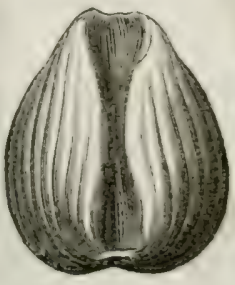

tudinalement de l'autie; d'un gris jaunâtre à l'cxtérieur et marqué de sillons uniformes causis par la dessiccation ; blanc et farineux à l'intérieur; d'une odeur nulie, d'une sarcur àcre et mordicante. Celle sarenr indigue que le tu-

bercule sec est loin d'elde dépourvu de propriélés médicales: cependint siorck et les autres médecins qui, d'après lui, ont conseillé l'usagn: du 
colchigue, recommandent de l'employer recent. C'ent égilement sous cet ctat que, d'après II. Want, chirurgien anglais, on doit s'en servir pour préparer la teinture anti-arthritigue dite eme médirinale d'Hussum. (Ann. de chim., t. XCIV, p. 324.)

Pelletier et M. Carentou ont retiré du Lubercule de colchique : I" unc matière grasse composée d'élä̈ne, de stéarine et d'un acide volatil particulier; $2^{\circ}$ un alcali végétal ([u'ils ont cru être semblable à celui trouré dans la racine d'ellébore blanc (teeratrem album) et dans la cévadille, ct auquel en conséquence ils ont donné le nom de vératrine; $3^{\circ}$ une matiere colorante jaune; $4^{\circ}$ de la gomme; 5" de l'anidon ; 6" de l'inuline en abondance; $7^{\circ}$ du ligneux ( $\mathrm{nm}$. chim. et phlys., I. MV, p. 82 ).

Postérieurement MIY. Hesse et Geiger ont annoncé que l'alcaloïle du tubercule et des semences du colchiģue différait de la vératrine et lui ont donné le nom de colchicine. Cet alcaloüde est amer, très vénéneux, mais non âcre ni sternutatoire; il est cristallisable, fusible à une douce chaleur, soluble dans l'eau, l'alcool et l'éther. Il neutralise bien les acides et forme des sels dont plusieurs cristallisent facilement. L'acide sulfurique concentré le colore en brun-jannitre et l'acide nitrigue en violet foncé. L'analyse n'en a pas été faite.

\section{Tubercule t'Hermotacte (fig. 86 ).}

Ce tubercule, inconnu aux anciens Grecs, parait avoir été mis en usage par les drabes. C'est évidemment une espèce de colchique qui nous vient d'Égypte, de Syrie et de la Vatolie; mais sa patrie parait ètre surtout la Syrie. Il est formé d’un corps tubéreux, amylacé, ayant la forme d'un cœur, marqué à la partie inférieure du côté conFig. 86. vexe, des vestiges d'un plateau de bulbe ordinaire; il est creusé profondément et dans toute sa longucur de l'autre côté, ct présente au bas du sillon unc cicatrice qui indique le point d'insertion de la tige principale.
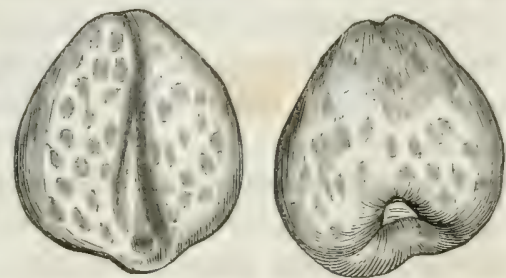

Sur la partie conrexe se troure une seconde cicalrice causée par l'insertion du jeune bulbe ; enfin le sommet du tubercule offre une dernière cicatrice d'on devaient s'élever les feuilles : comme on le voit, cette organisation est exactement celle du coichique. Cependant le tubercule d'hermodacte est facile à distinguer de celui du colchinue. Il est beaucoup plus blanc, non ridé à l'exterieur, d'une saıcur douceàtre, un peu mucilagineuse 
et un peu àcre. Il est légèrement purgatif et entre dans la composition des électuaires diaphœnix, caryocustin, et des tablettes diacarthami. On a prétendu que les Égrptiennes en mangeaient pour açuérir de l'enbonpoint.

L.es autcurs qui ont écrit le plus récemment sur la matière médicale, sont tombés dans une grande confusion au sujet de la plante gui produit l'hermodacte: I'un d'eux blàme arec raison Linné d'aroir attribué ce ubercule à l'iris tuberosa; il pense qu'il est fourni par le colchirum coriegatum L., et il donne à l'appui de cette opinion la description rt la figure d'une plante que Iatthiole arait recue de Constantinople sous. le nom d'hermoducte. Or la plante nommée par Iatthiole hermorlar. tylus verus, loin d'être le colchicum verrirgutum, n'est autre que l'iris tulerosa, L. Un autre, qui reut absolument que le tubercule amylacé du colchique soit un oignon, trouve que l'hermodacte est une racine ligneuse semblable à celle des iris, et il appuie en consé(quence l'opinion de Linné et de Tournefort, que cette substance est due à l'iris tuberosu, contre celle de Matthiole que c'est un colchique. Il ! a là beaucoup d'erreurs en peu de mots.

.Iathiole est le premier auteur de cette confusion : voulant toujours prouver que nous n'arons pas les véritables drogues des anciens, pour lui notre hermodacte est un faux hermodacte qui ne diffère pas du colchique vulgaire, et il accuse rertement d'ânerie ceux qui se permettent de l'employer, bien qu'il recomnaisse quu'il n'est pas aussi actif que le colchique. Ayant ensuile reçu deux plantes de Constantinople, il décrit l'une sous le nom de colchique oriental, et l'aure sous celui d'hermmdarte vrai, pour deux raisons, dit-il: la première est que cette plante est ainsi nommée à Constantinople, et la seconde est que sa racine est formée de plusieurs tubercules digités (gui paraissent aroir donné lieu au nom d'hermoducte (doigt d'Hermès). Si l'on rélléchit cependant que Sérapion a traité de l'hermodacte dans le mème chapitre que du colchique; que Lolsel a reçu d'Alep de Syrie la plante à l'hermodacte, et qu'il l'a décrite et figurée comme étant le colchicum illyricum d'Anguillara (Plantar. Hist. Antverpiæe, 1676, pag. 71) ; que Tournefort a trouvé l'hermodacte en Asie arec les feuilles et les fruits d'un colchique (Geoffroi, Mat. med.); que Gronowius l'a insérée dans sa flore d'Orient, sous le noun déjà donné de colchicum illyricum; enfin que l'hermodacte des officines n'a jamais été autre chose (qu'une espèce de colchique, il deviendra probable que llathiole a appliqué par erreur à l'iris tuberusu le nom qui devait être donné à son colchirun orientale.

Au total, l'hermoductylus verus de .Mathiole (iris tuberosu, I. ) ne produit pas notre hermodacte officinal. Celui-ci provient, d'après Lobel et Gronowius, et d'après Miller et Forskahl, cités par Linné, du col- 
chirmm illygrirum d'Anguillara: landis que suisant Murray ( Aymu-

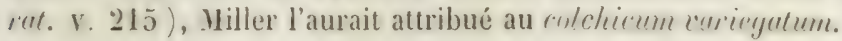

liacine d'ellébore blanc (6g. 87).

Corutimu albun. - Citr. gén. Fleurs hermaphrodites el fleurs màles arec un rudiment de pistil; périgone à 6 divisions très profondes, persistantes. 6 élamines à filaments appliqués par leur base contre les oraires; anthères biloculaires; 3 ovaires supères, soudés entre cux du còté interne, ovales oblongs, amincis par le haut et terminés par 3 styles

Fig. 87.

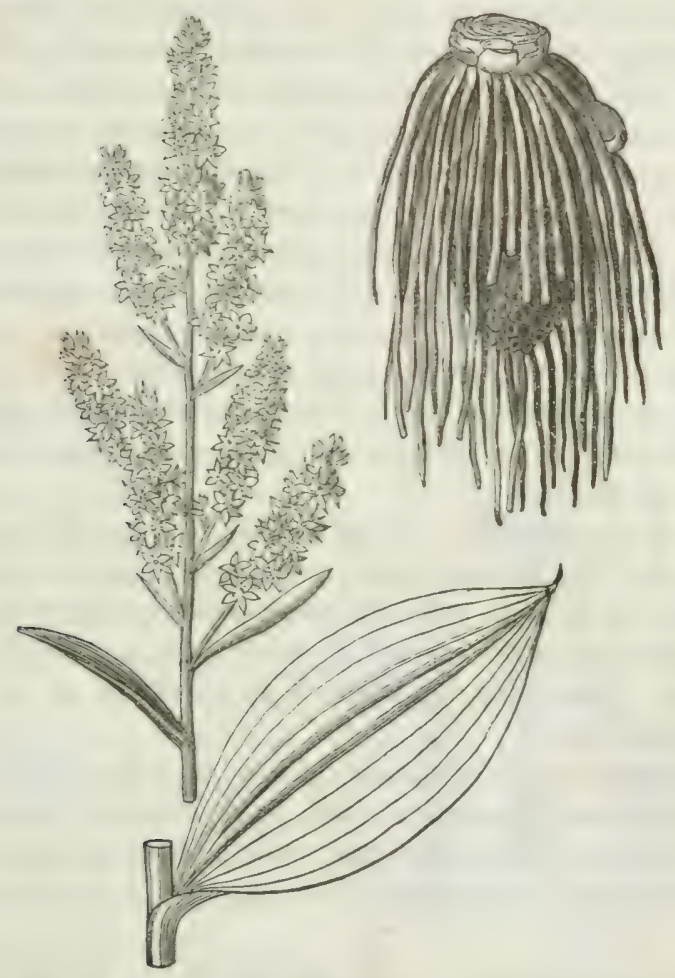

divergents et en forme de cornes. 3 capsules soudées par le bas, se séparant par le haut et s'ourrant du côté interne; semences nombreuses, comprimées, dont le testa (1) est prolongé cn aile au-dessus du raphié

1) Tunique externe de l'épisperme ou enveloppe de la graine. 


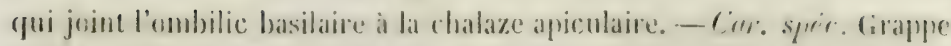
droite, ramense et paniculée; bractées des rameanx de la longuem des pédoncules; pélales redressés, excarés à la base, èlargis par le haut el dentés en scie.

Cente plante, d'un port élégant, pousse de sa racine une sorte de bullhe qui se prolonge $\mathrm{cu}$ une tige hante de 6 à 10 décimètres, enveloppée a sa partie inférieure par un grand nombre de feuilles grandes, larges, molles, plissées dans leur longueur, un peu velues. Elle porte en outre d'autres feuilles caulinaires plus espacies et plus petites, et au haut de lit lige une longue grappe ramense de fleurs d'un blanc verdâtre. Sa racine est composée d'un corps principal assez volumineux, garni de beaucoup de radicules blanches.

Celte racine, telle (fu'on nous l'apporte sèche de la Suisse, est sous la forme d'un cône tronqué de 27 millimètres environ de diamètre moyen, et de 5 à 8 centimètres de long. Elle est blanche à l'intérieur, noire et ridée au dehors; elle est privée ou garnie de ses radicules, qui sont très nombreuses, longues de 8 ì 10 centimetres, grosses comme une plume de corbeau, blanches a l'intérieur, jaunâtres à l'extérieur. Toute la racine est douéc d'une saveur d'abord douceàtre et mêlée d'anertume, qui devient bicntôt àcre ct corrosire. Elle a dans son ensemble quelque ressemblance arec la racine d'asperge, mais les radicules de celle-ci sont plus longues, à moins qu'elles n'aient été coupées, plus flasques, rarement sèches, d'une saveur qui n’est qu’un peu sucrée et amère; de plus, sa souche n'est ni conique, ni compacte comme celle de l'ellébore blanc.

La racine d'ellébore blanc est un romitif ct un purgatif drastique des plus violents. Elle n'est plus guère usitéc ru’à l'extéricur, dans les maladies pédiculaires et cutanées. Sa pulvérisation est dangereuse. On emploie concurremment avec elle, à ce qu'il paraît, la racine du reratrum lobeliomm, plante très semblable à la précédente et qui jouit des mêmes propriétés.

MIII. Pelletier et Carenton ont retiré de la racine d'ellébore blanc: une matière grasse composée d'élan̈ne, de stéarine et d'un acide rolatil ; du gallate acide de vératrine, une matière colorante jaune, de l'anidon, du ligneux, de la gomme. (. $1 \mathrm{~mm}$. de phlys. at de chim., 1. XIV, p. 81.)

liarine de verutere mir, Veratrum nigrum, J. Cette espece differe de la précédente par ses fleurs, dont les sépales sont d'un pourpre noiràtre, tries ourerts, à peine dentelés, et par ses braclées plus longues que les pédoncules. Sa racine, telle qu'elle a élé récolte dans le jardin de l'beole, n'offre, ats-dessous du bulbe foliace qui termine la tige par le bas, qu'un troncon très courl, garni d'un grand nombre de radicules 
imprégnées d'un principe colorant jaune beaucoup plus abondant qum dans le verutrum album.

Il est probable que re sont les propriélés énergigues et délétères du revatrum nigrum gui ont fait attribuer à la racine d'ellebore noir des officines (helleborus niger, renonculacées) une activité qu'elle est bien loin de présenter.

\section{Cevadille (fig. 8x).}

Celte plante croit an Hexique; son nom, qui signifie petit orge (de redudu, orgè, lui a été donné ì cause de ses feuilles semblables ì celles d'une graminée, et de ses fruils qui sont presque disposés en épi le long d'un pédoncule commun, ce qui lui donne, au tolal, une certaine res. semblance avec l'orge. Cie sont les fruits seuls qui parviennent en linrope. On les a attribués pendant longtemps à une plante de la chine que Retz a nommée veratrum sabadilla, parce que ses capsules lui ont paru tellement semblables à celles de la cévadille qu'il a pensé que ce devait être la même plante; mais indépendamment de ce que le pays d'origine est bien différent, comme on le voit, la plante de Retz présente un port el des caractères si peu pro. pres à justifier le nom de cévadille qu'il est étommant que ce botaniste si judicieux ait pu croire à leur identité. Le veratrum sabadilla, que l'on troure figuré dans l'atlas du Dictionnaire des sciences naturelles, ressemble beaucoup par ses feuilles larges et plissées, par son port et par la couleur de ses fleurs, au veratrum nigrum; seulement, la grappe est presque simple; les Fig. 88.

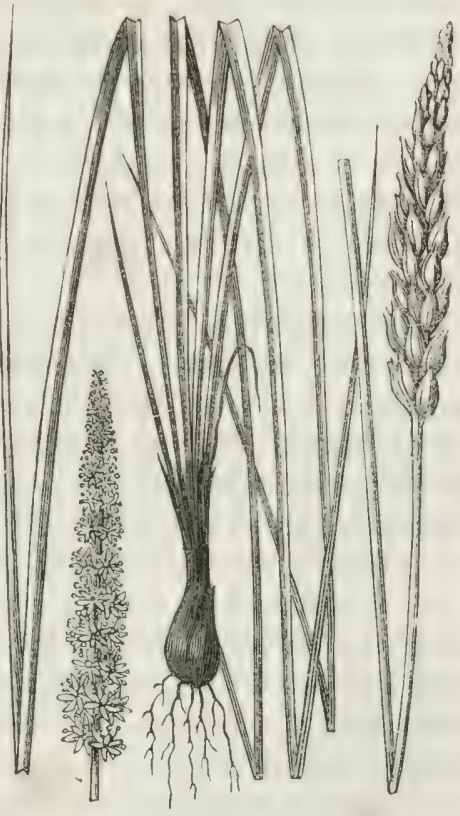

fleur's sont toutes penchées du même côté, et les fruits sont pendants.

La plante du Mexiques, décrite d'abord par Schlechtendahl sous le nom de veratrumi officinale, a été nommée par $\mathbf{~ I . ~ D o n ~ h e l o m i u s ~ o f f i r i - ~}$

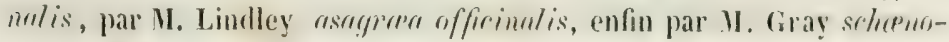


raulon officinale. Elle est bulbeuse par le bas, poursue d une lige: haute de 18 décinetres et de fruilles linéaires, Inngues de 42 décimbitres. Les fleurs forment une grappe simple, dense, spiciforme, longue de 45 centimères. Lilles sont hermaphrodites (Gray) ou pulygaunes (Lindley), très courtement pédonculées, dressiés contre l'axe et accompagnées chacune d'une bractée. Le périgone est herbacé, à six divisions linéaires obtuses, excarées à la base, prescjue distinctes, dressées, persistantes. Les étamines sont alternatirement plus courtes, à anthères reniformes, sous-uniloculaires, peltées après la fécondation. Les oraires sont au nombre de trois, atténués en un sṭ̂le très court et terminés par un stimmate peu apparent. 3 capsules acuminées, papyriformes; semences en forme de cimeterre, ridées, ailées supérieurement. Au total, il est visible que cette plante diffère p! us des ierutrum far son port que par ses caractères de fructification, et que le nom de reratrum "ffirinale pourrait bien lui suffire.

Le fruit de la cévadille, tel que le commerce le fournit, est formé d'une capsule à trois loges ouvertes par le haut; mince, légère, d'un gris rougeâtre, chaque loge renfermant un petit nombre de semences noirâtres, allongées, pointur's el recourbées en sabre par le haut. Ces semences sont très âcres, amères, fortement sternutatoires, excitent la salisation et sont très purgatives et trìs irritantes à l'intérieur; aussi la cévadille n'est-elle plus guère usitée qu’à l'extérieur pour détruire la rermine: et dans les laboratoires de chimie pour l'extraction de la vératrine.

Pour obtenir la vératrine, Pelletier ct casentou ont ajouté de l'acétate de plomb à un décocté agpueux de céradille, afin d'en séparer l'acide gallique et la maticre colorante. Ils ont fait passer dans la liqueur filtrée du gaz sulfhỵdrique pour précipiter l'excès de plomb ajouté, et ont traité la liqueur filtrée par un cxcìs de magnésie calcinée qui en a précịpité la vératrine. Le précipité a cité traté par l’alcool houillant, tt la vératrine a été obtenue par l'éraporation partielle du vélicule.

La vératrine ainsi ubtenue est blanche, pulserulente, jondore, d'une âcreté considérable (đuelyuess chimistes l'ont obtenue cristallisée). Elle fond à 50 degrés, est soluble dans l'alcoul et l'éther, insuluble dans l'eau, susceptible de former avec les acides des sels nentres incristallisables. 1.'acide nitrigge concentré la dissout en prenant une couleur écarlate, puis jamne; l'acide sulfurique concentre se colore en jaune d'abord, puis en rouge de sang, enfin en violet.

Il est possible d'ailleurs que les caracieres ul la composition de la rératrine ne soient pas exactement commus. In'iprics 11 . Coucrbe, celle obtenue par MI1. Pelletier et Carentou est un mélange de plusieurs substances dont une matière grasse, poisserise qui lui communique sa 
Grande fusibilite; insoluble dans l'éther et dans l'eau, soluble dans les acides sans les neutraliser; une troisième, nommée subutllline, est un alcaloüde cristallisable, très àcre, fusible à 200 degrés, soluble dans l'eau bouillante, insoluble dans l'éther, très soluble dans l'alcool (1); enfin la quatrième, ¿ laquelle .II. Couerbe conserve le nom de vératrine, est blanche, solide, friable, fusible à 115 degrés, soluble dans l'éther, etc. (Pharmacopép

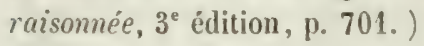

\section{FAMILLE DES LILIAGEES.}

Belle famille de plantes, caractérisée par un périanthe pétaloïde, ì 6 divisions régulières ou presque régulières, et disposées sur deux rangs. Les étamines sont au nombre de six, insérées sur le réceptacle ou à la base des divisions du périanthe. L'ovaire est libre, à trois loges polyspermes; le style est simple, terminé par un stignate trilobé. Le fruit est une capsule triloculaire, trivalve, à valves septifères. Les graines sont recourertes d'un légument tantôt noir et crustacé, tantôt membraneux. L'endosperme charnu contient un embryon cylindrique, axile, dont la radicule est tournce vers le hile. On pent diviser la famille des liliacées en quatre tribus.

1. Tulpacés : racine bulbifire; périgone campaniforme, à sépales distinctes ou à peine soudés par la base; épisperme membraneux et pàle. Genres erythronium, tuliper, fritillmin, lilium, methonirn, etc.

$2^{\circ}$ dGapaxthées : racine tubéruse ou fibreuse; périgone tubuleux ; épisperme membraneux et pàle. Gienres phormium, agrqumthus, pro. lyanthes.

3" ASPHonéLéEs : périgone tubuleux ou à six sépales distincts; ; episperme crustacé, noir, fragile. Genres à racine bulbeuse ou HaciNTHÉES: hyaciuthus, scilla, omithergalum, albucu, allium. Genres à racine fibreuse ou tubéreuse, on AnTHéricées: usplodelus, hemerncallis, anthericum.

$4^{\circ}$ ALOÏNEES : plantes charnues, quelquefois frutescentes, à racine libreuse fasciculéé ; périgone tubuleux, à six dents, quelquefois bilabié; scmences comprimées, anguleuses ou ailées, à épisperme membrancux pâle ou noirâtre: Genre uloe. Les yucca, qui se rapprochent beaucoup des aloïnées par la nature et la disposition de leurs feuilles, s'en éloignent par leur périgone campaniforme et à sépales distincts, semblable à celui des tulipacées.

(1) D'après M. E. Simon, la sabadilline est un résinate double de soude et de vératrine, ce qui explique en partie ses propriétés. 
In grand nombre de liliacies sont remarguables par la beante de leurs fleurs, et sont cultivers comme plantes d'ornement. (gui nta cutendu parler de la passion de's Itoilandais et des Flamands pour la tulipe des jardins (tulipon gesneriunn), dont ils ont quelquefois payé les belles variétés jusqu’à 4 et j000 florins (de 8600 à 10750 francs environ)? Si celles qui strivent n'ont pas été l'objet d'un culte aussi coûteux, elles ont cependant, pour la plupart, été très recherchées des amateurs; telles sont:

La fritillaire impériale, I.e lis blanc,

- du Japon,

- margaton,

- superbe,

- ligré,

La superbe du Malabar,

L'agapanthe blene,

I. a tubéreuse de l'Inde,

La jacintlie orientale,

L'ornithogale ombellé,

$$
\text { - pyramidal, }
$$

fritillaria imperial is.

lilium candidum.

- japonicum.

- margatom.

- superbum.

- tigrinum.

mellonica supperbar. agopanthus umbellatus. polyanthes tuberosa. hyacinthus orientalis. ornilhogalum umbellatum.

- pyramidale.

Plusieurs de ces fleurs, el notamment la tubéreuse, la jacinthe et le lis, sont pourwes d'une odem très suave, très expansire, mais qu'il est dangereux de respirer lorsqu'elle est concentrée rlans un lieu fermé. Le principe de cette odeur est tellement rolatit on altérable qu'on ne peut l'extraire par la distillation, à la maniere des autres huiles essenlielles. On l'obtient en meltant, dans un rase fermé, des couches altermatives de sépales et de coton imbibé d'huile de ben. Après quelques jours de macération, pendant lesquels l'essence éthérée de la plante s'est combinic a l'huile de ben, on renourclle les fleurs. On met ensuite le coton a la presse, pour en retircr l'huile odorante, et on traite cette huile par de l'alcool rectifié, qui s'empare du principe aromatique.

In grand nombre de liliacées contiennent un principe très àcre, mais qui se détruit par la coction, de sorte qu'elles deviennent alors propres a l'alimentation. Chez d'autres, cette icreté est accompagnce de principes moins altérables, amers, purgatifs on émétiques, qui les rendent des médicaments très actifs. Les aloès produisent un suc très amer et purgatif, gui porte leur nom, et dont l'usage médical est universellement répandu.

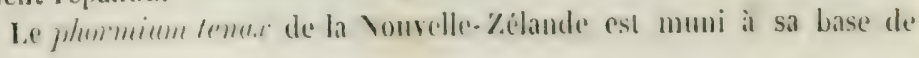


feuilles nombreuses, distiques et engaînantes, dont les fibres, très Iongues el pourves d'une trìs grande ténacité, peurent devenir d'une grande utilité pour la fabrication de cordages et de tissus très résistants. Il est aujourd'hui acclimaté cn France.

\section{Bulbe de lis.}

Lilium candidum. - Car'. gén. Périgone coroullö̈le, campaniforme, formé de 6 sépales un peu sourlés à la base, portant une ligne neclarifère à l'intérieur; 6 étamines; 1 style terminé par 1 stigntate épais, à 3 lobes; capsule allongée, trigone à 3 ralves loculicides. Semences nombreuses, bisériées, horizontales, aplaties, à épisperme jaunàtre et un peu spongieux; embryon droit ou sigmoïde, dans l'axe d'un endosperme charnu; cxtrémité radicale rapprochée de l'ombilic.

Car. spice. Feuilles éparses, atténuées à la base; périgone canıpaniforme, glabre à l'intérieur.

Cette plante fait l'ornement des jardins par la beaté de ses fleurs, qui sont d'une blancheur éblonissante et disposées en grand nombre le long du sommet de la tige. On en préparait autrefois une eau distillice et une huile par infusion (Eléolé).

Les bulbes de lis sont trìs gros et composés de squames courtes, épaisses et peu serrées. On les emploie en cataplasme, comme émollients, étant cuits sous la cendre.

\section{Bulbe d'ail.}

Allium satizum. - Car'. gén. Fleurs en ombelle, enveloppées d'une spathe. Périgone corollö̈de, à six divisions profondes, ourertes ou campanulées, connirentes. 6 élamines à filets filiformes ou élargis à la base; dont trois alternes sont quelquefois aplaties et terminées par trois pointes, dont celle du milieu porte l'anthère; ovaire triloculaire ou uniloculaire par l'oblitération des cloisons ; ovules peu nombreux; stỵle filiforme; stigmate simple; capsule membraneuse, trigone, quelquefois dépriméc au sommet, triloculaire ou uniloculaire, surmontéc par le style persistant. Semences réduites à 2 ou 1 dans chaque loge, à ombilic rentral, à épisperme noirâtre et rugueux. Embryon daus l'axe de l'endosperme, homotrope, sous-falciforme, à extrémité radiculaire rapprochée de l'ombilic. - Carr. spéc. Tige garnie de feuilles planes et linéaires; étamines alternativement à trois pointes; capsules remplacées par des bulbilles; bulbe radical composé de plusieurs petits bulbes (cryeux), réunis sous une enreloppe commune, et munis chacun de ses enveloppes propres.

Cette plante est pénétrée d'un suc àcre, qui réside surtont dans son bulbe. Celui-ci est pouru d'une saveur âcre et caustique el d'une odeur 
forte et très irritante. Il est usité comme assaisonnement. Il est auss i anthelmintigue et prophylactique, et entre daus la composition du vinaigre des quatre voleurs (oxpenlé d'alsinthe alliace', Il contient beaucoup de mucilage et une huile volatile sulfurée, âcre el caustique, que l'on peut obtenir en distillant les bulbes pilés avec de l'eau. Cette huile, (qui est d'vn jaune lrun, épaisse, plus pesante que l'eau, est d'une composition très complexe. Rectifiée à la chaleur d'un bain bonillant d'eau saturée de sel marin, llle devient beaucoup plus fluide, jaunâtre, plus légère que l'cau qui la dissout beaucoup moins (qu'auparavant, toujours très soluble dans l'alcool et l'éther. D'après les recherches très intéressantes de $\mathbf{1}$. Wertheim, cette essence rectifiée est ellemêne un mélange variable de plusieurs combinaisons de soufre et d'une combinaison d'oxigène arec un seul et même radical, représenté par $c^{6}\left[1^{5}\right.$, aurquel il a donné le nom d'allyle.

L'oxide d'allyle, qui existe dans l'essence rectifiée, $=1{ }^{6}{ }^{\circ}{ }^{\circ} 0$

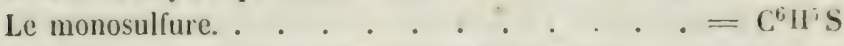

Les sulfures supérieurs n’ont pas été déterminés.

Le monosulfure d'allyle est la partie essentielle et principale de l'essence d'ail rectifiée; il en constitue environ les deux tiers, de mème que l'essence rectifice constituait elle-inêne les deux tiers de l'lubile brute distillée. Il possède toujours l'cideur propre de l'ail; il est liquide, incolore, plus léger que l'ean, réfractant fortement la lumière, susceptible de former avec les sels de platine, de palladium, d'argent, de mercure, des combinaisons plus ou moins compliquees, mais bien dé-

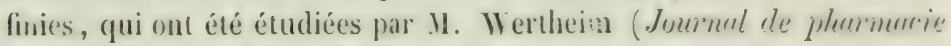
et de climie, I. VII, P. 174).

Autres espèces du genre allium usitées dans l'art culinaire.

La nocaunor.te (allium scorodoprosum), ì tige haute d'un mitre, contournée en spirale arant la floraison; fenilles planes crénelées; lleurs bulbifères.

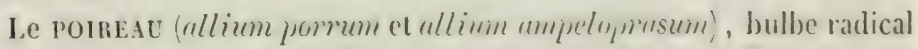
très allongé et presque cỵlindrigue, ligre haute de $1{ }^{\prime \prime}, 30$, droite, ferme, garnie de feuilles planes; étamines alternatisment a 3 pointes; ovaires capsulifères.

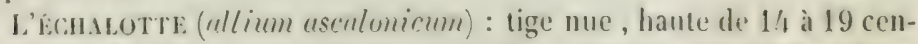
timetres; frnilles tontes radicales, subulies, dispostes en touffe; theurs purpurines, en ombelle serrée, globuleuse; 3 étamines à 3 pointes; originaire de la Palestine. Bulbe radical composé.

lat (atrTte ( 


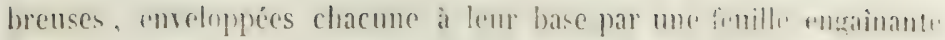
formant gazon ; fleurs purpurines.

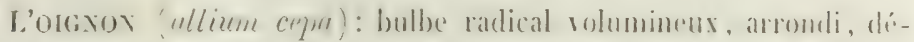
primé, formé de tuniques complites et concentriques; il en existe un grand nombre de variétés à tunicyues rougreattres on blanches; les feuilles sont radicales, cylindriques, creuses pointue's ; la tige est nue, cylindrique, rentle au milieu, creuse, haute de 1 mètre à $1^{\text {"w }}, 30$ el plus; les fleurs sont rougeattres, en onbelle splérique; les étanines sont alternatirement à trois pointes.

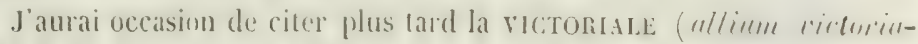
lis, L.), clunt le bulbe allonge ef entoure de fibres très finces, prose-

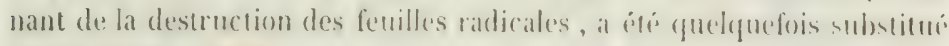
au spicanard indien.

bulbe de scille.

Scilla maritima, L. (fig. 89 ). - C'an. gén. Périgone coloré ì six divisions, campanulé, rotucéourert; 6 étamines insérées à la base des divisions; filets égaux subulés; oraire trilocuiaire; style filiforme droit ; stigmate obtus. Capsule obscurément trigone, à 3 valves loculicides. Semences peu nombreuses, horizontales, sous-globuleuses, à testa crustacé. épaissi vers le raphé, noirâtre, cu d'un brın pâle. Enbryon axile, de la longueur de la moitié de l'endosperme, à cxtrénité radicale parallèlement conliguë à l'ombilic. - C'ar. spéce. Hampe nue, trìs longue, garnie dans les deux liers supérieurs de fleurs blanches formant une belle grappe, un peu resserrée en épi. Chaque fleur est accompagnée d'une bractéc réfléchie en arrière, "t comme géniculée au milieu de sa longuenr. Les feuilles, qui paraissent après les fleurs, sont toutes lig. 89.

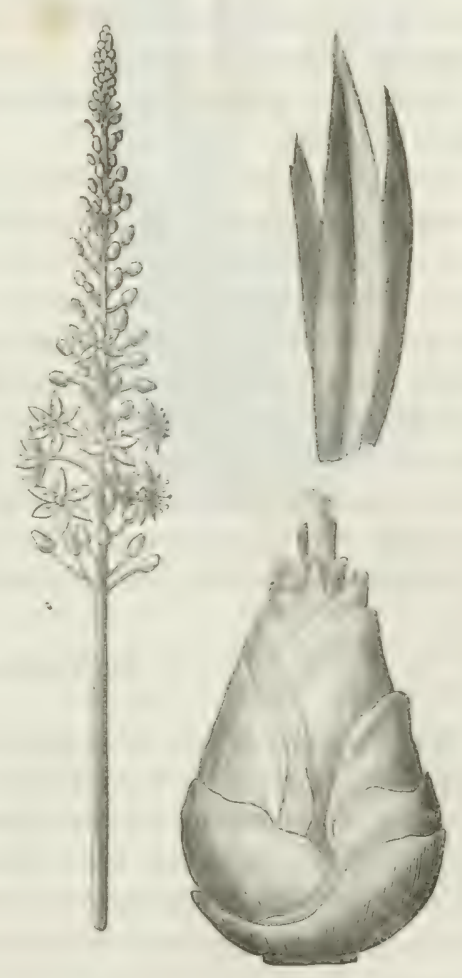
radicales, ovales-lancenlées, très grandes, charmues, glabres el d'un rert foncé. 
Cette plante crô̂t sur les còtes sablonnenses de la Mediterrance et de f'Océan. Son bulbe est très volumineux, composé de lunigues très nombreuses et serrées; il est rouge on blanc, suivant la rariété de la plante. La rariété rouge est la seule usitée en france, parce gu'on la croit plus aclive; taudis que la variété blanche se rencontre seule dans les pharmacies de l'Angleterre. Le bulbe de scille rouge nous est apportí récent d'Espagne et des îles de la Méditerranée. Ies premières tuniqques sont rouges, sèches, minces, transparentes, presque dépourvues du principe àre et amer de la scille; on les rejette. Les tuniques du centre sont blanches, très mucilarineuses et encore peu estimées. Il n'y a done que les tuniques intermédiaires que l'on doire empinter. Eilles sont très amples, épaisses et recouvertes d'un épiderme blancrosé; elles sont remplies d'un suc visquenx, inodore, mais très amer, trèsâcre et mème corrosif. Ces dcrnières propriétés se perdent en partic par la dessiccation, et l'amertume domine alor's. Pour faire sécher ces tuniques, on les coupe en lanières, on les enfile en forme de chapelets, et on les suspend dans une éture; il faut les y laisser longtempes pour être certain de leur entière dessiccation; il est nécessairc de les conserver dans un endroit sec, parce gu'ils attirent l'humidité.

La scille est employée en poudre, en extrait, en teinture, en mellite et en oximellite.

Suivant 11. Vongel, rqui a fait l'analyse du bulbe de scille, il est composé d'un principe particulier (scillitine) d'une amertume excessive, soluble dans l'eau et dans l'alcool, déliguescent, et aucuuel la scille doit une partie de ses propriétés, de sucre, de tannin, de gomme, de citrate de chaux, de fibre ligneuse, et d'un dernier principe àcre et corrosif, mais que l'iuteur n'a pu isoler (.1mn. de thim., t. LXXXII, p. !47). On troure également, dans le Inumal de pluminacie, t. XII, p. 63.5, l'exirait d'un travail de ir. Tilloy sur la scille, ducquel il réstalte que ce bublhe contient une matière grasse, en outre des principes dija nommés. Ni l'un ni l'autre de ces travaux ne nous fait connaittre complétement ta nature des principes actifs de la scille.

\section{Suc d'aloes on Mloes.}

Les aloi's sont de très belles plantes des pays chamds, qui appartiennent a l'hexandric monogynic et à la famille des litiacies. lilles sont remarquables par leurs feuilles épaisses, charnues, formes, cassantes, i bords dentés et piguants; leurs fleurs sont tubulées, sourent bilibiées, disposeres en épi sur mo long pédoncule qui sont du centre des fenilles.

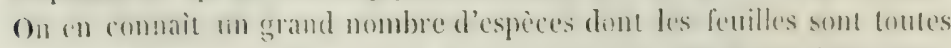

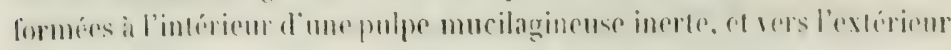




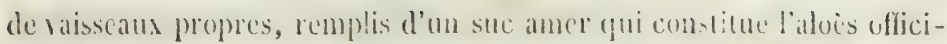
nal. I la rigueur, tontes les especes pouraient done fonruir ce produit

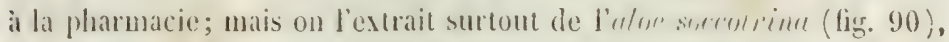
qui croit en Arabie, dans l'ile Socotora et diass toute la partie de l'Afrique qui est en regard. On l'extrait aussi, au cap de bonne lespérance, des aloe spicata et lingueforFivir. 90. mis; ì la Barbate et à la Jamaïgue des aloe vulgaris ou simuata. Les auteurs s'accordent peu sur le procédé au moyen duquel on en extrait le suc, d'où l'on peut conclure gu'il varic suivant les paýs. D'après les uns, les feuilles, coupées par la base, sont placées debout daus des tonneaux au fond desquels se rassemble le suc; ce procédé, sans doune peu productil, doit donner l'aloès le plus pur. Suirant d'autres, on hache les feuilles, on les exprime, et le suc, dépuré par le repos, est éraporé au soleil dans des rases plats. A la Jamaïque, on renferme les feuilles coupées par morceaux dans des paniers, et on les plonge pendant dix minutes dans l'ean bouillante. A près ce temps, on les retire et on les remplace par d'autres. On agit ainsi jusçu'à ce que la liqueur

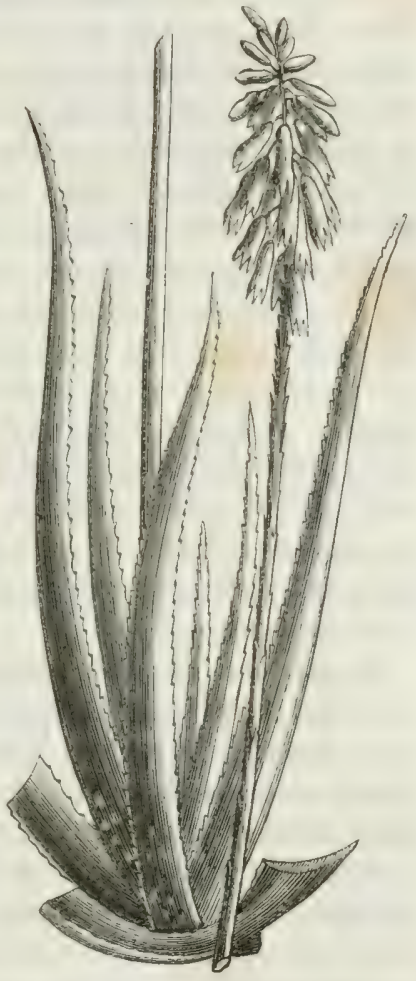
paraisse assez chargée: alors oil la haisse refroidir et reposer, on la décante et on la fait évaporer; lorsqu'elle l'est suffisamment, on la coule dans des calebasses, où clle acliève de se dessécher et de se solidifier. Dans d'autres pays on soumet directement les fenill s bachées it ha décoction dans l'eau. On conçcit combien les produits de ces différentes opérations doivent varier eil qualité. Voici d'ailleurs tes caractères de ceux que l'on trouve dans le commerce:

Aloes suecotrin ou mienx sncotrin. Cet alous a pris le nom de l'île Sucutora d'où il est principalement tiré; mais il en vient érgalement d'.1-

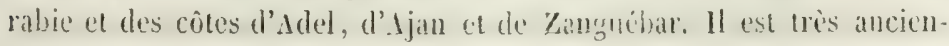


nement connu, car il n'est pats doutenx que ce ne soit la plus befle sorte d'alcès de Dioscoride, qu'il dit etre très andere, de bonne wdeur, pure, neue, fragile, facile à fundse, comparable an foie des animaus pour la coulenr et l'opiciti. Il renait anciennement par la roie de smyrne; mais aujourd'hui il arrive par celle de Bombay en Angleterre, oit il est trés estimé et d'un prix élevé. Il est très rare en France où l'on ne veut gŕnéralement que des drogues à bon marché. Il arrive contenu dans des poches faites avec des peaux de gazelle (I'éreira), renfermées ellesmêmes dans des tonneaux on caisses d'un poids considérable. La consistance en est très variable: la portion superficielle de change poche est ordinairement sèche, solide et fragile, tandis que la partie interne est sourent molle on même demi-liçnide. La couleur varie du ronge hyacinthe au rouge grenat; la cassure est unie, gylacée, conchoïdale; la poudre est d'un jaune doré. L'odeur est assez vire dans les échantillous récents, analogue à celle de la myrrhe, et toujours agréable.

Sous le rapport de la transparence, l'aloès succotrin peut être Iranslucide on oparque, sans que celle circonstance influe sensiblement sur sal qualité. Cés deux rariétés arrivent quelquefois séparées, et alors on donne plus spécialement à l'aloès translucide le nom d'uloés sncetrin, landis qu'on nomme celui gui est opacue alom hirpatique. Yais, le plus sourent, l'aloès translucide forme seulement des reines dans la masse de l'aloès opaque ou hépatique, qui est l'état le plus habituel de l'aloès socotrin.

J'ai reçu une fois de .u. P'éreira, sous le nom d'raluès hripatiqur rirui, un suc qui se distingue des deux précédents parce qu'il est tris dhe, tris f(nace el difficile à rompre. Ilalgré cela, il coule à la longue en s'arrondissant comme de la poix; il est opaque, de la coulcur du foie, d'une odeur douce et agréable; il est renfermé dans une poche de peau. Il e'st certain, malgré son caractère de duretí et de ténacité, que cet aloès est une simple varićté des deux précédents, et qu'il est retiré de la même p'ante, qui parait être, ainsi que je l'ai dit, l'aloe sucotrina.

L'aloès socotrin pulvérisé, trituré arec de l'eau, s'y divise facilement et finit par s'y dissoudre complétement en formant un liquide sirupeux, d'un jaunc très foncé. En ajoutant une plus grande quantité d'eau à ce lisfuide, on le décompose el l’aloès s'en précipite en partie sous forme d'une poudre jaune, qui se réunit an fond du vase en une masse plus ou moins molle ou cohérente.

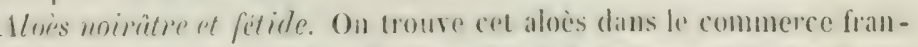
cais depuis quelgues amnées. Il ressemble il l'alowes socotrin par fe wolume et la nature des poches gui le comtienumemt; mais il est d'un brun noiratre, d'une ofleur animalisée el comme un pen putride. Iorsqu'il r'st desséché il e'sl fragile, tantòt preserntant une cansure luisante el de 
couleur un peu hépatique; tantôt sa cassure est terne, granuleuse ct se rapproche de celle de l'aloès barbade. Il paraît aussi contenir, dans certaines parties, des pierres, du sable ou d’autres impuretés. La forme des poches indique que cet aloès provient des mêmes localités que l'aloc̀s socotrir, tandis que sa couleur et son odeur différentes pourraicnt faire admettre yu'il n'est pas tiré de la même plante. Je présume que cêt aloès est celui que .1. P'éreira décrit sous le nom d'uloris molice.

Aloès de l'Inde ou mosambrun. On trouve dans les bazars de l'Inde plusieurs rarjétés d'aloès qui paraissent être noirâtres, d'une cassure terne et d'une qualité inféricure. M. Péreira en distingue sommairement quatre sortes sous les noms d'aloès de l'Inde sejtentrionale, de Guzerate, de Solem et de Trichinupoli. Elles peurent aroir été préparées dans l'Inde ou y avoir été apportées d'Arabie.

Alop's du crup de Bomne-Espróramere. Cet aloès paraît être tiré à peu près indifféremment des différentes espèces d'aloe qui croissent dans les environs du Cap, et être obtenu par éraporation sur le feu du suc écoulé sans expression, des feuilles coupées. I)'après 11. G. Dunsterrille, rité par u. Péreira, le suc concentré serait ensuite versé dans des caisses en bois d'environ un mètre de còté sur 0,33 mèt. de hauteur, ou dans des peaux de bonc ou de mouton; mais je ne l'ai jamais in, dans le com-merce français, que renfermé dans des caisses de bois dans lesguelles il forme une seule masse d'un poids considérable, d'une couleur brune noirâtre avec un reflet verdàtre à la strface. Il paraît opaque, ru cu masse, à cause de sa couleur foncée; mais il est très généralement transparent dans ses lanes minces et d'un rouge foncé. Sa poudre est jauneverdâtre; sa saveur est trì's amère; son odeur aromatique, forte, tout à fait particulière et peu agréable, telle qu'on est habitué en France à la regarder comme le sspe de l'odeur de l'aloès. Trituré avec de l'eau dans un mortier, cette odeur devient encore plus forte et l'aloès se réduit in une masse molle sur la fuelle l'eau froide a peu d'action. Le soluté est, d'après cela, d'un jaune peu foncé.

Cet aloès, malgré sa bonne préparation et sa pureté habituelles, est très peu prisé en Ingleterre, où il passe pour être beaucoup moins purgatif que les autres sortes. En 1831, il y valait seulement 6j cen. times les 500 grammes, tandis que l'aloès succotrin translucide coûtait $8 \mathrm{fr}$. $55 \mathrm{c}$., l'aloès hépatique $5 \mathrm{fr}$. $75 \mathrm{c}$., et l'alvès des Barbades $4 \mathrm{fr}$. 50 c. En krance, on le rend encore generalement comme aloies socutrin. Pour faire cesser cette coufusion, je mets ici en regard leurs principales différences. 


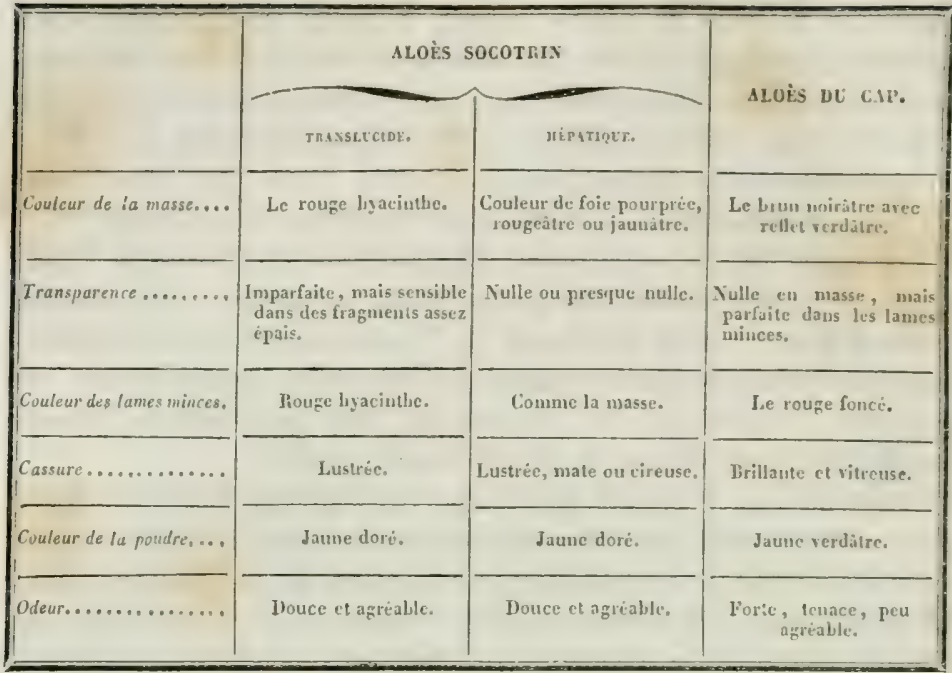

Aloìstu Cap, opaque. L'aloès du Cap n’est pas toujours transparent,. comme celui que je viens de décrire. Quelquefois il est brun, cntierement opaque, et alors on le vend comme aloës hépatique; mais il possède tous les autres caractères de l'aloès du (ap), dont il paraît cetre une qualité impure, prorenant de l'évaporation d'une liqqueur trouble, la liqueur supérieure et transparente ayant fourni la prenière ģualité. Cet aloès opaque est sec, fragile, non coulant et donne une poudre verdâtre; il n'a aucune des qualités du réritable aloc̀s hépatique et ne doit pas lui être substitué.

Aloès burbade. Cet aloès est envoyé de la Jamaïque et de la Iarbade renfermé dans de grandes calebasses. Il doit être extrait des clve tulgaris et sinuuta. Il est d'une couleur rougeâtre terne, analogue à celle du foie, derenant à la longue presque noire à sa surface. Il a une cassure terne, sourent inégale ou comme un peu grenue; il est prescjue opaque et moins fragile que l'aloès du Cap). Il a une odeur analogue à celle de la myrrhe, assez forte et qui ofre quelque chose de l'odeur de l'iode. Il donne une poudre d'un jaune rougeattre sale, qui devient d'un rouge brun à la lumière. Triture arec de l'eau, il s'! divise plus contplétement que l'aloès du Cap, et donne un soluté pilus colosé. Son odeur ne s'accroît pas par ce moyen, et clle se troure alors plus faible yue celle du premicr.

1hris colullin. On nomme ainsi tout aloès très impur destiné it l'usage des cheraus, parce qu'il est recu, en lance surtout, que ces précieux animaus doirent juende tout ce gu'il y a de phos mausais el de 
plus détérioré en fait de wédicaments. L'aloès caballin se prépare done, soit dans les divers pays qui nous fournissent cette substance, arec le dépôt des liqueurs, soit en Espagne ou au sénégal arec le's aloès qui s'y trourent et en les traitant par décoction. J'en ai deux sortes bien distinctes: l'une est évidemment formée du pied de l'aloès du Cap, que l'on observe assez pur à la partic supérieure de la masse; l'autre est en masses tout à fait noires, oplaques, à cassure uniforme, non fragiles, difficiles à pulvériser par trituration. Il parait gommeux sons le pilon, et donne une poudre verdâtre qui se délaie facilement dans l'eau, en formant un soluté brun.

L'aloès est un purgatif très échaufant qui ne convient pas à tous les tempéraments. Il entre dans la composition de beaucoup de masses pilulaires et dans celle des élisirs de Garus, de longue vie et de propriété de Paracelse. On en prépare aussi une teinture alcoolique simple et un extrait aqueus. Les chimistes ne sont pas encore fixés sur sa composition. Plusieurs, se fondant sur ce que lit dissolution arqueuse d'aloès, faite à chaud, se trouble et dépose une matière d'apparence résincuse par le refroidissemeni, l'ont cru formé de deux principes : de misine qui se précipite et d'estractif qui reste en dissolution. 11. Braconnot, au contraire, a regardé l'aloès comme formé d'une seule substance résinoüde, qui, étant plus soluble dans l'cau à chaud qu'à froid, s'en précipite en partie par le referoidissenent. Ce mème principe est soluble dans l'éblıer

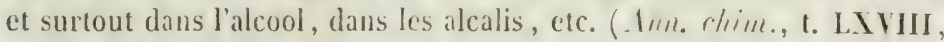
p. 20 et 155 ). 3. Berzélius est d'une opinion mixte. Suirant lui, l'aloès est essentiellement formé d'un principe primitif incolore, également soluble dans l'eau et dans l'alcool, yui, sous l'infuence de l'air, derient coloré, insoluble dans l'eau froide (apothème), un peu soluble dans l'eau bouillante, toujours très soluble dans l'alcool. Cec corps, mélangé à l'extractif non altéré, constituerait l'aloès du commerce. D'autres chimistes ont adnis dans l'aloès une livile volatile facile à obtenir par distillation, de l'acide gallique libre et quelques sels à base de potasse et de chaux. D’autres enfin se sont moins préoccupés de déterminer la nature propre de l'aloès que d'en obtenir par l'acide nitrique, ou par d'autres corps oxydants, de noureaux corps acides, colorés, susceptibles de nombreuses applications dans la teinture. Tels sont l'acide prolychronatique de M. Boutin, l'acide chrysolépique de II. Schunck, etc.

\section{Résines de Xanthorrhoea.}

Les xanthorihre sont des rérgétaux de la Youvelle-Hollande, appartenant à la tribu des asphodélées. Leur tige est ligneuse, très courte ou arborescente, simple ou divisée, gan ne de feuilles touffues, très longues 
ct tres étroites; elle produit une flèche terminale, longue de plusicurs mètres, torminée elle-même par un épi écailleux de fleurs très sórtées. Le fruit est une capsule trigone ct triloculaire, à semences noires et crustacées. Ces arbres laissent exsuder de Jeur trone une résine odorante et balsamique, dont la couleur varie suirant les espèces, et dont la concordance spécifique n'est pas parfaitement connue.

Rirsine jume de cronthorrhere. Cente résine est attribuée au druthervhre leustilis, ainsi nommé de l'usage que les naturels de la YouvelleHollande font de sa hampe, longue de 3 à 5 mètres et grosse environ comme le pouce, pour en faire des sagaies. Elle est en larmes arrondies, d'un volume variable, dont un grand nombre sont remarquables par leur forme parfaitement sphérique. Elle est d'un jaunc terne et brunâtre à l'extérieur, opaque et d'un jaune pur à l'intérieur, assez semblable à de la gomme gutte, mais d'une couleur braucoup plus pâle, et ne pouvant pas s'émulsionner par l'eau. Elle posside, lorsqu'elle est récente, une odeur balsamique analogue à celle des bourgeons de peuplier, mais beaucoup plus agréable. Cette odeur s'affaiblit et disparaît presyue, arec le temps, dans les larmes entières; mais elle se manifeste toujours par la pulvérisation ou la fusion à l'aide de la clialeur. La résine se dissout dans l'alcool à 40 degrés, en laissant environ 0,07 d'une gomme insoluble dans l'eau, analugue à la bassorine. Elle dégage, par l'action de la chaleur, une rapeur blanche pourant se condenser en petites lames brillantes, que Laugier a prises pour de l'acide benzoïque (Am. chime, t. LXXVI, p. 273), mais qui, d'après II. Stenlouse, sont en grande partie formées d'acide cimmanique (I/larmaceufical Jumal, t. VI, p. 88). Cette résine jouit donc de la composition et des propriétés générales des baumes, et serait employée arecgrand avantage dans les parfums.

Risire brume de exunthorrhern. Cette résine possède une odeur encinte plus développée et plus balsamique que la précédente; ses larmes sont arrondies, d'un brun rouge foncé à l'extérieur, et ont presque l'apparence du sang-dragon; mais elles ont une cassure brillante et vitreuse, une transparence parfaite en lames minces, et une couleur rouge hỵacinthe. Cette résine diffère de la précédente, surtout par l'absence de la gomme, car clle se dissout complétement dans l'alcool. Elle contient aussi plus d'huile volatile qui la rend visqueuse et collante dans quelques unes de ses parties.

brisine rouge de adanthorrhera. Ciette résine, telle que je: la possède, an lien d'ètre en larmes isolées, présente la forme de croùtes épainses, entremêlées d'écailles ou d'appendices foliacés, et paraissant arnir été détachées de la surface du trone de l'arbre, gue l'on suppose cutre le

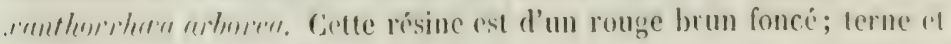


quelguefois councile d'me poussière d'un rouge vif, qui la fait toun a fait ressembler i du sang-dragon; mais elle a une cassure ritreuse, et se montre transparente et d'un rouge de rubis dans ses lames minces, ce qui n’a pas lieu pour le sang-dragon. Elle est complétement dépourvuc d'odeur à froid, on en conserve une balsamique plus on moins marquée; mais elle est toujours odorante à chaud; elle est complétement soluble dans l'alcool, à l'exception des parties ligneuses interposées.

\section{FAMILLE DES ASPARAGINÉES.}

Végétaux dont les fleurs sont tellement semblabies à celles des liliacées que plusieurs botanistes en font une simple tribu de cette fanille, fondée principalement sur la nature de leur fruit, qui est une baie an lieu d'être une capsule à trois loges. Tous les autres caractères sont variables et n'offrent pas la constance que l'on observe dans les raies liliacées. Ainsi nous trourons dans les asparaginées d'humbles plantes herbacées qu'une saison voit naître et flitrir (le muguet), et des arbres d'une étendue colossale et d'une durée qui semble défier la destruction (te dragonnier des Canaries). Les feuilles peuvent être alternes, opposíes ou verticillées, quelquefois très petites 't sous forme d'écailles. Les fleurs sont hermaphrodites ou unisexuées; le périanthe est à 6 ou s divisions profondes, disposées sur 2 rangs. Les étamines sont en nombre égal aux divisions du pirianthe et attachées à leur base. Les filets sont libres ou quelquefois soudés cusemble. L'oraire est libre, à 3 luges, rar'ment plus ou moins; le stỵle est tantôt simple, surmonté d'un stigmate trilobé, tantôt triparti ct pourru de trois stigmates simples, distincts. Le fruit est une baie globuleuse ordinairement à trois loges, quelquefois uniloculaire et monosperme par avortement. Les graines sont pourvu's d'un endosperme charnu ou corné contenant, dans une cavité assez grande, un embryon cylindrique guelquefois très petil.

Les asparaginée's forment 2 tribus: $1^{\circ}$ les paridées dont les stigmates sont séparés; genres paris, trillium, medeola; $2^{\circ}$ les asparayries dont le stigmate est simple et seulement trilobé; genres dracana, aspraragus, polygonatum, convallaria, smilax, ruscus, etc.

\section{Fleur de Mnget.}

Comealluria maialis, I. Cette plante, dont la racine est vivace, fibreuse et traçante, produit des hampes droites, très fines, rondes, glabres, hautes de 135 i 165 millimètres, garnies à leur base de 2 feuilles oval's-lancéolées, enveloppées ainsi que les 2 feuilles par plusieurs zuânes membraneuses, et terminées supérieurement par 6 à 10 fleurs 
petites, en forme de grelot, pendantes d'un mèue coté, blanche's el d'un parfun très agréable. Elle flem it en mai et en juin, dans lés bois de la lirance et du nord de l'Europe. Les fleurs, séchées et pulvérisécs, sont usitées comme sternutatoires.

\section{Hacine de Scean-tle-Salomon.}

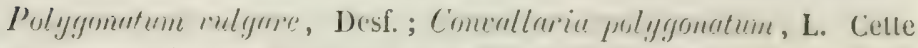
plante ressemble beaucoup au muguet, mais elle est plus élerée. Elle donne naissance à une ou plusieurs tiges simples, hautes de 30 centimètres ou plus, anguleuses, un peu courbées en arc, garnies dans toute leur partie supérieure de feuilles ovales, glabres, amplexicaules et tournées d'un seul côté. Les fleurs sont pendantes, d'un blanc un peu verdatre, solitaires ou portées 2 ensemble sur des pédoncules axillaires. L.e périanthe est d'une seule pièce, cylindrigue, un peu élargi en entonnoir, terminé par 6 dents aiguës. La racine est virace, horizontale, longue, articulée, grosse comme le doigt, blanche, charnue, garnie inférieurement de beaucoup de radicules. Elle possìde une sareur douccàtre; elle est astringente el cmployée comme cosmétique.

\section{Racine de Fragon épineux ou de Petit-Houx.}

Riuscus aculeatus (fig. 91). Cir. yrin. Feurs ordinairement dioïques; périanthe coluré, à 6 divisions ourentes, persistantes, dont les trois intérieures un peu plus petites. 3 ou 6 étamines soudéés en un çlindre renflé; anthères attachées au sommet du ç̣lindre, réniformes, à logges écartées, nulles dans les fleurs femelles. Ovaire triloculaire, avorté dans les fleur's mâles; 2 ovules collatéraux dans charque loge; style très court; stigmate globuleux; baie globuleuse, uniloculaire et sourent monosperme par arortement. - Crer. spréc. Feuilles mucronces-piquantes portant une fleur nue sur la face supéricure.

Le fragon épineus ou petit houx est un petit arbrisseau toujou!s vert à tiges rertes, glabres, cylindriques et cannelées, ramiliées, garnies de feuilles très entières, fermes, consistantes, orées-aiguës, terminces par une pointe piquante. Ces feuilles sont accompagnées, en dessous, d'une stipule cadtique. Les fleurs sont dioïques; elle's sont portées sur un pédoncule axillaire soudé arec le limbe de la fenille juscju'au tiers de sa longueur environ, et elles sont accompagnées d'une petite bractic caduque. Aux fleurs femelles succide une baic rouse sphérique qui, jointe an fenillage vert et pirquant de la plante, l'a litit comprarer an houx commun (ilere annifielium) et lui a valu son nom vulgaire. Le's tiges du petit-houx durent dius ans, et sont remplacées par moitic, chatgue 
amnere, par de nourelles pouses gui, forsfunelles cemmencent ì se montrer, peurent se manger comme colles de l'asperge. La racine est blanchàtre, grusse comme le petit doigh, longue, noueuse, articulée,

Iig. 91.

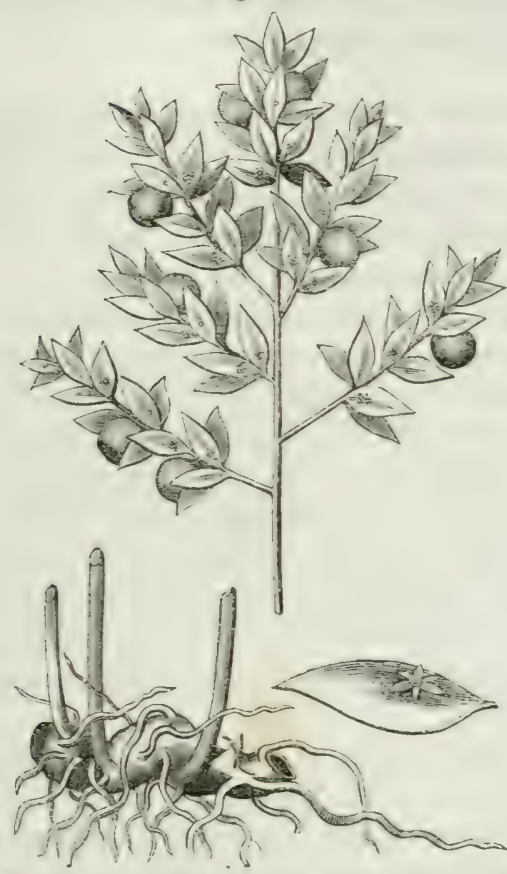
marquéc d'anncaux très rapprochés. El'e est garnie, du côté inféricur surtout, d'un grand nombre de radicules blanches, pleines et ligneuses. La racine sèche présente en masse une légère odem lérébinthacée; la saveur en est à la fois sucrée et amère. C'est une des cinq racines apéritires.

On peut employer, concurremment arec la racine de petit houx, celle de dleux espèces voisines : l'une est l'hypoglosse ou bislingue (muscus hypoglossum, I. ), dont les feuilles sont beaucoup plus grandes, allongées, plissées, accompagnées de stipules persistantes, et dont les fleurs diö̈ques et les fruits, portés sur la face superieture des feuilles, sont igalement munis d'une bractée foliacée persistante; l'autre espece est le lonerien ulefondrin (ruscus liypophlyllum, I. ), dont les fenilles, grandes, orales-lancéolaires, reinées, portent des fleurs à lenr face inférieure. Ces fleurs sont diö̈ques, pédonculies, et les fruits sont pendants; les stipules et les bractées sont caduques (1).

\section{Isperge el Racine d'Asperge.}

Aspraragus officinalis, I. Cur). grin. Fleurs hermaphrodites ou dioïques; pirianthe coloré à 6 divisions connirentes et en forme de cloche.

(1) Les bolanistes déerivent aujourd hui les fragons d'une manière différente. Pour eux, les cxpansions foliacées, anciennement regardées comme des feuilles, ne sont que des rameaus élargis, et les vérilables feuilles consistent dans les stipules el dans les bractee- caduques unu accompagnent les rameaux et les fleurs. 
6 étamines fixées ì la base des divisions; ovaire triloculaire, contenant diuns chague loge 2 orules superposés. Style court, à 3 sillons; stignatro trilobé. Baie globulense, rriloculaire; semences à test noir, corjace; ombilic rentral; embryon excentrigne, courbé, de la moitié de la longueur de l'endosperme. -- C'ar'. sprie. Tige herbacée, droite, çlindrique; feuilles sétacées.

L'asperge est cultivée dans toute l'Europe, à cause de ses jeunes pousses ou bourgeons verts, allongés, cylindrifues, qui fournissent un mets estimé, quoique rendant l'urine fétide. Lorsqu'on laisse croìtre ces jeunes pousses, elles s'élèrent jusqu’ì la hauteur de 1 mètre, cn se partageant en un grand nombre de rameaux gui portent des feuillessilacées, fasciculées, accompaguées à la base, ainsi que fes rameaux, de stipules persistantes. Les fleurs sont petites, campaniformes, verditres, pendantes, solitaires à l'extrémilé de pédoncules grèles et articulís an milieu, qui partent ordinairement deux ì deux de la base des raucaux ou des fascicules de feuilles. Le fruit est une baie spliérique, rougeâtre, de la grosseur d'un pois, renfermant des semences noires, dures at cornées. La racine est composíe d'un parguet de radicules de la grosseur d'une plume, fort longues, adhérentes à une souche conmune, presque horizontale et toute garnie d'écailles ces radicules sont grives au dehors, blanches en dedans, molles, glutincuses el d'une sarcur donce. Elles sèchent difficilement.

La racine d'asperge a été analşsée par .11. Dulong, pharmacien à

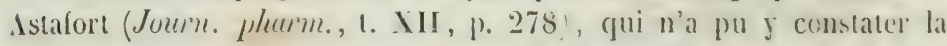
présence des principes particuliers extraits par Robiquet des jeunes pousses de la plante. Le suc exprimé de ces pousses contient une mattière verterésineuse, de la cire, de l'albumine, du phosphate de potasse, du phosphate de chaux tenu en dissolution par de l'acide acéticjue libre, de l'acétate de potasse; enfin, deux principes cristallisables que Vauquelin a reconnus depuis pour ètre, l'un de la mannite, l'autre un principe immédiat particulier, qu’il a nommé asporengine.

L'asparagine est insoluble dans l'alconl, peu soluble dans l'eau froide, plus soluble dans l'eau bonillante, et cristallisable en prismes droits romboüdanx. Sa dissolution n'affecte en aucune manicre le tomrnesol, la noix de galle, l'acétate de plomb, l'oxalate d'ammoniaque, le chlorure de barium et le sulfhydrate de potasse. Elle conticnt de l'azote an nombre de ses éliments, et sa composition est telle gu'elle preut citre représentée par de l'anmoniaque combince à un acide particulier qui a reçu le nom d'uride aspurlique : aussi se décompoe-t-elle facilement en ces deux corps, sous l'influence d'un acide minéral ou d'un alcali

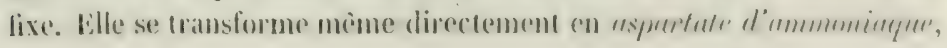


forsqu'on l'abandonne ì l'élat de dissolution acpueuse. Voici les formules de celte réaction :

L'asparagine cristallisée $=\mathrm{C}^{8} 11^{10} \mathrm{Az^{2 }} \mathrm{O}^{8}=\mathrm{C}^{8}\left[1^{8} \mathrm{Az}^{2} \mathrm{O}^{6}+\mathrm{II}^{2} \mathrm{O}^{2}\right.$.

l.'acide aspartique cristallisé $=\mathrm{C}^{4} \mathrm{11}^{7} \mathrm{Az}^{8}=\mathrm{C}^{8} \mathrm{H}^{5} \mathrm{AzO}^{6}+1 \mathrm{I}^{2} \mathrm{O}^{2}$.

$$
\mathrm{C}^{8} \mathrm{H}^{10} \mathrm{Az}^{2} \mathrm{O}^{8}=\mathrm{C}^{8} \mathrm{II}^{7} \overline{\mathrm{Az}} \mathrm{O}^{8}+\underline{H}^{3} \overline{\mathrm{Az}} \text {. }
$$

I.a racine d'asperge, de même que celle de petit houx, fait partic de celles qui sont employées collectirement sous le nom des rinq racines rpreitices. Les trois autres, les racines d'ache, de persil et de fenouil, appartiennent à la famille des ombellifères.

\section{Racine de Squine.}

Similac china, L. Les sinilax sont des plantes ligneuses, pourvues de tiges volubiles et très sourent épincuses; les feuilles sont alternes, pétiolées, cordées ou hastées, à nerrures réticulées, accompagnées de stipules sourent conrerties en rrilles. Les feurs sont disposéces en petits corvmbes ou en ombelles axillaires, quelquefois on longues grappes; elles sont diö̈ques et pourvues d'un périanthe à six divisions. Lés étamines sont au nombre de six, à filaments filiformes libres, à antheres linéaires dressées; l'ovaire est à 3 loges uni-urulées; il est surmonté d'un style très court el de 3 stigmates écartés. Le fruit est une baie à 1 ou 3 loges, contenant un même nombre de semences blanchàtres, à ombilic basilaire, grand, coloré. Il en existe une espèce très épineuse et à fruits rouges (smilax aspera), (t une autre moins épineuse et à fruits noirs (smilax nigre, W.), toutes deux communes dans les contrées méridionales de i'Europe; mais toutes les autres espèces apparliennent aux contrées chandes de l'isie, de l'A frique et de l'A mérique.

La squine, cn particulier (smilat china), croît naturellement dans la Chine et au Japon; sa racine, que le commerce nous fournit, est longue de 15 à 20 centimètres, épaisse de 4 à 5 , un peu aplatie, et offrant beaucoup de nodosités tuberculeuses. Son poids varie de 120 à 280 grammes. Elle est courerte d'un épiderme rougeâtre assez uni, sourent luisant, dépoureu de toul cestige d'écaille's ou d'onneaux. A l'intéricur, clle noffre pus de fibres ligneuses apparentes, mais sa conleur et sa consistance varient: tantôt elle est spongieuse, légère, d'un blanc rosé, facile à couper et à pulvériser; d'autres fois, elle est très pesante, très dure, d'une couleur brunâtre, surtout au centre, et gorgrée d'un suc gommeux-extractif desséché. Elle n'a qu'une saveur peu sensible et farineuse; elle conticnt beaucoup d'amidon, de la gomme et un principe rouge et astringent soluble dans l'eau.

La squine a acquis me sorte de cílébritr comme antivénérienne et 
antigontfense par l'usage qu'en a fait charles-0uint. File est encorc employéc seule ou associéc à d'autres sudorifiques.

Plusieurs autres espèces de smilux ont été supposées fournir la racine de squine, jusqu'à ce que la réritable plante eùt été décrite par Burmann. Telles sont la fausse squine d'Amboine, de Rumphius (smilrus zeylenict, I.), et les différentes plantes américaines qui ont ité confondues sous te nom commun de smiln. piseudo-chinm. - J'ai quatre racines de ce genre:

$1^{\circ}$ Sifuime de Horraccilo, tronvée mélangée dans la salsepareille de Maracaibo; elle est forméc d'une souche horizontale peu volumineuse, ligneuse, rougeatre, toute courerte de mamelons arrondis, de chacun desquels sort une racine fort longue, privée de son ćcorce et réduite à l'élat d'un méditullium ligneux, d'un brun rougeâtre, lisse et cỵlindrigue, avec ruelques pointes piquantes de radicules. Cetle racine présente la mène disposition de partics que la salsepareille, mais clle s'en distingue par le principe colorant rouge et astringent qui caractérise la squine.

2" Fuusse squine de Clusius, Pocayo de Recchus. Cetue seconde espèce, d'origine américaine égalemnet, constitue une souche ç lindrigure, annincie en pointe à ses extrémités, longue de 25 centimètres, ou plus courte et plus épaisse, orö̈de-allongée, de laquelle naissent des tubérosités latérales ayant la forme d'une pomme de terre. Ces souches porlent çà "t li, sur toute leur surface, des mamelons terminés chacum par une racine ligneuse; mais ces racines manquent. De plus, dans l'intervalle des mamelons, on roit des franges circulaires, semblables a celles des soucheis et des galangas, ct qui sont des restiges d'insertion d'ícailles foliacécs. I l'intérieur, cette souche est dure et compacte; la scie s produit me coupe uniforme, faure on d'un jaune rungeatre, arec un pointillé de raisseaux fibreux dispersés dans la masse. Cette racine se trouve figurce daus les Eicutice de Clusins, p. 83, et dans les Plant. nov. lisp. de Recchus, p. 398.

3o Sypune de Tüpurs. Celte racine, que je dois a l'obligeance de I. Iagonty, me paraît appartenir à la mème espèce que la frúccidente; (لlle a élé récoltée près de Tèques, dans la Colombie, vir clle porte le nom de iniz de china (racine de sguine). E!le est longue de 50 centimètres, épaisse de 5 à 7 , et pèse 6 乌 10 grammes; clle est un peu aplatie on anguleuse, amincie aux extrémités, en partic courerte par des ícailles foliacies disposées par bandes circulaires, ct pourve de mamefons épars d'où partaient les racines. La substance intérieure est semblable a celle ci-dessus.

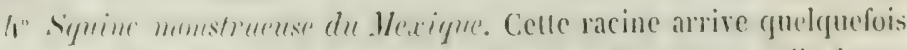

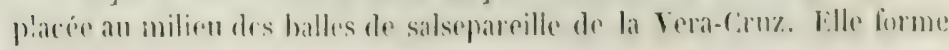


des souches monstrueuses, longues de 50 centimetres, épaisses de 10 , noureuses et articulées, du poids de $2^{\text {h }}, 500$, phus ou moins. Elle est dépourvue de franges circulaires et d'écailles foliacées, et ne présente que des mamelons peu apparents, d'ou sortent des racines déponillées de leur partie corticale, et réduites à l'état de longues fibres cylindriques, noires et brillantes à l'extéricur, rouges et complétement ligneuses à l'intérieur. Ia souche elle-mème est complétement ligneuse, d'un rouge foncé; elle prend sous la scie la couleur de le poli d'un bois d'acajou foncé à l'air.

Cette racine, autant par ses caractères que par le lien de son origine, me parait être le slimn michuonensis de Plumier fédition de Burmann, pl. 83 ), et le rhime mirhumensis ou phluen d'Hernandez. (Receh., p. 213$)$.

\section{Racine de Salsepareille.}

Les salsepareilles sont des plantes sarmentenses et volubiles, appartenant au genre smilnx, qui croissent dans toutes les contrées chaudes de l'Amérique. Leurs racines se composent d'une souche ligneuse et peu rolumineuse, (qui se propage par des nodosités naissant les unes ì côté des autres, et pourvoes d'un grand nombre de radicules fort longues, grosses comme une plume à écrire 't flexibles. Ces radicules sont formées d'une partie corticale succulente à l'état récent, et d'un méditullium ligneux à longues fibres parallèles, qui les parcourt d'un bout à l'autre, ce qui les rend difficiles à rompre transwersalement, mais très faciles à fendre dans le sens de leur longucur. Quatre espèces de smiln. sont citées surtout comme étant la source des différentes sortes de salseparcille qui nous sont fournies par le commerce.

Similax sarsaparilla, L. Tige anguleuse, sous-tétragone, munic d'épines éparses, recourbées. Feuilles de 5 centimètres est plus, oréeslancéolées, aiguës, qquelquefois un peu dilatées à la base, à 3 nervures élerées et épaisses; offrant en ontre sur chaque côté une nerrure peu marquée.

Certe plante habite le Nlexique et différentes parties de l'Amérique septentrionale.

Smilerix medica, Schlechtendahl (fig. 92). Tige anguleuse, armée rers les joints d'épines droites, arec quelques unes crochues dans les intervalles. Feuilles courtement acuminées, unies, non épineuses, à 5 ou 7 nerrures; les inférieures cordées, auriculées-hastées; les supérieures cordées-ovales. Cette plante croît sur les pentes orientales des Andes du Iexique. La racine qui en proviert est transportée à la Vera-Cruz, des villages de Papantia, Taspan, Nautla, Misantla, etc.

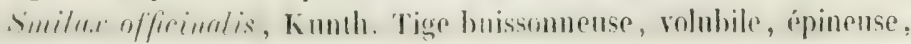


quadrangulaire, unie. Les jeunes jets sont nus et presque ronds. Fenilles ovales-oblongues, aignës, cordées, réticulées, à 5 ou 7 nerrures; elles sont coriaces, lisses, longues de 33 centimètres et larges de 11 it 15 centimètres. J.es jeunes feuilles sont étruites, acuminées, à 3 nervures.

Fig. 92.

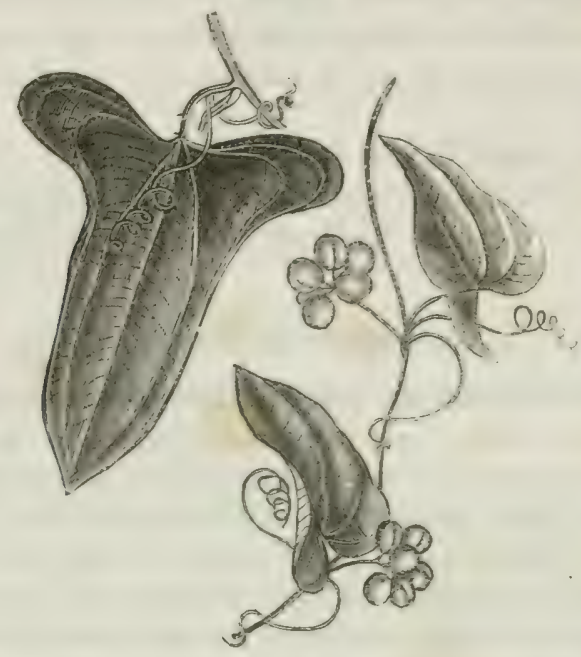

Cette plante croît sur lis bords de la Hagdcleine, dans la TourclleGrenade; on en transporte une grande ynantite à Carthagène et a Montpox.

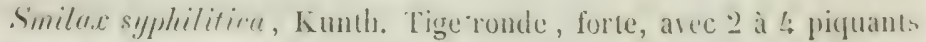
droils, seulement vers le's nauds. Feuilles orales-lancéolées, a 3 nervures, coriaces, lisses et luisantes, lungues de 33 centimètres. MII. de Ilumboldt et Bonpland ont observé cette plante dans la Colombie, près la rivière de Cassirguiare, et .I. Martins l'a trour cie au Frésil, à Yupura et à Rio-Negro.

On peut compter encore au nombre de's smilus qui conconrent à la production des salsepareilles du commerce:

Les Smilax laurifolia, Willd. - Intilles et Caroline.

$$
\begin{aligned}
& \text { - macrophylla, Willd. - Antilles. } \\
& \text { - obliquata, Poiret. - Pérou. } \\
& \text { - papyracea, Poiret. - Brésil. }
\end{aligned}
$$

II y en a probablement beaucoup d'autres.

\section{Deseription des Salsepareilles du commerce.}

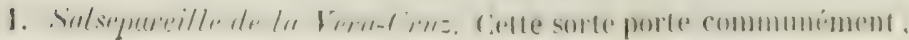




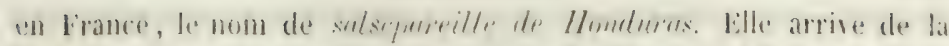

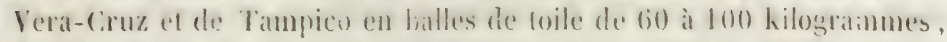
dans lespuelles les racines sont fortement assujeltics arec des cordes. Ces racines sont longues de 1 mètre à $1^{m}, 65$, presque dépourvaes de radicules, et sont garnies de leurs souches et de troncons de tiges. Les sonches sont grises à l'extérieur et blanchâtres à l'interieur; elles reliennent entre leurs nodusités une terre noire et dure, fui paraît arvir écé détrempée d'eau arant sa dessiccation. Les ligges sont jaunâtres, nouenses, giéniculées, presque cylindriques ou obscurément tétragones,

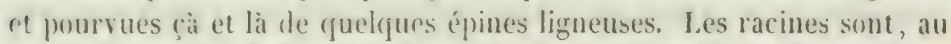
dehors, d'uic couleur noiratte, a cause de la terre gui les recoure: -lles offrent des cannelures longitudinales, profondes et irrégulieres, dues à la dessiccation de la partie corticale. Cotte partie corticale est rosée à l’intérieur, el recourre un coeur ligneux blanc, cylindrique, qui se continue d'un bout à l'antre de la racine. Ce coeur ligneux n'a qu'une saveur fade cot amylacée; mais la partie corticale en possède une mucilagineuse, accompagnée d'anertume et d'une légère àcreté. Ia racine ('ntière possède une odeur particuliere, qui se développe singulièrement par la décoction dans l'eau.

La salseparreille de la Vera-Cruz est sujette à être altérée par l'humidité, surtout dans l'intéricur des billes gui paraissent aroir ité serrées avant que la racine fùt complétement siche. Jais lorsqu'clle a été préservée de cette altération et quon la prive de la terre qui la salit cxtérieurement, et de ses sonches, qui sont moins actives que les racines, c'est une des sortes les plus efficace's. i'ai écrit anciennement que cette

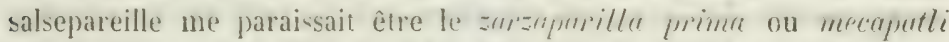
d'Hernandez, quil dit croitre dans les vallées et proche des fontaines qui fonrussent de l'eau à llesico, et parrillement a lampango et dans

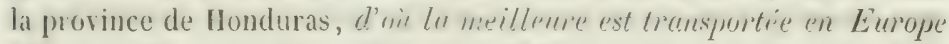
(Recch., Rerum med. not. hist., p. 28s, et Harcorav., Bres., p. 11).

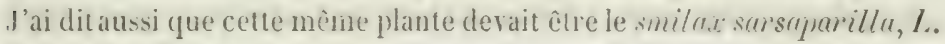
lujourd'hui qu'il me paraîl cerain que deux plantes et deux racines ont été comprises on confondues sous un seul nom par llernandez, j'aturibue plus spécialement la plante du Mesique et la racine de la VeraCruz au smilas medira de Schlechtendahl, et la plante et la racine de la province de Honduras au smilax sarsaparilla.

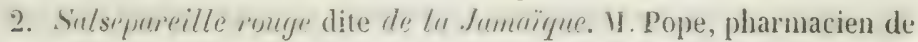
Londres, qui, le premicr, nous a fait comaintre cette racine, est d'aris qu'elle ne vient de la Jamaïque que par roie de transit, et que c'est un produit non cultivé de guelque partie du continent mexicain. Il est probable, en effert, qu'elle vient de la prescgu'ile de Honduras, et que c'est là la salsepareille superienure de Honduras dont parle Hernande\%, que 


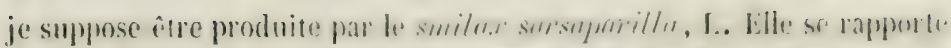
igalement it la salsepareille de Ilonduras de Vicolas Monardis, que cel auterr dit être plus palle et plus grole que celle du Mexique; celle-ci étant noirâtre el plus grosse icilus., simpl. med., cap. 22).

Celte racine vient en balles, comme la salsepareille du Mexigue; quelquefois isolée, d'autres fois mélangrée avec la première, dont ell. offre la forme générale. Cependant on y observe fuelgues différences. Les sonches sont moins ramassées on plus disposées en longneur; les tiges sont garnies d'épines iparses plus nonbreuses, plus fories et plus pirguantes, et les nœuds 'n offrent ordinairement tine rangée circulaire placée à la base d'une gâne foliacée; lorsque ces nouds se trourent aroir été recourerts de terre, ils se déreloppent en un tubercule ligneux, ct les épines se changent en racines, ce qui montre qu’elles ne sont que des racines arortées. Cette sorte présente donc souvent des souches espacées par des portions de tige derenues sonterraines, et comme disposées par étages. Lés racines sont nombreuses, longues de 2 mètres el plus, ridées et comprimées par la dessiccation, mais elles sont grêles ct entièrement propres nu privés de terre. Celte racinc se fend arec une grande facilité et sans aroir busoin d'être ramollie par une exposition plus ou moins prolongée a la cave, ce pui tient i ce gu'dle reste habitudlement plus liumide et plus souple que colle de la Vera-Cruz (elle contient une proportion plus forte de sel marin'. L'épiderme est ginéralement d'un rouge orangi, mas sourent aussi il est d'un gris rougeàtre ou blanchàtre, et ces deux conicurs ne constituent pas deux espèces différentes, car on les troure sourent réunies sur une mème souche. L'icorce, qui est moins nomrie que dans la première sorte, est sourent humide, comme il vient d'itre dit, et parait alors remplie d'un suc risqueux. lille a une sareur moins mucilagineuse, plus amère et plus aromatique. Il semble que celte salsepareille soit la racine d'une plante saurage ou cruc dans un terrain sec, et plus grêle, plus colorée, plus sapide, moins amylacée que celle de la plante cultivée. 11. P'ope et .11. Rubinet pensent que cette salseparcille est supé-

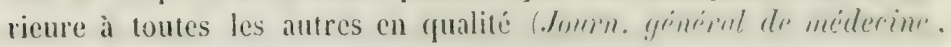
juin 1825).

3. Sulsepremeille dite des cutes. Cette salsepareille me me parait ètre autre chose qu'une qualité inférieure de la sorte précédente. Ville présente: les mèmes caractères généraux, mais clle est plus petite, plus grềe, plus sèche, d’un gris paile el jaunàtre, peu sapide et peu riche en principes actifs. Si la salsepareille rouge justifie par ses proprietés la superiorité qu'on lui accorde sur celle de la Vera-cruz, la salsepareille des cotes lui est certaincenent inferienre, (t n'arrive quatu troisieme rangr.

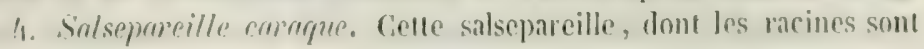




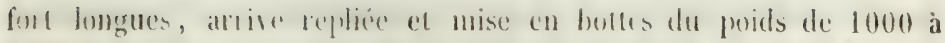
1500 granmes, longues de 6.5 centimetres ensiron, poursues de leurs souches et d'un cherelu assez considerable, assujentes par plusieurs tours de ses plus longues racines, el renfermées en grand nombre dans un rmballage de toile, comme la salsepareille du Mexigne. Elle est plus propre que celle-ci et non terreuse; elle est moins déformée par la dessiccation, étant généralement çtindripue el sentenent striée longitudinalement. Elle est tantòt presque blanche, d'antres fois rougentre à l'erlivieur, bien droite, et se fend aree une srande facilité. Elle présente un cœur ligneux blanc qui tranche agréablement avec le rouge bosé de l'écorce, lorsqu'clle a celte couleur.

Cette salsepareille, bien choisie, a donc une belle apparence, mais elle est presque insipide et tellement amylacée que, lorsqu'on la brise, it s'en échappe une poussiìre blanche d'anidon. Le's larres de villettes et de dermestes l'attarguent promplement el la réduisent en potissière. 1lalgre sa belle apparence, celte racine, élant presque privée du principe actif des salsepareilles, me parait deroir être rejetée de l'usage médical.

Beaucoup rle personnes attribuent !a silsepareille caracpue, soil an smilu,

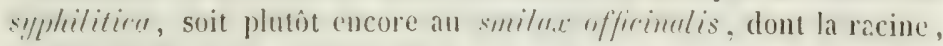
au dire de II. de IIumboldt, est transportie en grande quantité en Europe par la roie de Carthagène el de la Jamaïgue. J'ai combattu anciennement cette opinion, parce que ces deux smilex ont la tige épineuse, el cue je n’arais pas jusque la trouré de tigne épineuse dans la salsepatreille carraque; mais ayant obscrvé depuis quelgues tiges pourrues d'épines dans cette salsepareille, ce caractère me parait moins important, et j'admets ąujourd'hui que l'un ou l'autre des smilne décrits par .I. de Ilumboldt puisse prodnire lat silseparcille carayue. Cela ne change rien au jugement défarorable que je porte de sa qualité.

5. Sulsepureille de Y/armeribu. J'ai rencontrí une seule fois celte? racine, mise en pertites boltes longhes de ill centimètres, et entassées en travers dans des surrons en cuir qui ne recourent pas entièrement la marchandise. Le cuir est retenu arec dés lanières de même nature, disposées en lacet. Les racines sont conrtes, flexuenses, diffiziles à fendre, et portent beaucumpde cherelu. Du reste, elles sont rouges ou blanches, cylindriques et régulièrement striées, comme la précédente, ce qui semble indiquer qu'clles appartiennent à la même espèce. Ie's tiges sont quadrangulaires, verditres, sans aucune épine et un peu pubescentes. C'est dans cente sorte que j’ai trouvé l'espèce de squine dé. crite sous le nom de squine de Maracräbo.

6. Sulsepureillo du limiril dite de Ponturgul. Celte racine vient des

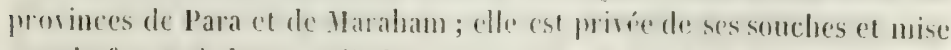

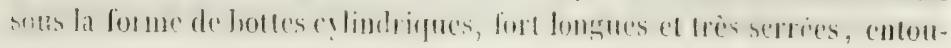




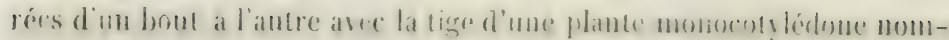
mée limbotition. Eille n'est jamais plus grosse qu'un pretit curan de plume; clle est d'un rouge terne of obscur à l'extérieur, cylincirique el marquée de stries longitudinales assez régulières. Fille présente moins de radicules que la salsepareille carague; mais beaucoup plus que cell. du Vexique. Vlle est blanche à l'intérieur et parait très amylacéc. Ville a une sareur un peu amère.

On troure parfois dans l'intérieur des bottes de salsepareille du Brésil des portions de souche et de tige. Celle-ci est radicantr par le bas. mulangulaire et pourrne, an moins dans la parlie qui aroisine la racine, d'un nombre considérable d'aignillons superficiels, disposés en lignes longitudinales et parallèles. Ces caracteres se rencontrent dans le smilax piquyracen de Poirct, que H. Wartins domne, en effet, comme la source de la salsepareille du Brésil.

Cette salseparcille a été très estimée ancienn-ment, et elle se vend cn. core plus cher que les autres, en raison de l'absence de ses souches. Iais elle est évidemment inférieure pour l'usage médical a célles de la Vera-Cruz et de Honduras.

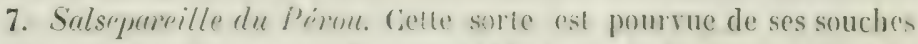
et elle tient li milieu, pour l'aspect géneral, entre les salsejareilles de la Vera-Cruz et de la Jamaïgue. Elle e.t propre el prive de terre, couverte d'un épiderme gris brunitre assez uniforme. Elle est plus grêle que la salsepareille de la Vera-tiruz, plus droite, mareguée de sillons moins profonds. Voici maintenant ce yui la distinceue, tant de la salsepareille de la Vera-Cruz que de celle de IIonduras on de la lamaïrque. Le méditullium ligneux, qui se trouve as:ez souvent mis à mu, est parfois coloré d'un rouge assez vif: les fubérosités d'où sortent lew tiges sont impregnées d'un principe orange, qui colore fortenemt, surtout, Ifs écaillés des bourgeons; enfin les tiges snnt manifistement phus voluminenses, mais elles sont spongieuses, ct leurs fibres ligneuses se laissent facilement séparer. Cefte salsepareille est sans doute produite par le smilax obliquata du Pérou.

8. Salsepurr ille mirutre, à grosses tiges aignillumbers. J'ignore d'oui rient cette salseparcille, yui offre d'assiz grands rapports avee la silsepareille du Pérou. lille forme des bottes considérables composées de racines et do souches. Les racines sont tries longnes, de la grosseur d'une petite plume, médiocrement cannclées, d'une contear générale brume noirâtre, peu amỵlacérs. Les sonches somt inluminenses, noires

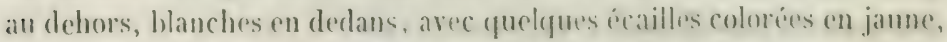
comme dans la salsepareille dn i'érout. Ies liges sont très erosses, maic peu consistantes, promrues d'un grand nombre d'angles marqués par fles rotes membraneuses qui se terminemt par des aiguillons papyraces. 
Celte salsepareilic dombe arec l'eau des décoctés d’un ronge de sang, el son extrait présente une odeur de valériane.

9. Sulsequmille liguemse. Cente sorte est remarcquable par le volume, la grandeur el l'aspect lignemx do toules ses parlies; sa souche est au moins grosse comme le poingr, nouruso, irrógulièe, lignense el d'un blanc grisitre ì l'intérieur; ses racines ont de 7 à 9 millimètres do diametre, sont fort Inogues, comvertes d'un épideme rouge-brum, et sont formées d'une écorce peu épaisse, desséchéc et profondément sillonnée, et d'un méditullium ligneux, large et d'une couleur de bois de chême. I.es tronçons de tige qui accompagnent la sonche sont épais de 25 millimètres, et sont tout hérissés de piquauts; ces piquants (aiguillons) sont superficiels et rangés par lignes longitudinales, comme dans les deux salsepareilles $n^{\circ 9} 6$ et 8 .

I.a salsepareillr ligneuse a une sarenr mucilagineuse, amère ế âcre ; clle est rare et peu estimée à Paris; mais nn m'a dit qu'elle était recherchée à Borkeaux pour l'usage méclical. On m'a dit aussi qu'elle venait de Mexico.

Plusieurs chimistes se sont occupes de chercher quel était lo principe aclif de la salsepareille. YI. Palout, le premier, ayant précipité une forle infusion de cetle lacine par l'eau de chaux, a traité le précipité, délayé dans l'eau, par un courant d'acide carbonique, pour convertir la chanx en carbonate; il a craporé la liquene à siccile, a traité le résidn par de l'alconl it 40 dlogrés, et a obtenn, par l'evporation, une matière blanche, astringente of nauséeuse, a larjuello il a donné le nom de parigline.

Un autre chimiste italien, le doctenr Folchi, ayant décoloré un macire de salsepareillo par le charbon animal, el l'ayant fait evaporer, a ru se diposer une mative cristalline qu'il a nommée smilacine.

Enfun Thubnenf, pharmacien à Parí, a obtenu de la salsepareille un malière cristallisée, en traitant li racine par de l'alcool faible, faisant concentrer la li(juenr, la laissant déposer et reprenant le dépôt par l'alcool rectifié bouillant; il a domné à cetle matière le nom de salsefurinr. Il a éçalement constaté dans la salseparcille la présence d'une huile brunc et udorante, qui ne doit pas être étrangère à ses propriétés.

D’après les expérionces récentes de 1. Poggiale, et d'après celles mêmes de Thubreuf, la smilacine, la parigline et la saiseparine sont un seul ef mrme corps, (qui parait insipide au gount lorsqu'il est sec et pulvérulent, ì cause de sa complète insolubilité dans l'ean froirle el la salive; mais round il est dissous dans l'eau bouillante on l'alconl, il offre ıne saveur amè̀e et àcre à la sorge. Son dissoluté a(jueux, quoiqu'il en contienur fort pen, mousse considérablement par l'agitation. 
La salseparine est insoluble dans l'écher; elle n'est ni acide ni alcaline, et est formée seulement de carbone, d'hỵdrogène et d'oxigène.

\section{Fauses Saisepareilles.}

Plusicurs racines atplpartenant ì des contrécs et à des familles de plantes très différentes ont été proposées comme succédanécs de la silsepareille, plutôt qu'elles n'ont été vendues par fraude pour elle. Cépendant ce dernier cas s'est plus d'une fois présenté. Celles de ces racines qui se rapprochent le plus de la salsepareille par leurs caractères et leurs propriétés, appartiennent, soit au genre smilax lui-même, soit au genre herreria, et croissent au Brésil, où on leur donne, de mème (ju’à la salsepareille, le nom général de jupicangu. Cependant ce nom parait appartenir plus spécialement à deux espèces, qui sont les smilac japicanga et sypringoüdes de Grisebach. J'ai deux racines de ce genre qui appartiennent très probablement à ces deux espèces : l'une est arrivée du Brésil sous le nom même de japicanga et m’áté remise par Il. Stanislas Martin, pharmacien à Paris; j’ai trouvé l'autre, il ̣̂ a très longtemps, chez $\mathbf{1}$. Dubail.

1. Racine de japicanga de M. Stanislas. Martin. Cette racine se compose d'un ou de plusieurs tubercules arrondis, assez volumineux, blancs a l'intérieur, arec indice d'un principe colorant rouge dans l'épiderme. Les tronçons de tige sont parfaitement cylindriques, de la grosseur d'unc forte plume, unis à leur surface, avec quelques rares épines, d'une couleur rerte d'aloord, puis jaune. Les racines sont toutes fendues par la moitié dans le sens de leur longueur, et elles sont formées d'une écorce d'un gris un peu rongeâtre, très mince et très ridéc, et d'un uéditullium ligneux, volumincux, mais complétement vide a l'intérieur, de sorte (que ce méditullium devait former un réritable tube d'un bout à l'autre de la racine. Dans un assez grand nombre de racines, qui probablement ont été monillées arant leur dessiccation, l'épiderme se dédouble en plusieurs fenillets, qui ont pris à l'air une couleur rouge assez foncée. La racine entière présente une saveur un peu salée ct mucilagineuse, finissant par derenir assez fortement amère. Elle est inodore.

2. Racine de japicangu de .V. Imbuil. Il paraît qu'une forte partic de celle substance a été importée en France vers l'améc 1820) on la prit alors pour la tige de l'urmlin mediemelis; mais le placement n'agant pu en être eflectué, on la réexpotta pour l'Allemagne, sauf une certaine quantité qui resta en la possession de M. Dubail. Fille a été décrite romme étant lit lige de l'metien nedicrntis, dims la deuxieme édition 


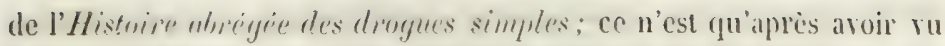
la racine précédente que j’ai reconnu la vaic nature de colle-ci.

Cette racine est entièrenent privée de ses souches, coupée par troncons de 40 a 50 centimètres, et mise en petites bottes retenues par une racine semblable qui lui sert de lien. Elle est pourrue d'un épiderme d'un gris un peu rougeâtre, profondément sillonné par la dessiccation, ce qui lui donne une grande ressemblance arec la salsepareille. Au-dessous se trouve une partie corticale grise ou blanchattre, spongieuse, molle, quelquefois gluante et comme gorgée d'un suc miellenx. A l'inlérieur est un corps ligneux blanchàtre, cylindrique, percé au centre d'un large canal, et ce caractère est celui qui distingue le mieux le japicanga de la salsepareille, dont le cocur est plein et solide. L'odeur en est fade et peu marquée; la sareur en est sucrée d'abord, puis assez fortement amère.

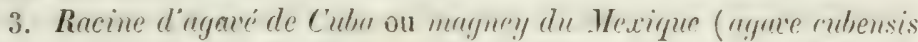
de Jacquin, famille des broméliacées ). Cette plante, qui affecte la forme d'un grand aloès, est portíe sur une souche pivotante, grosse comme la cuisse, garnie tout autour de longues racines du diamètre d'une petite plume et assez semblables ì celles de la salsepareille. l'écorce en est papracie, d'un rouge de garince, facile is séparer du cour ligneux. Celui-ci est hanc à l'intérieur, composé de fibres distinctes qu'il suffit de séparer pour en faire une filasse très forte, mais grossière, bonne à faire des cordages. L'odeur est nulle; l'écorce seule a une sareur faiblement astringente. Lorsque, en 1823, II. Pope eut attiré l'attention des pharmaciens sur la salsepareille rouge de la Jamaïque ou de IIonduras, quełqques persomnes dommèrent en sa place de la racine d'agaré qui n'offre arec la premicre aucun rapport de propriétés.

4. Racine de laiche des sobles ou de cured armarin. Cette racine a été usitée en Allemagne comme succédanée de la salscpareille. Elle a été décrite précédemment (page 108).

.. Racine incomme donnée anciennenent comme sulseprecille grise d'.llemagne. Cette racine, appartenant à une plante dicotylédone, est longue, cylindrique, poursue d'une écorce grise, très mince et difficile à isoler du cœur ligneux. Celui-ci est très volumincux, grisâtre, et composé de fibres très apparentes, excepté dans les plus petites racines qui l'ont plus blanc et plus amylacé. Cette racine ressemble beaucoup à la salsepareille, mais roici ce qui l'en distingue : clle est très difficile i fendre droit et, forsqu'elle est fendue par la moitié, si on essaie de la rompre, en la pliant de manière que la partie corticale soit en dehors, elle casse net, tandis que la salsepareille résiste à la même épreure. Lat racine en masse offre une odent peu marquée de vieux spicanard, "I 


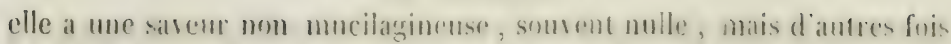
un peu aromatique et comme camphrée.

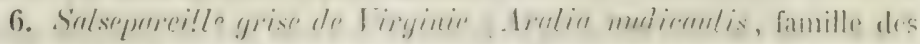
araliacées). Cette substance est une tige ramplante et non me racine; elle est ranifie, converte d'un épiderme gris-blanchattre on gris-pongeâtre el foliacé. l'écorce est jamnatre, spongiense, siehe; an contre se trouve un coenr ligneux blanc. Ciette tige prossede une ndeur fade, peu marpuér ; une savenr légèrement sucrée ot aromatique, comme celle de la racine de persil.

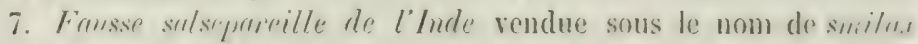

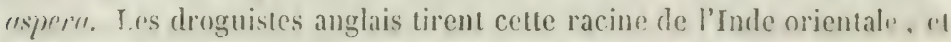

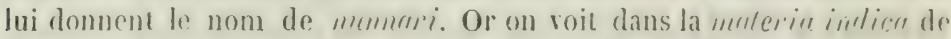
W. Ainslie, que la racine nommée solseparrille de l'Iude, nu unmun i-

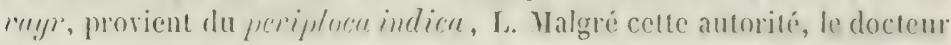
Thompson, ne trourant pas (une l'odeur agríable ni les proprichés médicales de cefte racine s'accordassent arec celles d'unr apoc nnée, en a

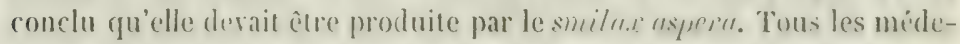
cins et pharmaciens anglais ont adopté cette opinion, et flusiours médecins et pharmaciens français également; il en résulte que cette racine est cquelquefois prescrite sons le nom de smiln.t reppera, bien qu'il snit facile de démontrer qu'clle n'appartient à aucune plante de ce genre.

Trois plantes ont porté le nom de smilex "sijereft: d'abord la salsepa-

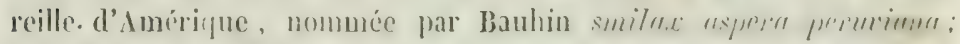

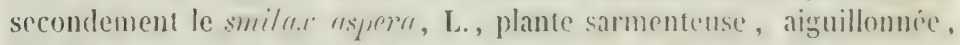
de l'Europe méridionale, dont la racine est formés d'une souche blanche, grosse comme le doigh, noucuse "t articulée romme celle du petit-honx, garnie de rarlicules longues, blanches et menues; troisiè-

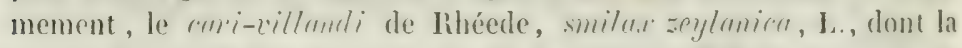
souche épaisse et tuberculeuse simule la squine officinale. Aucune de ces racines ne peut être celle qui nous occupe.

D'ailleurs la fauss salsepareille de l'Inde est sourent accompagnée de sa lige, qui offre, commo celle des plantes dicolylédones, une icorce distincte, un corps lignenx et un canal médullaire au centre; la plante ne pent donc pas citre un smilux. Enfin celte tige est sonvent carrie a la partie superieure, el les feuilles sont opposées. I'avais conclu de ces deux indices, ef dir quelyues autres, que ha plante appartenait à lit

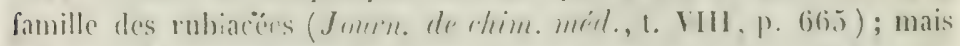
il est parfaitement rentain anjourd'bui quilelle n'est antre que le puri-

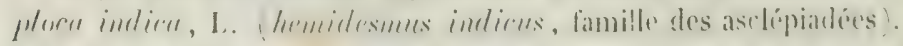

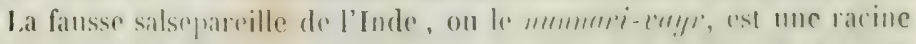

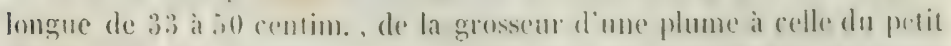

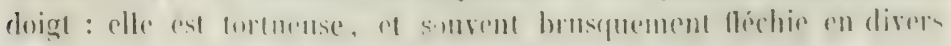




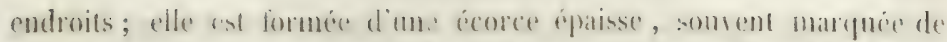
fissures transwersales, et se siparant, par plares, du midifullimu ligneus. Celui-ci est formé de fihres raynune's et contomrnées; il w rompl lorsgu'on le ploie, et sa cassure offre à la limpe mone infinite de lubes poreux. L’épiderme est d'un rouge ulsseur; l'intériur de l'écorce est grisatte, et le bois est d'mu blanc jaunatre. La saveur proprement ditr est a peine sensible; mais elle offre un parfum tris agréable do fère tonka, el la racine en masse présente la mème odeur.

\section{FAMILLE DES DIOSCORÉES.}

Cette petite fimille a éte établic par II. R. Brown pour placer les plantes de la famille des asparaginées de Jussien dont l'ovaire est infère. Elle comprend des régétaux à racine tubérense et amylacéc, à tige rolubile comme celle des smilur, à fouilles altermes ou quelouefois opposées, réliculées, entieres ou palmalidivisies ; les fleurs sont peu apparentes, le plus sourent diö̈gues, a 6 cilamines libres, eu pourvues do 1 ware somdi arec le fubu du périanthe et a 3 loges. Le fruil est unn

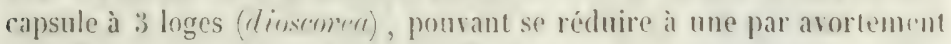
(rajania), ou une baic (genre tamus).

Les IGxayes (diosomen) sont répandurs dans loules les partios chaudes de la terre et principalement dans les deux Indes, "l dans toutes les îles et contrées qui les séparnnt de la Chine et du Japon: à la Guyane, dans les diitilles, dans la Floride et la Virginie. Ieurs tuber cules radicaux de formes rariées, bizarres et sonvent très volumincux. concourent puissamment ì la nourriture de l'homme.

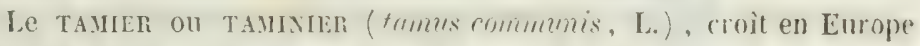
dans les haies; on lui donne aussi les noms de vigne noire ou de bryome noive, de sceau de Notre-Dane, racine vierge, racine de fermuc butfue. C'est une plante sarmentense, hante de 2 à 3 mètres, munie de feuilles pétiolées, cordiformes, pointurs et luisantes. I.es fruits sont des bairs rouges de la grosseur d'un grain de groseille. La racine est tubéreuse, grosse conme le poing, garnie tout autour de radicules ligneuses, grise au dehors, blanche en dedans, d'une saveur âcre et imprégnée d'un suc gluant. Elle est un peu purgative et hydragogue. Les gens du peuple lui attribuent la propriété de résoudre le sang épanché par suite de contusions, étant appliquéce dessus, ràpée et sous forme de cataplasme. C'est sans doate à cause de l'usage assez fréruent qu'en font les femmes du peuple que la plante a reçu le dernier nom mentionné cidessus.

C'est également à la famille des dioscores quil couvient de rapporter Ins tucro, plantes non volubiles cependant, et dont le port rappelle inn 
peu celui des aroülées. Ces plantes sont répandues dans l'Inde, it Madigascar et dans toutes les îles de l'océanic ; elles sortent d'un tulsercule radical tout couvert de radicules lignenses, de nature amylacée, naturellement amer et âcre, mais s'adoucissant par la culcure et pourant alors servir directement à la nourriture de l'homme. Depuis assez lonertempss déjà, les Anglais tirent de Taïti et répandent dans le commerce. sous le nom d'arron-root de Trüti, la fécule du tarcen pinumtifidn quis: croit en srande abondance. Cette fécule est blanche, pulsérulente, insipide, inodore, et présente les caractères généraux de ce genre de produits. Examinée au microscope, clle se présente sous la forme

Fig. 93.

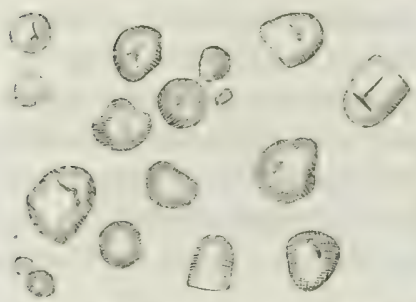

de granules sphériques, oroïdes ou ciliptiques, quelquefois courtement rétrécis au col ou coupés par un plan perpendiculaire à l'axe. Cette forme est très analogue à celle de la fécule de sagou; mais celle-ci est généralement plus aliongée, et celle du tuceu plus courte et plus arrondic; de plus, elle présente presgue toujours un lile très développé et lissuré en forme d'étoile (fig. 93). Elle se conduit aree l'cau bouillante comme la fécule de sagou-tapioka.

\section{FAMILLE DES AMARYLLIDÉES.}

Les amaryllidées sont aux liliacées ce que les dioscorées sunt aux asparaginées : elles en diffèrent surtout par leur ovaire infère. Ce sont des plantes à racine bulbifère ou fibreuse, à fenilles radicales embrassantes; a fleurs souvent très grandes et remarquables par leur forme et leur vire couleur, eirreloppées arant leur épanouissement dans des spathes scarieuses. Le périanthe est tubuleux, à 6 divisions; les étamines sont au nombre de 6 ; l'ovaire est soudie arec le tube du calice, à 3 loges polyspermes et pourvu d'un style simple et d'un sligmate trilobi. Le fruit est une capsule triloculaire et it 3 ralres septifères; quelquefois c'est une baie qui ne contient, par arortement, que L à 3 graines. Cielles-ci, gui offrent assez sourent une caroncule celluleuse, renferment un embryon cylindrigue et homotrope dans un endosperme charnu.

Les plantes de cette famille qui sont le plus cultivées pour la beauti de leurs fleurs, sont:

L'amaryllis de Saint-Jaçue's ,

Le crinum asiatique,

L'hemanthe sanguin, muneryllis formosissimu. crimem asiaticum. emanthus coccineus. 
Le pancrace maritime,

Le perce-neige,

Le narcisse des juëtes,

La jonquille, pancratimm marilimnim.

galantlus nivalis.

narcissus poeticus.

jonruilla.

I.es anraryllidées sont généralement des plantes dangereuses, et quelques unes, telles que l'anaryll is helladona des Antilles et l'homenthes turefrrmin du cap de Bonne-Espérance sont de violents poisons. Les bulbes de la plipart sont àcres et émétiques, et principalement ceux

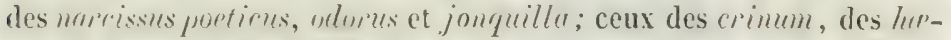

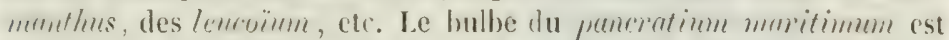
voluminenx, jonit de propriétés analugues ì celles de la scille et est quelquefois substitué a la scille blanche. Enfin les fleurs du Xalicisst:

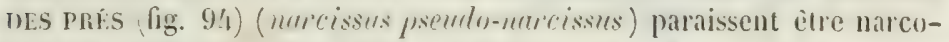
liques à petite dose; mais elles sont émétiques et rénéneuses à une dose plus élevée. Gelte plante es! commune en France dans les prés et dans les bois, où elle fleurit de trìs bonne heure; son bulbe tunicé donne naissance à des feuilles presque planes et de la longueur de la tige. La tige, haute de 16 it 20 centimètres, se termine par une spathe monophylle, de lacpuelle sort une fleur unique, penchée, assez grande, pen odorante, formée d'un périanthe tubuleux, soudé inférieurement arec l'ovaire, divisé supérieurement en six parties terminées en pointe; d'un jaune très pâle ou presque blanches. Ge périanthe est doublé à l'intérieur par une enreloppe corolloïle (nectaire, L.) , libre dans sa partic supéFig. 9\%. rieure, qui dépasse la longueur des divisions du périanthe ot d'un jaune plus foncé.

C'est à la famille des amarỵllidées qu'il baut rapporter les agane et les fircroya, plantes tellement semblables aux aloès par leurs feuilles rarinassées, épaisses, charmues, dentelées et piquantes sur leurs bords, qu'elles sont gínéralement culcivées dans les jardins sous le nom d'ulois: mais leur ovaire infere et leur fruit loculicide les distingue de cenx-ci. Les agavés sont d'ailleurs de dimensions beaucoup plus grandes et quelquefois gigantesques : ils joni-sent d'me longévilé extrandinaire. 
pendant laquelle ils paraissent ne fleurit qu'une fois, et alers la hamp."

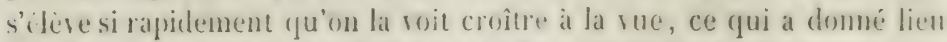
il la fable populaire que ces plantes ne flemrissent que tous les cent ans, alec une explusion semblable à celle d'un coup de canon.

I.es fibres lignruse's contenues dans le's feculles d'agaré peuren! fonrnir une filasse comparable au chansre, et beancoup plus fine que celle foun nie par les racines dont j’ai déjà parlé (p. 20.5). On la comnaît dans le commerce sous le nom de sorie rirgrifule. Cin des agavés du Mexique,

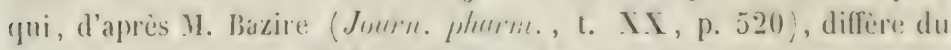

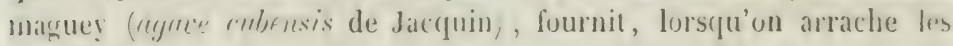
fenilles du centre, une liqueur transparente et sucrée dont on obtisnt, par la fermentation, une briscon vine recherchée des IIexicains.

\section{FAMULI.E DISS BROMÉLIACÉES.}

Les broméliacées sont des plantes anéricaines dont les fenilles, souvent rémies à la base de la tige, allongées, étroites, épaisses, ruiders, dentelées et épineuse's sur les hords, rappellent jusqua'à un certain puint colles des agavés. Les fleurs forment dés épis écailleux, des grappes ramenses on des capitules, dans lescrucls elles sont quelquefois tellement rapprochées (gu'elles finissent par se souder ensemble. Leur calice ('st tubuleux, adhérent à l'oraire, partagé par le haut en six divisions disposées sur deux rangs, dont les trois intériemres sont plus grandes et pétaloüdes. L'oraire est à trois luges, ponrru d'un style et d'un stignate it trois divisions subulies. Le fruit est gínteralement une baie triloculaire, couronnée par les lobes du calice.

La plante la plus urile de cente famille est l'ananas ( mumasen set iven, Lindl.; Inrmelin anmurs, L. ), dont les baies soudées et très souvent devenues aspermes par la culture, forment un sinese rolumineux, uveide-aigu, élégamment imbriçué à sa surface. rempli d'une chair acidule, aromatique et sucrée, et coupleti an nombre des fruits de table les plus estimés.

Ies fillandsin, que plusienrs botanistes jojgnent is colte famille. maleré leur ovaire libre, nous offrent une espèce, fillnudsin usmerdides, dont les tiges très menues, rolubiles, noires, ligneuses et prescutue semblables à du crin, (juant à la forme, peurent aussi le remplacer dans la fabrication des sommiers et des meubles. On en imporle en France une assez grande quantité, (jui est emplose edans ce but.

FAMILII: DES IRIDÉLS.

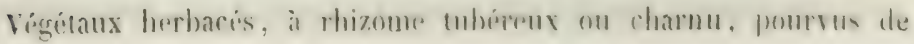


feuilles alternes, phanes, ensiformes, sourent distiques; fleur's enveloppées dans une spathe; périanthe lubuleux ì six divisions profondes, disposécs sur denx rangs; 3 étamines libres ou monodelphes, opposées aus divisions externes du périanthe et attachées à leur base; ovaire infère à 3 loges multiovulées; style simple terminé par 3 stiguales en forme de cornets aplatis, à bords frangés, prenant sourent une apparence pélaloïde ; fruit capsulaire à : loges, à 3 valres septifères. Principaux genres : sisyrinclium, iris, tigridia, ferraria, gladiolus, ixia, crocus.

\section{Iris commune on Flambe.}

Iris germanica ( fig. 95). Cette plante pousse des feuilles ensiformes, courbées en faux, distiques et engainnantes, glabres, plus courtes que la tige, qui est multiflore. Le périanthe est à 6 dirisions pétalö̈les, d'un bleu violet foncé, dont 3 plus étroites redressées, et 3 plus larges abaissées, chargées sur leur ligne médiane d'une raie barbue, d'une belle couleur jaune. Les étamines sont au nombre de 3 , insérées à la hase des dirisions extérieures, et recourertes par les stignates pétaloïdes du pistil. Le tube du périanthe est à peine aussi long que l'ovaire. Le fruit est une capsule triloculaire, s'ourrant par le sommet en 3 valves locuFig. 95.

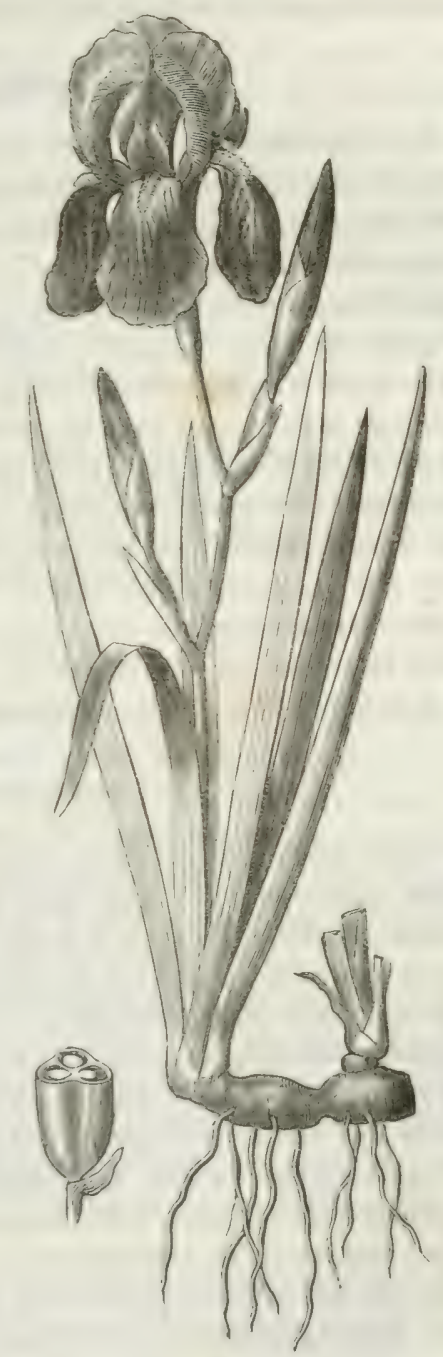

licides. Les semences sont nombreuses, horizontales, planes et marginées, fixées sur deux séries à l'axe central des loges. 
Le rhizome de l'iris llambe est horizontal, charnu, articulé, reconvert d'un épiderme gris, ou vert sur la face supérieure. Il est blanc col dedans, d'une odeur rircuse et d'une saveur àcre. Il est diurétiçue et purgatif, mais peu usité. Lorsçu'il est desséché, il est grisâtre à l’intérieur, et pourvu d'une faible odeur de violette. On l'emploie dans les buanderies pour communiquer celte odeur aux lessires.

\section{Racine d'Iris de Florence.}

Iris florentinn. Celte espèce ressemble beaucoup à la précédente; mais elle est plus petite dans toutes ses parties; ses feuilles sont courtes, ensiformes, d'un rert glaurjue; la hampe porte 2 ou 3 fleurs blanches, dont le tube est plus long que l'oraire, et dont les divisions extérieures présentent une ligne médiane barbue. I.a sonche est oblique, grosse comme le pouce et plus, articulée, et d'une saveur àcre. On nous l'apporte sèche et toute mondíe de la Toscane et d'autres endroits de l'Italie. Elle est d'une belle couleur blanche, d'une saveur àcre et anère, et d'une odeur de violette très prononcée. lille entre dans un certain nombre de compositions pharmacentiques, et les parfumeurs en emploient une très grande quantité. On en fabrique aussi de petites boules de la grossemr d'un pois, nommées prois d'iris, très usitées pour entretenir la suppuration des cautères. M. Yogel a retiré de la racine d'iris sèche une huile volatile solide et cristallisable, une huile fixe, un extrait brun, de la gomme, de la fécule, du ligneux (Jon'n. phanm., 1815, P. 481).

\section{Racine a'Iris fétide.}

Vulgairement gleryeul premt ou spratule fretide; iris firtidisimu, L. Cette plante croît en France dans les lieux lumides ct ombragés. Sa sauche est oblique, longue et grosse comme le doigt, marquée d'anneaux ì sa surface, garnie à la partie inférieure de beaucoup de fortes radicules. Elle donne naissance it des feuilles ensiforines, droites, itroites et fort longues, d'un vert foncé et rendant une odeur désagréabe lorsqu'on les écrase. La tige est imparfaitement cylindriuge, haute de 50 à 65 centimètres, garnie de feuilles, dont les dernières, en forme de spathes et de bractées, accompagnent 3 on 4 fleurs. Les divisions extérieures du périanthe sont allongées, rabattues, veinces, d'un violet pâle, dépourves de raie barbue. Le fruit est une capsule it : loges, s'ourrant par la partic supérieure et laissant voir des semences nombrenses, assez volumineuses, arrondies, courertes d'une en elopple succulente et d'un rouge vif.

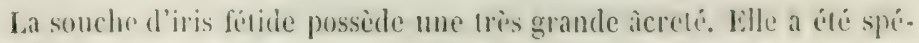

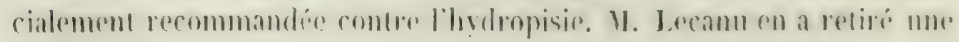


huile bolatile excessivement âcre, de la cire, une matière résineuse, une matière colorante orangée, du sucre, de la gonmme, un acide libre, etc. (Joum. pham., t. XX, P. 320).

\section{Macine d'Iris faux-acore.}

Vulgairement iris de's morenis, iris jume, glangrul des mornis (iris

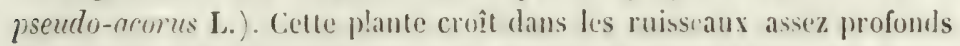
ct dans les endroits marécageur. Sit souche est horizontale, très forte, annelée, articulée, chevelue, poursue de feuillcs radicales embrassantes, ensiformes, très longues et très étruites. La lige est élerée de 60 à 100 centimetres, garnie de feuilles, et produit 3 ou 4 fleurs entierement jaunes, dont les truis divisions extérienres sont raballues, grandes, ovoüdes, tris entieres, dépourvoes de raie barbue; les trois divisions internes sont dressées, très étroiles, phus courtes que les stigmates.

Ia souche de l'iris des marais n'a pas d'odeur. Eille est trés âcre et purgative lorsqu'elle est récente; dessechée, clle acguiert une couleur rougeâtre à l'intérieur. Elle a été usitée comme sternutatoire. La graine torréfiée a élé proposée comme succédanée clu café.

\section{Safran.}

Crocus snticus. Cette petite plante a le port général d'une liliacée, mais elle produit un bulbe tubéreux et non écailleux ou tunicé; de ce bulbe s'élère une longue spathe d'où sortent un certain nombre de feuilles lineaires et un petit nombre de fleurs munies d'un périanthe violet-pâle, longuement tubulé, à 6 divisions dressées et presque égales, renfermant seulement 3 étamines et 1 pistil terminé par 3 stigmates creusés en cornet; le fruit cst une capsule à 3 loges.

Le safran, tel qu'il rient d'être décrit, ou le crocus satie'us, r., comprend deux variélés, ou plutòt deux espèces, dont une seule fournit ces longs stiguates colorés qui composent le safran officinal. L'espece non officinale, ou le crocus vermus, fleurit au printemps, et produit it la fois des feuilles et sa fleur, dont les trois stigmates sont redressés, non dentés, beaucoup plus courts que les divisions du périanthe; anssi ne paraissent-ils pas au dehors.

Le safran officinal, auquel on a conservé le nom de crocus saticus, fleurit en septembre ou octobre, un peu arant l'apparition des feuille'; il se distingue du précédent par ses longs stigmates rouges, inclinés ct pendants hors du tube de la fleur, et dentés it l'extrémité (fig. 96).

I.e safran parait être originaire d'I sie; mais depuis très longtemps on le cultive en Espagne et ch France : c'est mêtue le safran du Gatinais et 
de l'Orléanais, en lirance, qui comprennent partie des départements de Seine-ct-Marne, d'liure-ct-Loir ct tout le départenent du Loiret, c'est ce safran, dis-je, qui est le plus estimé ; après vient celui d'Espagne, et cufin celui d'.lngoulême, qui est le monins bon. Celui-ci, en effet, au lieu d'être coloré dans toutes sés parties, est privé de matière

Fig. 96.

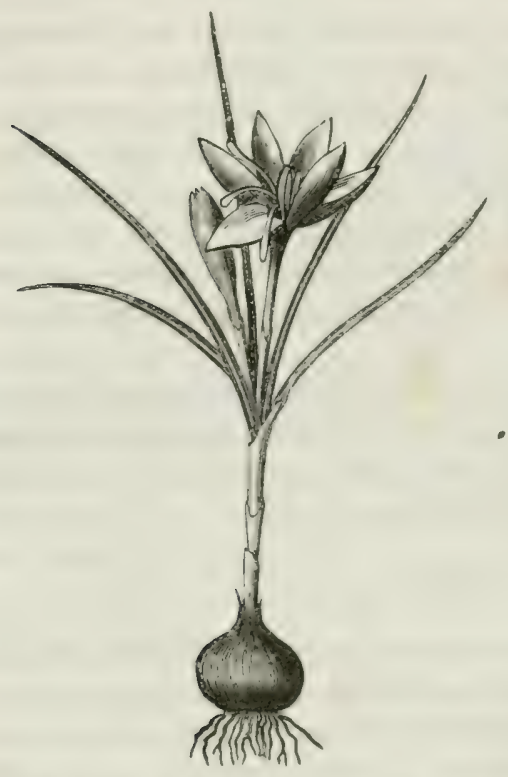

colorante dans son style et même dans la partie inférieure des sligmates, de sorte qu'il présente à la vue un mélange de filets blancs et rouges.

Les terres dans lesquelles le safian réussit le mieux sont celles qui sont légères, un peu silblomenses et noirâires. On les amende par des fumiers bien consommes, et on les dispose par trois labours faits depuis l'hiser jusqu'au moment où l'un met les bulbes en terre, ce qui a lien depuis la lin de mai jusqu'en juillet; ensuite on bine la terre de six scmaines en six se-

maines juscun'a la Roraison, gui a lieu en septembre ou octobre. Sa heur ne dore gu'un ou denx jours après son épanonissement.

C"est dans ce intervalle que des limmes soecupent sans relache à cueil lir le safran el à l'éplucher, c'est à dire à enler ar seulement les stignates, fue l'on se hâte de faire sécher sur de's tamis de crins chaullies par de la loraise. Ils perdent par cette opicition les guatre (inquiemes de leur poids. M. Pereina a calcule que 1 grain pesant 55 milligrammes) de safran du comnierce contenait les shies et les stigmates de 9) lleurs. A re comple, il faut 4320 fleurs pour fare 1 once ou 31 grammes de sa-

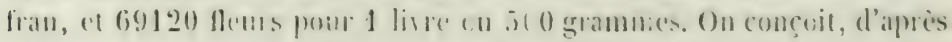
cela, pourgenoi le safran e's! tonjours d'un prix très élcré.

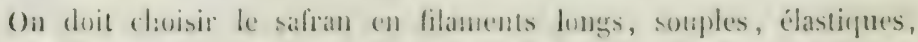

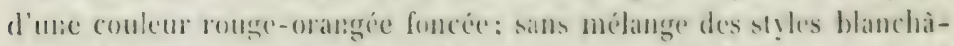
tres qui cartacterisent le safran d'.ugroulène, et prise d'etamines, qui

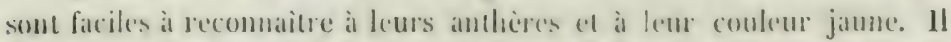

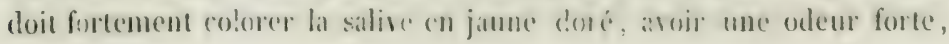


vire, pénétrante, agréable et qui ne sente pas le fermenté. On reconmande de le conserver dans un lieu humide, ce qui peut c̀tre utile pour en augmenter le poids; mais, comme toutes les substances organiques, le safran se conserre beaucoup mieux parfaitement desséché et renfermé dans des vases hermétiguement fermés que de toute autre manière.

Le safran donne à l'eau et à l'alcool les trois quarts de son poids d'un extrait qui contient une matière colorante orangée rouge, non encore obtenue à l'état de purcté, et qui paraît cependant se déposer en partie, à l'aide du temps, de sa dissolution alcoolique. Cet extrait contient en outre une huile volatie odorante; et, celui par l'alcool, une huile fixe concrète, ou cire régétale. Buuillon-Lagrange et Vogel y admettent en ontre de la gomme, de l'albusine et nne petite quantité de sels à base de potasse, de chaux et de magnésie (Annales de chimie, t. LXXX, p. 188).

Le safran est usilé comme assaisonnement dans plusieurs pays, et notamment en Pologne, en Italie, en Espagne et dans le midi de la France. Il est également d'un grand usige dans la teinture, dans l'art du confiseur et en pharmacie. Il entre dans la theriaque, la confection de safran composé, le laudanum liquide, l'élixir de Garus, etc.

Fulsificutions. Le safran est très sunvent falsifié dans le commerce avec de l'eau, de l'huile, du sable on des grains de plomb. Presque de tout temps aussi on l'a sophistiqué avéc des fleurons de carthame (carthamus tinctorius), qui en a mème pris le nom de snfranum ou de safran bîtard. Cette falsification est assez facile à reconnaître à la forme du carthame, qui est composé d'un tube rouge, disisé supérieurement en 5 dents, et renfermant à l'intérieur 5 étamines soudées en roûte par leurs anthères et traversées par un long style. De plus, le cardhame est sec et cassant, pourvu d'une odeur laible, et colore à peine la salive en jaune; mais comme ces caraclères se perdent par le mélange avec le véritible safran, c'est à la forme suitout gu'il fant s'attacher.

Enfin depuis quelques années le safran est falsilié, tant en France qu'en Allenague, arec les pétales de différentes fleurs, coupés en languettes, colorés en rouge antificiellement, imprégnés d'huile pour leur donner de la souplesse, et lellenent bien préparés qu’à la première vue, et même non mèlangés au safran, on les prendrait pour celui-ci. Les pétales qui ont servi jusqu'ici à cette préparation, sont ceux de souci, d'arnica et de saponaire. Pour reconnaitre toutes ces différentes falsifications, il faut prendre une poigne de safran au milieu de la nasse et la seconer d'abord ligèrenent sur une grande feuille de papies, ce qui en fait tomber le sable et les grains de plomb; ensuite on place une petite quantité de la matiere entre deux feuillets de papier non collé 
et on la soumet à la perstom : l'operation fuite, le papier ne dojt ètre ni monilló ni huilé. Enfun on étale complítroment une certaine quantité de safran sur la fenille de paprere en on l'esamine aree soin a la vue ou a l'aide d'une large lompe. Tous les brins, a l'exception de queldgues étamines isolées de ryous qui peusent s'y tronver, doriscul êre composés

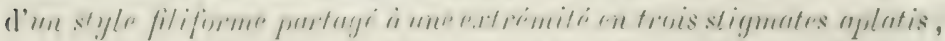

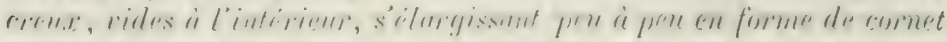

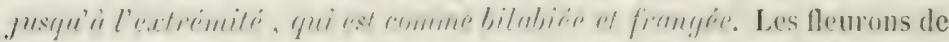

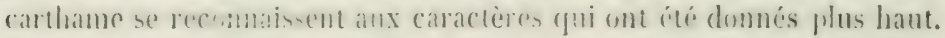

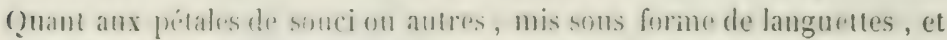
custite diveroment andus on contourtes, on les reconnaît à celte

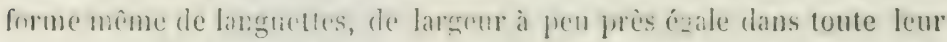

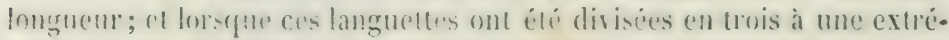

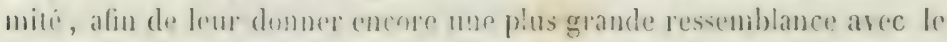

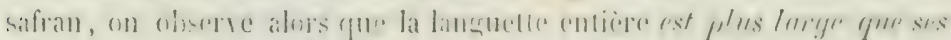
dirisimes, tandis que, dans le safran, chargue stigmate isole est plus large que te stỵle.

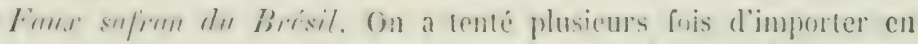

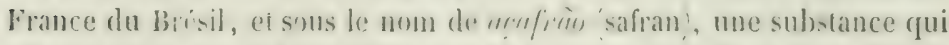
offre quelque rappert de coulenr de d'odeur arec le safran, mais dont la ferme est tout a lait diflerente. Cost me tris pelite corolle membraneuse, monopetale, lomgne dre o a s millimetres, cubuleuse, un peu courbe et un peru renflee pres du limbe, çui parait irregnlier, et a deux levres pen marqués; elle appartient probablement it la famille des

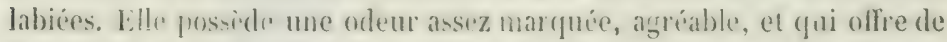
l'analugie asec collı du safran; fl'e colore atsorz lortrment la salive en jaune orangri, e' présente une saveur un peu anere. Il ent probable qu'on pourrait l'utiliser pour la teinture.

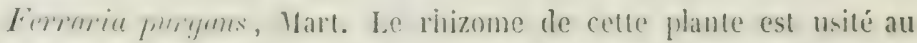
Brésil comme puratif, a la dese de 12 a 15 grammes. Tel gu'on le trouve dans les platamacies de ce payse, oì on lui domne les noms de

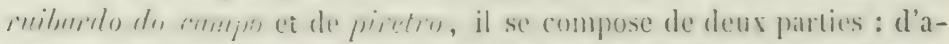

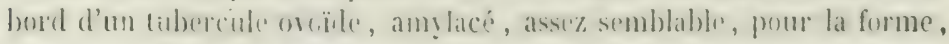

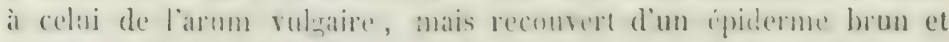
muni, sur tontr sa surface, de radicules lignemes qui dexcedent perpendiculairement le loner de tubercule; secondement d'ane sorte de

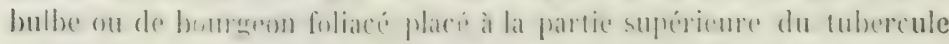

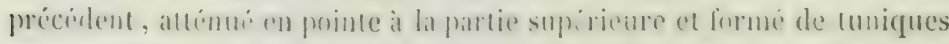

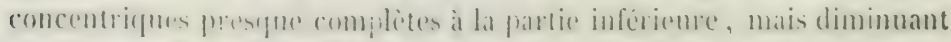

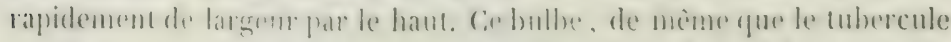

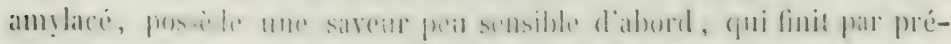

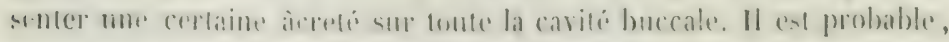


en raison do nom pirétro donne à la plante ou an rhizonse, gune cente àcreté était lseaucoup plus forte à l'élat récent.

\section{FAIILLE DES MLSACIÉS.}

Pantes herbacies ou lignasuses, pourvaes de feuilles longuement pi-

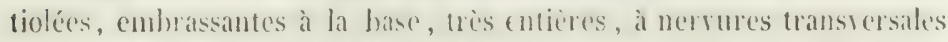
paralleles et frès serrées. Les flemes sont rembes en grand nombre dans des spathes; elles sont comprosées d'un périnthe épiosne à six disisions birériées inregnliores, de six étamines domt mo est preffue toujours

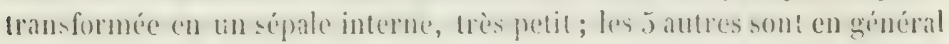
surmontées d’un appendice membrameur, coloré, qui est la continua-

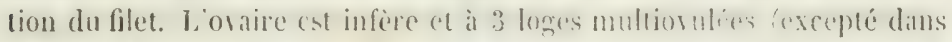

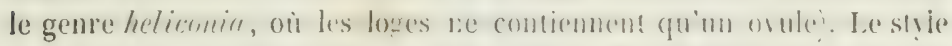
est terminal, smple, lidiforme, lemmini far 3 stigmates lincaires. Ide fruit est une capsule a 3 lueses at a 3 valus septiferes, ou me baie indéhiscente à 3 loges.

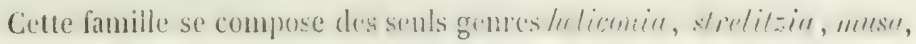

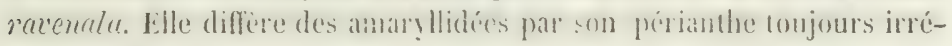
gulier, et des amomés, rui ront suirre, pall ses six abmines. Le strelitzia regime est une plante d'une grande beatu!é, originaire de l'Afrigue mérilionale. Ies bananiers (mesp) sont des herle's gigantesques, originaires des contrés chandes el homides de l'Isie et de

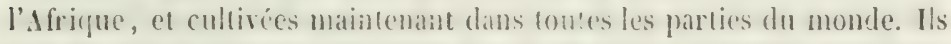
sont formés d'un bulbe allongé an forme de lige, qui rénule de la base embrassante et funice du pétiole des feuilles. Celle tige, hante de 5 à

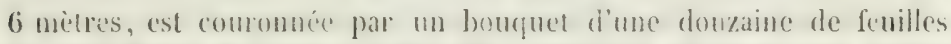
longnes de 2 a 3 melres sur 50 a 65 centimetres de barge. Du milieu de ces fenilles sort un péeloncule long de 1 mide a $1^{m, 3}, 30$, garni de fleurs sessiles, rassemblés par marpuels snats des éailles spathacés cadupues. Tontes ces fenrs sont licmaphodiles, mits de deux sortes, cependant; celles rapprochées de la base du régine élant seules fertiles, et celles de l'extremite étant steries. Les fruits som des baic's d'un jaune pâle, hongues de 1 j à 25 cembinères dius le musu paradisiaca), (ipaisses de 3 à 4 , obtusement triangulaires, at loges sourent oblitérées, el dont les semences disparaissent par la culure. Dans le mea stprientium, les fruits sont plus courts, phus droils, moins piteux et d'un goùt beaucoup plus agriable. Mais les uns et les antres sont une preure frappante de la transformation de l'anditon cen sticre, gui s'opère, dans l'acte de la régétation mème, solis l'inflnence des acides. Ces fruits, non mûrs, sont cout à fait blancs et amylacés dass Icur intéricur, el, descéchés ct coupés par tranches, ressemblent à de la racine d'artum 
sìche. Tout i fait mùrs, ils sont d'un goût sucré, viegueux, aigrelet, et prennent par la dessiccation l'aspect d'une confiture sèche. Ils sont d'un puissant secours pour l'alimentation des habitants des paỵs intertropicaux, qui trourent en outre dans leurs feuilles entieres une couverture pour leurs habititions, ct dans les fibres de la tige une filasse propre a faire des cordages, des toiles et même des citoffes légères.

\section{FAMILLE DES AMOMACEES.}

Plantes viraces dont la racine est ordinairement tubéreuse et charnue; les feuilles sont engainantes à la base, à nerrures latérales et parallèles; les fleurs sont disposces en épis imbriqués, en grappes ou en panicules. Le périanthe est double: l'extérieur forme un calice à 3 sépales réguliers, courts et colorés; l'intérieur est tubulé et terminé par 3 divisions colorées, plus grandes et presque rérgulières également; mais en dedans de ce calice intérieur se trourent d'autres appendices pétalö̈les, grands, inégaux, au nombre de :3 on 4 , dont un quelyuefois très déveIoppé et en forme de labelle. Ces appendices paraissent être des étamines transformées. Le's étanines fertiles sont an nombre de une ou de deux, à une seule anthère uniloculaire, et quelquefois sondies et formant une seule étamine à anthère biloculaire. Oraire à 3 loges pluriorulées, supportant sourent un petit disque unilatéral, qui doit être considéré encore comme une étamine avortée. Le stỵle est grêle, terminé par un stigmate en forme de coupe. Le fruit est une capsule triloculaire, Irivalve, loculicide et polysperme ; Ies graines contiennent un embrỵon cỵlindracé, place dans un endosperme simple ou double.

Les plantes contenues dans cette famille peurent se diriser en deux tribus que plusicurs botanistes considerent comme deux familles distinctes :

$1^{n}$ Les commares ou marantacres : rhizome rampant, ou racine fibreuse ; étamine fertile simple, uniloculaire, appartenant à la rangée extérieure des dtamines (1) et placée en face d'une des divisions latérales du périanthe interne; embryon contenu dans un endosperme simple. Genres thatia, maranta, myrosma, canna, etc.

10 Les zingibrincres : rhizome rampant, tubéreux ou articulé; une itamine double, ferlile, appartenant à la rangée interne et opposée au labelle. Embrton placé dans un double endosperme. Genres gloldun,

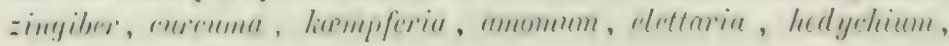
alpinia, hellenia, costus, ctc.

(1) On admet que le nombre orisinel des chamines est de siv ot quielles sont di-posies sur deux séries, de mème que dans les liliacées et dans la phupart des autres familles de monocotyledones à fleurs régulières. 
AMOMACÉES.

La diversite des principes constitunts et des propriélés médicales concourent, arec la différence des caractères botanicjues, pour séparer plus complétement les camnacées des zingibéracées : les premières sont dépourves de principes aromatiques, et sont remarquables sentement par la grande quantité d'amidon contenue dans leur rhizome; les secondes, indépendammont de l'amidon renfermé dans leurs tubercules, sont riches en huiles volatiles répandues dans toutes leurs parties, et en principes âcres et pipéracés qui les rendent émincmment excitantes et les font employer comme assaisonnements dans tous les pays. Parmi ces dernières, nous décrirons principalement les galangas. les gingenbres, les curcumas, les zédoaires, les cardamomes et les manigueltes.

\section{Racines fle Galanga.}

Les galangas sont des raciues rougeâtres, d'une texture fibreuse ct demi-ligneuse, articulées, marquée's de franges circulaires comme les souchets, aromatiques et d'une sareur âcre; produites par plusicurs plantes qui appartiennent à la monandrie monogyoue de linné, aux monocotylédones épigynes de Jussien et à la famille des amomérs. On en distingue deux espèes principales, commues sons les noms de petir at de grand grolangre, qui different par leur lien d'origine et par la plante quii les fournit. Sous le titre de gulaurga léger, j'en dicrirai une treisieme fune jai quelquefois trouróc dans le: commerce, mèlée à la promière.

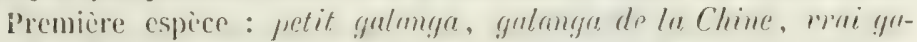

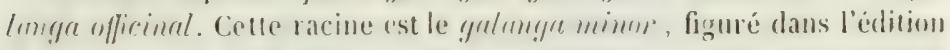

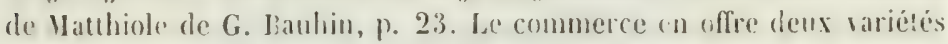
qui ne diffèrent pent-ètre que par l'ige de la plante. La plus pelite (figr. 97) est épaisse setilement de 5 à 10 millimètres. et la plus grosse ( fig. 98) est épaisse de 14 à 25 millim. ; toutes deux sont cylindriques, ramifiées, rougeâtres ou d'm brum noirâtre terne ì la surface, et sont marquées de nombrenses

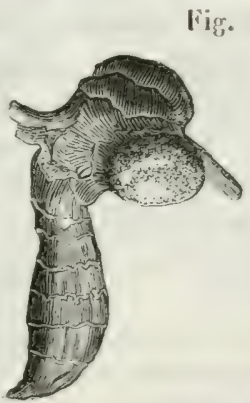
Fiig. 97 .

franges circulaires. A l'intericur, elles sont d'une texture fibrense, compacte et uniforme, et d'un fauve rongeattre; eiles ont une odem forte, aromatique, agréable, très analogue à celle des cardamonies; leur saveur est pignante, très àcre, brìlante et aromatique. Lemr poudre est rougeâtre et donne, par l'eau ct l'alconl, des trintures de mème. 


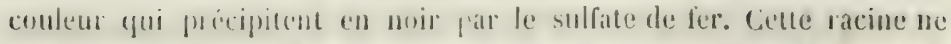
laise pats précipiter d'andidon lorsyere, étant concassée, on l'agite avec di: l'eau.

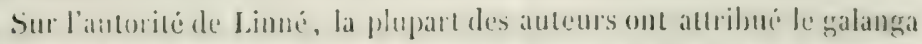

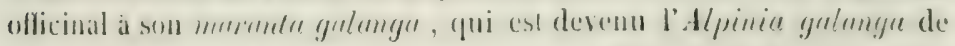

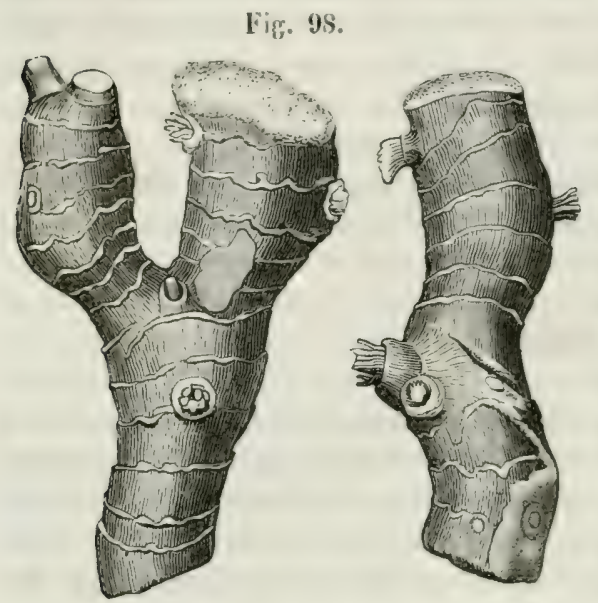

Wildenow. Cette plante, cependant, n'est autre chose que le grand galanga de liumplius, que cet auteur dit positivement ne pas produire le galanga de la Chine ou le galanga des pharmacies de l'Europe. Il faut donc Jui tromser une antre origine. Or, je pense ne pas me tromper en disant que notre galanga officinal est produit par le languas chinensis de Retz (Obs. fus:- III, P. 65), ou Ilelleniu chinensis Wr. Cette plante, ('II effet,

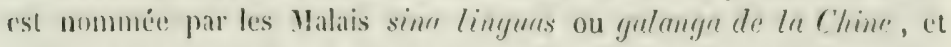
veciles caracteres donnés ì sa racine: "Pacine répandue lovizontalement sons terre, cylindrique, rameuse, entomée d'anneaus rirculaires, a sommets obtus et arromblis, de la grosseur du doigt majeu, blumelefe, aromalique, d'une sareur brûlante. Elle est cultivie daus les jardins de la Chine pour l’usagre médical. "

Celte description se rapporte exactement à notre galanga olficinal, hors la couleur blanche: mais cette différence peut être exphiguée, soit parce fue, dans son éfat maturel, cette racine serait recourerte d'une pellicule blanchatre, dont plusieurs morceaux me paraissent comserver des restiges, malgré la dessiccation et le frottement causé par le transport; soit parce gue la couleur rougeatle serait le résultat de l'acti.u de l’arr sur l'huile rolatile et le tannin contenus dans la racine (1).

(1) Les fascicules de Retz doment la description d'un autre galanga quil nomme languas vulyare usitatissimum, Maleys. Calanga alba. Radices horizontales, tereliusculep, cicatribus anmularibus obliquis, remotiusculis c nelu; ramose, albre, pollice crassiores, fibras filiformes recta descendentes subtus emiltentes. Colitur in hortis. Celle plante est l'hellenia alba de Willdenow : je ne pense pas que sa racine vientre en liurope; mais si c'est la meme que l'amomum medium de Loureiro, on en trouvera le fruil decril parmi les cardamomes. 
Deuxieme espece. Giulungr léger. Cette racine lient le milieu pour la grosseur entre les plus petits et les plus gros morceaux du rai galanga ; elle varie de 7 à 16 millimétres de diamche. Elle est de mème cntouréc de franges blanches, mais son épiderme est lisse, luismit et d'un rouge clair et jaunàtre; elle est d’un rouge très prononcé à l'intérieur avec des fibres blanches entremêlés. Son odemr, sa savem, son action sur le sulfate de fer sont semblables a celies du wai galanga, mais bien plus faibles. Son caractere le plus tranché consiste dans sa grande légèreté ; car en pesant des morceaux sensiblement égaux en rolume à d'autres de vrai galanga, leur poils me se troure être que le tiers on la moitié de ceux-ci. Une autre différence se tire de la forme générale de la racine : le galanga officinal est en tronçons sensiblement cylindrigues, ramifiés, et compés par les deux extrémités; de sorte qu’il est difficile d'en établir la longuenr réelle, tandis que le galanga léger présente des renflements tubéreux aux articulations, et offre des arlicles oroüdes funis, longs de 27 millimètres envirom. Je suppose que la plante qui produit ce galanga est très roisine de la précédente à coup sùr, ce n'est pas le kempferia galanga $\mathrm{L}_{\text {. }}$, ni aucun autre liempferia.

Troisième espèce. Girand gulanga ou galangre de l'Inde ou de Jarn.

lig. 9!.

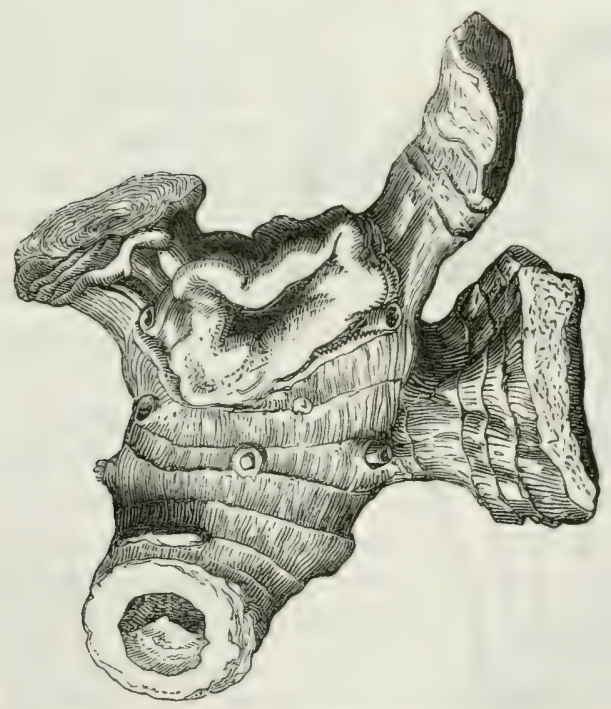

Ce galanga se troure très bien représenté par G. Baulin, dans son édition de Mathhiole. En le rapprochant des descriptions de Rumphius et d'Ainslie, il est difficile de ne pas croire qu'il suit produit par le galangu 


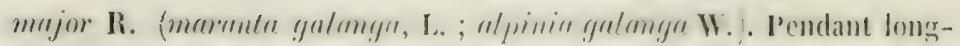
trmps, j’ai été réduit i n'anoir que quelyues morceaux très anciens de cette racine, qui mataien! peu permis de la bien déerie; mais un droguiste de Paris en agant recu une partie consilcérable venant de l'Incle, je me suis trouvé à méme de la faire mienx commaître.

Cette racine (fig. 99) est quelquefois cylindrique et ramifice conume lo petit galanga ; mais, le plus sourent. elle est plutôt tubéreuse et articulér comme le galanga léger. Elle est beaucoup plus grosse (jue l'un on l'autre, car son diamètre varie de 11 à 23 millimètres dans le's parties cylindriques, et s'étend jusqu’à 41 millimètres pour les tubérosités. Sa surface extéricure est d'un rougre orangé, et marquée de nombreuses franges circulaires blanches. L'intérieur est d'un blanc grisitre, plus foncé au centre qu’à la circonférence; elle est plus tendre, plus facile à couper et à pulvériser que le petit galanga, et sa poudre est presque blanche. Elle a une odeur différente de celle du petit galanga, moins aromatique, moins agrẻable et plus âcre. Cette odenr provoque l'étermument, et cependant la racine est bien loin d'offrir la saveur brûlante du galanga offirinal. Je grand galanga concassé, agité dans l'eau, laisse déposer une pondre blanche quii est de l'anidon; il colore tres faiblemint l'an ce l'aleonl, thes teintures ne noircissent pas par l'addition

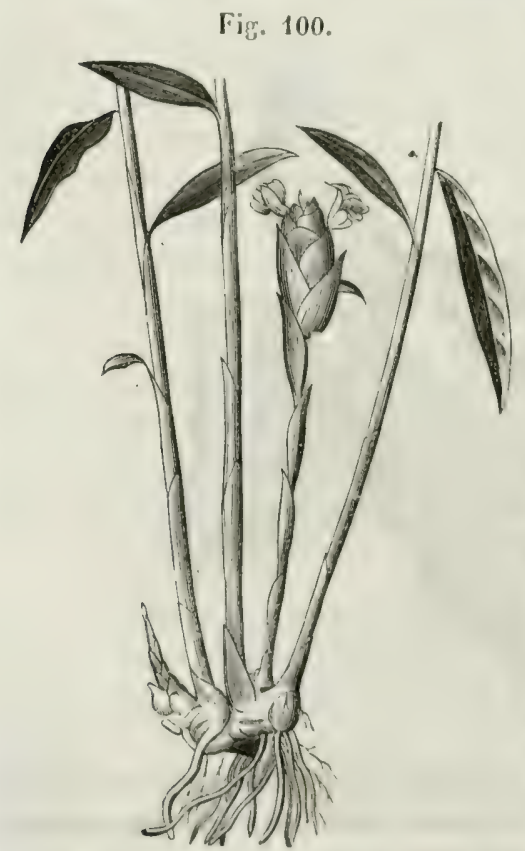
du sulfate de fer. Je ne pense pas que l'on doive substituer ce galanga au premier, gui seul est prescrit dans les alcoolats theriacal, de Fioratranti, et dans beaucoup d'autres compositions analognes.

\section{Gingembres.}

Les gingembres soist originaires des Indes orientales et des îles Molmymes: ce sont des plantes à rhizome tubéreux, articulé, rampant et virace. produisant des tiges annuelles renfermées dans les gânes disticpres des feuilles; les fleurs sont disposées en épis strobiliformes (fig. 100), portés sur des hampes radicales courtes et composés d'écailles imbri-

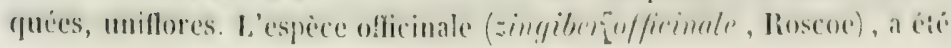


transportíe, il y a longtemps, au llexique, d'où clle s'est répandue dans les antilles et à Cavenne. Maintenant, ces derniers pays, et surtout la Jamaïque, en produisent une grande quantité. On tronve dans le commerce deux sortes de gingembre, le gris et le blane; ce dernice vient parliculièrement de la Jamaïgue, et n'est comnu en France que depuis 1815 , les Inglais, qui alors aftluerent chez nous, n'en usant pas d'autre. On pourrait croire que ce gingembre blanc cst une varieté produite par la transplantation de la plante ou la culture, ou bien, comme l'a pensé Duncan, que la différence des deux gingembres provient de ce que le gris (qu'il appelle noir) a été plongé dans l'eau bouillante avant sat dessiccation, tandis que le blanc a été pelé à l'élat récent, et séché par insolation (Edimb. nere dispens., p. 271). Il est possible mème qu'on prépare un faux gingembre blanc, en mondant le gingembre gris de son écorce et le blanchissant arec de l'acide sulfureux, du chlorure de chaux, on même senlement extérieurement arec de la chaux; mais cela n'empêche pas qu'il existe en réalité deux espèces de gingembre qui ont été distinguées par Rumphius, dans leur pạ̣s natal, par les caractères que nous leur comnassous (Zingiber allumn et rulurum, Herb. amboin., V, p. 156).

Le gingembre gris (fig. 101), tel que le commerce nous le présente, est une racine grosse comme le doigh, formie de tubercules articulés, ovoüdes et comprimés : il offre rarement plus de deux ou trois tubercules réunis, et beaucoup sont entièrement séparés par la rupture des articulations; il est couvert d'un épiderme gris-jaunâtre, ridé, marqué d'anreaux peu apparents. Dessous cet épiderme jaune se trouve une couche rouge ou brune qui forme le caractère distinctif du gingembre rouge de RumFig. 101 .

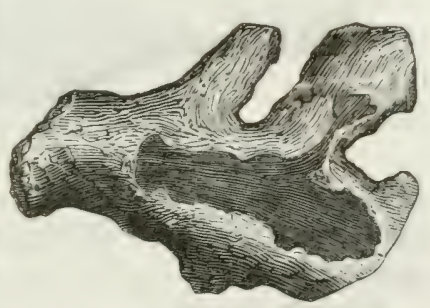
phins. Presque toujours l'ẹpiderme a élé enlevé sur la partie jroéminente des tubercules, probablement pour en fariliter la dessiccation, et à ces endroits dénudés la racine est noirâtre et comme cornée; mais l'intérieur est en général blanchâtre ou jaunàtre, entremèlé de quelgurs fibres Iongitudinales. Ce gingembre possède une saveur très âcre et une odeur forte et aromatique qui lui est propre ; il rxcite fortement l'éternument; il donne une poudre jaunâtre. II faut le choisir dur, pesant, compacte et non piqué des insectes, ce à quoi il est furt sujet. Je ne crois pas qu'il ait été trempé dans l'eau bouillante arant sa dessiccation, comme on le dit ordinairement, parce (qu'aucun des innombrables granules d'amidon qu'il contient n'a été brisé par la chaleur (ils se pré- 
sentent sous une forme ghob) Ifouse cuboüde; ; je croirais plutiot que ce gingembre áté simplement trempé dans une Jrssise alcaline ou mélangé de cendre seche, comme l'indique limmphius; ce que semblent indiquer les particules silicenses qui se tronscut souvent fixées à sa surface.

Gimgembie blanc (fig. 102, Cie gringembre est plus allongé, plus grèle, plus plat et plus ranitié que le gingembre gris. Il est naturellement recouvert d'une écorce fibreuse, jaunitre, striée longitudinalement, sans aucun inlice d'anneanx transrersanx; mais le plus ordinairement cette écorce a élé enleréc arec soin, et la racine est presgue blanche a l'extérieur, blanche à l'interienr, et domme une poudre très blanche. Ce gingembre est plus léger, plus tendre et plus friable sous le pilon que le gingembre gris; il est aussi bien plus fibreux à l'interieur; il a une odeur forte, moins aromatique ou moins heritense, si on peut le dire, et une saveur incomparablenent plus forte et plus brûlante. Certaine-

Fig. 102.

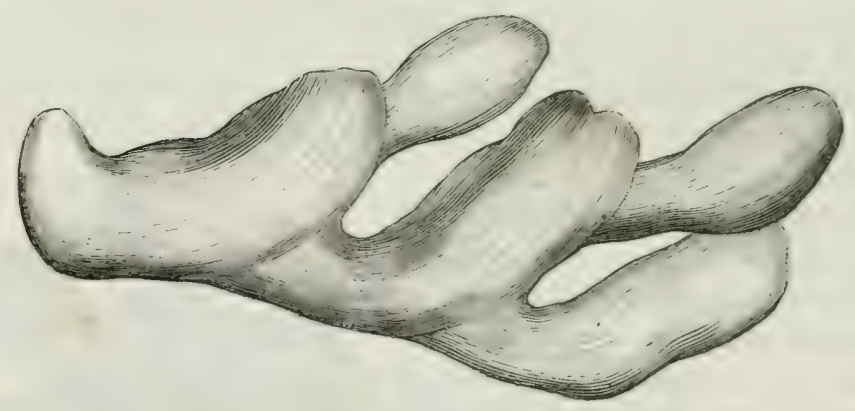

ment ces deux racines diflèrent par autre chose que par leur mode de dessiccation.

Il paraît que deux autres racines, appartenant au mème genre que le gingembre, ont quelquefois élé apportées par le comnerce: l'une est le gingembre sauvange, qui se présente sous lit forme d'une souche assez scmblable à celle du gingembre, mais plus volumineuse, fortement aromatique, d'une saveur anère et zingribéracée, mais sans une grande âcreté. Cette racine est prodnite par le Lmmpujum mujus de Rumphius (Herb. umb., t. V, p. 148, pl. 64, fig. 1); lintun-inseli-liun de Rheede; zingiber zerumbeth de Roxburgh et de R.oscoe, qui a eté confondu à tort, par la plupart des auteurs. arec le zimgiher lutifolium syleestre d'Hermann (Hort. lugyl., p. 636), lequel cat plutòt une esprece de

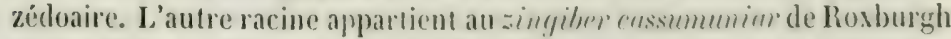
el de Roscoe. Lille est forme de tubercules volumineus, articulés. 
marqués de franges circulaires, bauchâtres au dehors, l'une couleur orangée à l'intérieur, et très aromatique.

\section{liacines de Curcuma.}

I. curcuma, nommé aussi terra-meritn, et par ies Ingliais turmer ir, est une racine grise ou jaunatre à l'extérieur, d'un jaune mangé foncé ou ronge à l'intérieur, d'une odeur forte et d'une saveur claude et aromatique; il est remarquable par l'abondance de son principe colorant jaune, qui est très usité dans la teinture.

On distingue gentralement denx sortes de curcuma : le long et lo rond, et beaucoup d'auteurs, moi-mème dans les premieres éditions de cet ourrage, nous arons supperé que ces racines étirient produites par deux plantes differentes. Il y a hien, à la rérité, plusieurs plantes à curcuma, mais chacune d'elles peut produre du curcuma long et rond, et leurs racines different moins par leur forme gque par leur rolume, leur couleur plus on moins foncée ct d'autres caracteres anssi secondaires.

limphius est sans contredit l'antemr yui ait le micux décrit les curcumas, et nous ne pourons miens fatre que de le suire pour trourer d'une manière certaine l'origrinc de ceux du commerce. D'après Rumphius (Herbair. ambuin., t. Y, p. \$602), les curcumas at les tommon (les zidoaires) forment un genre de plantes dont les especes sont iort rapprochées et lrès souvent confondues. Quant aux curcumas, il en distingue denx especes : une cultive et une sumenge. D'après la description qu'il en dome, celle-ci est tout à fait étrangère aux curcumas du commerce, et peut être mise de còté ; la première fournit un grand nombre de rariétés, qui peurent se résumer en deus sous espèces : une majeure et une mineure.

Le curcuma majeur (rupcruna domestica major limmph.) produit de sa racine 4 ou 5 feuilles pétiolées yui semblent former par le bas une sorle de stipe, et qui ont environ 50 centimètres de longueur, non compris le pétiole, et 16 centimetres de largeur; elles sont terminces en pointe des denx cotés, marcunes de sillons obliques en dessous, glabres, odorantes quand on les froisse.

Les fleurs sont disposées, non en cône fermé, naissant sur une hampe nue, comme dans les gingembres; mais clles formmt un épi central lìche, compose de braclées ourertes, imbriquées, demi-concaves, verdâtres et blanchissantes sur les bords. Ces bractées deviennent plus tard d'un brun pâle, surtont horsque la plante croît dans les forcêts.

Ia racine est composée de truis :ortes de parties: d'abord d'un tIIbercule central (motrit ratlicis Rimmph.), ducpuel sortent 3 ou / thbercules latéranx (qui ont la forme et la grosseur du doigt, et gni imitent, dans leur ensemble, les doigts de la main demi-fremé : ces lubrensitris 
allongées forment la seconde partie de la racine. Quant a la troisième, elle se compose de radicules sortant pour la plupart du tubercule central, longues de 135 à 160 millimetres, et dont guelgues uns portent ì la partic inferieure un lubercule blanc, de la forme d'une olise, purement amylacé et insipide. Il est évident que ces derniers tubercules me font pas partic du curcuma du commerce; mais Rumphius nous apprend que le tubercule central est desséché pour celte fin, et il est certain que les articles digilés s'y trouvent également. Les uns et les autres, Iorsqu'ils sont privés d'une pellicule externe blanchàtre, facile à délacher, sont d'une conleur de jaune d'œuf ou de gonune gutte; ils sont poursus d'une odeur el d'une saveur onguentacées, arec une acrimonie mêlée d'amertume.

Le curcuma mineur (curcuma domesticu minor Rmpls.) est plus petit daus toutes les parties que le précédent; les feuilles n'ont que 38 centimètres de long, y compris le pétiole, "t sont fortensent aromatiques; la racine est un assenblige élégant de 1 ou 2 cubserules centraux cintourés d'un très grand nombre d'articles digilés et recourbés, guni se divisent eux-inemes en d'autres, et forment un amas tuberçuleux bien plus étendu que dans l’autre espèce.

Le's articles digités du curcuma mineur sont plus minces que dans le C. majeur, plus longs, glabres et offrant une surface unie; ils sont, a l'interieur, d'une couleur très foncie; ils ont une saveur donce mais persistante, sans ancune amertume; leur odeur est aromatique et trés déveleppée.

Je suis entré dans ces détails afin de montrer exactenent l'origine du

$$
\text { Fir. } 103 .
$$

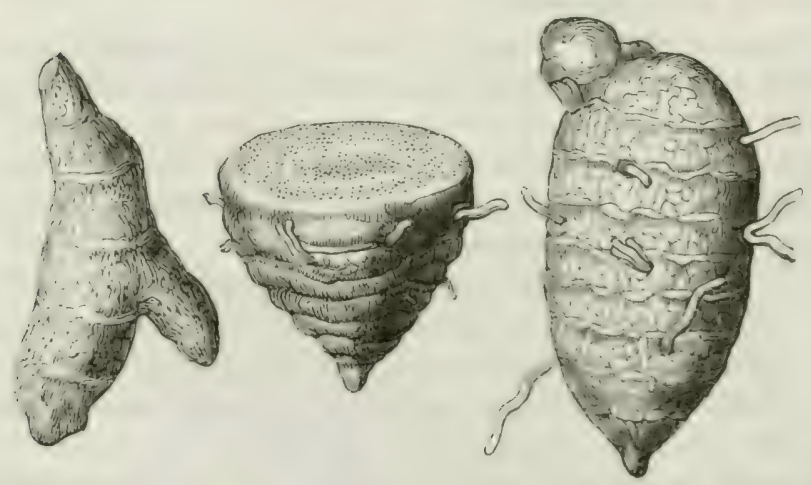

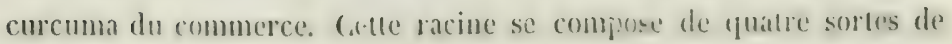
tubercules:

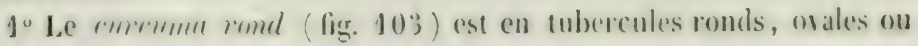


turbinés. de la grusseur d'un weuf de pignon et plus, d'un janne sale i l'extérieur, et à l'intérieur agant presque l'aspect de la gomme grotle. Il n'est pas denteux que ces tubercules ne soicut li's mutrieres rarleris du carcuma domestica major (1).

$2^{\circ}$ Le currema oblony (lig. 103) : je nomme ainsi un curcuma en tubercules allongís qui, par leur teinte extérieure jaune, leur coulcur incérieure, leur saveur et leur odeur, appartiennent éridemuent a la mêne espeice que le précédent, dont ils ne sont que les articles latcranx. Ces articles ont un caractire de forine qui les distingue des suivants : ils sont rentlés au milieu et amincis aux extrémités.

$3^{\circ}$ Curcumu lony (lig. 104 . Ce curcuma est on tulsercules cylin-

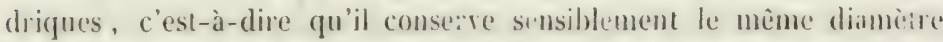
dans loute sa longueur, malgré Fig. 104. ses différentes sinuosités. Il est plus long que le précédent, mais beaucoup plus mince, n'élant jamais gros comme le petit doigt; sa surface est grise, sourent un peu verdâtre, rarement jaune, chagrinée ou plus souvent uette et unie. Il est à l'intérieur d'une couleur si foncée gia'il ('n paraît rouge brun, ou même noir. II ar une odeur aromatique très développée, analıgue à celle du gingembre; sa saveur est également très aromatique et cependant assez douce et nullement amère. Il est impossible de mé-
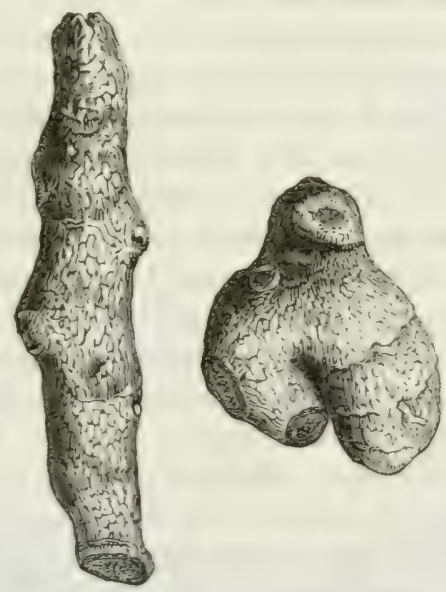
commaitre dans celle racine les articles digites do curemme domn's'irn minus.

4" Lufin, on troure dans le curcmua du commerce, mais en pelite quantite, des tubercules ronts die la grossenr d'une aseline, scimnut didymes, ou oflirant les restes de deus stipes foliacés (fig. 104). Cins tubercules offrent d'ailleurs tous les caractères des préccilents, et sont les matrices radicis du curcuma domestica minot.

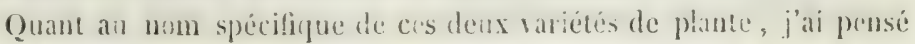
qu’il était nécessaire de Jeur en donner un nowreate. Car le nom de rme-

1) Indépendamment de ce curcuma rond, ciui est mondé et loujours trés propre à l'estéricur, on trouse aujourd'hui dan le comnerce des curcumas ronds de Java et de Sumatra, non mondés, yrisatres à l'extérieur, et pourvus d'un grand nombre de tronçuns de radicules. 
cuma domesticn n'est pas assez expressif ct pourrait tout aussi bien s'appliquer à une zédoaire. Celui de currumn longa ou rotundn convient cncore moins, soit parce que lat plante produit également l'une et l'autre racine, soit à cause de l'incertitude répandue sur ces deux dénominations de la nomenclature linnéenne (1).

A la rérité, Jacquin et Ilurray, après avoir retrouré la plante de Rumphius et l'avoir parfaitement distinguée de toutes celles qu'on avait confondues avec elle, l'ont décrite sous le nom d'amomum cur'cuma; mais la plante est cerlainement un curcuma el non un amomeum. Considérant alors que cette espèce est distinguée entre toutes les autres par l'abondance de son principe colorant, j’ai proposé de lui donner le nom de curcuma tinctoria; en roici les seuls synonymes :

Amomum curcuma; Jacquin, Hoit. eimel., vol. III, tab. 4 ; Murrạ,, Syst. végét., èd. 15.

Curcuma radica longa; Zanon, Hist., t. I.IX.

Curcumu damestira majow "t minur; Rumph., tmb., t. V, p) 162.

III. Vugè et Pelletier ont analysé le curcuma long, et l'ont trouré formé de matière ligneuse, de fécule amy̧lacéc, d'une matière colorante jaune, d'une autre matière colorante brune, d'une petite quantité de gomme, d'une huile volitile âcre et odorante, d'une petite quantité de chlorure de calcium. Le plus important de ces principes est la matière colorante jaune qui s'y trouve en grande quantité, et que son éclat rend utile dans la teinture, quoig̨u'elle soit peu solide.

Cetle matière colorante est très soluble dans l'alcool, dans l'éther et dans les huiles fires et rolatiles. Ille est très sensible à l'action des alcalis, qui la changent en rouge de sang. Aussi la teinture et le papier teint de curcuma sont-ils au nombre des réactifs que le chimiste emploie le plus sourent (Journ. de pharm., 1815, p. 289).

I.e curcuma est emplogé dans l'Inde comme assaisonnement. Il est tonique, diurétique, stimulant et antiscorbutique. Il sert en outre en pharmacie pour colorer quelques onguents.

\section{Racines de Jédoaires.}

On distingue deux sortes principales de zédoaires, la longue et la ronde, et une troisieme, la june, qui est plus rare et moins employée.

les zidoaires ont été inconnues aux anciens, on étaient usilées sous

(1) Dans les premieres dedilions du $S_{i}$ eries de limné, on trouve comme synonyme du C. rotunda le curcuma domestica major de Rumphius. I'resque partout ailleurs, le e. ronunda niest plus regrardé que comme synonygme du manja-liun de licede (hirmpperia pandurata, Ro-ce) : alors la plante de Rumphius est donnce comme svyonỵme du $C$. longa. 
d'autres noms. Par exemple, on a peusé que la zédoaire longue ou ronde était le costus syprinque de Dioscorides; la seule chose certaine que l'on puis-e dire sur ce sujet, c’est que notre zédoaire ronde a été succinctement décrite par Sérapion, sous le nom de zerumbet.

La zéloaire longue, qui est pent-ètre aussi le gollu'ar d'I vicenne, a été pendant tries longtemps la plus répandue dans le commerce et la seule sorte officinale. La ronde élait devenue tellement rare que C'usius, en avant trouré chez quelgues marchands d'Invers, a cru devoir en conserver la figure. Aujourd'hui la zéduaire ronde est presune la seule que l'ou troure à Paris. Ja pense gue crla lient à ce que la longue est regardée en Angleterre comme la raie sorte officinale cl y reste. Iu moins est-il vai qu'elle est seule mentionnée dans le dispensaire d'Édimbourg de Duncan.

Beaucoup d'auteurs ont considéré les deux zédoaires comme des parties de la même racine; entre autres Pomet, Date et Bergius. Dans mes premières éditions, j'ai combattu cette opinion, me fondant sur ce qu'on trouve quelquefois de lo zédoaire ronde pourrue de prolongements cylindrigues assez courts qui ne sont pas de la zédoaire longue; mais, après aroir examiné les nombreux curcumas fionrés par Roscue, j'ai compris que la mème plante jomenit produire les deux zidoaires, dont la ronde serait formíc des gros tubercules nommés par Rumph matrices rallicis, et la longue des articles digités qui entourent les premiers. Il paraît cependant que parmi les nombreuses plantes du genre curcuma, qui produisent des racines semblables, il ! en a $\mathrm{qu}_{\mathbf{i}}$ donnent plutôt des tubercules ronds, ef d'autres des articles digités; de sorte qu'en réalité les deux zédoaires, longue et ronde, proviennent de plantes différentes.

Zédoaire longue (fig. 10ز).

Racine un peu moins longue et moins grosse que le pelit doigt, terminée en pointe mousse aux deux extrémités, recouverte d'une écorce ridée,

Fig. 10\%.
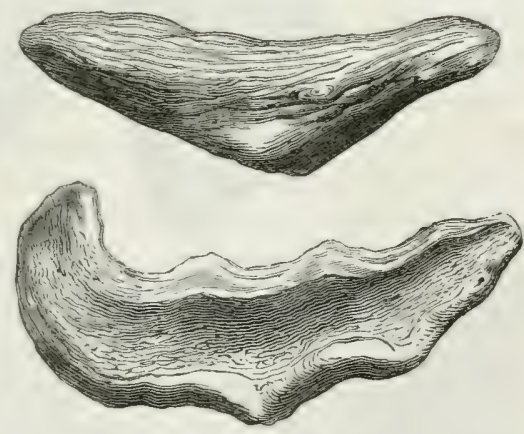
d'un gris blanchâtre; grise et sourent coméc à l'intérieur, d'une savenr amc̀re fortement camphrée. Lorsqu'elle est entière, son odeur est semblable à celle du gingembre, mais plus faible; pulvérisée, clle en prend une plus forte, analogue à celle du cardamome.

La zédoaire longue a une certaine ressemblance, ou, si l'on peut 
s'exprimer ainsi, un air de famille arec le gingembre. On les distingue cependant facilement: le gingembre est palmé ou articulé et très aplati; la zédoaire est formée d'un morcean unique, non divisé, peu aplati, rugueux et comprimé en différents sens: d'ailleurs l'odeur et la saveur sont différentes, et beaucoup plus marquées dans le gingeubre.

La zédoaire longue est produite par le liun de Rheede (Hort. malab., vol. XI, (ab. 7), cumomum zedrurita W. Yais cette plante n'est pas un amomum; c'est un cui'cuma, que Roxburgh a nommé curcuma zerumbet. Ce now est encore fautif, parce que le vrai zérumbet est la zédoaire ronde et non la longue. Le nom donné par Roscoe, curcuma zedoaria, doit être définitivement adopté.

\section{Zédoaire ronde (Gg. 106).}

Cette racine est le zerumbet de Sérapion, de Ponet et de Lemery. Elle est ordinairement coupée en deux ou en quatre parties, représ ntant des moitiés ou des quartiers de petits ceufs de poule : la partic conrexe est sonvent anguleuse et toujours garnie de pointes épineuses, qui

Fig. 106.
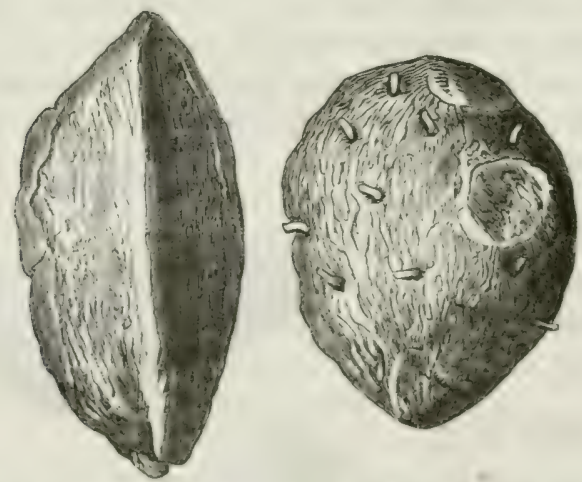

sont des restes de radicules. L'épiderme, "dans les morceaux qui n’en sont pas pricés, est comme foliacé, et mar(qué d'anneaux circulaires, semblables à ceux du souchet et du curcuma rond, mais moins nombreux et moins margués. Enfin, cette mème parlie offre sourent une cicatrice ronde de 9) it 11 millimètres de diamètre, provenant de la section d'un prolongement cylindrique qui unissait deux tubercules entre rux. D'après colte description, il est facile de se faire une idée de la zedoaire ronde dans son chat naturel; ce doit ère une racine tuberculeuse, arosse comme un ouf de poule, marquée d'anneanx circuaires enme le sonchet on le rurcuma, sarnie tout autour d un grand 
nombre de radicules ligneuses, tontes dirigées en bas, et unie, tubercule à tubercule, par des prolongements cylindriques de 9 à 11 millimètres de diamètre, et de 27 millimètres de longueur présumée. Cette disposition est entièrement semblable à celle du curcuma rond.

La zédoaire ronde est d'un blanc grisâtre au dehors, pesante, compacte, grise et souvent cornée à l'intérieur, d'une saveur amère et fortement camphréc, comme la zédoaire longue. L'odeur est égalensut semblable, c'est-à-dire analogue à celle du gingembre, mais plus faible lorsque la racine est entière, plus aromalique, et semblable ì celle du cardamome, lorsqu'on la pulvérise.

D'après ce que j'ai dit précédemment, on conçoit (fu'a la rigueur la zédoaire ronde puisse être produite par la même plante que la longue; cependant les auteurs anglais s'accordent pour l'attribuer à une autre espèce de curcuma, qui est le curcumu zedoaria de Roxburgh, que Roscoe a nommé curcuma aromatica, d'après son opinion que la plante qui produit la zédoaire-longue doit seule porter le nom de curcuma zedoaria.

\section{Zédoaire jaune.}

Cette racine est peu connue; on la trouve mêlée en petite quantité à la zédoaire ronde, à laquelle elle ressemble entièrement par sa forme, ses radicules et la disposition de ses prolongements cylindriques. Ëlle en diffère par sa couleur, qui est semblable à celle du curcuma; par sa saveur et son odeur, qui, tenant le milieu entre celles de la zédoaire et du curcuma, sont cependant plus désagréables que dans l'un et l'autre : elle se distingue, d'un autre côté, du curcuma rond, par son volume plus considérable, sa surface convexe souvent anguleuse, sa couleur extéricure plus blanche et semblabie à celle de la zédoaire, sa couleur intérieure plus pàle; an total, elle se rapproche plus de la zédoaire que du curcuma, et doit être fournie par une plante analogue à la première.

La plante qui produit cette racine a été parfaitement décrite et figurée par Rumphius. C'est son tommon bezaur ou tommon primum, que la plupart des auteurs font à tort synonyme du curcuma zedoaria de lioscoe, qui produit la zédoaire longue. Elle en diffère, à la première vue, par son épi floral rui surgit du milieu des feuilles, de même que cela a lieu pour le vrai curcuma, tandis du'il est porté sur une hampe nue, isolée du stipe foliacé, dans le $C$. zerloaria. Il conviendra de donner un nom spécifique à ce tommon, qui ressemble beaucoup, il est vrai, au curcuma tinctoria, mais qui en diffère par l'énorme grandeur de ses feuilles, ct surtout par la nature particulière de sa racine, laquelle joint à la couleur affaiblie du curcuma la saveur et l'odeur de la zídoaire. 


\section{Frults produits par les Amomacées.}

Ces fruits, d'après les caractères mêmes que nous avons indiqués pour la famille des amomacées, ont une grande analogie les uns arec les autres; car ils sont généralement formés d'une capsule mince, assez sìche, trigone, à 3 loges, et contenant un grand nombre de semences arnmatiques. On en rencontre cing espèces dans le commerce, oì elles sont connues sous les noms d'amome, de cardamome et de maniguette; mais on en tronve dans les droguiers un bien plus grand nombre, que je vais décrire succinctement.

1. Mwove Ex grappl; amomum racemosum (fig. 107). Ce fruit, dans son état naturel, est disposé en un épi serré le long d'un pédoncule commun, et il est quelquefois arrivé sous celle forme, ce qui lui

Fig. 107.

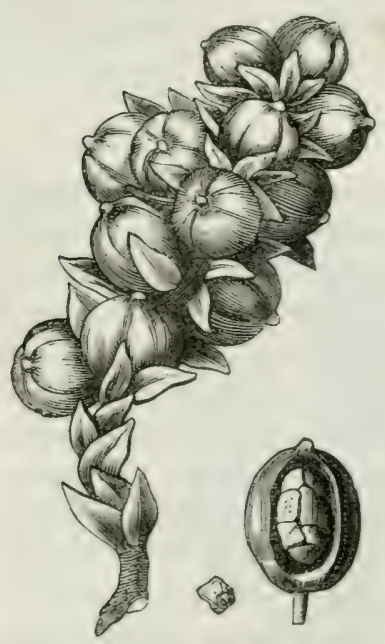

a valu son nom pharmaceutique; mais ce n'est pas une grappe, c'est un épi, qui se trouve d'ailleurs parfaitement représenté dans les Exotict: de Clusius, p. 377, et dans l'Herbarium de Blackwell, t. 371. Dans le commerce, on le trouve tonjours en coques isolées, qui sont de la grosseur d'un grain de raisin, presque rondes et comme formées de trois coques soudées. Cette coque est légèrement plissée longitudinalement, mince, ferme, d'une couleur blanche; mais elle prend une teinte rougeâtre ou brune par le côté qui est exposé à la lumière. Les semences sont brunes, cunéiformes, toutes attachées rers le centre de l'axe du fruit, ce qui en détermine la forme Globulcuse; clles ont une saveur àcre et piquante, "t une odeur pénétrante qui tienț de celle de la térébenthine.

L'amome en grappe rient des îles Moluques, des îles de la Sonde et surtout de Java II est produit par l'amomum cardamomum de Roxburgh, de Willdenow et de Limné (moins les synonymes tirés de Rheede et de Blackwell ), dont le caractère spécifique est d'aroir l'ípi radical, sessile, obové, W., ou la hampe très simple, très courte, à bractées alternes làches, 1. On pense généralement que cette espèce (amomum cordamomum) produit le petit cardamome; mais c'est une erreur causée ariginairement par Rumphius, qui a décrit celte plante sous le 
nom de curdemomum minus. Elle produit uniguement le fruit nomme an:omum racemosum.

2. Petit cardanome de Malabar (fig. 108); amomum repens de Sonnerat, alpinia cardunomum de Roxburgh, eletturiu cardamomum de Nlaton. Coque triangulaire, encore un peu arrondie, longue de 9 à 12 millimètres et large de 7 à 8 . Elle est d'un blanc jaunâtre uniforme, marquece de stries longitudinales régulières, un peu bossclée par l'impression des semences, d'une consistance ferme. Les semences sont brunàtres, irrégulières, bosselées à leur surface et ressenblant assez à des cochenilles, d'une odeur et d'une sareur très fortes et térébinthacées. Ce fruit est le rrai cardamome officinal, figuré et décrit par Rheede sous le nom d'eletturi (IIort. malub., vol. XI, lab. 4, 5 et 6 ).

3. Long Cardanome de Malabar (fig. 109 el 110); moyen cardamome de l'Histoire abrégée des drogues simples. Ce fruit est une simple variété du précédent; mais une variété constante reconnaissable à sa

Fig. 103.
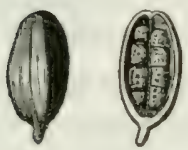

Fig. 109
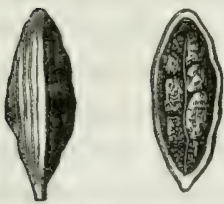

Fig. 111.

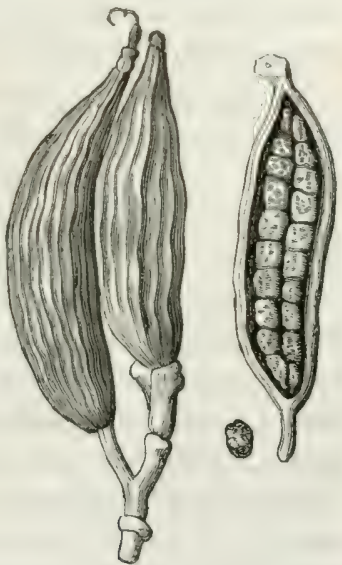

capsule plus allongée, toujours blanche et comme cendrée, et à ses semences rougeâtres. Longucur de la capsule, de 16 à 20 millimitres; largeur, de 5 à 11 millimètres. Les semences ont une saveur aromatique très forte.

4. Cardamome dE Ceylan (fig. 111); cardamome ensal de Gærtner (tab. XII); grand cardamome de Clusius, de Blackwell, de Murray, de l'Histoire des drogues simples; moyen cardanome de VaIerius Cordus, de Matthiole, de Pomet et de Geoffroy. Cette espèce est bien distincte des précédlentes et moins estimée : sa capsule est longue de 27 à 40 millimètres, large de 7 à 9, rétrécie aux deux extrémités 
et d'un gris brunàtre. Les semences sont irrégulieres, très anguleuses, blanchâtres, d'une odeur et d'une sareur semblables aux précédentes, mais plus faibles. Ce fruit est produit, dans l'île de C'eylan, par l'elettaria major de Smith, plante très roisine de l'elettarin cardamomum, mais plus grande et plus forte dans ses différentes parties.

5. Cardonome volr de G.tertwen; zingiber nigrum, Gærtn. C'est sur l'autorité d'un échantillon obserré anciennement au Iluséum d'histoire naturelle que j'assimile ce cardamome au zingiber nigrum de Gartuer. Il est de la grosseur du long cardamome du Malabar (fig. 109 , qui lui convient assez bien), de forme oroüde, mais pointu par les deux bouts, et comme formé de deux pyramides opposées. La coque est d'un brun cendré, toute marquée d'aspérités disposées en lignes longitudinales et causées par l'impression des semences pressées dans l'intérieur. Cette coque est plus épaisse et plus consistante que celle du petit cardamome; plus aromatique, mais toujours moins que ses propres semences, qui sont anguleuses, d'un gris brunâtre, et pourrues d'un goint fortement camphré, amer et salé.

6. Cardahome polic de la Chine (fig. 112). J'ai ru anciennement, dans la collection du lluséum d'histoire naturelle, plusieurs cardamomes confondus, mais mis dans deux bocaux différents. Les

Fig. 112.

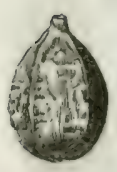
senences, privées de leur capşule et agglomérées en masses globuleuses, étaient contenues dans un-bocal et étiquetées cao-kieu. Les fruits entiers, renfermés dans un autre, portaient pour suscription les mots tsao keou. Dans ma précédente édition, j’ai cunsidéré ces cardamomes comme deux variétés d'un même fruit; mais un examen subséquent m'y a fait reconnaître au moins deux espèces distinctes. L'espèce ici décrite sous le nom de curdamome poilu de la Chine, et auquel se rapporte sans doute le nom tsu-keou, présente des capsules pédicellées. longues de 14 millimètres environ, ovoüdes, trigones, un peu terminées en pointe par le côté opposé au pédicelle, et d'un gris brunâtre. Lcur surface est toute rugueuse el toute parsemée d’aspérités, que l'on reconnaît, à la loupe, pour ètre les restes de poils qui recourraient la capsule. Cette cogue est assez mince, peu consistante, facile à déchirer et inodore; à l'intérieur, l's sentences sont agrglomérées en une masse arrondie, ou ovoüde, ou trigone. Cés semences sont noirâtres au dehors, blanches au dedans, d'une odeur très forte, camphrée et poirrée, et d'une sareur semblable. Ce cardamome, par sa dimension, sa couleur, et par les poils dont il est pourru, parait se rapporter à l'amomum ri losum de Loureiro; mais il s'en éloigne par sa forte gualité aromatique et par la synonymie. 
7. Cardanome rovd DE la ChINe; cro-keu ou mieux tsuo-keu. Ce cardamome présente lui-même deux variétés, ou peut-être encore deux espèces distinctes. La plupart des capsules, formant la première variété (fig. 113), sont pédicellées, presque sphériques, de 12 à 14 millimètres de diamètre, légèrement striées dans le sens de l'axe et de plus ridées en tous sens par la dessiccation; cependant le fruit récent devait être lisse. La coque est mince, légère, facile à déchirer,

Fig."113.

Fig. 116.
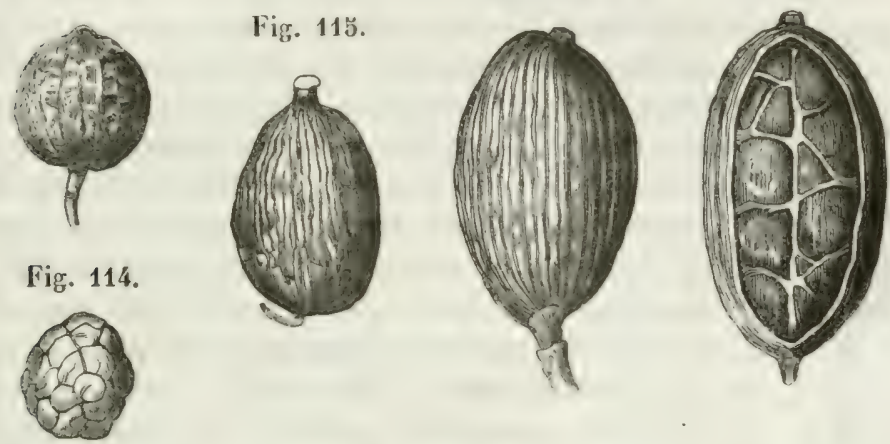

jaunâtre au dehors, blanche en dedans. Les semences (fig. 114) forment un amas globuleux, cohérent. Elles sont assez grosses et peu nombreuses, à peu près cunćiformes, d'un gris cendré, un peu chagrinées à leur surface, et présentent, sur la face extérieure, un sillon bifurqué qui figure un $y$; elles possèdent une odeur ei une saveur fortement aromatiques. Ce fruit présente tellement tous les caraclères de celui de l'amomum globosum de Loureiro, nommé également par lui tsao-keu, qu'il ne peut rester de doute sur leur identité.

8. Autre caroanome roni) de la (hine. Les secondes capsules, qui sont moins nombreuses, sont pius volumineuses et oroïdes (fir. 115), ayant environ 20 millimètres de longueur sur 14 d'épaissenr. Elles sont pédicellées, d'un gris plus prononcé à l'extérieur, marquées de stries longitudinales plus apparentes, d'une consistance plus ferme. Les semences sont plus petites que dans l'espèce précédente, chagrinées, d'un gris brunâtre, blanches en dedans et d'un goût arnmatique camphré.

9. CaRdauone ovoïdé DE LA CHIxe (figg. 116); amomum medium de Loureiro; hellenia alba Willd. Cette plante est une espèce de galanga que j’ai déjà eu occasion de citer (p. 200). Le fruit se trouve au Muséum d'histoire naturelle sous le nom de $t s(t 0-q u o$, que lui donne également Loureiro. Il est ovoïde, ou ovoïle allongé, long de 20 à 32 millimètres, épais de 14 à 18 , formé d'une capsule ferme, d'un rouge brunàtre, 
marquice de fortes stries longitudinales. Ies semences sont très grosses, pyramidales, à amande blanche, d'odeur el de ggoùt térébinthacés.

10. Un autre fruit analogue se trourait au Muséum, étiłueté quâ-leu.

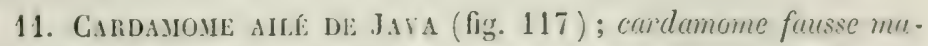
niguette de ma précédente édition; amomum maximum de Roxburgh. Capsule d'un gris rougcâtre foncé, offrant à sa surface comme les restes d'un brou fibreux desséché. M. P'ereira, en faisant l'observation que ce

lig. 117.

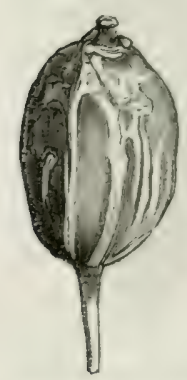
cardamome, mis à tremper dans l'eau, derient presgue globuleux et présente de 9 à 13 ailes membraneuses déchirées, qui occupent la moitié ou les trois quarts supérieurs de la capsule, a fait tomber plusienrs opinions erronées qui araient été émises sur l'origine de ce fruit, et a établi son identité arec celui de l'ommmum maximum $\mathrm{R}$. La capsule sèche est longue de 23 à 34 millimètres, épaisse de 11 à 16 , ayant taniôt la forme d'un coco ordinaire conveloppé de son brou, tantôt celle d'une gousse d'ail. Les semenres ressemblent à colles de la maniguette, par leur volume et leur forme arrondie; mais leur surface est terne et grisàtre, et leur odeur de cardamome, jointe à une saveur térébinthacée qui n'est ni âcre ni brûlante, les range parmi les cardamomes et les sépare de la manigueltr.

Indépendamment du fruit précédent, que j’ai pris anciennement pour celui de la maniguette, on en connait aujourd'hui un certain

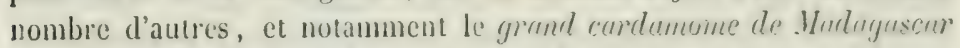
de Sonnerat, et le zingiber meleguelte de Giarner, qui ont été confondus par la plupart des anteurs arec la maniguette, malgré les anciens arertissements de Valerius Cordus qui avait bien domne les caractires distinctifs des cardanomes et des maniguentes. Parmi les savants de notre épogue qui ont le plus contribué à faire ce:ser la confusion de ces différents fruits, je citerai It. le docteur Jonathan Pereira, anteur d'une materia medica très estimée. Arant de parter des véritables maniguetles (car il y en a plusieurs ígalement), je traiterai des fruits qui tiennent aus cardamomes déji décrits, par leur (qualité fortement aro)matique, dépourvue de l'àcreté brùlante gui forme le caractire propre des maniguettes.

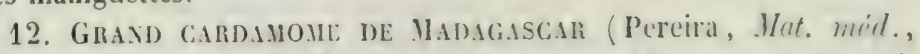
$2^{\mathrm{e}}$ ćdit., p. 1026, fig. 195). M. P'ereira comprend sous cetle dénonination le grand cardemome de Mauhiole, de Geoffroy, de Sunith et de Geiger; le grand cardamome de .larlagascur on amomum angustifolium de Sonnerat (Ioygrge aut Indes, 1. 1I, p. 242, pl. 137). I'unno- 
mum madayuscariense de Lamarck (Encyctup. Luterr., 1. I, p. 133 ; IIl., tab. 1). Je renroie à ces deux derniers ourrages pour la description de la plante et la figure du fruit. Je dirai seulement que les fleurs naissent au nombre de 3 ou 4 sur une hampe radicale peu élevée, conrerte d'écailles qui s'agrandissent au sommet et se changent en grandes spathes uniflores en forme d'oreille d'âne. Il n'y a guère qu'un ou deux fruits qui viennent à maturité sur charque hampe. Le fruit est une cap. sule charnue, rougeâtre, orale-oblongue, anincie cn pointe à la partic supérieure, longue de 68 millimètres et divisée intérieurement en 3 loges. Elle est remplie de petites semences orvïdes, luisantes, rougeâtres ou noirâtres, et enveluppées d'une pulpe blanche, d'un goût aigrelet et agréable. Ces semences ont un goût vif et aromatique et une odeur agréable. Voici maintenant la description du fruit du grand cardamome figuré dans la matière médicale de $\mathbf{H}$. Pereira.

Capsule orale, pointue, aplatie sur un côté, striée, offrant à la base une cicatrice large et circulaire, entourée d'une marge élerée, entaillée et froncée (1). Semences plus grosses que la graine de paradis, arrondies ou un peu anguleuses, creusées d'une gran le c svité à la base, d'un brun olivatre, pourvues d'une odeur aromatigne analogue à celle du cardamome et totalement prisées du goût âcre et brûlant de la maniguette. J'ajoute, en précisant davantage, que les semences ont la couleur de la fains (semence du firgns syleaticn) (t que leur surface, quoique luistnte, n'est ni lisse et polie comme on l'observe dans les semences des cardamomes de Clusius, dont il sera question ci-après; ni aussi rugueuse que dans la maniguette : elle pariît à la loupe être formée d'un tissu finement fibreux.

13. Capdinone D'A byssinie. Il est très probable, en raison de sa plus grande proximité des voies du commerce du Levant, que c'est ce cardamome, plutôt que celui de Vladagascar, qui a été anciennement connn sous le nom de grand cardamome. Cela pariît être vrai, surtout pour le grand cardamome de Valerius Cordus (IH istoria plantar., lib. 1v, cap. 28). D’après des échantillons et des renseignements assez récents

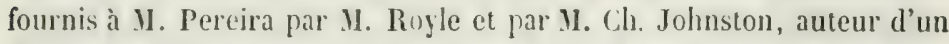
Toyage en Abyssinie, ce cardamome viendrait principalement de Guraque el d'autres contrées situées au sud et à l'ouest de l'Abỵssinie. Il y porterait le nom de korarima; mais les trabes le nommeraient khil on keil. Ce fruit, dont je donne ici la figure (fig. 118), a la forme habituelle de tous les grands cardamomes, oroïle - triangulaire et terminée en pointe par le haut. Il est traversé de part en part par un

(1) La figure 120 ci-après, quoique appartenant à un fruit différent, représente assez bien celui dont il est ici question. 
trou dans lequel passait une ficelle qui a dû servir à le suspendre pendant sa dessiccation. Il est long de 40 millimètres environ, épais de 15 à 17 dans sa plus grande largeur, formé d'une capsule consistante et solide, striée longitudinalement, mais présentant en outre deux sillons plus marqués qui doivent résulter de l'impression de la côte médiane de 2 spathes. L'intérieur est divisé en 3 loges par des cloisons très consis-

Fig. 118.

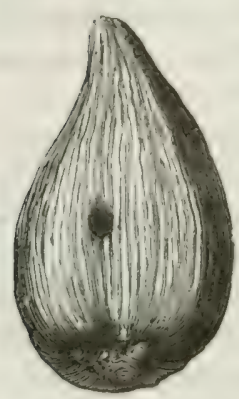
tantes également, et chaque loge est remplie par une pulpe rougeâtre desséchée, et réduite à l'état de membranes qui enreloppent les semences. Celles-ci sont semblables à celles du grand cardamome de Inadagascar, si ce n'est qu'clles sont d'une couleur plus pâle et qu'elles s' nt profundément sillonnées par la dessiccation, surtout du côté opposé au hile. il. Pereira pense que cz cardamome est produit, comme le précédent, par l'amomum angustifolium de Sonnerat. Je suis porté à partager cet avis, parce que les caractères particuliers remarqués dans le cardamome d'Abyssinie me paraissent provenir de ce qu'il a été récolté avant sa complète maturité.

14. Grand Gardanome de G.ertrer; zingiber meleguetta, Gertn. ( De fruct., rol. I, p. 34; tab. 12, fig. 1). Fruit unique, ovale-oblons, cutouré d'une douzaine de spathes qui devaient contenir autant de fleurs avortées; il est long de 5 centimètres, épais de 2 , ter-

Fig. 119.

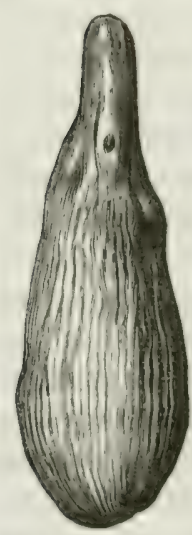
miné supérieurement par les débris lacérés des enveloppes florales; il est d'un gris rougeâtre, strié, triloculaire, à cloisons membraneuses. Les loges sont remplies par une substance spongieuse dans laquelle sont mêlées lès semences. Celles-ci sont nombreuses, ovoüdes-globuleuses, diversement anguleuses, à surface inigale médiocrement luisante, et d'une couleur plombée; elles sont creusées à la base d'un ombilic profond, entouré d'une marge blanchàtre un peu renflie. L'odeur en est aromatique et camphrée; la sarcur semblable, presque privée d'âcreté.

Le grand cardamome de Gertner se rapproche assez de la maniguette, pour que ce célèbre botaniste et, après lui, la plupart des anteurs, les aient confondus. Il se rapproche encore plus du grand cardamome de Madagascar et d'Abỵssinie; mais il s'en distingue par la couleur grise plombée, très caractéristique, de ses semences. Giertner n'a pas indiqué le lieu d’origine de ce fruit. M. Th. Miartius en a enrové un échan- 
tillon à la Société médico-botanique de Londres sous le nom de cardumome de Bunda. D'un autre côté, sir J.-E. Smith pense que la plante de Gartner n'est autre que l'amomum macrospernum de la côte de Guincé, où il porte le nom de mabsubo. Je donne ici (fig. 119) le dessin d'un fruit d'amomum macrospermum, provenant de la collection de Sloane, au Iusée britannique. Les semences, en effet, ne diffèrent pas de celles du zingiber meleguetta de Gærtner.

15. Cardanone a SEMlices polies, de Clusius. A vant d'arriver aux véritables maniguettes, je dois encore décrire quelques fruits qui se distinguent de tous les autres par leurs semences oroïdes-allongées, polies, miroitantes et d'une couleur brunâtre très foncée. Ces fruits se ressemblent par leurs semences, inais diffèrent tellement par la forme de leur capsule, (qu'ils forment probablement plusieurs espèces distinctes.

La première espèce est celle qui a été décrite et figurée par clusius daus ses Exoticue, lib. 11, cap) 15, n" 14. La figure représente quatre fruits réunis au sommet d'une hampe et entourés de spathes beancoup plus courtes que les fruits. Les capsules sont longues de 54 millimètres, d'une forme ovölde triangulaire très allongée, d'un brun rougeâtre, cartilagineuses, triloculaires, pleines de semences noirâtres, brillantes, plus grosses que du millet, rassemblées en une seule masse et enveloppées d'une membrane mince. Ces semences sont blanclies en dedans et douées d'une certaine âcreté.

Clusius ajoute que dans l'année 1601, des voyageurs lui remirent des fruits semblables aux précédents, qui araient été recueillis à IIadagascar, et qu'ils prétendaient ètre de la maniguette ou du grand cardamome. Mais ils étaient reconnaissables à leur forme plus grêle et plus oblongue, à leur capsule plus dure et assez fragile, à leurs semences moins nombreuses, plus grosses, d'un brun obscur et brillantes, enveloppées chacune dans une membrane blanche. Je donne ici les figures de deux cardamomes de ce genre que je dois à l'obligeance de M. Pereira.

Le premier (fig. 120) se rapproche beaucoup de celui décrit, en second lieu, par Clusius, comme renant de Iladagascar. Seulement la capsule est plus grosse et moins allungée. Hais elle est d'une couleur rougeâtre très prononcée, ferme, dure ct cependant cassante; elle est fortement plissée dans sa longueur, un peu aplatie du côté qui regardait l'axe du régétal, fortement bombce de l'autre. Les semences sont enveloppées dans une membrane blanclue très line; efles sont plus petites que la maniguette, d'un brun un peu verdàtre, très brillantes, ovoïdes, un peu aplaties, arec une cicatrice terminale, mais un peu déviée de l'axe; de sorte que ces semences ressemblent beaucoup, très en petit, 
à celles du staplinglea pimata. Je les troure fort peu aromatiques et peu sapides.

Le second fruit (fig. 121) est très grêle, et terminé par le limbe du calyce; le hile est prolongé en une sorte de collet fibreux, de couleur jaune. Le fruit enticr paraît assez aromatique; les semences ont une

Fig. 121.
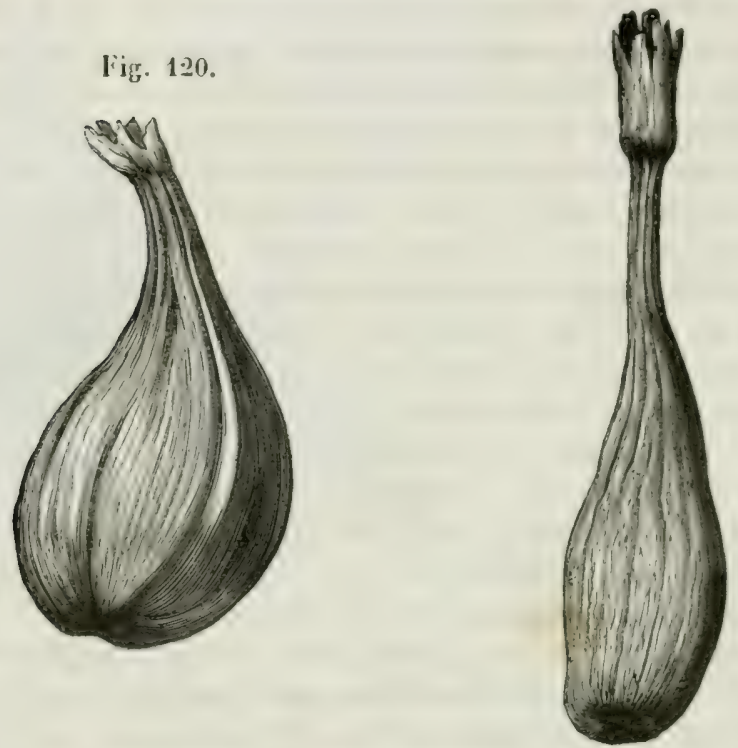

saveur téríbinthacéc beaucoup plus faible que celles des cardamomes officinaux. Au total, les cardamomes à semences miroitantes sont bien moins aromatiques que les autres.

16. Maxiglette on Graine du Paradis; cardamomum piperatum de Val. Cordus; kinjuput, Blackw., tab). 584, fig. 10-13; amomum grana-paradisi Afz., qu'il ne faut pas confondre arec l'amomum granaparadisi de Linné, lequel est une simple variélé de l'eletlari curdamomum, produisant le cardanome du Malabar. Amomum exscafum, Sims (Ann. bot., t. I, p. 548); ainomum Afzelii, Roscoe (Suc.lim. Lond., vol. VIII). Ixxcluez tons les autres sỵnonymes tirés de Matthiole, de Sonnerat, de Lamarck et de Gartner.

La maniguette du commerce vient exclusivement de la côte de Guinée, et principalement de la partic de cette côte qui porte le nom de malaguette ou de cùte des graines. Elle est toujours mondée de la pulpe qui l'enveloppe et de sa capsule; aussi le fruit enticr cst-il très rare et peu connu. 
On en troure cependant dans l'herbarium de Blackwell (éd. allem.) une excellente figure que je reproduis ici ( fig. 122) . II. Pereira en a également donné deux figures, d'après des échantillons tirés des collections de Londres (1/at. méd., fig. 193 et 19/), et une troisième (I'hatrmaceutical journal, vol. VI, p. 413 ) représentant deux fruits sur leur hampe et entourés de leurs spathes. Il faut arouer que ces fruits, par leur forme et leur disposition, présentent les plus grands rapports arec ceux de l'amomum angustifolium de Sonnerat, et que leur principale différence réside dans la qualité des semences. J'en possède un seul, trouvé anciennement dans une balle de maniguette, et tellement semblable à la figure de Blackwell qu'il semble lui avoir servi de modèle. Ce fruit est formé d'une capsule orale, obscurément trigone, longue de 41 millimètres, large de 27 millimètres, terminée assez brusquement

Fig. 122.
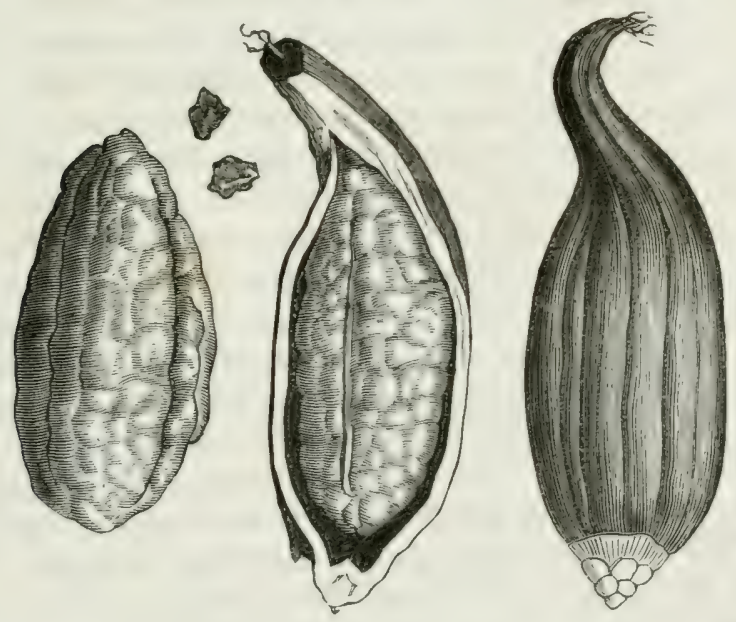

par un prolongenent fibreux épais de 7 à 9 millimètres ei long de 14. Cette capsule est d'un gris brunâtre, rugucuse à l'extérieur, épaisse d'un demi-millimètre, consistante, unie à l'intérieur, divisće en 3 loges par 3 cloisons membraneuses très minces, lesquelles, en se rompant près de la capsule, la laissent comme remplie par une seule masse pulpeuse, desséchée et blanchàtre. Celte masse contient, dans autant de petites cellules séparées, des semences grosses comme celles de fenugrec, anguleuses-arrondies, rouges et luisantes, qui, examinées à la loupe, paraissent comme courertes d'un poil ras collé sur la graine à l'aide d'un rernis. L'amande est très blanche, d'une saveur âcre et brûlante, d'une odeur d'acorns rerus lorsqu'on Ja pile. La robe de l'amande 
ne participe pas de ces propriétés, ce qui est cause que la semence entière paraît inodore.

On emploie la maniguette pour donner de la force au vinaigre et pour falsifier le poivre. Les rrais cardamomes, et surtout l'amome et le petit cardamome, entrent dans un cerlain nombre de compositions pharmaceutiqques; les parfumeurs et les distillateurs en font également usage.

17. Petite maxiglette du Meséusi. Il existe dans les collections du Iluséum, indépendamment de la rraie maniguette, un fruit plus petit, arec une étiquette arabe ou indienne, et cette traduction : folfel fondrnte, tinc elphic. Les semences sont entièrement semblables à celles de la maniguette; la pulpe est détruite.

18. Grande maniguette de Denérari; amomum meleguetla de Roscoe (Monand. plant. scitam.). En 1828, Roscue fit paraître le dessin et la description d'une belle plante scitanime,e, cultivée dans le jardin de botanique de Lirerpool et provenant de semences enrovées de Démérari. Cette plante, haute de 2 mètres, munie de feuilles étroites ct lancéolées, et de grandes fleurs monandre's d'un jaune pâle mêlé de cramoisi, était encore plus remar(quable par la dimension de son fruit qui n'arait pas moins de 14 centimètres de long sur 3 centimètres d'épaisseur. Ce fruit était en forme de fuseau, uni, charnu, d'un jaune doré, porté seul à l'extrémité d'une hampe et entouré par le bas de quelques spathes brunes. D’autres fruits reçus directement de Démérari ( 1 herm. journal, vol. VI) diffèrent du précédent par leur forme plus oröde et par leurs dimensions qui sont de 9 centimètres de Jong sur 5 d'épaisseur; mais les autres caractères sont semblables. D'après Roseve et .1 . Pereira, qui a examiné ces noureaux fruits, tous contiennent des semences semblables à la maniguelte; mais d'après les renseignements parrenus à celui-ci, la plante, quoiçue cultivée en assez grande abondance par les Yègres du Démérara, suffit à peine aux besoins du pars et ne fournit rien an conmerce. Cetle plante, d'ailleurs, parait originaire d'.lfrique, et $\mathbf{1 1}$. Pereira n'y trouve aucune différence suffisante avec l'amomum grana-prorarlisi, pour en former une espece distincte. Je ne partage pas cet avis, et je pense que l'omomun meleyuettu de lioscoe doit être considéré comme une espèce distincte.

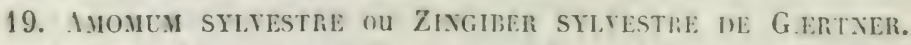
Capsule dure, de consistance ligneuse, en forme de coin triangulaire; les semences sont d'un brun noirâtre et arrondies; l'amande est blanche, inodore, d'une saveur presque nulle. Ce frut ne peut ètre considéré ni comme un cardamome ni comme une maniguette. J'en possède un écliantillon dont j'ignore l'origine. 
Fécules prodnites par les Amomacées.

1. ArRow-ROOT DES Axtilles. D'après M. de Tussac, celle ficule serait produite par deux plantes du genre maranta, qui ont la répulation d'être un remède contre les blessures faites pa: les flèches emproisonnées, ce qui leur a fait dommer le nom anglais arroul-root, c'rst-àdire fleche-racine. De ces deux plantes, l'une serait le marmet arundinacé de Plumier el de Limné, plante indigène à l'Amérigue et cultivée à la Guadeloupe et dans les autres Intilles, où sa fécule est nommie dictame ou moussache des $B$ arbarles; l'autre scrait le murumta indira, plante transportée de l'Inde en Amérigure, où sa fícule est nommie indian arrou'-root. Yais d'après M. Ricord Madianna, médecin résidant à la Guadeloupe, il n'existe qu'une seule plante de ce genre nommée arrou'-root; c'est le marantu arundinaced, ct l'aụtre espèce, nommée maranta indica, aurait élé établie par confusion avec le crma indica. Je suis d'autant plus porté à me ranger à l'avis de M. licord, que, d'après Sinslie, la fécule qui porte dans l'Inde le nom d'arrou'root, est extraite, à Travancore, de la racine du curcumn anfynstifolin Roxb. Je puis ajouter aujourd'hui, sur des renseignements certains, que le marunta arundinacea ou indica n'existait pas dans l'Inde il y a encore peu d'années mais que les Anglais l'y one Iranspurtic de la Jamaïque, et qu'on l'y cultire maintemant rle manière à livrer sa fécule au commerce. Cette fécule alors mérite mieux le nom d'indian arrouroot que lui dommaient les Anglais, tout en la tirant d la Jamaïque; mais sa production est toute moderne, et les preuves de l'origino anéricaine de la plante sont certaines.

Ia fécule du marantra arundinacese, qu'elle vienne de la Jaunä̈que, de la Guadeloupe on de l'Inde, n'offre pas de différence appréciable. Ello frarât moins blanchr que l’amidon de blé, ce qui ticut à sa moins grande ténuité et à sa transparence plus parfaite. Examinés à la loupe, ses granules sont transparents, nacrés et beancoup plus éclatants que ceux de l'amidon. Vue au microscope, elle manque totalement des irès petils grains qui forment une grande partie de l'amidon de blé. Elle est généralement égale aux gros grains d'amidon, ou même plus grosse; mais elle n'est jamais parfaitement circulaire comme eux; elle est toujoirs un peu irrégulière, snit elliptique, soit quelquefois obscurément triangulaire, comme la fécule de pomme de terre; mais clle est toujours d'un volume beaucoup moindre (fig. 123).

La fécule d'arrow-root donne à l'eau à peu près aulant de consistance que la fécule de pomme de terre, et beaucoup moins par conséquent que l'amidon de blé ; elle est tantôt complétement inodore, tantôt arec 
un léger goût de galanga. Elle offre des parties assez dures produites par l'agglomération des grains de fécule; il faut done la triturer dans un mortier et la tamiser pour l'avoir en poudre fine.

Arrow-root me Trafacone. Ainsi que je viens de le dire, celle fécule est extraite, dans l'Inde, de la racine du curcuma anyustifulia. Vue au microscope (fig. 124), clle se présente en granules assez volumineux, dont (quelques uns sont triangulaires arrondis, elliptiques ou

Fig. 123.

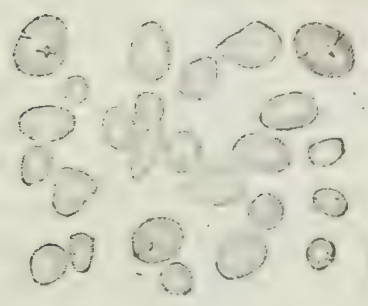

Fig. 124.

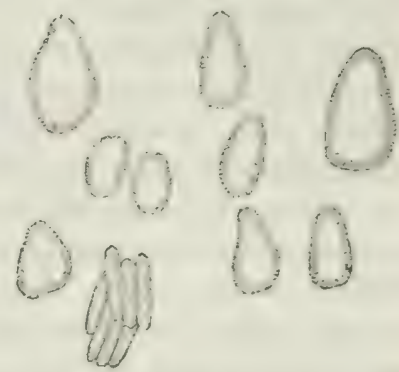

ovoîdes; mais la presque totalité sont rétrécis en pointe d'un côté. Tous ces grains ont peu d'épaisseur, comme on peut s'en convaincre en les faisant rouler sous l'eau; la figure en présente un certain nombre, naturellement serrés les uns contre les autres et gui se présentent de champ, ce qui permet d'en voir l'épaisseur.

FECLle DE TOLOMANE OU DE TOUS Les MOIS (fig. 125). Cette fécule est extraite de la racine du comna cucciner. Elle vient de's Intilles Fig. 12 .

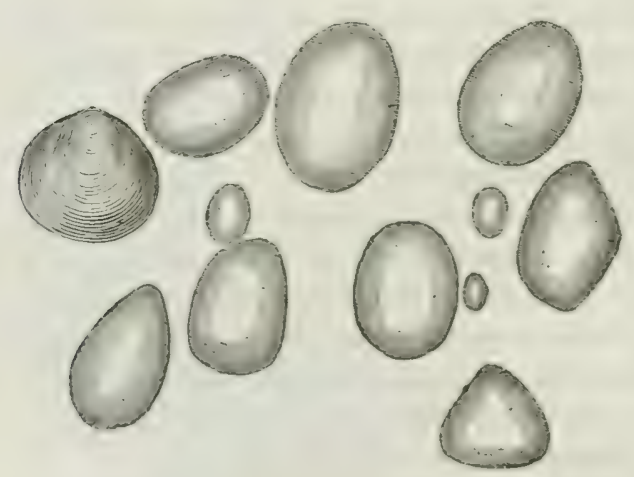

at es difficile à distinguer de la moussache et de l'arrow-root a la simple vue; mais on la reconnait ficilement an microscope, au volume extraor- 
dinaire de ses granules et à leur forme généralement elliptiçue. De même que la précétente, elle est d'une minceur remarquable. Elle est très soluble dans l'eau bouillante et est très facile à digérer.

\section{FAMILLE DES ORCHIDEES.}

Plantes risaces, qunelquefois parasiles, dont la racine fibreuse est sourent accompande de tubercules am lacés. Les fouilles sont simples, alternes, engainantes, naissant immédiatement de la tige ou do rameaux courts, renflés et charnus, nommes pseudo-bulbes. Les feurs sont pourrues d'un perianthe supere, à 6 divisions profondes, dont :3 exterieures et 3 inlérieures. I.es 3 exterineres sont assez sembiables entre elles, etalées on rapprocheres les unes dies autres a la partie supérieure de lia

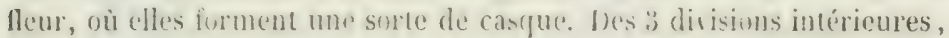

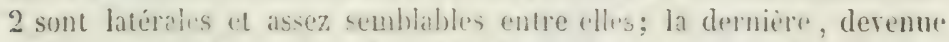
inférieure par la iorsion du pridiceils, est sousent ris développée, d'une forme bizarre et prorte le nom de lutwolln; clie at en outre sou-

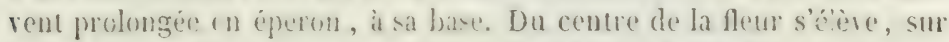
le sommet de lowaire, une coloune formée par la soudure da slyle et

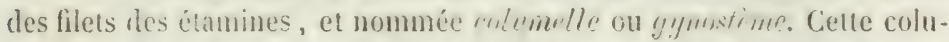
melle porte à sa partie supérienre et antérieure une fossette glanduleuse qqui est le stignate, et à son sommet une anthère à 2 loges contenant du pollen agyglonéré en une on plusieurs masses, (qui conserrent la forme de la casité fiui les renferme. Iu sommet de la colunelle, et sur les côtés de l'anthire, se trouvent 2 petits mbercules qui sont les anthères arortées de 2 étamines. (I)ans le seul genre cypripedinin ces 2 étanines latérales sont déreloppées et l'étamine du milieu, celle diamétralement opposece au labelle, avorte). Le fruit est une capsule à nie seule loge et at :3 valve's gni s'ourrent comme des panneaus, en laissant les 3 trophospermes unis et rappochés au sommet et ì la base et formant une sorie de chassis; les graines sont nombrenses, composées d'un embrybr oroüle très renfé, pourru, dans une petie forselle, d'une gemmule presque nue.

Ln assez grand nomine d'urchidées ont été autrefois usitées en mí. decine et phusieurs le sont encore dans les diverses contrées qui les produisent. Elles se recommandent à nous par trois produits, dont les deux premiers sont l'ubjet d'un commerce ascez important : ce sont le salep, la ramille et le fahom.

Salep.

Le salep nous est apporté de la Turquie, de la . Iatolie et de la Perse; il a la forme de petits bullips oroüles. ordinairement enfilés sous forme 
de chapelets, d'un gris jannâtre, demi-transparents et d'une cassure cornér. Il a une odeur faible approchant de celle du mélitot, et une saveur mucilagineuse un peu salée. Ces caractères phlysigques qui lui donnent l'apprarence d'une gonme, sont cause qu'on n'a pas soupconné pendant longtemps yur le salep fut une racine. Enfin Geoffroy, auteur

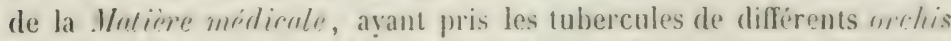
indigènes, les arant nondés de leur épiderme, larés, plongés dans l'eau bouillante et séchés, obtint du salep en tout semblab!e à celui des Orientaux. Il proura par là deux choses: d'abord que le salep est un tubercule d'orchis; ensuite que les tubercules d'orchis indigènes, préparés de la manière qu'il venait d'indiquer, pouvaient remplacer le salep d'Orient.

Depuis Geoffroy, et à plusieurs reprises, des pharmaciens et des agronomes sont revenus sur la posibibilité d'obtenir du salep avéc nos orchis, et j'en possède, aỹant cete origgine, quni rivalise arec le plus beau salep d'Orient; mais il faut qune le prix de la main-d'oeure on la rareté des respèces s'opposent à cette fabrication en France; car elle a toujours été très restreinte. Les esperes qui peuvent servir à cet uragge sont cependant assez nombreuses; ce sont principalement les

$\begin{array}{lc}\text { Orchis morio, } & \text { Orchis pyramidalis, } \\ \text { - mascula (fig. 126), } & \text { - hircina, } \\ \text { - militaris, } & \text { - maculata, } \\ \text { - fusca, } & \text { Ophris antropophora, } \\ \text { - bifolia, } & - \text { apifera, } \\ \text { - latifolia, } & - \text { arachnites. }\end{array}$

Un chimiste a cru pouroir conclure de ses expériences sur le salep que celte substance ćtait principalement formée de lonsorrine, d'un peu de gomme soluble ct de très pru d'amidon. Mais pour se faire une juste idée du salep, il faut l'examiner d'ahord à l'état de tubercule récent: alors on le trouve composé, comme prescgue toutes les racines ficulentes, d'une grande quantité d'anidon qui, examiné an microscope et coloré par l'iode, est en gamules à peu près égaux, d'un bleu de ciel, sphériques ou elliptiques, à peu près de la grosseur des gros grains d'anidon de blé. Cét anidon, antant que j'en ai pu juger par un essai, n'est pas organiéé comme celui de la pomme de terre, comme l'arrowroot et meme comme l'anidon de blé, qui, sons une coschople plus ou moins dense et resistante, renferment une matiere interieure facile à dissoudre dans l'eau bonillante. L'anidon du salepe de mème que celui du sagou, ma a paru formé d'une masse pulpeuse, fort peu soluble dans l'ean bouillante, mais susceptible de s'y gronfler considérablenrent, cr ¿, ui explique l'abondance et la grande consistance de la gelée de salep. Le 
reste des tubercules récents se compose de membranes épaisses, colurées en jaune par l'iode, de globules trés minimes, transparenits, comme grélatineux, non colorés; enfin sourent on y aperçoit des aiguilles acérées, qui disparaissent par la moindre addition d'acide nitrique, et qui sont du phosphate de chanx, d’après les expériences rapportées par 11. Raspail, dans son Système de chimie organique.

Si on examine ì son lour, an microscope, le salep du commerce, délayé dans de l'eau convenablement iodée, on y observe encore quel-

Fig. 126.

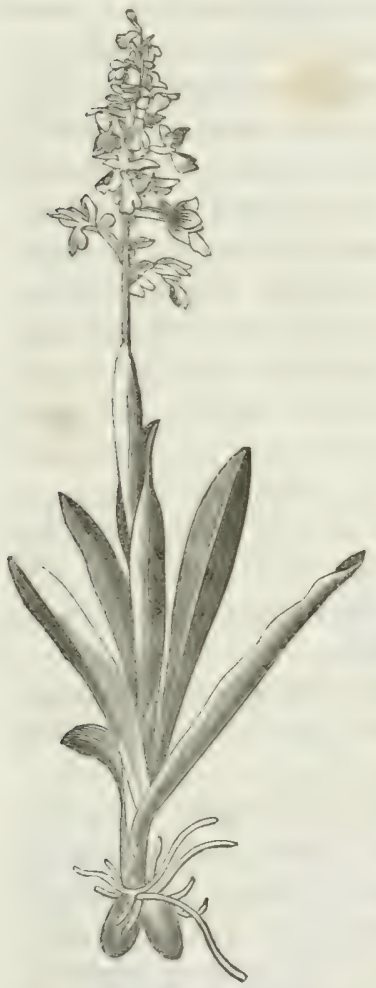

Fig. 127.

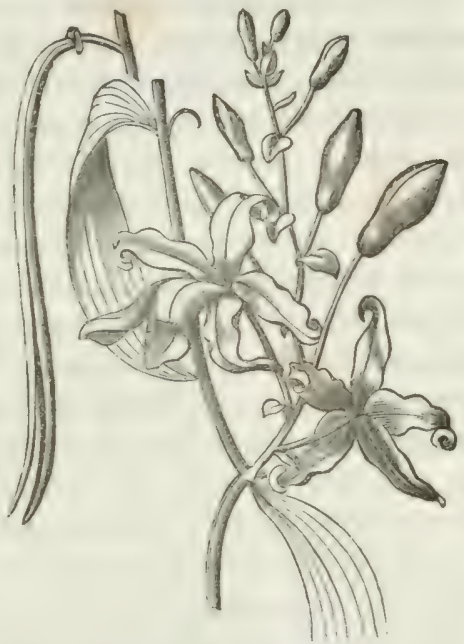

ques grains de fécule non altérés; mais la plus grande partie se compose de tégu'ments gonflés, déchirés, gélatineux, d'un bleu magnifique, et qui indiquent que le salep n'a pas subi une simple immersion dans l'eau bouillante, et qu'il y a séjourné pendant un certain temps.

Le salep ne jouit probablement pas de la propriété aphrodisiaque (qu'on lni a suppesée pendant longlemps; mais il est au moins tries nourrissant. On l'mpipluie en gelée, sucré et aromatisé, ou incorporé dans du chocolat, qui prend alors le nom de chocolat unaleptique an salep, etc.

\section{Vanille (fig. 127).}

Timille arometicu, Swartz; rpidesudinu comilla, L. Plante sarmenteuse et grimpante qui croit dans les contrées maritimes du liexique, 
de la Colombie el de la Ciugane, sur les rires des criques abrites par les mangliers et sujettes a cetre submergées dans les lantes marées. Ses tiges sont vertes, cylindriques, noucuses, de la grosseur du doigt. Eilles sont pourves de villes ou plutôt de racines adrentives gui s'implantent dans l'écorce des arbres roisins et servent autant à la nourrir gu'à la soutenir, puisquu la plante peut continuer de végéter après aroir été séparie de terre. Ses fenilles sont sessiles, alternes, rlistantes, ovalesoblongues, aignës, lisses, un peu épaisses, longues de 25 à 27 centimètres sur 8 de large, pourrues de nerrures longitudinales, Les fleurs sont disposées, vers le sommet des tiges, en grappes axillaires pédonculér's. Le périgone est arliculé arec l'ovaire, d'un vert jannâtre an dehors, banc à l'intérieur, formé de 6 sépales, dont 3 extérieurs égaux "réruliers, et \$ intérieurs dont 2 planes, ondulés sur leurs bords, et le troisième roulé en cornet et soudé arec la columelle. La columelle est dresséc el privée d'appendices lateranx; l'anthère est terminale, mperculéc, à 2 logeses, dont charume contient une masse de grains de pollen agglutinés. Le fruit est une capsule charmue, longne et siliquiforme, déhiscente, uniloculaire, mais is "s ralres, dont chacune porte un trophosperme sur la ligne mediane. I.es semences sont tres nombreuses, noires, glohuleuses, cutourées d'un suc hrun, épais et balsamique. On cueille ce fruit arant sa parfaite malurité, pour éviter qu'il ne s'ourre et ne laisse écouler le suc (gu'il contient. On le suspend à l'ombre pour le faire sécher; on l'encluit ensuite légèrement d'une couche d'huile dans la rue de lui conserver de la sonplesse el d'en idoigner les insertes; enin on en forme des botues de 50 au de 100 , rfu'on nous envoie dans des boîtes de fer-blanc.

On trouve dans le commerce trois sortes de vanille, dont deur peuvent appartenir à denx variétés de la même plante: mais la troisième appartient à une espèce différente.

Ia première sorte, yui est la plus sestimée, se rapporte à la plante que les tespagnols nomment imuille les on légilime; runillu satien de Schicde. Elle est longue de 16 a 20 centimètres, épaisse de 7 a 9 millimètres, ridée et sillonnée dans le sens de sa longueme, ritricie aux deux extremités et recourbe à la base. Iille est un peu molle et visqueuse, d'un brun rougeattre foncé, el doncéc d'une odeur forte, analogne à celle du baume du Pérou, mais beacoup plus suare.

Conserve daus un lien sec el daus un ras? qui ne soit pas hermétiquement fermé, cette ranille ne tarde pas à se recourrir de cristaux aiguillés ot brillants qui sont de l'acide henzoïgue on cinnamique; on la nomme alors romille gimpre. Cecter sanille est tonjours d'un prix très élex́e.

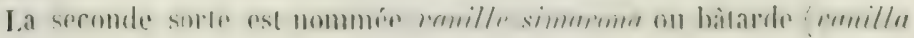


syleestris de Schiède - Elle présente tous les caracteres de la précédente, dont elle ne parait ètre qu'une raricité; majs cile e'st plus courte, plus grêle, plus sèche, d'une conlem moins foncée. Blle est moins aromatique et ne se girre pas.

La dernière sorte, nommée chez nous imuillen, et par les Espagnol:

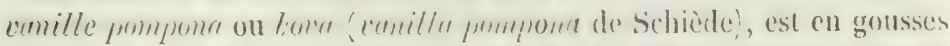
longues de 14 i 19 centimètres, larges de 1.4 ia 21 millimètres; elle est très brune, mème presque noire, molle, visunense, presque tonjours ouverte, et parât avoir dépassé son point de maturité. Elle possède une odeur forte, beaucoup moins fine et moins agréable que celle des deux premières sortes, et moins balsamigne; sourent anssi clle offre un goût de fermenté. Enfin elle est à vil pris, comparce aux deus premières. La ranille est usitée surtout pour aromatiser le chocolat, less crêmes, les liqueurs et d'autres compositions analogues.

On cultive depuis plusieurs années, dans les serres de liegge ed du

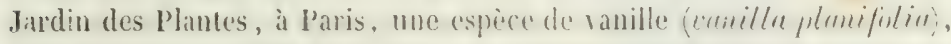
qui a produit, à différentes fois, un numbre consilérable de fruits qui mettent une amnée a murre. Cies fruits ne different con rien de la plus belle vanille du commerce; its sont aussi aromatiques et d'une oleur aussi fine et aussi suare. Ils pourraicut être l'objet d'une exploitation lucrative.

\section{Feltille de Faham.}

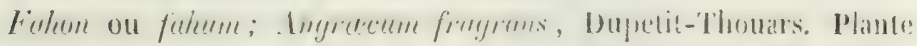
très rapprochée des ranilles, parasite comme beancoup d'orchidées exotiques, croissant aux îles Maurice, où elle est usitex conme digestive et contre la phthisie pulmonaire. Les fenilles senles nous parviennent par la voie du commerce. Eiles sont longucs de 8 à 16 centimètres, larges de 7 it 14 millimètres, entières, coriaces, marquéc's de nerrures longitudinales rapprochées, donées d'une odeur très atgréable, semblable à un mélange de fève tonka et de vanille, et d'une saveur très parfumée. On les emploie en infusion theiforme et on en fait un sirop très agréable au goût. 


\section{CINQUIEME CLASSE.}

\section{Dicotylédones monochlamydies.}

\section{FAMILLE DES CONIFERES.}

Cette famille se compose d'arbres et d'arbrisseaux dont on peut se faire une idée générale en se rapprelant les pins et les sapins.

Leurs fenilles sont coriaces, roides, pres(jue toujours persistantes,

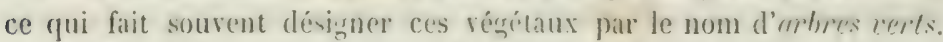

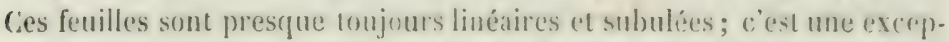

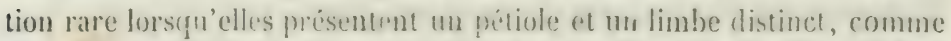
la plupart des autres dicolytedones. Les flems sont unisexués, dispo-

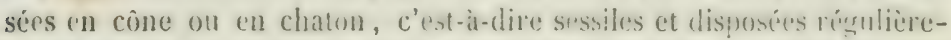

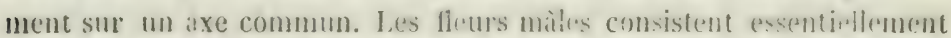
dans une étamine nne ou placérà l'aisselle d'une écaille yni hui so't de

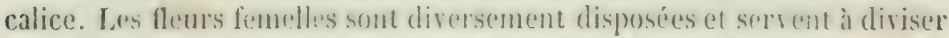
les coniferes cn trois tribus que plusieurs bolanistes élevent au rang de familles distinctes.

$1^{\text {re }}$ trilue, raxisels : llems femelles isolées, attachérs à mne écaille ou contenus dans une cupule fomant derenir charnue ; fruit simple.

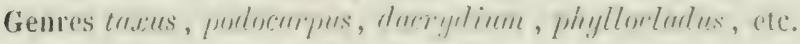

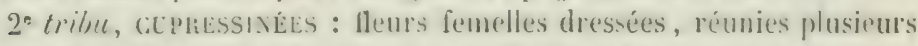
ensemble a l'aisselle d'écailles peu nombreuses formant un galbule ou un malaccône (bage 28 ). Ciemres juniperus, thumg, crupressus, tritodium, elc.

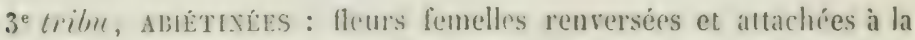

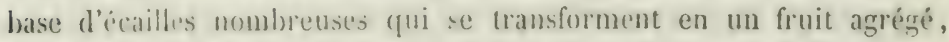

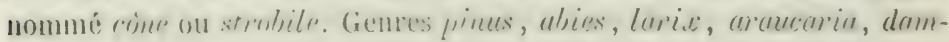
maru, etc.

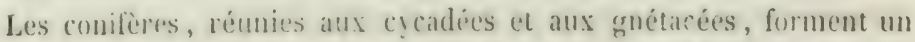

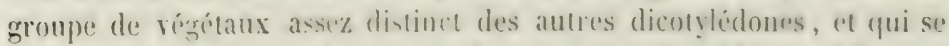

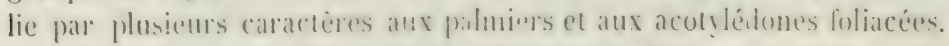

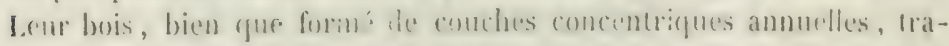

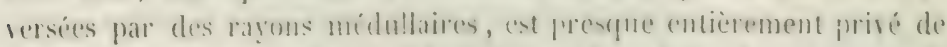

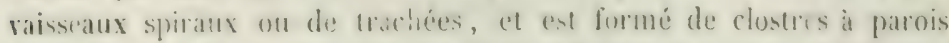

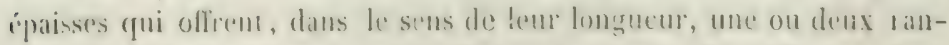

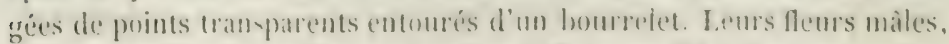

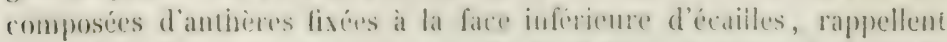

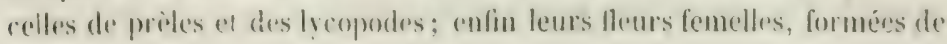


plusieurs enveloppes mun fermpes, présentent, an centre de l'enveloppe la plus intérieure, un ovule unique que l'on regarde comme mu, ainsi que le fruit qui en provient. Aussi les botanistes qui admettent cette manière de roir, distinguent-ils le groupe formé des cycadées, des conifères et des gnélacées. par le nom particulier de gymmunspermes. Ce fruit, dépouillé des écailles ou autres enveloppes florales qui l'entourent sourent, contient, sous un tégument propre, un endosperme charnu et un embryon cylindrique dont la radicule est sondex arec l'endosperne el dont l'extrémité conlýédonaire se civise en 2, 3, 4-10 cotylédons verticillés.

Presque tous les régétaux coniferes contiemnent, dalas leur bois on dans leur écorce, un sur résineux dont nous traiternos d'une manière spéciale après avoir décrit les principaux d'entre eux et leurs propres parties, qui sont assez sourent usitées dans l'art de guérir.

$$
\text { If ( fig. 125). }
$$

Taxus baccata. Arbre d'Europe dont la tige s'élère à 12 ou 14 mètres, en se partageant latéralement en branches nombreuses, presque verticillées; les fenilles sont linéaires , persistantes, d'un rert foncé, très rapproclices les unes des autres et disposées sur deux rangs opposés. Elles ont une odeur forte, et l'on assure que celte odeur, augmentée par l'épaisseur du feuillage, est très nuisible aux personnes qui y dor ment à l'ombre. Les fleurs sont axillaires, monoïques

Fig. 128.

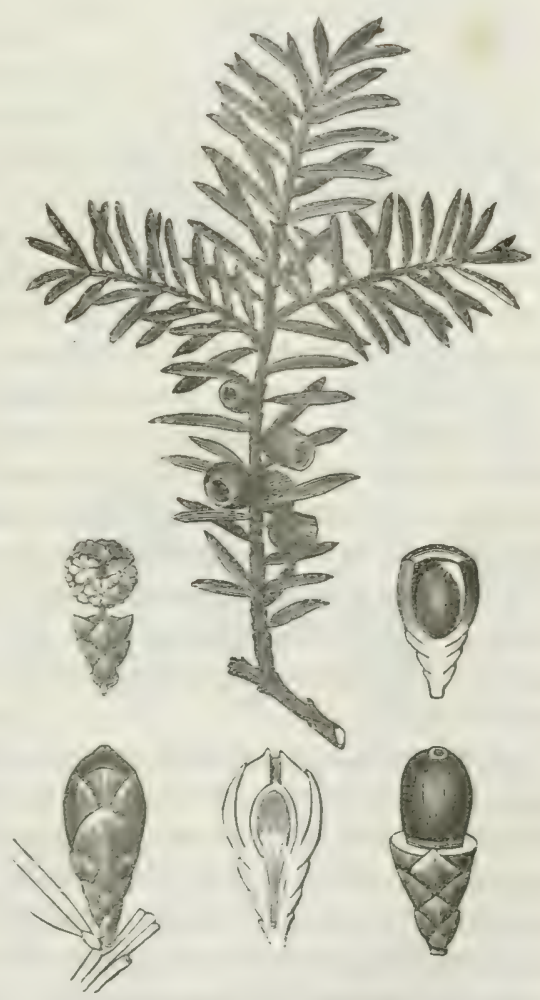
ou dion̈gues. Lés fleurs mâtes forment, vers l'extrémití des rameaux, de petits chatons spherigues entourés par le bas d'un critain nombre d'écailles imbriquées; ces flemrs sont portees sur une colonne centrale 
divisée superienement en filets ragonnants dent chacun sélargit en un écusson à plusieurs loges recoubrant autant de loges polliniferes. Les lleurs femelles sont soliaires, entourées par le: bas d'écalles imbriçuées, et sont formées d'une cupule ourcrte part he hant, renfermant un matre surmonté d'un stigmate pen afprarent. Cette copnle grossit, derient succulente, d'un bean rouge, et laisse boir, jan bure lange onserture,

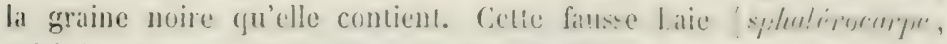

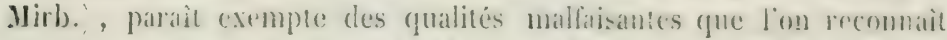
gréneralement anx feuilles, à l'eccere ct a la racine d'if. Le bojs d'if

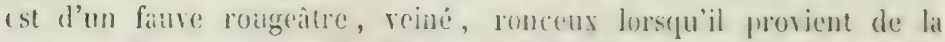
soncle, d'un grain fin el susceptible de receroir un beatu proli. Il est très recherché par les ébenistes, les luhiers et les tonrnenrs. II est d'une tris longue durée.

(iypres.

Cupressess sempervirens L. Arbre très élevé qui se recunnait iो si forme pramidale, it se's rameaux dressis contre la lige, il ses feuilies d'un rert sombre, tres petites, synamitormes, imbrignées str quatre rangs et persistantes.

Les fleurs sont monoüques, terminales, fiacies sur des raneanx diffe-

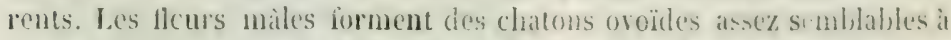
ceux de l'if et entourés d'écailles par le bas. Les chatons fe:melles somt grlobuleux, formés de 8 a 10 écaill's col forue de bouclier, portant it leur partic inféricure tin grand nombre de fleurs femelles dressécs,

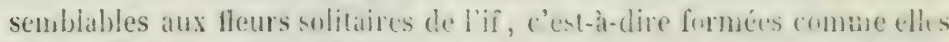
d’une uréole presque fermée contenant un osaire terminé far un stigmate. Les fruits forment un cône presque globulenx dont les ćaillè sont charnues et soudées avant leur maturite; nais clles se deasichent et se séparent à maturité complète. et praraissent alors sous la forme de clous it grosor tete, implantés sur mo axe central, très court. Les graines sont petites, anguleuses, munies latéralement de dens ailes membraneuses.

On doit cheilit les cones du cyjuris, nommes vulgaireneme noir de rypures, lorscu'ils sont encore rerts el charnus ; ils sont alors tre's astringronts et sont usités comme teis. Plus tard ils deviennent lizneux et

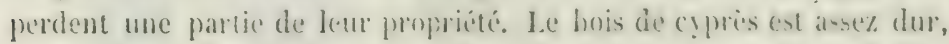

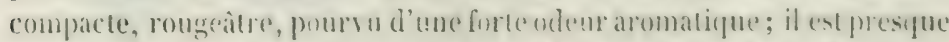

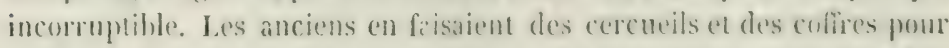
renfermer leurs objors les plus précieux. De tous temps aussi cet arbre a été consacré anx morts et a été l'accompagnement obligé des tmmbeaux. Son feuillage d'un rert foncé et si épais que le soleil ne jeut le traverser, l'a sans cloute fait destiner ì cet usage. 


\section{fincurriers.}

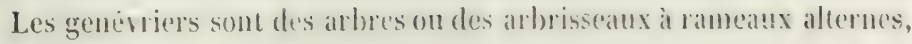
a feuilles simples, petiles, persistantes, rapprochées, opposées, verticillées ou imbriquées; et domt les fleurs sont ordinairement diö̈pues et disposées en petits chatons avillaires, entomrés par le bas de bractées imbriquées. Les flems mailes forment des chatons oroüdes ou cylindrigues, composés d'écailles stifnitées qui portent à leur partic inféricure et externe de 3 à 6 anthères uniloculaires. Les fleurs femelles sout portées sur un pédoncule écailleux dont les écailles supérieures, rapprochées et en partie soudées, forment un involucre turcéolé qui contient autant de cupules ourertes par le haut (fig. 129) qu'il y a d'écailles soudées à l'iurolucre (de 3 à 6 ). Chacune de ces cupules, tout à fait semblable à la cupule solitaire de l'if ou aux cupules nombreuses du cyprès, contient un ovaire surmonté d'un stignmate. Cilsaque petit fruil est un cariopse osseux comtenant un embryou dicotylédoné à radicule cylindrique, supère. 'lous les fruits réunis, recouverts de leurs cupules et renferunés dans les écailles sondées, accrues et derenues succulentes, forment un corps Fig. 129 .

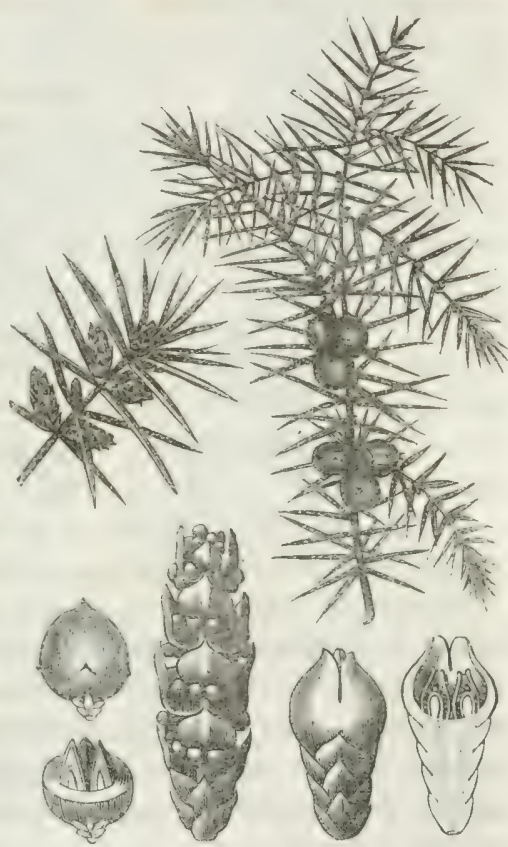
qui porte rulgairement le toin de lure, mais que nous avons désigné par cului de muluremo (cone mou). L'espèce de genévier la plus usitée et la plus commune en Europe est :

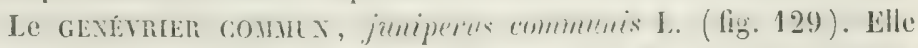
forme dans le midi de l'enrope et dans nos jardins un arbre de 6 a 7 metres de haut, dont le tronc pent acquérir de 20 à 30 centinètres de diametre; mais dans les pays dı Tord, où ce végétal croît en abondance, il ne forme getere qu'un arbrisscan à rameaux diffus, haut de 2 à 3 mètres; sur le sommet inculte des montagnes, où on le rencontro égalemont presque partout, il est presque réduit à l'état d'un buisson 
épineux. Partout on le recommaît à ses feuilles opposées trois à trois, sessiles, linéaires, très aignıës et piquuantes. Les chatons femelles sont très petits, verdàtres, formés au sommet de 3 écailles soudées, et contiennent 3 cupules dressées ot 3 oraires qui se convertissent en 3 petits fruits osseux entourés des écailles accrues et devenues charnnes. Le tout réuni forme un malncrône globuleux, presque sessile, de la grosseur d'un pois, et d'un violet noiràtre à sa maturité, qui n'arrive qu'au bout de deux ans. On lui donne communement le nom de baie de genière. Il contient une pulpe succulente, aromatique, d'une saveur résincuse, amère et un peu sucrée. Dans le nord de la France, en Belgique, en Hollande et en Allemagne, on en prépare une eau-de-vie par fermentation et distillation, une essence ou huile rolatile, et un extrait tout à la fois suré et gommo-résineux. Ces trois produits se trourent dans le commerce; mais l'extrait étant souvent très mal fait avec le résidu de la distiliation de l'essence, les pharmaciens doivent préparer eux-mêmes leur extrait de geniève, arec les baies récontes concassíes et par infusion. Il est alors lisse, sucré, aromatique, fort agreable à prendre et offre un bon stomachicpue. Il se grumète à la fongue, comme celui du conmerce; mais cet effet est dù au sucre qui cristallise, e't nou à de la résine. J'ai déjà fait la remargue (page 121 ) que la haie de genièrre, comme tous les fruits sucrés non acides, conticnt du sucre cristallisable, tamlis que les fruits acides ne contiennent que du glucose.

I.e bris des gros genérriers est pres(rue semblable à celui du cyprès et peut être employé aux mêrnes usages.

Gexevruer oxicenre ou cade, juniperus oriredrus I. Celle espèce a les plus grands rapports avec la précédente; mais ses fruits sont deux ou trois fois plus gros, d'une couleur rouge, et contiennent des ossplets renflés à la base, comprimés à la partie supérieure, tronquis an sommet, avec une petite pointe an milieu. Elle croît naturelleurnt dans les lienx secs et arides du midi de la France, en Espagne et dins le levant.

Le bris de l'oxicèdre brùlé dans un fourneaus sans courant d'air, comene on lo praticue pour la fabrication du goudron, laisse découler un lignide brunâtre, huilenx, inflammable, d'une od hur résinense et

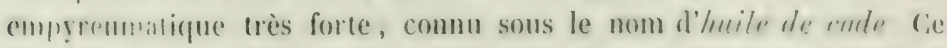
liguide, prurvu d'une saveur àcre presque canstique, est employé pour la enérison des ulcères des chevanx of de la gale des moutons. On Jui substitue sourent l'huile de goudron de pin, qui lui est inférieure en propriétés, ef, très sourent a present, lhuile des goudrons de houille, qui présente une composition chimique el des propritiss très différentes. 
SabIxe, junipuerus subliun L. (lig. 130). Arbrisseau diö̈rue à petites fenilles ovales, conrexes sur le dos, pointues, appliquées sur les rameaux, imbriquées sur quatre rangs, les plus jeunes opposées. Les fruits sont arrondis, de la grosseur d'une groseille, d'un blen noirâtre. Ils ne contiennent ordinairement qu'un seul osselet, par suite de l'arortement des deux autres. La sabine croît dans les montagnes du Dauphiné et de la Provence, en Espagne et en Italie. On la cultive dans les jardins. On en comnaît deux rariétés: la première, haute de 3 à 4 mètres, dite sabine mâle ou a feuilles de cyprès; la seconde, beaucoup plus pelite, dite sabine femelle ou i feuilles de tamarisc. Toutes deux sont tonjours vertes, résincuses, d'une odeur très forte et désagrảable. Elles sont·enménagogues, anthelmintiques, très âcres, dépilatoires et même un Fig. 130.

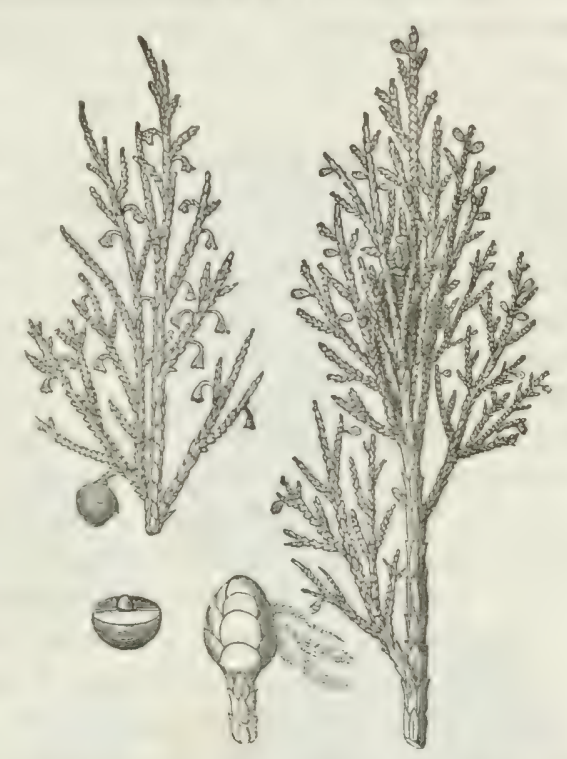
peu corrosives. Elli's peuvent derenir poison, étant prises à trop forte dose à l'intérieur.

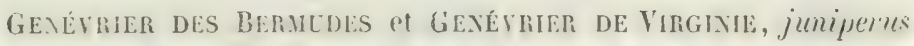
bermulianu et junipems ciryinima L. Ces deux arbres, dont les nouns spécifiques indiquent le pays originaire, ont beaucoup de rapport arec la sabine, mais sont élevés de 14 à 16 mètres. Le dernier porte aussi le nom de cedre ronge ou de cedle de lirginie. Leur tronc est formé d'rn aabier blanc et d'un coeur rougeàtre, un peu violacé, très otorant, léger, d'un grain très fin ct facile à travailler. C'est arec ce bois, qui porte dans le commerce le nom de bris de cietre, gue l'on fabrigue les pelits cylindres dins lesguels ain reuferme les crayons fins de graphite; mais on l'enpluic anssi ì beanconp d'antres usages. Le genévrier des Bermudes parâ̂t avoir été le premier exploité; mais il est devenu rare, et le bois de ceille actuel du commerce parait être principalement fourni par le genévrier de Virginie.

En cxaminant anciennement l'intérieur d’un stétoscope fait en bois de 
cèdre de Virzuinie, je l'ai tromé tapissé de cristaux aciculaires, blancs ct éclatants, d'une substance odorante et volatile, et j'ai depuis bien des fois observé les mimes cristaux sous la face inférieure d'échantillons du même bois, conscrvés dans les collections. Ce sont ces cristaux qui, ainsi que l'essence du buis distillé, ont été étudiés depuis par les chi-

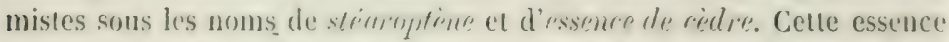
et le bois lui-même ont été sourent attribués par erreur, et par suite de similitude de nom, at cinlere dn libm, ront il sera question ciaprès.

\section{Pins.}

lir. grin. : Fleurs monoüques; fleurs mâles en chatons ramassés en grappes. Etamines nombreuses, biloculaires, insérées sur l'axe, surmontées d'un connectif squamiforme. Flenrs femelles en chatons solitaires ou rassemblés; écailles imbriquies, portant à leur base el du coté interne 2 oraires rensersés, dont le somnet est tourné en bas et parât terminc par 2 stignaies. Com fon mi par les écailles accrues, derenues ligneuses, étroitement appliquées les unes sur les autres, à sommet épaissi el ombiligué, à base inlerne creusée de deux fossettes contenant chacune un fruit entouré d'une aile membraneuse. Ce fruit, que plusirurs botanistes regardent comme une graine nue, est composi d'une cupule ligneusé perforie ì stin sommet rensersé, et d'une sémence à épisperme nucmlıaneus, contenant, dans l'axe d'un endosperme huileux, un einbrỵon à 3-12 colṣedons rerticillés.

Les pins sont des aribes résineux, ì rameaux rerticillés, dont les feuilles subulées et persistantes sont rémies par le bas, au nombre de 2, de 3 can de 5 , datus une gaine nembraneuse. Les especes principales sont les suivantes:

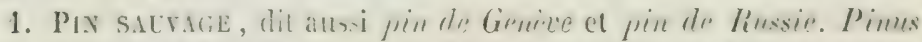
sylecstris L. Arbie de forme et de grandeur très rariables, suirant les localités et le sol wi il croil, mais pourant s'élerer a la hauteur de 25 mitres et dasandagr. Sin fruilles sont lineaires, demi-crlindriques, glabres, enrelopperes cleux a cienx a leur base par une gaine courte. Les connes sont drux ans a muirir. Ils ont alors de 4 a 7 centimètres de longueur, sont arrondis par la base et parfaitement coniques à l'extrémité, d'un rert foncé. Ce pin croit spontanément sur une grande partie des montagnes de l'Europe, et principalement dans les contries du Ford, où son boils est employé pour les constructions civiles et navales, et ou il sert à l'ex!raction de la térobenthine. Bien qu'il soit aussi commun en Fratce, dans les Vusges, les . Ifpes el les Pyrenies, cependant il est peu explosté, la culure dn pin maritime ayant pris une grande extension dans les Landes, et sulfisant aux besoins do commerce. 
2. Pix taricio on PIX De Conse, pimes lar iriu, l'oiret. (cet arbere, le plus bean de nos pins indigènes, śéleve à la hantem de 35 it 50 mètres. Ses feuilles sont géminées, longues de 1'/ it 19 centimètres, très menues; les cones, ordinarement disponés deux à deux, sont d'une forme prramidale, un pea recourbés a l'extrémité vers la terre, longs de jà a $\mathrm{S}$ centimètres. Ce pin croît principalement en corse et en Hongrie. D’après i. Loiselenr Deslongchamp̧s, il croit ínalement dans le nord de l'Amérique, où Mlichaux l'a déFig. 131.

crit sous le nom de pin rouge. Son bois est inférieur pour la force et la durée à celui du pin sauvage.

3. Pix inaritule, pinus maritima. Cet arbre forme une belle pyramide dont les rameaux sont disposés par rerticilles réguliers. Ses feuilles sont géminées, roides, très étroiles, longues de 22 à 27 centinètres ; les chatons mâles sont groupés à la base des bourgeons qui doirent former la pousse de l'année. Les cônes sont roussâtres, luisants, d'une forme conique, longs de 13 à 16 centimètres, épais de 65 millimètres à la base. Ce pin croît naturellement dans le midi de la France et de l'Europe, dans les contrées roisines

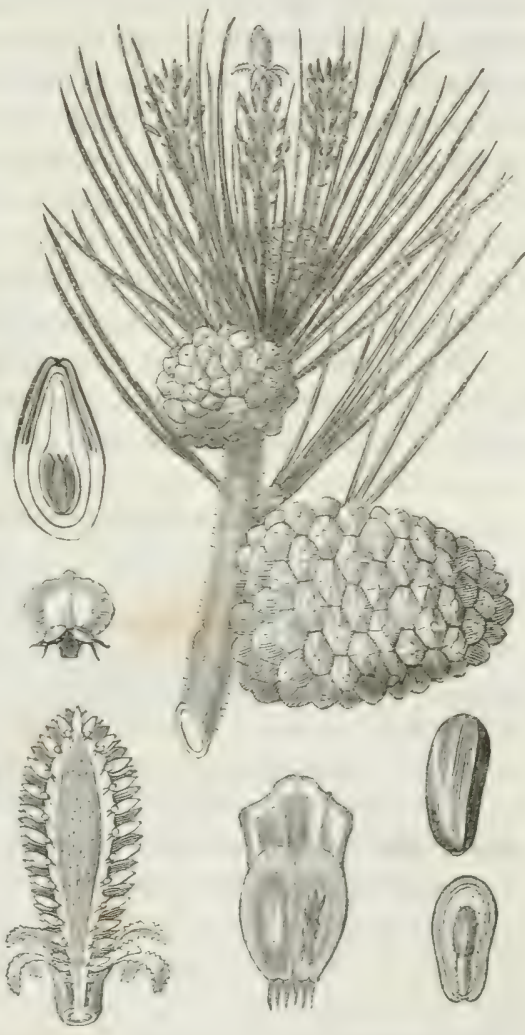
de la mer. On le cultive surtout dans les landis qui s'étendent de Bordeaux à Bayonne, et c'est Lui cuni fournit la plus grande partic de la lérébenthine et des résines communes emploỵes en Francr pour le besoin des arts.

4. Pin pixier ou PIN a pignons, pimus pinere L. (fig. 131). Cét arbre se recomnaît ì l'étendine de sa tite, dont les branchess sont 
étalées horizontalement et un peu relerées à l'extrémité, sur une tign de 16 à 20 mètres de hautenr. Ses fruilles sont d'un vert foncé, longues de 16 à 19 centimètres, cntourées denx ensemble par une petite gajue. Les chatons màles sont réunis en grappes, au nombre de 15 à 20 , sur des rameaux grèles : charue chatun n'a gue 14 millimètres de longucur et les anthères sont surmontées d'une crète arrondie et denticulíe. Les cônes sont trois ans à mûrir; ils sont ovoüles-arrondis, longs de 10 à 11 centimètres, formés d'écailles serrées, dont la partie saillante a la forme d'une prramide surbaissée et arrondie, à sommet ambiliqué. Les fruits sont brancoup plus gros que dans Jes autres especes de pins, et sont pourrus d'une aile compaativement plus courte et très facile à séparer. On donne toujours ì ces fruits le nom de prignones douc, pour les distinguer des fruits âcres et purgatifs dı

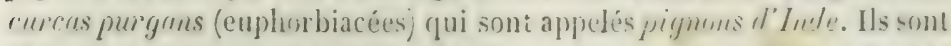
oblongs, un peu angulenx, formés d'une cupule osscuse presyute fermée el d'une semence it anande blanche, huilense, d'une saseut douce et ayréable. Ces amandes sont recherchies sur la table ('n Italie et en Provence, et on en fait aussi diexcellentes dragées. ()n les a fruelequefois prescriles en émulsion. Le pin à pignoms cot miginaire de l'Orient el de l'Afrique septentrionale; il est répaudu en Ytalie, en Espagne ct dans le midi de la France. Son bois sert pour les constructions navales.

\section{Pins à trois feuilles dans la méme gaîne.}

Prix nerisse, jinus rigidn; - Amérique septentrionale.

PIN TÉDA, pinus toeda; - Caroline et Virginie.

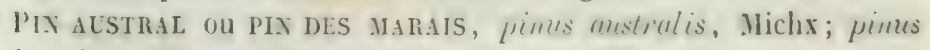
pulustris, Yill, : - Virginie, Caroline, Géorgie, Floride.

\section{Pins à cinq feuilles dans la même gaine.}

Pin cembro, pinus cembra; - Alpes, Sibéric.

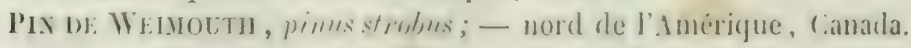

\section{Sapins et Mélèzes.}

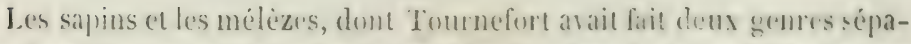

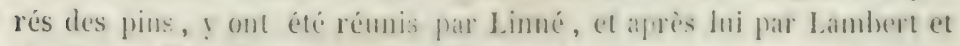
Endlicher. Hs different cepundant atseg de's pins pal he ur pont ex par

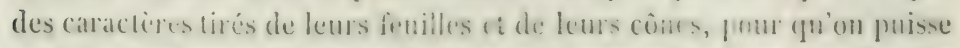
en farre des genres distincts. Lees sapins (geme abirs) ont les fenilles coutes, roides, solitaires, el les counes formés d'écille's annincies et à bord arromdi an sommet. I.es melèzes (genre luirit ont les cònes for- 
més d'écailles amincies an sonmot, comme les sapins; mais leurs feuilles sortent fasciculíes de bourgeons sous-globuleux, et deriemnent ensuite éparses et solitiares lorspue le bourgeon s'allonge pour former les jeunes rameaux.

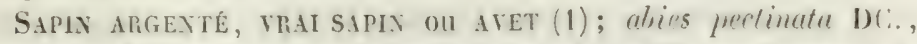
ubies tncifutiu Desf., pimus piceu I. Cet arbre s'úlève en pyramide a la hauteur de 30 à 40 mètres; ses branches sont disposées par verticilles assez réguliers ef sont dirigcées horizontalement; ses fenilles sont éparses sur les jeunes rameaux, mais sont conme comprimées et dirjgérs sur deux rangs opposés, ce qui leur donne l'aspect du feuillage de l'if ou des dents d'un peigne ( de là le nom d'abies taxifuliun ou purliuntaj. Ces feuilles sont linéaires plumes, coriaces, obtuses on íchancrírs au sommet. Elles sont luisantes et d'un vert foncé en dessus, hlunchities ind dessuns (sauf la ligne médiane verle), ce qui a valu à l'arbre, vu d'en bas, le noin de sapuin argenti. Le's fleurs mâles forment des chatous isonlís dans l'aisselle des fenilles; mais trìs rapprochés el nombrenx vors l'extrimití des rameaux superieurs. Ies fleurs femelles forment des chatons presque cylindrirgues, rougeàtres, disposís an nombre de 2 on :3, non à l'extrémité des rameanx latérax, mais sur la dernière ou l'arantdernière ramification. Ces chatons sont dirigés vers le ciel et conservent cette position en derenant des cônes oroüdes - allongés, formés d'écailless planes, arrondies, non excavées à la base, serrées et imbriquées. Cihaque: écaille est accompagnée sur le dos l'une bractée persistante, terminie par une pointe aiguë, qui parait an dehors du còne. Les fruits sont assez volumineux, au nombre de 2 à la base de chaque écaille, entourés d'une aile membraneuse persistante.

Le sapin crôt sur toutes les hautr's montagnes de l'Europle, el principalement sur les Alpes du Tyrol, du Valais, du Dauphiné; dans les Círeunes, les Vosges, le Jura, la Forèi-Yoire: en Suc̀de et en Russie. Indépendaniment de sa térébenthine, dont nous parterons plus loin, et de son buis, qui est un des plus usilés dans toutes les constructions civiles, navales, et même pour l'intérieur de nos habitations et pour nos meubles, il fournit à la pharmacie les boniggeons de squins, qui sont composés de jou 6 hourgeons coniques-arrondis, rerticillés autour d’un bourgena terminal, plus gros et long de 1't à 27 millimètres. Ils sont revêtus d'écailles rougeâtres, agghlutinées, et sont tous gorgés de résine, dont une partie exsude sous forme de lan mes à leur surface. Leur odeur et leur sareur sunt résineuses, légèrement aromatigues. On les emploie dans les affections scorbuticines, gontteuses, rhumatismales et contre les maladies du poumon. I.es bourgeons de sapin les plus estimés

1) Avel est derivé de l'italien abeto, qui vient lui-mème de abies. 
vienuent du nord de l'Europe et surtout de la Irussie; ils sont plus résineux et plus aromatiques que ceux des Vosges, qui ont aussi l'inconvénient d'etre farilement attargurs par les larves de vrillettes, qui les réduisent en poussière.

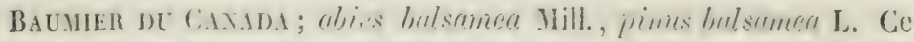
sapin a les plus grands rapports arec notre sapin commum, car il a le même pont; ses fenilles sont planes, distiques, blanches en dessous; ses cônes sunt dirigés vers le ciel, ovö̈les, à écailles minces, arrondies, accompagnées de bractées; mais il forme un arbre beaucoup moins ílevé; ses étamines sont chargées d'une petite crête qui n'a le plus souvent qu'une dent, et ses hraclées sont orales au lien d'ètre allongées. Cat arbre croît naturellement dans les régions froides de l’amérique septentrionale; on lo troure également en siberie, d’après II. Ferry. Il fournit, an Camada, une lérébenthine d’une odeur très suave, qui présente également les plus grands rapports arec celle du sapin.

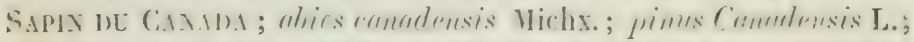
hemlurk sprum ou peruse. Albre de 20 a 27 mètres de hauteur, a fenilles linéaires, planes, obmes, longnes de 11 i $1 / 1$ millimètres, vertes et luisantes en dessns, d'un rent phus pile et un peu blanchàtre en dessous, iparses, mais disposies de manière à paraitre placées sur deus rangs opposés. Les fleurs mâles sont réunies en chatons axillaires très courts 't arronlis; les fleurs femelles sont situées à l'extrénité des ranteaux, et il leur succide de petils cones ovales, pendants. Ce sapin croit au Canada et dans Jes parties septentrionales des bials-Linis. Son bois est d'une mauraise qualité, mais son écorce est utile pour le tannage des cuirs. Je ne comnais pas son produit résineux.

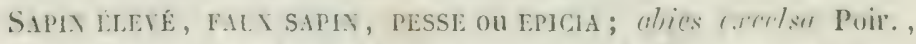
jums abies L. (Cet arbre habile les montagnes de l'lentope, et princi-

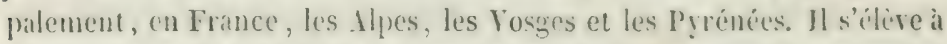
40 metres et plus íc hatuteur; ses rameaux sont rerticillés, ourerts à angles droits, et formant me pyamide réguliere. Ses fenilles sont lineiares, quentangulnims, pointues, d'un rert sombre, insíves tont antour des rameaux, "t articulies sur un petit renflement de l'icorce. I.'s fleurs mâles forment des chatons épars ça et lì le long des rameaux; les chatons femelles sont solitaires a l'extrémité des jeunes rameanx, et produisent des cones pendants, longs de 11 a 16 centimètres, cylindriques, quelynefois d'un rouge vif dans lenr jeunesse, roussatres ì leur maturite. Leurs icailles sont planes et échancrees au sommel. Cet arbre probluit une lírébenthine épaisse el presune sulde, nommée communément poix de Bourgogne.

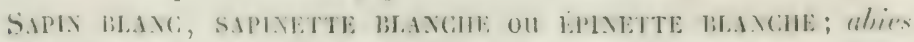

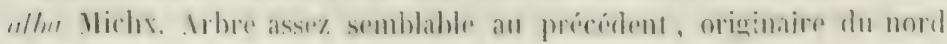


de l'Imérique, très commun en France dans les grands jardins et ter pares d'agrément. Il n'excide pas 16 meitres daus son pays natal, a lis fluilles trìs courtes, d'un vert pâle el comme blenàtre; les chatons màles ressemblent à ceux de l'epirirt; mais les cones n'ont que 4.5 it 68 millimetres de longueur et sont épars en grand nombre le longr des rameaux, ou sont solitiires, opposés ou verticillés ì l'estrémité. Lus écailles sont parfaitement arrondies et sans échancrure au sommet.

SAPIy volr, lPINeTte volne. Originaire du nord de l'Imérique, et moins répandu dans les jardins que le précédent, cet arbre serait cependant plus utile par son bois, qui réminit la force à la légèretí ; il peut s'élever jusqu'ì 24 on 25 mètres; ses feuilles sont semblahles it celles du sitpin blanc, mais d'un vert plus foncé, ct ses fruits sont encore moitié plus petits. En Imérigue, on prépare arec une décortion de ses jemes rameaux, additionné de mélasse ou de sucre, une sorte de bière, dite bière de spruce. L'arbre est peu résinenx.

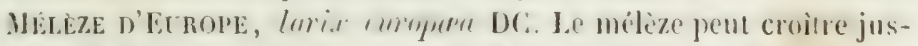
qu’à 30 ou 35 mètres de hanteur. Son tronc, parfaitement droit, produit des branches nombreuses, horizontales, disposées par étages irriguliers, et dont l'ensemble forme une raste pyramide. Ses fenilles somt étroites, linéaires aiguës, éparses su les jeunes rameaux, mais fasciculées sur les autres et caducques l'hiver, ce qui distingue le mélèze de tous les autres arbres conifires d'Europe. Ies chatons mâles et femelles sont très petits, épars sur les raneaux, et les derniers deviennent des cônes redressés, oroüdes, longs de ij centimitres rnviron, formés d'écailles assez làches, minces, arrondies, arec une petite pointr à l'extrémité. Le mélèze croìt sur lés Ipes et sur l'.lpennin en Italie, en Allemagne, en Russie et en Sibéric. Il n'existe naturcllement, dit-on, ni en Angleterre ni dans les P'rrénées. Son bois, qui est rougeàtre, plus serré et plus fort que colui du sapin, résiste pendant des sières aux actions destructives de l'eau, de l'air et du solejl. Les chalets suisses sont sourent entièrement construits en bois de mélèze, qui leur donne une durée presque indéfinie.

- C’est sur le tronc des vieux mélizes que croît l'agaric blanc ( $y$ m/yyror'us officinalis), dont nous arons parlé précédemment (page 6í. C'est également le mélège qui formit la mume do Brimeram, substance blanche, sucrée et laxative, comme la manne des frênes, qui exsude sous la forme de petits grains blanes, des feuilles des jeunes individus, Ie matin arant le lever du soleil, dans les mois de juin et de juillet. Hais cette substance est rare ef inusitee, et le principal produit du mélèze est sa téréhenthine, dont il sera traité plus loin.

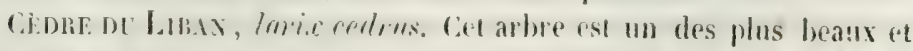

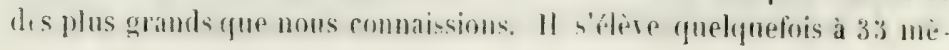




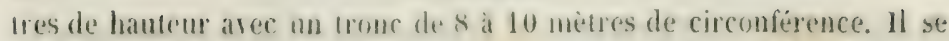
distinguesulont par des ranilications puissantes qui s'étendent horizontalement à une grande disance, ressemblant plutòt elles-mèmes à des arbres qu'à des branches. Ses foulles sont étroites, triangulaires, glahres, persistantes, éparses sur les plus jeunes rameaux qui poussent en longueur, elisposées par parpuets on fasciculées sur les rameaux à fleurs, qui sont àgés de quelques années. Les cones sont elliptiques, longs de 8 a 9 centimètres, épais de ja a 6 , formés d'écailles trés serrées, planes et très larges, portant ì la base deux fruits surmontes d'une aile membraneuse et à semence huileuse.

Le cèdre est originaire du mont Liban; il en découle, pendant l'été, une résine liquide et oduriférante, nommée anciennenent ceedrio. Il a été transporté pour la premiere fois en Angleterreen 1683, ct de là, en France, en 1734. Le premier pied planté au Jarlin des Plantes de Paris par Bernard de Jussieu, s' voil encore à l'entrie du Labyrinthe. Il est àge de cent quatorze ans, "t n'a pas plus de $3^{\mathrm{m}}, 28$ de circonfirronce; on peut juger d'après cela que les cèdres cités par plusienrs royageurs pou aroir 12 mètres de tour deraient être âgés de neuf à dix siècles (1).

i.es écrivains hébreux ont souvent parlé du cèdre et en ont fait l'omblème de la grandeur et de la puissance; ils regardaint son bois comme incorruptible, et ont assure quele temple de Jérusalem, bati par Salomon, avait été construit arec des cèdres compés sur le mont

1) Le grand cèdre du Jardin des Plantes, mesure le -20 juillet 18is, a $1,0 ̈$ mètres de terre. mª présenté 3,28 mètres de circonférence. Si l’on pouvait supposer que son accroissement en grosiene eut èté égal pendant lés cent trente quatre années de son existence, il en résulterait un accroi-sement annuel en circonférence de 0,0274 mètres: d'où l'on conclurait cnsuite yui un cèdre de 12 metres de circonférence serait àgé seulement de quatre cent quatre-vingt-dix ans; mais celle evaluation serait bien au-de-sous de la vérité. En effet, le 20 jansier 1917 , le mème cèdre, mesuré par $\mathbf{~ I . ~ J . o i s e l e u r ~}$ Derlougchamps, à $1^{\text {in }}, \breve{3}$ de terre, avait 8 pieds 10 pouces de circonference, soit 23m,87. En comparant cette mesure à celle donnée ci-dessus, nous trouvolls :

Augmentation en circonférence, en $31:+n s, 5 . . . .00,41$

$$
\text { année moyenne... } 0,013016
$$

- en diamètre, annéc moyenne. ..... 0,00:159 sur le rayon, ou épaisseur d'une couche annuclle................ 0,002079

Si l'on calcule l'àge d'un cèdre du Lihan de 1:2 mètres de circonférence, a raison d'une aurmentation annuelle de $0^{m, 013}$, on tronse neuf eent ingtdeux ans. Mais il ext certain qu'un pareil ièlre serait encore beaucoup plus àge, la lenteur progressive de la croisiance, apres le premier siccle, dépassaut debeancoup l'excedant de croissance pendant les premieres annees. 
Liban. Mais le bois de cet arbre est loin de mériter sia réputation; il ent léger, d'un blanc roussâtre, peu aromatique, sujet à se fendre par la dessiccation. Il est possible gu'on ait pris pour du bois de cèdre des bois de mélèze, de cyprès ou de genévriers, qui sont, en effet, plus beaux, plus aromatiques et beaucoup plus durables.

Je parlerai des dammaru at des aroucuria, conifères gigantesques de l'Australasie et de l'Amérique mérilionale, en trailant de leurs prorluits résineux.

\section{PRODUITS RÉSINEUX DES ARBRES CONIFẺRES.}

\section{Résine sandaraque.}

Suivant une opinion anciennement et généralement suivie, cette ré sine découlerait, en Afriq̨ue, d'une grande variété du genévrier commun (juniperess conmunis), ou de l'oxicèdre (juniperus oricedrus). Plusieurs auteurs ont même décrit la résine de l'oxicèdre et lui ont donné des caractères qui se rapportent à ceux de la sandaraque. llais, d'après Schousboe, rovageur danois, le genévier commun ne croît pas en Afrique; et d'après Broussonnet, cité par Desfontaint's $(F l$. Allant., 1. 353), le thuyu urticulutu produit la résine sandaraque, dans le royaume de Vlaroc. II est possible, après tout, que ceux qui ont répandu la première opinion, aient pris le thuya articulé pour un genévrier.

La sandaraque est en larmes d'un jaune très pâle, allongéés, recouvertes d'une poussière très fine, à cassure vitreuse et transplarente à l'intéricur; elle a une odeur très faiblt, nne sarpur nulle; elle se réduit en poudre sous la dent, an liea de s'! ramollir comme le fait le mastic; elle est insoluble dans l'eau, soluble dans l'alcool, peu soluble dans l'éther, insoluble dans l'essence de lérébenthine; elle forme avec l'alcool un très beau vernis, d'où mène lui est venu le nom de rernix (que lui donnent plusicurs auteurs; elle est très peu employée en médecine, et sert surtout à la préparation des vernis; on l'emploie aussi réduite en poudre, sur le papier déchiré par le gralloir, afin d'empêcher l'encre de s'y répandre et de brouiller l'écriture.

\section{TERÉBENTHINES ET AUTRES PRODUITS IES SAPINS LT DET PINS.}

Chez les anciens, le mot trérbenthine n'élait d'abord qu'un nom adjectif, qui, joint au nom générique résine, s’appliquait exclusirement an produit résineux du pistacia terebinthus. Resinaterebinthinu voulait dire résine de térébinthe, comne resina lentiscinu signifiait résine de lentisque; resinu ubietina, résine de sapin, et ainsi des autres. 
Mais la préuninence qui fut pendant longtemps arcordée à la résine firébenthine, juinte à la suppression du mot ressim, ont funi par convertic l'adjectif on un nom substantif et spécifique, et ce nom est derenu générique à son tour. Iorsqu'on l'eut appliqqué à d'autres résines liqguides, que l'on s'est cru antorisé à substituer à la première. Fufin, de nos jours le nom triphenthiur a reçu encore une plus large application, qui consiste à le donner à tout produit végétal, coulant ou liquide, essentiellemont composé d'essence et de résine, sans acide benzö̈que ou cinnamique, telles que les résines liquudes des cropratifero, halsannodendron, heduigia, crlophyllum, ete. II ne sera question pour le moment que des lérbenthines prorluites par les coniferes, les autres derant être décrites snirant l'ordre des familles des arhres qui les fournissent.

\section{Térébenthine an Mètèze.}

Célte résine était connne des anciens qui la tiraient des mêmes contrées que nous; car IDioscoridle nous dit: "On apporte de la Gaule subalpine lat savoie) une résine que les habitants nomment larie. c'est-à-dire tirée du luri, n; mais il ne nous en apprend pas darantage. Pline la définit assez bien en disant: " La résine du lurie est abondante; elle a la couleur du mich, (st plus tenace et ne se durcit jamais; " mais il conmaissait bien peu l'arbre, puisigu'il le suppose tonjours vert, comme les pins et les sajins.

Galien loue beancoup la résine du mélèze et l'assimile prescrue à la térébenthine. "Parmi les résines, unus dit-il, il y en a deux très douces : la premiere est nommée triphlonthime, la seconde larice."

Et ailleurs : "Quant à nous qui sasons que la meilleure de toutes les résines est la térébenthine, nous l'employons pour la confection des médicaments; et cependant si nous n’arons que de la larice, qui cmpechera que nous ne nous en servions, puisquu'rlle est presqque seli]blable à l'autre? etc. "

On peut dire gue ceses Galien qui a fait la réputation de la résine du mélèze, "t qui a dé cause aussi de la confusion qui a si longtemps existé entre les différents produits qui portent aujourd'hui le nom de lérébenthine; d'abord par la dişparition pressue complese de celle du térébinthe que l'on jugrait à peu près inutile de se procurer; ensuite par l'idée qui s'est généralement répandue que la térébenthine du méleze desait etre bit plus belle dre celles de l'buropre occilentale, ce qui n'est vai que pour la lérébenthine du sapin; de tolle sorte que presque tonjours les commercants ont pris pour léribenthine du mélize colle du sapin, et réciproquement.

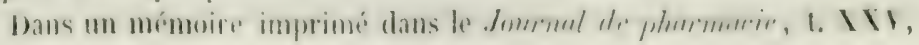


p. 977 , jai dit comment j'arais dù un premier échantillon anthentig̨uc de térébenthine du mélèze à 11 . Bonjean père, pharmacien à Cihambéry. Cette térébenthine, récoltée exprès dans les hois de l'évèque de llatlrienne, êait épaisse, très consistante, uniformément nébuleuse, d'une odeur toute particulière, tenace, un peu fatjonte, plus faible cependant que celle de la térébenthine citronnée du sapin, mais bien moins agríable; plus faible aussi que celle de la térébenthine de Bordeaux ol loute différente. Elle offre une sarveur très anière, persistante, jointe a une grande âcreté à la gorge.

La térébenthine dı mélèze conserve très longtemps sa mème consistance, sans former à l'air, et encore moins dans un vase fermé, me pellicule sèche et cassante à sa surface. Iorsyu'on l'expose à l'air, éten due en couche mince sur une feuille de papier, quinze jours après le doigt (fu'on y pose y adhère aussitòt el fortement. Sa propricte siccatire est donc à peu près nullı, ainsi que l’ont dit Pline et Jean Batuhin. Elle ne se solidifie pas non plus sensiblement par l'addition d'un scizieme de magnésie. Enfin elle se dissout complétement dans cincl parties d'alcosl à 35 degrés.

La térébenthinc du méleze u'est pas lare dans le commerce de l'aris, ou l'on trouve trois espèces de ce gemre bien distinctes:

$1^{\circ}$ La térébenthine commune, on téribenthine de Burdeaure, épaisse. grenue, opaque, d'odeur forte, très usitée chez les marchands de couleurs, mais rejetée de l'officine des pharmaciens;

2 ' La térébrnthine an citron, la plus belle de toutes, liguide, d’une odeur très suave, d'un prix élevé, rarement employée;

$3^{\circ}$ La térébenthime finc melinaire, la plus usitée dans les pharmacies, oi on la nomme sourent triblumthine de strusbung, mais renant en réalite de Suisse. C'est celle-ci qui est produite par le mélèze. Ja seule différence qu'elle présente arec l'échantillon de Maurienne, c’est que, élant récoltée en grrand, el filtrée ou reposée cn grandes masses, elle est plus coulante et transparente, mais jamais liquide et jamais aussi transparente que la belle térébenthine du sapin. Lés autres caractères sont tels que ci-dessus.

Le mélèze fournit très pen de térébenthine par les fissures naturelles de l'écorce, ou même en! faisant des entailles avec la hache. Pour l'obtenir, on fail avec une tariere des trous an tronc de l'arbre, en commençant à 1 mètre le terre, et en continnant jusqu'à la hauteur de 3 à 4 mètres. On adaple à chaque trou un canal en bois qui conduit la résine dans une anģe, d’où elle est retiréc pour être passée an tamis. Lorsqu'm trou ne laisse plus couler de résine, on le bonche arec une cherille, et on le rourre quinze jours après; il en donne alors mose nourelle quantite et plus que la premiere fois. La recolte dure dis 
mois de mai jusqu’au milieu ou à la fin de septembre; un mélèze vigourenx fournil ainsi 3 ou 4 kilogrammes de térébenthine par année, et il peut en produire pendant quarante ou cinquante ans; mais le bois qui en provient n'est plus aussi bon pour les constructions.

La térébenthine du mélèze, distillée arec de l'eau, fournit 15,24 pour 100 d'une essence incolore, très fluide, d'une odeur assez douce, non désagréable, mais rqui est rejetée par les peintres, qui s'imaginent que la qualité de l'essence est en raison de la force et de l'âcreté de son odeur. Je parlerai pluś loin de ses propriétés optiques.

\section{Terebenthine tu Sapin.}

Térébenthine un citron, térébenthine d'Alsuce, te Surasuming, de Venise, Bigeon. Cette térébenthine est produite par le rrai sapin, reconnaissable à ses feuilles planes, solitaires, disposées sur deux rangs, blanches en dessous, et à ses cônes oroüles, dressés ver's le ciel, à écailles minces et arrondies, accompagnées de bractées persistantes et piquantes.

Le suc résineux suinte à travers l'écorce et vient former, à sa surface, des utricules (jui paraissent deux fois l'an, au printemps et à l'automne. Les habitants des Vosges et des Ilpes qui ront la réculter ce sont ordinairement des gardeurs de troupeaux), crèrent ces utricules en râclant l'écorce arec un cornet de fer-blanc qui reçoit on même temps le suc résineux. Ils vident ce cornet dans une bouteille suspendue à leur côté, et filtrent ensuite la résine dans des entonnoirs faits d'écorce. Celte térébenthine est rare et toujours d'un prix assez élevé ; d'ahord parce que les utricules de l'arbre en contiennent si pen que charque collecteur n'en peut guère ramasser plus de 125 grammes par jour (Bélon, Sur les conifères, 1553 ); ensuite parce que les sapins ne commencent à en fournir que lorsqu'ils ont 25 à 27 centimèlres de circonférence, et gu'ils cessent d'en donner (guand ils ont acquis un mètre de tour. Ilors, en effet, l'écorce est trop dure et trop épaisse pour que les utricules puissent se former à sa surface, et on n'en rencontre plus qu'au sommet de l'arbre, où il est dangereux de l'aller chercher.

La térébenthine de sapin est peu coloree, très fluide, quelquefois presque aussi liquide que de l'huile, ce qui justifie le nom d'oulin d'areto (huile de sapin que le peuple lui domme en Italie. C'est clle aussi qui a presque toujours été rendue sous te nom de trifibentlime de: renise (Bélon). Elle est trouble et blanchatre lorsculedle vient d'être récoltée, quoique lo suc résinenx snit parfaitement transparent dans les utricules de l'arbre: mais il est facile de concevoir que l'humidité des parties déchirées se mèle à la résine el lui donne de l'opacisi. Par la 
filtration an soleil, on par un long repos, l'humidite se sépare ou disparait, et la résine forme alors un liquide transparent et à peine coloré. Son odenr est des plus suaves, analogue à celle du citron; la saveur en est médiocrement âcre ct médiocrement ancèe. Lille est assez promptement siccative à l'air pour cu'une couche mince, étendue sur un papier, soit complétement sìche et non collante après quarantehuit heures. Elle forme une pellicule dure et cassante à sa surface, pour peu que les rases qui la conticnnent ne soient pas hermétiquement fermés; elle acquiert en même temps une coloration en jaune, qui augmente arec le temps; elle se solidifie avec un seizième de magnésie calcinée. Enfin elle est imparfaitement soluble dans l'alcool.

Ce dernier caractère, indépendamment de tous les autres, peut serıir à distinguer la térébenthine du sap̣in de celle du mélèze : ainsi prenez de la téréhenthine du mélèze, même très nébuleuse, elle formera un soluté transparent avec l'alcool rectifie; prenez, an contraire, de la térébenthine de sapin, bien transparente, son soluté alcooliqque sera trouble et laiteux, et déposera une résine grenue insoluble.

Cette dernière térébenthine a été le sujet d'un beau travail chimique par a. Imédée Caillot, que je vais faire commaitre arant de passer outre. Ce médecin avant distillé de la térébenthine de strasbourg arec de l'eau, en a d'abord retiré l'huile volatile dans la proportion de 0,335. La résine cuite est restée dans la cucurbite arec l'excédant de l'eau qui avait acquis de l'amertume el la propriété de rougir le tournesol. Cet acide saturé par les bases alcalines et autres, a offert tous les caractères de l'acide: succinique. Déjà, avant 1I. Caillot, H. Singiorgio, chimiste italien, et 11 I. Lecann et Serbat, avaient démontré la présence de l'acide succinique dans le produit de la distillation à feu nu de la térébenthine; mais on pourait le supposer produit par l'action du feu, tandis que l'expérience de H. Caillot montre qu'il y existe tout formé.

La résine restant dans l'alambic, qui n'était autre que la téréberthine cuite des pharmacies, a été traitée par l'alcool froid qui a laissé une résine insoluble, et a dissous deur autres substances qui ont été séparées par la potasse.

On érapore, en effet, le soluté alconlique à siccité; on traite deux fois le résidu par un soluté de carbonate de potasse; on décante l'excès de dissolution saline, et on délaie le savon résineux dans une grande quantité d'eau. Le saron se dissont, tandis qu'il reste une résine insuluble, non saponifiable, non acide ni alcaline, très fusible, très solubie dans l'alcool et facilement cristallisable. L'autear a nommé cette substance abiétine.

Quint à celle que le carbonate alcalin anait convertie en savon, on la précipite de sa dissolution par un acide, et on oblient une résine très 
électro-négatire, nommée nerile abriftique, qui rougit le tourneson, est soluble en toutes proportions dans l'alcool, l'éther et le naphthe, et g̨ni peut neutraliser les alcalis. Voici les résultats de cette analyse :

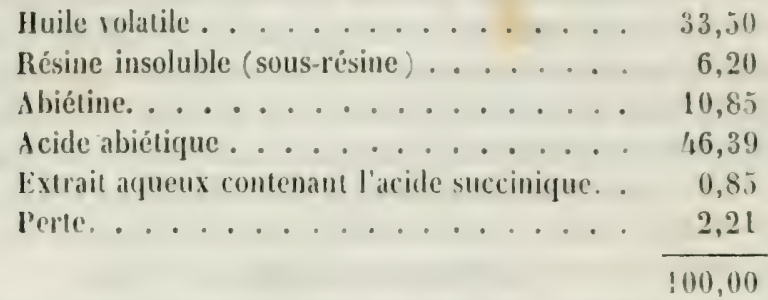

L'essence de térebenthine du sapin pese 0,863. Elle est très flnidr, incolore, d'une odeur très agréable et assez analogue à celle du citron pour qu'clle puisse quelquefois la reinplacer (par exeutjle, pour déta. cher les éfoffes!. La résine cqui reste dans l’alambic est jaune, Iranspatrente et conserve une odeur très surare, semblable à colle du baume du Canada. Ces deux produits, s'ils n’étaient pas d'un prix assez élevé, seraient bien préférables à l'essence et à la colophone du pin de Bordeaux.

\section{Têrbenthine te l'Abies balsamea.}

Cicte lérebenthine, plus connue sous te nom de brume de limudn. est produite, au Canada, par l'ubie's brelsamen, arbre qui a les plus grands rapports arec notre sapin argenté page $240^{\circ}$. La résine se pro. duit et se récolte de la même manière : ainsi, dans le temps de la sère. on voit paraitre sous l'épiderme de l'écorce des utricules pleines d'un suc résineux que l'on extrait en crevant les utricules arec un cornet yni sert is la fois de récipient pour le liquide. On purifie ce produit en le liltrant ì travers un tissu.

Le baume du Canada est liquide, presque incolore en nébuleux lor'fu'il cst récent; mais il s'éclaircit par le repos et devient alor's completement transparent. Il prossede une odeur tres suave qui lui cst propre,

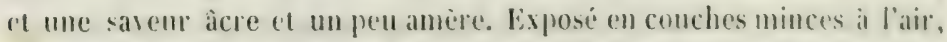
il sy siche completement en quarante-huit luters; it se drserde de meme dans des houteilles fermées, mais en vidange, et en prenant une couleur d'un jaune dorí de plus con plus foncée. La tirébenthine du sapin présente de même caraclere de coloration, meme d'une man'ire beacucop moins marcuée.

1.e banme du Canada se solidifie par un seizieme de magnésic calcinece, "t il est très imparfaitement soluble dans l'alcool. On roit que tous 
ses caractèes sciut semblables à ceux de la lérebenthine de sapin; aussi est-ce celle-ci qu'il faudrait employer pour le premier, s'il venait à nous manquer ; de mème que la térébenthine de Chio n'est bien remplacéc que par le mastic. Quant à la térébenthine du mélèze, qui ne ressemble à aucune autre, elle ne peut ni les remplacer ni être remplacie par elles.

Le baume du Canada a été rendu auciennement en Angleterre commc brume de filénd, et en a conservé le nom dans le commerce. Le rai baume de Gilead, dit aussi bumme de Judé et boume de la Merque, est une térébenthine liquide et d'une odeur toute différente, guoique thès agréable également, produile par le bulsumodendron opobulsmmm, de la famille des burséracées.

\section{Poix des Vosges.}

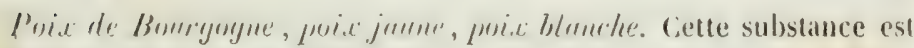
unc lérébenthine deni-solide, obtenne par des incisions faitos au tronc

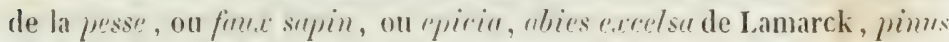
ubies de limné (1). Ciet arbre difere autant du sapin par le sirge et la nature de son suc résineux que par ses caractères botaniques, qui nnt élé indiqués précédemment $\Gamma$. 240). Il ne présente pas d’utricules ré. sineuses sur l'écorce, et tandis (fue le sapin, d'après Inuhamel, ne produit que très peu de résine par des incisions faites à l'écorce, la résinc de l'épicia ne peut être obtenue autrement.

Cette résine est incolore d'abord, demi-fluide, trouble, et son odeur ofre beancoup; d'analogie arec celle de la rérbenthine du sapin; clle coule le long du tronc, se dessèche a l'air et prend, par parties, unc couleur fleur de pècher ou lie de vin, et açuiert une odeur plus forte qui, sans être désagréable, présente quelque analogic arec celle du castoréum. Le tout, détaché arec une ràcloire, et fondu arec de l'eau dans unc chandière, donne une poix opaque et d'une coulewr fruene Issez funcée. Cette poix cst solide et cassante à froid ; mais elle coule toujours arec le temps, se réunit en une seule masse, et prend la forme des vases qui la contiement. Elle est très tenace et adhère fortement a la peau; elle possède unc odeur toute particuliere, assez forte, joesque

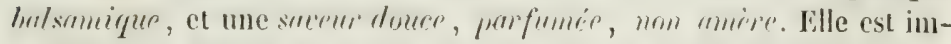
parfaitement soluble dans l'alcool, foumit un soluté alcoolique rougुeâtre et amex, et laisse un résidu insolub!e. analugue à celui de la lérébenthine du sapin.

(1) Linné s'ent quelquefois trompé dans l'emploi qu'il a fait des noms anciens ou vulgaires des végélaux. Dans le cas présent, il a certainement eu tort de donner au urai sapin, abies des Latins, le nom de pinus picea, et is la pesse ou epicia, le nom de pinus abies. 
A Bordeaux, à Rouen et dans d'autres villes manufacturieres, on fabrique une poix blanche factice qui est substituée, la plupart du temps, à la poix naturelle. Celte substitution peut parâtie peu importante à beaucoup de personnes, et cependant si la savenr, l'odeur ol la nature propre des medicaments ne sont pas sans influence sur terurs pronpriétés médicales, il faut reconnaitre que la confusion qui s'est élablie entre cess deux substances résineuses est loin d'ètre indifférentr.

La poix blanche factice est fabriguée arec du galipot du pin maritime, ou de la résine jaune, et de la térébenthine de liordeaux ou de l'essence de térébenthine; le tout fondu et brassé arec de l'ean. Celte poix est presque blanche, ou l'est d'autant plus qu'elle continnt plus d'eau interposée Elle est conlante; mais elle devient facilement sèche et cassante à sa surface. Elle a une sateur amère très marquée, mème non dissoutr dans l'alcool; elle possède l'odeur forle de la térébenthine de Bordeaux ou de son essence; quelquefois même elle présente une ndeur de prix noire; enfin elle est entièrement soluble dans l'alcoul.

\section{Encens de Suède ou de Russle.}

Il y a bien des années déjà que mon confrère, II. Béral, m’a remis l'échantillon d'une résine de pin, usitée m Russie pour faire des funigations atro:matiques dans les appartements. Cefle résine était en larmes irrégulières, fragiles, rougeâtres à la surface, mais oplaques et blanchàtres à l'intérieur; d'une odeur forte et halsamique, tenant quclyur chose du castoréum; d'une saveur très amère; clle était contenne dans un cornet fait l'écorce d'épicia. Une princesse russe, résidant à Paris, roulut en rain se procurer chez nous cette résine à l'usage de lacpuelle elle était habituée; ne pourant \ parrenir, elle fut contrainte de la faire reinir de Russie.

Celle substance, cependant, était déjà parrenue plusjeurs fois en France; car, une première fois, clle m’arait été donnée comme résine furmungue, et je la décrivis sous ce nom dans la denxième édition de l'H istoire ubrége des drounes simples. Plus tard, je la retrourai dans le droguicr de l'École de pharmacio, contenue dans la mème icorce d'arbre mentionnée ci-dessus; plus réremment enfin, II. Ramon de la Sigra apporta de l'îte le cuha, parmi un grand nombre d'autres produits, la même résine odorante, produite par un pin de cuba, dont il n'avait pu determiner l'espèce. Cente résine était en larmes sphéripues assez, volumineuses, d'un aspect terne et rougètre à l'extériemr, mais blanchitres, "parques et d'une cassure nette a l'interieur. Cette cassure rougit a l'air, et alors la résine prend une singulière ressemblance aver cerlains castoréuns à cassure rouge et résineuse. Sa poudre a la conleur 
de la brique pilée. Sa solution dans l'alcool parâit complète, à cela près des impuretés qu'elle peut contenir.

Je parle de cette substance a la suite de la poix de l'ubies extedser, parce que, suivant Haller, cité par llurray, la résine qui se fait jour spontanément à travers l'écorce de cet arbre, se concrète sous la forme de larmes qui répandent une odeur agréable lorsqu'on les brûle, ce quii lui fait donner le nom d'encens (en suédois grom licedn); parce que cette résine, en se desséchant sur l'arbre, prend en partic, ainsi que nous l'avons ru, la couleur rouge et l'odeur particuliere de l'encens de Russie; enfin parce que celui-ci se trouve contenu dans une écorce rouge et compacte qui me paraît bien être de l'écorce d'épicia, ce qui établit autant de présomptions qu'il e'st produit lui-mème par l'épicia. Cependant Vurray ajoute que, suivant d'autres personnes, cet encens est produit par le pin saurage, et ilous renons de dire qu'en Russie, comme à Cuba, on l'attribue à un pin ; il y avait donc une sorte d'égalité, pour la valeur, entre ces deux opinions.

Je cherchais à m'éclairer sur ce sujet lorsqur visitint, au Jardin des l'lantes de Paris, des troncs d'arbres abattus, j'en trouvai un courert d'excroissances d'une résine tout à fail semblable à celle qui fait le sujet de cet article. Ce tronc appartenait à un pin laricio, et j'en trourai un antre, encore sur pied et maladif, qui moffrit une exsudation résineuse toute semblable. Je crois donc pouroir dire que la résine balsamique, nommée encens de Riussie, peut être fournie par plusieurs arbres coniferes, et qu'elle l'est certainement par l'épicia et le pin laricio.

\section{Terébenthine de Bordeaux.}

Ciette térébenthine découle du prims maritima, qui crô̂t abondanment dans les environs de Bordeaux, et entre cente ville et Bayonne. On commence à exploiter l'arbre à l'âye de trente ou de guarante ans, et on le travaille chaque année depnis le mois de férrier jusqu'au mois d'octobre, plus ou moins, selon que l'annéc a été plus ou moins belle. Pour cela on fait une entaille au pied de l'arbre arec une hache dont les angles sont relevés en dehors, afin qu'elle n'entre pas trop avant, et on continne tous les huit jours de faire une nourelle plaie au-dessus de la première, jusqu'au milieu de l'automne. Cha'pue entaille a 8 centimètres de largenr et environ $2 \cdots \cdots, 5$ de hanteur, de sorte que lorsqu'on a continué d'en faire du même còté pendant quatre ans, on se trouse arrivé à la hauteur de $2^{m}, 6$ ì $2^{m}, 9$. Ilors on entame le tronc par le côté opposé, et on continue ainsi tant qu'il reste de l'écorce saine sur l'arbre: uais comme pendant ce temps les anciennes plaies se 
sont cicatrisées, forsqu'on a fait le tour de l'arbre on recommence sur le bord de ses plaies. De cette manière, quand l'arbre est vigourcux el que l'exploitation est bien conduite, elle pent durer pendant cent ans.

La résine qui découle de ces incisions est reçue dans un creux fait au pied de l'arbre. On vide ce creux tous les mois, et on transporte lat résine dans des seaux de liége jusqu'aux réservoirs qui l'attendent. On la nomme alors térébenthine brute, et, dans le pays, gomme molle.

On purifie la térébenthine avant de la lirrer au commerce, au moven de deux procédés. Le premier consiste à la faire fondre dans une grande chaudière et à la passer à travers un filtre de paille; le second, qui ne peut avoir lieu que pendant l'été, s'exécute en exposant au soleil la térébenthine contenue dans une grande caisse de bois carrée, dont le fond est percé de petits trous. La térébenthine, liquéfiée par la chaleur. coule dans un récipient placé au-tessous, tandis que les impurctés restent dans le vase supérieur. La térébenthine ainsi puriliée, nomméc férébenthine an soleil, est plus estimée que l'autre, parce qu'elle a moins perdu de son huile essentielle et gu'elle a l'odeur de la térébenthine vierge. Elle est néanmoins inférieure a celle de Strasbourg; elle est en général colorée, trouble et consistante, d'une odcur désagréible. d'une saveur âcre, amère el nauséeuse.

La térébenthine de Bordeaux présente d'ailleurs un ensemble de caractères qui la distingue également des deux térébenthines du mélèze el du sapin.

$1^{\circ}$ Elle a une consistance greme, et lorsqu'on la conserve dans un rase fermé, elle forme un dépôt résineux, comme cristallin, au-dessus duquel surnage un liquide consistant, transparent, quelquefois pent coloré, d'autres fois d'un jaune foncé.

$2^{\circ}$ Elle est entièrement soluble dans l'alcool rectifié.

$3^{n}$ Exposée en couches minces à l'air, elle y derient complétement sèche en vingt-quatre licures.

$4^{\circ}$ Mêlée avec un trente-deuxième de magnésic calcinée, elle forme en peu de jours une masse pilulaire et même cassante, de sorte qu'en ajoutant à du copahu, non solidifiable par la magnésie, un sisième de térébenthine de Bordeaux, on lui donne cette propriété.

Ia térébenthine suisse on du mélèze jouit d'une propriété toute contraire: non seulement elle ne se solidifie pas par la magnésie, mais, ajoutée is du copahu qui jonit de celte propriété, elle la lui retire.

La lérébenthine de Bordearx contient environ te yuart de son poids d'une huile volatile qui est très usite en lirance, dans les arts, sous le nom d'essence de tépébenthine, on plus simplement d'essence. On ohtient ce produit en distillant sans cau la térebenthine dims de grands alambics de cuive munis d'un serpentin. L'essence distille accompa- 
gnée d'un pou de phlegme acidule par les acides acétique el succinigur. et la résine reste dans la cucurbite.

Cefle essence est incolore, iris fluide, d'une odeur forte et d'une saveur chaude, non âcre ni amère. Elle pèse spécifiquement 0,87 à 0,880 . Elle so dissout en toutes proportions dans l'alcool anhỵdre, mais sa solubilité diminue si rapidement arec la force de l'alcool, (fu'il faut 10 à 12 parties d'alcool à 85 centièmes pour en dissoudre une d'essence. Celte essence paraìt être un mélange de plusieurs corps isomériques, tous composés de $\mathrm{C}^{20} \mathrm{H}^{16}$, condensés en 4 rolumes $(1)$. Elle absorbe une grande rquantité de gaz chlorhỵlrique ot se convertit en deux composís, dont l'un solide, blanc et cristallisé, a recu le nom de romplar artificiel $\left(\mathrm{C}^{20} \mathrm{II}^{16}+\mathrm{Cl} \mathrm{II}\right)$.

\section{Térébenthine de Boston.}

Ciette térébenthine vient en Europe par la roie de Boston, dont elle porte le nom; mais elle est lire principaloment de la Virginie et de la caroline, nu elle est produile par le juinus porlustris, et sans doute aussi en partie par le pimss terdu. Elle est uniformément oparque et blanchâtre, coulante, sans ténacité, d’une odeur forte, analogue à celle de la térébenthine de Bordeaux, et d'une sareur amère. Elle ressemble à un miel coulant, et elle ne se sépare pas, comme la lérébenthine de Borieaux, en deux parties, dont une tramsparente. Elle foumit par la distillation arec l'eau une essence (pui se distingue de toutes les antres par la déviation qu'elle fait éprouver à la lumière polarisée.

M. Biot avait observé anciennement que l'essence de térébenthine du commerce français imprimait aux rạ̧ons de lumière polarisée une déviation de 34 degrés rers la gauche, et ayant ensuite examiné diverses lérébenthines, il avait trouví que toutes également déviaient la lumière polarisée vers la gauche, excepté le baume du Canada, qui lui faisait íprouver une dévialion à droile. Or, M. Soubeiran aỹant extrait l'essence du baume du Canada arec de l'eau et sans eau, celte essence, dans le premier cas, déviait la lumière de - $7^{\circ}$, et dans le second de - $19^{\circ}$. M. Biot en avait conclu que dans tous les cas l'essence de térébenthine léviait la lumière polarisée vers la gauche.

Or, la seule essence que l'on trouve en .Ingleterre étant celle retirée de la lérébenthine de la Caroline, II. J. Pereira trouva ru'elle déviait

(1) Celle composition ne differe de celle de l'essence de citrons que par une condensation double, car l'essence de citrons égale $\mathrm{C}^{10}{ }^{8}$ condeusés en quatre volumes. On pourrait se demander, daprès cela, si l'essence de sapin, yui nffre une si grande analogie d'odeur avec celle de citron, v'en contiendrait pas de toute formée. 
ansez. fortement la lumière polarisée vers la droite; de là quelques expériences que nous avons faites, 11 . Bouchardat et moi, dans la vue d'étudier ce même caractère sur plusieurs térébenthines et essences de lérébenthine que j'avais à ma disposition. Ces expériences laissent beaucoup à désirer sans doute, par rapport aux térébenthines dont la teinte plus ou moins colorée nuit ì l'exactitude du résultat.

Baume du Canadra: déviation à dioite. ....... $12^{\circ}$

I. Biot a trouvé pour l'essence distillée sans eau. . . . 19"

Et pour l'essence distillée avec de l'eau. ....... $7^{\circ}$

Térébenthine du sapin : déviation à gauche. . . . . . $5^{\circ}$ Id. $\quad$ id. . . . . . $7^{\circ}$

Essence distillée aree de l'eau (densité, 0,863). . . . - 130,2

Térébenthine du méteren: Ia déviation n'a pu être ubservón.

Essence distillée a vec de l'eau (densité, 0,867) . . . . jo jo

T'érébenthine de Bordeaux transparente. . . . . - 6

Essence du commerce non rectifiée (densité, $0,880 \ldots \ldots-33^{\circ}, 1$

- rectifiée sans eau (densité, 0,871 ) . . . - 37 $37^{\circ}, 7$

- rectifiće avec de l'eau (densité, 0,872 ). . . . - 36

- rectif. asec de l'rau, dernier produit (dens. 0,889 _ - 260

Térébenthine de la Caroline, filtrée. . . . . . . - 9

Essence distillée avec de l'eau, du commerce anglais (densité, 0,863$) \ldots \ldots \ldots \ldots \ldots \ldots+22^{\circ}, 5$

Cette dernière essence e'st donc la seule qui dévie vers la droite less rayons de lumière polarisée. lille est aussi limpide que de l'ean; elle offre, dans son odeur aflaiblie, un cachet indéfnissable, que l'en rétroure dans tes vernis anglais, at qui pent servir à les distinguer des vernis français préparés avec l'essence de Bordeaux.

Après les térébenthines viennent d'autres produits résineux tirés des pins ou de la térébenthine elle-mème, tels sont le luarras ou gatiput. la colophone, la résine jaune, li poix noire el le goudron.

Barras ou galipot (anciennement garipot). Cette résine est le produit des pios, et surtout, en France, du pin de Bordeaux. On conçoit . en cffet, que lorsqu'or cesse chargue année la récolte de la térébenthine, les dernieres plaies conlent concore; mais comme la température n'est plus asso devé pour faire écouler promplement la résine jusqu'au pied de l'arbre, on peut-êtr l'huile solatile qui lui-donne de la fluidité ne s'y tromant plus on allssi grande quantile, elle se desseche it lair sur le tronc, ol se salit depuis la plaie jusqu'à terre. On récolte celle 
résine l'hiver et on la met à part; c'est le grulipert. Il e'st sons la forme de croùtes à demi-upacques, solides, seches, d'un blanc jaunatre, d'une odeur de térébenthine de pin et d'une sareur amere. Il est entièrement soluble dans l'alcool.

Brei set, arcunson ou colopjene. On nomme ainsi la résine de lia térébenthine de Bordeaux privée d'essence; on en troure deux sortes dans le combierce: 1" la colophome de galipot, obtenue en faisant cuire sur le feu et dans une chandière découverte le galipot, préalablement fondu et purifié par la filtration (1). Elle est transparente, d'un jaunc doré, fragile, mais encore un pen molle et coulante avec le temps. Elle n'est pas complétement privée d'essence, et parait très odtorante lors'qu'on la pulsérise. $2^{\circ}$ La colophone de téréberthine, qui reste dans li cucurbite de l'alambic, aprés la distillation à feu nu de la térébenthine. On la sontire par un conduit atdapté à la partie inférieure de la cucurbite, et on la fait couler dans une rainure creusée dans le sable. Elle est solide, d'une coulenr brune filus ou moins foncée, e'n raison de la forte chaleur qu'elle a éprourée; mais elle est toujours vitreuse et transparente cn lame mince. Eille est inodore, trìs sèche, cassante et friable. Elle est très soluble dans l'alcool, l'úther, les huiles grasses et volatiles. Le pétrole rectifié la sépare en deux parties, dont l'une se dissout ct l'autre pas. Pareillement, en traitant la colophone à froid par de l'alcool à 72 centièmes, on la sépare en deux parties: l'une insoluble, mais que l'on dissout dans le même alcool bouillant, et qui cristallise par le refroidissement; on lui donne le nom d'acide sylrigue'.

La portion dissonte par l'alcool froid est précipitce par un sel de cuirre; on décompose le sel cuirreux par un acide et on en retire une seconde résine acide, non cristallisable, nummée uride pinigne. I) reste, ces deux acides sont isomériflues arec la colophone, ct paraissent composés, comme elle, de $\mathrm{C}^{20} 11^{16} \mathrm{O}^{2}$. C'est-à-dire gu'on peut les considerer comme fant le résultat de l'osigénation directe de l'essence de térébenthine.

Résime jaume on poil-résine. Si, au lien de soutirer simplement le résidu de la distillation de la térébenthine, on le brasse fortement arec de l'eau, on lui fait perdre sa transparence, et on lui communique une conleur jame sale. Ainsi préparée, cette résine porte les deux nums ci-

1) Lorsque le galipot, au lieu d'être sec, est encore mou et abondant en huile volatile, on ne le dessèche pas à l'air libre : on le fait cuire dans un alambie avec de l'eau; I'huile qu'on en retire se nomme huile de rase. Elle a une odeur plus parfumce el moins forte que l'essence de térébenthine; elle est moins estimée des peintres, sans plus de motif sans doute que l'essence de mélèze. 
dessus. Fille est en masse jaune, oparque et fragile, encore un peol odorante el à cassure vitrense.

Colophome d"Amerique. Cente résine tient le milien, pour la couleur, entre les deux sortes de colophones qui proviennent du pin de Bordeaux. Elle est d'un jaune verdatre et noirâtre vue par réflexion; mais mise entre l'œil et la lumière, elle paraît vitreuse, transparente et d'un jaune faure un peu verdatre. Elle s'arrondit et prend la forme des vases qui la contiennent. Elle se pulsérise entre les doigts en dégageant une odeur aromatique assez agréable. Il est probable qu'elle a élé apportée des Ĺtats-Unis d'Amérique.

Puix noire. La poix noire se prépare sur les lieux mêmes où croissent les pins et sapins, en brûlant les filtres de paille qui ont serri à la purification de la térébenthine et dı galipot, ainsi que les éclats du tronc qui proviennent des entailles faites aux arbres. Cette combustion s'opere dans un fourneau sans courant d'air, de 2 mètres à $2^{m, 3}, 30$ de circonférence et de $2^{\mathrm{m}}, 60 \mathrm{a} 3^{\mathrm{m}}, 30$ de hauteur. Ce fourneau étant entièrement rempli des matières ci-dessus indiquées, on y met le feu par le hant: de cette manière, la chaleur fait fondre et couler la résine vers le bas du fourneau, avant que le feu ait pu la dícomposer entièrement. Cette résine est conduite par un tuyau dans une cure à demi-pleine d'eau; lia elle se sépare en deux parties: l'une liquide, qu'on nomme huile de poix (pisselreon); l'autre plus solide, mais qui ne l'est pas assez cependant, et que l'on met bouillir dans une chaudière de fonte jusçu'à ce qu'elle devienne cassante par un refroidissement brusque. On la conle alors dans des moules de terre et elle constitue la poix noire. lille doit être d'un beau noir, lisse, cassante à froid, mais se ramollissant très facilement par la chaleur des mains, et y adhérant très fortement.

Goudron. Le goudron est un produit dı pin, analogne a la pois noire, mais beaucoup plus impur. On le prépare seulement arec le trone des arbres épuisés. Pour cela, on divise ces troncs en éclats, rfu'on laisse sécher pendant un an. On en remplit un four conique creusé en terre, et on les élère an-dessus du sol de manière à en former un cône semblable au premier, et disposé en sens contraire. On recourre le cône supérieur de gazon, et on y met le feu. I.a combustion du bóis se trouvant ralentie par cette disposition, la résine a le temps de couler, très chargée d'huile et de fumée, vers le bas du fourneau, oì elle est recue dans un canal qui la conduit dans un réservoir exlérieur.

C'est là le gondron. Il laisse surnager, de mème que la poix, mene huile noire que l'on donne en place de l'meite de ronde. Celle-ci doit etre retire, par la distillateno à fen $\mathrm{mu}$, du bois d'une sorte de genti-

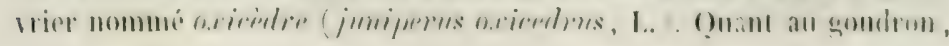


il est d'me rouleme brune, gramulems, demi-liquide, done d'une odem

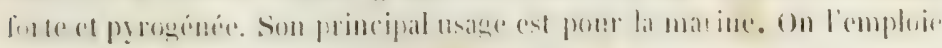
cu pharmacie pour faire l'ean de gondrou.

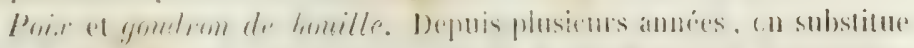
wès somrent dans le commere ba pois et le gondron qui prosienment

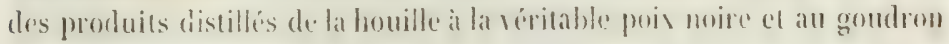
des arbres conilòres

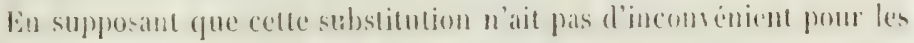
arts industrick, il n'en ent pas de meme pour la composilion des móndicaments, en raison de la malne fonce différente des principes qui ennslifuent ces deus ordres de produils. Il n' a aucune pariti a ctablir, par rxemple, pour l'odeur ct la couleur, chere l'ongzent hasilicum préparé arec la waie poix noire, at celui pour lergud on a employé de la poix de lumiile. Il n'y a de mème ancm 1 apmont de composition ui de propric-

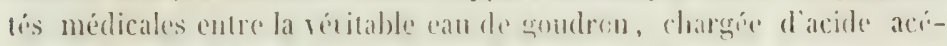

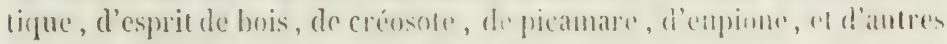
produits pardiculiers prosenant de la deromposition des principes rési-

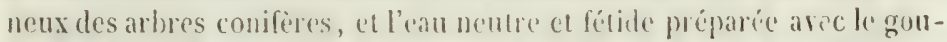
dron de houille. Voici donc les mosens de reconnaine la substimtion do ces derniers produits aux premiers.

La poix noire et le gondron veritables sont d'ua brun rouge en lante mince, et possedent une ndem qui, bien yue fortement emprreuma-

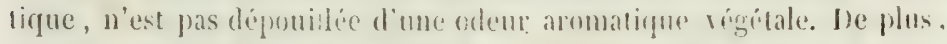
lodeur du gombron est manifestement acide; onfin l'un on l'autre, houllis pendant ynelunes instants dans lean, lui communique une acidite tres manifeste an papoere de fournesol. I.a pois el le gondron de

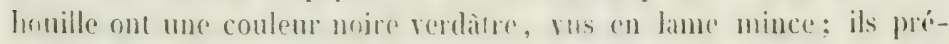

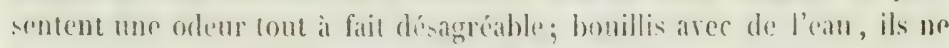

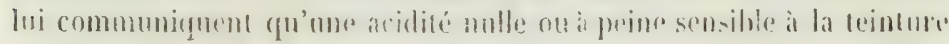
te tommesol.

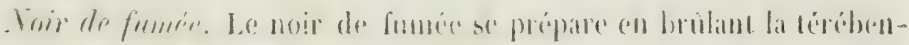
thine, le galipot et les autres produits résinenx du pin, qui sont de rebut, dans un fommeau dont la cheminée aboutil a mo chambre, qui

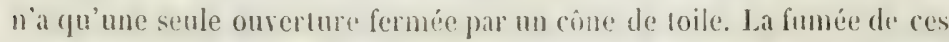

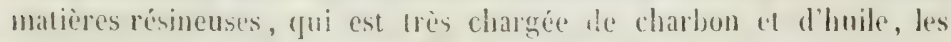
-al)andonnte en totalité dans lit chambre, on on les ramasse ensuite sous

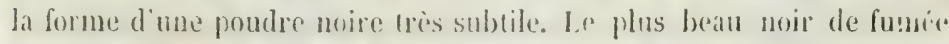
se prépare à l'arjs. Il entre dans la composition de l'encre d'imprimerio el sert dans la peinture.

On pent le débarassee de son luble par l'alcool, et mieux encore par la calcination dans un vase fermin: alors il ofire lo charbon le plus pure que l'on prisse obtenir. 


\section{liésines de lammara.}

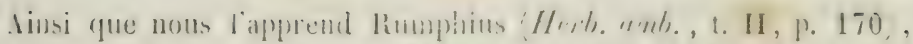
frememer est un nom malais qui dénote tonte résine cenlant d'un arbre 't s'enflammant au fou; de mème que gutter ou gittr s'applipne aux sucs agueux el laiteux, produisant des gommenes qui sp dissolvent dans l'eau et s'enflamment diflicilement. Il ne faut donc pas cruire, ainsi que plusieurs personnes l'ont fait, que toutes les résines qui purusent arrirer de la Malaisie, sous le nom de trmmmrt, soient dr mème nature, ou qu'elles doivent être produiles par un arbre conifere du ggenre demumm, ; loin de là, je pense aroir démontré 1 ) yne la plus abondante de cos ré-

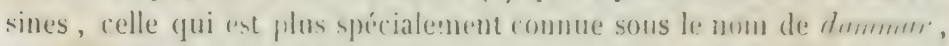
est produite par un arbre que l'on a cro alpartenir a ha famille des amo-

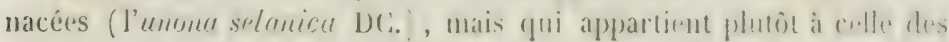
juglandées. Plusienrs antres résines, cefondant, nom mons implortanles,

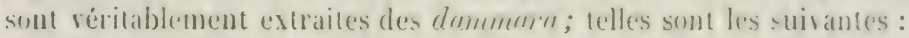

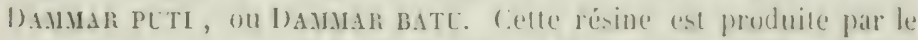

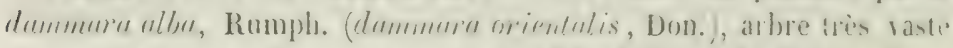

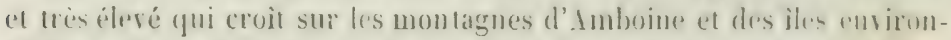
mantes, el qui se distingue des renilieres dont nous arome latiti jun-

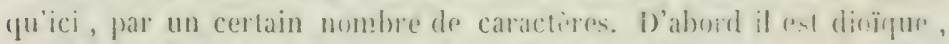

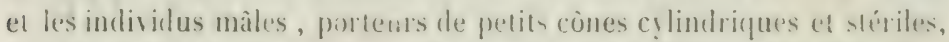
paraissent beaucoup) monios nombreux que les imdisidus femelles diont

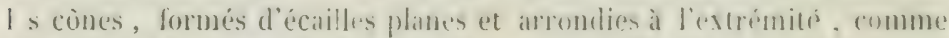

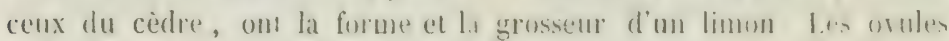

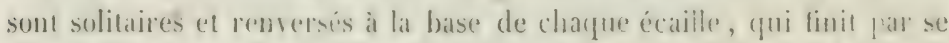

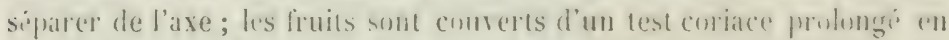

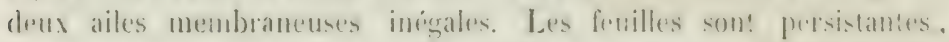

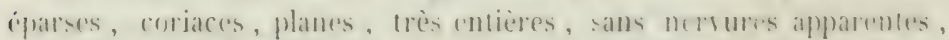

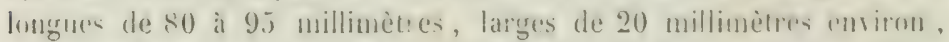
annincies en pointe anx deux extrémilés, presçue sessiles.

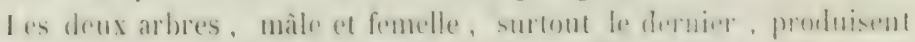

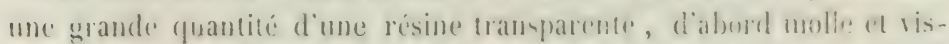

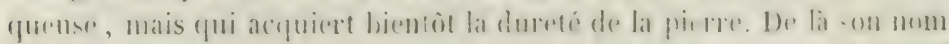
demmar batu, gui vent dire résine-pierre. Quant au nom dummai

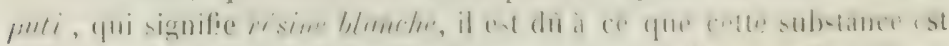

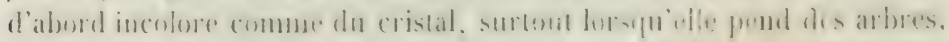

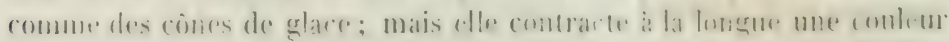

(1) Mémoire sur les résines connues sous les noms de dammar, de copal et d'animé (Revue scientifique, 1. XVI, p. 177). 


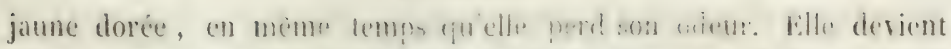

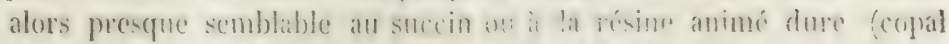

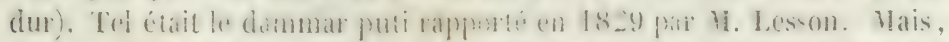

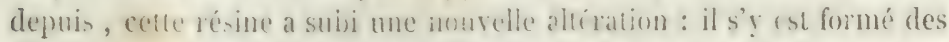

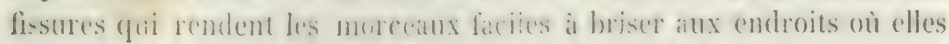

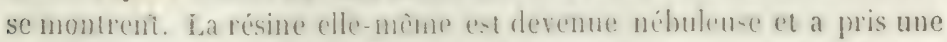

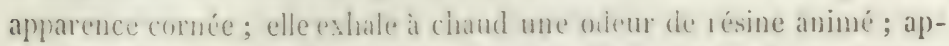
prochée de la liambe d'une boun ice, cile s'onflamme en se boursouflant, sans couler par gontles, 4 on répandimt une fumée imilante et acide Limmphims); humeclér d'alcool rectifie, si sufface reste sèche comme colle dusuccin el ne devient pas collante comme celle de l'a-

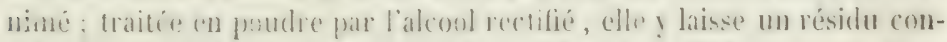

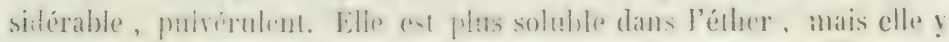

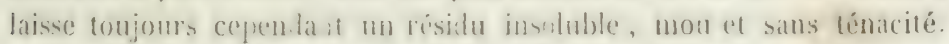

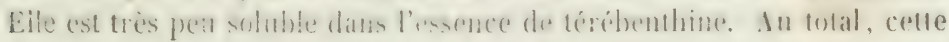
résine prósente de grands rapports arec le succin.

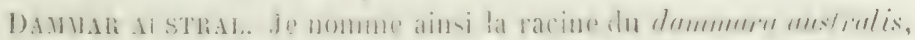

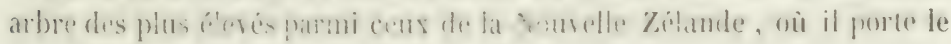
nom de laumi on linuri. Il laisse découler de son trone une résine

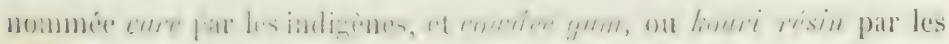

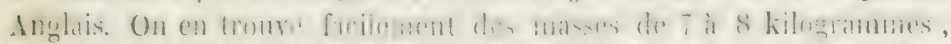

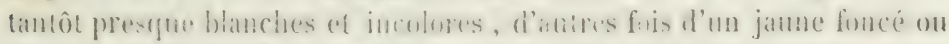

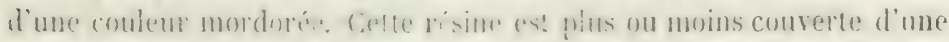

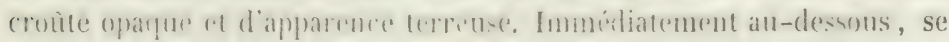

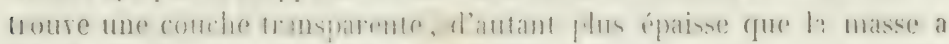

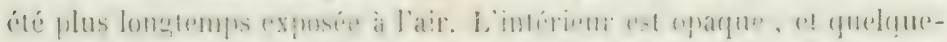

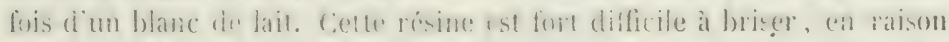

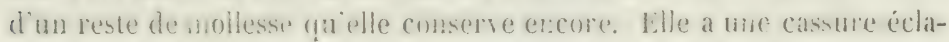

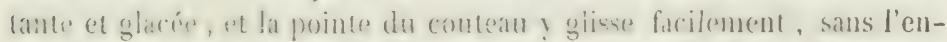

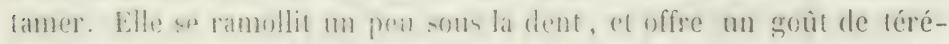

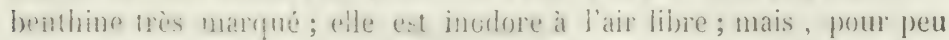

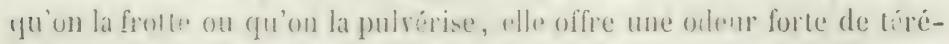
benthine de Bordeaux, mêlée d'odeur de carvi.

Le dammar anstral, traile par l'alemel a 92 centienses, se gonfle con-

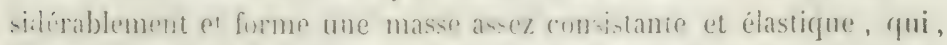

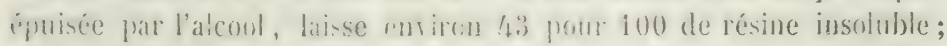

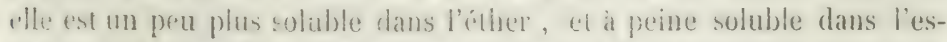

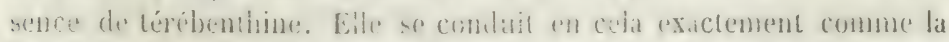

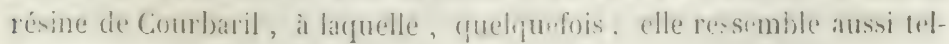
lement par son aspect, qu'on a peine à les distinguer.

banuar alionatiogue. Je dome igahement à cette résine le nom do drmmmar relibes, parce que je ne donte pas que ce ne soit celle que 


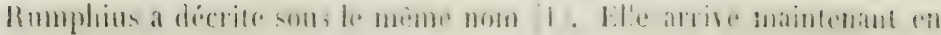

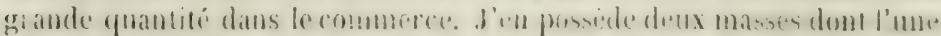

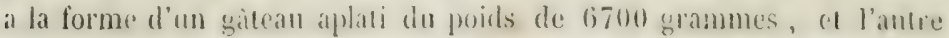
celle d'une stalactite qui pese 3200 grammes. La surface d'une de cos masses est seulement ternir à l'air ; l'autre est recourerte d'une croute mince, opalpus el d'apparence terrense ; au-dessons se trouve une couche pen épaisse, transparente, el d'une conlen de miel; le reste de la masse est d'une trinte uniformément nébulense on laitense. Cofle résine offre en maste une odeur aromatique agreahle, gue je compare a relle de l'essence d'orange vicillie et en partie résinifúce. Celle odrur devient très forte par une fracture récente, par lo finttement ou la pulvérisation.

Le dammar aromatique a mne rassme vitrense, conchoüde et à âêtes fianchantes, comme l'anime dure; il est presque aussi diflicile à entamer arec le couteau : il n'est ni àre, ni anor, el parfume senlement la bouche du gont aromatigue gui lui est propre. Pulvérisó el waité par l'alconl à 900 , il parail d'abord se diviser en deur parlies, dont une, insoluble, se rejose au fond, ayan! l'aspert d'un mucilige; mais presque tout finit par se dissondre. Il continat en reiliti, rependant, une résine insoluble gu’on pent précipiter con dendant la dissolulion roncentrée arec une plas grande quantití d'alcoul; ahos, cette résine presente l'apparence ghlulineose des résines insolubles de l'anime lendre: -1 du dammar austral; mais allo on differe, pare fu'dle se dissout rompletement dans l'alcool bonillant ; clle se prépipite de nouseau par le refroidissement. I.a soluhilité juesque complete du dammar aroma-

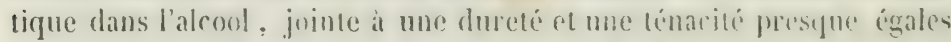
¿ celles du copal on anime dure, doivent ini assurep une des premieres places parmi les substances qui servent a la labricalion de's rermis. Il est commlatement soluble dims l'oblure, el puesgur insolublo dans l'essence de térẻbenthine.

\section{Résine Jactéc.}

J'ai décrit anciennement sous ce nom me résine inconnme qui marat ate remise par feu Pelletier, ef dont voici les singulieres propriétés.

lille est en un morcean d'un volume assez considivahle, dont la surface seule a pris une couleur jame paille par l'ellol de la réluslé; car

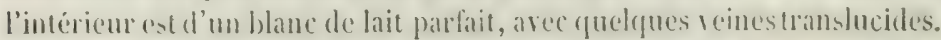
Elle a me cassure concheöle a arètes tranchantes, un eclat assez vif et

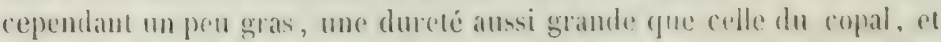
mue ténacilé supéricure; car elle est fort difficile à rompre.

(1) Voir l'Ilerbarium amboinens: , 1. 11, p, 179), el mon memoire sur les risiues dammar, p. 191 el 198. 
Eille résiste à lit dent el y semble un pren édotique; chle at une saveur d'abord acide, puis analoghe ì celle du riz. Flte ne se fond pas sur un fer chatud, ct s'y divise en une poudre trumeleuse qui exhale me odcur analugue à celle de la résine animé, mais piguante et excitant la toux. Elle se fonl i la flamme d'une bougie, brulte as ec une flamme blanche, et dégage une même odeur aromatique trìs irritante. Elle est très difficile à pulvériser, et exhate alor's une osteur qu'on peut comparer à celle du fruil de cassis; mouilice par l'alcool, sa surface reste sèche comme celles du succin et du dammar puti.

Conte résine, traitée plusieurs fois par l'éther, a laissé 0,67 de parties insolubles qui n'ont plus rien cédé ni à l'alconl ni à l'ean bouillante. seulement, celle-ci filtre se troublait un preu pai l'oxalate d'ammoniaque.

Ce résidu insolnble est analogue a la résine inoluble du copal. Jorsqu'on le chaulfe dans un crenset, il coltale uni: funce d'abord aromatique, non désagréable, approchant de celle du bois d'aloés; puis la résine se colore sans se fondre; l’odeur derient forte, fitigante ct désaugréable, sans arrie le piqquant et l'arome particulier des produits prrogénés du succin. La matiere se charlonne, ct laisse en dernier résultat un résidu très peu considerable, formé de quelyues grains sab!onnemx et de chaux.

La batièrer que l'êher avait dissonte: pesait 0,39; clant desséchée, elle paraissait inodore: nais, en la trailant par l'alcool. on déreloppail (n elle une forte odeur de cassis. L'alcool ne laissait gu'un résidu de 0,044, semblable a la résine insoluble dams l'éblure ; par l'éraporation, une nouselle portion cie cette matiere se précipitait au fond de la cap-

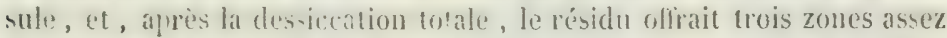
distinctes : la partie du fond élait blanche ef opraque. celle du milieu franshucide el cristalline, la pirtie superieure éait transparente et comme fondue. Il cat évident rue ces trois zones sont dues a l'isolement imparfait de deux principes: l'un insoluble dans l'alconl par lui-même c'est la résine dont j'iri parlé d'abord), mais soluble à l'aide du second principe, qui est de nature huileure et très suluble dans l'alcool. Celui-ci est le plus abondant au bord supérieur de la capsule, et le premier est presque pur au fond. (ouand, à l'aide d'une térébenthine, d'une huile volatile on du camplire, on dissout la résine insoluble dans l'alcool, on ne fait ru'y ajouter le principe qui lui manque pour devenir soluble, el cela mous rapproche de l'opinion imise par P'elletier au sujet des sous-résines de 31. Iunastre; c'est que la plupart des résines que nous comnaissuns ne doirent poutètre lemr solubilité dans l'alcool ru'à une semblable combinaison.

()ntre les deux principes dont je viens de parter. Ie produit alcoulingu 


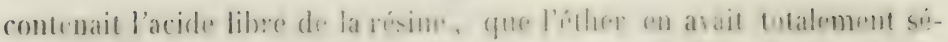

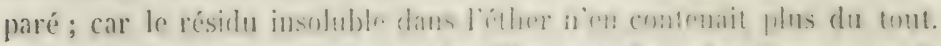

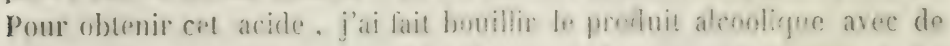

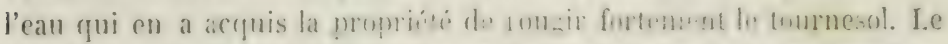

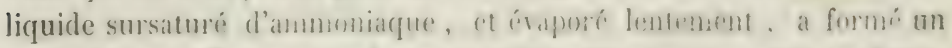

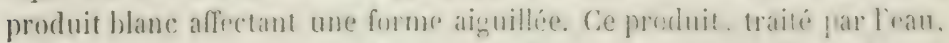

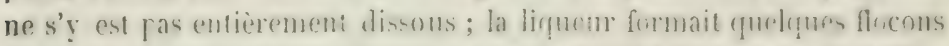

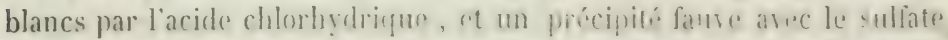

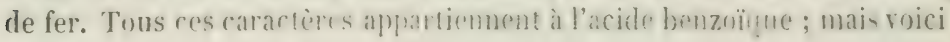
ce qui peut faire douter que s'en soit récllement :

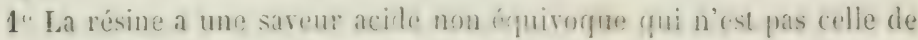
l'acide benzoügue : 2 le reiscu blane yue le s I ammonimal laiss ph se

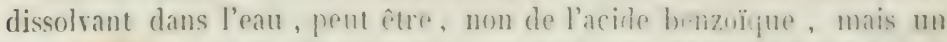

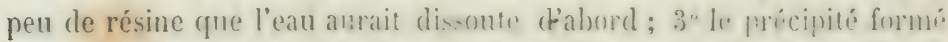

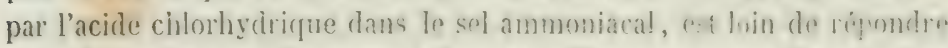
à celui formé en pareil cas par le benzoate d'ammoniarme. Il serait alors

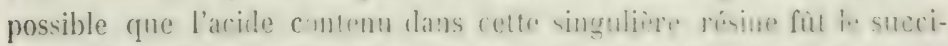
nique. Ia petite quantité de matiere sur laguelle j'ai mpiré ne m'a pas permis de décider la question.

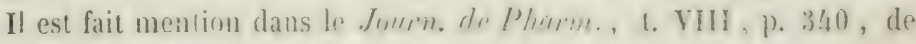

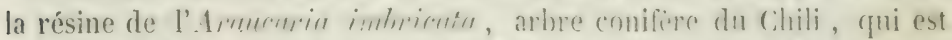
d'un blanc de lait, et quri ne pent se fometre an feu sins se dícomponser.

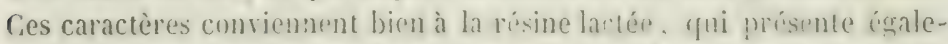
ment une grante analogie arec les résines des thommon. Toutes ensemble paraissent confirmer l'h șulhèse que j’ai émiste, tome I, p. 130).

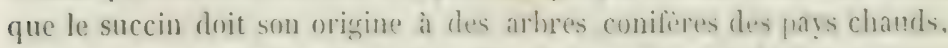
qui ont récu autrefois dans los climats que mons habitoms aujomd'hui.

\section{FAMILLE DES PIPERITÉES.}

Petit groupre de plantes que les holanistes ont place d'abord parmi lev monocotylédones et anpres de aroülies, en raismn d'une creraiuse analogie dans la disposition des fluems; mais la strumelure de la lize et la

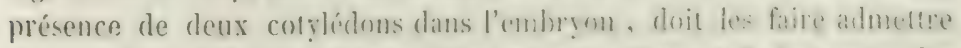

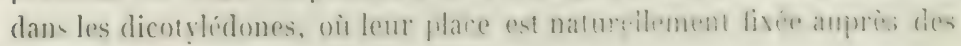
végétaux à fleurs en chatons, dits végétoute amentarés.

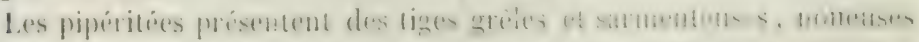

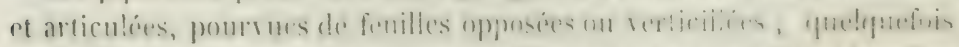

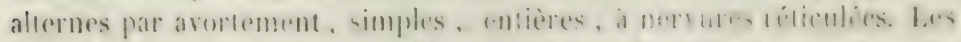

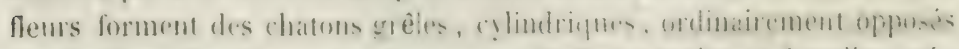

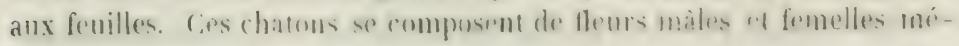




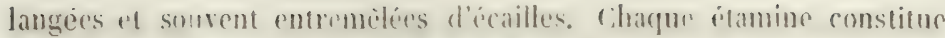

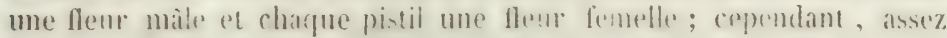

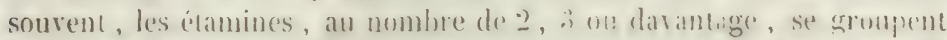
antour des pistits d'une maniore réguliere, of smblent alors former antant de fleurs hermaphrodites. L'ovitire est libere, it une seule logere, contenant un orule dressé, "l porlè à son sommet tantot un stigmate simple, tantot trois petits stimmates soms forme de mamelons rapprochés. Le fruil est me baie pen succulente et monosperme. La graine contient un condosperme assez dur, creuse a soln sommet d'une petite cavité dans laypuille on trouve, renfermi dans un sac ammintique, un très petit embryon dicotylédoné.

Ie principal genre de cette famille, et le seul qui nous intéresse, est le genre pripr. qui nous fournit les poises woir, blame, Inng, is queue, etc.

\section{Poivre noir (fig. 152).}

Le poive croit spontanément dans les Indes orientales; mais cent surtout au Valabar, à Java et à Sumatra cun'il est cultivé arec le plus de succès. Lorsque les habitants de cette dernière île veulent former une plantation de poirre, ils choisissent, dit-on, l'emplace-ment d'une vieille forèt, où le détritus des végétaux a rendu la terre très propre à la culture. Ils détruisent, par le feu, toutes lis plantes qui peurent encore y exister ; ensuite ils disposent le terrain, et le divisent par des lignes parallèłes qui laissent entre elles un espace de 13 à 16 décimètres ; ils plantent sur ces lignes, et de distance en distance, des branclies d'un arbre susceptible de prendre racine par ce moyen, et de donner un feuillage destiné à servir d'abri ì la jeune plantation. Cela fait, ils plantent deux pieds de poirre Fig. 132.

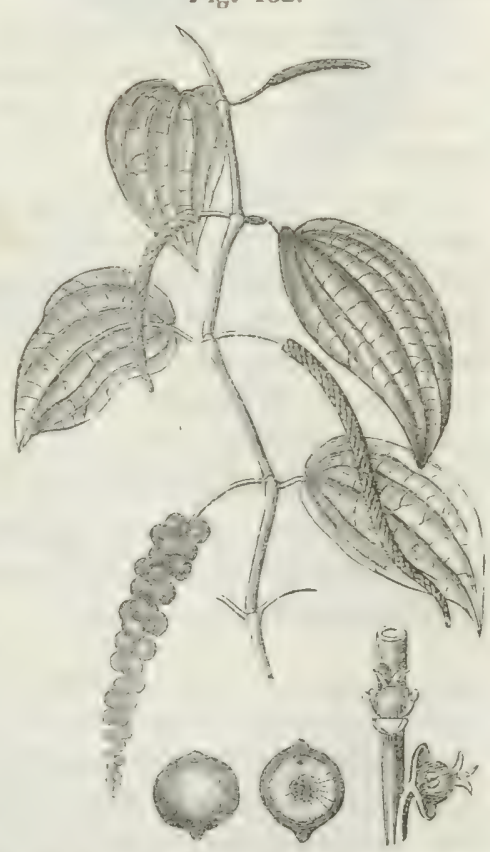
aupres de chaque arbrisseau, et les laissent ponsser pendant dorois 
ans; alors ils compent les liges a 110 metre du sol, et les recombent horizontilenent, atin de concentrer la sève. C'est ordinainement a dater de celle éporgue que le ponivior domme du fruit, et il con donne tous les ans pendant un certain nombre d'années. Ja récolte dure longtemps, cat le fruit mettant quatre ou cincl mois a murir, "t n'arrisant que successivement a maturité, on le cucille atu fur et a mesure (fo'il arive, et meme un pen aupararant, afin de ne pas le laiser tomber spontanément. On le fait sécher étendu sur des toiles, on sur un sol bien sec; on le monde des impurelés qu'il contient, 1'l on mous l'enroie.

Le poire noir, tel que nous l'arous, est sphéripue el de la grossente do la resce; il est recousert d'une écosce brune, tres ridie, due a lat partie sucrulante de la baic desséchée. On pent facilement redirer celtu

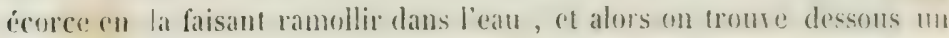

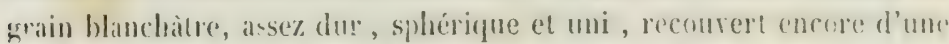
prilicule mince qui g adhere fortement, ("L formó d'me matière gui as comme corné à la circonférence, farinense et amylacée au centre. La saveur de ce grain, ainsi que celle dro som écorce, est icre, brulante e! aromatique.

I, poirre found, a la distillation, une essence theide, frestaie incolore, plus légère que l'eau, ef d'une orleur analogue à la sienne proppre.

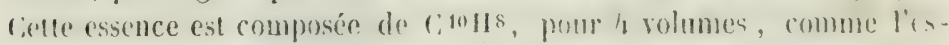
scuce de citrons.

le poirre noir a été analysé par l'elletier, qui en a retiré, culré

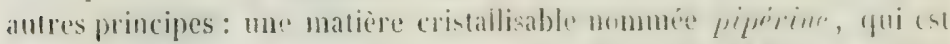
azotée, non alcaline, insipide, inodore, incoluble dans l'an, oolublre

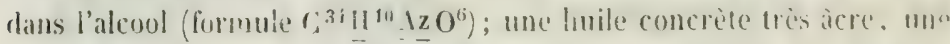
huile rolatile mentionnce ci-dessus, une matiere gommense, mn prin-

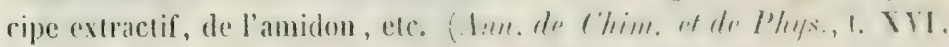
1. 337 ; Phamacopéc raisomée, 1). 704).

Le poive noir est généralement usité comme épié dans las cuisinges

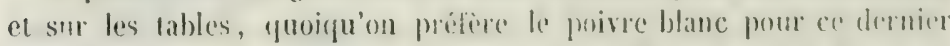
usage. Mais le poiste noir doit l'omprorter pone l'usage medical, common ifant le plus actif.

\section{poive blate.}

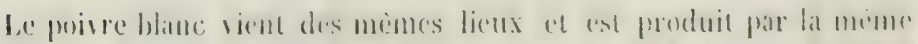

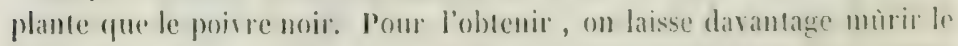

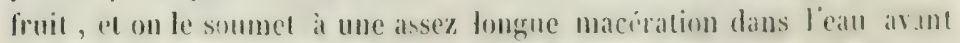
de le hare sécher: an moyen de celat, la partie charmue de la baice 
qui ent formé la premiere enveloppe de proisere, se'n détache par ha dessiccation et par le frottement entre les mains (1).

I.e proise blancest sphérique, blanchitre el nui ; d'un coté il est margué d'une pelite pointe, el de l'aure d'une cicatrice ronde qui, détruisant. souvent la contimuité de l'enreloppere, laisse soir à nu la substance cormée de la semence; cette substance, de mème que dans lo poire noir, est cornée il l'exterieur, farineuse, "t souvent creuse au centre.

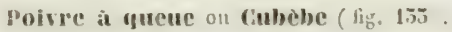

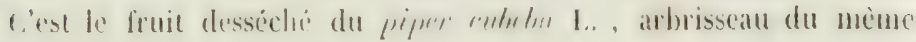
genre et des mênes classes que le piper ni!rum; mais il offere dans sa structure quelques différences arec le poive noir.

D'abord le poirre ì quene est plus gros, el il est muni d'un pédicelle 'qui y tient par te fortes nervures. La partic corlicale ridée, qui était ta parlic charnue du fruit, paraìt avoir été moins epaisse et moins succulente que dans le poivre noir. On troure, immédiatement dessous, une liig. 133 .

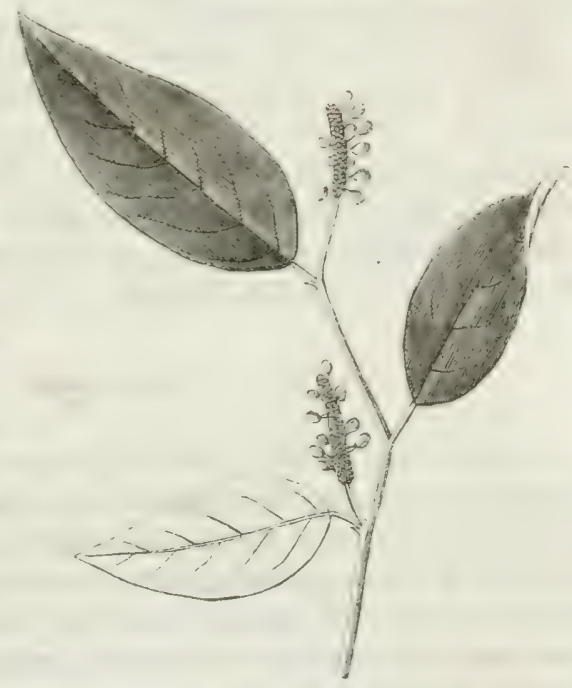
conpue ligntuse, dure et shérigue, renfermant une semence isolée de

1) Telle est l'opinion géneralement admios sur lorigine du poivre blanr: cependant il semblerait resulier d'un pasiage de liarcias ab horto, appuyi des figures données par Clusiu, Exot., P. 192, . que la plante an poirre blan n'est pas identicue arec le poivre noir.

Voici ce que dit Garcia- : "Il y a une si pelite difference entre la plante " uni produit le poise noir el celle qui donne le poirre blane, qu'elles sont "distinguées par les seuh indigenes. Quant à non*, nous ne les reconnaisson. ") que quand elles portent des fruits, et encore lorsque ceux-ci sont mûrs.

"La plante qui donne le joivre blanc est plus rarre et ne croit gueere quw "dans certains lieux du Malabar el de Malacca."

Clusins donne à l'appui de ce texte une figure comparée des deux poivres 


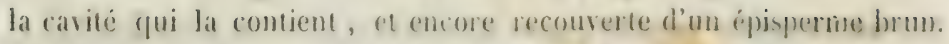
I. interieur de la semence est plein, blanchatre ef huileux. ba saseur

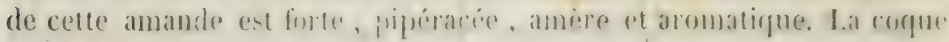
a peu de propriétés.

Le poive cubèbe fonrnit, par la distillation aser de l'ran, une: a-siz.

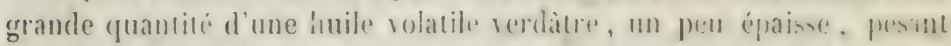
0,930 , et qui présente la meme compusition relative que les exsence's de poive, de citrons, de térébenthine, cte. (6; $\left.{ }^{5} 1^{4}\right)$ : mais la combensation des eléments parait etre difièreme, et son érguiralent igale

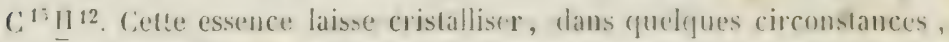
un straroptène qui paraìt inodore guand il cot prive d'huile volatile. Le cubcilge contient en outre une resime riren que l'on peent oblenir par le

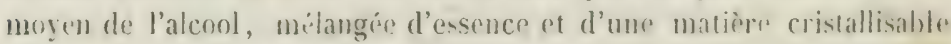
qui est sans doule de la pipérine.

On emploie le cubèbe en poudie contre les memes aflections que fe

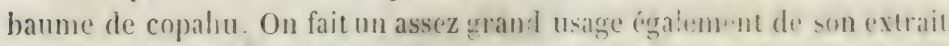

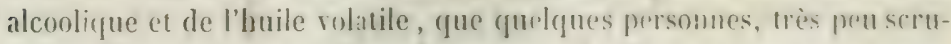
puleuses, préparent avec les cubibes entiers, afin de se réserrer la possibilité de les reverser dans le commeren, épaisés de leurs principes actifs. Les cubèbes, ainsi traités, se reconnaiss'nt à lent couleur noire et à leur défaut d'odeur el de saveur.

\section{poivre long.}

Le poive long est te frait non parfaitement mur et desséche du fipmes

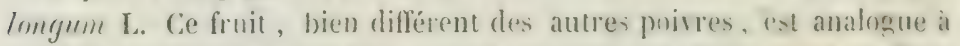
celui du mûrier; c'est ì-dire, qu'il est composé d'un srand nombre d'oraires qui ont appartenu à des fleurs distinctes, mais très serrées. rangées le fong d'un axe commun, oxaires qui, en se développlant, se sont soudés de manière à ne figurer qu'un seul fruit. Tol que nous l'arons, il a la grosseur d'un chaton de bouleatu; il est sec, dur, pesant, tuberculenx el d'unc couleur grise obscure. cihaque tubercule renferme dans une petite lege une semence rouge on noiratre, blanche

noir et hlauc parrenus a leur maturite; de lapuelle il résulte que le chaton du poivre blance est beancoup plus allonere que celui du noir; que les orains sont pluts gros. beanconp plus espaces et range comme un à un le long du pedoncule commun; lantis que, dans le poiste noir. l'epi est tolalement couvert de grains Irès serrés.

Ces deus sortes de fruile existent dana la collection de likcole de pharmacie. Je conelus de ceci que, si le poive blane provient aujourd'hui, en Iregrande partie, du poisre noir écorce, ecpendant il esisle une flante pui sn a plus spécialement porté le nom et quile produisait autrefois. 
à l'interienr. d'une sarene encore plus atcre el plus brulante que celle

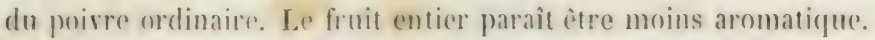

I. proirre lones entre tans la eomposition de la thériague et du dias-

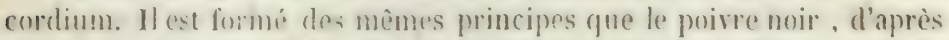
fanalyse qu'en a faite 1I. I)ulong d'Istafort. (Journ. de Phurm., t. XI, page 52.)

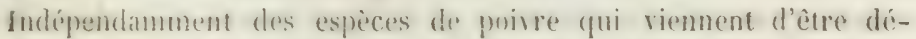
criles, beancoup d'aulres sont usitées dans les pars qui les produisent.

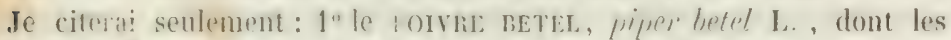
fenilles somt employese, dans toute l'. Isie orientale, prom envolopper le

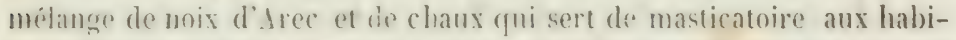

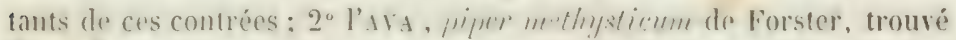
far ce naturaliste, compagnon de Cook, dans les îles de la Sociéte, où sa racine sert a la préparation d'une boisson enivrante; 3" le jmripurolu, piper unhellutum I.., dunt la racime. très usitéc an Brésil, a ché exa-

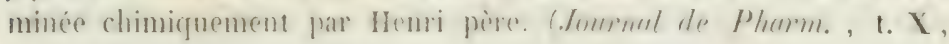
page 165.)

Lin assez grand nombe dr frubs cirangers à la famillo des piperiters. mais donés d'me qualité icre ot aromatique, et employés comme condiments, ont reçu le nom de proive; tels sont, entre autres :

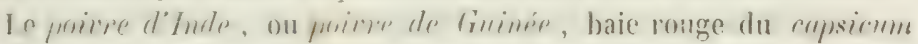
anniuum (solanées) ;

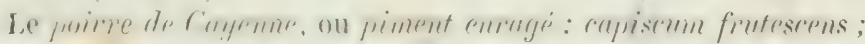

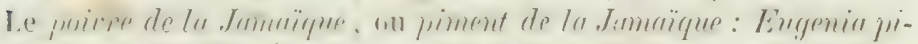
menta (myrtacées) ;

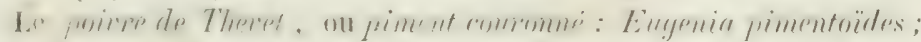

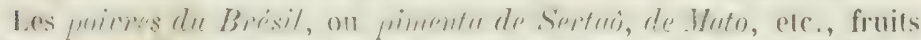
des xylopia frutescens, grandiflora, etc. (anonacées);

Le poiure d'Ethiopie, anonn athiopicr (anonacées);

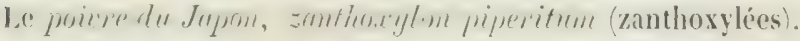

Cies fruits seront décrits à leurs familles respectives.

\section{GROUPE DES AMENTACEES.}

Aimi que je l'ai dit précédemment, 1.-L. de Jussieu arait formé

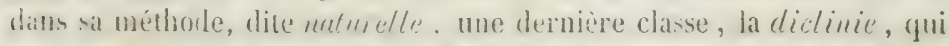
renformait la plupart des regétaus a flents unisesuelles. Cette classe

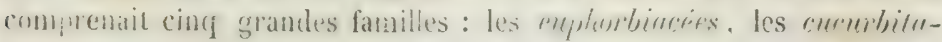
rées, les urticées, les annentacées et les conifères.

I a famile des annentircers, qui doit nous s:ccuper maintenant, el 'pue l'on peut tonjours considérer comme un groupe naturel assez rap- 
proché des conileres, fire son nom de ha disposition de ses flems en

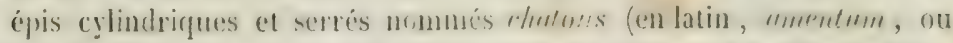
inhus). Eille contient en grénéral des végétanx ligneux, à fenilles simples, alternes et stipulées. Les fleurs moiles, disposies en longs chitons, sont formées d'étamines en nombre fixe cun indétermine, portées tantôt sur un calice d'une senle piece dirersement décrupé, tantiot sur une simple éraille. Les lleurs fumclles, dieposées de même, on rassemblées par pelits palguels sur le's ramcaux, ou solitaires, sont pourves d'un calice semblable ou d'unc écaille rntourant un ovaire simple, surmonté d'un ou de deux st!les terminés par plusinurs stignates. Le fruil est une capsule coriace ou osseuse, tantòt libre, tantòt soudéc avec le calice, el contenant une seule semence, ruclquefuis deux ou trois, dont l'embryon est démé de férispernue. Aujourd'hui, le groupe de's amentacees est divisé en un certain nombre de familles, au milien desquelies M. Endlicher intercale mène colles gui forment les anciennes urticies de Jussien, gue la disposition de heurs fleurs rapproche on effet brauconp des premières. Tout en comsenant de l'oplortunicé de cente réllnion, je ponse guion peut sniste pour ces familles, anxoulles je joins les juglandées et les monimiacées, un ordere qui permette de ne pas confondre les deux anciens gronjes de Juscien. Voici res familles, dont je n'examinerai que celles qui fommissme ginelque chose à la matiere médicale.

$\begin{array}{lll}\text { Casuarinées. } & \text { Balsamilnées. } & \text { Murées. } \\ \text { Iyricées. } & \text { Salicinées. } & \text { Artocarpées. } \\ \text { Bétulacées. } & \text { Lacistemées. } & \text { Urticacées. } \\ \text { Cupulifères. } & \text { Ilonimiacies. } & \text { Cannabinées. } \\ \text { Juglandées. } & \text { Ulmacées. } & \text { Intidesinées. } \\ \text { Platanées. } & \text { C'dtidées. } & \end{array}$

FMULLE DLS MURCLLS.

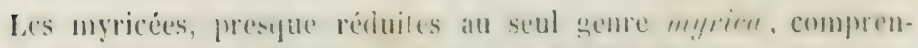
nent des arbrisscaus à rameanx épars, à fenilles alternes, dentées et incisées, parsemées de gulandes résinemses, ainsi gue les autres parties.

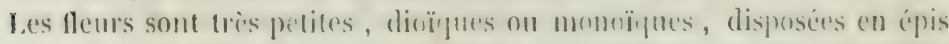
allongris, tannot sentement stiminiferes on pistilliferes, tantòt pistilliferes

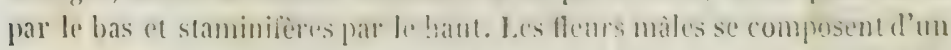

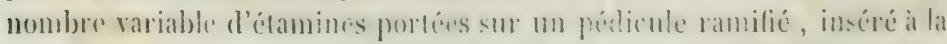

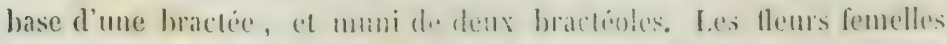

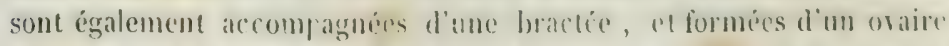

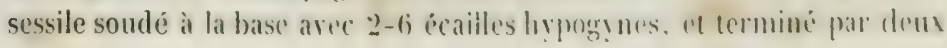


stigmates écarlés. Le frmit est mu drupe see, fres pelit, ì meyan osseus,

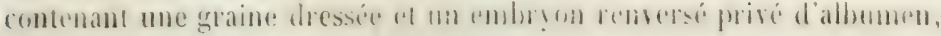
à cotylédons charmus et à radicule supuere.

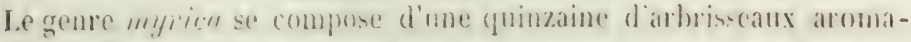

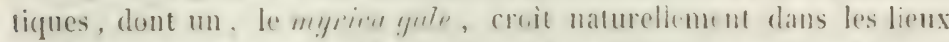
marécagenx en France, en Hollande el daus diverese comberes du mord de l'Europe ef de l’smérigue. Un lui domne vulgairement les noms de

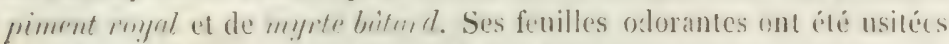
en infusion théiforme, el ont mione, pentant quelque temps, éte consi-

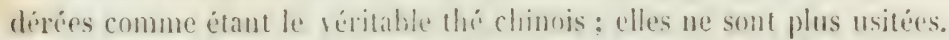

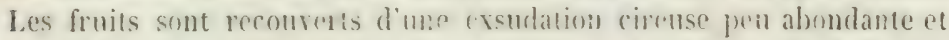

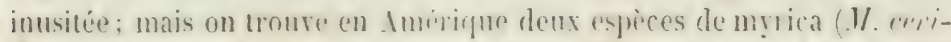

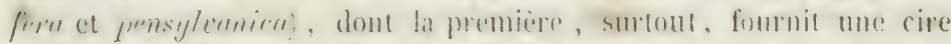
abondante qui notes est fommie par le commerer. I.es fruils de cet ar-

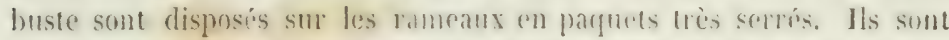

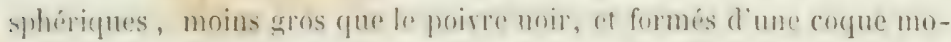

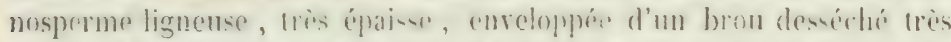

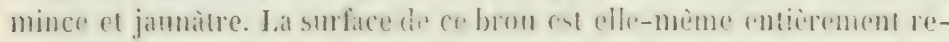

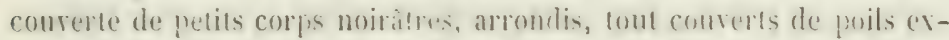

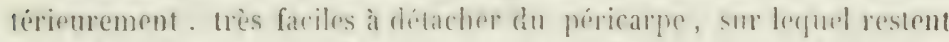

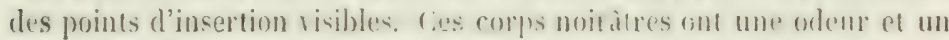

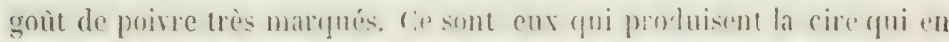
exsurle do coules parts al les recomre d'mo comche maforme, d'm

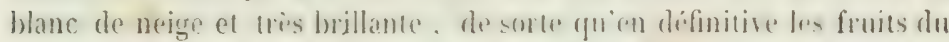

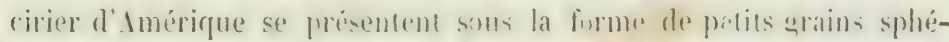
riques, à surface toute blanche et tuberculeuse.

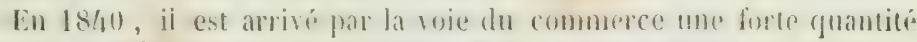
de cire des Élats-L nis, at je pense qu elle n'a pas resse de venir depuis.

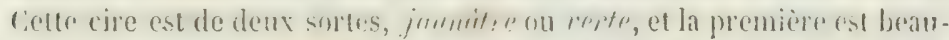
coup plus aromatique que la sicomrle. Suivant Dohamel, om obtient la rire jannatre en rersant de l'ean bouillanfe sur les baies ef la faisant conuler dans des barguets, apres quolgues mimutes dre contart. On concoit, en effet, gu'on nobtienne ainsi que la cire exterinur presque pure; mais comme il en reste apres le; fruice, on fait bouillir le mare

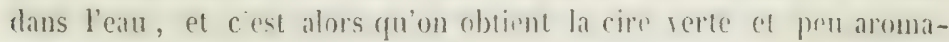
lique.

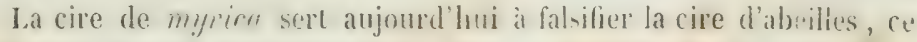
roii n'est pas sans inconrénient jour les usages auxquels celle-ci est des-

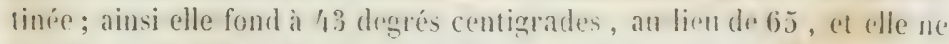
prend pas le même lustru par le frottrment. Có denx defants dispa-

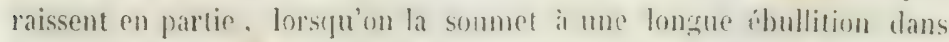

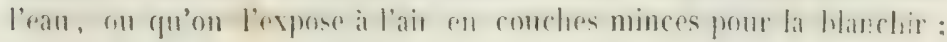


mais elle est tonjours fusible a 19 degrés. Eille parait, du rate, composie de cérine el de my ricine, comme la cire d'abeilles. On pent recommaitr.

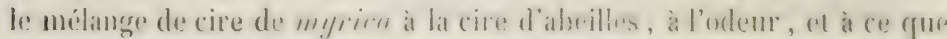
la première étant plus fusible, le mélange se ranne,llit dasantage dans les doigts et s'y attache, tandis que la bonne cire d'abeilles so laisse petrir daus les toigts sans s'y attacher.

\section{FAIILLE DES CUPUTIFERES}

Irbles ou arbrisseaus très rameus, à fenilles alternes, simples,

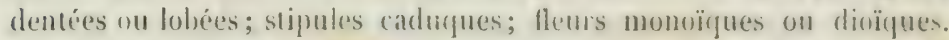
fileurs miles en chatous cylindrigues, nuts ou munies diune lractie squantiforme; périgene lantò sqquaniforme, indisis ou bifide, tantòt caliciforme à 4 on 6 o dirisions; ftamines uniloculaises, pluri-

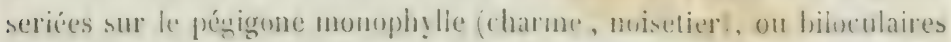
et miseriees a l'interiem du perianthe caliciforme of en nombre ingal, donble on trijple de ses dirisions (chêne, hềre, chàtaignier). FHenrs femelles fasciculées, disposcés en épis ou ressiles el en petit nombre, an fond d'un insolucre. Involucte fobiace on esathiforme, sousent squameus a l'extérieur, persistant; tantit s'accroissant et ensideppant le fruit; d'autres fois l'entourant d'une cupule it sa base. P'erianthe soudé arec l'ovaire, à limbe supere, court denticulé, disparaissant or-

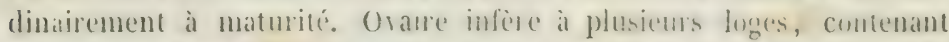
2 orules pendants à l'angle interne de chacpue loge, surmonte parantant de stigmates qu'il ! a de loges. Fruil balane protegre par limsulucre, persistant et :ousent accru, derenu uniloculaire par la destruction des cloisons, et ordinairement monosinerme par arorement. (iraine pendante, sonvent accompagnee des orules avortés privisperme mul: rmbryon homotrope, dicotylédoné, à radicule supère.

les cupulières appartiennemt principalement anx farlies tempérées de l'Europe el de l'Amérigue septentrionale, et fournissent in nos forcits

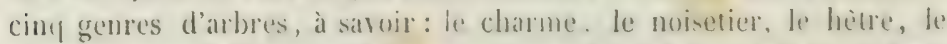

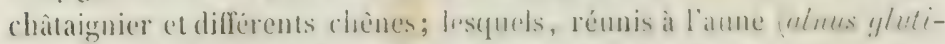

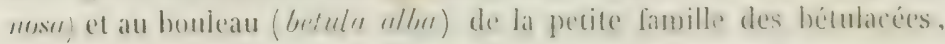
compescut presque entièrement nos forèts.

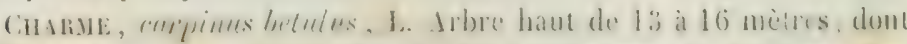

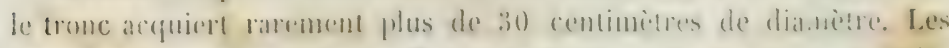
branches forment une lete tondfue al irreguliere; les feuillessont pétio-

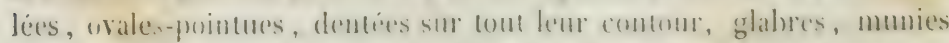

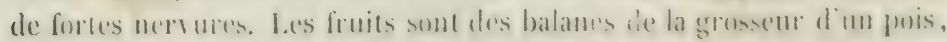

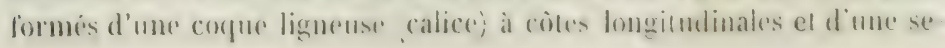


mence à testa membranens; ces balanes sont portés charun a hat base d'une grandr bracté fulacée, a :3 lobes a les bractées forment par leur rénnion des épis foliacés et pendants.

le bois de charme est blanc, très lin, très serré, et accuicrt unt grande dureté par la dessiccalion. On l'emploie pour les ourrages de charronnage et pour des roues de poulies, des dents de roues de monlins, des vis de pressoir, des manches d'ontil, etc. C'est également un de nos meilleurs bois de chauffage.

Noisetier ou counder, curylus acellune, L. Arbrisseau de $j$ i 7 mètres de hauteut, dont les fleurs paraissent pendant l'hirer et bien anant les feuilles: les màles se font remarquer par leurs longs chatons jaunatres; le's fleurs femelles, réunies en petit nombre, forment, a d'autres endroits des ranteanx, de petits chatons oroïdes, inférieurement courerts d'écailles imbriquées, et chacune d'elles est particulièrement cntourée d'un involucre à 2 ou 3 folioles très petiles, lacúrées, persistantes, prenant un grand acroiss ment pendant la maturation du fruit et l'entourant. Le fruit (balane), rédnit ordinairement à une senle semence, est renfermi dans le calice aceru et derenu ligneux. La semence rst d'un gonit fort agriable, et fournit, par l'expression, 60 pour 100 d'une huile granse (huile de noisentes) très agréabide a manger, non siccatise, d'une pesanteur spécificue de 0,9242 .

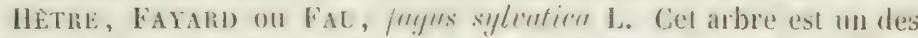
plus beaux de nos lorêts. Il peut s'élever à 20 ou 27 mètres sur un tronc de $2^{\text {m }}, 60$ à $3^{m}, 25$ de circonlirence. Son écorce est tonjours très unie et blanchatre; ses fenilles sont osales, luisantes, d'un vert clair, a peine dentées sur le bord. Les fleurs males forment des chatons arrundis, longuemrnt pédonculés et pendants; les fleurs femelles sont réunies deux enseinble daus un inrolucre à 4 lobes et hér issé; chacune d'elles se compose d'un ovaire infere conronné par les dents du calice "t termine par 3 stigmates. Les fruits sont des balanes cartilagineux, triangulaires, monospermes, renfermés an nombre de denx, comme les fleurs dont ils proviennent, dans l'involncre accru, hérissé de pointes, s'ourrant supérieurement en 4 lobes.

Le fruit du hetre porte te nom de fuine. 1) le recueille daris les forèts pour en retirer l'huile par expression. Conte luile est d'un janne clair, inodore, fade, très consistante, d'une pesanteur spéciligue de 0,9225 . Elle est très usitée dans l'est die la france comme aliment "t pour l'éclairage. Le beis de hêtre est blanc, tenace, flexible, et tries usité pour faire des meubles, des bois de lit, des brancards, des instruments de labourage, des rames, des pelles, des barpuets, des sabots, etc. Employé comme buis de: chanflage, il brùle plus vite que le chêne, mais il produit une chaleur plus vive; ses copeaux servent a clarifier le 


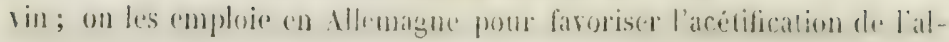
cool.

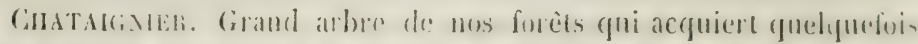
une grosseur prodigiense et dom on ne peut fiser la durée. On en eonmat wn en France, pres de Sancerre (Cher), gui a plus de lo metres de circonférence, à hauteur d'homme, et andulal on suppose 1000 ans d'age. J.'Etna en nomril un grand nombre dont quelpures uns ont de 12 a 1:) metres de circonférence; 10 al antre en a 25 metres; mais le phas

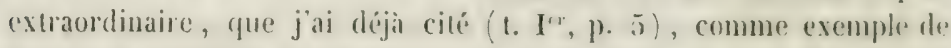
la grande longevité des régétaux, est celui décrit par Jean Iloucl, en 1776, qui arait alors 175 pieds de circonférence $\left(56^{1:}, 75\right)$, et ampuel on ne peut pas altribuer moins de 4000 ans d'existence.

I.e chataignier portr des fenilles alternes, oblongues-lanciolées, piliolées, longues do los à 19 continètres, fermes, Inisantes, hordées de grandes dents ainnës. I.es fleurs males sont disposées an chatuns filiformes interrompus, el sont composés d’un perianthe a jom o divi-

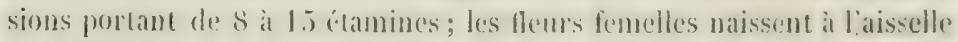
des fenilles ou à la hase des chatoms males. Elles sont renfermées, an

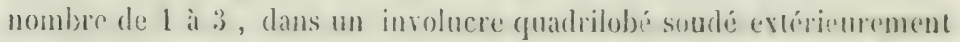
anec de nombreuses bractées lincides. Eilles sont formés d'un perianthe soudé arec l'ovaire, rélréci smpérjeurement el s’érasa l ('n un limbe à $5-8$ divisions portant des étamines arortées, mais quelyuefois lertiles; alors les fleurs sont hermaphrodiles. L'onare est termini par

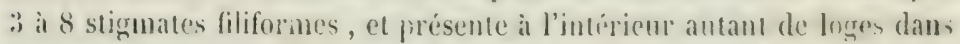

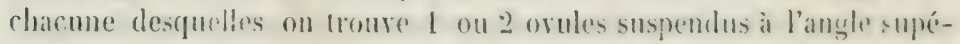

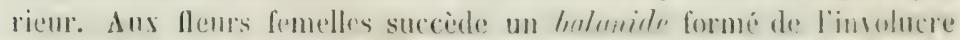

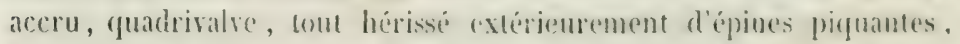

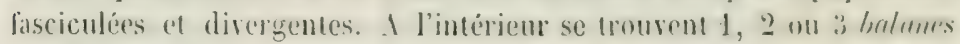
nommés chrifreigmes ou mommes, suivant la raviélé, compqosés d’un épicarpe cartilaghnen encore surmonte du limbe du calice el des styles, al contenant a l'inferieur une seule semence an sommed de latpurle se

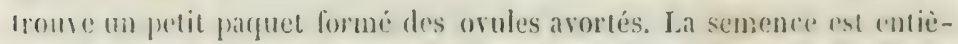

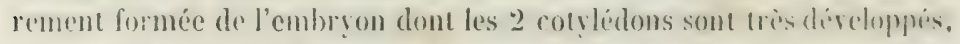

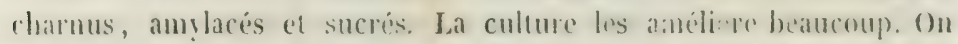

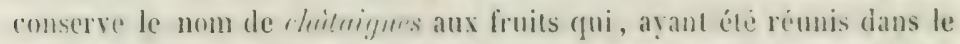
meme involuere, sont aplatis d'un còté el conreses dr l'antre. On les mange ordinairement cuits dams l'ean, on on le's fait sicher pum les

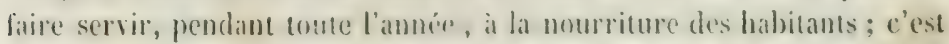

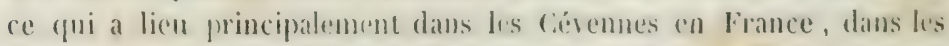

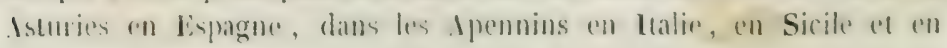
(iorse.

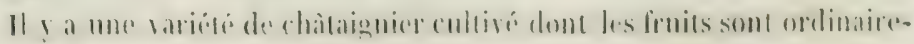


ment isolés dans l'involucre et qui sont alors plus gros et arrondis. On les nomme marrons et on les mange surtout rôtis ou confits au sucre. Les plus estimés viennent du département de l'Isère et des environs de Luc dans le département du Gard.

CHEnes. Arbres ou arbrisseaux à feuilles alternes, simples, entières ou, le plus sourent, incisées ou lobées. Les fleurs màles sont pourvues d'un périanthe à 6 -s dirisions et portent de 6 à 10 étamines; elles forment des chatons filiformes, grêles et interrompus, pendants, qui sortent de l'aisselle des feuilles inférieures. Les fleurs femelles, solitaires ou portées en petit nombre sur un pédoncule commun, sont placées dans les aisselles des feuilles supérieures. Chacune d'elles est entourée d'un involucre hémisphérique, sondé extérieurement arec des bractées écailleuses, très petites et imbriquées; le périanthe est soudé avec l'ovaire et terminé par 5 petites dents supères; l'ovaire est à 3 loges contenant 2 ovules suspendus a l'angle interne et supérieur; il est terminé par 1 stỵle très court, divisé en 3 stigmates étalés. Le fruit, nommé gland ou balame, est cntouré par le bas de l'involucre persistant et accru, et se compose d'un péricarpe coriace terminé par les petites dents du calice, et contenant une seule graine privée de périsperme, à cotylédones charnus.

Les chênes appartiennent exclusivement aux zones tempérćes; on en connaît environ quatre-vingls espèces, dont une moitié appartient à l'ancien continent et l'autre au noureau. Deux de ces espèces forment la base de nos forêts. Limné les arait réunies en une seule, sous le nom de quercus robur; mais on les a séparíes de nouveau. A la première appartient le véritable chine rouere, quercus rolum W. (quercus sessiliflora Lamk.), qui s'élère à 20 mètres et all-delà, sur un tronc de 2 à 4 mètres de circonférence. Ses feuilles sont caduques, pétiolées, ovales-oblongues, sinuées on bordées de lobes arrondis; les fleurs femelles et les fruits sont sessiles. Son bois est l'un des plus solides et de's plus durables parmi ceux de l'Europe; c'est également un des meilleurs pour le chauffage.

La seconde espèce est le cheine blane, ou gravelin, quercus pethunculatu IV. (\%. racemosa Lamk.), dont le tronc est plus droit, plus élevé, et le bois moins noueux et plus facile à travailler; ses feuilles sont presque sessiles, luisantes en dessus, un peu glauques en dessous; ses fleurs femelles sont sessiles, au nombre de 4 ì 10 , le long d'un pédoncule commun.

L'écorce de chêne varie selon l'àge de l'arbre : lorsqu'il est vicux, elle est épaisse, raboteuse, noire et crevassée au dehors, rougeâtre en dedans; lorsqu'il est jeune, elle est moins rude ou presque lisse, courerte d'un épiderme gris-bleuâtre diversement dessiné; d'un ronge 
pâle, ou pressque blanclie à l'intérieur. Alors aussi, elle est bien plus riche en principe astringent, et jonit d'une odeur fade particulière, qui est celle que l'on sent dans les lanneries. Cette écorce, séchée et réduite en poudre, prend le nom de tan, et sert à tanner les peaux. On l'emploie aussi en médecine comme un puissant astringent.

Les glands renferment une grande proportion de fécule, et sont recherchés comme nourriture par plusieurs animaux, et surtout par les cochons. Leur ìpreté les rend impropres à la nourriture de l'homme. Ce n'est pas qu'au moyen de quelques traitements chimiques on ne puisse leur cnlever leur principe astringent, et en obtenir tune fécule aussi donce que beancoup d'autres; mais le prix alor's en derient trop) éleré, et jamais ces tentatives n'ont eu de résultat suivi.

Quant à l'opinion si généralement répandue que les glands ont servi de nourriture aux hommes dans les temps qui ont précédé leur civilisation, il faut remarquer d'abord que les anciens dommaient le nom de lralanos ou de glands à la plupart des fruits des arbres des for èts, comme le hêtre et le noỵer; ensuite que plusieurs chènes des pạ̣s méridionaux ont des glands doux et sucrés qui servent encore aujourd'hui à la nourriture des habitants : tels sont le chêne-liége (tuuercus suber), le chêne-yeuse (quercus ilex), et surtout le chêne - ballote (quricus bullota).

Les glands ordinaires sont quelquefois prescrits, torréfiés, pour remplacer le café, aux personnes forcées de suspendre l'usage ca'elles en font habituellement. C'est, sans contredit, une des substances qui simnle le mieux le café, et il est étonnant que l'emploi n'en soit pas plus répandu.

Fig. 134.

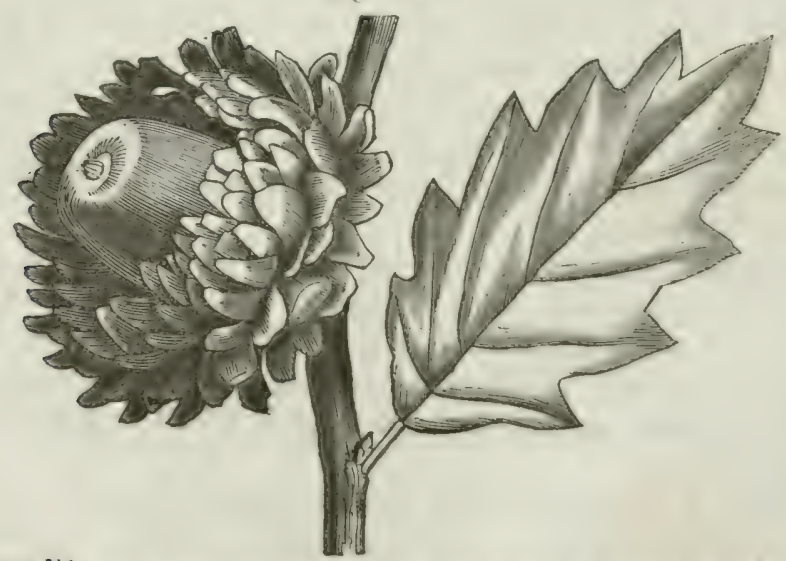

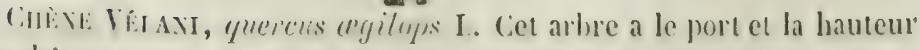
du chène rouvre. Sez feuilles sont longues de so millimèles, larges 
de 55 , pétiolées, bordées de grosses dents, dont clacune so termine par une pointe aiguë. Ces mèmes feuilles sont vertes en dessus, blanchàtres et cotonneuses en dessous. Les fruits sont très gros, courts, déprimés au sommet, profondément enfoncés dans une énorme cupule dont les écailles sont libres à leur partie supérieure, et étalées ou hé. rissées (fig. 131). Ce chène croìt en Sicile, dans les îles Grecques et dans la Xatolie. On fait un commerce assez considérable de ses fruits, ou plutôt de ses cupules qui en forment la partic principale, pour la teinture en noir et le tannage des peaux. On leur donne le nom de vélnvicle, ou d'arelanide, el sourent aussi celui de gallon du Leverut, gullom de Tiurquie.

CHêne-Liége, que'cus suber' L. Les feuilles de cet arbre sont ovalesoblongues, indivises, dentées en scie, cotonneuses en dessous et persistantes. Il croìt en Espagne, en Italie et dans nos départements méridionaux. Il se distingue des autres espèces par le développement extraordinaire qui s'opère dans les couches sous-épidermoïlales de son écorce, qui devient très épaisse el fongucuse, et constitue le liége. Il commence à en fournir à l'itge de quinze ou seize ans, et il peut en donner de nouvelle tous les six à huit ans, jusqu’à cent cincuante ans, sans périr. Lorsque, par des incisions transrersales (t longitudinales, on a obtenu le lićge en grandes plaques cintrées, on le chauffe et on le charge de poids pour le redresser; alors on le fait sécher très lentement, afin de lui conserver sa flexibilité. On doit choisir le liege épais, llexible, élaslique, d'une porosité fine, d'une couleur rougeâtre, non ligneux dans son intérieur.

En Espagne, on brùle les rognures de liége dans des rases clos, et on en retire un charbon très noir et très léger (qui est usité en peinttre.

Le liége a été regardé, pendant quelques années, comme un principe immédiat anguel on donnail le nom de sulve', mais il est évident qu'une partie d'écorce n'est pas un priacipe immédiat. Tunt ce gu'on peut dire, c'est que la majeure partic du liége est un corps particulier, analogue au ligneux, mais en différant en ce que, traité parl l'acide nitrique, il donne naissance à un acide particulier qui a été nommé aride suberique.

On doit à M. Cherreul une analysse du liége. Cette substance a d'abord perdu 0,04 d'ean par la dessiccation. Traitée ensuite par l'eau dans le digesteur distillatoire, elle a fourni à la distillation une petite quantité d'huile volatile et de l'acide acétinne. La liqueur restant dans le digesteur a donné un princigre colurent june, un principe astringent, une matière animalisée, de l'acide gullique, un autre acide, du gallate de fer, de la chaux, en tout 0,1425 ; la partie insoluble dans l'eau, ıraitée par l'alcool, lui a cédé les mêmes principes que ci-dessus, plı 
une matière analogne à la cire, mais cristallisable, qui a été nommée cérine; une résine molle que II. Cherreul croit être une combinaison de cérine avec une autre substance qui l'empêche de cristalliser; drint: metres matières paraissant encore contenir de la cérine unie à des principes non déterminés : en tout 0,1575. Le liége, épuisé par l'eau ct l'alcool, différait peu du liége maturel : il pesait 0,70 ( $1 \mathrm{~mm}$. de 1 'him., t. X(CI, p. 115). ('est à cette partie, supposée entièrement privée de ses principes sulubles, que l'on peut appliquer le nom de subriviur.

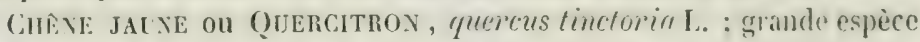
de chêne qui croît dans les forêts de la Pensylranie. On se sert de son écorce pour tanner les peaux; mais on en exporte aussi une grande quantité en liurope, à cause de sa richesse en un jurincipe colorant jaune que l'on peut substituer à celui de la gaude. Cel arbre parât se naturaliser au bois de Boulogne, près de Paris, oì, en 1818, on en a fait un semis considérable. Ses fenilles sont orales-oblongues, sintées, pubesrentes en dessous, partagées en lobes anguleux et mucronés.

CHì AU heruies, querrus cucrifera L.; arbrisseau it feuilles orales, coriaces, persistantes, glabres des deux côtés, bordées de petites dents épincuses. Les chatons mâles sont réunis plusieurs ensemble en petites panicules; les fleurs femelles sont sessiles et en petit nombre le long d'un pédoncule conımun. Les glands, qui ne mùrissent que la seconde année, sont à moitié enfoncés dans une cupule hérissée d'écailles cuspidées, étalées et un peu recourbées. Cet arbrisseau croît dans les lieux arides et pierreux du midi de la France, en Espagne, en Italie et dans le nord de l'Dfrique. C'est sur lui que vit le liermès, petit insecte hémiptère du genre des cochenilles, et nommé coccus ilicis, l'arbre aỵant été regardé anciennement comme une espèce d'yeuse et ayant porlé le nom d'ilex coccigera.

Chine a ta galde ou Chìne des teintuliens, queidus infectoria Olivier ( fig. 135). C'est à Olivier que nous derons la connaissance de celte espèce qui est répandue dans toute l'Asie-Mineure, juscu'aux frontières de la Perse, et qui nous fournit l'excroissance nommée noic de yalle, ou gralle du Levont. C'est un arbrissean tortueux, haut de $\mathrm{y}^{\mathrm{m}}, 30$ à $1^{m \prime}, 60$, à feuilles oblongues, mucronérs-dentécs, luisantes en dessus pubescentes en dessous, portées sur des pétioles longs de 13 à 18 milmètres. Les glands sont allongés et sessiles.

Cet arbre sert d'habitation à un insecte hyménoptère et pupirore nommé cynips guller tinctorice, dont la femelle perce les bourgeous it peine formés des jeunes rameaux, ì l'aide d'une tarière dont son abdomen est pourvu. Elle dépose un ouf daus la blessure, et bientôt le bourgeon, dénaturé par la présence de cet ouf, se cléreloppe d’une manière particulière, et forme un corps à peu près sphérique qui ne 
retieut plus de sa forme primitive que des aspérités dues aux extrémités des écailies sondées. L’euf, ainsi renfermé, éclot, et l'insecte passe

lig. 133.

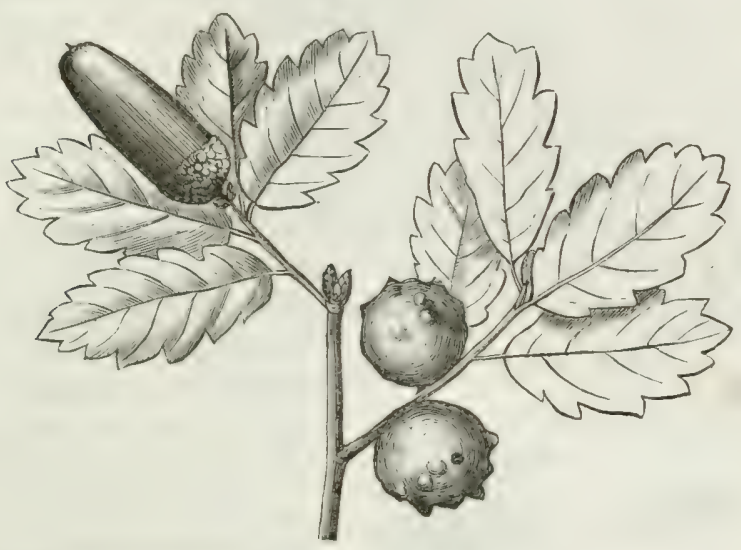

par les états de larve, de nymphe el d'insecte parfait; alors il perce sa prison et s'enrole.

1. La noix de galle nous est apportée surtout de la syrie et de l'dsieIlineure. La meilleure porte dans le commerce le nom de galle noire, ou de galle verte d'Alep, à cause de sa couleur et parce qu'elle vient des environs d'Alep en Sịrie. Elle est grosse comme une noisette ou une aveline, d'me conleur verte noiràtre ou verte jaunâtre, glauque; elle est compracte, très pesante et très astringente ; elle doit en partic ces propriétés au soin qu'on a eu de la récolter avant la sorlie de l'insecte; car les galles que l'on oublie sur l'arbre, et qu'on ne cucille qu'après, sont blanchâtres, légères, peu astringentes, et se reconnaissent d'ailleurs au trou rond dont elles ont été percées par l'insecte. Elles forment, sous le nom de galle blanche, une sorte du commerce bien moins estimée que la première.

Ia galle de Sinyrne, ou de l'Asie-Mlineure, differe peu de celle d'Alep; cependant elle est généralement un peu plus grosse, moins foncée en couleur, moins pesante et plus mélangée de galles blanches. Elle eșt moins estimée pour ceux qui la connaissent; mais, la plupart du temps, elic est vendue comme galle d'Alep) aux débitants et au public.

On sait qu'on donne, en général, le nom de galles à des excroissances ou tumeurs qui se déreloppent sur toutes les parties des végélaux , par suite de la pirgûre d'insectes de différentes familles, mais qui sont principalement des cymijs de la famille des hyménoptères, et des pucerons (aphis) de celle des hémiptères. Il ! a peu de végétaux qui ne 
présentent de ces dirgénérescenres de tissu, dont les plus communes ont été observérs sur l'orme, les peupliers, le bonleau, les pins et les sapins, l'églantier, le chardon hémorıhoïdal, la sange, le chamedris, le lierre terrestre, or. Cre qu'il ! a de bien particulier, c'ent que, suivant la remarque de Réaumur (t. III, 12 e mémoire, p. 119), l'espice de l'insccte influe beancoup sur la forme et la consistance de la galle, quoigu'on ne roie pas de quelle manière cela puisse aroir lieu. Ainsi, de plusieurs galles formées sur une même feuille par différents insectes, les unes seront constamment ligneuses, les autres spongieuses, et toutes auront de; formes différentes et spéciales. J'ai fait à cet éggard ine ob)servation encore plus singulière : ayant analysé la galle d'slep, et y ayant trouré de l'amidon, dont la présence avait échappé jusque-là aux

Fig. 136.
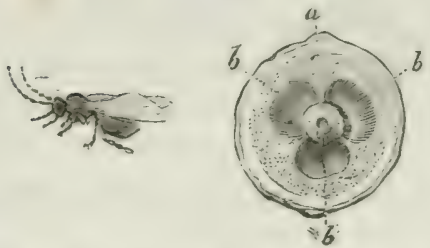

chimistes, j’ai désiré connaître le siége de ce principe dans la noix de galle. On sait que cette production présente au centre une petite carité où a été déposé l'œuf du cynips (fig. 136, lettre $a)$. L'enveloppe immédiate de cette cavité constitue une pe-

tite masse spherique, un peu spongieuse, d'une couleur faure on brunâtre dans sa masse, mais blanche à sa surface; et tout autour de cette petite sphère on troure une snbstance plus étendue, compacte, à structure radiée, laquelle paraît formée, à la loupe, de particules brillantes et transparentes. Enfin, tout à fait à l'extérieur, se troure une envoloppe verte contenant de la chlorophrylle et de l'huile volatile.

J'ai fait tremper plusieurs fois de la noix de galle, cassce par morceaux, dans l'eau, pour la prirer de ses principes solubles, et je l'ai recouserte d'un soluté d'iode : la seule partic qui ait paru se colorer en bleu foucé est la petite sphère intérieure spongieuse; le tissu rayonné n'a éprouré aticune coloration. A yant donc mis à part la petite sphère spongieuse, je l'ai écrasée dans un verre arec un peu d'eau, et ayant examiné la liq̨uen trouble au microscope, après y aroir ajouté de l'eau salurée d'iode, j’y ai ubsrré une très grande quantité de granules d'amidon, sphériqu:s, ovales ou triangulaires, d'un bleu trìs foncé. Les granules l'emportaient de beaucoup en guantile sur les débris du tissu qui le's contenatent, de sonte qu'on peut dire que la petite sphère qui entoure immédiatement la larre de l'insecte est principalement composée d'amiclon.

Ayant, an contraire, écrasé dans l'ean la matière raỵonnée qui cntoure la première, je n'ai pu y observer que dos flocons informes de tissu déchiré et des particules isolies, très petites, mais solides, épaisses, 
anguleuses, transparentes et incolores, malgré l'addition de l'iode; d'où il suit que la seule partie de la mois de galle qui contienne de l'amidon est la petite sphère centrale où se tronte nichép la larre du cỹnips.

Cette disposition waiment remarquable semble indiquer un rapport encore inconnu et peu compréhensible entre l'action vitale du chêne à la galle et celle de l'œuf animal yui s'y troure déposé.

On conçoit, en effet, jusqu’à un certain point, que l'instinct de l'abeille la détermine à remplir ses ravons du miel qui doit nourrir la génération destinée à perpétuer son ripece, et que les frmelles des autres insectes déposent généralement leurs œufs à portée des matières qui doirent servir à la nourriture des larres (jui en sortiront; mais en vertu de quelle loi l'anidon, qui n'existait pas cn quantité appréciable dans le bourgeon du chêne, s'y forme-t-il après l'introduction de l'oul, et rient-il s'amasser uniquenent autour de la larve du cynips, comme dans le double but de la protéger contre l'action du tannin et de lui servir de nourriture? Il y a là une canse occulte qui vaudrait la peine d'être recherchẻe.

J'ai fait récemment une autre observation du même genre que la précédente. Beaucoup de galles, même parmi celles qui croissent sur le chêne, sont d'une texture lâche et poreuse, ou présentent des conduits qui permettent à l'air de pététrer jusqu'à l'insecte; mais la galle d'Alep est tellement dure, compacte et privée de tonte onserture extérieure arant la sortie de l'insecte, que je me stuis longtemps étonné qu'un être pût y respirer. Or, j'ai découvert dernièrement, dans un grand nombre de galles d'Alep, et principalement autour de la petite masse sphérique amylacée, des cellules (fig. 136, lettre 1) (qui paraissent formées par l'écartement ou le dédoublement d'écailles conchoüdes charnues, et qui doivent servir à la respiration de l'insecte. Le bourgeon de chêne, après aroir reçu l'œuf, paraît donc s'organiser de manière à fournir à l'insecte la nourriture et l'air qui lui sont indispensables.

Les chênes produisent un grand nombre d'espèces de galles dont plusieurs se trouvent dans le commerce.

lig. 137 .

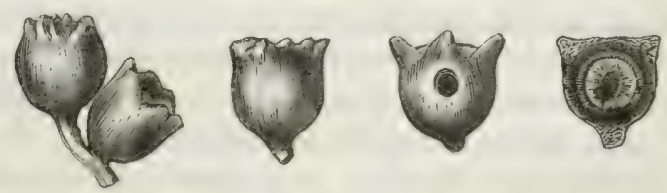

2. Petite galle couronnéc d'Alop) (fig. 137). Cette espèce se troure mêlée à la galle d'Alep et doit provenir de la piqûre des bourgeons terminaux à peine déreloppés, par un cynips. Elle est grosse comme un 
pois, courtement pédiculée par le bas, couronnée supérienrement par un cercle de pointes disposées comme la comronne d'un fruit de myrte ou d'eugenia. L'intérieur est formé de quatre couches concentriques rayonnés, dont la plus intérieure seule est amylacée. Au centre se troure une cavité unique. Cette galle ne peut pas être prise pour une jeune galle commune d'slep, parce qu'elle est souvent percée d'un trou trìs large qui indique qu'elle est parvenue à toute sa grosseur.

3. Gulle marmorine. Cette galle rient du Levant; elle est d'un gris peu foncé, jaunâtre ou rougeâtre, ayant de 10 à 15 millimètres de diamètre. Elle est presque sphérique, seulement un pen allongée en pointe du côté qui forme le pédicule, à peine marquée d'aspérités et cependant à surface rugueuse. Elle a une cassure uniformément rayonnée et d'un jaune prononcé. La couche amylacée cst très mince, rayonnée et peu distincte de celle qui l'entoure; la cavité centrale est spacieuse et régulière.

4. Galle d'Istrie. Petite galle globuleuse de 9 à 12 millimètres de diamètre, allongée en pointe du côté du pédicule, généralenent d'une couleur rougeâtre, prirée d'aspérités pointues, mais profondément ridée par la dessiccation. Elle est très sourent percée et vide d'insecte. La cassure en est rougeâtre, rayonnéc, assez compacte; la couche amylacée peu distincte; la carité centrale raste et régulière. Celte galle est peu estimée.

5. Gallon de Hongrie ou du Piémont (fig. 138). C'est une excroissance très irrégulière qui provient de la piqûre faite par un cỵnips à la cupule du gland de chêne ordinaire, quercus robur $\mathrm{I}_{\text {., }}$, après que l'ovairc a été fécondé. Cette excroissance, qui part le plus sourent du

Fig. 138.

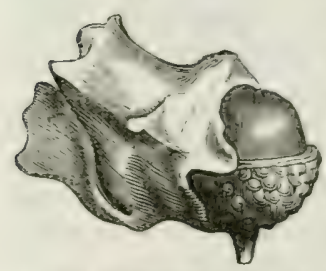
centre même de la cupule, s'élève d'abord sur un pédicule qui n'empêche pas tonjours le gland de se développer à côté; mais sourent aussi l'excroissance remplit toute la cupule, déborde par dessus de tous les côtés et la recourre à l'extérieur. Cette galle présente, au centre d'une enveloppe ligneuse, une carité unique prenant de l'air par le sommet, contenant une corque blanche qui a dû servir aux métamorphoses de l'insecte, etrenfermant quelquefois le cynips lui-même, pourvu de ses ailes. Il ne fitut pas confondre cette excroissance arec la suirante, qui s'y troure mćlangée, mais dont la nature est bien différente.

6. Galle corniculéc (fig. 139). Je présume que cette galle est celle que Réaumur a figurée planche 44, fig. 5 , et qu'il a confondue à tort avec la galle en artichout (planche 43, fig. 5). Elle est généralement comme assise par le milieu sur une très jeune branche, et comme for- 
mée d'un grand nombre de cornes un peu recourbées a l'extrémité. Elle est jaunatre, ligneuse, ligère, creusée à l'intéricur d'un grand nombre de cellules entourées chacune d'une couche de substance rayonnée, s'ouviant toutes à l'extérieur par un trou particulier et chacune ayant servi de demeure à un insecte.

7. Gulle en urfichunt (fig. 140); Réaumur, pl. 43, fig. 5. 'Celte galle, assez commune sur le chêne rourre de nos contrées, ressemble à des cônes de houblon. Elle provient du déreloppement anormal de l'involucre de la fleur femelle avant la fécondation. 'Telle que j'ai pu l'observer, après l'aroir ouverte longitudinalement on deux parties, elle est formée inférieurement d'une sorte de réceptacle ou de thorus ligneux qui provient du déreloppement contre nature de la base même de l'invoJucre. Réaumur a comparé avec raison cette partie au cul de l'artichaut (fig. 141). Ce thorus se relève un peu en forme de coupe sur le bord et présente deux sortes d'appendices. Ceux qui garnissent l'extérieur ne sont autre cliose que les écailles Fig. 139.
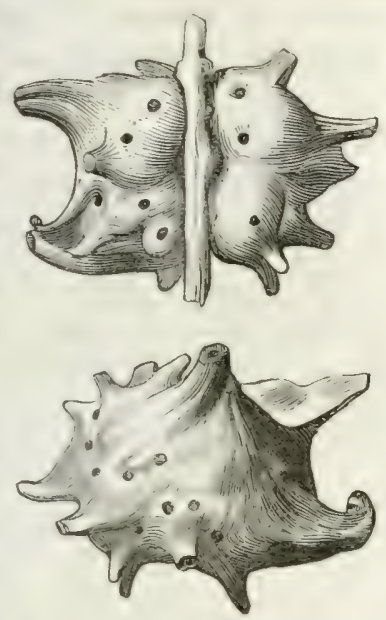

de l'involucre, développées et restées libres, un pen épaissies el velues sur leur milieu, amincies et transparentes sur le bord, lequel présente quelquefois la dentelure lobée de la feuille de chêne. Ce développement anormal montre bien que lés écailles de l'involucre du chêne ne sont que des bractées ou des feuilles arortées. Quant aux appendices qui se sont développés sur la surface supéricure du thorus, et qui ressemblent à de longues paillettes soyeuses de synanthérées, le germe en existait sans doute à la surface interne de la cupule qui embrassait l'ovaire. L'ovaire manque quelquefois; mais le plus sourent je l'ai trouvé resté stationnaire sur le milieu du thorus et parfaitement intact. Il est indubitable que le développement de cette galle a dû être précédé de la piquure d'un cynips, et Réaumur dit aroir observé dans le thorus direrses cavités dont chacune servait de logement à une larve, el dans le pistil également une ou plusieurs cavités dont chacune est occupée par un insecte. Je n'ai ru ni les unes ni les antres. Je rappelle d'ailleurs que l'insecte décrit par Réaumur comme produisant cette galle pourrait bien appartenir à la précédente. 
8. Galle roude de liyeuse, yulle de Fromere ( fig. 14.2). Cette galle se trouve dans le commerce. Lille est parfaitement sphérique, arec un diamètre de 19 à 22 millinètres. Elle est tantôt entièrement unie à sa surface et d'autres fois légerrement inégale et ridée comme une orangette. Elle est très légère, d’un gris verdàtre ou un peu rougeâtre. Il est

Fig. 140.

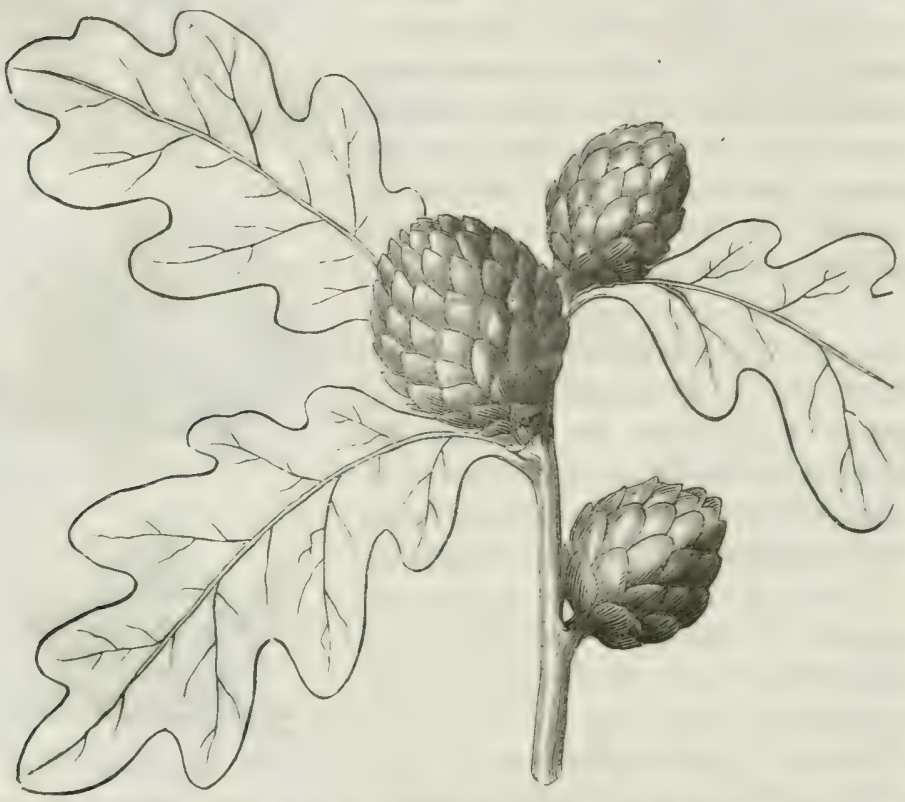

difficile d'en trouver qui ne soit pas percée. Elle offre une cassure rayonnée, uniforme, spongieuse, d'une couleur brunâtre toujours assez foncée, excepté la couche la plus intérieure qui est plus dense et blanchâtre, sans cependant ètre amỵlacée. L'insecte lui-même, que j'ai

Fig. 141.

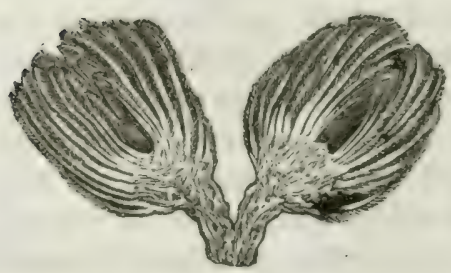

Fig. 142.
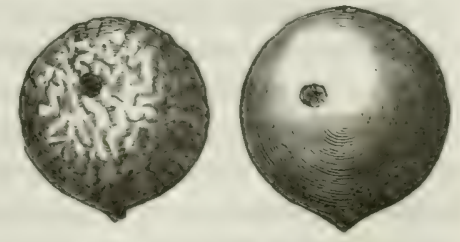

rencontré une fois, est d'un ronge brun. Cectte galle vient sur le querrus ilex, dans le midi de la France et en Piémont. On la troure aussi, en 
certaine quantití, dans la galle de Smyrme; mais je ne puis dire si elle est originaire d'Asie, on si elle y a été mélangée en France. Cette galle a beaucoup de rapport arec la strirante; je présume que sa seule différence tient à l'espèce de chêne qui l’a portée.

9. Gralle roude du chine ruure (fig. 143); galle du pritiole de chène, Ríaumur, pl. 41, fig. 7. Cette galle croît sur les jeunes rameaux du chêne rourre, aux environs de Paris, et sur le chêne tauzin (quermes pyprenuica) auprès de Bordeaux. Elle est sourent rapprorhée, au nombre de 4 ou 5 , à l'extrémité des rameaux. Elle est parfaite-

Fig. 143.

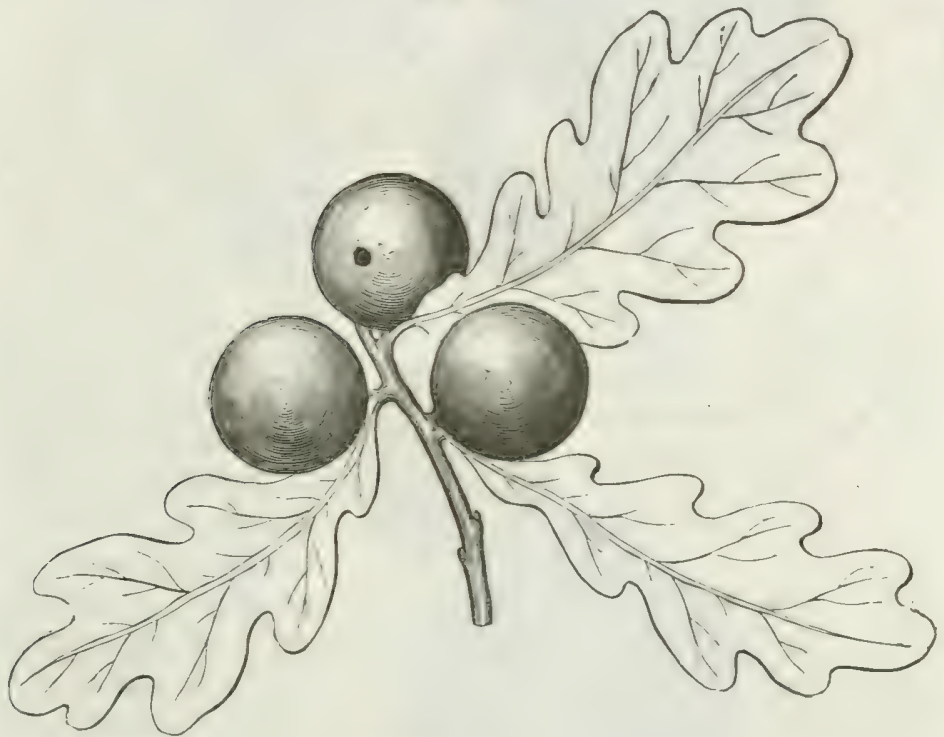

ment sphérique, de 15 à 20 millimètres de diamètre, très unie, d'une couleur rougeàtre, légère et spongiense. La cavité centrale est tantôt unique et ne loge qu'un insecte, tantôt divisée en 3 ou 4 loges - dont chacune contenait un cynips.

10. Crulle ronde des fmilles de chine. On troure sur les feuilles de nos chênes un grand nombre de galles de diverses natures, dont deux, entre autres, qui ont été décrites par Réaumur sous les noms de grulle en cerise et grulle en grorin de groseille (fig. 144 et 145). Ces deux galles sont de même uature, mais de grosseur bien différente. Elles sont sphériques, lisses, d'un beau rouge et succulentes à l'état récent, ct se rident considérablement par la dessiccation. Desséchées, elles sont spongieuses et très légères ; elles ne présentent qu'une cavité 
centrale. Elles sont complétement délaisscées, ainsi qu'une galle des chatons milles, éparse sur le rachis, que je passe sous silence.

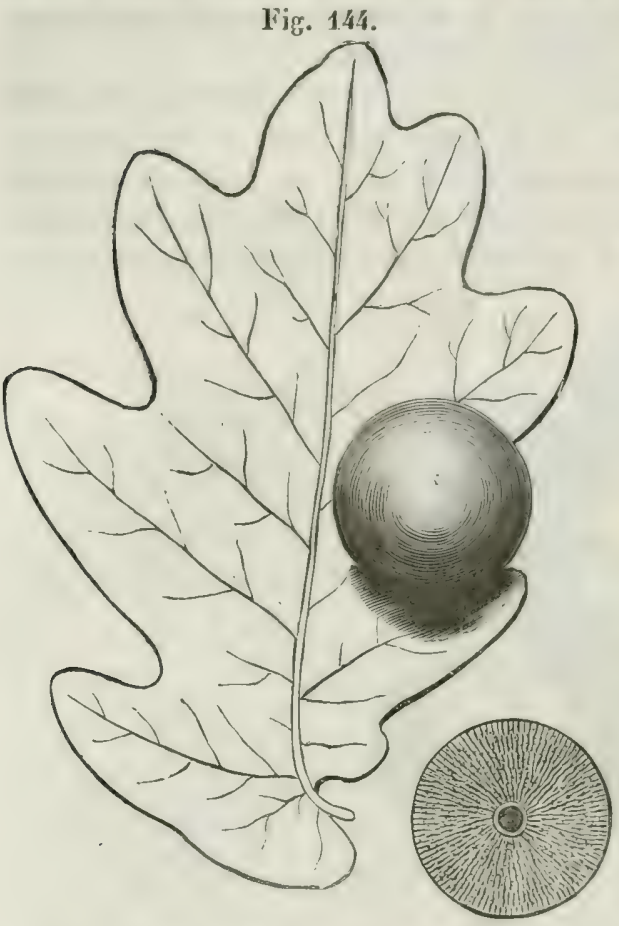

11. Pomme de chêne. Réaumur a décrit sous ce nom une galle terminale, conme didyme et à plusieurs loges, que je n'ai pas été à même d'observer, et rui n'est pas la galle à laquelle on donne généralement le nom de pomme de chêne. Celle-ci, la plus rolumineuse des galles de chêne, est commune dans les environs de Bordeaux, dans les Landes et dans les Pyrénées, sur le chêne tauzin, quercus pyrenaica. Sous le nom de ouk apple, elle est également bien connue en Angleterre, où ello croît sur le quercus pedunculata. Enfin la fi-

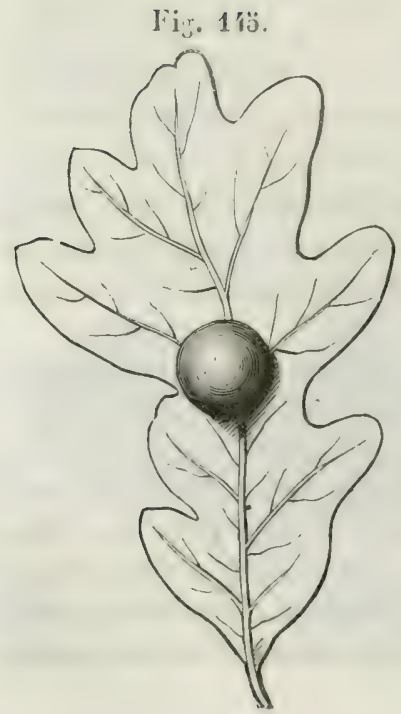
gure donnée par Olivier du quercus infectoria (Voyage, pl. 15) porte à la fois de la noix de galle ordinaire et une pomme de chêne. Cependant ces galles ne sont pas parfaitement semblables. La pomme de chêne figurée par Olivier est complétement sphérique et porte une couronne de pointes vers le milieu de sa hauteur ( fig. 146). Les pommes de chêne de Bordeaux sont ou sphériques ou oroïles et portent leur couromne vers l'extrémité supéricure (fig. 147). En roici d'ailleurs la description plus détaillée. Cette galle est sphérique ou ovoïde, de la grosseur d'une petite pomme on d'un petit œuf de poule ( 35 à 40 millimètres de 
largeur sur 35 à 50 millimètres de hauteur). Sa surface est parfaitement unic, sauf, rers la partie supérieure, une couronne de 5 à 6 pointes dont quelques unes sont doublées, et une petite éminence

lig. 146.
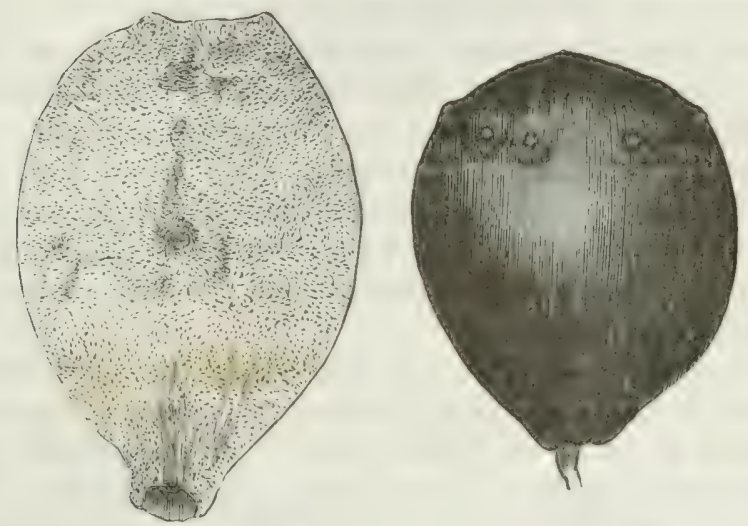

centrale crense et à bords repliés en dedans. On peut remarguer, ì ha base, gue le pédoncule est aussi rentré en dedans et est en partie recouvert par la turgescence de l'enveloppe. La disposition et le nombre des pointes supérieures paraît d'ailleurs indiquer que celle galle provient du développement monstrueux de la fleur femelle piquée avant la fécondation; à l'intérieur, celte galle est d'une texture spongieuse uniforme, et elle devient très légère par la dessiccation. Tout à fait au centre se trouve une coque unique, blanclie, ovale, dont j'ai retiré quelquefois l'insecte vivant, peu de temps après avoir recu Fig. $14 \%$.

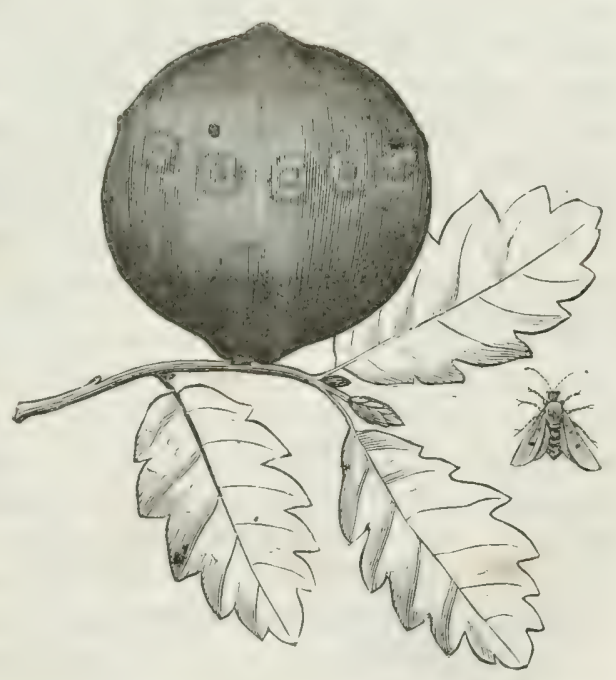
cette galle de Bordeaux, d'où elle sn'arait été envoyéc par M. Magonly. C'est une chose smerenante d'abord de roir sortir du cencre d'une 
masse solide et parfaitement close, de 18 à 20 millimètres de raỵon, un insecte qui après un moment d'exposition à l'air commence à remuer les pattes, nettoie ses ailes et tente de s'envoler; mais j'ai reconnu ensuite qu'il existait à partir du pédoncule jusqu'à la coque un étroil conduit aérifère.

J'ai dit plus haut (qu'ayant longtemps cherché à comprendre comment l'insecte de la galle du Levant, renfermé au centre d'une masse dure et compacte, pourait y respirer, j'avais enfin observé dans l'intérieur des cellules pleines d'air qui pouraient servir à cet usage. L'ne autre observation qui est commune aux autres galles, c'est que lant que l'insecte Y est enfermé, la galle du chêne tauzin offre une couleur rougreâtre et rerdàtre, et une surface luisante qui indiquent qu'elle participe à la vie de l'animal; tandis qu'après sa sortie, elle prend une couleur terne et grisâtre et semble mourir.

Tature chimique de la noix de galle. On savait depuis longtemps que la noix de galle contenait en abondance un principe astringent qui a reçu le nom de tamnin ou d'aride tamique, et que Berzélius paraìt avoir obtenu le premier à l'état de pureté. On sarait également qu'on retirait de la noix de galle, par divers procédés, un autre acide nommé aride gallique; mais c'est à $\mathbf{3 1}$. Pelouze que l'on doit d'aroir fait connaître un procédé (le traitement par déplacement, au moven de l'élher), qui permet de retirer immédiatement 35 à 40 prour 100 de tamnin de la noix de galle. Cependant je puis dire que la composition de cette singnlière production naturelle était encore loin d'être connue, non senlement parce qu'elle contient beaucoup plus de tannin qu'on ne l'annonçait, mais encore parce qu'elle renferme beaucoup d'autres principes dont l'existence y était ou contestée ou mẻconnue, tels sont de l'acide ellagique, un nourel acide aurguel $\mathrm{j}$ 'ai domné le nom de lutéogullique, de la chlorophylle, une huile volatile semblable à celle des myzica, de l'amidon, du sucre et divers autres dont je me borne à donner le tableau, renroyant pour le reste an Jémoire inséré dans la levue scientifique, 1. XIII, 1. 32.

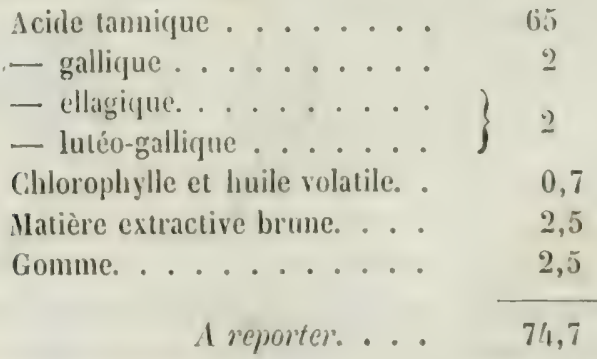




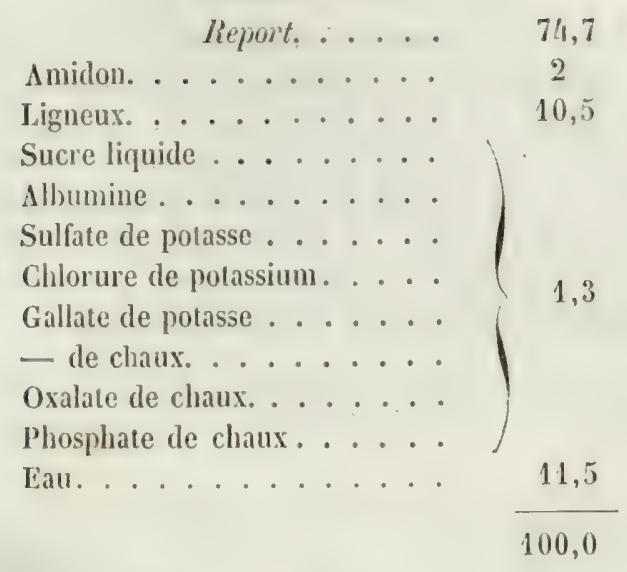

FAMILLE DES JUGLANDEES.

Arbres à fleurs monoïgues; fleur's miles en longs chatons axillaires, accompagnées d'une bractée écailleuse et composées d'un périanthe découpé en 5 un 6 lobes inégaux et concaves, et d'étamines nombreuses, insérées sur la nervure médiane du périanthe. Fleurs femelles tantôt rassenblées en petit nombre à l'extrémité des rameanx, tantôt disposées en épis lâches; composées d'un involucre et d'un périanthe soudés ensemble et arec l'oraire, mais chacun à limbe supère et quadriparti. Oraire infère contenant un seul orule dressé sur un placentaire central, d'où émanent 4 lames formant des cloisons incomplètes qui rendent l'ovaire guadriloculaire à la base; fruit charnu infère, indéhiscent, à noyau osseux (caryone), contenant une graine saus périsperme, à emibryon renrersé, pourru de z cotglédones épais, charnus, de furme irrégulière.

Les juglandées se distinguent de toutes les autres familles amentacées par leurs feuilles pinnées, yui scmblerairnt devoir les faire placer beaucoup plus hant dans la série des dicotylidonées. Aussi Jussieu les avaitil annexées aux térébinthacécs, place yui leur a été conservéc par 11. Endlicher. Cependant la disposition de leurs fleurs mâles, qui est exactement celle des cupulifères, ct la constitution des fleurs femelles et du fruit qui offre encore de très grands rapports arec les fleurs femelles et les fruits des myricu et des cusurminn, ont déterminé d'autres botanistes à ne pas séparer les juglandées des amentacées. Celte famille se compose des quatre genres carya, juglans, pterocarya, engelhardtia, dont le premier appartient exclusirement à l'Amérique septentrionale, et fournit des semences huileuses et comestibles que le commerce nous 
offre quelquefois sous le nom de nuis pacmes. Le genre juyluns appartient aussi principalement à l'Imérique septentrionale; mais il se recommande surtout par notre noyer commun, que la nature a séparé de ses congénères par un long espace de mers et de terres, en le faisant naître en Perse. Les entyellermollin sont propres aux contries méridiunales de l'Inde et aux îles de la Malaisie. Une de leurs espèco's fournit an commerce une résine, le dummer selem, dont les fabricants de rernis consomment aujourd'hui une énorme quantité.

\section{Noyer commun ( lig. 168 ).}

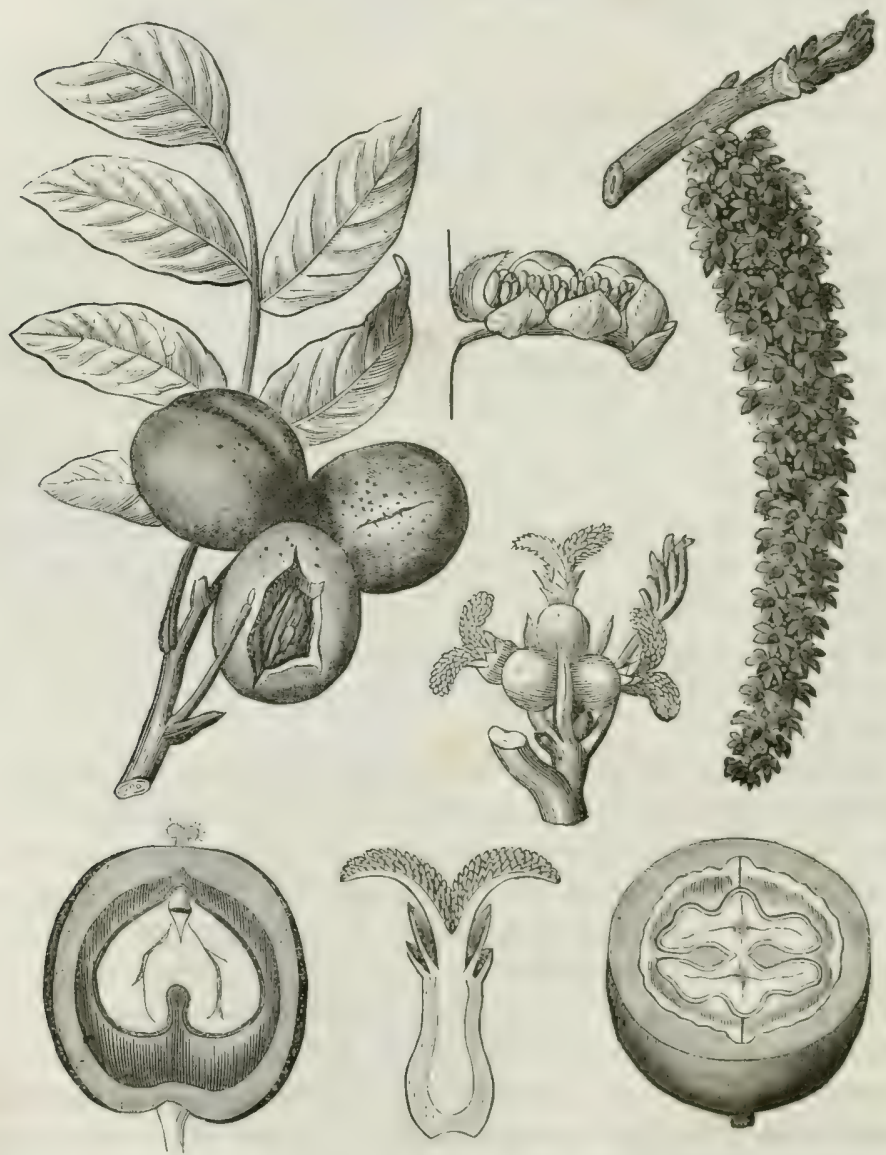

Juglans regia. Grand ex bel arbre originaire de Perse, mais cultive depuis si Iongtemps en Vurope, gu'on ne pent fiver l'épogue de son 
introduction. Le tronc est lisse et d'une couleur cendrée, dans les jeunes arbres; il se gerce avec l'àge et peut acquérir de 3 à h melres de circonférence. Les fenilles sont amples, ailées arec impaire, d'une odeur forte et agréable; les fleurs mâles sont portées sur de longs chatons simples; les fleurs femelles sont solitaires ou rémies en petit nombre à l'extrémité dés rameaux. I.e fruit, nommé noil', est un cary̧one globuleux, formé d'un sarcocarpe rort et succulent (broui) yui répond à l'inrolucre de la fleur; d'un endocarpe ligneux, sillonté ("i à 22 valies, qui répond au calice, et d'une semence dont l'amande huileuse est formée de 2 cotglédons très déreloppés, divisés en 14 lohes par le bas, et à surface très inégale figurant les circonvolutions du ccrveau.

La noix se sert sur les tables, ou non parfaitement mûre et portant le nom de cernecu, ou mùre et récente, on sèche. On rn retire par expression à froid une huile donce, très agréable et utilisée comme aliment. Cétte huile étant siccative est aussi très usitéc dans les arts; mais alors on l'exprime à chaud.

On connaissait anciennement en pharmacie une cau distillée aromatique nommée emu des trois noid, qui était faite en trois fois et à trois époupes différentes, arec les chatons en fleurs, arec les noix nonse'lement nouées et arec les noix presque mures. On emploie encore anjourd'hui les fenilles de noyer et le hrou de iovix, en decoction on an extrait, contre l'ictère, la syphilis, les affections scrofulenses. Ce's dirux parties régétales paraissent posséder les mèmes propriétés et les mêmrs principes, parmi lesquels il faut compter de l'huile volatile, du tamnin précipitant en vert les sels de fer (probablement de l'acide cachutiju(c), ct un autre principe âcre et amer, et très aride d'oxigène, qui lui communique une couleur noire et une complète insolubilité dans l'cau. (.'est à cette matière que le brou de noix doit a propriécé de teindre d'une manière presque indélébile les doigts el l's lissus.

L'écorce interne du noyer commun passe pour être purgative, âcre ('t mème résicante; mais ces propriétés sont beaucoup plus marquées dans l'écorce du juglens cinerea de l'I mérique septentrionale. Par un contraste assez marqué, ces deux arbres sont remplis d'une sève abondante et sucrée qu'on peut en extraire en perçant le tronc arec une tarière, jusqu'au centre, ainsi yu'on le pratique pour l'érable à sucre: le liqunide évaporé fournit du sucre cristallisable; mais cette opération nuisant à la récolte des fruits, il ne paraît pas cqu'il y ait de l'arantage it la pratiquer. Enfin, tout le monde coniâit l'usage qu'on fait du bois de noyer pour meubles, à cause de son grain fin, de son beau poli et de sa couleur inégalement bistrée. 


\section{Dammar selan on Dammar frJable.}

Vers l'année 1835 , je vis pour la première fois, chez plusieurs commerçants, à Paris, une résine venue de Marseille sous le nom de ropual tendre de vubie. Elle était en grosses larmes arrondies ou allongées, vitrense et transparente à l'intérieur, terne et blanchâtre à sa surface, et ressemblant assez à de très grosse résine sandaraque; mais chle se distinguait de la sandaraque par sa facile et entière solubilité dans l'éther et dans l'essence.

La grande facilité arec laçutelle on put faire arec cette résine des vernis incolores, quoique peu solides, la fit rechercher, et bientôt il en rint des quantités considérables: non plus par la roie de Varseille et d'Égyte, mais par les entrepots de Hambourg, d'Amsterdam et de Londres, qui la tirent des îles Molurgues. En même temps elle prit un nom plus approprié à son origine, car on l'appela derminar on misine

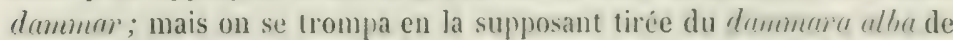
Rumphius, arbre de la famille des conifères qui produit une résine très dure que j'ai précédemment décrite (page 258). Je prouvai par l'examen altentif de ses propriétés que cette nouvelle résine n'élait antre que le dummar solan de Rumphius, résine prodnite an très grande abondance par un arbre gigantesque (50 à 70 mètres de hauteur), qu'il a nommé dammara selanica (Itrmoive sur les résines dommar, lievue srientifique, t. XVI, p. 177) : seulemeni, daus la description incomplete gu'il a faite de cet arbre, Rumphius l'arant plusienrs fois comparé aux cananga (unumu), De Candolle le comprit dans la famille des anonacées et dans le genre unma, sons le nom d'umona selanica; mais .11. Blume lui a assigné sa véritable place, en le reconnaissant pour une espèce d'engulhurdtio, genre appartenant à la famille des juglandées. II. Blume pense même que le drummurer sélatnicu ferminu de Rumphius, qui produit principalement la résine dammar, ne diffère pas de l'engelleardtin spicatu (Fl. Javan., t. II, p. 5). Cependant il ajoute que, quant à lui, il ne lui a pas vu produire de résine, ce qui tient sans doute, ainsi que le dit Rumphius, ì ce que cet arbre n'en fournit que dans un âge très arancé.

Le danmar sélan se présente quelquefois sous la forme de larmes arrondies on allongées, de 1 ì 2 centimètres d'épaisseur sur 2 à 4 centimètres de longurur (c'est sous cette forme qu'il a paru d'abord, comme étant apporté de Nubie); mais on le troure plus sourent anjourd'hni en larmes plus rolumineuses, mamelonnées à lenr surface, bonjours vitreuses ef incolores à l'intérieur, ou en masses irrigulières, angulenses, d'un aspect gris ou noiràtre, et mélangées d'impurrtés qui lenr ôtent leur transparence. 
Cetle résine est inodore à froid, mais tle exhale, par la chaleur, une odeur aromalique très donce et très agréable. I.orsqu'on la renferme dans la main, elle fait entendre des craquements successifs, causés par la rupture des larmes en morceaux. Elle se brise arec la plus grande faciliti, et se pulrérise rien qu'en faisant mouroir deux doigts l'un sur l'autre. Touchée et pressée un peu arec les mains, clle devient poissense à sa surface, et les mains conservent pendant lumgtemps une odeur analogue à celle de l'oliban. Elle se fond dans l'eau bouillante; exposée à la flamme d'une bougie, elle petille, iclate et lance des particules qui s'enflamment c't font l'effet de l'essence exprimie du zeste d'une orange. Fnsuite la résine se fond et coule par gouttes liquides.

Le dimmar sélan pulsérisé forme, arec l'alcool à 92 rentièmes, un liquide blanc comme du lait et qui tarde beaucoup it s'écharcir. Eille paraît composée de trois résines inégalement solubles dans ce menstrue, à savoir :

Résine soluble dans l'alcool froid, environ. . . 75

- soluble dans l'alcool bonillant. . . . . . 5 5

— insoluble dans l'alconl bouillant. . . . . 21

101

L'augmentation porte sur la résine soluble qui retient opinitióment une petite quantité d'alcool.

La même résine se dissout promptement et presigue complétement dans l'éther sulfurique. Elle se dissont facilement et rempletement a froid dans l'essence de terbunthine. Nul donte que cute facile s. Jubilité, jointe à la blancheur du produit, ne soit la cause de la grande faveur dont jouit cette résine auprès des fabricants de reruis.

\section{FAMILLES DES PLATANEES ET DES BALSAMIFLUEES.}

C'es deux familles, très voisines l'une de l'autre, cnt été formées pour les seuls genres plritnmus et liquidumbar. Les platanes sont remarquables par leur tronc élevé ct d’un diamètre quelquefois prodigieux, recouvert d'une écorce unie, d'un rert grisâtre, qui se détache annurcllérent par grandes plaques minces. Leurs feuilles sont ilternes, pétiolées, à lobes palmés; les fleurs sont monoïgues et disposées à la surface de réceptacles globuleux, porlés de 3 à 6 ensemble sur des pédoncules pendants; Jes fruits sont des askoses coriaces, implantés à la surface du réceptacle accru, et entourés à la base de poils fragiles. Ces arbres, et principalement le platane d'Orient, pour lequel les anciens ont montré une 
prédilection particulière, servent encore aujourd'hui à l'ornement des parcs d'agrément: leur hois est susceptible de recevoir un bean poli.

Les liquidambars présentent par leurs feuilles et la disposition de feurs fruits la plus grande ressemblance arec les platanes; mais ils en different beaucoup par leur suc résineux et balsamique. On en comaît trois espèces, dont l'une, le liquidambrer stypaciflun, produit ('n Imérigne le baume liquidambar; une seconde, nommée liquidmubrir oitentale, paraît fournir le styrax lirguide; la troisième espèce, nommée liquidambar altingia, forme, aux îles de la Sonde, un arbre gigantesque, dont le suc balsamique, semblable aux précédents, ne parait pas renir jusqu’à nous.

\section{Banme liquidambar.}

Liquidambar styraciflua (fig. 149). Cet arbre croît dans la Louisiane, dans la Floride et au Mexique, où il porte le nom de copprlme. Il pro duit denx baumes assez différents par leurs caraclères physigues: l'un

lig. 149.

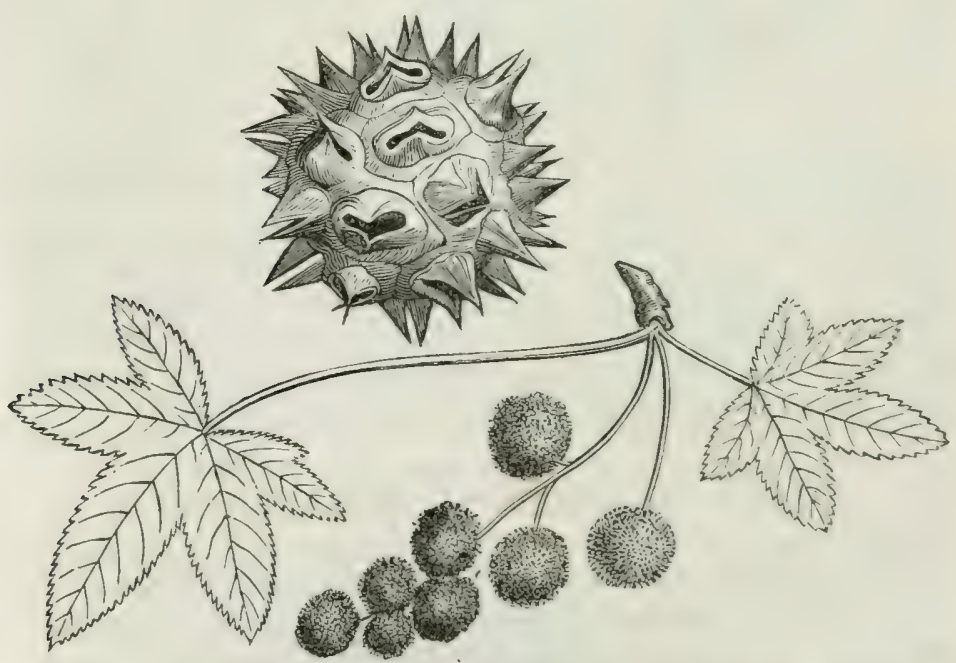

est liquide et transparent comme me huile; l'autre est mon, blanc ut opaque, comme la poix de Bourgogne.

Liquidumbar liquide, dit huile de liquidumbar. Ce baume est ohtenu par des incisions faites à l'abre, reçu immédiatement dans des rases qui le soustraient ì l'action de l'air, et décanté pour le sćparer d'une partie de baume opaque qui se dépose au fond. Il a la consistance d'une huile épaisse; il est transparent, d'un jaune ambré, d'une odeur 
forte, qui est celle du styrax liquide, mais plus agriable; d'une saveur très aromalifile et àcre al la gorge. Il contient une assez grande quanlité d'acide benzen̈que ou cinnamique; car il suffit d'en mettre une goutte sur du papier de tournesol pour le rougir fortement; et son décoctum, saturé par la potasse et concentré, laisse précipiter de cet acide par l'acide chlorhydrique. Il laisse, lorsqu'on le traite par l'alçol bouillant, un résidu blanc, peu considérable, et l'alcool filtré so trouble en refroidissant.

Liquidambar mou ou blanc. Ce batume provient, soit du dépôt opaçue formé par le précédent, soit des parties de baume qui ont coulé sur l'arbre et se sont épaissies à l'air. Je suppose que ces deux portions fondues ensemble et passées produiraient exactement le liquidambar mou, tel gue nous le voyons. Il ressemble à une térébenthine très épaisse ou à de la poix molle; il est opaque, blanchâtre, d'une odeur moins forte que le précédent, d'une sitsenr parfumée, douce, mais laissant de l'àcreté dans la gnorge. Il contient de l'acide benzoüque qui vient souvent s'efleurir à sa surfice; il se solidifie par une longue exposition à l'air, devient presque transparent, mais conserve très pen d'odeur. Il ressemble alors un peu au banme de Tolu, et plusieurs personnes s'en servent pour falsifier ce dernier. Il s'en distingue toujours par son gout de styrax et par une ancrtume assez marquée qui s'y est développée par l'action de l'air.

\section{Styrax liquide.}

Suivant Geoffroy, les anciens Grecs ne connaissaient pas ce baumc, qui a d'abord été distingué du storax calamite par les Arabes (1). Il règne cucore une assez grande inceritude sur son origine: beaucoup de personnes ont pensé que ce n'était que du storax calamite altéré arec dı vin, de l'huile, de la térébenhine et des matières terreuse's; d'autres ont écrit qu'il ne différait du storax que parce qu'il a été obtenu par décoction de l'écorce et des jeunes rameaux de l'arbre; cnfin d'autres estiment (qu'il est produit par un arbre différent.

Pendant quelque temps la première opinion ne m'a pas paru fondé, parce que je n'arais pas pu réussir, en mélangeant direrses proportions de styrax et de térébenthine, ou d'autres corjs résineux, à obtenir un mélange qui eût l'odeur du styrax liquide; mais depuis que j’ai vu le marc encore humide de baume de Tolu, traité par la chaur, prendre, élant abandonné à lui-même, l'odeur forte et tenace du styrax liquide;

(1) Il est probable, cependant, ique le styrax liquide est la substance que les Grees nommaient Stactè (Diosc., lib. r, cap. 62). 
depuis également (que j’ai obserró, nombre de fois, la même odeur se manifester dans un sirop tres fermontescible contenant du baume de Tolu, j’ai compris, à plus forte ratom, gu'un mélage humide de storax et d'autres matieres pourrait arguérir l'odeur forte du styrax liquide. Cependant je ne crois pas qu'en réalité ce dernicer soit dustorax alléré, parce qu'il n'y aurait aucun arantige, pour les falsificateurs, à dematurer une substance aussi chère gue le storax pour la rendre un prix très inférieur, sous le nom de stırax liquide; dès lors on peut être certain qu'ils ne le font pas.

La seconde origine n'est pas mieux assurée, parce que l'odeur du styrax liquide est plus forte que celle du storax et sa consistance plus liquide, et que l'effet constant de l'ébullition de l'eau sur un corpls composé de résine et d'huile volatile est, au contraire, d'augmenter la consistance et de diminuer l'odeur du composé. Il faut done admettre que le styrax liquide est produit par un autre arbre que le storax calamite.

Snitant toutes les probabilites, le styrax liquide est tiré d'Arabie, d'Éthiopic el de l'ìle de Cobras, dans la mer Rouge, où, d'après Petiver, l'arbre qui le produit est nommé rusa mallos. Cet arbre paraît être le liquidrumbur orientule des botanistes (1); il diffère peu du liquiduntur stypreciflun, qui donne en dmérique le baume liquidambar. Pour olbtenir le styrax liquide, toujours d'ap̣ès Petiver, on fait bouillir l'écorce de l'arbre, préalablement pilée, dans de l'eau de mer, et on recueille le baume qui vient nager a la sufface. Comme il contient encore beaucoup d'écorce divisée, on le fond de nouveau dans de l'eau de mer et on te passe. On renferme séparément dans des barils le styrax purifié et le résidu de la purification: tous deux sont rersés dans le commerce; mais ils sont très souvent altérés par toutes sortes de mélanges, e't il est presque impossible d'y trourer le stgrax purifié dont parle Petirer.

I.e styrax liquide du commerce est de la consistance du miel, d'un gris brunâtre, opague, d'une odeur forte ct fatigante, d'une sarcur aromatigue non àcre ni désagráable. Conservé longtemps dans un por, je lui ai su former, à sa surface, une cfllorescence d'acide cinnanique. Il se dissout très imparfaitement dans l'alcoul froid: l'alcool bouillant le dissout compléteme'nt, saufles impuretés; la liquerur filtrie se trouble et précipite en se refroidissant (styracine?) : par son éraporation spontance, clle laisse précipiter une resine molle, et forme enfin une cristallisation d'acide cimnanique. Le résidu, qui pèse les 0,16 du tout, est composé de terre et de fragments d'écorce.

(1) Il est bien remarquable que te liquidambar alsingia porte presque le même nom (rassa mala) anx iles de la Sonde. 
Mais on conçut que la proportion de ce résidu doire varier dans le styrax du commerce; il faut choisir celui qui en laisse le moins, qui contient le moins d'eau, qui a l'odeur balsamique la plus forte, et sans mélange d'aucune autre.

II. Édouard Simon a examiné arec soin la composition du styrax liquide.

20 livres de ce baume, distillées avec 14 lirres de carbonate de soude cristallisé et de l'eau, ont fourni 5 onces d'essence nommée styrule. Cette essence neutre, limpide, incolore, soluble dans l'alcool et dans l'ésher, est composée de :

$$
\begin{array}{rr}
\text { Carbone. . . . } & 92,46 \\
\text { Hydrogène. . . } & 7,54
\end{array}
$$

Cette essence, exposée à l'air, en absorbe l'oxigène et se convertit cu un corps gélatineux, transparent et visqueux, insoluble dans l'eau, l'alcool et l'éther, nommé uxide styrolique. La même essence, traitée par l'acide azotique, se convertit en oxide styrolique, acides nitro-benzoïgue, çanhỵdrique, et en un corps solide, cristallisable, azoté, d'une forte odeur de cannelle, aussi àcre et aussi rubéfiant que l'essence de moutarde. On donne à ce corps le nom de nitro-styminle.

Je reviens au résidu de la distillation du styrax liquide arec le carbonate de soude. Ia liqqueur contient du cimmunte de soude, dont on peut précipiter l'acide par le moyen de l'acide chlorhỵdrique. La résine est prise à part, lavée, séchée et traitée par l'alcool bouillant, qui la dissout, sanf les impuretés. On retire les deux tiers de l'alcool par la distillation, et on expose le reste dans un lieu frais: Ia styrurine se dépose sous forme de grains cristallins, tandis que la risine proprement dite reste en dissolution. On lave le dépôt arec de l'alcool froid, et on le redissout dans l'alcool bouillant pour le faire cristalliser.

La styracine est sous forme d'écailles fines et légères; elle fond à 50 degrés, est presque insoluble dans l'eau, soluble dans 3 parties d'alcool bouillant, 22 parties d'alcool froid, "3 partiés d'éther. Elle a pour formule $\mathrm{C}^{24} \mathrm{H}^{11} \mathrm{O}^{2}$.

Le styrax liquide entre dans la composition de l'onguent et de l'emplàtre de styrax, et dans l'emplàtre mercuriel de V'igon.

\section{FAMILLE DES SALICINÉES.}

Arbres élevés ou arbrisseaux à feuilles alternes, entières ou dentées, accompagnées de stipules écailleuses et caduques, ou fuliacées et persistantes; fleurs dioïques, toutes disposẻes en chatons, munies chacune 
d'une bractée scuamiforme, persistante; périanthe nul ou remplacé par un torus glanduleux, annulaire ou obliquement urcéolé; fleurs mâles à deux étamines ou darantage, dont les filets sont distincts ou monadelphes, arec un rudiment d'ovaire au centre; fleurs femelles compo. sées d'un oraire sessile ou pédicellé, diphṇlle, uniloculaire, accompagué à la base d'étamines rudimentaires; orules nombreux, ascendants ; 2 styles très courts plus ou moins soudés, terminés chacun par un stigmate bi- ou trilobé; fruit capsulaire, uniloculaire, à 2 valres siminifères qui se séparent par le sommet et s'enroulent en dehors; graines dressies, nombreuses, très petites, pourvues d'un funicule très court et épais, s'épanouissant en une touffe laineuse, ascendante, qui enveloppe toute la graine. Embryon dépourru de périsperme, droit, à radicule infère.

Les salicinées se composent de deux genres d'arlures, les stumles et les perpliers, dont le premier, surtout, très nombreux, tries rariable de forme et de grandeur, à espèces changeantes et d'une étude très difficile, se trouve répandu dans les lieux humides et marécageux, tempérés on froids, de l'hémisphère nord des deux continents. Ces arbres poussent arec une grande rapidité, ont un bois blanc, líger, nexible, et une écorce amère qui a été employée pendant longtempss comme un fébrifuge incertain, arant que .1. Lecoux, phatmacien à Vitry-le-Français, en eût retiré le principe actif qui est la sulicine. J.es principales espèces dont on a retiré ce principe sont :

1. Le saule blane, salic alba L. ; arbre de 10 à 13 mètres, à rameaux rougeâtres ou brunâtres, garnis de feuilles lancéolées, courlement pétiolées, soyeuses et blanchâtres des deux còtés;

2. L'Osier jaune, salic vitellina L. , dont les rameaux sont d'un jaune plus ou moins foncé, et les feuilles étroites-lancéolées et glabres;

3. Le sanle à feuilles d'amandier, ou Osier rouge, salix anyydalinu; 8 à 10 mètres de hauteur; ramcaux rougcâtres ou jaunattres; fuilles oblongues-lancéolíes, glabres et d'un beau rert en dessus, grlauques en dessons, bordées de dents très aiguës. Cette espèce et la précédente sont les plus estimées pour tous les usages auxquels on desline l'osier ;

4. Saule précoce, salic prepcos Willd.; 10 à 13 mètres de hauleur; rameaux d'un rouge foncé sowrent recourerts d'une poussière gliaque; feuilles ovales-lancéolées, dentées, à nerrure médiane très prononcée ;

5. L'Osier blane, sulix viminulis L. ; arbre de 5 à_ 7 mètres, it rameaux très droits, très effilés, revêtus d'un duret soỵeux dans leur jeunesse ; feuilles linćaires-lancéolées, acuminées, très entièr es, légè- 
rement ondulies, vertes en dessus, soyeuses et blanches en dessous, arec une nervure très saillante;

6. saule héliee, salic helix L. ; 3 à 4 mètres d'élévation ; rameaux très effilés, glabres, luisants, cendrés ou rougeâtres; feuilles sourent opposées, linéaires lancéolées, acuminées, glabres, un peu glauques en dessous ;

7. Osier ponapre, salic purpurea L.; fenilles opposées ou alternes; orales-lancéclées ou lancéolées-linéaires, entières par la parlie inférieure, légèrement dentées par le haut, un pen glaugues en dessous.

Autres espèces dont on n’a pas retiré de salicine:

8. Sante frasile, solir: frongilis L. ; 10 a 13 mètres de hauteur; rameaux brunâtres, cassant ave: une grande facilité près de leur insertion sur les branches; feuilles lancéolées, dentées, glabres, pétiolées ;

9. Sante pleureur, salix bulyylunicu L. La tige de cet arbre, haute de 6 à 8 mètres, se partage en branches étalées, prescune horizontales, divisées en longs rameaux grèles et pendants, garnis de feuilles glabres, étroites et lancéolées. Il est originaire d'Isie, d'où il a été apporté assez tard en Europe. La disposition de ses rameaux qui s'inclinent vers la terre comme la cherelure dénonée d'une femme, lui donne un aspect triste et gracieux qui l'a rendu l'emblème de la douleur et du deuil.

10. Sanle Marceau, ou Marsault, salix caprefu L. ; arbuste de 6 à 8 mètres de hauteur, dont les jeunes rameaux sont brunâtres, pubescents, garni de feuilles assez grandes, ovales-arrondies, glabres en dessus, blanchattres et cotonneuses en dessous, dentées sur le bord, pointues au sommet, sourent accompagnées de stipules arrondies. Cette espèce de saule, si différente des autres par son feuillage, crồt facilement dans toutes sortes de terrains; on en fait des échalas, des cercles de tonneaux, des fagots pour cuire la chaux, le platre, la tuile, etc. Les bestiaux, et surtout les chèrres, recherchent ses feuilles arec aridité , ce qui lui a valu son nom linnéen.

Les peupliers sont beaucoup moins nombreus que les saules, puisqu'on n'en compte guère qu'une trentaine d'espèces. Ils sont en général bien plus élevés, et portent des bourgeons entourés d'écailles enduites d'un suc résineux et balsanique; les fenilles sont alternes, souvent arrondies ou triangulaires, dentées, portées sur de longs pétioles comprimés latéralement au sommet, ce qui donne à la feuille une extrême mobilité et la rend inpressionnable au moindre vent. Cet effet est particulièrement sensible dans le tremble (populus tremula), qui en a pris le nom gu'il porte. Les peuplier's se distinguent en outre des saules par leurs bractées découpées, leur torus en godet, prolongé 
obliquement en dehors; par leurs élamines plus nombreuses, de 8 à 22 ; leur oraire est entouré à la base par le torus; les stigmates sont plus allongés, à 2 ou 3 divisions. Les espèces principales sont le penplier. noix (populus nitgra), gui fournit surtout les bourgeons résineux et balsamiques qui font la hase du lipreroli de peuplier (onguent popu-

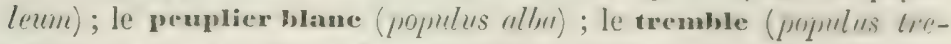
mulu), et le peuplier drtalie (populus fustigiatu), qui paraît être originaire de l'Orient.

II. Braconnot a constaté la présence de la salicine dans l'écorce de plusieurs espèces de peupliers, et notamment dans celle du tremble; mais elle y est accompagnce d'une autre substance analogue nommée populine. (Consulter, pour l'extraction de ces deux principes et pour l'exposé de leurs propriétés, la Pllur'mucopéce raisonnée, p. 6!18, et les traités de chimie.)

\section{FAMILLE DES ULMACÉES.}

Grands arbres ou arbustes à feuilles alternes, simples, pétiolies, penninerrées, dentées, rudes au toucher, accompagnées de deux stipules cadurgues; fleurs fasciculées, hermaphrodites ou quelquefois unisexuelles par arortement; périanthe campanulé, à 4,5 ou 8 divisions; étamines insérées à la base du périanthe, en nombre égal et opposéés à ses divisions; oraire libre formé de 2 feuilles carpellaires à bords rentrés en dedans, et atteignant l'ase, ce qui rend l'ovaire biloculaire (ulmus), ou à bords raccourcis (ovaire uniloculaire, plomerit) ; osule solitaire dans chaque loge, suspendu à la cloison près du sommel, ou au sommet de la loge unique; 2 styles continus avec les 2 feuilles carpellaires, écartés, stigmatifères sur leur face interne. Le fruit est une samare uniloculaire, ou un askose accompagné à sa base par le périanthe persistant, mais non accru ; graine pendante, à test membraneux, à raphé saillant; pas de périsperme, embryon homotrope, radicule sulpère.

\section{Ĺcorce d'Orme champetre.}

1 Lmus cumpestris L. Cet arbre croît dans les forèts de l'Europe, ou il pent s'élever à 25 ou 27 mètres de hauteur et acquérir, arec le temps, un tronc de 4 à 5 mètres de circonférence. On le cultive aussi pour border les ruutes et former des allées dans les promenades publiques. Ses fleurs, qui sont rougeàtres et disposées en paquets serrés le long des rameaux, paraissent au mois de mars avant les feuilles, et les fruits sont mûts un mois ą̧rès. 
L'écorce intérieure de l'orme, ou le liber, a lungtemps été rantée contre l'hydropisie ascite et ensuite contre les maladies de la peau. On la trotive dans le commerce, où on lui donne le nom d'recuree d'orme I'!rromidul, divisée en lanières rougeàtres fibreuses, d'un goùt pâteux et mucilagineux. La teinture d'iode y indigue la présence de l'anidon.

I.e bois d'orme est assez dur, rougeàtre ei usité surtout pour le charronmage. Cilui que l'on nomme torlillurd, surtum, est employe pour faire des moyeux de roues, des pieds de mortiel's, des vis de pressuirs, cte. Ce même arbre est sujet à produire, sur son tronc, des excroissances ligneuses d'un volume considérable, qui, travaillées par les ébénistes, forment des meubles d'une grande beauté, à cause des accidents rariés et bizarres que leur coupe a mis au jour.

\section{Écorce d’orme fauve t'Amérique.}

I lmus fulcu $11 \mathrm{x}$. I, liber de cet arbre est tellement mucilagineux qu'on en fait des cataplasme's et des gelées nourrissantes. Les Américains le réduisent en pouder aussi fine que de la farine, et en font sous cente forme un commerce assez considcrable. Cette poudre est d'un jaune-rosé très pâle, et forme dans la bouche un mucilage analogue à celui de la gomme adragante. On l'emploie, sous toutes sortes de formes, dans un grand nombre de maladies inflammatoires.

Il y a un certain nombre d'année's, on a annoncé qu'on employait dans les Antilies l'erenter d'ormes à la clarification du sucre. Depuis, ce moyen a paru peu arantagenx; dans tous les cas, ce n'est pas l'écorce d'un arbre du genenre ulmus quii servait à cet usage, c'était celle du

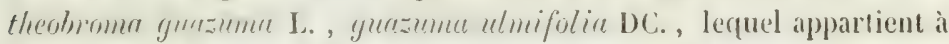
la famille des brttuériacées, et porte le nom d'orme à la Guadeloupe.

\section{FAMILLF DES MORÉES.}

Cette famille, qui fait partie de l'ancien ordre des urticées de Jussieu, comprend des végétaux de toutes grandeurs, à suc souvent lactescent, à fenilles alternes accompagnées de stipules caluques ou persistantes; à fleurs monoïques ou dioḯpues. Les fleurs mâles sont très sourent disposées en chatons, et sont composées de 3 ou 4 étamines insérées au fond d'un périanthe à 3 ou 4 dis isions; les fleurs femelles sont disposées en chatons, ou rassemblées sur un réceptacle globuleux, ou bien encore sont placées, mélangées aux fleurs mâles, à la surface d'un réceptacle plane, ou contenues dins un réceptacle pyriforme percé au sommet d'une petite ouverture. L'oraire est uniloculaire, rarement biloculaire, à un seul ovule fertile. Les fruits sont des askoses ordinai- 
rement entourés par le périanthe devenu charnu, et soudés en sorose, ou portés sur un réceptacle tantôt élalé, tantôt relevé et fermé en forme de figue. Embryon courbé en crochet, dans un endosperme plus ou moins développé ; radicule supère.

\section{Racine de Contrayerva oflicinal.}

Inrsteniu brasiliensis Lam., crete-cyia de Maregraff et Pison. Culle plante (fig. 150) croît au Brésil ; elle pousse de sa racine 3 ou 4 fenilles longuement pétiolées, cordées-ovales, obtuses, crénclées; et une ou

Fig. 130.

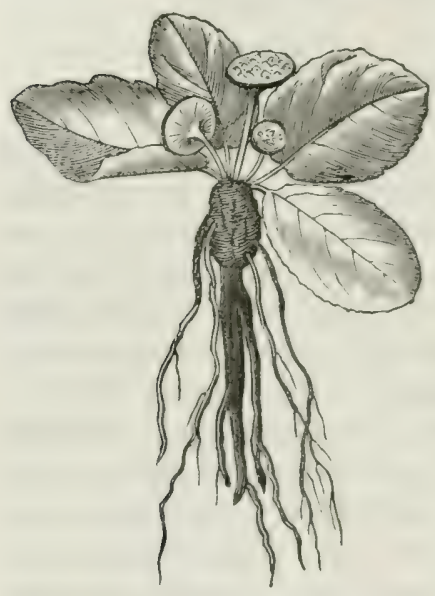
plusieurs hampes nues, qui supportent chacune un réceptacle orbiculaire garni de fleurs mâles ct femelles mêlées (fig. 151) : les premières ont 2 étamines et les secondes 1 oraire surmonté de 1 style et de 2 stigmates. Il succède a chacun un fruit monosperme logé dans l'épaisseur du réceptacle qui s'est accru. Cette fructification ne diffère de celle du figuier que parce que, dans celui-ci, le réceptacle commun est globuleux et cntièrement fermé, si ce n'est au sommet, tandis que le réceptacle des dorstenia est plane et élargi.

La racine du dorstenia brasiliensis possède une odeur aromatique, faible ct agréable. Elie est d'une couleur faure rongeâtre à l'extérieur, blanche à l'intérieur, d'une saveur peu marquée d'abord, mais qui acquiert de l'âcreté par une mastication un peu prolongée. Elle est composée d'un corps oroïde terminé inférieurement par une queue recourbée qui lui dome à peu près la figure d'un scorpion; elle est garnie en outre de quelques radicules.

Sur l'autorité de Linné, un grand nombre d'auteurs ont attribué la racine de contrayerra au dorstenia contraygeree L.; à la rérité, ia racine de cette espèce, de même que celle de plusienrs autres dorsteniu, porte aussi le nom de contrayereve (1); mais la racine oflicinale vient du Brésil, où elle est produite par le dorstenin hrusiliensis, qui a seul la racine tubéreuse, allongée el terminée par une forte radicule recourbée', comme on le voit dans notre contrayerva.

(1) Ce nom, qui est espagnol, veut dire contre-venin. 
Le dorstenie controngerva (fig. 151) croît au Mexique : il se distingne du précédent par ses feuilles pinnalifides, assez semblables à celles de la berce, et par son réceptacle à fleurs qui est lni-même comme incisé on lob,í, et à peu près carré. C'est à cette épuèce probablement, ou à une autre ruisine (le D. Houstoni ou le $D$. drakena) qu'il faut attribuer Fig. 131. la racine de Drake, qui a d'abord été rapportée du Pérou par Drake, et ensuite décrite et figurée par Clusius (Exot., lib. IV, cap. 10). En 1834, celtc même racine a été apportce de Guatimala, par II. Bazire, sous le nom de contrayeria. Elle est noirâtre au dehors, blanche en dedans, et porte cà et là des fibres menues, dont les plus grosses, dures et ligneuses, donnent naissance à d'autres nodusités semblables aux premières. Elle est inodore et douée d'une sarcur un peu astringente d'abord, qui laisse dans la bouche une acrimonic

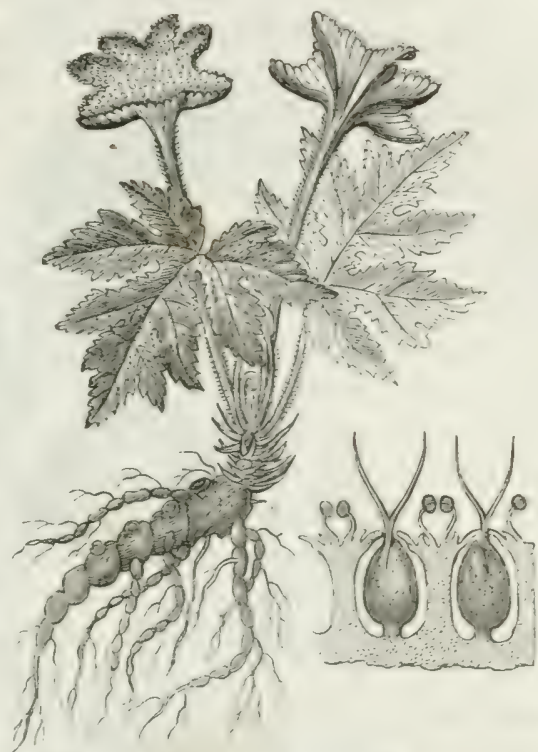

légère et suare. Cette racine diffère du contrapersa ufficinal par sa forme noueuse et tout à fait irrégulière, par sa coulentr noirâtre au dehors et par son manque d'odeur.

Figuier et Figue (fig. 152).

Ficus corrica L. Cet arbre paraît indigène au midi de l'Europe, on bien, s'il y a été transporté dlu Lerant, il y a si longtemps, que l'éporque en est inconnue. Dans toutes ces contrées, il peut s'élever à la hauteur de 8 à 10 mètres, sur un tronc de $1^{\mathrm{m}}, 5$ à 2 mètres de tour; mais sons Io climat de Paris, il ne forme guère qu'un arbrisseau de 3 à 5 mèlres, dont les tiges nombreuses s'élèrent d'une souche commune. Les feuilles sont alternes, pétiolées, plus grandes que la main, échancrées à la base", décompées sur leurs bords en 3 ou j lobes, d'un rert foncé en dessus, conrertes de poils nombreux en dessous, rudes au toucher. Les réceptacles (ri) qui portent les fleurs naissent dans l'aisselle des feuilles : ils sont arrondis ou pyriformes, arec une petite ourerture au sommet, et 
portent des fleurs màles à leur partie supérieure et des fleurs femelles, plus nombreuses, sur tout le reste de leur face interne. Les fleurs mâles (b) ont un périanthe à 3 divisions et 3 étamines; les fleurs femelles (c) sont à jo divisions et portent 1 oraire supère surmonté de 1 style à 2 stinmates. Charjue ovaire devient, après la fécondation, un askose mou ( $\bullet$ ) dont la semence contient, au centre d'un endosperme

Fig. 152.

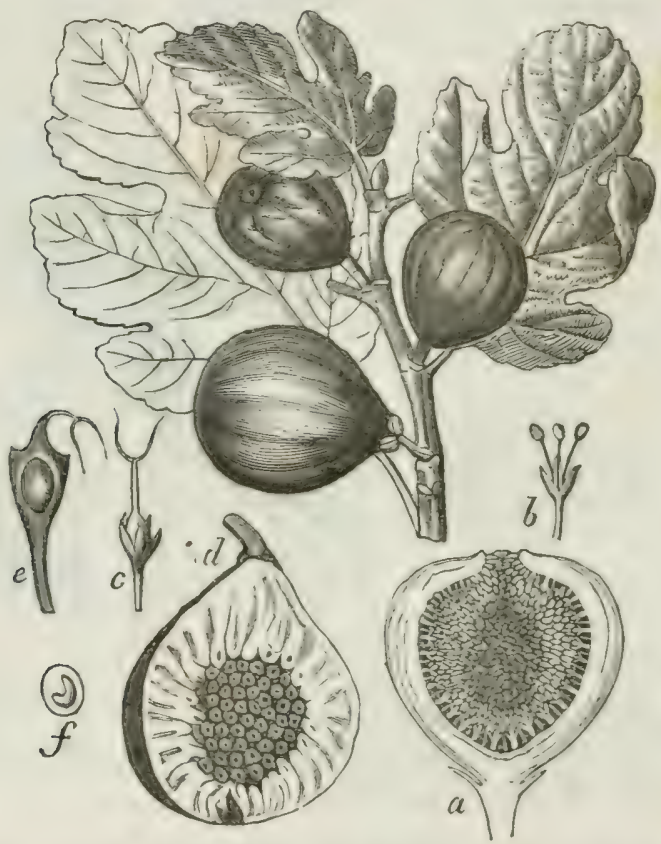

charnu, un embryon un pen courbé en crochet ( $)$. La réunion de tous les askoses mûris dans le réceptacle, constitue la fuym. (d) que le vulgaire considère comme un fruit, mais qui forme l'espece particuliere

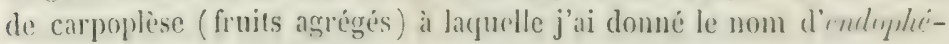
vide (syncone de MI. Nirbel).

I.es fignes du nord de la lirance et des environs de Paris li sont peu sucrées et ne peuvent pas se conserver. Celles du commerce viennent du midi de la France et de l'Europe; nn en distingue un grand nombre

(1) On cultive le figuier principalement a Argenteuil (Scine-et-Oise); on y trouve surtout la grosse figue blanche et la figue violetle ou figue mouissonne. 
de variétés dont les plus communes sont les pritites figmes bilunchers, les figues violettes et les figues grasses.

Les premières, qui proviennent de lat prtite figne de M/urstille desséchée, sont petites, blanches, parfumées et tris sucrées; elles sont réservées pour la table. Les secondes, beaucoup plus grosses, d'une conleur blenatre ou violitte, prorirmnent de la figue munissome de Provence; il faul les choisir reches et nonvelles; ce sont celles qui se conserrent le mieux en bon élat et que, pour cette raison, je préfère pour l'usage de la pharmacie. Le's figurs grusses proviennent de la frusse figue blanche ou de la grosse figne jumme de Provence. Elles sont très grosses, visfueuses, très facilement attarquées par les mites.

Dans queldues contrées du l.rvant, pour augmenter le nombre des figues qui murissent et leur volume, on pratique mue opération qui porte le nom de caprifiration, laquelie consiste à prendre les jeunes figues du fignier samrage nomue raprifiras, et a les fixer sur les rameaux du figuier cultivé. Linné a pensí que l'utilité de cette opération consistait à rapprocher des fleurs femelles du liguier cultivé, chez lequel les fleurs mâles sont peu nombreuses ou altérirs, les réceptacles du figuicr saurage, (qui sont mieux pourrus sous ce rapport; mais on croit que le but de cette opération est de propager sur le fignier un insecte dugenre cynips, qui vit habituellement sur l'arbre sauvage. Cet insecte s'attache particulièrement aux figuc's; il s'y introduit, s'y loge et y cause une afluence de sucs qui tourne à l'arantage du firuit. Cette pratique est peu suivie aujourd'hui.

Figuel siconolis, ficus sycomorus L. Arbre d'ligypte très élevé et d'une viste étendue, dont les fruits sont l'ohjet d'me grande consommation de la part des Arabes. Son bois, qui est très léger, passe pour incorruptible et servait à faire les caisses destinées anx corps embanmés. J'ai su en effet des caisses de momies antiques, en figuier sycomore, dont le bois était parfaitement conservé.

L'écorce du fignier commun, lorsqu'on y fait des incisions, laisse découler un suc laiteux, àcre et caustique, qui contient une quantité notable de caoutchouc. Les firgiers des climats chauds, et principalemont le figuier élastique (firus clustirca), le figuier des Pagodes (ficus religinsa), le fignier du Bengale (firms lienghulensis) el le figuier des Indes (ficus indicri), pourraient probablement en fournir au commerce. Le port de cette dernière espèce et la manière singulière dont elle se propage, ont toujours été un sujet d'admiration pour les royageurs. Elle forme un grand arbre toujours vert dont les branches produisent de longs jets qui descendent vers la terre pour y prendre racine. Bientôt après ces jets forment des trones semblables au premier, qui produisent à leur tour de nouveaux jets propres ì s'enraciner; de sorte 
qu'un arbre, en se prọageant ainsi de tous côtés sans interrupuion, pourrait former à lui seul une forêt.

Indépendamment des arbres qui apparliennent au genre fignier, plusieurs autres régétaux dont les fruits ont paru aroir quelque rappont arec la figue, en ont porté le nom. Iinsi le bananier (musut furtulisincri) a reçu le nom de fignier des Indes, fignier d'. Adtrin on de Pharroon. I.e figuier d'Inde est un cartus ; le figuier des Inttentors, un mesembryanthemum; le figuier de Surinam est le rerropire polfulu: In figuier maudit est le clusia rosea, etc.

\section{Résine laque.}

La laçue est une matière résineuse produite par la femelle d'un insecte hémiptère nommé coccus lacea, larguelle vit dans l'Inde sur plusicurs

Fis.s. 133.

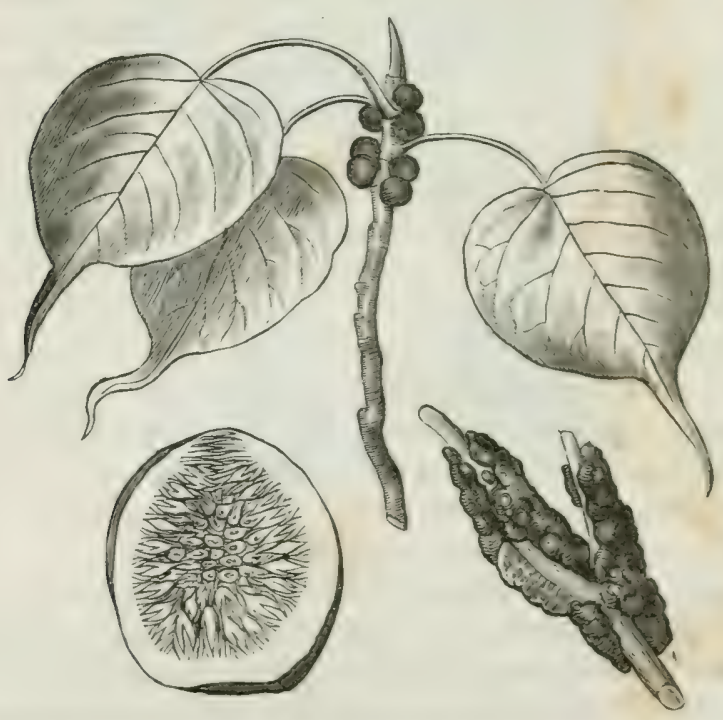

arbres qui sont entre autres le firms religinsat x. (fig. 153), les firms int lien L., rhammus jujuba L., bufeu firmedosu Roxb., elc. (1,. C.ess femelles,

(1) Le croton lacciferum de Ceylan laise exsuder naturellement, dans l'aisselle des rameanx, ou par des inci-ions fates a son écorce, une résine qui parait avoir les propriétes de la laque; cependant Vilmont de Bomare avertit de ne pas confondre edte résine avec celle une le cocens lacca produit sur d'autres arbres. C'est celle-ci seule qui parait former la laque du commerce. 
de même que celles du hermès ct de la cochenille, se fixent seules sur les arbres cités, se rassemblent en grand nombre sur leurs jeunes branches, et s'y serrent tellement qu'elles ne laissent aucun vide entre elles. Là, elles se soudent au mosen de la matière résineuse qui exsude de leur corps, et bientôt après elles ne forment plus chacune qu'une cellule remplie d'un liquide rouge, au milieu duquel se trowre me vingtaine d'oufs ou plus. Ces œufs éclosent, les larves se nourrissent du liquide qui les environne, et sortent ensuite à l'état d'insecte's parfaits, laissant leur dépouille dans la cellule (qui les contenait. Il parait qu'il est préférable de réculter la laque plutôt avant qu'après la sortic de l'insecte.

Un connaît dans le commerce trois sortes de laque : celle en britoms, celle en grains, et la laque plate ou en écailles.

La laque on buttons est celle qui se troure encore attachée à l'extrémité des branches de l'arbre. Elle y forme une couche plus ou moins épaisse, d'un rouge plus ou moins foncé. Elle est transparente sur les bords, brillante dans sa cassure, et offre, à l'intéricur, un très grand nombre de cellules disposées circulairement tout autour du bois, et dont plusieurs conticnnent encore l'insecte entier. Cette layue colore la salive lorsqu'on la mâche pendant quelque tempss ; elle répand une odeur forte et agréable quand on la chauffe ou qu'on la brùle.

La laque en yrains est celle qui s'est brisce et ditachée des branches. Pour la pharmacie, on doit choisir la plus foncée en couleur, car on la décolore souvent dans l'Inde, où son principe colorant est très usité dans la teinture des étoffes.

La mène chose a lieu pour la laque en écailles, qui se prépare en faisant fondre les deux autres sortes, après les as oir fait bouillir dans l'ean pure ou alcalisée, les passant à travers une toile et les coulant sur une pierre plate. Cette laque ressemble pour la forme au verre d'antimoine; mais elle varie beaucoup en couleur, suirant qu'elle a élé plus ou moins privée de son principe colorant : de là la distinction que l'on fait encore de Ja laque en écailles, blunde, ruuge ou brme. Pour les arts, qui en emploient une assez grande quantité, c’est la moins colorée qui est la plus estimée : pour la pharmacie, on doit préférer celle qui est rouge et transparente, comme étant plus rapprochée de son état uaturcl.

La lacpue n'est pas une résine pure; elle est compusée, cependant, d'une résine qui en fait la plus grande partie, d'une matière colurante rouge soluble dans l'eau et les acides, de cire et de gluten. Toici, au reste, l'analyse comparée des trois sortes de laque, par Hatchett: 


\begin{tabular}{|c|c|c|c|}
\hline & $\begin{array}{l}\text { J.aque } \\
\text { cil bâlons. }\end{array}$ & $\begin{array}{l}\text { I.aque } \\
\text { en grains. }\end{array}$ & $\begin{array}{l}\text { Laryuc } \\
\text { plute. }\end{array}$ \\
\hline Résine. . . . & 68 & 88,5 & 90,9 \\
\hline Matière colorante. . & 10 & 2,5 & 0,5 \\
\hline Cire. . . . . & 6 & 4,5 & 4,0 \\
\hline Gluten..... & 5,5 & 2,0 & 2,8 \\
\hline Corps étrangers . . & 6,5 & 0,0 & 0,0 \\
\hline Perte..... . & 4,0 & 2,5 & 1,8 \\
\hline & 100,0 & 100,0 & 100,0 \\
\hline
\end{tabular}

Les propriétés médicales de la laque sont d'être tonique et astringente; clle est employée comme dentifrice; mais son plus grand usage est pour la fabrication de la cire à cacheter, pour la chapellerie et la teinture.

On emploie aussi dans la teinture denx préparations indiennes de la laque; l'une 'st le lac-laigue, qui est an précipité formé par l'alun dans une dissolution alcaline de résine laque (Ann. de chim. ef de phys., t. III, p. 225); l'autre est le lac-dye, composition analogur, mais dont la préparation n'est pas bien comnue. Pent-ître est-ce celle qui se trouve indiquée dans le Joum. de plut'm., t. VIII, p. 52/.

Lanpe de Guatimala. Cette résine est sous la forme de globules sphériques, de la grosseur d'un petit pois, offrant d'un côté l'empreinte de la branche d'où on les a détachés, quelquefois soudés plusieurs ensemble, mais le plus souvent isolés.

Chaque globule est creux à l'intérieur, et les plus petits renferment les débris d'un insecte et un nombre considérable de petites larres desséchées; mais le plus grand nombre sont percés d'un tron et rides. Ces circonstances presque semblables à celles qui signalent l'existence du coccus lacca de l'Inde, nous indiquent que nous avons affaire à une production de même nature; senlement l'espèce doit être différente.

Celte laque, apportée de Guatimala par M. Bazire, se trourait dans le droguier de l'́́cole de pharmacie, partie dans son état naturel, partie fondue et sous la forme de bitons longs et étroits réunis en bottes à l'aide d'une écorce fibreuse. Cette lacue est moins rouge que celle de l'Inde, et lorsqu'elle a été fondue, elle a une tcinte noirâtre peu agréable. Elle exhale, étant chaude, une odeur analogrue a celle de la laque de l'Inde, et brùle de même arec une belle flamme blanche. Ia chaleur lui communique, en outre, une élasticité qui la rapproche du caoutchouc; enfin elle oftre dans sa saveur un gnût marqué d'acide succinique. 
Mrorier noir (fig. 154).

Horus nigra $\mathrm{L}$. Arbre de 7 à 13 mètres de hauteur, formant tme tète plus ou moins arrondie. Les feuilles sont pétiolées, cordiformes, aiguës à l'extrimitó, dentées, glabres et rudes au toncher en dessus, pubescentes en dessous, très sourent entières, quelquefois partagiu's en plusieurs lobes. Les fleurs mâles et les femelles sont disposées in chatons séparẻs, tantôt portés sur le mêue individu, d'autres fois dioïques. Les fleurs mâles forment des épis allongés, et sont pourvues d'un périanthe à quatre divisions ovales, et de 4 étamines à filets droits plus longs que le périanthe. Les fleurs femelles forment des chotons ovoïdes et'denses, courtement pédonculés. Chaque neur porte un périanthe à 4 divisions opposées, dont 2 extérieures plus grandes. L'ovaire est supère, sessile, pourvu de deux styles divergents, et divisé intéFig. 13\%.

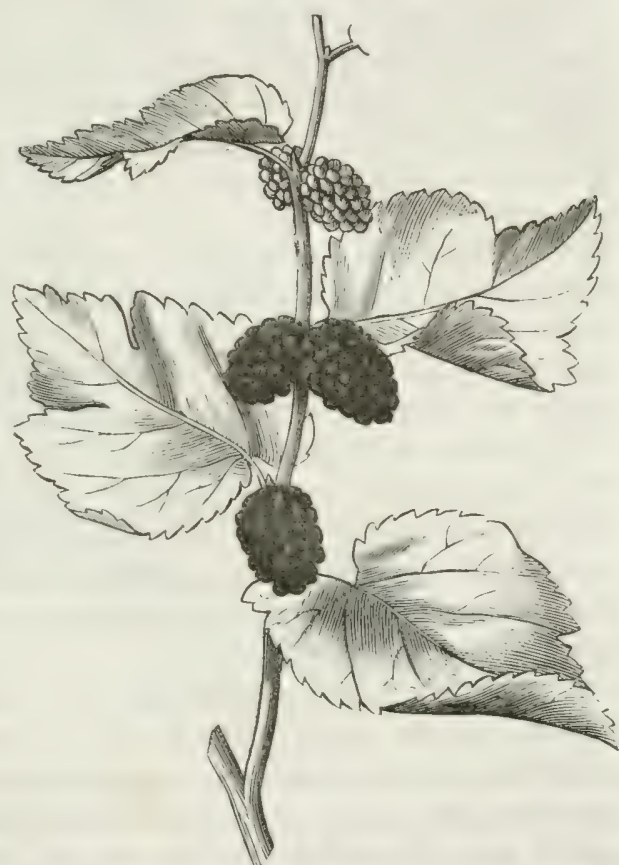
rieurement en deux loges dont chacune contient un orule; mais un de ces ovules et sa loge avortent constamment, et le fruit est un askose qui reste entouré par les folioles du périanthe accrues et devenues succulentes et bacciformes. Tous ces fruits, très rapprochés, forme:t un carpoplèse oroüle et succulent qui a reçu le nọm particulier de sorose : le vulgaire considère ce sorose comme un fruit et lui donne le nom de mûre. Il mùrit depuis la fin de juillet jusgu'au mois de septembre: il est rert d'abord, puis rouge, enfin presque noir. Il est alors rempli d'un suc rouge très foncé, très visqueux, sucré, acicle et d'un goût assez agréable. On en prépare un sirop rafraîchissant et légèrement astringent. Le mûrier noir, de même que la plupart de nos arbres fruitiers, paraît originaire dı Jevant, mais il a été introduit, il y a si 
longtemps, dans la Grèce et dans l'Italie, qu'on l'y regarde comme indigène. Ce sont les Romains qui l'ont apporté dans la Gaule, où il se rend utile, non seulement par ses fruits, mais encore par ses feuilles qui peuvent servir de nourriture pour le ver à soie. Mais il le cè̀de beaucoup, sous ce dernier rapport, au mûrier blanc (morus albu L.), qui est originaire de la Chine, comme la culture du rer ì soie, et qui a suivi cette culture de la Chine dans l'Inde et dans la Perse; de la Perse à Constantinople, sous le règne de Justinien ; plus tard en Sicile et dans la Calabre, du temps de Roger; enfin en France, après la conquête de Naples par Charles VIII. On roṿait encore, en 1802, ả Allan, près de IIontélimart (Drôme), le premier mûrier blanc qui y fut planté par Guy-Pape, vers l'époque dont nous parlons.

L'écorce de mûrier noir, et principalement celle de la racine, est âcre, amère, purgative et vermifuge. Dinscoride la cite comme propre à détruire le tænia. Le bois de mûrier, à part l'aubier qui est blanc, est d'un janne foncé, très solide, susceptible de poli, inattaguable par les insectes, et peut servir à faire des meubles ou des ustensiles. Il présente sur sa coupe perpendiculaire à l'axe et polie, des cercles blanchàtres, régulièrement espacés sur un fond jaune, avec des lignes radiaires très serrées et un pointillé blanchâtre dû aux fibres ligntreuses. Il a l'inconrénient de prendre à l'air une couleur brune peu auréable.

Le bois du mûrier rouge d'Amérique (mumus rulora) est entièrement semblable. Celui du mùrier blanc est d'un jaune plus pâle et brunit moins à l'air ; de sorte qu'on pourrait en faire de beaux meubles. Je citerai encore, comme produisant des bois utiles ou pourant être utilisés, les arbres suivants :

Le Jî́RIER a PAPIER, morus papyrifera L., broussonetia papyrifera de Ventenat. Arbre originaire de la Chine, dont on n'a connu en Europe, pendant longtemps, que les indiridus mâles, jusqu’à ce qque Broussonet eùt décourert en Écosse le pap̧rier femelle qui y était cultivé sans y être connu. Cet arbre est très répandu dans la Chine, au Japon et dans les îles de l'Océanie, où son écorce fibreuse sert à faire du papier et des étoffes. Son bois est d'un jaune très pâle, poreux, léger et prenant mal le poli. On ne pourrait guère l'utiliser que pour l'intérieur des meubles.

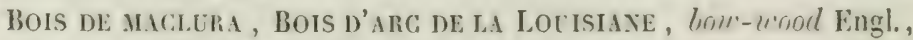
maclura auremtiacn Jutu. Cel arbre porte une sorose globuleuse de la grosseur et de la couleur d'une orange, pleine d'un suc jaune et fétide dont les Indiens se peignent la face pour se rendre plus effrayants à la guerre. Le bois est tout à fait semblable à celui du mùrier noir ; mais il perd sa couleur jaune à l'air et à la lumière, pour en prendre une brune foncée, désagréable. 
BOIS JIUXE DES TEINTURIERs, morus tinctorin L., bronssonetia tincturia Kunth., maclura tinctoria Nuttal. Cet arbre croît aux Antilles et au Mexique, où il açuiert des dimensions considérables, et où ses soroses sapides sont employées par les médecins en place de nos mûres. Son bois vient principalement de Cuba et de Tampico : il est en bùches quelquefois énormes de grosseur et de poids (150 kilogrammes), mondées à la haclıe, d’un brun jaunâtre à l'extérieur, d'un jaune vif et foncé à l'intérieur, avec des filets d'un rouge orangé. Ce bois est dur, compacte, susceptible d'un beau poli, et pourrait faire de très beaux meubles, malgré la couleur mordorée qu'il prend à l'air, lagutelle, d'ailleurs, est loin d'être désagréable; mais il est exclusivement employé pour la teinture en jaune. Il contient, en effet, un principe colorant jaune (le moriil) cristallisable, peu soluble dans l'eau, plus soluble dans l'alcool et dans l'éther, faiblissant par les acides, devenant orangé par les alcalis, et colorant en rert le sulfate de fer.

J'ai eu l'occasion d'examiner anciennement me matière résinö̈le nommée moelle de Cuba, gui était proposée pour le traitement de la teigne. J'ai facilement déterminé l'origrine de cette substance, en ayant trouvé plusieurs fois de semblable dans des cavités ou fissures du bois jaune de Cuba. Cette substance, qui me paraît ètre formée du principe colorant jusqu'à l'état de pureté, est sous la forme de plaques jaunes, eflorescentes, marbrées de louge à l'intériuur, et ayant presque l'aspect de l'orpiment naturel. Elle a une saveur amère et sucrée non désagréable, est très peu soluble dans l'eau froide, mais facilement et entièrement soluble dans l'alcool.

Les Anglais désignent à tort le bois jaune sous le nom de fustic, et les Portugais sous celui de fustrte, ce qui tend à le faire confondre avec le vrai fustet (rhus cotinus).

BoIS JAUNE DU BréSIL. M. Martius mentionne, dans son Systema materia med. veget. brasiliensis (page 123), trois espèces de broussonetia à bois jaune, qui peuvent répondre indifféremment au tatui-ibu de Vargraff et Pison, et qu'il nomme br. tinctoria, santhoxylon, brasiliensis. Il n'est donc pas étonnant qu'on trouve dans le commerce deux bois jaunes du Brésil différents de celui de Cuba, produits sans doute par les deux derniers broussometir, sans qu'on puisse les atribuer phus spécialement à l'un ou à l'autre.

Le premier, comnu dans le commerce sous le nom de bois juune du Brésil, arrive en billes considérables équarries, d'un jaune pâle à l'intéricur. Ce bois a une texture très fine, compacte, prend un poli satiné, et ne change pas à l'air. Il imite assez bien le bois citron de Haïti, ou hispanille; mais il est inodore. Il est quelquefois pourvu de 
débris d'une écorce épaisse, dont la conclıe subéreuse est imprignée d'un suc jaune analogue à la moelle de Cuba.

BOIS Jaune DE Para. Ce bois, fort différent du précédent, a ses fibres disposées par conches encheretrées, comme celles du santal rouge et de guelques autres légumineuses. De guelque côté qu'on le coupe, ces fibres viennent former à la surface de petites lignes creuses, comme des traits de burin, qui nuisent à son poli. Ce défaut, joint à son changement de couleur (qui, du jaune pâle, passe au brun sale, doit nuire à l'emploi de ce bois pour l'ébénisterie. Sa force et sa ténacité peurent cependant le rendre utile d'une autre manière.

Ce même bois est quelquefois vendu sous le nom de noyer de la Gutdelmupe, par confusion, sans doute, arec un bois du même genre provenaut de cette île. Il est en effet arrivé de la Guadeloupe, dans ces dermières années, sous le nom de bois de liésolu, un bois d'un jaune fale qui a beaucoup de rapports avec le bois jaune de Para, et qui est probablenent celui gui a porté le nom de noyjer de la fiundeloupe.

Bors IBAGASSE, brigussen guyanensis d'Aublet. Bois d'un jaune foncé devenant d'un jaune brun foncé à l'air. Il a une structure semblable à celle du bois jaune de Para, mais bien plus grossière ; il n'offre pas sur la coupe les cercles concentriques blanchattres des bois de mûrier et de machure. Il ne prend gu'un poli imparfait.

\section{FAMIILE DES ARTOCARPÉES.}

Les vịgétanx compris dans cette famille ne diffèrent guère des précédents que par l'absence complète de l'endosperme dans la graine. Ce sont donc, en général, des arbres à suc laiteux, à feuilles alternes simples on divisées, accompagnées de stipules caduques. Les fleurs sont monoïınes ou dioïques : les fleurs mâles disposées en chatons deuses et allongés, et les tleurs femelles portées en grand nombre sur des réceptacles charnus ; les fruits, formés par la soudure des ovaires féconlés, constituent des soroses qui peurent acquérir de grandes dimensions, par exemple dans le jaquicer ou arbre ì pain (artorarpus, de ä:s=s, pain, xxpros, fruit), dont les fruits servent encore aujourd'hui de pain a une partie des peuples de la Malaisie et de l'Océanie. Il y a deux espèces principales d'artorarpus; l'une, nommée rima (artocurpus incisir), est un ar Jore haut de 13 a 14 mètres, dont les feuilles, trìs grandes et incisées, ressemblent à celles du figuier; les fruits, ou soroses, sont rerdatres, plus gros que la tête, couverts de tubercules polyédrigues, et contiennent, près de la surface, au milieu d'une pulpe farineuse, de 40 ì 60 semences grosses comme des chataignes, et quni se mangent cie la même manière. Mais c'est la pulpe farineusé qui forme la partic 
la plus importante du fruit; car on la mange comme du pain, apres l'aroir fait cuire au four. Il y a une variété de rimu à sorose apyrène, plus grosse que la sorose à graines, et plus utile encore, puisqu'elle est unicquement formée de pulpe propre à faire du pain. Cet arbre, répandu naturellement dans toutes les îles de l'Océanie, est anjourd'lıui cultivé dans les Antilles.

La deuxieme espèce, le jaca (artoren'pus infegrifulia), appartient plus spécialement aux îles Malaises et à l'Inde. L'arhre est élevé de 13 à 16 mères, sur un tronc considérable; les feuilles sont plus petites que dans la première espèce, et entières. Les chatons miles et femelles, et par suite les soroses, sont portés sur le tronc et les gros rameaux. Ces dernì̀res pèsent de 25 à 30 kilog., et quelquefois 40 kilog. Les graines sont plus peties que dans la première espèce, et également bonnes à manger. La pulpe est jaunâtre, mollasse, très sucrée, mais d'une odleur désagréable.

On troure dans le commerce anglais, sous le nom de jucti-nood, le bois de l'un ou l'autre des deux arbres précédents. Il est d'un jaune pàle, perdant sa couleur et brunissant à l'air lorsqu'il n'est pas verni, mais il conserve une belle couleur jaune lorsqu'il est verni. Il est u'ès léger et un peu satiné.

Je dois citer encore comme appartenant aux artocarpées, deux arbres de propriétés et d'usages bien différents, puisque l'un sert à nourrir les hommes, et l'autre à les détruire. Le premier est l'arlure di la vache (yalactodendrum utile), observé par .II. de Humboldt dans plusieurs parties de la Colombie. Cet arbre fournit, par des incisions faites au tronc, une grande quantilé d'un suc blanc et doux comme du lait, que les habitants boivent à l'instar du lait de rache (.1 nm. chim. et pluys., t. VII, p. 182); le second est l'antiar des Javanais (antiuris toxicaria, dont le suc, très vénéneux, sert aux indigènes pour empoisonner leurs flèches. Enfin, je tois nommer le juratinera juianensis d'Aublet, arbre de 16 à 18 mètres d'élévation, dont le tronc peut avoir 1 mètre de diamètre ; le bois en est blanc, dur et compacte, à l'exception du cour, qui forme au centre un cylindre de 10 à 15 centimètres de diamètre. Ce dernier bois est très dur, très compacte, d'un rouge foncé, arec des taches noires qui imitent sur la coupe longitudinale l'écriture chinoise. De la vient qu'on lui donne le nom de bois de lettres de Chine, ou de bois de lettres mouchete; on le nomme aussi bris d'amourette moucleté. Il vient de Cayenne, ainsi qu'un autre bois plus large, nommé plus spécialement amourette de Cayenne, qui est très dense, d'un rouge marbié de noir, muni d'un aubier rougêtre. très pesant pareillement, bien moins large que le bois. Ce bois conticnt quelquefois, dans ses parties cariées, unc résine brune, insoluble dans 
l'eau, soluble dans l'alcool et les alcalis. J'ignore quel arbre le produit.

FAMILIE DES URTICACEES.

lienilles opposées on alternes, pétiolées, entières, dentées on quelquefois palmées; stipules ordinairement persistantes; fleurs polygames, très sourent monoïgues ou dioïqués par avortement, disposées en épis, en tête, ou paniculées; vraire libre, sessile, uniloculaire, contenant un seul orule dressé; fruit nu, ou renfermé dans le périanthe sec ou devenu bacciforme. Semence dressée, couverte d'un épisperme souvent soulé arec l'endocarpe ; embryon antitrope, dans l'axe d'un endosperme charnu; cotylédons ovés, plats ; radicule courte, cylindrique, supère.

\section{Orties.}

Ces plantes sont généralement herbacées, à écorce fibreuse suscepptible d'être traraillée conme le chanrre et le lin ; à feuilles stipulées, dentées, pourrues de poils canaliculés et glanduleux à la base, par où s'écoule une liqueur ìcre et caustique qui produit une chaleur brùlante et des ampoules sur la peau. Les fleurs sont verdàtres, unisexuelles, ordinairement monoį̈ques; les fleurs mâles sont disposées en grappes et formées d'un périanthe à 4 folioles arrondies et de 4 étamines. Les fleurs femelles ont un périanthe à 4 folioles dressées, dont 2 extérieures plus petites, quelquefois nulles, et 2 intérieures plus grandes; l'oraire e: supère, surmonté d'un stigmate velı; le fruit est entouré par le pírianthe persistant, membraneux, ou ayant l'apparence d'une baic. Le's deux espèces principales de notre pays sont :

L'Ortal grieche ou Or'tie brolaxte, urtirn urens L. Plante annuelle, haute de 3.3 à 50 centimètres, à feuilles opposées, orales, portées sur de longrs pétioles; les fleurs sont monö̈ques, réunies en grappes courtes, opposées et axillaires. Toute la plante est courerte de poils très piquants et brùlants; on s'en sert pour pratiquer l'urticutien, qui consiste à battre arec une poignée d'orties frâtches une région du corps sur largelle on reut appeler l'irritation. La plante sèche perd toute action irritante.

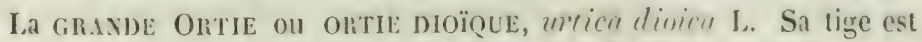
tétragone, hatite de 65 centimètres à 1 mètre, pubescente, très fibreuse : ses leuilies sont opposies, lancéolies-cordiformes, grossièrement dentées, moins piquantes que celles de l'espèce précédente; ses fleurs sont dioïques, herbacées, en grappes pendantes; ses semences sent oléagineuses, diurétiques suivant les uns, purgatives suivant d'autres. La 
grande ortie sert de nourriture aux bestiatux, dont elle angmente le lait. Les anciens l'employaient comme excitante, emménagogue, apéritive et astringente. II. le docteur Fiard a publié, dans le Journul de phermacie, I. XXI, p. 290, une observation sur les effets singuliers des tiges de l'ortie dioüque. (C'est par erreur que le Mémoire imprimé nomme l'ortie brûlante.)

\section{Pariétaire.}

Purieturiu "ffirinalis L. - Car. gén. Périanthe court, évasé, à 4 folioles; 4 étamines à filaments subulés, recourbés avant la fécondation, se redressant alor's avec élasticité et devenant plus longs que le périanthe ; oraire supère, ovoïde ; stỵle filiforme ; stigmate en pinceau ; un seul fruit luisant, oroïde, au fond du périanthe persistant.

La pariétaire présente une racine fibreuse, vivace; une tige rougeâtre, ramifiće dès sa base, haute de $0^{\mathrm{m}}, 50$, pubescente, toute garnie de feuilles; les feuilles sont alternes, pétiolées, ovales-lancéolées, pointues, un peu luisantes en dessus, velues et nerveuses en dessous, s'attachant facilement anx habits; les fleurs sont petites, rertes, ramassées par pelotons dans l'aisselle des feuilles, presque sessiles; on observe dans chaque groupe plusicurs fleurs hermaphrodites à ovaire stérile, et une seule fleur femelle. Celle plante est commune dans les fentes des vieux murs et le long des haies. Elle paraît contenir une quantité notable de nitre, auquel elle doit sa propriété diurétique.

\section{FAMILLE DES GANNABINÉES.}

Ilerbes annuelles, dressées, ou vivaces et volubiles, à suc ałpueux; feuilles opposées, à stipules persistantes ou caduques. lileurs dioïcues : fleurs mâles en grappes ou paniculées; périanthe herbacé, pentaphỵlle; 5 étamines insérées au fond du périanthe et opposées à ses divisions; fleurs femelles en épis agglomérés, accompagnées chacune d'une bractée, ou en chatons à bractées foliacées, imbriquées, biflores; périanthe monophylle embrassant 1 oraire uniloculaire, surmonté de 1 style court ou nul et de 2 stigmates filiformes, pubescents. Le fruit est un cariopse bivalve, indéhiscent, ou un askose renfermé dans le périanthe accru et persistant. La semence est dressée, privée d'endosperme ; l'embryon est recourbé en crochet ou en spirale; la radicule est supère. Cette famille se compose des seuls genres crmmabis (chanrre) et humulus (houblon). 
Ghanve cultive (fig. 13̌š).

C'minuthis sortirn : belle plante originaire de l'Asie, dont la tige est droite, d'une hauteur très variable, ramifiẻe, garnie de feuilles profondéncnt incisées, à divisions palmées, dentées, aiguës; feuilles oppuscés sur le bas de la tige, alternes à la partie supérieure. Les fleurs

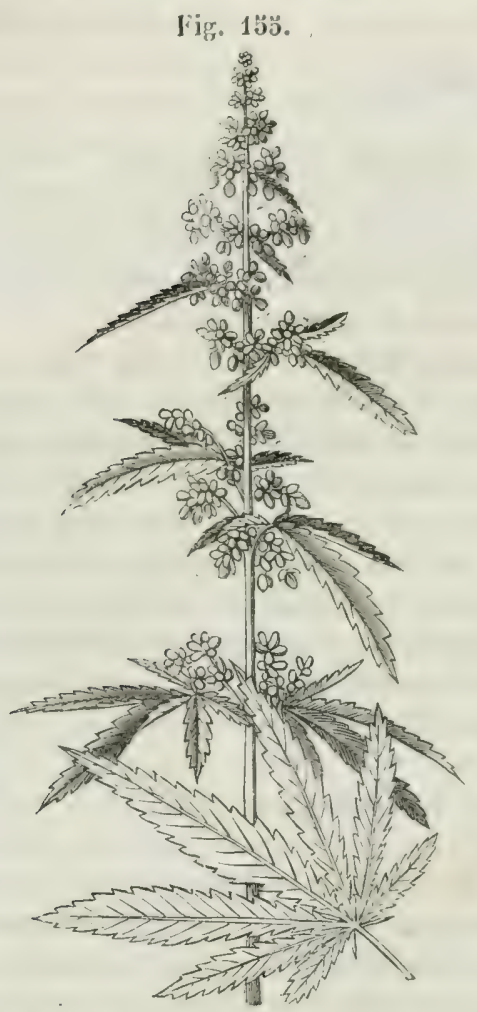

sont dioïques; l'individu mâle est plus petit, plus grêle et se dessèche plus vite que l'inclisidı femelle; cette faiblesse relative est cause que le vulgaire donne au chanvre mâle le nom de chanvre femelle et réciproquement. Les fleurs mâles ont 1 périanthe pentaphylle et 5 étamines; le périanthe des fleurs femelles est monophylle, persistant et embrasse le fruit qui est un askose ovale, lisse, verdàtre, à 2 valves se séparant par la pression. La semence est huileuse, émulsive, d'une odeur un peu vireuse. On en retire une huile qui sert pour l'éclairage et pour la fabrication du savon noir.

Le chanvre est cultivé dans presque tous les pays à cause de ses fibres corticales, qui, séparées de la partie ligneuse par le rouissage (1), constituent la filasse dont on fabrique ensuite de la toile et des cordages.

Ie chanre est pourvu d'une propriété enivrante, exhilarante et

(1) Le rouissagye est une opération qui consiste à faire tremper, pendant un certain nombre de jours, le chanve dans une eaustagnante, afin de dissoudre ou de détruire, par la putréfaction, les parties mucilaģineuses ou aulres, fui unissent les fibres corticales entre elles et au bois. Celte opération communique à l'eau des qualités malfaisantes, et les émanations qui s'en chlalent peuvent occasionner des maladies graves dans les lieux ou on la pratique. Aussi est-il defendu d'établir des routoirs dans le voisinage des habitations, et dans les rivières ou dans les eaux qui servent à la boisson des hommes el des animaux. (Voyez Annales d'hygiène publique ot de médecine légule, 1. I, p. 335; 1. VII, p. 237.) 
narcotique, qui parait résider dans une matière glutino-résineuse qui exsude de glandes placées à la surface de la tige et des feuilles. Ilais cette propriété est beaucoup plus déreloppée dans le chanvre de l’Inde et de la Perse, dont quelques botanistes ont fait une espèce particulière, sous le nom de cmmabis indica. Aujourd'lui on ne lui reconnait aucune différence essentielle arec le chanve d'Europe, ct on attribue la différence réelle qui existe entre leurs propriétés à l'influence générale de la température sur la production des principes actifs des régétaux. Cette raison est sans doute très fondée, mais il me semble aussi que les deux plantes ne sont pas complétement identiques. La plante de l'Inde est beancoup plus grande, puisque, dans nos jardins mimes, clle atteint facilement 4 et 5 mètres de hauteur; ses feuilles sont plus souvent alternes et ses fruits sont manifestement plus petits.

On se procure la résine de cette plante par un procédé singulier qui a de l'analogie avec celui qui est usité dans les îles grecques pour la récolte du ladanum. Des hommes, recouverts d'un habillement de cuir, parcourent les champs de chanrre, en se frotlant autant que possible contre les plantes. La résine molle qui les recourre s'altache au cuir; clle en est ensuite séparée et pétrie en petites boules auxquelles on donne le nom de churpus ou de cherris. En Perse, on prépare le churrus en exprimant la plante pilée dans une toile grossière. La résine s'altache au tissu et est séparée par le râtissage. Cétte résine possède à un très haut degré les propriétés enirrantes de la plante. La plante ellemême, séchée arec soin, est rendue pour l'usage des fumcurs sous les noms de ganja, gunjah et de bang. Enfin, on emploic de temps immémorial, en Arabie et dans tous les paỵs qui ont été soumis à la domination arabe, une préparation grasse de feuilles de chanvre, qui porte le nom de hashish ou hachich. C'est cente même préjaration dont les effets enivrants et hilarants ont été étudiés assez récemment par quelques Lommes sérieux, mais qui pourra devenir une source de dépravation pour beaucoup d'autres qui, blasés sur les plaisirs permis, en recherchent d'impossibles dans les divagations d'un entendement perverti.

\section{Howblou (fig. 156).}

Humulus lupulus L. Le houblon est pourvu de racines fibreuses, ligneuses et viraces, qui produisent tous les ans des tiges herbacées, sarmenteuses, hautes de 5 à 6 mètres, grimpant et s'entortillant autour des arbres ou des supports qui se trouvent à leur portée. Les feuilles sont opposées, pétiolées, échancrées en cœur à la base, à 3 ou 5 lubes, et dentées sur le bord. Les fleurs ont une couleur herbacée et sont tout's mâles sur un pied, toutes femelles sur un autre. Les premières 
sont en petites grappes paniculées au sommet des rameaux; les fleurs femelles naissent aux aisselles des feuille's supérieures; elles sont disposées en cones formés d'écailles membraneuses, au bas de chacune desquelles se trouve 1 ovaile surmonté de 2 styles subulés, ourerts, à stigmates aigus. Le fruit qui succède à chaque fleur femelle est une petite graine arrondie, roussâtrc, enveloppée par l'écaille calicinale qui a persisté.

Le houblon croît en France dans les haies : il est cultivé avec soin

lig. 156.

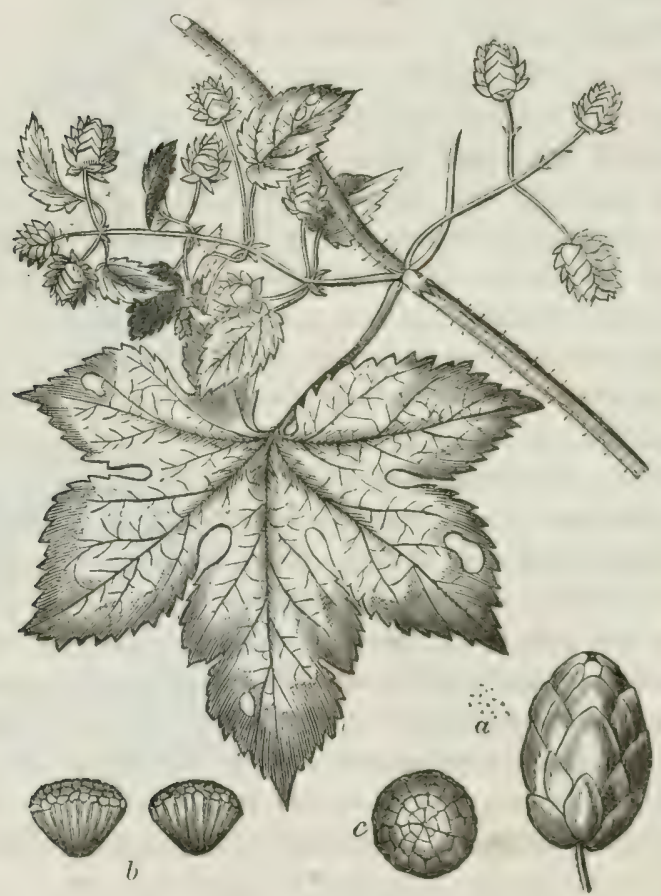

dans plusienrs contrées, notamment en Flandre et en Belgiçue, à cause de ses connes résineux et odorants, qui entrent dans la falrication de la biere. Tontes les parties de la plante sont pourves d'un principe amer qui les fait emplover contre les maladies da système lỵmphatique; mais ce sont surtout les cones (qui, lorsqu'ils sont d'une bonne qualité, sont chargés d'une poussière résineuse, jamne, odorante, à layuelle on attribue principalement les propriétés médicales du houblon. Cette poussière avait d'abord été considérée comme un principe immédiat et avait reçu le nom de lupuline; mais l'examen chimique a montré 
qu'elle était elle-même formée d'un grand nombre de principes inmédiats, et surtout de résine, d'huile colutile et d'une matière amime, soluble également dans l'eau et dans l'alcool, et communiquant à l'eau la propriẻtẻ de mousser fortement par l'agitation.

C'est cette matière amère qui porte aujourd'hui le nom de lupuline, bien que ce ne soit pas encore sans doute un principe immédiat pur.

On doit à II. Raspail une observation fort curieuse sur la ponssière jatme du houblon. C'est que cette matière qui, à la loupe, paraît sous la forme de petites gouttes résineuses, transparentes et homogènes, est véritablement organisée. Irais, à part cela, je n'ai pu rérifier les détails d'organisation obserrés par .I. Raspail, et, par conséquent, je n'almets pas, d'après lui, que cette substance soit un pollen solitaire, naissant sur toutes les parties des cônes du houblon femelle et pourant servir à sa fécondation, et encore moins que les glandes résiculaires des jeunes feuilles de houblon soient également un pollen nécessaire au déreloppement des bourgeons. Tout ce que l’observation microscopique m'a fait roir dans la poussière jaune du houblon, après l'avoir épuisée de ses principes solubles dans l'alcool, consiste à l'aroir trourcéc formée d'une masse uniforme de tissu cellulaire, amincie én cône et Pédiculée du còté qui l'attachait à la plante, érasée é bombée du côté opposé et telle que la représente la figure 156 (1). Je suis porté, en conséquence, à considérer cutte matière comme une glande formée par l'exubérance de petites parties du lissu cellulaire, et imprégnée de résine, comme cela peut aroir lieu natureliement sur un régétal abondant en parties résineuses, ou peut-être destincé à l'excréter au dehors.

\section{FAMILLE DES EUPHORBIACÉES.}

Feuilles communément alternes, quelquefois opposées, accoinpagnées ou privées de stipules; quelquefois nulles elles-mêmes, la plante étant réduite à l'état d'une tige charnue, cactiforme. Les fleurs sont unisexuelles, monoïques ou dioïques, solitaires, fasciculées, ou disposées en grappes ou en épis; (quelquefois les fleurs mâles et femelles sont entourées d'un involucre commun, simulant me fleur hermaphrodite.

Le périanthe est libre, simple, rarement double, à $3,4,5$ ou 6 divisions munies intéricurement d'appendices écailleux ou glanduleux; les étamines sont en nombre défni ou indéfini, insérées au centre de la fleur ou sous un rudiment d'oraire; les filets sont libres ou soudés, les anthères introrses ou extrorses, biloculaires, à loges sourent dis-

(1) a poussière jaune de grosseur naturelle; $b$ poussière jaune vue debout, au microscope; $c$ la même, vue perpendiculairement du cóté bombé. 
tinctes; les fleurs femelles ont un oraire libre, sessile ou très rarement stipité, ordinairement triloculaire, rarement bi- ou pluriloculaire ; charque loge renferme 1 ou 2 ovules collatéraux, suspendus ì l'angle central, au-dessous du sommet. Du sommet de l'oraire naissent antant de stigmates qu'il y a de loges, généralement sessiles, allongés, bifidés ou même multifides. Le fruit est sec ou légèrement charnu, comprosí d'autant de coques soudées (u'il ! arait de loges à l'ovaire; charfue coqque, ordinairement bivalse et s'ourrant avec élasticité, contiont une ou deux graines suspendues à l'angle interne; l'épisperme est crustacé, épais et formé de deux couches très distinctes; l'endosperme est charnu, huileux, renfermant un embryon homotrope, à colỵlédons foliacés, à radicule supère.

Les euphorbiacées composent une famille très vaste, multiforme ct cependant très naturelle, (qui tire son principal caractère de la siructure de son fruit polycoque. La plupart sont pourrues d'un suc laiteux, très âcre et sourent rénéneux; quelyues unes sont aromatifures. Les semences sont huileuses, rarement comestibles, le plus souresil pins ou moins fortement purgatives. Quelques enphorbiacées sont p'inrwes de racines féculentes qui sont d'un grand intérêt pour la nomriture des peuples de l'Amérique.

1I. A. de Jussieu a divisé la famille des euphorhiacées en sir sections ou tribus qui ont èté adoptées par tous les botanistes.

Premiere tribu, Euphorbiés. Loges de l'oraire uni-orulies; fleurs apétales, monö̈ques dans un inrolucre commun. Exemple: euphorbia.

Deuxième trihu, IIppomaxises. Loges mi-orulés; flemrs appétiles, en épis ou cu clatons, ponrues de grindes bractées min-ou multiflores. Exemples : cexcurarin, hurn, hipmomame, stillingin, stapium, etc.

Troisième tribu, Acadxpulis. Loges de l'oraire uni-orulées; fleurs apétales, conglomérées en épis on preșue en grappes. Genres: mercurialis, acalypha, alchornea, etc.

Quatrième tribu, Crotonliks. Loges uni-ovulécs; lleurs trìs sourent corollées, fasciculées, en épis, en grappes ou en panicules. Cienres :

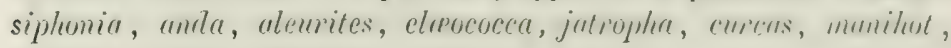
ricinus, croton, crozophora, etc.

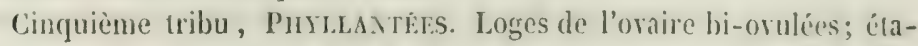
mines insérées au centre de la fleur. Genres: clnjtiu. andruchne, phyllanthus, emblica, etc.

Sixieme tribu, Buxéts. Loges bi-ovulíes; étamines insérées sous un rudiment d'ovaire sessile. Exemple : buxus. 


\section{Euphorbes.}

Il y a peu de genres dans le règne végétal qui justifient mieux que celui-ci l'idée que les végétaux analogues par leurs caractères de classilication, le sont érgalement par leurs principes constiluants et par leurs propriétés toxiques ou médicales. Il n'y a, en effet, pas une de's espèces qui le composent qui ne soit remplie d'un suc laiteux, ct donéc de propriétés âcres et corrosires tellenent intenses qu'on ne saurait les employer arec trop de prudence, et seulement à défaut do médicaments moins actifs, dont il suit plus facile de régler les effets.

Linné, considérant les euphorbes comme hermaphrodites, les avait rangés dans sa dodécandrie trigynie, et leur donnait pour caractère un calice monophylle i) 4 on 5 divisions; une corolle à 4 ou 5 pétales alternes arec les divisions du calice; 12 à 15 étamines fixées au réceptacle et entremêlées de filaments stériles; un oraire pédicellé au centre de la fleur, surmonté de 3 styles bifides; une capsule saillante hors du calice, formée de 3 coques monospermes. Hais aujourd'hui les botanistes considèrent le calice et la corolle de Linné comme un involucre qui renferme autant de fleurs monandres qu'il y a d'étanines, accompagncees chacune d'un périanthe propre écailleux, lacinié; au centre de toutes ces fleurs mâles se troure une seule fleur femelle pédicellée, accompagnée (quelquefois d'une autre arortée (royez la ligure 157). Celte manière de voir s'accorde mieux arec la place que nous donnons à la famille des euphorbiacées, à la suite des urticées et des amentacées.

Le port des euphorbes est très variable: quelques uns ont une tige épaisse, charnue, anguleuse, aphỵlle, ressemblant beaucoup à celle des cactus, et armée sur les angles d'épines géminées ou solitaires; les autres, qui sont les plus nombreux, ont des tiges frutescentes ou herbacées, garnies de feuilles Fig. 13\%.
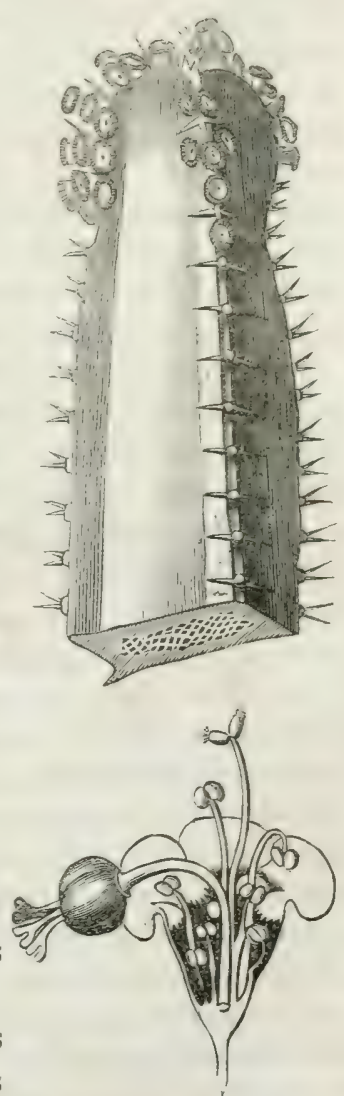
simples, sourent alternes. quelquefois opposées on rerticillies. Cies 
tiges sont presque tonjours ramifiées à leur partie supérieure, et les ramifications, le plus souvent disposées en ombelle et ensuite plusieurs fois dichotomes, portent des fleurs à leurs extrémités; une fleur solitaire, tenant la place d'une troisième branche, se trouse en outre dans chacune des bifurcations supérieures. On obserre d'ailleurs à la base de l'ombelle et à chaque bifurcation une colleretle de bractées verticillées ou opposées.

EuPIORBE DES ANCIExs, euphorbia antiquorum L. Tige triangulaire ou quadrangulaire, articulée, ramifiée, munie sur les angles de petits appendices foliacés et d'épines géminées, discrogrnte's. Les fleurs sont portées sur de courts pédoncules simples ou divisés et triflores; chaque fleur ou chaque involucre ne contient que 5 à 6 étamines. Cette plante croît en Afrique, en Arabie et dans l'Inde.

Euphorbe des Cavaries, enphorbia conariensis L. (fig. 157). Tige épaisse, quadrangulaire, haute de $1^{\text {"n }}, 3$ à 2 mètres, garnic de rameaux ouverts, dont les angles, ainsi que ceux de la lige, sont munis de tubercules rangés longitudinalement, de claacun desfuels partent denx aiguillons courts et dirregents, dont un est recourbé en crochet. Les fleurs sont sessiles, placées au-dessons des aiguillons, accompagnées de bractées ovales; l'involucre est à 10 divisions, dont jolus internes, charnues et d'un rouge obscur. Le fruit est très petit, lisse, jaunitre, formé de 3 coques monospermes. Cette plante croìt naturellement dans les îles C'anaries.

Luprorbe officinal, cuphorlia offeinurum I. Tige épaisse, droite, souvent simple comme un cierge, haute de $1^{\text {m }}, 3$ à 2 mètres, pourvue, sur toute sa longueur, de 12 à 18 côtes saillantes dont la crête anguleuse est garnie d'une rangée d'épines géminées. Les lleurs sont presque sessiles et d'un vert jaunâtre. Cette plante croìt naturellement dans l'Éthiopie et dans les parties les plus chandes de l'Afrique.

\section{Gomme-résine a'Euphorbe.}

La plupart des auteurs s'accordent à dire que c'est en faisant des incisions à l'écorce de l'enphombia officinumun et des deux esprices précédentes qu'on se procure l'euphorbe du commerce; mais la forme sous laquelle se présente toujours cette substance, indique ciu'elle a du couler naturellement, el les débris de rameaux toujours quadrangulaires, qu'on y troure quelquefois, n'est pas farorable à l'opinion que l'euphurlia officinarum en est la source principale. On en conclurait plutôt que l'euphorbe des pharmacies est exclusirement proshuit par l'euphlor'bia canariensis ou par l'euphorbia antiquorum.

L'euphorbe est en petites larmes irrigulières, jaunitres, demi- 
iransparentes, un pei friables, ordinairement percées de un ou de deux trous coniques qui se rejoignent par la base, et dins lesiquels on troure encore sourent les aignillons de la plante, dont un est recourbé. Il n'a presque pas d'odeur; sa saveur, qui est d'abord peu sensible, devient bientôt àcre, brùlante et corrosire. Sa poudre est un très violent sternutatoire, ce qui la rend dangrereuse à préparer.

L'euphorbe a quelquefois été administré à l'intérieur comme purgatif; mais, comme il est encore plus corrosif, son usage a presgue toujours été suivi des accidents les plus funestes. Il faut donc absolument se borner à l'employer à l'extérieur, où il produit un effet vésicant presque égal à celui des cantharides.

D'après les analyses de Braconnot, de Pelletier et de Brandes, l'euphorbe est composée de:

\begin{tabular}{|c|c|c|c|}
\hline & Bracounot. & Pelletier. & Brandes. \\
\hline Résine...... & 37,0 & 60,8 & 43,77 \\
\hline Cire ....... & 19,0 & 14,4 & 14,93 \\
\hline Caoulchouc. .... & , & $"$ & 4,84 \\
\hline Bassorine. . . . . & $"$ & 2 & $\nu$ \\
\hline Malate de chaux . & 20,5 & 12,2 & 18,82 \\
\hline - de potasse. . . & 2,0 & 1,8 & 4,90 \\
\hline $\begin{array}{l}\text { Sulfate de potasse. } \\
\text { - de chaux. . . } \\
\text { Phosphate de chaux. }\end{array}$ & $"$ & 1 & 0,70 \\
\hline Matière ligneuse . . & 13,5 & $"$ & 5,60 \\
\hline Eau ....... & 5,0 & 8 & 6.40 \\
\hline \multirow[t]{2}{*}{ Perte...... } & 3,0 & 0,8 & \\
\hline & 100,0 & 100,0 & 100,00 \\
\hline
\end{tabular}

La résine est d'une excessive âcreté, brunâtre, friable, fusible, soluble dans l'alcool, l'éther et l'essence de térébenthine, trè̀s peu soluble dans les alcalis. La cire ne paraît pas différer de la cire d'abeilles. Il résulte de ces analyses que l'euphiorbe n'est pas à proprement parler une gomme-résine, puisgu'on y trouve de la cire, du caoutchouc, et, au lieu de gomme, des malates de chaux et de potasse.

L'existence d'une grande quantité de surmalate de chaux dans les plantes charnues, à quelque famille qu'elles appartiennent, est un fait bien remarquable et gui semble indiquer une liaison encore inconnue entre la présence du sel et l'état de plante; de telle sorte que la production dans l'économie végétale d'une grande quantité de ce sel calcaire soluble, semble causer l'hypertrophie du parenchyme. Je citerai pour exemple les euphorbes charnus, les cactus, qui leur ressembleut 
tant en apparence, les jouharbes, les smlum, les agave, les aloìs, etc.

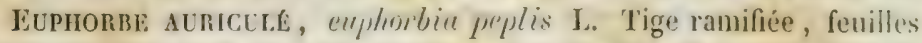
assez grandes, entières, orales-obtuses, auriculées d'un seul côté à lit base; fleurs axillaires, solitaires; rameaux tombants.

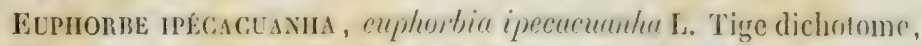
f euilies très entières, lancéolées ; pédoncules axillaires, uniflores, igalant les feuilles; lige dressée.

La racine de cette plante est très longue, fibreuse, cylindrarèe, blanchâtre, inodore, peu sapide et cependant romitive à la dose d'une dizaine de grains. Elle est employée comme ipécacuanha dans l'I mérique septentrionale, où elle est indigène. La racine de la plupart de nos euphorbes jouit de la même propriété.

Ésele ronde, erephorbin peplus L. Ombelle trifide; rameaux plusieurs fois dichotomes, munis d'inrolucelles orés; feuilles très entières, obovées, pétiolées. Cette plante est trìs commune clans les lieux cultivés, autour des habitations.

EPCRGE, exphorbia lathyiris L. (fig. 158). Racine pivotante, bisannuelle, produisant une tige droite, cylindrique, haute de $0^{\mathrm{m}}, 60$ ì

Fig. 158.

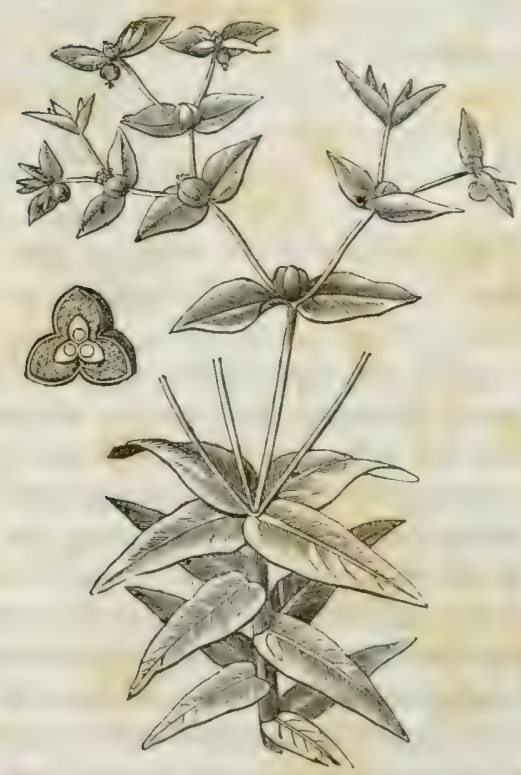

1 mètre, garnie de feuilles opposées, sessiles, oblongues, d'une couleur glauque. Celle tige est terminée par une ombelle à 4 rayons qui se bifur. quent plusieurs fois. Les bractées sont presque triangulaires et les pétales sont fortement échancrés en. croissant. Cette espèce se troure dans les lieux cultivés et sur le bord des chanups, en France, en Suisse, en Allemagne et en Italie. L'écorce le la racine desséchée et réduite en poudre purge à la dose de 1 gramme ì 1 gr $^{r}, 5$. I.cs semences, nommées autrefois grana regia minora, sont employées comme purgatires par les gens de la

campagne. On a proposé, il y a quelques années, de se servir dans le même but de l'huil obtenuc par expression. On en retire environ 
40 pour 100 . Celte huile est d'un fauve clair, bien fluide, d'une saveur àcre et d'unc odeur très marquée. Elle est complétement insoluble dans l'alcool; elle purge à la dose de 1 à 2 grammes; mais e'le a l'inconvénient de provoruer souvent le vomissement.

RéreiLle-matin, equhorbia hedioscopin L. Ombelle générale quinquéfide; partielle trifide; particulière trifiele ou dichotome. Involucelles obovés; feuilles cunéiformes dentées.

Ĺsule, enphorbir esula L. Ombelle multifide-bifide; involucelles sous-cordiformes, pétales subbicornes; rameaux de la tige stériles; feuilles uniformes.

La racine d'ésule, ou plus exactement l'écorce de racine d'ésule, a élé usitée autrefois comme un purgatif hydragogue ; mais il faut avoner qu'on n'est pas certain de la plante qui doit porter le nom d'ésule; ou plutôt ce nom paraît avoir été porté par un certain nombre d'euphorbes à feuilles étroites, plus ou moins semblables à celles du pin, tels sont les euphorbia pithyusa, esula, gerardiana, cyparissias, etc.

\section{Mercuriales.}

Genre de plantes à fleurs dioïques, très rarement monoïques, ayant In périanthe simple à 3 ou 4 divisions; les étamines sont au nombre de 9 ì 12 , à filets libres et exsertes, à anthères globuleuses, didymes. Les fleurs femelles portent un ovaire à 2 lobes ct biloculaire (rarencut à 3 lobes et à 3 loges), surmonté de 2 ou 3 styles divergents, deruticulés. Ia capsule est à 2 cơues (rarement 3 ) monospermes, épincuse ou cotonneuse.

Ce genre comprend une dizaine d'espèces indigènes ou exoliques dont deux sont très communes dans nos contrées et ne doivent pas être confondues pour l'usage médica!, à cause de leur activité très différente.

Mercuriale anxuele on Fomolr, mercurialis ammer L. Racine blanche et fibreuse; tige haute de 33 à 50 centimètres, lisse et branchue; feuilles opposées, longuement pétiolées, ovales-lancéolées, aignës, d'un vert clair et très glabres, comme la tige. Les fleurs sont dioïjues, les mâles rassemblées par petits parfuets sur des épis axillaires, grêles, interrompus, longs et redressés; les femelles solitaires ou géminées et presque sessiles. Elles sont formées d'un périanthe vert, à 3 folioles, comme les mâles, et d'un oraire didyme et à 2 styles divergents (1). Cette plante croît dans les lieux cultivés, antour des

(1) J'ai quelquefois trouvé sur la mercuriale un nvaire à 3 lobes el ì 3 styles, dont le fruit était par conséquent à 3 coques monospermes, soudées et hérissées de piquants. Ce fruit ressemblait alors parfaitement à celui du ricin. 
habitations ; elle a une odeur nauséeuse; clle est laxative et quelquefois drastique, mais toujours beaucoup moins que la suivante.

Mercurale vivace ou des boIs, mercurinlis perennis L. Tiges droites, non divisées, à peine hautes de 35 centimètres, chargées de quelques poils, et garnies de feuilles courtement pétiolées, ovales-lancéolées, pointues, dentées, un peu rudes au toucher et d'un rert sombre. Les fleurs, mène femelles, sont assez longuement pédonculées. Cette plante croît dans les bois; elle est plus fortement purgative que la première, et son ingestion dans l'estomac a sourent été suivie d'accidents plus ou moins graves. Elle contient une petite quantité du même principe colorant bleu qui distingue la maurelle ou tournesul, et son suc colore le papier en bleu. La mercuriale annuelle en offre également, comme on peut le voir par la couleur bleue que prend l'écorce de sa racine pendant sa dessiccation.

Maurelle ou Tournesor, crozojphore tinctorin Yeck., crotur tinetorium L. Cette plante, comprise dans le genre roton par Linné, en differe par des caractìres très tranchés et notamment par la présence d'une corolle et par le petit nombre de ses étamines. Elle est pourvue d'une racine fibreuse et d'une igge grêle, rameuse, lraute de 35 centimètres environ. Ses feuilles sont molles, alternes, pétiolées, wéesrhomboïdales, ondulées sur le bord, cotonneuses et blanchàtres. Les fleurs sunt monoïques, petites, disposées en grappes courtes; les mâles rassemblées à la partie supérieure, les femelles placées à la base et longuement pédonculées. Les premières ont un calice à 5 divisions, une corolle à 5 pétales, et 5 étamines (rarement $\mathrm{S}$ ou 10 ) dont les filets sont soudés par le bas en une colomne centrale; anthères extrorses. Les fleurs femelles ont un calice à 10 parties linéaires, la corolle nulle, l'ovaire sessile, triloculaire. Le fruit est longuement pédonculé et pendant; il est épineux et à 3 coques monospermes, comme celui des ricins.

Je pense que celte plante doit son nom de maurelle à une certaine ressemblance avec la morelle (solemum nigrum), et celui de foninesol ou d'héliotrope, à l'ancienne fable de Clytie amante du suleil. Elle croît daus le midi de la France, en Lspagne, en Italie et dans le Ifvant. On la cultive principalement an Grand-Gallargues (Gard) pour la préparation du toumesol en dropecux. A cet effet, on récolte les fruits et les sommités de la plante, on lés écrase et on en exprime le suc dans lequel on trempe des chiffons ou de la toile grossière, que l'on fait sécher. Cela fait, on suspend ces chiffons dans une cure en en pierre, an fond de laquelle on a mis un mélange d'urine putréfiéc et de chaux vive. Par l'action de l'ammoniaque qui se dégage, et de l'oxigène de l'air, les chiflons que le suc de la plante arait teints en 
rert deviennent rouges; on leur fait subir une seconde immersion dans le suc de maurelle et une nouvelle exposition à la rapeur ammoniacale, et on les envoie dans différentes parties de l'Europe et surtout en Hollande, où leur matière colorante est utilisée pour la coloration des fromages, des pâte's, des conserves et de diverses liqueurs. Mais, ainsi que je l'ai dit précédemment (page 82 ), its ne paraissent pas servir à la fabrication du tournesol en pains.

Excecinta arallocha, arbre armylant. Grand arbre des îles Moluques qui a été ainsi nommé parce que si par malheur, en le coupant, le suc âcre et laiteux dont il est rempli, tombe dans les yeux, on court risque de perdre la vue. Son bois est d'une couleur ferrugineuse, dur et fragile comme du verre, très amer, résincux et s'enflamme arec une grande facilité. Il a une si grande ressemblance arec le calambac qu'on peut à peine l'en distinguer, et plusieurs personues ont assuré ì Rumphius qu'il était enroyé en liurope comme bois d'aloès. Je pense aroir tronré ce bois dans les anciens droguiers de l'Hôtel-Dieu de Paris et de la Pharmacie centrale. Il est noueux, très pesant, compacte et étonnamment résineux. Il est à l'extéricur d'un brun rougeâtre uniforme; mais la nouvelle section qu'y produit la scie offre une couIeur un peu plus grise, margnée de taches noires dues à un suc particulier extravasé. Sa cassure transversale n'ofire pas de tubes longitudinaux, ce qui tient sans cloute à la grande quantité de résine dont tous ses raisseaux sont gorgés. Il a une forte odeur de myrrhe et de résine animé mêlées; son intérieur présente des excavations remplies d'une résine rougeàtre qui a qunclque analogie arec la mỵrhe; il se réduit en poudre sous la dent et jouit d'une saveur amère; il répand un parfum très agréable lorsqu'on le brùle ou (qu'on le chauffe sur une plaque métallique.

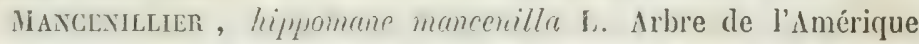
inter-tropicale, célèbre par la qualité vénéneuse de son suc laiteux, qui serrait autrefois aux naturels pour empoisonner leurs flèches, et que les nègres emploient encore aujourd'hui comme poison, par des motifs de rengeance. On a même été jusqu'à dire que l'ombre de l'arbre était dangerense, ainsi que la pluie qui arait lavé son feuillage; nais ces dernières assertions ont été démenties par plusieurs voyageurs et par Jacquin en particulier. Les fleurs sont monoïques; les màles disposées par petits parguets ou par épillets alternes, le long d'un axe commun, chaque épillet étant pourvu de deux bractées concares; les fleurs femelles solitaires ou placées à la base des épillets mâles. Le fruit est un drupe qui a la forme, la couleur et l'odenr d'me petite pomme; aussi peut-il être l'objet de méprises funestes pour les enfants. Il est formé d'uu sarcocarpe à suc laiteux, qui, en se desséchant, se divise en 
14 côtes peu marquées, séparées par des sillons réguliers allant dlu pédoncule au pôle opposé. L. noyau est osseux, épais, indéhiscent, à surface inégale, sillonnée, armée d'apophṣses tranchantes, irrégulières. Les loges sont monospermes, sourent privées de semence.

Sablier elastiQ̨ee, hu'e creppitans L. Grand arbre de l'A mérique, à suc laiteux très âcre, à feuilles grandes, alternes, cordiformes, longuement pétiolées, ct à fleurs monoïgues. Les fleurs mâles forment des chatons denses, multiflores, longuement pédonculés; les fleurs femelles solitaires, présentent un oraire à 12-1S loges, surmonté d'un long style terminé par un large stigmate radié, offrant autant de rạons qu'il y a de loges à l'ovaire. Le fruit est une capsule ligneuse recourerte d'un sarcocarpe très mince, et composée d'un grand nombre de corgues qui, en se desséchant, s'ourrent arec élasticité en deux ralies, se détachent instantanément de la colonne centrale qui les tenait unies, et sont lancées au loin en produisant un bruit semblable à celui d'un coup de pistolet. Ses semences sont plates, lenticulaires, à épisperme ligueux, à amande sèche et purgative, mais inusitée.

\section{Siphonle Clastlque, - Caoutchouc.}

Siphonia elastica Pers.; siphonia caluchu Rich. ; hevea guianensis Aubl. ; jatropha elastica L. f. Arbre de 16 à 20 mètres le hauteur, sur un tronc de 80 centimètres de diamètre. Les rameaux sont garnis à leur extrémité de feuilles rapprochées, longuement pétiolées, composées de 3 folioles ovales-allongées, pointues, entières. Les fleurs sont monoïgues, munies d'un périanthe simple à 5 divisions. Les étamines sont soudées en une colonne portant 5 ou 10 anthères, verticillées en une ou deux séries, fixées au-dessous du sommet. L'oraire est à 6 côles, triloculaire, a 3 loges uni-ovulées. Le fruit est une grande capsule formée de 3 corques ligneuses, arrondies, s'ourrant avec élasticité en 2 valves, à la manière du sablier élastique. Les semences sont arrondies, à épisperme lisse, roussâtre, marbré de noir. L'amande est blanche, huileuse, d'un goût agréable. On peut la manger sans aucun inconvénient.

I. caoutchouc, nommé vulgairement gomme élastique, est une substance d'une nature toute particulière qui se troure ì l'élat émulsif dans le suc laiteux d'un grand nombre de végétaux appartenant, pour la plupart, à des fanilles riches en plantes rénéneuses on suspectes; tels sont la plupart des figuiers, l'arbre à pain, plusieurs apocynées, lactucées et paparéracées. Mais aucun de ces régétaux ne peut être comparé pour l'abondance du produit à l'hécé de la Guỵane. I.e suc laiteux de cet arbre, obtenu par des incisions faites au tronc, se prend à l'air en une masse tenace et très élastique. Mais ordinairement, tandis qu'il 
est encore bien fluide, on l'applique, couche par conche, sur des moule's de terre, et on fait sécher chaque conche à l'air arant d'en ajouter une nourelle. Lorspu'on juge l'épai-seur suffisante, on brise le moule el on le fait sortir en morceaux par une ourerture lainsée au vase fabriqué par ce moren. La forme la plus ordinaire du caoutchonc est donc celle d'une gourde; quelquefois cependant les Indiens lui doment celle d'un oisean ou de quelque autre animal : on se contente aussi, depuis un certain nombre d'années que le canutchonc est derenu l'objet d'un commerce étendu, de le réduire en masses solides assez volumineuses.

Le caoutchonc, tel gue nous l'avons, est une substance brunattre, demi-transparente lorsqu'elle est en lame mince, très souple et éminemment élastique. Il se fond au feu, se boursoulle considérablement, et brùle arec une llanme très blanclie, en rípandant une fumée odorante très épaisse. Il est insoluble dans l'ean froide, se ramollit senlement dans l'eau bouillante; est insoluble dans laalcool, mais soluble dans l'éther pur, dans le sulfure de carbone, le naphte et les huiles rolatiles. L'acide sulfurique le charbonne superficiellement ; l'acide nitrique le dissout, en dégageant de l'azote, de l'acide carbonique, de l'acide cyanhỵdrique, et formant de l'acide oxalique. L'acide chlorhydrique, l'acide sulfureux, le chlore, l'ammoniague, n'ont pas d'action sur lui. Cette inaltérabilité du caoutchouc en présence de plusieurs agents chimiques très éncrgiques, le rend précieus pour la disposition des appareils de chimie, et pour la fermeture des flacons à produits volatils.

On a supposé pendant longtemps que die caoutchouc était composí de carbone, d'hydrogène, d'oxigène et même d’azote, parce que celui du commerce, décoinposé au feu, domne une petite quantité d'ammoniaque. Mais cela tient à des principes étrangers et surtont à l'albumine du suc régétal, qui ont été entraínés dans sa coagulation. II. Farada! ayant analı́ sé du caoutchouc pur et très blanc, séparé par lui du suc récent du siphonii, l'a trouvé uniquement composé de carbone 87,2; hygdrogène 12,8 ; ce qui répond à $\mathrm{C}^{8} \mathrm{HI}^{7}$.

Le caoutchouc distillé fournit $0,8.5$ de son poids d'une huile volatile très fluide et très légère, qui est un mélange de plısieurs hydrures de carbone de composition et de volatilité différentes (1); mais qui, dans son cusemble, peut devenir d'une grande utilité par la propriété qu'elle a de dissoudre le caoutchonc mieux que ne le font l'éther, le naphte th les huiles volatiles ordinaires. On peut employer au mème usage les essences rectifiées des goudrons de bois et de houille et, d’après II. Bon-

(1) Bouchardat, Journal de tharmacie, I. XXIII, p. $45 \%$. 
chardat, l'essence de térébemhlhine clle-même, ap̣rès qu'elle a été distillée sur de la brique chauflée. Cépendant tous ces dissolvants présentent linconvinient de donner an canutchouc qu'ils abandonnent par leur exaporation, une qualité pois-ense qu'il ne perd que par me très longue exposition à l'air.

Le caoutchouc est devenu l'objet d'un commerce considérable par l'application gui en a élé faite à la fabrication de tissus élasticyues ot d'iroffes imperméables, indépendamment de l'usage flu'on continue d'en faire pour fabriguer des chanssures imperméables à l'ean et pour enlerer, à l'aide du frottement, les traces de cravon sur le papier.

\section{Manihot, Manioc ou Magnoc.}

Les mamihot constituent un genre de plantes que Limné avait encore réunies aux jutropha, mais qui s'en distinguent principalement par l'absence de la corolle et par leurs étamines libres, au nombre de 10, dont 5 alternativement plus courtes. II. Kunth avait domne à ce grenre le nom de janipher; mais II. IEndlicher et I. Pohl lui ont rendu le nom de momilnet qui lui avait été domné par Plumier et par Adanson, bien que cette appellation barbare sorte des règles ordinaires de la nomenchature linnéenne. On en connaît un assez grand nombre d'espèces ou de variétés dont deux surtout méritent d’être citées tant par l'opposition de leurs propriétés, qui rappelle celle qui existe entre les amandes douces et amères, que par l'usage général que les habitants de l'Amérique font de leurs racines féculentes pour leur nourriture.

I'une de ces espèces, qui porte les noms de manioc domr, rumugune, aipi, jura dulee (momihot aipi $\mathrm{Pohl}$ ), ne contient dans sa racine aucun principe dangereux, de sorte qu'on peut la manger simplement cuite sous la cendre, ou dans l'eau, comme les pommes de terre, et que les animaus la mangent crue, sans aucun inconrénient; mais l'autre espèce, nomméesplus spécialement mumilnut, mermiur comer, jura ameargn,

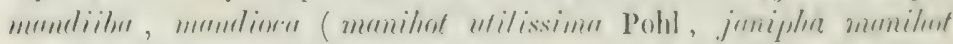
Kunth), contient dans sa racine un suc chargé d’un poison des plus v jolents. Ce prison, gui est trìs altérable, paraît être de l'acide cyanhludrique ou un corps ficilir it se transformer en cet acide, deapres les experiences de My. Boutron et $\mathrm{O}$. Henry (1); la wolatití de ce priucipe et la facilité arec layuelle on le détruit par la fermentation, explicyue comment les peuples grossiers de l’. Imériçue ont trouré le moven de retirer de la racine amylarce qui le renforme, un aliment abondant et salutaire.

A cel cefer, on mende lat racine de son écoree, on la réduit en pulpe an moỵen d'une ripe, fet un la renferme dins un sac de palmier fort

1) Mémoires de l'Académio de médecine, l'aris, 1836, t. V, P. 212. 
long, étroit, et tellement tissu qu'il pent s'allonger ou se rétrécir ì rolonté, chl deignant ou en rapprochant ses deux extrémités: on suspend ce sac par sa partie supérieure à une perche posée horizontalement sur deux furches de bois: ct, après l'aroir agiti pendant quelque temps, on suspend à son extrémité inferiemre un raissean très pesant qui, faisant loffice de poids, ex exprime le suc de le recoit en mème templs. Lorsque le sac est bien exprimé (1), on l'expose dans des cheminées, et, fuand il est sec, on en retire le contenu pour le pulveriser. La poudre que l'on obtient ainsi est noumée furime de immirior: : c'est un mélange d'anidon, de fibre régétale ct d'un peu de matiere extractive; on en fint du pain en la mélangeant arec de la farine de froment ; mais on obtient de la racine seule du manioc beaucoup l'antres produits alimentaires, qui portent les noms de counpre, messme, monssache ou cipipa, tapiolia, etc.

Le romarne se prépare arec de la racine de manioc râpée, exprimée, et séchée d'abord sur des claies exposées it la chaleur. On la crible alors pour lohtenir en petites parties d'un volume a peru près égal, et on la chauffe par partie, danss de's chaudières de fer modérément chauffées, jusqu'à ce que la racine ait subi un commencement de torréfaction. Cette substance se gonfle prodigieusement quand on la clauffe arec de l'eau ou ciu bouillon, et forme des potages très nourrisithits.

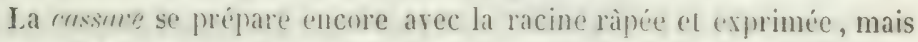
non séchée, que l'on ćlend en forme de gàteau mince sur une plaque de fer chauffée. L'anichn et le mucilage, en cuisant et en séchant, lient toutes les parties de la pulpe et en forment un biscuit solide, qui jouit d'une grande faveur auprès des créoles.

La moussarthe on le cipiju est la fécule pure de manioc qui a été entraincée far le suc de la racine soumise à l'expression, et que l'on a parfaitement lavée et séchée à l'air. Depuis quelques années on a importé de la Martinique en France une quantité considérable de cette fécule, qui a ėté vendue comme arrow-root. Cétle même fécule, séchée sur des plaques chaudes, se cuit en partie et s'agglomère en grrumeaux durs et irréguliers, qui portent le nom de trpiokia.

La moussurche se distingue facilement de l'arrow-root lorsqu'on l'examine au Fig. 159.

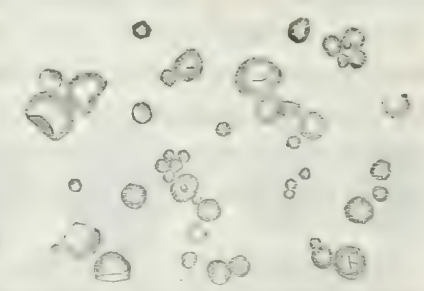
microscope (fig. 159). Elle y paraît formée de granules presque tous

(1) Cet ancien procédé des naturels américains a depuis longtemps été remplacé par l'usagre de presses plus ou moins analogues à celles dont nous nous servons. 
sphérigues, beaucoup plus petits que ceux de l'arrow-root, plus petits aussi que les grains adultes de l'amidon de blé et d'une égalité de volume beaucoup plus grande.

Le tripiolir est en grumeaux très durs et un peu élastiques; gonfle et délayé dans l'ean, il fournit une dissolution qui blenit fortement par l'iode. Délayé dans l'ean et vu an microscope, il offre encore un grand nombre de très petits grains sphérigues semblables à ceux de la moussache; Ic reste se comprose de tíguments gonllés et plissés.

Le tapioka n'est pas entièrement soluble dans l'cau froide, comme quelyues personnes l'ont avancé. Il forme avec l'eau bouillante un empois qui offre un caractère particulier de transparence et de viscosité. Soumis a une longue ébullition dans une grande guantité d'eau, il laisse un résilu insoluble qui se précipite facilement. Ce résidu, étendu d'eau ct coloré par l'iode, paraît au microscope sous la forme de flocons muqueuc' qui n'ont aucun rapport avec les téguments primitifs.

\section{Ricin (fig. 160).}

Ricinus communis L. Le ricin crô̂t naturellēment dans l'Inde, en Afrique et sans doute aussi en Imérique; on le cuitire arec succès dans le midi de la France et même dans nos jardins. C'est une très belle plante annuelle (1), haute de 2 à 3 mètres, clont les feuilles sont très larges et à $S$ à 9 divisions palmées, ce qui lui a fait donner le nom de palmu christi; clle est ruclquefois dioïque on polygame; d'autres fois Jes fleurs mâles et femelles sont sur un même pied, et disposées en épis síparés; mais le plus ordinairement, et tel paraît être l'état maturel de la plante, ces deux sortes de fleurs sont réunies sur un même épi, less fleurs mâles au bas, sous la forme de houpes jaunes dorées, et les fleur's femclles à la partie supérieure, formées en pinceaux d'un rouge foncé. Les fleurs mâles sont formées d'un involucre ou calice à 5 divisions, renfermant un grand nombre d'élamines à filaments très ramiliés, dout chaque extrémité est poursue d'une anthère à 2 loges. Les fleurs fomelles sont formées d'un calice à 5 divisions et d'un oraire triloculaire hérissé de pirfuants, terminé par un style court et par 3 stygmates profondément bifides, ronges, et plumeux. Le fruit est formé de 3 coqués épineuses qui se séparent à maturité. Chaque coque renferme une semence

(1) Beaucoup de personnes pensent que le ricin, qui esl herbacé et annuel daus nos climats, peut devenir arborescent et virace dans les elimats chauds, et notamment en Afrique. Mais, d'aprés Willdenow, jamais te ricin annel ne devient visace, et, réciproquement, jamais le ricin vivace, gu'il nomme ricinus ufrienms, ne devient aunuel. Alors ces deux ricins constitueraient deux espèces différentes. 
ovale, convexe et arrondie du côté extérieur, aplatie ct formant un angle saillant du còté intérieur. La surface de la semence est lisse, luisante et d'un gris marbré de brun. La robe est mince, dure et cassinte; l'amande est blanche, d'unc sareur douceâtre, mêléc Fig. 160.

d'une àcreté plus ou moins marquéc. L'ombilic est sulmonté d'un appendice charnu, assez volumineux, qui, joint à la forme générale de la semence, lui domne assez de ressemblance avec la tique des chiens, autrefois nommée ricin, d'où la semence a pris son nom. Immédiatement au-dessous de l'appendice, du côté externe, se trouve un espace comprimé qui simule un écusson.

On trouve dans le commerce deux sortes de ricins, ceux d'Amérique et de France; plus rarement ceux du Sénégal.

Les ricins d'Amérique (fig. 161) sont plus gros, d'une couleur plus foncée, d'une marbrure plus décidée, d'une âcreté très mar--

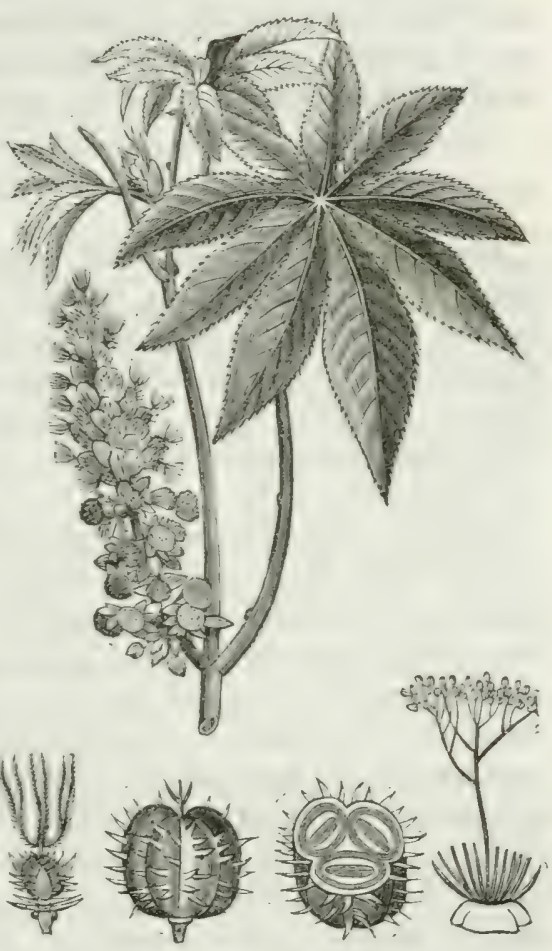
quée. La pellicule qui recourre l'amande est argentée, et exsude guelquefois une natière spongietue et brillante qui remplit tout l'intervalle entre elle et la robe.

Longueur de la semence, 14 millimètres; largeur, 9 millimètres ; épaisscur, 7 millimètres,

Les ricins de France (fig.

Fig. 161.

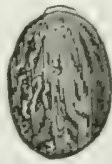

Fig. 162.

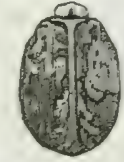

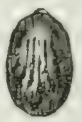

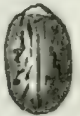
162) sont petits, plus pâles, d'une marbrure moins prononcée, presque privés d'âcreté. Longueur, 9 à 13 millimètres; largeur, 7 à 8 millimètres; épaisseur, 5 à 6 millimètres.

Les ricins du Sénigyal sont semblables, pour le volume, à ceux de France; mais ils présentent la marbrure foncée des ricins d'Amérique. 
Les ricins servent en France, comme en Amérique, à l'extraction d'une huile qui est très usitée comme purgative. On a longtemps prétendu que l'àcreté plus on moins mar(fuée de cette huile ne résidait pas en elle-mème ou dans les lobes de l'amande, et qu'clle était due à un principe particulier, contenu, soit clans la robe de la graine, soit dans le germe; nu des premiers j'ai annoncé que la corgue était insipide, que le germe n'arait pas une sareur beaucoup plus marquée que l'amande, et que l'amande privée de germe était àcre par elle-même.

\section{Huile de ricins.}

Autrefois cette huile nous était exclusirement fournie par l'Amérique, et principalement par le Brésil et les Antilles; mais elle était toujours mêlée d'huile de pignon d'Inde (cuires purgans), ce qui obligeait à la faire bouillir pendant longtemps avec de l'eau, pour volatiliser le principe àcre de la dernière semence. Halgré cette opération, l'huile élait toujours très âcre, plus ou moins colorée et d'un emploi fort désagrẻable.

En 1809, pendant la grande guerre continentale, on a commencé à extraire l'huile des ricins cultivés dans le milli de la France; alors, se fondant sur le procédé usité en Amérique, on pilait les ricins et on les faisait bouillir daus l'eau pendant longtemps ; il en résultait une écume huilense, qum l'on chanffait dans une autre bassine, pour évaporer l'eau; on passait l'huile à travers un blanchet; on obtenait ainsi une huile très douce, mais colorée. Bientôt aprèn on a recomnu l'inntilité de toutes ces opérations et on n'extrait plus aujourd'hui l'huile de ricins que par la simple expression à froid, ou à l'aide d'uue faible chaleur. L'huile obtenur à froid est presgue incolore, transparente, épaisse, filante, d'un goût à peine sensible et d'une odeur nulle. Elle purge doucement à la dose de 15 à 45 grammes. Le tourteau épuisé d'huile est un purgatif beaucoup plus actif, ce qui semble prourer que l'huile ne doit sa propriété qu'à me petite quantité du principe drastique qu'elle a dissoute pendant l'expression (Joum. chim. mirl., 1825, p. 108; Journ. de pharm. et chim., 1848, p. 189).

Pendant quelques années, la récolte des ricins de Nìmes ayant manqué, le commerce nous a fourni de nourean de l'huile de ricin d'Américune et de l'Inde, et alors nous arons ajpris que les Inglais et les Américains, éclairés par la belle qualité de l'huile de ricin de Vimes, avaient aussi abandonné l'ancién procédé de fabrication et se bornaient à la seule expression à froid.

D'après II. P'éreira, les deux huiles d'Amérique et de l'Inde peurent ètre aussi incolores et aussi privées de goùt que celle extraite à froid en 
Europe; mais je leur troure toujours une légère âcreté, et surtout une odeur assez marquée. Eilles sont du reste parfaitement belles (1), et pour donner une idée de l'importance acquise a leur importation, je dirai qu'en 1831, il est entré en Angleterre:

D'huile de ricins de l'Inde orientale. . . . 343373 livres.

des colonies anglaises d'Amérique ...... 25718

- des Étals-Unis d'Amérique. 22669

391760

L'huile de ricins est siccative; elle est soluble en toute proportion dans l'alcool absolu, propriété qui la distingue de toutes les autres huiles fixes. Cette solubilite diminue rapidement arec la force de l'alcool; celui à 88 centièmes n'en dissout plus que le 6" de son poids. L'huile de ricins diffère d'ailleurs des autres huiles par sa nature intime : andis que le plus grand mombre de celles-ci se convertissent, par la saponification, en glỵcérine et ('n acides oléique et margarique; l'huile de ricins, dans les mêmes circonstances, fournit une très petite quantité d'un acide solicle, nacré, cristallisable, fusible senlemu'nt i $130^{\circ}$, nommé ucide marguritique $\left(\mathrm{C}^{3.5} \mathrm{II}^{31} \mathrm{O}^{6}\right)$; la presgue totalité de l'acide gras constitue un autre acide nommé ŕlnüud lypre, liquide, cristallisable cependant à quelduess degrés au-dessous de zéro; soluble en toutes propor-tions dans l'alcool et l'éther.

L'huile de ricins traitée par l'azotate de mercure ou par l'acide hypo-azotique se prend, au bout de quelque temps, en une masse jaune et d'apparence cireuse qui, lavée à l'eau et traitée par l'alcool bouillant, fournit un corpss gras nommé prnlmine. Celui-ci, saponifié par les alcalis, fournit un acide julmique, cristallisable, fusible à 50 degrés, facilement soluble dans l'alcool et l'ẻther.

\section{Semences de Médicinier sauvage.}

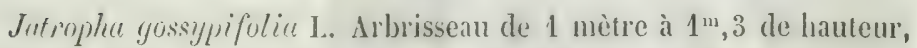
croissant dans les contrées chandes de l'Amérique. Ses feuilles sont cordiformes, à 3 ou 5 lobes acuminés, ct finement dentées; les fleurs sont disposiés en petits corymbes opposés aux feuilles, monoüques ou polygames, pourvues d'un calice à 5 divisions et d'une corolle à 5 pétales distincts, deux fois plus longs que le calice; les étamines sont au

(1) Celle des Ėtats-Unis laisse précipiter par le froid une quantite assez considérable de stéarine. 
nombre de 8 a 10 , monadelphes par le bas, libres par le haut; l'ovaire est entouré par 5 glandes aigruës, et surmonté de 3 stỵles filiformes bifides. Le fruit est une capsule unie, arrondie, grisâtre, formée de 3 coques monospernes. Les semences (fig. 163) ressemblent presque exactement à celles du ricin; mais elles n'ont que 7 millimètres de

Fig. 163.

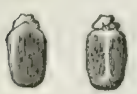
longueur, 5 de largeur et 3 d'épaisscur. La caroncule charnue de l'ombilic est très développée, et non accompagnée de l'écusson comprimé qui distingue le ricin.

La robe est lisse, luisante, fauve, avec des taches blanches et noires. N'ayant eu en ma possession qu'une petite quantité de ces semences, je n’ai pu en extraire l'huile, pour en déterminer les propriétés.

\section{Semences de Gurcas purgatif.}

Pignon d'Inde, pignon des Barbades, gratne de yédicinier. Curces purgans Adans.; jatropha curcas L. L'arbrisseau qui produit cette semence croît dans toutes les contrées chandes de l'Amérique, aux lieux un peu humides. Il est de la grandeur d'un fignier, très tonffu, rempli d'un suc laiteux, âcre et vireux. Les fleurs sont petiles, nombreuses, réunies en lsouquets axillaires ou latéraux. Elles sont monoïques, pourvues d'un calice très petit ì jo divisions, et d'une corolle quinquéfide dans les fleurs mâles, à 5 pétales distincts dans les neurs femelles. Les étamines sont an nombre de 10, monadelphes par le bas, dont 5 externes plus petites, alternant arec autant de glandes conoüdes. L'oraire est placé sur un disque à 5 lobes, surmonté de 3 styles filiformes, distincts, à stygmates bifides et épais. Le fruit entier (fig. 164) est une capsule rougeâtre ou noirâtre, oroüde, un pen charnue, et de la grosseur d'une petite noix. Par la dessiccation elle derient

Fig. 164.

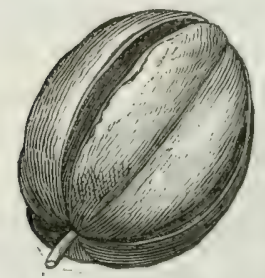

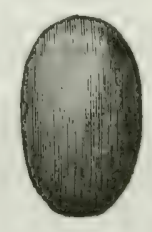
ferme, coriace, trigonearrondie, et s'ourre en trois valves loculicides. Chaque loge renferme une semence dont la forme générale est celle du ricin, mais qui a 16 à 18 millimètres de longueur, 11 millimètres de largeur' el 9 d'épaisscur. Cette semence est noiràtre, unie, faiblement luisante, pricée de caroncule et sans écusson comprimé sur le dos. La face extérieure est bombée, arrondie arec un angle peu marqué au milien; la face interne présente un angle plus saillant. La rohe est épaisse, dure, compacte, a cassure résineuse. 
L'amande est couverte d'unc pellicule blanche, souvent chargée de paillettes cristallines très brillantes. C'est surtont de celte semence que l'on a dit que le principe purgatif était uniģuement renfermé dans l'embryon, et que l'amande en élait dépourve; mais cette assertion n'est pas plus vraie que pour le ricin. Trois de ces amandes, écrasées dans du lait, sulfisent en Amériçue pour procurer d'alondantes évacuations alvines. En Europe, l'usage en serait moins certain, à cause de la rancidite ordinaire des semences que nous avons. On en relire par expression une huile âcre et drastique, qui, mèlée anciemement à celle des ricins d'Amérique, la rendait beaucoup plus active que celle préparce en rrance, malgré l'habitude où l'on était de la soumettre à une longue ébullition dans l'eau pour en volatiliser le principe âcre.

Les semences de curces se rencontrent assez souvent dans le commerce; elles fournissent, par kilogramme, 314 grammes d'épisperme et 656 grammes d'amandes, dont on pent retirer 265 grammes d'une huile incolore, très fluide ou sans consistance, laissant cependant précipiter par le froid une grande quantité de stéarine. Elle diffère du reste totalement de l'huile de ricins par son peu de solubilité dans l'alcool (elle ne se dissout pas dans 24 parties d'alcool absolu). Elle purge à la dose de 8 à 12 gouttes.

\section{Semences du Médlelnier multifle.}

Noisette purgative, mentciner d'Espagae. Curcas mullifudu, jutroplen multifida L. Arbrisseau de l'Amérique méridionale, rempli d'un suc visqueux âcre, amer et limpide; orné de fenilles grandes et profondément palmées, ordinairement à 9 lobes pimnatifides. Les faurs sont d'un rouge écarlate, disposées en cimes ombellées. Les fruits (lig. 165) sont de la grosseur d'une noix, formés d'une capsule mince, jaunâtre, renflée, trigone et arrondie du côté du pédoncule, amincie en pointe par l'extrémité. Je la crois indéhiscente. Elle est à 3 loges monospermes. Les semences sont grosses conme des avelines, ar-

Fig. 16ว.

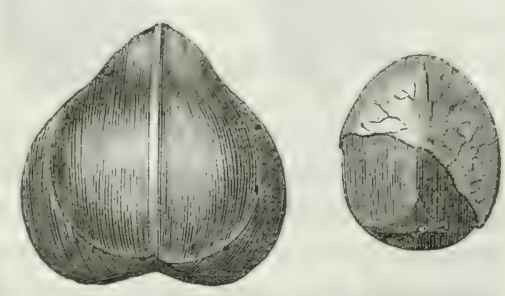
rondies, mais toujours anguleuses du côté interne. L'épisperme est lisse, marbré, assez épais; l'amande blanchàtre et fortement purgative.

Grains de Tilly.

Petit pignon D'INde, graine des Molcotes. Frofon tiglium L. 
Cur. yrin. Fleurs monö̈ques, ou trìs rarement diö̈ques; fleurs mâles pourvues d'un calice à 5 divisions ralvaires et d'une corolle a 5 prétales qui alternent arec 5 glandes; 10 à 20 étamines ou plus, inséries sur le réceptacle; filets libres, dressés, exsertes, à anthères introrses adnées au sommet du filet. Fleurs femelles formées d'un calice persistant, sans corolle, et pourrues seulement de 5 glandes accompagnant l'ovaire. Oraire sessile, à 3 loges monospermes; 3 styles bifides ou multi-dirisés, à divisions intérieurement glanduteuses.

L'arbrisseau qui produit les grains de Tilly ( fig. 166), croît dans les

Fig. 166.

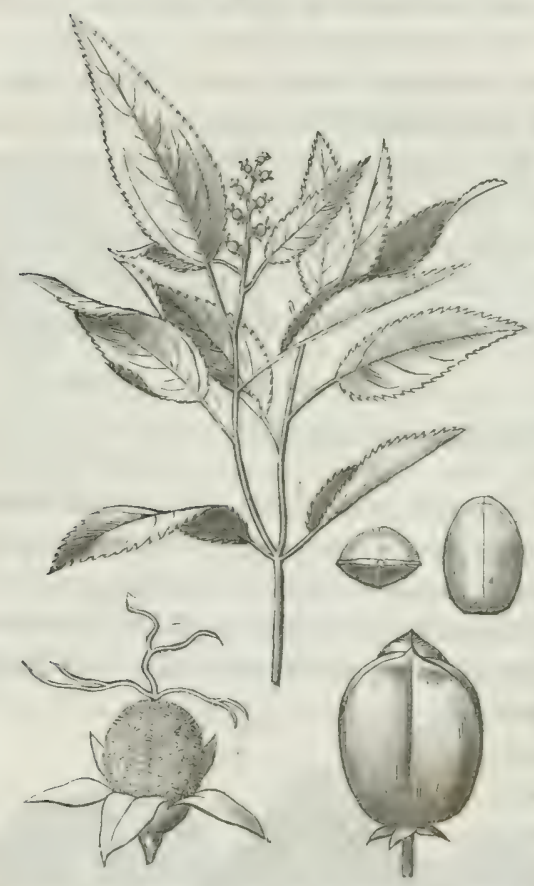

îles Holurues, et son bois, qui est léger et purgatif, se nomme bois purgatif, bois des Moluques ou de Pavane.

Le fruit, qu'il nous importe surtout de connaitre, est de la grosseur d'une aveline, glabre, jaunâtre, à 3 coques minces, renfermant cliacune une semence.

Cette semence est ovaleoblongue; la face interne n'est pas beaucoup moins bombée que l'externe, et toutes deux offrent un angle très arrondi, de sorte que la semence paraît sensiblement quadrangulaire. Tantôt la surface est jaunâtre, à cause d'un épiderme de cette couleur qui la recourre, et qui lui donne une grande ressemblance arec les pignons

du pin; tantôt elle est noire et unie, par la suppression de cet (iphiderme. Dans tous les (as, la semence oflre, de l'ombilic: au sommet, plusieurs nervures saillantes, dont les deux latérales sont plus apparentes el forment deux petites gibbositers arant de se réunir i la partie inférieure de la graine. Ce caractère, (fui est essentinl, fait facilement distinguer le grain de 'Tilly des gros pignons d'Inde et des ricins. Longueur de la graine, de 11 à 14 millimetres; largeur, d'une des nervures latérales à l'autre, de 7 à 9) millimètres; ćpraisseur, de 6 à 8 millimètres. 
Quelquefois la corgue du roton tiglium, au lieu de contenir trois graines, n'en renferme que denx, par suite de l'avortement de la troisième; alors les deux semences, étant entièrement accolées par l'ur surface interne, prennent la forme de deux grains cie café, et offrent le même sillon longitudinal formé par l'impression de l'axe central dı fruit. Du reste, ces semences sont semblables aux premières.

Toutes les parties de cette graine sont douées d'une propriété âcre ct corrosive gui en rend l'usage interne très dangereux. Cependant elle a quelquefois été usitée comme purgatire, à la dose d'une demi-graine jusqu'à deus. Depuis plusieurs années aussi on en emploie l'huile exprimée sous le nom d'huile de croton, soit comme purgative à l'intérieur, soit comme rubéfiante et éruptire à l'extérieur. Mais elle varie beatucoup en activité suivant son origine. Celle qui rient de l'Inde, par la roie de l'Angleterre, est jaunâtre, bien liquide, transparente et comparatirement peu actire; tandis que celle que nous pourons retirer nous-mèmes des graines fournies par le commerce, est brunâtre, d'une odeur analogue à celle de la résine de jalap, d'une grande causticité, et purge i la close de 1 goutte à 2 . Cette huile est assez ćpaisse et laisse déposer une matière analogue à la stéarine. Elle est soluble en totalité dans l'éther; mais en partie seulement dans l'alcool froid, qui en sépare un tiers environ d'une huile grasse et fade, et en dissout deux tiers d'une huile caustique, contenant un acide volatil nommé acide crotonique; mais il s'en forme davantage par la saponification et mème par l'action de l'air sur l'huile, ce qui peut expliquer jusqu'à un certain point pourquoi l'huile extraite des semences rieillies dans le commerce est plus actire que celle obtenue dans l'Inde des graines récentes. Je ne pense pas cependant que ce soit là l'unique cause de la différence d'action c'es deux huiles, et je suis porté à croire que l'huile préparée dans l'Inde est mélangée d'huile de ricins ou de curcas.

Ce sont les grains de Tilly (cruton tiglium) qui ont été analysés par MI. Pelletier et Caventou sous le nom de pignon d'Inde ou de jatropha curcas (Journ. pharm., t. IV, p. 289).

Ne pouvant citer tous les autres fruits d'euphorbiacées qui ont été usités, soit dans la médecine, pour leur propriété purgative, soit dins l'économie domestique, à cause de la grande quantité d'huile qu'ils contiennent, je me bornerai aux suivants.

ARbre A SLIF DE LA CHIXe. Croton sebiferum L.; stillingia sebifera Hx. Arbre de la Chine naturalisé aujourd'hui sur les côtes maritimes de la Caroline, en Amérique. Les semences, indépendamment de l'huile qu'elles contiennent à l'intérieur, sont couvertes d'une substance sébacée, très blanche, qui sert à la fabrication des chandeiles. Ces semences offrent encore cela de particulier qu'étant suspendues à 
l'axe du fruit par trois filets, elles persistent sur l'arbre, après la chute des six valves de la capsule.

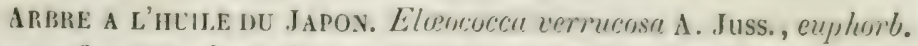

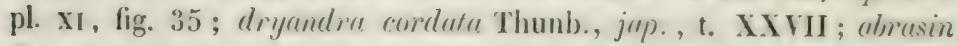
Kœmpf., aman. ; vernicin momtanu Lour. ; dryanden ternicia Correa, Ann. mus., t. VIII, pl. 32. Le fruit de cet arbre (fig. 167) est une

Fig. 167.

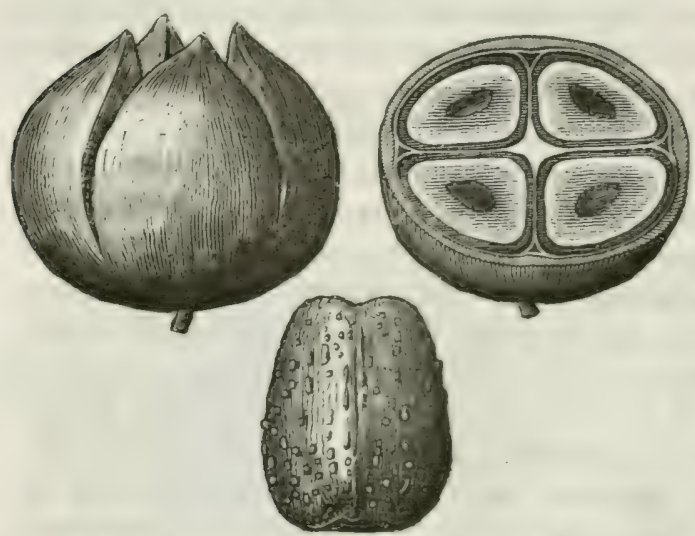

capsule ligneuse, globuleuse, terminée par une pointe courte, de 5 centimètres de diamètre. Il s'ouvre par la dessiccation en 4 valves septicides, quelquefois en 3 ou 5 , et contient autant de scimences oroïdes triangulaires, longues de 25 mil-

limètres environ, larges de 20 , bombées du côté extérieur, anguleuses du côté interne, recouvertes d'un épisperme dur, marqué de lignes tnberculeuses à leur surface. L'huile extraite de l'amande est emploỵée pour l'éclairage.

Camiri, jolx de Bancoll, nolx des Molcoges. Aleurites amFig. 168.

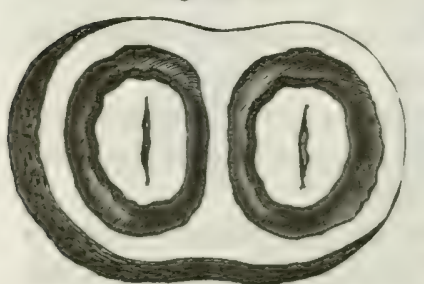

binux Pers.; croton moluccanum L. ; camirium Rumph., t. II, tab. 58; Gœrtn., tab. 125. Petit arbre des îles Moluques, naturalisé à Ceylan et à l'île de la Réunion, d'où les semences sont souvent enroyées en France. Son fruit (fig. 168) est un gros drupe charnu, plus large que long et comme formé de deux drupes accolés. Ce fruit contient

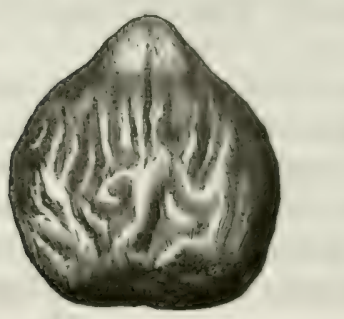
dans son intérieur deux semences osseuses aussi dures que de la pierre, grosses comme de petites noix, pointues au sommet, arrondies à la base et offrant les deux gibbosités qui sont propres aux semences de croton; arrondies par le côté externe, elles sont 
aplaties et marquées d'un léger sillon sur le côté interne. Ia sunface de ces semences est très inégale, hosselíe et recourerte d'un enduit blanc, d'apparence crélacée; l'épisperme lui-même est noirâtre, épais, à peine attaguable par le fer; l'amande est blanche, trìs huileuse, d'un assez bon goùt lorsfqu'elle est récente, bonne à manger "t soulement un peu indigeste. On en extrait une huile qui sert aux usages économiques. On a proposé aussi de l'utiliser pour la fabrication du saron.

AXdaSSU ou ANDA-ACU; ANDA DE PIsON. Bras., p. 72 ; Marcgraff, p. 110 ; andn Gomesii A. Juss., enplevil., tah. xu, fig. 37. Grand arbre du Brésil dont l'écorce sert à enirrer les poissons. Le fruit est gros comme le poing, formé d'un brou mince, noiràtre, et d'un noyau volumineux (fig. 169), jannâtre, épais et ligneux, arrondi par le bas, terminé en pointe par le haut, et offrant 4 angles assez marqués, dont 2 , plus

Fig. 169.
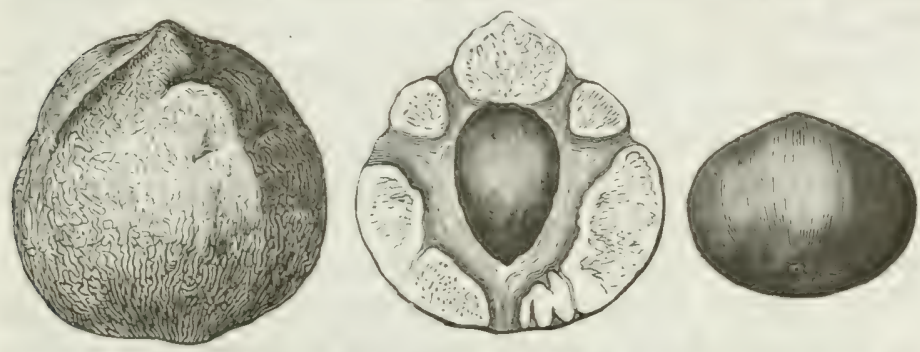

obtus, sont percés de trous qui répondent à un commencement de dédoublement de la cloison qui sépare les 2 loges. Charpue loge contient une semence à épisperme dur, brunâtre, déponillé d'un tesła spongicux, dont il reste quelques restiges. Cette semence a presque la forme et la grosseur d'une châtaigne, c'est-à-dire qu'elle est arroudic, plus large que haute, un peu terminée en pointe par le haut, et plus bombée du côté externe que de l'interne. Elle a environ 30 millimètres dans son plus grand diamètre, 20 millimètres d'épaisseur et 25 de hauteur. L'amande est blanche, purgative, et souvent usitée conme telle au Brésil, étant mise en électuaire arec du sucre, de l'anis et de la cannelle. On en retire par expression une huile presque incolore, de la consistance de l'huile d'oFig. 170.

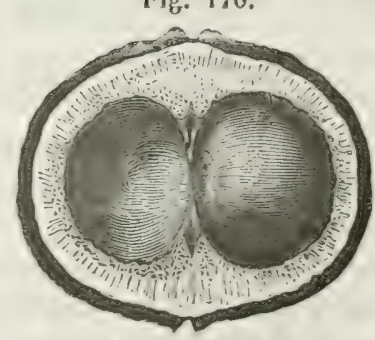
lives liquide, insoluble dans l'alcool, purgative à peu près au mêne degré que celle de ricins.

J'ai reçu du Brésil, mêlís au fruit précédent, un fruit et des semences (fig. 170 ) qui doirent constituer une autre espèce d'anda. Le fruit, 
dans son entier, est presque semblable au premier; seulement il est un peu plus petit et pourru de son brou desséché et fendu en quatre, à l'endroit des angles du noyau ligneux; tandis que le premier anda en est presque toujours privé, comme l'attestent les figures qui en ont été domées par Marcgraff, par M. A. de Jussieu, et tous les fruits que je possède. Comme dans la première espèce, les semences sont pourvues d'une première enveloppe blanchâtre et spongieuse qui a presque entièrement disparu. La seconde enveloppe est lisse, d'un gris cendré, très mince, souvent entamée elle-même, et laissant roir au-dessous une troisieme tunique brune, solide et cassante. La membrane la plus interne est douce au toucher et d'un blanc nacré. Cette multiplicité de couches dans l'épisperme se retroure plus ou moins dans les autres semences d'cuphorbiacées. Ce qui distingue celle-ci, c'est sa forme ronde et un peu ovoïde, qui la fait ressembler à une petite muscade ronde, et une sorte de plexus proéminent situé au point d'attache.

Myrobalax eublic. Emblica officinalis Gartn. ; phiyllanthus emblica L. Arbrisseau du Malabar dont le fruit, bien différent des rrais myrobalans, peut cependant être considéré comme un drupe. Dans l'état naturel, et arant sa maturité, ce drupe est entièrement splhérique; mais en mûrissant et en se desséchant, le brou s'applique plus exactement contre les faces du noyau, sourent même se sépare en 6 lobes, et le fruit devient hexagone. Tel qu'est donc ce fruit desséché, il est gros comme une areline, presque sphérique ou hexagone, et se séparant en 6 lobes; il est très rugueux, d'un noir grisàtre, d'un goût astringent et aigrelet; il me paraît n'être pas dépourru de toute odeur aromaticjue; sous le brou se trouve un noyau ou capsule ligneuse hexagone, qui par la maturité se sépare en 6 valres formant en tout 3 loges, dont chacune contient deux petites semences rouges et luisantes.

Ce myrobalan était autrefois très employé comme purgatif; les Indiens le font servir au tannage du cuir et pour faire de l'encre.

\section{Écorce de Cascarille.}

Chacrille, quinquina aromnatique, feorcéleutérienne. Cette écorce est produite par un arbrisseau des Antilles et des îles Lucaỵes, qui parait ètre le croton eluteria de Swartz, plutôt que le croton crascurille $\mathrm{L}$. , auçuel elle est encore généralement attribuée. Ce dernier est très abondant à IIaïti, où il a porté le nom de sauge du port de la l'aix, parce que ses feuilles ont à peu près la forme, le goût et l'odeur des feuilles de sauge et servent aux mêmes usages; mais aucun des anteurs originaux qui en ont parlé, tels que Brown, Sloane, Desportes et Nicholson, ne dit que ce soit cet arbuste qui fournisse la cascarille du commerce. 
Il est possible, cependant, que l'opinion contraire, après avoir été admise pendant longtempss en Europe, ayant été reportée en Amérique, ait déterminé l'exploitation du crofon cascorilla et niême celle de quelques autres crotons aromatiques. Ce qui semble le prouver, c'est que l'on trouve dans le commerce, depuis plusieurs années déjà, un certain nombre d'écorces plus ou moins analogues à la cascarille, mais toutes inférieures en qualité, qui doivent être produites par le croton cascarilla et par quelques autres espèces analogues, telles que les $C r$. lineare, micans, humile, balsamiforum, etc. Voici les caractères distinctifs de cés lifférentes écorces.

1. Cas:arille vaic on officinale, produite très probablement par le croton eluteria. Cette écorce est généralement lrisée en fragments de 3 à 5 centimètres de Jong, de la grosseur d'une plume à colle du petit doigt, roulée, compacte, dure et pesante, ayant unc cassure résineuse, finement rayonnće. Elle est d'un brun obscur et terne, et donne une poudre de la même couleur. Elle est nue on recouverte en partie d'une croûte blanche, rugueuse et fendillée comme celle du quinquina. Elle a une sareur amère, âcre, aromatique, et une odeur particulière, agréable, surtout lorsqu'on la chauffe. Elle contient beaucoup de résine, et donne à la distillation mne huile volatile verte, arcmatique et suare, pesant spécifiquement 0,938 . Elle est très fébrifuge; mais elle échauffe beaucoup, et, à cause de cela, ne convient pas à tous les tempéraments. Elle arrête le romissement et la dyssenterie; on la mêle au tabac pour l'aromatiser; mais elle enirre à trop forte dose. Elle forme arec l'eau bouillante un infusé brunàtre et aromatique qui se fonce et prend une teinte faiblement noiràtre par les sels de fer.

2. Casearille banchatre. Cetle écorce a la forme de longs tuyaux gros comme le doigt, comme le pouce ou darantage, toujours pourvus de leur épiderme, qui est blanc ou grisâtre, uni ou marqué de légères fissures longitudinales, mais ni dur ni fendillé transversalement. Les grosses écorces ont une cassure rayonnée, d'un rouge brun du côté du centre, et blanchâtre dans la partie qui touche à l'épiderme; les plus jeunes sont presque blanches; le tout pulvérisé donne une poudre blanchâtre; l'odeur est assez aromatique et analogue à celle de la première sorte; la saveur est amère, âcre et camphrée; l'infusion aqueuse est très aromatique, d'une couleur peu foncée, et forme arec les sels de fer un précipité vert noirâtre.

3. Cansearille rougeàre et téréhinthacéc. Écorce quelquefois très large et paraissant avoir appartenu à un tronc d'arbre ou à dés rameaux d'un assez fort diamètre. Quelquefois pourvue d'une croûte iongueuse, peu épaisse, jaunàtre, sillonnée longitudinalement, a vec indice d'avoir été recouverte d'une couche blanche, crélacée, dont on 
troure les restes dans les sillons. Le plus souvent le liber est entièrement dénudé; il est alors d'un rouge pâle et comme cendré à l'extérieur, marqué de profonds sillons longitudinaux, arec des norvures proéminentes qui formen ginelyuefois une sorte de treillis allongé. Il est d'un rouge assez vif à l'intúrieur, d'une structure fibreuse très fine, compacte et rayomnéc. Sa poudre est rosér. I,écorce a une odeur térébinthacée et une saveur un peu amère et piquante, qui offre le goût aromatique du mastic. L'infusé arpueux est rouge, d'une odeur de mastic ou de lérbinthine, et précipite le fer e'ln noir verdâtre; c'est des trois écorces que je viens de décrire celle qui est la moins aromalique, la moins âcre et la plus astringente.

4. Ceoree de copalehi. Celte écorce paraît avoir été apportée pour la première fois à Hambourg, en 1817, sous le nom de cascrille de la Trinité de Cubn; en 1827, 30000 livres pesant furent enroyées de Liverpool à Hambourg, comme étant une sorte de quinquina blanc; mais elle fut promptement reconnue pour une espèce de cascarille originaire du Mexique, où celle porte le nom de copralche ou cripalchi, et où elle est produite par le croton pseudo-china de Schiede. D'après 11. Don, celte espèce de crotom ne diffère pas du rototru crssarrilln.

l.'icorce de copalchi est en lones tubes droits, cylindriques et unis, sousent roulés les uns dans les autres. Elle est couverte d'un épiderme blanc, très mince et adhérent, qui paraît un peu usé par le frottement. Quelques parties du liber sunt dénudies. Le librre est épais de 1 à 2 millimètres, dur, compacte, entièrement d'un rouge brun, offrant une structure fine ct ravonnée. L'écorce entière a une odeur peu marquée. Lorsqu'on la pulvérise, elle en répand une de térébenthine ou de résine commune. Sa sareur est amère et térébinthacée. L'infusé aqueux est rougeâtre, et précipite le fer en noir rerdâtre. Cétle écorce diffère de la précédente plus par sa forme que par ses propriélés.

11. Brandes a analyssé une écorce de copalchi dont il a retiré une résine àcre et aromatique; un principe amer, jaune, soluble dans l'eau et dans l'alcool, une huile grasse concrète, etc.

En 1825 , 11. Hercadieu a soumis à l'analysé une écorce bien différente de la précédente, qu'on lui avait dit venir du Mexique, où elle portait le nom de copulchi. Cetle écorce était formée d'une couche extérieure jaunâtre, épaisse et fongueuse, et d'un liber noir, compacte, inodore el d'une amertume excessive.

M. de Itumboldt, à qqui elle fut présentée, présuma qu'elle pourait appartenir au croton suberosum (Jour, chim. meid., 1825, p. 236). Plus tard, Ir. Virey dicrivit par erreur cette mème écorce comme

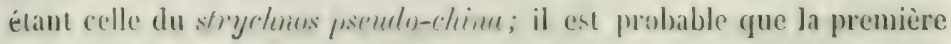
origine n'est pas plus fondée que la seconde, et l'on peut dire que l'é- 
corce analysée par M. Mercadieu est encore inconnue, quant à l'arbre qui la produit.

5. Casearille noiratre et poirre. Écorce en longs tuljes cylindriques, ou en morceaux aplatis, presque complétement dénudée d'épiderme; elle est d'un gris noirâtre et striée longitudinalement au dehors: unie et d'une couleur de bois de chène en dedans. La coupe transversale est très compacte et finement rayonnée ; l'odenr en est peu marquéc en masse; mais elle derient assez forte, aromatique et poirrée, lorsquu'on la pulvérise. La sareur en est àcre el tires amière. J'ignore aujourd'hui d'où me vient cette écorce, que je possède depuis quelques années.

\section{Bols et ecorce de buis.}

Buxus sempervirens. Arbre toujours vert, qui rarie singulièrement de grandeur, suivant les climats et la culture : dans le Levant, c'est un arbre assez grand et fort pour offrir un tronc de 30 à 40 centimètres de diamètre; dans nos climats, c'est un arbrisseau de 12 à 15 pieds que l'on peut réduire à l'état nain, de manière à le faire servir de bordure aux plates-bandes de nos jardins. Les fenilles du buis sont opposées, orales, lisses et d'un rert foncé. l.es fl'urs sont monoïques, jaunâtres, disposées par petits pạuets aux aisselles des feuilles. Les fleurs mâles ont un calice à 4 folioles et 4 étamines; les fleurs femelles ont un calice pentaphylle et un oraire is 3 loges, surmonté de 3 styles persistants. Le fruit est une petite capsule à 3 cornes, à 3 loges et à 6 graines.

Le bois de buis est jaunc, dur, compacte et susceptible d'un beau poli. Celui du Lerant, qui est le plus estimé, pèse jusqu’à 1,328, tandis que celui de France est sourent plus léger que l'eau. Les tourneurs en consomment une quantité considérable. En pharmacie, on emploie quelquefois l'écorce de la racine, qui paraît jouir de propriétés actives dans la syphilis constitutionnelle et les rhumatismes chroniques. Cette écorce est d'un blanc jaunâtre, un peu fongueuse et très amère.

II. Fauré, pharmacien de Bordeaux, a retiré de l'écorce de buis un alcali particulier, nommé burine, que .1. Couerbe est ensuite parrenu à obtenir cristallisé. Voy. Journ. de plarmencie, t. XVI, p. 428 , et $\mathbf{X X}$, p. 52.

\section{FAMILLE DES ARISTOLOCHIÉES.}

Petite famille de plantes principalement caractérisée par l'insertion de ses étamines franchement épigynes et souvent soudées avec le pistil, 
et par le nombre ternaire de ses parties. Le périanthe est soudé arec l'oraire et se prolonge an-dessus en un tube sourent renflé, terminé par trois segments tantôt égaux, tantôt très inégaux et irréguliers. Les étamines sont au nombre de 6 ou de 12 , tantôt sessiles et portées sur un disque annulaire, soudé avec le style, tantôt à filets distincts. Le fruit est une capsule ou une baie à 3 ou 6 loges, renfermant un grand nombre de petites graines dont l'embryon droit est contenu dans un endosperme charnu ou corné.

Cette famille se compose principalement des deux genres aristolochia et asarum, dont toutes les racines sont plus ou moins pourvues d'huile rolatile et d'une substance résineuse amère, auxquelles elles doirent des propriétés très actires, sudorifique, excitante ou romitive.

Les aristoloches, en particulier, sont des plantes herbacées ou sousfrutescentes, à tige flexible et sourent volubile; à feuilles alternes, simples et pétiolées; à fleurs très irrégulières, formées par une scule enveloppe tubuleuse, soudée inférieurement arec l'oraire, ventrue audessus, à limbe oblique, ligulé, bifide ou trifide. Les étamines sont au nombre de six, presque sessiles, insérées sur un disque épigyne soudé avec la base du style (gynandrie hexandrie L.) ; stigmate à 6 clivisions; capsule coriace, à 6 loges et à 6 ralves septicides. Semences nombreuses, anguleuses, à testa élargi en membrane, contenant, à la base d'un périsperme dur et presque corné, un très petit embryon droit, dont la radicule est plus longue que les cotylédons et se dirige rers le point d'attache. Les aristoloches sont en général des régétaux très actifs, donés d'une odeur forte, sourent désagréable, et d'une sareur amère. Les principales espèces usitées sont:

1. L'ARistolocile roxde, aristolochia rotunda L. (fig. 171). Cette plante s'élève à 50 centimètres de hauteur; sa tige est faible et garnie de feuilles cordiformes-obtuses, presque sessiles; les fleurs sont solitaires dans l'aisselle des feuilles, à périanthe tubuleux terminé en languette; elles sont jaunes au-dehors, d'une couleur orangée brune en dedans. Toute la plante est âcre, aromatique, et laisse sur la langue une amertume désagréable. Elle croît dans les champ̣s, surtont dans les pays chauds; et, en France, dans le Languedoc et la Provence, d'où on nous apporte sa racine sèche. Cette racine est tubéreuse, ligneuseamylacée, assez grosse, pesante, comme mamelonnée à sa surface, grise, unie ou quelquefois légèrement ridée; elle est jaunâtre à l'intérieur, d'une saveur amère, d'une odeur peu sensible lorsque la racine est entière; mais quand on la pulrérise cette odeur devient assez forte et désagréable.

2. Aristoloche longue, aristulochia longa L. Cette plante croit dans les mêmes lieux que la première et lui ressemble beaucoup. Cepen- 
dant ses feuilles sont pétiolées; ses fleurs sont jaunes avec des bandes brunes au-dehirs, à languetle plus courie el entièrement jaune. Sa racine, au lieu d'être arrondie, est cylindrique, quelquefois longue de

Fig. 171.

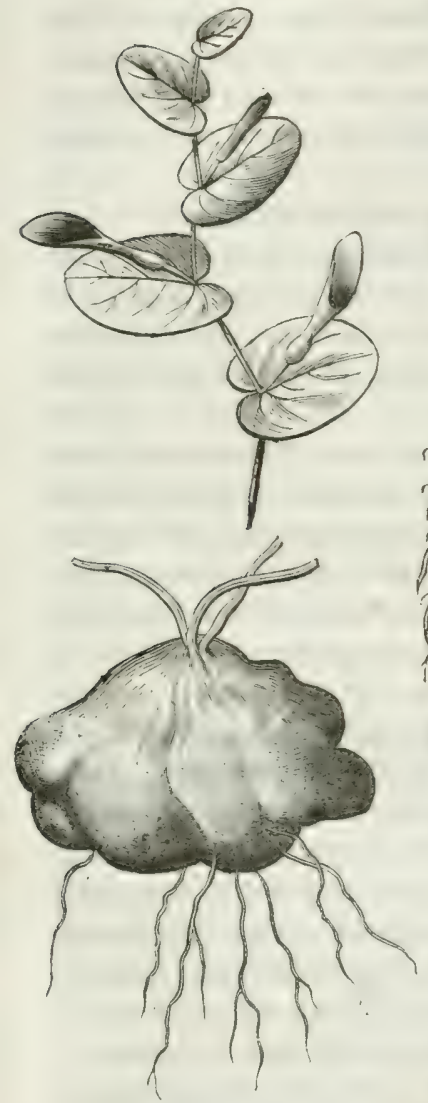

30 centimètres et grosse à proportion; du reste, elle a la même couleur, la

Fig. 172.

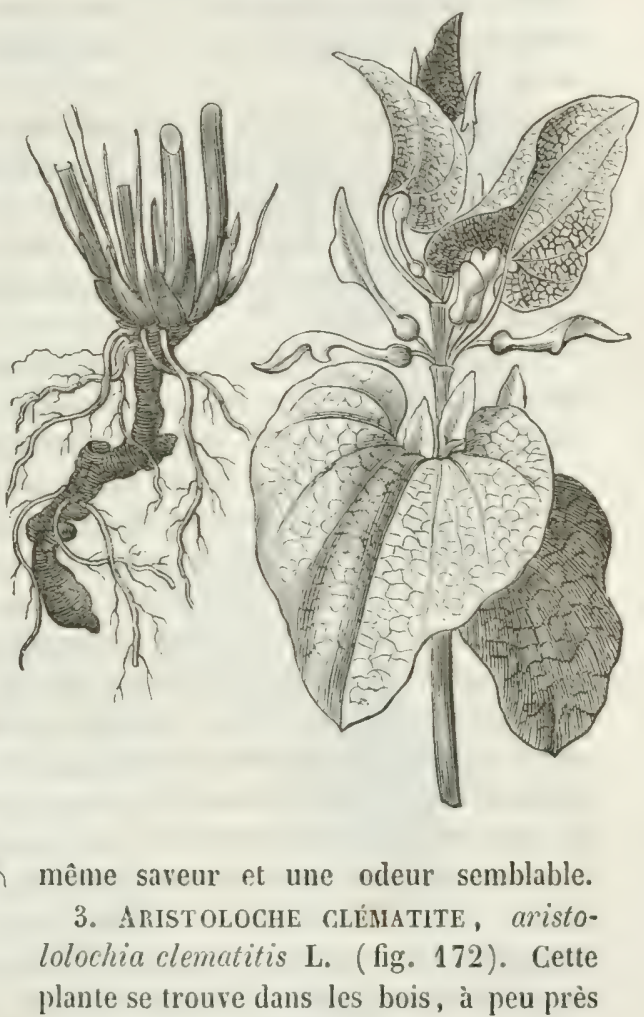
dans toute la France, et encore plus dans le Midi; sa tige est droite et porte des feuilles pétiolées, comme l'aristoloche longue; mais ses feuilles sont cordiformes pointues, et les fleurs, au lieu d'être solitaires, sont ramassées au nombre de 3 à 6 dans l'aisselle des feuilles. Le périanthe est entièrement jaune, terminé en languette aiguë. La racine, fort différente des précédentes, est composée de quelques fibres brunes, tiès longues, de la grosseur d'une plume d'oie, serpentant de tous côtés, et d'un petit nombre de radicules. Elle a une odeur plus forte que les précédentes, et une saveur âcre, amère et fort désagréable.

4. Aristoloche petite, aristolochia pistolochia L. Cette espèce 
est plus petite dans toutes ses parties que les précédentes, et s'élève rarement à plus de 25 centimètres de terre. Ses fenilles sont pétiolées, cordiformes, obtuses, un pen sinuées sur les bords; les fleurs sont solitaires, jaunâtres, terminées par une languette noirâtre. La racine est composée d'un petit rronc de la grosseur d'une plume, et d'un grand nombre de radicules très deliées, d'un demi-pied de Inngueur. Elle a une couleur grise jamnâtre, une odeur aroimatique qui n'est pas désagréable, et un goût ârre et amer. Elle vient de nos paỵs méridionatix.

I.es différentes espèces de racines d'aristoloche sont détersives, emménagogues et propres à favoriser l'expulsion des loclies, d'où leur est venu leur nom. Les trois premières ont été connues de Dioscoride et des anciens Grecs. La dernière ne l'a été que de Pline, qui l'a décrite sous les noms de pistolochia et de polyrrhizos : ce dernier nom signifie nombreuses racines.

5. Aristoloche serlext.ire, Serpextaine de Virgixie ou VipéRIXE IE VIRGixe. La plante qui produit la racine de serpentaire de Virginie paraît aroir été décrite, pour la première fois, par Thomas Johnson, en 1633. C’est, lorsqu'elle est récente, un spécifique presque certain contre la morsure de plusieurs serpents renimeux. Il parait même qu'elle est nuisible aux serpents eux-mèmes, mais dans In moindre degré qu'une autre espèce du même genre, qui est l'A r. amgricida L. Sa racine, telle qu'on l'apporte de l'Amérique septentrionale, est formée d'unc souche très menue, garnie d'un chevelu touffu et très fin. Elle a une couleur grise, une odeur forte ct camphrée, une sareur amère également camplirée. Elle est presque toujours accompagnée de portions de sa tige flexueuse, et de quelques feuilles qui, humectées et déreloppées sur une feuille de papier, peuvent servir à la distinguer d'espèces voisines moins aclives, ou de racines de nature toute différente, qu'une ressemblance de forme pourrait faire confondre arec la véritable; telles sont les racines de collinsonia scubriuscula (labiées) et de spigeliu marylandica (loganiacées) que l'on dit avoir été quelquefois mélangées par fraude à la serpentaire de Virginie, quoique je ne les y aie jamais trouvées. Quant ì celle dernière, il en existe dans le commerce trois sortes, produites par trois ou quatre plantes qui ont été confondues par les botanistes sous le mêne nom d'aristuluchia serpentaria; mais dont une au moins doit être soigneusement distinguée des autres, tant parce qu'elle forme une espèce différente, que parce que sa racine est beaucoup moins aromatique et moins active.

A. Première serpentaire de Virgonic. La véritable serpentaire de Virginie, ou, si on l'aime mieux, la plus ancienne et la seule que l'on trouvât dans le commerce arant 1816, est celle que j'ai décrite 
d'abord, formée d'une petite souche garnie de radicules très fines. courles et cherelues. J'insiste sur la disposition de ces radicules qui sont courtes, chevelues, replies sur elles-mêmes, formant un petit parguet emmelé. Cette racine est trìs aromatique et fortement camphrée. En déreloppant, au moyen de l'eau, la lige et les feuilles qu'on y troure quelguefois, je suis parrenu à en former la plante représentée figure 173, que j’ai complétie avec la ligure et la description qu'en a données Woodville dans son Medical botany, t. II, p. 291, fig. 106. On la troure également représentée par Plukenet, sous le nom de aristolochia pistolochia seu serpentaria virginiana, caule nodoso (Almag. 50, t. CXLVIII, fig. 5 ). Celte plante est pourrue d'une lige faible, flexueuse ou même coudée en zig-zag à l'endroit des feuilles, qui sont alternes, longuement pétiolées, creusées d'un sinus large et profond à la base. Elles sont proportionnellement très larges, terminées cependant en pointe à l'extrémité. Le bord du limbe est très entier, la feuille est également verte sur les deux faces, très mince, presque transparente, à nervures très peu proéminentes; elle est entièrement glabre, ainsi que la tige. Les fleurs sortent en petit nombre du collet de la racine; elles sont longuement pédonculées, à périanthe tubulé, ré-

Fig. 173.

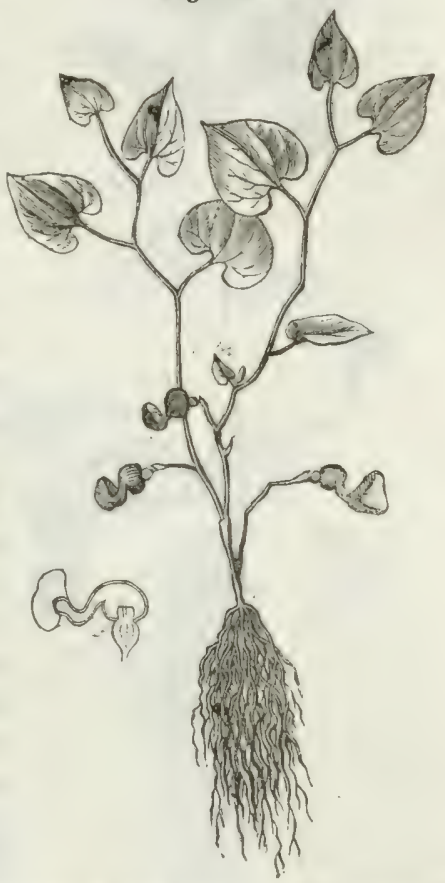
tréci au-dessus de l'ovaire, fortement courbé en cercle, enfin terminé par un limbe renflé, à ouverture obscurément triangulaire. Le fruit, que l'on troure sourent arec la racine du commerce, est une petile capsule sphérique, derenue hexagonale par la dessiccation.

$B$. Seconde serpentaire de virginie (fig. 174). Cette sorte a paru pour la première fois dans le commerce, à Paris, en 1816. Elle est composée de radicules jaunâtres, manifestement julus grosses que dans la première sorte, moins pourvues de cherelu, plus longues, plus droites, et formant des faisceaux allongés et plus réguliers. Elle est généralement pourrue d'une partie de ses tiges qui sont minces, anguleuses, mais droites et non géniculées. Les feuilles sont cordiformes par le bas, oblongues et insensiblement terminées en pointe par le haut. 
Du reste elles sont de même nature que celles de la première espèce, c'est-à-dire qu'clles sont très glabres, très entières, très minces, vertes et comme transparentes. Les fleurs naissent près de la racine; elles

Fig. 174.

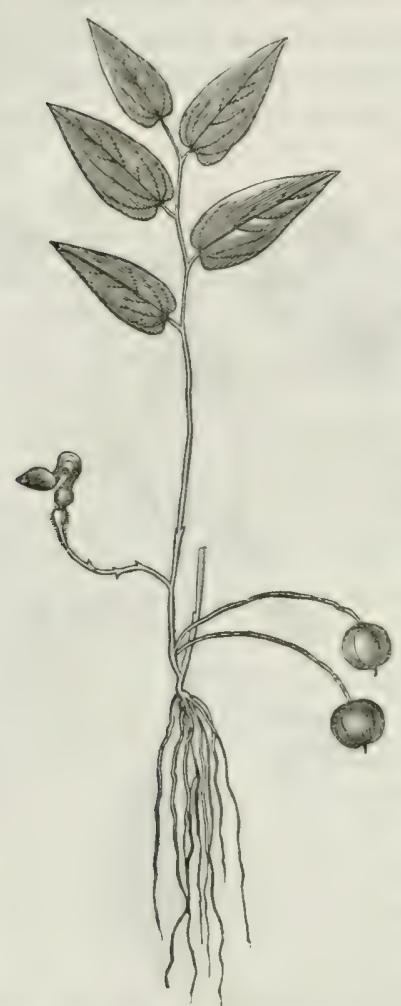
sont d'un violet pâle; à limbe coupé obliquement et terminé par une languette très courte. Les fruits ressemblent à ceux de la plante précédente.

Celte plante est celle que l'on trouve décrite et représentée sous le nom d'aristolochia officinalis, dans les plantes médicinales de Nees d'Esenbeck, ct sous celui d'aristolochia serpentarin dans l'American medical botany de Bigelow, vol. III, p. 82 , fig. 49. Je la considère, ainsi que la première. comme deux variétés d'une même espèce à laquelle je conserve le nom que lui a donné Linné, aristolochia serpentaria, et je les distingue par les épithètes de latifolia, appliquée à la plante de Woodville, et d'angustifolia donnée à la plante de Bigelow.

\section{$C$. Serpentaire de Birginic n}

feuilles hastées. Cetle plante, représentée par Plukenet, sous le nom de aristolochia polyrhizos, auricularibus foliis (tab. 78 , fig. 1), se rapproche beaucoup de la variété à feuilles étroites de l'aristolochia serpentaria. En effet, sa lige est droite, sa racine est composée de radicules assez fortes, droites et perpendiculaires, et ses feuilles sont élroites, très minces et transparentes. Nais elles sont encore plus étroites, plus allongées, auriculées et même un peu hastées par le bas; la tige, les pétioles et le limbe des feuilles sont munis de poils épars. Lnfun, d'après la figure donnée par Plukenet, le limbe du périanthe e'st terminé par une languette très prononcée. Que l'on considère cette l lante comme une simple variété de l'aristolochiu serpentaria ou qu'on la regarde comme une espèce différente, l'épithìte de hastote pourra servir à la désigner plus particulièrement.

I). Wausse serpentaire de virginic. Celte racine se trouve aujourd'hui en abondance dans le commerce; elle diffère des sortes pré- 
cédentes par ses radicules plus grosses, moins nombreuses (1) et beaucoup moins aromatiques; elles sont beaucoup moins camphrées surtout. On y trouve des fragments de tiges coudées et noueuses à l'endroit de

Fig. 173.
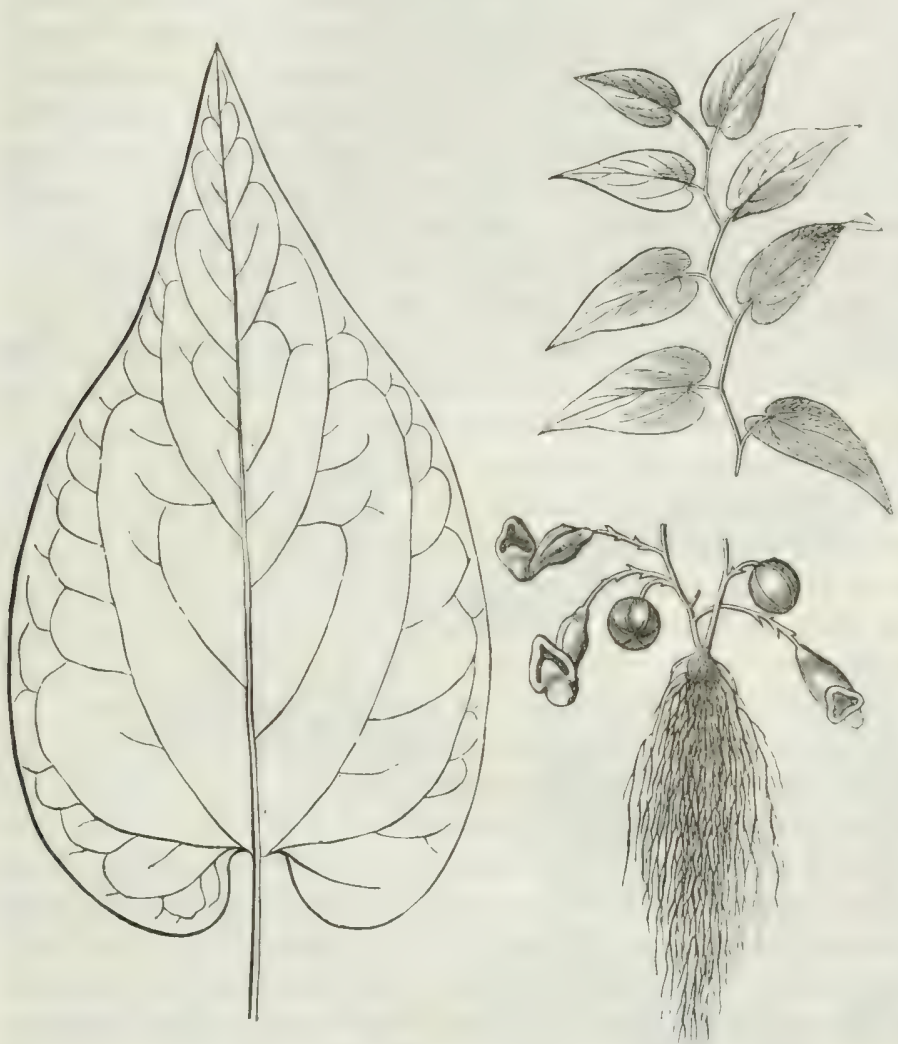

l'insertion des feuilles, lesquelles sont cordiformes, larges, presque sessiles, rudes au toucher, épaisses et à nervures proéminentes, un peu dentées sur le bord et légèrement poilues. La fleur naît près de la racine. Elle est velue, d'un pourpre sale, terminée par une gibbosité qui s'ouvre en une fente à 3 rayons. Cette plante a été parfaitement décrite par Jacquin (2), mais sous le nom d'aristolochia serpentaria, que

(1) La figure 173, empruntée aux plantes médicinales de M. Nees d'Esenbeck, diffère en quelques points de la description que je donne ici d'après des échantillons du commerce.

(2) Hort. Schicnbrun., vol, III, tab. 385. 
11. Nees a cru deroir lui conserver. Je pense que c'est ì tort, puisque cette plante differe de l'aristolor:hia serpentaria de Linné, et qu'elle ne produit pas la véritahle serpentaire de Virginie. J'ai proposé, il y a longtemps déjà, de lui donner le nom d'aristoluchia pseudr-serpenteria.

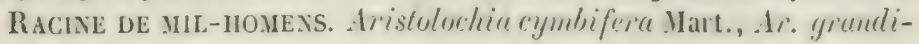
flora Gom. Cette plante sarmenteuse croìt au Brésil; elle dépasse la hauteur des plus grands arbres, et se fait remarguer par la grandeur de ses fleurs, dont le diamètre est d'environ 22 centimètres, et par l'odeur forte dont toutes ses parties sont pourrues. Le corps de sa racine est tubéreux et donne naissance à plusieurs jets longs de 30 à 60 centimètres, garnis eux-mêmes de radicules de la grosseur d'une plume de pigeon, longs de 10 à 16 centimètres. Les jets desséchés, tels que je les ai reçus de 11 . Théodore Martius, sont de la grosseur d'une plume à écrire, d'un brun noirâtre à l'extérieur, presque semblables à ceux de l'aristoloche clématite, mais d'une odeur beaucoup plus forte, analogue à celle d'un mélange de serpentaire et de rue. Leur saveur est amère, aromatique et camphrée. L'intérieur de la racine est blanchatre, et la coupe transrervale offre: un cercle de vaisseaus lubulés par lesquels on peut aspirer très aisément de l'eau. L'analyse a montré qu'elle contenait une luvile volatile, de la résine, du tannin, un principe amer, de la gomme, de l'amidon it des sels calcaires el polassiques. Cette racine, récente, passe pour être rénéneuse; sìche, tlle est conşeillée contre l'hydropisie, la dyspepsie, la paralı̣sie, etc.

J'ai reçu deux autres racines d'aristoloches du Brésil : l'une, qui m’a été donnée par II. Martius, sous le nom d'Ar. antilysterica, ressemble à la précédente par sa couleur extérieure noirâtre, sa couleur blanchâtre à l'intérieur et son odeur; mais elle est à peu près grosse comme le petit doigt, et son écorce est molle et fongueuse. La seconde a été reçue du Brésil par M. Stanislas Yartin, comme étant celle de milhomens ou d'aristolochin grandiflore; mais elle est sans doute produite par l'une des autres aristoloches brésiliemnes ordinairement confondues avec la premiere, telles que les .1r. mancoure Com., Lrosilimsis Mart., labiusa Bot. reg. ou ambuibre-endu de Marcgraft, elc. Ciette mêne racine a écé rapportée de Cạenne par 11. P'rieur. Elle ést en jets fort longs, composés d'un corps ligneux de 1 à 2 centimitres de diamètre, rayonné comme celui de toutes les aristoloclues et des ménisprermes, et d'une écorce spongieuse très épaisse, profondément sillonnée el yuelquefois partagée par côtes jusçu'au corpes ligneus. Cette racine présente une teinte gínérale jaune-faure, une odeur très forte analugue à celle de la rue, et un goùt aromatique semblable que je ne troure aujourd'hui ni âcre ni amer. Je ne sais si anterieurement sa sareur a été plus marquée. 


\section{Raclue d'Asarum ou de Cabaret.}

Asurum muropurum L. (fig. 176). L'asarum, devenu rare dans les environs de Paris, croît surtout dans les lieux ombragés des Alpes et du midi de la France. C'est une petite plante basse, toujours verte, dont les feuilles, réniformes et obtuses, fermes, vertes et lisses, sont portées sur de longs pétioles réunis deux à deux près de la racine. C'est de l'en-. droit de leur réunion que sort un pédoncule court, supportant une fleur brune composée d'un calice coloré, persistant, campaniforme, à 3 divisions ouvertes; à l'intérieur se trouvent 12 élamines posces circulairement: les anthères sont allachées ¿. la face externe des filets; le style est hesarone, et le stigmate à 6 lobes; il lui succède une capsule tronquie, palysperme, ì 6 lobes Ia racine est grise, fibreuse, rampante, garnie d'un cherelu blanchâtre. On nous l'apporte sèche de nos provinces méridionales, mais récoltće sans soin et mêlée d'un gran! nombre de racines étrangères : telles sont entre autres celles de fraisier, de tormentille ou d'autres analogues; d'arnica, d'asclépiade, de polygala commun, et surtout de valériane sauvage, en assez grande quantité pour communiquer à toute la masse une forte odeur de valériane; c'est ce qui a causé l'erreur de quelques auterurs de matière médicale, qui donnent cetle odcur comme un caractère propre à la racine d'asarum. Voici

Fig. 176.

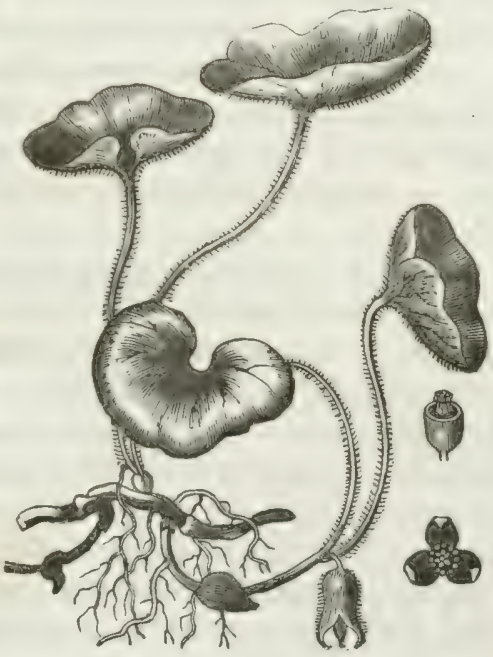

les caractères de celle racine lorsqu'elle est mondée de toutes celles qui lui sont étrangères : elle est grise, de la grosseur d'une plume de corbeau, quadrungulaire, ordinairement contournée et marquée de distance en distance de nodosités, d'vù partent des radicules blanchâtres, très déliées. Elle est garnie ou dépourvue de ces radicules. Elle a une saveur de poivre, et une odeur forte, analogue également à celle du poivre, qui se développe surtout lorsqu'on écrase le chevelu entre les doigts. Elle fournit à la distillation une huile volatile camphrée, cristallisable en lames carrées et nacrées. My. Lassaigne et Feneulle, qui ont 
obtenu ce résultat, ont encore retiré de la racine d’asarum une lauile grasse très âcre, une matière brune soluble dans l'eau, d'une saveur amère et nauséeuse, de la férule, du citrate et du malate de chaux. (Joum. de pharm., t. VI , p. 561.)

La racine d'asarum est fortement purgative et émétique, et était employée comme telle arant l'importation de l'ipécacuanha. Les feuilles, qui sont aussi très aclires, serrent à faire ume poudre sternutatoire qui a sourent réussi pour dissiper les maux de tête invétérés.

Le nom d'asurum est grec et reut dire je niorne pas, parce que, suivant Pline, cette plante n'était jamais employée dans les couromes ou dans les guirlandes dont on se parait dans les fètes. Le nom de cuburet vient, dit-on, de l'usage que les ivrognes ont fait de cette racine pour se débarrasser de l'excès de leur hoisson ; celui d'oreille-d'homme, de la forme des feuilles; colui de nurd saucerge, des propriélés énergiques de la plante, ou de sa ressemblance accidentelle, quant à l'odeur, avec les valérianes, dont trois espèces portaient le même nom chez les anciens. (Voyez ces dernières racines.)

inacine d'asarum eamadense. Ciette racine, envoyée de Philadelphie par .1. E. Durand, ne me parait différer en rien de celle de l'asarum europremen. Les deux plantes sont d'ailleurs tellement voisines, que beaucoup de botanistes les regardent comme deux variétés d'une même espèce.

Racine d'asarine. J'ai quelguefois vu vendredans le commerce, au lieu de racine d'asarum, celle d'une autre plante nommée asarine, ả cause de la ressemblance de ses feuilles avec celles de l'asarum. Mais cette autre racine, bien différente, est formée d'un corps ligneux, quelquefois gros et long comme le doigt, garni d'un grand nombre de radicules fort longues et menues comme celles de l'asclépiade, ce qui lui donnerait de la ressemblance arec cette dernière, si elle n'était d'une couleur grise foncée et d'un goût amer très prononcé. La même racine d'asarine pourrait plutôt encore se confondre avec celle de la valériane phu; mais celle-ci a l'odeur propre aux valérianes, et la première a une faible odeur de racine d'arnica. L'asarine est l'untirmlimum asarina $\mathrm{L}_{\text {. }}$, de la didynamic angiospermic, des dicotylédones monopétales hypogynes et de la famille des antirrhinées de Jussieu.

\section{FAMILLE DES SANTALACÉES.}

Végélaux herbacés ou frutescents, tous exotiques, à l'exception d'une seule espèce, l'osyris albu, qui croît dans le midi de la France et de l'Lurope; leurs fenilles sont alternes ou opposées et privées de stipules; les fleurs sont très petiles, formées d'un périanthe adhérent, 
à limbe supere a 4 on jo divisions; les élamines some en nombre égal, opposées aux divisions du périanthe et insérées a lour base ; l'ovaire est infere, uniloculaire, contemant mo petit nombre d'orules portés an sommet d'un podosperme filiforme cfui s'éleve du fond de la loge ; le style est simple, terminé par un stigmate lobé; le fruil est indéhiscent, monosperme, guelquefois charnu; la graine contient un embryon axile dans un endosperme charnu.

La famille des santalacées tire son nom du genre smitulum, forme d'arbres répandus depuis l'Inde justu'aux îles de l'océan Pacifiguc, et qui fomnissent a la pharmacie, a la parfumerie ot à l'ébénisterie, différens bois aromatiques sonrent confondus sous les noms de smatul ritrin et de suntul blunc, et dont l'origine précise est encore loin d'ètre complétement connue.

Les arbres du genre smutulum ont les feuilles opposées, très entières, un peu épaisses, fermes et lisses; les fleurs sont disposées en thyrses axillaires, très petites, formées d'un calice urcéolé, à limhe supere, quadrifide, tombant; de 4 glandes, écailles on petites folioles, insérées à la gorge du calice, alternes avec ses divisions et pourant ètre considérées comme une corolle rudimentaire; de 4 étamines alternes arec les folioles précédentes et opposées par consé(guent aux dents du calice. L'oraire est semi-infère, miloculaire, à 2 ovules pendants; le fruit cest un caryone ou drupe infère, succulent, monosperme, couronné par ce qui reste du limbe du calice. Les especes qui composent ce genre sont principalement :

$1^{\circ}$ Le santulum album de Rosburgh (flora indicu I, 442), anbre ayant environ la forme et la grandeur d'un noyer, croissant sur les montagnes roisines de la côte de llalabar. Il a les feuilles courtement pétiolées, lancéolées-obtuses, longnes de 4 à s centimètres; les flems sont d'abord jaunatres, devenant d'un rouge pourpre foncé; clles sont inodores, de même que toutes les autres parties de l'arbre. I.e hos lıi-même est inodore, lorsqu'il est frais, et n'açuiert l'odeur forte qui le caractérise que par la dessiccation. Les fruits sont noirs à maturiti, succulents, de la grosseur d'une cerise. On pense que le santal de la Cochinchine, de Timor et des îles adjacentes, apparticnt ì la mèni espece; quoique celni de Timor fournisse un bois plus volumincus ed moins aromatique, et que le bois de santal de la Cochinchine, qui est le plus gros de tous, soit si peu aromatique, au dire de Loureiro, quion l'emploie à peine dans les fumigations.

$2^{n}$ Le suntalum myrtifolinu Roxb., natif des montagnes de Circar', sur la côte de Coromandel; Roxburgh l'a définitirement considéré comme une espèce distincte de la précédente, beaucoup moins élevée et fournissant un bois inusité ou de peu de valcur. 


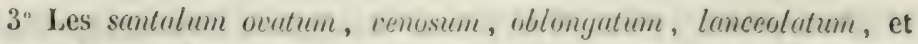
wbtusifolium, observís par le célèbre 11. R. Brown, dans la NouvelleHollande.

4" Les suntulum freycinetiunum et ellipticum rapportés par 11. Gaudichaud des iles Sandwich. Le premier est un arbre à feuilles lancíoléesobtuses (j'ajoute un peu spululées), reineuses; les grappes terminales, simples; les lieurs opposées, roses.

Les bois du nom de smutal ont été inconnus anx anciens firecs et aux Romains; les Arabes en ont parlé les premiers sous le nom de sumdal, dérivé de l'hindou chandana, ou du malais tsjendance. On e'll a toujours distingué trois sortes, dont une, le santal rouge, est un hois inodore et d'un rouge plus ou moins foncé, produit par un ptertectrjus, arbre de la famille des papillonacées, dont il sera traité plus tard. Il the sura donc question en ce moment que des autres bois nomués santal citrin et santal blanc.

Au dire de presque tous les anteurs, le santal blanc n'est autre chose que du santal citrin abaltu dans sa jeunesse, ou que l'aubier des anbres âgés, dont le cocur seul a acquis l'odeur forte et la couleur faure qui le caractérisent. Cetle opinion peut ètre raie ou fausse, suirant la matière ¿qui en fait le sujet; c'est-à-dire qu'on a pu vendre, en effet, quelquefois, comme santal blanc, l'aubier du santal citrin, ou le bois complet de l'arbre au santal citrin, récolté très jaune; mais il est certain aussi qu'on a toujours vendu comme santal blane, un bois bien différent du premier, à odeur de rose, et qui ne peut appartenir au mème arbre. Enfin on troure dans le commerce, depuis quelques années, un troisième bois de santal caractérisé par une odeur de muse ; je vais décrire successivement ces différents bois et leurs variétés.

1. Sanzal ceitrin ala Malabar. Ce bois, parfailement caractérisé par Loureiro, et produit part le suntalum allom de Roxburgh, constitue depuis longtemps la presque totalité de celui du commerce. Il se présente sous forme de bûches privées d'aubier, arrondies à la hache, ayant 1 mètre de longueur et 6 à 8 centimètres de diamètre. Il est d'une couleur faure, médiocrement dur et compacte, plus léger que l'eau. Il exhale une odeur très forte et aromatique, tout à fait caractéristique, que l'on compare ordinairement à un mélange de musc et de rose. Il a une légère saveur amère. Il est formé de couches concentriques, irrégulières et ondulées, dont le centre répond trìs rarement au centre de la bûche. Lorsçu’il est poli, il paraît satiné. Il fournit à la distillation une huile volatile jaune, oléagineuse, un peu plus légère que l'eau, d'une saveur âcre et amère.

Je possède un morceau de santal citrin semblable pour la forme au précédent et probablement de même origine; mais il est d'un fauve 
foncé et rougeâtre, plus dense que le premier et cependant encore un peu plus léger que l'eau. Il est comme implégné d'huile et d'une odeur encore plus forte que le premier. Il est carié à l'intérieur et la cavité formée par la carie présente une exsudation résineuse. De même que pour le bois d'aloès, il est probable que la vieillesse et la maladie ont àugmenté la qualité de ce bois.

2. Santal citrin de Timor? Tronc unique, parfaitement cylindrique et uni à l'extérieur, ayant encore néanmoins 26 centimètres de diamètre, et formé de couches concentriques ondulées dont le centre coüncide arec chlui de la bùche. Il est un peu moins dense et un peu moins aromalique que le premier; mais il offre la même couleur faure, le même manque d'aubier et une odeur semblable. J'arais anciennement conclu de cette similitude de caracteres que l'arbre qui le produit était de la même espèce que le premicr. La preuve ne me paraît plus suffisante aujourd'hui, que j'ai vu le santal citrin des îles Sandwich être semblable à celui de la côte du Malabar, quoique appartenant à une espèce distincte.

3. Santal eitrin pàle. Ce bnis se trourait anciennement asșcz fréquemment chez les droguistes; à une éporque plus rapprochée d'aujourd'hui je désespérais de l'y retrouver, lorsigu'un morceau m'en fut présenté sous le nom de stmenal blanc. Cie bois pent avoir de 8 à 16 centinètres de diamètre; il est cylindrique et uni à l'extérieur, d'un jaune très pâle arec un aubier blanchàtre; il e'st un peu plus léger que l'eau; il offre une fibre droite et une texture fine et compacte; il est bien plus dur, plus uni et susceptible de prendre un bien plus beau poli que les deux précédents; mais il a une odeur bien plus faible. Celui que j'ai retrouré paraissait mème inod re, et n'a repris son odeur de santal citrin qu'après que les surfaces eussent élé rruouvelées.

Ce bois est probablement un de ceux qui, sous le nom de strutal blunc, a été considéré comme du santal citrin abatu avant que l'âge lui eût communiqué toute la qualité (qu'il peut acquérir. Mass il me semble gu'un bois plus jeune devrait être moins dur et moins compacte que l'autre, et c'est le contraire qui a licu; je pense donc plutôt que le bois que je nomme ici santul citrin pulle est produit par un arbre different du premier.

4. J'ai vu anciennement, dans le Droguier de la Pharmacie centrale des hôpitaux cirils, un morceau de santal qui présentait des caractères tout particuliers; il provenait d'une racine ou d'un tronc rabougri; il était tortueux, très difficile à fendre, d'une couleur très pâle et presque blanche; il était léger, sans distinction apparente de bois et d'aubier, et néanmoins toujours un peu plus dense et plus coloré an centre qu'ì la 
circonférence. Il était tout à fait inodore à froid et ce n'était que par l'échauffement causé par la râpe ou la scie que le centre acquérait une faible odeur de santal citrin.

Ce bois, que j'ai décrit anciennement comme santal blanc, se rapproche bien plus par sa texture du véritable santal citrin cque celui du numéro précédent. Il peut provenir d'un arbre très jeune ou qui aurait crû dans des circonstances très défarorables à son déreloppenent.

5. Santal eitrin de Gandwich. Je duis à l'obligreance de II. Gaudichaud un échantillon de ce bois, produit à l'île Walıo par le suntulum fieycinetirmum (fie-arn des habitants). Il faisait partie d'une buche à contour elliptique, de 55 et 70 millimètres de diamitre. Le centre des couches ligneuses est assez près d'une des extrémités de l'ellipse. Du reste, il offre si bien tous les caractères du santal citrin du Nalabar, cqu'il est fort difficile de l'en distinguer. Le santal citrin des iles Sandwich a été signalé pour la première fois en 1792, par Yancouver. Il a été, pendant plusieurs années, l'objet d'une exportation assez considérable pour la Chine, mais il paraìt presque épuisé aujourd'hui.

6. Il est arrivé l'année dernière, des îles Harquises, un échantillon de santal en bûche à peu près triangulaire, formé d'un cœur faure brunâtre, tandis que le reste du bois est faure pàle et blanchâtre. L'odeur n'est pas très forte et incline vers celle de la rose, plus que le véritable santal citrin.

7. Santal blane at odeurde rose. Ce bois se troure en bùches ou en tronçons de bûches de 5 à 12 centimètres de diamètre. Sourent il est parfaitement çlindrique et recouvert d'une écorce d'un gris noirâtre, assez mince, dure et compacte. I l'intérieur il est formé presque entièrement d'un cœur ligneux, généralement plus lourd que l'eau, trìs dur et comme huileux; tout autour et immédiatement sous l'écorce se trouve un cercle d'aubier peu épais, presque aussi dense et aussi dur que le bois.

Ce bois est à fibres droiles et se fend facilement. Il est d'un blanc jaunattre, très fin, très compacte et susceptible d'un beau poli saliné; on en ferait de beaux meubles s'il était plus rolumineux; malleureusement les plus grosses bùches que j'en ai rues n'araient pas plus de 12 centimètreș de diamètre.

Enfin ce bois a une sareur assez fortement ancire, ci a une odeur de rose presque pure, qui ne permet pas de penser qu'il soit dù au même arbre que le santal citrin. Cette odeur justifie le nom que je lui donne de santal à odeur de rose.

Je me suis demandé si ce bois ćlait un véritable santal qui cût tonjours été connu pour tel, ou si ce n'était pas un bois nouveau substitué au santal blanc des auteurs; mais je pense gue c'est un véritable santal, 
parce que tous les auteurs qui parlent de la préparation de l'essence de rose en Asie, et surtout en Perse, disent qu'on en augmente la quantité en ajoutant aux roses que l'on distille du bois de santal. Or, comme il serait impossible de falsifier l'essence de rose arec celle de santal citrin, il faut bien que cette assertion se rapporte au santal à odeur de rose, et que ce bois soit reconnu dans l'Orient comme une espèce de santal; mais je n'ai aucune idée sur le lieu de sa provenance.

8. Santal a odear de muse. Ce bois a paru il y a peu d'années dans le commerce. Il se rapproche du précédent par son écorce grise foncée, dure et compacte; par sa densité considérable, sa compacité, la grande finesse de son grain et le beau poli qu'il peut recevoir. Voici maintenant les différences : il n’est pas satiné; il est formé d'un cœur faure foncé et d'un aubier beaucoup plus pâte, assez rolumineux, mais toujours presque aussi dur et aussi compracte que le cœur; de même que dans les bois précédents, la diflérence de l'aubier au cœur du bois, réside presque uniquement dans la couleur. Récemment coupé, il exhale une odeur de musc très marquée; mais celte odeur se perd à l'air et le bois ancien parait inodore; il faut l'action de la ràpe ou de la scie pour lui rendre son odeur. I'ai deux échantillons de ce bois : l'un est un tronçon régulièrement cylindrique, de s centimètres de diamètre, dont le cœur nettement terminé occupe 4 centimètres; l'autre est un tronc irrégulier, large de 19 centimitrts, à cœur ondulé, et comme nuageux sous le poli. J'en ignore le lieu d'origine.

9. Fanux hois de santal citrin. J'ai vu chez un fort marchand de bois des îles, quelques bùches trìs considérables d'un bois qu'il rendait comme smital citrin, enrers et contre tous et malgré tout ce qu'on pourait lui objecter à cet égard. Je présume que ce bois renait d'Amérique. Il ressemblait tout à fait, par sa couleur faure foncée et par les nombreuses reines brunes irrégulières, qui le faisaient parâtre mar.Lrí, à un autre bois d'Amérique gue sa ressemblance avec le bois d'olivier d'Europe a fait nommer aussi bois d'olivier. Nais ce bris d'olivier d'Amérique est inodore ou plutôt exhate, lorsqu'on le coupe, une odeur scnsible d'acide acétique; tandis que le prétendu santal citrin du marchand de bois des île's offre, lorsqu'on le râpe, une forte odeur de térébenthine. Du reste, ce bois est compacte, susceptib!e d'un beau poli, et serait arantageusement employé dans l'ébénisterie.

\section{FAIILLE DES DAPHNACÉES OU THYIELEACÉES.}

Arlorisseaux à feuilles entières, éparses on opposées, dépourrues de stipules. Fleurs hermaphrodites, quelquuefois diö̈ques par avortement, à périantihe coloré et pétaloïde, offrant 4 ou 5 divisions imbriquécs 
arant la floraison. Étamines généralement sessiles et disposées sur deux rangs, à l'intérieur du périanthe. Style simple, terminé par un stygmate simple, ovaire uniloculaire contenant un seul ovule pendant. Le fruit est unc baie monosperme ou un askose entouré par le tube du périanthe qui a persisté. La semence est pendante et contient, dans un endosperme peu développé, un embryon orthotrope à radicule petite et supère.

Le genre le plus important de cette famille est le genre dujphe, dont toutes les espèces sont pourvies d'un principe âcre qui peut les faire employer comme exutoires; les principales sont.

$1^{\circ}$ Le garou ou SAIN-BOIS, diphne gnidium L. (fig. 177). Arbrisseau du midi de la France et de l'Europe, qui s'élère à la hauteur de

Fig. 177.

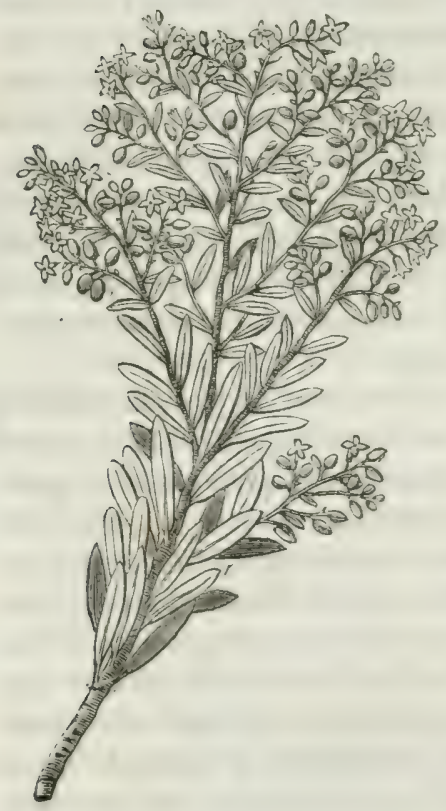

6 à 10 décimètres. Ses rameaux supérieurs sont garnis, sur toute leur longueur, de feuilles étroites, aiguës, sessiles, rapprochées les unes des autres et glabres. Les fleurs sont petites, d'un blanc sale, disposées au sommet des rameaux et dans les aisselles des feuilles supérieures, en petiles grappes serrées qui forment dans leur ensemble un corymbe terminal. Le périanthe est monophylle, infundibuliforme, à limbe quadrifide; les étamines sont au nombre de huit, insérées sur deux rangs et incluses sur le tube du périanthe; le style est terminal, très court, terminé par un stigmate globuleux; le fruit est une baie du volume d'un gros grain de poivre, formée d'un péricarpe succulent très peu épais, et d'une semence presque sphérique, mais

terminée supérieurement par une pointe courte. L'épisperme offre trois couches distinctes : une première membraneuse, trìs mince, jaunitre, marquée, près du sommet, d'un hile très apparent et d'un raphé proéminent gui s'étend du hile à la chalase, située à l'extrémité inférieure opposíe; la deuxième enveloppe est noire, lisse et luisante, d'une épaisseur sensible, dure et cassante; la troisième est très mince, jaunitre et membraneuse comme la première; l'amande est blanche et 
huileuse. Toute cette semence est pourrue d'une âcreté considérable; elle était usitée autrefois comme purgative, sous le nom de grana gnidia ou de cocea gnidia, d'où les habitants du Midi ont donné au garou le nom de coquencudier, et aux semences celui de sementes de coupuenaudier. Illes peurent causer des superpurgations dangereuses; les feuilles ont aussi été usitées en décoction; ainsi employées, elles sont moins actives et moins dangereuses que les graines.

2. MÉzénéon ou boIs deNTIL, duphne me zereum L. Tige droite, rameuse, haute de 6 à 10 centimètres; feuilles lancéolées, éparses, sessiles, caducues; les fleurs paraissent pendant l'hiver avant les feuilles; elles sont odorantes, purpurines ou blanches, sessiles et attachées trois à trois le long des rameaux; les fruits sont des baies rouges on jaunes. Cet arbrisseau est cultivé dans les jardins, pour l'agrément de ses fleurs pendant l'hiver. Son écorce et ses semences sont souvent substituées à celles du garou et peuvent servir aux mêmes usages.

$3^{\circ}$ La THYMEr.É, daphlue thymelea L. Sous-arbrisseau qui n'a souvent que 8 à 12 centimètres de hauteur, et qui dépasse rarement 20 ou 25 centimètres. Il porte des tiges nombreuses, simples, garnies de feuilles lancéolées et sessiles; les fleurs sont jamnatres, sensiles, axillaires, solitaires ou deux ou trois ensemble. Il croît dans le midi de la France, en Italie et en Espagne, où les paysans se purgent avec ses feuilles pulvérisées.

$4^{\circ}$ La LALrEOLE, deplme lmureolu L. Ce petit arbrisseau, à tiges faibles et pliantes, croît dans les bois, par toute la France. Ses rameaux sont garnis de fenilles lancéolées, coriaces, luisantes, persistantes, courtement pétiolées; les fleur's sont rerdâtres, réunies au nombre de cinq ou six en petits groupes axillaires.

Les feuilles, et surtout l'écorce de laurćole, sont pourvues d'une causticité remarquable el elles sont souvent employées comme exutoires, à l'état récent, par les geus de la campagne. Mais c'est surtont l'écorce du garou (duphrne gnidium) que l'on troure dans le commerce, à l'état de dessiccation et qui est destinée à cet usage. Cette écorce est très mince et néanmoins difficile à rompre. Elle est courerte d'un épiderme demi-transparent, d'un gris foncé, crispé ou ridé transversalement par le fait de la dessiccation, et uniformément maryué de distance en distance de petites taches blanches tuberculeuses. Dessons cet épiderme se trouvent des fibres longitudinales trìs tenaces, que l'on pourrait filer comme le chanvre, si elles n'étaient courertes, du côté de l'épiderme, d'une soie très fine, blanche et lustrée, qui, en s'introduisant dans la peau, y cause des démangeaisons insupportables. L'intérieur de l'écorce est d'un jaune de paille et uni, mais déchiré longitudinalement. Toute l'écorce a une odeur faible, et cependant 
nauséeuse, une saveur âcre et corrosire. Ellle est épispastigne ćtant appliquée sur la pean en ćcorce, en prodre ou en ponmade. Fille nous arrive en morceaux longs de 32 à 65 centimetres, larges de 27 a 54 millimètres, pliés par le milieu et réunis en bottes. On dloit la choisir large et bien séchée.

On nous envoyait aupararant, au lieu de l'écorce de garou, les rameaux mêmes de l'arbrisseau desséchés, et on était dans l'usage d'en séparer l'écorce à Paris, à mesure du besoin, en la ramollissant préalablement dans l'eau, ou, ce qui est encore pis, dans du vinaigre. Il est érident que l'écorce qui a été enlevée de dessus le bois récent, sans macération préliminaire, et qui a été séchée promptement, cloit être plus efficace. Il faut donc préférer au bois de garou l'écorce toute préparée que nous offre le commerce.

L'écorce de garou a été analỵsée par un grand nombre de chimistes, notamment par Vauquelin, Gmelin, Coldefy-Dorly et Dublanc jeune; voici ce qui résulte de leurs différents travaux:

Celte écorce, traitée par l'alcool, donne une ligueur brune verditre qui laisse précipiter de la cire par son refroidissement. Le soluté alcoolique étant décanté et distillé presque entièrement, il s'en sépare une matière verte-brune, épaisse, dont l'éther extrait une huile verte très vésicante: il reste une matière résinoïde brune qui ne jouit d'aucune propriété épispastique.

L'huile verte n'est pas âcre et résicante par clle-même, et le principe résicant peut en être isolé en traitant directement l'extrait alcooliqque par de l'eau aiguisée d'acide sulfurique. On filtre, on ajoute à la liçueur de la chaux ou de la magnésie et on distille. Vauquelin a obtenu de cette manière une eau distillée très âcre et alcaline, d'où on a conclu que le principe âcre du garou était alcalin; mais Vauguelin, ạant constaté ensuite la présence de l'ammoniaque dans la liqueur distillée, a pensé que l'alcalinité du produit ́́tait due à cet alcali. Cependant, comme il est certain que l'addition d'un acide facilite la solution du principe âcre, et que celle d'un alcali est nécessaire pour que ce principe passe à la distillation, il me parait probable qu'il est alcalin par lui-même.

Lorsque, au licu de traiter l'esprit alcoolique par de l'eau acidulíe, on le traite par l'eau seule, et qu'on précipite la liqueur par de l'acélate de ploub, on obtient une laque d'une belle couleur jaune. La liqueur, privée de l'excès de plomb par le sulfide hỹdrique, et évaporce, laisse cristalliser une substance que l'on purifie par de nourelles solutions et cristallisations. Cette substance est blanche, d'une saveur amère un peu astringente, peu soluble dans l'eau froide, très soluble dans l'eau bouillante, soluble également dans l'alcool et dans l'éther, ni acide ni 
alcaline. Cenc matière a été tronvéc d'abord par Vauquelin dans l'écorce du depplune alpinu; MII. Gmelin et Bar l'ont retirée ensuite de l'écorce de garou et lui ont donné le nom de dephluine. Il ne faut pas la confondre arec le principe âcre des depplune clont j’ai parlé d'abord.

\section{FAMILLE DES LAURAGÉES OU LAURINEES.}

Cette famille, quoique peu nombreuse, est une des plus intéressantes à étudier à cause du grand nombre de parties ou produits aromatiques qu'elle foumit à la pharmacie, à l'économie domestique et aux arts. Llle comprend des arbres ou des arbrisseaux, à feuilles alternes, quelquefois opposées en apprarence, ordinairement épaisses, fermes, persistantes, aromatiques et poncuées (1) ; stipules nulles; fleurs hermaphrodites, monoüques, diö̈ques ou polygames; périanthe calicinal monosépale, à quatre ou six divisions imbriquées; disque charnu soudé arec le fond du périanhe, persistant, s'accroissant sourent avec le fruit; étamines périgynes, insérées sur plusieurs rangs à la marge du disque, en nombre quadruple, triple, double ou égal aux divisions du périgone; les filets sont libres, les intérieurs pourrus à la base de deux glandes pédicellées qui sont des étamines rudimentaires; les anthères sont adnées, à 2 ou à 4 loges s'ourrant de bas en haut par des valrules; ovaire libre, formé de 3 folioles soudées, uniloculaire, ne contenant le plus ordinairement qu'un orule pendant. Le fruit est une baie monosperme accompagnée à la base par la fartie entière du périanthe qui a persisté. La graine est inverse, recouverte par un épisperme chartacé, à hile transversal, à raphé se dirigeant obliquement rers la chalaze située à l'extrémité opposée. Elle renferme un embryon saus périsperme, orthotrope, complosé de 2 gros cotylédorrs charnus et lıuileux; la radicule est très courte, rétractéc; supère.

La famille des laurinées comprend aujourd hui plus de quarante genres, dont la plupart ont été primitivement compris dans le genre laurus: tels sont, par exemple, les genres sassafiras, ocotea, nectandru, persea, cimnamomum, camploora; le tableau suivant indique les caractères qui les distinguent principalement.

(1) Les cassyta qui ont été réunies aux lauriers, sont, par exception, des plantes parasites, volubiles, privées de feuilles et ayant l'aspect de la cuscute. 


\begin{tabular}{|c|c|c|c|c|c|c|c|c|c|c|}
\hline 尖 & 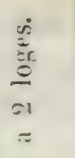 & $\begin{array}{l}\stackrel{0}{0} \\
\stackrel{00}{0} \\
\stackrel{-}{\square}\end{array}$ & 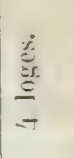 & 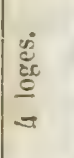 & $=$ & 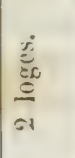 & $\begin{array}{l}\underset{8}{0} \\
\stackrel{0}{0} \\
\stackrel{0}{=1}\end{array}$ & $\begin{array}{l}\underbrace{0}_{0} \\
\stackrel{x}{0} \\
\stackrel{0}{\square}\end{array}$ & $\begin{array}{l}\mathscr{c}_{0}^{\circ} \\
\stackrel{0}{0} \\
=\end{array}$ & 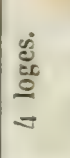 \\
\hline$\sum_{=}$ & 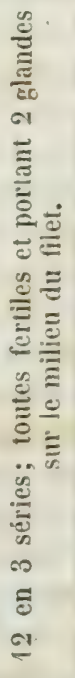 & 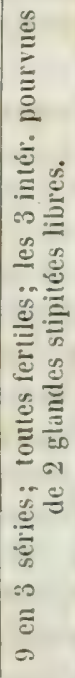 & 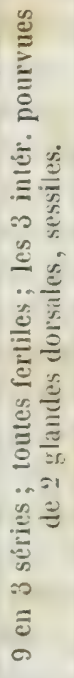 & 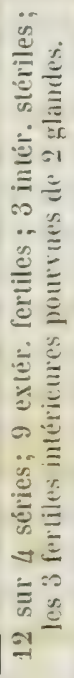 & 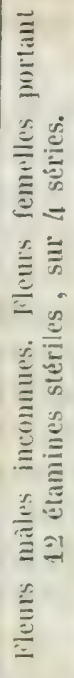 & 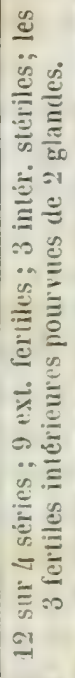 & 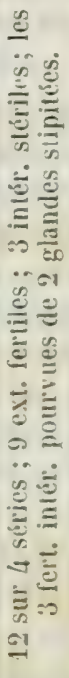 & 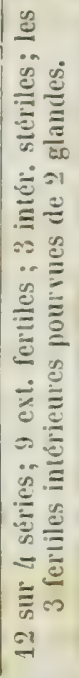 & 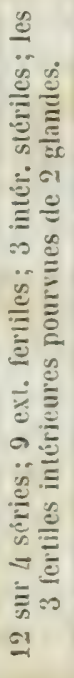 & 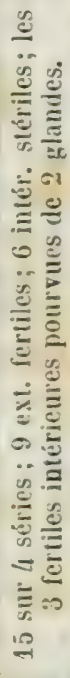 \\
\hline$\sum_{3}^{\frac{1}{3}}$ & 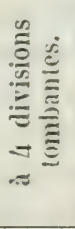 & 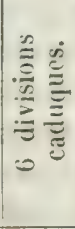 & 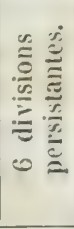 & 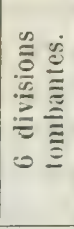 & 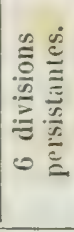 & 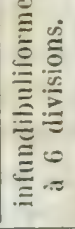 & 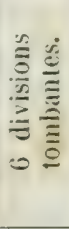 & 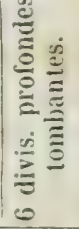 & 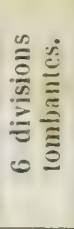 & 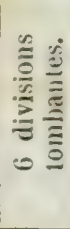 \\
\hline$\stackrel{5}{=}$ & 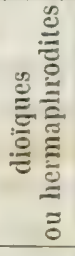 & 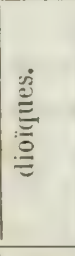 & 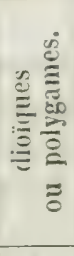 & 竞 & 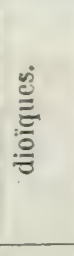 & 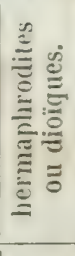 & 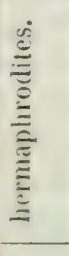 & 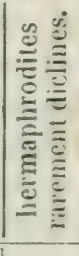 & 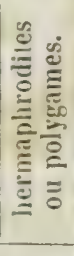 & 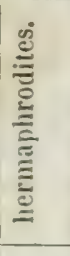 \\
\hline$\underset{c}{2}$ & $\begin{array}{l}\dot{ } \\
\dot{ } \\
\dot{0} \\
\stackrel{3}{3} \\
\vdots\end{array}$ & 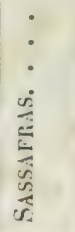 & $\begin{array}{l}\dot{ } \\
\dot{0} \\
\dot{4} \\
\dot{3}\end{array}$ & 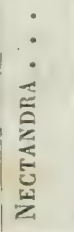 & : & 豙 & : & 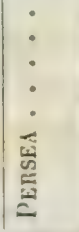 & $\begin{array}{l}: \\
\vdots \\
\vdots \\
\vdots \\
\vdots \\
\vdots \\
\vdots \\
0 \\
0\end{array}$ & $\begin{array}{l}: \\
\dot{\bar{z}} \\
\frac{0}{0} \\
\frac{0}{3}\end{array}$ \\
\hline
\end{tabular}


Laurler commun ou Laurier d'spollon.

Laurus nutilis L. Le laurier est un arbre de l'Lurope méridionale, qui est cultivé dans nos contrées, mais qui s'y élève peu. Sa lige est unie et sans nœuds; son écorce est peu épaisse et sun bois est poreux. Ses feuilles sont longues comme la main, larges de deux ou trois doigts, lisses, pointues, persistantes, d'une texture sèche, d'une odeur agréable et d'une saveur âcre et aromatique. Ses fruits sont gros comme de petites cerises, noirs, odorants, huileux et aromatiques.

Les feuilles de laurier sont stimulantes, carminatives et pédiculaires; elles servent d'aromate dans les cuisines.

Les baies de laurier sont composées d'un péricarpe succulent, mais très mince, et d'une semence volumineuse, formée d'un épisperme en forme de capsule sèche, mince et cassante, et d'une amande à 2 lobes, faures, d'une apparence grasse et d'une sareur amère et aromatique. Ce fruit contient deux huiles, l'une grasse, l'autre rolatile, qui sont mélangées dans le péricarpe et dans l'amande; mais le péricarpe contient plus de la première, et l'amande plus de la seconde. On peut obtenir ces deux huiles mélangées par une forte expression à chaud, ou par une légère ébullition dans un alambic. Le produit est d'un beau vert, très aromatique, granuleux, et de la consistance de l'huile d'olives figie. Il est rare dans le commerce, ou il est remplacé par de la graisse chargée par digestion du principe colorant rert et des huiles des fruits et des feuilles de laurier. Les baies de laurier font partie de l'alcoolat de Fioravanti.

\section{Sassafras officinarum} Nees; laurus sassafras $\mathbf{L}$. Le sassafras ou pavame est un assez bel arbre qui croît dans la Virginie, la Caroline et la Floride. On le trouve également au Brésil, à l'île Sainte - Catherine, d'où $\mathbf{M}$. Gaudichaud en a rapporté un tronc tout à fait semblable, pour la qualité aromatique, à celui de l'Amérique septentrionale. Il peut également venir en France, mème sans culture, comme on en a eu la preuve, il y a un certain Sassafras ( fig. 178).

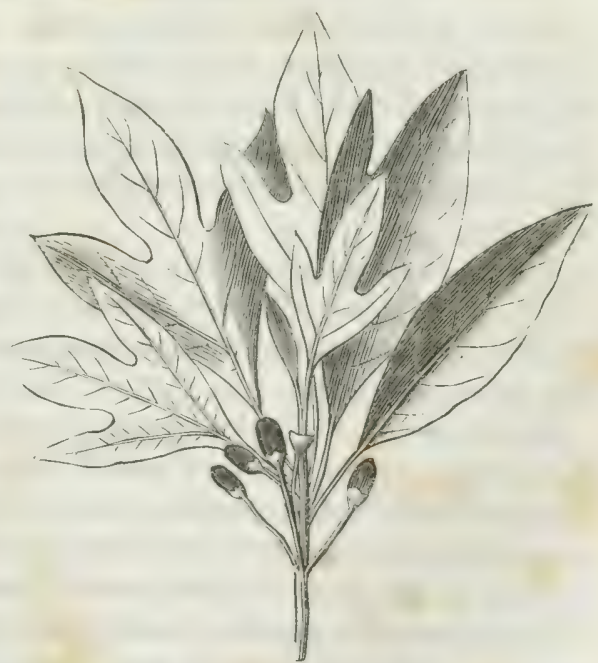


nombre d'annćes, par un trìs gros sassafras qui s'est trouvé abattu dans la coupe d'un bois près de Corbeil; mais il était moins aromatique que celui du commerce.

Le sassafras a les feuilles alterncs, très variées de forme et de grandeur, glabres et d'un rert foncé en dessus, glaugues en dessous; les fleurs sont petites, disposées en bouquets ou en petites grappes liche's; le fruit est une petite baie orale, blenâtre, soutenue à sa base par un calice rougeâtre en forme de cupule. Sa racine, que l'on trouve dans le commerce, est en souches ou en rameaux de la grosseur de la cuisse ou du bras; elle est formće d'un bois jaunatre ou faure, poreux, liger, d'une odeur forte qui lui est propre. L'écorce est grise à la surface, d'une couleur de rouille à l'intérieur, encore plus aromatique que le bois. Le bois et l'écorce fournissent il la distillation une lonile vulatile plus pesante que l'eau, incolore lorsun'elle est récente, mais se colorant en jaune arec le temps.

Écoree de sassafras officinal. Cette écorce se trouve ígalement daus le commerce séparće de la racine ou des rameaux de l'arbre. Llie est épaisse de 2 à 5 millimètres, tantôt recourerte de son épiderme gris, tantòt râclée et d'une couleur de rouille. Elle est spongieuse sous la dent, d'une odeur très forte, d'une sareur piquante ct très aromatique. La surface intérieure, qui cst unie et d'un rouge plus prononcé que le reste, offre quelquefois de très petits cristanx blancs, assez semblables à ceux observés sur la fère pichurim. Céte écorce derrait être employée en médecine, comme sudorilique, préférablement au bois.

Bois de sasserfirus indore. Ce bois existe depuis longtempes dans la collection du Muséum d'histoire naturelle, et j'en ai un échantillon provenant du commerce, où il parait qu'on le troure quelquefois, mèlé au sassafras oficinal. Il lui ressemble tellement en teature, en couleur et en écorce, qu'il est impossible de ne pas le reconnailre pour un sassifras; mais il est complétement inodore. Il provient du tronc et non de la racine.

On troure dans le commerce ou dans les droguiers un assez frand nombre d'autres bois, d'écorces et de fruils qui ont l'odeur du sassafras, et dont l'origine exacte est encore courerte de quelque obscurité. Tels sont les articles suivants:

Bbois d'anis ou Bois de sassafras de rorézorgue. l'omel, Geoffroy et J. Bauhin ont fait mention d'un breis d'mnis qui, de leur temps, était quelquefois substitué au sassafras, el que son odeur a fail prendre à tort, par plusieurs auteurs, pour le bois de l'anis étoilé de la Chine fillirinm mnisenfum). Beaucoup de personnes ont pensé ensuite que ce bois ne différait de celui du sassafras oflicinal que parce que celıi-ci est produit par la racine de l'arbre, tandis que le lu, d'anis en serait le tronc. Mais: 
relte opinion est réduite à néant par la comparaison du bois d'anis arec les parties de tronc gui accompagnent sourent les racines de sassafras du commerce. Reste alors l'opinion beaucoup plus probable de LemaireJizancourt, qui a présenté le bois d'anis à l'Académie de médecine sous le nom de sassufius de l'Obrinorum (urufru cymlurum H. B.) ; cependant je dois dire (que le bois d'anis, quoique plus dur gue le sassafras officinal, ne me parait pas mériter l'épithèle de durissimum que lui donne 2I. de II umboldt; je suis platôt porté à le croire produit par l'ucutre pichurim dont je parlerai dans un instant.

Le bois d'anis se présente dans le commerce sous forme de buiches çlindriques privées d'écorce et dianbier, de s a 11 centimètres, ou en troncs de 30 it ju centimètres de diamètre, également privés d'aubier, ce qui indiquie un arbre de première grandeur. Il est d'un gris verditre, plus comjacte et plus penant que le sassafras, mais surnageant encore l'eau, et ne prenant gu'un poli imparfait ; lorsqu'on le ràpe, il déreloppe une odeur mixte de sassalras et d'anis, mais bien moins forte gue celle du sassafras et moins persistante. Iussi les pharmaciens doirent-ils rejeter les copeaux de ce bois, que l'on trouve aujourd hui très abondamment chez les droguintes, parce que les ébénistes et les tourneurs, préférant pour leur usage le bois d'anis au sassafras, versent une grande quantité de ces copeaux dans le commerce. Il n'y a aucune comparaison à faire entre eux pour l'odeur et les propriétés, et ceux que l'on prépare soi-mème arec la racine du vrai sassafras. Enfin, le bois d'anis graisse la scie, et sa coupe transversale, étant polie, offre un pointillé blanchàtre sur un fond jaunâtre obscur.

Autre bois à odesu de sassafras. Il y a très longtemps que ce bois m'a été remis par II. Boutron Charlard sous le nom de bris de Varghes: sentunt l'anis. Virey, qui le tenait de la mème source, a cru pouroir l'attribuer, en raison de sa grande duretí, au mesua ferrea L. (nagassenrium Rumph., guttifères) (qui fotrnit un bois tellement dur, que les Portugais lui ont donné le nom de bris de fer (Jomin. jhorrm., I. IX, p. 468). Mais je doute fort que celte opinion soit rraie, parce que Rumphius et Burmann, qui ont fait mention de l'odeur des fleurs du naryassarimem, n'ont nullement dit que son bois fùt aromatique. Je crois plutòt, en raison des rapports éridents de ce bois avec le précédent, qu'il est fourni par un ocotra, et sa trìs grancle dureté, jointe à sa forte qualité aromatique, me font l'attribuer à l'ocoteu cymbrimun de Humboldt et Bonpland. Je ne l'ai jamais ru dans le commerce; tel que je l'ai et tel qu'il existe aussi dans le droguier de l'École de pharmacie, ce bois provient d'un tronc d'un diamètre considérable; il pèse spécifiquement 1,094 ; il est très dur, brun noirattre avec un aubier jaune faure, presque aussi dense que le bois; il est susceptible d'un beau poli, et sa compe 
perpendiculaire it l'axe présente, sous un fond brun foncé, un pointillé blanc très serré. Il jouit d'une odeur et d'une sareur très fortes de sassafras.

Beorce pichurim. Ilurray, dans son "fpuntulus med icmmimm (t. IV, p. 554), fait mention d'une écure de pioburim produite par l'arbre qui donne la feve pichurim, rque je suppose être encore l'ocufen rymbarum II. B.; ; sorte que cet arbre donnerait à la fois le bois d'anis très dur, la fére pichuriun et l'écorce pichurim. J'ai trouvé anciennement dans le commerce, sous le nom d'ecorre de sussufiras, une substance différente de la véritable écorce de sassafras, et yui anait tous les caractères de l'écorce pichurim de Ilurray. Celte écorce est mince et roulée, couverte d'un épiderme gris-blanchâtre, jaunâtre ou brunàtre. I.e liber est d'une conleur de ronilie terne, devenant brunàtre arec le temps; la texture en est assez compacte, fine, fibreuse et fenilletée. Son odfur et sa saveur sont celles du sassafras, mais plus faibles et plus suaves; la surface intérieure, qui est assez unie, offre très sourent une sorte d'exsudation blanche, opaque, cristalline, qui me paraît analogue à celle de la fève pichurim.

11. Lessoil, qui a fait comme pharmacien le royage autour du monde sur la corvette lu Corprille, a rapporté de la Youvelle-Guinée unc érrice de mossong anciennement décrite par Rumphius (. Iml., t. II, p. 62 \%. Celte écorce ne différait de la précédente que par une odeur de sassafras plus forte, qu'elle devait probablement à ce qu'elle était toute nourelle lorsque je l'ai examinće. Tous les autres caractères étaient semblables. Il est du reste érident, par la description de Rumphius, que le mussuy est congénère des ocoten d'Amérique.

Leoree de sassafias de Ginatimala. Cette écorce, rapportée plar II. Bazire, est en tuyaux roulés, minces, et de la grosseur d'une plume à celle du petit doigt ; l'extérieur est blanchâtre et fongueux; l'intérieur est d'un gris rougeâtre; la cassure offre une séparation tranchée des deux couleurs; l'écorce entière possède une forte odeur de sassafras dominée par celle de l'anis, et une sareur semblable. Cette écorce est employée, comme sudorifirque et antivénérienne, à Guatimala; l'arbre qui la produit, et qui porte le nom de sussufress, croit près des côtes de la mer du Sud.

\section{Semence ou Feve pichurin.}

On troure dans le commerce deux espèces de fève pichurim, aux(quelles on applique indifféremment les noms de péchrim, pichonin, pichula, pichora, tous corrompus du premier, et celui de noi.t de sassafras, qui leur a élé donné à cause de leur odeur, el parce que les arbres qui les produisent portent sur les hords de l'Orénoque le nom de sussu- 
fras, bien qu'ils diffèrent du véritable sassafras officinal. Voici les caractères des deux semences:

semence pichurim vraie. Cette espèce est rare aujourd'hui chez ncis droguistes; (dle consiste en deux lobes cotylédonaires semblables ì ceux qui forment la semence de laurier, mais beaucoup plus gros, toujuns isolés et entièrement nus. Ces Iobes sont elliptiques-oblongs, longs de 27 à 45 millimètres, et larges de 14 à 20. Ils sont convexes du côté ex terne, et marqués ordinairement de l'autre d'un sillon longitudinal formé probablement pendant leur dessiccation. Ils sont lisses, unis on légèrement rugueux à l'extérieur, et présentent dn côté intérieur, près de l'une des extrémités, une petite cavité dans laquelle avait élé logé l'omhryon. Ils sont brunâtres au-dehors, d'une couleur de chair et un je'u marbrés en dedans; et cette marlorure, analogue à celle de la muscarle, mais moins marquée, est due à la même cause, c'est-ì-dire à la présence d'une huile butyracée qu'on peut en retirer par l'expression à chaud ou par l'ébullition dans l'eau. Leur sareur et leur odeur tiennent le milieu entre celles de la muscarle et din sassafras: enfin cette semence, conservée pendant quelque temps dans un bucal de verre, ne tarde pas à en altérer la transparence par la volatilisation d'un principe aromatig̣ue qui se fixe contre le verre, et y forme un enduit blanc; presque toujours même, la surface de la semence offre une guantité plus ou moins grande de petits cristaux blancs, dus au même principe, le(puel constitue un acide analogue à l'acide benzoïque ou cinnamique.

semence pichurim batarde. Celte semence est sourent entière ct recouverte par une par tie d'épisperme rugueux ct d'un gris rougeâtre. Elle est oblongue-arrondie, quelquefois presque ronde et toujours plus conrte et plus ramassée que la première ; car sa longueur varie de 20 à 34 millimètres, et sa largeur de 14 à 20. La surface privée d'épiderme est presque noire; le sillon longitudinal des lobes séparés est peu marqué. L'odeur de la semence entière est à peine sensible et ne se dér(loppe que lorsqu'on la râpe. Enfin, je n'ai jamais observé de cristaux à sa surface, ni qu'elle ternit les vases de verre qui la renferment. Elle est donc, au total, beaucoup moins aromatique que la première, et ne doit jas lui être substituée.

Cette semence me paraît produite par l'ocoten pichurim de IIumbolat et Bonpland, arbre de la province de Vénézuéla, que ces célèbres royageurs ont ainsi nommé pour avoir pensé qu'il pouvait produire la fère pichurim, et dont ils disent ce qui suit: Drupse forme $\epsilon t$ magnitudine olicke, calyce persistente cincta. An faba pichurim ob vim febrifugrmm celebratu? Liymum suaveolens. C'est à ce même arbre que j'ai attribué plus haut le bois d'anis de Pomet ou bois de sassafras des tourneurs. Quant à la véritable fève pichurim qui a été si bien décrite par Murray, elle 
doit être produite par l'oecotéa rymuluman des forèts de l'Orénorjue, dont

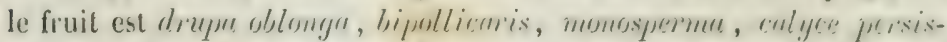

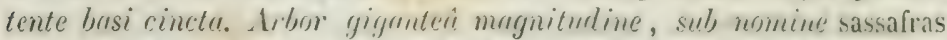

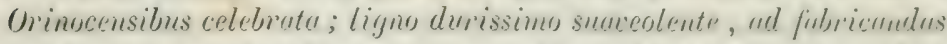
scruphers insereinte (Toxu generu, L. II, p. 132). C'est à ce mème arbre que j'ai rapporté le prétendu bois de naghas à odeur dl'anis, et l'écorce pichurin.

Yota. J'ai conservé les synonymies précédentes dont rien ne me démontre, quant a présent, l'inexactilude. Je dois dire cependant gue .11. Martits atIribue les deux fèves pichurim à deux ocolea différents de ceux dicrits par Humboldt et Bonpland, et nommés par lui ocntea puehring major et neotea pu:hury minor. J'ajoute que, par suite du tranaport d'un ceriain nombre d'espréces d'ocotea dans le genre nectandra, l'ocotea cymbarum II. B. =: Yectandra cymbarum Nees. L'ocotea puchury major . Iart. = Yectandra puehury major Yees. L'ocolea puchury minor Marı. = Yectandra luchury minor Nees.

C'est donc à ces trois espèces de nectandra ru'il faut altribuer, d'aprés MM. Nees et Míarlius, le bois d'anis trés dur, el les deux fères pichurim.

\section{Bois, écorce et fruit de Bebeeru.}

Les tourneurs et les ébénistes anglais connaissaient depuis longlemps, sous le nom de green-heart (cœur vert), un bois dur, pesant, el d'un jaune verdàtre, qui est originaire de la Guyane, mais dont l'espèce était inconnue. C'est au docteur Rodie que l'on doit d'aroir décrit l'arlsre et d'en aroir extrait un alcaloüle féibrifuge, dont l'usage commence à se répandre en sugleterre. Cet arbre porte dans le pays le nom de buteru; il est élevé de 24 à 27 metres, sur un tronc droit et cỵlindrignte, laut de 12 à 15 mètres et de 2,5 à 3,5 mètres de circonférence. L'écorce en est blanchattre et unie; les feuilles sont opposées, oblongues-aiguës, entières et brillantes. Les fleurs sont disposíes en cymes axillaires; elles sont très petites et d'une forte odeur de jasmin. Les fruits sont obcordés ou oborés, de la grosseur d'une petite pomme, formés d'une coque peu épaisse et cassante, et d'une amande à 2 lobes charnus et jaunitres, lorsqu'ils sont récents, mais devenant bruns et très durs par la dessiccation. Cette amande est très amère et plus riche en alcaloüde que l'écorce. Celle-ci, telle que le commerce la fournit, est en morceaux plats, grisâtres, épais de 6 à 8 millimètres, médiocrement fibreux, durs, pesants et fragiles. Elle est très amère et dlipourrue de tout principe aromaticjue. En la soumettant au procédé par lequel on obtient le sulfate de quinine, le docteur Rodie en a retiré deux alcaloüdes fúbrifuges, dont l'un, nommé beheerine, forme arec l'acide sulfurique un sulfate très coloré, ạant 
l'apparence de l'extrait sec de quinquina, et dont la vertu fébrifnge paraît être à celle du sulfate de quinine comme 6 est à 11. L'alcaloüde lui-mème, obtenu à l'élat de pureté, se présente sous la forme d'une Inatière translucide, jaunâtre, extractiforme, très suluble dans l'alcont, moins soluble dans l'ether, très peu soluble dans l'eau. J'après l'analis se qui en a été faite par Mu. Tilley et Douglas Maclagan, il serait formé de $\mathrm{C}^{35} \mathrm{H}^{20} \mathrm{Az} \mathrm{O}^{6}$.

Quant au genre auquel doit appartenir l'arbre bebeeru, sir Robert Schomburgh l'ayant examiné sous ce dernier rapport, pense qu'il appartient aux nectandra, et lui donne le nom de nectundra liodei. Ce genre se trourant placé dans la famille des lanrinées auprès des genres ocotea, angathophyllum, licariu, dicypellium, qui fournissent tous des bois, écorces ou fruits très aromatigues, et lui-même en produisant aussi, comme on vient de le roir, c'est donc une exception bien remarquable que d'y roir accoler une espèce dont le bois, l'écorce et le fruit sont complétement dépourvus de principe aromatique, et possèdent une sareur amère comparable à celle de la gentiane ou du quinquina.

\section{Écorce dite Canuelle girontée.}

Cette écorce a porté aussi le nom de bris de rrabe on de bois de yirofle, à cause de son odeur, et ce nom 'st cause qu'on l'a attribuée d'abord au ravensara de. IIadagascar (agathophlyllum aromaticum), dont le fruit est appelé aussi noix de girofle, et dont l'écorce doit être en cffet très semblable à la cannclle giroflée. Ensuite on l'a crue produite par le myrtus corynjhlugllatu de Linné, espèce mal définie qui comprenait le syzygium caryou,lygllceum de Gærtner, myrtacée aromatique de Ceylan, et le myrtus urris de Willdenow, autre myrtacée du Iexique et des Antilles. Aujourd'hui, il paraît bien prouvé que la cannelle giroflée vient du Brésil (1), où elle est prorluite par un arbre de la famille des laurinées, nommé dicypellium coryophyllatum. Cette écorce, telle qu'clle s'est toujours montrée dans le commerce, est sous forme de bâtons solides, longs de 80 décimètres environ, de 27 millim. de diamètre, et imitant une canne. Ces bâtons sont formés d'un grand nombre d'écorces minces, compactes, très dures et très serrées, roulées les unes autour des autres, et maintenues à l'aide d'une petite corde faite d'une écorce fibreuse. La cannelle giroflée est unie ct d'une couleur brune foncée, lorsqu'elle est privée de son épiderme, qui est gris blanchâtre; mais

(1) Pomet, tout en attribuant la cannelle giroflée au ravensara de Madagascar, reconnait qu'elle est principalement apportée du Brésil, où elle est nommée cravo de Marenham.

II. 
quelquefois elle en est pourvue. Elle offre une forte odeur de girofle et une saveur chaude et aromatique; elle est très dure sous la dent.

Elle jouit des propriétés du girofle, et peut le remplacer dans les assaisonnements, (quoiqu'elle soit plus faible.

\section{Bois tle Llcarl.}

Aublet, dans ses plantes de la Guyane, décrit imparfaitement, sous le nom de licrria guirenensis, un arbre qui paraît appartenir ì la famille des laurinées. I.e tronc s'élève à la hauteur de 16 à 20 mètres sur un mètre et plus de diamètre; son bois est jaunâtre, peu compaçe, d'une odeur (fui approche de celle de la rose. Les Galibis lui domnent le nom de licari Kíssali; les colons celui de bris de ruse, et, lorsqu'il est très âgé, colui de sassafras. Les ouvriers rui lo: travaillent à Paris le nomunent hois de poìre, à rause de l'âcrelé de sa poussière. Enfin, je l'ai ru rendre sous les noms de bois jaume de f'angenne et de bris de vitron de Cinyemre. Tous ces noms, et d'autres que je pourrais rapporter, tels que indre juune, copalu, etc., ne pourant que causer une grande confusion, je pense gu'il faut se borner au nom de lonis de licrni ou à celui de bris de rose de Cayenne, qu'il mérite si bien par son odeur.

On connaît d'ailleurs à Cayenne deux especes du nom de buis de rosé: l'un, nommé bois de rose minle, est le bois de licari. Il est assez dur et assez pesant, formé de couches ligneuses encherêtrées, d'une odeur de rose très marquie, d'une saveur semblable, jointe à une certaine amertume; il fournit à la distillation une huile volatile jaunàtre, un peu onctueuse, d’une pesanteur spécifigue de 0,9882 . Il se recourre à sa surface et il présente dans les fissures de l'intérieur une efllorescence blanche qui est un sléaroptène très finement aiguillé; il açuiert, étant poli, une teinte fauve qui se fonce beaucoup avec le temps.

L'autre bois est nommé à Cayenne bois cle rose femelle et aussi crelie blanc. Il est très tendre el tris léger, d'un blanc un peu verdâtre lorsqu’il est récent, devenant jaunâtre à l'air. Il possède une odeur forte tout à fait différente du précédent; car cette odeur est celle du citron ou de la bergamolte; aussi suis-je d'avis qu'on derait le désigner spécialement par le nom de bois de citron de ('ayenne. Ce bois, de mème que le précédent, arrive en trones entiers d'un rolume considérable.

Le nom de bois de rose, que ces deux bois portent à Cayenne, semblerait indiquer qu'ils appartiennent à un mène genre d'arbre ; cependant je doute qu'il en soit ainsi. Je suis plutòt porté à croire que le bois de rose femelle est produit par un icica, probablement par l'icicu ultissima d'Aublet.

M. Nees d'Esenbeck, daus son Systemo Inumomm, et I. Martius, 
dans l'ourrage intitulé Systema muterice med. Irasiliensis, admettent que le licario guiumensis ne diffère pas du dicypellium crnyoyluyllatum. Il me parait bien difficile que deux choses aussi différentes que la cannelle-giroflée et le bois de licari proviennent d'un seul et même arbre. Il est plus probable qque les deux arbres sont complétement différents.

\section{Nolx de Ravensara ou Nolx de Girone.}

L'arbre qui produit ce fruit a été nommé par Sonnerat ratensura

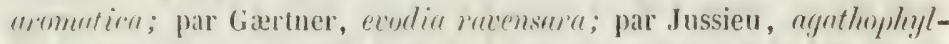
Cum "romuticum. Il crô̂t à Madagascar et appartient à la famille des laurinées; il est grand, touffu, muni de feuilles alternes, pétiolées, entières, fermes et épaisses. Les fleurs sont hermaphrodites ou plutôt diöques par arorlement; les fleurs mâles, disposées en petites panicules axillaires; les femelles solitaires. Le calice est petit, à 6 divisions très courtes, accompagné d'une corolle à 6 pétales courts, velus en dedans. I.es étamines sont au nombre de 12, dont les trois plus intérieures stériles et les trois fertiles intérieures pourvues de 2 glandes globuleuses; les anthères sont à 2 loges, s'ourrant par des valvules; l'ovaire est infère ou soudé avec le calice, uniloculaire et uniovulé; le fruit est un caryone ou drupe infère, couronné par les dents du calice, et quelquefois par 6 tubercules plus intérieurs, qui doivent répondre aux pé. tales. Il renferme, sous une chair peu épaisse, un noyau ligneux divisé inférieurement en six parties par des replis de l'endocarpe; mais il est uniloculaire à l'extrétinté, de sorte que l'amande, divisée en 6 lobes du côté du pédoncule, est entière par la partie opposée.

L'écorce, les feuilles et les fruits de ravensara sont pourvus d'une forte odeur très analogue à celle du girofle, et je suis persuadé que l'ćcorce, si nous l'avions, différerait peu de la cannelle giroflée; mais il ne parait pas qu'elle suit apportée par le commerce. Lés feuilles sont très usitées à Marlagascar comme aromate, et sont queldquefois apportées en Europe; elles se présentent sous une forme toute particulière, ayant été repliées plusieurs fois sur elles-mêmes, puis enfilíes en forme de chapelet, avant d'être soumises à la dessiccation; elles sont coriaces, brunes, luisantes, très aromatiques, et conservent pendant très longtemps leur odeur. Les fruits, tels que nous les arons, sont deux fois gros comme une noix de galle, arrondis, formés d'un brou desséché, d'un brun-noirâtre au-dehors, jaunâtre à l'intérieur, d'une forte odeur de cannelle girofléc ou de piment jamaïque. le noyau ligneux est jaunâtre et peu aromatį̣ue; l'amande est jaunâtre également, très chargée d'huile, moins aromatique que le brou, et tellemrnt âcre, qu'on peut la dire caustique. 


\section{Ẻcorce précieuse ou Casca pretiosa.}

Écorce de cryptocarye aromatique de ma précédente édition. Cryjptocarya pretiosa de Iartius; aujourd'bui mespilodaplene pretiosa de Yees d'Esenbeck. Ecorce épaisse de 2 à 5 millimètres, courerte d'un épiderme gris, mince et foliacé; elle est formée de longues fibres dures et piquantes, et elle est très pesante en raison de la grande quantité de principes oléorésineux qu'elle contient. Sa surface intérieure a pris une teinte noiràtre; mais elle est rouge dans sa cassure avec des fibres blanches. Telle que je l'ai, elle présente une très forte odeur de cannelle de chine, dont elle offre aussi le goût aromatique sans en avoir le piquant. D'après M. Martius, son odeur répond à un mélange de sassafras, de cannelle et de rose. On en retire par la distillation une essence jaunâtre, plus pesante que l'eau, comparable à l'essence de cannelle.

\section{Avocatter.}

Persea gratissima Gærtn., laums persea L. ; grand arbre originaire de l'Amérique méridionale, d'où il fut d'abord transporté à l'île de France, pour revenir ensuite aux Antilles où il est généralement répandu. Etant dépourvu de principe aromatique, il n'est utile que par son fruit qui consiste en une baie nue, ayant la forme et le volume d'une belle poire, et contenant, sous une chair épaisse et butyreuse, une grosse semence privée d'huile, mais remplie d'un suc laiteux qui rougit à l'air et tache le linge d'une manière indélébile.

Ce fruit est recherché pour la table; mais on le mange comme horsd'œuvre avec les viandes, et non au dessert; il a un goût de pistaches fort agréable (Ricord-1Ladianna, Journ. phumm. , t. XV, p. 44). On remarque qu'il est aussi bien mangé par les anjmaux carnirores que par les herbivores; ainsi les chiens, les chats, les vaches, les poules, etc., s'en nourrissent également.

\section{Canuelle.}

La cannelle est une écorce aromatique qui a été connue des anciens sous les noms de casia ou cassia et de cimnamomum. Indépendamment des différences spécifiques qui motivaient l'emploi de ces deux noms, il parait que le cassia était une écorce mondée, comme l'est notre cannclle actuelle, tandis que le cinnamomun était formé de jeunes branches pourvues de leur bois, jusqu’à ce qu'on ait reconnu que le bois était pet odorant, et qu'on se soit borné, pour toutes les espèces et dans toutes les contrées cinnamomiferes, à ne récolter que l'écorce. 
Depuis un temps que je ne puis préciser, on distingue dans le commerce français deux espèces de cannelle connues sous les noms de connelle de Ceylun et de ramelle de Chine. Cette distinction est fondée sur une différence bien réclle des denx écorces; et, le dernier nom est la traduction bien appliquée du nom Dấ-Sini (bois de chine), que porte dans une grande partie de l'Asie l'écorce du laums cassir I. L'autre espèce de cannelle est produite par le laurus cimnamomum $\mathbf{L}$.

Indépendamment de ces deux cannelles, on troure dans le commerce une écorce connue depuis bien longtemps sous le nom de cassia ligner, et des feuilles gui ont été désignées de tout tempss sous ceux de malathrum et de folium indicum (ferille d'Inde). La plupart des auteurs ont plus ou moins confondu tous ces produits, ainsi que les arbres qui lesfournissent. Burmann cependant les avait bien distingués dans sa Flore indica (1768); mais après lui la confusion élait rederenue aussi grande qu'aupararant : elle a cessé, grâce ì la sarante dissertation de MII. Nees d'Esenbeck (I)e cinnamomo disputatio, Bonnæ, 1823), et il nous est permis aujourd'hui d'indiquer avec certitude l'origine des différents produits des arbres cinnamomifères (1).

\section{Cannelle de Geylan.}

Cimannomum zeylanicum, Breyn; cinnamomum follis latis veatis, fruegiferum, Burm., Zeyl., t. XXYI; Ialabur or Jaca cinamom, Blackw., tab. 354; laurus cinumomum L., sp. pl., t. II, p. 528 ; Yees De ciman. disput. tab. 1; Fr. Yees Plant. medicin., tab. 128.

Le cannellier de Ceylan est exclusivement propre à cette île, qui est la traprolume des anciens; mais il a été propagé por le moyen des fruits aux îles Maurice, à Cayenne et aux dntilles, dont plusieurs fournissent au commerce une écorce qui riralise jusquàà un certain point avec celle de Ceylan.

On distingue à Ceylan plusicurs variétés ou espèces de cannellier dont les noms expriment les principales différences; tels sont:

$1^{\circ}$ Le rasse corronde ou curunde, c'est-à-dire cannellier piquant et sucré, véritable cannellier officinal ou vrai cimamomum zeylanicum.

$2^{\circ}$ Le cahatte coronde ou cannellier amer et astringent, dont l'écorce récente a une odeur agréable et une saveur amaricante; mais desséchéc elle devient brune, presque inodore, à saveur camphrée. Sa racinc est très camphrée.

(1) Dans un ouvrage plus récent intitulé Systema laurinarum (1836), M. Chr. God. Nees a modifié en plusieurs points le résultat des précédentes recherches faites en commun avec son frère, M. Th.-Jr.-Louis Nees. Je n’ai pas cru devoir adopter ces modifications. 
$3^{\circ}$ Le crupuerue comonde, ou cannellier camphiré, dont l'écorce et la

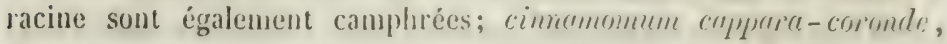
Blume.

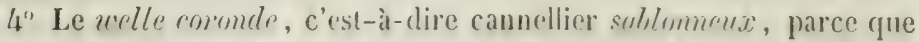
son écorce mâchée croque sous la dent. Racine peu camplirée.

5" Le seuel coronde, ou cannellier mucilagineux, de la sareur de son écorce.

6" I.e nielie coronde, c'est-à-dire cauncllier à feuilles de niekegas (vitex negundo).

$7^{\circ}$ Le deuel coronde ou cannellịer-tambour; ce nom lui est donné à cause de l'usage que l'on fait de son bois pour fabriquer les tambours. Cet arbre forme un genre particulier, sous le nom de litscen zeylanicn.

$8^{\circ}$ Le catte coronde ou cannellier épineux.

$9^{\circ}$ Le mael (mâl) comond? on cannellier fleuri. Cimnamomum perpetuoflorens Burm., Zeyl., tab. 28; laurus Burmami Yees, C'inn. disp., lab. 4; lanes multiflora lioxb. : cimamomun zeylanicum var. (cassia), C. G. Yees, syst. Lmurin., et Fr. Nees, plant. officin., suppl.,

Fig. 179.

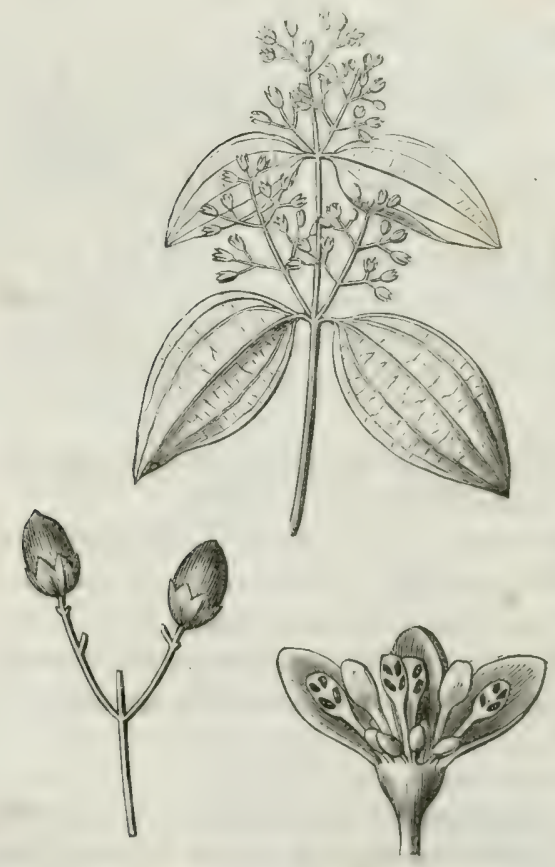

fig. 25 ; canella javanensis, Bauh. pin., p. 409. Comme on le roit, cette espèce est aujourd'hui considérée par II. C. G. Nees comme une simple variété du cinnamomum zeylanicum, duquel elle se rapproche beaucoup en effet; mais, suivant moi, M. G. Nees lui donne de nouveau à tort, comme synonymes, le Inurus cassia de la Mutière médicale de Linné, le kama de Rlieede ( $\mathbf{I}$, tab. 57), et le cussia lignea de Blackwell, t. 391, dont la distinction avait été clairement établie dans l'ouvrage De cimnamom. disputatio, p. 53, tab. 3 .

Le rrai cannellier (fig. 179), rasse coronde ou cinnamomum zeylanicum, est

un arbre de sa à 7 mètres de baut, porté sur un tronc de 30 à 45 centi- 
mètres de dianètre. Les pétioles et les jeunes rameaux sont glabres; les feuilles sont presque opposées, ovales-ohlongues, obtuses, les plus grandes ay ant de 11 à 14 centimètres de long sur 5 à 7 centimètres de large; mais elles sont sourent beacoup plus petites. Ces feuilles sont fermes et coriaces; elles offrent, ontre la nervure du milieu, deux autres nervures principales, qui partent comme la première du pétiole, s'arrondissent en se rapprochant du bord de la feuille, et se dirigent vers le sommet, sans l'alteindre. Independamment de ces trois nervures, les fenilles les plus larges en offrent deux autres tont près du bord; enfin ces feuilles desséchéesprennent une teinte jaune hrunâtre, due à l'oxigénation de l'huile volatile qu'elles renferment. Les fleurs sont petites, jaunâtres, disposées en panicule terminale. Le fruit est un drupe ovale, assez semblable à un gland de chêne, d'un brun bleuâtre, entouré à la base par le calice; il est formé à l'intérieur d'une pulpe verte et onctueuse, et d'une semence à amande huileuse et purpurine.

On cultive le cannellier surtout dans la partie occidentale de l'île de Cejlan, thans les environs de Colombo, et dans un espace d'environ quatorze lienes de longueur. Lorsqu'il est bien exposé, il peut donner son écorce au bout de ciny ans; mais clans une position contraire, il n'en donne de bonne qu'au bout de huit ì douze ans. On l'exploite jusqu'à trente ans, et on en fait deux récoltes par an, dont la première et la plus forte dure depuis le mois d'avril jusqu'au mois d'aoutt; la seconde commence en novembre et finit en janvier.

Four y procéder, on coupe les branches de plus de trois ans qui paraissent avoir les qualités requises; on détache, avec un conteau, l'épiderme grisâtre qui les recourre. Ensuite on fend longitudinalement l'écorce, et on la sépare du bois. Cette écorce ressemble alors à des tubes fendus dans leur longreur; on insère les plus petits dans les plus grands et on les fait sécher au soleil. Les menus sont distillés, et fournissent de I'huile volatile qui est versée dans le commerce.

La cannelle de C'eylan est en faisceaux très long;, composés d'écorces aussi minces que du papier, et renfermées en grand nombre les unes dans les autres. Elle a une conleur citrine blonde, une saveur agréable, aromatique, chaude, un peu piquante et un peu sucrée; elle est donée d'une odeur très suave, et ne donne guère à la distillation que 8 grammes d'huile volatile par kilogramme; mais cette huile est d'une odeur très suave, quoique forte.

Cannelle mate. La substance qui porte ce nom est l'écorce qui provient du tronc du cannellier de Ceylan, ou des grosses branches de l'arbre abattu lorsqu'il est devenu trop âgé pour produire de bonne cannelie. Elle est privée de son épiderme, large de 27 millimètres, plus ou moins, épaisse de 5, presque plate ou peu roulée; son extérieur est légèrement 
rugueux et d'un jaune foncé; son intérieur est d'un jaune plus pâle ct comme recouvert d'une légère conclie rernissée et hrillante; sal cassure est fibreuse comme celle du quinquina jamne, dt brillante; clle a une odeur et une saveur de cannelle agréables, mais très faibles. Cettecannelle doit être rejetée de l'usage pharmaceutique.

Cannelle de Inde on du Malabar. Il ne faut pas confondre cette cannelle actuelle du commerce avec l'ancienne cannelle du Halabar produite par le laurus cassia L. , et qui a été détruite par les IIollandais, ainsi qu'il sera dit plus loin. La cannelle actuelle de l'Inde est produite par le cannellier de Ceylan que les Anglais ont naturellement cherché à propager dans l'Inde. Cette cannelle a presque tous les caractères et la qualité de la rraie cannelle de Ceylan, et, à Paris, elle est vendue comme telle. Je troure qu'elle s'en distingue cependant par une couleur plus pâle, uniforme, par une odeur un peu plus faible et qui se conserve moins longtemps. Elle est disposée en faisceaux aussi longs; mais les écorces sont en réalité plus courtes, et la longueur des faisceaux est due à ce que, en renfermant les écorces les unes dans lés autres, on les a étagées sur leur longueur, à la manière de tuyaux de lunette. Les écorces ne sont pas tout à fait aussi minces que dans la cannelle de Ceylan; les tubes sont plus gros et bien cylindriques.

Connelle de cayenue. Cetle cannelle prorient du cimamomum zeylanicum cultivé à Cayenne. Elle est en écorces aussi minces et presque aussi longues que celle qui vient de Cẹlan, dont elle offre aussi l'odeur et le goût. Seulement elle est un peu plus large et plus volumineuse, d'une couleur plus pâle et comme blanchàtre, mais marquée de taches brunâtres. Eille est d'une odeur et d'un goût un peu plus faibles, et qui se conserrent moins longtemps. Beaucoup de personnes vendent et achìtent aujourd'hui cette écorce comme de la cannelle de Ceylan.

Le même cannellier est également cultivé au Brésil, dans l'île de la Trinité, dans les Antilles, et fournit au commerce des écorces de qualités très variables, toujours inférieures à l'écorce de Ceylan. Celle du Brésil est la moins bonne de toutes; elle est comme spongieuse et presque inodore.

Fleurs de cannellier, flores cassiel, off., clacelli cimamomi. Cetle substance paraît venir de la chine, et est attribuce, par la piupart des auteurs, au même arbre qui produit la cannelle de Chine. Son odeur fine et très agréable, quoique forte, me ferait penser plutòt qu'clle est produite par le cannellier de Ceylan. Elle se compose des fleurs femelles de l'arbre fécondées, et lorsque l'ovaire a commencé à se dérelopper, de sorte qu'on pourrait tout aussi bien la considérer comme formée des fruits très imparfaits; elle ressemble un peu par la forme au clou de girofle; elle est principalement formée d'un calice plus ou moins ourert 
ou globuleus, très rugueux ì l'extérieur, brun, épais, compacte, et s'amincissant a je pen pointe jusquan pédoncule çui le termine. Au centre du calice se troure le petit fruit, qui est amer, globuleux, brun et rugueux en dessous, rougeâtre el lisse en dessus, et présentant à son point le plus éleré un restige de style.

Le calice a une odeur et une saveur de cannelle très fortes et agréables; il est très riche en huile essentielle, qu'on peut en retirer par la distillation. Il jouit des mêmes proprićtés médicinales que la cannelle.

Le fruit mùr ne se troure pas dans le commerce; son amande donne par expression une huile concrìte dont on forme à Ceylan des bougies odorantes.

\section{Camnelle de chine.}

Cimnamomum aromnticum, G. Yees syst. Iaur; cinnamomum cassia Fr. Tees (1); luu'us cussiu L., Ilut. med.; Nees Ite cimn., p. 53, tab. 3 ; Fr. Jees Plant. medicin., tab. 129 ; rnssia lignea Blackw., tab. 391 ;

Fig. 180.

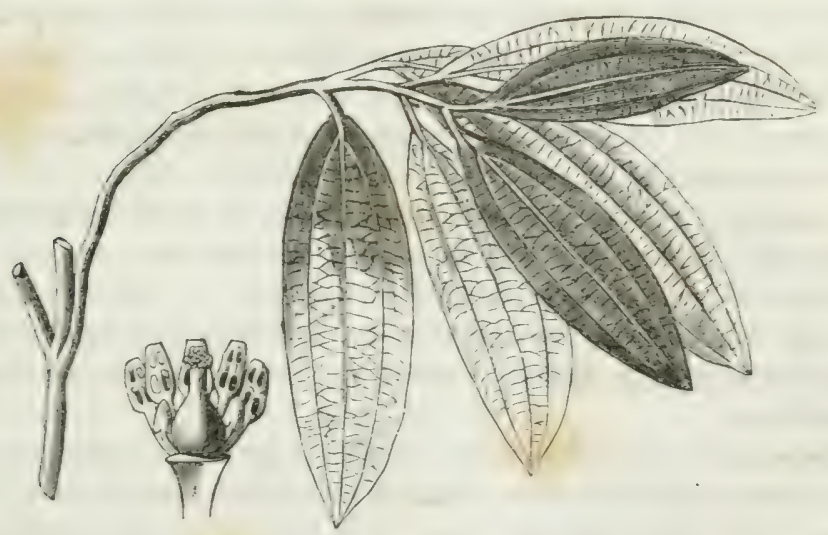

kamu, Rheede Wulctl., I, tab. 57. Ce cannellier (fig. 180) croît au IIalabar, à la Cochinchine, dans la province de Kwangse en Chine, et dans les îles de la Sonde. Il s'élève à plus de 8 mètres; ses feuilles sont alternes, très

(1) Je pense que le nom de cinnamomum cassia devrait être adopté, comme étant la transformation obligée du véritable laurus cassia $\mathbf{L}$.; alors le cinnamomum perpotuoflorens de Burmann, soit qu'on le considère comme une variẻlé du $C$. zeylanicum, soit qu'on en fasse une espèce distincte, reprendrait son nom, ou prendrait celui de floridum ou de multiflorum que lui a donnẻ Roxburgh. 
entières, longues, dans leur plus grand déreloppement, de 18 ì 25 centimètres, larges de 5 à 6 , amincies en pointe aux deux extrúnités; elles sont triplinerees, c'est-ì-dire que les trois nervures principales qui parcourent la feuille, du pétiole jusqu’à l'extrémité, se réunissent en une seule sur le limbe de la feuille, à (quelque distance du pétiole. Ces trois nervures sont fortes, parfaitement régulières et divisent la feuille en quatre parties ígales; l'esjace qui les sépare est traversé par une infinité de nervures très fines et aussi très rérgulièe's; la surface supérieure est lisse; la face inférieure est grise et pubescente; le pétiole et les jeunes rameaux le sont également. Le pétiole màché offre le goût particulier de la cannelle de Chine.

Le cimnamomum cossia était très abondant autrefois sur la côte de Vlalabar, qui faisait un commerce considérable de son écorce et de son huile distillée; mais ce commerce a cessé lorsque les Hollandais, s'étant rendus maitres de Ceylan, curent acheté du roi de cuchin le droit de détruire tous ses cannelliers, afin de donner plus de valeur à ceux de Ceṛlan. Aujourd'hui cette espèce de cannelle est tirée de la Chine par Canton. Elle est en faisceaux plus courts que celle de Cerlan, et se compose d'écorces plus épaisses et non roulées le's unes dans lés autres; elle est d'une conleur faure plus prononcie, et son odeur a quelgue chose de peu agréable; sa sareur est chaude, pirguante pt offre un groût de punaise ; enfiu elle est moins estimée gue la cannelle de Ceylan. Elle fournit plus d'huile volatile à la distillation; mais cette huile partage l'odeur peu agréable de l'écorce.

Vanquelin, ayant fait l'examen des canucl!es de Ceylan et de Chine, en a retiré également de l'huile volitile, du tammin, du mucilage, une matière colorante et un acile (Journ. de plum'm. , I. III, p. 433). La cannelle de ( hine dnit contenir en outre de l'amidon, car lorspu'on le distille avec de l'eau, le décucté prend une consistance tremblante en se refroidissant.

Essences de canne!le. On trouve dans le commerce trois sortes d'essences de canmelle: $1^{\circ}$ celle de cannelie de cẹlan, qui est d’un jaune doré, d'une odeur des plus suaves, d'une saveur sucríe et bruilinte et d'une pesanteur spécifirque de 1,05 à 1,09; clle est toujours d'un prix très élevé; 2" celle de cannelle de chine, qui prossèle les mimes propriélés, à cela près de l'orleur et de la sareur qui sont beaucoup moins suares et qui présentent quelque chose du goût de punaise; le prix en est très inférieur à la première; $3^{\circ}$ celle de fleur de cannelle qui se rapproche beaucoup de la première, quoique d'une odeur moins fute et moins suave, el que l'on vend comme essence de Ceylan de seconde qualité. Tontes ces essences résultent du mélange en quantité variable de deux huiles volatiles, dont la principale, nommée hyjtrure de cimamyle, est 
composée, d'après II. Dumas, de $\mathrm{C}^{18} \mathrm{II}^{8} \mathrm{O}^{2}$. Cette essence est essentiellement caractérisée par la propriété de s'unir directement arec l'acide azotique concentré, et de domner naissance à un composí éminemment cristallisable; elle se combine également avec l'ammoniaupe et forme un composé cristallisable et permanent; elle absorbe rapidement l'oxigène de l'air et se convertit, partie en corples résineux qui restent dissous dans l'essence, partie en acide cimmuigur cristallisable, dont la formule igale $\mathrm{C}^{18} 11^{8} \mathrm{O}^{4}=\mathrm{C}_{1}{ }^{8} \mathrm{H}^{7} \mathrm{O}^{3}+\mathrm{HO}$. Ce mème acide se forme souvent par l'action de l'air sur l'hydrolat de cannelle, et crisiallise an fond. Il a été pris longtemps pour de l'acide benzö̈que dont il dillère beaucoup par sa composition.

\section{Cannelle de Sumatra.}

J'ai reçu une fois, sous ce nom, une cannelle en partie courerte d'un épiderme gris-blanchâtre, assez épaisse, roulée, d'une couleur rouge prononcée, d'une odeur assez forte et agréable, d'une saveur à la fois astringente, sucríe et aromatique; enfin se réduisant en pàte dans la bouche, tant elle est mucilagineuse.

\section{Cannelle de Java.}

Cette cannelle, qui est assez commune, ne diffère peut-ètre de la précédente que par son ancienneté dans le commerce; elle est en tubes épais, roulés isolément les uns des antres, bien cylindriques, d'une couleur rouge assez prononcée, d'me odeur et d'une sareur semblables à celles de la camelle de Cinine, mais plus faibles; elle a une saveur très mucilagineuse. En vieillissant, elle devient d'un brun noiràtre et perd presque tonte odeur. C'est cette écorce que l'on rend aujourd'hui dans le comnerce sous le nom de cassic lignea.

La cannelle de Java parait due au rimmomomum perpetuoflorens de Burmann, laurus multifloru de Roxburgh, laurus Burmumi des frères Nees d'Esenbeck.

\section{Cassia lignea et Malabathrum.}

J'ai dit précédemment que le cassia ou rresia des anciens paraissait être notre cannelle actuelle; plus tard il prit le surnom de syringis ou de fistularis ou de fistula, en raison de sa disposition en tubes creux, et enfin lorque le nom de cassin fistula ent été réservé exclusirement au fruit purgatif qui le porte aujourd'hni, on désigna, comme moyen de distinction, l'ancienne écorce de cressia par le surnom de lignea. Ainsi 
je pense que, à une certaine époque, l'expression cassia lignea rẻpondit à notre nom actuel comolle, sans distinction d'espèces ou de variétés. Mais bientôt après, les marchands d'épices et les apothicaires ayant appris à en distinguer plusieurs espèces, les noms de connelle et de rimnamomum furent réservés aux écorces les plus fines, tant en épaisseur (fu'en qualité, et le nom cossin lignea fut affecté aux écorces plus épaisses, d'une apparence plus lignense et d'un goùt moins parfait. Fimniliares habeo eruditos viros medicos arabes, turcos et corranes, qui ommes cunellan crassiorem cassiam ligneam appell ont (Garcias ab horto, Lromatum hist., cap. xv). A partir de ce moment, les meilleurs auteurs, tels cjue Valerius Cordus, Pomet, Lemery, Charas, Geoflroy, ont donné la même signification au cassia lignee, et l'ont appliọncée soit à la cannelle de Chine, soit plutôt encore à celle de Java ou de Sumatra.

Je dois dire cependant que vers l'année 1805 , époque à lacquelle j'ai commencé l'étude de la pharmacie, j'ai vu dans les bunnes officines et chez les principaux droguistes de Paris, sous le nom de cassir lignea, une écorce qui différait de toutes les cannelles précédentes par un manque presque complet d'odeur et de saveur, et j'ajoute que vers l'année 1812 ou 1813, Jorsqu'on fit expressément renir de Ilollande les substances qui devaient composer le grand drognier de la pharmacie centrale des hôpitaux, afin que leur qualité fùt mieux assurée, c'est cette mème écorce inodore qui nous fut envovée comme crissia lignea : c'est donc à elle seulement que j'en conserverai le nom.

Je puis dire la même chose pour les fenilles du malabathrum : la plupart des anteurs parlent de leur qualité aromatique et de leur forme plus ou moins arrondie on allongée; et assez récemment, II. G. Kees d'lisenbeck a trouvé des feuilles de malabathrum qui lui ont paru ą) partenir à diverses espèces de cimamomum : tels sont les cimainomum tamala, albiflorum, eucalyptoides (nitidum Hook et Blume), obtusifolium, iners, etc. II. Blume, de son côté, pense que ces feuilles sont fournies presque exclusivement par son cimamomum nitidum. Or, depuis que je suis dans la pharmacie, je n'ai jamais vu qu'une seule espèce de feuille de malabathrum, et cette fenille, par son manque complet d'odeur et de saveur, me parait appartenir au même arbre que le cressiu lignea dont je viens de parler. Voici la description de ces deux substances :

Cassia lignea. Cette écorce, dont il ne me reste plusqu'un faible échantillon, était en tubes fort longs, comme cenx de la caunelle de cieylan, mais non roulés les uns dans les autres, et offrant l'épaisseur de la belle canmelle de chine (c'est-ì-dire qu'elle était plus épaisse que la cannelle de (ẹlan, et moins épaisse que la cannelle de (hine commune); elle était d'une couleur fauve rougeattre, e't se distinguait de l'une et l'autre 
cannelles par la parfaite cylindricité de ses tubes (la cannelle est toujours plus ou moins llexueuse); elle était prirée d'odeur, et sa saveur était mucilagineuse.

Malabathrum (fig. 181). Ces feuilles sont oblongues lancéolées ou linéaires lancéolées, amincies en pointe aux deux extrimités; elles varient beaucoup de grandeur, car elles ont depuis \& centimètres de long sur 2,7 centimètres de large, jusqu'à 25 centimètres de long sur 5,8 centimètres de large. Comme on le voit, ces feuilles sont toujours beaucoup plus étroites que celles du cinnamomum cassia, et, à plus forte raison, que celles du cimnamomum zeylanicum. Elles sont plus minces que les unes et les autres, et sont simplement trinerves, c'est-à-dire que les trois nervures qui vont de la base au sommet se séparent à partir du pétiole; de plus, les deux nervures latérales sont beaucoup plus rapprochées du bord de la feuille que' de la nervure du milieu, de sorte que la feuille n'est pas partagée en parties égales comme celles du cinnamomum cassia. La feuille de malabathrum est lisse et luisante en dessus, glabre en dessous, et les nervures et le pétiole sont lisses et luisants, au lieu d'être pubescents comme dans le cinnamomum cassia. Elle est complétement inodore, et le

Fig. 181.

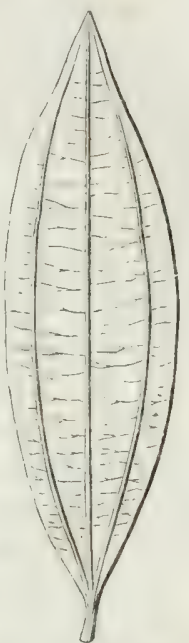
pétiole qui est très mince, élant mâché, n’offre aucun goût de cannelle. Enfin, cette feuille présente une couleur verte qui résiste à la vétusté, ce qui tient à l'absence complète de l'huile volatile.

Maintenant quelle est l'espèce de cimnamomum quii produit à la fois le cassia lignea et le malabathrun? J'ai toujours pensé que ce devait être le katou karua de Rheede (IIort. Malab. , t. V, tab. 53 ), qui est le laurus malabathrum de Burmann, le cinnamomun malabathrum de Batka, et peut-être aussi le cinnamomum iner's de Blume. Je sais bien que Rheede compare, pour l'odeur et la saveur, le licutou Farna au liamu (cannelle de Chine); mais il est possible que cette odeur, déjà plus faible, se perde à la dessiccation; elle paraît être nulle dans le cimnamomum iners.

Voici, dans le Rumphia de M. Blume, les figures qui se rapportent le mieux aux feuilles de malabathrum el qui, suivant moi, appartiennent à une seule et même espèce.

$1^{\circ}$ Cinnamomum malabathrum, tab. 13, fig. 3 et 4 (ult. opt.). 2० - ochraceum, tab. 10, fig. 2, 3 et 4 (tria opt.). 3. - Rauwolfi, tab. 9, fig. 4,3 . 
Les figures suivantes se rapportent moins bien au malabathrum.

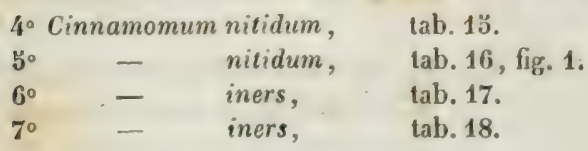

Écorce de Gulilawan.

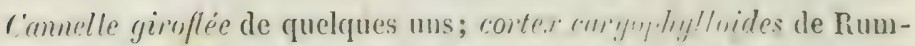
phius; lmerus culilanem L.; cinnumomem culitunen de Blume. Cet arbre a les feuilles presque opposées, triplinrrvées, orales-acuminces, glabres, coriaces, rertes en de'ssus, un peu glauques en dessous. L'écorce, telle que le commerce nous l'uffere, est en morceaux plus ou mins longs, presque plats ou peu convexe's, épais de 2 à 7 millimètres, fibreux, Jâclés à l'extérieur ou recourerts d'un épiderme blanchatre; elle est d'un jaune rougeàtre à l'intérieur, "l tessemble assez à de maurais quinquina jaune. Elle a une odeur de cannelle et de girofle mêlés, (qui, lorsqu'on la pulvérise, acquiert quelque chose de l'essence de térébenthine; clle a une saveur aromatique chaude, un peu piquante et mếée d'un líger goût astringent et mucilagineux; clle donne une huile volatile ì la distillation; elle est peu employée.

Le nom de cette écorce est iiré du malais liulit lan'any, qui signifie écorce giroftée.

Totu. Le groupe des îles Malaises, des îles Philippines et de la terre des I'apous, parait produire un grand nombre d'espèces de rimunuomum à écorces caryophỵllées, qui peuvent être facilement confondues. Rumphius distingue deux espèces ou variétés de culilawan dans la seule île d'Amboine: l'une blanche, c'est le cinnamomum culilmi'(m Bl.; l'autre rouge, dont \$. Blume a fait son cimnamsmum rubrum, et dont l'écorce, suivant l'échantillon qui m'en a été communiqué, est d'un rouge de cannelle foncé, de forne cintrée, mondée et unie à l'extérieur, lustrée ct comme satincé à l'intérieur, épaisse de 4 à 5 millimètres, d'une texlure fibreuse fine et spongieuse. La sareur en est trìs aromatigue, très piquante, et offre un goût mélangé de cannelle fine et de girofle.

Rumphius mentionne aussi une écorce de sindoe que le inlgaire confond arec le culilawan, quoiqu'elle soit différente et provienne d'un arbre différent. Cet arbre est le cinnamunum sintue de Blune. L'écorce, d'après l'échantillon que j'en ai, et d'après lés figures qu'en a domnées 11. Blume, ne me parait pas différer de celle de culilawan ordinaire. Peut-être cependant est-elle un peu plus compacte; elle est fortement aromatique. 
Vient encore une écorce de cuilawan des papous qui ne paraît différer du culilawan commun ou blanchatre que par la couleur bistı́n de son liber; enfin une ceorce de massoy de la souvelle-fiuince, différente de celle ì undeur de sussafius, qui a élé rapportée par 11. Lèsson, et dont il est possible qu'il y ait plusieurs espèces : telle que je me la suis procurce à une exposition qui a eu lieu il y a quelques années à Paris, sous le nom de imnsiée jupnnmis, cette écorce est cintrée, épaisse de 7 à 8 millimètres, courerte d'un épiderme gris-rougeitre légèrement tuberculeux, et formée d'un liber gris rosé, dur et compacte, à structure un peu radiée sur sa coupe transversale. Elle posside une odeur très forte, analogue à celle du cumin, et une saveur très âcre, arec le même goût de cumin.

Enfin je dois décrire ici une écorce trouvée il y a quelques annies chez un commerçant qui la vendlait comme étant de l'écorce de Wintur, et que je ne puis micux designer que par le nom de cannelle brùlante. Cette écorce doit provenir d'une racine et non d'un tronc on de branches; elle présente un cerlain nombre de morceaux demi-roules dout le plus considérable n'a pas plus de a centimètres de longureur sur 3 centimères de largeur et 8 millimètres d'épaisseur; les autres unorceaux affectent toules sortes de formes, et sont souvent plissés transicr salement, conme le sont très souvent lés écorces de racines. Ces morceaux irréguliers et plissés ont sourent plus d'un centimètre d'épaisseur. L'écorce présente une teinte générale rouge terne; la surface extérieure est inégale, souvent tuberculeuse, couverte d'un épiderme gris blanchâtre ou gris noiràtre, dont les parties proéminentes sont sourent usées par le frottement; la surface intérieure est rude an toucher, rougeâtre ou noirâtre, comme formée de fibres agglutinées. L'écorce, en ellemême, est d'un fauve rougeâtre, à struclure raỵonnée, offrant, dans sa coupe transversale, des filres ligneuses blanches el épaisses sur un fond rougeâtre, et paraissant gorgée, surtout à l'intérieur, d'un suc brun noirâtre, qui me paraît ètre de l'essence résinifiée. Cette écorce présente une odeur très agréable que je compare à un mćlange d'orange et de cannelle fine; elle possède une sareur véritablement brûlante; clle cause de violents éternuments lorsqu'on la pile.

On connaît dans le commerce, sous le nom de cannelle blancle, une écorce qui n'a d'autre rapport avec la camnelle que sa qualité aromatique; elle appartient à la famille des guttifères.

\section{Camphre du Japon.}

Le camphre est un principe immédiat de la nature des huiles volatiles, qui est solide, incolore, transparent, plus léger que l'eau, d'une odeur 
très forte et pénétrante, d'une sareur très âcre et aromatique, accomplagnée cependant d'un sentiment de fraîcheur. Il est assez rolatil pour se dissiper entièrement à l'air libre; il est inflammable et brûle sans résidu, même à la surface de l'eau. Il n'est pass sensiblement soluble dans ce liquide, auguel cependant il communique une odeur et me sareur très prononcées. Il est très soluble dans l'éther, l'alcool, les huiles fixes et volatiles.

Le camphre existe dans beaucoup de régétaux, et Proust en a retiré d'un assez grand nombre d'huiles volatiles de plantes labiées. La zédoaire, le gingembre, le galanga, le cardamome, le schœuanthe sont aussi cilís pour en contenir ; les racines de la plupart des cannelliers en fournissent à la distillation; mais tout le camphre du commerce paraît être retiré d'un grand laurier du Japon, que Kæmpfer a fait connaître le premier (Amoen., p. 770), que Linné a nommé lmurus crmmphorr, et qui est aujourd'hui le camphore officinarum, Nees.

Pour obtenir le camphre, on réduit en éclats la racine, le tronc et les branches du laurier-camphrier; on les met arec de l'eau dans de grandes cucurbites de fer, surmontées de chapiteaux en terre, dont on garnit l'intérieur de paille de riz; on chauffe modérément, et le camphre se volatilise et se sublime sur la paille. On le rassemble et on l'envoie en Europe, enfermé dans des tonneaux. Il est sous la forme de grains grisâtres, agglomérés, huileux, humides, plus ou moins impurs.

Les Hollandais ont été longtemps seuls en possession de l'art de raffiner le camphre, et de le mettre sous la forme de larges pains à demi fondus et transparents. Ils ont gardé le monopole de cet art longtemps encore après la publication du procédé ; car il n'y a guère qu'une trentaine-d'années qu'on raffine le camphre en France, et cependant le procédé s'en trouve décrit avec détail dans la Matière médicale de Geoffroy (t. IV, p. 21), et dans le llémoire de Proust cité plus haut (Am. de chim., t. IV., p. 189); il paraît même avoir été connu de Lemery. Plus récemment, M. Clémandot l'a encore décrit d'une manière très exacte (Journ. de pharm., t. III, p. 353). Ce procédé consiste à metre le camplure brut dans des matras à fond plat, placés chacun sur un bain de sable, et entièrement couverts de sable. On chauffe graduellement jusqu'à fondre le camphre, et le faire entrer en légère ćbullition : on l'entretient en cet état jusqu'à ce que toute l'cau qu'il contient soit éraporéc. Alors on déccurre peu à peu le haut du matras en retirant le sabie, de manière à le refroidir et à permettre au camphre de s'y condenser. On continue ainsi jusqu'à ce que le matras soit entirèement déconvert, et on altend que l'appareil soit complétement refroidi pour en retirer le pain de camphre.

J'ai dit plus haut que le camphre du commerce était tiré du laurier- 
camphrier du Japon. Beaucoup de persomnes pensent anjomd'hui que la majeure partie de cette marchandise provient d'un arbre différent, qui croît dans les îles de Bornéo et de Sumatra. On lit en effet dans la Materie indien d'.linslie (t. I, p. 49), (que la plus grande partie du camphre et de l'essence de complire gue l'on trouve dans les bazars de l'Inde, n'est pas produite par le lourus cainjh/on'u dn Japon, mais qu'elle est apportíe de Sumatra et de Bornéo; que déjà, depuis longtemps, Kampfer avait suggéré l'idén que le camphre apjorté en Eurrye de Bornéo et de Sumatra, n'était pas produit par le lourus cominghere; mais que, grâces aux recherches éclairées de X. Colebroke, il est maintenant certain qu'il est produit par un arbre d'un genre different, nommé dryolbal anops comphorer, lequel croìt à une grande hauteur dans les forêts de la côte nord-est de Sumatra (Asint. res., rol. XII, p. 539). Pour se procuice l'essence de camphre, qui est encore plus estimée que le camphre lui-mème dans ces contrées orientales, il est seulement nécessaire de percer l'arbre, et l'essence découle pall l'orifice. Pour obtenir le camphre concret, l'arbre doit être abattu, lorsqu'on y décourre comme de petits glaçons blancs, situés perpendiculairement, et en reines irrégulières, au centre ou près du centre du bois.

L'arbre dont il est ici question, sous le nom de di'yobelanepos crmplowe arait été décrit depuis longtemps par Brẹn et par Rumphius, qui avaient parfaitement vu qu'il était différent du camphrier du Japon. Gar'tner fils, sur l'inspection senle du fruil, l'arait distingué par le nom de Inyubulauryss armatica, et II. Correa de Serra l'arait nommé pterigium costutum (Amo mus., t. VIII, P. 397). Cet arbre, réinni à cuelgues autres genres analogues, constitue la petite famille des diptérocarpées, roisine des tiliacées; mais rien ne prowre rue le camphre qui cn prosient soit apporté en Europe. D'abord Kæmpfer ne dit nullement qu'il y soit apporté, comme on serait tenté de le supposer, d'après Ainslie; Kxmpfer dit seulement qua dans les îles de Bornéo et de Sumatra, il croît un arbre qui produit un camphre naturel, cristallin, très précieux ct très rare, mais que cet arbre n'est pas du genre des lauriers. Secondement, toutes les autorités citées par tinslie pronvent seulement que le camphre de Sumatra est usité dans l'Inde comme il l'est en Chine ct au Japon; mais on ne voit pas qu'aucun dise qu'il soit apporté en Europe. Troisièmement, enfin, ce que rapporte Ainslie de l'extraction du camplure et de l'essence de camphre du camphrier de Sumatra, paparaît extrait de Rumphius, et liumphius dit positivenent que ce camphre ne vient pas en Europe. Voici un extrait de ce qu'en rapporte Rumplius :

"Le camphre de cet arbre, nommé capjur baros, da lieu où il crôil, se concrète naturellement sons l'écorce et an milieu du bois, sous la 
forme de larmes plates, qui ont l'apparence de la glace ou du mica de Moscovie; mais plus souvent il est en fragments de la grandeur de l'ongle. Ce camphre, très estimé, se nomme cubessa. Vient après celui qui est en grains comme le poirre, ou en petites écailles, que l'on nomme bariga; celui qui est pulvérulent comme du sable ou de la farine se nomme pee. C'es trois sortes sont mêlées ensemble et renfermées dans des ressies enreloppées d'un sac de jonc; sans ces précautions, le camphre Cabessa se volatilise et prive de son odeur le restant de la masse, qui est plus vil et plus léger (1).

"Le camphre du Japon n'est pas si volatil, ce qui est cause que la compagnie des Indes laisse le camphre de Baros et némeoir en Hollonde. rien autre chose que celui du Jupon.

"Au contraire, les Chinois et autres recherchent le camphre Cahessa, et le transportent avec un grand bénéfice au Japon, où la livre vaut de 22 à 60 impériaux, suirant la grandeur des morceaux * (Herl. ambl, t. VII, p. 68) (2).

Je dois à M. le professeur Cihristison un échantillon de camphre de Bornéo; il est en fragments incolores et d'une transparence un pen nébuleuse, ressemblant à de petits morceaux de glace. Ces petites larmes, dont les plusgrosses ne pèsent pas plus de 1 décigramme, sont généralement plates d'un côté et différemment anguleuses de l'autre. Ellles ont une odeur camphréc moins forte que celle du camplure du Japon, ct mèlée d'une odeur de patchouly. Elles sont un peu dures sous la dent, et s'y pulvérisent en émellant dans la bouche une très forte sarcur camphrée. Ce camphre a élé analysé par 1I. Pelouze, qui lui a trouvé une composition un peu différente de celle du camphre du Japon.

Le camphre du Japon est composé de $\mathrm{C}^{20}{ }_{-}{ }^{16} \mathrm{O}^{2}$ pour 4 volumes de. vapeur. L'essence liquide qui l'accompagne en petite quantité dans l'arbre. $=\mathrm{C}^{20} \mathrm{H}^{16} \mathrm{O}$. Cette essence, Iraitée arec précaution par les agents oxigénants, se convertit en camphre. L'hydrogène carburé $\left(\mathrm{C}_{\mathrm{C}^{20}} \mathrm{H}^{16}\right)$ qui forme le radical de ces deux corps, est isomère arec l'essence de térébenthine, dont le camphre et son essence représentent les deux premiers degrés d'oxidation. L'acide phosphorique anhỵdre enlère au camplore $2 \mathrm{HO}$, el le change en camphogène $=\mathrm{C}^{20} \mathrm{H}^{14}$.

Le camphre traité par 10 parties d'acide sulfurique hydraté additionné

(1) Il résulterait de ce passage, et d'autres de Rumphius et de Breyn, que le camphre cabessa est plus volatil que celui du Japon; mais qu'il est souvent mêlé, dans le camp̧hre en sorte, d'une autre substance peu ou pas volatile et non odorante.

(2) Deux commerçants m'ont assuré cependant que, dans ces dernières années, il élait arrivé par la voie de Hollande une certaine quantité de camphre de Bornéo, lequel avait été employé mélangé avec celui du Japon. 
d'eau, se sépare, après quelque temps, sous forme d'une huile liquide qui est isomérique arec le camphre.

Le camphre, traité à froid par l'acide azotique concentré, s'y dissout en grande proportion; mais aussitôt le mélange se sépare en deux parts, dont la partie surnageante, autrefois nommée huile de crmmplire, est un liquide jaune et oléiforme, composé de camphre et d'acide nitrique anhygdre. Il ne faut pas confondre cette huile de complner artificielle arec les essence's naturelles des camphriers. I.e camphre, traité à chaud par 6 à 10 partie's d'acide azotique, se convertit en acide camphorique $\left(\mathrm{C}^{10} \mathrm{H}^{8} \mathrm{O}^{4}\right)$, c'est-ì-dire qu'une molécule de camphre $\left({ }^{20} \mathrm{H}^{16} \mathrm{O}^{2}\right.$ prend $\mathrm{O}^{6}$ et forme $\mathrm{C}^{20} \mathrm{II}^{16} \mathrm{O}^{6}=2$ molécules d'acide camphorique hydraté.

L.e camphre de Bornéo a pour formule $\mathrm{C}^{20} \mathrm{H}^{18} \mathrm{O}^{2}$; traité par l'acide phosphorique anhydre, il perd $2 \mathrm{HO}$ et forme $\mathrm{C}^{20} \mathrm{H}^{16}$, identique arec

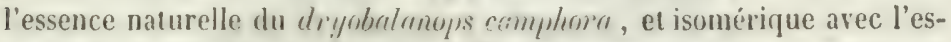
sence de térébenthine. Traití par l'acide azotique avec précaution, et à la température ordinaire, il perd $\mathrm{H}_{2}$, et se convertit en camphre du Japon.

\section{FAMILLE DES MYRISTACÉES.}

Petite famille d'arbres exotigues et intertropicaux, dont le principal genre (myristicu) arait été rangé d'abord.dans la famille des laurinées; mais elle s'en distingue par tun asse'z grand nombre de caractères, tout en conservant cependant arec les laurinées assez d'analogies pour qu'il soit convenable de ne pas les isoler.

Les myristicn ont les feuilles alternes, courtement pétiolées, très entières, privées de stipules; les fleurs sont dioïques, très petites, rarement terminales, pourvues d'un périgone simple, coloré, urcéolé ou tubuleux, à 3 divisions valvaires. Les fleurs mâles présentent à leur centre une colonne formée par la sondure des étamines, et cette colonne porte, à sa partie supérienre, de 5 à 15 anthères linéaires, biloculaires, disposées circulairement, et s'ouvrani par deux fentes longitudinales. Les fleurs femelles contiennent un ovaire unique, supère, uniloculaire, à un seul ovule dressé, anatrope. Le stigmate est bilobé. Le fruit est unc baie sèche, s'ourrant en 2 valves, et contenant une semence à épisperme solide, recouvert par un arille charnu, plus ou moins lacinié. L'embrion est petit et situé à la base d'un ondosperme huileux. La radicule est courte et infère.

Le genre myristica renferme un assez grand nombre d'espèces, dont la plupart appartiennent aux îles de la Malaisie; les autres se trouvent dans l'Amérique méridionale.

Muscadier aromatique, Muscade et Macis.

Myristica moschata Thunb.; M. officinalis L. f. et Grertn. ; M. fra- 


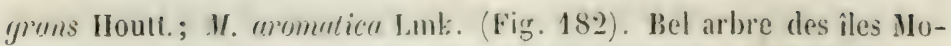
luyues, cultivé surtout anx îles Banda, et introduit, en 1770 , dans celles de France et de Bourbon. C'est de ces îles qu'il est ensuite passé en Amérique. Son fruit est une baie pyriforme marquée d'un sillon longitudinal et de la grosseur d'une petite pêche. L'enveloppe en est charnue, mais peu succulente, et s'ourre en deux ralres (quelquefois en

Fig. 18 .

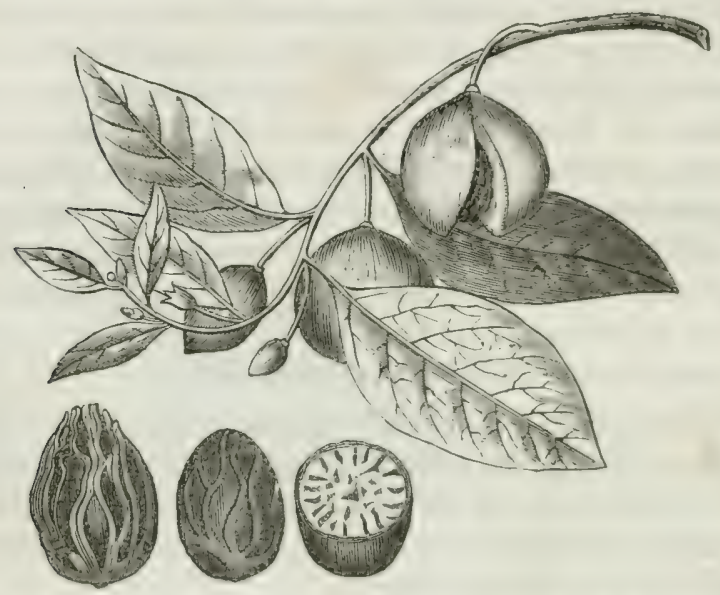

quatre) à mesure qu'elle mùrit et se dessèche. On roit quelquefois en Europe de ces fruits entiers, confits au sucre ou conservés dans de l'alcool ou de la saumure.

Dessous ce brou, qu'on rejette ordinairement, on aperçoit un arille profondément et irrégulièrement lacinié, charnu, d'un beau ronge lorsqu'il est récent, mais devenant jaune par la dessiccation : c’est le macis. On le sépare de la semence qu'il tient comme embrassée, et on le fait sécher après l'avoir trempé clans l'eau salée, ce qui lui conserve de la souplesse et empèche la déperdition du principe aromatiçue. On doit le choisir d'un jame orangé, épais, sec, et cependant souple et oncmeux, d'une odeur forte, très agréable, et d'une saveur très âcre et aromatique.

Dessous le macis se trouve l'enreloppe même de la graine, qui a la forme d'une coque arrondie ou ovoüde, d'une conleur brune, impressionnée à sa surface par l'application de l'arille; solide, sèche, cassante, inotore. On la rejette conme inutile.

linfin, l'anande fui se trouve au centre du fruit, et que le commerce nous présente presque tonjours dépouillée de ses différentes enveloppes, ronslitue la musrodlo. Fille est d'ume forme arrondie nor ovoüde, grosse 
comme une petite noix, ridée et sillonnée en tous sens; sa couleur est d'un gris rougeàtre sur les parties saillantes et d'un blanc grisittre dans les sillons; à l'intérieur elle est grise et veince de rouge, d'une consistance dure et cependant onctucuse et attaquable par le couteau; d'une odeur forte, aromatique et agréable; d'une saveur huileuse, chaude et àcre. On doit la choisir grosse, pesante et non piquée, ce à quoi elle est fort sujette, malgré la précaution que l'on prend en 1 sie, avant de l'envoyer, de la tremper dans de l'eau de chaux. Les commerçants sont fort habiles à boucher les trous d'insectes arec une pàte composée de poudre et d'huile de muscade; il faut y regarder de près si l'on ne veut pas y être trompé.

Wuscade de Cuyjenne. Le muscadier aromatique transporté à Cayenne y a prospéré ; mạis les semences, plus petites et moins huileuses que les muscades des Moluques, ne sont guère reçues que dans le commerce français. Elles arrirent toujours renfermées dans leur coque. qui est d'un brun foncé ou mème noiràtre, lustrée et conme vernie; l'intérieur de la coque est gris et dépourru d'enduit pulvérulent et blanchàtre, de mème que la surface de l'amande. L.es dimensions de la coque sont de 26 à 27 millimètres sur 19 , et celles de l'amande varient de 19 à 23 pour la longueur, sur 15 à 18 d'épaisseur. Les muscarles des Moluques en coques ont de 27 a 31 millimètres de lonsueur sur $2 / 4$ millimètres d'épaisseur ; l'amande nue a de 23 à 26 millimètres de tongueur sur 20 ou 21 millimètres d'épaisseur.

\section{Muscade Iongue des Moluques.}

Yommée aussi musrade sanuage ou muscade mile, la muscade officinale étant nommée, par opposition, muscrude cultivée et muscade femelle. L'arbre qui produit la muscade longue (Myristicu tomentosu Thunb. et Willd.; myristica fatur IIoutt. et Blum. ; myristicn dretyloïdes Gartn.) est plus élevé que le premier, te porte des feuilles plus grandes, pubescentes en dessous. Les fruits sont elliptigues, cotonneux à leur surface; la semence est elliptique, terminée en pointe nousse à l'extrémité supérieure, longue de 4 centimètres environ, épaisse de 2 à 2,5 centimètres. La coque (épisperme) dont elle est toujours pourrue, présente l'impression d'un macis partagé en quatre bandes assez régujières, allant de la base au sommet. L'amande est elliptique, unie, d'un gris rongeâtre uniforme ì sa surface, marbrée en dedans, moins huileuse et moins aromatique que la muscade ronde des IIoluques, mais à peu près autant que la muscade de Carcnne. De même que cette dernière, contenant proportiomnellement plus d'amidon, elle est très facilement piguée par les insectes, dont il faut toutes deux les préserver 
en les laissant renfermées dans leur épisperne ligneux. Le macis, que je n'ai jamais ru, paraît être très peu aromatique.

Essence et huile de muscade et de macis. La muscade contient une essence ou huile volatile gu'on peut obtenir par la distillation avec de l'ean, et une huile fixe et solide qu'on retire des semences par l'expression à chaud; nais elle est mêlée arec l'essence qui lui communique son odeur et de la couleur. Celte livile mixte, nommée communément beurre de muscade, se prépare sur les lieux mêmes où croît la muscade, arec celles de's semences qui sont brisées ou d'une qualité inférieure. On la troure dans le commerce sons la forme de jains carrés longs, semblables à des briques de savon, et enveloppés dans des feuilles de palmier; elle est solide, onctueuse au toucher, de consistance friable, d'un jaune pâle ou d'un jaune marbré de rouge, d'une odeur forte de muscade; elle est souvent altérée dans le commerce, soit parce qu'on en a retiré une partie de l'huile volatile par la distillation, soit par l'addition de qquelque graisse inodore. Les pharmaciens devraient donc la préparer eux-mêmes : on l'obtient alors d'un jaune très pâle, d'une odeur très forte et très suare, et comme cristallisable à la longue.

Suivant II. Playfair, lorsqu'on traite le beurre de muscade par de l'alcool rectifié à froid, on en dissout l'essence ainsi qu'une graisse colorée, et il reste environ 0,30 d'une graisse solide, blanche et inodore, qui s'obtient par des cristallisations réitérées dans l'éther, sous forme de cristaux nacrés. Cette graisse, nommée myristicine, fond à 31 degrés; saponifiée par les alcalis caustiques, elle donne naissance à de l'acide myristicique, fusible à 50 degrés, et cristallisable en feuillets larges et brillants.

Le macis contient également deux huiles fixes : une rouge, soluble dans l'alcool froid, qui dissout en même temps l'huile rolatile; l'autre joune, soluble seulement dans l'éther. L'essence de macis, obtenue par distillation, se trouve dans le commerce; clle est incolore, très fluide; d'une odeur très suave; elle pèse spécifiquement 0,928 .

Un assez grand nombre d'espèces de myristica fournissent des produits plus on moins analogues : tels sont le myristica spuria des îles Philippines, le myristica madagrscariensis de Madagascar, le mypristicu bicuiba du Brésil, le myristica otoba de la Colombie; enfin le myristica sebifera (virola sebifere Aubl.) dont la semence fournit en abondance un suif jaunatre, faiblement aromatique, d'apparence cristalline, propre a faire des bougies.

\section{FAMILLE DES POLYGONEES.}

Plantes herbacées ou sous-frutescentes dans nos climats, mais comptant quelques grands arbres dans les pays chauds; leurs feuilles sont 
alternes, engainantes à la base ou adhérentes ì une gaîne membraneuse et stipulaire; les fleurs sont hermaphrodites ou unisexuelles, disposées en épis cylindriques ou en grappes terminales; périanthe formé de 4 à 6 sépales, libres ou soudés par leur base, quelquefois disposés sur deux rangs et imbriqués avant leur évolution; étamines de 4 à 9 , libres, disposées sur deux rangs, à antlières s'ourrant longitudinalement; l'ovaire est libre, uniloculaire, contenant un seul ovule dressé; il est terminé par 2 ou 3 styles et autant de stygmates. Le fruit est un askose ou un cariopse sourent triangulaire, très sourent entouré par le calice persistant. La graine contient un embrỵon cỵlindrique en partie roulé dans un endosperme farineux; radicule supère:

La famille des polıgonées se recommande surtout auprès des pharmaciens par les racines officinales qu'elle leur fournit, telles que celles de bistrite, de putionce, de shapontir et de thulurbr. Toutes ces racines sont pourvues d'un principe colorant et astringent, jaune ou rouge, et d'amidon. Leurs feuilles sont tantôt acides, tantôt astringentes, et souvent l'un ct l'autre à la fois. Les fruits de plusieurs espèces de fungopyrmm (F. esculentum, tuturicum, emuryinutrun), connus sous le nom de hei norir ou de sarrizin, sont farineux et nourrissants, mais font un pain lourd et difficile à digérer. Le fruit de la renonée ou centinode (prolygmmm ruviculure) passe au contraire pour être émétique. Lne autre espèce de pulygmum (pulygonum tinctorium), originaire de Chine, et cultirée dępuis un certain nombre d'années en Europe, contient dans ses feuilles de l'indigo soluble, que l'on transforme en indigo blen en la soumettant aux mêmes traitements que les indigofero. Enfin, on troure dans les Antilles et sur les côtes du continent roisin plusieurs espèces de corcololun, dont une, nommée concolobn mifera (raisinier des bords de la mer), est un grand arbre à bois rougeâtre et à fruits rouges bacciformes, disposés en grappes comme le raisin, mais qui sont en réalité des cariopses entourés par le calice accru et derenu succulent. On retire du bois, par décoction dans l'eau, un extrait rouge-brun et astringent, qui est une des espèces de hino du commerce. Une autre espèce de curcululum des Antilles, le cocroloba puhbescens, est un arbre de 20 à 27 mètres de hauteur, dont le bois très dur, pesant, d'un rouge foncé, presque incorruptible, est un de ceux auxquels on a donné le nom de bois de fer.

Bistorte (tig. 183).

Pulygunum bistorta. Car. gén. : fleurs hermaphrodites ou polygames par arortement; périanthe coloré, quinquéfide, rarement tri- ou quadrifide, très suavent accrescent. Etamines 5 ou 8 , rarement 4 ou 9 , 
à filaments subulés, à anthères didỵes, versatiles; ovaire uniloculaire, comprimc ou triangulaire; ovule uni(jue, basilaire, droit. Style bi- ou trifide, quelquefois presque nul; askose lenticulaire ou triangulaire,

Fig. 183.

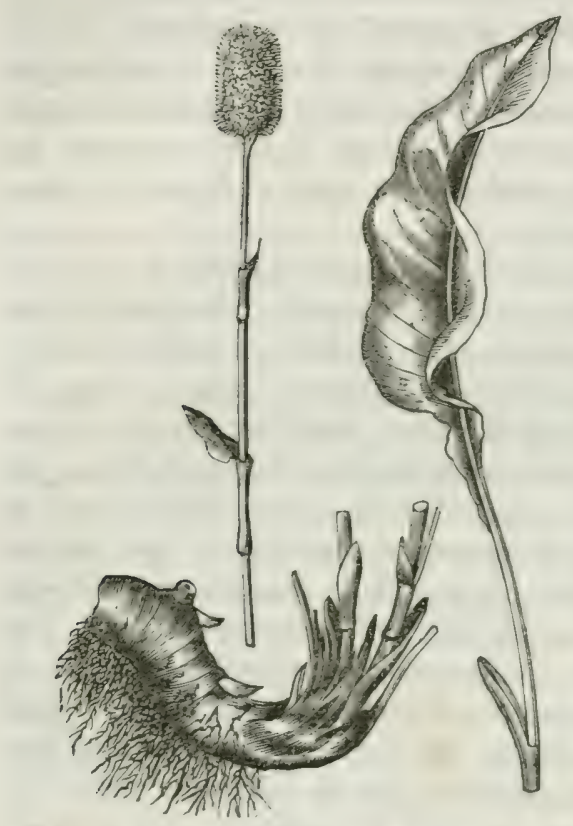

renfermé dans le périanthe.

- Car. spéc. : 9 étamines; tige très simple, à un seul épi ; feuilles ovées-lancéolées, décurrentes sur le pétiole.

La bistorte croît en France, dans les lieux humides; ses feuilles ressemblent un peu à celles de la patience, mais elles sont d'un vert plus foncé et régulièrement reinées; ses tiges s'élèvent à la hauteur de 50 centimètres, et supportent chacune un seul épi d'une couleur incarnate ou purpurine; sa racine est grosse comme le pouće, comprimée, deux fois repliée sur elle-même, rugueuse et brune à sa
odore, d'une saveur austère surface, rougeàtre à l'intérieur, presçue inodore, d'une saveur austère et fortement astringente. On nous l'apporte sèche de nos départements méridionaux.

La décoction de bistorle est très rouge et précipite fortement les dissolutions de fer et de gélatine, ce qui indique qu'elle contient du tamnin. Jille renferme aussi beaucoup d'amidon; aussi, dans les temp de disctte s'en est-on nourri quelquefois, après lui aroir fait subir une première infusion dans l'eâu; elle fait partie de l'électuaire diascordium.

\section{Patience saurage ou Parelle.}

Rumex ucutus L., Car. gén. : fleurs hermaphrodites on diclines par avortement; périanthe à 6 folioles, dont 3 extérieures herbacées et $\mathrm{c} 0$ hérentes ì la base, et 3 intérieures colorées, plus grandes, persistantes, nues ou accompagnées d'un tubercule ì la base, connirentes; 6 étamines opposées deux par deux aux folioles extérieures, filets très courts, anthères oblongues fixées par la base; oraire triangulaire surmonté de 
3 styles capillaires, terminés chacun par un stigmate déchicqueté; cariopse triangulaire, recourert sans adhérence par les 33 folioles internes du périanthe, qui se sont accrues.

I.e rme.t arutus croit naturellement dans les lieux humides et a le port d'une grande oseille; sa tige est rougeâtre, haute de 50 à 60 centimètres, ramifiée, garnie de feuilles corlées-oblongues, pointues, plus larges au bas de la tige, plus étroites et plus agguës à la partie supérieure. Ces feuilles sontplanes, fermes et d'un gout âpre. Les fleurs sont petites, disposées en grappes paniculées, hermaphrodites; les folioles in térieures du périanthe sont tuberculeuses à la base. La racine, qui est la partic usitée, est fusiforme, charnue, brune à l'extérieur, jaune à l'intéricur; clle est pourrue d'une odeur qui lui est propre et présente une sareur amère et austère; elle est employée récente ou sìche, comme dépurative et antiscorbutique; elle contient un peu de soufre.

Le genre rumr $x$ de Linné comprend des plantes que Tournefort arait dirisées en deux, d'après la forme el la sareur de leurs feuilles : celles à feuilles munies d'oreilletles et à saveur acide, formaient le genre oseine ou ucetosu; celles à feuilles entières et îpres composaient le genre patience ou loprolhum. Il est en effet remarquable que le genre rumex puisse être dirisé assez nettument en deux sections, de propriétés médicales et économiques différentes, et que toutes les espèces soient acides et munies de racines rouges et inodores, comme les oseilles, ou âpres et munies de racines jaunes et odorantes, comme les patiences; de telle sorte que les espèces de chaque section puissent être emplovées les unes à la place des autres: ainsi, pour les patiences, ce n'est pas seulement la racine du rumex ucutus qui est employée en pharmacie, sous ce nom; ce sont aus:i celles des rumex patientia, crispus et aquaticus. On pourrait même y joindre le rumex alpinus, que le volume de sa racine a fait nommer rhubarbe des moines, et le rumes sanguineus auquel la couleur rouge foncée de ses pétioles et des nervures de ses feuilles a fait donner le nom de sangdragon. De même on emploie indifféremment, sous le nom d'oseille, les feuilles des $R$. acetosa, acetosella et scutatus. Les fevilles de ces trois plantes sont riches en suroxalate de potasse et fournissent en Suisse la plus grande partie du sel d'oseille que l'on verse dans le commerce.

La racine d'oseille est rougeàtre, longue, ligneuse, inodore, d'une saveur amère et astringente. Elle est employée comme diurétique.

\section{Racine de Rapontic.}

Rheum rhaponticum L. Car. gén. : fleurs hermaphrodites; périanthe herbacé, à 6 divisions profondes, égales, marcescentes; 9 élamines 
opposées deux par deux aux divisions extéricures, et séparénent aux divisions intérieures du périanthe; filaments subulés; anthères ovoïles, versatiles; vaire trigone à 3 stigmates sous-sessiles, cutiers, étalés. Cariopse triangulaire, ailé sur lés angles, entouré par la base du périanthe flétri.

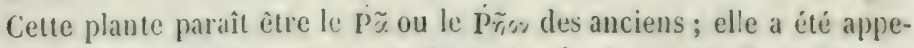
lée depuis rhr-pronticum, c'est-it-dire rha des brods du P'mt-Euxin, lorsqu'il fut devenu nécessaire de la distinguer d'une autre espèce apportée de Scy thie, et qui fut ponr cette raison nommée tha barbarum, les Romains enveloppant sous la même désignation de brerbares tous les peuples assez forts ou assez éloignés d'eux pour se défendre contre leur esprit de domination universelle. Comme on le voit, celte nouvelle racine, nommée rhr-barbarum, est notre rhubarbe actuelle.

Le rhapontic croît naturellement dans l'ancienne Thrace, sur les bords du Pont-Euxin ; mais on le troure plus abondamment encore au nord de la mer Caspienne, dans le's déserts situés entre le Volga ot l'Yä̈ (l'Oural), qui paraissent même en être la première patrie; car, par un rapprochement assez curieux, tha est aussi l'ancien nom du Volga, soit que le fleure ait donné son nom ì une plante abondante sur ses bords, soit que l'inverse ait eu lieu. Le rhapontic crôt également en Sibérie, sur les montagnes du Krasnojar : il ne s’est répandu en Europe que postérieurement à l'année 1610, époque à laquelle Alpinus en fit venir de Thrace.

Le rhapontic, cultivé maintenant dans nos jardins, ponsse de sa racine des feuilles très grandes, cordiformes, échancrées à la base, obtuses à l'extrémité, lisses, d'un vent foncé, portées sur de longs pétioles sillonnés en dessus, arrondis à la marge. La lige, luante de 60 centimètres à 1 mètre, porte des feuilles semblables aux premières, mais plus petites, et est terminée par plusieurs panicules touffues de fleurs blanches. La racine est brune au dehors, jaune et marbrée en dedans, grosse, charnue, sourent divisée en plusieurs rameaux; d'une sareur amère, astringente et aromatique.

Le commerce nous présente celte racine sèche sous deux formes. Suivant l'une, elle est grosse comme le poing ou moins, d'une apparence ligneuse et d'un gris rougeâtre à l'extérieur; sa cassure transrersale est marbrée de rouge el de blanc, de manière que ces deux couleurs forment des stries très serrées, rajonnantes du centre a la circonférence. Elle a une saveur très astringente et mucilagineuse, teint la salive en jaune rougeàtre et ne croque pas sous la dent. Son odeur est analogue à celle de la thubarbe, mais plus désagréable, et peut en être facilement distinguée. Sa poudre a une teinte rougeàtre que n'a pas celle de la rhubarbe. 
Cette racine provient des thapontics qui sont naturalisés dans les jardins des environs de Paris, où ils croissent presque sans soin et sans culture. C'est elle qui se trouve décrite et analỵsée dans le mémoire de II. Henry sur les rhubarbes (Bulletin de pharmacie, t. VI, p. 87), sous le nom de rhulorlte de Franer. Je rappellerai plus loin les résultats de cette analyse

L'autre sorte de rhapontic ressemble tout à fait à celui décrit par Lemery. Elle est longue de 8 à 11 centimètres, grosse de 5 à $S$ centimètres, d'une apparence moins ligneuse que la précédente, d'un jaune pâle, plus dur ou moins rougeâtre à l'extérieur, ce qui lui donne une plus grande ressemblance arec la rhubarbe, et permet à quelques personnes d'en mêler, par fraude, à la rhubarbe de Chine ou de Iloscovie; mais sa cassure rayonnante, sa saveur astringente, mucilagineuse, non sablonneuse, et son odcur semblable à celle de la première sorte, l'en font facilement distinguer. Cette sorte de thapontic provient aujourd'hui surtout de Clamart, village assez élevé, situé au sud de Paris.

Lorsque le rhapontic était encore parmi nous une substance exotique, nourelle et recherchée, on tentait de lui substituer quelques racines indigènes, comme aujourd'hui on substitue le rhapontic à la rbubarbe. L'une de ces racines était une espèce de patience nommée rhuturbe des moines ou rhingentic de montagne (rumed alpinus L. ), assez semblable au vrai rhapontic; une autre était le rhapontic nustrus, produit par la grande centaurće (contmuen centanriun L.), et (quelques autres plantes congénères. Cette dernière se distinguait facilement du rhapontic par son épiderme noir, sa saveur douceàtre et son odeur très prononcée de bardane.

\section{Racine de Rhubarbe.}

Cette racine, connue postérieurement au rhapontic, nous vient des contrées les plus saurages de l'Asie, ce qui explique pourquoi on a été si Jongtemps indécis sur la plante qui la fournit; car on l'a successivement attribuée à quatre espèces de rheum, et, en dernier lieu, on l'a crue produite principalement par le rheum australe. Je vais discuter ces différentes origines, en donnant les caraclères de chaque plante.

Rheum undulatum L. Après le rhoum thayonticum qui fait le sujet de l'article précédent, la première espèce qui ait été connue est un heum croissant naturellement en Sibérie, dont la tige s'élève de $1^{\mathrm{m}}, 3$ à $1^{\mathrm{n}}, 6$; dont les pétioles sont planes et lisses en dessus, demi-cỵlindriques en dessous, à bords aigus, et qui est pourru de feuilles grandes, cordiformes, échancrées par le bas, fortement ondulées, un peu velues. Aussitôt que cette espèce fut connue, Linné lui attribua la rhubarbe. 
et la nomma en conséfuence rherem rhabrerbemen; mais il changea d'avis après la découreste du iheum puluatum, el donna à la premiere plante le nom de rhemm undulutum. Pendant que l'on regardait celle plante comme la source de la rhubarbe, le gourernenent russe ha fit cultiver en grand dans la Sibérie, et si clle l'eût produite véritablensent, il est évident que ce gourernement, qui fait le commerce exclusif de la rhubarbe en Sibérie, aurait cessé d'en acheter aux Buclares; mais il n'a jamais pu, avec le rleum undulntum, faire de la vraie rhubarbe, et il est certain que la rhubarbe dite de. Moscowie appartient a un autre rheum, qui croît dans les pays montagneux ct presque inaccessibles qui bordent la chine au nord-onest. On la troure également dans toute la partie méridionale de la Tartarie el dans tout le Thibet, depuis la chine jusqu'aux frontières de la Perse; $e$, suivant qu'elle provient de ces différentes contrées, suirant la manière tlont elle a été préparée ct séchée, suivant enfin la route qu'elle a prise pour arriver jusqu'à nous, cette racine constitue les différentes sortes connues sous les noms de rhubarbe de Moscovie, de Chine el de Perse.

Riheum compactum. J'ignore quand cette espèce a été comnue. Fille est munie de feuilles cordiformes très obtuses, avec une échaticrure inférieure presfue fermée à l'ourerture. Ces feuilles sont d'un vert foncé, entièrement lisses des deux côtés, un peu lobies sur leur contour, munies de petites dents aiguës et un peu ondulées; les pétioles sunt denicylindriques et bordés de charue côté d'une rôte élerée, d'une épaisseur égale aux deux extrémités. Les liges sont hautes ele $1^{\text {m" }}, 3$ à 2 mètres, médiocrement ramifiées par le hatut; les fleurs sont d'un blanc jaunâtre, disposées en panicules dont les grappes particlles sont ctroites et pendantes (?). Cette plante vient très bien dans les jardins, de mème que les Rh. undulatum et rhaponticum, et toutes trois donnent des produits peu différents qui sont confondus dans le commerce sous le nom de rhubarbe de France. Celte rhubarbe, lorsqu'elle est bien séchée et parée, imite assez bien la rlubarbe de Chine; mais, après avoir essuyé la poussière jaune dont elle est recourerte, on la reconnait tonjours facilement à sa couleur rougeâtre ou d'un blanc rosé, à son odeur de rhapontic (commune aux trois espèces) différente de l'vdeur de la raie shubarbe, à sa marbrute rayomante el serréc, enfun à ce qu'clic colore à peine la salive et ne crorgue pas sous la dent.

Rheum lataricum. Cette plante, origninaire de la pelite Tartarie, est très rapprochée de la précédente, mais elle est beaucoup plus basse; ses feuilles sont cutières et non sinuíes ì leurs bords, trìs glabres, très amples; les panicules sont a peine plus longues que les feuiles.

Rheum ribes. Espèce particulièrement remarquable par ses fruits enveloppés d'une pulpe rouge et succulente. Elle produit de fortes tigges 
strices, peu ramifiées, munies à leur base de feuilles médiocrement pétiolées, étalées sur la terre, arant sourent 65 centimètres de largem sur 33 centimètres de longueur. Leur surface est très rude, comme rerrugueuse; les bords sont ondulés et frisés; les nervures sont couvertes de poils rudes; les pétioles sont planes en dessus, striés, arrondis à leurs bords.

Cette plante croit sur le mont Liban et dans la Perse, où elle est recherchée à raison de la saveur agréablement acide de ses pétioles, de ses feuilles et de ses jeunes tiges, que l'on emploie comme aliment et comme médicament et dont on fait des conserres arec du sucre. On la vend sur les marchés de la P'erse comme plante potagère et on en fait une grande consommation.

Rherem folmentum (fig. 184). Celte plante se cultive aussi dans les jardins; mais on a plus de peine à ia conserver et ses racines acquièrent rarement un grand rolume. Ses feuilles sont cordiformes, mais divisées jusqu'à la moitié en lobes palınés, pinnatifides, acuminés; elles sont pubescentes en dessous; la tige cst d'une hauteur médiocre, divisée supérieurement en panicules droites, nombreuses, à ramifications presque simples. Cette plante croît surlout dans les provinces de l'empire chinois qui sont traversées par le fleurc Jaune (hoâng-ho) et par ses aflluents; et il est véritablement remarquable qu'à l'instar du rhapontic, dont l'ancien nom, rha, était aussi celui du Volga , la rhubarbe (là-loâng) Fig. 184.

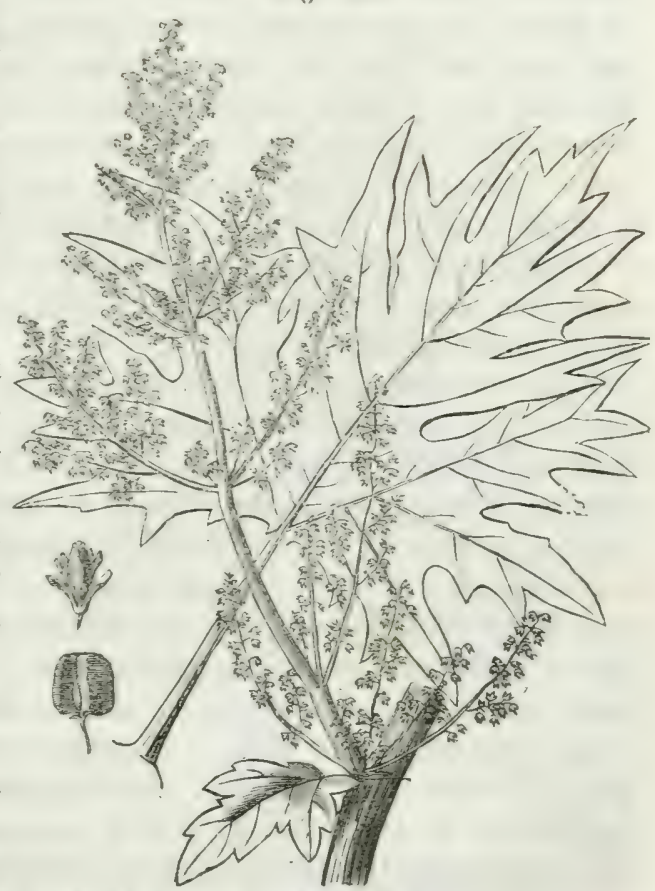
ait écralcment emprunté le nom de fleure Jaune, ou le fleure Jaune celui de la racine.

Voici, d'après Murray, comment la rlubarbe palmée a été déconverte: 
Vers l'année 1750 , sur le désir de hauw Boërhaave, premier méde. rin de l'empereur de Russie, le sénat chargea un marchand tartare de lui procurer des semences de rhubarbe, ce qui fut exécuté. Ces graines, semées à Saint-Pétersbourg, produisirent du iheum undulutum, qui était déjà connu, et du rheum pulmatum, encore inconnu. Alors, comme on arait déjà la preure que le rherme undulutum ne produisait pas la rhubarbe, et que le themm pulmatum venait d'une contrée plus méridionale, on pouvait croire, arec quelque raison, qu'il était la vraie rhubarbe. Ce fut le sentiment de David de Gorter, de Monsey, de Hope et de Linné, et cette opinion fut admise sans opposition jusqu'aux nouveaux doutes élevés par Pallas et Géorgi, qui ont éludié l'histoire naturelle de la Russie sur les lieux mêmes. Des Buchares assurèrent à Pallas ne pas connaître les feuillés du rheum palmatum, ajoutant que lẹs feuilles de la vraie rhubarbe étaient rondes et murquées sur le burd d'un grand rombre d'incisions, d'où Pallas conclut ru'ils voulaient lui décrire le rheum compactum. Ln Cosaque dépeignit à Géorgi le rheum undulatum pour la véritable espècc. L'un et l'autre pensent que, sur les monts plus méridionaux, plus décourerts et plus secs, comme le sont ceux du Thibet, le rhenin undulutum peut produire une racine plus belle que sur les montagnes froides et humides de la Sibérie; et ils déterminent les lieux de la Russie les plus propres it la culture de cette espèce. On pourait conclure de tout ceci, ainsi que l'a fait Murray, que la rhubarbe vendue aux Russes, et tirée de la Tartarie chinoise, provenait également des trois espèces de rheum susmentionnées; mais je pense avoir acquis la preure que de ces trois espèces, le $k$. patimutumn est le seul qui produise la rhubarbe.

J'ai dû anciennement à la bienveillance de Jean Thouin, jardinier en chef du Jardin des Plantes, des échantillons de racines des rlemm julmutum, undulutum, compactum et rhaponticum. Ces plantes, cultivées dans un terrain probablement différent de celui de leur mère-patrie, avaient pu éprouver des altérations plus ou moins grandes; mais ces altérations devaient être du même genre; et, supposé que l'une des racines précitées nous présentât des caractères beaucoup plus rapproches de la rhubarbe de Tartarie que les autres, nous pouvions en conclure, presque avec certitude, que c'est la réritable espèce.

Or, de ces échantillons, deux se ressemblaient parfaitement pour l'0deur, la saveur et la marbrure, c'étaient ceux provenant des rherum rhupromticum et undulatum. Celui du li. compuctum s'éloignait encore plus de la vaie rhubarbe, mais cela tenait it la grande jeunesse de la plante, comme je l'ai reconnu depuis.

Le rhemm palmatum seul jouissuit exartement de l'odeur et de la saceur de la rhubarbe de chine (sanf le craquement sous la dent), et 
le premier caraclère surtout était si marqué, et tranchait tellement avec le même caractìre dans les autres espècr's, gu'il ne m'est plus resté de doute, et que j’ai regardé le rlemm frulmatum comme la source de la rraie rlubarbe. Depuis, j'ai observé les mêmes différences d'odeur et de saveur entre le rhrum palmatum cultivé à Rhéumpole et les autres espèces qui ỵ élaient exploitées, et j’ai été confurmé dans le même sentiment; j’y persiste encore aujourd'hui, malgré l'abandon général dont paraì menacé le rlurmm palmatum, par suite de la découverte du lih. mustrule; je ne vois pas d'ailleurs, quand les lih. undulutum, cumumr. tum, et même rhomonticum, produisent des racines semblables, quant à la forme, à l'odeur, la saveur el la couleur, pourquoi les rhrum jualmutum et amstrale ne donneraient pas également des racines douées des caractères de la vraie rhubarbe.

Suivant II rray, le ilimum folmatum croit spontanément sur une longue chaine de monlagnes en partie dépourvue de forêts, qui, bordant à l'occident la Tarlarie chinoise, commence au nord non loin de la ville de Selin, et s'éFig. 185.

tend als midi jusque vers le lac Koconor, voisin du Thibet. I.e sol en est retourné par des taupes : l'âge propre à la récolte des racines est indiqué par la grosseur des liges (c'est ordinairenıent la sixième année). On les arraclıe dans les mois d'avril et de mai , et quelquefois anssi en automne. On les nettoie, on les coupe en morceaux, et, après les aroir percées et enfilées, on les suspend soit aux arbres voisins, soit dans les tentes, soit même aux cornes des brebis. Lorsque la récolte est finie, on les porte aux habilations, où, sans doute, on achère de les faire sécher. Selon Duhalde, les Chinois terminent cetle dessiccation sur des tables de pierre, chanffées en dessous par le moyen du feu. 
likenin austrule (fig. 185). Le docteur Wallich, directeur du Jardin de botanique de Calculta, ayant reçu de la graine de rhubarbe tirée de l'Hṣmalaya, ou des montagnes du Thibet, les sema et vit germer un nouveau rheum, qu'il surnomma emodi, mais qui fut décrit plus tard par le docteur Colebroke sons le nom de rheum australe. Celte plante, que l'on commence à cultiver en Europe, a les feuilles trìs grandes, rondes et dentées, caractère qui s'accorde avec ce que les Buchares disaient à Pallas des feuilles de la vraie rhubarbe.

\section{Caractères des Rhubarbes du commerce.}

Bhulurbe de Chine. Cette rbubarbe vient probablement du Thibet, et traverse la Chine méridionale pour arriver à Canton, où les vaisseaux européens viennent la chercher. Elle est ordinairement en morceaux arrondis, d'un jaune sale à l'extérieur, d'une texture compacle, d'une marbrure serrée, d'une couleur briquelée terne, d'une odeur prononcée qui lui est particulière, d'une sareur amère. Elle colore la salive en jaune orangé et crorgue très fort sous la dent. Elle est généralement plus pesante que la suirante, et, pour la couleur, sa poudre lient le milieu entre le fauve ct l'orangé.

La rhubarbe de Chine est souvent percée d'un petit trou dans lequel on troure encore la corde qui a servi à la suspendre pendant sa dessiccation. Sa couleur, plus terne que celle de la rhubarbe de Moscovie, peut provenir en partie du long royage qu'elle a fait sur mer. C'est cn partie aussi à la même cause qu'on doit attribuer l'inconrénient qu'elle a de présenter souvent des morceaux gâtés et roussâtres dans leur intérieur; mais, lorstu'elle est choisie arec soin, bien saine ('t non piquće des vers (1), clle n'est guère moins estimće que les suirantes.

Rhubarbe de Woscovie. Cette sorte est originaire de la Tarlarie chinoise; des marchands buchares lit transportent à Kiachta, en Sibérie, et la vendent au gourernement russe. Il y a dans celte ville de Kiachta des commissaires chargés d'examiner scrupuleusement lit rhubarbe, et de la faire nettoger et monder morceau par morceau, car le

(1) La rhubarbe est sujette à être piquéc; dans le commerce on masıue ce défaut en bouchant les trous arec une palte faite de poudre de rhubarbe et d'eau, et ensuite en roulant les morceaur secs dans de la poudre de rhubarbe. I'i des premiers soins, lorsqu'on achète de la rhubarbe, doit ètre d'enlever celle poussière trompeuse qui la recourre, et de casser les morceaux les plus pesants et les plus légers. Les premiers sont ordinairement humides et noirs a lintérieur; les scconds sont pulvérulents à force d'avoir été traversés en lous sens par les insectes. 
gouvernement n'achète que celle qui est tout à lait belle. Cette rhubarbe est ensuite expédiée pour Pétershourg, où elle est encore visitée avant que d'ètre livrée an commerce. C'est elle que Murray désigne sous le nom de thuburbe de Buchurie. Elle est en morceaux irréguliers, angulenx et percés de grands trous faits en Sibérie, lors de la remise de la rhubarbe aux commissaires russes, dans la rue d'approprier les trous primitifs qui araient servi à suspendre la racine, et d'enlever les parties environnantes, qui sont toujours plus ou moins altérées. Cette shubarbe est d'un jaume plus pur à l'extérieur, et sa cassure est, en général, moins compacte que celle de la rhubarbe de Chine. Elle est marbrée de reines rouges et blanches très apparentes et très irrégulières. Elle a une odeur très prononcée, ot une saveur amère astringente. Elle colore fortement la salive en jaune safrané, et croque sous la dent. Sa poudre est d'un jaune plus pur que celle de la rhubarbe de Chine. Cette rhubarbe est très estimée.

Rhuburlie de Perse. Cette belle rhubarbe venait autrefois du Thibet par la Perse et la Sỵrie; de là ses différents noms de rhudurbe de P'erse,

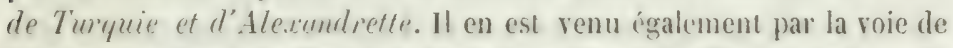
Russie; mais aujourl'hui les Anglais la tirent de Canton, comme la rhubarbe de: Chine, et lui donnent le nom de dutch-trimmed rhulurb) (rhubarbe hollandaise mondée) ou de buturiom rlubarb, parce que, arant eux, les Hollandais la transportaient de Canton a Batavia, et de là en Europe. Quelle que soit la route que celte racine ait prise pour arriver jusqu'à nous, elle n’a jamais varié de caractères, qui sont tels que j’ai toujours déclaré qu’elle appartenait à la même espèce que la rhubarbe de Chine. Elle est en effet d'une texture serrée et d'une couleur terne qu'on ne peut attribuer à aucun état de détérioration. Elle est percée de petils trous, comme celle de Chine; mais elle est encore plus dense et plus serrée, entièrement mondée au couteau et affectant deux formes régulières : celle qui provient des racines peu rolumineuses est à pen près cyllindrique; celle qui a cité lirée des grosses racines est coupée longitudinalement par le milieu, et offre ainsi des morceaux allongés, plats d'un côté et convexes de l'autre; celle-ci est connue particulièrement dans le commerce sous le nom de rhubarbe plrte. Sa grande compacité la rend moins sujette à se détériorer que les autres; je la regarde comme la rhubarbe par excellence, préférable même à celle de Iloscovie.

lilubarbes de l'Himalayn. Le docteur Royle, dans ses Illustrontions de botrnique des monalannes de l'Himalayr, fait mention de quatre espèces de theum propres à ces contrées, les Rh. emodi on australe, webbianum, spiciforme, et moorcroftianum.

La première espèce produit, d'après le docteur Wallich, une sorte II. 
de rhubarbe qui arrive dans l'Inde, à travers les provinces de Kalsee, Almora et Boutan. M. Péreira en arait reçu anciennement un échantilIon du docteur Wallich; mais cette sorte n'a été connue dans le commerce anglais que sur la fin de 1840 , alors que la rlubarbe de Chine était rare et d'un prix fort élevé.

Dix-neuf caisses en furent importées à Londres: mais celte rhubarbe fut trouvée de si mauraise qualité, que huit caisses seulement purent être vendues à raison de 40 centimes le demi-kilogramme, et que le reste fut vendu et embarqué pour lew-lork, au prix de 10 centimes. Iprès cet essai malheureux, II. Péreira doute qu'on en fasse revenir en Angleterre. Cette rhubarbe esi en effet de la pius mauvaise (qualité possible. Elle est généralement noirâtre et d'apparence ligneuse, légère et toute piquée des vers. Quelques morceaux provenant des rameaux de la racine, sont un peu plus sains et d'un jaune terne à l'intérieur. En voyant pour la premiere fois cette racine, si différente en apparence de la rhubarbe officinale, je me suis demandé comment le docteur. Wallich avait pu arancer que le sheum anstrole était la source ou une des sources de la rhubarbe. Hais un examen plus attentif m'a fait revenir à un sentiment plus farorable. En brisant les morceaux, on y troure quelques parties saines qui, par leur belle marbrure rouge et blanche, par leur sareur et par l'abondance des cristaux d'oxalate de chaux, sensihles sous la dent, peuvent être comparés à la meilleure rhubarbe officinale; $\mathrm{et}$, chose remarquable, ces parties saines, par leur vire marbrure et leur légèreté, se rapprochent plus de la rhubarbe de Huscovie que de celle de Chine. Je pense donc aujourd'hui que la rhubarbe de l'Himalaya, préparée et séchée arec soin, fournirait une belle sorte commerciale. J'en ai d'ailleurs la preuve entre les mains, dans un échantillon que je dois à l'ubligeance de II. Batha de Prague, échantillon qui n'est autre que de la racine de rheum australe, provenant de semences qui lui furent données par le docteur Wallich. Cette racine récoltée et séchée par M. Batka, constitue en effet une fort belle rhubarbe, très croguante sous la dent, colorant fortement la salive en jaune, et d'une saveur très amère et astringente.

La racine du rheum webhiemum ne parait pas former une sorte commerciale; H. Roỵle en a rapporté de l'Himalaya une petite quantité qui est fort différente de la rhubarbe officinale. Eille est cin tronçons cytindriques très courts et au plus de la grosseur du pouce. Elle est courerte d'un épiderme noirâtre, profondément sillomé par la desciccation. Chargue morceau est percé vers le centre et dans le sens de l'axe d'un trou assez large, gui a dû serrir à la suspension de la racine. La structure en est rayonnée, la couleur interne faure jamàtre, la sarcur mu- 
cilagineuse et amère, arec un líger crorjuement sous la dent. L'odeur est à peu près nulle.

Je ne puis dire autre chose des racines des rheum spiciforme et morreroftirmun, que ce que 11 . Péreira nous en apprend lui-même. Ces racines sont d'une couleur plus claire que les précédentes et d'une texture plus compacte (1).

lehulurbes de Frence. Il n'y a pas de pays en Europe où l'on n'ait cherché à naturaliser la rhubarbe; malheureusement le rheun palmatum, qui pourrait en fournir de réritable, est de toutes les espèces qui ont été cultivées jusqu'ici, celle qui a le plus perdu par son cxpatriation. Il en réculte qu’à Rhéumpole (2) même, on en délaišait la culture pour s'attacher plutôt aux espèces dont les produits ćtaient plus abondants el se rapprochaient le plus en apperence de la raie rhubarbe. Peut-être aussi cette différence, qui est toute au désarantage du rhenm palmatum, tenait-clle à ce gue les autres humm, cultivés à Rhéumpole, s'y trouraient dans un terrain propre à leur déreloppement et à leur conservation; tandis rue le premier, originaire du plateau central de l'Asie, aurait besoin d'ètre cultivé dans un sol dont la nature, l'élévation et la sécheresse répondissent anx lieux d'ou il est sorti. J'ai sous les yeux un échantillon de iltrum pulmutum de Rhéumpole : celle racine, surtout lorsqu'elle est un peu âgée, est pour moi celle qui se rapproche le plus, par son odeur et sa couleur, de la rhubarbe de Chine; mais clie a la compacité d'une substance qui a été gorgée d'eau arant sa dessiccation : elle a une sareur mucilagineuse et sucréc, indépendamment de l'amertume qui se déreloppe cusuite; clle oflece à sa surface une infinité de points blancs et brillants, qui s'y sont formés depquis quelques années que je la conserve (le rhemun palmatum cultivé au Jardin des Plantes n'offre ni cette saveur sucrée, ni ces points brillants); enfin elle ne contient qu'une très petite quantité d'oxalate de chaux, et cette différence arec la rhubarbe de Chine paraît constante dans celle qui a été cultivée jusqu'ici en Lurope; car Schécle l'a observéc sur la rhubarbe de Suède, et llodel sur celle de SaintPétersbourg.

La rhubarbe de France ne provient donc pas de la culture du rheum prolmatum; elle est produite, ainsi que je l'ai déjà dit, par les rhecum

(1) On trouvera dans le Journal de pharmacie et de chimie, t. VIII, p. 3322 , la description de quelques autres sortes de rhubarbes d'origine asiatique.

(2) On nommait ainsi, il y a un certain nombre d'années, un endroit situé près de Lorient, dans le déparlement du Morbihan, ou l'on cultivait en grand les rheurn undulatum, compactum et palmatum. Il parait que cet établissement n'existe plus. 
rhupronticum, undulutum, el surtout rompurtum. Il est inutile de revenir sur ses caractères, qui se trourent rxposés précédemment.

Analyse chimique des rhubribes. Etant it la pharmacie centrale, il y a trente-six ans, sous la direction de M. Henry père, j'ai fait l'analyse comparée des rhubarbes de Chine, de Moscovie et de France. J'ai trouré dans la rhubarbe de Chine un principe particulier, auguel elle doit sa couleur, sa saveur et son odeur, qui a été nommé depuis par d'autres cophopicrite et rhabrobarin; mais dont j'arais determiné toutes les propriélés, à la cristallisation près, qui ne me paraît pas encore être un fait bien pronvé. Ce rhabarbarin est solide, jaume, insuIuble dans l'eau froide, soluble dans l'eau chaude, l'alcuol et l'éther. Il se volatilise en partie au feu sous la forme d'une fumée jaune odorante; il a une sareur amère irès âpre, qui est celle de la rhubarbe, concentrée. Il donne, arec la potasse et l'ammoniaque, des dissolutions rouges, d'où les acides le précipitent en lui restituant sa couleur. Il est rougi et précipité par l'eau de chaux.

Il forme arec tous les acides (hormis, je crois, l'acide acétique) des composés jaunes, insolubles : arec les dissolutions de plomb, d'étain, de mercure et d’argent, des précipités jaunes : avec le sulfate de fer, un précipité vert noirâtre; arec la gélatine, un précipité casiécux coriacé. Il est très difficilement altérable par l'acide nitrique, qui ne le clange ni en acide malique, ni en acide oxalique.

Le second principe de la rhuharbe est une huile fixe, douce, rancissant par la chaleur, soluble dans l'alcool et dans l'éther. Il n'ỵ existe: qu'en très petite quantité.

On y troure une assez grande quantité de sur-malate de chaux, une petite quantité de gomme, de l'amidon, du ligneux, de l'oxalate de chaux, qui fait le tiers de son poids, une petite quantité d'un sel ì base de potasse, une très petite quantité de sulfate de chaux et d'oxide de fer.

La rhubarbe de Moscovie, malgré un extérieur assez différent de la rhubarbe de Chine, ne paraît pas s'en éloigner dans sa composition plus que ne peurent le faire deux parties pareilles tirées d'indiridus de la même espèce. On y retroure les mêmes principes et presque r'n nêmes proportions. Il faut faire observer cependant qu'une quantité un peu plus fail)le d'oxalate de chaux parait constante dans la rhubarbe de Moscorie, Schéele ayant obtenu un résultat semblable. ('est pourquoi aussi la rhubarbe de Joseovie croque moins sous la dent.

La rhubarbe de France, rheum rhupontirum (?), contient une bien plus grande quantité de matière colorante, mais ce principe est rougeàtre au lieu d'être jaune. On y troure aussi beaucoup plus de mattière amrlacée, re qui est une suite de cre qu'elle comtient moins d'oxalate 
de chaux, car la quantité de celui-ci s'élève au plus au dixième du poids de la racine. (Bull. de plearm., t. VI, p. 87.)

La rhubarbe est stomachique, légèrement purgative et vermifuge. On l'emploie en poudre, en infusion dans l'eau, dans l'alcool, en sirop et en extrait. Elle entre dans un grand nombre de préparations composées.

\section{PAMILLE DES CHENOPODÉES.}

Plantes herbacées ou sous-frutescentes, à feuilles alternes ou opposées, quelq̨uefois charnues, privées de stipules. Les lleurs sont très petites, hermaphrodites, quelquefois diclines par arortement, disposées en grappes rameuses ou groupées à l'aisselle des feuilles; périanthe calicinal a 3,4 ou 5 dirisions plus ou moins profondes, persistantes et s'accroissant pour envelopper le fruit; les élamines sont opposées et en nombre égal aux divisions du périanthe, souvent en nombre moindre par arortement, insérées sur le réceptacle ou sur un annean adhérant au périanthe; alternant quelquefois avec un même nombre d'écailles hypogynes. L'oraire est libre, uniloculaire, contenant un seul ovule dressé ou porté sur un podosperme ascendant; le style est simple, terminé par 2-4 sligmates subulés; le fruit est un askose renfermé dans le périanthe accru et quelguefois devenu bacciforme; la graine contient un embryon cylindrique, homotrope, annulaire et entourant l'endosperme (ryclolubées), ou roulé en spirale et presque privé d'endosperme (spirolobées).

Les chénoporlées, si l'on considère leur port humble et leurs fleurs presçue inaperçues, paraîtront, tout au plus, bonnes à brùler; mais elles mériteut, plus que bien d'autres plantes, de fixer notre attention si nous les considérons sons le rapport de Jeurs applications alimentaires, médicales ou industrielles. Beaucoup de chénopodées, en effet, d'un tissu làche, dépourves de principes àcres ou aromatiques, riches au contraire ch sels et en mucilage, sont comptées au nombre des aliments modérément nutritifs et de facile digestion; tels sont l'épinard (spinacin olerucen ) dont le nom rappelle que c'est par l'Espagne que les Maures l'ont introduit en Europe; l'arroche des jardins (atriplex hortensis) nommée aussi bonne-dame; le bon Henry (chenopodium bonushemicus L., "rguthophigtum bonus-henricus Hor.); la poirese hanehe et la betterave (betn cicla et $B$. melyaris Willd.), etc. D'autres sont aromatiques et pourvues de propriétés digestives, antispasmodiques ou antheluintiques, tels que la camplurée de Hontpellier, le botrys, le thé du Hexique, l'anserine vermifuge, la vulvaire, etc. Ib'autres enfin, tolles que les solsola, les sueda, les salicornia, qui croissent en abon- 
dance dans les lieux maritimes et qui sont riches en scls a base de soude, fournissent par leur incinération la sourde urfurelle qui a longtemps suffi aux besoins des arts; mais qui se trouve presque annililée aujourd'hui par l'extension prodigieuse donnce aux fabriques de soude artificielle. Yous dirons quelques mots des principales de ces plantes.

BETTE ou polnée, hetu ricla. Car. gén. : fleurs hermaphrodites; périanthe urcéolé à 5 divisions persistantes; כ̃ élamines insérées sur un anneau charnu à la gorge du tube; écailles hypogynes nulles; ovaire déprimé; 2 stigmates courts, soudés à la base. Askose globuleux, renfermé dans le tube épaissi du périanthe et couvert par son limbe charnu; semence horizontale, déprimée. - Car. spéc. : feuilles radicales pétiolées; celles de la tige sessiles; fleurs ternées sur de longs épis latéraux. On en connaît troi rariétés: $1^{\circ}$ la poirce blanehe, qui a les fenilles d'un rert blanchâtre el les fleurs disposées trois à trois; $2^{\circ}$ la poirée bionde ou carde groirce, dont les feuilles sont d'un blanc jaumâre, et dont les côtes longitudinales se mangent à l'instar de celles de l'artichaut-cardon (cincrin rrrdumrulus L.) ; $3^{\circ}$ la poirée ronge, dont les feuilles sont d'm rouge foncé.

Les feuilles de poirée sont rafraîchis-aintes; clles entrent dans la composition de la boisson laxative dite bouillon aux herbes.

BetTerave, beta culguris L. Cette espèce diffère de la précédente par ses racines sourent tres rolumincuses et charnues, par ses feuilles inférieures orées et par ses fleurs ramassées.

La betterave n’a été considérée, pendant longtemps, que comme plante potagère ou comme propre à être employece arantageusement à la nourriture des bestiaux. En effet, sa racine charnue et stucrée était usitée sur les tables, et ses feuilles sncculentes et d'une régétation vigoureuse, offraient aux bestiaux une nourriture abondante, saine ct agréable. Hais cette plante, déjà si précicuse à l'agriculture, a acquis une importance encore plus grande, depuis qu'on a recoinu qu'on pouvait en retirer un sucre cristallisable entièrement semblable ì celui de la canne. La première annonce de ce fait est due à Vargraff; Ichard, de Berlin, est le premier qui ait tenté de l'utiliser, en extrayant le sucre de la betterave pour le commerce; depuis, les procédés de son extraction ont été perfectionnés en France; ei il a été démontré, par Chaptal, que ce sucre pouvait, même en temps de paix, soutenir la concurrence, pour le prix, arec le sucre des colonies (rovez son mémoire, Anneles de chimie, t. XCV , p. 233). Voici l'indication des principales variélés de betteraves, rangées suivant les plus grandes proportions de sucre qu'elles fournissent (Payen, Jumern. de chim. médic., 1. I, P. 389): 
$1^{\circ}$ La betterave blanche; sa racine et les côtes de's feuilles sont blanches ou verilâtres.

$2^{\circ}$ La betterave jume; sa racine et les côtes des feuilles sont d'un jaune pâle.

$3^{\circ}$ La betterave rouge; sa racine est d'un rouge de sang, et les feuilles d'un rouge foncé. On la distingue en grande et en petite.

4" La betterare éinép ; sa racine a la surface ronge et l'intériem blanc, arec des veines roses. En Allemagne, on nomme cette variété racine de disette, el on la cultive en grand pour la nourriture des bestianx.

Camphrie de Moxtpeldier, rmmphmosmu mmspeliaca L. - Car. gén. : fleurs hermaphrodites; périanthe quadrifide dont deux divisions plus grandes, carénées; 4 étanines insérées au fond du périanthe et opposées à ses divisions ; oraire comprimé ; style bi- ou trifide, à divisions sétacées; askose membraneux, comprimé, renfermé dans le périanthe non accru. - Car. spéc. : feuilles velues, linéaires.

La camphrée de Ilontpellier est une plante basse, rameuse, touffue, dont les rameaux sont courerts de feuilles linéaires et velues, aux aisselles desquelies naissent les fleurs. Elle croit surtout aux environs de Montpellier, d'où on nons envoie ses sommités sèches sous la forme de très petits épis d'un vert blanchàtre, d'une odeur forte et aromalique lorsqu'on les froisse entre les mains; d'une sareur âcre, légèrement anère.

Botrus, chenryodium butrys L. - Car. géu. : fleurs hermaphrodites; périanthe quinquéfide; 5 étamines insérées au fond du périanthe et opposées à ses divisions; oraire déprimé; 2 stigmates filiformes très courts; askose membraneux, déprimé, renfermé dans le périanthe connirent, derenu pentagone, semence horizontale, déprimée-lenticulaire; testa cruslacé; embryon annulaire, périphérique, entourant un endosperme copieux et farineux ; radicule centrifuge. - Car. spéc. : feuilles pétiolées, oblongues, profondément sinuées; grappes très nombreuses, axillaires, courtes, relues, privées de feuilies.

Celle plante ne s'élère guère qu'à la hauteur de 30 centimètres; elle a le toucher visqueux et une odeur agréable; on l'emploie en infusion contre la toux.

AMrroisie du Mexin̨ue ou Thé DU Mexiǫue, chenopodimn ambrosivides L. Cette plante est originaire du Mexique et est cultirée dans les jardins; elle s'élève à la hauteur de 65 centimètres et porte des feuilles sessiles, lancéolées, dentées; ses grappes sont simples et garnies de petiles fevilles. Elle a une odeur très forte et agréable; une sareur àcre et aromatique. Llle est stomaclique ct tonique, élant prise en infusion théiforme. Les fruits sont anthehmintiques. 
ANSERINe (1) verafoge, rhenopodium anthelmintirmu L. Autre espèce américaine, virace, très odorante, cultivée dans les jardins, très usitée aux Élats-Unis comme vermifnge. Sa tige, haute de 60 centimètres à 1 mètre, est rameuse, garnie de feuilles orales-oblongues, dentées, ayant à leur aisselle, vers les sommités, de petites fleurs vertes disposées en grappes nues.

Les fruits de cette plante, auxquels on donne communément le nom de srmences, à cause de leur petitesse, ont également une forte odeur aromatique, presique semblable à celle de l'ambroisie du Hexique, et sont employés comme anthelmintiques, ainsi que l'essence qu'on en retire par distillation.

Quroa, chenopodium quinua W. Plante annuelle du Chili, semblable à notre chenopodium album, propagée par la culture dans toute la région occidentale de l'Amérique; à cause de ses semences amỵlacées qui servent à faire des potages très nourrissants:

Volvaire, chenopodium vulvarin L. Plante herbacée, commune en Europe dans les lieux incultes, le long des murs et dans les cimetières. Ses tiges longues de 20 à 25 centimètres, rameuses et conchées sur la terre, sont garnies de feuilles ovales-rhomboïdales, enticres, glauques, et portent à la partie supérieure de petites grappes axillaires de fleurs vertes. Elle exhale une odeur de poisson pourri; elle a été recommandée comme antihystérique; on l'emploie en lavements et en fomentations.

Mu. Chevallier et Lassaigne, ayant analysé la vulvaire, y ont trouré du sous-carbonate d'ammoniague tout formé, premier exemple d'un fait dés plus intéressants. Cette plante contient de plus de l'albumine, de l'osmazome, une résine aromatique, une grande quantité de nitrate de potasse, etc. (Journ. de pharm., III, 412.)

BON-HENRY ou ÉPINARd SAUVAGE, chenopodium bonus-henricus L., agathophlygtum homus-henricus Moq. Cette plante croît dans les campagnes, autour des lieux habités; elle pousse une tige haute de 30 centimètres, portant à son sommet des grappes de petites fleurs, ayant dans leur ensemble une forme pyramidale, et garnie à la partie inférieure de feuilles en fer de flèche, farineuses en dessous, ayant à leur bord quelques dents obtuses et écartées; elle se distingue des chencyodium par sa semence verticale, ses fleurs polygaures, et parce que son fruit n'est qu'imparfaitement recouvert par les folioles tlétries du périanthe. On pent manger ses feuilles comme celles de l'épinard; elles sont légèrement laxatives.

(1) Anserine (de anser, tris, oie), nom donné aux plantes de ce gुenre, pour remplacer leur nom vulgaire patte doie, due à la forme halituelle de leurs feuilles. Ce dernier nom n'est lui-mème que la traduction du mot grec

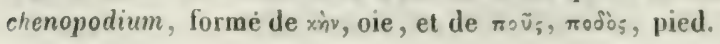


Chovan. On trourait autrefois dans le commerce une substance nommée clumun, dont l'histoire offrait d'assez grands rapports arec celle du semem-rontro pour qu'on pùt les confondre l'une arec l'autre. Ces deux substances venaient par le commerce du Levant; et toutes deux, regardées comme des semences, n’étaient en effet qu'un mélange de fleurs et de pédoncules brisés; seulement on remarquait que le chouan élait plus gros, plus léger et d'un goùt tant soit peu salé et aigrelet. Il paraissait dépourvu d'odeur; enfin son seul usage était de servir à la préparation du carmin, conjointement avec une écorce inconnue du Levant, nommée cmutrur (1). Telles étaient les seules données que l'on eût sur le chouan, lorsque M. Desraux reconnut qu'il était produit par les sommités de l'alunnesis tamariscifolia L. (halogetum tmmariscifolium Heyer), plante voisine des soudes et apprartenant comme elles à la famille des chénopodées (Journ. pharm., t. II, p. 414).

On m'a présenté une fois, sous le nom de lirli ou de flenr de Turquip, une substance tout ì fait analogue au chouan, et serrant comme lui, dans l'Orient, à la préparation du carmin. Cette substance était formée de petites fleurs de l'mizmm conmrimse, de la famille des ficoïdées.

Socues. Plantes demi-ligneuses, à feuilles alternes ou opposées, rarement planes, sourent ç lindriques et charnues, quelquefois épineuses, rarement nulles; les fleurs sont hermaphrodites, accompagnées de 2 bractées; le périanthe est à 5 divisions profondes, persistantes; les étamines sont au nombre de 5 ou de 3 , insérées sur un disque bỹpogyne; l'ovaire est déprimé, surmonté de 2 styles courts, à stigmates recourbés. Le fruit est un askose déprimé, contenu dans le périanthe derenu capsulaire. Semence horizontale, formée d'un testa très mince et d'un embryon roulé en spirale, p̣rivé d'endosperme.

Les soudes croissent en abondance dans les lieux maritimes des cli-

(1) Autour, écorce approchant en forme et en couleur de la cannelle, mais plus épaisse, plus pâle et ayant en dedans la couleur d'une muscade cassée, avec beaucoup de points brillants; elle est presque insipide et inodore.

\section{(Lemery.)}

J'ai trouvé au Muséum d'histoire naturelle l'écorce d'autour étiquetée loude-birbouin, balucor et oulmara. M. Gonfreville l'a rapportée de l'Inde, vid elle est employée pour la teinture, sous le nom de lodu putlay. Elle existe dans le commerce des couleurs à P'aris, mais elles'y vend fort cher. Elle est en fragments longys de 6 centimètres au plus, d'une forme cintrée, épais de 4 à 6 millimètres; clle est rouggeàtre et fongुueuse à l'extérieur, plus pàle, jauuâtre, ou même blanchàtre à l'intérieur, à fibre courte, grossière et comme grenue. Elle s'écrase et se triture facilement sous la dent; elle a une saveur ànre et astringente, jointe à une légère àcreté; elle est inodore. 
mats tempérés, et principalement, en france et en Espagne, sur les côtes de la Méditerranée. Eilles y puisent les éléments des sels à base de soude qu'elles contiennent, tels que l'acétate, le citrate ou l'oxalate. Ces sels décomposés par le feu se convertissent en carbonate. Dans la vue d'en extraire l'alcali, on soumet à la culture quelques espèces de soude, qui sont principalement la soude commune, la soude cultivée et le kali (salsola soda, S. satica et S. liali). Ces plantes, récoltées et séchées, sont brûlées dans de grandes fosses creusées en terre. On en ajoute de nouvelles à mesure que la combustion s'opère, et de manière à l'entretenir pendant plusieurs jours ; alors la chaleur s'élère au point de fritter la cendre et de la réunir en une seule masse. On laisse refroidir, on casse la masse par morceaux et on la livre au commerce.

La soude ainsi obtenue est composée, en différentes proportions, de carbonate et de sulfate de sonde; de sulfure et de chlorure de sodium; de carbonate de chaux, d'alumine, de silice, d'oxide de fer; enfin de charbon échappé à la combustion, el qui donne ì la masse une couleur grise plus ou moins foncée. La meilleure est celle qui nous venait autrefois d'Alicante; on connaissait aussi le salicor' ou sonde de Narbonne et la blanquette ou solde d'Aiguemortes; mais tous ces produits sont presque entièrement remplacés aujourd'hui par la soude urfificielle, obtenue en calcinant dans des fours à réverbère un mélange de sulfate de soude, de craie et de charbon.

Toutes ces soudes fournissent par lixiviation et cristaflisation le carbonate de soude cristallisé ou sel de soude du commerce. Souvent aussi, on fait entièrement dessécher le sel de soude, ce qui en diminue le poids de 60 pour 100 , le volume à proportion, et par suite allège beaucoup les frais de transport et d'emmagasinage. Lnfin, on prépare un sel de soude caustique, en prisant le sel de soude ordinaire de 1/4 ou de 1/3 de son acide carbonique. Il est pulvérulent.

Pour déterminer la valeur réelle de ces différents produits, on emploie aujourd'hui le procédé alcalimétrique de M. Gay-Lussac, qui consiste à déterniner, au moỵen de la saturation par l'acide sulfurique, la quantité de soude pure (SdO) contenue dans 100 parties du produit. Ce procédé se trourant décrit dans tous les ourages de chimie, je me dispenserai de le rapporter ici.

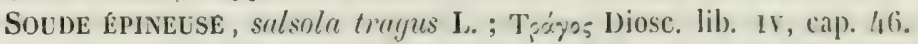
Celte plante croît très abondamment sur les côles de la Manche; elle s'élère à la hauteur de 30 à 45 centimètres, et se dirise en rameaux cỵlindriques et striés, garnis de fenilles charnues, embrassantes, glabres, triangulaires, terminées par une pointe épineuse. Les fleurs sont axillaires, solitaires, pourves d'un périanthe membrancux. Elle est emploréc avec succès contre la gravelle, ce qu'il faut sans doute attribuer à la 
grande quantité de sels qu'elle contient; mais ce qu'il y a de singulier, tant à cause du genre de plantes auquel elle appartient qu'aux lieux qui la fournissent, c'est qu'elle ne contient que des sels à base de potasse et de chaux. Suivant l'analyse que j'ai faite de ses cendres (Journ. rhim. méd., 1840 , p. 128$)$, je les ai trouvées composées de :

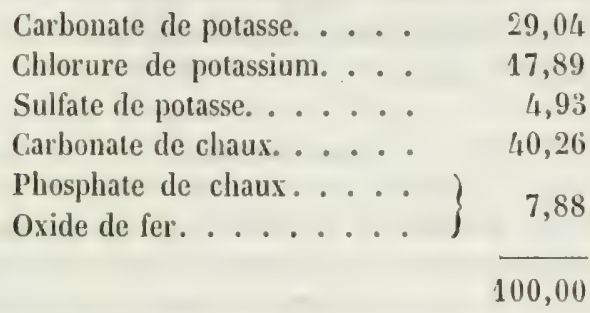

\section{AMARINTACÉES, NYCTAGINEES, PHYTOLACGACÉES.}

Ces trois familles de plantes, qui terminent la classe des dicotylédones monochlanydées ou à périanthe simple, fournissent peu de chose à la médecine. Les amarantacées ont les plus grands rapports avec les chénopodées, et un assez grand nombre sont employées comme aliment, à l'instar de l'épinard : tels sont, dans le midi de la France et de l'Italie, l'amarantus blitum L.; au Brésil, l'ommentus viridens; à la Jamaïque, l'omaramtus spinosus. D'autres ont une vertu laxative marquée; d'autres sont astringentes; mais aucune, excepté peut-être le yomphrena officinalis Hart., et le gompherena macrocephala Saint-Hil., dont les racines portent au Brésil le nom de paratudo (propre à tout), ne paraît jouir de propriétés actives.

Les nyctaginées, qui doivent leur nom au genre nyctugo ou miralitis (belle de nuit), sont généralement douées d'une propriété purgative ou émétique. Plusieurs d'entre elles, telles que le mirabilis jalripa, belle plante cultivée dans nos jardins, et le mirabilis longiflor a, ont même été considérés, pendant quelque temps, comme la source du jalap officinal. Le bocrhaavia hirsuta (erva toustâo Bras.) est employé contre l'ictère, le boerhawia tuberosa contre la syphilis, le boerhania procumbens comme antifébrile et purgatif, etc.

Les phytolaccacées, plantes d'abord réunies aux chẻnopodées, s'en distinguent par leurs étamines alternes avec les divisions du périanthe, par la pluralité des ovaires rangés circulairement autour d'un axe, enfin par la prés nce de principes âcres et drastiques. Le pihytolacer decan$d r(t$, belle plante de l'Amérique septentrionale, aujourd'hui cultivée dans les jardins de l'Europe, purge très fortement; le suc des fruits, 
d'un beau rouge carminé, a été emplosé en Portugal à la coloration des vins, non sans inconvénient pour les consommateurs, et l'usage en a été prohibé. La racine du phujtolacén dirasticre du Chili, purge aussi très violemment; Ies peficria, douées d'une odeur alliacée, sont usitées en Amérique comme antifébriles, diaphorétiques, diurétiques et anthelmintipues. De toutes les plantes ou parties de plantes qui viennent d'être citées, je ne parlerai en particulier que de celles qqui se sont rencontrées dans le commerce.

\section{Raciue de cinaya.}

En 1818, un pharmacien présenta à la société de pharmacie de Paris une racine nommée chuyg, longue de 13 à 16 centimètres, grosse comme de minces tuyaux de plume, torlueuse, composée d'une écorce et d'un ineditullium ligneux, blanchàtre; elle est inodore ct offre une saveur mucilagineuse et légèrement salée. On la disait envovée de la Tartarie chinoise, et l'on donnait à la plante une tige lisse, également mucilagineuse, des feuilles obrondes et cotonneuses, des fleurs à périanthe simple, unisexuelles, à 6 étamines; on supposait qu'elle pouvait appartenir à la famille des asparaginées. Si les caractères sexuels, qui n’ont pu être vérifiés, étaient exacts, il faudrait renoncer à déterminer la plante qui produit cette racine. Mais on lit dans la Flur' indica de Roxburgh, t. II , p. 503, et dans la I/uteria indica d'Ainslie, t. II, p. 394, qu'on vend au Bengale, sous le nom de chungu, la racine mucilagineuse de l'achyrantes lanula Rosb., Ereu lmatn J, amarantacées. Celte racine, au reste, ne parait jouir d'aucune propriété essentielle, et je l'aurais passée sous silence s'il n'élait pas nécessaire de la distinguer du chaya-cangr, racine tincturiale de l'Inde, et de l'ipécacumnka blanc du Brésil, en place duquel clle a élé vendue dans le commerce.

\section{Haclue de Faux-Jalap.}

Virabilis longiflora L., et aussi les mirabilis jalenga el dichotomu. Car. gén. : Involucre caliciforme, campanulé, quinquéfide, uniflore, persistant; périanthe corollö̈de, infundibuliforme, à tube allongé, rentru à la base, persistant, à limbe plissé et à jo dents, tombant; j élamines insérées sur un godel glanduleux qui entoure l'ovaire; filets libres, adhérents au tube rétréci du calice, prolongés alt-dessus et terminés chacun parr une anthère biloculaire; oraire uniloculaire, style simple, stignate en tète; ashose libre, renfermé dlans la base induree du périanthe, et entouré par l'involucre persistant.

Le miralilis julnpa est aujourd'hui cultivé dans lous les jardins, vi 
il forme des touffes d'un heau vert, sur lesquelles ressortent ses fleurs nombreuses, réunies en un corỵmbe serré el d'un rouge foncé, quelquefois aussi jaunes, blanches ou panachées. Cers fleurs ne s'ourrent qu'à la muit et se ferment le matin, ce qui a valu à la plante le nom de brelle-de-mit. Le mirabilis dichotoma, très rapproché du précédent, s'en distingue néanmoins par ses feuilles beaucoup plus petites, par ses fleurs toujours d'un rouge pourpre, bien moins grandes également, presque solitaires et s'épanouissant ara I lia nuit, d'où leur est venu le nom de flours de quatre hempes. Enfin le mirabilis lomgiflora (fig. 186) intéresse par l'odeur donce et musquée qu’il répand pendant la nuit; ses tiges sont longnes de 1 mètre environ, très faibles, divisées en rameaux grêles, pubescents, garnis de feuilles Fig. 186 . opposées, visqueuses, un peu velues, molles et ciliées; les supérieures sessiles. Les fleurs naissent à l'extrémité des rameaux, réunies en une tête épaisse et glutineuse. Le tube du périanthe est fort long, recourbé, velu; le limbe plissé, d'une couleur blanche. Ces trois plantes, mais surtout la dernière, sont pourrues d'une racine pirotante, un peu napiforme, grosse el charnue, presque noire au dehors, blanchâtre en dedans. Cette racine desséchée, dont j'ai vu une fois dans le commerce une partie assez considérable, élait à peu près cy̆lindrique, épaisse de 25 à 55 millimètres, coupée en tronçons de 55 a 110 millimètres, d'un gris liride, plus foncé à l'extérieur el plus pàle intérieurement. Les surfaces extrêmes sont marquíes d'un grand nombre de cercles concentriques très serrés, d'une couleur plins foncée el un peu proéminents. La coupe opérée à l'aide de la scie est polie et presque noire, et marquée des mêmes cercles. La racine est dure, compacte, très pesante, d'une odeur faible et nauséeuse, et d'une sareur douceâtre, laissant un peu d'àcreté dans la bouche. On la dit assez fortement purgative.

\section{Racine de pipi.}

I'etiverin allincen et petiverin tetrandra. La première de ces plantes 
croît dans les prairies, à la Jamaḯpue et dans la plupart des autres îles de l'Amériquue. La seconde croît au Brésil. Toutes deux sont pourvues d'une forte odeur alliacée et produisent des racines ligneuses, fil)reuses, jaunâtres, d'une odenr très forte et désagréable et d'une sareur âcre et alliacée. Ces racines sont très fortement diurétiques, ainsi que l'indiq̣ue leur nom, et usitées contre l'hỵdropisie, la paralysie, les rhumatismes articulaires, etc.

\section{SIXIEME CLASSE.}

Dicotylédones corollifores.

\section{FAMILLE DES PLANTAGINÉES.}

Petite famille de plantes herbacées, sourent privées de tiges et à feuilles toutes radicales, à fleurs hermaphrodites ou unisexuelles, disposées en épis simples et serrés, pourrues d'un calice et d'une corolle à 4 divisions régulières; de 4 étamines et d'un ovaire libre ì 1, 2, ou très rarement 4 loges contenant un petit nombre d'ovules. Le style est capillaire et termine par un stigmate simple ou bifide; le fruit est tantôt un askose, tantôt une pixide biloculaire, à loges mono- ou dispermes; les semences sont courerles d'un épisperme membrancux, it hile ventral ; l'embryon est droit et cỵlindrique, dans l'axe d'un endosperme charnu.

Cette famille nous présente, dans le genre j!!mutago, quelques plantes autrefois très usitées, aujourd'hui presçue tombées en désuélude. Ces plantes sont les plantains et les psyllium.

\section{Plantains.}

Les plantains ont un calice it 4 divisions persistantes; une corolle gamopétale tubuleuse, persistante, a limbe quadripartagé. Lees filets de's étamines sont plus longs que la corolle, surmontés d'anthères horizontales. Le stỵle est plus court que les étamines et terminé par un stigmate simple. On emploie indiffércmment trois espèces de plantain, it savoir :

Le garand plantain, plentugn mujor, offrant des fenilles radicales grandes, coriaces, presque glabres, ovales, rétrécies en pétioles, marquées de 7 nerrures saillantes, sourent sinmées sur les bords. La 
hampe dípasse la longueur des fenilles; elle est cylindrique, un peu pubescente et porte un épi droit, long, cylindrique, étroit, composé de fleurs serrées, rerdàtres ou rougeâtres. La capsule pixidéc est divisée en deux loges par une cloison longitudinale, rui porte plusieurs graines rougeâtres sur chaque face.

Le plantain moyen, plantagn media, a le port du précédent, dont il diffère par ses feuilles relues et par sa capsule qui ne contient qu'une graine clans chaque loge.

Le plantain bancedé, plontrngo lancenluta, a les feuilles étroiteslancéolées, amincies aux deux extrémités, ordinairement velues et à 5 nerrures; les hampes sont anguleuses, pubescentes, terminées par un épi brun, orale el ramassé. Ces trois plantes sont communes dans les jardius, les champs et les prairies. Leurs fenilles sont inodores, amères et légèrement styptiques; les fleurs possèdent une odeur douce et agréable. L'eau distillée de la plante entière était anciennement très usitée dans les collyres.

\section{Semences de psyllium.}

Plantrigo psyllium I. Cette plante diffère des précédentes par sa tige rameuse, haute de 16 à 29 centimètres, munic de feuilles opposẻes, linéaires, quelqquefois dentées. Les fleurs sont rćunies en capitules ovoüdes, munis de bractées très courtes; les divisions du calice sont lancéolées-aiguës; les fruits sont des pixides à 2 loges polyspermes; les semences sont très menues, oblongues, d'un brun noir, lisses et luisantes d'un côté, creusées en nacelle du côté du hile, ayant quelque ressemblance d'aspect arec des puces, ce qui a valu à la plante le nom d'herbe aux pues. Ces semences contiennent dans leur épisperme un principe goumeux, susceptible de se gonfler considérablement dans l'eau, qui leur donne une propriété très émolliente. On en faisait autrefois usage et on pourrait les employer tout aussi utilement aujourd'hui dans les ophthalmies inflamma'oires, l'irritation des voies intestinales, etc.

Plantain des salles, jlantrigo "renuriu Waldst. Cette plante, longtemps confondue arec la précédente, en diffère par sa tige plus rameuse et plus élevée; par ses capitules plus allongés, munis de bractíes deux ou trois fois plus lungues que les calices, dont les divisions sont dilatées au sommet, membrancuses ei très obtuses; les graines sont oroïdes. Il paraît que les négociants de Yimes et de Montpellier en font un commerce assez ćtendu, pour le gommage des mousselines.

FAMIILL: DES PLUMBAGINÉES.

Famille de plantes herbacées, ì feuilles alternes, quelquefois toutes 
réunies à la base de la tige el engainantes. Les fleurs sont réunies en tête, ou disposées en épis ou en grappes rameuses et terminales. Le calice est tubuleux, persistant, à 5 divisions; la corolle est tantô! gamopétale et pourrue de 5 élamines hỵpogines, comme dans les raies plumbaginées; tantôt formée de pétales ígaux, légèrement soudés à la base, et portant sur les onglets 5 étamines opposíes aux pétales, comme dans les staticées. L'ovaire est libre, à un seul ovule anatrope, pendant au sommet d'un podosperme filiforme, partant de la base de la loge. L'ovaire est terminé par un stỵle dirisé en stigmates (plumblugo) (on par 5 styles, pourvus chacun d'un stigmate simple, filiforme, glanduleux (statice). Le fruit est monosperme, enveloppé dans le calice persistant; tantôt il est indéhiscent (askose), se séparant du réceptacle par déchirement (statice); tantôt il est capsulaire et s'ourre supérieurement en 5 valves (plumbago). La semence est inverse mais simule souvent une semence droite, par la soudure du troplosperme avec le péricarpe. L'embryon est orthotrope, an milieu d'un endosperme farineux; radicule supère. .

Cette petite famille, comme on le voit, se divise nettement en deux tribus, qui empruntent leur nom de leur principal genre, statire et plambago, dont les propriétés sont aussi très distinctes; les stotice sont pourvus d'une astringence très marqueie; les plumbagyo sont juresque caustiques. Quoique ces plantes soient aujourd'hui presque oubliées, nous en mentionnerons deux le behen rungre et la dentelaire d'Eurrype.

\section{Behen rouge.}

Les Arabes et les Grecs du moyen âge ont employé, sous le nom de behen, deux racines différentes. L'une appelée brhen blunr, pouvait être longue el grosse comme le doigt, d'un gris cendré à l'extérieur, blanchâtre en dedans, d'un goût un peu amer (suirant d'autres, ìcre et odorante). Cette racine a toujours été attribuée au renturentrehen I., de la grande famille des synanthérées et de la tribu des carduacées; mais comme elle était originaire de la Perse et fort rare, on lui substimait celle du behen nostress ou curubulus luhen, plante de la famille des caryophỵllées, à calice renflé, qui croît dans nos champs. L'autre espèce de behen était le brhene rmuge, que l'on décrivait comme une racine sèche, compacte, d'un ronge noirâtre, complée en morceaux comme le jałap, un peu styptique et aromatique. On l'auribuait généralement au stutice limonium L., plante qui croit dans les prairies humides, roisines de l'Océan et de la Méditerranée. Cette racine était tout à fait oubliée du commerce, et je ne pense pas qu'ancun clroguiste de notre àge en êt vu, lorsque, il y a quelques années, on importa à Marseille, de 
Taganrog, ville russe, à l'embouchure du Don, et sous le nom de kermis, 800 kilugrammes d'une racine rouge et ligneuse qui n'est autre chose que le liutran ronge de Pallas (t. V, p. 170), usité pour le tannage des peaux, et attribué par lui à un statice voisin du limomium; cette plante est le stutier lntifutin de Smill. En rapprochant toutes ces circonstances, il me parait à peu près certain que ce katran rouge de Pallas est le vrai behen rouge des anciens, dont voici alors les caractères plus précis.

Racine ligneuse, pivotante, cylindrique, longue de 30 à 40 centimètres, épaisse de 2 à 3 , terminée par le haut par plusieurs collets viraces, qui portent alternativenent d'un côté et de l'autre, la cicatrice des tiges annuelles. L'écorce de la racine est très compacte, d'un rouge brun foncé, épaisse de 2 à 3 millimètres, et a dù être succulente. Le cœur est ligneux et à structure rayonnante. La surface de la racine est marquée, surtout à la partie supérieure, de stries circulaires qui, à partir du collet, deviennent des sillons circulaires profonds et réguliers. Cette racine possède une saveur très astringente avec un Fig. 187. goût particulier qui se rapproche de celui du tabac. Elle fournit avec l'eau une liqueur rouge qui précipite fortement le fer et la gélatine. Cette racine serait donc très propre au tannage et à la teinture en noir.

\section{Hacine die Dentelaire.}

\section{Plumbago europera L. (fig.} 187). Cette plante croît dans le midi de la France; sa tige est ronde, cannelée, glabre, haute de 65 centimètres; ses feuilles sont oblongues, amplexicaules, chargées de poils glanduleux sur leurs bords;

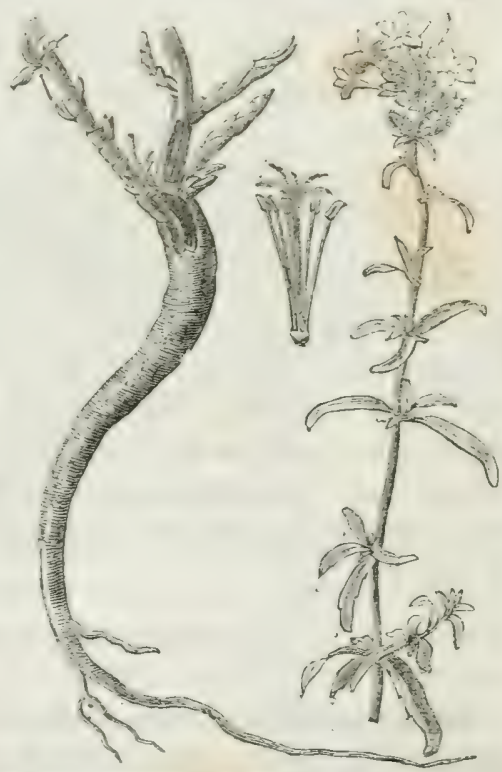
d'une sareur brûlante. Les fleurs sont purpurines ou bleues, ramassées en bouquets au sommet de la tige et des rameaux; elles sont pourvues d'un calice persistant à 5 divisions, hérissé de poils glanduleux; d'une corolle tubulée, à limbe étalé et quinquéfide; de 5 étamines à filets ćlargis inférieurement et insérés sous l'ovaire; d'un style aussi long que 
le tube de la corolle, et terminé par un stignate quinjuéfide. Le fruit est un askose enceloppé par le calice.

La racine de dentclaire est longne, pivotante, blanclie, d'une saveur caustique. Par la dessiccation, elle conserve en partic sa causticité, prend une teinte rougeàtre, et parait formée d'une écorce ridéc longitudinalement, qui s’isole en partie d'un méditullium ligneux, trìs épais, à fibres rayonnées. Céte racine, conservée dans un bocal fermé, arec une étiquette de papier, offre le singulier phénomiene de faire prendre au papier une couleur rougcâtre plombćc, qui parât due ì l'action de l'air sur un principe volatil échappé de la substance. I.a plante, écrasée entre les doigts, lcur communique la même conlen. plombée, ce qui lui a valu le nom de plumbreno, et celui de molylidéne, qui, en grec, signifie la même chose. Le nom de dentelnire lui vient de la propriété qutelle partage avec d'autres substances très âcres, de calmer souvent la duuleur des dents; on l'appelle aussi mullucrle ou manurise herbe.

Ia racine de dentelaire était employée autrefois comme émétique, mais son effet était incertain et dangereux. On l'emploie aujourd'hui avec plus de succès, à l'extérieur, contre la gale.

11. Dulong, pharmacien à Istafort, est parvenu à jso!er le principe âcre de la dentelaire, en épuisant la racine par l'éther ; ce liquide, évaporé, latise une matière grasse, de conleur nuiràtre, que l'on traite par l'eau bouillante. L'eau prend une coulenr jaune, et dépose, par le refoidissement, des flocons james, qui, repris par l'alcool, cristallisent arec facilití. Cette matière est sous la forme de petits cristaux aciculaires, d'un jaune orangé, font peu solubles dans l'eau froide, plus solubles dans l'ean bouillante, très solubles dans l'élher ct l'alcool, n'offrant ancun caractère acide ou alcalin, fusibles à une douce chaleur, et se volatilisant sans altération à une température un pen plus derée. Les acides n'en changent pas la couleur et u'en facilitent pas la solution dans l'eau; les alcalis, au contraire, la dissolrent facilement et lui donnent une couleur rouge-cerise. (Journ. de phur'm., 1. XIT, p. $25 \%$.)

\section{FAMILLE DES PRIMULACÉES.}

Plantes herbacées à feuilles tontes radicales, comme dans les primevères, ou bien opposées et mème quelquefois rerticillées sur la tige (lysimachie), rarement alternes. Fleurs completes, régulières ou un peu irrégulières, tantòt solitairess on ombellées à l'extrémité d'un hamp̣e, tantôt solitaires dans l'aisseclle des fruilles, ou en grappes axillaires ou terminales. Calice gamosépate, ordinairement libre et à 5 disisions; 
corolle hypogyne (pirigrne dans le genre smbolus), gamopitale, à 4 lobes alternes arec ceux du calice, a prélluraison imbriquie ou contourné; étamines insérées au haut du lube de la corolle ot opposées en nombre égal à ses divisions, sourent accompagnées d'un même nombre d'étamines stériles, alternant arec ces mêmes dirisions. L'oraire est libre (demi-soudé dans le genre sumolus), uniloculaire, à orules nombreux attachés it un trophosperme central. Le stỵle et le stignate sont simples. I.c fruit est une capsule uniloculaire et polvsiperme, s'utvrant en 3 ou 5 valres (primerère et lysimachie), ou une pyxide operculée (ammgullis). I.es graines offrent un embryon cỵlindrique placé transversalement au hile dans un endosperme charnu.

Les primulacées sont inusitées aujourd'hui en médecine, quoiqgu'elles soient génélalment douécs de propriétés aclives. La primevère

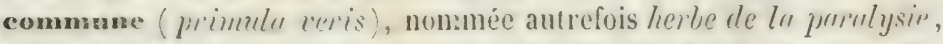
présente dans sa racine une forte odeur d'anis, due à une essence qu'on peut en retirer par distillation, et une substance amère analosne a la sénégine. L'oreille-d'ours, originaire des Alpes, ! est recommandée contre la pluthisie, mais est bien plus connue par l'élégance de ses fleurs et par les imnombrables variétés que les horticulteurs en ont obtenues. Les denx monrons, rouge et hicu ( anurgallis phernicen et (111. ceruleri), sont des plantes nausceuses, amcires el douées d'une certaine âcreté, qui ont été usitées autrefois contre l'atonic des viscères, l'hydropisie, la manie, l'épilepsie, et que le peuple des campannes regarde encore aujourd hui et sans aucune raison, comme un remede contre la rage. Il ne faut pas conlondre ces deux plantes, qui sont un poison pour les oiseaux, arec la morgeline (nlsine media, caryogh hillés, dont on rend une si grande quantité à Paris, sous le nom de muron dies viseaux, qu'on estime à 500000 francs la somme que la classe peu aiséce dépense annuellement pour ce seul objet.

\section{Racine de Gyelane ou de Pain-de-Pourceau.}

Cyclamen curopecum L., arthemitu off. (firg. 188). Cette plante pousse de sa racine de longs pétioles qui portent des feuilles presq̣ue rondes, marbrées en dessus, rougeâtres en dessous. Il s'élère parmi de longs pédoncules qui soutiennent de petites fleurs purpurines, d'une odeur agréable. Ces fleurs sont formées d'un calice persistant, à 5 divisions; d'une corolle hypogyne, à tube court, épaissi à la gorge, à limbe réfléchi parıgé en 5 divisions égales, plus longues que le calice. Les 5 ćtamines sont connirentes par leurs anthères; le style est terminé par un stigmate aign ; le fruit est une capsule charnue, polysperme, à 5 valves. La racine de cyclame est virace; elle a la forme d'un pain orbiculaire oplati; elle est brune au dehors, blanche 
en dedans, garnie de radicules noirâtres. Elle a une sareur âcre et caustique. Geofroy, dans sa Iatiere médicule, annonce qu'elle perd toute son âcreté par la dessiccation; cela jeut arriver quelquefois, mais

Fig. 188.

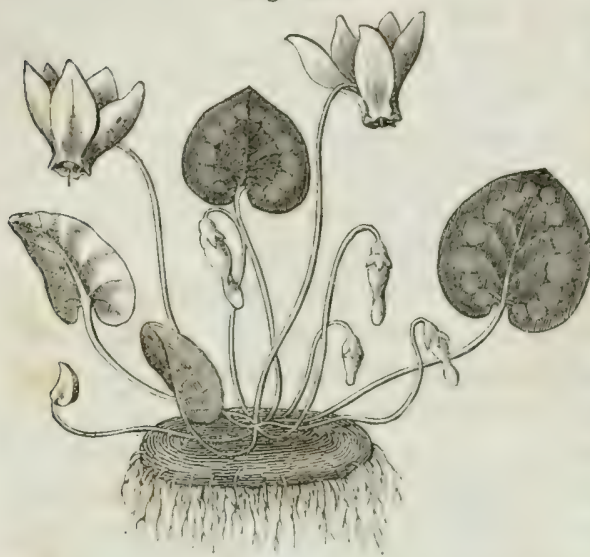

celle que j'ai jouit encore d'une saveur vraiment insupportable. Elle est émétique, purgative et hydragogue, même appliquée extérieurement. Malgré des propriétés si énergiques, cette racine est peu employée maintenant, peutêtre à cause du danger et de l'inconstance de ses effets. C'est elle qui donnait autrefois son nom à l'onguent d'ar'-

thamita. Quant au now de prin-dr-poureern, il lui est renu de sa forme et de la recherche que les porcs en font pour leur nourriture.

\section{FAIILLE DES GLOBULARIEES.}

Cente petite famille est formée par le seul genre globuloria, dont les

lig. 189.

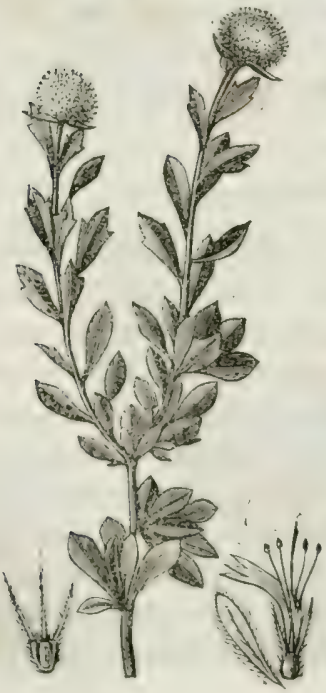

espèces peu nombreuses appartiennent à l'Europe méridionale et tempérée, ainsi qu'aux îles de l'océan Atlantique. Une des espèces les plus connues est celle qui porte le nom de globulaire inrbith, globularia alypum L. (fig. 189) ; c'est un arbrisseau de 60 à 100 centimètres de haut, dont les feuilles sont glabres, lancéolées-ovées, aiguës, rétrécies en pétiole à la base, entières on munies de une ou deux dents au sommet; les fleurs sont bleuâtres, réunies en capitules pourrus d'un involucre polyphylle, et sont portées sur un réceptacle paléacé; le calice de chaque petite fleur est à 5 divisions et persistant; la corolle est monopétale et a deux lères, dont la supérieure est presque nulle; le fruit est un askose ovoïde entouré par le calice. 
La gglobulaire-turbith croît dans le midi de la France; on hui avait attribué des propriétés dangerenses, qui lui avaient fait donner le nom de frute terribilis; mais il a été reconnu, surtout par II. Loiseleur-Peslonchamps, que ses feuilles formaient un purgatif plus doux que le séné, moins désagréable, et qu’elles pouvaient très bien lui être substituces, ì dose double. Elles ont tue saveur âcre, très amère, sont privées d'odeur nausécuse, et forment avec l'eau un infusé transparent, légèrement verdâtre.

\section{FAMILLE DES IABIÉES.}

Les labiées forment une des familles les plus naturelles du rìgne végétal; elle comprend des plantes herbacées ou des arbrisseaux à rameaux opposés ou verticillés et tétragones; les feuilles sont opposées on rerticillées, entières ou divisées, privées de stipules. Les neurs sont complètes, irrégulières, groupées aux aisselles des feuilles súpérieures, et forment, par leur rapprochement, des épis ou des grappes rameuses. Leur calice est gamosépale, tubuleux, à j dents inégales. La corolle est inséréc sur le réceptacle; elle est gamopétale, tubuleuse, irrégulière, orlinairement partagée en 2 lères, l'une supérieure, l'autre inférieure. Les étanines sont au nombre de 4 et didynames, sauf dans un petit nombre de genres dans lesquels les denx étamines courtes avortent ou manquent complétement. L'ovaire, porté sur un disque charnu, est profondément divisé en 4 lobes, très déprimé au centre, d'où s'élève un style simple surmonté d'un stigmate bifide. L'ovaire, coupé en travers, présente 4 loges contenant chacune un orule dressé. Le fruit est un askosuive formé de 4 askoses ( royez pagres 21 et 27 ) contenus dans l'intérieur du calice persistant; askoses dressés; embryon droit, entouré d'un endosperme très mince, qui disparaît sourent complétement.

Les labiées sont en très graude partie des plantes très aromatiques et riches en huile volatile; aucune n'est vénéneuse; la bétoine seule présente une àcreté assez marquée qui l'a fait employer comme sternutatoire. Il cn est peu qui, à une époque ou à une autre, n'aient été usitées en médecine. Je me bornerai à décrire les principales.

\section{Basilics.}

Genre orimum : calice ové ou campanulé à 5 dents, dont la supérieure plus grande, plane et orbiculaire; corolle à tube court et à 2 lèvres, dont la supérieure est quadrifide et l'inféricure, à peine plus longue, plane et cnticre, abaissie; 4 ćlamines penchées, les inférieures plus longrnes, les 
superiemes appendiculeres at la base d'une dent on d'un faiscenu de poils ; style courtement bifide an sommet; 4 askoses pelis.

I.es basilies sont exotigues et la phupart viement de l'Inde. Cee sont des herhes ou de pelits arbrisseans pourus de feuilles simples et donés d'une odeur pénétrante et sourent très agréable. Les deux espèces les plus communes sont :

I.e wrand basilie, orimum lusilirum, I., très cultivé dans les jardins, haut de 15 it 20 centimètres, muni de tiges légìrement volues, de fenilles pétiolées, ovales, lancéolées, un peu ciliées et un peu dentelées sur le bord; les fleurs sont blanches, purpurines ou panachées, disposées en verticilles peu garnis, accompagnées de braclées rerles ou pourpres: les calices sont ciliés ou barbus.

Le potit basilie, ocimun minimun, L., cultivé dans des pots sur les fenêtres et les cheminées; il forme, par ses ramifications, une jolie boule de verdure, chargée de feuilles nombreuses, aignës ou obtuses, un peu épaisses, vertes ou rougeàtres; les fleurs sont pelites et blanches.

\section{Lavautes.}

Car. gén. : Calice ové-tubuleux, strié, à 5 petites dents presque égales; la dent supérieure tantôt un peu plus large cependant, tantôt augrmentéc au sommet d'un appendice dilaté; tube de la corolle plus long que le calice, dilaté à la gorge; limbe obliquement bi-labié, à lèrre snpéricure li-lobée, l'inféricure à 3 lobes, tous les lobes presque égaux ct ourerts; 4 étamines recourinées, les inféricures plus Inngues; filets glabres, libres, non pourvus de dents; anthères ovées-réniformes, confluent s, uniloculaires; style courtement bifide an sommet, à lobes aplatis. Askoses ghabres, lisses, attachés aux quatre écailles concaves du discrue.

Trois espèces de larandes sont surtout usitées :

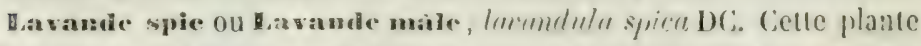
offere une sonche ligneuse, disiser en rameaux dressi's: les uns courts, steriles, persistants; les autres Jongs, ferbiles, anumels, hauts de 60 a 100 centimètres. Le's fouilles sont linéaires-élargies, longues de 55 à 80 millimetres, larges de 6 ì 12, à bords roulés en dessous; elles sont courertes des deux côtés d'un duret trìs court et blanchàtre; les tiges florales sont tres peu fetillées, termincés par un ipi assez long, sourent recourbe an sommet; les bracties qui accomplagnent les fleurs sont linéaires, snbulées; Ies caliers fortement striés, à proine cotonneux; les corolles sont blenes, queldruefois blanches par variété.

Ia lavande spic croit en Afrigue, en sicile, en Italie et dans le midi de la france: toutes ses parties cxhalent une odeur forte, mais agréable, due a une huile rolatile quion extrait dans les lieux mèmes où on lat 


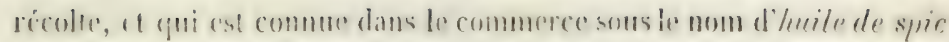
ou d uspur. Lille est très usitie en peinture, sourent mélangée d'essence de téréhenthine.

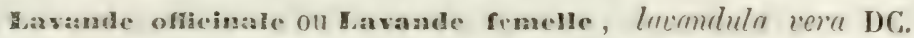
Celte plante ressemble beaucnup à la précédente, et Linné n'en avait formé qu'une seule espèce, sous le nom de larmelula spica; elle diffère le la première, cependant, par ses fenilles tout à fait linéaires, plus étroites et moins blanchattres; par ses épis courts, droits, maigres et à verticilles interrompus; par ses braclées orées-rhomboil lale's, acuninées; par ses calires converts d'un duret abondant; enfin par ses corolles deux fuis plins grandes que le calice, pubescentes en dehors. Elle craint moins le froid que le spic, el c'est elle que l'on cultive surtout dans les jardins du Yord, wù elle sert sourent à former des bordures. Jille a une odeur moins furte el plus agréable que la précédente, et on la préfère pour la préparation de l'atconlat de lavande qui est si généralement employé comme eau de toilette.

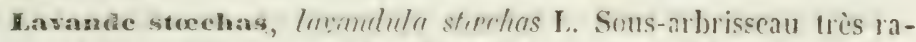
meux, s'élesant à la hauteur de 60 à 100 centimitres; fenilles sessiles, oblongues-linćaires, longrues de 14 millinidres, cotonneuses, blanchittres, à bords roulís en dessous; fleurs d'un pourpre foncé, resserrées en épis denses, ovales-oblongs, et accompagnées de bractées cordiformes, acuminces, cotonneuses; les braclées supéricures, privées de leurs feurs arortées, forment un faisceau de petites fenilles colorées au-dessus de l'épi.

Les fleurs de stoechas, qui sont la seule partie usitée, nous venaient

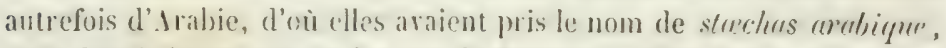
mais depuis lenglemps on le's tire de P'orence. Elles somt sous la forme d'épis denses, ovales ou ciblongs, comme écailleux, d'un violet pourpre rt blanchatre, d'une odeur forte et térébinthacée, d'une sareur chande, ice et amere. Elles fournissent une assez grande fpumtite

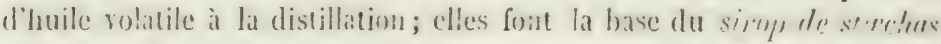
compose.

\section{Patchouly.}

Vers l'annéc 1825, on a commencé à impronter en France, sous le nom de pretchonly (1), une plante de l'In le, dessichée el grossièrement hachée, que ses tiges carríes, ses fenille's opposées et fortement odorantes, ont faciement fait reconnaître pour une labiée. On a supposé d'abord qu'clle n'élait autre que le plectranthus momuticus de lioxburgh (colens aromatirus Benth., coleus mubrinicus Lour., marru.

(1) Som corrompu de patciey elley ou feuilles de paténes. 
bium ulbum amboinicum Rumph.), plante voisine des basilics et thès aromatique, usitée comme telle depuis l'Inde jusqu'aux île's Moluçues; mais en 1844 , le patchouly ayant fleuri dans les serres de II. VignatParelle à Ortéans, fut reconnu par M. Pelletier pour appartenir au genre poyostemon, assez voisin des menthes, et fut décrit par lui sous le nom de poyostemon patchouly. Cette plante a les tiges ligneuses à la base, les feuilles longuement pétiolćes, ovales-aiguës, grossierrement dentées; un peu cotonneuses comme les tiges; les épis, qui manquent toujours dans le patchouly du commerce, sont terminaux ou axillạires, longuement pédonculés. Le patchouly n'est guère employé que pour préserver les hardes et les fourrures de l'attaque des teignes. Son odeur est tellement forte que beaucoup de personnes ne peurent la supporter.

\section{Menthes.}

Les menthes se distingnent des autres labiées par la régularité presgue complète de leurs fleurs. Le calice est tubuleux on campanulé, à 5 dents presque égales; la carolle est très courte, à limbe campanulé presque régulier, à 4 lobes dont le supérieur est un peu plus large et ordinairement échancré ; les étamines sont au nombre de quatre, presque égales, dressées, écartées les unes des autres; les filets sont glabres ct nus; les anthères sont biloculaires, à loges parallèles; le stỵle est courtement bifide au sommet; les askoses sont secs et polis. Les espèces en sont très varuables et difficiles à déterminer. Voici les plus communes et les plus usitées.

Menthe sauvage, mentha sylvestris L. Tige droite, rameuse, haute de 30 à 50 centimètres, cotonneuse ainsi que toute la plante; feuilles sessiles, oblongues-lancéolées, inégalement dentées, blanchâtres; verticilles de fleurs rapprochés en épis allongés, au sommet de la tige et des rameaux; fleurs d'un rouge clair, étamines plus longues que la corolle.

Menthe a feuilles rondes ou menthastrum, mentlin intuntifirlin L. Tige droite, haute de 30 à 50 centimetres, cotonneuse; feuilles sessiles, ovales-arrondies, ridées en dessus, cotonneuses en dessous, dentées; fleurs blanches ou d'un rouge très clair, disposées en épis denses, souvent interrompus à la base; les élamines sont plus longues que la corolle; les dents du calice sont très courtes.

Yenthe verte menthe de Votre-Dame, menthe romaise, mitha rividis L. Tige droile, glabre comme toute la plante, garnie de feuilles lancíolées, sessiles, bordíes de dents écartíes; fleurs purpurines, nombreuses à charue verticille, et disposées en épis allongés. 
Les étamines sont plus longues que la corolle ; dents du calice linéairessubulées.

nenthe poisace, mentlue piperita I. (fig. 190). Tige ascendante, rougcâtre, très glabre ou munie de poils très rares; feuilles d'un vert foncé, très glabres ou ciliées sur les nervures de la face inférieure; elles sont pétiolées, ovalesaiguës ou ovales-lancéolées, dentées en scie; les fleurs sont purpurines, nombreuses à chaque verticille, formant à l'extrémité des tiges des épis obtus, inter-rompus à la base; les calices sont striés, glanduleux; les étamines sont plus courtes que la corolle.

Menthe erépue, mentha crispa $\mathbf{L}$. Feuilles sessiles, cordées, ondulées, bordées de grandes dents inégales; fleurs d'un rouge très clair, formant un épi allongé, non interrompu; calice très velu à dents presque égales à la corolle; étamines incluses.

Fig. 190.

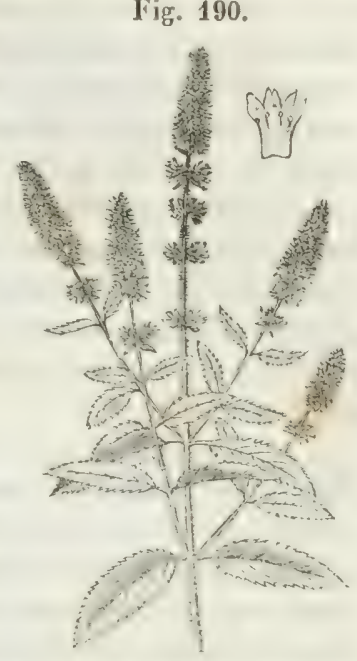

Henthe aumatique, mentha armutica I. Tigge hérissée de poils réfléchis ; feuilles pétiolées, orées, arrondies à la base, pointues à l'extrémité, glabres sur les deux faces; rerticilles peu nombreux ( 2 ou 3 ) réunis en une tête oblongue, ou le plus inférieur distancé; fleurs d'un pourpre pâte; calices et pédicelles velus. Étamines plus longues que la corolle, arec des anthères d'un pourpre plus foncé. Cette plante croît en Europe sur le bord des ruisseaux.

La menthe velue, mentha hirsuta L., n'est qu'une variété de la menthe aquatique à feuilles velues.

Menthe des champs, mentha arwensis I. Tiges diffuses; feuilles ovées-aiguës, dentées, velues; fleurs en rerticilles axillaires et séparés; étamines égalant la longueur du limbe de la corolle.

Mentåc cultivé, mentha sativa L. Feuilles pétiolées, ovales, pointues, dentées, ou rétrécies aux deux extrémités, rugueuses en dessus; fleurs verticillées, étamines plus longues que la corolle.

Nearthe bauare on hamme des jardins, mentha gentilis L. Racine traçante et produisant des jets qui s'étendent au loin; tiges hautes de 50 centimètres, rougeâtres, un peu relues, très rameuses; feuilles pétiolées, ovales, pointues, dentées; Пleurs disposées en verticilles dans les aisselles des feuilles supérieures, purpurines, à élamines renfermées dans le tube de la corolle; calice glabre à la base, ainsi que les pédicelles. 
Cente plante croît sur le bord des fossis, ct près des puits dans les jardins. Elle possède me odeur forte ct agréable analogue à celles du basilic et de la mélisse mélangées. M. Bentbam fait de cette plante et de lia précidente de simples variélés du mentha revensis; ce rapprochement arait déjà été indiequé par d'autres botanistes.

arentse pouliot ou ponliot vugarire, menthr puleginu L. Tige presque cylindrique, pubreccute, trìs rameuse, couchée à sa base, longue de 15 à 35 centimetres, garnie de futilles ovales, obtuses, à peine dentées, assez semblible's à celles de l'origan. Les fleurs purpurines et disposées par verticilles épais, occupent une grande partie de la longueur des tiges. Cette plante croil dans les lieux incultes, sur le bord des marais et des ćlangs. Elle est pourve d'une odeur très pénétrante et d'une saveur très âcre et très amere. Son suc rougit fortement le tournesol.

Presque toutes les espèces de menthe ont été usitées en médecine. Aujourd'hui la menthe poirrée est presque la seule employée. Elle possède une odcur très forte et une sareur aromatique accomparnée d'une grande fraicheur dans la bouche. Elle est tellement chargée d'huile volatile qu'elle incommode les renx à une grande distance; anssi en prépare-t-on un liydrolat très odorant et très at tif; les feuilles et les fleurs font partie d'mu grand nombre d'autres préparations de pharinacie.

L'essence de menthe fuit la base des pastilles et des tabletles de menthe; la plus estiméce est préparée en Angleterre; les Etats-Lnis d'Amérigue en fournissent au-si une très grande gunantité au commerce, mais qui est moins suare que colle d'Ingleterre; celle preprate en lrance a toujours un gout désagréable, qui tient de la menhe cripne. On attribue la supériorite de l'rssence d'Angleterre au soin que l'on prend de détruire toutes les autr's espèces de menthe qui croissent dans les contries où l'on cultive la menthe poirrée, afin d'empêcher l'abatardissement de l'espèce; ce soin est tout à fait négligé en lirance. La menthe poivrée passe d'ailleurs pour être originaire d'Angletere, et il e'st certain gue les anciens botanistes du continent, tels que les frères Bauhin, Geoflerọ, ('tc., n'en font pas mention; mais il serait possible gu'elle ý cût été importée d'.lsie. Je suis cerlain an moins que c’est un médicament très usité en Chine, l'aỵant tronvée dans une collection de 84 medicaments les plus usuels de la Chine, wi elle cat momme lin (smo. Ie poulig̨t fait partie aussi de la même collection, sous le nom de pou hó ou de po ho.

L'essence de menthe poirrée contient an moins trois principes immédiats : un rilerroptine on e'ssence liquide, un strumptime on essence solide "l cristallisable, une buile gralsse susceptible de rancir; con ha rectiliant 


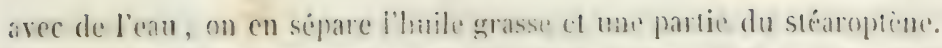
On en retire alors une e'ssence tris fluide, incolore, légere, dn goùt le plus pur, d'une pesanteur spécificue de 0,599 , bouillant it 190 degrés, composée de $\mathrm{C}^{20} \mathrm{H}^{19} \mathrm{O}^{2}$.

L'essence de menthe d'Amérique se congèle presçn'à zéro; rectifiće lentement et en fractionnant les produits, le dernier produit est si chargé de stéaroptine qu'il se convertit, à la temipérature ordinaire, en magnifiques cristaux primatigues. Ce stearoptène foud a $34^{\circ}$ et bout a 213 ; il possède à un haut degré l'enleur et la sareur de la menthe; il est composé de $\mathrm{C}^{20} \mathrm{HI}^{20} \mathrm{O}^{2}=\mathrm{C}^{20} \mathrm{H}^{18}+2 \mathrm{II} \mathrm{O} ; \mathrm{C}^{20}$ II $^{18}$ représentant le menthine, hychure de carbone liquide que l'on ubtient en traitant le stéaroptène par l'acide plsosphorique anhydre.

\section{Origans.}

Car. gén. : Fleurs environnées de bractées imbripecées, formant des épis tétragones. Calice oré, campanulé, a 5 dents igales, ou bilabié; corolle tubulcuse à deux lèvres, dont lia supérieure est échancrée ou lígèrement bifide; l'inférienre est plus longue, écartie, trifide; les yuatre étanines sont ascendantes et écartíes; le stigmate est it deux lobes dont le postérieur est sotrent plus court.

Oriman valgaire, mignemm inlgme I. Tiges pubescentes, sourent rougeâtres, hautes de 2! a 10 centimètres, rameuses seulement dans le haut, gamiı's de feuilles ovales, pétiolces, un peu velues en dessous. Le's fleurs sont purpurines, quelgurfois blanches, disposies au sommel des liges en épis courts, rapprochés en corymbe; les bractées sont orales, d'un rouge violet, phus longnes que les calices qui sont un pen hérissés, i j dents imales, fermes par des poils après la floraison. Cette plante est commune en France, dans les bois secs et montueux. Elle est tries aromalique, tonique et excilante.

Marjolaine vagaire, migenum mojomun L. Plante anmulle, haute de 25 centimètres, à tiges grêles, ligneuses, un peu relues ct rougeàtres, ramiliées, garnies de feuilles elliptiques-obtuses, chilières, pétiolées, blanchàtres, d'une odeur pénétrante, d'une saveur un peu âcre, un peu amère et aromatiçue. Les liges portent à la partie supérieure, dans les aisselles des feuille's, des épis très courts, arrondis, réunis trois à trois, formés de bractíes serrées, blanchattres, disposies sur quatre rangs.

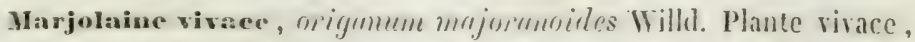
dont la tige est plus ligneuse que dans la précédente, les fenilles plus petites, plus cotonneuses et encore plus arematifues. Du reste, ces denx épèces sont fortement excitautes et leur poudre est sternutatoite. 
Dietame de crete, migrmum dirtammes L. Tiges diffuses, rou geattres, hautes de 25 it 30 centimetres, garnies de feuilles orales-arrondies, pétiolées, grandes comme l’ongle du poure, et tontes courertes d'un duret cotonneux, épais et blanchàtre. Les fenilles supérieures sont arrondies, sessiles, glabres, sonrent rougeâtres, ainsi que les bractées, et chargées les unes et les autres de nombreux points glanduleux. L.es bractées sont longues de 7 ì 9 millimètres, rougeàtres, disposées cul épis lâches et penchés.

Cette plante, très célébréc par les anciens pour la guérison des blessures, crôit principalenıent dans l'île de Crète ou de Candie; clle possède une odeur très fragrante et très agréable, et une saveur âcre et piquante. Elle entre dans l'électuaire diascordium et dans la confection de safran composée.

Origan ale Toumefort, origmum Toumefortii Ait. ?. M. Menier a bien voulu me faire part, celte année, d'un échantillon d'une plante sans indication de nom ni d'origine, mais possédlant une très forte odemr de dictame de Crète. Cet échantillon ne complend guère que les dernières sommités de la plante, incisées. Less épis sont rougeâtres, assez longs, prismatiques, droits ou recourbes, plus denses que cenx du dictame de cirte. Les feuilles son cordiformes, tries petiers, sersiles, toutes convertes de points glandulenx, ainsi que les bractées, et cilices sur le bord; les tiges sont ronges, carrées, in pen ciliées; quelques feuilles inférieures sont plus grandes que les autres, cordiformes, à nervures très apparentes et pétiolées. Ce dernier caractère est le seul

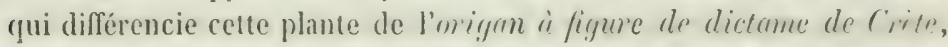
trouvé par Tournefort daus l'ile d'Imorgosos. Elle ne me paraît pas être inférieure en propriété au véritable dictame de crète.

\section{Thyms.}

Car. gén. : Calice strié, fermé par des soies pendant la maturité; i 2 lères dont la supéricure à 3 dents et l'inferieure bifide. Corolle à 2 levres, la supérieure plane et échancrée, l'inférieure à 3 lobes dent celui du milieu plus large. Pelites plantes ligneuses, très aromaticue's, souvent blanchâtres, à fenilles petites, très entières, reineuses, it hords souvent roulés. Verticilles paucillores, tantot tons distancis, tantot ranprochés en petits épis làches, denses ou imbriquées.

Thym vuigaiser, thymmes melyriris L. Tiges droites ou ascendantes; feuilles sessiles, très petiles, ovées-lancéolées aiguies ou linéaires, blanchitres, à bords roulés en dessous; retticilles rapprochés au sommet des rameaux. Cetle plante est commume sur les collines sèches dans le midi de la litance, et on la cultive dans les jardins où on en fait de's 
bordures. Elle possède une odcur forte, pénétrante et agríable, qui la fait employer dans les cuisines comme assaisomnement. L'huile volatile qu'on en retire par la distillation est sourent brunâtre, mais devient limpicle et incolore par Ja rectification; clle est àcre, tris aromatigue, d'une pesanteur spécifique de 0,905 .

serpolet, thymus serpyllum L. Tiges nombreuses italíes sur la terre, divisées en rameaux qui se relèvent à la hauteur de 6 a 10 centimètres ou davantage, suirant les variétés; les feuilles sont plus grandes que celles du thym, orales, rétrécies en un court pétiole, glabres ou velues, sourent ciliées sur le bord; les fleurs sont purpurines, disposées en épis oblongs, ou rapprochées en lète à l'extrémité des rameaux. Cette plante est commune sur les coteanx exposés au soleil; elle est moins fortement aromatique (fue le thym; on l'emploie souvent en infusion théiforme contre la débilité gastrique et intestinale, dans les catarihes chroniques, etc.

\section{Sariette tes jartins.}

Suturecir hertmsis L. Car. gén. : Calice campanulé a 10 nerrures ef à 5 dents presque égales. Corolle à peine bi-labiée, à 5 lobes presque égaux; lobe supérieur dressé, pline, entier ou un pen íchancré; l étamines écartées les unes des autres. - Car. spéc. : l’ige droite, rougreâtre, pourvue de poils rudes, hate de 22 à 27 cenlimètres, divisíc en un grand nombre de rameaux étalés, gamis de feuilles linéaires-lancéolées, glanduleuses; fleurs purpurines, géminées sur charue pédoncule, plus courtes que les feuilles florales et rapprocliées en petites grappes terminales; bractées linéaires, courtes ou arortées; gorge du calice entièrement uue. Toute cette plante a un goût pi(juant, aromati(jue et une odeur analogue à celle du thym. Elle est stimulante et employée dans les assaisonnements.

\section{Calament de moutagne.}

Calamintha officinalis Mouch; Melissa culamintha I. Car. gén. : Calice tubuleux, strié, bi-labié; lèvre supérieure souvent ouverte et à 3 dents; lère inférieure bifide. Corolle à lube droit, nu en dehors, souvent exserte; gorge souvent reaflée; limbe bi-labié à lèvre supéricure un peu voûtée, entière ou un peu échancrée; lèrre inférieure renversée, à lobes planes, celui du milieu souvent plus grand; 4 étamines didynames, ascendantes, comniventes par paires, au sommet. Le calament croît sur les collines, dans les bois et au bord des champs; ses tiges sont redressées, hautes de 25 à 50 centimètres, un peu pubescentes, ainsi que toute la plante, garnies de feuilles pétiolées, orales, un 
peu en cœur à la base, bordées de dents obtuses; les lleurs sont purpurines, assez grandes, portées sur des pridoncules axillaires qui se div isent en deux ou en plusienrs autres ombellés et uniflores; elles sont penchees d'un même côté de la plante. Toute la plante est douée d'une odeur agréable. Elle est quelquefois usitée, encore aujourd'hui, comme sudorifique et stomachique, prise en infusion théiforme; mais la plupart du temps, dans le commerce de l'herboristerie, à Paris, on lui substitue la menthe saurage (menthen sylecestris) dont j'ai précédemment donné les caractères.

On employait autrefois, concurremment asce la première, deux autres espèces de calament, à savoir : le calaminlle grandiflore dont les feuilles et les fleurs sont plus grands, et le calamintha nepeta dont les fenilles et les fleurs sont beaucoup plus petites et d'une odeur de pouliot.

\section{Mélisse oflicinale.}

Melissa offecinulis I. Car. gén. : Calice tubuleux campanule, à 2 lères, la supérieure tridente, l’inférieure bifide; corolle à tuhe recourbé, ascendant, élargi à la gorge, à limbe bi-labié; lère supérieure dressée, bifide; l'inférieure à 3 lobes, dont celui du milieu plus grand, abaissé, souvent échancré; 4 ćtanines didynames rapprochées en arc sous la lère supéricure; rerticilles axillaires, làches, pauciflures.

Ia mélisse croît naturellement dans le midi de la France et est cultirèe dans les jardins; celle s'élère à la hauieur de $6 j$ centimètres; les feuilles en sont pétiolées, assc'z grandes, largement ovécs, obluses, III peu cordiformes par le bas, d'un vert clair, à surface très rugueuse, crénelées sur le bord, un pen villeuses. I.es fleurs sont portées, plusieurs ensemble, sur des pédoncules axillaires courts et cependant rameux; les corolles sont jaunâtres, une fois et demie plus longues que les calices.

La mélisse est pourve d'une odeur douce, analogue à celle du citron, ce qui lui a fait donner le nom de mélisse citroméce ou de citromells. On l'emploie en infusion théiforme comme antispasmodiçue. On en prépare également une eau distilléc (hỵdrolat), un alcoolat simple et composé, et on en extrait l'huile volatile plar la distillation.

\section{IIysope (fig. 191).}

IIyssopmes offecinalis L. Car. gén. et spéc. : Calice cyllindrique, strié, a 5 dents aigueis; corolle cubuleuse arant son limbe partagr en 2 lèrres, dont la supérieure est droite, courte el éhancrée, et l'inlirieure partagée

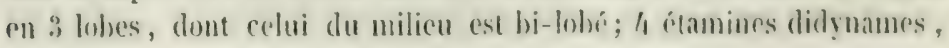


droites, écartés, saillantes. Tiges droites, ligneuses dans leur partie inférieure, hautes de 30 à 40 centimèfres, garnies, smr toute feur longueur, de feuilles longues et étroites. Ies fleurs sont nedinatement bleues (rarement rouges ou blanches), presune sessiles, réunies plusieurs ensemble dans l'aisselle des fenilles supéricures, et formant un épi tomrné d'un seul côté. Toute la plante possède unc odeur aromatique, pénélrante, assez agriéable, et une saveur un peu âcre. Elle fournit un peu d'huile rolatile à la distillation On l'emploie en infusion théforme ; on en fait une eau distillée et un sirop.

Sauges.

Car. gén. : Calice campanulé, strié, à 2 lèrres, dont la supérieme est sourent à 3 dénts et l'inféricure à 2; corolle tul,ulée à linbe bi-labié; lerre supérieure dressée ou recourbée en faucilie, souvent échancréc à l'extrémité; lère inférieure ouverte, à 3 lobes, dont le moyen est plus large et échancré; élamines supériemres nulles; ćlamines inféricures à filets courts, portant un connectif transrersil, terminé à son extrémité supéricure par une anthère fertile, et inféricurement par une anthère stérile. Le genre des sauges ne comprend pas moins de h00 espèces, dont quelques unes sont assez usitées.

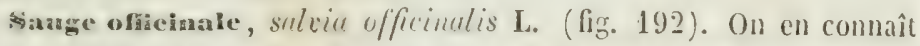
trois variétés: l'une, dite grande smuye, a l's liges viraces, ligncuses,

Fig. 191.

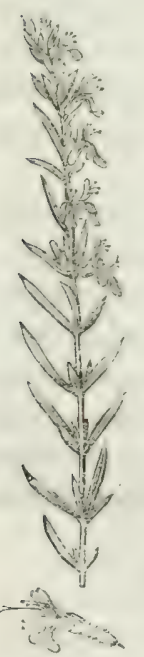

Fig. 192.

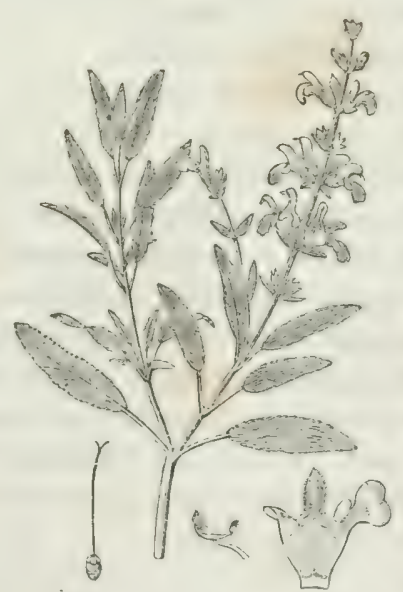

rameuses, velues, garmies de feuilles pétiolées, oblongues, obtuses , épaisses, ridées, blanchâtres et cotonneuses, finement crénelées sur le bord. Les fleurs sont bleuâtres, disposées en verticilles peu garnis, qui forment un épi interronpu et terminal. Toute la plante est peu succulente, d'une udeur forte et agréable, d'un goût aromatique amer et un peu âcre.

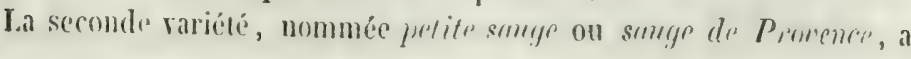


les feuilles plus petitrs, moins larges, plus blanches, d'une orleur et d'un goùt encore plus aromatiques. La troisième sariété, dite somgr de Cutulogne, a les feuilles encore plus étroites que la précédente, blanches des deux côtés, de propricités semblables. Les fleurs sont presique toujours blanches.

Le nom de salviu, dérivé de salcare, saurer, indique suffisamment que les anciens attribuaient à cette plante de grandes propriétís médicales. Qui ne comnaît ce vers de l'École de Salerne:

Cur moriatur homo, cui salvia crescit in horto?

aucuel un grand philosophe a répondu :

Contra vim mortis non et medicamen in hortis?

1)e toutes les labiées aromaliques, la sauge est cependant une de celles dont la propriété stimulante est le plus marquée. Prise à l'intéricur, elle agit éminemment comme tonique et stomachique. Elle fournit à la distillation une eau distillée très aromatique et beaucoup d'huile rolatile. Elle entre dans beancoup de médicaments composís.

sauge des prés, sulvin protensis L. Cête plante, très commune dans les prés secs et sur le bord des champs, produit une tigge herbacée, quadrangulaire, haute de 30 ì 50 centimètres, hérissée de poils rares, garnie de feuilles pétiolées, oblongues, un peu cordiformes à la base, épaisses, réticulées, d'un rert foncé, crénelées sur le bord. Les fleurs sont d'un bleu foncé ou clair, rarement blanches ou roses, verticillées au nombre de 5 ou 6 ; la lèvre supérieure de la corolle est très grande, courbée en faucille, parsemée de glandes visqueuses. Cette plante peut jusfu'à un certain point remplacer la sauge officinale; mais elle est moins aromatique et d'une odeur moins agréable.

sange selaré ou orrale, tonte-honne, sfrlvia srlurea L. Tige très velue, haute de 60 centimètres, garnie de feuilles pétiolées, grandes, cordiformes, chagrinées, crénelées. Les fleurs sont d'un bleu très clair, grandes, rerticillées ì pen près six ensemble, environnées de bractées concares, colorées, acuminées, plus grandes que les calices, qui sont à 4 dents terminées par une pointe sétacée. Cette plante croit en France, en Italie, en Espagne, etc. ; elle a une odeur trìs pénétrante. On l'emploie dans quelgues cantons, en phace de houblon, clans la fabrication de la bière.

\section{Semence de Chia.}

Les médecins homœoprathes, dans la vue sans doute de se faire une médication particulière, dont les élements fussent inconnus ou très peu 
répandus, ont sonvent cmprunté à des pays lointains des substances dont les analogues se seraient rencontrées facilement sous leurs mains. Telles sont les semences de chic, apportées du Mexique, où elles sont produites par une espèce de sauge ( salcia hispanica?). ('es semences sont plus petites que celles de psyllium, auxquelles clles ressemblent beaucoup; rues à la loupe, elles ressemblent encore micux à de très petits ricins, par leur forme et par leur robe luisante el grise taché̉ de brun. Celte ressemblance forme pour elles un caractire gui les fera facilement reconnaitre. Mlises à tremper dans l'eau, elles s'cutourent fromptement, de même que les semences de psyllium, d'une enreloppe mucilagineuse de la nature de la gomme adragante, qui se divise on se dissout dans l'eau à l'aide de la chaleur, en formant une boisson très adoucissante, sans fadeur et sans goût désagréable, de sorte qu'on peut la faire servir de boisson habituelle aux malidıs, sans ancune addition. Je pense que les semences de coings et de psỵllium pourraient être employées de la même manière.

Les semences de chia, semées à l'École de pharmacie, ont produit une plante à tige carrée, haute de 35 centimètres, presque glabre dans toutes ses parties. Les feuilles sont opposées et régulièrement espacées à 5 centimètres; les pétioles sont très grêlles, longs de la à 6 centimètres; les feuilles sont assez minces, orales-lancéolées, régulièrenent dentées; les plus grandes ont 10 centinuetres de longs sur 6 de large. L'aisselle de chaque feuille a donné naissance à un petit rameau grêle, qui n’a pu se développer, la plante ạ̣ant alors dépéri, bien avant d'être arrivée à l'état de floraison (1).

\section{Romarin (fig. 195).}

Rersmurrimus offirinalis L. Car. gén. et spéc. : Calice tubulé à 2 lèrres, la supéricure entière et l'inférieure bifide; tube de la corolle plus long que le calice, et limbe partagé en deux lèrres, la supérieure plus courte et bifide, l'inférieure à 3 divisions dont la moyenne est beaucoup plus grande et concare; 2 étamines à filaments subulés, arqués vers la lère supérieure qu'ils surpassent, munis d'une dent au-dessous de leur partie mojenne et portant une anthère linéaire, uniloculaire; style à lobe supérieur très court.

Le romarin est un arbrisseau haut de 10 à 13 décimètres, très ra-

(1) La figure donnée par lixertner des pelits fruits du salvia hispaniea se rapporte tout à fait aux semences de chia ; cependant Gartner met le salvia hispanica au nombre des espèces dont les fruits ne sont pas mucilagineux; il cite comme ayant les fruils mucilagineux les salvia verbenaca, $d$ sermas, argentea, ceratophylla, epthiopis, urticifolia, canariensis, elc.

II. 
meux et très pourru de feuilles opposées, sessiles, étroites, linéaires, persistantes, ghabres et luisantes en dessus, blanchâtres et cotonneuses en dessous. Les Beurs sont d'un bleu pâle, disposées par petits groupes

Fig. 193.

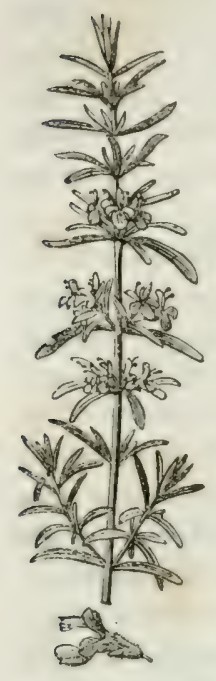
dans les aisselles des feuilles supérieures. Il possède une odeur fortement aromatique due à une huile volatile camplirée; il est cultivé dans nos jardins, mais il croît naturellement dans le midi de l'Europe. C'est à la grande quantité de celte plante, répandue dans les environs de Narbonne, que le micl de ce pars doit sa saveur aromatique.

Le romarin est stimulant, stomachique el emménagogue; on en fait un vin aromatique ( romarin), une eau distillée, un alcoolat, et on en retire lhuile volatile par distillation.

\section{Cataire commune ou Iferbe aux chats.}

Nepeta cataria I. Car. gén. : calice tubuleux à 5 dents; corolle à tube allongé, élargi par le haut, à limbe bilabié, à lère supérieure échancrée, à lèrre inférieure écartée, trilobée, les deux lobes latéraux petits et renversés, celui du milieu plus grand, concave, crénclé ; 4 étamines didynames, rapprochées par paires, bi-loculaires.

La cataire commune s'élève à la hauteur de 6 à 10 décimètres; la tige est carrée, pubescente, garnic de feuilles pétiolées, ovées-pointues, un peu cordiformes à la base, profondément crénclées, rugueuses, rerles en dessus, blanches en dessous, rapprochées; ses fleurs sont rúunies en rerticilles serrés, accompagnées de bractées sétacées; elles sont blanches on purpurines, rapprochées en épis terminaux. Ia plante croît le long des haies et sur le bord des chemins, en Europe et en Asie; clle possède une saveur âcre ê amère, et une odeur aromatique un peu forte, qui attire les chats; elle est stomachique, carminatise et emménagugue. Elle entre daus le sirop d'armoise composé.

\section{Lierre-terrestre.}

Gilechoma hederacea $\mathbf{L}$, nepetn glerhnma Benth. Celle plante diffère plus de la précédente pour son port et ses caraclères extérieurs, que par ceux tirés de ses organes floraux. Sa racine virace domne naissance à des tiges conchées, radicantes, à rameaux lloriferes ascendants, poursus d'un perit bounged de poits a l'endroit de l'insertion des feuilles. 
Cêlles-ci sont très distancées, longuement pétiolées, ríniformes nu cordiformes arrondies, crénclées sur le bord, vertes des deux côtés, glabres ou pourrues de poils rares. I.es fleurs sont purpurines ou bleuâtres, disposées au nombre de 2 à 3 dans l'aisselle des feuilles; le calice est tubuleux, strié, à 5 dents inégales; le tule de la corolle est dilaté au-dessus du calice; le limbe est à 2 lèvres dont la supérieure redressée et bifide; l'inféricure est à 3 lobes, dont celui du milieu est plus grand, abaissé et échancré. Les étamines sont didynames, ayant leurs anthèresả loges divergenteś, rapprochíes deux par deux en forme de croix.

Cette plante possède une saveur Fig. 194.

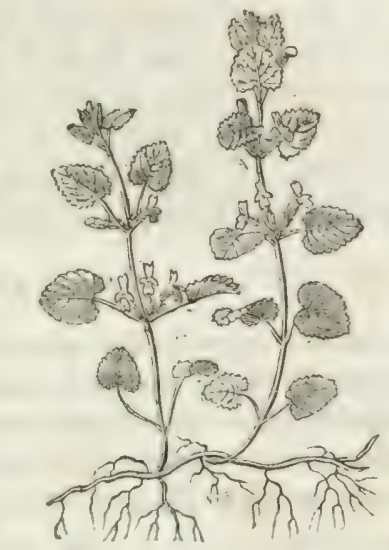
amère et une odeur aromatique agréable. Elle est emp̧loyée comme béchique, tonique et antiscorbutique.

\section{Mélisse de Moldavle.}

Inrencephalum molduricum L. Plante cultivée dans les jardins, lante de 65 centimètres, à tiges glabres, rameuses, quadrangulaires, munies de feuilles orales-lancéolées, presque glabres, crénelées sur leur contonr. Les dentelures des fleurs florales et des bractées sont terminées par un filet sétacé. Ies fleurs sont hlenes, purpurines ou blanches, réupies en verticilles axillaires, formant une grappe longue de 1 ì à 30 centimètres; leur calice est strié, à dents mucroncées. I.c tube de la corolle est très renflé ou rentru à la partie supérieure; le limbe est à deux lères, dont la supéricure un peu voûtée et échancrée, l'inférieure ouverte, à 3 lobes, dont celui du milieu très grand et échancré; 4 étamines didynames, ascendantes.

Cctte plante possède une orleur pénétrante, assez agréable, qui se rapproche un peu de celle de la mélisse, ce qui lui a valu son nom. Elle passe pour être cordiale, céphalique et vulnéraire. On l'emploic en infusion théiforme.

\section{Marrube blanc.}

Marrubium mulgare L. Car. gén. : calice tubuleux à 5 on 10 nervures et à 5 ou 10 dents aiguës, sous-épineuses; corolle à tube inclus 
dans le calice, à limbe bilabié, à lèvre supérieure presque plane, entière ou bifide, a lère inférieure ourerte, trifide; lobe mitoven plus large et sourent échancré; 4 étamines renfermées dans le tube; stỵle terminé par 2 lobes courts et obtus.

Le martube vulgaire croît dans les lieux incultes et sur le bord des chemins. Il est haut de 30 à 35 centimètres, cotonneux, blanchâtre, aromatique, d'une saveur âcre et amère; ses feuilles sont presque rondes, ridées, crénelées et velues; Ies verticilles sont multiflores, distancés; les calices sont cotonneux, à 10 dents recourbées; la lèvre superieure de la corolle est anincie en pointe et bifide.

\section{Marrube noir ou Ballote fétide.}

Ballota nigra L. Car. gén. : calice infundibuliforme, à 10 nerrures, à 50 10 dents; corolle à tube en partic sorti, poilu intérieurement; limbe bilabié; lèrre supérieure dresséc, oblongue, un peu concare, échancrie au sommet; lèrre inférieure rabattue, à 3 lobes, dont celui du milieu plus grand et échancré; étamines dressées sous la lère supéricure.

La ballote noire croît partout à la campagne, dans les décombres et le long des haies. Elle a la tige carrée, les feuilles pétiolées, orales, crénelies, glabres on velues, d'un vert obscur. Les fleurs sont porlíes stur des pédoncules courts, en faisceaux tournés d'un même côté. La

Fig. 193.

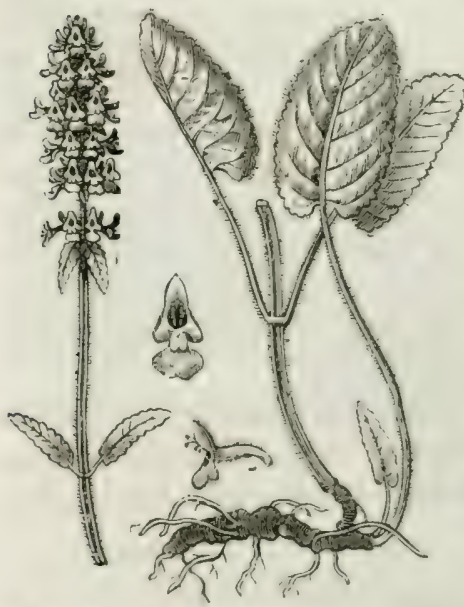
corolle est rougeâtre. Cette plante présente une certaine ressemblance avec le marrube blanc; elle s'en distingue cependant facilement à la couleur foncée de ses feuilles, à la couleur rosée de ses fleurs et à son odeur désagréable, lorsqu'on la frotte entre les doigts. Elle est inusitée.

\section{Détoine ( fig. 1985)}

Betonica officinalis L. Car. gẻn. : calice tubulé à 5 dents très aiguës, nu à l'intérieur; corolle tubulée à 2 lèrres; le tube çilindrigue, courice, plus long que le calice; In levre supérieure plane, arrondie, dressée, entière; l'inféricure à 3 lobes, dont celui du milieu plus large et échancrí; † étamines paralletement ascendantes sous la livere suprórieure. 
Lil béloinc officinale croil dans les prés el dans les lieux ombragés; elle pousse près de la racine beancoup de feuilles longuement fétiolées, larges, oblongues, crénelées sur le bord et rudes au toucher. Il s'élère du milieu une tige portant de distance en distance des feuilles opposces, dont les supérieures sont presque sessiles. La tige est terminée par un épi composé de verticilles serrés, mais interrompu à la base. Le calice est glabre et lisse au-dehors; la corolle est purpurine ou blanche, deux fois plus longue que le calice. Cette plante, quoique sensiblement inodore. émet cependant une exhalaison pénétrante qui incommode ceux qui la récoltent en grande quantité. Elle est douće d'une certaine àcreté; on la fume et on la prise comme le tabac.

\section{Ortie blanche.}

Lamium "lbum L. Car. gén. : calice à 5 dents aiguës; corolle urbuleuse, renfléc à l'orifice, à deux lèvres, dont la supérieure est roûtée et l'inférieure a 3 lobes; les 2 lobes latéraux sont très courts et munis d'une dent aiguë, le lobe infériem est très élargi et échancré à l'extrénité; étamines exsertes; anthères rapprochées par paires; askoses triangulaires, tronqués au sommet. Les rerticilles sont très garnis, axillaires, les supérieurs rapprochís.

L'ortic blanclıe a la tige presque glabre, haute de 20 à 30 centimètres, garnie de feuilles pétiolées, cordiformes, acuminées, bordées de dents aiguës; ses fleurs sont assez grandes, d'une belle couleur blanche; les dents du calice sont linéaires et hérissées; les anthères sont velues. Cette plante croît dans les haies et dans tous les lieux incultes et humides, au milieu de l'ortic commune, à laquelle elle ressemble par ses feuilles qui, cependant, ne sont pas piquantes. On l'en distingue aussi par ses tiges carrées et par ses fleurs. Llle est inodore; la fleur desséchée est usitće comme astringente, contre la leucorrliéc et les hémorrlıagies.

Germandrées (fig. 196).

Genre textrium : calice tubuleux à 5 dents égales; corolle à tube court et à une seule lèrre, la lèvre supérieure étant remplacée par une échancrure profonde, qui Iiig. 196.

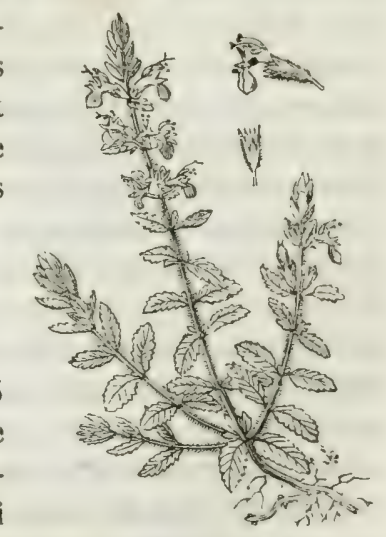
sịpare les 2 divisions supérieures du limbe; lèvẹ inférieure à 3 lobes, 
dont celle du milieu est très grande et fortement abaissée; 4 étanines didynames sortant de lat corolle prar l'échancrure supérieure; anthères à logres confluentes; askoses rugueux ou réticulés. Ce genre comprend anjourd'hui plus de 80 espèces, dont quelgues unes sont assez usitées.

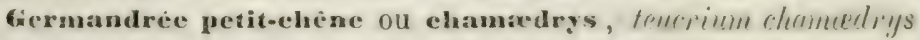
L. Racine virace rampante; tige couchée, diviséc dés sa base en rameaux pubescents, étalés, puis redressés, hauts de 45 à 30 centimìtres; feuilles courtement pétiolées, petites, ovales-oblongues, crénelées sur le bord, glabres et sourent luisantes en dessus, veineuses et un peu relues en dessous, d'un rert gai. Les fleurs sont purpurines, disposées 2 à 3 ensemble dans les aisselles des feuilles supérieures qui sont à peine dentées, bractéiformes et colorées d'une teinte rougceitle. Cette plante est faiblement aromatique; elle a un goût aner et un peu âcre; elle est cmployée comme stomachique.

Germandrée femelle ou borrys, teurrium botiys L. Times lierbacées, annuelles, ramenses, hautes de 15 à 27 centimètres; feuilles pétiolées, velues, divisées en 3 ou 5 découpures; fleurs purpurines rassemblées au nombre de 3 à 6 dans l'aisselle des feuilles. Plante peu aromatique, très peu usitée, à distinguer du rlemopordium brollys, qui l'est beaucoup plus.

Germandrce marime, marum ou herbe aux chats, telcithl marum L. P'etite plante très rameuse, ligneuse et blanchâtre, qui a presque le port du thym vulgaire; les rameaux florifères sont hauts de 8 à 16 centimètres, blancs; les feuilles sont courtement pétiolées, très entières, ovales, longues de 5 à 9 millimètres, blanches en dessous; les fleurs sont presque solitaires dans l'aisselle des feuilles supérieure's et sont rapprocliées de manière à former une grappe longue de 25 à 50 millimètres, tournée d'un seul côté. Les calices sont très petits, velus et blanchis; la corolle est pourprée, relue en dessus. Toute la plante possède une odeur forte et camphrée et une sareur âcre et amère ; elle est aphrodisiaque pour les chats qui se vautrent dessus et la detruisent. L'huile rolatile obtenue par distillation contient une assez forte proportion de camphre.

scordium, chamaras ou germandréc d'ean, tencritm sriflium L. Racine rampante, virace; tiges velues, ramenses, haules de 16 a 22 centimetres, garnies de feuilles sessiles, ovales-oblongures, demtées sur le bord, vertes sur les deux faces, molles au toucher; bis flenrs sont rongeâtres, portées sur de courts predoncules, solitaires on placées en très petit nombre dans l'aisselle des fruilles supériemres. Les calices sont campanulés, divisés en 5 dents courtes et obluses. Celle plante croil dans les prés liumides et marécagrus; elle ressemble assez au chamedrys a la première rue, mais elle developpe une odeur 
alliacie Jurspu'on dit fivisse entre les doigts; elle est stomachique et antiseplifye et fait partie de l'électuaire diascordium qui lui doit son nom. I.e mot même scurdium est tiré du grec exopejor, qui signifie ail.

Germandréc sausage ou scorodone, teucrium scorodonia I. liacine rirace, traçante, proluisant des liges dressées, velues, quadrangulaires, hautes de 30 à 60 centintréres; les feuilles sont pétiolées, cordiformes-allongées, tris rugneuses, fmement crénclées sur le bord, ce qui leur domne asse'z de rensemblance arec celles de la sauge et a valu a la plante, indépendamment des noms ci-dessus, celui de sauge des lmis. I.es fleurs sont d'un blanc jaunatre, pourvues d'un calice gibbeux à la base, irrégulier, bilabié, à 5 dents dont une, formant la lerre supérieure, est beaucoup plus grande que les 4 autres; ces fleurs sont solitaires, pédicellées et pendantes dans l'aisselle de's feuilles supérieures, réduites à l'état de bractíes plus petites que les calices; elles forment par leur réunion des épis grèles tournés d'un seul côté.

Ia scorodone possiede une odeur alliacéc beaucoup plus faible que celle du scordimn et ne doit pas lui être substituée, comme on le fait sourent. Elle est, du reste, très facile à reconnaîte aux caractères qui viemnent d'être indiqués.

Iu nombre des espèces de trurium que l'on pourrait encure citer, se trouvent plusieurs plantes nommées ponhot de montagne, les unes à fleurs jaunes, tels gue les foucrium anreum et flacescens, les autres à fleurs blanches, tels que les teucrium jolium et montmum. Il ne faut pas confondre ces plintes arec le rérilable poulion, qui est une espèce de menthe, le mentha pulegium L.

\section{Bugles.}

Ce geme de plantes ("ijugu) a tellement de rapport arec les teucrium yue les botanistes ont sourent fait passer des especes de l'un à l'autre; le principal caractère des ajuga réside dans leur corolle, dont la lère supéricure est pour ainsi dire nulle et à dents à peine marquées, de sorte que le limbe ourert est presque réduit aux trois lobes de la lèvre inféricure, dont celui du milieu est échancré.

Buọle rampante, ajưge reptens L. Celle plante croît dans les lieux lumides et dans les bois; elle présente au bas de la tige une touffe de feuilles assez larges, oblongues, obovées, légèrement dentées, et des jets traçants qui produisent, de distance en idistance, un pied semblable au premier. La tige florifère est droite, simple, carrée, peu devée, munie de feuilles sessiles semblables aux premières et portant 
des verticilles de fleurs blenes, disposés en épi terminal, interrompu par le has. Cette plante est inodore, un pen amère et astringente. On l'employait autrefois conme cicatrisante ou pour consolider les plaie's, d'où lui venait le nom de consolida media.

Iverte ou chamapitys, "juga chomrppitys: Sclıreb., teucrium chemerpitys L. Cette plante est partagée, des sa base, en rameaux étalés, velus, longs de 14 à 24 centimètres, garnis de feuilles velues, longues de 27 à 30 millimètres, divisées jusgu’à la moitié en 3 lobes linéaires; les fleurs sont jaunes, arec une tache rougeâtre, longues de 15 millimètres au plus, sessiles et solitaires dans les aisselles de's feuilles supériemres. Toute la plante est pourvue d'une odeur forte et résineuse. Jille a été vantée autrefois contre la goutte. Elle est annuelle.

Isetre musquéc, ajuga ina Schreb., teucrium iua L. Celte plante ressemble beaucoup à la précédente par la disposition de ses rameaux nombreux et étalés, munis de feuilles touffues; mais elle est virace, ses tiges sont plus dures, ses feuilles sont entières ou simplement munies d'une ou deux dents rers l'extrémité, ses fleurs sont rougeàtres (rarement d'un jaune clair) et longues de 18 à 24 millimètres. Elle possède une saveur amère et résineuse et une odemr forte qui se rapproche du musc. On l'emploie sèche, en infusion théiforme, comme antispasmodique, tonique et apéritive.

\section{FAMILLE DES VERBÉNACÉES.}

Les végélaux compris dans cette famille présentent d'assez grands rapports avec les labiées. Ainsi leurs tiges ou leurs rameaux, lorseju'ils sont herbacés, sont généralement quadrangulaires; leurs feuilles sont opposies, quelquefois verlicillées, rarement alternes, tantôt simples 't entières ou incisées, tantôt composées, digitées on imparipinnées. 1.curs fleurs sont complètes, sonvent irrégulières; le calice est unbuleux, persistant, à divisions égales on inćgales; la corolle est insíree sur le réceptacle, tubuleuse, à limbe quadri- ou quincquétide, très souvent bilabice. I.es élamines sont insérées au tube ou à la gorge de la corolle, très rarement au nombre de 5 , le plus sourent au nombre de 4 didynames, quelquefois réduites ì 2 par l'arortement des 2 superiemres. Ovaire libre contenant ordinairement 4 ovules, dans 1, 2 ou 4 loges, aul bas descuelles ils sont attachés; style unique, terminé par 1 stigmate simple on bilide, oblique on milaterat dans les genres a 2 loges uni-orulíes. I.e fruil est une baic ou un drupe contenant un noyau à 2 ou à 4 loges, souvent monospermes. La graine se compose. 
outre son tingument propre, d'un endosperme très mince qui recourre un cubloryon droit, à radicule infère.

\section{Verveinc onticiale.}

Verlene offirinalis r. Car. gén. : calice tubuleux à 5 côtes el à 5 dents, dont une est plus courte que les autres; corolle tubuleuse, courbée, à limbe oblique divisé en 5 lobes irréguliers; \& élamines incluse's, diclynames; un ovaire supère, à 4 loges uni-ovulées; un style égalant les étamines, bifide ou bilobé au sommet; le fruit qui est renfermé dans le calice accru, est une capsule divisée à maturité en 4 coques striẻes longitudinalement.

Ia rerveine officinale est pourvue d'une racine fibreuse et virace, de laquelle s'ilèvent plusieurs tiges effilées, tétragones, rudes sur les angles, hautes de 35 à 60 centimètres, gainies de feuilles oralesoblongues, rélréciés en pétiole à leur base, les inférieures dentées, les movennes et les supérieures profondément incirés ou pinnatifides. Les fleurs sont très petiles, d'un violet pâle, presque sessiles, alternes, disposíes à la partie supérieure des tiges et de's rameaux en longs épis filiformes. Cette plante a joui autrefois d'une grande célébrité et était employée dans les actes religieux de plusieurs peuples et dans les pratiques superstitieuses des magiciens et des sorciers. Aussi lui domnaiton le nom d'herbe sacrée. Elle est faiblement aromatique et un peu amère, ce qui n'indique pas qu'elle doire jouir de bien grandes propriétés médicales; elle est à peine usitée aujourd'hui.

\section{Verveine odlorante.}

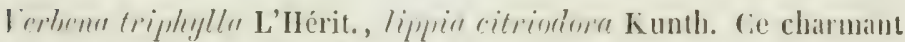
arbrisseau, originaire de l'Amérigne méridionale, est cultivé dans les jardins, où il suit le régime des orangers. Ses rameaux, droits el élancés, sont munis de fenilles rerticillées, ternées on quaternées, lancéolées, amincies en pointe aux deux extrémités, exhalant une odeur de citron lorsqu'on les froisse. Les fleurs sont dispocées en épis axillaires ou en panicule terminale nue; les feuilles séchées sunt employées en place du thé et pour aromatiser des crèmes.

\section{Arnus castus.}

Vitex rymus-rastus L. L'agmus restus ou gatuilier est un arbrisseau des pays chauds (Italie, Sicile, Ievant), que l'on peut cultiver dans nos jardins. Il pousse des branches très droites, longues et flexible's; des feuilles opposcies, digitées, dentées; des fleurs en épis verticillés: 
ses fruils sont ronds et gros comme le poince, d'un hrun noiratre à la partie supérieure, revêtus inférieurement, et environ à moitié, par le calice de la fleur qui a persisté. Cee calice est ì 5 dents inégales et d'un gris cendré.

Ces petits fruits ont quatre loges dans leur intérieur; ils ont une odeur assez donce lorsqu'ils sont secs et entiers; mais quand on les écrase ils en dégagent une qui est fort désagréable et analogue à celle du staphỵsaigre. Ils ont une saveur âcre ct aromatique.

Ce fruit élait renommé, chez les Grecs, comme utile à ceux qui faisaient vœu de chasteté. Aussi le nommaient-ils áyroz, c'est-à-dire chaste; on y a joint depuis le mot latin cestus, qui signifie la mème chose, et on en a formé le nom hétéroclite argmus ccistus, qui paraît d'autant moins lui conrenir, qu'une substance aussi aromatique doit être peu propre à refroidir l'appétit vénérien.

\section{Bois de tek.}

Telin grandis Lamk., tectome grandis L. f. Cet arbre, un des plus grands ague l'on connaisse, forme de rastes forits dans les deux presqu'iles de l'Inde et dans l'archipel Indien. Son bois jouit depuis longtemps d'une réputation méritée pour la construction des maisons et des vaisseaux, joignant une grande solidité à la légèreté et à une grande durée. Il est d'une couleur fauve brunâtre, et d'une texture fibreuse très apparente; il prend un poli un peu gras et est onctueux au toucher. Sa conpe perpendiculaire à l'axe présente un très grand nombre de couches concentrifues, dont chacune est plus dense et d'une couleur plus funcée du côté externe que du côté du centre; le buis de colle coupe, vu à la loupe, présente quelque cliose de gras el de demitransparent. Les tubes ligneux sont uniformément répartis dans la masse, mais sont plus volumineux du côté interne de chargue couche, où on en roit, ì la limite, une série circulaire qui sont très grands et très ourerts. Ja même coupe présente des lignes radiaires parallèles très régulières, qui traversent sans interruption tontes les couches ligneuses. Linfin le bois de tek possède une odeur forte, analogue à celle de la tanaisie, qui le met à l'abri de l'attaque de's insectes.

Dans ma précédente édition, j’ai dit avoir trouse a l'ĺcole de pharmacie un échantillon de bois étiqueté bois de teli qui était d'une conleur de rouille de fer uniforme, d'une tri's grande dureté, ot un preu plus lourd que l'eeue, ce qui, itant un grand inconvenisut puar la construction des vaisseaux, me faisait douter que l'échantillon füt vai. J'ai acquis depuis la certitude gu'il était faux; et je pense maintenant que ce bois, quii éait caractírisé en outre par une odeur e't un goùt 
très prononcés de patience, est très probablement celui du curcolotuu pubescens dont il a été qquestion page 391.

Je dois à l'ubligeance de M. Morson, pharmacien-chimiste à Londres, deux échantillons de bois de tek de l'Inde qui ne sont pas entièrencnt semblables et qui doirent provenir de deux espèces de tectoma; et trois échantillons de bois qui portent dans le commerce anglais le nom de buis de tidi d'afrique; ceux-ci n'ont de commun arec le bois de tek de l'Inde que l'usage semblable qu'on en peut faire prour les constructions.

\section{FAMILLE DES SGROPHUTARIACÉES.}

Ilcrbes ou arbrisscaux ayant encore quelquefois les rameaux tétragones et les feuilles opposées ou verticillées ; fleurs complètes, irrégulières, à calice libre, persistant, penta- ou tétramère, à folioles libres ou soudées, dont la posterieure est plus grande que les deux antcrieures, (yui surpassent elles-mêmes les deux latérales. Corolle hypogyne, gamopétale, presque toujours irrégulière, bilabiéc ou personée (1); It étamines didynames, fuelquefois une cinquieme étamine fertile, ou d'autres fois deux seule's étamines, les trois autres avortant. L'ovaire appliqué sur un disque hịpog̣nne est à deux loges polyspermes; le style est simple, terminé par un stigmate bilobé; le fruit est une capsule biloculaire dont le mode de déhiscence est très rariable. Les graines contiennent, sous leur légument propre, une amaade composée d'un endosperme charnu qui renferme un embryon droit; la radicule est proche du hile basilaire. La famille des scrophulariacées fournit à la pharmacie deux médicaments d'une très grande énergie, la digitule et la gratiole, et d'autres d'une activité moindre, mais cependant encore usités, lels que l'euphruise, la véromique, la linuire, la scroplueluire et le bouillon-blanc.

\section{Euphraise.}

Euphrasia officinalis L. Petite plante haute de 16 à 22 centimètres, dont la tige est un peu ligneuse, très rameuse, garnie de petites feuilles sessiles, opposées inférieurement, alternes à la partie supéricure, ovales et dentées. Les fleurs sont petites, blanches, mêlées de jaune et de violet clair, axillaires, presque sessiles, rapprochées en épis à la partie supérieure des tiges et des rameaux. Le calice est monophyglle, à 4 divisions inégales; la corolle est tubuleuse inféricurement, à limbe

(1) C'est-à-dire en forme de masque (de persona masque). On a aussi donné à ces plantes le nom de rhinanthices, de pir ovfos, fleur en nez, et celui de mufiers. 
bilabie, dont la lève supirienre est concare ct l'inférieure a 3 lobes; 4 etamines didrnames ayant leurs anthères terminées par une pointe; ovaire supère surnonté d'un style de la longueur des étamines; stigmate globuleux; capsule ovalc-sblongue, à 2 valies et à 2 logres polyspermes.

L'euphraise possède une saveur un peu anère ct une odeur douce ct agréable qui se déreloppe par la friction; l'écu distillée en est laiteuse, aromati(jue, agréable. Elle est usitée contre les maladies des yeux.

\section{Véroniques.}

Car. gén. : calice persistant, à 4 ou 5 divisions aigueis; corolle à lube souvent très court, à limbe sourcut étalé en roue et partagé en 4 lobes dont l'inféricur plus étroit, le plus sourent d'une couleur bleue; 2 étanines fixies an tube de la corolle; 1 oraire supère, surmonté de 1 style filiforme à stignate simple; capsule ovale ou en forme de cœur renversé, comprimée, à 2 loges, contenant plusieurs graines arrondies.

Les verronigues sont des plantes herbacées on sous-frutescentes dont les feuilles sont ordinairement opposées et les fleurs disposées en grappes ou en épi. Quclequefois les feuilles sont alternes et les fleurs axillaires et solitaires. (ie genre comprend aujourd hui environ 150 espèces dont un grand nombre sont très jolies et peurent être cultivées comme plantes d'ornement; je n'en citerai que deux espèces usitées en pharmacie.

Véronique officinale dite veronique male, reronica offecinulis $\mathbf{I}$. Tiges couchées à la base et radicantes, redressées à la partie supéricure, longues de 11 à 16 centimètres; feuilles opposées, ovales, dentées, rétrécies c'n pétiole court à la base, légèrement velues comme tonte la plante; fleurs d'un bleu tendre, portées sur de courts pédicelles el disposées en grappes assez longues et serrées.

Cette plante est très commune en France dans les bois, sur les cullincs et dans les prés; elle possède une odeur faible et agréable et une sareur amère, un peu astringente. Lorsqu'eile est séchée avec suin. elle peut jusqu'à un certain point remplacer le thé.

Beceabunga, veronica beccalungug L. Cette plante croît dans les Jieux acquatiques; ses tiges sont molles, comme transparentes, rougeitles, couchées et radicantes par le bas, puis redressées et hautes de 22 a 40 centimètres; ses feuilles sont épaisses, glabres, orales-obtuses, dentées en scie. Ses fleurs, d'un bleu pâle, sont disposées en grappes; la plante a une saveur un peu amère, icre et piquante. On l'emploie à l'état récent, comme diurétique et antiscorbutique. 
Gratiole (fig. 197:

Girntiulu offirinnlis L. Car. gén. : calice à 5 divisions un peu incigales, muni de deux bractées à la base; corolle gamopétale, campanulée ou tubuleuse, irrégulière, is 2 lirres peu distinctes at à $q$ lobes, dont le supérieur entier ou légèrement bifide; 2 étamines postérieures fertiles, renfermées dans le tube; 2 étamines antérieures stériles, réduites à leurs filets ou nulles. Style fléchi au sommet, terminé par un stigmate à 2 la mes; capsule biloculaire, orale pointue, à deux valres souvent bifides au sommet, se séparant de la cloison qui était engagée dans leur suture. Semences petites et nombreuses dont la surface est marquée de petits points creux, visibles à la loupe.

La gratiole officinale croît dans les prés et atteint environ 33 centimètres de hauteur. Elle est pourvue de feuilles opposées, sessiles, glabres ainsi que la lige, lancéolées, dentées sur le bord; les fleurs sont solitaires dans

Fig. 197 .

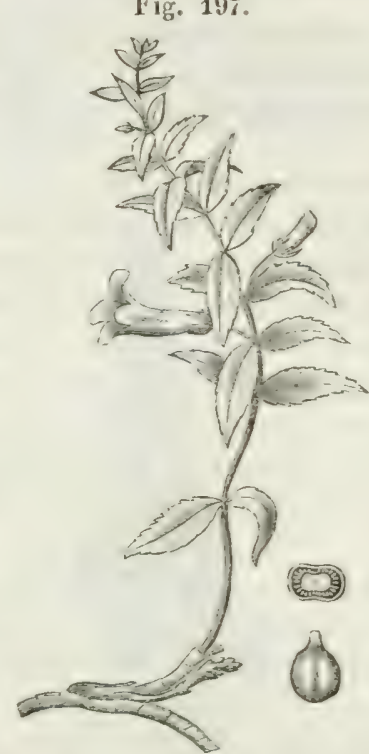
l'aisselle des feuilles, pédonculées; le tube de la corolle est beancoup plus long que le calice, courbé, le plus souvent jaunâtre, avéc un peu de rouge sur le limbe; la plante possède une odeur nauséabonde et une sareur très amère; clle est émétique et purgative drastique; on ne doit l'emploger qu'arec la plus grande prudence. Son nom d'herle ¿ tout ceux de la campagne, pour se purger, d'où il en résulte sonvent de fàcheux accidents.

Ia gratiole a été analyséc par Vauquelin. Son suc exprimé n'a rien fourni à la distillation; éraporé en consistance d'extrait et traité par l'alcool, il a laissé, comme partic insoluble, de la goume et du malate de chanx, tandis que l'alcool a dissous une matiere résinoüle d'une très forte amertume : plus, du chlorure de sodium, un acide rigrital, et un sel régétal à base de potasse. La matière résinoïde est peu soluble dans l'eau, mais s'y dissout facilement à l'aide des autres principes. Le mare de la gratiole. exprimé et lavé, contenait du phosphate de chaux, 
un antre sel calcaire ì acide végétal, du fer probablement phosphaté, de la silice et du ligneux.

Vauquelin pense, d'après cette analyse, que c'est au principe amer résinoïle que la gratiole doit sa propriété purgatire. (Amoles de chimic, 1. LXXII , p. 191.)

\section{Digitale pourpreee (fig. 198).}

Iligitulis purpuren. Car. gén. : calice persistant à 5 dlivisions incigrales ; corolle penchée, à tube sentru, courbé, à limbe court, oblig̣ue, i) 4 disisions obtuses, inégales, dont la supéricure est sourent échan-

Fig. 198.

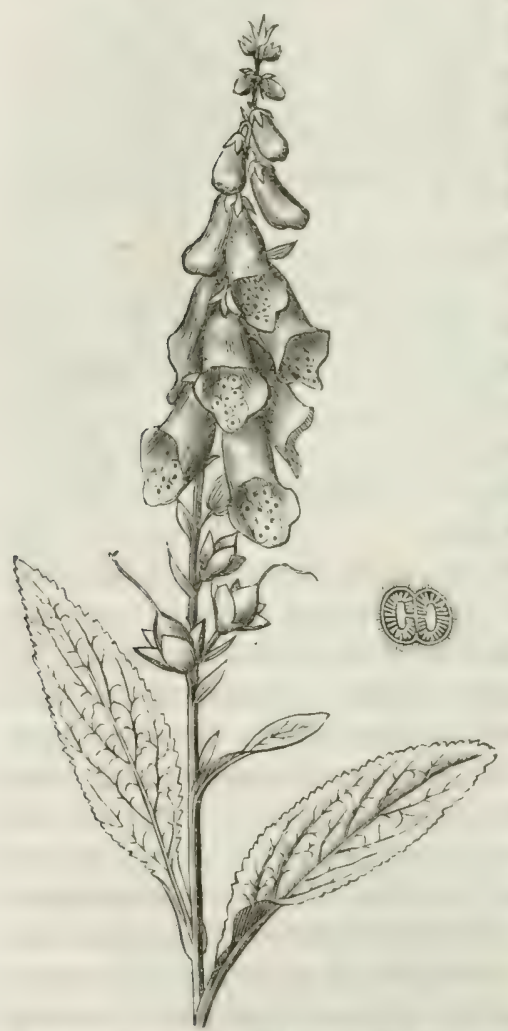

crée; 4 élamines didynames plus courtes que la corolle; anthères rapprochées par paires; style courtement bilobé an sommet, à lobes glanduleux du côté interne. Capsule ovale, bivalve, dont les valves rentrées en dedans se séparent à moitić de la cloison placentifère; semences nombreuses, petites, oblongues, sous-anguleuses.

La digitale croît dans les bois et sur les collines, en France et dans plusieurs autres parties de l'Europe ; on la cultive aussi dans les jardins. Sa tige est simple, anguleuse, relue, sourent rougeâtre, haute de 1 mètre environ, garnie de feuilles alternes, oblongues-aiguës, décurrentes le long du pétiỏle, très grandes vers la racine, diminuant de grandeur à mesure qu'elles ap)prochent des fleurs qui forment une longue grappe simple a l'extrémité de la tige. Ces fleurs sont purpurines, marquées à

l'intéricur de taches blanches en forme d'yeux, nombreuses et pendantes d'un mème côté; leur corolle a dans son ensemble la forme d'un doight de gant, de lis le noun de gunt de . Tulre-Lume et celıi même de digitale donné à la plante. 
Toutes les parties de la digitale ont été usitées; mais ce sont les feuilkes surtout dont on se sert aujourd'hui. Elles possident une saveur très amère, jointe à un peu d’àcreté; elles sont émétiques, stupéfiantes et fortement toxigues, à une dose un peu élevée; mais administrées en très petite quantité et en commençant par quelques centigranmes, elle produit plusieurs effets dont la médecine fait des applications très utiles: tels sont l'augmentation de la sécré'ion urinaire et de la sueur et le: ralentissement de l'action du cour. On emploie ces feuilles en poudre, en infusion aqueuse, en teintme alconlique on ethérée; elles sont très actives sous ces différentes formes; cependant c'est la teinture alcooligue qui paraît jouir rle plus de propriétés médicales.

Pendant longtemps les chimistes ont inutilement cherché à isoler le principe aclif de la digitale; ce n'est qu'en 1840 ou $18 / 11$ que Mu. Homolle et Quérenne sont parrenus à l'extraire, par un procédé qui a valu à $\mathbf{H}$. Homolle un prix de la Sociélé de pharmacie de Paris. Ces deux messieurs ne dissimulent pas cependant avoir été guidés en partie par un trarail antérieur de M. A. Jenry, pharmacien à l'hôpital militaire de Phalsbourg (Joumal de phrmmarie ot de chimie, t. VII, p. 59). Leur procédé. (que l'on tronse exposé an même volume, p. 63, a été simplifié de la manière suivante par .I. Ossian Henry (ibid., p. 460$)$.

On traite deux ou trois fois un kilogramme de poudre de digitale par de l'alcool à 82 degrés centésimaux; on distille les liqueurs et on traice l'extrait obtenu par de l'eau légèrement acidulée arec de l'acide acétique.

La liqueur claire et filtrée est étendue d'ean, en partie neutralisée par l'ammoniaque et additionnéc d'une infusion de noix de galle, qui en précipite la digitaline à l'état de tannate. On décante, on lave le dépôt poisseux arec de l'eau, on le délaie arec un peu d'alcool ct on le trilure pendant longtemps arec de la litharge porphyrisée. On traite le mélange. par de l'alcuol bouilant; on distille une partie du liquide el on évapore le reste sur des assietles. Enfin on traite le proriuit sec par l'éther, pour enlever quclques matières étrangères à la digitaline.

La digitaline est une substance blanche, inodore, pulrérulente, très amère lorsqu'clle est dissoute, excitant de violents éternuments lorsqu'on la pulvérise. Elle se dissout dans 2000 parties d'eau cinviron; elle est très soluble dans l'alcool, presque insoluble dans l'élher; elle ne paraît pas contenir d'azote; clle ne neutralise pas les acides; l'acide chlorhydrique, en la dissolvant, prend une belle conleur rerie.

La digitaline produit des phénomènes d'excitation générale et est très vénéneuse à la dose de 1 à 2 centigrammes. Sa dose utile ne dépasse pas 1 à 1 milligrammes. La diffenté de manier mo si petite dese de 
médicament, jointe à des caraclères de pureté peu certains, rendent préférable l'emploi direct de la poudre de digitale.

Comme il est très important de ne pas confondre les feuilles de diggitale avec celles de guelques autres plintes qui peurent aroir quelgue ressemblance de forme arec elles, telles que celles de bourrache, de grande consoude, de molène thapsoïle, et surfout de conyze squarreuse, je vais préciser davantage les caractères des premières. Les feuilles de digitale (fig. 199) sont orales-oblongues, tantôt plus larges, tantôt plus étroites, pourant acquérir au muximum 12 centimètres de largeur sur 25 centimètres de longueur, non compris le pétiole qui peut aroir du tiers à la moitié de la longueur du limbe. Le limbe est terminé à l'extrémité en pointe mousse, insensiblement rétréci du côté du pétiole et prolongé en aile étroite sur toute la longueur de celui-ci. Le pétiole est coloré en pourpre à la base ; il est creusé sur la face supérieure d'un sillon aigu et forme sur la face opposée un angle saillant qui se prolonge

Fig. 199.

Fig. 200.
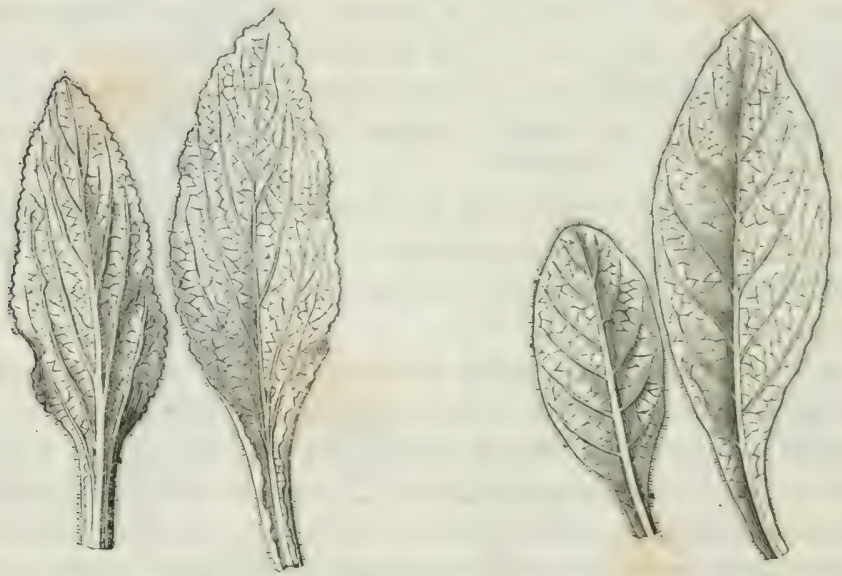

jusqu'à l'extrémité du limbe. Le limbe est régulièrement et grossièrement denté ou crénelé et souvent un peu ondulé sur le bord; les dents sont arrondies. La face supérieure est verte dans les feuilles adultes, blanchâtre et comme argentée dans les plus jeunes; toujours donce au toucher, parsemée de poils très courts, transparents, brillants et cristallins; elle est bosselée et proémincnte entre les nerrures, rgui sont an contraire marquées en creux. La face inférieure est blanchatre, el d'autant plus que les feuilles sont plus jeunes; toutes les nervures y sont fortement marguées en relief; les poils y sont beaucoup plus abondants que sur la face supérieure, toujours très courts, transparents et cristallins, ce qui est cause de la couleur argentie de la fenille. 
De toutes les fenilles que l'on pent confondre arec celles de digriale, celles qui leur ressemblent le plus sont les feuilles de conver spuarreuse (imula conyz: DC., fig. 200 ); mais elles sont rudes au toucher. presque entières sur le bord et eshalent me odeur fétide lorsquon les froisse.

On emplovait autrefois en médecine, comme astringentes et vulniraires, un certain nombre d'autres plantes de la famille des scrophulariacées qui sont aujomrd'hui completement oublices; telles sont les suivantes :

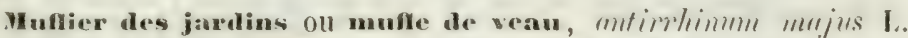
Racine vivace; liges cylindriques, élevées de 30 à 60 conlimètrés et darantage, à fenilles lancéolées, d'un rert foncé, opposées at quelquefois ternces vers le bas des tiges, alternes dans la partic supérieure. Les fleurs sont grandes, disposées en belles grappes terminales; dles sont composées d'un calice persistant ì 5 divisions, d'une corolle gamopétale, irrégulière, bosste à la base, ventrue, fermée à son orifice par une éminence convexe nomméc pulfris, et ayant son limbe parlagé en deux lèves, dont la supérieure bifide et l'inférieure à 3 disisions; 4 étamines didynames renfermées dans le tube ; le fruit ust une capunle ovale ou arrondie, obligue à sa bise, à 2 loges, s'ourrant au sommet par trois trous irrégnliers. Cette plante croît naturellentent dans les fentes des vieux murs et dans les lienx pierreux; on la cullive dans les jardins pour la beauti de ses fleurs, dont la couleur sarie du blane au rose et au rouge le plus foncé.

Ginaire commune, linetrin rulgnis is loench. Plante hante de 30 à 45 centimètres, croissant dans les terrains incultes, munic de fenilles linéaires-lancéolées, nombreuses, sessiles et d'un vert glauque. Les fleurs sont jaunes, rapprochées en un épi terminal; le tube de la corolle est éperonné à la base; la capsule s'ourre au sommet en 3 à 5 valves irrégulières.

Serophulaire noueuse ou grande serophulaire, serophulurid norlosa I. Racine fibreuse munie de tubercules irréguliers noiraitres; lige quadrangulaire, d'un ronge hrun, haute de 60 i 120 centimètres, garnie de feuilles opposées, pétiolées, grlabres, d'un vert sombre, ovales-lancéolées, crénelées sur le bord. Ses fleurs sont d'un pourpre noirâtre, disposées en une grappe droite, paniculée, terminale; elles sont formées d'un calice à 5 divisions arrondies; d'une corolle dont le tube est renflé et presque globuleux, et le limbe is 5 divisions formant presque 2 lèrres; il y a 4 étanines didynames, terminées par des anthères ì une seule loge, s'ouvrant par le sommet. Lat capsule est à 2 valres et ì 2 loges dont la cloison est formée par les bords rentrants des valves.

II. 
Cette plante a unc odeur fétide, nausécuse, et une sarcur amìre; elle passait autrefois pour résolutire, tonique, sudoriftque et rermifuge. Il est probable qu'elle jonit de propriétés actires qui demanderaient à être déterminées de nouveau.

Molene ou Boullion-blanc ( fig. 201 ).

Terbescum thrupsus. Car. gén. : calice à 5 divisions profondes; c0rolle étalée, presque rotacée, à 5 lobes un peu inégaur; 5 étamines dont les filaments sont barbus en tout ou en partie, rarement nus.

liig. 201.

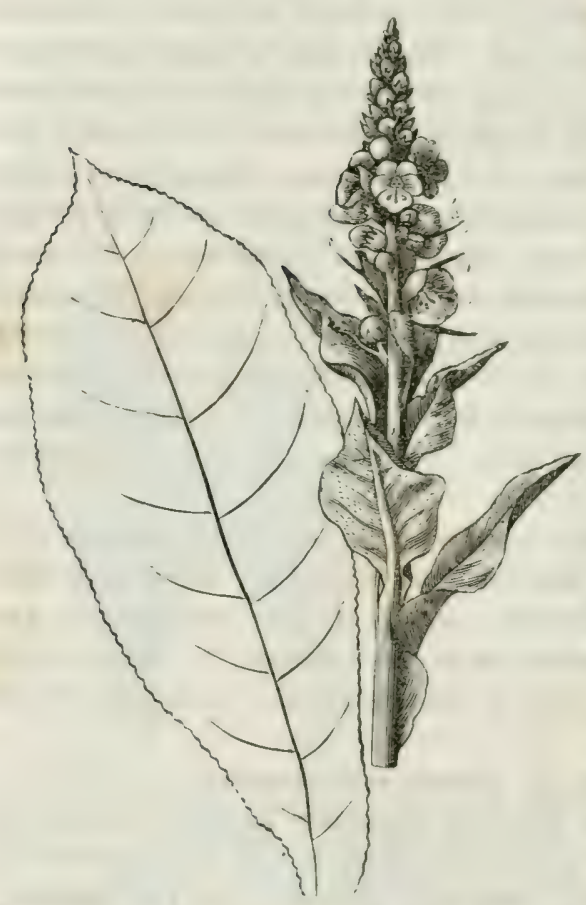

Style dilaté et comprimé au sommet ; capsule oroïde, déhiscente. Car. spéc. : racine pirotante, assez grosse, bisannuelle; tige simple, cylindrique, un peu rameuse supérieurement, haute de 1 mètre et plus, revêtue, ainsi que les feuilles, d'un duret très épais et très doux, formé de poils rayonnants; feuilles radicales pétiolées, Jancéolées; celles de la tige longucment décurrentes d'une insertion à l'autre; toutes très cotonneuses, douces au toucher et blanchâtres; fleurs jaunes, fasciculées deux ou trois ensemble, presque sessiles et disposíes en un épi qui s'allonge considé-

rablement, at mesure qu'elles se déreloppent, de manière it atteindre une hauteur de 2 à 3 mètres. Ces fleurs ont une odeur douce et suave et sont employées en médecine comme béchirpues et calmante's, mais souvent mélangées de celles de quelques espices veisines, qui sont les rerbasrum montunum, crussifrtium, thupsuides, thensifurmer, phlomnides. lilles demandent ì être séchées arec soin et conservées dans un lieu très sec, car elles se ramollissent et noircissent très promptement ì l'air humisle. 


\section{FAMILLE DES SOLANACEES.}

Plantes herbacées annuelles ou viraces, ou arbrisseaux à sucs afueux, à fenilles alternes, somvent rapprochées deux ensemble, à la partie supérieure des tiges. Fleurs completes formées d'un calice libre, gamosépale, à 5 divisions, persistant en tout ou en partie ; corolle gamopétale, le plus sourent à 5 lubes plissés, réguliers, quelquefois un peu irréguliers; 5 étamines libres; oraire à 2 loges pluri-orulées, rarement it un plus grand nombre; style simple terminé par un stignate bilobé. I.e fruit est une capsule ou une haie à 2, 3 ou 4 loges polyspermes; les graines sont ordinairement réniformes, à surface chagrincée, contenant un embryon plus ou moins recourbé dans un endosperme chamu.

La famille des solanacées offre de grandes anomalies sous le rapport des propriétés toxiques, médicales ou alimentaires. Elle contient des grenres complétement dangereux el qui présentent une propriété narcotique très intense, tels sont les genres hynsciamus, nicotiana, datura, atropu; d'autres gemres offrent des espèces dangereuses et d'autres alimentaires ; par exemple le genre solanum qui, à côté de la morelle noire et surtout du solamum mammosum, poison très dangereux, produit la pomme cie terre et l'aubergine; d'autres gemes sont tout à fait privés de principe narcotique, comme les cripsicum et les lycopersirum.

Sous le rapport botanique, les solanacées sont divisées d'abord en deux sous-familles :

1. Les rectembryées, dont l'embryon est prescgue droit, les cotylidons foliacés et la radicule infère; tels sont les genres cestmm, dumrlin, habrothammus, dont le fruit est une baie, el les genres restia et sesseer, qui ont pour fruit une capsule. Ces plantes sont peu nombreuses et toutes américaines.

2 Les curvembryées, dont l'embryon est plus ou moins recourbé et les cotylédons demi-cylindriques. Ces plantes, qui constituent les rraies solanacées, se divisent en quatre tribus.

1. Ticotianées : capsule biloculaire, loculicide, bivalve; genres petunia, nicotiana.

2. Daturées : Frnit à 4 loges incomplètes; il n’y a véritablement que 2 loges; mais un trophosperme très déreloppé dans chaque loge la divise incomplétement en deux parties. Le fruit est une capsule dans le genre datura et une baie dans le genre solandra.

3. Hyoscianées : capsule biloculaire s'unrant par un opercule; genres hyosciamus, anisodus, scopolia.

4. Solanécs : baie à 2 ou plusieurs loges, à trophospermes centraux; wès rarement une capsule indébiscente; genres nicmud’u, physollis, copsirum, solmum, lyrupersicum, atropun, mandragma, lycium. 
Tabac ou Nicotiane.

Ticotemu tuburun L. Car. gén. : calice en tube partagé jusçu'a la moitić en 5 divisions; corolle infundibuliforme ou hypocratériforme à 5 lobes et à 5 plis; 5 étamines égales renfermées dans le tube ; ovaire a 2 loges mulli-orulées; stigmate en tête; capsule entourée par le calice persistant, biloculaire, s'ouvrant par le sommet en deux ralves septicides, bifides, retenant les placentas séprarés.

Le nleotisne-tabae (fig. 202) est une plante glotinense, courerte, dans toutes ses parties, d'un duret très court. Ses tiges sont droites,

Fig. 202.

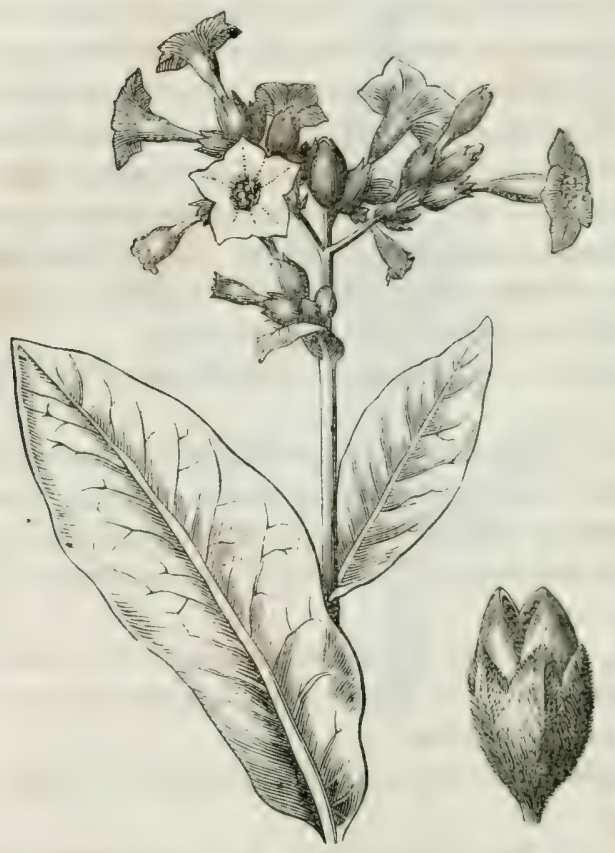

hautes de $1^{\text {ma }}, 60$ environ, rameuses, chargées de feuilles alternes, sessiles, demi-amplexicaules, fort grandes, d'un vert pâle, ovalesoblongues, très entières, les supérieures lancéolées; les fleurs sont disposées en une belle panicule terminale; le calice est visqueux à divisions droites et ovales; le lube de la corolle est allongé, renflé vers le sommet; le limbe est étalé, à 5 plis et à 5 lobes pointus, d'une couleur rose : les capsules sont orales, a l sillons externes, à 2 loges; la cloison est chargée sur chague face d'un placenta fongueux, remplissant toute la loge, marquí de fossettes à sa surface, et courert de semences brunes, ridées, très petiles.

Tabace rustigue, nicotimn msticn L. ( (ig. 2013). Cielle plante est velue el glutineuse comme la précédente; mais clle ne s’élère qu'à la hanteur de 6 décimètres à 1 mètre ; ses feuilles sont pétiolées, oralesobluses, ipaisses et d'un vert foncí; ses fleurs sont plus petites, pani- 
culées, furmées d'un calice court, renflé, à jo divisions obluses ; d'une corolle verle-jaunàtre, à tube court et relu, à peine plus long que le calice, à limbe court, à 5 lobes arrondis; la capsule est arrondie.

Ces deux plantes sont originaires d'Amerique : la première espece a élé importée en France, en 1560, par Jean Nicot, ambassadeur près de la cour de Lis. bonne; de là lui est venu le nom de nicotiane et aussi celui d'herbe à la reine, à cause de Catherine de Médicis à qui Nicot fit présent des semences; quant au nom de tabac ou $t a-$ baco rui a préralu chez presque tous les peuples du monde, il est tiré de celui de l'île Tabago, où la plante croissait en grande abondance et où les Espagnols l'ont trourée d'abord. Je pense que la nicotiane rustique a été comnue un peu plus tard; toutes deux jouissent des mêmes propriétés et sont employées à la fabrication du tabac.

Fig. 203.

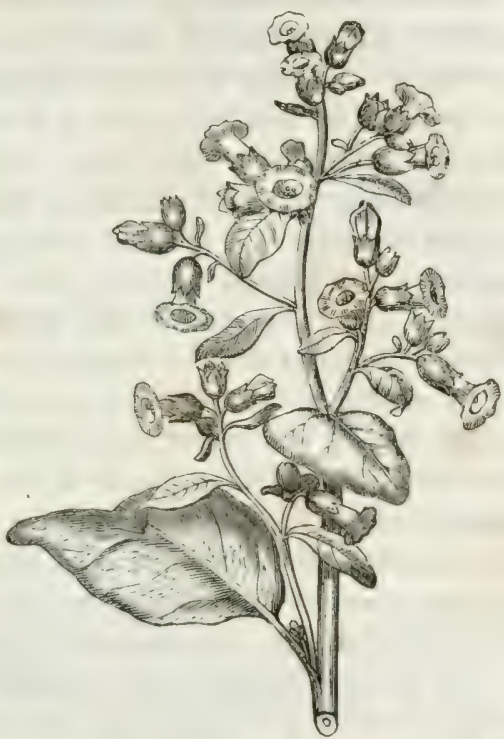

Les feuilles de nicotiane sont par elles-mêmes âcres, émétiques et drastirues à l'intérieur; mais elies sont en outre stupéfiantes, et causent le délire, des conrulsions et la mort, lorsque leur principe délétère se trouve introduit dans la circulation. Cependant ces feuilles, simplenent séchées, sont loin de présenter l'odeur âcre et la haute qualité stcrnutatoire qui les a rendues d'un usige unirersel, malgré la saine raison et en dépit des persécutions, ou peut-être à cause des persécutions, dont plusieurs souverains ont frappé d'abord ceux qui en faisaient usage. Aujourd'hui que l'jmpôt dont cette plante est frappée forme, dans un grand nombre de pass, une partie importante du revenu public, on ne peut que plaindre ceux qui se créent volontairement un besoin quelquefois aussi nuisible à leur santé qu'au bien-être de leur famille ct à la propreté.

Vaupuelin a fait anciennement l'analyse des feuilles de nicoliane e' en a reviré de l'abumine, du surmalate de chaux, de l'acide acéligue, du nitrate de potasse, du chlorme de polassium, du chlorisclrate d'am. moniague, une matiere rouge soluble daus l'ean et l'alcool, enfi!n un principe àcre, volatil et alcalin, qui depuis a éte nommé nicotime: il 
est soluble dans l'eau et dans l'alconl; on lui a attribué à bon droit les propricités enivrantes et toxigures du tabac; il existe dans la plante combiné avec un acide en excès. On prut le mettre en liberté par un alcali fixe et l'obtenir par distillation.

Pour obtenir la nicotine, on distille donc la plante sèclse arec de l'eau additionnée de potasse ou de soude caustiqque. On reçoil le produit distillé, qui contient à la fois de la nicotine et de l'ammoniangue, dans un flacon contenant de l'acide sulfurique étendu d'eau; on concentre ce liquide à un petit volume et on le redistille dans une cormue arec de la sonde caustique en léger excès. On obtient alors un liquide incolore et ammoniacal que l'on concentre à froid dans le vide : loute l'ammoniaque se dégage et la nicotine reste sous la forme d'un liquide oléagineux, d'une conleur ambréc, d'une pesanteur spécifique de 1.048; soluble dans l'eau, encore plus soluble dans l'alcool et dans l'éther, soluble également dans les huiles fixes et volatiles.

Ia nicotine a une odeur presque nulle à froid; mais, à chaud, celle odeur devient très vire et très irritante. C'est un poison très violent; elle rétrécit la pupille au lieu de la dilater; elle est fort alcaline, sature complétement les acides, forme des sels très solubles et difficilement cristallisables. De même que la ciculine et quelques autres alcalis obtenus par le moyen de la distillation avec un alcali caustique, elle ne contient pas d'oxigène : sa composition égale $\mathrm{C}^{10} \mathrm{H}^{8} \mathrm{Az}$.

J'ai dit précédemment que les feuilles de nicotiane simplement séchées n'avaient pas l'odeur âcre, forte et particulière du tabac préparé. Pour obtenir celui-ci, on humecte les feuilles sèches arec une solution de s'l marin (1), et on en forme un tas considérable qui ne tarde pas à fermenter et à s'échauffer. Au bout de trois ou quatre jours, on défait le tas pour nelloyer, écôter les feuilles et en mélanger les différentes 'qualités; on mouille de nourcau le tahac, soit arec de l'eau s'il est destiné ì être fumé, soit arec de la saumure s'il doit être prisé, ct on le soumet a une nouvelle fermentation; on lui domne ensuite, à l'aide de moyens mécaniques, la forme gu'il doit aroir en raison de l'usage auguel il cst destiné.

Il est facile de comprendre ce qui se passe dans la préparation du tabac : pendant la fermentation qu'il éprouse, fermentation qui se trouse modifiée et fixée à un certain degré par le sel marin, l'albumine ou quelque autre principe azoté se décompose et forme de l'ammoniarpue: celle-ci sursature l'acide de la plante et met à nu une certaine quantité de

1. Ouclques fabricants ajoutent ì l'eau salee du sucre, de la nuelasse, une décoction de figues ou du sue de regli-se ; le labac de la regie française u'e-l préparé yu'avec de l'eau salée. 
assez grosse, aunuclle, une tige grosse comme te doigh, led le, romble, creuse, trìs branchue, hante de 1 mitre à $1 \%, 60$, représentant un petit arbrisseau; res feuilles sont pétiolées, larges, angulenses, sinnies sur le bord et à dentelures aigneis; elles sont rertes sur les denx faces et répandent une odeur nauséeuse et vireuse; la corolle est blanche, très longue, infundibuliforme, à 5 plis; le calice tombe, à l'exceptirn d'une courte collerette rabattue qui supporte le fruit. Celui-ci a la forme d'une capsule hérissée de piquants, rerte, charnue, orée, à 4 argles arrondis et à 4 valres. Il n'a que 2 loges à l'intérieur, bien qu'il en présente 4 à la partie inférieure, à cause du placenta très dévcloppé qui remplit chaque loge et la divise imparfaitement en deux parties. I.es placentas sont entièrement recourerts de semences qui sont assez grosses, noires à leur maturité, jaunâtres aupararant.

Le stramonium est fortement narcotique et vénéneux. On en forme un extrait arec le suc, un extrait alcoolique, un élaeslé simple, et il entre de plus dans la composition du baume trancuille. Jus semences sont également très actives. Mu. Geiger et llesse en ont retiré un alcali cristallisable nommé daturine, très narcotique et déterminant la fisité et la dilatation de la pupille.

On cultive dans les jardins un certain nombre d'espeices de deturn de propriétés semblables à celles du stramonium, et qui peureat lui citre substituées; telles sont, entre autres:

Le datura tatula, presque semblable au stramoniun, mais deux fois plus éleré; ses tiges sont pourprées, ses feuilles ont les dentelures plus aiguës, ses corolles sont plus grandes; se's fruils et ses scurences sont semblables.

Le datura féroee, deture froror L., à feuilles moins profondement sinuées, pubescentes sur les nervures; i corolles plus petiter; a capsules armées de pointes plus forles, dont les quatre stpréricures sont plus grosse's, plus fortes que les autres et conrergentes.

Le daura fastueux, datura fastumse L.., dont les fenilles sont orales, médincrement anguleuses; les fleurs plus grande's, blanches en dedans, violettes en dehors ; les capsules glubuleuses, inclinces, nuberculeuses, peu épineuses.

Le datura metel, muni de feuille's oriles, entières ou ì peine sinuées, portées sur de longs pétinles, pubescentes sur les denx faces: les fleurs sont grandes, blanches, placées dans la bifurcation de's ratmeanx; les eapsules sont globulenses. inclinces, hérissées de pointes très nombreuses.

Le daturn a fraits liswes, defure lurris L., differe du stramonium par ses capsules glabres, dipourvues de pointes épineures el de tubercules: 


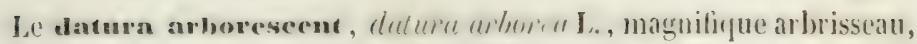
lıant, daus nos jardins, de $2^{m}, 9$ a $3^{n}, 25$; ses feuilles sont sourent géminées, orales-lancéolées on oblongues, glabres en dessus, un peu puhescintes en dessous; ses fleurs sont axillaires, pédonculées, pendantes, répandint le soir une odeur très agréable: les corolles sont blanches, longues de 24 à 27 centimètres sur 14 a 16 de diamètre à l'ourcrture. Les solandru, solanées volubiles très voisines des duture, dont elles different par leur fruit bacciforme, ont les fleurs encore plus grandes; elles sont cultirées dans l'orangerie.

\section{Jusq[uiames.}

Genre hyjesciumus : calice urcéolé à 5 dents; corolle infundibuliforme, it limbe plissé, à 5 lobes obtus, ineigaux, les deux inférieurs écartés; 5 citamines insérées au fond du tube de la corolle, inclinces ; anthères longitudinalement déhiscentes; oväire biloculaire, it placentas attachés à la cloison par une ligne dorsale; style simple; stigmate en tête; capsule renfermée dans le calice accru, ventrue à la base, rétrécie par le haut, biloculaire, s'ouvrant à la partie supérieure par un opercule en forme de couvercle.

Les semences sont nombreuses, réuiformes ; l'embryon est arqué et presque périphérique dans un endosperme charnu.

Jusfyiame noire ou hannebane, hyosciamus niger L. (fig. 205). Tige ronde, dure, liTig. 205 .

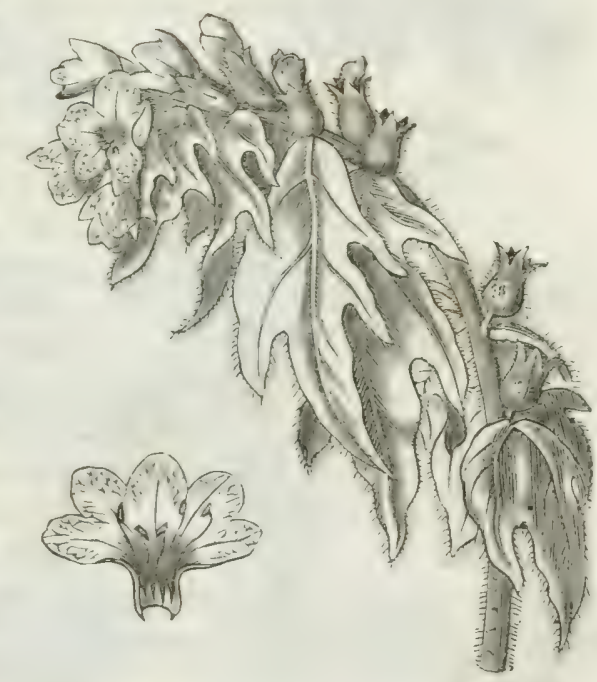
gneuse, rameuse, haute de 50 ì 60) centimetres, couverte, ainsi que les feuilles, de poils denses, doux au toucher. Les feuilles sont ovileslancénlées, sinnées ou déconpées, d'un rent pâle; les radicales très grandes et rétrécies en pétiole à la base; les supéricures sessiles, anplexicaules, molles, cotonneuses, d'un toucher visqueux, sinuées et 
profondément découpées sur le bord. Les fleurs sont sessiles dans l'aisselle des fenilles supéricures, et disposées, à l'extrémité des ligges et des rameaux, cn épis unilatéraux; les corolles sont d'un jaune pâle sur le bord, arec des veines d'un pourpre foncé au milieu, d'un aspect terne et peu agréaile. Le fruit est renfermé dans le calice de la fleur accru, durci et à dents derenues piquantes. I.es semences sont très petites, réniformes, à surface réticulée, noire à maturité. La racine est annuelle, pirotante, longue, grosse, rucle et brune au-dchors, blanche en dedans; toute la plante a une odeur forte, désagréable et assoupissante. Elle contient un suc visqueux, très narcotique; les feuilles entrent dans la pommade de populéum et le baume trancuille.

ansquiame banche, hyjuscirmms albus L. (fig. 206). Tige haute de 30 centimetres environ, relue, peu rameuse, garnie sur toute sa longueur de fenilles pétiolées, ovales, relues, les inférieures sinuées, a lobes obtus, les supérieures entières. Les fleurs sont blanchàtres,

Fig. 206.

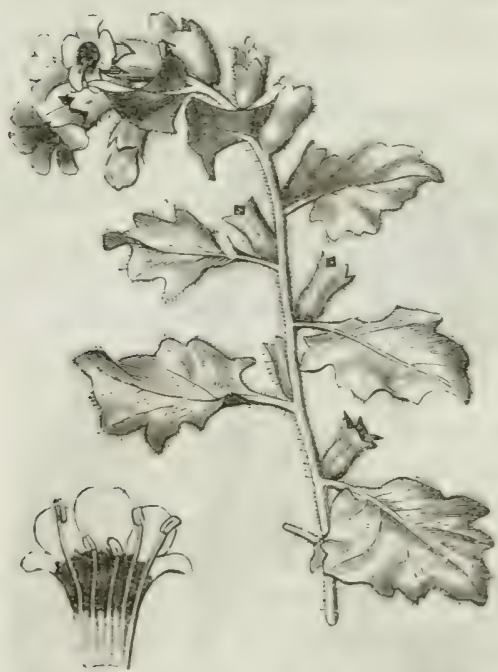

sessiles, solitaires daus l'aisselle des feuilles supérieures, et disposées en un long épi unilatéral; les semences restent blanclies à maturité. Cette plante est plus petite dans toutes ses parties que la précédente; elle croît dans les lizux incultes du midi de la France et dans les jardins; elle a une odeur moins virense et paraît ètre moins aclive. Les semences de jusquiame du commerce étant loujours blanches, on pourrait penser qu'elles appartiennent à ceite espèce ; il paraît cependant qu'clles sont tirées de la jusquiame noire; mais - qu'elles sont récoltées

arant leur maturite; elles sont luilenses, très fortement narcotiques, et font partie des pilules de cynoglosse.

Jusuguiame doree, hyuscimmus mureus L. Celte plante, par sa taille, par ses feuilles pétiolées, arrondies, par se's flemrs jaunes, re'sscmble beaucoup, à la première vue, a la précédente; mais elle est bisannuclle; ses fenilles sont pres(que grabres sur la face supéricure, à labes un peu aigus et imrgulierement dentis; les fleurs sont presque terminales, drès irrégulières, les deux lobes inférieurs ćant trìs raccourcis et dépassés par les élamines. 
Différents chimistes se sont occupés de chercher le principe actif de la jusquiane noire et, à plusieurs reprises, ils ont annoncé avoir extrait de cette plante un alcaloüde nonmé hyosriomine; mais il était toujours de proprietés différentes. Enfin IIU. Geigret et llesse sont parvenus a extraire des semences de jusquame un véritable alcaloïde, assez soluble dans l'eau, très soluble dans l'alcool et dans l'éther, cristallisable, en partie rolatil et en partic décomposable par la chaleur, décomposable par les alcalis. Il est fortement narcolique, clilate la pupille, produit des conrulsions tétaniques et canse la mort, ì très petite dose.

\section{Mandragore.}

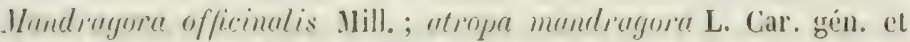
spéc. : calice quinquéfide; corolle campanulée, plissée, à 5 divisions; 5 élamines à filets dilatés à la base; anthères terminales à déhiscence longitudinale; oraire biluculaire, dont la cloison porte les placentas; style simple; stigmate en tête; baie soutenue par le calice persistant, uniloculaire par l'oblitération de la cloison ; senrences nombreuses, sousre̊niformes.

La mandragore est une plante vivace dont la racine est épaisse, longue, fusiforme, hlanchâtre, entière ou bifurquée; les fenilles sont toutes radicales, pétiolées, étalées en rond sur la terre, très grandes, pointues, ondulées sur le bord; les Fig. 207.

lleurs sont nombreuses, portées sur des hampes racticales, beaucoup plus courtes que les feuilles. On connâ̂t d'ailleurs ileux variéte̊s de mandragore: l'une, nommée mandragore mâle (lig. 207), a les feuilles longues de 45 centimètres,

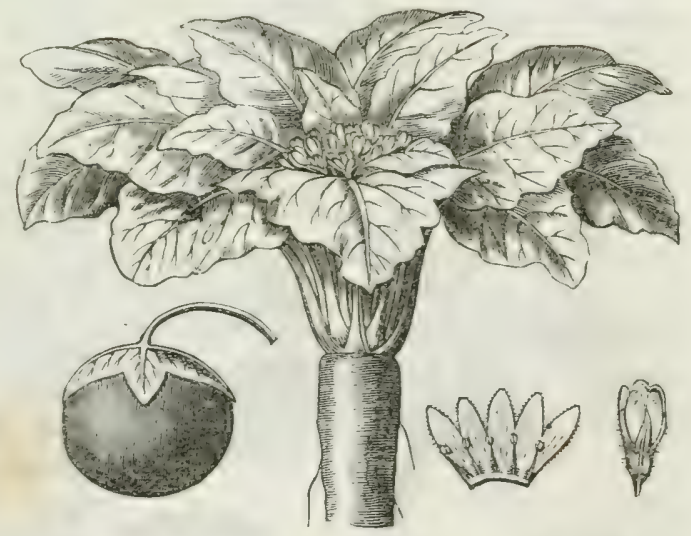
jarges de 12 ; les fleurs blanches ì divisions obunses, les baies rondes, jaunes, de la grosseur d'une petite pomme, entourées à la base par le calice dont les divisions sont larges quoique pointues. Ia seconde rariété, dite menedrongre femelle, a les feuilles plus pelites et plus étroi- 
tes, les fleurs pourprées, à divisions aiguës, les baies plus petites, ovées, entourées par le calice dont les divisions sont plus aiguës.

La mandragore avait été rangée par Linné dans le genre atropica (belladone); clle a été rétablie depuis comme genre distinct, à cause de ses filets d'étamines élargis à la base, de sa baie uniloculaire ct de son port complétement différent; toutes ses parties sont pourves d'unc odeur désagréable et sont fortement narcotiques et stupéfiantes; le's baies ont été souvent funestes aux enfants qui les prennent pour de petites pommes; les fenilles font partie du baume tranguille (filcols des solunées composé). On a comparé autrefois la racine bifur(juée à la partie inférieure du corps de l'homme et on lui avait donné le nom d'unthropomorphon, en lui attribuant des propriétés merveilleuses it surnaturelles qui s'éranouiront à mesure que les peuples deviendront plus éclairés.

\section{Bellatone.}

Genre atropta : calice à 5 divisions; corolle campanulée, plisscée, à 5 ou 10 divisions; 5 étamines à filets filiformes et anthères longitudinalement déhiscentes. Oraire biloculaire dont les placentas sont fixés à la cloison par une ligne dorsale; style simple; stigmate déprimé, pelté; baie portée sur le calice persistant, biloculaire, à semences nombreuses, réniformes.

La helladone officinale, atroyse belladune L. (fig. 208), pousse

Fig. 208.

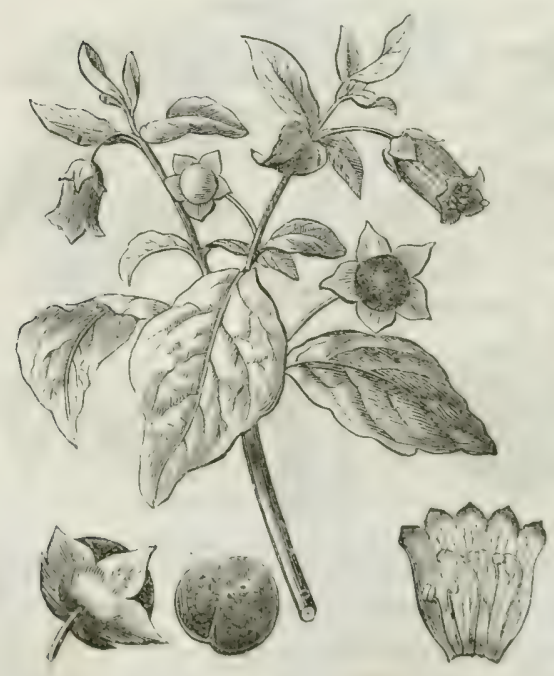

des tiges hautes de 1 mètre à $1^{m}, 30$, rondes, rameuses, un peu velues, d'une couleur rougeâtre; ses feuilles sont alternes, les supérieures géminées; clles sont ovales, terminées en pointe aux deux extrémités, très entières, vertes et molles. Les fleurs sont solitaires dans l'aisselle des feuilles, longuement pédonculées, munies d'unc corolle d'un pourpre violacé, en forme de cloche allongée, deux fois plus longue que le calice, i 5 dents courtes et obtuses; les étamines sont renfer- 
móes dans la corolle, à filets torses et inéganx: les baies, entources à la base par le calice persistant, sont de la grosseur d'un grain de raisin, rondes, un peu aplaties, marquées d'tin léger sillon qui marque la place de la cloison intérieure; elles sont très succulentes, noires et luisantes à maturité, et contiennent un grand nombre de petites semences réniformes. Filles sont très vénéneuses et ont été sourent funestes aux enfants, (qu'elles trompent par leur forme el par leur saveur donceàtre et un peu sucrée. Toute la plante est très narcotique, et agit spécialement sur la pupille, qu'elle dilate et paralyse pendant le temps que dure son action. Les feuilles entrent dans la composition du baume tranguille et de l'onguent populéum. L'extrait des feuilles, les feuilles pulrérisée's, la racine réduite en poudre, sont très sourent prescrites à petites doses contre la coqueluche, la scarlatine et différentes nérralgies.

Vauquelin a publié quelques essais andlytiques sur la belladone. Il cn résulte qu'elte contient une matière albumineuse; une autre matière animalisée insuluble dans l'alcool, soluble dans l'eau, précipitable par la noix de galle; une matière soluble dans l'alcool et jouissant à un assez haut degré des propriétés narcoticfues de la belladone; de l'acide acétique libre; beaucoup de nitrate de potasse; du sulfate, du chlorlyydrate et du suroxalate de potasse, de l'oxalate et du phosphate de chaux, du fer et de la silice (Ann. de chim., t. LXXII, p. 53 ).

Depuis la déconverte de la morpline, beaucoup de chimistes se sont occupés de rechercher dans la belladone et dans les autres plantes narcotiques, l'existence d'un alcali régétal anquel on pùt attribuer leur propriété. Pour la belladone en particulier, Mu. Brandes, Pauquy, Runge, Tilloy, etc., ont successirement annoncé avoir retiré cet alcali de différentes parties de la plante. Enfin, dernièrement, Hy. Geiger et Ilesse d'une part, et M. Mein de l'antre, paraissent aroir réritablement retiré de la tige, des feuilles et de la racine de belladone, un alcaloïde particulier auquel on avait donné d'avance le nom d'atropine. Le procédé d'extraction se trouve décrit dans le Joumal de plarmacie, t. XX, p. 88. L'atropine pure est blanche, cristallisable, soluble dans l'alcool absolu et dans l'éther sulfurique; soluble également dans 500 parties d'eau froide et dans moins d'eau bouillante; fusible, un peu rolatile; son soluté aqueux précipite en jaune citron le chlorure d'or, et en couleur isabelle celui de platine.

\section{Morelles.}

Genre solamum : calice à 5 ou 10 dents; corolle en roue, plisséce, ì 5 ou 10 divisions (rarement à 4 ou 6); 5 étamines (rarement 4 ou 6 ) insérées à la gorge de la corolle, exsertes; filets très courts; anthères 
connirentes, s'ourrant au sommet par deux pores; oraire à 2 loges, rarement à 3 ou 4 , à placentas insérés sur les closisons, multi-ovulés; style simple, plus long que les élamines; stignate obtus; baie à 2 logres, rarement à 3 on 4; semences nombreuses, sous-réniformes.

asorebe noire, solumum nigrum L. (fig. 209). Plante annuclle, très commune en lrance le long des haies et près des lieux habités;

Figr: 209.

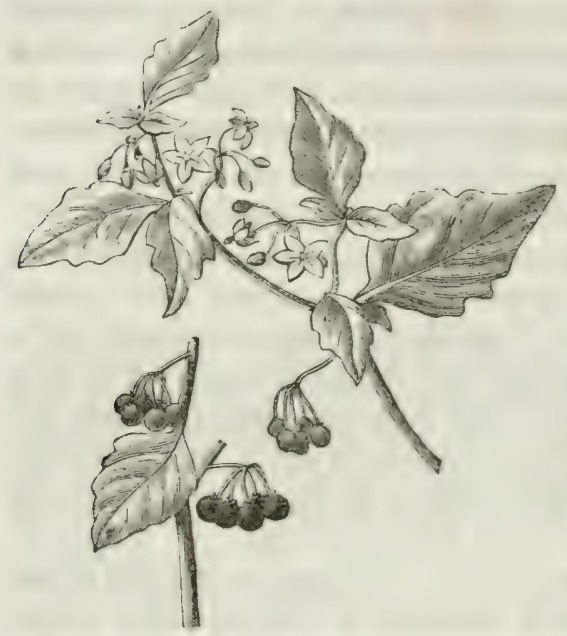

sa racine fibreuse et blanchâtre donne naissance à une tige haute de 2 à 3 décimètres, divisée en rameaux élalés; les feuilles sont pétiolées, sourent géminées, ovales-lancíolées, un peu trapézoïdales, molles au toucher et d'un vert foncé. Les fleurs sont disposées, au nombre de 5 ou 6 , en petites ombelles pédonculées, dans l'aisselle des feuilles. Il leur succède des baies rondes, vertes d'abord, puis noires, de la grosseur d'une groseille.

Cette plante est faiblement narcotigue; quelques personnes même la considèrent comme alimentaire, et assurent qu'on peut la manger cuite, à la manière des épinards. Il est possible que l'exposition et la culture influent sur ses propriétés; mais, dans tous les cas, il est prudent de la bannir du nombre des aliments.

II. Desfosses, pharmacien à Besancon, a retiré des baies de morelle un alcali organique auquel il a donné le nom de solanine. Son procédé, qui est très simple, consiste à précipiter le suc des baies de morelle par l'ammoniaque; on lave le précipité arec un peu d'eau; on le fait sécher et on le traite par l'alcnol bouiliant qui, par son éraporation spontanée, laisse précipiter la solanine sous la forme d'une poudre blanche, nacrée, insoluble dans l'eau froide, un peu soluble dans l'eau bouillante, très soluble dans l'alcool, un peu solub'e dans l'éther. Cet alcaloüle, qui a ché trouré cusuite dans plusieurs autres solumem, est narcuticjue, mais i) un bien moindre degré que ceux tirés des autres solanées médicinales, ce qui expliq̧ue pourguoi les solumun sont en général peu rénéneux. If faut en excepter cependant le solmum manmusum des ìles de l'Amérigue, à tige herbacér, aiguillonnée, à feuilles cordiformes, anguleuses of lohées, dom le fruit jaune, arrondi, mais terminé par un mamelon 
allongé qui lui donne la forme d’une petite poire renrersié, parait être un poison très actif.

Yorelle faux-pinent ou pommier d'amour, solemum j) smdecapsirum L. Arbrisseau de l'ile de Madère, à feuilles lancéolées, entières ou légèrement sinuées, rétrécies en pétiole ì la base; les fleur's sont blanches, petites, pédonculées, solitaires, géminées ou disposées plusicurs ensemble le long des jeunes rameaux. Les fruits sont des baies globuleuses, d'un rouge if et de la grosseur d'une petite cerise. On le cultive dans l'orangerie, conme arimrisseau d'ornement; il passe pour être dangereux.

Douce-amere, solamum dulcumart L. (fig. 210). Plante ligneuse et grimpante qui crồt communément dans les haies et sur le bord des bois; sa lige est divisée dès sa base en rameaux salmenteux, légèrement pubescents, longs de $1^{\mathrm{m}}, 6$ à 2 mètres ou plus, qui ne se soutiennent qu'en s'appuyant sur les arbustes voisins. Les feuilles sont alternes, pétiolées, légèrement pubescentes, les unes très entières et ovaleslancéolées, les autres profondément auriculées à leur base. Les fleurs sont violettes, quelquefois blanches, disposées en cimes Fig. 210.

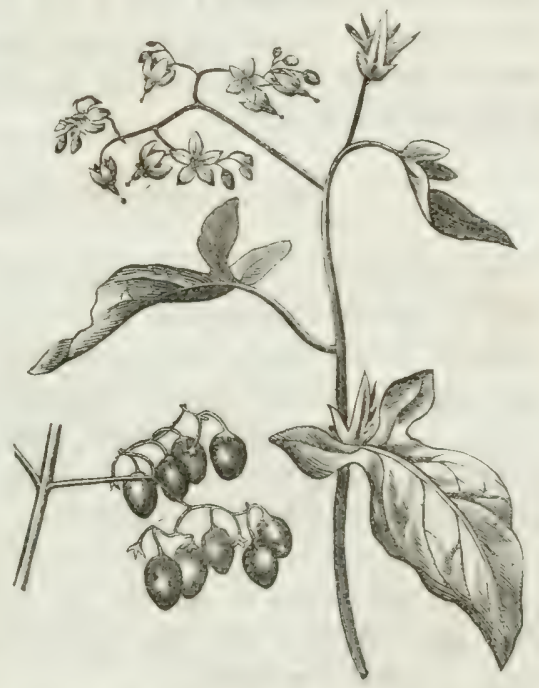

il l'opposition des feuilles; les baies sont ovoïles, d'un rouge éclatant; elles ne paraissent pas être rénéneuses.

Les tiges récentes ont une odeur fort désagréable; sìches, elles sont presfue inodores, d'une saseur amère avec un arrière goût doucêttre. On les emploie comme dépuratives. M. Morin y a constaté la présence de la solanine.

Quina de Saint-Paul, selemum psendoquinu A. Saint-Hilaire. Arbuste de la province de Saint-Paul, dont l'écorce est usitée au Brésil comme fébrifuge. Elle est ordinairement roulée, courerte d'un épiderme mince et fendillé; elle est jaunâtre ou blanchâtre dans son intérieur, avec une texture granuleuse. Elle ressemble beancoup à la cannclle blanche: mais elle est inodore el sa surface intérieure, au licu 
d'être blanche, est d'un gris yui tranche asec lat cassure blanche et grenue de l'écorce. La sareur est très amère et résagréable. Vautudin en a fait l'analyse (Jozm. phemm., t. XI, p. 49).

Aubergine ou melongrene, solcnum melongronu I. Plante annuctle des pays chauds, à tige herbacée, mais ferme, haute de 30 à 45 cenli. mètres, cotonneuse, un peu rameuse; les feuilles sont ovales, sinncics sur le bord, assez longuement pétiolées, colonneuses. Les fleurs sont blanches, purpurines ou bleuâtres, grandes, latérales, sourent sulilaires; le pédoncule et le calice sont garnis de quelques aignillons courts; le fruit est une baie pendante, très grosse, oroüde-illongée, lisse, luisante, ordinairement violette, quelquefois jaune, contenant une chair blanche. On le mange cuit dans un grand nombre de pays, sans aucun inconrénient; mais il faut éviter de le confondre avec une espèce voisine, le solumum oxigerum, dont le fruit blanc a tont à fait la forme d'un ouf de poule, et dont les semences sont enveloppées d'une pulpe trìs âcre et délétère.

Morelle tubercuse ou pomme de terre.

Sol anum tuberosum L. Cetc plante est pourrue de racines fibreuses dont les ramifications portent des tubercules volumineux, oblongs ou arrondis, de différentes couleurs audehors, blancs en dedans et contenant une très grande quantité d'anidon. Elle produit des tigges anguleuses, herbacées, un pen velues, hautes de 4.5 a 65 centimetres; ses fenilles sont ailées avec impaire, composées de 5 it 7 folioles lancriolées avec de petites pinnules intermédiaires; ses fleurs sont assez grandes, violettes, bleues, rougeâtres ou blanches, disposées en corymbes longuement pédonculés et opposés aux feuilles daus la partie supérieure des liges. Les baies sont plus grosses que celles de la morelle, d'un rouge brunâtre à maturité.

La pomme de terre, originaire de l'Amérique méridionale, est la plus précieuse acquisition que l'Europe ait tirée du noureau monde. On ignore le moment précis de son introduction en Europe. On sait, à la vérité, qu'elle a été apportée de la Caroline en Angleterre, en 1586 , par Walter Raleigh ; mais déjà, à cette époque, elle était répandue dans plusieurs lieux de l'utalie, où elle servait à la nourriture des animaux domestiques. Elle ne s'est répandue que plus tard et bien inégalement dans les autres pars. Linsi, en France, elle a élé culticée diss la fin du $x \mathrm{xl}^{\mathrm{e}}$ siècle dans le Lyonnais, la Bourgogne, la FrancheComté et la Lorraine; tandis que l'Alsace ne l'a comne qu'au commencenent du xvin siècle et les habitants des Cérennes seulement à la fin. I.e prejgugé çu’elle produisait la lèpre nuisait partout à son usage 
comme aliment, et l'on sait quelles perines s'est donníes Parmentier pour la faire admettre sur les tables du riche et sur celles du paurre, dont elle forme aujourd'hui la principale nourriture.

On connaît un très grand nombre de variétés de pomme de terre, dont les principales sont :

La pomme de terre naine hitive, jaune, ronde, mûrissant en juin ;

La truffe d'août, rouge, pâle et fort bonne;

La legllanduise jume, longue, aplatie, très farineuse, recherchée;

La rouge longue ou vitelotte, de chair ferme, estiméc pour la tahle;

Ia putronue blunche, très grosse et farineuse; se réduit en pulpe par la cuisson : très productive;

La patrarue juune, très amylacée et très produclive; est employée pour les fabriques de fécule;

La drecroisille, rose, allongée, d'excellente qualité, etc., etc.

On peut propager les pommes de terre par les semences, mais on préfère le faire au moyen des tubercules. On met ccux-ci en terre au printemps, entiers ou coupés en plusieurs morceaux, et on fait la récolte des noureaux tubercules dans les mois de septembre et d'octobre.

On peut conserver les pommes de terre tout l'hirer dans une cave; mais, all printemp̧s, elles germent et se gâtent. Pour obvier à cet inconvénient, qui a lieu ì l'époque de la plus grande rareté des substances alimentaires, on a conseillé d'en faire sécher une partie en automne, ce qui permet alors de les conserver très longtemps. Pour cela on les monde de leur épiderme, on les plonge pendant quelques minutes dans l'eau bouil. lante et on les fait sécher dans une bonne éture. Jilles deviennent alor's très dures, cassantes et cornées, et l'air ne pent plus les attarpuer. Il faut les conserver dans un endroit sec et à l'abri des insectes.

Vauguelin, chargé par la Société d'agriculture d'analyser quarante. sept variétés de pommes de terre, en a obtenu les résultats suivants:

Mille parties de pommes de terre contiennent:

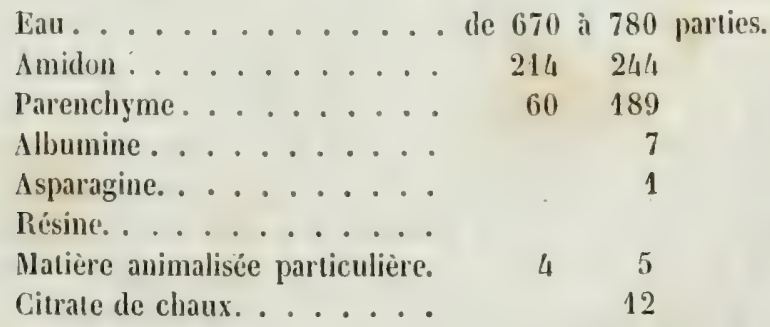

Plusieurs chimistes ont inutilement cherché la solanine dans le tubercule de la pomme de terre; mais Baup et y. Jul. Otto de Brunswick 
('n ont extrait des germes, ct on peut croire que le jenne tubercule pent 'n contenir lui-même, en raison des lígers accidents dont son ingestion est quelquefois suivic.

On extrait très en grand la fécule de pomme de terre, en râpant les tubercules au-dessus de vases pleins d'ean. On divise la pulpe dans l'eat, on jette le tout sur des tamis, qui laissent passer l'eau et la fécule; on laisse reposer, on lave le dépôt plusieurs fois et on le fait sécher.

la fécule de ponme de lerre a la forme d'une poudre blanche et éclatante, beaucoup moins fine que celle de l'anidon de blé; vue au microscope, elle affecle loutes sortes de formes, depuis la spliérique qui appartient aux plus petits, jusqu'à l'ellipticjue, l'oroüde ou la triangulaire observée daus le's plus gros ( firg. 211). Les petits granules sont d'ailleus jen nombreux; l's autres présentent souxent une surface

Fig. 211.

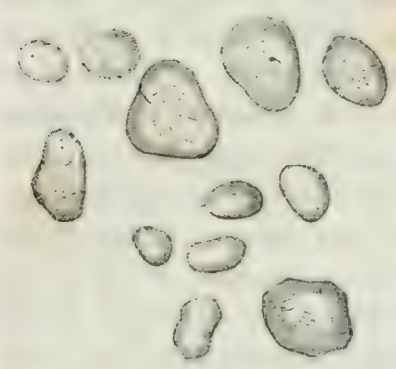

bosselée et des stries irrégulièrement concentriques autoür du hile, qui est situé vers l'une des extrémités du gra. nule. La fécule de pomme de terre est tout à fait insoluble dans l'eau froide et s'y conserve pendant longtempls sans altération; une forte trituration on la porphyrisation, même arec l'intermède de l'eau, sulfit pour la rendre en partie soluble. Eille forme avec l'eau bonillante un empois bien moins consistant que

l'annidon de blé, et son tégnment peut disparaitre enticrement par une ábullition longlemps prolongée dans une suffisante quantité d'eau (roir aussi précédemment pages 130 et 131 ).

On emploic beaucoup dans les cuisines, sous le nom de comare ou ponme damour, le fruil du solemum lyrepressicum I., dont on a fait depuis un gemre particulier sous le nom de lycopersicum psententum. Corte plante ressemble aux solemum par sa corolle rotacée el ses anthere's comnirentes, et se rapproche plus particulierement de la pomme de terre par ses fenilles supérieures, qui sont pinnés arec impaire et incisces. Ses caracteres particuliers consistent daus son calice et sa corolle it 7 divisions (rarement 6 on 5 j; par ses étamines en mime nombre et par son fruit a 7 lobes arrondis de a 7 logere intericures, contenant des graines velues. I.e fruit est d'ailleurs de la grosseur d'une pemme, d'un ronge vif, lisse et brillant, rempli d'une pulpe orangée, aigrelete, et d'un parfum doux et agréable. On con fait des sances très estimées. La

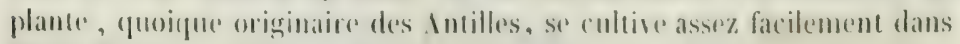
les jardins. 


\section{Baie d'Alkélienge.}

Physul is .lliekengi L. Celte plante est encore très voisine des morelles et ressemble assez à la morelle noire, quoique étant plus droite et plus élevée. Sa corolle est rotacée, à 5 divisions; ses 5 étamines sont connirentes par les anthères; mais le calice prend, après la chute de la corolle, un développement considérable, et forme une ressie membraneuse, colorée en rouge, qui renferme la baie également rouge, lisse, succulente et de la grosseur d'une petite cerise. Cette baie est aigrelette el un peu amère; elle passe pour diurétique et laxative. Elle entre dans la composition du sirop de rhubarbe composé.

\section{piment tes jardins.}

Corail des jardins, poivre dinde, poivre de Guince, (nIpsifmm tmmunm L. Car. gén. : calice persistant, à 5 divisions ; corollo à umbe très court, à limbe rotacé, à j lohe's; jo ctamines cusertes dont les anthères oblongues sont comniventes al s'onvrent sur leur longuenr ; baie seche, renflée, à 2 lnges incomplètes, par suite de loblitíanion de la cloison ci des trophospermes; semences nombrenses, réniformes.

Le copsicum ammum, originaire des Indes, est généralement cultivé aujourd'hui en Ifrique, en Imérique, en Espagne, dans le midi de la france, et juscjue dans nos jardins, ì cause de son fruit qui est doué d'une âcreté considérable, ce (ui le fait employer comme stimulant et assaisonnement dans l'art culinaire. C'est une plante annuelle, luerbacée, haute de 30 à 35 centimetres; sa tige est cylindrique, presque simple; ses feuil'es sont alternes, quelfuefois géminées, longruement pétiolées, ovales-aiguës, tròs entières; les lleurs sont solilaires, latlérales; le calice est trìs ouvert at la corolle blanchàtre; son fruit "sl do forme et de volume variables; mais ordinairement gros el long comme le pouce, conique, un peu recomrlé à l'extrémité, lisse ct luisant, vert avant sa maturité, d'un rougge éclatant lorsqu'il est mûr.

Quelle yue soit la sareur àcre et causligue de ce fruit, elle n'est pas comparable à celle des piments cultivés dans les Indes et en Améripue, soit que le climat cause cutte différence, on que ce soit la diversité d'espèce; et cependant les Indiens, les Portugais, les Espagnols et les autres habitants de ces pays, en font une si grande consommalio r dans leurs ragoùts, que, au dire de Frezier, une seule contrée du Pérou en exportait chaque année pour plus de 80000 écus.

Voici les caractères de deux de ces piments trouvés dans le commerce, où on les désigne sous le nom de piment enragri.

Piment de Cayenne, ropsirm fintessens I. Rouge on verditre, 
long de 20 ì 39 millimetres, large de 7 ì 9 a la partire infériullore, rétréci à l'endroit du calice, qui est en forme de gudet; tandis que dans le piment des jardins le caiice est évasé en forme de plateatu. Odeur très àcre, comme animalisée; sareur insupportable.

Piment de l'ile Mauriee. Il est rouge on rert, long de 11 i 18 millimètres, large de 3 à 6 , rétréci en godet ì l'endroit du calicen, muni de pridoncules Iongs de 25 millimetres. Il a une odeur de verdure; il passe pour être le plus âcre de tous.

Le piment de's jardins a été analysé par Mi. Braconinot (. I $1 \mathrm{~m}$. rhim, it physs., t. VI, p. 122).

\section{FAMILLE DES BORRAGINERS.}

Plantes herbacées, arbustes ou arbres, à tiges on rameaux cyllindriques, à feuilles alternes, prirées de stipules, entières ou incirées, plus on moins couvertes de poils rudes, ce qui les fait nommer par plusieurs bolanistes rsperifoliérs. Les fleurs sont tantôt solitaires dans l'aisselle des feuilles, tantôt paniculées ou en corymbe, très sourent en épis ou en grappes terminales, tournées d'un seul côté et roulées en crosse ou en spirale avant leur déreloppement. Le calice est libre, persistant, gamosépale, à 4 ou 5 divisions; corolle hṛpogrne, gamopétale, cadurque, infundibuliforme, sous-campaniforme ou rotacée, à limbe quinquéfide, régulier ou quelquefois un peu irrégulier; la gorge est nue ou fermée par 5 appendices saillants, opposés aux divisions du imbe ou duelquefois alternes. Les élamines sont au nombre de 5 , alternes avec les divisions de la corolle. L'ovaire, porté sur un disque hypogsne, est le plus souvent profondément quadrilobé et formé de 4 carpelles monospermes accolés du còté du centre au sțle qui less traverse. Quelquefois les 4 carpelles sont soudés dans toute leur longueur, forment un oraire indivis, à / loges et portant le style à son extrémité supérieure. Les ovules solitaires sont suspendus au còté interne ou à l'angle interne de la loge. I.e fruit est lantòt un drupe à 4 loges monospermes, tantôt un ashosaire formé de 1 alskoses tout it fait distincts, ou rapprochés deux à deux. I.es semences sont inverses, it cudosperme nul ou très peu abondant, et sont pourrues d'un embryon homotrope, à radicule supère.

La famille des borraginées peut être dirisce d'aburd en deux sousfamilles, suivant la nature du fruit :

$1^{\circ}$ Les ConndacéEs, dont l'ovaire est indiris, le strle terminal et le fruit drupace; elles comprennent trois tribus: les rmdires, les thiliées et les héliotropiées.

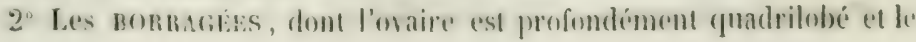


fruit formé de 1 askoses séparés (1). M. Mpph. De Candelle les divise

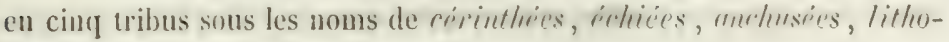
spermées et cynoglossées.

Les borraginées se rapprochent des labiées par la disposition de leur fruit, mais n'ont presque aucun rapport arec elles, soit pour leur forme générale, soit pour leurs propriétés. Ce sont en général des plantes inodores, mucilagineuses, quelquefois faiblement amères ou astringentes, souvent chargées de nitrate de potasse, complétement dépourrues de principes àcres ou rénéneux; qquelques unes, faisant partic de nos plantes indigènes, sont encore usitées en médecine.

\section{Sebestes.}

Les scbestes sont les drupes desséchés du corrlin mixe L., arbre originaire de l'Inde, qui a été transporté il y a fort longtemps en Ég!pte, d'où les fruits nous renaient autrefois. Ils sont longs de 16 à 20 millimètres et ont l'apparence de petits pruncaux desséchés. On en trouve deux rariétés dans les droguiers; les uns sont grisâtres, d'une forme ovale, pointus aux deux cxtrémités et sont formés d'un brou see et très mince, appliqué contre le noyau dont il a pris la forme; les autres sont noirâtres, arrondis et formés d'un brou épais et succulent déformé par la dessiccation. On troure mêlés avec ces fruits les calices persistants, striés et érasés, qui le's embrassaient à la partie inférieure. Le noyau est volumineux, de consistance ligneuse, ovoïde, un peu aplati et un peu élargi dans le sons de son plus grand diamètre par un angle proéminent. Il présente une surface très inégale, comme caverneuse ou sillonnée; à l'intérieur il présente $4 \operatorname{loges,~dont~1,2~on~} 3$ sont toujours très oblitérées, de sorte que le fruit est réduit à 3,201 une seule loge séminifère. L'intérieur des loges fertiles est tapissé d'une membrane très blanche. Les semences renferment, sous un épisperme membraneux, un embryon privé d'endosperme, à radicule supère, et i cotylédons formant un grand nombre de plis frangés, conformément à la description qu'en a donnée Gartner (De fruet. I, P. 364, tab. 76, fig. 1).

La chair des sehestes est très mucilagineuse et un peu sucrée. On les employait autrefois comme arloncissants et légèrement laxatifs, dans les affections bronchiques et pulmonaires; ils sont aujourd'hui complétement inusités.

(1) Excepté dans le genre cerinthe, dont l'oraire se sépare cu deux carpelles biloculaires. 


\section{Bourache ou Bourrache.}

Borugo offuciurlis $\mathbf{L}_{\text {. }}$ Car. gín. : calice à 5 divisions; corolle rotacée, pourvue à la gorge de 5 écailles échancrées; limbe quinquéfide, à divisions ovées el acuminées; 5 étanines insérées à la gorge de la corolle, exsertes; filaments très courts, pourvus extérieurement à la partie supérieure d'un appendice cartilagineux; anthères lancéolées, acuminées, connirentes en cône; ovaire quadrilobé; style filiforme, stigmate simple; 4 askoses distincts, excavés à la base, portés chacun sur un disque renflé.

La bourache est annuelle et s'élève à la hauteur de 50 centimètres environ; sa tige est ronde, creuse, ramifiée, munie de feuilles alternes, les inférieures pétiolées, les supéricures sessiles et amplexicaules; elles sont orales, vertes, très ridées, ondulées, courertes de poils très rudes, ainsi que la tige et toutes les parties vertes. Les fleurs naissent an sommet de la tige et des branches, portées sur de longs pédoncules penchés d'un mème côté, et formant par leur ensemble une panicule très lâche. las fleurs, d'abord purpurines, deviennent d'un très beau bler. Les askose's mûrs sont ovoüdes, noirâtres, ridés et scrobiculés.

Toutes les parties de la bourrache ont une odeur un peu vireuse el sont remplies d'un suc fade, très visfueux, abondant ch nitrate de potasse. Elle pousse à la sueur et aux urinc's, élant administréc cn infusion théiforme, et est cmployée arec arantage, comme tompérante, dans les fières ardentes, bilieuses et éruphires, dans les engurgements du foic, etc.

\section{Viperrine commune.}

Erhium velfyare L. Galice à 5 divisions linéaires-lancéolées, souségales. Corolle infundibuliforme, à gorge nue, à limbe oblique et à 5 lobes inégaux, arrondis; étamines dont les filets sont soudés inférieurement au tube de la corolle, libres supérieurement, inégaux; anthères fixées par le dos; style filiforme, stigmate bilobé, 4 astoses distincts, à base triangulaire, imperforés, turbinés, rugueux, coriaces.

Ia vipérine est une plante bisannuelle, très commune dans les lieux incultes et sur le bord des chemins; sa tige est droite, simple inférieurement, chargée supérieurement de rameaux latératux florifères. Elle est hérissée de poils rudes, insérés sur des points bruns qui lui domment (quelque ressemblance arec la peau d'une vipère, d'où lui est venu son nom. Ses fenilles sont lancéolies lincaires, herissees ainsi que les calices de poils semblables a ceux de la tige. Les fleurs sont 
presune sessiles, disposiés en épis lateraux, simples, feuillés, roulés à leur extrémité; elles sont pourvues d'une corolle pourprée, devenant bleue, deux bis plus longue que le calice. Ces fleurs conserrent leur couleur blene par la dessiccalion, bien mieux que celles de bourrache, et cela est cause qu'clles sont très somvent rendues en place de cette dernicre, daus le commerce de l'herboristerie. Elies sont faciles à distinguer à leur corolle lubuleuse, dépourve d'appendices à la gorge.

\section{Buglose.}

Genre amrhusu : calice à à divisions; corolle it tube droit ç lindrique, à limbe oblique à 5 divirions, à gorre fermée par 5 érailles voùtées, obtusers, opposées aux slivisions du limbe. Inthères incluses; ovaire quadrilobé; 4 askoses mís du foud du calice, rugueux, à base concave perforée et pourvue d'une marge renflée et striée.

On emploie indifferemment deux especes de buglose qui se ressemblent par leurs tiges dressies, hispides, hatutes de 60 centimitres environ, garnies de feuilles lancenlies, plus on moins comites, ct par leurs flems rouges passant an bleu, disposies a la partie superieure des tiges eil épis paniculés. On anduct que la première, plus abondante dans le nord de l'Europue, et nommée par linné anchenst offerimalis, a les dirisions du calice moins profondes et moins aiguës, les ácailles vontérs de la grorge seulement veloutés et le limbe de la corolle regulier ; tandis que la seconde espèce, plus commune dans le vidi, décrite aussi par un grand nombre de botanistes sous le nom d'onclmsart offirinulis, mais nommée aujourd'hui morlunsu itulicn, a les divisions du calice plus profondes et plus aignëe, les appendices de la corolle longuement barbus ou pénicillés, et les divisions du limbe inégales. De plus, les fleurs sont tomrnées d'un senl côté le long d'épis grêles et géminés. Au reste, ces deux plantes peurent être employées indifféremment, et jouissent des mêmes propriétés que la bourrache, à laquelle elles sont sourent substituées.

\section{Pnlmonaire onlicinale.}

l'ulmunuriu officinulis I. Car. grins. : calice yuinguéfide, pentagone, campanulé après la floraison. Corolle infundibuliforme, à tube étroit, fermé à la gorge par 5 faiscanx de poils alternes arec les ćtamines; 4 asko:es distincts, turbmes, lisses, à base tronguée et imperforée.

La pulmonaire officinale pousse de sa racine des feuilles larges, ovées, prolongées en ailes étroites le longr du pétiole, el une ou plusieurs tiges portant des feuilles plus petites et sessiles, et terminée's chacune par 
deux ou trois grappes de fleurs purpurines ou bleues. Toute la plante est courerte de poils rudes et les feuilles sont presque toujours marquées de larges taches blanches, dues à un état particulier et glanduleux de l'épiderme. Ce sont ces taches, qui ont été comparées à celles présentées par un poumon coupé, qui ont fait donner à la plante le nom de pulmonaire; peut-être aussi ce nom lui vient-il de l'usage rgu'on en fait dans direrses affections du tissu pulmonaire.

La plante, nommée julmonaire de chène, est une espèce de lichen dont il a été parlé page 76.

\section{firande Consonde.}

Symphytum officinale L. Car. gén. : calice à s divisions; corolle cylindrique-campanulée, dont la gorge est fermée par cing appendices

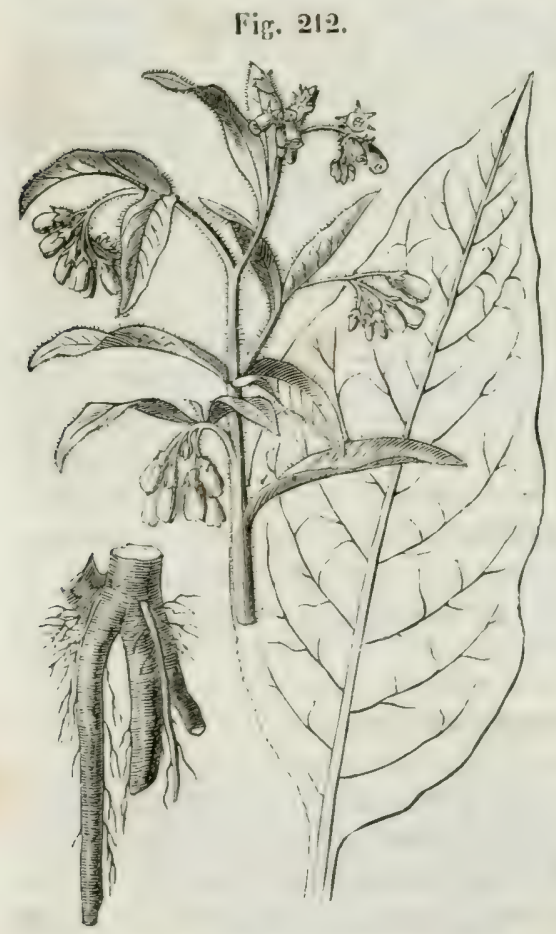
subulés, connivents en cône ; limbe à 5 dents; 5 étamines incluses, dont les anthères acuminées alternent arec les appendices; ovaire quadrilobé, style simple, stigmate obtus; 4 askoses distincts, ovés, rugucux, perforés à la base et ceints d'une marge renflée.

La grande consoude (fig. 212) crôt dans les lieux bumides et s'élève à la hauteur de 60 à 100 centimètres. Ses liges sont quadrangulaires, velues et rudes au toucher, ainsi que les feuilles. Ciellesci, près de la racine, sont très grandes, ovées-lancéolées et aniucies en pétiole; celles de la tige sont lancéolées, sessiles ou décurrentes, les supérieures sourent opposécs. Les feurs sont disposées en grappes unilatérales sonvent géminées; elles sont blanchâtres, jaunîtres ou rosées.

La racine de grande consoude est longue de 30 centimètres environ, grosse comme te doigt, succulente, facile à rompre, noiràtre au 
dehor's, blanche, pulpeuse et mucilagineuse en dedans, d'un gout visqueux, d'une odeur peu caractérisée. Elle c'st adoucissante et un peu astringente; elle entre, ainsi que les feuilles de la plante, dans la composition du sirop rui porte son nom. On les cmployait également autrefois dans la préparation de plusieurs médicaments externes destinés à cicatriser et runsolider les plaies, et c'est de là que la plante a tiré le nom de comsolide ou de consoude. On lui a donné le surnom de fromele, pour la distinguer d'autres plantes auxquelles les mêmes propriélés, vraies ou supposées, araient fait donner le même nom. Ces dernières plantes étaient : le consulidn medio (ajugn reptons L.), on la bugle; le consolida minor (brllis peremnis L.), ou la pàquerette; le consolidn regalis (delphinimn consolidn $\mathbf{L}$.), ou le pied d'alouette.

\section{Racine te Cymoglosse.}

Cymuglessmu "ffirime L. Car. gén. : calice à 5 divisions; corolle infundibuliforme dont le tube est ì peine plus long que le calice, fermée à la gorge par 5 appendices obtus; limbe à 5 divisions très obtuses; étamines incluses; 4 askoses imperforés à la base, fixés latéralement à la base du style et hérissés de piquants.

La cynoglosse officinale (fig. 213 ) s'élève à la lauteur de 6.5 centimètres; sa tige est simple inférieurement, ramifiée dans sa partic supérieure, garnie de feuilles sessiles, ovéeslancéolées, d'un rert blanchâtre et toutes courertes de poils rudes. Ce sont ces feuilles, comparcées à la langue d'un chien, qui ont fait domner à la plante le nom de cynoglosse. Les fleurs sont rouges on bleues reinées de rouge, disposées en grappes lâches et tournées d'un seul côté. La racine est longue, grosse, charnue, d'un gris foncé au dehor's, blanche en dedans, d'une sareur fade et d'une odeur vireuse. C'est sans doute cette odeur qui a fait penser que la racine de cynoglosse était narcotique ou calmante; ct comme elle se manifeste principalement dans l'écorce, on rejette le meditullium pour ne faire sécher que la partie extérieure. Celte

Fig. 213.

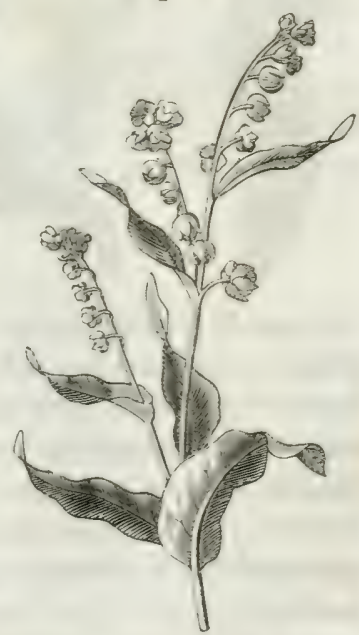
partie corticale, réduite en poudre, fait partie des pilules de cynoglosse. Elle altire fortement l'humidité, et doit ètre conservée dans un endroit sec. 


\section{Sacine d'oreanette.}

Allinune tinctorin Tausch.; melusu tinctorin L., Lan. et Willd.; lithospermum tincturium $\mathrm{DC}$., non Willd. Car. gén. : calice à 5 divisions; corolle régulière à tube souvent poilu intérieurement à la base, dilaté à la gorge, pourvu souvent, au milieu, de rugosités calleuses transversales; lobes obtus; étamines incluses; appendices nuls à la gorge; oraire quadrilobé; askoses souvent réduits à 2 ou 1 par asortement; réticulés ou rugueux, fortement courbés, à base plane, stipités, portés sur un torus subbasilaire.

L'orcanette (fig. 214) croît dans les lieux stériles et sablonneux tout antour de la Méditerranće; elle pousse plusieurs tiges étalíes, longues

Fig. 214.

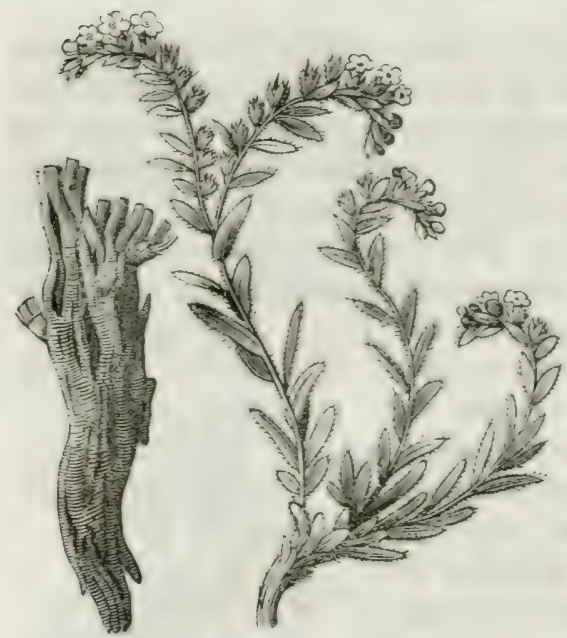
de 22 centimètres, très velues comme tout le resle de la plante; les feuilles sont sessiles, oblongues; les épis sont feuillus, tournés d'un seul côté; les calices courerts de poils, à divisions linéaires un peu plus courtes que le tube de la corolle; les élamines sont alternes avec les gibbosités du tube, 3 insérées entre elles, 2 insérées au dessous; les anthères sont attachées par le milieu du dos; les askoses sont tuberculeux.

La racine d'orcanette, telle que le commerce nous lollie, est grosse comme le doigt, formée d'une seorce foliacée, ridíe, d'un ronge violet très fonci; sons cette écorce se troure un corps ligneux compose de libres c!lindripues, ordinairement distinctes les unes des autres et senlement atcolies ensemble; elles sont rouges également à lextériemr, mais blanches intiriemrement. La racine entiere est inodore el prescune insipide. On l'emploie cians lat teinture, et en pharmacie pour colorer quelyunes peunsmades.

La matiere colorante de l'orcanelte a été examinér par 31 . Pelleties. Elle est insoluble dans l'eau, soluble dans l'alicool, l'éher, les luniles et tous les corps gras, auxquels elle communique une belle couleur 
ronge. Lille forme, arec les alcalis, des combinaisons d'un bleu superbe, solubles ou insolubles; précipitée de sa dissolution alcnolique par des dissolutions métalliques, on en obtient des laques diversement colorées, que l'on pourrait utiliser. (Bulletin de pharmacie, 1814 , p. 445 .)

Plusieurs autres plantes de la famille des borraginées sont pourvues de racines rouges qui peurent être substituées à celle d'orcanette. Telles sont, dans le midi de la lirance, l'omsmu echioides, et, dans l'Orient, l'arnethin tinctoriu Forsk. (lithospermun tinetorium Vahl) et les arnebiu peremnis et tingens d'. Ipls. De Candolle. Il ne faut confondre aucune de ces p'antes avec celle qui porte dans l'Orient le nom de henné (1), qui a servi de tous temps, aux peuples de l'Asie, aux ligytiens et aux Arabes, à se teindre les mains, les chereux, la barbe, les ongles et différentes parties du corp̣s en rouge jaunâtre. Ie lienné, qui "st le "yymus des anciens Grees, l'allitmun ou le tmmerhendi d'A vicennes, est un arbrisseau de $2^{\text {nin }}, 6$ de hauteur, dont les feuilles sont opposées, courtement pétiolées, elliptiqunes, pointues aux extrémités et longues de 25 millimètres. Les fleurs répandent une odeur hircine; on en prépare une cau distillée dont les peuples de l'Orient se parfument dans les visites et dans les cérémonies religieuses, telles que celles de la circoncision et du mariage. C'est sans doute à cause de cette même odeur que les Ilébreux répandaient des fleurs de henné dans les habits des nouveaux mariés et que les ligytiens (n conservent dans leurs appartements. Ce sont les fenilles qui servent à la teinture; on les ramasse avec soin, on les fait sécher et on les rédnit en poudre grossière dans des moulins. Il suffit, pour s'en servir, d'en former une pâte arec de l'eau, et d'en recourrir les parties du corps que l'on veut teindre. Après cinq ou six heures de contact, Jorsque la pâte est desséchée, les parties couvertes se trourent teintes d'une manière durable.

\section{Grémil ou Herbe-aux-Perles.}

Lithospermum officinule I. Car. gén. : calice à 5 divisions; corolle infundibuliforme ouverte, à gorge nue on plus rarement offrant 5 gibbosités alternant arec les étamines; anthères oblongues, très courtement stipitées, incluses; stigmate en tête, sous-bilobé; askoses tronqués et imperforés à la base.

Le grémil rient dans les lieux incultes; sa tige est herbacée, haute de 60 centimètres, garnie de fenilles sessiles, lancéolées, courertes de poils couchés, très courts. Les fleurs sont petites, blanchâtres, courte-

(1) Lawsonia inermis, famille des lythrariées. 
ment pédonculées et solitaires dans l'aisselle des feuilles supérieures. Les askoses sont d'un gris de perle, arrondis, durs et lisses, réduits i 2 ou 1 dans chaque calice, par l'asortement des autres. On attribuait autrefois, bien gratuitement, à ces grains, la propriété de dissoudre on de disgréger la pierre dans la ressie. Elles sont aujourd'hui complélement inusitées.

\section{FAMIILLE DES CONVOLVULACÉES.}

Herbes ou arbrisseaux dont la tige est très souvent volubile, it feuilles alternes, cordiformes, entières ou palmati-lobées, privées de stipules; fleurs complètes, régulières, dont les pédicelles portent très souvent deux bractéoles quelquefois rapprochées du calice et accrescentes après la fécondation; calice à jo sépales, sur une, deux ou trois síries, persistants, souvent accrescents igalement. Corolle insérée sur le réceptacle, gamopétale, campanulée, infundibuliforme ou lı̣pocralériforme, à limbe presque entier, plane ou à 5 plis; 5 ćlamines à anthères introrses, biloculaires; oraire quelquefois ceint a la base par un anneau charmu; le plus sourent indivis (gamocarpe), à 2, 3 ou 4 loges; quelquefois divisé ou npecrnpe, formé de 2 carpidies unilocnlaires, ou de 4 carpidies réunies par paires; orules soliaires ou giminées dans chaque loge. Style central et basilaire dans l'ovaire apocarpe (1), terminal daus l'oraire gamocarpe, indivis, bifile ou bipartagé; sligmate simple très souvent bilobé; fruit capsulaire, à déhiscence valvaire, ou bacciforme et indéhiscent; de 1 ì 4 logres monospermes ou dispermes; semences arrondies par le dos, glabres ou villeuses, insérées vers la base de l'angle interne des cloisons; testia dur et noiràtre; albumen uncilagineux; cotylédons foliacés et plissis dans le plus grand nombre, épais et droits daus les merripu, nuls dans les cuscutes, qui sont de perites plantes prasites et privées de fenilles, comprises dans la famille des convolvulacées.

Les convolvulacées nous présentent un grand nembre de plantes pourves d'un suc gommo-résineux purgatif, très abondant dans le jalap, la scammonée, le turbith, et que l'on retrouve également dans les liserons de notre pays; mais toutes ne sont pas pourvues de ce principe purgatif, et deux, entre autres, font une exception bien grande it la loi des analogies : l'une est la patate (bututus edulis), dont les racines produisent des tubercules semblables it ceux de la pomme de terre, amrlacés, sucrés et très nourrissants; l'autre est le liscron à

(1) Ce caractère montre l'analogic des comblvulacies qui le présentent. avee les borrayginces, et d'une manière plus èloignée avec les labiées. 
ndeur de rose des C'anaries, dont la racine est gorgie d'une huile volitile analogue à celle de la rose.

La famille des convolvulacies ne comprenait guère an commencement que les genres comrolvelus et ipmmere, déja assez peu dis tincts, et cependant le nombre des espèces s'y est successirement multiplié à un tel point que les botanistes ont senti la nécessité de les diviser en un plus grand nombre de genres dont roici les principaux, arec l'indication des espèces les plus importantes qui s'y trourent comprises. Je reviendrai ensuite sur celles qui sont réritablement officinales.

Irgirema : corolle campanulée; stigmate en tète, bilobé ; ovaire biloculaire, tétrasperme; fruit bacciforme sourent entouré par les sépales du calice indurés et rougis.

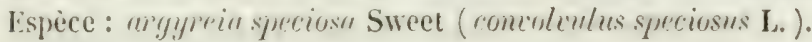

Quanocr.it : corolle cylindrique; étamines exsertes; stigmate en tête, bilobé; oraire ruadriloculaire à loges monospermes; herbes rolubiles.

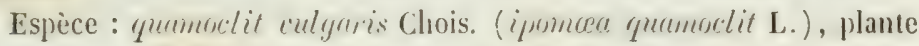
originaire des Indıs orientales, remarquable par ses feuilles pinnatifides, à divisions presque filiformes et par ses fleurs d'une belle couleur écarlate.

BataTAS : corolle campanulée; étanines incluses; stigmate en lète, bilobé; ovaire quadriloculaire ou, par avortement, tri-biloculaire.

Espèces : bututas jalupu rihois. (comerolenlus julupu L.). Plante à lacpuelle on a faussement altribué pendant longtemps le jalap officinal.

Butntas edulis Chois. (comiolculus butatas L.), patate eomestible. Plante originaire de l'Inde, à tiges herbacées, rampantes, longues de 2 à 3 mètres, prenant racine de distance en distance; feuilles le plus sourent hastées, ou à 3 lobes; fleurs disposées presupu'en ombelle's sur des pédoncules axillaires plus longs que les feuilles; racines fibreuses produisant des tubercules ovoïdes, blancs ou james, amỵlacés et sucrés.

PHarisits : corolle campanulée; stigmate arrondi granuleux; oraire à 3 loges, rarement à 4 ; loges dispermes.

Plumbitis hispidn Chois. (comeleulus purpureus L.). Plante volubile, originaire de l'Imérique méridionale, très cultivée dans les jardins pour ses grandes fleurs d'un pourpre violet, quelquefois conpées de bandes blanches.

Caroxyctox: corolle infundihuliforme très grande, imitant celle 
des doturu; étamines exsertes; stigmate arrondi bilobé; ovaire biloculaire ou sons-quadriloculaire et à \& ovules; pédicelles charnus.

Calonyction speciosum Chois. (ipomoen bronu-nox L.).

Exogoniun : corolle tubuleuse; etamines exsertes; stigmate arrondi, bilobé; ovaire à 2 loges biovulées.

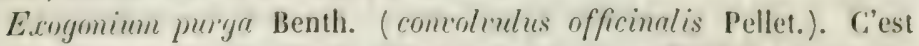
cette plante qui produit le jalap tubérenx ou vrai jalap officinal.

Iponok : corolle campanulée; élamines incluses; stigmate en tête, souvent bilobé; ovaire biloculaire à loges dispermes; capsule biloculaire.

Ipomcea turyethum Br. (concolculus turpethum L.) ; racine purgative, turbith des offieines.

Iprmaec operculnen Mart. Racines purgatives usitées au Brésil.

Ipomue arizabcusis Ledanois; jalas male ou jalap fusiforme.

Coxrorrudus : corolle campanulée; 2 stigmates linéaires-cylindrique's; oraire biloculaire à leges biovulées; capsule biloculaire. Plantes volubiles et non volubiles.

Comoleulus scopurrius $\mathbf{L}$. Liseron des îles Canaries produisant le bois de IBhodes des parfumeurs.

Concolvulus artensis L., liseron des champs; jolie plante volubile, à feuilles sargittées, à pédoncules unis ou biflores, à corolles roses ou blanches, qui croît dans les blés et dans les jardins, où elle est très difficile à détruire, à cause de ses racines fort longues, profondes et très menues.

Comeoleulus hirsutus Stev.; ligge strice allongée, toute converte d'un duvet blanc; feuilles velues, cordés hastées; pédoncules très longess uni-triflores, munis de hractéoles linciares et velues; corolle velue audehors, capsule très relue. Cette plante croût dans l'Asie-Mineure et dans l'île de Samos où, suirant Tournefort, clle produit une sorte de scammonée de qualité inférieure.

Comedemlus strmmmonin L.; liseron produisant la seammoné alsep.

Carystegia : deux bracliés opposées entourant la fleur; corolle campanulée; stignate bilobé, à lobes linéaires ou oblongss ovaire biloculaire, quadriloculaire au sommet, à cause d'une cloison incomplète.

rulystegin sepium Brown (concolculus stpium L..), wrand liseron des haries. liacines vivaces, longues, mentes, blanchattres; liges grêle's, volubiles, hautes de 2 ì 3 mètres; feuilles pétiolées, glabres, d'un vert fonce, sagittees, les denx lobes latéranx trongues: fleurs so- 
litaires, longuement pédonculées, munies, à la base du calice, de deux grandes bractées; corolle blanche, entière; anthères sagittíes; stigmates orales, grenus. Les cheraux mangent cette plante avec plaisir, mais non les vaches; la racine est purgative et peut fournir une résine purgative.

Culystegiu soldanella Brown (romeolvulus soldmellu L. ); soldanelle (1) ou chos marin. liseron maritime. Racines grêles, blanchâtres vivaces; lige conchée, ramifiée, garnie de feuilles réniformes, glabres, longuement pétiolées; les fleurs sont roses, longuement pédonculées, de couleur rose rayée de blanc; le calice est muni à sa base de deux grandes bractées. Cette plante est commune dans les sables, sur les bords de l'Océan et de la Méditerranée; sa racine pulvérisée purge bien ì la dlose de 3 ì 4 grammes; la résine purge à la dose de 1 gramme à $1 \mathrm{gr}^{\circ}, 5$.

\section{Racine de Jalap ominal ou tubéreux.}

Le jalap tire son nom de linlupu, ville du Mexique, auprès de laquelle la plante yui le produit parait être fort commune; mais cette plante a été le sujet de beauconp) de controverses : on l'a considérée successirement comme une lryone, une rlublumbe, un liseron, une belle-de-muit, enfin, et avec raison, comme un liseron; mais pendant très longtemps elle a été confonduc avec d'autres plantes du même genre, et l'on peut dire même qu'elle était véritablement inconnue.

1)'après quelques auteurs, Monardès est le prenier qui ait décrit le jalap, dans son Histrive des médiernrents du nruecen monde, publiée ('n 1570 ; mais, dans cer ourrage, Monardes traite seulement du méchour:m, apporté en Europe trente ans aupararant, c'est-ì-dire en 1540 ; et il n'ajoute que peu de mots sur deux autres racines purgatives apportées de Xicaraga et de Quito, dont l'une peut bien être le jalap, mais yu'il se contente de nommer mechoucren sumerye.

I.e premier auteur qui ait vraiment parlé du jalap est Gaspard Baulin, qui, dans son Prodromus theutri botunici, publié en 1620 , le décrit bien sous le nom de Bryona merhoucrana nigricans, ab Alexandrinis et Massiliensilus Jalapium dicte (2). In le nomme anssi méchoa-

(1) Il ne faut pas confondre cette plante avec la soldanclle des Ipes, soldanella alpina L., de la famille des primulacées; il existe pareillement une autre plante du nom de chun marin, e'est le crambe maritima, de la famille des crucifères.

(2) Antoine Colin, apothicaire de Lyon, a décrit le jalap un peu avant Bauhin el d'une manière plus précise, dans sa traduction de l'ourrage de Monardés, de laquelle j’ai une seconde édition publiée en 1619. Voici ce 
rfm moir ou mâle, et en fait remonter l'arrivéc an Enrope onze ans auparavant, c'est-ì-dire en 1609 . Il ne paraît pas avoir éu comnaissance de la plante qui le produit.

Les botanistes qui vinrent après lui (Ray Plukenet, Sloane) firent du jalap) un crmerolenlus; Tournefort, sur le témoignage de Plumier et de Lignon, le mentionna sous le nom de julapa (mirrabilis L.), officinmmu fructu mugoso. Linné l'altribua ensuite au mirabilis lomyiflurn, et Bergius au mirubilis dichotume, dont la racine lui avait offert une propriété purgative beaucoup plus marquée que celle des autres espèces. Cependant déjá IIouston avait rapporté d'Amérique une plante à racine purgative et semblable au jalap, que Bernard de Jussieu reconnut ître un liseron. Celte plante fut communiquée à Linné qui la nomma convolvulus jalripa.

Thierry de Ménonville, qui a visité le Mexirgue en 1777 , a décrit une plante trourée près de la Vera.Cruz comme étant celle qui produit le jalap; une des racines qu'il en tira pesait 25 lirres. Cette plante était la même que celle de IIouston et de Linné, et ne différait pas non plus de celle que Michaux arait décrite sous le nom d'ifmuren imurmorhiza, et dont il arait enroyé au Jardin des Plantes de Paris des semences, et une racine pesant plus de 50 jirres. II. Desfontaines en fit une nouvelle description dans le II volume des. A unules du. I/usinum sous le nom linnéen de crmelivelus julopor. Personne ne doutait que celte plante, qui est le bututus jalupa Chois., ne produisit en effet le jalap officinal ; c'était cependant une erreur.

En 1827, le docteur Redman Coxe, de l'unirersité de Pensỵlranie, reçut de Xalapa la rraie plante au Jalap et la cultisa dans son jardin. Il la décrivit dans l'American journul of the mediral scienres, febr. 1830; mais il la crut encore semblable ì l'iprmmen macruidizar et il lui domna le nom d'ipuneen jalnpe vel mucruhiza. C'est II. Daniel Smith qui, dans un lémoice inséré dins le Junenul of the philarl. phrerm. jan. 1831 , a démontré la différence des deux plantes, et a émis l'opinion que la plante décrite par le docteur Cose devait être la seule qui produisît le jalap officinal.

D'un autre côté, II. Ledanois, pharmacien françăis qui a demeuré au Hexique, n’arait rien négligé pour éclaircir ce point important

ru’il en dit (proue 131) : "La racine de méchoacan domestigue et sauvage ") me remet en mémoire une autre nouvellement apportée en France, laçuelle " est de grrand usage parmi nous, pour évacuer les eaux ef sérosités. Nous "l'appelons racinc de jalap. Elle ressemble fort au méchoacan, encore s) qu'elle soit plus ronde, pas si grosse, et de lia ligure d'une poire de moyeune "Eroseur; clle est beaucoup plus compacte, plu- "rive-noiratre ave des " cornes antour de la racine, " 
dhistoire naturelle médicale. Dans les premiers mois de l'imnie 1827, aussitot après son arrivér à Orizalba, ville du Hexirgue, il s’était efforcé de se procurer la rraie plante au jalap); mais les indigènes avaient refusé toutes ses offres, dans la crainte de se roir enlever une des sources de leur fortune. Entin l'un d'eux, qui avait l'habitude de lui rendre du jalap sec, étant pressé d'argent, lui apporla des racines dans un élat imparfait de dessiccation; 11 . Ledanois les mit en terre et eut le plaisir de leur roir produire plusieurs plantes complètes. Il en adressa une courte description à $\mathbf{3}$. Chevallier, dans une lettre qui fut lue à l'Académie royale de médecine, le 8 août 1829 (Jour p. 478), et en enroya des échantillons à $\mathbf{Y}$. de Humboldt à Paris, joints a cenx d'une autre esprece désignée sons le nom de jullu! mrile. Malheureusement la lentre d'envoi fut égarée, on Desfontaines, chargé par l'Académie des sciences de faire un rapport sur cesplantes, était trop persuadé (jue la plante décrite par lui-même était le vrai jalap, pour faire beaucoup d'allention aux assertions de M. Iedanois (Jomrn. de rlime méd., t. VII, p. 85, et t. IX, p. 520). Cee ne fut qu'après le retour en France de H. Jedanois que l'on put se convaincre, par les échantillons qu'il me remit, et qui furent décrits arec soin par \$I. Gabriel Pelletau sous le nom de convolvulus officinalis (Jounn. de chim. méd., t. X, p. 1), des droits de ce pharmacien à la découverte de la plante du jalap officinal.

Voici en quoi la plante au jalap ou le convolvulus officinalis (fig. 215 ), que je nomme anjourd'hui, avec 11. Bentham, exogonium purya (1), diffère du convolvulus julapa de Linné et de Desfontaines (batatas jalapa Chois.). Le batatas jalapa a la tige rugueuse, les feuilles cordées-orées, rugueuses, velues en dessous, entières ou lobées; less pédoncules sont uni- ou multiflores, les fleurs sont blanches, et les semences convertes de

Fig. 21 .

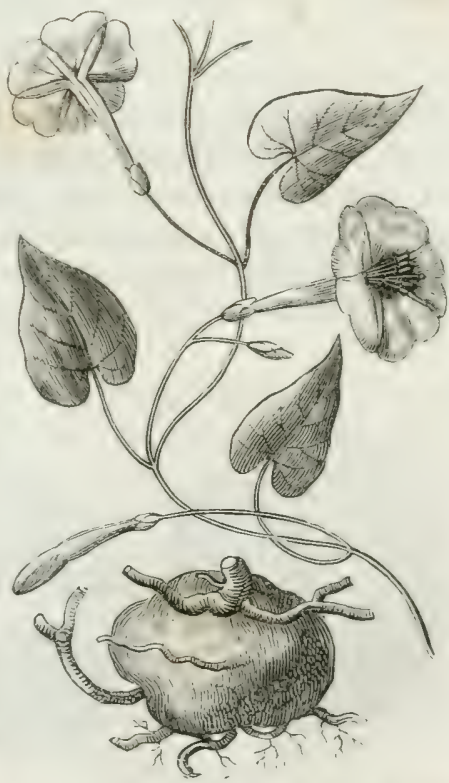

(1) M. Choisy comprend cette plante dans le genre ipomaa, sous le nom d'ipomoet purga (De Cand. Prodrom. IX, p. 37 i). II est cerlain cependant u'elle appartient aux exognonium. 
poils soyenx. Enfin sa racine, très volumineuse, peut acruérir un poids de 25 ì 30 kilogrammes; ce n'est pas la notre jalap officinal.

L'ecogonium pury" Benth., folonpretl des Mexicains, a la racine tubéreuse-arrondie, remplie d'un suc lactescent et résineux; elle est noirâtre extérieurement et blanchâtre à l'mtérieur; quelques radicules partent de sa partie infériemre; et du centre de sa partie supérieure, qui est un peu allongée en poire, s'élere une seule tige ordinairement, mais quelquefois aussi denx ou trois.

I.es liges sont rondes, herbacées, d'un brm brillent, volubiles, et, comme toute la plante, parfaitement lisses.

Les feuilles sont cordiformes, mtirres, lisses, lomguement umemineres, profondément échancrées à la base, et un peu hastécs (?).

Les pédoncules portent uine fleur, rarement deux.

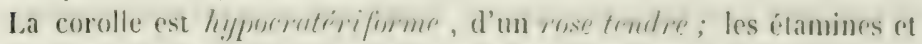
le pistil sont trìs longs ct sortent du tube de la corolle.

\section{Les semences sont lisses.}

La racine de jalap officinal a généralement la forme d'un navet gui serait allongé en poire par la partie supérieure. Ordinaircment une seule tige, un seul tubercule et quelques radicules partant de la partie inférieure, paraissent avoir composé toute la plinte ; mais (puclquefois on troure plusieurs tubercules accolés, et d'autres fois encore les radicules sont remplacées par des lubercules qui naissent de la partic inférieure du lubercule principal, et qui se recourbent en forme de corne, par l'extrémité, pour chercher la surface du sol.

Le jalap) du conmerce (lig. 216) est souvent entier; alors même son poids dépasse rarement une livre, et très sourent il est beaucoup moindre. Presque toujours il est marqué de fortes incisions gu'on y a

Fig. 216.
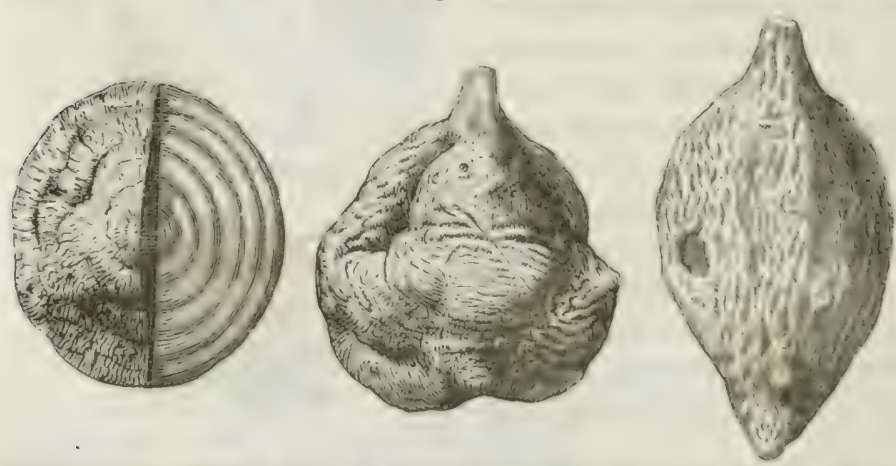

pratiquies pour on fariliter ha dessiecation ; d'antres fois it est entierement roupe par quart on par moitié. Il a ume surfare ruguruse. 
d'un gris reiné de noir: son intéricur est d'un gris sale, sa cassure est compacte, ondulée et à points brillants; il est généralement très pesant; il a une odeur nauséabonde, et me saveur îcre et strangulante. Il est dangereux à piler.

La racine de jalap est trìs sujelte à être pignè des vers. Celle qui offre ce défant ne doit jas être employée pour préparer la poudre, call les insectes n’attaquant que la partie amylacée et laissant la résine, dins laquelle réside la propriété purgative, la poudre en deviendrait trop actire. Mais on peut sans inconvénient emploỵer le jalap piçué à l'extraction de la résine.

Le jalap est un fort purrealif, assez constant dans se's effets, et pririens pour le peuple à cause de sun prix peólevé. On en prépare un extrait agueus, une teinture alcooligue, ot une résine beancoup plus purgative que la racine elle-même.

M. F. Cadet a donné, ainsi gu'il suit, les résultats dle l'analyse de lat racine de jalap : eau 4,8 ; résine 10 ; extrait gommeux 414 ; fécule 2,5 ; albumine 2,5 ; liznewx 29 ; phosphate de chanx 0,8 ; chlorure de potassium 1,6 : carbonate de potasse 1$), 4$; carbonate de clanx 11,4 ; carbo-

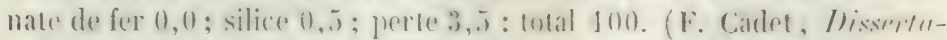

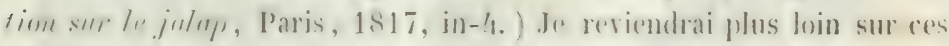
résultats.

\section{Racine de Jalap fuslformc.}

J'ai clit précédemment que 13. Ledanois asait moroyé ì Paris, outre le rrai jalap officinal, la racine ef la plante d'une autre espèce qque l'on drisigne au Mexique sous le nom de jullup urite. Cette racine, dont 11. Smilh a signali levistence dans, le commerce des États-Lnis, se troure aussi cn srande quantite chrz le's droguistes de Paris, qui le nomment julup lingre. Je préfere à ces deux dénominations celle de jalup fusiforme.

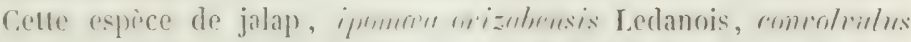
nrizabensis Pell. (Joum. de chim. méd., t. X, p. 10, pl. II, fig. 1), presente une racine grosse, cylindrique, fusiforme, pourant aroir jusqu'ì j't centinetres de long, ramifué dans la partie inferieure. Elle est janne rextérienrement, d'un blanc sale à l'intérieur et lactescente.

La plante est légèrement relue de tuntes parts. La tige est r lindrique, rerte, assez ferme, pen rolubile, et peut se passer de support; les fruilles sont très grandes, arrondirs, profondément cordiformes, conrtement acuminces, velues surtout sur lés nervures infériemres; les pétioles sont aussi velus, de la mème longneur que le limbe.

Les pédoncules sont grêles, uni- rarement biflores.

La corolle est campaniforme, d'un rouge pourpre. plus forte et plus épaisse que celle du rrai jalap, à limbe peu ourert. 
Les élamines et le pistil sont courts et inclus.

Le stigmate est it 2 lobes arrondis et tuberculeux.

La capsule est à 2 loges monospermes.

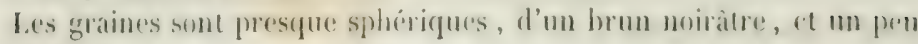
rugheuses.

Le jalap fusiferme (lig. 217) se troure daus le commerce sous forme dre rouelles larges de 55 i so millim. ou en troncons d'un moindre diametre et plus longs; il est profondement rugueux a l'exteriemr, d'un gris plus uniforme dans les tronçons allongés que dans les routlles, qui oftrent souvent une couleur plus noire à la surface et plus blanchatre à l'intérieur. Les uns et les autres présentent i l'intérienr un grand nombre

rig. $21 \%$.
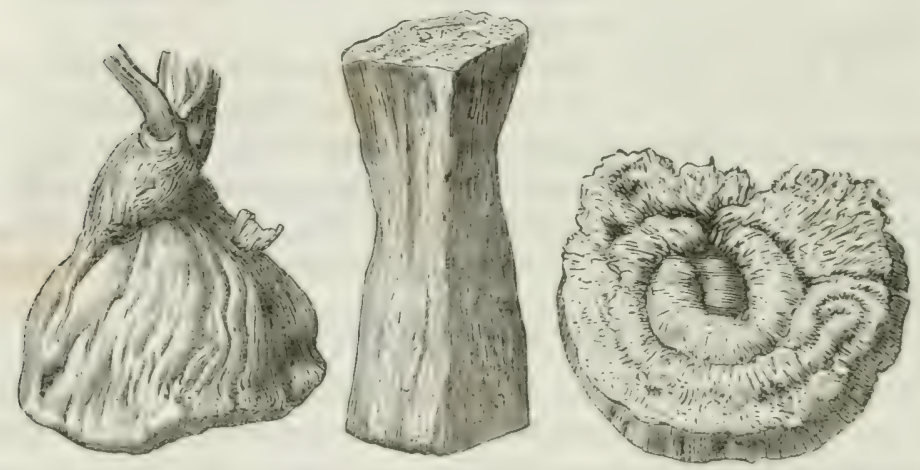

de fibres lignomses, dont les extrémites dépassent leurs surfaces transversales, deprimers par la dessicration L'velenr et la sasent sont semlibables a celle's du jalap officinal, mais plus faibles. 11. Ledanois a retire de 100 parties de jalap fusiforme : résine s ; extrat gommenx

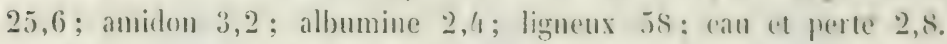
(Joun. de clim. méd., t. V, p. 508.)

\section{Riacine de faux Jatap.}

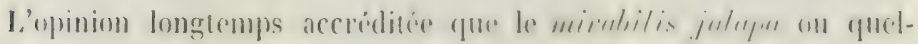

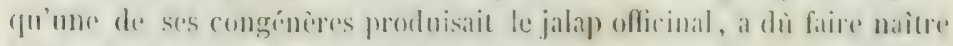

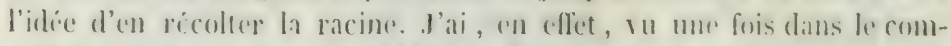

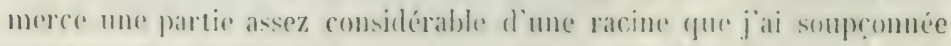

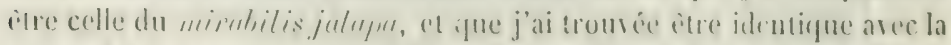

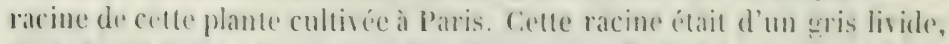

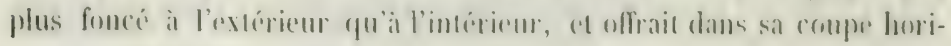


zontale un grand nombre de cercles concentriques tress serrés. Sille a été décrite précédemment (page 413 ).

Faux jalap gouge (fig. 218). On troure quelquefois mêté an jalap, dans le commerce, une substance que plusieurs personnes ont présumée ètre une excroissance renue sur le tronc de certains arbres, mais qui me parait être la racine tuhéreuse d'une convolvulacie. Cielte sul)stance provient évidemment d'un tubercule arrondi, coupé en plusieurs parties; elle doit aroir perdu heaucoup d'eau de végétation, et ses morceaux sont plus ou moins contournés par la dessiccation. La surface exterienre est d'un grris brunàtre ou noirattre, et profondément rugueuse comme celle du jalą). La suface intérieure présente des stries

\section{Iig. 218.}
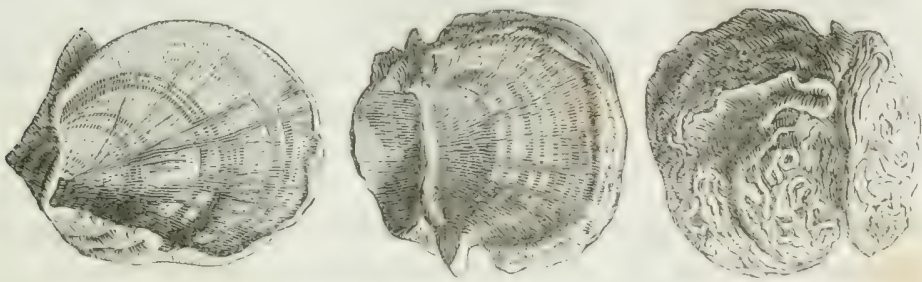

concentriques et radiaires d'une grande régularité et qui caraclérisent tout à fait cette substance. L'intéricur est d'un rouge rosé ou conlem de chair, un peu spongieux sous la dent et insipide. Son décocté apueux est d'une belle couleur rouge et précipite le fer en vext noiràtre; il ne contient pas d'amidon et ne bleuit pas par l'iode.

Faux jalap à odeur de rose. En 1842, M. Brazil, droguiste à Paris, me remit une racine qu'il avait trourée mélangée à des balles de jalap venant du Mexique; clle ressemblait tellement au jalapp, par son extérieur, qu'il était difficile de l'en distinguer; elle en différait tant, cependant, sous le rapport de la composition el des propriétés médicinales, qu’il était très essentiel d’apprendre ì la connaître et à la séparer.

Le vrai jalaj) est généralement d'un gris noirâtre cxlérieurement, lourd, compacte, ì cassure brunitre, à odeur forte et nauséeuse, it saveur âcre et strangulante; la surface, a part les incisions qu'on y a pratiquées, est souvent assez unie; lorsfu'on le scie transversalement, la coupe, après avoir étí polie, est triss compacte, d'une apparence de

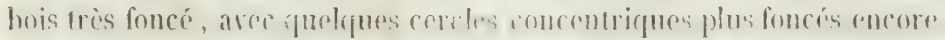
Tel est le meilleur jalap oflicinal; mais il arrive assez sourent que cette racine ayant été prinitivement plus aqueuse, plus amylacée et moins résineuse, est légère, blanchàtre, et profondément sillonnée par ha dessiccation; alor: Ie jalap présente la plus grande ressumblance aver 
la nourelle racine; mais il s'en distingue toujours par son odeur caractéristique et par sa saveur âcre, quoique plus faible.

La nouvelle racine signalée par M. Brazil (fig. 219) est généralennent en lubercules oriäles, allongés et annincis en pointe aux deux extré-

Fig. 219.

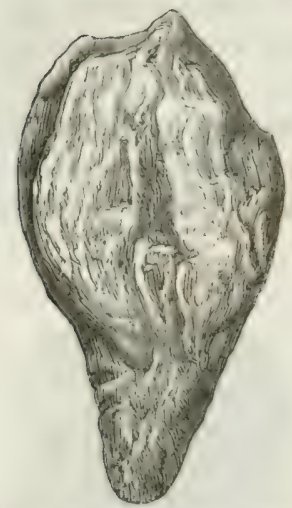

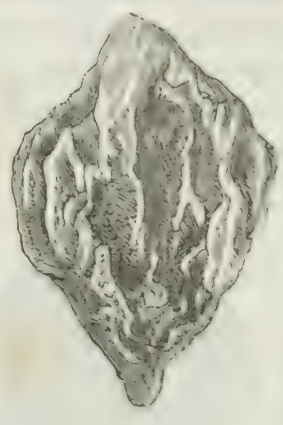

mités; la surface en est toujours très profondément sillonnée, noirâtre dans le fond des sillons; mais presque blanche sur les parties proéminentes; l'intérieur est presque blanc; la coupe, faite à la scie, n'est pas polissable; elle est poreuse, blanchâtre surtout au centre, arec des cercles bruns. En-

fin celte racine, respirie en masse on pulvérisiée, exhale une odeur de rose assez marquée; lil saveur en est donceitte, un peu sucréc, nullement âcre.

J'ai fait l'analyse de cetle racine qui m’a présenté, conte atutes principes, une quantité assez considérable de sucre. ("'est altors que voulant comparer mes résultats a ceux précédemment obtenus pour le jalit), jo trourai tant de discordance cutre ces derniers, que je crus devoir analiser le jalap) lui-même, et je tromvai, a ma grande surprise, que le jalap officinal contenait encore plus de sucre que celui à odeur de rose. Voici les résultats comparés des deux analyses, dont on trourera les

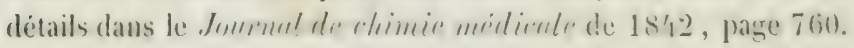

\begin{tabular}{|c|c|c|}
\hline & $\begin{array}{l}\text { Julay, } \\
\text { oflicinal. }\end{array}$ & $\begin{array}{l}\text { Paux juliay } \\
\text { at oudente de ruse }\end{array}$ \\
\hline liésine. . . . . . . . & $17,6.5$ & 3.23 \\
\hline Mélasse obtenue par l’alcool. . . & 19 & 16,47 \\
\hline Extrait sucré, obtenu par l'eau. & 9,05 & $5,9^{\circ}$ \\
\hline 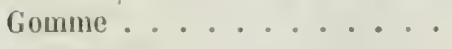 & 10,12 & 3,88 \\
\hline 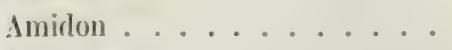 & 18,78 & 22,69 \\
\hline Ligneux . . . . . . . & 21,60 & 46 \\
\hline \multirow[t]{2}{*}{ 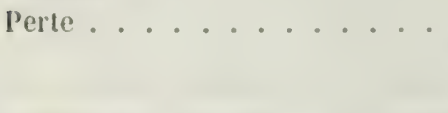 } & 3,80 & 1,81 \\
\hline & 100,00 & 100,00 \\
\hline
\end{tabular}

La résine du faux jalap à odeur de ruse est a peine purgatise, de 
sorte que la racine qui la contient ne l'est pas du tout. Je n'ai pas commu, quant ì moi, la plante qui produit ce faux jalap. Mais sur la description que j'en ai donnée, M. le doctemr Grosourdy la recomnut pour ètre la racine d'une variété de patate jaune cultivée aux Antilles, de sorte que son vai nom doit ètre pertute is odeur de rose (Journ. chim. méd., 1843, p. 175).

\section{Hacine de Méchoacan.}

Il résulte de l'onrrage de Monardès, sur les plantes médicinales du noureau monde, publié en 1569 et 1580 , qu'on apportait alors du Mexique en Europe, oil clle était trés usitec comme purgative, une racine dite de mérhouram, du nom de la province du Mexigue qui la produisilit. Personne ne de ute non plus, d'apres l'opinion unanime des

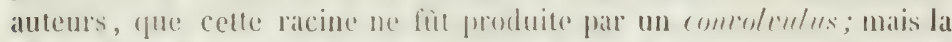
plante élatit da reste si peu comnue que quelgues auteurs lui domnaient un fruit semblable à un pépon, ed d'antres des fruits en grappes de la grossenr de grains de coriande. Deperis, ancune nourelle lumière n'est venue sur ce végétal, et si, plus tard, quelques botanistes ont admis,

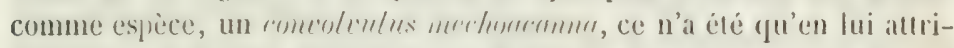
buant les caractères d'une plante: du Brésil, beaucoup misux décrite par Pison el Maregraff sous le mème nom de merfenerren, et sous ceux de jefiruren et luelutu de puryn (il sera traité de cette plante ci-ipress). Quant aux caractères de la racine de méchoacan du Mexigue, tout ce qu'on peut conclure des écrits du mène temps, c'est que c'était une racine très volumineuse, qui était apportée couFig. 2200. pée en rouelles ou en morceaux de différentes dimensions, blancs, légers, un peu jaunâtres au-dehors, peu sapides. La racine que l'on trouve encore aujourd'hui dans le com-
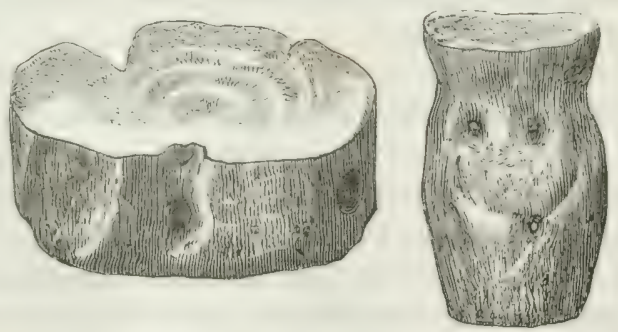
merce, sous le nom de mrechur:m, et que je n'ai jamais ru varier, se rapporte bien aux caractères précédents (fig. 220) : elle est coupée en rouelles assez grosses ou en morceaux de toute autre forme; clle est mondée de son écorce, dont on aperçoit cependant anelgues vestiges jaunâtres; elle est tout à fait blanche "t farineuse à l'intérieur, inodore, d'une saveur presque nulle d'abord, suivie d'une légère âcreté. Lufun, et j’appuic sur ce caractère, on observe sur tontes le's parties de la 
racine qui élatent a l'exterieur, des taches brunes et de's pointes ligneuses provenant de radicules ligneuses. Or, ce caractere n'appartenant à aucun comerolculns. tubéreux que je connaisse, il y a longtemps que j'ai pensé que notre racine de méchoacan, au lieu d'être produite par un comcolenlus, fouvait l'être par un tomus, dont les racines présentent le mène caractère de radicules ligneuses dispersées sur toute leur surface. J'en étais resté à celte idée, lorş̧ue j’ai trouvé dans la traduction française de l'ourrage de Monardès, publiée en 1619, par Colin, apothicaire s'e Lyon, que l'on vendait de son temps, an lieu de méchoacan, les raciues de sceau de Votre-1)ame (tmmus (rmmmunis), desséchées et coupées en rouelles. Je ne m’étais donc pas trompé dans l'assimilation que j'arais faite de la racine de méchoacan du commerce arec celle de tmme; seulement, n'en ayant jamais ru d'autre, j'en suis toujours à me demander si cette racine est véritablement le produit d'une substitution ou si elle ne vient pas d'Amérigue, et si, seulement, on ne se serait pas trompé sur le genre de plante qui la produit.

La racine de méchoacan du commerce, qu'elle soit rraic on fausse, est sourent mélangéce d'une certilne quantité de racine d'arum serpentaire qui, mondice de sa pellicule et cuupée par rouclles, lui ressemble beaucoup. On reromait celle derniere racine a ce que ses ronelles sont toujours rondes, d'une sareur àcre, et complétencnt privées des restes de radicules ligneuses (qui distinguent le méchoacan.

\section{Patate purgative ou batata de purta.}

On cmpluse sous ce nom, au brésil, les racines de deux plantes que

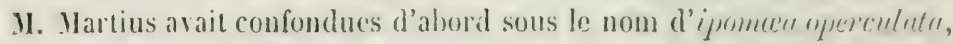
mais qu'il a distinguées ensuite sous rens de piptrestegin P'ismis et de jiptostegia Gomesii.

La preniere de ces plantes, anciennement décrite par Pison et Maregrall sous le nom de jeticuen at de méchurem, devenue ensuite

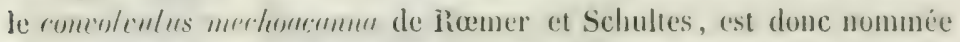
aujourd'hui, par M. Martius, piptesstegin P'ismes. Elle pourra prendre

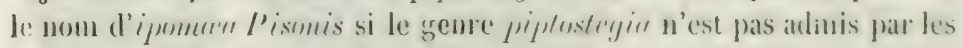
botanistęs. lifle a les liges volubiles, anguleuses, très longnes, pourvues de feuilles cordiformes, sourent auriculées par le bas; les fleurs sont d'un blanc rosé an dehors, pourpres en dedans; Jes semences sont noirâtres, triangulaires, à peine de la grosscur d'un pois; la racine est longur de 15 a 30 centimetres, prespue aussi épaisen ol prespue tomjours double on bilide. Elle est remdrée on brunctre an dehors, blanche en dedans; on la coupe en roudlles pour la faire sécher, on bien on l'exprimse recente pour en extraire Ir sue qui laisse déposer une fécule grise, emplosece également comme purgative. 
La racine de jeticueu, telle qu'elle a été rapportée de Rio-Janeiro par II. V. Chatenay, pharmacien, et telle que H. Stanislas Martin l'a reçue de la mème ville, est sous la forme de rouelles minces, dont les plus grandes ont seulement 5 centimètres de diamètre. L'épiderme de la tranche est très rugueux et noirâtre; la surface des rouelles est d'un gris blanchâtre, marquée de 4 ì 5 cercles concentriques proéminents et rendus rudes au toucher par l'extrémité des fibres ligneuses qui les forment. La substance niême de la racine est dure et comme imprégnée d'un suc gommeux desséché. Lille a une saveur gommeuse suivie d'une assez grande âcreté.

La fécule purgative de la mène racine porte au Brésil les noms de

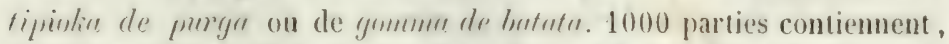
d'après Buchner, 947 parties d'amidon, 40 de résine drastique et 13 d'extrait soluble dans l'eau. Cette fécule, telle que II. le docteur Ambrosioni a bien ronlu me l'envoyer de Fermambouc, est d'un gris condré mélangé de blanc. Il est évident qu'elle consiste en un mélange variable d'anidon et de principe résineux; ce doit donc être un médicament incertain auçuel il comviendrait de substituer la résine purifiéc.

La seconde plante, décrite par Gomez sous le nom de crmmoleulus uperenlutus, et par Martius, d'abord sous le nom d'ipumuren operenleten, puis sous celui de priptustergin riprerculute, parait aroir les feuilles à 5 lobes palmés, dont celui du milieu séparé des autres et commc un peu pétiolé. La racine, telle que je l'ai recue du docteur Ambrosioni, est formée, soit d'un seul tubercule napiforme, d'un décimètre de diamètre, dont je n'ai pas l'extrémité inférieure; soit de deux tubercules collatéraux, arrondis, de 5 à 6 centimètres de diamètre et terminés chacun, à la partie inférieure, par deux fortes radicules (celle configuration est la même que celle donnée par Pison au jeticucu). Ces deux racines sont d'un gris noirâtre à l'extérieur, d'un gris blanchâtre à l'intérieur; elles ont souffert pendant la traverséce et ont été fortement endommagées par les insectes.

\section{fiacine de Turbith.}

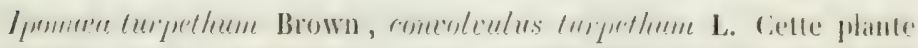
vient dans l'Inde, à Cevlan et dans les îles Malaises. On lui dotine ordinairement une lige quadrangulairé ét ailée, sur l'autorité d'Hermann: mais les liges inférieures, jointes anx racines du commorer. sont cylindrigues et ligneuse's, ot la planche 397 de Blachwell les montre cylindrigues dans toute leur étendue; les fenilles sont petiolées, cordiformes, crénelées sur le bord, velues sur les deux faces; les bractées sont caduques; l's sépales du calice fort grands; les csiérieurs velus, 
les intérieurs glabres; la corolle est blanche et semblable à celle du colystegio sepium; les étamines sont exsertes, comme dans les certyonium.

La racine de turbith, telle qu'on la trouve dans le commerce (fig. "21, ", ") est rompue en tronçons de 13 à 16 centimètres, tantôt pleins à l'intérieur, tantôt consistant en une écorce épaisse dont on a retiré le cecur; le diamètre des morceaux varie de 14 à 27 millimètres; leur extéricur est d'un gris cendré et rongeâtre; l'intéricur

Fig. 221.

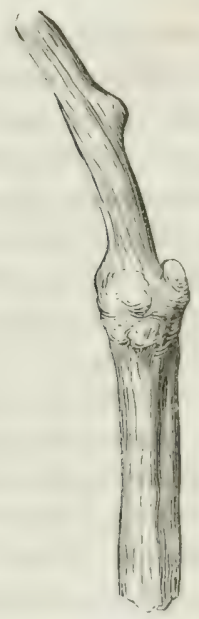

l)

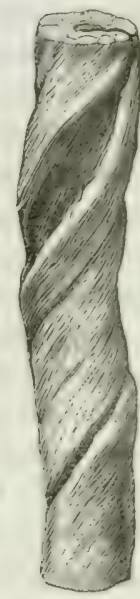

a

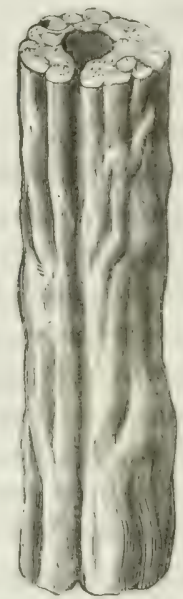

(t

est blanchaitre; la partie corticale paraît formée de faisceaux de tibres, approchés les uns des autres, et figurant comme des côtes cordées à l'extérieur. Elle est compacte et gorgée d'une résine qui exsude souvent sous forme de petites larmes jaunatres, par l'extrémití des morceaux rompus. La partie du centre, lorsqu'clle esiste, et quelyuefois aussi l'écorce elle-mème, sont criblées aux extrémités de pores ronds, très apparents à la vue simple. Le turbilh n'a pas d'odeur; sa saleur est peu sensible d'abord, mais elle laisse une impression naurecuse assez forte. C'ést un fort purgatif.

Dans le commerce, la racine de turbith est sturent mélangée d'une assez grande (juantite de tronçons de tige ( 1 ) qui sont beaucouj) moins résineux que la racine et moins actifs; aussi doit-on les rejeler. I)'un autre côté, le turbilh ressemble assez au costus arabique pour qu'on puisse les coufondre à la première vue. Mais les diflérences d'odeur, de saveur et de texture, qu'on y remarque bientòt. Ies font facilement distin- 
guer. Il faut igalement ne pas le confondre avec le jalą fusiforme, bien que tous deux soient de genre et de propriété semblables. Ce dernier se reconnaît à sa couleur grise-noirâtre et à son odeur de jalap.

\section{Ścammonée.}

La scammonce est une gomnate-résine produite par deux comeroleulus qui croissent en Syrie et dans l'Isie-Mineure; depuis longtemps aussi on en distingue deux surtes principales, dites d'. llop et de Simyrne; mais ces dénominations se rapportent pen à l'origine véritable des produits, par l'habilude qui a élé prise de donner le nom de scommemée

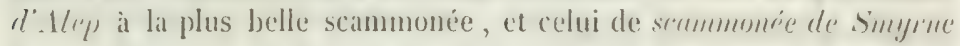
a toute scammonéce impure on de qualité inférieure, quel que soit le lieu d'origine de l'une ou de l'autre. (guant à moi, il me paraît plus utile de distingner deux espèces de scammonées, véritablement différentes par la plante qui les produit et par leurs caracteres plissiques; chactune d'elles pouvant d'ailleurs se rencontrer pure, mais étant aussi très sourent falsitiée. ("est ce que je rais essager d'établir en m'appuyant sur l'autorité des auteurs auxiquels on peut accorder le plus de confiance.

Diescoride, que je citerai d'abord, a parfaitement décrit l'une des especes de scammonée, ainsi que la plante qui la produit. Cente plante pousse plusieurs tiges longues et flexibles, garnies de fenilles ielues et triangulaires. La fleur est blanche, creusée en forme de corbeille; lat racine est fort longue, grosse comme le bras, blanche, d'veleur désagréable, pleine de suc. Pour obtenir la scammonée, on conpe la lète de la racine et on creuse celle-ci en forme de coupe, dans laquelle se rassemble le suc, (que l'on puise ensuite arec des coynilles. La meilleure scannmonée est légère, brillante, poreuse, ayjont lu coulenr de la colle: dr Inurem, telle est celle que l'on apporte de 11 ysie (de Smyrne); clle blanchit (quand on la touche arec la latigue, et ne doit pas brùler guand on la goûte, ce qui indiquerait qu'elle est falsifiée arec du tithymale.

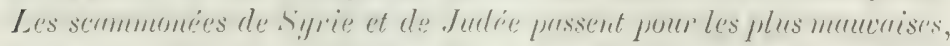
étant pesantes, massive's et suphistiquées de tithymale et de farine d'orobe. Voilà ce que dit Dioscoride.

D’après Tournefort, la scammonée de Samos n'est guère bonnc : elle est rousse, dure et très difficile à pulvériser; elle purge arec violence. La plante qui la produit est un liseron dont les feuilles ressemblent a celles de notre petit liseron; mais clles sont plus grandes, velues et découpées moins proprement à lit base que celles de la scammonée de Syrie. La scammonéc de Samos répond bien à la description qu'en a faite Dioscoride; elle nait dans les plaines de Mysie; mais il est surpre- 
nant que du temps de Dioscoride, on préférât le suc de cette espiece à la scammonéc de Jukle et de Syrie, que l'usage nous a appris a recommaîre pour la meilleure. Colle de Samos et de Scala Nova se consomme dans l'Anatolie ; on n'en charge guere pour l'Occident.

Geoffroy distingue doux sortes de scammonées, celle d'Alep el celle de Surgrne: la première est légère, friable, à cassure noiràtre et bril. lante, recouverte d'une poudre blanchâtre. Il ajoute, ce (qui est incxact, qu'elle a un groùt amer, un peu âcre, et une odeur puante.

La scammonée de Smyrne est noire, plus compacte el plus pesante. Elle est apportée à Smyrne de la Galatie, de la Lycanie et de la (aip)padoce, près dı mont laturus, où on en fait une grande récolte. Un préfère la scammonéc d'Alep.

La plante qui produit la scammonéc d'Alep est le comentmlus syrinrus de Morisson (comeroleulus semmmonin I..). Il a les fenilles trian-

I.ig. 222.

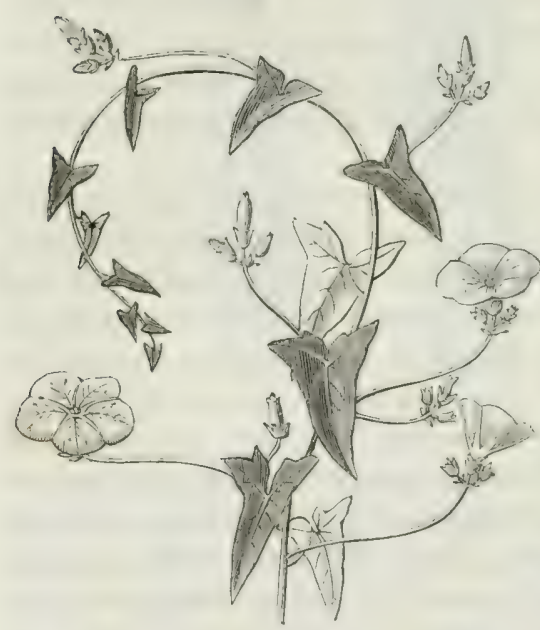

gulaires (fig. 222) hastées par le bas, lisses. If diflere par conséquent de la plante de Dioscoride, à feuilles velues, observée par 'Touruefort à Samos et dans les campagnes de la Natolie.

Geoflroy a donc demandé a Shérard, bolaniste anglais qui a longtemps vécu à Smyrne, si l'on tirait effectivement de la scammonée de la plante à feuilles velues. Shérard lui répondit qu'il arait aussi observé ce même liseron auprès de Smyne, mais fu'on n'en tirait aucun

suc. Il a ajoulé que le commlrulus à fenilles glalores y croit en si grande:

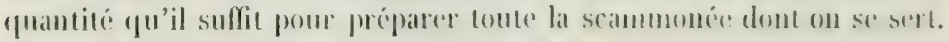
Ponr obtenir cetle scammonéc, on déconre la racine el on y fait des incisions sous lesquelles on met des coquilles de monles ponr recrovit Ie suc laiteux gu'on y fait sécher. Cette semmmonre en rugnilles est ré-

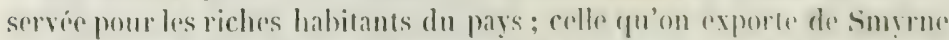

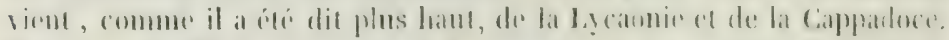

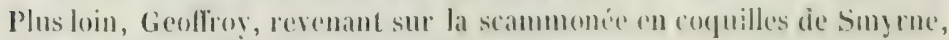
qui est la meilleure, dit qu'elle est transparente, blanchitre on jaunâtre, semblable à de la résine ou à de la colle forte.

il me paraît difficile de ne pas conclure de ce qui précede qu'il existe. 
véritablement denx espèces de scammonée : l'une blounde on jaunatre et translucide, produite par le liseron ì feuilles velues de Dioscoride et de Tournefort (1); l'autre noirâtre et opacgue produite par le ronevolrulus scrnmmmin (2). Cès deux cspèces présentent ensuite une grande variation dans leur qualité, suirant qu'elles ont été préparées avec le suc haiteux pur, provenant de l'incision des racines, ou arec le suc exprimé des racines, quelquefois avec le suc des fenilles; suirant enfun qu'elles ont élé falsifiées par une addition de sable, de terre, de carbonate ou de sulfate de chaux, d'amidon; car toutes ces falsifications sont mises en usage, soit en Orient, soit ailleurs.

Voici maintenant la description des principales scammonées :

1. Seamuone blonde de smyrne, en coquilles: seammonce de Mysie de Dioseoride, J'avais depuis longtemps cette sorte de scammonce, provenant du droguier de Ilenry père, mais j'étais incertain de son origine, lorsque je l'ai vue chez M. L. Marchand, ancien droguiste, contenue dans des coquilles où le suc découlé de la racine s'est avaporé spontanément. Cette scammonée est en petites masses souvent proreuses, d'autres fois unies, d'un gris rougeàtre on d'un gris blanchàtre à l'extérieur; elle est tries fragile et présente une cassure brillante et vitreuse très inégale. Elle est jaunàtre et transparente dans les lames minces; elle forme avec la salive une émulsion blanchâtre qui devitut très poisseuse en se séchant; elle possède une odeur forte et désigréable distincte de celle de la scammonée d'Alep; elle fond a la flamme d'une bougie, s'enflamme et continue à brûler seule après l'éloignement de la bougie.

2. Seammoné bonde de Trébizonde. Cette scammonée répond, par ses propriétés, à la scrummunce de Summs de Tournefort. Elle est en masses considérables, d'un gris rougeàtre terne à l'extérieur, tenaces et difficiles à rompre; la cassure est inégale, de couleur rongeâtre, d'apparence cireuse; elle est translucide et mêne transparente, par places, dans ses lames minces. Elle possède l'odeur de brioche de la scammonée d'Alep; elle forme arec la salive une émulsion d'un gris

(1) Convolvulus hirsutus Stev, convolvulus sayittifolius Sibth., convolvulus sibthorpii de Romer et Schultes.

(2) Il e:t vrai que Geoffroy a décrit sous le nom de scammonée en coquille une scammonée jaunâtre đư'on peut supposer être la même que Shérard a vu extraire du $C$. scammonia; mais on remarquera qu'il n'y a pas une liaison nécessaire entre les deux faits. Enfin, dans ces dernières années, il est arrivé dans le commerce une quantité assez considérable de scammonée blonde dont on ne peut expliquer la différence essentielle observée entre elle et la scammonée d'Alep, autrement que par une différence spécifique dans la plante. 
sale, poissense, plus on moins marguée; clle brûle arec flamme et en bouillonnant, Iorsqu'on l'approche d'une bougie alluméc; elle continue de brûler avec flamme lorsqu'elle en est éloignée.

3. Seammonée noiraitre, d'Mlep, superieure. 1. Celte sorte est en fragments peu volumineux, très irréguliers, recourerts d'une poussière blanchâtre; clle se brise très faciloment sous l'effort des doigts et offre une cassure noire et brillante, rui, vue à la loupe, présente çà ed la de petites cavités, et dont les éclats sont demi-transparents et d'un gris olisâtre. Elle blanchit sur le champ par le contact de l'eau ou de la salive; mise dans la bouche. clle offre un goùt très marqué do beure cuit ou de brioche, sans aucune amertume, et accumpagné seulement d'une âcreté tardire; clle jouit d'une odemr semblable de brioche; sa poudre est d'un blane grisâtre; approchée d'une bougie allumée, clle brtile arec flamme et en se boursouflant; mais elle s'éteint aussitcit qu'on l'éloigne de la bongie.

B. Il est rare de voir à Paris de la scammonce d'Alep aussi jume que la précédente: celle qui en approche lo phus est ch morceaux plus

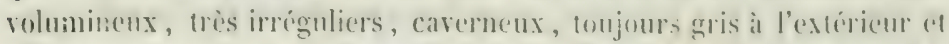
d'une cassure moire et brillante; mais elle est moins fragile et hanchit moins lorsqu'on l'humecte; son odeur est semblable.

1. Seamunone noire et compacte dalep. Cette scammonép a dì cetre évaporée an fen jusqu'en consistance solide, ef formée en pains orbiculaires gui so sont aplatis pendant leme refondissement. lille est compacte, pesante, sans aucune cavité dans som intririour. Ville offie une cassure noire el ritrense; plle est transparente dans ses lames minces, à la manière d'une résine; eile rst assez friable sous le doigt et d'une odeur semblable à la précédente, mais plus faible. Flle fond a la flamme d'une bougie, s'enflamme et continne de brùler après en aroir été écartée.

5. Sieammonée plate dite dantioehe. Celle scammoné parait etre le résultat d'une falsification. Elle est sons furme de gâteams aplatis, larges de 10 a 11 contimetres, epais de 2 comtimelres colviron, ou en morceaux (qui en proviennent; clle e'st d'un gris cendré assez uniforme ì l'extérieur, et présente une cassure terne, d'un gris foncé, sur laquelle on remargue un grand nombre de petites carités, la phupart lenticulaires, of des taches blanchàtres dont la substance fait diervescence ave l'acide chlorhydrique, ce qui indigue que ce sont des parlicules de pierre calcaire. Elle est peu friable, blanchit peu ot devient un peu poisseuse par l'action de l'ean on de la salise. Sen odeurest sumblable a celle de la scammuné d'Alep, mas un peu plus faible of yn peu dísigréable. Elle ne se fond pas a la flamme d'une bougie; clle y houillomor seulement par petites places, y hrvile diflicilement aves 
flamıne, et paraît s'éteindre aussitôt qu'elle en est éloignée. Ceppendant elle continue de bruler pendant quelque temps sous la cendre blanche qui se forme, en répandant une odeur fort désagréable.

6. Scammonées inféricures dites de smyrne. J'ai dit e'll commençant qu'on donnait communément, dans le commerce, le nom de scrmmmóe de Sintjme à celles de qualités inférieures et qui sont évidemment falsifiées. Il est difficile d'en indiquer les caractères, qui peuvent varier suivant l'adultiration plus on moins grande qu'elles ont subie. J'en ai depuis longtemps une sorte qui est d'un brun terne, tris pesante, très dure, non friable, non carcruense, à cassure terme et terreuse, d'une odeur faible ct cependant désagréable, paraissant avoir élé enreloppée d'une peau garnie de son poil. J'en ai vu depuis beaucoup d'autres auxquelles il est inutile de s'arrêter.

7. Seammonce de Montprllier on scammonce en galetes. On fabrique celte prétendue scammonce, dans le midi de la France, arec

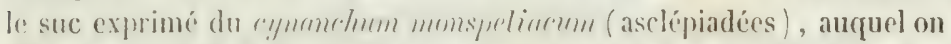
ajoute diffirentes résines on autres substances purgatives. Elle peut done rarier beaucoup dans ses caractìres physsiques el sa nature; celle que j'al est tont is fait noire, très dure at très rompacte, formér en galchles aplaties de 10 centimetres de diamère sur 2,j centimètres d'épaissent. Elle présente une faible odent de banme du Pérou et forme arec la salive un licpuide d'un gris foncé, gras, onctueux et tenace.

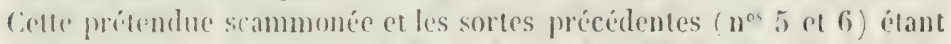
des produits falsifiés, doirent être rejetées de l'officine du pharmacien.

La scammonéc est un purgatif violent quui doit être employé avec circonspection. Lilie entre dans la pondre de tribus, les pilules mercurielles de Bellosie et dans un grand nombre d'électuaires et d'alcoolés purgatifs. dutrefois, on lui faisait subir différentes préparations dans la rue de l'adoucir; mais ces préparations. qui ne faisaient qu'en rendre les crlets p'us incertains, ne sont plus usitées. Aujourd'hui on l'emploie simplement pulvérisée ou réduite à l'état de pure lésine par le moyen de l'alcoot rectifié. Cette résine jouit de quelgues propriétés particulieres qui la rendent plus facile à aduninistrer que celle de jalap) (voir ma P'larmacopée raisonnce, Paris, 1847, p. 370).

La scammonée a été analỵéc ancienncment par Bouillon-Lagrange et logel; mais ces chimistes ạant opéré sur des sortes très inférieures, j'arais publie une autre analyse de ha scammonére d'Alep que je ne rapprollerai pas ici, préférant dommer les résultats obtenus par M. Clamor Marquart sur luit scammonées du commerce (1).

(1) Phaimaceutisches central blatt, 28 october 1837. 


\begin{tabular}{|c|c|c|c|c|c|c|c|c|}
\hline & I. & II. & III. & W. & v. & II. & vii. & vill. \\
\hline Résine............ & 81,25 & 78,5 & 77 & 50 & 32,5 & 18,5 & 16 & 8,5 \\
\hline Cire. ............ & 0,75 & 1,5 & 0,5 & $n$ & $n$ & $n$ & 0,5 & $n$ \\
\hline Matière extractive... & 4,50 & 3,5 & 3 & 5 & ; & 7 & 10 & 8 \\
\hline - arec sels...... & $n$ & 2 & 1 & 3 & 4 & 6 & 5 & 12 \\
\hline Gomme avec sels... & 3 & 2 & 1 & 1 & & 2,5 & 3 & 8 \\
\hline $\begin{array}{l}\text { Amidon............. } \\
\text { Téguments d'amidon, }\end{array}$ & ) & 1,5 & $n$ & 5 & 1,5 & 15,5 & 36 & 17 \\
\hline bissorine et gluten. & 1,75 & $1,2.5$ & " & 5 & ) & 42,5 & 2.1 & 7 \\
\hline Albumine et fibrine. & 4,50 & 3,5 & 3,5 & 4,5 & 2 & 6,5 & 12,5 & 16,5 \\
\hline carbonate de chaux & & & & & & & & \\
\hline $\begin{array}{l}\text { et magnésie....... } \\
\text { Sulfate de chaux... }\end{array}$ & 3,75 & 2,75 & 12,5 & 22 & 6,75 & $\begin{array}{l}12,5 \\
22,5\end{array}$ & $\begin{array}{l}1,5 \\
n\end{array}$ & 1 \\
\hline \multirow[t]{2}{*}{ Sable............ } & 3,50 & 3,50 & 2 & 4 & 32 & 2 & 3 & 4 \\
\hline & 100. & 400. & 100. & 100. & 100. & 100. & 100. & 100. \\
\hline
\end{tabular}

I. Scrommonée d'Alep suprérienu't, répondant à mon $n^{\circ} 3$, A. Pes. spéc. 1, 2.

II. Scammonée d'Alep belle, répondant à mon $n^{\circ} 3, B$.

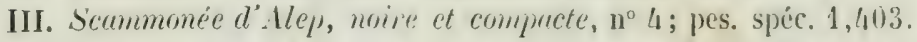
Je ne crois pas cependant que la scammonée que j'ai décrite sous ce nom puisse contenir une aussi grande quantité de sel calcaire; ct : i clle en contient, la chaux ne doit pas y être à l'état de carbonate, tel fu'on l'obtient par l'incinération; elle y existe probablement à l'état de malate.

IV. IIorceau plat et fort, couvert à la face inférieure d'une légère conche farineuse qui manque à la face supérieure. Cassure cireuse; ì l'intérieur, mélange de poils menus; difficile à fondre, d'une pesanteur spéc. de 1,421. L'extrait contient des chlorures de calcium et de magnésium. Le carbonate de clsaux des cendres pèse seul 21 pour 100.

V. Scammonée décrite par Nees d'Esenbeck et libermeyer comme sccummoné de Simyrne, ce qui ne veut dire autre chose ici que scammonée falsifiée. Celle-ci est remarquable par l'énorme quantité de plàtre qu'elle contient.

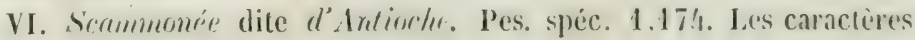
assignés frar l'auteur ì cette scammonce se rapportent i ceux de mon n" 6, sanf fu'il indigue dans la science de grandes cavilés dues à des passages d'insectes. Quelle que soit l'impuretí de cette sorte de scammonée, je n'y ai jamais observé ce demier caractère.

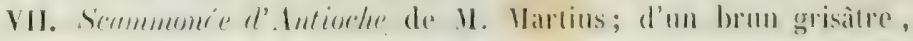
courerte d'une poussiere blanche à l'exlérieur, asec beancoup de passages d'insectes; poudre d'un gris de condre; pess speéc. 1,12. 


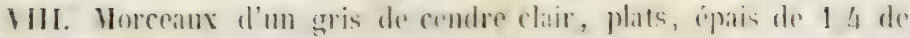

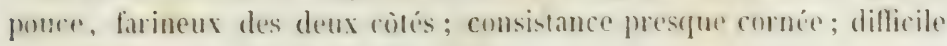
it pulvériser, poudre d'un brun chair.

Il est evident que des huit scammonies dont l'analse précide, fer trois premieres sont les seules que fon doire emploser; j’ai clonné lat composition des autres, alin de montrer jusqu'où peut aller le peu de: valeur des sortes du commerce. Je ne pense pas cependant qu'il faille toujours en accuser nos négociants. Il est certain, par exemple, yue les racines qui ont été épuisées de suc laiteux par des incisions, sont pilées et exprimées, et que le suc éraporé sert à produire une sorte inférieure de scammonéc; or, un pareil suc, naturellement chargé l'une quantité variable de fécule, peut fort bien donner un produit analogue aux deux dernières sortes du tablean précédent, sans qu'il soit besoin de supposer qu'on y a introduit à dessein de l'anidon élranger.

\section{Bois de rose des Canaries.}

Vulgairement bois de Ezho:les on ligmm Rehordium. On dit que le nom de bois de Rhodes a été donné à cette substance parce cu'elle venait autrefois de l'ile de Rihodes; mais aucune recherche n'a pu me convaincre que ce que nous appelons buis de lihodes soit jamais provenu de l'île de ce nom, ou de l'ile de Chypre, ru'ou a dit également le produire. Au contraire, aucun ancien auteur, Théophraste, Dioscoride ou Pline, ne fait mention du bois de Rhodes, dont on n’a véritablement parlé que depuis la découverte des îles Canaries. C'est alors qu'on a roulu le retrouver dans les livres anciens, et qu'on a pensé que c'était l'uspulruth de Dioscoride. Hais il est beaucoup plus probable que cles deux espèces d'aspalath dont parle cet anteur, l'une était le bois d’aloès, et l'autre le bois du cytišs laburnum (faux ébénier), du rytisus spinusus, ou de l'chenus cretica, lesquels croissent en effet dans les îles du Lerant.

I.e nom de lignum, Rhudium, donné au bois qui nous occupe, ne signifie donc rien antre chose que bois it orlestr do prese; mais maintenant il faut dire que, prescue de tout temps, on a confondu sous ce nom deux bois différents; l'un venant des Canaries, qui est propreurent le bris de Rihordes des parfumeners; l'autre, apporté en partie d'Imérique, est le bois dr rose des ébénistes; il ne scra question ici qque du premier.

Ce bois est produit par un liseron arborescent et non rolubile qui a longlemps été pris pour un genêt, dont il a le port, à cause de ses rameaus nombreux, droils et munis, sur leur longueur, de fenilles très espacécs, entières et très étroites, et, à lixtrémité, de fleurs jau- 
nitres, alsser prtites, mais convolvulacées. Cente plante est le rmurn/rulus scryurius L. Le bois du commerce se compose de racines ou de sonches ligneuses, de S à 11 centimètres de diamètre, toutes contournées, tantôt couvertes d'une écorce grise, un peu fongueuse et très crevassée, tantôt dénulies; quelquefois le bois est a l'intérieur d'une seule teinte jaune uniforme; mais le plus ordinairement il est blanchâtre ì la circonférence, jaune orangé et comme imprégné d'lunile an centre. Ce bois doit en effet son odeur de rose très prononcée à une lunile peu volatile et onctuense qui est la cause du caractère indicué. Les tiges, yui accompagnent presgue toujours la souche ou la racine, sont cylindricjues, grosses comme le pouce, courerles d'une écorce grise; clles sont formées d'un bois blanchâtre. Iorsqu'elles sont jeunes, devenant peu à peu jaune ct huileux an centre à mesure gru'elles deviemnent plus àgées; elles somt d'antant plus aromatignes dqu'elle's somt phus grosses ot efu'elles se rapprochent darantage de ha souche.

L'erssener de bois de Rhodes est linuide, onctueuse, jaunitre, d'une odeur de rose, d'une sarcur amcre comme le bois, un peu plus ligire que l'eau.

\section{FAMILLE DES PIGNONIACÉES.}

Cette famille comprend des arbres ou arbrisseaux souvent rolubiles, ou des herbes à fenilles opposées ou ternées, rarement alternes, et le plus souvent composées. Les fleurs ont un calice gamosépale, sourent persistant et à 5 lobes, se rompant quelguefois d'une manière irrégnliere; corolle gamopétale, irrézulière, it j divisions; le plus sonvent 4 étamines accompagnées d'un lilet stérile; oraire porté sur un discfue hypogyne, à une ou deux lorges pluri-orulies; plus rarement à 2 ou 4 loges uni-ovulées; style simple terminé par un stigmate bilamellé. Le fruit est une capsule à une on deux loges, s'ourrant en deux ralres parallèles ou transtersales à la cloison; rarement il est charnu, ou dur "t indéhiscent. Les graines, sousent bordées d'une membrane sur tout leur contour, renferment un (mibryon dressé, sans endosperme.

Les bignoniacies ont une grande affinite avec les scrofulariacées, dont elles different par leurs semences sans endosperme, sourent ailées; elles offrent peu d'espèces médicales, mais un certain nombre méritent d'ètre connues pour lèr utilité dans les arts, dans l'économie domestique, ou comme plantes d'ornement daus les jardins.

sesame de rinde, sestumum indicum I)C., et le secumum mientule L., qui en est une rariété. Cette plante, originaire de l'lnde, s'est répandue dans toute l'Asie, en Égypte, en Italie ct dans une partie de l'Amérique. Son fruit est une capsule à la loges qui renferment des scmences blanches, 1 pe'n plus petites que la graine de lin, ovoüles, 
pointues par un bout, un peu bombées d'un côté, aplaties de l'antre. On en extrait une huile qui remplace celle d'olives dans la plupart des contrées qui viennent d'ètre nommées; et aujourd'hui mème, on en consonme une grande yuantité à Marseille pour la fabrication du savon. Cette plante et sa semence portent aussi, suirant les contréc's, les noms de jungertine, gigriri, grengeli. Colle des Antilles est noirâtre.

Calebassier, couis et calchasse, crestrutir cujete L. Arbre de movenne grandeur, croissant dans les Antilles et sur tout le littoral de l'Amérique qui les conrironne; ses fruits sont très gros, couverts d'une écorce dure, revte, ligneuse, et remplis d'une pulpe blanche, agrelette, contenant des stmences comprimées, un pren cordiformes. Ia congur de ces fruits est emplonée en Amérique pour fabriguer des nstemsiles de ménace, on fi rmer des saso propres a contenir de l'eau, des

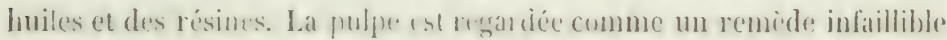
comtre un grand nombre de maladies, et on en fobrique un sirop,

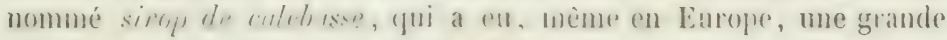
célébrité contre plusietrs aflections du potmon.

Garoba. Suns ce nom, on emploie au brósil, comme antisyphili-

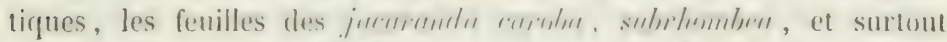

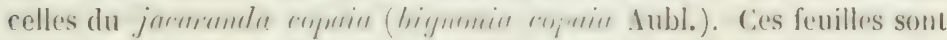
tres grandes, deux fois pinnies, la première fois arec impaire, la seconde fois sens impaire. Les folioles sont ellipligues, coriaces, tres ghabres, Juisantes et d'un rent fencé, riches en un principe auner, âcre $\mathrm{et}$ astringent.

Jaearanda du Eresil, jurntunln lumsilinsis Pers. Par une fausse interprétation de Jarcogralt His. liras., p. 136) , on a auribué à cét arbre le bois de palissandre dn commerce. Varcgraff, en effet, men-

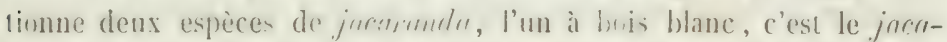

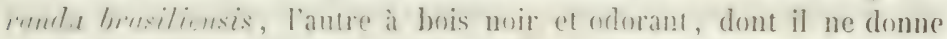
ancune deacriphion : c'est celui-ci gui parduit he bois de palissandre. Il appartient aux dalbergiées.

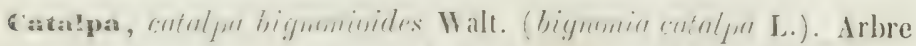
de movenne grandeur, originaire de la Caroline ct de la Lonisiane, aujourd'hui acclimaté dans nos jardins. Il est remarquable par l'ampleur de ses ferilles simples, cordiformes, d'un rert tendre, un peu pubescentes en dessous, et par ses fleurs blanches milées de pourpre, disposées en nombreuses panicules ì l'extrémité des rameanx. Ce's fleurs portent deux étamines ferliles et trois filaments stériles; les fruits sont des capsules grises, très lomgues, çlindriques, pendantes, à 2 valres; la cloison est opposée aux ralves; les semences sont bordées d'une membrane re munies an sommet d'une houpe de poils. Le bois de calalpa 


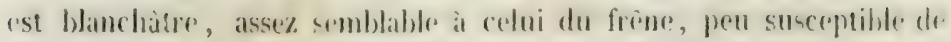
recevoir le poli.

Catalpa a fenilles do chene, chesue noir dimerigue, rululpull Lnngissima Sims (bignumin longyissimn Jacr.). Arbre de 10 pieds, it fenilles glabres, ondulées sur le bord; les fleurs sont blanchâdes on paniculées, disposées en belles grappes paniculées; les fruits sont longs de 60 centimètres et plus ; le bois a la solidité du chêne et n'est jamais percé par les vers; aussi est-il très utile pour la construction des navires; il vient des $\Lambda$ ntilles.

Ibène verte de Cayenne, teroma lencorylon Mart., bignomia leu-

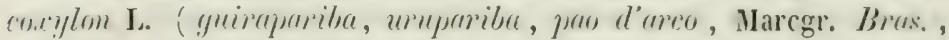
p. ils). Arbre du Brésil, de la Guyane et des Antilles, dont le tronc est formé d'un aubicr blanc très épais et d'un coeur jaune verditre, pen dense, formé de fibres enchevètées les unes dans les autres. fir bois exhale, lorsqu'on le rippe, une odeur aromaticjuc faible mon désagréable; il cèle à l'ean un peu de matière colorante janne qui rougit par les alcalis. On eonnait à la Guyane, sous le nom d'ribrur iren ou d'ribine noim, un autre bois auquel je donne, pour le distinguer, le nom d'cirine rrele-brune. Il est beaucoupplus dense que le précédent, sourent plus lourd que l'eau; il est entouré d'un aubier blanchâtre peu épais, et d'une écorce fibreuse. Il a une couleur verteolive (gui brunit beaucoup et devient presque noire à l'air; il exhale, lorsqu'on le rìpe, une odeur peu agréable, analogue à celle de la racine de barlane; il est d'une texture très fine ot très serrée, el pent acojuélil un beau poli ; il cède facilement à l'eau une matiere colorante verte qui rougit par les alcalis. Ce bois est, sans aucun doute, celui qui a élé désigné par Haregraff (page loS) sous le nom de yniripuribu, donné igalement à l'úbène verte (page 115); mais les caractères des feuilles sont bien diflérents. Ces deux mèmes bois sont ciles arec iloge, et comme incorruptibles, daus un lémoire sur l'exploitation des bois de la Guyane, par Guisan (Cayenne, 1785 ); je ies ai vus, au contraire, être facilen:ent attaqués par les insectes.

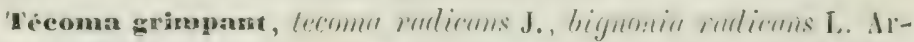
brisseau d'une grande beaté, nommé communément jusmin de lïgimie, dont les tiges sarmenteuses s'accrochent an murailles par de. pelites racines et s'élevent justgüa 10 à 13 mètres de hauleur. I.es feuilles sunt opposées, ailées avec impaires, orales-aignës, dentées on scie, d'un vert foncé. Les fleurs sont grandes, d'un ronge éclatant, dieposées en bouquets a l'extrúmite des rameaux. Cente plante est originaje de la Virginie; on la cultive facilement dans les jardins.

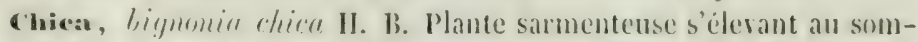

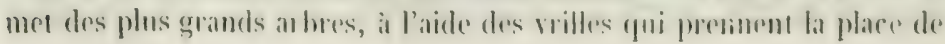


la foliole terminale de ses feuilles bipinnées; les fleurs sont violettes, munies de /t étamines fertiles et d'un filet sterile; le fruit est une silique pendante, longue de 30 à 60 centimètres, très étroite, séparée par une cloison parallèle aux valres; les semences sont ovales, ailées, imbriquées sur la cloison au bord de laquelle elles sont fixées.

Cet arbrisseau croît en très grande abondance sur les bords de l'Orínoque et du Cassiquiare, en Amérique. On retire de ses feuilles, par un procédé analogue à celui qui sert à l'extraction de l'indigo, une matière rouge, pulvérulente, insoluble dans l'eau, un peu soluble dans l'alcool et dans l'éther, dont les naturels se servent pour se peindre la figure et quelquefois tout le corps. Cette substance est arrivée dernierement dans le commerce, sous le nom de lirujuru. Il résulte de quelques essais anciennement tentés par M. Mérimée qu'ello pourrait être appliquée à la teinture.

\section{FAMILE DES GENTIANAClES.}

Plantes herbacées, rarement frutescentes, portant des feuilles en tières, presque toujours opposées, privées de stipules. Fleurs solitaires terminales ou axillaires, ou réunies en épis simples; calice monosépale, sourent persistant, presque toujours à 5 divisions; corolle hypogrne, gamopétale, régulière, ordinairement à 5 lobes imbriqués et contournés arant leur déreloppement; ctamines en nombre égal aux lobes de la corolle et alternes; oraire à une seule loge ou simulant deux loges par le repliement des ralves, très rarement à deux loges complètes; vvules très nombreux fixés à deux trophospermes pariélaux el suturaux, bifides du côté interne; style simple ou profondément biparti; fruit capsulaire à une seule loge, à 2 valves contenant un grand nombre de: graines fort petites; enbryon dressé et homotrope, renferné dans l'axe d'un endosperme charnu.

Les gentianacées sont remarquables par bit forte amertume de toutes les plantes qui en font partie, amertume qui a porté les peuples de tous les pays à les employer comme fébrifuges et stomachiques. Je ne citerai que les principales.

\section{Gentiane jaunc.}

Géntiane luten L. Car. gén. : calice à 5 ou 4 divisions, se fendant quelquefois par moitié en forme de spathe; corolle infundibuliforme, campanulée, ou rotacée, à gorge nue ou harbue, à limbe ordinairement quinquéfide, rarement à 4 ou à 10 divisions ; étamines en nombre ighal aux divisions de la coroile, à filaments éraux par la base: antheres 
dressées ou rapprochées, ì déhiscence longitudinale; ovaire uniloculaire, aminci au sommet, surmonté de deus stigmates arrondis. Capsule oblongue, fourchue ou bifide à sa partic supérieure, uniloculaire, bivalve; senences nombrenses, entourées d'un rebord membraneux et portées sur le bord rentrant des valves.

La gentiane jaune (fig. 223) pousse de sa racine, qui est vivace, une tige haute de 1 mètre, garnie de feuilles opposées, sessiles, con-

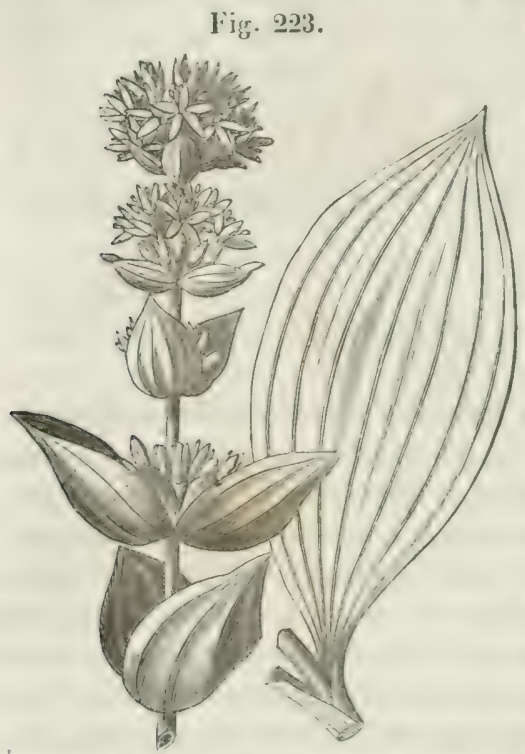
nées à leur base, ovales, larges, lisses, plissées sur leur longueur, comme celles de l'ellébore blanc. Les fleurs sont jaunes, nombreuses, disposces par faisceaux opposés dans l'aisselle des feuilles supérieures, et comme verticillées; la corolle en est profondément découpée et étalée en roue. Cette plante croît en France, dans les Alpes, les Pyrénćes, le Puy-de-Dôme, la Côte-d'Or, les Vosges, d'où on nous apporte sa racine sèche. Celte racine peut être grosse comme le poignet, très longue et ramifiée. Elle est très rugucuse à l'extérieur, d'une texture spongieuse, jaune, d'une odeur forte ct tenace, d'une sarcur tris amère. On doit choisir celle qui est mediocrement grosse ct non cirriée.

Inenry père et .1. Carentun, qui ont fait l'analyse de la racine de gentiane, en ont retire de la glu, une huile odorante, nne huile fixe, une matière très amère soluble dans l'eau et l'alcuol (yentimnin), de la gomme, du sucre incristallisable, quelgues sels et pas d'amidon (Journ. jhlorm. , t. V, p. 97, et t. V'II , p. 173). La quantité de sucre est aruzz considérable pour que les habitants des montagnes où croût la gentiane la fassent fermenter et en retirent de l'alcool par la distillation.

In 1537, 11. Charles lecomte, dans sa These inaugurale, a montré

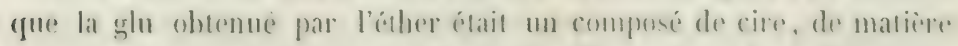

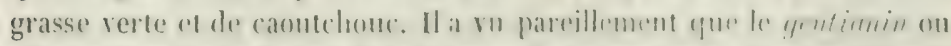
extrait alconligue jaume ef tres amer de la sentiane, étant taite par l'eau froide, latissait des flocons composies de maticre grasse et d'un principe cristallisable qu'on pousait ubtenir en tratant la matiere blanche par l'alcool bouillant el faisant cristalliser. Cie principe, gui a 
reco le nom de yrutivin, forme environ 0,001 du poids de la racine: il est sous forme de longues aiguilles très légères et d'un jaune pàle; il n'a pas de saveur el est sans action sur l'économie animale. Il est presque insoluble dans l'eau froide et n'est guère plus soluble dans l'eau bouillante. Les acides n'en augmentent pas la solubilité; mais les alcalis le dissolvent en prenant une belle coulem jaune et en formant des composés cristallisables jaunes. Il est évident que ce corps ne constitue pas le principe ane jaune de li gentiane, mais il est probable que celui-ci est dérivé du premier par oxigénation ou autrement.

La gentiane jaune n'est pas la seule espece dont la racine puisse ète

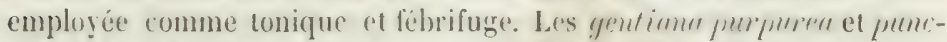
full produisent des racines encore plus amies, et la premiere est principalement usitée en Allemagne et daus le nord de l'Europe.

Tachi de la Guane. Turhin finimasis lubl. Arbrissean de 2 mères de hauteur, portant des branches quadrangulaires, nouenses, opposées en croix, et des feuilles opporées dans l'aissclle desquelles naissent res fleors solitaires, de conleur janne; la capsule est rntomér du calice gui a persisté. La racine de cenc plante est lignense, courerte d'une écorce unie, mince et blanche, semblable à l'extérieur à celle du quassia: le bois en est tendre, blanchitre, à structure finement el uniformément ravonnée. Elle posside une annertume considérable;

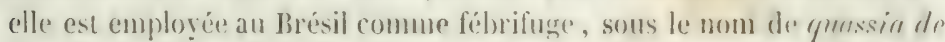

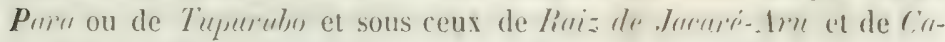
ferana.

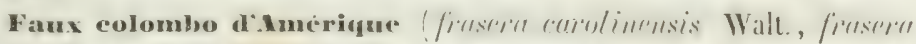
Il illori Mich.). Ia racine de cette plante, l'une des plus inertes de la famille, est substituéce en Inérique au colombo. I'en domnerai les caracteres distinctifs en parlant de ce drunicr article famille des ménispermées).

petite centaurece.

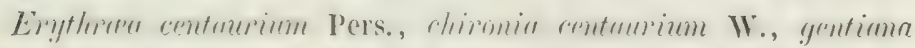

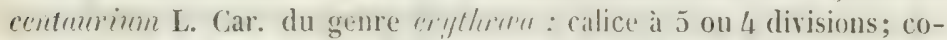
rolle infundibuliforme, nue, à tube celindrigue, à limbe à 50014 lobes. Étamines 5 ou 4, insérées au lube de la corolle; anthères dresseres, exsertes, tordues en spirale; oraire muiloculaire ou demi-biloculaire par l'introflexion des ralres; sı̣le distinct, tombant; sliguate à 2 lanes ou jadivis et en tête. Capsule uniloculate ou semi-J)iloculaire; semences sous-globuleuses, lisses, très mentues.

La petite centaurée ( ligg. 224) s'dèce à la hauteur de 30 à 95 centimètres; elle pousse de sa racine. qui esl fibreuse, une lige simple, anguletise, entourée par le bas de fenilles radicales oblomerues, dispo- 
sées en rosette; les feuilles de la tigne sont sessiles el upposées, les supéricures très étroites et les bractées linéaires. Ia lige se divise et se

lig. 224.

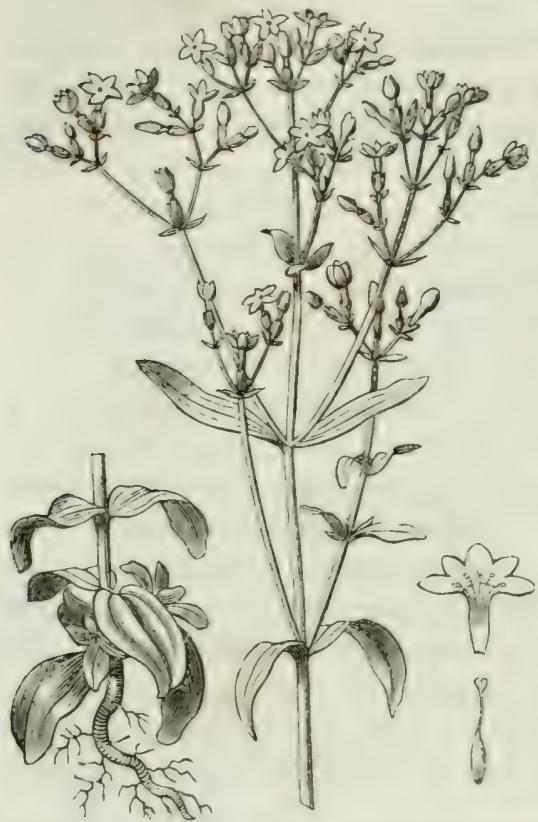
subdivise par le haut en plusieurs rameaux quelquefois dichotomes, portant de pelites fleurs rouges, disposées en corymbe et d'un très joli effel. Ces fleurs, principalement, sont usitées, bien qu'clles soient moins amères que la tige et surtout que la racine; mais leur aspect agréable les a fait préférer. Pour leur conserver leur belle conleur pendant la dessiccation, on les partage par petils paquets que l'on enveloppe de papier.

Cachan-lahuen, erytheed chilensis Pers., chironia chilensis W. Petite plante du Chili et du Pérou, à tiges très menues, hautes de 15 centinètres environ, munies de feuilles toutes opposées, mresque linéaires ; la panicule supérieure cst plusieurs fois dichotome; les feurs sont longuement pédonculées et éloignées des feuilles floraies; les capsules sont uniloculaires. Cotte plante jouit d'une assez grande célébrité comme fúbrifuge, emménitgogne ct résolutive, dans une grande prattie de l’Imérique méridionale.

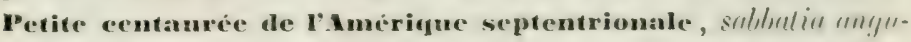
'uris Pursh, rhironin angularis $\mathrm{L}$. Celte plante ressemble completrment à notre petite centaurée, seulement elle est beaucoup plus grande dans toutes ses parties, et ses tiges tétragones sout membraneuses sur les angles; elle est employée aux nêmes usages.

\section{Chirayta el Calamus aromaticus.}

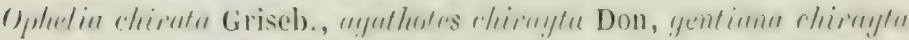
lioxb. Plante très anère de l'Inde, qui est emplovée arec sucrìs commor fibrifuge et pour remédier ì l'atonie des roies digestives. Eille est ì plou près inconnue en France, mialgre l'analyse que MII. Lassiggne et Boissel

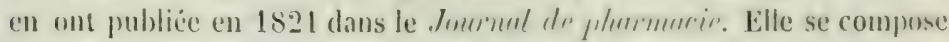

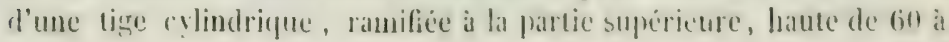


100 centimetres, portant des feuilles opposées, sessiles, lancéolíes, a nervures longitudinales. Les fleurs forment à l'extrémité de la tige et des rameaux une cime lâche, ombelliforme; le calice est à 4 dirisions plus courtes que la corolle; la corolle est jaune, à 4 segments profonds, rotacés, pourvus à la base de 2 fossettes glanduleuses; les étamines sont au nombre de 4 , à filets subulés, un pen soudés à la base; oraire uniloculaire, surmonté de 2 stigmates sessiles, roulés; capsule uniloculaire, biralre; semences très nombreuses, non ailées. Ce sont les liges surtout (qui sont usitées; elles sont grosses comme une forte plume, brunâtres, formées d'une substance demi-ligneuse, d'un blanc jaunâtre, très amẻre et offrant au centre un canal médullaire assez large, vide ou rempli d'une moelle moins amère que le bois. Enfin la partic inférieure de ces tiges présente un caractère constant et par conséquent remarquable; c'est un collet renflé et toujours incliné par rapport à l'axe de la tige. La racine est fibreuse et n'offre rien de particulier.

On conçoit que cette substance d'une amertume forte, pure et privice de tout principe aromatique, soit très usitée dans l'Inde; mais elle sera toujours probablement pen usitée en France, où nous possédons ses é(quiralents dans la grande gentiane et la petite centaurée. Elle nous offre cependant un autre genre d'intérêt, par sa grande ressemblance avec la substance qui élait connue anciennement sous le nom de calamus verus, aromaticus ou odoratus.

Cette substance, assez célèbre dans l'antiquité, est derenue tellement rare dans les temps modernes qu'on s'est accordé, depuis très longtemps, à la remplacer par la souche de l'acorus ierus (page 104). Voici cependant les caractìres que lui donnent Pomet, Lemery it Valmont de Bomare, d'après Prosper Alpin et quelques auteurs:

Fragments de tiges de la grosseur d'une plume, rougeatres au dehors, parsemés de nœuds, remplis d'une moelle blanche, d'un gout fort amer, se divisant en éclats lorsqu'on les brise.

La plante croît à la hauteur de 3 pieds; de chacun des nouds pous. sent deux feuilles longues et pointues; les fleurs naissent aux sommitis de la tige et des rameaux et sont disposées par petits bouquets jaunes: il leur succède de petites capsules oblongues, pointues, noires, contenant des graines de la même couleur.

On a longtemps et généralement attribué le culamns verus à une plante graminée; on ne remarquait pas alors que des feuilles et des rameaux opposés, et des graines contenues dans une capsule, ne courenaient pas à une plante de cette famille. Plus tard on a pensé que cette plante pouvait être une ombellifère ou une lysimachie; je puis dire qu'on n'arait en que des idées fausse's sur le vrai culanus des anciens avant qque je m'en fusse occupé. 
En 1825, M. Boutron voulut bien me renettre plusieurs tiges d'une substance qui existait depuis longtemps dans sa maison, sous le nom de crulcumus v'erus. J'y reconnus facilement le véritable calamus décrit par Lemery, et je ne tardai pas non plus à trouver le genre de végétal qui le produit.

A part la faible odeur de mélilot que conservait cette substance, je fus d'abord frappé de sa grande amertume, de sa teinte générale jaunàtre, et de sa propriété de teindre l'eau en jaune foncé, même ì froid. Je pensai aux gentianées, et trourant en effet que tous les caractères de la plante concordaient arec cette supposition, je priai M. Boissel de me donner quelques tiges du chirayta de l'Inde qu'il avait analysées avec II. Lassaigne. Alors je trouvai une ressemblance tellement frapprante entre les deux tiges, qu'il ne me fut plus possible de douter que le culcamus cerus ne fût la tige d'une gentiane de l'Inde.

Une chose remarquable, c'est que le chirayta possède lous les caractères de la plante du calomus : tige branchue à sa partie supérieure. feuilles simples opposées, fleurs jaunes terminales, hauteur de 60 à 100 centimètres; bien plus, la disposition et lit forme des racines sont telles qu'on dirait qu'elles ont servi de modile aux figures de conlomus données par Clusius, Chabræus et Pomet.

Je n'hésiterais donc pas à dire que le colmmıs rerus des anciens et le chirayta sont une seule et même plante, si, indépendamment de quelques différences dans la couleur extérieure des deux tiges, dans leur consistance et dans la manière dont l'amertume se développe dans la bouche, le chirayla n’était entièrement dépourvu d'odeur, tandis que le cultamus verus en offre une douce et agréable, qui a dù être plus marquée (bien que Pomet et Lemery n'en parlent pas), puisigue son

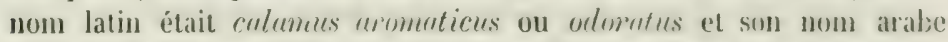

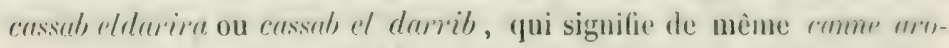
mutique. Au moins faut-il admettre que ces deux végétaux appartiennent à deux espèces voisines ou deux rariétés de la même espèce. (Journ. chim. méd., 1825, p. 229.)

\section{Ményanthe ou Trètle d'eau.}

1tenymulurs trifulintu L. (lig. 225). Celte plante, réunie ì quelpues antres, constitue une tribu particulière de la famille des gentianacies qui diflëre des raies gentianées par l'estiration induplicative de la conrolle, par la consistance ligneuse du lest de la semence, par son albumen plus petil que la cavité qui le renferme, culin par la disposition alterne et congainnante de ses feuilles. La ményanthe en particuliere croit dans les lieux marécageux; il est pourvu dl'un thizome horizontal. 
noneux, vivace, gui dome naissance a un petit nombre de feuilles engainantes longuement pétiolées et partagées par le hant en trois grandes folioles orales, très glabres. Les fleurs forment une belle grappe simpleà l'extrémité d'une hampe haute de 18 à 27 centimètres; elles sont pédonculées et accompagnées d'une bractée à la base; le calice est à 5 divisions; la corolle est infundibuliforme, à 5 divisions ouvertes, ciliées sur le bord, d'une couleur rosée à l'extérieur. Le style est filiforme, persistant, terminé par 2 stigmates; la capsule est uniloculaire, bivalve. Les semences sont très nombreuses et brillantes.

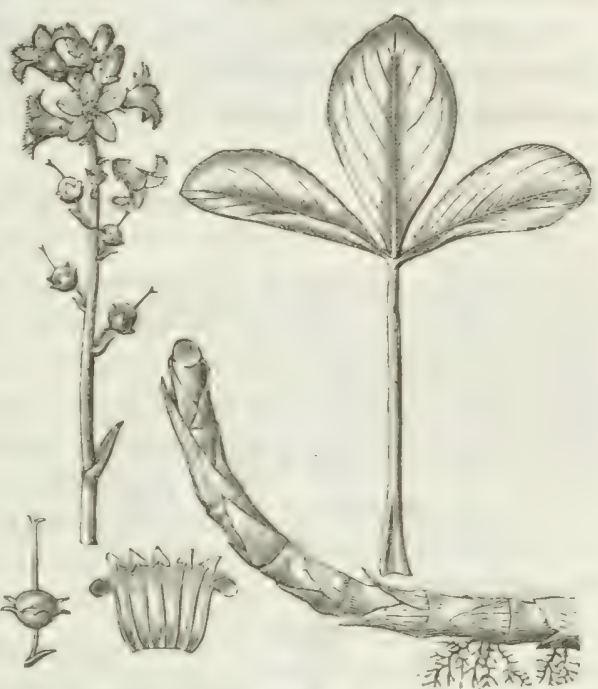

Cinte plante ent très amere, tonique, fébrifuge et antiscorbutique. On l'administre sous forme de suc, d'extrait on en siregl). Elle est e'n1plosée, dans quelques contrées, en place de houblon, pour la labrication de la bière.

\section{FAMILLE DES LOGANIACÉES.}

Cette petite famille a été établie d'abord par 11. R. Brown pour! flacer un certain nombre de genres rapprochés des rubiacies, mais qui end diffèrent par leur ovaire libre; .1. Endlicher y a réuni ensuite les strycturess séparées des apocsnées, les sprigelin, les lorgunin at d'autres genres distraits des gentianées, et en a formé un groupe peu homogène, intermédiaire cutre ces trois familles, qui differe des rubiacées par un ovaire non soudé arec le calice, des apoctnées et des gentiancées par la présence de stipules. Ce sont donc des régétaux à fenills entieres, opposies ot slipulés, prumsus de fleurs dont le calice est libre el à jou 14 disisions; la corolle est reguliere, a 5 ou 4 lobes contournés ou valvaires; les étanines sont ordinairement en nombre égal, tantôt alternes, tantôt opposées, que'quefois en partic alternes et en partie opposées aux divisions de la curvelle; l'ovaire est libre, ordinaire- 
ment à 2 loges; le style est simple, iourvu d'un stigmate simple ou double. Le fruit est tantôt hacciforme, tantôt capsulaire, ì '2 valse's rentrantes portant les placentas; les semences sont sourent pelties, quelruefois ailées; l'albumen est charnu ou cartilagineux, l'embryon droit, les cotylédons foliacés.

Ce petit groupe, si peu nombreux qu'il soit, renferme des régétaux d'une grande puissance médicale et des poisons très énergiques principalement fournis par la tribu des strychnées.

\section{Splgêlie anthelmintique (fig, 296).}

Syigrglin anthelmin L. Plante annuelle du Brésil, de la Guyane et des Antilles; la racine en est fibreuse et menue; la tige simple ou peu rameuse, droite, haute de 40 à 50 centimètres, ggarnie de quelques feuilles opposćes; les quatre feuilles supérieures sont en croix; les lleurs sont verdâtres, presque sessiles, munies de bractées et disposiés

liig. 226.

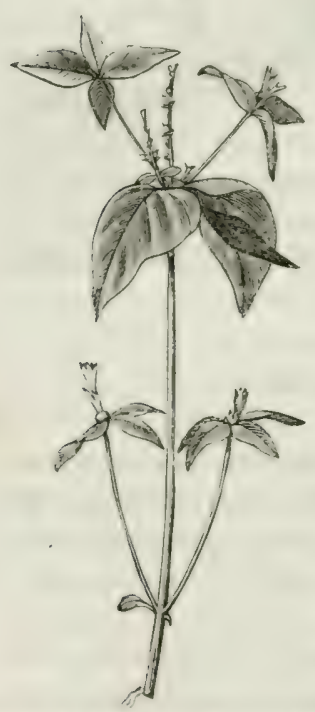
d'un mème côté en épis grêles et filiformes, à l'extrémité de la tige et des rameaux. les fruits sont des capsules didymes, dicoques, quadriralves, entourées inférieurement par le calice persistant. Cetle plante passe pour vénénense, et elle a été appelée Brinvillière du nom de la maryuise de Brinvilliers, fameuse empoisonneuse du temps de Lotis XIV; mais il faut que la dessiccation lui fasse perdre cette propriété, car on l'emploie sans inconvẻnient et, à ce qu'il parât, avec succìs contre les vers intestinaux. Desséchées, ses feuilles sont d'un vert foncé et d'une odeur du genre de celles des racines d'arnica ou de pyrèthre, c'est-à-dire forte, sans qu'on puisse dire cependant que la substance soit aromatique; leur saveur est un peu amère et un peu âcre. Cette plante est assez rare dans le commerce.

Spigélie du Maryland, sprigeliu marylundica L. Celte espèce croìt dans la Caroline, la Virginie et le Maryland; elle diffère de la précédente par sa racine virace, sa tige plus ferme et tetragone, ses feuilles toutes opposées deux à deux, ses fleurs beaucoup plus grandes et rouges an dehors. On trouve quelquefois cette plante dans le commerce, racine, tige et feuilles mèlées; la racine est très menue, fibreuse, 
fresçue semblable à celle de la serpentaire de Virginie, mais non aromatique; elle a une saveur amere, un peu nauséeuse, et paraît spongieuse sous la dent. Les tiges sont droites, fermes, tétragones à leur partic supérieure; les feuilles sont d'un vert pâle, sessiles, longues de 55 à 80 millimètres, sans odeur bien caractérisée et presque insipides; les feurs manquent. Cette plante est emplogie comme anthelmintique, en place de la premiere, mais clle est bien moins active; il est probable que c'est elle dont II. Fenculle a public l'analyse (Journ. de pharm., t. IX, p. 197 ).

\section{Volx Igasur ou Fève de Saint-Ignace.}

Iynatio amarn I. f., strychnos Iynutii Berg. Cette semence et la plante rui la produit ont été décrites en 1699, par Ray tu Peliver, swr la communication qui leur en arait été faite par le père Camelli, jussuite Timanctions philosmphiques, 1699 , no 250). La plante est grimpante et monte en serpentant jusqu'au sommet des plus grands arbres; son tronc est ligneux, quelquefois de la grosseur du bras; ses fenilles sont npposées, orales, entières, pourvues de 5 nerrures longitudinales; sa fleur ressemble à celle du grenadier; le fruit est ovale, plus gros qu'un melon, lisse, d'un vert olive, présentant sous une peau fort mince, lisse et charnue, une seconde enreloppe ligneuse et fort dure. L'intérieur du fruit est rempli par une chair un peu amère, jaune et molle, dans laquelle sont renfermées 20 à 2 /4 semences couvertes d'un duret argenté, et de la grosseur d'une noix lorsqu'elles sont récentes, mais devenant anguleuses et se réduisant au rolume d'une aveline par la dessiccation. On peut roir ce fruit figuré dans les Tirmsartions philosonjhipues de 1699 et dans la Flore mridicale de Chaumeton et Turpin.

Les caractères donnés par Linné fils sont plus précis et un peu diffé.. rents : les fleurs sont disposées en petites ombelles axillaires pédonculíes; les coroltes en sont penchées, très longues, blanches, d'une odeur de jasmin; le fruit est courert d'une écorce sèche, très glabre, de forme orée, atténuée en col et de la grandeur d'une poire de bon chrétien. La description donnée par Loureiro est conforme à celle de I.inné : baie grande, arrondie, atténuée en col, unilıculaire, sèche, polysperme, à écorce glabre, ligneuse, blanchâtre, semblable à celle du cucurbita lagenaria.

I.es semences de Saint-Ignace, telles que le commerce les fournit, sont plus grosses que des olives, généralement arrondies et convexes đlı còté qui regardait l'extérieur dı fruit, anguleuses et ì 301 / facettes du côté opposé, ordinairement plus épaisses et plus larges vers une des extrímitis, oì se trouve une ouverture répondant ì lat base de 
l'embrỵn, qui est beaucoup plus petit que la cavití qui le renferme: mais cette plus grande largenr répond quelquefois à l'extrémité opposée. Tantôt les graines sont pourvues d'un reste d'épisperme blanchâtre, tantôt elles sont réduites à leur chlosporme corné, demi-transp̧arent, fort dur, d'une saveur très amère el inodore.

La fève de Saint-Ignace est purgative et a guelquefois guéri des fièrres quartes rebelles; mais on doit l'employer avec la plus grande précaution; car, prise à une dose même peu considérable, elle cause des vertiges, des romissements et des convulsions. C'est un vrai poison du genre des narcotico-âcres.

On doit à Pelletier et à M. Caventon une belle analyse de la fève de Saint-Ignace. Ils l'ont d'abord râpée et traitée par l'éther, qui en a sćparé une matière grasse. Ensuite l'alcool bouillant en a extrait, entre autres principes, un peu de matière cireuse rani s'est précipitip par le refroidissement du liøuide. Celui-ci, évaporé, a produit un extrait qui, redissous dlans l'eau, a formé aréc les alcalis un précipiti ahondant, très ficilement cristallisable lorsqüil a eté purifié. neutralisant complétement les acides, ramenant au blen le tournesol rongi, anfin jouissant de toutes les propriétés d'un alcali végétal.

Cét alcali a été nommés stryrchnime, non seulement parce que beancoup de botanistes regardent l'iguntira munre comme un véritable strychers; mais encore parce que la meme base a éte trouve dins la

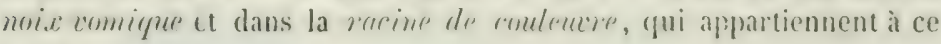
même genre (1).

La liqueur d’où la potasse avait précipité la strychnine contenait une? matière colorante jaune peu importante. et l'acide auruel le nouvel alcali végétal se trourait combiné. Cet acide, dont la nature particuliere n’a pas encore été bien constatée, a ćté nommé cependant uride igursu. vique, du nom malais igasur de la fève de Saint-Ignace.

La fère de Saint-Ignace, épuisír par l'étler et l'alconl, a ét' traitér par l'eau froide et lui a cédé une asséz grande quantité de gonmene. l'eau bouillante en a encore extrait un peu d'amidon: le résidu insonluble, gélatineux et très volumineux, a cté jugi analogue is la bassonrine.

\section{Noix vomique ( fig, ⒉27).}

La noix romique est lis semence d'un arbre de l'Inde, nommé

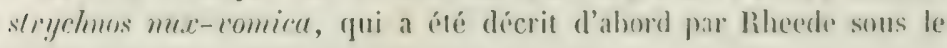

(1) Dans ces différentes substances, la strychnine est accomparnuce d'un autre aleali végétal nommé brucine, qui diffère du premier par une beaucoup plus grande solubilité dans l'alcool et par la propriété de prendre une couleur rouge écarlate par l'acide nitrique. (Voir, pour les autres propriétés de ces denx alcalis, ma Pharmucopece raisonnéc. Paris, 1817. payes 697-700. 
nom de camir(min (Hort. malab., vol. I, 67, tab. 47), et postérieurement par Ioureiro et par Roxburgh. Ciet arbre a une racine épaisse, couverte d'une écorce jaunâtre, et douée d'une très grande amertume. Le tronc peut être embrassé par deux hommes et est recourert d'une écorce grise-noirâtre; les rameaux sont volubiles, pourvus d'un ćpiderme tantôt d'un gris cendré, tantôt orangé, et munis de feuilles opposées, ovales-arrondies, a 5 nervures; les fleurs sont petites, disposées en ombelles axillaires, d'une odeur faible non désagréable; la corolle est tubuleuse, à 5 divisions étalées; l'ovaire est à 2 loges polyspermes. Le fruit est une baic globuleuse, ayant la forme d'une orange, mais converte d'une écorce ronge, dure et lisse; il est mniloculaire et ne présente d'autre vestige de la seconde loge de l'ovaire qu'une petite cavité observée dans l'épaissemr de la coque, près du pédoncule. L'intéricur' est rempli par une pulpe visqueuse, au milieu de laquelle sont logées un pelit nombre de semences orbiculaires, aplaties, fixées

Fig. 227.

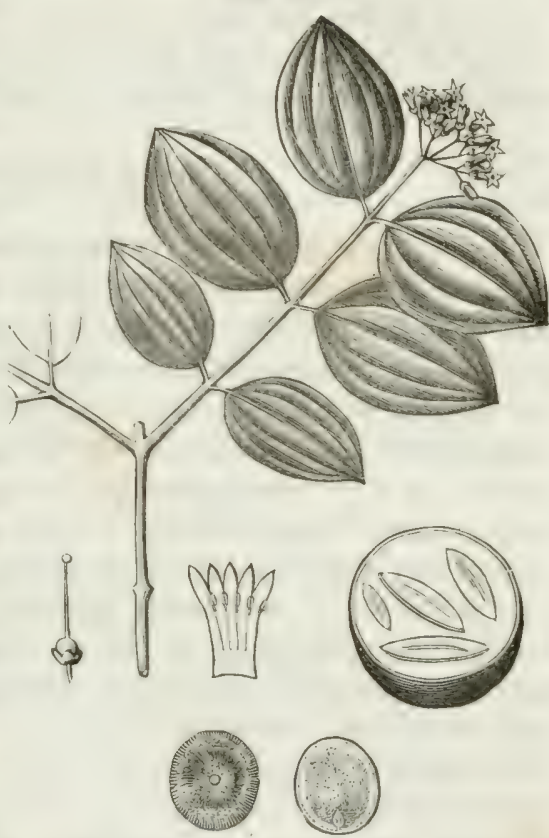
par leur centre, grises et d'un aspect velouté au dehors. Ces semences sont formér's à l'intérieur d'un endosperme corné, d'une très forte amertume, soudé intimement avec l'épisperme; elles présentent, sur un point de leur circonférence, une légère proéninence répondant i la chalaze et à la radicule de l'embryon (Gaertn., De frurtilus, (ab. 179).

On trouve décrites dans l'ourrage de Rheede trois antres espèces de runiram: l'une est le ts.jpru-lintu-talli-comirum (t. VII, pl. 5), dont lis fenilles sont ovales-lancéulées, à 3 nervures; le fruit est orangé, du volume d'une grosse cerise, et contient au milieu d'une pulpe. amere: ou 4 semences semblahles pour la forme à la noix vomirgue, mais presque dépourves d'ancrtune. Cet arbre, dont le trone ne dépasse pas 21 i 2 la centimètres de diamètre, wet le stryclmos mimor

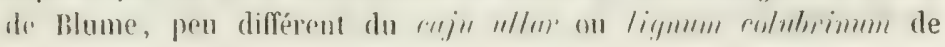


Rumphius, gui est le strychuss ligustrimu Blume. Je mets au raner des

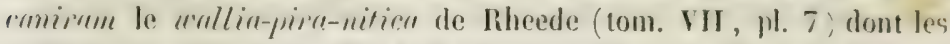
fenilles ressemblent à celles de la vigne; mais une espèce plus impertante est le modira-comirame (tom. VIII, pl. 24), strychnos coluInine L. (1), dont le fruit est aussi gros que celui du strychmos mu, romica, et contient des semences semblables qui font quelquefois partie de celles du commerce (2); mais les fruits mûrs sont d'un châtain noirâtre; les feuilles sont ovales, pointues, à 3 nerrures, et se trouvent quelquefois remplacées par une vrille ou crochet; enfin la plante est beaucoup plus volubile et présente un trone de moindre dimension.

\section{Bois de Couleurre.}

Les pays intertropicaux et ceux qui, soumis à une température moins élerée, sont cependant encore peu habités par les hommes et sont converts d'immenses forêts, ces pays sont infestés d'un grand nomibre de reptiles dont la morsure est sourent suivie de mort. Les habitants de res contrées ont donc cherché dans les productions naturelles qui les entourent les moyens de se préserver de l'atteinte de ces animaux dangereux, et il est renarquable que le règne végétal leur en ait fourni plusieurs dont l'efficacité paraît constante; telles sont, en Amérique, les semences de nhandirobe (fecillon comdifuliu), les racines des aristoluchin unguicida, serpentaria, cymbiforn, etc., et celles de polyyuln senega; telles sont encore en $\Delta$ sie les racines de différents stryctmos, colle de l'ophioxylum serpentinum (apocynées), et celle de l'ryshiohliza mungos L. (rubiacées). Ce sont ces racines asiatiques qui ont reçu d'abord le nom générique de bois de couleure, lerguel est ensuite resté aux racines de strychnos.

Je dis donc que plusieurs racines de stryctmos ont porté le nom de bois de couleure; car sans parler du conju ullar que Rumphius nomme autrement ligmum colubrimum, commelin nous apprend que le bois des denx strychnos, mus-romica et colubrina, forme également le bois de couleuvre. Cependant le second élait plus spécialement nommé par

(1) Il faut remarquer, à l'égard de celte espèce linneconne, que par suite d'une fausse citation qui a rapporté le modra caniram au tome VII, pl. 5 de Rheede, on a fait le strychnos colubrina synonyme du tjeru-liatu-vallicaniram de Rheede, et du caju-ullar de Rumphins. On a vu plus haut que ces deux-ci constituent deux espèces anse\% voisines, mais très distinctès du stryclinos colubrina.

(2) Je rapporte à celle esjece des semences trousces dans la unix romique du commerce, qui different des semences ordinaires par une couleur verte blenalre foncéc. 


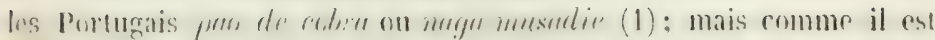
brameoup plus rare, on lui substinue somsent le premier (Rosburgh) : de sorte quo, fante de reuseignoments plus précis, il ne nons est guèro possible de dícider si le bois de coulewre du commerce est produit par le strychnos nux-vonicu ou par le colubrince

I.c bois de couleure le plus ordinaire du commerce provient d'une racine qui parait aroir, dans son entier, 2. centimètres de diamètro : il se présentr pas d'aubier, 't l'écorce n'a pas plus de 1 millimètre d'épaisscur. Elle est trìs compacte, dure, d'un hrun foncé arec des taches superficielles d'une conche jaune orangée, qui a dù la recourrir omicrement; clle posside me très grande amertume. Le bois a la couleur et prestgue l'apparence du bois de chene; mais oil l'en distingue facilement par des fibres blanches et soyeuses fui sont, en très grand nombre, mểées aux libres ligneuses; il est moins amer gue l'écorre. le possède d'ailleurs drux variétés de ce bois: l'une est plus compactr, plus amère, à fibres ondulées, et présente à l'estérieur de l'écorce dos lignes circulaires proéminentes, tres nombreuses et très rapprochées; l'autre est un peu plus lérèe, un pen moins amere, à écotce nnice et a libres droites; malgré ces diflérences, ces deux bois me paraissent provenir dı même arbre.

Je pense qu'il peut encore a etre de mème d'un second bois de conleure dont j'ai deux morceanx provenant, l'un de la partie inférieure d'une raciue, l'autre d'une ranification de :s centimetres de diamètre. Ce bois est d'unc texture très fine, d'une conleur janne foncée, Wès amer, comrert d'unc écorce très mince, d'un gris à la fois brunâtre el orangé; mais il n'(n) est pas de mème d'un troisiène bois de conlemre provenant toujours d'une racine, qui est marbré de jaune et de vert, ce qui rend thès apparentes les fibres blanches et soyeuses dont j'ai parlé. I'écorce est formée de deux conches: une intérieure brune noiràtre et très mince, répondant à l'écorce du premier bois de couleuvre; l'autre extérieure, plus épaisse, blanchàtre, recourcrte d'un épiderme jaune orangé. P'eul-être ceute racine appartient-elle au mèm strychnos que la noix romique d'un vert foncé dout il a été question plus haut. Linfu je possède un quatrième bois de couleurre provenant d'une ligge de 7 centimìtres de diamètre, pourvu d'un canal médullaire excentrique, rempli d'une moelle cloisonnée, ayant la couleur et l'apparence du bois de chêne, mais grossier, pen compacte, privé de fibres hanches et Instrées. L'écorce est orangée, épaisse de 2 millimètres, fibreuse, peu serrée; courerte d'un épiderme gris noiràtre, et pourrue

(1) Maga est un des noms indiens du serpent ì lunettes, cobra de capella Port., coluber nuja $\mathbf{I}$. 


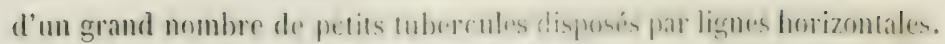
Cebois est d'ailleurs trés ancien, mamere anx vers, et il me possible (pur la vétusté en ait modifié les caractères physiques.

l.e bois de couleurre est cmployé dans l'Inde comme fébrifuge et comme antidote de la morsure des sirpents renimeux; a lministré a dose trop élevée, il occasionne des rertiges, des secousses tétanigues ot peut même donner la mort, ce qu il fant attribuer ì la strẹchnine et à la brucine qu'il contient.

\section{Leoree de Vomiquier, dite Fansse Angusture.}

En 17s5, on apporta pour la premiere fois, de l'île de la Trinité en Angletere, une écorce fébrifuge ariginaire drs conirons d'. Ingustulat dans la colombie; cette écorce, produise far un arhre du genre gyolifren (lamille des diosmées), fut emphoyee en Europe, pendant mur vinglaine d'annees, arec succes, comme lébriluge: mais vers 1 Sit 7 on 1sos, de graves sṭptomes d'empoisonnentent suétant présentés par suite de son usage, on reconnut que l'écorce dlangusture élait milangien d'une autre fort dangereare qui lint, dis cette éporgue, désignese ans 1. nom de finesse munusture, mais sur l'origine de langelle on cut pendant longtemps une opinion fort erronce, en l'attribuant an lnomen

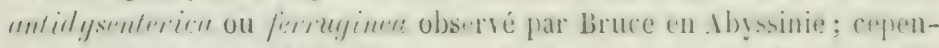
dant, des l'année 1816 , Vires, se fondant sur ce que l'action de la fansse angusture sur les animans était semblable a celles de la noix vonique et du bois de couleurre, anait pensé que cetle écorce desait venir de l'Inde et qu'elle derait ètre produite par un stryghms, cente opinion fut confirmée phus tard par M. Bathil, droguiste a Prague, qui nous apprit que la fausse angusture, écorce du stigrdimes muir-immir arait été apportie de l'Inde en Ingleterre, en 1 șo6, dians la vor de l'enployer conne lébrifuge, ainsi qu'eile l'ctait dans l'Inde; mais yme

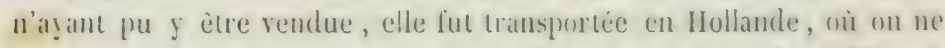
troma pas de meilleur mogen de l’utiliser que de la méter à l'érorce d'angusture d'Amerigue. En dernier lieu, un envoi d'ecorce di siryelmess nut-emmian fait directement par l'apothicaire gencral de Calcutla à M. Christison, est renu òter tous les dentes yuion aurait encore pu conserver à cet égard; cette écorce n'etait autre chuse pue la fausse angusture du commerce.

L'écorce de vomiquier est ordinairement demi-ronlée, épaisee de 's is 5 millimètres, d'un gris blanchâtre, compacte, très dure et common raccornic ou comme tourmente par la dessiccation. Quelquedois, eependant, elle a pris une teinte noiratte a l'interieur. Lal surface exte-

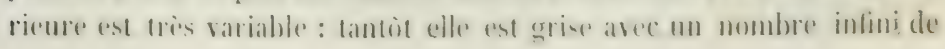


petits tubercules blanes: d'autres fois a lle est comrerte d'une substance épaisse, fongueuse, d'une conleur orangée-rouge, gui a éti prise par tous les obsersateurs pour un lichen du genre rhimetertum Ich.; mais une observation attentive, appuyée de l'examen de l'écorce du s/ryglhus: 1seudo-chinu, dont il sura question ci-après, m’a démontré que ceette matière orangée, très souvent recourerte de l'épiderme blanc grisitre du végútal, faisait partie de l'écorce et était due à un déreloppement extraordinaire du tissu subéreux. Cette mème matière orangée se montre d'ailleurs presque constamment dans l'écorce de la racine des s/ry.lunus, où clle ne peut être attribuéc à la présence d'un lichen.

C'est en faisant l'analyse de hatusse angusture que Pelletier et II. Caventou ont découvert l'alcali végétal aucquel ils ont donné le nom de brucine, d'après l'opinion qui réguait alors que cette écorce était produite par un ln-merl. Hais ce nom, qui consacre une hérésie an histoire naturelle médicale, dermait être changé en celui de romicine ou de eraisemuime, maintenant qu'il est prouré que la fausse angusture

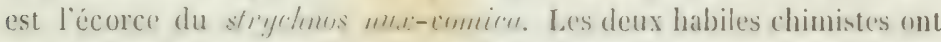
retiré, en outre, de l'écorce, une matière gratsse non rénéneuse, beaucoup de gomme, une matiore jaune soluble dans l'eau et dans l'alcool,

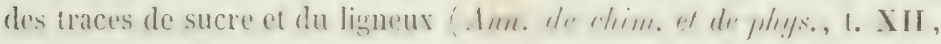
p. 113 ).

Pelletier a également analșsé la matière orangée qui recourre sonrent lécorce de fausse angusture. Il ('n a obtenu une matière grasse, d'une sareur donce; une natière colorante janne, insoluble dins l'ean, remarquable par la belle coulcur verte qu'clle prend arec l'acide nitrique; une autre matière jaune soluble, un peu de gomme, pas d'amidon, de la fibre ligneuse (Jummul de plinum., t. V, p. 546 ).

Les caractères si tranchés de coloration que la romicine et la matiere orangíe de l'écorce prement arec l'acide nitriejue peurent servir a faire reconnaitre la fausse angusture. Il suffit, en effet, de toucher aree une gnutte d'acide nitrique la surface intérieure de l'écorce pour lui communicyer une couleur rouge de sang, et de toucher la couche orangée de l'extéricur pour lui faire prendre une couleur verte. Cependant j'ai montré que ces caractères n'araient pas la valeur qu'on arait voulu leur attribuer, puisque l'écorce de strychnos pseudo-chinn, bien que ne contenant pas de brucine, les possède tous les deux; j'ai montré pareillement que beaucoup d'autres écorces, telles que le cuscu d'intu du Brésil, l'écorce de crillesiu et surtout l'écorce de garou, prennont une conleur rouge très vive par l'acide nitrique (Jun'n. phlarm. 1. XXV, p. 708-710).

Antérieurement à la décourerte de la brucine dans la fausse angusturr, f'arais chercbé à distinguer cette écorce de l'angusture vraie par 


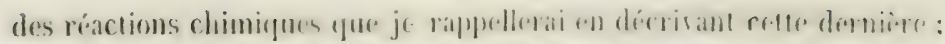

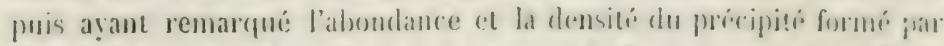
teinture de noix de gatle daus le macere de fausse angusture et l'eniere décoloration de la liqueur, j'en conclus que la noix de galle poulait ère un contre-poison pour l'angusiure, et j'en fis l'essai. I n thien à qui je fis araler $4 . \bar{j}$ centigrammes de poudre de fausse angusture, incorporés dans du miel, mourut en trois quarts diheure, apries dr. biolentes et nombreuses attaques de tétanos. Ln autre chicn, do mom force, a pris 120 centigranmes de fausse angusture of ensuite l'infusi: aỵueux de 30 granmes dr noix de galle; il est mort trois henres trois quarts après, sans consulsions, ayant les pupilles trìs dilatées, le ventre tries dipriné, devenant de plus en plus faible, et rendant par la bonche une grande quantité de liquide sanguinolent. Junobstant ce résultat défavorable, la grande différence observée dans les symptônes, et Ir temps beaucoup plus long pendant lequel l'animal arait vécu, malgrí une dose triple de poison, me firent penser que la noix de galle pouvait btre considerée comme un contre-poison de la fausse angusture. Je m'en suis servi, en effet, arec un succès complet, plusieurs fois depuis, pour gnérir des chiens empoisonnés par les bouletles que la police fait répandre dans les rues. L'emploi du tannin, adopté aujourd'hni pour neutraliser généralement les effets des alcalis vigétaux vénéneux, n’est qu'une extension du fait que j'avais signalé d'abord.

\section{Senences de Tiran-Cotte.}

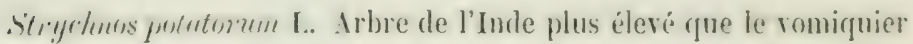
et beaucoup plus rare. Ses fruits sont de la grosseur d'une cerise, d'un rouge obscur, et ne contiennent qu'une senle semence orbiculaire, beaucoup moins aplatie gue la noix romicue, plus petite el d'une conleur jaune de paille. Cette semence ofire une des nombrenses exceptions que l'on peut opposer it la loi que l'on a cru prouroir établir, que jes végélaux de nirène famille, et à plas forte raisın de même genre, jouissent des mêmes propriétés chimiques et médicales. Loin que la semence de titan-cotte soit amère ct rénéneuse comme la noix vomigne, elle est privée d'ameriume et sert dans l'Incie à échaircir l'can destince a la boisson des habitants. On a fait beaucoup de suppositions sur la manière dont cette substance agit. Je pense gu'elle angit par son mucilage abondant (pertiue?) (qui s'unit aux substancre terreuses tenues en suspension dans l'eau, et les précipite.

\section{strychnos Tieute, lpas Tieute.}

Les naturels des iles Molngues et de's iles de la Somde se serrent,

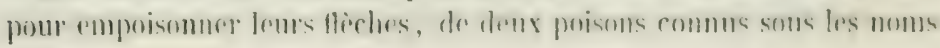


d'upus antien et d'upus tieute. I.e premier est produit par l'antiur is

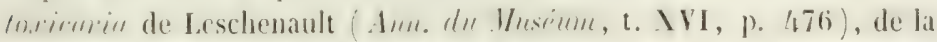
famille des artocarpées (p. 311); le second, encore plus dangerens, ést retiré du stryelunes tieutr. Celui-ci est un végètal lignenx et grimpant gui crôt uniquement dans les solitudes de Blanbangang, où mème heurcusement il est rare. I'en ai ru une tige, rapportée par M. Lesson, qui arait 4 centimètres de diamètre; le bois en était poreux et d'un blanc jaunitre; l'écorce était blanche, rugucuse, couverte d'un enduit crétacé et offrait en grande abondance un petit cryptogame noir du genre oyregrnpher. La racine éiait couverte d'un épiderme fin, couleur de rouille, et le bois en était blanchatre. C'est arec une décoction rap)prorhée de l'écorce que les Javanais préparent l'upus tirute, que Pellelier et II. Carentou ont décrit comme un extrait solide, brun-rougeâtre, un peu translucide, et que j'ai su sous la forme d'une poudre d'un gris brunitre. Cet upas, analrsé par ces deux habiles chimistes, leur a domé une très forte proportion de strychnine sans brucine, mais accompagnée d'une matière brune qui jouit de la propriété de verdir par l'acide nitrique (Amn. chim. et physs, t. XXVI, p. 45).

Arare. Les Indicns de l'Orénorpue, du Cassiquiare, du Rio- Yegro et du Iupura, en Imérique, empoisonnent égalencnt lenrs llèches avec plusieurs poisons de nature analogue, connus sous les noms de

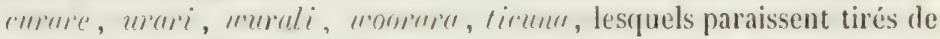
plusieurs strychnées qui sont le strychuos tracifurn Benth., le roulurmun guimme d'Aublet et le roulumen? curcure DC. Il paraît que le curare peut être ingéré sans inconrénient dans l'estomac et qu'il n'est vénéneux que lorsqu'il est introduit dans le sang. MII. Roulin et Boussingault et Pelletier, qui l'ont examiné successirement, n'ont pu en rxtraire aucun alcali cristallisable, et n’ont obtenu la matière vénéneuse que sous la forme d'un extrait coloré, très soluble dans l'cau et dans l'alcool, précipitable par la noix de galle (.1un. chim. phys., t. XXXIX, p. 24, et t. XL, p. 213 ).

\section{Quina do Campo.}

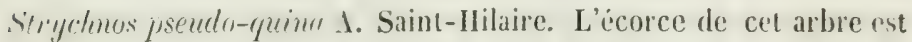
III des médicaments toniques et fúbrifuges les plus importants du Brésil. Bien qu'appartenant au même genre que la fausse angusture, la nois romique 't la fère de Saint-Ignace, whe li'exerce aucune action malfaisante sur l'íconomic animale, et Vanquelin a constaté, en effot, qu'clle ne contenait ancun des deux alcalis ugui communiquent atux trois autres substances leurs propritís médicales, mais anssi leurs qualités délétere's (Anneses du Wuséun, annie 1823). Cotte écorce, telle que 
Guillemin l'a rapportée de lio-Jancion, en 4839 , présente les caractères suivants:

Elle est en morceaux comris, très irreguliers, plats ou demi-roulés, formés de deux parties bien distinctes, le liber et les couches subéreuses.

Le liber est très mince ou très épais, presque sans intermédiaire, ce yui semblerait indiquer deux varjétés d'écorce, l’une peut-être atppartenant à la racine ou au tronc, l'autre aux branches. Géneralement ce sont les écorces les plus larges gui offrent le liber le plus mince (1 millimetre); les écorces roulées l'ont an contraire épais de 5 a 7 millimètres.

(Ce liber a pris à l'air une couleur grise plus ou moins foncef ; mais il est blanchâtre à l'intérieur; il a une cassure grenue plutôt que fibreuse, surtout celui qui rst épais; il possède une très forte antertume.

Que le liber soit mince ou épais, les couches subéreuses sont semblables, appliquées en grand nombre les unes sur les antres, jusryùi une épaisseur de 10 à 1 j millinètres, et ordinairement crevassées jusqu'au liber. Ces conches subereuses sont recourertes d'un ípiderme blanc et conne crétacé ; mais elles sont ì l'intérieur d'unc helle conleur rouge orangéc; elles possident une sarcur amère anssi forte et aussi persistante que celle du liber:

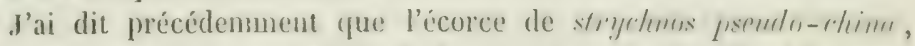
quoique complétement privée de brucine, rougissait à l'interieur par l'acide nitrique, tandis que les couches orangées prenaient, au moỵn du même acide, une conleur verte noirâtre, et (fu'elle se comprortait en cela exactement comme la fausse angusture (voir igalement . Immonul d, phanmacie, t. XXV, p. 706 ).

Dans ma précédente édition, j’ai donné une description incxacte de

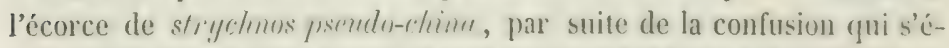
tait élablie cutre cette écorce et une antre précédemment analỵsie par II. Mercadieu, sous le nom de copulrhi, et présentée ensuite par Virẹ comme élant colle du stryrtums pspute-rlimu (voir précédemment, p. 342). Je reviens un instant sur cette dernicre écorce. Fille est on morceaux courts, formés d'un liber dur el fibremx (qui a dì cilre jaunitre, mais qui est devenu presque complément noir par la dessic. cation on par l'action prolungere de l'air. Ca liber est ordinairement

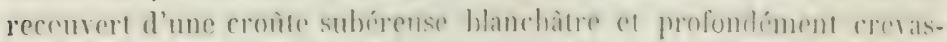

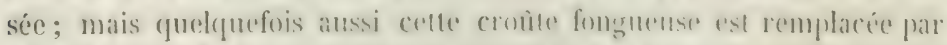
des tubercules blanes rqui ('n sont commo le commencement : le loul ist d'une amertume excessive. Cetle écoree présente done, en cefled, de grands rapports aree celles des stryrluns. mais l'espece en est incont- 


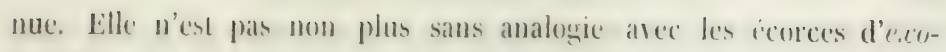
stemmu.

\section{FAMILLE DES ASCLEPIADÉES.}

Plantes herbacés ou arbrisseaus rolubiles, quelquefois charmus, el dont lo suc est sourent lactescent. Les fenilles somt opposées, plus rarement verticillées on alternes (abortires ou rudimentaires dans les espèces charmmes), priblés, simples, tres entieres, prirées de stipules ou guedguefois munies de poils interpétiolaires. les fleus sont complètes, régulières, ombetlies ou fasciculées sur des pédoncules axillaires; de caliece est lihre, à jo divisions imbriquées avant la floraison; la corolle est insére sur le réceptacle, gamopétale, tombante, à divisions concournés, offrant i la gorge i appendices plus ou moins développés el de forme varié Ies étamines, an nombre de 5 , sont insérées a la gorge de la corolle; leme filets sont somdés et forment un tube dit I! fnostryimm gui renferme le pistil et porte au dehors les 5 appendices pétalö̈les. Les anthères sont fixées longritudinalement à la partie supérieure du tube, sont à 2 logres et recoirent dans chayuc loge une masse de pollen qui lui est ruroye par un perit corps ghandulaire placé sur le stigmate. L'ovaire est double et pourvu de 2 styles qui se terminent far I stigmate commun, pentagone, portant a charpue angle un des petils corps grlandulaires, dupuel pendent ou s'écartent en se redressant denx ou fuatre masses pollinigues qui sont renfermées, mon dans les deux loges d'mone mème anthere, mais dans denx loges de denx anthères roisines. le fruit est un firllirmire, c'est-à-dire un fruit composé de denx follicules distincts, contenant m grand nombre de graines sourent aigreftees, dont l'embryon est homotrope an centre d'un endosperme charmu.

Cette famille a beancomp de rapports arec celle des apocrnees domt clle est un dimembrement, ot s'en rapproche également par la propriéte toxigue, imetique ou purgative d'un grand mombre d'espècrs : tels sont principalement le periplorn granec qui est un poison pour les

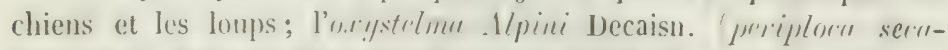
mome L.), dont on peut retirer un suc laiteux et jaunitre que l'on a cru produire une sorte de scammonéc le serrmmuse emntirn de l'Inde

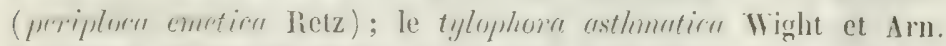

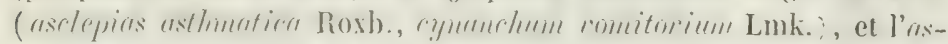
reprias murnstriven des Intilles, dont les racines somt usitées comme vomitives et comme succédanées de l'ipécacuanlit dans les pays qui les

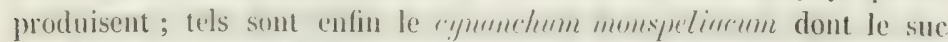
sert à la préparation d'unc manvaise scammonce indigène, ed le sole- 


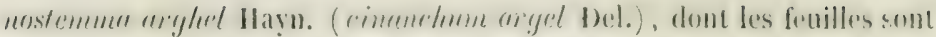
tonjours mêlées à celles du séné de la palte. fe décrirai les fenilles d'argnel auprès de crlles du séné, dont il est important de les distinguer; je parlerai de mème de la plupart des racine's enmplovées comme: vomitives, a la snite de l'jpécacuanha, de sorte qu'il ne me rest" a mentionner ici que trois plantes gque leurs propriétés spéciales recommandent à l'attention des médecins.

\section{Racine d'Aselépiate ou Dompte-venin.}

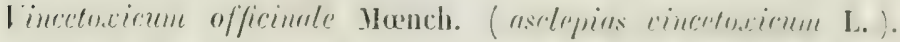
L'asclépiade (fig. 228 ) croît abondamment dans les bois, ('n Irance, dans d'autres contrées de l'Europe et en Asir. Elle pousse plusicur

lig. 228.

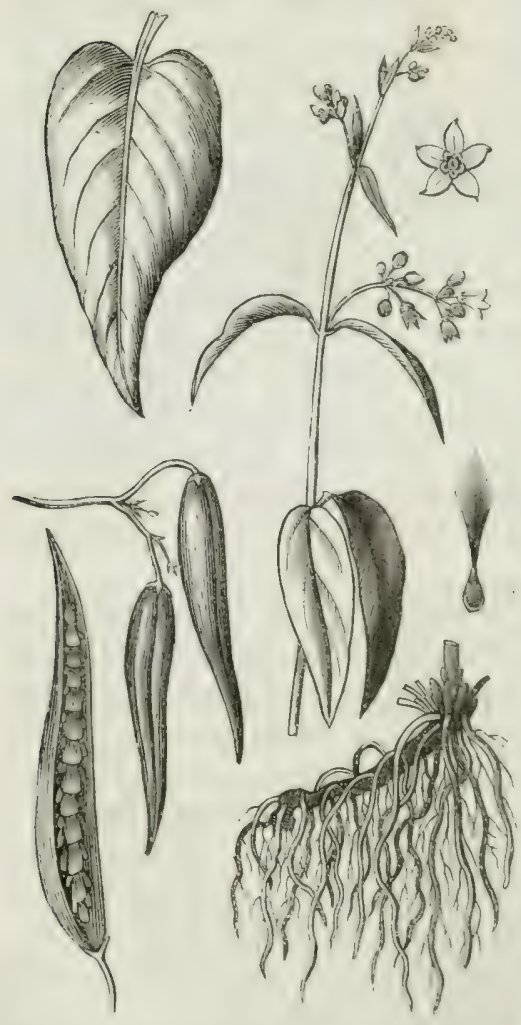
tiges droiles, à la hauteur de 60 centimèt., rondes, pliantes et flexibles, pubescentes sur deux côtés; les feuilles sont opposées, très entières, oralesJancéolées, ciliées à la margye et sur la nervure médiane; les fleurs sont blanches, disposées en ombelles on en cimes axillaires ou terminales; la couronne staminifère est en forme de bouclier, charmue, à 5 ou à 10 lobes ovales, surpassant un peu le gynostégium; les anthères sont terminées par une membrane; les masses de polIen sont ventrues et pendantes; les follicules sont ovales, anincis en pointe à l'extrémité et glabres; les semences sont surmontées d'une aigrelte.

La racine d'asclépiade ést composée d'un grand nombre de fibres Jongnes, blanches et menues, qui sortent tantôt d'un seul corps ligneux irrégnlier, lantor de plusieurs points de la

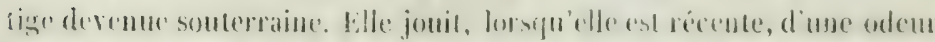

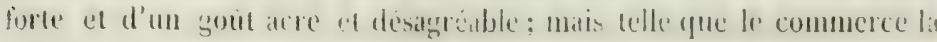




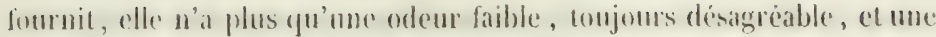
saveur douce, à peine suive d'un sentiment d'acrele. Elle a conservé sia blancheur naturelle.

On attribuait antrefois a cetle rácine de grandes proprietes, et entre autres celle que les anciens prodiguaicut lant, de risister an ermin. Lille parait ètre sudorifigue et diurétique : c'est à ce titre qu'elle entre dims le vin dimetique amer de la Charite. On doit à 11 . Feneulle nne analyse de la racine de dompte-venin (.mum. dr phrmm. I. II, P. 305).

\section{liacine gle Mutar.}

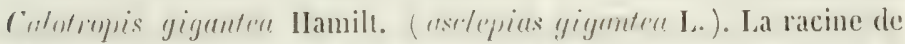
crlle plante, telle que je l'ai recue d'André buncan, est dure et ligneuse, épaisse de 27 à 10 millimètres, longue de 22 a 24 centimolres, fusiforme, dommant naissance, de distance en distance, a de fortes raticules cylindrigues et flexuenses. L'écorce est mince cl couverte d'un épiderme ocracé; tout le reste de la racine est d'une conleur lilanche; la sareur en est amere ct l'odem nulle. Les tiges sont ligneuses, hlanches et pourvues d'un canal médullaire toes apparent. La raciuse rst usitée dans l'Inde contre l'éléphantiasis et d'autres affections culatnies.

\section{Hacine de Vummai.}

Cette racine, employéc dans l'Inde comme succédanée de la sitsepareille, est produite par l'hemidésmus imdirus li. Br. Elle a élé décrite i) la suite de la salsepareille, page 186.

\section{FAUILLE DES APOCYNACÉES.}

Végélaux à tige ligneuse, rarement herbacée, très sourent lactescente; fenilles simples, entières, opposées, très rarement alternes, privées de stipules, mais munies sourent de glandes qui en tiennent lieu; fleurs en cimes ou en grappes, regulieres, sourent fort belles; calice a 5 sépales ordinairement libres, à estivation quinconciale; corolle gamopitale régulière, sourent munie à la gorge d'appendices on de poils ('n forme de couronne. Les étamines an nombre de cing (1), insérées an tube de la corollo, il filets tris comes ou nuls, libres on rarement un

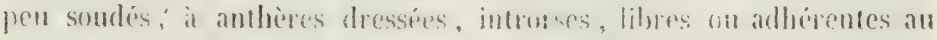
milien du stigmate, sur lequel s'applique immexdiatement le pollen qui est granuleux el ellipsö̈de. Orate supere, double, quelquefois simple

1) Très rarement la fleur uc presente que \& sépales en calice, 4 lobes à la corulle et 4 étamines. 
à une on denx loges, porté sur un disque. Styles rémis en un sent terminé par un stigmate plus ou moins discuïde; le fruit est compuré de 2 follicules quelquefois charnus, ou d'un seul follicule bacciforme: ou drupacé. Les graines, attachées à un trophosperme sutural, sont nues ou couronnées par une aigrette soỵeuse; elles contiennent un embryon droit dans un endosperme charnu ou corné.

Beaucoup d'apocynacées doivent au suc laiteux, sonvent âcre et amer qu'elles renferment, une propriété émétique ou jurgative exemples :

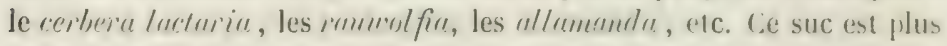
ou moins abondant en caoutchouc, principalement dans l'mexter r/as-

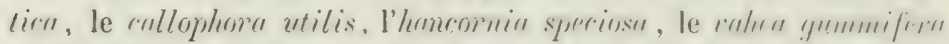
et le cuheu madryascariensis; il est presque privé d'àcreté et mème. entièrement doux dans un petit nombre d'espèces, et peut alors servir at la nourriture de l'homme (ex. le suc laiteux si abondant du tuluermumontunn utilis). Plusieurs fruits sont égalenent recherchés comme

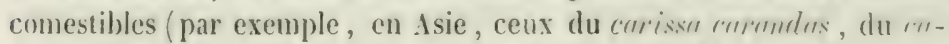

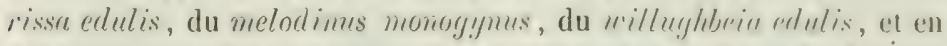
Amérique ceux des cimblelmuin, des purrumin, des roumn et des humionni(r). D'autres fruits sont au contraire éminemment rénéneux: telles sont principalement. les semences du tomghiniu et des therfin. Iinlin plusieurs racines, bois ou écorces amères, astringentes ou aromatiques. sont usitées en médecine ou dans la teinture.

\section{Tanguin de Madagascar.}

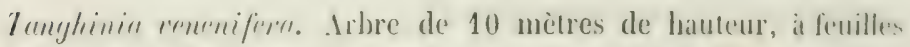
très contières, alternes, rapprochées vers l'extrémité des rameinus le's fleurs sont formées d'un calice longuenent tubuleux, et d'une corolle tubuleuse également, dont le limbe est à 5 divisions contournées et étalées. Le fruit, qunoique succédant à un ovaire à 2 loges, est un drupe uniloculaire et monosperue. Il présente à peu près la gyrosseur et la forme d'un ceuf; il est formé d'un silrcocarpe charnu-fibreux at d'un endocarpe ligneux, contenant une semence huilense el très vénéneuse, (jui est employée à Madagascar pour constater juridipuement, par l'épreuve du poison, la culpabiliti ou l'innocence des accusés dont le crime ne peut être prousé autrement. L'anal ș: chimiçue des semences de tanguin, faite par II. O. Henry, se troure dans le Jounal de phamacie, t. X, p. 49.

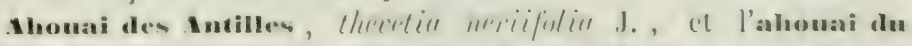
Bresil, theretion uhumi J. Arbres assez beaux à feuilles alternes, it suc laiteux fort dangereux; le fruit est un drupe presque sec, contenant un noyau osseux a 4 logees monospermes, chatque loge primitive de l'uraire 
se tromsant divise en denx par mo fausse cloison. I.amande de ces fruits e'st un poison mortel; les noyanx vides servaiem aux naturels de l'Amérigue à faire des colliers dont le bruit leur était agréable en marchant el surtout en dansant.

\section{Écorce de Pao pereira.}

Tillesin inditu. Irbre sylrestre do Brésil à feuilles altermes, péliolées, lancéolées, atténuées en pointe des deux côtés, lisses et brillantes. Elles sont le plus souvent longues de 6 centimitres et larges de 2,2; les plus grandes sont longues de 7,5 cemimères et larges de 3,5 . L écorce de cet arhre est renommíc an Brésil comme tonique et fébrifuge. Le commerce la présente en morecaux longs de 6 jo centimetres, souvent très larges el presgue plats. Ia couche subéreuse est marquée de profondes crevasses longitudinales et couverte d'un épiderme gris-jaunatre. La substance en est faure, spongieuse, pres(juc: insipide. I.e liber est formé de lames plates, appliquées les unes sur les autres, faciles à séparer, mais difficiles à rompre, d'un jaune foncé et d'une forte amertume. D'après plusieurs chimistes, cette écorce contient une matiere alcaline ćminemment fébrifuge nommée píreirin, larguelle forme arec les acides des sels neutres solubles daus l'ean et dans l'alcool; elle est accompragnéc dans l'écorer d'une matière ancie extracto-résineuse dont il rst difficile de la sieparer. Cette maticre est insoluble dans l'eau et dans l'éther, mais très soluble dans l'alcool.

Casea d’anta. Autre écorce très amère apporléce du Brésil par Guillemin, et atribuce par lui à un smunotfir. Elle est formér d'm lihere épais, dur, compacte, d’un blanc jantitre ou rerdatre, ou d'un vert noiràtre, et comme gorogé d'un suc laitenx desséché. lie liber est recouvert d'une couche subéreuse plus ou moins épaisse, d'une comlent' de rouille de fer el quelquefois orangée à l'instar de la fausse angusture. Cette écorce et celle de irllesin prennent une couleur d'un rouge vif, par l'acide nitrique (1).

\section{Écorces de Paratulo.}

Au Brésil, le $n$ om de purteturlo, qui signilie fmromor a tout, a été dommé à plusieurs substances médicamenteuses, comme chez nous les noms de tonte-snime et do tonle-lume ont été appliqués à des plantes fort différentes, auxq̨uelles on attribuait autrefois de grandes propriétés médicales. Indépendamment de la racine du yomplumun offirimelis : que

1) Le mème nom de cusca dinnta (écorce de tapir) est donné au Brésil a une écorce bien différente, produite par un drymis. 


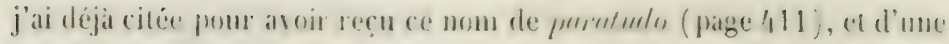
écorce aromatique analugne a crile de 11 inter qui le porte égalemsent, it n'est donc pas étonnant que deun autres écorces aient été apportées du Bréil sous la même dénomination. Cés deux écorces, arrivées mélangées et asse\% semblables entre elles, n'ont pas cité séparées dans l'ana-

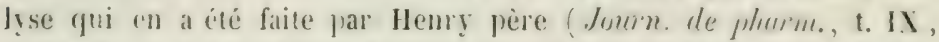
p. \$10), ce gui rend le's résultats de cette analyse peu utiles a rapporter. Il en est de mème de lindication fournie par .I. Auguste SaintIlilaire que l'écorce analysée par Henry père appartient à un ariore de la famille des apocynées, à moins qu'on n'admette que les deux écorces appartiennent également à cette fanille. I)ans l'incertitude où je reste à cet ígard, je me borne à décrire ici ces denx écorces, sous le nom de furturtudo amuer $n^{\circ} 1$ et $n^{\circ} 2$. L'écorce aromatiçue, analogue à celle de Winter, sera décrite plus tard sous le nom de purrominn aromentique.

Baratudo amer n" 1. Ecorce large, peu cintrée, épaisse de j millimètres, non compris la couche subéreuse; elle est légère, à cassure srenue, jaunâtre et marbrée; la partie interne est recouverte d'unc: pellicule mince et blanchâtre. La conche subéreuse est épaisse de 2 à 3 millimètres, profoncénent crevassée et facile à séparer du liber: elle est grise à l'exterieur. d'un vert jannitre a l'intérieur, et parait formée de couches concentriques nombreuses et très serrées. L'écorce se broic facilement sous la dent et a une saveur très amère.

J'ai trouvé chez I. P'inart, droguiste, sous le nom d'rerrire de' romromille, une écorec que je crois semblable à la précéclente, malgré son rolume beaucoup plus considerable. Elle a fait partie d'un tronc. d'arbre; elle est cintrée, Jarge de 8 à 9 centimètres, épaisse de 11 millimetres, non compris la couche subérense qui en a 40115 . Celle-ci est d'un gris foncé et marguée de sillons Jongitudinanx qui la partagent jusqu'au liber. Les autres caractères sont semblables.

Feoree de paratudo amer $\mathbf{n}^{\circ} \mathbf{2}$. licorce large, plus compacte que la précédente, épaisse de 7 millimètres au plus, à cassure seatre, marbrée et grenue, excepte is la partie interne yui est forme de quelques lames minces, très fibreuses et d'un gris foncé. La couche subéreuse est épaisse de 2 millimètres, adherente au liber, ruguetuse df cresassie, d'unc texture semblable à celle du liegge, et ayant comule: lui les fibres perpendiculaires à celles du liber. Cene deorece, dont la

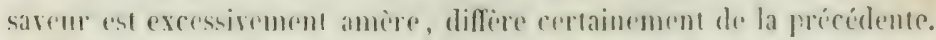
Cone: conséguence derient rencore plus evidente fall la manière dont leur macérí aqueux (s grammes de poudre d'écorece pour 90 stammen d'eau) se comporte arec les réactifs. 


\begin{tabular}{|c|c|c|}
\hline RÉACTIFS. & PARITUDO $x^{*} 1$. & P.R.ITTDO X" 2. \\
\hline 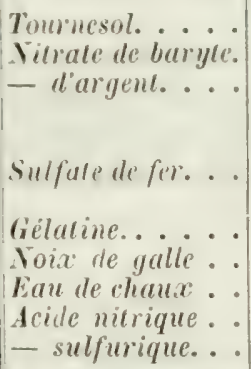 & $\begin{array}{c}\text { rien. } \\
\text { précipite. } \\
\text { trouble qui disparait pres- } \\
\text { que complétement par l'a- } \\
\text { cide nitrique. } \\
\text { prictipite blanchâtr. } \\
\text { rien. } \\
\text { précipite. } \\
\text { rien. } \\
\text { trouble. } \\
\text { trouble. }\end{array}$ & $\begin{array}{l}\text { rien. } \\
\text { rien. } \\
\text { précipité de chlorure. } \\
\text { liqueur verte moirillr, } \\
\text { précipité vert. } \\
\text { rien. } \\
\text { précipité. } \\
\text { rien. } \\
\text { rien. } \\
\text { rien. }\end{array}$ \\
\hline
\end{tabular}

Bois anner de Bosurbon, ropisen rylopirsm Pet. Th. Petit arber de l'île Bourbon dont le bois est très compacte, d'un jaune plus fonrí que celui du buis, qu'il peut remplacer potir les ourrages at tour. Il a une saveur amère gu'il commmuitue à l'ean; il est regardé commo très stomachique.

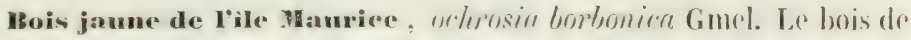
ret arbre est d'un jaune orangé arec un aubier blanc; il est très dense, d'un grain très fun et susceptible d'un beau poli. Il est tries amer ret jouit des mêmes propriétés que le précédent.

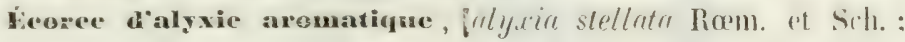
"lyrin aromuticu Reinw. ; Julussorni Rumph. Ciet arbrisseau croit dams les iles de la Malaisie et de l'Océanie. Son écorce mondée ressimble presque, pour la forme et la conleur, à la cannelle blanche; mile est pourvue d'une odeur de mélilot très agréable et d'une saveur un pru amère et aromatique. Eille est cmployée contre les fieve's penucionses qui désolent les îles de la Sonde et surtout Batavia.

cicoree de codagapala, "rightin antidysenterich Brown, "lerimu antidysentericum L. Écorce du tronc ou des branches de l'arhre, brisée en fragments, épaisse seulement de 1 à 2 millimètres, assurz compacte et cassant net sous les doigts; la surface interne est unie, doner au toucher, blanchàtre, grise ou jaunatre; la surface extériure rest d'un brun rougeâtre, assez rugueuse el sourent tuherculense; la coupe transversale est brunatre avec des lignes blanches disposées en cercles l'éguliers et concentriques; la sareur est très amère, l’odeur nulle.

\section{Laurier-rose.}

Trovimu olemaler L. Car. gén. : calice à 5 divisions ; corolle infun-

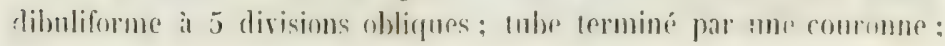


jétamines; anthires hastóes, frominées par un faiscean de soies; 1 style portant 1 stigmate cylindrique, tronqué: 2 oraires; 2 follicules droits; semences plumenses. - Car. sperc. : fenilles ternére, lincaireslancéolées; corolles couroninées.

Le laurier-rone e'st un très bel arbrisseatu que l'on cultive dans des caisses pour l'ornement des jardins. Ses feuilles sont rertes, longues, épaisses, d'une texture sìche, persistantes; ses flemrs sont adorantes, fort belles, disposées en rose, romeres oul blanches; les fouilles passent pour vénéneuses.

\section{pervenches.}

linc:n L. Genre de plantes de la famille des appocynées, qui offre pour caractères un calice persistant à 5 divisions, une corolle hypocratériforme à 5 lobes obtus et contournés; ítamines, 1 st!le, 1 stiggmate aplati; fruit composé de 2 follicules eylindrigues, polyspermes: semences nues.

On commaît deux espèces de pervenche indigènes, la grmute et la petite. Ia grande pervenche, riurre menjor, I,., croît surtont dans le midi de la France; ses tiges sont conchées, puis dressees, garnies de lenilles larges, un peu cordiformes, vertes, lisses, un peu cilices sur les bords : ses fleurs sont grandes, d'un hlen d'azur, portées sur des pédoncules solitaires, plus comis gue les feuilles. Ia petite pervenche, rim-n mimo L., croît dans nos bois, aux lieux montagneux; ses tigges sont griles, rampantes, munes de rameaux axillaires redressés; ses feuilles sont ovales-oblongues, pointues, vertes, lisses, fermes et coriaces: les pédoncules sont solitaires, phus longs que les feuilles; les fleurs somt d'un bleu clair et fort jolies; les fruits arortent généralement, et la plante se propage surtout par ses liges rampantes et radicantes.

Les feuilles de pervenche ont mne saveur amere et astrimente ct jonissent d'une propriéte astringente thes marguér. Tes femmes du peuple lui attribuent la propriété de supprimer le lait, et il ent rare que celles (qui sèrent leurs enfants n'en prenuent pas pendanc quelyur temps en infusion.

\section{lacine te Chynlen ou de Mangouste.}

Il est peu de substances qui aient porté phus de nouns que colle-ci: car, si je ne me trompe; c'est elle dont les auteus ont vomlu parter sous les différentes dénominations de chumlin, rhumlime, rlülim,

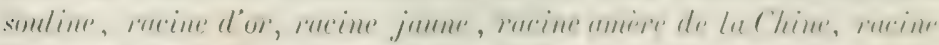

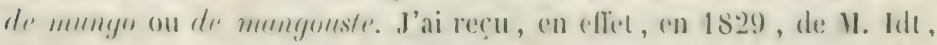

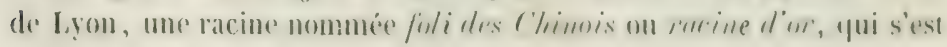




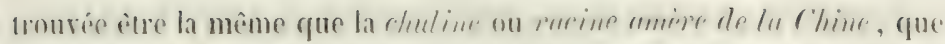
jobtenais dans le mème moment de l'obligeance de .I. Lodibert; et en comparant ces denx racines an rhyulen de Bergius (1/uterin medirn, 1. II, p. 967) et au rui= de mungu décrit par Rumphius, it m'a paru que ces substances n'offraient aucune différence essentielle; de sorte que l'origine bien conmue do cette dernière peut être raisonnablement appliquée à toutes les autres.

La racine de chynlen, telle que je l'ai reçue de 18 . Idt (fig. 229), sous le noun de armine d'm, est de la grossem d'une petite plume a

Fig. 229.
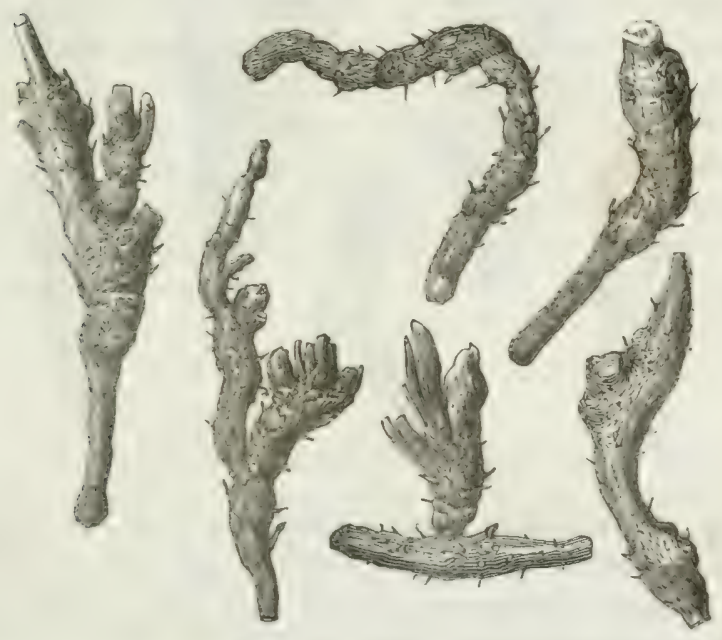

irrire, Iongur de 25 millimètres et plus, tortueuse, d'une teinte générale jaune-obsemr, inodore et d'une forte amertume. Flle colore la salive en jame safrané, et forme arec l'eau un infusé jaune, très amer, rougissant par le sulfate de fer.

Examinée plus en détail, cette racine est presque toujours formée d'une souche un peu renflée, annclée ou ondulée, armée de courtes pointes épincuses, rétrécie brusquement à sa partie inférieure, et terminée par un prolongement cylindrique et ligneux, qne l'on prendrait pour la tige de la plante, si une petite touffe de pétioles radicaux, qui reste souvent à l'autre extrémité, ne montrait où se trouve la partie supérieure de la racine. Ce prolongrement ligneus est tellement gorgi: de matière extractive desséchée qu'il offre souvent une cassure vitrense' : la souche présente la mème cassure dans son écorce, tandis que le centre est formé de fibres d'un beau jaune et rayonnées. 


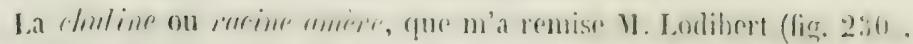
ne differe en rien, dans les plus petites racines, de la racione don; mais elle est généralement phus grosse, pourant acquérir le volume du petit doigt, et une longueur de 55 millimetres. Elle parait plus inge: ou mieux nourric, ct amylacée, car les larves d'insectes l'attaquent

Fig. 230 .

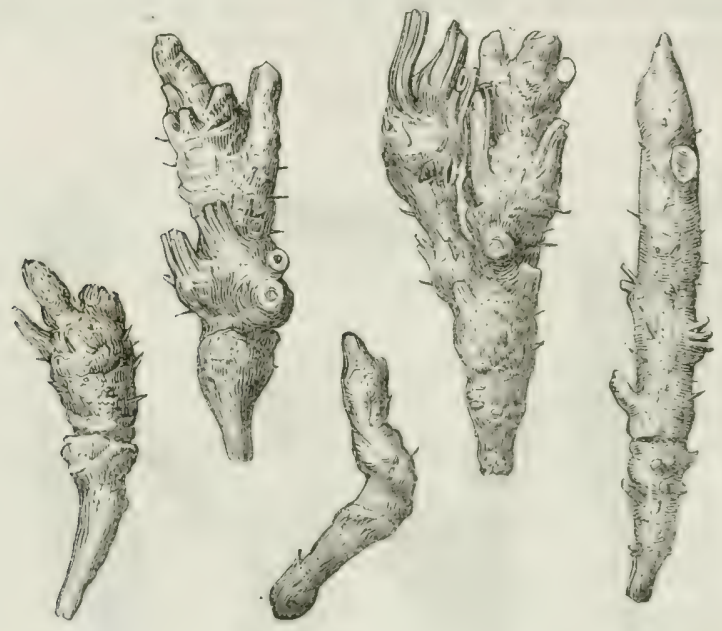

facilement, "t sa coulemr, étant affaiblie, est d'un jaume plus pur: sa cassure est plutot ligneuse que vitrense; elle offro un plus grand nombre de radicules piguantes, "t som collet, qui est très ruguenx, est sourent cntouré de fibres dressées qui sont des débris de pétioles dés ferilles radicales.

Occupons-nous maintenant de la plante qui fournit le chỵnlen on la racine d'or. J'ai répété apres un auteur moderne, dans une notice sur

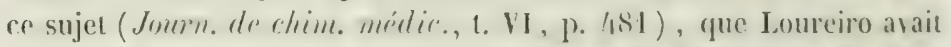
attribué la racine d'or au thulictrum simense' de sa Flere de cochinchine. Dans cet ourrage, Lomeiro ne parle pas de la racine d'or, of

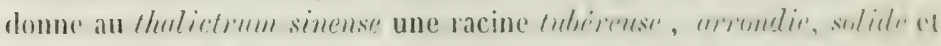
thes blunche, ce qui ne convient aucunement au chynlen: l'erreur ne peut done pas lui etre reprochée. D'antres attribuent senlement lat racine d'or à un thentirtrmm, sans designation d'espece; mais cette upinion sans preure doit céder à codle que j’ai énisise, fondée sur la conformite de caracteres du chynlen ou de la racine d'or ares lat rume de monyouste de Rumphius (IVerb. Amboin., t. VII, p. 29, tab. 16).

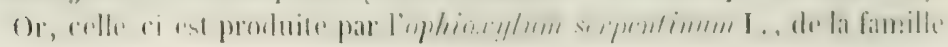




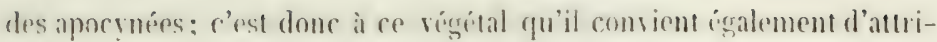
buer les autres (1).

I.a racine de mangouste tire son nom de ce que la mancrousfe, animal du grente des civettes, en mâche préabablement lorsfu'elle: vent conbattre les serpents, on apres en aroir bé blessée. Ce fait, qui est atlesté par Garcias, Kampler et Rumphius, a conduit les labitants de l'Inde, de Ceylan, des iles de la sonde et des iles Holurgues, à adopter la racine de mangouste comme antidote de tonte espexce de venin. A Batavia, on l'emploie contre l'anviér, la fievre, les coliques et les vomissements. En Chine, la racine de chynlon est usitée contre les mènes aflections, et licrgins l'a emplotece ave arantage, en observant qu'elle produit quelquefojs un eflet imetique, suivi cependant de soulagement.

Ja racine de mangounte est encore une de celles qui ont porté Jo nom si prodiguí de lmis dre roulemre, à cause de l'usage gu'on en faisait comtre la morsmre des serpents renimenx; c'est mème, de tombes, celle qui élait le plus estimée, pusisgue Garcias la decrit sous le nom de

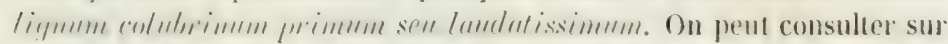

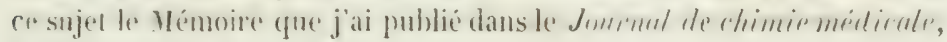
t. VI, p. 481 , année 1830 .

\section{lacine de Jean Lopez.}

Celle racine tire son nom de furm Lopre Jineiro, qui, d'apres Redi, l'apporta le premier de la côte de Zanguebar, en Afrique; suirant d'autres, elle viendrait de Goa, ou plutòt de Malaca, d'où clle aurait été portée par le commerce dans les divers pays qui ont été censís la produire. Ia racine de Jean L.opez varie beaucoup en grossenr; elle est sous la forme de bitons qui ont jusqun'a 22.2 a 27 centimères de long et 3 à centimères de diamère, ou sous celle d'un tronc ligneux de 14 à 16 centimetres de diamètre. Le bois en est blanc-jamnitre, plus ligger que l'eau, poreux et néanmoins susceptible d'être poli. Il a une sareur anère et une odeur nulle. L'écorce est brune, compacte, amère, recouverte elle-mème d'un tissu subéreux jaune, spongieux, doux au toucher et comme relouté. Cette racine est quelquefois employée comme antidrssentérique; mais elle est très rare et fort chère.

On a fait plusiems suppositions sur l'arbre qui fournit la racine de

(1) Il est possible d'ailleurs que racine de chynlen soit synonyme de racine de mun!jo; car cliulon est le nom du chat-cersier dans la Tartarie chinoise, et le nom de cet animal, assez voisin des civelles, a puetre employe par les Chinois comme la traduction de mungo. 


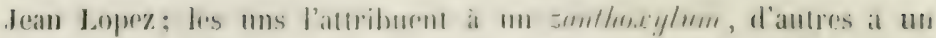
menisyermmm. Je prise que celte racine, qui a éte vanté d'abord contre la morsure de's serpents, les fières tierces et quartes et la dissenterie, n’a été apportée en Ėurope que parce qu'olle jouissait de la mème réputation en Isie ; autrement, ponrquoi l'aurait-on apportie?\}. et qu'elle appartient encore, par conséquent, à l'un des nombreux régétaux qui ont porté le nom de bris de cronlenrre, peut-être au stmlomure de Rumphius ( $1 \mathrm{~m}$ ). II , p. 129$)$, dont la description se rapporte en effet au dean Lopez (1). D'un autre côté, je possiede une racine ligneuse apportée de l'Inde et de l'île Bourbon, qui se rapproclıe beaucoup par ses caraclères physiques de celle de Jean Lopez. Elle est produite par le toddulia aculentu ou par le toddulien proniculatu, de la famille des zanthoxỵlées; elle est formée d'un bois assez dense et jaunâtre, et d'une écorce brune el compacte, courerte d'une couche subéreuse jaune el spongieuse. Cetle racine ressemble donc beaucoup) it celle de Jean Lopez; mais je ne l'ai jamais rue qu'en rameaux cylindriques ayant au plus 2 centimetres de cliamètre; de plus elle possede une odeur analogue à celle de la rhubarbe et une saveur nauséeuse pareille à celle de l'angusture raile. Je ne puis donc pas dire que ces deux racines soient identiques, et je laisse toujours dans le donte l'originc. de la racine de Jean Lopez.

\section{FAMILLES DES JASUINÉES ET OLÉAGÉES.}

La famille des jasminces, telle qu'elle a été élablie d'abord par A.-L. de Jussieu, comprend des arbres ou arbustes a feuilles ordinairement opposées et à fleurs hermaphrodites, excepté dans le genre fresinus, qui les a polyganes. Le calice est très petit, rarement nul; ta corolle est très petite, gamopétale ou divisée profondément en 4 ou 5 lobes qui la font paraitre polypétale. Les étamines sont an nombre de deux seulement; l'oraire est a 2 loges contenant chacune 2 orules; le style est terminé par un stiguate bilobé.

pendant longtemps beiuconp de botanistes, ainsi gue le fait encore aujourd'lui .1. Richard, se sont contentés de diviser cetre famille en deux sections, suivant gue le péricanpe est sec (lilacés) on charmm (jasminées); mais aujourd'lui le plus grand nombere des botanistes la partagent en deux familles distincles:

I. Les Jasmanes, dout les fleurs sont tonjours complètes a regu-

(1) I.e soulamoe de Rumphius (soulamea amura lamk.' e-t un genre anormal de la fanille des polygalées. 


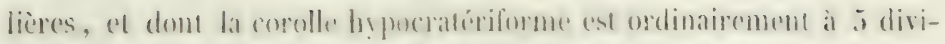

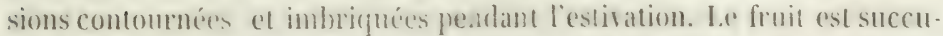
lent; les remences sont droites, prespue puriées d'allumen, tandis que les cotylédons devienment charmus. Cetue famille ne comprend que les genres jasminum et nyctanthes.

II. Les OLEACELS, clont le calice et la corolle sont divises par quatre parties, dont les semences somt pendantes et le plus somsent pourvese d'un albumen charnu. On partage cette fanille en quatre tribus :

$1^{\circ}$ Les fraxinces, dont le linit est sec, samarö̈le, biloculaire, indehiscent, et les semences endospermées: exemple le genre firtirilles.

2* Les syringoes, dont le fruit ent cajpsulaire, biloculaire, à déhis-

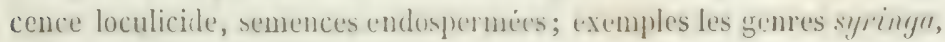
fontunesia.

$3^{\circ}$ Les oleinaes, dont le fruit est charmu, drupace on bacriformo

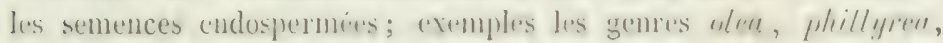
ligustrum.

$4^{\circ}$ Les ehionamehees; fruit drupatce, charmu; semences privés d'endosperme; exemple le genre chionanthus.

Les jasmins sont des arbrisseanx orignaites des pays chands, dont les ramcatux nombreux somt disposes en buisson, ou sont grèles, bolubiles et grimpants sut les corps gui sont dans leur voisinage ; leurs linilles, opposée's on alternes, sont pinnées atrec impare, mais somvent

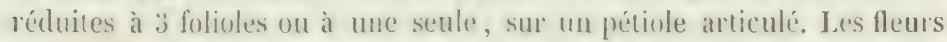
sont janies ou blanchess, souvent rosées extériemement, ordinairement disposées en panicules pen garnies el d'me vileur très suare. Les especes les plus usitées sont :

l.e jasmian drarabic, jusmimmm somblur lit., à feuilles opperées, mifoliolées, a fleurs trè blanche diune vdeur très suare, surtout pendant la nuit. Cet arhrissean est cultivé partout daus l'Inde el dans l'Arabie, à cause de l'arome de ses fleurs.

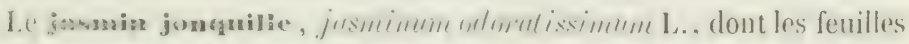

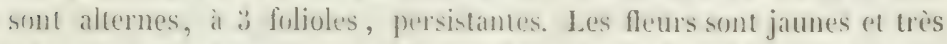
odurantes. On le cultive en Europe depruis pres de deux siecles; on le rentre l'hiver dans l'orangerie.

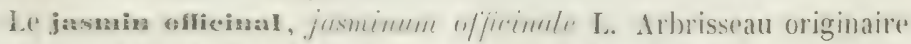
l." l'Isie, hant de 6 metres et plus, cultive depuis très longtemps en Eurnpe ou il supporte bien le froid de mos hirers ; ses fenilles sont op)posies, composées de $T$ folioles dont la dernière est beaucoup plus srande que les autres; les fleurs sont blanches et d'un parfum tres agréable.

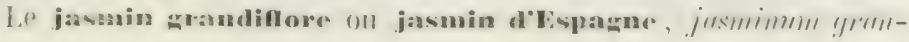




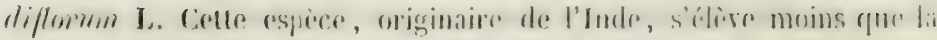
précédente, supporte moins le froid ot doit être rentrée dans l'oranger ir prendint l'hiver. Ses fleurs sont plus grandes, blanches, nuancées die iouge en dehor's, à disisions obtuses, d'unc orleur tres suare.

L'essence des jasmins est tellenent volatile et difficile it coucu qu'on ne peut l'obtenir dissoute dans l'ean on l'alcool, par la distillation. Pour l'obtenir, il faut imbiber du coton cardé arec de l'huile de ben yui est inodore et peu susceptible de rancir, et disposer ce croton, conche par couche, entre des fleurs de jasmin, dans des tamis fue l'on couvre bien; vingt-quatre heures après, on sépare le coton qui s'est imprégné de l'odeur du jasmin et on te renet arec de nourelles fleurs; on répète celte opération jusqu'à ce que le coton sente le jasmin commo la fleur même; alors on le soumet ì la presse pour en retirer l'huile que les parfumeurs conservent dans des flacons pleins et bien bouchés.

Les lilas (gemre sypingri sont des arbrisseaux à feuilles opposées, simples et entières, dont les fleurs sont disposées en belles grappes pyramidales, purpurines ou blanches suirant les espèces on les variélés, d'une odeur très suave. Le calice est très petit, ì l dents peu sensibles et persistant. Ial corolle est infundibuliforme, i tube plus long gue le calice, à limbe partagé en 4 lobes arrondis; les étamines, prestue se'ssiles, sont insérées a l'orifice du tube de la corolle ct portent des anthères ovales; l'oraire est surmonté d'un style et d'un stignate 1 prou épais et bifide. le fruit est une capsule pointue, comprimée, il 2 valves opposées à la cloison, et à 2 loges contenant cliacune une ou deus graines bordées d'une aile membraneuse.

Les lilas fleurissent au mois de mai et font à cette éporpue l'ornement des jardins par leur bean feuillage et par le nombre, l'élégance ot la stravité de leurs lleurs. Le's feuilles sont très amères et ne sont bronties par aucun quadrupède; dles ne sont mangées par les cantharides yu'i défaut des feuilles de frêne. Le bois de lilas e'st dur, d'un grain fin, veiné de brun, susceptible de prendre un beau poli et pourrait faire de jolis ourrages de tour. I.es Tures font des turaux de pipe arec les jeunes rameaux vilés de leur moelle; c'est sans doute par allusion is cet usage que Limné a donné à ce genre le nom de sypringu.

Les frènes sont des arbres élevés gui habitent les partien Lempéries de l'Amérique septentrionale at de l'turope. Leturs feailles sont opposées, presfue toujours ailées arec impaire; leurs fleurs son polyganes ou diö̈ques par arortement; pourrues d'un calice le plus somvent nul ou fort petit et a 4 divisions: la corolle est ordinairement nulle, plus rarement composéc de 4 pétales; le fruit est un carcérole ì 2l luges domt une oblitere el sterile el lautre monesperme; ce carcinule est prolongé en une aile membramense suirant l'axe do fruit. 


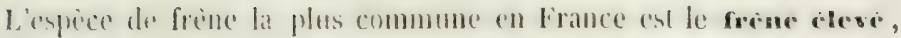

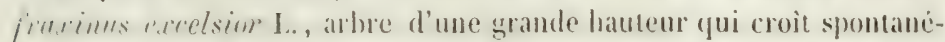
ment dans nos forèts et que l'on plante arec avantage dans les pares. sion bois est blanc, veiné longitudinalenent, assez dur, liant et élaslique, ce rui le rend utile pour faire des brancards et des timons de voitures, des échelles, des chaises, de's manches d'outils, elc. On l'emploie peu pour la charpente, parce qu'il est sujet à la vermoulure après un certain temps.

Let frène peut difficilement ètre planté dans les jardins d'agrement ou priss des habitations, par l'inconvénient qu'il a d'attirer les cantharide's, dont le voisinage peut ètre dangereux et qui, se nourrisant de ses fenilles, l'en dépouillont presque tous les ans, vers le milieu de juin. L'écorce de frêne est amère et était emploỵe comme fébrifuge arant la découverte du quinquina.

\section{IIanne.}

La manme est tui suc sucré, concret, apporté de la Sicile el de la Cialibre, où on la récolte sur deux espèces de frène nommées firrri-

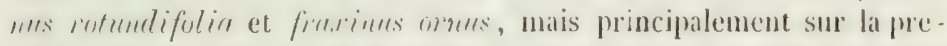
mière. Plusieurs botanistes font de ces deux arbres un genre particulier sois le nom d'urnes, parce que leurs fleurs sont pourrues de corolle et presque toutes hermaphrodites, tandis que les fleurs des autres frènes sont privées de corolle et polygames; mais cette séparation n'est pas généralement admise.

Le frêne à feuilles rondes, (quand il est cultivé, contient une si grande quintité de suc sucré que celui-ci en exsude sourent spontanément, ou far la piqùre d'une cigale nommée cymrnte mmi; mais celle qui est lirrée au commerce est le produit d'incisions que l'on commence ordinairement au mois de juillet, et que l'on continue de faire jusqu'au mois de septembre ou d'octobre. On obtient ainsi plusieurs produits qui varient en pureté, suivant l'époque de la récolte et suirant que la saison a élé plus ou moins pluvieuse.

Aiusi, dans les mois de juillet et d’août, la saison étant en général chatude et sèche, le suc se concrète presqu'à sa sortie des incisions, sur l'écorce mème des arbres, on sur des fétus de paille que l'on a disposés à cet effet, et constitue la manne la plus sèche, la plus blanche et la plus pure, qui est nommée manne en Iarmes.

Pendant les mois de septembre et d'octobre, la saison étant moins chaude et sourent pluvieuse, la manne se dessèche moins vite et moins complitement. Elle coule le long de l'arbre et se salit. Elle contient 
cependant encore une grande quantite dre protites larmes, et en ontre: des parties molles, mintres, arrolutinées, formant ce qu'on nomme des marrons. Ce mélange constitue la manne cu sorte.

Ia manne en larmes vient prestgure eschusisement de Sicile, et la manne en sorte se divise en manne de sicile ou manne areacy, et manne de Calabure on masaze caparey. Colle-ci contiont de plus belles larmes et en plus grande quantite que la manme guracy, par la raison (gu'on ue les ren relire pas pour en former une sorte particulibre; aussi parait-elle plus belle et plus blanclie lorsqu'elle est récenie; mais, comme elle est tomjoms très molle et risgur use elle fermente ct jamnit avec une grande facilité, et se convertit en mumm grosse au bout de lannée. Ia manne de Sicile se consenve plus longtemps, mais crpendint guere plus de deux ans: alors clle jaunit egalement, se ramo!lit ol fermente. Il faut donc aussi la choisir nouvelle.

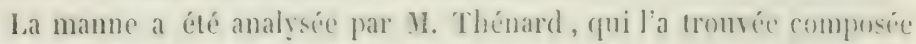
de trois principes : de sucre, d’un principe doux et cristailisable, ol d'une matiere: nauséeuse incristallisahle. ()n n'en pent istrer le stere

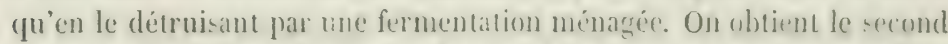
principe en évaporant le liguide fermenté à sicciti, et traitant lr riebilu par l’alcool chaud, qui le dissout romplétement, mais qui latse cristalliser le principe doux par le refroblissement. Lableol ćapore domme: le principe incristallisable.

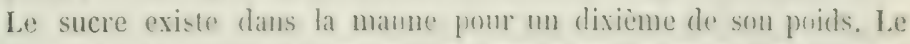
principe doux cristallisible comstitue prespue entierement la manne en larmes, et lui dome toutes se's propriétes. Inssi l'a-t-on mummi mum-

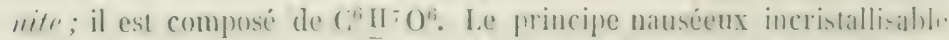

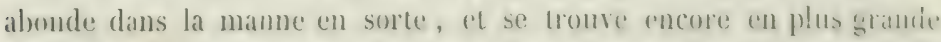
quantite dans la mamne grasse. Il y a lout lieu de croire que ce 11 int que de la mannite altérée.

On comnaissait autrefois, et senlement comme objets de cuniosite, trois autres sortes de manne (qui somt tout a fait oubliés. Ce sont lat manne de Briançon, la manne d'Allagi et le téréniahin.

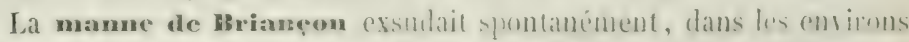

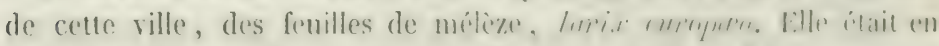

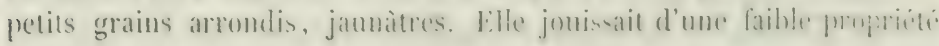
purgative.

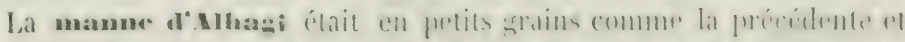

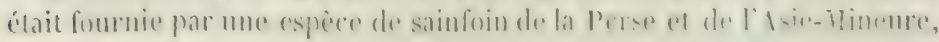
nommée alhayi (alhagi mauro)'um Tourn.).

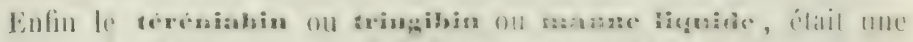

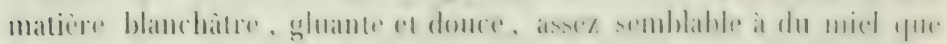

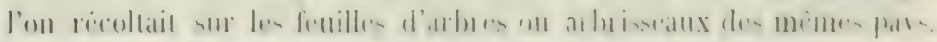


Suisant plusiens's auteurs, cette manne chait poduite iugalement par l'alhagi.

Mamme tombce du eicl. In 1845, a la suite d'une pluie, on a trouvé sur le sol, en Austolie, une substance grisitre fue les habitants

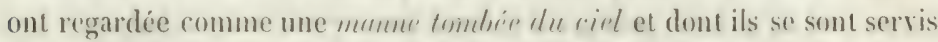
pour faire du pain. Colle salsstance présemte me tres grande ressemblance avec lo lirhen esenlemfus de lallas, dont on a voulu faire depuis

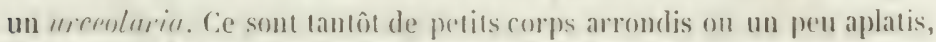
de 1 centimenro de diamere, et d'antres fois des masses plolus considélables, mamelomneres, larges de 2 crmtimètres i 2, 2 , mais n'ayant toujours environ gue 1 centimetre d'oplasseur. Com prtits corps ou ces masses ont d'ailleurs leur surface entiorement comserte par de petits tubercules gris, de formes tres variers, dont les podicules se rémnissent a l'interieur rn une pelite masse de forme irreguliere, a vant tont a fait la couleur, la consistance el l'apparenee de l'agaric blane. Iinsi, en reprenant mantenant la deseription par le crntre, mous voyons une petite masse irregulière, blanche et fongneuse, qui se ramifie tout ausour en un grand nombre de tubercules prodiculés de nature semblable, mais cependant termines par une enveluppe grise, de nature grobtineuse, analogue i celle des lichens. Ces corps tuberculeux ne présentent aucun prolongement on aucune grifre qui pùt les fiser au sol, dont ils étaient certainement isolés, chacun d'eux pourant être comparé, dans son entier, a une petite truffe. Ils ont une saveur fade et terreuse; ils ne contirmuent pas d'amidon, si ce n'est pent-chre une tres petite yuantité, dans la couche gélatineuse externe. Cetle substance, dont les séminules ont sans donte été transportées par les vonts et développées par la fluie, est curieuse par l'analogie de forme, d'origine el d'application ru'elle présente avec la manne dont les Ilébrenx se somt nourris dans le désert.

\section{Olivier, Olives, IIuile d'Olives.}

(I) murngurtr I. ( fig. 231). Arbre originaire d'Asic, d'où il s'est propagé naturellement ou par la migration des anciens peuples, en Grèce, en Ifrique, en Italic, en Provence et en Espagne. En Provence, sa tige acquiert par le bas de 1 à 2 mètres de circonférence, et se divise, à la hauteur de $30 u$ mètres, en branches qui s'élèvent à 7 on 10 mitres; mais dans les pays plus chands il devinnt beancoup plus gros et s'élive jusqu' ‘ la hauteur de 16 mères. Il croit très lentement et peut virre cing ou six siècles et plus ; son bois est jamatre? marbré de reines brunes, tres dur, compacte ('t susceptible d'm beau poli ; il est à regretter qu'il ne soit pas plus emplové. 
L'olis ier est pourvu de leuilles opposées, persistantes, coriares, enlières, longues et étroites, vertes en densus, blanchâtres chllessoun; les fleurs ont un calice à 4 dents, une corolle infundibuliforme, à 4 . divisions planes; 2 élamines insérées à la base de l'ovaire; 1 ovaire arrondi surmonté de 1 style épais et de 1 stigmate en tête ou à 2 lobes peu marqués ; l'oraire est à 2 loges dont chacune contient 2 orules pendants; to fruit est un drupe à noyau uniloculaire et monosperme, par avortement.

L.es olires varient de forme, de grosseur et de couleur, suivant les variétés et les contrées où on les cultive. Celles de Prorence, les plus ordinaires, sont oralesoblongues, à peu près de la grosseur d'un gland, d'un vert noirâtre et possèdent une saveur âcre, amère et désagréable; mais on parrient à adoucir celte saveur et même à la rendre agréable, en faisant macérer les fruits dans de la saumure. Ces fruits se

Fis. 231.

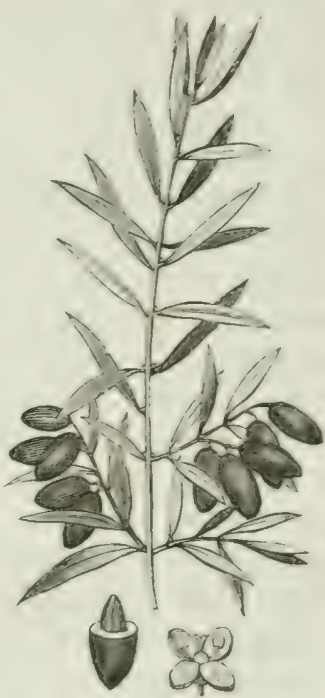

distinguent de la plupart des autres drupes paree gu'ils contiennent de: l'huile lixe dans leur péricarpe tout anssi bien que dans l'amande. C'est cette huile qui est le produit le plus important de l'olivier; elle tient le prenier rang entre toutes les huiles pour l'alimentation et pour la falmication du savon. On l'extrait des olives mùres à l'aide des dillivents procédés (jui influent beaucoup sur sa qualité et qui lui font dommer les

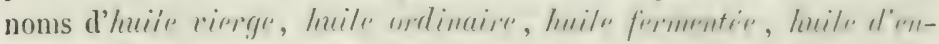
fer, etc.

Du côté de IIontpellier, on appelle hnile virn'y celle qui surnage la paite des olives écrasées au moulin, ou qui se rassemble dans des creux qu'on y a pratiqués. Ceqte huile, peu abondante, ne se troure pas dans le commerce ; clle est toute consommée dans le pays, snit comme remède adoucissant, soit pour huiler les rouages d'horlogerie. Dans les environs d'Aix, on nomme huilr rirg'y" celle rue l'on obtient en soumettant à une premiore pression modérée les olives icrasécs. Cedto buile, conmue dans le commerce soms les noms d'huil. d'.lit ou

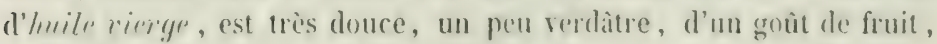
facilement solidifiable par le froid, tres recherchée pour la lable.

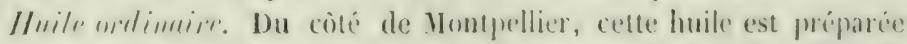
e'll sommedtant a la pression les olines érrarés et milangées d'ean buvillante; du cùté d'six, on l'ublient de la mente maniere aree les 


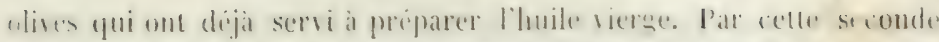
pression, plus forte que la premiere, on obtient me hoile inferieme

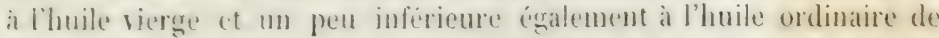

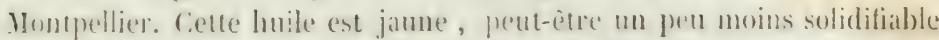

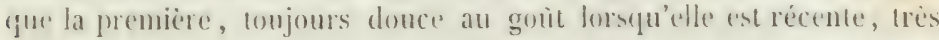
usitée pour la table.

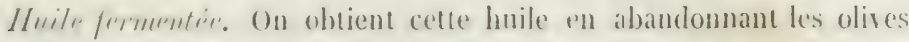
fiabless, con las considerables, pendant un tempi plus on moins long, arant de les écraser: on les mélange de meme d'eau bouillante et on les eyprome. Pendant la fermentation que les olises éprourent, leur parenchyme se ramollit et se difruit en partie, ce qui permet d'en relirer l'huile plus facilement et en plus grande guantité mais celle huile est moins agréable que les précédentes, un peu àcre et pourbe guelguefois d’un goùt de moisi. Inssi le procéle de la fermenation, encore usité en Espagne, est-il presugue abanelonue con France.

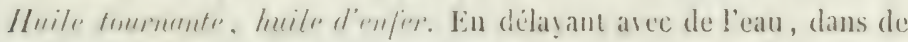

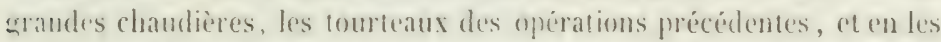
s:munettant à une dernière cxpresson, on en extrat encore une certaine (quantité d'une louile désagréal)'t qui est emplonée dans les saromneries et pour l'éclairage. Enfin, l'ean qui a servi it toutes les opérations et dont on a séparé !'hate après purelpues heures de: repos, est combluite dans de grands réservoirs nommés rm/i is, où, après plusieurs jours de repos, elle laisse encore surnagger une certaine quantité d'huile qui sert aux mêmes usages que la précédente.

L'huile d'olives est flès sourent falsifice dans le commerce, el elle: l'ost d'autant plus, maintenant, que dat grande estension domné à lat fahrication des savons de llarseille a appelé, dans le midi de la linance, l'importation d'une très grande variélé d'huiles on de semences huileuses élrangères. Cependant la substance arec laguclle on falsifie loujours, le plus habituellement, l'huile d'olives destinée à l'usage de la Lible et de la pharmacie, est l'huile de semences de parots, connue

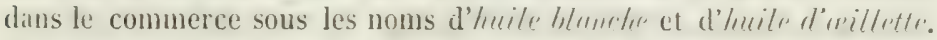
C'est donc principalement à décourrir cette falsification que nous allons nous attacher.

L'huile d'olives est toujours liquaide dans l'été, mais elle se solidific en partie dès que la température s'abaisse au-dessous de 11 degrés, et elle se présente alors sous la forme d'une masse gremue d'antant phos ferme qu'il fait plus froid ; clle forme arec les alcalis des sarons solides et ave l'oxide de plomb (intharge) un emplatre blanc, solide et cassant. Elle n'est pas siccative a l'air et est si peu soluble daus l'alcool que 1000 grontes de celui-ci n'en dissolvent que 3 gonttes (Panche).

L'lnaile de parots est toujours liquide et ne forme un dépot de mar- 
garine que dans les temps de gelée. Elle est plus fluide que l'huile d'olives liquide, d'une couleur plus pâle, d'une odeur et d'une saveur presque nulles lorsqu'elle e'st récente; 100 gouttes d'alcool en dissolvent 8 ; elle est siccative à l'air et elle forme avec l'oxicle de plumb) un emplâtre mou qui açuirt promptement une odeur rance, et rui jaunit et se dessèche à sa surface.

Beaucoup de moyens ont été proposés pour reconnaître le mélange de l'huile de parots arec l'huile d'olives. Le plus simple, qui est bon pour l'usage ordinaire, consiste à remplir à moitié une fiole à médecine de l'huile suspectée et à l'agiter fortement. Si l'huile d'olires est pure, après quelque temps de repos sa surface sera très unie; si elle est mélangée d'huile de pavots, il restera tout antonr une file de bulle's d'air, ce gu'on exprime en disant qu'elle forme le rlunpelot. Ce procédé pent faire reconnaître 0,1 d'huile de parots dans l'huile d'olives.

En deuxième moyen consiste à refroidir l'huile dans de la grlace pilíe: l'huile d'olives s'y fige complétement (d'autant plus qu'elle est plus récente) : celle qui est mélangée d'huile de parots y reste en partic liquide; un mellange de denx parties d'huile d'olives sur une d'huile blanche ne s'y fige pas du tout.

Troisième moyen, diagomìtse de Ronss'one. La pièce principale de cet instrument est une pile électrique sèche, c'est-à-dire formée de disques métalliques très minces, cuirre et zinc, alternés arec des disques de papier. Ces piles ont une très faible tension, unais elles lit conservent très longtemps. Dans le diagomètre, cette pile agit sur une aiguille faiblement aimantée, libre sur son pirot, et placée sous une cloche, en regard d'un cercle gradué dont le zéro répond au plan du méridien magnétique. Lorsque l'aiguille est en repos et à l'abri de toute excitation étrangère, elle marque donc zéro.

Maintenant, si l'on soumet cette aiguille à l'influence de la pile sieche, au moyen d'un disque de cuirre qui la touche à zéro, et qui communique arec la pile, on conçoit que l'aiguille et le disque se trourant chargés de la même électricité, l’aiguille, qui est mobile, s’éloignera du disque d'une quantité proportionnelle à la force qui agit sur elle, el si on interpose entre le disque et la pile un corps peu conducteur, on obtiendra une déviation de l'aiguille d'antant moindre que le corjos laisse moins facilement passer le fluide électrique. Or, l'auteur de cet instrument a ru que l'huile d'olives conduit l'électricité 675 fois moins que les autres huiles régétales, ct qu'il suffit d'ajouter 2 gouttes d'huile de faine ou d'œillette à 10 grammes d'huile pure pour quadrupler son pouvoir conducteur (roir frum. de phumm., t. IX, P. 587, et t. I, p. 216). Ce moyen est done très bon pour recombaitre la pureté de l'huile doolises, bien yue la propriéte sur linguelle it est fonde ne suit 
pas rolusine à cette huile. Ainsi l'huile séparée de la graisse des animanx ruminants partage arec l'huile d'olives la faculté non conductrice de l'ólectricite; mais elle ne sert presque jamais à la falsifier.

Promide dr. 1\%. P'ontert. Hettez dans une fiole 6 parties de mercure et 7 p. 1/2 d'acide azotique à :38 degrés; lorsque la dissolution est opérée, pesez dans une autre fiole 5 grammes de la liqueur ( qui consiste en un mélange de proto-azotate et de deuto-azotate de mercure, d'acide hypo-azotique ct d'acide azotique) et 60 grammes d'huile; agitez fortement le mélange de dix minutes en dix minutes, pendant deux heures, après lesfuelles on le laisse en repos. Le lendemain toute la masse est solidifiée, si l'huile d'olive était pure. In divieme d'huile blanche lui donne une consistance d'huile d'olives figée. Au-delà de cetie proportion, une portion d'huile liquide surnage le melange, el est d'antant plus abondante que l'huile d'olives contenait plus d'huile étrangère. On pent mine jurer, par approximation, de la quantite de celle-ci par la première, en operant la solidification de l'huile falsifice dans un tulse cylindrique gradué.

Ce moyen de reconnaitre la pureté de l'huile d'olives est très bon forsque la dissolution mercurielle est récente (1); mais il cesse d'être evact lorsun'olle est ancienne, et cela s'explique par les expériences de 3. Félix bondet, quii a vu que de tous les corjes renfermés dans la liquenr mercurielle, re n'est ni l'acide azotique ni les azotates de mercure qui agissent; mais seulement l’acide hypo-azotique. Anssi u. Félix Boudet a-t-il proposé un autre moyen d'essaỵer la pureté de l'huile. Cie unoyen consiste dans l'emploi de l'acide hypo-azotiçue étendu de 3 parties d'acide azoligue; 12 parties de ce melange solidifient en cinf quarts d'heure 100 parties d'huile d'olises pure. I In centième d'huile de pavots relarde la solidification de 190 minutes ; un vingtieme la retarde de 90 minutes; un dixieme la retarde infiniment plus; enfin l'huile de pavots pure reste toujours liquide (2).

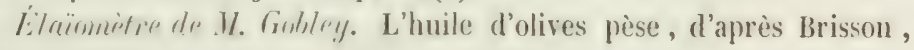

(1) MII. Soubeiran et Blondeau, dans une note très intéressante sur les moyens de reconnaitre la purcté de l'huile d'olives (Journal de pharmacie, 1. XXVII, p. -2 $^{2}$ ), reprochent au réactif Poutet de cristalliser peu de moments après la dissolution du mercure, ce qui oblige à le refaire, lorsque cet effet est arrivé. Il faut que ce résultat tienne à quelque circonstance particulière de la préparation, peut-êlre à un degreć différent dans la force de l'acide, car en opérant exactement comme l'auteur, je n’ai jamais vu la liqueur cristalliser. Le seul défaut de ce réaclif, c'est qu'il perd sa propriété en vieillissant.

2) Les experiences de MII. Soubciran el Blondean n'ont pas confirmé pleinement le- reultato ublemu par M. Boudet. Ces deux chimistes pensent 
$0,915.3$ a da température de 12",5, cemligrades, el l'huile de parols prise 0,9258. Si ilonc, on plongre un arconetre à lige tris déliee, successiroment dans ces deux liquides, il en résultera une diflérence considirable dans l'enfoncement de la tige, et cette différence, partagie ('n centiemes on en cinquantiemes, indiquera des quantités correspondantes dans le mélange des deux huiles. Soil, par exemple, de l'huile de parots pesant 0,9284 i la température de $12 ", 5$ et marquant zero au bas de l'échelle de l'élaïomètre, et de l'huile d'oires pesant 0,9216 ¿ la même température, et marquant 50 degrés au haut de l'échelle; il est érident que ces deux degrés jndiqueront toujours des huiles pures, et que 25 degrés, par exemple, indiqueront $25 / 50^{\text {r }}$ ou 0,50 d'huile d'olives; 40 degrés, $110 / 50^{\text {es }}$ ou 0,80 d'huile pure, etc.; tel est l'élaïomètre de II. Gobley.

y. Gobley ayant gradué son instrument à la température de 12, ,j centigrades, qui est sensiblement celle des cares où l'on conserve les huiles, il a calculé que la dilatation des deux huiles ou de leur mélange chait de $3^{4}, 6$ pour I degré centigrade; de sorte que, au-dessus de de $12^{n}, 5$ centigrades, il faut retrancher de l'indication de l'élaïomètre autant de fois $3^{4}, 6$ qu'i! y a de degrés de température supérieure. Soit par exemple une huile cui a la temperature de 15 degrés centigrades, marque 35 divisions à l'élaïomètre; cette huile, ramenée at 1200 degrés, marquerait e'n moins $3,6 \times 2,5=9$ divisions; c'est-à-dire qu'elle ne doit compter que pour 26 divisions indiquant 26,5 (t) ou 52 centièmes d'huile d'olires pure.

Je pense que l'élitomètre de Y. Gobley pourra rendre de stands services au commerce et qu'il suffira, pour en étendre l'nsige, d'en rende la construction plus facile. Je dirai done qu'en comparant ase soin cet instrument arec l'alcoomitre de H. Gay-Lussac, j’ai trouri que

$$
\begin{array}{rlrl}
\text { le } 0 \text { de l'élä̈omètre } & =53^{4}, 25 \text { Gay-Lussac. } \\
50^{d} & i d . & =57,100 & i d . \\
58^{d} & i d . & =58,00 & i d .
\end{array}
$$

de sorte ru'il suffit de diviser en 58 parties l'espace compris entre

d'ailleurs, et je erois que e'est avee raison, que la présence du sel mercuriel n’est pas aussi étrangère à la réaction que l'a pense M. Boudet. Jajoute une dernière observation, non ulile pour la pratique, mais qui indique une aclion bien differente des huiles dolives et de parots sur le sel mercuriel. Lihnile d'olises pure, solidifice par le réactif P'outed, el consersée pendant phu-ieurs anners, reste parfaitement solide et janue, sans aucune appitrene de réduction du mescure. L'huile de pavols on le mélange de celle luvile asee l'huile d'olives, se colore en brun fonce arec le lempes reste liquide ou redevient en partie liquide, et le mercure se depose reduit an fond de la boutcille. 


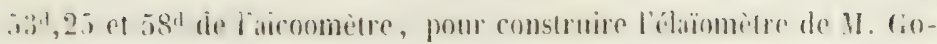
bley.

Gomme a ohiver.

Cenc substance était en grande réputation chez les anciens, ot f.isait partie d'un grand nombre de médicaments extériems, cicatrisants et vuluéraires. Elle élail complétement oublice, lorsque les expériences de 1I. Paoli et de Pelletier (Joum. de pham., ใ. II, p. $111 \mathrm{et} 337$ ) ont appelé de noureau sur clle l'attention; P'elletier, surtout, en a rotiré une matière particulière, nommée ol hive, qui la constime presque en tolalité; qui est soluble dans 32 parties d'eau bouillante, bien plus soluble dans l'alcool, et cristallisable par l'évaporation ou le refroidissement de ce dernier dissolvant. Ia gomme d'olivier n'est donc ni une gomme ni une résine; c'est me matière particulière qui n’a gauère d’analogue que la smroreulle, parmi les produits naturels des régélaux.

La gomme d'olivier venait antrefois d'lithopie; mais elle est produitr. aujourd'hui par les oliviers sauvages et cultivés qui croissent abondamment dans le royaume de Vaples. Flle est sous forme de larmes arrondies, rougeâtres, souvent agroglutinées ensemble, transparentes on opaques; sourent aussi oparques à l'intérieur et transparentes à la surface. blle se ramollit par une chaleur modérée, se fond et se réunit en une masse qui simule le baume de 'Tolu ; elle se dissout complétement dans l'alcool houillant : ce liquide refroidi ou éraporé spontanément, laisses cristalliser l'olivile sons la forme d'aiguilles aplaties. L'alcoul rolient en dissolution une matière résineuse, colorée, soluble dans l'éther.

Lolivile pure est blanche, fusible à 70 degrés; clle partage la propriété idio-électriyue des substances résineuses; elle se dissont dans les alcalis ; elle ne produit pas d'ammoniaque par sa décomposition au f(').

\section{Sarcocolle.}

I.a sarcocolle est unc substance connue des anciens firecs et des Irabes, que tous leurs auteurs font venir de Perse, de sorte qu' (elle nr

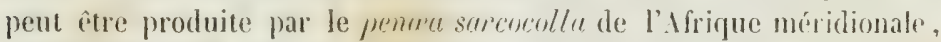
dont la place dans l'ordre des familles naturelles est cogaloment tris incertaine.

On a rangé pendant longtemps la sarcocolle an nombre des gommesrésines; mais 11 . Thomson, dans son Systrme de chimie, l'a considérée comme tenant le milien entre le sucre el la gुomme, et l'a placée en ronséguence: depuis, M. Pelletier en a repris l'analyse, ('l l'a lrouvéce composie de : 


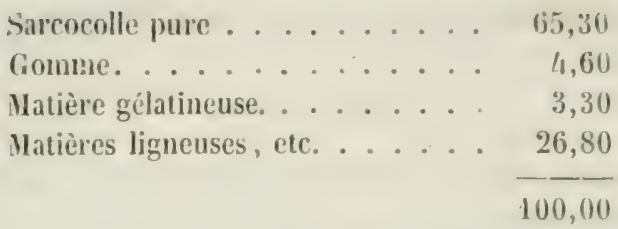

La matière gélatineuse a quelques propriétés communes avec la bassorine et d'antres guni l'en font différer. La gomme est de la gomme ordinaire. La sarcocolle pure, ou la surrorolline, est un principe sui yeneris, d'une saveur sucrée-amère, d'une odeur faible, mais particulière, soluble dans 40 parties d'eau froile et dans 25 d'eau bonillante. Sa dissolution, saturée à chaud, laisse précipiter par le refroidissement une partie de la sarcocolle sous la forme d'un liquide sirupeux, qui n'est plus soluble cians l'eau (cette propricté semble indiguer une nilture composée dans la sarcocolle). L'alcool dissout la sarcocolle pres(que en toutes proportions; l'eau trouble cette dissolution, uais ne la précipite pas. (Voy. Bull. de plarm., t. V, p. 5.)

\section{FAMILLE, DES SAPOTÉES.}

Calice infère, non adhérent ì l'ovaire, divisé supérieurement en 5, 4 on 8 lobes imbrigués, persistants; ynelguefois accompange d'icailles motericures; corolle hypoggne, samophtale, régulière, divisie in anrant de lobes que le calice. Ĺtamines à filets distincts, inserries au tube de la corolle, tantôt en nombre double des lobes et alors toute's fertiles; tantôt en nombre égal el opposies aux lobes, mais séparies par des languettes alternes qui représentent autant de filets d'etamines steriles. L'ovaire est supère, à plusieurs loges contenant charunc un wule fisé a la partie supérieure on inférieure de l'angle central. le fruit est un drupe: ou une baie à loges monospormes domat plusieurs arorlent smvent. Les graines sont courertes d'un tignument pressue ossems, excepté ¿l l'ombilic qui est infère ou latẻral, sourent très grand. Le périsperme est charmu ou huileux, manquant guelguefois. Les sapotions sont des arbres ou des arbrisseaux ì suc laiteux, dont les feuilles sont ilternes, entières, coriaces, penninervées, conrtement pútiolées, mivées de stipules. On les rencontre et on les cultive dans les contries intertropicales, soit pour leur bois qui est généralement très dur, soit pour leurs fruits succulents qui sont très estimés, ou pour leurs semences huibuses, on pour leur suc laiteux qui fomrnit une sorte de cantchonc. 


\section{Seore de Buranhem on de Guaranhem.}

Celle écoree ent arrive du brésil sous le nom de moliren, dont ii est possible qu'on ait fait, par cuplonnic, le nom de: monesin, sous leyuel elle a ete introduite en France dans la therapeutigue. L'arbe qui la produit, anciennement décrit par Pison, sous le nom de ihirme (Brms., p. 71), a éti reconnu par 31 . liedel pour un rlirysophlyllum el a éte

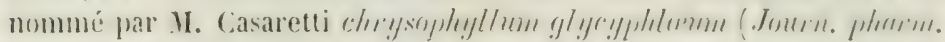
of chim., VI, p. 64). L’écorce, telle que nous la rocerous, est généralement ties plate, ipaisse de 4 à 6 millimberes, non fibrense, sans conche subéreuse on herbacée. Elle est formée d'une substance uniforme, brune, dure, compacte, pesante, tonte gorgée d'un suc à la fois sucré, astringent et amer. Elle contient, d'apres l'analyse du IIII. Henry et Payen :

Matière grasse, cire et chlorophylle . . . . . 1,2 Glycyrrhizine ................... 1,4

Monésine (matière grasse, analogue à la saponine) $\quad 1,7$

Tamin ..................... 7,5

Matière colorante rouge (acide rubinique). . . 9,2

Malate acide de chaux. ................. 1, 3

Sels de polasse, de chaux; silice, etc...... 3

P'ectine et ligneus. . . . . . . . . . 71,7

100,0

On apporte également du Brésil l'extrait d'écorce de Buranlem tont preparé; il est noir, sec, en masses plates, enfermées entre deux finilles de papier : il possèce une saven d'abord sterie, puis successirement astringente, amère, très âcre et fort désagréable.

\section{Senenees de Sapotillier ou Saporille.}

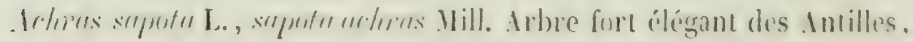
dont lo fruit est mne grosse baic globuleuse et charnue, assez esimme pour la table, presentant intérieurement 10 a 12 loges monospermes. font un certain nombre avortent tomjours. Ies semences sont lenlicularires-riliptiques, longues de 18 a 25 millimberes, larges do s i 12, polies, brillantes, d'une content marom fonce, ase un lones

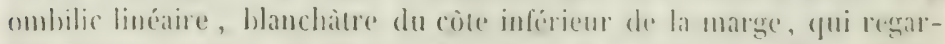

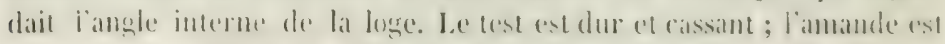

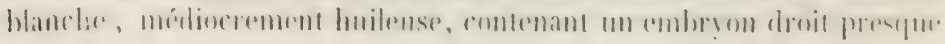




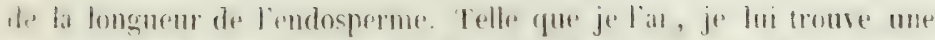

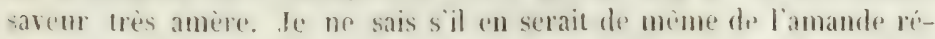
cente. Celte semence passe pour être diurétique.

sapotille manmé, lurunm mummusn Gartu. Arbre très clevé des Antilles, de la Colombie et des missions de l'Orénogue, dont le fruit rst une baic tres volumineuse ne contenant ordinairement qu'une senence oroüde, pointue, longue de 6 à 9 centimetres, offrant un angole arrondi du côté externe du fruit et un ombilic très large, occupant toute la longuenr de la semence, du côté interne. Le test en est ligneus, très dur, poli, luisant, d'une conleur de marron claire et jaunàtre. L'ombilic est terne, rugneux et jamàtre. L'endosperme est nul; les cotỵlédons sont charnus, fres rolumineux et composent toute l'amande; la radicule est infère, tris petite. Cette belle semence est frécpuemment apportée d'Imérirfue comme objet de curiosité. II. Candido Gaytan a

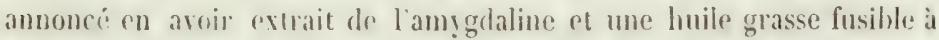
15 degrés, composée d’oléme eq de stéarine, puisfue l'acide solide qu'on en obtient par la saponification n'est fusible qu’a 70 degrés.

Inile arllipe: Le brsin! lomgifulin, gui jroduit cetle lıuile, est un des arbres les plus uniles de l'Inde, à cause de son bois qui est plus dur et anssi durable que le bois de tek; par les usages médicinaux de son écorce et de ses fenilles; par la qualité nutritive de ses fleurs, enfin par l'huile extraite de ses semences, qui sert a la fabrication du saron, pour l'éclairage, et mème comme assaisonmement, bien qu'elle soit infórieure à cet égard an ghee (ghii) et au beurre de coco. On en a importé en France paur la fabrication du savon.

L'huile d'Illipé mériterait autant que d'autres de porter le nom de benrre, carr elle est solide à la température de 22. ou 23) degrés centigrades et ne se liquéfie qu'à celle de 26 à 28 degrés. Ellle est d'un blanc rerdâtre à l'état solide et devient jaune par la fusion; elle est à peine soluble dans l'alcool bouillant; elle paraît être forméc d'élaïne et de stéarine, comme l'huile de lucuma.

On extrait aussi dans l'Inde l'luile des semences du hassir latifolin, mais elle ne sert que pour l'éclairage. Les fleurs, qui ont un gôt sucré et vineux, sont reclierchées comme aliment par les hommes, par les rhiens et par d'autres animaux. On en obtient par la fermentation et la distillation une liqueur très enivante.

Enfm le bessiu butyrarea fournit un beurre solide, connu sous le nom de gher ou yhi, plus estimé que les hniles précédentes et réservé pour les aliments et pour les usages de la médecine. Il est probablement fort analoguc au suirant. 


\section{Beurre de Galan.}

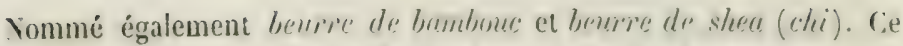
beurre est tiré des royanmes de Bambouc et de Bambara, silués dans l'intérieur de l'Afrigue, à l'est du Sénégal; il y ext extrait des semences d'une espèce de hrssiu qui a élé décrite par Mungo-Park et qui se nomme en conséquence busiur I'urliei (De Cand., Poudr., t. VIII, 1. 199); il est parfaitement propre à la préparation des aliments et est l'objet d'un commerce assez considérable pour les contrées qui le produisent. Il est d'un blanc sale, guelquefois faiblement rougeâtre ef a l'apparence du suif en pain; mais il est plus onctueux que le suif et graisse les rloigts à la manière de l'axonge, cn y laissant quelques parlies plus solides; il a une légère odeur et une saveur donce privée de toute âcreté.

Ce beurre, fondu au bain-marie, laisse déposer des flocons rougeâtres d'une substance sucrée et des plus agréables, qui doit provenir de la pulpe du fruit; le beurre, refroidi lentement, connence is se solidifier à 29 degrés, mais n’est complétement solide (ju’à $21^{\text {¿a }, ~ 2 . . ~ I I ~}$ se dissout complétement à froid dans l'essence de térébenthine, incomplétement à froid dans l'éther, et la matière insoluble paraît être de la stéarine. Il est pres(jue insoluble dans l'alcoul. Les alcalis le saponifient arec une grande facilité (Jurn. rhim. mid., 1525, p. 175). I1 ! a แn certain nombre d'années qu'il est arrire par les roies du commerce a Paris, une assez grande guantité de beurre de Bambonc. Il avait une forme toute particuliere qui l'a fait recomnaitre aussitôt par M. P'errotes: il était en pains orbiculaires, plats sur la face inférieure, bombés supérieurement, agant 25 à 26 centimètres de diamètre, complétentent recouverts de grandes feuilles à nervures palmées et a lobes arrondis; le tout était maintenu à l'aide d'un réseau làche formé par des lanirires d'une écorce fibreuse. Chaque pain pesait de 18 à 1900 grammes.

\section{Gutra-Percha ou fiettania.}

Cette substance, qui est appelée à rendre de grands serricrs a l"industrie, a élé apportée pour la premiere fois en Ingleterte, en 184.2, et en France, en 1S46, par la commission du conmerce enroger en Chine. Elle découle en abondance, à Bornéu, dans les iles Malaises et dans les environs de Singapore, d'un arbre de la famille des sapoteres qui appartient au genre isoncendı, caraclérsé par un seul rang d'étamines, toutes fertiles. Cet arbre, mommé par M. Hooker ismumblim yulle, s'idive a la hanteme de ho pieds; yes fenilles somt altermes, 


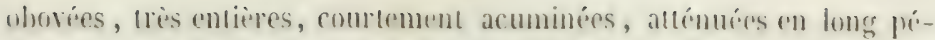
tivle a la base, verles en dessus, durées en desouns, comme dans les rleysoyshyllum; les theurs sont axillatires, fasciculés, à 6 dirisions, a 12 étamines; l'ovaire est à 6 loges; le fruit est une baic dure sous-globuleuse, à 2 loges fertiles, monospermes.

Le guthe fmortur apporté par la commission de chine a la forme d'un pain rond, un peu aplati. II est blanchître, solide à l'extérieur, encore un jeu mou à l'intérieur et comme formé de couches superposées, libro-membraneuses et min peu nacrées. Il a une odeur fort désagriable et un peu putride de fromage atigre. Lorsqu'il a acquis tuute sa solidité et à froid, il a une comsistance très ferme, très dure, tres tenace; il résiste au choc et au frottement, et est susceptible, par conséquent, d'un très longr usage. Il se ramollit très facilement dans leau chaude, devient alors d'une extreme plaslicité, prend toutes les formes funon reut lui domner et les comserve en se refroidissant. C'est cette jorpriété surtout qui rendra le gutu purchu très utile pour remplacer le cuir dans un grand nombre de cas, et pour fabriquer des fouets et des manches d'outils.

I. yull f"r.rlu brut contient un certain nombre de substances différentes yui comprosaicnt le suc laitewx de l'arine et qui se sont desséchées enemble à l'air. Ainsi on y troure un aciele régétal que l'eau chambis lui enlive facilement, de la caréume, une résine soluble dans l'alcuol et une aulle soluble dans l'élher. Malis ces matières ne forment yu'un' minime partie de la masse, et le reste peut étre considéré comme

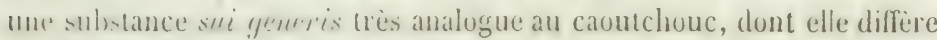
cepentunt par sal consistance friteuse, sa faible élasticité, son insolubiliti dans l'élher, sa plus grande solubilité daus l'essence de térében-

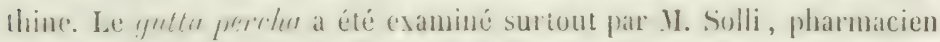

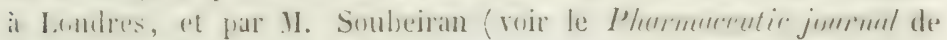
J. Hell et le Jumnal de plurmacie et de chimie, t. XI, p. 17).

\section{FAMILLE DES EBEXYACEES.}

Irbres m abrisseaux non lactescents, à fenilles alternes, coriaces, Lrie mlierres, privies de stipules. Les fleurs sont tris sourent diö̈ques par arortement, formées d'un calice gaurosépale a :3-6 lobes persislints, et d'une corolle insérée sur le réceptacle, ganopétale, à 3-6 lubes imbriqués et contournés, presque toujours velus à l'extérieur. Les éamines sunt insérées a la base de la corolle oil sur le réceptacle, ('I) nombre double des divisions de: la corolle, rarement quadruple, très rarement égal et alors alternes et incluses. 


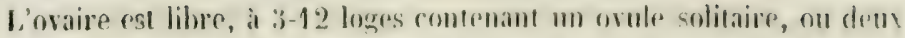
ovules collatéranx et pendants. Sigles distincts on plus 60 moins sondés, répondant an nombre des loges; baie globuleuse, a un petit nombre de: loges contenant chacune une semence pendante, oblongue, comprimée, lisse, coriace, à endosperme cartilagineux.

Les ébénacées diffèrent des sapotées par leur suc non laiteux, leurs ovules pendants et leur style très sourent divisé; leur genre le plus important est le genre diospyros (Plaqueminier), dont plusieurs espèces, répandues sur la côte de Nozambique, dans l'île de Vadagascar, daus les îles Iaurice, dans l'Inde et dans la Cochinchine, fournissent des bois noirs connus sous le nom d'ébène. Ces espèces sont principalement :

Le diwspypros reticulatı Willd., croissant aux îles Haurice et probatblement à Nadagascar et à Mozambique.

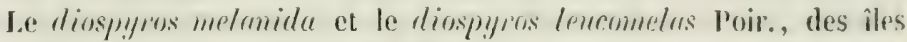
Naurice, à hois noir panaché de blanc.

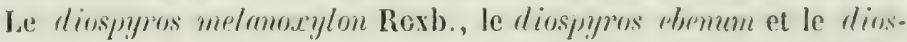
fy!jos ebenaster de Retz, croissant à Ceylan, dans l'Inde et aux îles Moluques, à bois parfaitement noir.

Le plus bean hois d'ébène rient des îles Naurice; il est formé dı cœur de l'arbre, l'aubier, (jui est fort épais et blanchâtre, ayant été enlevé. Il est parfaitement noir, très pesant, l'un grain si fin qu'on n'y décourre, forspu'il est poli, aucune trace de couches ou de fibres ligneuses, et il est susceptible d'un poli si parfait qu'il ressemble à un? miroir. Il a une saveur piquante et répand une odeur agréable sur les charbons alluués. On le connaît dans le commerce sous le nom d'atiene manrice.

On connait à Londres, sons le nom de brois de Cirmmmulel ou de C'almmander, un bois de l'Inde généralement attribué à un diospyros. Il est volumineux, pourvu d'un aubier dur, compacte, nerreux, d'un gris rougeâtre, un peu satiné, et d'un cơtur noirittre nuancé de larges reines de la conleur de l'aubicr. C'est un fort beau bois, mais dont le poli est altéré par une infunité de petites lignes creuses provenant de raisseaux ligneux ouverts à la suríace.

Dans le commerce français, on donne le nom d'ribine at un cerlain nombre de bois qui n'ont que des rapports éloignés arec le bois d'ébene. L'un d'eux, cependant, nommé ébrine ronge de Brésil, me parait dui is Inn d'iospyros : il est très dur, pesant, pourvu d'un aubier gris et d'un coxur noirâtre arec des reines rubanées d'une teinte rougeâtre assez. prononcéc. Ce bois, du reste, offe de si grands rapports arec celui de Coromandel, qu'il est évident qu'ils appartiennent tous denx an

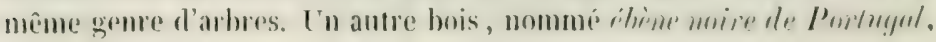


mais renant egalement du Brisil, parait presfue noir d'abord ; mais it est d'un brun trìs foncé avec des reines violacées. Il est très dur, très pesant, d'un tissu très fin, et prend un bean poli. Il est pourvu d'un aubier jaune, peu épais, égaleunent dur et serré. Il est privé de son écorce, qui a dû être fibreuse et qui a laissé sur le bois des stries longitudinales très marquées. Il présente en outre, de distance en distance, 2 ou 3 tubercules ligneux rapprochés sur une ligne horizontale, yui doirent aroir servi de base à des épines. Ce bois, très rapproché de certaines espèces de grenadille, me paraît appartenir à la famille des papilionacées; il est possible gu'il soit produit par le melunniylone brauna de Schott, arbre du Brésil à bois noir, exploité.

On donne le nom d'chime erente on de bois d'erilusse à deus bois verdatres, dont l'un est produit par le ligmmin leuctus:y/on mentionné précédemment ( page 500) ).

\section{FAMIIAE DES STYRACINEES}

Arbres ou arbrisseanx à feuilles alternes, privées de stipules, à fleurs complètes et régulières dont le calice libre, plus ou moins soudé avec l'ovaire, présente 4 ou ij divisions imbrignées. Corolle insérée sur le calice, Ie plus souvent divisée en 5 parties; étamines insérées la base de la corolle, en nombre double, triple ou quadruple des divisions; filets soudés en tube sur toute leur longueur, ou monadelphes par la base; ovaire libre ou soudé, à 2,3 ou 5 loges; orules au nombre de 4 ou plus dans chaque loge, bisériés, de directions différentes, les inférieurs étant horizontaux ou ascendants et les supérieurs pendants, tous anatropes. Style simple; stigmate crénelé ou lohé; drupe charmu ou desséché, quelquefois ailé par les nerrures accrues du calice; noyau à 3 ou 5 loges , souvent réduites à une et devenues monospermes par arortement ; embryon orthotrope dans l'ase d'un endosperme charnu.

Cette famille, peu nombreuse, derrait faire partie des caliciflores, puisque la corolle est insérée sur le calice au lieu de l'être sur le réceptacle, comme dans les familles précédentes; cependant elle présente tant de caractères communs arec la famille des ébénacées qu'elle ne peut en être séparée. Elle fournit à la pharmacic deux baumes d'un très grand prix, le benjoin et le sfornx calamite.

\section{Benjoin.}

Le benjoin est un baume ì acille benzoïgne, solide et d'une odeur très agréable, qui est apporté des iles de la Sonde et de Malaca. L'arbre qui le produit a ćtc longtemps inconnu. D'abord on l'a attribué a un 


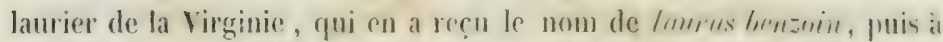

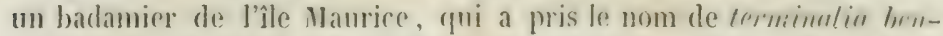
sorie; enfin l'arbre qui le produit, asant éce observé par Inrander at

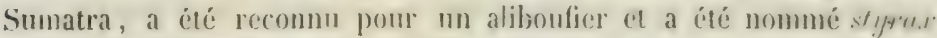
ben-nin. Cé arbre croît abondamment dans la parlie méridionale de. Sumatra, ì Java et daus le royaume de siam. Ie baume en découl: par des incisions, sous la forme d'un suc blanc qui se solidifie ce se colore par le contact de l'air. Chajue arbre peut en fomrnir trois lirres ef les incisions peurent être continuées pendant dix ou douze années.

On trouve anjourd'hui dans le commerce deux espèces de benjoin gui diffrent par leur lieu d'origine et sans doute aussi par la maniere dont elles ont élé produites. Ia première, nommée henjoin ar siam, est assez nouvellement connue, on plutot a reparu de nouveau apres avoir été longtemps perdue. Iille est en larmes toutes détachées ou en masses formées de larmes agghlulinées. I,es larmes délachées sont grandes, plates, auguleuses, et paraissent s'ètre formées naturellement sous l'écorce de l'arbre. Elles sont blanches, opargues et d'une odcur très suare de ranille, ce qui a ralu aussi ì celte sorte le nom de benjoin a odrur de vanille. Je pense, malgré guelques opinions contraires, que ce baume est produit par le même arbre gute le suivant; au moins doil-ce être une espèce très voisine.

Lorscue ce benjoin est en lames plus pelites, réunies en masses, il faut remarquer rque la matire qui aggrlutine les masses est d'un hrun foncé, vitrêse et transparente.

Ia seconde espèce de benjoin, ou berajoin de sumatra, qui, depuis très longtemps. étail la seule connue dans le commerce, préscule éralement deux qualités, le hemjuin mmygrlalö̈le et le hrojoin ammm!run.

Le premier est en masses considérables, formées de larmes blanches et opargues, en forme d'rmmondes, empattées dans une masse rougcatre: opaque, is ressure incignle ret remillense. Ce benjoin a évidemment ćli obtenu par de larges incisions faites à l'arbre. Lorsqu'il est récent, it exhale une odeur manifeste d'amandes amères.

Le brnjoin crmmun est en masses rougeâtres semblables, mesffur privées de larmes et contenant des débris d'écorces.

Le benjoin posside me saveur d'abord donce et balsamique, mais qui finit par irriter fortement la gुorge. Il se fond au feu, et dígram, une odeur forte et une fumée qui, condensée sur un corps froid, ofler des cristaux d'acide benzö̈que. Il excite fortement l'étermument lorsqu'on le pulvérise.

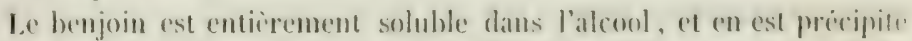
par l'ean ot les acides. (on en retire lacide benzoïrue par la suhlima 
lion. on a l'aide d'm alcali et ensuite par la précipitation an moren de l'acide chlorhydrique; mais ces deux produits ne somt pas pus . le premier contient de l'huile a le second de la résine; il faut le's punifier. par la sublimation, apues les aroir mêlés arec du sable el du charbon.

I. henjoin entre dans la composition du baume du Commandeur et daus celle des clous fumans. (On en fait aussi une teinture simple, qui, étendue d'ean. forme ce qu'on nomme le lnit rirginal. L'acide benzoïque huileux obtenu par la sublimation, et non purilié, entre dans les pilules balsamiques de Morton.

\section{Baเme storax $(1)$}

Suivant Dioscoride, le strrax est wne larme produite par un arbre yui ressemble au coignassier ; le meilleur est onctueux, jaune, résineux, mêlé de grumeaux blanchâtres: il est trìs persistant dans son odeur, et domme par la fusion une liqueur qui ressemble à du miel; tel est celui rfui vient de Gabala (ville de Phonicie), de Pisidie et de (ilicie. On en trouve une sorte qui est transparente comme nne gomme, et semblable à la mrrolic; on le sophistigue arec la poudre de son propre bois, arec du miel, de la cire, etc.

Pline fait renir le styrax de différents licux de la sirrie, de la Ploenicie, de la Séleucie, et cite aussi celui tiré de Cilicie, de l’isidie et de Pamphỵlie; il dit (que l'arbre ressemble au coignassier, (ju'il est creux en dedans comme un roseau, et tout rempli de suc. Il est évident que Pline prend pour le hois de l'arbre les roseaux dans les(quels on transportait son produit balsamique.

Galien ne dit rien autre chose du styax, si co n'est qu'on doit choisit pour la thériague celui (pui est apporté de Pamphilie dans des tiges de roseaux, et comme le roseau est nommé calmmms cu latin, ou rsh sus en grec, il en est résulté que les pharmaciens ont donné le nom de styru, ou strurat relmmite à la meilleure sorte de storax, bien qu'on ne l'apporte plus du tout dans des roseaux.

Apròs des indications si précises de lieux tous roisins les uns des autres, il est bien difficile de ne pas croire que les anciens tirassent en effet leur styrax calamite de la syrie et de l'Asie mineure. Il a donc fallu chercher l'arbre ressemblant au coignassier, ([ui devait le produire, et on l'a trouré dans l'alibumfiro de Provence, fui croit aussi en Italie

(1) Quoique le mot storax ne soit qu'une corruption de styrax, cependant, dans la ve de micux distinguer le baume dont il est ici question du styrax liquide précédemmen! décrit ( page 293 ), je suirrai l'usage actuel de donner le nom de storax au slyrax calamile, et celui de slyrax au styrax liquide. 
at dans tout le Levant ; dont toutes les parties sont imprégnées de l'ydeur du storax, et qui en laisse sortir quelque peu lorsque son écorce se trouve percée par des insectes, on incisée artificiellement. En conséquence, cet arbre a été nommé par Limné styrox officinale. Il appartient à lia décandrie monogynic, et donne sen nom à la petie famille des styracinées séparée de celle des ébénacées.

Rien ne paraît plus logique et plus certain que ce qui précède, et cependant il m’a semblé que si le storax calamite découlait dans l'asie mineure d'un arbra qui parait y être commun, ce ne serait pas une chose plus rare et plus chère que l'opium, par exemple. Aussi ai-je pensé, pendant un certain temps, que notre storax calanite pousait bien ne pas être une production dı Levant. Déja Imatus Lusitanus le faisait venir d'une île Zoma, située près des Indes, et je pense qu'il s'agit ici de Jarr. ne son côté, Garcias, le premier auteur qui nous ait donné des notions exactes sur l'origine du benjoin (Armunt. hist., lib. I, c. 5), en distingue plusieurs espèces, savoir : le benjoin rumygdeloïle renant surtout des provinces de Siam et de Martaban; le benjoin en sunte tiré de Jara et de Sumatra, et un troisieme noir, découlant, dans l'île de Sumatra, d'arbres nommés nueella, et appelé benjoin de bonimus, à cause de la suavité de son odeur. Colui-ci est dix fois plus cher que le premier. Un fragmient de ce baume, enroyé en don a Garcias, laissait les mains imprégnées d'une odeur d'une fragrance admirable.

Garcias arait pensé sourent que ce henjoin de frminus: était un mélange de benjoin et de stgrax liquide (que les Cininois nomment irer. merlhor), parce (que son odeur a quelque repport arec celle du styrax. Mais, ayant essayé plusieurs fois d'opérer ce mélange, il n'obtint qu'un parfum bien inférieur au benjoin de boninas.

Il m'arait paru difficile que ce henjwin de hominus, d'un prix si ćlevé ct d'une odeur si excellente, qui offre cependant un peu de rapport arec celle du styrax liquide, ne fût pas notre storax calamite actuel, et pendant quelque temps, ainsi que je l'ai dit plus haut, j'ai regardé le fait comme probable; mais aujourd'hui que la description du benjoin de boninas peut se rapporter au benjoin it odeur de ranille, cette opinion a perdu presgue toute sa valeur, et je suis revenu à ne considérer le storax calamite, que j'attribuais is un aliboufier de l'Inde, que

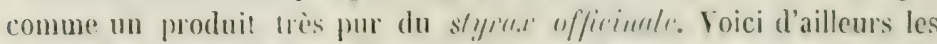
differentes sortes de storax que l'on tromse dans le commerce ou les droguiers.

1. Storax blance. Ce storax est composé de larmes blanches, opanges, asse $\%$ valumineuses, molles et réunies on une seule masse par leur adlierence réciproque. Il prend, par suite de la méme mol- 
lesser, la forme des rases qui le renferment, ef resemble alors au galloanum blanc en masses II a tue odene lute, "t cependant smase, qui tent à la fois du licquidambar et de lit ranille, une sarrur douce, parfumée, finissant par derenir amire. Cette sorte me paraît être celle que Demenve derrit comme storax calamite; je la crois natmelle. On la distingue dı liquidambar blanc d'Imérique par son odeur plus forte et plus suave, et par les larmes blanches (qu'elle renferme. Cette substance doit être le produit d'incisious faites à l'arbre.

2. Storax amyodaloäde. Ce slorax est en masses sèches, cassantes, formées cependant, comme le précédent, de larmes agglutinces, et prenant encore à la longue la forme des rases qui le renferment. Sa cassure offre, sur un fond brun, des larmes amyggaloüdes d'mn blanc jamnàtre, ce qui lui domme de la ressemblance arec du beau galbanum vieilli; les portions brunes, qui, ì la suite du temps, coulent et remplissent les vides compris entre Ies parties inférieures de la masse er la paroi du rase, forment me conche vitrense, transparente ut d’un rouge clair. Son odeur est des plus suaves, analogue a celle de la vanille, plus douce que celle du précédent; sa sareur est douce ct parfumće.

Je pense que ce storax, qui est celui nommé par Iemery stom colrmite, ne differe dı premier que par son âge dams les droguiers; ses rariations de consistance, de couleur, d'odeur et même de sareur, s'expliquent facilement dans cette hypothèse.

L'un et l'autre de ces baumes, traités par l'alcool bouillant, laissent, indépendamment des impuretés, un petit résidu blanc insoluble, et la liqueur filtrée bouiliante se trouble en refroidissant.

3. Storax rouge-brun. Ce storax diffère du précédent par un mélange de sciure de bois qui apparait aux aspérités de sa surface. Il jouit néanmoins d'une certaine tenacité, et se ramollit encore bien sous la dent. Il a me couleur rouge brune, une saveur donce, une odeur très agréable, moins forte que la première sorte; on y obscrve ça ce là quelques larmes rougeâtres.

4. Storax liquide pnr. Je dois un échantillon de cette substance à II. Pereira : j’ai supposé d'abord que ce pourait être du liquidambar d'Amérique épaissi à l'air ; mais son odeur, qui offre le parfum de vanille particulier aux différents produits du stypor officinale, me fait séparer cette substance du styrax lifjuide ordinaire et du liquidambar, pour le joindre aux produits du styror officinale. Cette opinion se trouve d'ailleurs conforme aux informations fournies à M. Pereira par M. Landener, l'un des éditeurs de la l'harmarmpre grecrque, "que le storrax liquide (nommé buchuri-jory ou huile dre strmor est obtenu i cos et à

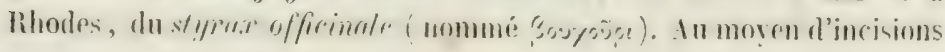


longitudinales, l'écorce de la tige est enlevée sous forme de lanires étroites dout on forme des bettes de 2 lirres environ, qui sont exprimées à chaud. Le storax en découle sous forme d'un liquide épais, d'une couleur grise et d'une odeur analogue à celle de la vanille."

Cé storax, rui, pour moi, est une chose différente du styrax liquide du commerce, a l'aspect d'une térébenthine d'un jaune brunattre et nébuleuse. Il forme un sublimé blanc et acide, contre la paroi supérieure du vase qui le contient. Il ressemble considérablement au liquidambar mou d'Amérique, mais il s'en distingue par son odeur.

5. Storax noir. Ce storax forme une masse solide, d'un brun noir, coulant un peu à la longue, à la manière de la proix, dans le vase qui le renferme; sa surface offre un éclat un peu gras, et se recouvre à la longue de petits cristaux très brillauts; il possède une odeur fort agréable, analogue à celle du vanillon; il contient une assez grande quantité de sciure de bois. Je ne serais pas étonné que ce baume fùt obtenu par décoction des rameaux de l'arbre, et solidifié ensuite par l'addition de la sciure du bois. C'est avec cette sorte que l'on prépare à Marseille le faux storax calamite, en y incorporant des larmes de gomme ammoniaque ou de résine tacamaque, de l'acide benzoïrge, du sable, etc.

6. Storax en pain ou en sarilles, seiure de storax. Cetle sorte arvive en masses de 25 à 30 kilogrammes, recourertes d'une toile; il est d'un brun rougeàtre, facile ì diviser en une poudre grasse ch grossire (uni se remet en masse par la pression. Il a une odeur analugue à celle du précédent, mais moins agréable. P'eut-ètre est-il formé seulement de l'écorce de l'arbre broyée au moulin et pourve de la quantité de baume qu'elle contient naturellement.

7. Éconce de storax, stomax rouge du commerce. D'après la note de 11. Landener, citée plus haut, il me parait certain que cette substance est formée de l'écorce du styrux offiénule qui a été divisée rol lanières et soumise à la pression pour en retirer le baume. Jille est en eflet sous forme de lanières étroites, minces, rougeàtres, pressces les unes contre les autres, sècles, mais conservant encore une forte odeml balsamique; it la longue, il s'y forme par places une efllorescence d'acide. Il parait, d'après ce que dit Mathiole, que cefte sulsstance portait autrefois dans les officines le noin de tignume, qu'il pernse itre

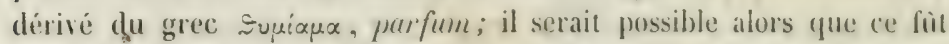
d'elle que parle Dioscoride, sous le nom de mercophlithem.

storax de Bbogota. On trouve en Amérique un grand nombre d'espèces du genre styrax, dont on peut extraire un baume analogue au benjoin ou au storax; tels sont, au Brésil, les styrme meticulutum el

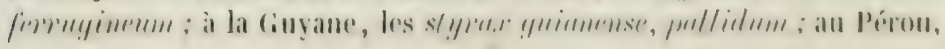


le styprat raremosum; dans la Colombie, le styrac tomentosum, et beaucoup d'autres.

En 1830 , II. Bonastre a décrit (1) un storax de Bogota nouvellement introduit dans le commerce, mais que je n'y ai pas vu depuis. Il était sous forme d'un pain orbiculaire un peu aplati, de 13 à 16 centimètres de diametre, sur 2,5 à 4 centimètres d'épaisseur. La surface en était rouge-brune et comme vernissée ; à l'intérieur il était opaque, de coulenr de brique, à cassure sèche, écailleuse et inégale, tout à fait semblable à celle du benjoin commun; mais il présente l'odeur mixte de liquidambar et de vanille des storax. Il est moins aromatique que le benjoin et le storax, et pourra difficilement leur faire concurrence en Europe.

\section{Indton à l'article Manne rombè du ciel (page 534).}

Lorsque j'ai rédigé cet article, j'ignorais que la substance qui en fait le sujet eût été examinée par .I. Ed. Liversmann, professeur à Casan, par M. Fr. L. Tees d'Lsenbeck et par d'autres savants étrangers. M. Eversmann a décrit trois espèces de lexumuru dont la dernière, nommée lecrunira esculenta, est le lichen rsculentus de Pallas; la scconde, nommée lecunor'u "ffinis, est la mame tombré du rirl, et l'excellente figure qui accompagne le Mémoire représente très exactement notre substance. La premiere espèce, nommée lesrmura finticulosu, est assez différente des deux autres.

Dans une notice de II. Fr. Tees, jointe au Mémoire de M. Eversmann, se trouve la citation suirante dont je dois la traduction i l'abligeance de M. Nicklès.

(Journal de Schweigger, 1830 , I. III, I" 4, P. 393 ; Recherches chimiques de $\mathbf{1 1}$. Goebel à Dorpat, sur une pluictombér en Perse).

"La substance qui constitue cette pluie est le prmmeliu esculentu. Elle m'a élé remise par 11. Parrot, qui ajouta ce qui suit : cette substance a été recueillie durant un voyage sur l'Ararat. Elle est tombée vers l'année 1828 , dans quelques districts de la Perse, où elle a recourert la terre d'une couche de 5 à 6 pouces de hauteur. Les habitants de la contrée l'ont employée comme aliment. Iussi paraît-elle être à II. Parro! d'origine organique.

" Les résultals analytiques m'ont donné la certitude que cette substance est un lichen arraché au sol par des vents électriques et transporté par eux dans des contrées éloignées; ce qui expliquerait com-

1) Journal de pharmacie, t. XVI, p. 88. 


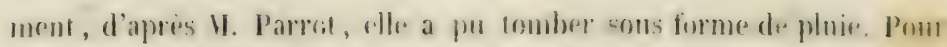
la mieux comnaitre, j'ai prié 11 . le profeseur ledebour d'en fare l'examen botanique. .1. I.edebon' y a reconmu tous les caracteres du prormelice esculenta, et il a ajouté qu'il avait fréguenment rencontré ce lichen dans les steppes des Kirgis, et qu'en général dle se trouse abondamment dans l'Asie-Mineure, dans les terres argileuses, ains une dans les fissmres des rochers, ou souvent elle apparait subitement à la suite de fortes pluies, de sorte que II. Ledebour ne croit pas que ce cryptogame soit tombé comme pluie, mais plutôt qu'il s'est déreloppé subitement, pendant la nuil, à la suite d'une forte pluie.

"Quclie que soit la manière dont cette plante soit apparue en Perse, clle est remarifuable par la grande quantité d'oxalate de chaux qu'elle renferme et par l'absence des autres substances minérales que l'on trouve ordinairement dans les virgétaux. Son abondance dans les contries nommes plus haut ot sa richesse en oxalate de chaux font supposer i II. Ledehour qu'elle pourail servir arec avantage it la préparation de l'acide oxalique el des oxalates.

" 100 parties de parmelia esculenta renferment:

Chorophylle contenant une résine molle de sareur âcre. 1,7.j Résine molle inodore et insipide, insoluble dans l'alcool. 1,7, Substance amère soluble dans l'eau et l'alcool. . . . . 1

Inuline. . . . . . . . . . . 2, . 2,50

Gelée (pectine sans doute). . . . . . . . 23

Pellicules de lichen............ 3,25

Oxalate de chaux ............... 65,91

$99,16 \|$

La seule observation que je me permettai de faire sur cette note, c'est que 11. Ledebour assimile la plante dont il est ici question an lirhen resculentus, et qu'il est certain qu'clle se rapporte exactement au lesamon'r affinis de M. Eversmann. 



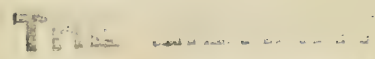

FACULTY OB P:AP WNIVERSITK OF TCFOHTO 
FACULTY OF PHARIACY
UNIVERSITY OF TORONTO 


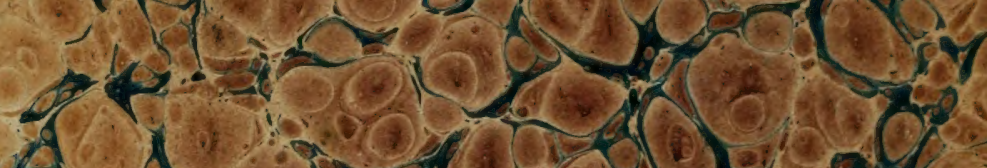

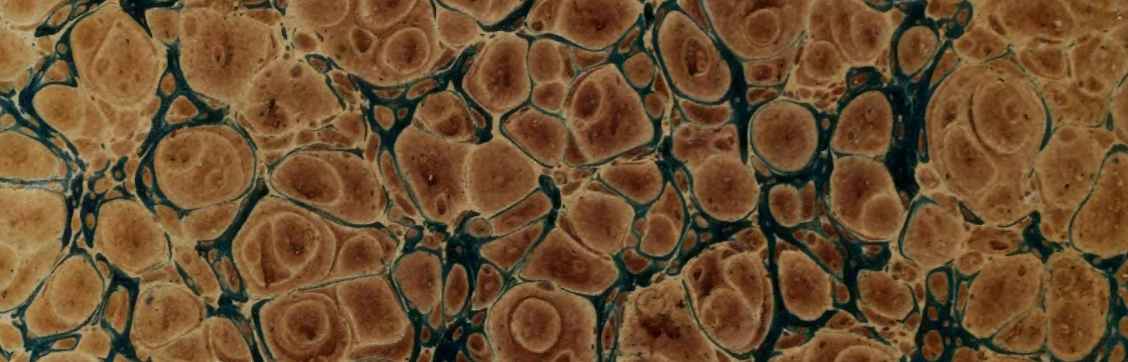

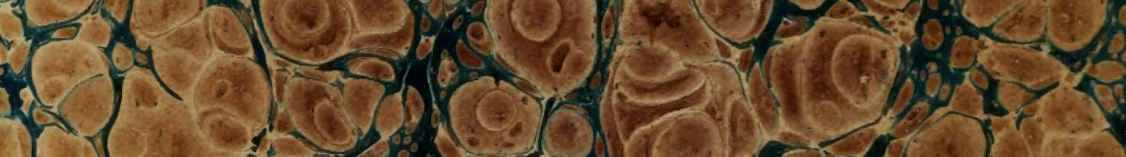
- a nobron

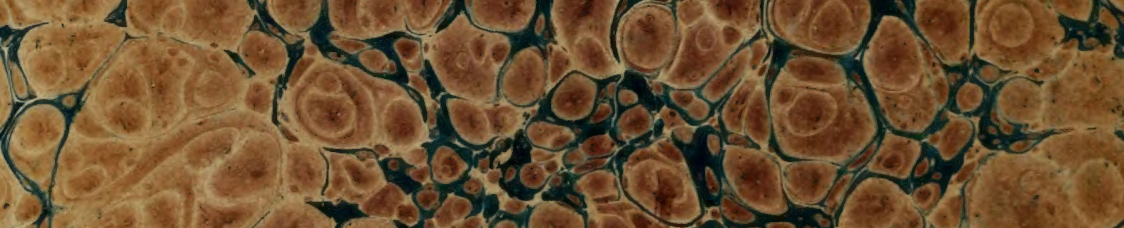

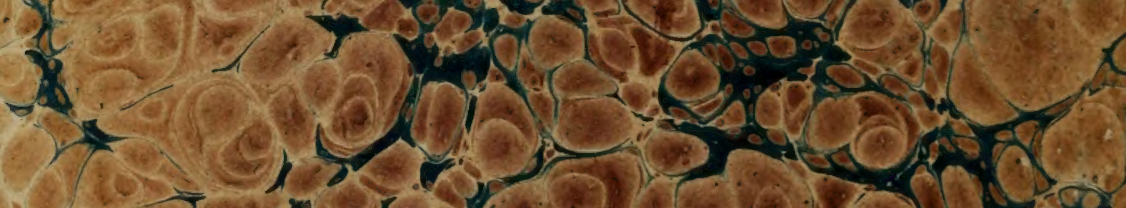
a 1 -

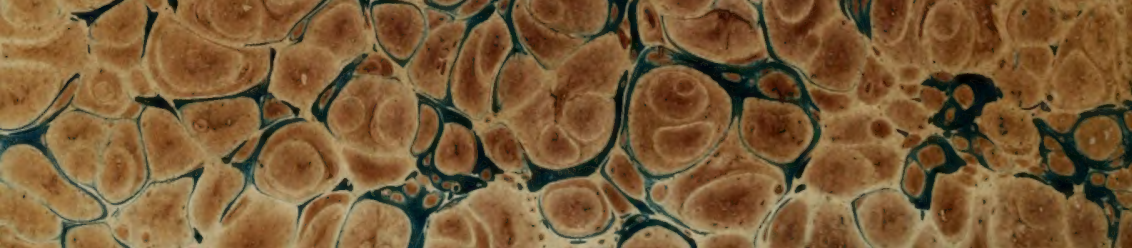



